


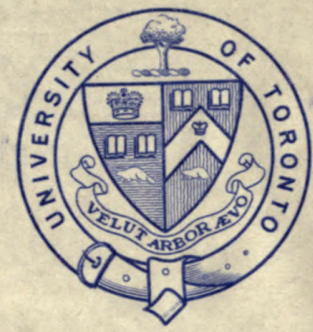

Jilesented to The Tithrary of the

杰niuersity of Taranta hy

Mrs. C. Dorothy Burns 


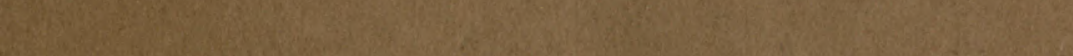
(6) ton 

A UNIVERSITY TEXT-BOOK OF BOTANY 
Thes $>$ if 



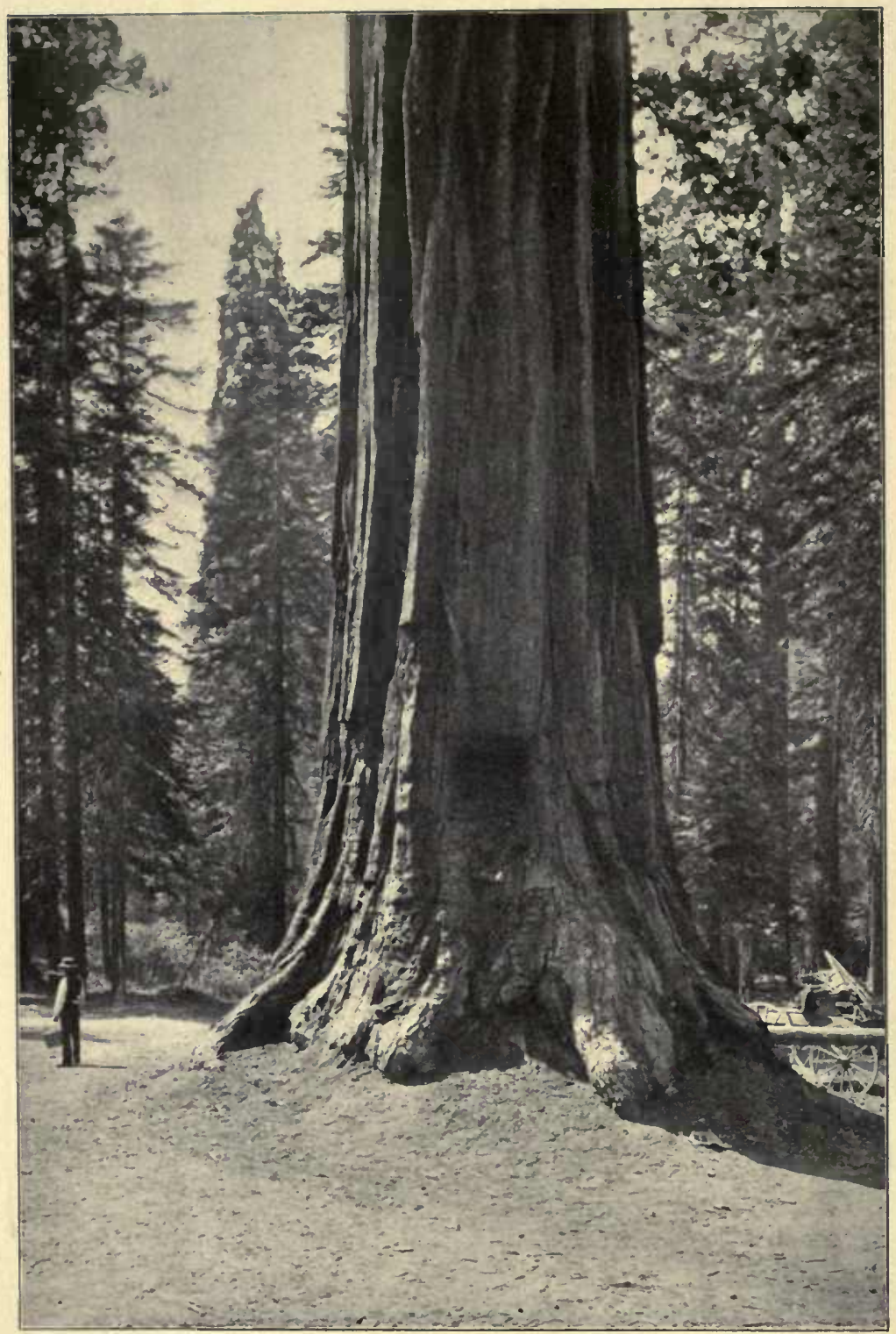

PLATE I (Frontispiece)

Mixed coniferous forest of the Sierra Nevada; in the background Libocedrus decurrens, Abies sp.; in the foreground Seguoia gigantea. 


\title{
A UNIVERSITY TEXT-BOOK
}

\author{
OF \\ BOTANY
}

BY

\section{DOUGLAS HOUGHTON CAMPBELL, Ph.D. \\ PROFESSOR OF BOTANY \\ IN THE LELAND STANFORD JUNIOR UNIVERSITY}

WITH MANY ILLUSTRATIONS

SECOND EDITION - REVISED AND CORRECTEP

Xrew 祭ork

THE MACMILLAN COMPANY

LONDON: MACMILLAN \& CO., LTD.

1910 
Copyright, 1902, 1907,

BY THE MACMILLAN COMPANY.

Set up and electrotyped April, rgo2.

Second Edition, April, I907;

October, Igro.

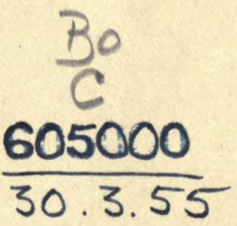

tis 


\section{PREFACE}

Is the preparation of the present volume an attempt has been made to present in as compact a form as possible an outline of the essentials of modern botany.

The book is not intended as a laboratory manual, but is designed primarily as a work of reference, and for this reason no attempt has been made to introduce laboratory exercises. Being prepared for the use of students in American colleges and universities, it has seemed proper to use largely as illustrative material plants drawn from the native flora, and it is hoped that this will add to the value of the book to American students.

In the taxonomic portion, a somewhat conservative attitude has been taken, in view of the very unsettled condition of nomenclature at the present time. The classification is largely based upon that of the standard work of Engler and Prantl, "Die naturlichen Pflanzenfamilien."

A short bibliography, comprising the more useful works on the various topics, has been appended to each section of the book. By consulting the works thus indicated, it is believed that the student can acquaint himself with the liserature bearing on the subject.

In Chapter XIII the materials are drawn largely from the work of Sachs and Pfeffer, the recent physiological text-book of Professor Pfeffer being used as a basis. The work of other physiologists has also been freely used.

Most of the illustrations have been made by the author, many of them expressly for this work. Where figures have been borrowed, due acknowledgment is made. Of these, a considerable number have been taken from the "Cyclopedia of Horticulture," edited by Professor L. H. Bailey. 
The author is especially indebted to his colleague, Professor G. J. Peirce, for valuable assistance in the preparation of Chapter XIII; to Professor W. R. Shaw for many microscopical slides, which were of great service in making many drawings, as well as for the use of several photographs. Other photographs were furnished by Dr. J. C. Branner and Dr. F. M. MacFarland of Stanford University, and Professor W. Trelease of St. Louis. To all these gentlemen the author wishes to express his sincere thanks.

DOUGLAS HOUGHTON CAMPBELL.

Stanford University,

March, 1902. 


\section{CONTENTS}

\section{CHAPTER I}

\section{INTRODUCTION}

Organic and Inorganic Bodies

Protoplasm .

Sources of Energy

Structural Resemblances of Plants and Animals . $\quad . \quad$. $\quad . \quad 3$

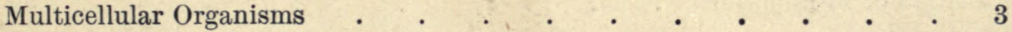

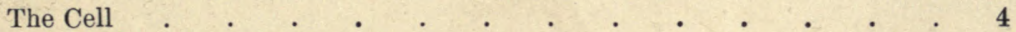

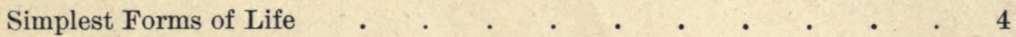

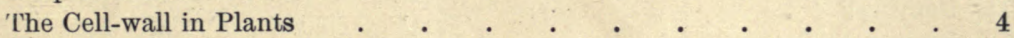

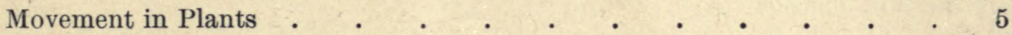

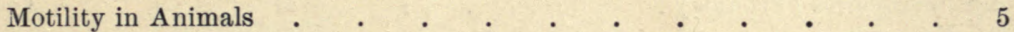

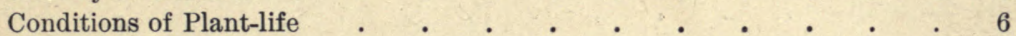

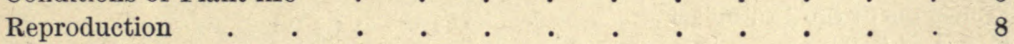

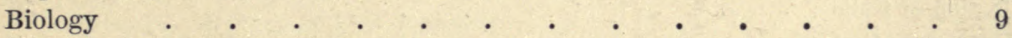

Morphology . . . . . . . . . . . . 10

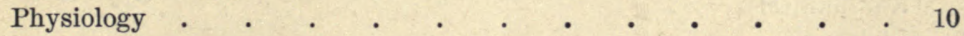

Taxonomy $. \quad . \quad . \quad . \quad . \quad . \quad . \quad . \quad . \quad . \quad . \quad . \quad 10$

Geographical and Geological Distribution .- . . . . 11

\section{CHAPTER II}

The Plant-Body

The Plant-cell

Reproduction

Unicellular Plants

Filamentous Plants

The Thallus .

Root and Shoot

Vascular Plants

Branching

Symmetry

Organs of Vascular Plants .

The Stem (Caulome)

The Leaf 
The Root

Trichomes

Emergences .

Reproductive Parts

Morphology and Classification

Bibliography

\section{CHAPTER III}

\section{The Plant-cell}

Physical Properties of Protoplasm . . . . . . . . 34

Differentiation of Protoplast $\quad . \quad$. $\quad . \quad . \quad . \quad . \quad . \quad . \quad 35$

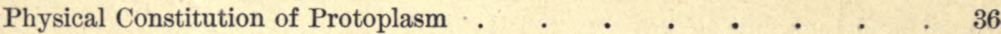

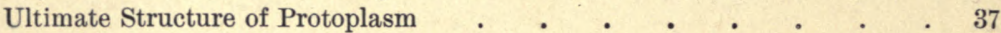

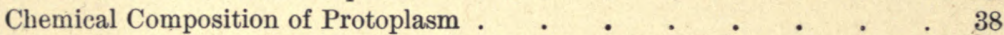

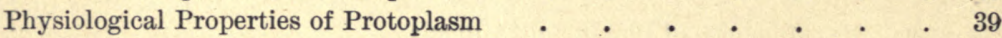

Nutrition of Protoplasm $\quad . \quad$. $\quad . \quad . \quad . \quad . \quad . \quad .42$

Irritability . . . . . . . . . . . . . 42

Reproduction $. \quad . \quad . \quad . \quad . \quad . \quad . \quad . \quad . \quad . \quad . \quad .44$

The Plant-cell . $. \quad . \quad . \quad . \quad . \quad . \quad . \quad . \quad . \quad . \quad . \quad .44$

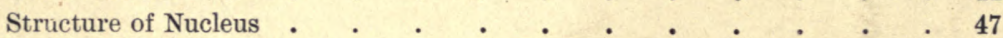

Chromatophores (Plastids) . . . . . . . . . . . . 48

The Cell-wall $\quad . \quad . \quad . \quad . \quad . \quad . \quad . \quad . \quad . \quad . \quad . \quad .50$

Inclusions of the Protoplast. $\quad . \quad \ldots \quad . \quad . \quad . \quad .53$

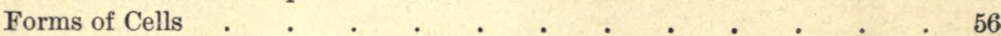

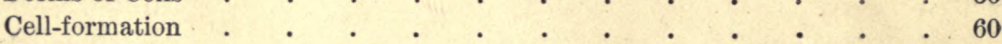

Karyokinesis . . . . . . . . . . . 60

Budding . $. \quad . \quad . \quad . \quad . \quad . \quad . \quad . \quad .63$

Internal Cell-division . $. \quad . \quad . \quad . \quad . \quad . \quad 64$

Free Cell-formation $\quad . \quad . \quad . \quad . \quad . \quad . \quad . \quad . \quad . \quad . \quad 64$

Conjugation . . . . . . . . . . . . . 64

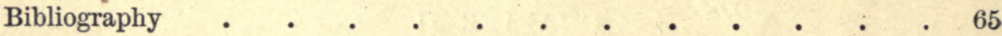

CHAPTER IV

Classification; the Simplest Plant-forms

The Simplest Organisms

Flagellata

Myxomycetes

Schizophyta .

Bacteria (Schizomycetes)

Reproduction of Bacteria

Biology of Bacteria

Aërobic and Anaërobic Bacteria

Classification of Bacteria 
Myxobacteriaceæ

SCHIZOPHYCEE

Structure of Schizophyceæ . . . . . . . . 80

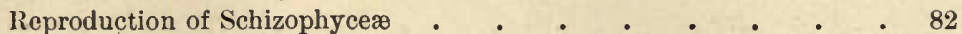

Movements of Schizophyceæ $\quad$. . . . . . . 83

Classification of Schizophyceæ $\quad$. . . . . . . 84

Peridineæ . . . . . . . . . . . . . 84

Diatomaceæ (Bacillariales) . . . . . . . . . 86

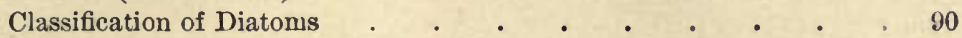

Bibliography . . . . . . . . . . . 90

\section{CHAPTER V}

The Alg ex

Class I. Green Alge (Chlorophycen) • • • • . 92

Classification of Chlorophyceæ . . . . . . . . 94

Order I. Volvocaceæ . • . . • . • • • • . 95

Order II. Protococcoideæ . . . . . . . . . 98

Order III. Confervoideæ . . . . . . . . . 101

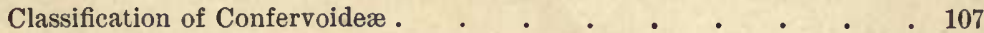

Order IV. Conjugatæ . . . . . . . . . . 108

Order V. Siphoneæ . . . . . . . . . . 112

Order VI. Characeæ . . . . . . . . . . 116

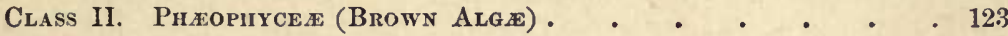

Order I. Phæosporeæ . . . . . . . • . . 126

Order II. Cyclosporeæ (Fucaceæ) . . . . . . 130

Classification of Phæophyceæ . . . . . . . . . 134

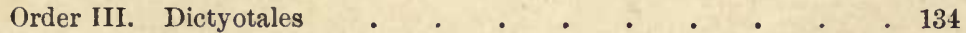

Class III. Rhodopirces (Red Alg \&) • • • . . . . 134

Subclass I. Bangiales . . . . . . . . . 137

Order. Bangiaceæ . . . . . . . . . 137

Subclass II. Florideæ . • . . . . • . • 138

Order I. Nemalionales . . . . . . . . 140

Order II. Gigartinales . • . . . . • . . 141

Order III. Rhodymeniales . . . . • . . . 142

Order IV. Cryptonemiales . . . . . . . . 144

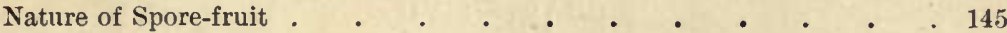

Affinities of Rhodophyceæ . . . . . . . . . . . 145

Fossil Rhodophyceæ . . . . . . . . . . . 147

Bibliography of Algæ . . . . . . . . . . . 147

CHAPTER VI

FUNGI

Structure of Fungi

Affinities of Fungi 
Classification of Fungi

Class I. Phycomycetes (Alga-Fuagi) • • . . . 152

Order I. Chytridineæ . • . • • • . . . 152

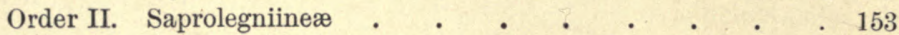

Order III. Peronosporineæ . . . . . . . . 155

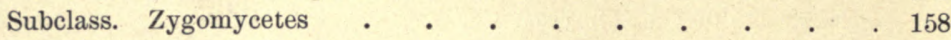

Order I. Mucorineæ . . . . . . . . . 158

Order II. Entomophthorineæ • . • . • . . 161

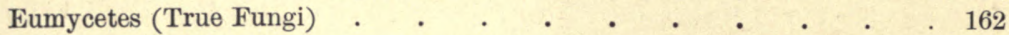

Class I. Ascomycetes . . . . . . . . . . 163

Subclass I. Hemiascineæ . . . . . . . . 164

Subclass II. Euasceæ • . • • • . . . . 165

Order I. Protoascineæ $\quad . \quad . \quad . \quad . \quad . \quad . \quad . \quad .165$

Order II. Protodiscineæ . . . . . . . . . 166

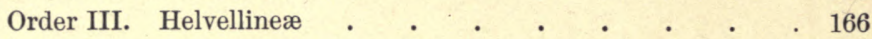

Order IV. Pezizineæ $\quad . \quad$. $\quad . \quad . \quad . \quad . \quad .167$

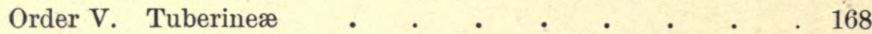

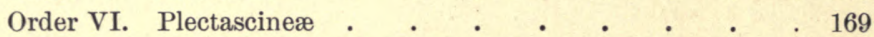

Order VII. Pyrenomycetes . . . . . . . 170

Order VIII. Laboulbeniaceæ . . . • . . . 173

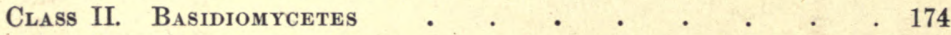

Subclass I. Hemibasidieæ $. \quad . \quad . \quad . \quad . \quad . \quad . \quad .174$

Order I. Ustilagineæ $\quad . \quad$. $\quad . \quad . \quad . \quad . \quad .174$

Subclass II. Protobasidiomycetes . . . . . 175

Order I. Auricularineæ (Rusts) . . . . . . . 175

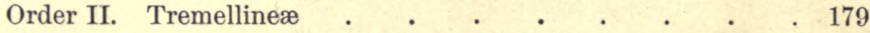

Subclass III. Autobasidiomycetes . . . . . . 180

Order I. Exobasidiineæ . . . . . . . 180

Order II. Hymenomycetineæ . . . . . . . . 180

Gasteromycetes . . . . . . . . . . . . 185

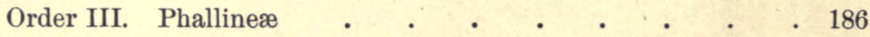

Order IV. Lycoperdineæ . . . . . . . . 187

Order V. Nidularineæ $. \quad . \quad . \quad . \quad . \quad . \quad . \quad .187$

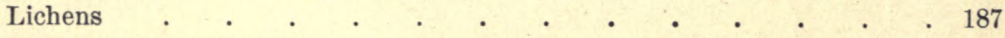

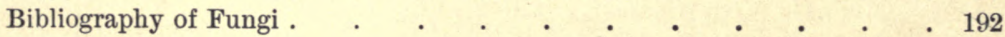

\section{CHAPTER VII}

The Archegoniate; Muscinee

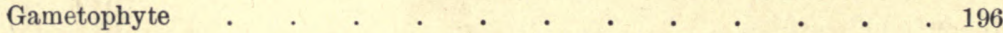

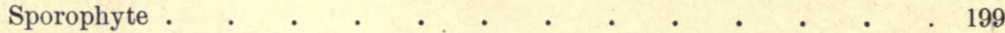

The Muscineæ (Bryophyta) . . . . . . . . . 200

Hepatice. . . . . . . . . . . . . . 202

Order I. Marchantiales • • • • • • . . 205

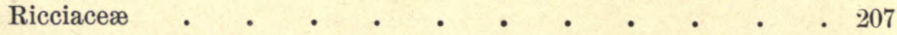

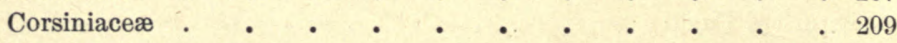

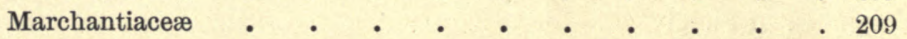


Order II. Jungermanniales

Anacrogynæ .

211

Acrogynæ

\section{Anthocerotales}

Musci .

Order I. Sphagnales

Order II. Andreæales

Order III. Bryales

Bibliography

\section{CHAPTER VIII}

\section{Pteridophyta (Ferns)}

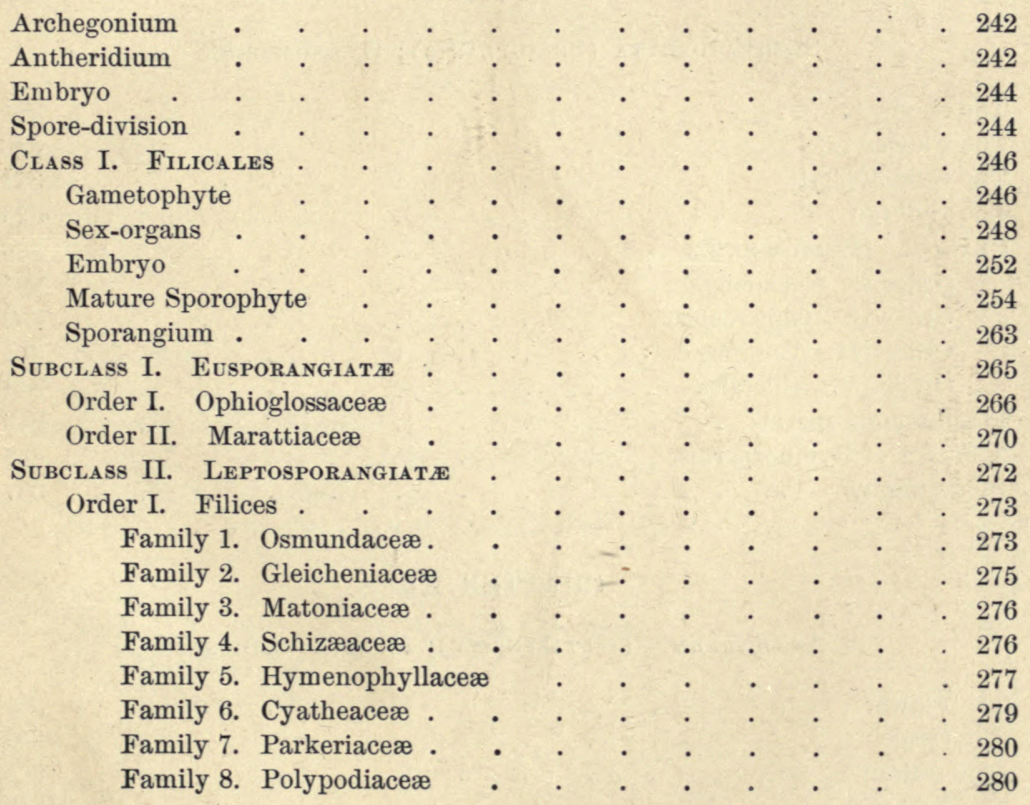

CHAPTER IX

Pteridophyta (Concluded)

Salviniaceæ .

Marsiliaceæ . 
Class III. Lycopodiales .

Lycopodiineæ . . . . . . . . . . . . . 504

Gametophyte . . . . . . . . . . . 304

Sporophyte . . . . . . . . . . . 507

Psilotineæ . . . . . . . . . . . . . . . 309

Selaginellineæ $. \quad . \quad . \quad . \quad . \quad . \quad . \quad . \quad . \quad . \quad .310$

Gametophyte . . . . . . . . . . . . . 311

Sporophyte . . . . . . . . . . . . 313

Isoetineæ . $\quad . \quad . \quad . \quad . \quad . \quad . \quad . \quad . \quad . \quad 315$

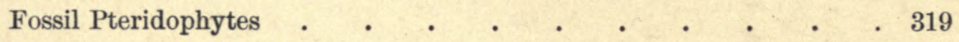

Bibliography

319

\section{CHAPTER $\mathbf{X}$}

Spermatophyta (Seed-plants); Gymnosperma

The Seed

The Flower .

The Gametophyte

The Embryo

Class I. Gymnosperme . . . . . . . . . . . . . . 325

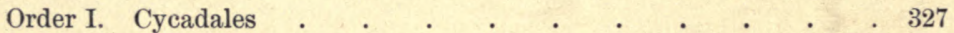

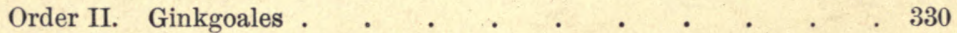

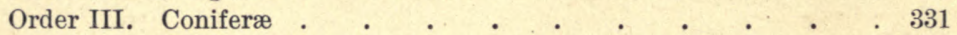

Order IV. Gnetales . . . . . . . . . . . 344

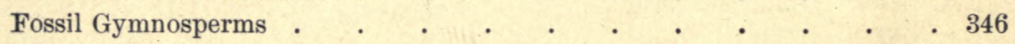

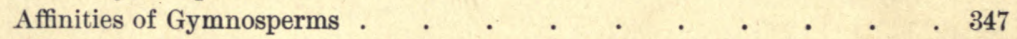

Bibliography . . . . . . . . . . . . . 347

CHAPTER XI

Angiosperme (Metasperme); Monocotyledones

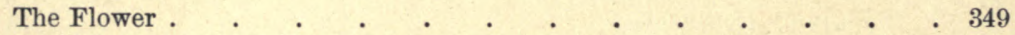

The Ovule . . . . . . . . . . . . . . . 354

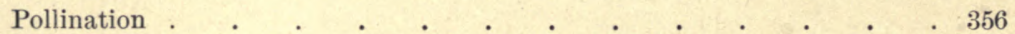

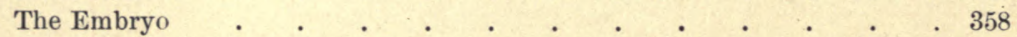

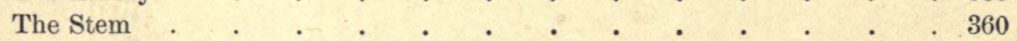

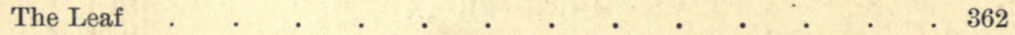

The Root . . . . . . . . . . . . . 363

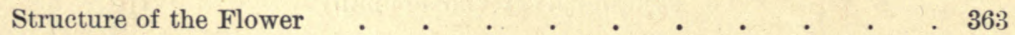

The Fruit . . . . . . . . . . . . . 367

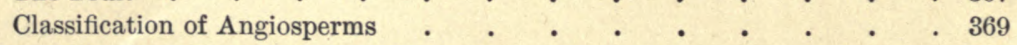

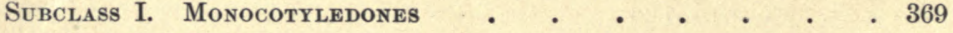

Gametophyte . • • . • • • • • • . 370

Embryo . . . . . . . . . . . . . . 371

Germination . . . . . . . . . . 372 
Mature Sporophyte

Order I. Helobieæ (Fluviales) . . . . . . . . 381

Order II. Pandanales $\quad . \quad$. $\quad . \quad . \quad . \quad . \quad . \quad .383$

Order III. Glumifloræ . . . . . . . . . . 384

Order IV. Principes (Palmæ) . . . . . . . . 386

Order V. Synanthæ . . . . . . . . . . . 388

Order VI. Spathifloræ . . . . . . . . . . 388

Order VII. Liliifloræ $\quad . \quad . \quad . \quad . \quad . \quad . \quad .390$

Order VIII. Farinosæ . . . . . . . . . . 392

Order IX. Scitamineæ $\quad . \quad$. $\quad . \quad . \quad . \quad . \quad . \quad .393$

Order X. Microspermæ . . . . . . . . 395

\section{CHAPTER XII}

\section{Dicotyledones}

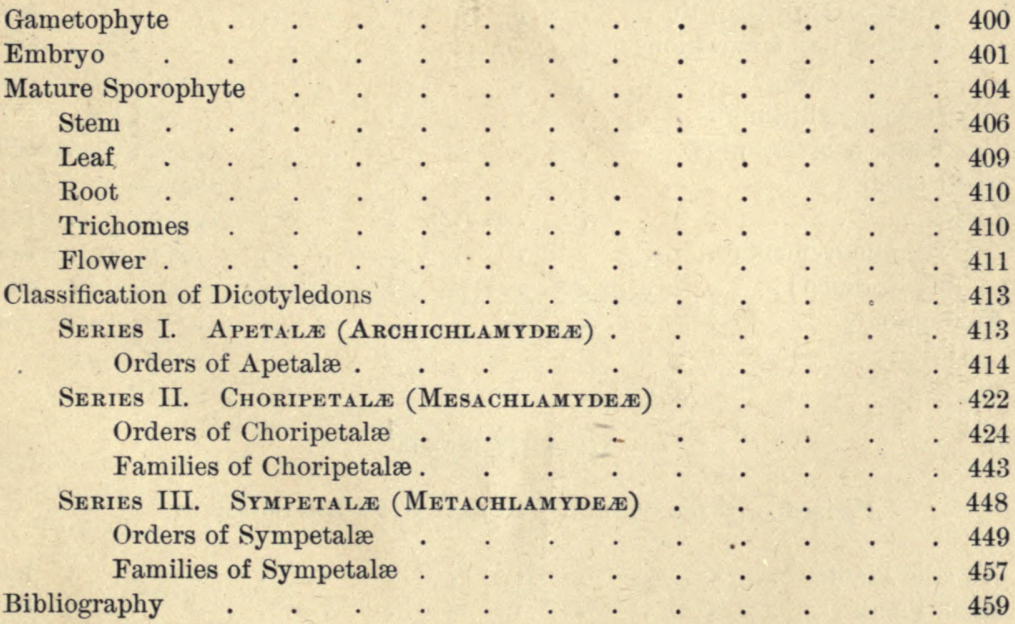

\section{CHAPTER XIII}

Physiology ; Nutrition, Respiration, Growth, Irritability

Food of Plants

Sources of Food

Imbibition

Mechanics of Absorption

Translocation

Movements of Gases

Osmotic Pressure . 
$\cdot+\cdot \cdot \cdot \cdot+467$

Properties of the Soil . . . . . . . . . . . . 468

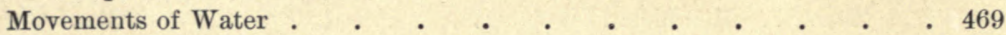

Transpiration . $. \quad . \quad . \quad . \quad . \quad . \quad . \quad . \quad 470$

Photosynthesis . . . . . . . . . . . . . . 472

Products of Photosynthesis . . . . . . . . . 473

Chemosynthesis . . . . . . . . . . . . . . 475

Assimilation of Organic Food $\quad . \quad$. $\quad . \quad . \quad . \quad . \quad . \quad . \quad . \quad 475$

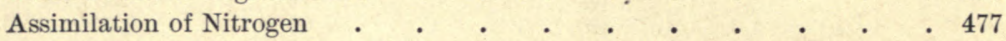

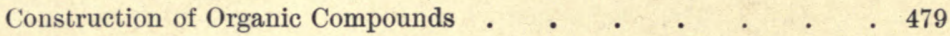

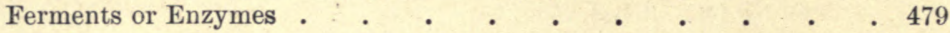

Excretion . . . . . . . . . . . . . . . 480

Respiration . . . . . . . . . . . . . 480

Growth

Anaërobic Respiration . . . . . . . . . . 481

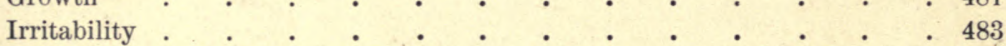

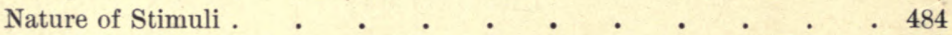

Movements of Growth . $\quad . \quad$. $\quad . \quad$. . . 484

Movements of Variation _ . . . . . . . . . 486

Chemical Stimuli . $. \quad . \quad . \quad . \quad . \quad . \quad . \quad .487$

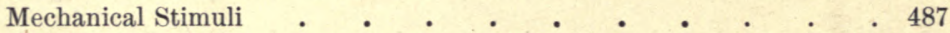

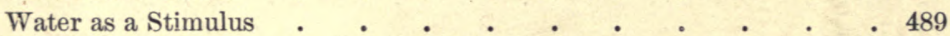

Geotropism . . . . . . . . . . . . . . . 491

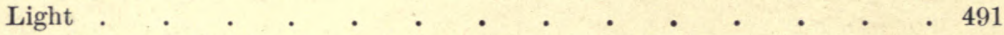

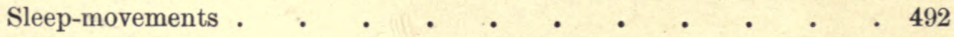

Heliotropism. . . . . . . . . . . . 492

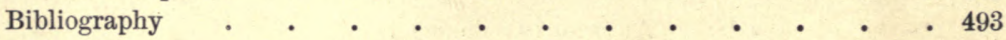

\section{CHAPTER XIV}

Physiology (continded); Relation to Environment

Aquatic Plants

Land Plants

Mesophytes

Xerophytes

Epiphytes

Climbing Plants

Protection against Cold

Parasites and Saprophytes

Carnivorous Plants

Symbiosis

Reproduction

Distribution of Seeds . $\quad . \quad$. $\quad . \quad . \quad . \quad . \quad 511$

Pollination

Hydrophilous Flowers 


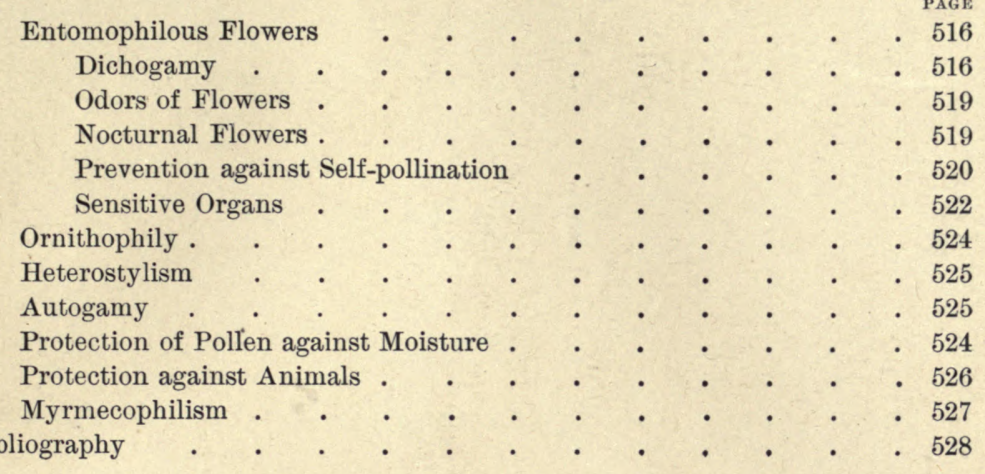

\section{CHAPTER XV}

\section{Geological and Geographical Distribution}

Fossil Plants

Thallophytes.

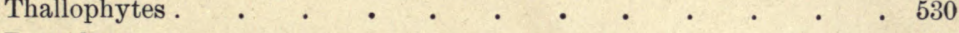

Bryophytes . $. \quad . \quad . \quad . \quad . \quad . \quad . \quad 531$

Pteridophytes $\quad . \quad . \quad . \quad . \quad . \quad . \quad . \quad . \quad . \quad . \quad .531$

Gymnosperms . $\quad . \quad . \quad . \quad . \quad . \quad . \quad 535$

Monocotyledons . $. \quad . \quad . \quad . \quad . \quad . \quad . \quad . \quad .536$

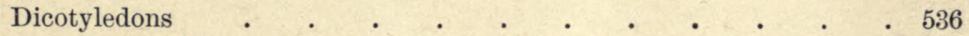

Factors influencing the Distribution of Living Plants _ _ . . . $\quad .536$

Climate. . . . . . . . . . . . . 537

Isolated Floras $\quad . \quad+\quad . \quad . \quad . \quad . \quad . \quad . \quad . \quad . \quad 541$

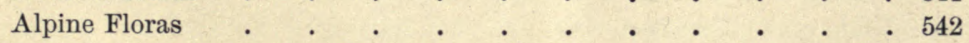

Similarity in Remote Regions . . . . . . . . . 542

Flora of the United States . . . . . . . . . . . 544

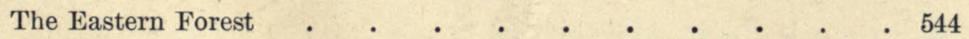

Prairies. . . . . . . . . . . . . . 545

Deserts . . . . . . . . . . . . . . 546

Flora of the Pacific Coast . . . . . . . . . . 547

Bibliography . . . . . . . . . . . . 550 



\section{BOTANY}

\section{CHAPTER I}

\section{INTRODUCTION}

Continuous change is necessary in order that the material universe may remain in its present condition. Since the amount of matter is constant, it follows that the particles of matter must be capable of dissociation and recombination, otherwise, sooner or later, a stable condition is reached which is incompatible with the existence of life. Living organisms, plants and animals, are the most important agents upon the earth in this redistribution of matter. 'The inert, inorganic substances are decomposed through the activity of living organisms, the components being united with others into the innumerable compounds of which living substances are composed. The organic compounds in turn undergo repeated changes within the organism, which may itself serve as food for others. The simpler compounds resulting from the chemical changes within the organism may remain inert, like the masses of limestone developed from the skeletons of coral polyps, or the flinty deposits left by the accumulated shells of Diatoms ; or, like carbon-dioxide, they may again be utilized as food for plants.

It is the province of biology, in its broadest sense, to study the part played by plants and animals in the economy of nature - their relation to each other and to the inorganic world.

Organic and Inorganic Bodies. - It is not possible to draw a hard and fast line between the so-called "organic" and "inorganic" bodies. While many of the substances characteristic of living bodies have as yet baffled the chemist's skill, he has, nevertheless, succeeded in manufacturing in the laboratory so many "organic" compounds, e.g. uric acid, glucose, sugars, vegetable alkaloids like coniin and others, oil of bitter almonds and other essential oils, etc., that it is no longer held that these substances can be formed only through the agency of the supposed vital force.

Nevertheless, all living things are, as such, radically different in certain respects from all inanimate forms of matter. They are always, to a certain extent, capable of spontaneous movement; they 
all assimilate food substances from without, which undergo profound chemical changes before they are incorporated with the substance of the organism, which by virtue of this food-assimilation grows; they respire, i.e. develop energy by the decomposition of complex substances through oxidation, or occasionally otherwise; finally, they always show some form of reproduction by which new individuals are formed.

Thus a flowering plant absorbs through its roots water and various dissolved mineral constituents, and through the stomata, small openings in the epidermis of the leaves, takes in carbon-dioxide from the atinosphere. By virtue of energy derived from sunlight, the green cells of the leaves are able to decompose water and carbon-dioxide, from which they manufacture the elementary organic compounds which are needed to build up the tissues. Oxidation of the tissues, resulting in the evolution of heat and giving off of water, accompanies all the vital activities. This respiration is not as active in green plants as it is in animals, but is otherwise much the same.

For a long time - sometimes many centuries - the assimilation of food exceeds the loss through respiration and otherwise, and the plant increases in bulk. Finally the growth declines and the plant dies. During its active growth provision is made for continuing the species, either by the separation of buds from the parent plant, or by the formation of seeds.

While movement in the higher plants is seldom conspicuous, a study of the behavior of the plant will show that movement of various parts is often easily demonstrable.

Protoplasm. - In living tissues there is invariably present a peculiar substance, protoplasm, with which all vital functions are associated, and which has, therefore, very aptly been termed the physical basis of life.

Every living organism is a factory in which there is a never-ceasing production of substances which help to build up the body. This is accompanied by the formation of waste-products, which may, however, serve as food for other organisms.

Sources of Energy. - In order that these vital processes may be maintained, a supply of energy is necessary, and this is furnished either by the decomposition of organic food, or, in the case of green plants, directly by the sun's rays. So far as we certainly know, only such organisms as possess the peculiar green pigment, chlorophyll, or leaf-green, or its physiological equivalent bacterio-purpurin, have the power to assimilate the carbon-dioxide of the atmosphere, which is the ultimate source of all the carbon in the cells of plants and animals. The green cells absorb the light-rays whose energy is employed in the decomposition of $\mathrm{CO}_{2}$ and water, and the manufacture of the primary organic carbon compounds, of which starch and sugar are 
usually the first to be seen. Since green plants alone can manufacture these carbohydrates, the whole carbon supply for both plants and animals is ultimately dependent upon these green plants.

While the power to assimilate carbon-dioxide seems to be confined to green plants, it is not impossible that certain Bacteria which do not possess chlorophyll, may have this power to a limited extent. In such forms there is found a red or purple pigment which may possibly replace chlorophyll in the process of decomposing carbon-dioxide. Moreover, the so-called nitrifying Bacteria ar'e able to decompose the simple nitrogen compounds, like ammonia, and manufacture the nitrogen compounds which are available for the higher plants. Still other Bacteria, which inhabit tubercles on the roots of various leguminous plants, can use free nitrogen. The fixation of nitrogen by these Bacteria is of very great importance in the economy of nature, but has only been understood of recent years.

With the possible exception of a few Bacteria, all plants without chlorophyll, such as Fungi and many parasites and saprophytes among the flowering plants, e.g. Dodder, Indian-pipe, etc., must obtain their carbon in the form of organic compounds, thus behaving like animals. In case they attack living plants or animals, as do many Bacteria and Fungi, or such flowering plants as Dodder or Mistletoe, they are called parasites; if they feed on dead matter, like many Moulds, Toadstools, etc., they are saprophytes. Thus the power to manufacture the primary organic compounds is by no means universal among plants, and cannot be used as a certaiu criterion to distinguish them from animals.

Structural Resemblances in Plants and Animals. - The essential structures of plants and animals are extraordinarily similar, - so great, indeed, that among the simpler forms it is often difficult to say to which kingdom they belong. In all cases, life is bound up with the presence of protoplasm, which so far as can be judged by ordinary physical and chemical tests is alike in plants and animals. Of course there must be inherent peculiarities in the protoplasm of different organisms, but at present we have no means of distinguishing these. The simplest known organism consists of a minute, usually nucleated mass of protoplasm which exhibits sensitiveness, motility, and the power of nutrition and respiration. By simple division two new individuals arise - the simplest form of reproduction. In short, such a nucleated particle of protoplasm is capable of manifesting all the characteristics of a living organism.

Multicellular Organisms. - While many animals and plants consist of a single nucleated protoplasmic mass, or are "unicellular," much the greater number are composed of cell-aggregates or tissues, but each individual, however complicated, may be traced back to a single such cell. The extraordinary likeness in the structure and behavior of 
the cells of animals and plants is perhaps the strongest evidence, to the biologist, of the intimate counection between all living things.

The Cell. - With few exceptions the protoplasm is segregated into masses of definite form known as cells, and each cell contains an organized body, the nucleus, while in many plant-cells, other parts like the cell-wall and chromatophores are present. The character of the cell-plasma, or cytoplasm, and that of the nucleus of the animal and vegetable cell are extraordinarily similar, and this is true, also, of the phenomena connected with the formation of new cells.

The Simplest Forms of Life. - The lowest organisms are often so slightly differentiated that it is not possible to assign them positively

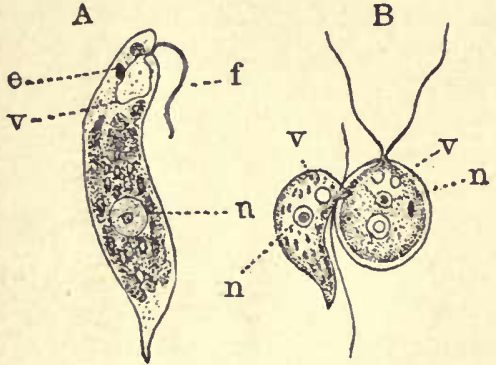

Fig. 1.- $\boldsymbol{A}$, Euglena viridis, a green Flagellate; $e$, eye-spot; $v$, contractile vacuole; $n$, nucleus; $f$, flagellum $(\times 700) . \quad B$, a colorless Flagellate, Bodo caudatus, attacking a ciliated green plant, Chlamydomonas; lettering as in $A(\times 520)$. (After Bütschli.) to either the animal or vegetable kingdom ; indeed, there is much diversity of opinion as to the affinities of many of these simple forms. Most of these exhibit active movements, and at first sight would be at once classed as animals. Many of them, however (Fig. $1 \mathrm{~A}$ ), possess green chromatophores, and in other respects show unnistakable plantaffinities. It is not at all unlikely that some existing forms are real. ly intermediate in character, and resemble the common ancestors from which the two great organic kingdoms may have diverged.

The presence of chlorophyll may be considered a strictly vegetable characteristic. Where chlorophyll occurs in the body of animals, e.g. Hydra viridis, fresh-water Sponges (Spongilla), various Infusoria, etc., it has been shown that the chlorophyll belongs to minute unicellular plants (Algæ) which are associated with the animal. Where chlorophyll is certainly present in the cells of an organism, its vegetable nature may be pretty safely assumed. However, as we have already seen, many unmistakable plants are quite destitute of any chlorophyll.

The Cell-wall of Plants. - Another character common to all typical plants is the substance composing the cell-membrane. The cells of most plants are surrounded by a definite membrane, which in its early stages, at least, is made of a characteristic carbohydrate, cellulose, much resembling starch in its chemical composition. In some cases, especially among Fungi, the cell-wall is composed of a substance differing slightly from ordinary cellulose, and among the Bacteria a true cellulose membrane is rare, although it sometimes occurs. 
Animal cells rarely show so definite a cell-wall, and this, when present, is not of cellulose, but of a nitrogenous compound more nearly resembling the cytoplasm. Very often in animal tissues the boundary of the individual cell is not clearly marked, and the result is a "syncytium," or multinucleate protoplasmic mass, rarely found in plants.

Movement in Plants. - The development of a firm membrane about the cell interferes, of course, with its motility, and we thus find plants, as a rule, much less motile than animals, this being especially true of the larger multicellular forms.

The lower plants, especially many unicellular forms, are often actively motile, the movements being due to the vibration of delicate protoplasmic threads (cilia), which are either prolongations of the naked cell-body, or pass through openings in the cell-wall. By means of the cilia, the plant swims freely in the water like an Infusorian. The possession of cilia in the ordinary vegetative condition of the plant is confined to a comparatively small number of the lower forms; but these often show at times a passive stage, e.g. the so-called "Palmella" stage of certain Volvocaceæ-the "Zoöglœea" stage of many Bacteria. This latter condition becomes the rule in all the higher plants, and only the reproductive cells show a reversion to the free-swimming, ciliated type. With the assumption of the non-motile vegetative conditions, the stationary character of the typical plant-organism is established.

Motility in Animals. - The case is different with animals. In these the active cells remain permanently naked, or at any rate destitute of a rigid nembrane. In consequence, the cells are capable of much greater change of form and size than is ever the case with plants. The power of spontaneous locomotion in plants becomes less marked as differentiation proceeds, and in the highest forms is entirely lost. In animals the reverse is true, and the most highly specialized forms show most perfect motility. We rightly, then, consider locomotion as a distinctly animal attribute, although not confined exclusively to the animal kingdom.

The power of locomotion is no doubt associated with the question of food. Plants being able to use the inorganic compounds derived from the atmosphere and earth, which are renewed from time to time, and above all the power of green plants to utilize the energy of the sun's rays, make it unnecessary for them to move away from the spot where they grow ; and except for the establishment of new individuals, they do not develop means of locomotion. A few animals, like the Corals and many Mollusks, where the currents of water bear them renewed supplies of food, behave in this respect much like plants; but most animals must be able to range over a large area in order to obtain the food necessary to support life. 
While it is impossible, then, to make any absolute distinctions between animals and plants, we may say that in general, the most marked characters of typical plants, as distinguished from animals, are (1) the presence of chlorophyll, and the accompanying power of photo-synthesis; (2) the presence of a cellulose membrane about the cells; (3) the absence of locomotion in the plant-body.

\section{Conditions of Plant-life ${ }^{1}$}

Since all animals are directly or indirectly dependent on plants for food, it follows that wherever animal life exists, plants can also grow. Green plants, of course, can only thrive where a certain amount of sunlight is present, since photo-synthesis, or the assimilation of carbon-dioxide, is dependent on light. The amount of light necessary is extremely various. Thus, many Seaweeds grow in water so deep as to exclude rnuch of the light, and some Ferns and Mosses live in dimly lighted caves, or flourish in the twilight of dense forests; while Cacti and Palms endure the full blaze of an unclouded tropical sun. We shall consider later some of the ways in which plants adapt theinselves to the varying amount of light.

Temperature. - There is a certain range of temperature within which the vital functions of plants are active. As might be expected, this range is different for different plants. Some plants flourish at a temperature close to the freezing point of water, and may be frozen while actively growing, without injury. Others are quickly killed by a temperature considerably above the freezing point, while they thrive best at a high temperature which would almost instantly destroy a Seaweed accustomed to the cold water of the northern Ocean, or an Alga growing in an icy mountain stream.

It is among the lower plants, and the dried resting structures, like seeds and spores of the higher ones, that the greatest powers of resistance to extremes of temperature are found. Even in their active condition, many Bacteria can endure an extraordinary range of temperature, but it is the resting stages, or spores of these, as well as the seeds and spores of the higher plants, which are most resistant, especially to extremely low temperatures.

The presence of water in the cells makes them far less resistant to both high and low temperatures. Especially sensitive are plants like many Seaweeds, which grow in cold water which varies but little in temperature throughout the year. These plants are destitute of the protective structures which have been developed by land plants.

Water in Plants. - All manifestations of life are bound up with the presence of water. Without it the protoplasm cannot act; and

1 The special physiology will be treated more fully in later chapters. 
although not necessarily killed by the withdrawal of water, it remains passive until the proper amount of water is supplied. Water possesses both a mechanical and a nutritive function. Unless saturated with water, so that it assumes a semifluid condition, the protoplasm cannot act ; moreover, all normal plant-cells must be in a turgid condition in order to be active; and finally, water is the vehicle by which most of the food elements are brought into the cells. Water itself is an important source of food, as it is decomposed by photo-synthesis and supplies the hydrogen for the primary carbohydrates manufactured in the green cells.

The amount of water, of course, varies in different plants and in different parts of the same plant. It is highest in subinersed aquatics like Algæ, Pondweeds, etc., and lowest in dry, woody, desert plants, and dried seeds and spores, which are especially adapted to resist desiccation.

Food of Green Plants. - While animals can ingest solid food, this is with rare exceptions impossible for plants, which absorb food in a gaseous or liquid form. The main sources of food supply for green plants are the $\mathrm{CO}_{2}$ of the atmosphere, water, and dissolved mineral constituents from the earth. The elements which are absolutely essential are comparatively few, the most important being Oxygen, Hydrogen, Carbon, and Nitrogen, which constitute the principal part of the protoplasm and cell-walls; while, in addition, Sulphur, Phosphorus, Potassium, Calcium, and Iron are never absent from normal green plants.

Other elements which are not essential are regularly met with in certain plants. Thus Grasses always show a large amount of Silicon; Chlorine and Sodium are regularly found in salt-marsh plants; Iodine occurs in the large brown Seaweeds.

Nutrition of Plants without Chlorophyll. - Since the power of assimilating $\mathrm{CO}_{2}$ is confined to green plants, such forms as have no chlorophyll must derive their carbon from organic sources. Hence Moulds, Toadstools, and other Fungi, and many Flowering plants, e.g. Indian-pipe (Monotropa), Snow-plant (Sarcodes), Beechdrops (Epiphegus), etc., feed either as parasites upon living plants or animals, or grow as saprophytes mpon dead organic matter, or in soils filled with decaying organic substances, like leaf-mould. A small number of plants are still more like animals in their habits, actually capturing living animals - Insects or Crustaceans - which furnish them with nitrogenous food. Among the most familiar of these carnivorous plants are the Pitcher-plants, Sundews, and Venus's Flytrap.

Respiration. - All organisms must respire; i.e. develop energy through the decomposition of organic matter. This is in much the greater number of cases oxidation of carbonaceous compounds with 
evolution of heat. While respiration is usually more active in animals than in plants, it differs in no other respect in the two kingdoms, and sometimes respiration is active enough in plants to show a very marked rise in temperature. Thus the heat in a hot-bed is the result of the active respiration of the Bacteria in the manure, and germinating seeds respire actively enough to produce a very evident rise of temperature. So, also, large inflorescences, especially when enclosed as they are in many Araceæ and Palms, show a marked evolution of heat while the pollen is being shed.

The popular error that in respiration plants inhale $\mathrm{CO}_{2}$ and exhale oxygen, is based upon a misconception of what respiration really is. Respiration is here confounded with the assimilation of $\mathrm{CO}_{2}$ by green plants, or photo-synthesis, a process entirely different from real respiration, which goes on in green plants, as well as in others, quite independently of light.

Movements in Plants. - While movements are usually less pronounced in plants than in animals, still no plants are entirely destitute of some power of movement. As long as there is living protoplasm in the cells, this must retain the power of movement; and movements of the plant, as a whole, or of special organs, are familiar phenomena even among the most specialized plants. Locomotion is confined to the simpler forms of plant-life which are not fixed. These low organisms, like Volvox, may be ciliated, and swim rapidly in the water, or the movement may be a slow, creeping one, such as many Diatoms and Desmids show, or a few filamentous plants like Oscillaria and Nostoc. Free-swimming reproductive cells are common in a great many of the lower plants, and this power is retained by the spermatozoids of the Ferns and Cycads. The movements of the growing parts of the higher plants, and such periodic movements as the opening or closing of flowers, sleep-movements of leaves, etc., illustrate some of these movements.

\section{Reproduction}

All living things are capable of reproduction in some form, and in this respect differ from non-living bodies. Plants and animals agree very closely in their reproduction, and we find much the same development of this power in both great groups of organisms. The simplest form of reproduction is the division of an individual into two similar ones by fission. This is very common in a large number of the lower animals and plants. Such reproduction is, of course, strictly, non-sexual, and we caunot speak of special reproductive cells as distinguished from purely vegetive (or somatic) ones.

Non-sexual reproduction occurs in various forms in all plants, while among animals it is rare except in the lower types. In many 
of the lower plants it is the only form of reproduction known. A number of non-sexual types of reproduction are known in plants, the two principal being either by spores, - usually single cells, which become detached and grow into new individuals; or by budding, or the formation of branches, which, on becoming detached, already show the principal organs complete; indeed, it is not easy to say what limits the individual in plants, as there is such a repetition of parts. A tree, for example, may be compared to a stock of Coral, with its multitude of similar individuals, rather than to a highly organized individual like an Insect or Vertebrate. If a branch is severed from the tree, it may under proper conditions develop roots, and establish itself as a new stock. This never occurs among the higher animals, where the power to restore lost parts is exceedingly limited, and new individuals must always be produced from special sexual reproductive cells.

Sexual Reproduction. - Sexual reproduction consists in the production of a new individual by the fusion of two cells, generally the product of different individuals. There is extraordinary similarity in the character of the sexual cells of plants and animals, as well as in the phenomena connected with their development and union. This is the more striking because it is clear that sexuality has developed quite independently in widely separate groups, and there are still existing a number of classes of plants which show all stages of the process. In the simplest form of sexual reproduction the cells are quite similar, but there is usually a well-marked separation into male and female cells, distinguished by differences in size, and in many instances by the motility of the male element (sperm), which is a free-swimming, ciliated body, while the much larger female cell - egg-cell or ovum - is usually passive. The sperm-cell penetrates the egg, and its nuclear substance mingles with that of the egg, which is thus stimulated into further growth, and produces, directly or indirectly, the new generation.

\section{Biology}

Animals and plants agree so closely in their cell-structure and the essential life-functions - nutrition, respiration, and reproduction that these points may be made the subject of biological study irrespective of whether the organisms concerned are plant or animal, all coming equally within the domain of Biology. However, since the peculiar animal or vegetable characters become manifest very low down in the scale of development, it is possible to relegate most organisms to either the animal or vegetable kingdons, and we therefore recognize two coördinate branches of Biology, - Zoölogy and Botany. 
In studying plants and animals we may consider them from different standpoints. Thus we may einphasize the study of structure; or the working of the organism - its functions - may be the phase dwelt upon; or its position in the scale of development - its relationship to other organisms - may be made the principal subject of study. As one or the other of these is emphasized, Biology falls into the three great divisions of Morphology, Physiology, and Taxonomy.

Morphology. - Morphology is that branch of Biology which deals primarily with structure. The structure of the cell, the combinations and changes of cell-structures to form tissues, and the combinations of tissues into organs are the principal subjects of morphology, which may be divided into several sections; General Morphology, Gross Anatomy, Organography, are terms often employed to express such general study of the structure of an organism as can be made without much optical assistance. Thus the form and position of the parts of the higher plants - leaf, stem, root, flowers, etc., - or dissections of an animal, come under the head of General Morphology. Should we call in the aid of the compound microscope to see the character of the tissues composing the organs, we then enter the domain of Histology, which deals with the origin and structure of tissues. Finally, Cytology is the department of morphology which concerns itself with the structure of the cell. Cytology has made very great advances of late years, owing to the improvements in microscopical lenses, and the labors of bioloyists in perfecting methods of fixing and staining the various constituents of the living cell. The study of the development of the organism from the egg-cell, or Embryology, may also be considered as a special department of morphology, and might be extended to include the early stages in the development of the young organs as well.

Physiology. - Physiology, in its proper sense, is concerned purely with function, although, of course, any study of function must necessarily take into account the structure of the organs concerned. The problems of nutrition, movement, respiration, and reproduction are the principal subjects of physiological study, but there are some others which may properly be considered physiological. Thus the various ways by which an organism becomes fitted to its special environment are physiological problems, which are now treated as a special department of physiology, under the name CEcology.

Taxonomy. - All living things are assumed to be more or less intimately related. It is therefore important that some system of classification should be adopted which will indicate, as nearly as may be, the degree of relationship. 'The earlier systematists, especially Linné, who was the most influential, accepted the dogma of the immutability of species, i.e. that all species were created in their present form. 
Hence there was no question of any real relationship such as now is universally accepted among biologists. These early efforts to establish a uniform system of classification, while necessarily more or less artificial, still laid the foundation for the modern "natural" system. The aim of the modern systems is to express as exactly as possible the degree of relationship existing between different groups of organisms. Thus the two great divisions - the animal and vegetable kingdoms - are divided into branches or sub-kingdoms, these into classes, classes into orders, etc., each expressing a closer degree of kinship than the one above. Thus the White Elm of our Eastern States was named by Linné Ulmus Americana to distinguish it from all other Elms, which with it comprise the genus Ulmus. These are united with the Hackberries and a small number of other trees into the family Ulmacece. The following table will illustrate:-

Sub-kingdom - Spermatophyta (Seed-bearing plants).

Class - Angiospermæ (Plants with closed ovary).

Sub-class - Dicotyledones (Seed-plants with two seed-leaves).

Order - Urticales ; Elms, Nettles, Figs, etc.

Family - Ulmaceæ; Elm family.

$\left.\begin{array}{l}\text { Genus Ulmus } \\ \text { Species Americana }\end{array}\right\}$ White Elm.

Geographical Distribution. - The study of the distribution of plants upon the earth is a most interesting phase of botany, and may be treated as a special department under the name of Plant Geography, or Phyto-geography. As this is largely a question of adaptation to environment, it is really a part of Ecology.

Geological Distribution. - While the fossil remains of plants are often imperfect, and the geological record has many extensive gaps in it, nevertheless much light has been thrown upon the development of plant-life upon the globe by a study of the fossils which have been discovered; and it may be confidently expected that much more remains to be accomplished. These discoveries are of special importance in connection with Morphology and Taxonomy, but we may consider the fossil plants apart, as the subject of the special branch of botany known as Palæophytology, or Fossil Botany. 


\section{CHAPTER II}

\section{THE PLANT-BODY}

Some of the simplest organisms, like Amœba (Fig. 2), and the Slime-moulds or Myxomycetes, consist of naked, highly contractile protoplasm, which in the latter contain many nuclei. Usually the

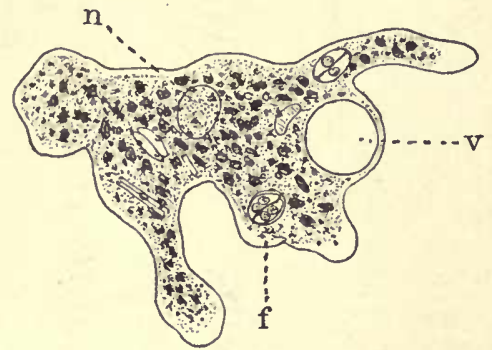

FIG. 2. - Amœba proteus, an organism consisting of a naked protoplast; $n$, nucleus; $v$, contractile vacuole; $f$, food-vacuole containing a Diatom $(\times 200)$. protoplasm is segregated into definite masses or cells, each with a single nucleus, and in plants, surrounded by a membrane or cellwall of cellulose. The cell-wall is not an essential part of the cell, and can be reproduced through the activity of the protoplasm. Such a large multinucleate mass of protoplasm as the plasmodium of the Slime-moulds cannot properly be considered a single cell, and this may be said of the large "cells" or Cœnocytes of such plants, as the Siphoneæ; e.g. Botry-

dium. The name "Energid" has been proposed for the structural unit of organisms, an energid being defined as a single nucleus with the surrounding cytoplasm which is under its influence. A plasmodium of a Slime-mould, or the multinucleate cell of Cladophora, would then represent an aggregate of as many energids as there are nuclei.

\section{The Plant-cell}

The typical vegetable cell consists of a cellulose membrane enclosing the cytoplasm or cell-plasm, in which is embedded the nucleus and one or more green bodies, the chromatophores or chloroplasts. Many of the lower plants consist of a single such cell, which exhibits all the functions characteristic of the higher plant-forms. Such a green cell represents the simplest form of a typical plant, and it performs all the essential functions found in the highest plants. It absorbs through the permeable cell-wall water containing in solution various inorganic salts; and from the air, or dissolved in water, oxygen and carbon-dioxide. Through the energy derived from light, 
and by oxidation, the food elements are decomposed and recombined into the organic compounds needed to build up the cell. These unicellular plants are very often actively motile, a condition which in the higher plant-forms is usually restricted to special cells. These active movements are due to cilia - delicate vibratile protoplasmic threads which propel the cell through the water. This free-swimming condition is probably more primitive than that in which the cells are stationary, and such motile plants show evident relation to similar unicellular animals. The occurrence of such ciljated cells in many of the lower plants, and the frequent reversion to the free-swimming condition in the reproductive cells of the higher ones, indicate that the earliest plant-forms were probably actively motile, and much like the simpler existing Volvocaceæ.

\section{Reproduction}

The simplest form of reproduction in these unicellular plants is by mere fission, or the division of the cell into equal parts, each of which becomes at once a complete organism like the original one. Sometimes, instead of the whole cell dividing, it is simply the cellcontents, which divide into two or more parts, each with its own nucleus and chromatophore. These new cells escape from the old one, most often as ciliated bodies, which may at once come to rest and form a new individual, or two of them may fuse into a single cell. This is the simplest type of sexual reproduction, and is absent in a good many of the lower plant-forms, like the Bacteria and Bluegreen Algæ, in which reproduction is always strictly non-sexual.

It is clear, then, that a single green cell can feed, respire, grow, move, and reproduce; in short, can perform all the vital functions which are essential to the existence of the most highly differentiated plant or animal.

\section{Unicellular Plants}

While the typical unicellular plants possess a definite nucleus and chromatophore, there are still simpler forms, like the Bacteria and Blue-green Algæ, in which a definite nucleus cannot certainly be demonstrated, and in which either no chromatophore is present, or it is imperfectly differentiated. Of course where no chlorophyll is present, the organism is dependent to some extent upon organic food.

More advanced than these, and perhaps to be regarded as the starting point for the development of the higher plant-forms, are the free-swimming organisms related apparently to the flagellate Infusorians, from which they differ in the presence of a chromato- 
phore. These green Flagellata are not necessarily naked cells, but may show the characteristic cellulose nembrane, which is perforated
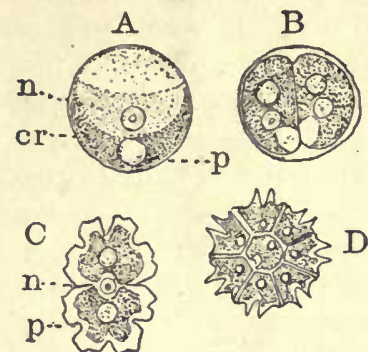

Fig. 3.- Types of unicellular $s p$ ? ( $\times$ about 1000$) ; B$, two individuals resulting from division; $c r$, chromatophore, enclosing the pyrenoid, $p$; $n$, nucleus; $C$, a Desmid, Euastrum elegans $(\times 300)$; $D$, 8-celled colony of Pediastrum $(\times 500)$. plants ; $A, B$, Chlorococcum

to permit of the protrusion of the cilia.

In all but the lowest forms of plants, the power of locomotion is lost, except in the reproductive cells, and the development of a continuous cellulose membrane prevents any protrusion of the protoplasm outside the cell, and the vegetative cells are normally stationary. Such cells present a strong contrast to the animal-like green Flagellata and motile Bacteria.

Most unicellular plants are either oval or globular - the natural form a free cell assumes where pressure is alike in all directions. There are, however, many exceptions to this, and the single cell may show much variety in form and size. Sometimes the cell is so minute as to be barely visible with the very high powers of the microscope; on the other hand, some of the cells, or more properly cœnocytes of the peculiar group, the Siphoneæ, may be ten centimetres or more in length. Of the strictly unicellular forms, probably the Desmids (Fig. 3, C) offer the greatest known variety of form. In the Siphoneæ, like Caulerpa (Fig. 4), the extraordinary differentiation of the cœnocyte is perhaps better comparable with that of a multicellular plant-body in which the division walls are suppressed, as the multinucleate protoplasm is made up of many energids. These cœnocytes, or similar multinucleate complexes, are commoner in animals than in plants.

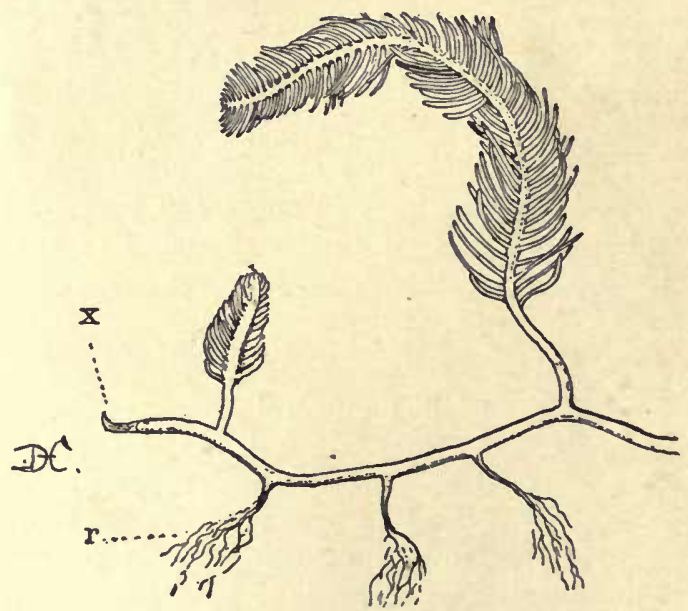

FIG. 4.-Caulerpa plumaris, a non-cellular plant or conocyte, showing differentiation into stem, root, and leaf; $x$, growing point; natural size. 
Colonies. - Sometimes, among the lower plants, unicellular individuals are associated in colonies of very definite form, in which the originally independent nembers may become intimately grown together so as to simulate a tissue formed from the repeated fission of an original cell (Fig. 3, D).

The result of fission in a unicellular organism is the production of two complete individuals. If, however, instead of separating as soon as the division is completed, the cells remain together, and fission is repeated in these cells in the same plane as before, the result is a chain of united cells, which increase in length as the cells undergo repeated division. This is really what happens in the next type of plant-body - the simple filament or cell-row, a type that is very common among the lower water-plants, or Algæ, such as Spirogyra or Conferva. In these the plant-body is a row of perfectly similar cells which arise from the repeated transverse division of a single cell, and its descendants. Every cell being similar, it might be almost as well to speak of such a filamentous Alga as a colony of unicellular individuals. The life-history of such a form as Conferva, for example, shows that the plant passes successively through a free-swimming stage, followed by a unicellular stationary conclition, which by repeated transverse fission develops into the cellrow of the adult plant. Other forms, e.g. Spirogyra, never have a free-swimming condition.

It is not uncommon for some of the filamentous Green Algæ to remain for a considerable time in the unicellular condition, in which they divide rapidly, the cells separating after division and closely resembling the permanent condition of true unicellular Algæ with which they are easily confused. These stationary cells may either grow directly into a filament, or they may-first assume again the free-swimming condition previous to the formation of a filament.

Indeed, the life-history of many of the filamentous Algæ repeats what was probably the process of evolution of these forms from the free-swimming unicellular organisms from which we may fairly suppose they originally came.

\section{Filamentous Plants}

While the simplest type of filament is that in which all the cells are alike and there is no distinction of base and apex, there are other forms, e.g. Edogonium (Fig. 5), in which the filaments are attached by a more or less modified rootlike cell, whose base corresponds to the forward end of the zoöspore from which it grew. There is here a beginning of the specialization found in higher plants. Of the two cells formed by the first division of the germinating spore, the lower is at once set apart as a mere organ of attach- 
ment, and has relatively little chlorophyll; the upper one alone

A

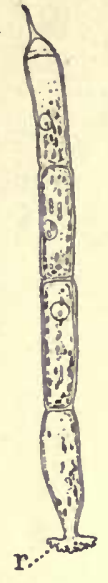

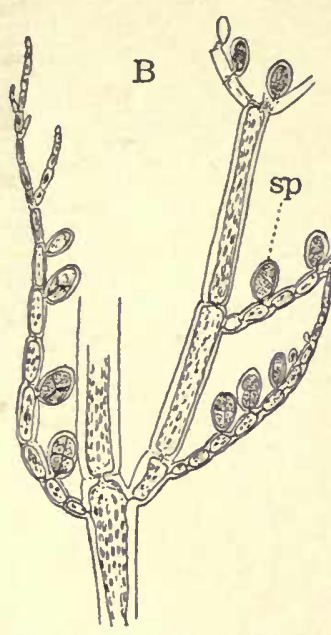

divides further, and furnishes the whole of the active cells of the plant.

Branching filaments are still more common and occur in a great many Algæ and Fungi, or even in the earlier stages (Protonema) of Mosses. The branches may be all alike, or there may be a main axis with lateral branches of different form; the latter are often - e.g. Draparnaldia, BatraFig. $5 .-A$, simple tilament of Edogonium sp. chospernum, - numer-
$\quad(\times 300) ; r$, the holdfast; $B$, branching filament of ous and crowded, and Callithamnion floccosum; $s p$, tetrasporangia.

contain relatively larger chloroplasts than the cells of the principal axis, to which they bear much the same relation that the leaves of an ordinary shoot do to the stem. These much ramified lateral branches are undoubtedly specially adapted to increase the area of green cells exposed to light.

Apical Growth. - In most of the branching filaments - less often in unbranched ones a further specialization is evident; i.e. growth from a definite apical cell (Fig. 6). In such forms, except in the case of the formation of a lateral branch, the ordinary cells do not undergo fission after they are cut off from the apical cell, which alone contributes to the growth in length of the axis.

The transition from the filament composed of a single row of cells (Monosiphonous) to the more complicated forms, where the axis

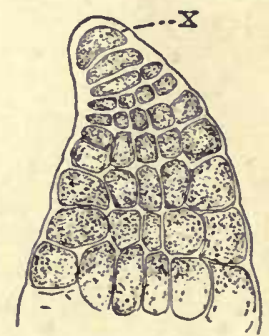

Fra. 6. - Growing point of Polysiphonia Woodii, showing the apical cell, $x(\times 500)$.

is composed of more than one cell-row, is very gradual. In the latter type, the segments of the apical cell, instead of remaining undivided, divide longitudinally, so that each joint is composed of a group of cells instead of a single one (Fig. 6). The further divisions of the segments derived from the apical cell may result in massive branching structures, such as characterize many of the larger Red and Brown Seaweeds. In these massive forms it is the 
outer cells in which the greater part of the chloroplasts are placed, and it is clear that a provision for the most favorable exposure of the green cells to light is one of the principal causes for many of these modifications of the plant-body.

\section{The Thallus}

The increase of the area of green tissue is attained in another way in many of the lower plants, where the plant-body has the form of a flat plate or Thallus. A simple example of this is the common Sea-lettuce (Ulva), and larger examples are many of the Kelps, or Brown Algæ (Fig. 7). This type of plant-body is the result of celldivision in two planes, so as to form a single layer of cells, which in most cases later becomes thicker by divisions in a third plane also. A thallus of much the same structure is found in the lower Mosses or Liverworts, and in the sexual plants (Gametophyte) of many Ferns (Fig. 7, C).

A soinewhat different type of thallose body is seen in the peculiar plants known as Fungi, which differ from the Algæ in not possessing

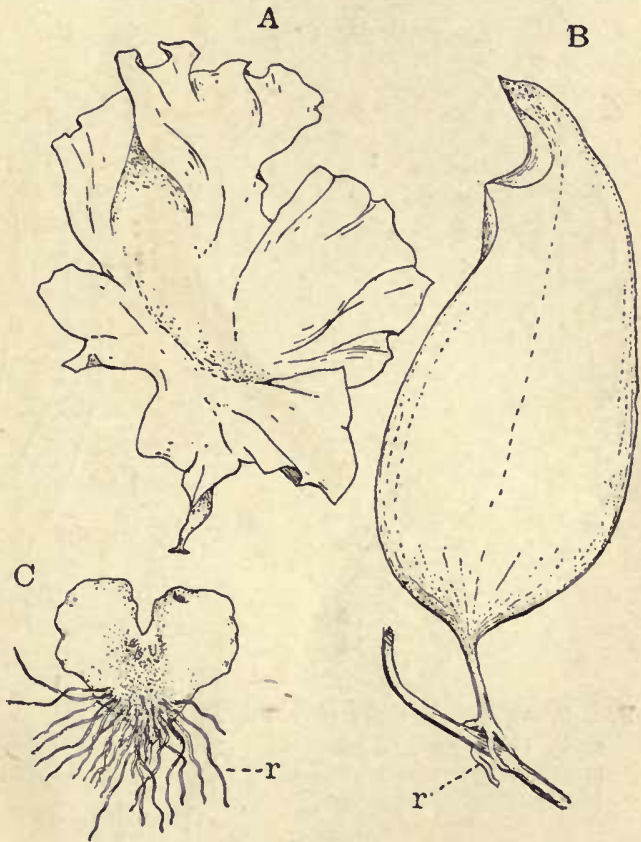

Fig. 7. $-A$, Thallus of Ulva lactuca, slightly reduced; $B$, young plant of Laminaria Farlowii, showing the stem and holdfast or " root," $r$, slightly reduced; $C$, prothallium of a Fern (Struthiopteris Germanica); $r$, root-hairs $(\times 8)$.

chlorophyll. In these the plant-body is made up of filaments ( $\mathrm{Hy}-$ phæ) which may form a loose, fluffy mass as in the common Moulds, or may be closely interwoven into a thallus of definite form as in many Lichens. Most of them produce characteristic fruiting structures (Sporophores) which are composed of densely interwoven and frequently coherent hyphæ, so that in section they often present the appearance of a true tissue like those of the higher plants (Fig. 8), although these masses of tissue are the result of the coalescence of 
originally independent hyphæ, and not the result of repeated celldivision of a single primordium.

\section{Root and Shoot}

As the plant-body becomes more complex, the division of labor, resulting in the development of special organs, is more and more evident. The single cell, representing a root in the filamentous Algæ, may be replaced in the larger Seaweeds, which are often

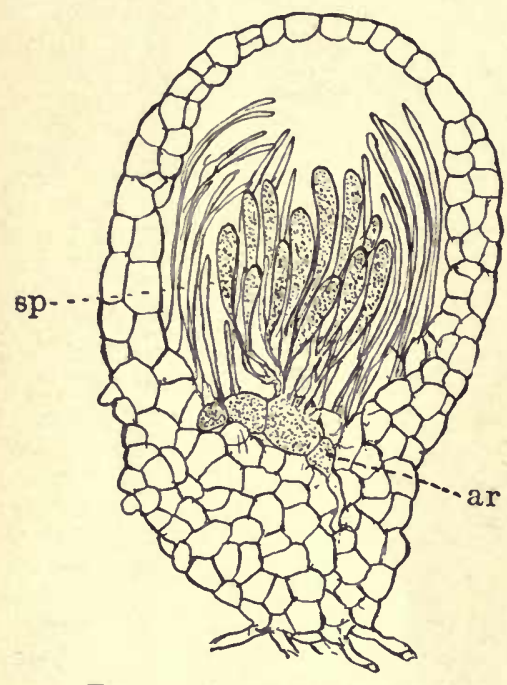

FrG. 8. - Fruiting body of a Fungus (Ascobolus), showing a spurious tissue composed of originally isolated elements.

plants of great size, by powerful hold-fasts that anchor them firmly to the rocks. These roots are simply organs of attachment, as the absorption of dissolved food materials is performed by the whole surface of the plant. In these large Seaweeds the upper portion, the "shoot," shows a more or less clear division into the stem, or axis, and leaves, flat plates which comprise most of the chlorophyll-bearing tissue. While the leaves of the common Gulfweed, for instance, are in structure and origin very 
different from those of the Ferns or Flowering Plants, they have undoubtedly arisen in response to the same needs, and perform the same function. They are, in short, analogous, but not homologous, organs.

A similar transition from the thallose to the leafy shoot is found among the Mosses, where there are many interesting forms intermediate between a flat thallus and a true leafy shoot (Fig. 9, B).

\section{Vascular Plants}

It is among the so-called Vascular Plants, i.e. Ferns and Flowering Plants, that the most perfect development of the plant-body is found. The gametophyte or plant which bears the sexual reproductive cells is always a very simple thallus in these plants; but from the egg there is developed a very complicated plant (Sporophyte), which produces non-sexual spores only. It is the sporophyte only, in these plants, which exhibits the great variety of structure that is associated with the vascular plants, which are now the predominant plant-types.

In the typical vascular plant (Fig. 10 ), the sporophyte is clearly differentiated into a root, which serves the double purpose of attachment and absorption, and the shoot, which consists of the stem and the leaves. The root is at first a direct continuation of the shoot, but it may be replaced by secondary roots, and, like the shoot, it is capable of brancling.

The Shoot. - In all but aquatic plants the shoot develops a complicated system of "mechanical tissues," which give it the requisite rigidity to maintain its upright position in the air. These mechanical tissues in the leaves also give the necessary support to the spread-out masses of delicate green cells. From the main shoot may be

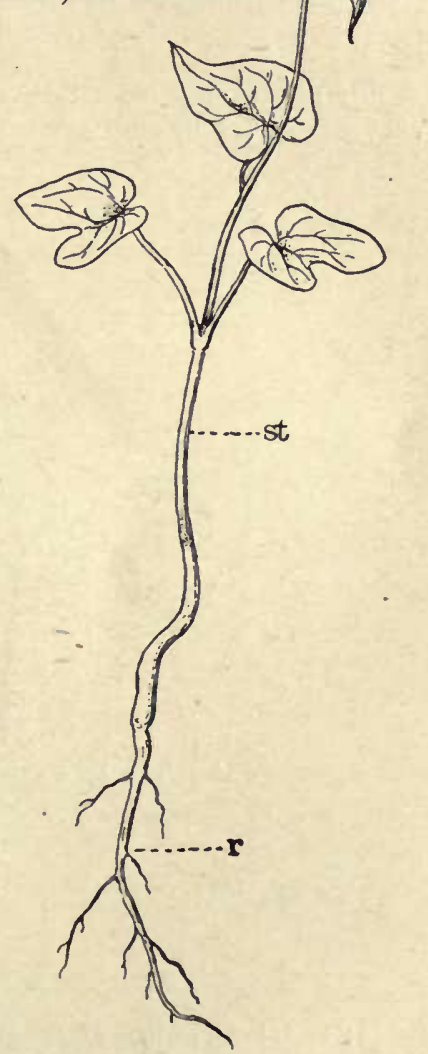

FIG. 10. - Seedling of a Morningglory, a vascular plant with highly developed stem, root, and leaves; slightly reduced. developed secondary shoots, resulting in an extensive branch system.

Besides the leaves and branches, there are developed from the 
shoot superficial outgrowths - hairs, scales, etc. - and the important reproductive structures, the sporangia.

The Growing-point. - In unicellular plants, and in such simple filamentous forms as Spirogyra and Oscillatoria, all the cells are equally capable of fission; but in most plants there is a definite region, the growing-point, to which the formation of new cells is mainly restricted. The growing-point is usually terminal, but may occasionally - e.g. many Kelps - be intercalary. The tissues at the growing-point may owe their origin to the divisions of a single apical cell (Fig. 6), or there may be a mass of initial cells of greater or less size.

\section{Branching}

The plant-body usually branches, and this is often repeated until very extensive branch systems arise, like those of trees or the tufted,
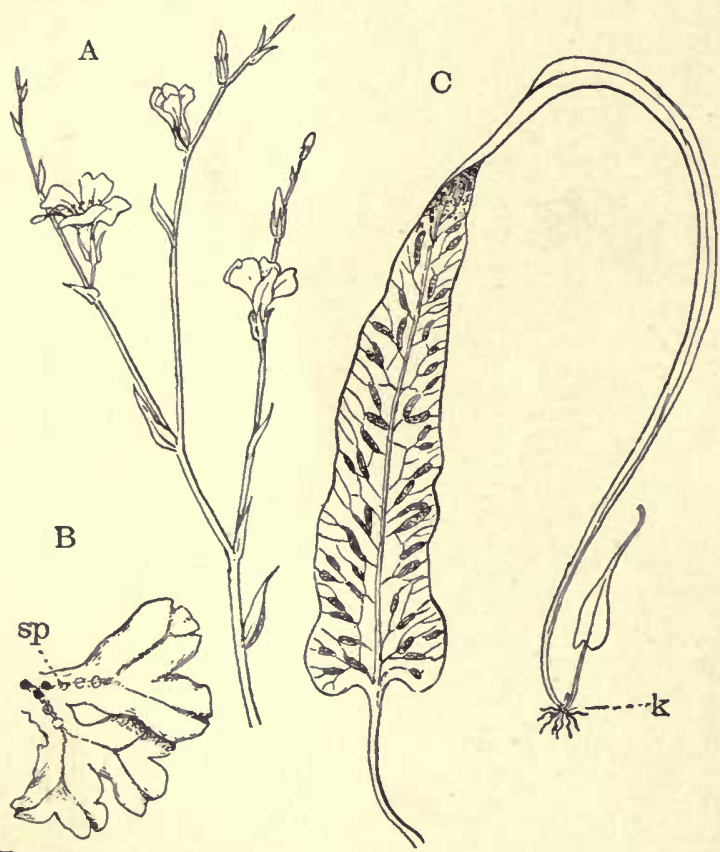

Frg. 11. $-A$, inflorescence of Linum Virginianum, showing monopodial branching. $B$, dichotomously branched thallus of Riccia glauca, enlarged; $s p$, sporogonia. $C$, leaf of the Walking Fern, Camptosorus rhizophyllus, showing adventitious bud at the leaf apex. ( $C$, after GrAY.) dichotomy. If one of the branches grows less rapidly than the other, as in the early leaves of many Ferns, the real nature of the closely branched bodies of many Seaweeds. There are two principal types of branching, the Dichotomous and the Monopodial.

Dichotomy. Dichotomy is the formation of two branches by the equal forking of an original one. The growingpoint is divided vertically into equal parts, each of which becomes the growing-point of one of the new branches (Fig. 11, B). The common Rockweed (Fucus) and many Liverworts are common ex- 
branching is concealed. On the other hand, two lateral branches may develop close to the growing-point, as in Cerastium and other Caryophyllaceæ, and a false dichotomy results.

Monopodial Branching. - Monopodial branching consists in the formation of secondary lateral branches, while the original growingpoint remains undivided. This is by far the commonest type of branching, especially among the higher plants (Fig. 11, A).

Adventitious Branching. - Branches are not infrequently formed on the older part of a plant, which are quite independent of the growing-point. Such shoots, or "suckers," as arise from the roots of the Ailanthus, or Locust, or the leafy shoots developed from the leaves of Bryophyllum and the tip of the leaf in the Walking Fern (Fig. 11, C), are entirely secondary in their origin. Such branches are known as "Adventitious" shoots, to distinguish them from the normal branches. Such adventitious shoots must be carefully distinguished from the apparently secondary shoots which arise from the older parts of plants where they have remained dormant. Thus, in some species of Horsetails (Equisetum), lateral buds are regularly formed near the growing-point, but ordinarily remain undeveloped. Under certain conditions, however, they may be made to develop.

Origin of Branches. - Branches usually develop as outgrowths of the superficial tissues; and such branches are said to be exogenous. More rarely the fundament of the branch is formed within the body and breaks through the overlying tissue. Such endogenous branching is the rule in the formation of roots in vascular plants, but is rare in other cases. In some Liverworts the adventitious branches are of endogenous origin.

\section{Symmetry}

Plants generally exhibit marked symmetry, both as regards the arrangement of the tissues and the position of the organs with reference to each other. This symmetry may be either Radial or Bilateral. Radially symmetrical parts are those which may be equally divided by more than two vertical
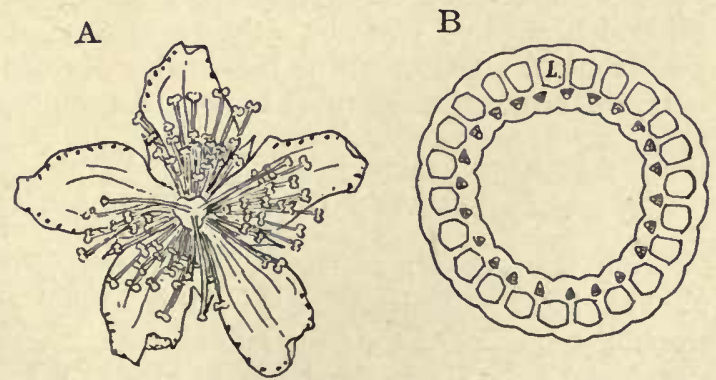

FIG. 12.- Radial symmetry. A, flower of Hypericum perfoliatum. $B$, cross-section of internode of Equisetum telmateia $(\times 3)$. 
planes passing through the centre (or axis). The simplest type is seen in a globular organism, like Volvox. A cylindrical stem, like the trunk of a Pine, is also radially symmetrical; and the so-called "regular" flowers of a Buttercup or Rose show a radial arrangement of the floral organs. Radial symmetry is also apparent in the arrangement of the leaves on the shoots of many plants ; e.g. most Mosses, shoots of Oak, etc.

Parts are bilaterally symmetrical when they can be divided into similar halves in one or two planes only. A few unicellular plants, like most Desmids (Fig. 3, C) and Diatoms (Fig. 13, A), are bilaterally symmetrical; and among the higher plants shoots with tworanked leaves, leaves themselves, and the so-called "irregular" or "zygomorphic" flowers, - e.g. Orchids, Snapdragon, etc. - are

A
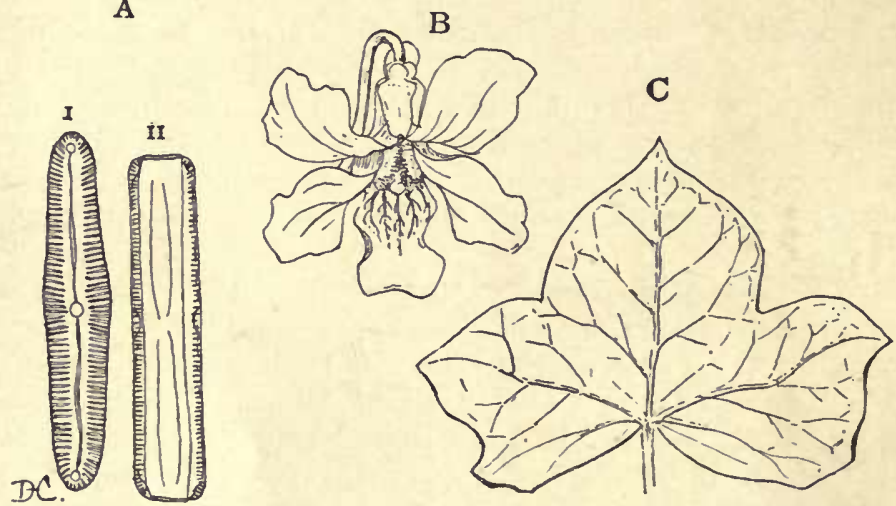

Fra. 13. - Bilateral symmetry. $A$, two views of a Diatom, Pinnularia viridis. $B$, zygomorphic flower of Viola cucullata. C', leaf of Ivy.

familiar examples. Bilateral structures may be either Iso-bilateral or Dorsiventral. In the former case, e.g. Desmids, vertical leaves of Iris or Manzanita, phyllodia of Acacia, etc., the organ may be divided into equal parts by either a horizontal or a vertical plane. Dorsiventral structures can be equally divided by a vertical plane only, e.g. ordinary horizontal leaves ; the thallus of most Liverworts, etc.

\section{ORGANS OF VASCULAR PLANTS}

With few exceptions the body (Sporophyte) of a vascular plant always shows a clear separation into root and shoot; and the latter normally consists of the stem and leaves. There are also, very often, developed from the surface various kinds of Trichomes, - hairs and scales; finally, the sporangia (pollen-sacs, ovules) or reproductive structures, are developed, usually as appendages of modified leaves. 


\section{The Stem (Caulome)}

The stem is the axis of the shoot which serves primarily to support the leaves and raise them to the light. It is also the medium of communication between the subterranean absorbent organs, the roots, and the aerial assimilating organs, the leaves. We find, therefore, that in the stem, the highly specialized conductive tissues forming the vascular bundles, are best developed, and besides this, the inechanical tissues, like wood and fibrous tissue, are present.

Modified Stems. I - While the stem is primarily a structure for support and conduction of food, it may become much changed and thus serve other purposes. It may be buried in the earth, and replace to some extent the roots, which are absent (Psilotum, Corallorhiza); but more commonly the subterranean stems mainly serve as reservoirs of food,

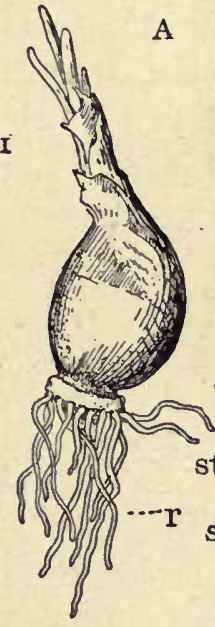

A

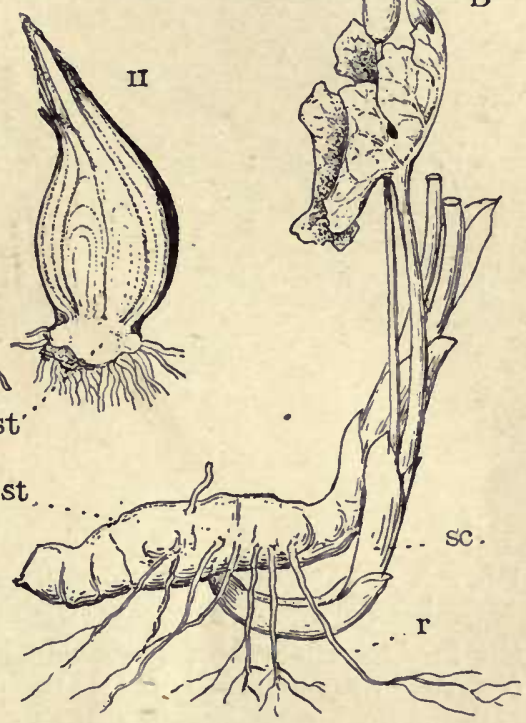

Fra. 14. - A, I, bulb of Narcissus jonquilla ; II, longitudinal section of $I$, showing the short stem, st, and the thick scaleleaves; two young bulbs are forming as buds within the old one. $B$, rhizome of Sanguinaria Canadensis; two aerial shoots with scale-leaves, $s c$, at the base; $r$, roots.

where starch and other reserve stuffs accumulate for future use. Such underground stems are especially common in plants of cold or dry regions where the growing season is a short one. Many of the early flowers of our northeastern States, like the Springbeauty (Claytonia), Bloodroot (Sanguinaria), Spring-cress (Cardamine and Dentaria), Trillium, etc., develop thickened underground stems (Tubers, Rhizomes) (Fig. 14), in which are stored up, during the short period of growth, the necessary nourishment for the rapid growth of the flowering shoot in the spring. Resembling the tubers, but of more regular forms, are the Bulbs and Corms, which are especially common in the Lily family. The wild Tiger-lilies and Dog- 
tooth Violet (Erythronium) are familiar examples of common wild flowers with bulbous stems, and in the dry regions of our Pacific coast, as is true in other similar regions, the number of bulbous plants is very great. The beautiful Mariposa Lilies (Calochortus), Brodiæa, Fritillaria, among others, may be mentioned. In our gardens, too, many plants with corms and bulbs, like the Crocus, Gladiolus, Tulip, Hyacinth, Narcissus, etc., are familiar examples.

Another modification of the stem, in plants of dry regions, is illustrated by the Cacti and other so-called Xerophytes. In these, protection against drought is effected by a reduction of leaf-surface, which

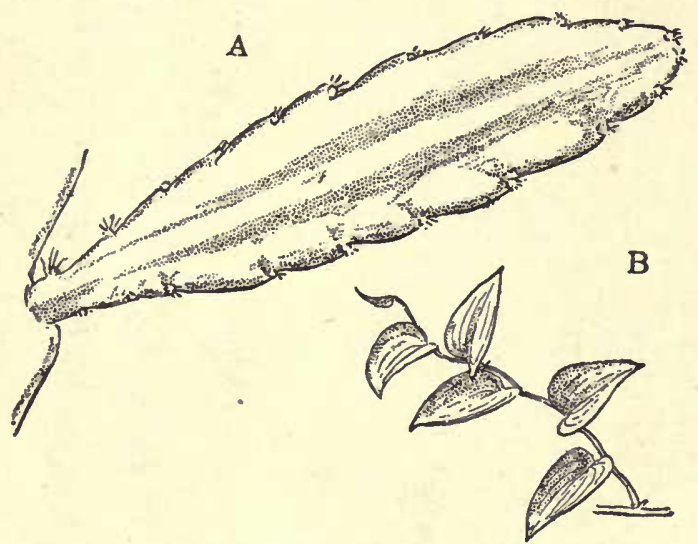

Fia. 15. - $A$, leaflike shoot of a Cactus (Cereus). $B$, leaflike shoots (phylloclades) of Myrsiphyllum.

in extreme cases results in a complete suppression of the leaves. In such plants the stem develops a large amount of green tissue which is protected by a very thick epidermis, or masses of hairs. Parts of the stem may become flattened and resemble a leaf also in form. Thus the flattened joints of a Prickly Pear or the apparent leaves of the gardener's "Smilax," and the threadlike "leaves" of Asparagus, are really all modified stems (Fig. 15).

Stems may be modified, for the purpose of climbing, in two ways. Either the whole stem may twine as it does in a Morning-glory or Hop, or branches may be changed into tendrils, like those of the Grape or Virginia Creeper.

Creeping stems, like the runners of the Strawberry, or the underground "Stolons" of Mint and many Grasses, are stems modified for purposes of propagation.

Thorns developed for protection against attacks of animals are often modifications of stems. The great branched thorns of the Honey-locust show their cauline nature very clearly, often, when young, having leaves growing from them like those from normal shoots.

\section{The Leaf}

The normal leaves of vascular plants, while exhibiting a great diversity of form, agree in the main in their essential structure. The 
primary function of the leaf is the very important one of assimilating carbon-dioxide, and to facilitate this, the green cells are spread out in such a way as to offer the most favorable exposure of the cells to the action of light. The typical leaf (Fig. 16) has a broadly expanded thin lamina, or Blade, exposing a maximum surface of green tissue to the light. The vascular bundles form a skeleton which gives the necessary support to the leaf, and at the same time they serve as channels for the conduction of water and food. Covering the delicate green tissue, and protecting it against loss of water, is the epidermis, which is, however, perforated by the stomata, pores which permit communication between the air-spaces within the plant and the outside atmosphere.

The leaf is usually connected to the stem by a stalk or Petiole, which is more or less modified, at the place of junction, into the "Leaf-base," from which there are often developed

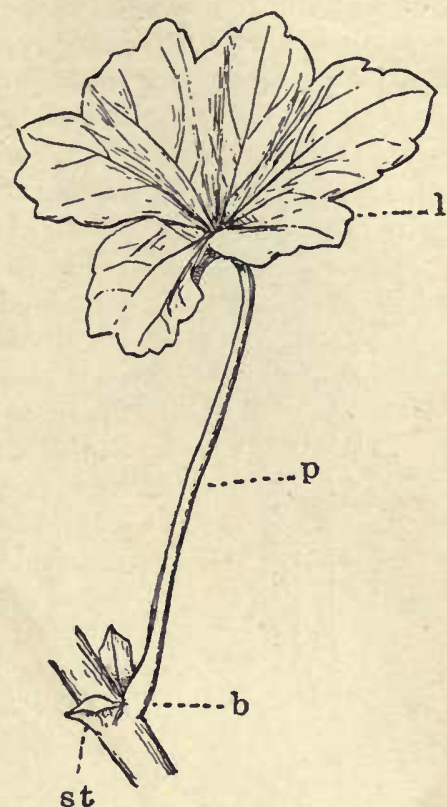

Fra. 16. - Typical foliage leaf of Pelargonium sp.; $l$, lamina; $p$, petiole; $b$, leaf-base; $s t$, stipules. leaflike appendages, or Stipules (Fig. 16). In case no petiole is developed, the leaf is "Sessile," and occasionally two opposite sessile leaves are coherent, as in the "Perfoliate" connate leaves of some
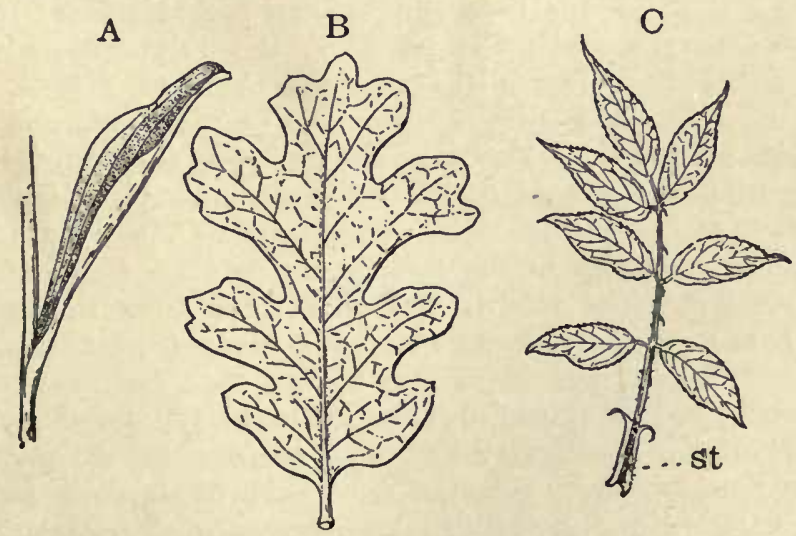

Fig. 17. $-A$, simple sessile leaf of Pogonia ophioglossoides. $B$, lobed leaf of Quercus lobata. C, pinnately compound leaf of Rose; st, stipules. 
Honeysuckles. The blade of the leaf shows great variety of outline. Some of the commoner types are shown in the illustration (Fig. 17).

Modifications of the Leaf. - Leaves also show many adaptive modifications. They may lose much of the green tissue and become scales, such as enwrap the winter buds of

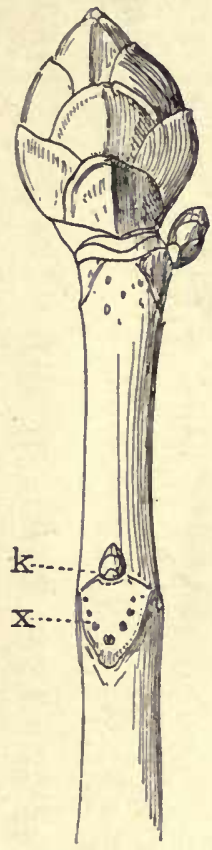

Fig. 18. - Shoot of horsechestnut with winter buds protected by thick scale-leaves; $k$, small axillary bud; $x$, leaf-scar. many trees and shrubs. These protective scales are sometimes very large and conspicuous, as in the Hickory and Horsechestuut (Fig. 18). Somewhat similar are the scaleleaves of such bulbs as the Tulip and Onion. Here the function of these leaves is twofold - protective and nutritive, as there is stored up in them a large amount of reserve food. Scale-leaves are usually derived from the leafbase, the petiole and lamina being suppressed. This often shows in the transitional forms which may be seen in an unfolding bud, where there are sometimes all intermediate forms between the scales and the perfect foliage leaves. Scale-leaves of a somewhat different nature are the rudimentary leaves of many desert plants, and those of colorless parasites and saprophytes, like Dodder or Indian-pipe, where they are quite useless as organs of assimilation.

Bracts. - A flower, or a group of flowers (inflorescence), is often protected by more or less modified leaves known as Bracts. Besides their protective function, it is not uncommon for bracts to become highly colored, and to take the place of the bright-colored floral leaves for the attraction of insects. The Flowering Dogwood, Calla Lily, and many Euphorbias offer examples of these showy bracts (Fig. 19, C).

Leaf-tendrils. - The tendrils of many climbers, instead of being stem structures, may be modifications of leaves. These leaf-tendrils are especially common in the Pea family, but are frequently met with elsewhere. The tendril may be derived from the leaf-base (Smilax), the petiole (Clematis), or the blade (Sweet Pea) (Fig. $19, \mathrm{~B})$.

Leaf-spines. - The spines of Thistles, Barberry, and many other prickly plants are modifications of foliar structures (Fig. 19, D).

Insect Traps. - Among the most remarkable of all plant structures are the extraordinarily modified leaf structures developed by the Pitcher-plants, Sundews, Bladder-weed (Utricularia), and others for 
the capture of living animals - mostly small Insects and Crustacea. Among the lower plant-forms similar traps occur in a few tropical Liverworts.

Sporophylls. - The sporangia of the Ferns and Flowering Plants are usually borne upon special leaves, Sporophylls, which may be little changed in the ordinary Ferns, but are sometimes very different from the foliage leaves, as in the Sensitive Fern (Onoclea). In the Flowering Plants, or Seed-plants, the sporophylls are much
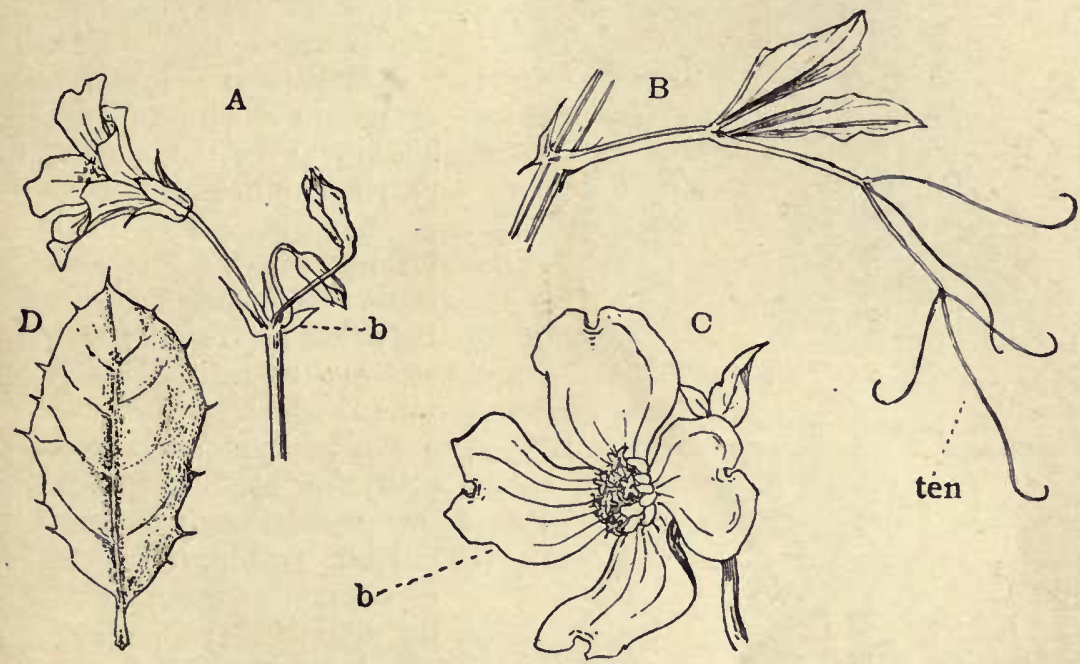

FIG. 19. - $A$, inflorescence of Oxalis $s p$, with bracts, $b$. $B$, leaf of Sweet Pea, the terminal leaflets modified into tendrils, ten. $C$, inflorescence of Cornus florida, the inconspicuous flowers surrounded by showy bracts, $b$. $D$, spiny leaf of Quercus agrifolia.

changed, and are given special names - Carpels and Stamens. The carpels bear the sporangia (ovules) which later form the seeds, and the stamens, the pollen-sacs, in which are produced the pollen-spores. The sporophylls, together with the other floral leaves, Petals, and Sepals, constitute the flower of the Seed-plants.

\section{The Root}

The primary root in the young plant is generally a continuation of the shoot, and this persists throughout the life of the plant in those forms with a tap-root (Fig. 20). More commonly the primary root is replaced by secondary lateral ones, as in all Ferns and Monocotyledons. The normal roots of vascular plants have the growing point protected by a conical mass of cells, the root-cap.

The roots have two principal functions, that of anchoring the 
plant, and that of absorbing water and soluble food-compounds from the earth. As the amount of the water absorbed varies with the extent of leaf-surface, there is found to be a pretty constant correspondence between the absorbing surface of the roots and that of the surface of the leaves. The increase in the absorbing surface

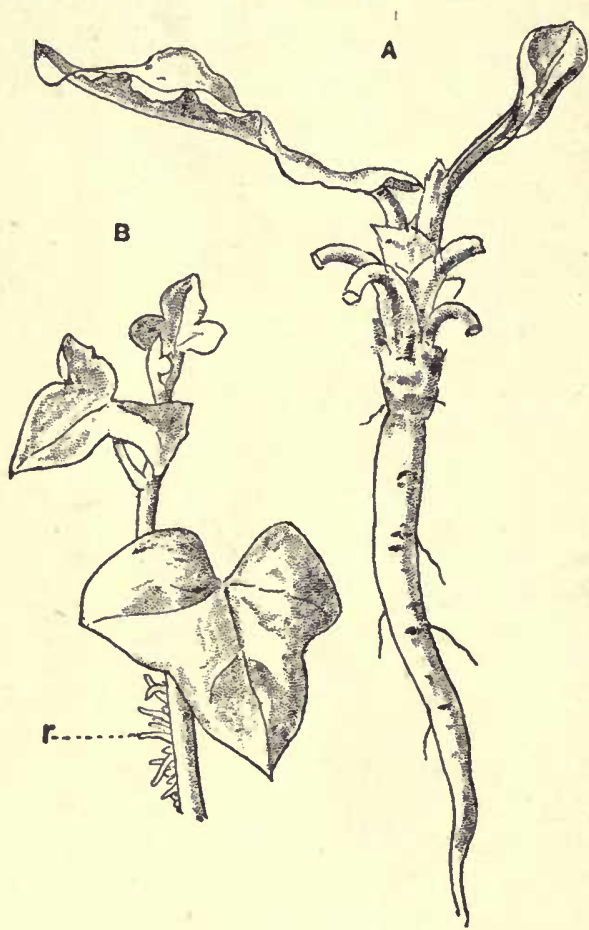

Fig. 20.-A, young plant of Rumex crispus, with enlarged tap-root. $B$, young shoot of Ivy climbing by root-tendrils, $r$. of the roots is brought about by the ramifications of the roots and the development of absorbent root-hairs.

Modifications of Roots. Roots are sometimes quite absent, as in the aquatic Salvinia and certain saprophytic plants; e.g., Corallorhiza. In the first case slender submersed leaves function as roots, in the second rootlike subterranean stems.

Very commonly, especially in biennial plants like the common Thistle, Carrot, 'Turnip, etc., the root is much enlarged, storing up during the first season food which is drawn upon by the plant in its rapid growth in the second year, when flowers and fruit are developed. These enlarged roots may be a tap-root, as in the Carrot and Dock (Fig. 20), or they may be lateral roots, as in the Sweet Potato.

Aerial Roots. - In the Tropics it is very common to find roots developing from the aerial parts of plants. Such aerial roots are occasionally met with in plants of temperate regions - e.g. the roottendrils of Ivy and the Trumpet-creeper; but it is in the moist forests of the Tropics that these aerial roots are best seen. In many species of Fig, for example, they are formed upon the branches and grow downward until they reach the earth, when they fasten themselves and finally develop into a stout trunk, which functionally is a stem. The many trunks of the Banyan Fig are of this nature, and there are numerous similar species. Very much like these roots 
are the numerous buttress-roots which grow from the base of the trunk in many Palms, and in the curious Screw-pines (Pandanus). On a small seale the same thing occurs in Indian Corn, and the Mangroves of tropical swamps also offer examples of such aerial roots (Fig. 21).

Another type of aerial roots is seen in some epiphytic Orchids, whose fleshy roots hang free in the air, from which they absorb moisture, especially through the spongy tissue of the root-cap. These roots sometimes develop more or less chlorophyll, and then may function also as assimilative organs. Root-tendrils, like those of Ivy (Fig. 20, B) and other similar forms, are especially abundant among certain tropical climbers, such as the Araceæ.

Roots of Parasites. - Many parasitic plants attach themselves to other plants into which they send their roots, which become more or less modified into suckers, or Haustoria. In Dodder (Cuscuta) these haustoria pene-

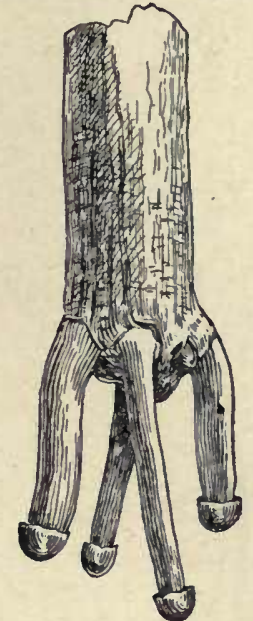

Fig, 21. - Aerial roots of Mangrove. (After BaILey.) trate the stem-tissues of the host, while in root-parasites, like Beechdrops (Epiphegus) and Gerardia, the haustoria are connected with the roots of the host.

\section{Trichomes}

Under the name Trichome are comprised the hairs and similar outgrowths which are developed from the-superficial cells of the plant. The simplest of these are single elongated cells, but they may assume various shapes and sizes. Hairs may be unicellular or multicellular, simple or branched, and sometimes are tipped by a gland which secretes mucilage or an essential oil, as in many species of Geranium and Pelargonium (Fig. 22).

Epidermal scales differ from hairs in having cell-divisions in two planes. Like the hairs, they may be glandular, e.g. the chaffy scales or paleæ on the young parts of many Ferns. Shield-shaped or peltate scales sometimes occur, and may quite cover the surface of certain leaves; e.g. Shepherdia (Buffalo-berry) and Elæagnus (Fig. $22, \mathrm{E})$.

\section{Emergences}

Differing from the trichomes in not being of strictly epidermal origin, are the "emergences," of which the commonest are the prickles and spines on the stems of many plants. The prickles on 
the stems of Roses and Blackberry, and the spines upon the leaves of the Century-plant, are examples of such emergences (Fig. 19, D).

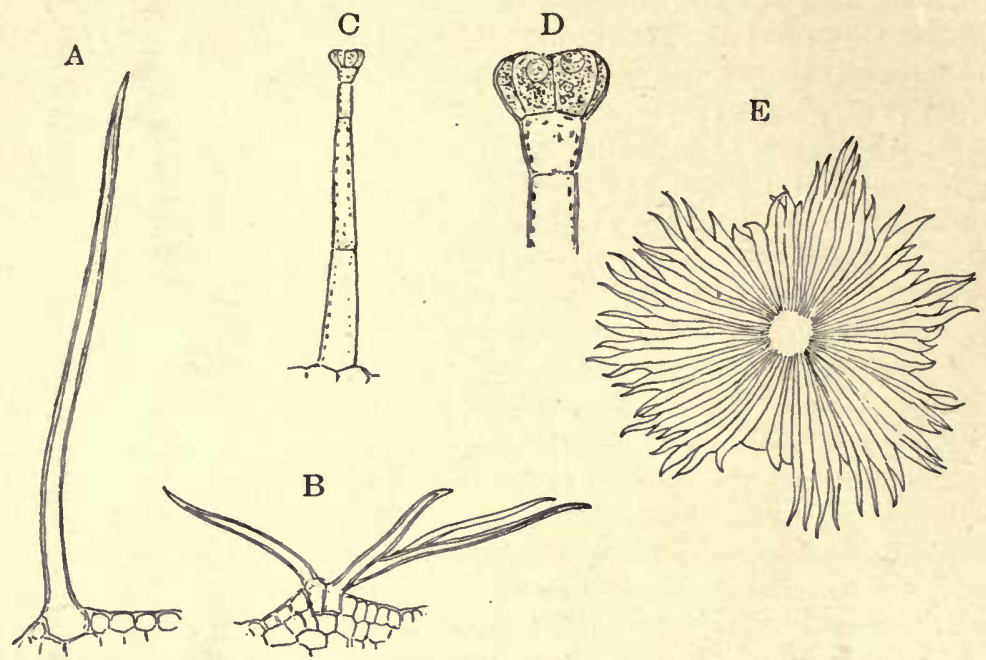

Frg. 22. $-A$, simple hair of Hollyhock $(\times 60)$. $B$, section of stellate hair from the calyx of the Hollyhock $(\times 60)$. C, glandular hair of Paulownia imperialis $(\times 60)$. $D$, upper part of $C$ more highly magnified. $E$, peltate hair of Elæagnus argenteus $(\times 100)$.

\section{The Reproductive Parts}

Among the lowest organisms the same cell is both vegetative and reproductive, since it divides by simple fission into two equal parts which become at once new individuals, or by budding, individuals

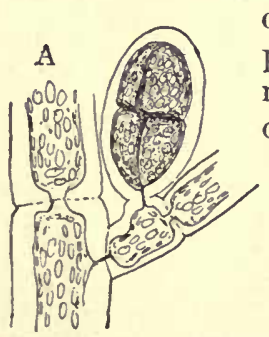
of unequal size are formed. Even in the highest plants there is found an analogous formation of new individuals by means of suckers or runners, or the artificial propagation by means of cuttings.

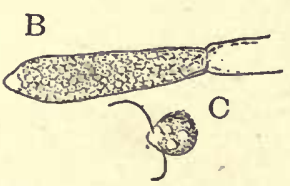

Fig. 23. - $A$, tetrasporangium of Callithamnion floccosum. $B$, zoösporangium of Saprolegnia sp. $\quad C$, a zoöspore of Saprolegnia.
In all but the lowest plants, lowever, there are developed special reproductive cells, which may differ but little from the vegetative cells, or may be much altered. The simplest of these are the resting-spores of many low Algæ, developed by a thickening of the wall in the ordinary cells, and other slight changes which make the spore more resistant than the vegetative cells, and better fitted to carry the plant through unfavorable seasons. Usually the non-sexual reproductive 
cells of these lower plants are naked, often motile cells (spores) formed in special structures, sporangia, from which they are set free, and germinate immediately (Fig. 23).

Gametes. - Sexual cells, or Gametes, are also found, often closely resembling the non-sexual spores, from which they differ in not being capable of independent growth. Two of these gametes must unite to produce the germ of the new plant. One of the gametes is usually much larger than the other, and is retained within the organ where it was formed; the smaller gamete, the male or sperncell, is often actively motile and swims to the female cell, with which it fuses. The gametes are borne in
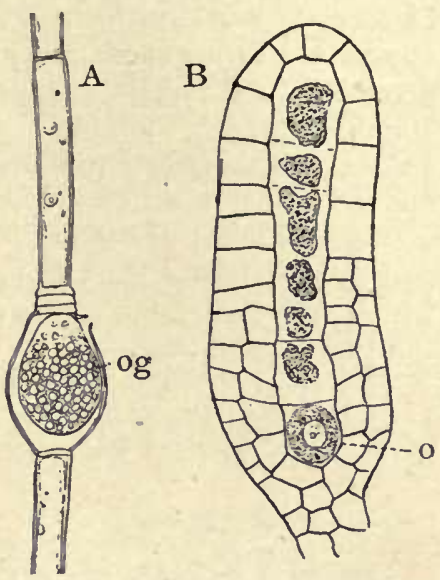

Fıg. 24. $-A$, äggonium of $E$ Edogonium Boscii $(\times 200)$. B, archegonium of Madotheca platyphylla $(\times 300) ; 0$, the egg.

structures much like the sporangia, but which sometimes show considerable complexity (Fig. 24).

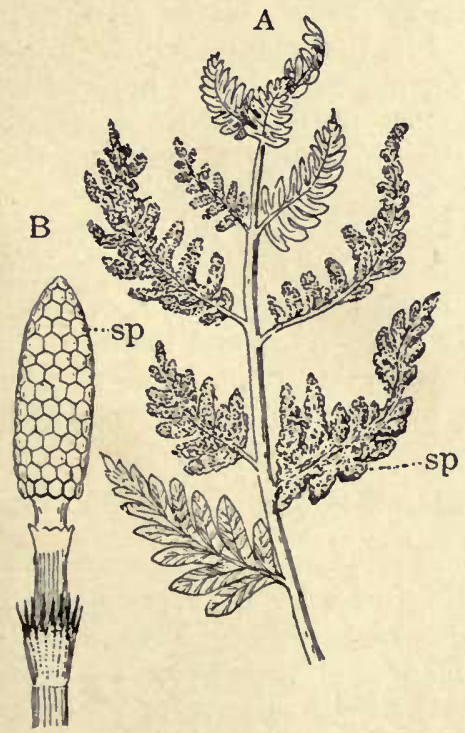

Fig. 25. $-A$, sporophyll of Osmunda Claytoniana; $s p$, fertile leaf-segments. $B$, sporophylls of Fquisetum, arranged in a cone at the apex of the shoot.
Alternation of Generations.Among the higher plants there is a marked difference between the plants which produce the sexual and those which bear the nonsexual reproductive cells. The sexual generation is known as the "Gametophyte," the non-sexual as the "Sporophyte." There is an increasing tendency among these plants toward the suppression of the sexual phase, which becomes excessively reduced in the Flowering Plants, where the sporoplyte is the plant as we ordinarily recognize it.

The spores of the Ferns and Flowering Plants are produced in characteristic sporangia which most commonly are outgrowths of the special leaves, or Sporophylls (Fig. 25). The spores germinate at once and produce the gametophyte.

The sporangia of the Ferns are 
capsules of striking form, which are usually alike, but in the more specialized forms show two kinds, one producing large spores which give rise to a female gametophyte, the other to smaller ones, from which grows the minute male gametophyte. The origin of the spores and their essential structure is remarkably uniform throughout the higher plants.

The sporophylls of the Ferns are sometimes of quite peculiar form, and in the similar Horsetails and Club-mosses are arranged in cones which are comparable to the flowers of the simpler Seed-plants, like the Pines and Firs.

The sporophylls of the "Flowering Plants" (Spermatophytes, Phanerogams) are always of two kinds, known respectively as Carpels and Stamens. Upon the former are borne sporangia (ovules),

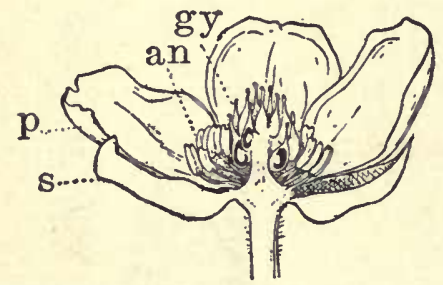

FIG. 26. - Section of the flower of Ranunculus repens, slightly enlarged; $s$, sepals; $p$, petals ; $a n$, stamens; $g y$, carpels. which contain the large spores (macrospores), and upon the stamens are the microsporangia, or pollensacs, in which the small spores (microspores) are contained. In most Flowering Plants the foliar nature of the sporophylls is much less obvious than it is in the Ferns (Fig. 26).

Accessory Floral Leaves. - Associated with the sporophylls of the Spermatophytes, there are often other more or less modified leaves, the Sepals and Petals, which, with the sporophylls, make up the Flower (Fig. 26).

The macrospore in the Spermatophytes never leaves the sporangium (ovule), but germinates and passes through the development of the gametophyte within the ovule. The latter grows with the developing gametophyte within it, and finally drops away and is known as a Seed, which is only a metamorphosed sporangium. The carpels undergo a corresponding growth and produce the "Fruit" of these plants.

\section{Morphology and Classification}

A comparative study of the structure of plants is the surest clew to their relationships, and must form the basis of every natural classification. All modern systems of classification are based upon the assumption that structural resemblances indicate to some degree, at least, actual genetic relationship. As the life-history of the individual is supposed to repeat to a certain extent the development of the race, the importance of Ontogeny, or individual development, in determining the Phylogeny, or pedigree, of any group of organ isms, is sufficiently obvious. 


\section{BIBLIOGRAPHY}

'98. 1. Atkinson, G. F. Elementary Botany. New York, 1898.

'98. 2. Bailey, L. H. Lessons with Plants. New York, 1898.

'01. 3. Bergen, J. Y. The Foundations of Botany. Boston, 1901.

'88. 4. Bessey, C. E. Text-book of Botany. New York, 1888.

'99. 5. Campbell, D. H. Lectures on the Evolution of Plants. New York, 1899.

'00. 6. Coulter, J. M. Plant Structures. New York, 1900.

'87. 7. Goebel, K. Outlines of Special Morphology and Classification. Oxford, 1887.

'00. 8. — Organography of Plants. Oxford, 1900.

'79. 9. Gray, A. Structural Botany. New York, 1879.

10. Kerner, A., and Oliver, F. W. Natural History of Plants. New York: Holt \& Co.

'82. 11. Sachs, J. Text-book of Botany. Oxford, 1882.

'96. 12. Scott, D. H. Structural Botany. London, 1894-1896.

'97. 13. Strasburger, E. Das Botanische Practicum. 3d ed. Jena, 1897.

'98. 14. — A Text-book of Botany. London and New York, 1898.

'91. 15. Van Tieghem. Traité de Botanique. Paris, 1891.

'96. 16. Vines, S. H. A Student's Text-book of Botany. London \& New York, 1896.

'95. 17. Warming, E. Handbook of Systematic Botany. London \& New York, 1895. 


\section{CHAPTER III}

\section{THE PLANT-CELI,}

WHILE a plant may consist of a single cell, much more commonly it is made up of many more or less modified cells. The cellular structure of plant-tissues was demonstrated by Robert Hooke, in 1667 ; but the real nature of the cells was first recognized a few years later by the Italian Malpighi and the English botanist Grew. Owing to the imperfections of the first microscopes, only the cellwalls were seen by these investigators, and it was nearly two hundred years later before the real structure of the cell was understood, and it was recognized that the cell-wall is a secondary product of the Protoplasm or living body of the cell. Protoplasm received its name from the German botanist, Von Mohl, one of the brilliant group of investigators who about the middle of the nineteenth century laid the foundations of modern biology. It was soon made clear that there was no appreciable difference between the protoplasm of plants and the so-called "sarcode" of animal tissues, and the latter term was abandoned in favor of the former, which is now universally employed to denote the living substance of both animal and vegetable cells - the "Physical Basis of Life," as it was so aptly called by Huxley.

\section{Physical Properties of Protoplasm}

Protoplasm rarely occurs in quantity large enough to be readily handled, being generally segregated in microscopically small masses or protoplasts within the cell. There are, however, certain organisms, notably the remarkable Slime-moulds or Mycetozoa (Myxomycetes) which are composed of large masses of naked protoplasm. These have long been the favorite objects upon which experiments have been made. Such a mass of protoplasm has a slimy, viscid consistence, much like the albumen of an egg, which it resembles closely also in its chemical properties. The semifluid condition of active protoplasm is due to its high percentage of water, which is essential to the activity of all protoplasm. Much of this water may be withdrawn without killing the protoplasm, but it then loses the power of movement and enters a dormant condition. The dry protoplasm has a horny consistence, but may be restored to the active 
condition by the access of water. Other familiar examples of dormant protoplasm are offered by the spores of the lower plants and the seeds, bulbs, tuber's, etc., of many of the Flowering Plants.

Where the protoplasm is free from secondary pigments it appears, in mass, more or less whitish or milky from the numerous granules imbedded in its transparent ground substance. These granules are evident as soon as it is sufficiently magnified. The protoplasm then shows an appareutly homogeneous colorless ground substance (Hyaloplasm), in which are imbedded many granular bodies of different sizes. The larger granules are usually not essential parts of the protoplasm, being either food bodies taken from without, or else products of the activity of the protoplasm itself, like starch granules and albuminous granules. There are, however, numerous extremely minute granules (Microsomes), which give the protoplasm a finely punctate appearance, and which are usually considered to be integral parts of its substance. The protoplasmic mass is always bounded by a more or less evident layer of hyaloplasm, and a similar layer lines the vacuoles, or spaces filled with fluid, which occui within the protoplast. The outer hyaloplasm is less fluid than the inner granular plasma, and is much less motile. Where the protoplasm is included within a cell-wall, the hyaloplasm forms a continuous layer between the cell-wall and the granular portion of the protoplasm.

\section{Differentiation of the Protoplast}

While the term Protoplasm is used for the whole living contents of the cell, it must be remembered that these are by no means homogeneous, and in all but the lowest organisms there is an evident differentiation of the protoplast, or living cell-body, into definite parts, which are essential elements of the cell, and capable of being increased only by division of similar parts. These special parts are the Cytoplasm, Nucleus, and Plastids or Chromatophores. Of more doubtful nature are the Centrosomes and Tonoplasts, which have been also considered to be permanent constituents of the cell.

Cytoplasm. - The main body of the protoplast, in which the other protoplasmic structures are imbedded, is known as Cytoplasm, which is not infrequently called simply protoplasm in distinction from the Plastids and Nucleoplasm (Karyoplasm). The cytoplasm always shows an apparently homogeneous ground substance, or hyaloplasin, in which are imbedded the microsomes and other granular bodies which are present. The granules are confined to the inner, more fluid portions, while the layer bounding the outside of the protoplast, and the inner part surrounding the sap-cavities, or vacuoles, are firmer and quite homogeneous. The larger granules are of various kinds, - starch, aleurone, crystals, etc. Sometimes the ap- 
parently solid granules are really small vacuoles filled with soluble substances, like the tannin-vesicles of Zygnema; or these small vacuoles may themselves enclose small solid granules.

Vacuoles. - There are found in most plant-cells cavities of greater or less extent, filled with watery fluid, and known as Vacuoles. They are always bounded by a layer of hyaloplasm, much like the limiting outside portion of the protoplast. It has been found possible to kill the surrounding cytoplasm by means of a solution of nitre, leaving the film of living hyaloplasm about the vacuole. Under certain conditions the vacuoles have been observed to divide, and it has been assumed that the film of hyaloplasin surrounding the vacuole differs from the rest of the cytoplasm, and the name Tonoplast has been given to it, under the supposition that, like the nucleus and plastids, the tonoplasts are integral parts of the cell, and can never arise de novo. This, however, has been shown not to be the ease, and there seems no question that vacuoles may arise free in the cytoplasm, and form about themselves a layer of hyaloplasm, without any reference to preëxisting tonoplasts.

Protoplast of Schizophytes. - The lowest plants are the Schizophytes, comprising the Bacteria, and the Blue-green Algæ. There is much controversy as to the structure of the protoplast in these forms, especially in the Bacteria, which often show an apparently homogeneous protoplast. In the larger forms a so-called "central body" is often present, and may perhaps represent a primitive form of nucleus. It has been claimed that in many Bacteria nearly the whole protoplast is composed of such a central body, the outer cytoplasm being almost entirely absent.

Protoplast of Typical Plants. - The protoplast of the typical plantcell shows a nucleus and one or more plastids or chromatophores. The latter appear in the young cells of the growing-point of a stem, or in the cells of an embryo, as minute colorless granules, usually in the neighborhood of the nucleus. These may remain colorless, or they may develop into the green chloroplasts, or the red or yellow chromoplasts. Fungi show no chromatophores, and they are unknown in the cells of animals, unless some of the Flagellata with chromatophores are admitted to be animals.

\section{Physical Constitution of Protoplasm}

During the past twenty years the structure of the protoplasm has been the subject of most assiduous study, and great advances have been made in the methods of fixing and staining the protoplasm in order to differentiate its different components. In spite of these studies, and the numerous ingenious theories propounded to explain 
the structure of living protoplasm, the conclusions of different observers are so conflicting that none of them can be accepted without qualification. ${ }^{1}$ While it is by no means clear that the protoplasm always has the same structure, it is certain that sometimes, at least, it shows a fine honeycombed or foamy appearance. A very similar appearance is exhibited by placing a small particle of a paste compounded of finely rubbed olive oil and potassium carbonate in contact with a drop of water. A fine emulsion is thus produced, which under the microscope presents a remarkable resemblance to the structure of living protoplasm. This has led the discoverer of this fact, Bütschli, to the conclusion that the protoplasm is really composed of a similar structure, the living portion occupying the walls surrounding the cavities, which contain a more fluid substance. The recent studies of Wilson (13) confirm in general Bütschli's conclusions, although modifying them in certain respects.

While the protoplasm is never strictly a liquid, the degree of cohesion of its particles varies much in different cases. Thus the outer ectoplasm or hyaloplasm is more coherent than the inner granular plasma, but it is itself subject to differences which have been compared to those taking place in gelatine when it is alternately warmed and cooled. The coherence of cilia and fine pseudopodia is very great. Where the protoplasm occurs in small naked masses, it tends to assume a globular or oval form, due to the strong surface tension.

While we are accustomed to speak of protoplasm as if it were a definite substance, and we cannot recognize any visible difference between the protoplasm of different organisms, it is evident that important inherent differences must exist. The ovum of a Fern, although closely resembling that of a Moss, could not be conceived as developing into anything but a Fern. There must be some essential peculiarities of the components of the protoplasin which determine that the naked protoplast shall become a Fern and not a Moss.

\section{The Ultimate Structure of Protoplasm}

It is not at all likely that any of the visible structures observed in the protoplasm really represent its ultimate component parts. It seems much more probable that the real protoplasmic units - "Pangens," "Biophores" - are much too minute to be visible to any lenses which we now possess. These protoplasmic units are not necessarily similar in composition, and may perhaps be of many kinds. They are supposed to be capable of arrangement in a great variety of ways, comparable to the different arrangements of the atoms in the so-

${ }^{1}$ For a full discussion of the more important theories see Fischer (3). 
called isomeric chemical compounds. The protoplasmic units are not supposed to be molecules, but are conceived as made up of many molecules, and represent, therefore, not chemical but physical complexes. These units are supposed to combine with more and more complicated structures which finally become large enough to be visible by the aid of the microscope. The pangens must be assumed to have the power of growth and division, resembling in this respect the essential organs of the cell, - the nucleus and plastids.

\section{Chemical Composition of Protoplasm}

Protoplasm is in no sense of the word a definite chemical substance like starch or fat, for instance, but is a physical mixture of different units, each of which is in turn made up of excessively complicated molecules, principally albuminoid in character. The component parts of the protoplasm are exceedingly unstable, continual change being a necessary condition for the maintenance of its activity. As a result of this activity there are constantly produced substances which serve either as plastic material for the growth of the protoplasm, such as starch, sugar, aleurone, etc., or are waste products like resins and crystals. It is not always easy to decide as to the nature of some of these mannfactures of the protoplasm which are not always to be distinguished from microsomes which are parts of the active protoplasm. It becomes clear, then, that any definite chemical formula for protoplasm is out of the question, and all analyses are merely approximate.

Active protoplasm is always saturated with water, which ordinarily constitutes about $75 \%$ of its weight, sometimes amounting to $95 \%$ in delicate aquatic plants. A large part of the water may be extracted by drying, and the residue, on analysis, always reveals certain chemical elements which are never absent, and which can be shown to be essential for the building up of the protoplasm. Other elements are also usually present, but may be absent in many cases. The most important components of the proteids which form the basis of the protoplasmic structures are Oxygen, Hydrogen, Carbon, and Nitrogen. Sulphur and Phosphorus are also probably essential constituents of protoplasin, and for the normal growth of green plants, Potassium, Calcium, Magnesium, and Iron are necessary. These elcments may be combined in an infinite variety of ways, many of which have been artificially produced, but most of which have not as yet yielded to the tests of the laboratory.

A considerable number of other elements are sometimes found, but are not present in all plants. Thus in the large Kelps, Iodine and Bromine are present, and Silicon is a very common element in many land plants, such as the Grasses, Horsetails, and many others. 
A number of the metals - Lead, Copper, Silver, and several others - are also occasionally met with.

The extraordinary complexity of the compounds which make up the protoplasmic mass may be illustrated by the formula for Albumen $\left(\mathrm{C}_{60} \mathrm{H}_{100} \mathrm{~N}_{16} \mathrm{O}_{20}\right)$. The result of an analysis of the plasmodium of a Slime-mould (Athalium septicum) showed $71.6 \%$ water, and $28.4 \%$ solid matter. The latter was composed of $30 \%$ of nitrogenous compounds : plastine, vitelline, myosine, pepsine, lecithine, guanine, sarcine, xanthine, and ammonia carbonate; $41 \%$ was composed of ternary compounds, including paracholesterine, resin, and a yellow pigment, sugar (non-reductive), various fatty acids, and neutral fatty substances. The remainder was composed of mineral substances, including calcium combined with various acids, phosphates of potassium and magnesium, and chloride of sodium. While this probably does not represent the constitution of the ordinary protoplast, it illustrates the extraordinary complexity of the protoplast, and the impossibility of obtaining more than an approximation of its chemical composition.

\section{Physiological Properties of Protoplasm}

Protoplasm being the essential living part of all organisms, it is in the protoplasm that the peculiar physiological properties of living things reside. These properties are motility, nutrition, respiration, irritability, adaptability, and reproduction.

Motility. - Whether the protoplasm occurs as a naked protoplast, or whether it is enclosed within a membrane, one of its most marked characters is its power of spontaneous movement. This is especially marked in such naked protoplasts as an Amæba or zoöspore. In the former, movement of the whole mass is effected by the protrusion of arms or pseudopodia, which is followed by the contraction of the rest of the mass, resulting in a slow creeping movement by which it progresses. Such a movement only takes place when the protoplast is applied to a solid surface. The amøoboid movement involves two kinds of movement, the extension of the outer hyaloplasm, of which the pseudopodium is at first composed, and second, a rapid streaming of the softer granular plasma into the extended pseudopodium. The amœboid movements serve two purposes, the shifting of the position of the protoplast, and the ingestion of solid food, which is surrounded by the extended pseudopodia and thus taken into the protoplast.

Ciliary Movement. - Small naked protoplasts more commonly show another type of movement, - the ciliary movement. Ciliated cells are very common among the lower organisms, Bacteria, Infusoria, and Algæ, but also occur in higher ones; e.g. the spermatozoids, or 
male reproductive cells both of plants and animals. Cilia are ex-

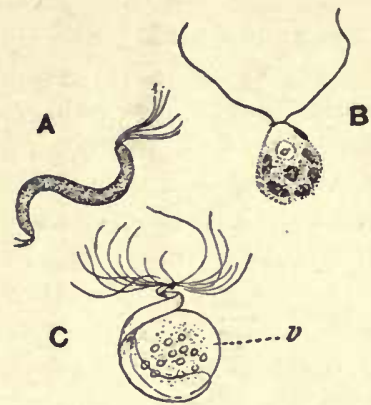

Frg. 27.-Ciliate cells. $A$, Spirillum undula. $B$, zoöspore of Cladophora sp. C', spermatozoid of Equisetum maximum. tremely delicate threads of protoplasm, which are extensions of the outer hyaloplasm, or, in the case of Bacteria, of the cell-membrane, which is evidently not similar in composition to the protoplasm. Sometimes there is a single stout ciliun, or flagellum, but more coinmonly there are two or more. The movement of the cilia is very active, and more or less undulatory. Ciliary movement is only possible in water, and is the method of propulsion of all free-swimming cells (Fig. 27).

Where the protoplast is enclosed within a cell-membrane, it cannot shift its position beyond the confines of the cell; nevertheless, active movements can often be seen within the protoplast, and careful study will reveal slower movements within most cells, resulting in a shifting of the position of different organs. The protoplast may, also, in some cases, escape from the cell, as in the formation of zoöspores, and it then for a time resumes the power of locomotion by developing cilia.

Movements within the Cell. - An enclosed protoplast may show three types of movement. The first of these, "Rotation," occurs within the cells of a number of aquatic plants; e.g. the elongated cells of Chara (Fig. 28) and Nitella, the leaf-cells of Vallisneria and Elodea. In these plants, the cytoplasm forms a thick layer lining the cell-wall, and surrounding a large central vacuole. The hyaloplasmic layer next the wall does not take part in the movement,

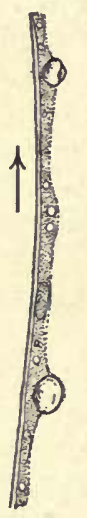

A
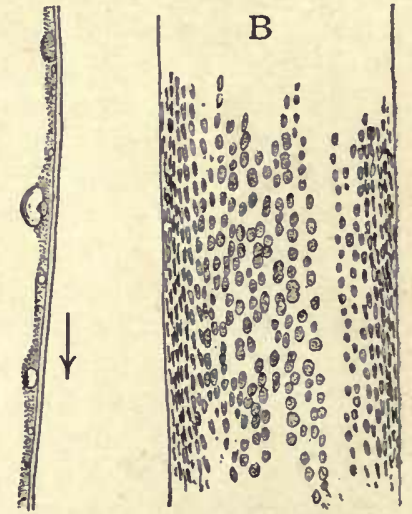

Fra. 28. $-A$, portion of a rhizoid of Chara $s p$., showing the rotating cytoplasm; the arrow indicates the direction of the current (X about 200 ). $B$, surface-view of a large internodal cell from a leaf of the same species, showing the arrangement of the chloroplasts and the neutral line which contains no chromatophores.

and in Chara and Nitella the chloroplasts remain stationary; but in Vallisneria the chloroplasts are carried along with the rotating granular cytoplasm, which moves in a direction corresponding to 
the long axis of the cell. The effect of the rotating mass is that of a broad stream running up one side of the cell and down the other.

The second type of movement-streaming or circulation - is much commoner, and may readily be seen in the cells of many hairs, such as those of Geranium or Petunia. 'The large bristly hairs on species of Cucurbita are especially good objects for demonstration, as are the well-known stamen hairs of species of Tradescantia. In such cells the nucleus is usually imbedded in a mass of cytoplasm from which delicate threads or lamellæ run to the peripheral cytoplasm which surrounds the large sap-cavity. These radiating threads consist of a sheath of hyaloplasm within which the granular plasma is seen to be in active streaming motion. Similar movements may be seen in the peripheral cytoplasm. The movements are for the most part to and from the nucleus, and even in very delicate threads two currents moving in opposite directions may often be noted, and a streain which has been moving in one direction may have its motion reversed. The mechanism governing these movements is not clearly understood.

Movements of Orientation. - Slow movements within the cell, resulting in the change in position of its organs, are not uncommon, and can often be explained as a response to certain stimuli. The most familiar of these movements is the change in position of the chromatophores under the influence of light. Similar movements of the whole cell are seen in the free-swimming green zoöspores of many Algæ, whose movements are strongly influenced by light. A good example of the shifting of the chloroplasts within the cell is offered by the Alga Mesocarpus (Fig. 83), where the single axile flat chromatophore revolves on its axis, presenting either the edge only, or the whole surface, as the intensity of the light varies. So in the cells of a Moss leaf, the chromatophores spread themselves evenly over the onter cell-wall if the light is diffuse, but retreat to the lateral cell-walls and present their edges to the light if it is too intense. These movements are obviously closely associated with the question of the regulation of the intensity of light to which the chromatophore is exposed.

Water in Protoplasm. - All protoplasmic movements require the presence of water, whether these are ciliary or amœboid movements of a naked protoplast, or movements within the protoplast. Without water the labile character of the protoplasm must cease, and when it is withdrawn the protoplasm loses its viscid consistence, and becomes hard and rigid. The withdrawal of water does not necessarily kill the protoplasm, which may be restored to activity by supplying water, but its activity is effectively checked. This is illustrated in dried spores and seeds, which begin to grow as soon as water is supplied. 


\section{Nutrition of Protoplasm}

No less characteristic than its motility, is the ability of protoplasm to assimilate food. For this process the presence of water is as esseutial as it is in movements. Dry protoplasm is incapable of nutritive activity, as water is necessary both for the physical and chemical processes comnected with nutrition or metabolism. In plants food can only be taken into the cells in solution, so that water is a necessary vehicle for the transport of food elements; and finally the decomposition of water itself is the source of the hydrogen and part of the oxygen which enter into the carbohydrates manufactured in the green cells under the influence of light.

Through the activity of the protoplasm the food elements undergo various changes until they form new elements for building up the protoplasmic substance, which thus increases in amount, or grows. All of the metabolic processes, however, are not constructive, and there are formed also certain waste products. Some of the waste products arise from the decomposition of the protoplasm, with an evolution of energy. The most familiar of these destructive metabolic processes is respiration, where the atmospheric oxygen acts upon the carbonaceous protoplasmic structures, which are decomposed, yielding as waste products carbon-dioxide and water, and evolving heat.

\section{Irritability}

Irritability, or response to external stimuli, is a universal attribute of protoplasm. Light, heat, moisture, mechanical shocks, electricity, and many chemical substances exercise marked influences upon the protoplasm.

Light. - Protoplasm is often exceedingly sensitive to the action of light, whose effects are especially noticeable upon the green cells of plants. The movements of zoöspores, and of the chloroplasts within the cell, have already been alluded to. Here the importance of the light-rays in the assimilation of carbon-dioxide is the reason for the movements. The movements of free-swimming green cells, like the zoöspores of any Alga in which these are freely produced e.g. Chætophora, Ulva - are most striking. If the Algæ are placed over night in a glass or porcelain dish, of which one side is more strongly illuminated, the masses of motile cells will be found in the morning collected on the lighted side, and visible to the naked eye as a deep green line on the surface of the water. If a few of the active spores are examined under the microscope, they will be found to swim to the side of the slide toward the window. In these motrle green cells there is very often present a red pigment-spot, which is associated in some way with the perception of light, and is compar- 
able to the so-called eye-spot of some of the lower animals. The well-known effect of the intensity of light upon the movement and rate of growth in the organs of the higher plants is necessarily connected with the behavior of the protoplasm in the cells of the growing part.

Heat. - Below a certain temperature, which varies much in different cases, the activity of the protoplasm stops. Very few plants show activity when the temperature falls below the freezing point of water, but they are not necessarily killed at this temperature. As the temperature rises, there is an increase in the activity of the protoplasm, especially evident where movements are present, but this continues only up to an optimum temperature varying in different cases. Above this optimum the protoplasmic activity decreases rapidly, and finally ceases entirely. The albuminous substances coagulate, and the protoplasm dies. Since some organisms, like Bacteria and allied forms, can endure a temperature nearly or quite up to the boiling point of water, it is evident that in these forms the albuminous protoplasmic constituents must be modified, as the ordinary proteids coagulate at a much lower temperature.

Electricity. - In general, the effect of electric currents passing through protoplasm is to cause contraction and a cessation of movement. Long-continued currents finally result in a complete disorganization of the protoplast. In free-swimming cells, where the current is not too violent, there is a tendency for the cell to move toward the negative pole.

Mechanical Stimuli. - An Infusorian or other naked protoplasnic mass, on being touched, will contract strongly, and the same effect is seen when the water is agitated. Where the protoplasm is within a cell-wall, the movements of the currents are checked, or completely stopped, by a violent shock. If a hair is torn off from a stem and examined with the microscope, it does not at first show the streaming movements, which are only resumed after it has recovered from the mechanical shock.

Chemotaxis. - Various chemical substances exercise a powerful influence upon protoplasm, seen especially in the directive power in its movements. Bacteria collect in great numbers about Algæ which are giving off oxygen, and the Bacteria serve as a very delicate test of the amount given off at different points. The motile male cells, or spermatozoids, of Ferns have been shown to be strongly attracted by a dilute solution of malic acid, and other organic substances have been shown to exercise an attraction on many organisms. This sensitiveness to chemical influences has been called Chemotaxis.

Hydrotropism. - As might be expected, the presence of water affects the movements of protoplasm. A well-known example is the behavior of the plasmodium of the Slime-moulds. If placed in the 
dark on a piece of filter paper, unequally moistened, the protoplasm will become aggregated at the moister spots. The plasmodium also has the peculiarity of growing against a slow stream of water, and by allowing a stream to flow down a glass slide, by means of a strip of filter paper dipping into a vessel of water, the plasmodium will creep up the vertical slide, against the descending stream, and spread itself over the wet surface.

Adaptation. - The extraordinary ability shown by certain organisms to adapt themselves to changing conditions resides primarily, of course, in the protoplasm, and this adaptability to environment must be considered one of the manifestations of protoplasmic irritability.

\section{Reproduction}

The living protoplast, by division into equal parts, or fission, shows the simplest form of reproduction. This power is also shown by the various essential organs of the protoplast, - the nucleus and plastids, - and presumably is shared by the invisible pangens, or ultimate protoplasmic units.

\section{THE TYPICAL PLANT-CELL}

With few exceptions, such as the ova and spermatozoids, the

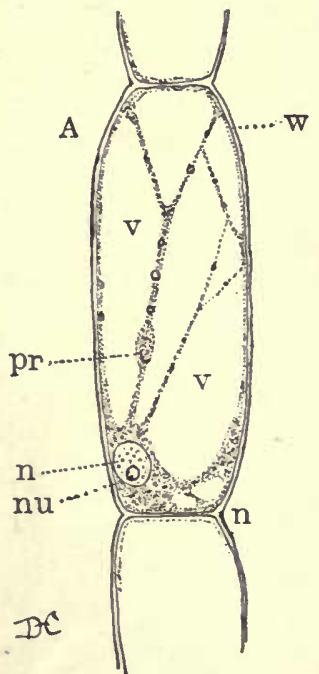

Fig. 29. - Cell from a stamenhair of Tradescantia ; $w$, cellwall ; pr, cytoplasm; $n$, nucleus; $n u$, nucleolus; $v$, racuoles. protoplast of the vegetable cell is contained within a definite membrane, the cell-wall, usually composed of cellulose. It was the cell-wall which first attracted the attention of the early students of vegetable tissues, who quite overlooked the much more important protoplast.

Until a comparatively recent time it was assumed that the protoplast of the simpler plants consisted of quite homo. geneous protoplasm, but it is exceedingly doubtful if such simple forms really exist. The excessively minute size of some cells, like certain Bacteria, may account for the failure to demonstrate a definite organization of the protoplast. A further discussion of the structure of the protoplast in the Bacteria and the allied Schizophyceæ will be deferred until another chapter.

In the cells of all typical plants there may always be detected a nucleus (or sometimes many nuclei) and usually one 
or more chromatophores, or plastids, wanting in animal cells, which are also, as a rule, less clearly delimited. The limits of the vegetable cell are marked by the membrane, or cell-wall, composed usually of cellulose, a carbohydrate occurring but rarely in animal tissues; e.g. the mantle of certain Tunicates. Owing to the presence of this membrane, exteusions of the protoplast, except through openings in the membrane, are impossible; and the tissues made up of such cells are less freely motile than the tissues of animals. While the cells of plants show a good deal of variation in form and in the character of the cell-wall, they are very seldom so changed that their cellular nature is not perfectly apparent. Where cells are isolated, as in many unicellular plants and the reproductive cells of the higher ones, the form of the cell is usually globular or oval; but in sections of tissues the cells appear more or less polygonal, owing to the flattening of the walls by mutual pressure.

The Cell-wall. - The young cell-wall is delicate and quite colorless. As a rule, it is composed of pure cellulose, whose chemical formula is $\mathrm{C}_{6} \mathrm{H}_{10} \mathrm{O}_{5}$. Cellulose gives a characteristic reaction when treated with iodine and sulphuric acid, or with chloriodide of zine. In both cases

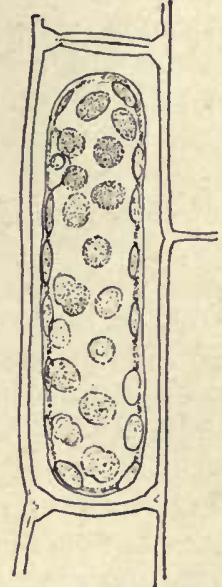

FIG. 30.- Plasmolyzed cell from the leaf of Funaria hygrometrica; some of the discoid chromatophores are dividing $(\times$ about 500$)$. the colorless walls assume a blue or violet color. The membrane may later become much thicker, and the cellulose may be more or less completely replaced by other substancès. The thickening of the wall is either by the addition of uniform layers, or the thickenings may be unequal, resulting in characteristic sculpturing of the walls, like the spines and ridges in many spores (Fig. 33) and the pits, spiral bands, or reticulate thickenings on the inner walls of the woody elements of many stems.

In its normal condition, the cell-wall is strongly distended by the pressure of the fluid contents of the cell. By placing a turgid cell in a denser solution, e.g. a $10 \%$ solution of salt or sugar, a portion of the water will be withdrawn from the cell, accompanied by a contraction of both the protoplast and the cell-wall. This contraction of the protoplast under the influence of a fluid denser than the cell-sap is known as Plasmolysis.

While the protoplasm is for the most part confined to the protoplast, it is probable that in all active tissues the cell-wall is perforated by minute pores, which place the protoplasts in direct communication by means of delicate cytoplasmic filaments. It seems probable, also, 
that in the growing cell-wall there is more or less living protoplasm concerned in the laying down of new cellulose molecules.

Vacuoles. - In very young cells the cytoplasm as a rule fills the cell completely, but as the cells increase in volume there is not a corresponding growth of the protoplast, which in consequence develops cavities within it filled with watery fluid, or cell-sap. In old plantcells there is generally a single large central vacuole, and the cytoplasm is reduced to a thin membrane closely appressed to the cell-wall by the pressure of the fluid contained within the central vacuole. Not infrequently, as in the cells of many plant-hairs (Fig. 29), the large vacuole is traversed by threads in bands of cytoplasm in which active streaming can usually be seen.

In the free-s wimming zoöspores of many Algæ, and in the vegetative cells of the Volvocaceæ, there are found small vacuoles which contract and expand rhythmically, and are comparable to the contractile vacuoles found in many Infusoria. The fluid within the vacuoles is not pure water, but contains various substances in solution, which may become precipitated. Such precipitates are the characteristic calcium crystals met with in many plants.

The Nucleus. - In all typical cells there is a definite Nucleus, which has been shown to be a structure quite distinct from the cytoplasm. In all cases the nucleus arises by division of a preëxisting nucleus. In the living cell the nucleus usually presents a more or less granular appearance and contains one or more nucleoli. The nembrane bounding the nucleus is analogous to that about the vacuoles, and like it belongs to the cytoplasm.

Plastids (Chromatophores). - In most plant-cells there can usually be found characteristic bodies embedded in the cytoplasm, and which, like the nucleus, can never be formed de novo in the cytoplasm. These are the Plastids, or Chromatophores, and include the green corpuscles, or chlorophyll-granules (Chloroplasts), which give the characteristic green color to plants.

Centrosomes. - In the cells of some Brown Algæ (Fig. 31), and also in a few Liverworts, e.g. Pellia, structures known as Centrosomes have been detected, which resemble the corresponding structures in the cells of animals. These are minute granules lying close to the nucleus, and sometimes showing a marked radiation in the surrounding cytoplasm. It has been assumed that these bodies are of much importance as centres of energy, and are constant structures like the nucleus; but the results of later study tend to prove that they are absent from the cells of the higher plants, and are probably of much less importance than was formerly supposed.

Multinucleate Cells. - While most plant-cells possess but a single nucleus, there are many examples of protoplasts provided with several or many nuclei. Such are the giant cells of the Water-net 
(Hydrodictyon), the common Alga Cladophora, and the group of Algæ known as Siphoneæ. In these cases the nucleus may divide repeatedly without any division-wall being formed, so that the protoplast remains undivided. In Hydrodictyon, the number of nuclei may be several thousand. In these cases, nuclear division is of the usual type (Karyokinesis), but occasionally - e.g. the long cells of the Characeæ (Fig. 43), old cells of Tradescantia - the nucleus may divide by direct constriction, or fragmentation. Such direct division, however, never occurs in young cells.

\section{Structure of the Nucleus}

The nucleus is evidently of great importance to the life of the cell, and the protoplast is incapable of protracted existence if deprived of the nucleus. Thus if the protoplast is divided into two parts by plasinolysis, which can be done without otherwise injuring the cell, it is found that the part of the protoplast containing the nucleus can develop a new wall and become a normal cell : the other piece soon dies. The latter can in some cases manufacture starch in the presence of light, but seems to be incapable of using it, and the starch accumulates until finally the mass dies.

In the living cell the nucleus has the form of a vesicle with a clearly defined membrane, which, as already stated, is the limiting layer of the cytoplasm which surrounds the nuclear cavity. The latter may appear homogeneous, or more commonly shows a more or less definitely granular appearance. The nucleolus is usually conspicuous, and is a globular, highly refractive corpuscle.

The nuclear structures, when more carefully investigated by means of proper fixing and staining agents, are found to be very complicated. The nuclear cavity is filled with an apparently homogeneous fluid, the nuclear sap, in which the solid elements form a complicated network of fibrils. This is made up of a single, much-tangled thread, which is more or less fused together where the strands touch, resulting in

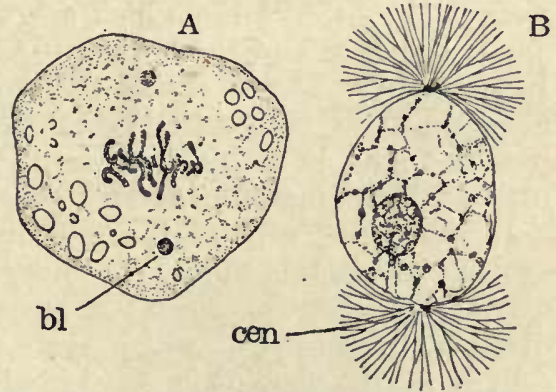

Fra. 31. $-A$, young spermatogenic cell of Marsilia vestita in process of division; $b l$, blepharoplast. (After SHAw.) $B$, nucleus from a cell of Dictyota dichotoma, showing the centrosomes, cen, with the radiating kinoplasmic filaments. (After MotTIER.)

the reticulated structure which can be made out in the resting nucleus. In the latter the filaments composing the nuclear network 
are chiefly composed of a substance (Linin) which does not easily take up the various stains employed in studying the nucleus. Imbedded in the linin-thread are more or less numerous granules, composed of a substance (Chromatin) which is remarkable for its avidity for staining-agents. The number and size of the chromatin granules vary much at different times. One or more nucleoli are generally present. These are usually globular, highly refractive bodies, which stain freely with certain reagents, but differ from the chromatin bodies in the color they assume. During the process of cell-division the nucleolus disappears, but just what becomes of its substance is not entirely clear.

Blepharoplasts. - Closely resembling in appearance the centrosomes, are special structures known as Blepharoplasts, which occur in the later stages of development of the spermatozoids of Ferns and other related forms. From the blepharoplast are developed the cilia with which the spermatozoid is furnished. There has been some discussion as to the nature of the blepharoplasts, one suggestion ${ }^{1}$ being the possibility of their being in some way connected with the nucleolus. As the nucleolus is absent from the nucleus, which becomes transformed into the spermatozoid, it is possible that the blepharoplast may be composed of nucleolar substance which has been ejected from the nucleus into the cytoplasm.

\section{Chromatophores}

In the cells of all green plants there are always found the chromatophores or plastids, which are wanting in the cells of Fungi. These bodies are of three kinds-Chloroplasts, Chromoplasts, and Leucoplasts. The first are the green corpuscles containing the green pigment chlorophyll; the second, the red and yellow,corpuscles found in many flowers and fruits; the latter, the colorless plastids, including the so-called Starch-formers.

In the young cells of the growing-point of a stem, or in young spores, the plastids appear as minute granules, usually in the vicinity of the nucleus. They may sometimes be observed undergoing division, by means of which their number is increased. As the cells grow, the plastids increase in size, and they may develop chlorophyll, or later assume a red or yellow color. In cells which are not exposed to the light the plastids remain colorless, but these may on exposure to light develop chlorophyll, and thus change into chloroplasts.

Chloroplasts are with few exceptions - e.g. prothallium of Pilularia, cotyledons of Pinus, young embryo of Celastrus - produced

1 Fischer (3), p. 247. 
only in cells exposed to the light, as their function is that of the assimilation of carbon-dioxide, which can only take place in the light. In the lower plants, like many Green Algæ (Fig. 32, A), there is but a single chloroplast in each cell. It then may have the form of a cup, as in most Volvocaceæ, a central axile band, as in Mesocarpus, an equatorial band, as in Chætophora, etc. In the higher plants the chloroplasts are usually numerous, and most commonly are oval, flat disks. The body of the chloroplast shows the same spongy structure as the cytoplasm, and the green pigment in a soluble form is supposed to occupy the spaces of the spongy body, from which it can be readily extracted by means of alcohol, ether, and other reagents. The colorless matrix is then left unchanged in size or form.
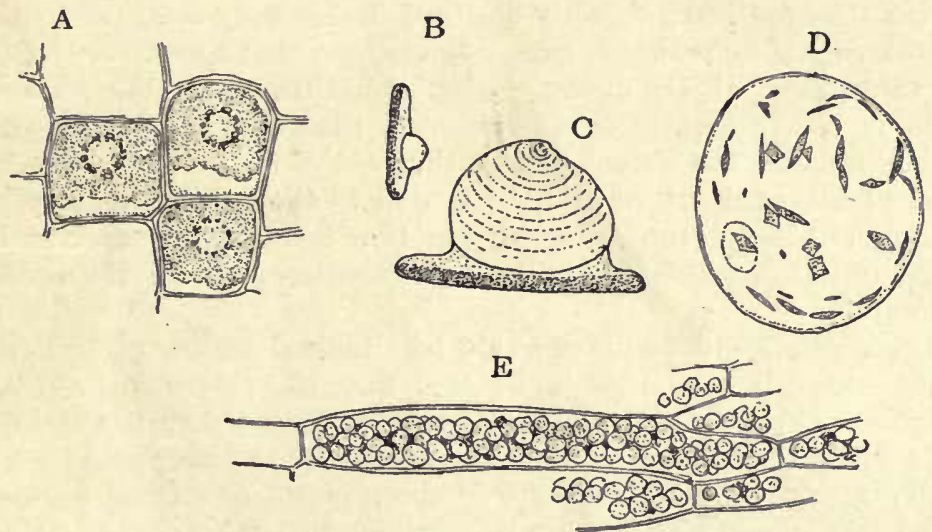

Fig. 32. - A, three cells from the thallus of Coleochæte scutata, showing the single chromatophore and pyrenoid in each $(\times 600)$. $B$, leucoplast, with young starchgranule, from the pseudo-bulb of Phajus grandifolius. $C$, leucoplast with fully developed starch-granule, of the same species $(\times 540)$. ( $B, C$, after STras BurGER.) $D$, a cell from the pulp of a "hip" of Rosa rubiginosa, showing the orange-red chromoplasts $(\times 250)$. $E$, cells from a ray-floret of Gazania splendens, showing rounded, orange-red chromatophores $(\times 500)$.

Pyrenoids. - Associated with the chloroplastids, especially among the Algæ, are special bodies, Pyrenoids (Fig. 31, A), whose exact nature is still not clearly settled. These very often have about them an accumulation of starch which suggests that they may be concerned in the process of carbon assimilation, but they have also been considered as themselves products of the activity of the chloroplast, and to be merely masses of reserve nitrogenous food. The former view is perhaps the more probable. Chloroplasts are not necessarily green, as in some cases, e.g. Red and Brown Algæ, accessory red or brown pigments are associated with them. Even where the chloroplasts appear green, it is readily shown that in addition to the chlo- 
rophyll there are two other pigments present, - a reddish one, Carotin, and a yellow one, Xanthophyll. These, like the chlorophyll, seem to be dissolved in an oily substance, which is extracted by alcohol and other solvents. If an alcoholic solution of chlorophyll is examined, it shows a strong fluorescence, appearing reddish by reflected light. If the green alcoholic solution is shaken up with benzole, on settling the latter will dissolve out the yellow xanthophyll, leaving the chlorophyll in the alcohol.

The Chromoplasts differ from the chloroplasts in their red or yellow color. They give the color to many red and yellow flowers like the Nasturtium and Marigold, and the yellow and orange fruits, such as Rose-hips, Mountain-ash, Pumpkin, Peppers, Squash, etc. They may differ but little in form from the ordinary chloroplasts, from which they are often directly derived, or they may arise from small indifferentiated chromatophores. Sometimes they are of very irregular forms (Fig. 31, D), owing to the crystallization of the pigment. This is either carotin or xanthophyll, the relative abundance of which renders the chromoplast either red or yellow. The yellow color of leaves deprived of light is due to their failure to develop chlorophyll, thus rendering visible the yellow pigment, xanthophyll (etiolin), which is hidden by the chlorophyll in the normal chloroplast.

Leucoplasts. - If we make a thin longitudinal section of an herbaceous stem, it may usually be seen that the chloroplasts of the outer cells are replaced by similar but colorless bodies in the inner cells where the light is more or less cut off by the overlying tissues. Every gradation between the true chloroplasts and these colorless leucoplasts may often be found. Leucoplasts which occur in roots, or other subterranean parts, may, when exposed to the light, develop into normal chloroplasts. This is clearly seen in the outer tissues of potato-tubers, which soon turn green when exposed to light.

Starch-formers. - One important group of the leucoplasts are the starch-formers (Fig. 31), which occur in tissues where reserve-starch is being manufactured. The starch-grains arise within the leucoplast, just as they do in the chloroplasts when exposed to light, but the formation of the starch-grains by the leucoplasts is quite independent of light, and the materials of which the reserve-starch is composed are derived from the starch manufactured in the chloroplasts under the influence of light.

\section{The Cell-wall}

Unlike the nucleus and plastids, the cell-wall is not a permanent organ of the cell, but may be renewed from time to time. The cellulose found in the walls of most young plant-cells is replaced in 
Fungi and Lichens by a substance-Fungus-cellulose - somewhat different in composition from ordinary cellulose, and there are some other modifications of it. Some of these which are more readily attacked by acids and alkalis have been termed "Hemicelluloses." In Fungi, moreover, the cellulose may contain chitin, in this respect resembling some animal tissues, and the Bacteria and other Schizophytes seldom show an unmodified cellulose wall. How far these changes are secondary is not certain. Most cells, as they grow older, show modifications of the wall, which may be of two kinds, - mechanical thickening and chemical changes.

Thickening of the Cellwall. - The older cellwall often shows a marked stratification, which is sometimes very pronounced; e.g. old cells of Cladophora. Here the thickening is apparently due to the deposition of new layers of cellulose

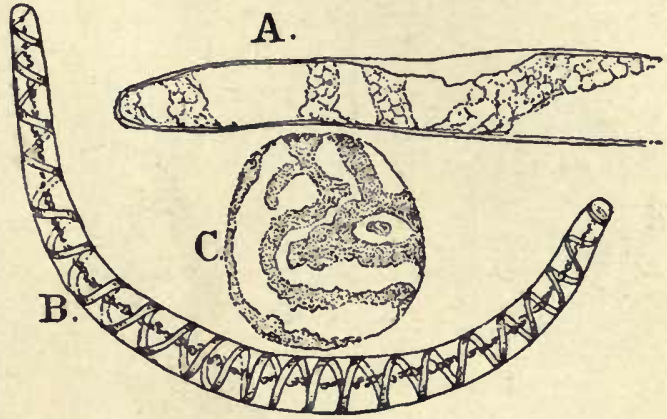
on the inner surface of the wall. Where the thickenings are upon the outside of the cell-wall, as in the sculpturings of certain Desmids, or the formation of hairs upon such Algæ as Coleochæte, it is probable that the cell-wall is more or less completely perneated by the living protoplasm, which, in the case of the Desmids at least, has been shown to pass through the cell-wall by means of extremely fine pores. The sculpturings upon the outer surface of the spores of Mosses and Ferns and the corresponding pollenspores of the Phanerogams can in most cases be attributed to the activity of the protoplasm surrounding the developing spores. Where the deposit on the inner surface of the wall is unequal, there result markings of various kinds, such as the characteristic spirals, pits, and reticulations found upon the walls of the tracheary or water-conducting tissue of the higher plants.

Much controversy has been aroused in regard to whether the wall grows by simple apposition of new material, or whether it may grow 
by the introduction of new particles between the old ones; i.e. by Intussusception. It seems probable, however, that both processes are active in its growth.

Incrustation. - Mineral substances often occur in the cell-wall, sometimes to such an extent as to render the tissues of stony hard-

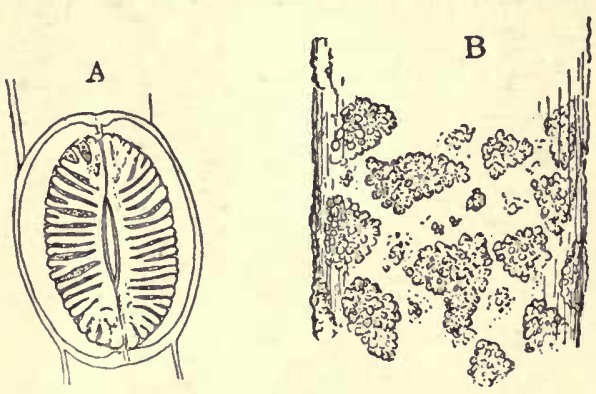

FIG. 34. - A, inner surface of a stoma of Equisetum lævigatum, showing the silicions bars $(\times 250) . B$, surface of a large internodal cell from a young plant of Chara $s p$., showing masses of carbonate of lime $(\times 250)$. ness. This reaches its maximum in certain Algæ, particularly the marine Corallines and Siphoneæ, which live especially about coral reefs, to the building of which they often largely contribute. Here the incrustation is carbonate of lime, as it is in the tissues of the true Corals. Of fresh-water Algæ, the Stoneworts, species of Chara, are the best-known examples of calcareous incrustation.

Silica is also a common incrusting agent, and is abundant in the epidermal tissues of many land plants - e.g. Grasses, Equisetum - whose epidermis is either hard and polished as is the stems of Bamboo, or rough like sandpaper, as in Equisetum and the harsh cutting margins of many Grass leaves. Beautiful examples of the impregnation of the cell-wall with silica are offered by the shells of Diatoms. By burning away the organic matter, the silicious skeleton may be obtained.

Chemical Changes of the Cell-wall. - Of the various chemical changes which the cell-wall may undergo, lignification and suberization are perhaps the most familiar, although the exact nature of these changes is not entirely understood. Lignification is the change into wood found especially in the water-conducting tissues of the higher plants. It seems likely that the change into wood involves a chemical change in the constitution of the original cellulose membrane, combined with an infiltration of various substances, including gum, mineral constituents, etc. The woody membranes are good conductors of water, especially when young, and are of special importance to the plant in this connection. Their firmness also makes the woodcells the most important of the skeletal elements of the higher plants.

The suberized or corky cell-walls, unlike the woody walls, are impervious to water, and are especially developed where it is desirable to protect the tissues against loss of water. Cork-cells are 
largely developed in the outer bark of many trees and shrubs, the cork of commerce being derived from the Cork-oak (Quercus suber) of Southern Europe. Very similar is the cutinization of the exposed epidermal cells of leaves and stems, in which the outer wall of the epidermal cells develops a thick, impervious layer, or cuticle, which in its chemical composition seems to be much like cork. It has been supposed that the character of the suberized menibranes was due to an infiltration of the cellulose membrane by a fatty or waxy substance, suberin; but later researches have made it more likely that the cellulose undergoes a chemical change as well. This is indicated by the destruction of the suberized membranes by reagents which do not attack cellulose.

The cell-walls of many Algæ are mucilaginous in consistence, or they may be imbedded in masses of gelatinous matter, which are probably in part derived from a transformation of an originally cellulose membrane, but are with little question also in part a direct secretion of the protoplast. There are, moreover, all intermediate conditions between mucilage and cellulose, with which it is chemically closely related. Mucilaginous and gelatinous walls are remarkable for their power of swelling when wet, and it is this property which is of value to the plant. The mucilaginous change in the walls of the cells in the reproductive organs of many plants, e.g. zoösporangia of Algæ, sexual organs of Ferns, etc., is the main factor in the opening of the organs and the discharge of their contents. The development of mucilage, either by secretion from the cells or by changes in the cell-walls, is of great importance in protecting delicate parts from excessive loss of water. This is especially well seen in many Seaweeds which are exposed for long periods between tides.

\section{Inclusions of the Protoplast}

Besides the living cell-contents, there are present various substances which are the products of the activity of the protoplasm, and may be either plastic substances, capable of being used by the protoplasm as food, or they may be excretions or waste products.

Soluble Substances. - Within the cell-sap are dissolved many substances, like sugar and pigments, as well as inorganic bodies. The blue and crimson pigments of leaves and flowers are, with few exceptions, dissolved in the cell-sap of its superficial cells. Sugar, inulin (found in roots of various Compositæ), and similar carbohydrates occur in solution in the cell-sap, and may be crystallized out by proper methods. The shining granules occurring in the cells of the common Alga Zygnema are minute vacuoles filled with a solution containing tannic acid; and other organic acids, e.g. malic, oxalic, occur in solution in many plants. 
Imbedded in the protoplasm there may be detected various solid, or semi-solid, substances which are secondary products of the protoplasm. The commonest of these are granular, and are either of albuminous nature, like the gluten-granules in the outer cells of the wheat-grain, or carbohydrates, of which starch is the commonest form. These are especially abundant in the cells of seeds, spores, tubers, and other stores of reserve-food.

Starch. - Starch is one of the commonest products of the cell, and often occurs in great quantities in the cells of structures like bulbs, tubers, seeds, and similar reservoirs of reserve-food. Thus potatoes, grains of various kinds, Arrowroot, Sago, etc., owe their value as
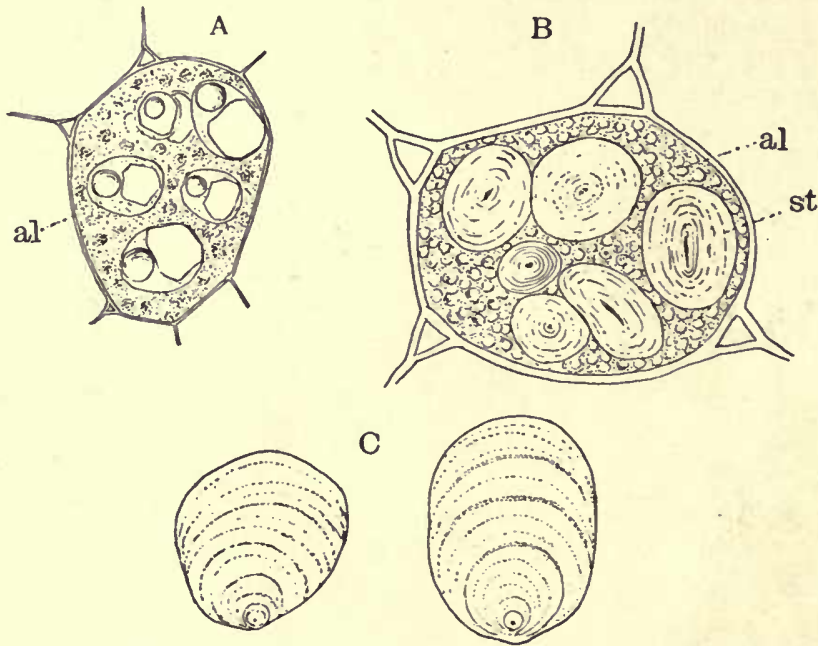

Fig. 35. $-A$, a cell from the endosperm of Ricinus communis, showing aleuronegrains, $a l$, containing albumen-crystals and globoids $(\times 500) . B$, cell from the dry cotyledon of Pisum sativum, filled with small aleurone-granules, al, and large starch-granules, st $(\times 500)$. $C$, two large starch-granules from the rhizome of Canna Indica $(\times 250)$.

food largely to the starch contained in their cells. Starch appears in most chloroplasts as the first visible product of the assimilation of $\mathrm{CO}_{2}$, and this starch may be used at once for the growth of the tissues, or it may undergo a change into a soluble compound (usually glucose), which is conveyed to the cells where the reserve-starch is reconstructed from the glucose, this process being independent of light, which is essential for the original manufacture of the starch. As in the green cells, the formation of reserve-starch is also bound up with the plastids, here known as starch-formers.

Starch-grains (Fig. 35, B, C) are usually ellipsoid, or the smaller ones globular, this difference being due to the fact that the smaller 
grains are completely imbedded in the starch-forming leucoplast, and grow equally on all sides, while the larger oval ones become free on one side, which ceases to grow, while new material is only deposited on the side in contact with the leucoplast. The larger starch-grains generally present a distinctly laminated appearance, due to layers of different density, and there is a small spot, the hilum, about which the lamellæ are arranged concentrically. Good examples of such starchgrains are offered by the Potato, species of Canna, and the spores of Marsilia. Compound starch-grains, such as those in oatmeal, are not uncommon, and in species of Euphorbia they are dumb-bell shaped. Chemically, starch is closely related to cellulose and sugars like glucose, into which it is easily converted. The chemical formula is the same as that of cellulose. ${ }^{1}$

Albuminous Granules. - The granules of reserve-food may often be of albuminous nature, i.e. they contain nitrogen, and differ much less

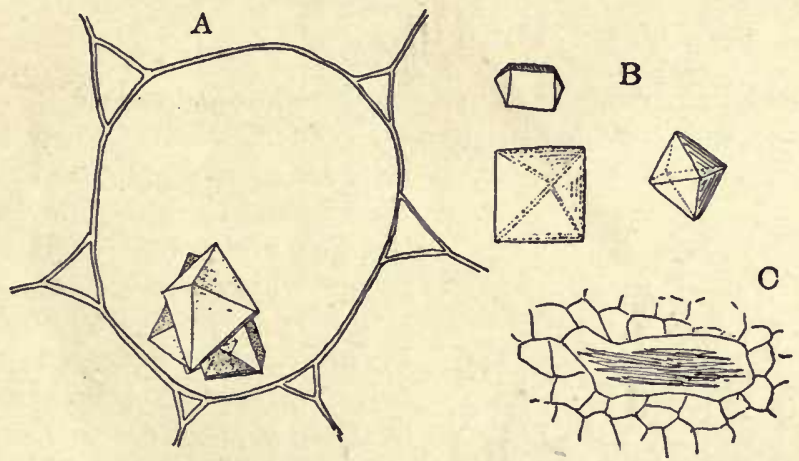

Fic. 36. $-A$, cell from the stem of a Begonia containing crystals of calcium-oxalate $(\times 250)$. $B$, separate crystals from the same plant. $C$, cell from the ovary of Sparganium eurycarpum, with needle-shaped crystals, or rhaphides $(\times 250)$.

from the living proteids than do the starch-granules. These albuminous bodies may be roundish or irregular grains, as in the glutencells of the wheat-grain ("Aleurone-grains"), or sometimes they assume a crystalline form. Such protein-crystals occur in many seeds, e.g. the Brazil-nut (Bertholletia excelsa) and the Bur-reed (Sparganium). They may also be found in the cortical cells of the potato-tuber. The protein-crystals, or "crystalloids," as they are often called, may be found in all parts of the cell, even within the nucleus.

Oil. - In some plants the starch is partly or entirely replaced by fatty oil. Thus in the common Alga Vaucheria, oil replaces the starch as the first visible product of photo-synthesis. In many

1 See also Zimmermann (p. 225) for a discussion of substances related to starch. 
seeds also, e.g. Flax, Almond, Nuts of various kinds, the reserve-food is largely oil, and in many spores, e.g. most Ferns and Mosses, oil is very abundant.

Crystals. - Lime-crystals are of common occurrence in plant-cells, much the greater number being calcium-oxalate, which appears in two forms (Fig. 36), either as needle-shaped crystals or Rhaphides, very common in many Monocotyledons, or tetragonal crystals of different forms. These crystals are not soluble in acetic acid, which quickly attacks calcium-carbonate, but they yield readily to hydrochloric acid. Small crystals of calcium-sulphate occur in the vacuoles in certain Desmids, and in old leaves of the Fox-grape (Vitis labrusca) there have been detected crystals of calcium-tartrate. Calcium-carbonate rarely occurs except as an incrustation of the cell-wall. Curious accretions of this substance, Cystoliths, are found in the leaves of some plants, notably the India-rubber tree (Ficus elastica).

\section{FORMS OF CELLS}

The simplest plants are single cells, either naked, motile ones, or stationary and provided with a definite cell-wall. Such isolated

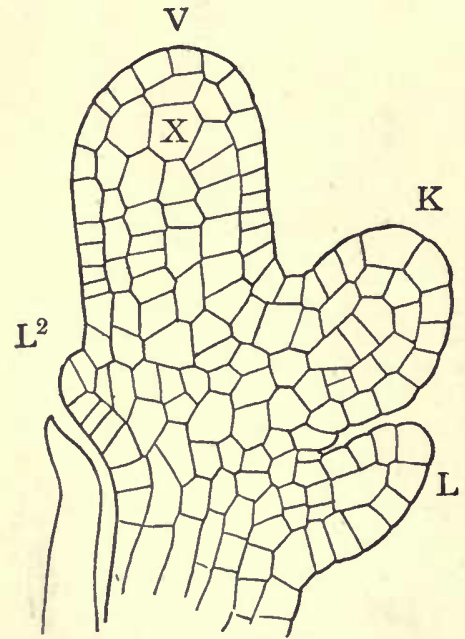

Fig. 37.-Apex of a shoot of Naias flexilis, showing the arrangement of the meristematic tissues; $X$, the initial cell for the plerome, or central cylinder of the shoot; $K$, a lateral shoot; $L, L^{2}$, young leaves. cells are mostly globular or oval in form, which is also the case with the eggs and spores of the higher plants, which represent the simple, primitive type of cell. Such a cell by growth and repeated division gives rise to a simple cell-aggregate or tissue, such as composes the young parts of the higher plants (Fig. 37). These young tissues have cells of nearly equal longitudinal and transverse diameters, or are isodiametric, and have thin cellulose membranes. The undifferentiated cells become gradually transformed into the permanent elements making up the characteristic tissues of the higher plants. The progress of these changes can be readily traced in longitudinal sections or series of transverse ones, passing through the apex of a growing shoot or root.

Parenchyma. - The commonest form of tissue is parenchyma, in which the cells are thin-walled, and but little altered from their orig. 
inal form, although sometimes much elongated. The whole of the body of the lower plants, and most of the active tissues of the higher ones, are parenchymatous.

Mechanical Tissues. - Plants growing in the air require certain skeletal structures to give them the necessary rigidity. These supporting tissues are known as mechanical tissues, but are not necessarily devoted to this purpose only. The strongly distended cells of ordinary parenchyma give firmness, and may to some extent be considered mechanical tissue, but large aerial plants require something

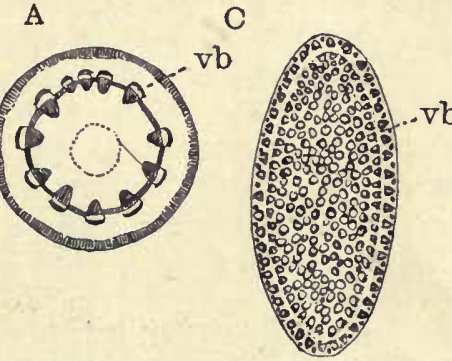

B

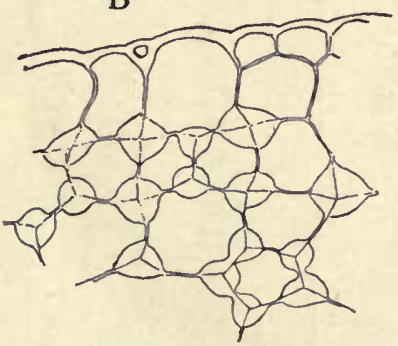

D

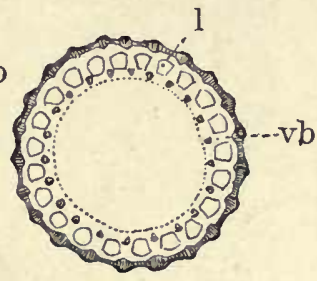

$\mathrm{E}$

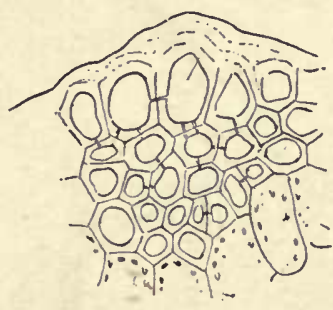

Fig. 38. - $A$, cross-section of the stem of a Begonia, showing the circle of vascular bundles $(\times 3) . \quad B$, collenchyma, or thick-angled tissue from the outer part of the cortex of the same plant, more highly magnified. $C$, cross-section of the peduncle of the inflorescence of Phcenix Canariensis, showing the numerous scattered vaschlar bundles $(\times 2)$. D, cross-section of an internode of the shoot of Equisetum lævigatum, showing the ring of vascular bundles, $v b$, alternating with large airspaces, $l$. $E$, sclerenchyma, or fibrous tissue, from the outer part of the stem $(\times 250)$. The shaded portions of $A$ and $C$ indicate the mechanical tissues.

more, and we find special tissues developed. In the vascular plants there is generally found below the epidermis a greater or less developed system of supporting tissues (Hypoderma), which may be in the form of elongated, thick-walled fibres, with pointed ends (Prosenchyma, e.g. Wood-fibres), or thick-angled elongated elements (Collenchyma, e.g. Begonia), or shorter, very thick-walled stony cells (Sclerenchyma, e.g. the rhizomes of most Ferns).

Most important in this connection are the vascular bundles of the higher plants, which form a very complete skeleton of firm, woody 
tissue. The wood of the stem, and the framework, or veins of the leaves, belong to the vascular system. The mechanical elements of the vascular bundle are of two kinds, Fibres - either wood or bast fibres - and tracheary tissue. The latter is also the principal waterconducting tissue of these plants, and may be coinposed either of Tracheids, which are single elongated cells, or Vessels, which are rows of cells in which the transverse partitions have disappeared. Both forms of tracheæ, when mature, are destitute of living contents, and their walls are marked by rings, spirals, reticulations, or pits, due to unequal thickening in the growing wall.
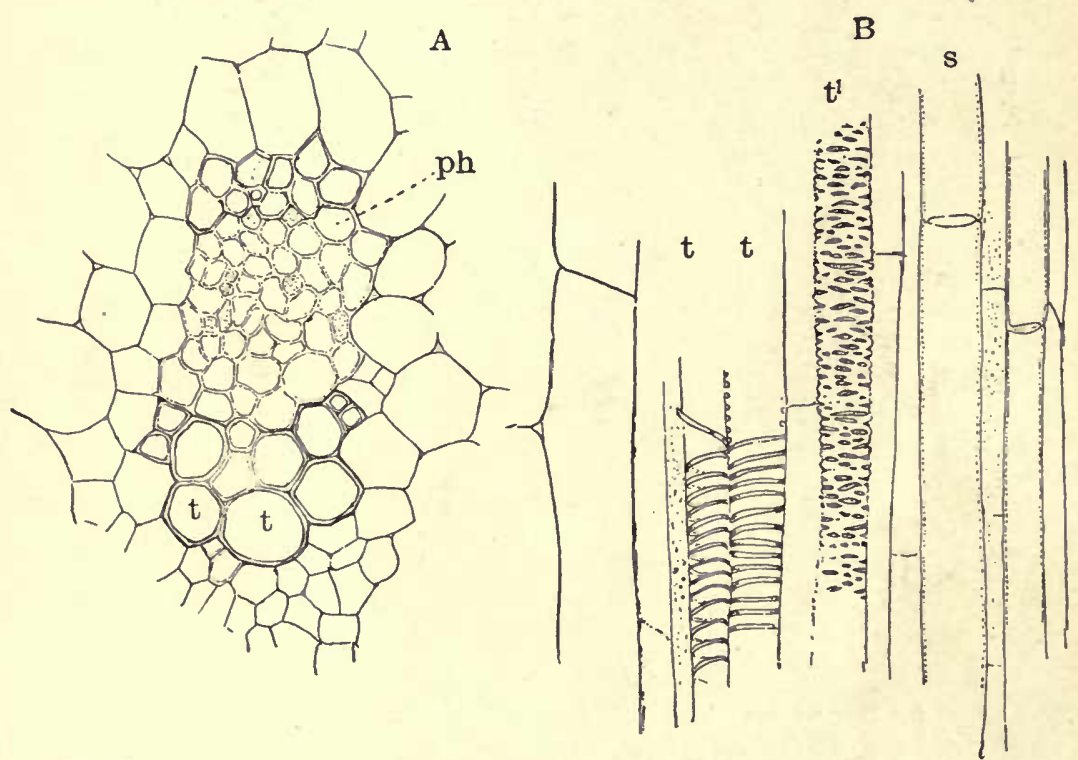

Frg. 39. - A, cross-section of a vascular bundle from the scape of Iris Florentina $(\times 250) ; t$, tracheary tissue; $p h$, phloem. $B$, longitudinal section of the same; $t$, spiral, $t^{\prime}$, reticulate vessels; $s$, a sieve-tube.

In some of the lower plants, like some Seaweeds, firmness is given to the plant by great thickening of the walls of the superficial cells, such as occurs in many forms which are exposed to the heavy surf. Others, like the calcareous Algæ, attain the same end by a heavy deposit of lime in their outer cells.

Protective Tissues. - All of the superficial cells of plants exposed to the air are provided with a heavily cutinized membrane, which is especially developed in plants of dry regions. This thick cuticle prevents excessive loss of water from the delicate inner tissues. The layers of cork-cells in the stems of woody plants serve the same purpose. 


\section{Conductive Tissues}

Besides the tracheary tissue already referred to, there are other forms of conducting tissue met with. Most important are the sievetubes (Fig. 40) found in the outer or bast portion (phloem) of the vascular bundles. The sievetubes closely resemble the tracheæ of the woody part of the bundle, but differ in not having the walls lignified, and in retaining the living cellcontents. While the tracheæ are mainly concerned with the conduction of water, the sieve-tubes are the important agents in the transfer of assimilated food-elements. Very similar in appearance to the sieve-tubes of the vascular plants are those found in many of the large Kelps, or Brown Algæ.

Another type of conducting tissue is seen in the so-called Laticiferous ducts, which occur in plants with milky juice, like the Poppy, Lettuce, Milkweed, Euphorbia, etc. Sometimes the latex is red, e.g. Bloodroot (Sanguinaria), yellow (Argemone), or colorless (Eschscholtzia).

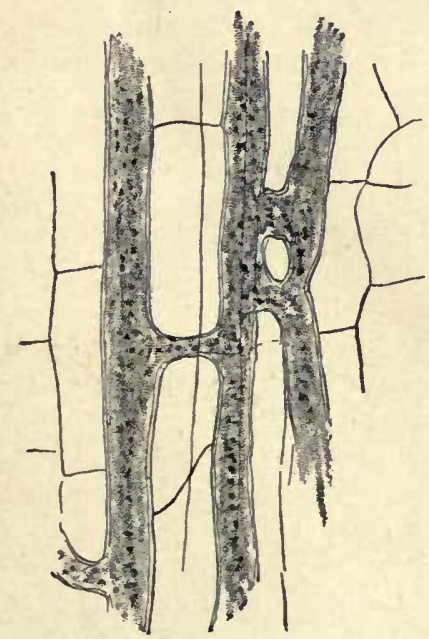

Frg. 41.-Anastomosing laticiferous vessels from the stem of Sonchus oleraceus.

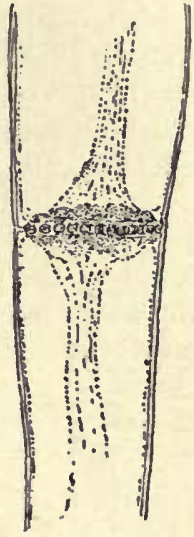

Fig. 40. - Longitudinal section of part of a sieve-tube of Megarrhiza Californica; the eytoplasm has been contracted by the action of alcohol $(\times 600)$.

\section{The laticiferous} ducts may be either very long and branched single elements, e.g. Euphorbia, or the much more common irregularly branching system formed by the coalescence of many cells (Fig. 41). It is somewhat questionable how far the laticiferous ducts are of importance in the transfer of plastic materials. Much of the contents are apparently excretions, whose functions, if any, are not certainly known.

\section{Special Secretory Cells}

Special secretory cells are of wide occurrence. Such are the cells secreting the various aromatic substances to which plants owe their characteristic odors. The oil-glands in the Orange and Lemon belong to this category, as do the mucilage and oil-cells in many Liverworts. 


\section{CELI_FORMATION}

New cells may arise by division, or by the union of two (occasionally several) into a single cell.

Fission. - The commonest form of cell-multiplication is the division of the cell into two, usually equal, parts. This mode of division, or Fission (Fig. 42), is the only method by which new cells are formed in the lowest organisms, such as Bacteria. In the Bacteria, where a distinct nucleus cannot be certainly demonstrated, the cell-division consists merely in the constriction of the protoplast, and its division without the complicated changes in the nucleus which characterize cell-division in the higher plants. Sometimes there is no evident constriction of the protoplast, but a division-wall cuts the cell into two parts, which may remain connected, and by repeated divisions give rise to a cell-row. In these lowest forms, all the cells are alike, and there

A
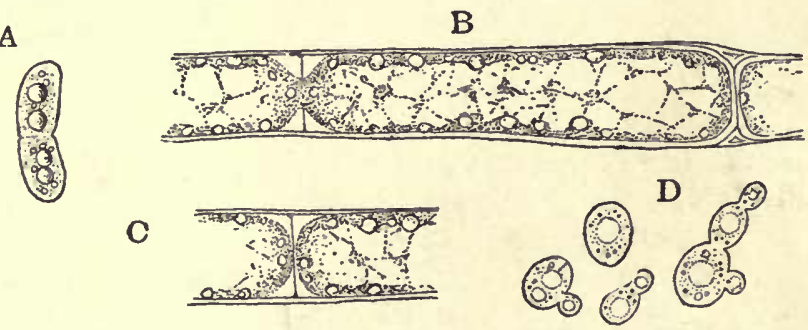

Fic. 42. $-A$, cell of a Bacterium, Chromatium Weissii, in process of division $(\times 1000) . B$, a living cell of Cladophora glomerata, in process of division; the division-wall is not complete. $C$, the same cell an hour later $(\times 200) . \quad D$, cells of Yeast, Saccharomyces cerevisiæ, multiplying by budding $(\times 700)$.

is no distinction between vegetative and reproductive cells. In somewhat more specialized forms, certain cells may be somewhat changed, and become modified into thick-walled resting spores, which are, however, derived from ordinary vegetative cells.

Where a definite nucleus is present in the cell, as occurs always in the cells of the typical plants, the division of the protoplast is preceded by a division of the nucleus. The only exceptions to this are multinucleate cells, or Conocytes, in which nuclear division and celldivision are quite independent. The formation of the division-wall may begin as an equatorial ring of cellulose, which grows centripetally, until it cuts the protoplast in two; or there may be formed simultaneously in the protoplast an equatorial cell-plate, which extends completely across the cell.

\section{Karyokinesis}

The division of the protoplast is preceded by extensive changes in the nucleus, which finally become divided into two daughter-nuclei. These changes are known as Mitosis, or Karyokinesis. 
The Resting Nucleus. - The resting nucleus (Fig. 44, A) contains a complicated network, made up of linin-threads, in which are imbedded more or less numerous chromatin-granules. One or more nucleoli are also usually present.

Prophases. - The first sign of approaching division is a shortening and thickening of the lininfilaments, which sometimes may be shown to constitute a single long and very much tangled thread. This is accompanied by an increase in the amount of chromatin, which forms a series of disks arranged along the linin-thread, like beads, separated by short intervals (Fig. 44, D). The spaces between the chromatin disks may almost completely disappear as the thread shortens, so that the thread appears almost homogeneous. There next
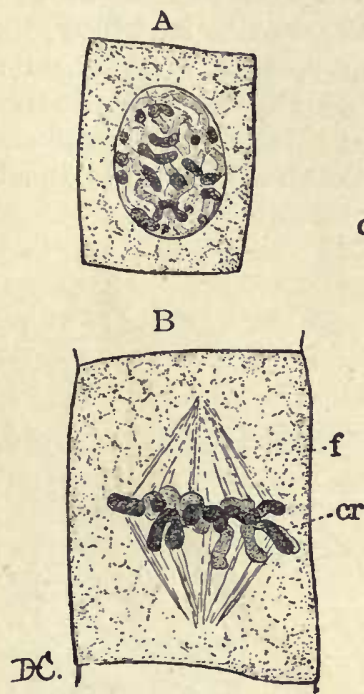

Frg. 43. - Cells from the root-tip of an Onion, dividing by mitosis, or karyokinesis $(\times 525)$.

follows a longitudinal splitting of the nuclear filament, which thus forms two threads, lying close together and often hard to distinguish.

Chromosomes. - Each filament divides transversely into a definite number of pieces - nuclear segments, or Chromosomes, which are in pairs, one segment of each pair belonging to each half into which the original nuclear filament splits longitudinally. The two chromosomes of each pair sometimes fuse more or less completely together. The chromosomes appear homogeneous, and stain very strongly with the usual nuclear stains. Their form varies a good deal, from almost globular to elongated, straight, or bent rods.

While these changes are taking place in the nuclear filament, the nucleolus usually shows signs of disorganization, and finally is no longer visible. Just what becomes of its substance is still doubtful.

Spindle-fibres. - In the cytoplasm immediately surrounding the nuclear eavity, there may be detected extremely fine filaments, which sometimes form a thick tangled layer about the nucleus, but later show a more or less distinct radiation (Fig. 44, B, C). These begin to penetrate into the nuclear cavity, whose wall becomes less evident, and finally quite unrecognizable.

Metaphases. - As the nuclear membrane disappears, the chromo- 
somes arrange themselves in a more or less distinct plate which occupies the equator of the dividing cell. The cytoplasinic fibres are now seen to converge at several points in the cytoplasm, and some of them are connected with the chromosomes, which may each show a sheaf of these attached to it, while other fibres remain free. The several converging points, or poles, in the cytoplasm move toward each other, and usually form two in the long axis of the cell, and at equal distances from the equatorial nuclear plate. The free fibres run from pole to pole, while the bundles connected with the

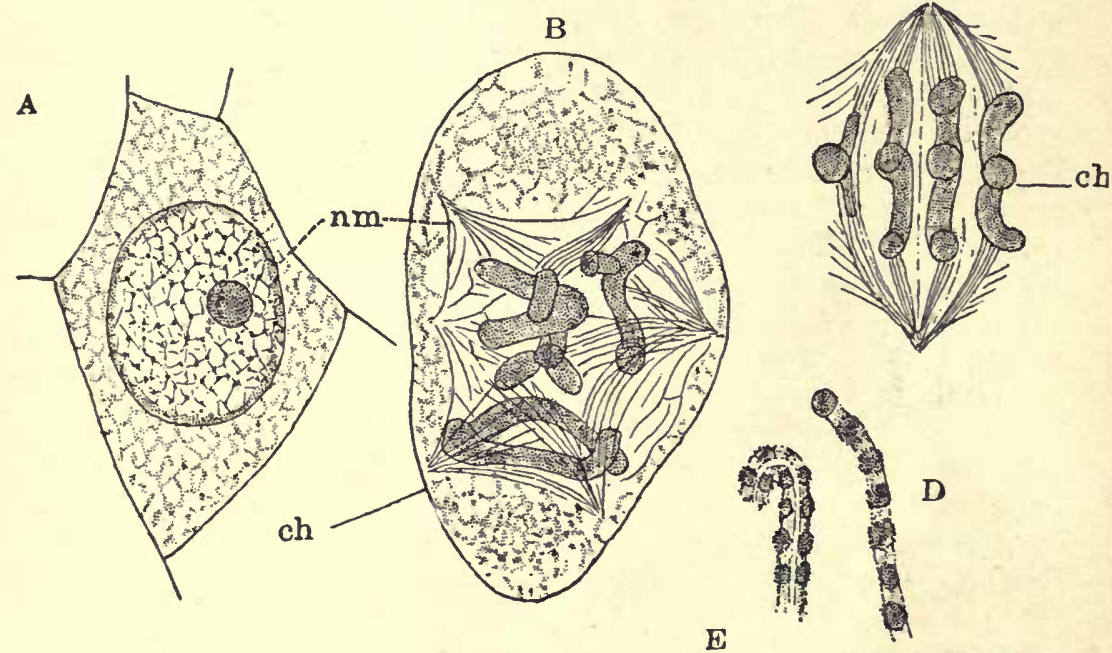

FIG. 44. $-A$, pollen mother-cell of Podophyllum peltatum, showing the resting nucleus, with the net-work of nuclear filaments, and the nucleolus. $B$, late prophase of division; the nuclear segments (chromosomes) are separate, the spindle-fibres arranged in several groups. $C$, completed nuclear spindle; the chromosomes have divided into two. $D$, part of the nuclear filament of Helleborus fotidus, showing the chromatin-granules imbedded in the linin-thread. $E$, a later stage, showing the splitting of the filament. (All figures after MotTiER.)

chromosomes are attached to one pole only. The whole mass of fibres is spindle-shaped, hence the whole figure is known as the Nuclear spindle, and the filaments as Spindle-fibres.

In the nuclear plate the pairs of chromosomes separate, and begin to move toward opposite poles of the nuclear spindle, perhaps due to the contraction of the bundle of spindle-fibres attached to each. It has also been conjectured that the centrosomes, sometimes found at the poles, may be concerned with the attraction of the chromosomes to the poles. Besides the so-called connecting fibres, which run from pole to pole, and the " mantle-fibres," which are attached to the chromosomes, there have also been detected, at the outside of the spindle, 
free fibres which are attached at one end at the poles, but end free in the surrounding cytoplasm.

Anaphases. - As the chromosomes approach the poles of the spindle, they become crowded together, and finally grow together, end to end, and constitute a single filament, which gradually assumes the condition found in the resting nucleus. The nucleolus is formed again, as well as the nuclear membrane, and the nucleus has now all the characters of the typical resting nucleus.

Cell-plate. - While the two groups of chromosomes are moving toward the poles, there suddenly becomes evident, in the equator of the spindle, a disk, formed of small granular bodies, which finally coalesce into a continuous membrane, - the Cell-plate. The granules of which the young cell-plate is composed are formed by swellings in the connecting fibres, whose substance, apparently, is transformed into the elements of the cell-plate. In case the Cell-plate does not extend entirely across the cell, new elements are added to its margin by the peripheral spindle-fibres. The cell-plate finally splits into two lamellæ, and thus the division of the protoplast is completed. The new cell-wall is then deposited in the space between the protoplasts, in the same way that a cell-wall is formed upon the surface of a naked protoplast, such as a zoöspore.

The changes in the nucleus up to the formation of the nuclear plate are known as the Prophases; the separation of the chromosomes and their movements to the poles, the Metaphases; the reconstitution of the daughter-nuclei, the Anaphases.

Direct Nuclear Division. Sometimes in large cells, like the internodes of the Characeæ, and those in the stem of

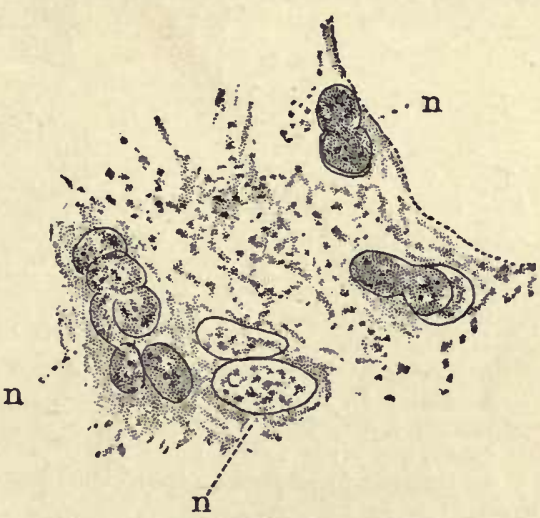

Fia. 45. - Direct (amitotic) nuclear division in an internodal cell of Chara fragilis $(\times 750) ; n$, dividing nuclei.

Tradescantia, the nucleus may become constricted, or divided directly. This is known as direct or amitotic division, but only occurs in old cells, and is never accompanied by a division of the protoplast (Fig. 45).

\section{Budding}

The form of fission known as budding consists simply in a protrusion of the cell-wall, which is then separated from the parent-cell by fission. This occurs regularly in the Yeast-fungi, and is also seen in the branching of many filamentous Algæ. 


\section{Internal Cell-division}

Internal cell-division differs from the ordinary form of fission only in having the division confined to the protoplast, a new cell-wall

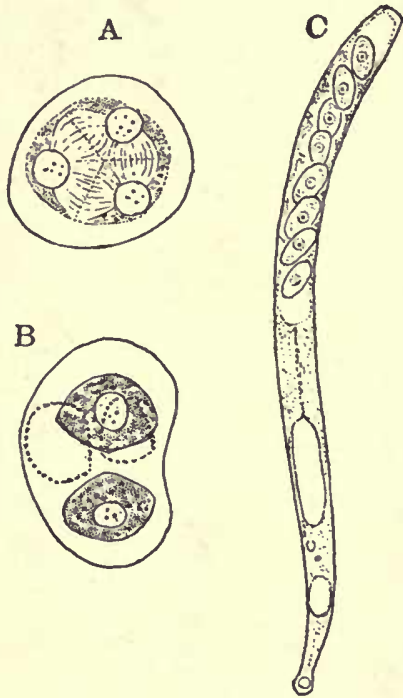

Fig. 46. $-A$, sporogenous cell of Azolla filiculoides, dividing into four by internal division $(\times 800) . \quad B$, an older stage, with the four spores completely divided; only two of the spores are completely shown in the section. $C$, ascus, or sporesac, of a Cup-fungus (Peziza), containing eight spores formed by free cell-formation $(\times 250)$. being formed about the new cells, either while still contained within the mother-cell or after their escape. Where the protoplast divides after each nuclear division, it is hardly distinguishable from typical fission; but often there is repeated nuclear division and a simultaneous division of the protoplast into as many parts as there are nuclei. Internal division is especially common in the formation of the reproductive cells of many plants, such as the zoöspores and spermatozoids of many Algæ, the pollen-spores of Flowering Plants, etc.

\section{Free Cell-formation}

Free cell-formation is a form of internal cell-division, where a cell-wall is formed about the nuclei in the protoplasm, leaving a certain amount of the cytoplasm unused. The commonest example of this is found in the formation of the so-called "Ascospores" of many Fungi and Lichens. Free cellformation has also been observed in the development of the embryo in Ephedra and some other Gymnosperms.

\section{Conjugation}

In most plants there arise, at certain times, new cells, formed by the union of the protoplasm of two independent cells. 'These uniting cells are the sexual cells, or Gametes, and the cell produced from their union is a Zygote. In their simplest form the gametes are entirely similar, either free-swimming ciliated cells, e.g. Pandorina, or non-motile, as in Spirogyra, where the protoplast of one cell flows through a tube into a neighboring one.

In most plants there is a marked difference in the character of the two gametes. One is much larger than the other, and is passivethis is the female cell (Egg or Ovum). The other, the male or sperm. 
cell, is much smaller and often actively motile, when it is termed a Spermatozoid. The fusion of the latter with the egg constitutes fertilization, or fecundation, without which the egg, except in rare cases, is incapable of further development. The greater part of the spermatozoid is composed of nuclear matter, which fuses more or less completely with the nucleus of the eggcell before the latter divides.

The differentiation of sexual cells has taken place quite independently in several widely separated groups of plants, where nearly every gradation between perfectly similar gametes and well-marked male and female cells may still be seen.

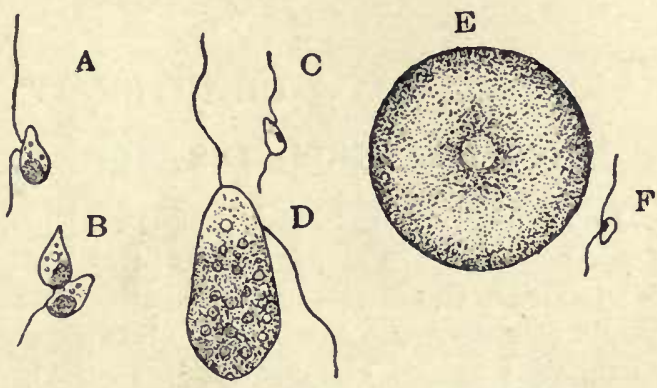

Fia. 47. $-A$, single gamete. $B$, conjugating planogametes of Ectocarpus siliculosus $(\times 790)$. $C$, male gamete. $D$, female gamete of Cutleria nultifida (×960). E, egg. F, spermatozoid of Fucus vesiculosus $(\times 300)$. ( $A, B$, after Berthold $C, D$, after ReINKE.)

Thus in the Brown Algæ many forms, including the largest ones, produce no sexual cells at all, but only zoöspores, which germinate directly. Ectocarpus and various other allied genera produce similar motile gametes (Planogametes); Cutleria produces two kinds of motile gametes, of very unequal size; while in Fucus, the common Rockweed, the non-motile egg-cells are enormously larger than the active, ciliated spermatozoids (Fig. 47).

\section{BIBLIOGRAPHY}

'87. 1. De Bary, A. Comparative Anatomy of the Ferns and Flowering Plants. Oxford, 1887.

'01. 2. Chamberlain, C. J. Methods in Plant Histology. Chicago, 1901.

'99. 3. Fischer, A. Fixirung, Färbung and Bau des Protoplasmas. Jena, 1899.

'96. 4. Haberlandt, G. Physiologische Pflanzenanatomie. Leipzig, 1896.

'98. 5. Henneguy, L. F. Leçons sur la Cellule. Paris, 1898.

'98. 6. Hertwig, O. Die Zelle und die Gewebe. Jena, 1898.

'82. 7. Sachs, J. Text-book of Botany. Oxford, 1882.

'00. 8. Strasburger, E. Histologische Beiträge, I-VI. Jena, 1890-1900.

'97. 9. - Das botanische Practicum. 3d edition. Jena, 1897.

'89. 10. Tschirch, A. Angewandte Pflanzenanatomie. Leipzig, 1889.

'98. 11. Van 'Tieghem, Ph. Traité de Botanique. Paris, 1898.

'96. 12. Vines, S. H. Students' Text-book of Botany. London and New York, 1896.

'98. 13. Wiesner, J. Anatomie und Physiologie den Pflanzen. Vienna, 1898.

'00. 14. Wilson, E. B. The Cell in Development and Inheritance. New York. 1900. (This contains an excellent bibliography of the subject.)

'03. 15. Zimmermann, A. Botanical Microtechnique. New York, 1893. 


\section{CHAPTER IV}

\section{CLASSIFICATION; THE SIMPLEST PLANT-FORMS}

Ir is generally assumed that a real genetic relationship exists among all plants, and the aim of a natural system of classification is to express the degree of this relationship. An ideal classification would represent the family tree of the vegetable kingdom, but unfortunately such a classification is not to be hoped for, owing to the complete disappearance of many plant-forms, which has resulted in the survival of many isolated types that are only distantly related to other known forms, and to which it is impossible, at present, to assign a certain position in the system of classification. Among such isolated groups may be mentioned the Diatoms and Characeæ.

Factors in Classification. - In determining the degree of relationship between plants, probably the general structure, or morphology, is of the first importance; but as certain parts, especially the reproductive structures, are less subject to change from external conditions, these less variable structures are, of course, especially important in classification. Where plants are obviously closely related, as, for instance, two species of the same genus, it is differences, rather than resemblances, that are considered in assigning them their places. Where relationships are less obvious, it often becomes necessary to study all phases of the development of the plant - its "life-history" - in order to determine its affinities with other forms. No single point of structure can be safely used alone; and, so far as possible, all the structures must be considered.

Ontogeny and Phylogeny. - It is assumed that the life-history, or "Ontogeny," of the individual repeats, to some extent, the evolution of the race, "Phylogeny," and a study of the developing organism, is often of the greatest importance in making out its relationship to other and especially lower forms. All Mosses and Ferns, for example, produce minute motile reproductive cells (spermatozoids), which closely resemble similar cells among the Algæ, and indicate that these land plants have sprung from aquatic ancestors resembling the existing Green Algæ.

The geological record, so far as it goes, is of very great value in tracing the evolution of the vegetable kingdom; but unfortunately 
the record is very incomplete, especially as regards the very perishable structures of the lower plants, and we can never expect to have much light thrown on the origin of these lower plant-types, from a study of fossils.

\section{Classification}

The vegetable kingdom may be divided into a number of primary groups, "Subkingdoms," or "Branches," as to whose limits there is a good deal of difference of opinion. We shall assume here five of these subkingdoms, viz. Schizophyta, Algæ, Fungi, Archegoniatæ, Spermatophyta. Besides these there are two groups of organisms, sometimes included among plants, the Myxomycetes (Mycetozoa) and the Flagellata, both of which show unmistakable animal affinities as well.

Each subkingdom is divided into classes, these into orders, families, genera, and species, which are sometimes still farther subdivided.

\section{THE SIMPLEST ORGANISMS}

Many of the lowest organisms known are so simple in structure as to make it impossible to decide positively whether their affinities are with plants or animals. They are simply undifferentiated living beings, such as we may reasonably infer existed before there were any true plants or animals.

Protista. - To these lowest forms of life Haeckel gave the name "Protista," and assumed that some of them consisted of quite undifferentiated protoplasm. The more perfect methods of investigation now in use have demonstrated that it is exceedingly doubtful whether any organisms of such extreme simplicity really exist, and most of the Protista have been relegated to one or the other of the two great organic kingdoms. Nevertheless, there are two groups of organisms, the Flagellata and the Myxomycetes or Mycetozoa, which seem to lie on the border line between plants and animals.

\section{FLAGELLATA}

The Flagellata (Fig. 48) are unicellular organisms, which are provided with one or two (occasionally more) flagella or cilia, by means of which they are able to move rapidly in the water. The cell may be quite naked, or there may be a more or less marked membrane, which very rarely, however, is composed of cellulose. The cell contains a single nucleus, and sometimes chromatophores, which may be either green (Euglena) or brown (Hydrurus). The forms which possess chromatophores are able to assimilate carbon-dioxide, like normal plants, but those which are destitute of these feed upon organic matter. Some of the more highly organized forms possess a mouth, so that they can ingest solid food, which in the lower forms may be taken in at any part of the protoplast. 
Reproduction is either by a division (mostly longitudinal) which may occur while the cell is active, or it may first become encysted, after which the proto-

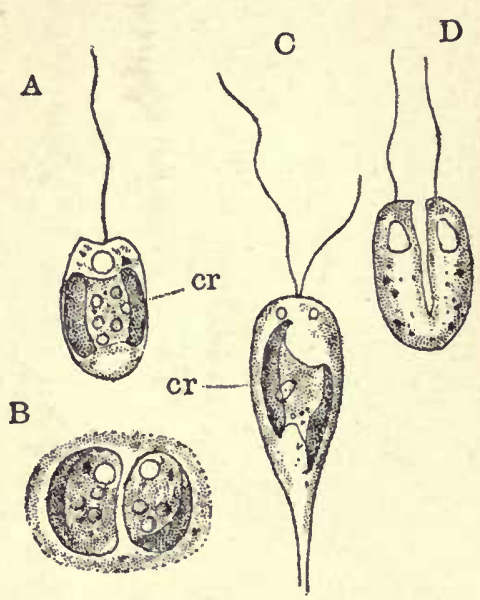

Fig. 48. - Flagellata. $A, B, C h r o m u-$ lina ovalis. $A$, active cell, showing the single flagellum and the chromatophore, $c r ; B$, encysted cell which has just divided $(\times 1500)$. C. Euroglena volvox, a biciliato form, with chromatophore $(\times 1000)$. D, Scytomonas pusillus, individual dividing $(\times 2000) . \quad(A, B, D$, after KLEBS; $C$, after IwANOFF.) plast divides into two new individuals. No sexual reproduction has yet been certainly demonstrated for any of them.

Affinities of Flagellata. - The Flagellata show affinities on the one hand with the Infusoria, and on the other with the lower plants. The Volvocaceæ, which are sometimes included with the Flagellata, are forms which to a certain extent conncct the typical green plants with the true Flagellata. The Myxomycetes or Slime-moulds, the Brown Algæ, and possibly the Bacteria, also show evidences of relationship with the Flagellata, which are thus seen to be a group almost exactly intermediate between the lowest animal and plant forms.

\section{MYXOMYCETES}

The Myxomycetes or Mycetozoa constitute another group of organisms which exhibit both animal and vegetable characters. Some of them are aquatics, apparently related to some of the lower Flagellata, and perhaps to the Rhizopods among the Protozoa. A second division, the Myxomycetes proper, or Slime-moulds, are not aquatic, and develop a fruiting condition which is very similar to that of the Fungi.

The Myxomycetes receive their popular name of Slime-mould from the vegetative condition, which is a large naked mass of protoplasm, or Plasmodium, of a slimy consistence, and usually whitish or yellow in color. The best known of the Slime-moulds is Athalium. septicum (Fuligo varians), which is especially common on spent tanbark, where the bright yellow plasmodia are sometimes very conspicuous. Slime-moulds, however, can usually be found in wet weather, about rotten logs, decaying leaves, etc.

The Plasmodium. - The plasmodium shows active creeping movements, and quickly spreads itself, in the form of a network, over the substratum on which it is growing. It shows marked irritability, avoiding strong light, and seeking moisture and food. Soft organic substances, such as a large Fungus, may be 
completely surrounded by the plasmodium, which may very quickly completely digest them. When fixed and stained, there are seen to be very many small nuclei scattered through the substance of the plasmodium.

As described in the last chapter, the plasmodium may be made to creep upon a glass slide down which a fine stream of water is running, and in this way may be examined under the microscope. The protoplasmic mass then clearly shows the homogeneous hyaloplasm in which are imbedded granules of various kinds, including yellow pigment-corpuscles. The granular plasm exhibits very active streaming movements, while extensions of the plasmodium, or pseudopodia, are pushed out, and thus the plasmodium is spread out over the wet slide, and forms a complicated network of slimy yellow threark.
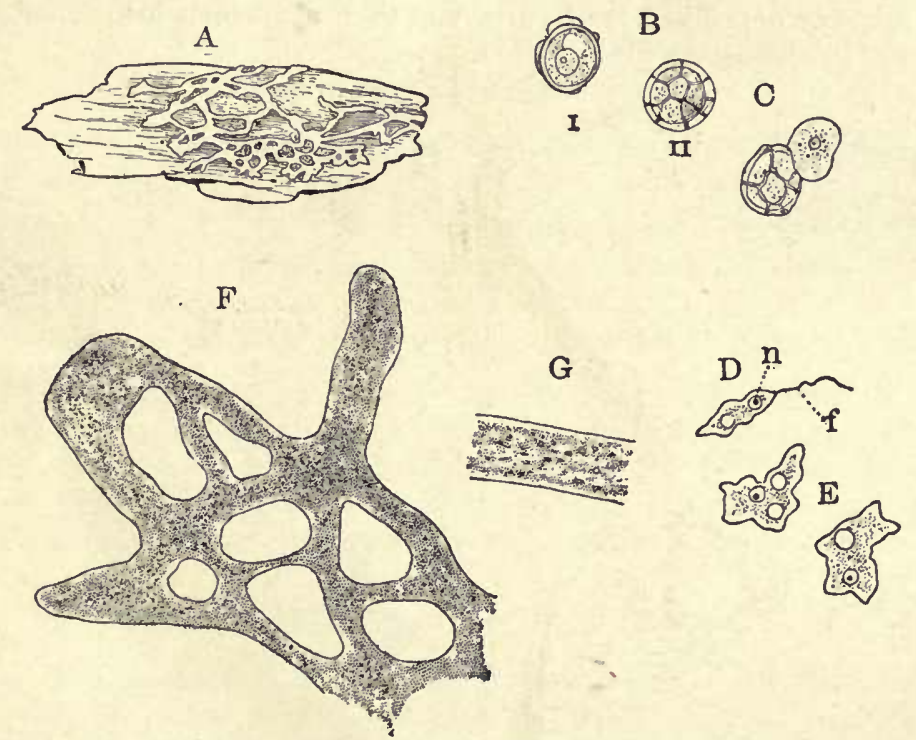

FIG. 49. $-A$, plasmodium of a Slime-mould upon a piece of decayed wood $(\times 2)$. $B$, two sp res of Trichia favoginea, $I$, in optical section. $C$, a spore with the contents escaping. $D$, ciliated swarm-spore, showing the flagellum, $f$, and the nucleus, $n$. $E$, two amcboid swarm-spores. $F$, part of a plasmodium which has spread over a glass slide $(\times 60)$. $\quad G$, a portion of $F$ more highly magnified.

Sclerotia. - When the plasmodium is partly deprived of water, it may retract the pseudopodia and form a cakelike body, which is usually composed of closely packed roundish masses of protoplasm, which have a more or less definite membrane sometimes of cellulose. These masses (sclerotia) have a waxy or horny texture, and may remain dormant for several months without losing their vitality, resuming the form of active plasmodia if provided with water.

Spores. - Usually, at the close of the vegetative period, the plasmodium retracts the pseudopodia and becomes divided into small bodies of definite form, known as Sporocysts. These may be merely 
cakelike, or irregular roundish structures, or they may assume a constant form characteristic of different genera. Thus in the common genus Stemonitis (Fig. 50, B) the sporocysts are cylindrical bodies borne upon a long stalk, prolonged upward into the axis of the cylindrical sporocyst. Other genera, e.g. Arcyria, have pearshaped or oblong stalked sporocysts, while in Athalium and similar forms (Fig. 50, A) the irregular, densely crowded sporocysts are packed together into a solid cakelike mass (Ethalium), which is covered with a sort of crust which protects the underlying sporocysts. The wall of the sporocyst is often colored, and there may be a heavy deposit in it of carbonate of lime, which also sometimes occurs in the active plasmodium.

A
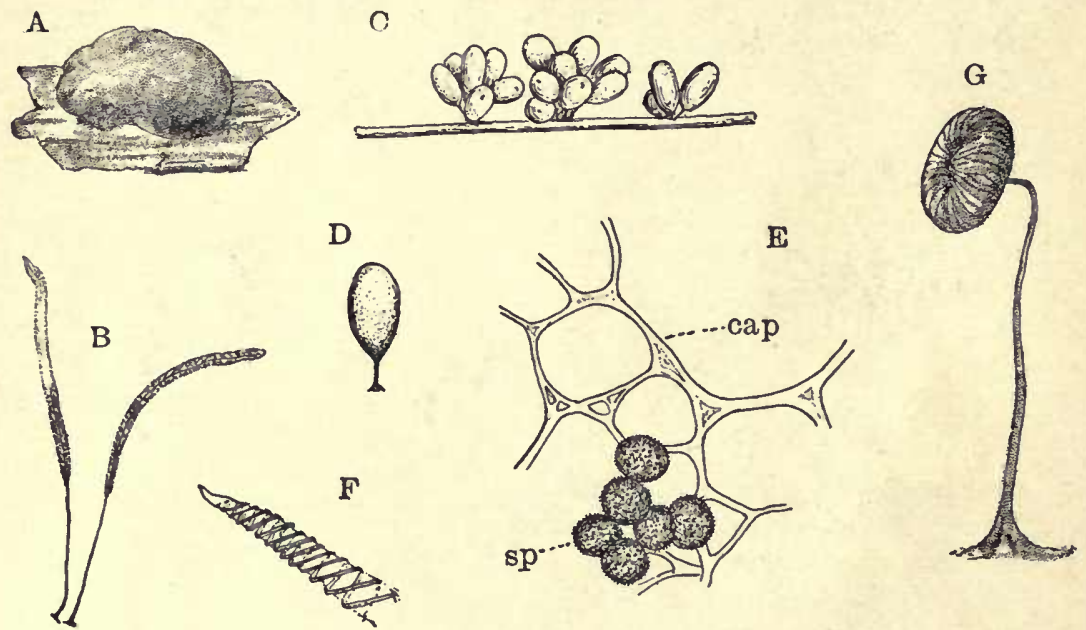

Frg. 50. $-A$, æthalium of Enteridium splendens $(\times 1) . B$, two sporocysts of Stemonitis fusca $(\times 3)$. C, sporocysts of Leocarpus fragilis, attached to a stalk of grass $\left(\times 2 \frac{1}{2}\right) . \quad D$, a single sporocyst more enlarged. $E$, capillitium and spores of the same species $(\times 500) . \quad F$, end of a capillitial filament of Trichia favoginea. $G$, sporocyst of Dictydium cancellatum $(\times 25)$. ( $A$ and $G$ after MACBRIDE.)

Spore-formation. - The protoplasm within the sporocyst divides into many small globular cells, each containing a nucleus, and developing about it a membrane which usually is colored, and is marked with characteristic sculpturing, much like the spore-membranes of the higher plants. These spores do not completely use up the protoplasm, but a part remains to form a system of threadlike structures, the Capillitium, which are often of peculiar form. The capillitium may be composed of solid, more or less confluent threads (e.g. Stemonitis), or it may be made up of separate (Trichia) or united (Arcyria) hollow tubes, with spirally thickened walls.

Germination. - The ripe spores germinate quickly under proper conditions. The early stages may often be seen by placing the spores in water; but for the further development a proper nutrient solution is necessary. The spore ger- 
minates in twenty-four hours or less, by bursting the membrane and allowing the enclosed protoplast to escape in the form of an amcboid body, or a zoöspore with a single flagellum, which strikingly resembles some of the simpler Flagellata. These zoöspores have a single nucleus and one or two contractile vacuoles. They increase in size, and if the conditions are suitable may also multiply by division until their number has greatly increased. Finally they begin to fuse together, at first in small groups, which later grow together into a sinall plasmodium. In Dictyostelium the separate zoöspores never completely fuse, but form a pseudoplasmodium.

One small group of the Slime-moulds consists of parasites which live within the tissues of living plants. The best-known species is Plasmodiophora brassica, which infests the roots of cabbages, and produces a serious disease characterized by distorted enlargements on the diseased roots.

\section{Classification of Myxomycetes}

Professor Macbride (10) gives the following classification of the Myxomycetes:-

A. Parasites, in the cells of living plants. Order 1. Phytomyxinæ. $B$. Saprophytes, growing oll decaying vegetable matter.

a. With free spores. Order 2. Exosporeæ.

$b$. With spores formed in sporocysts. Order 3. Myxogastres.

Much the greater number of the Slime-moulds belong to the Myxogastres. The Exosporeæ comprise but a single genus, Ceratiomyxa, whose affinities are somewhat doubtful. In this genus the plasmodium develops a columnar mass, upon the outside of which are borne small prominences with a spore at the apex of each.

\section{SUBKINGDOM I. SCHIZOPHYTA}

Leaving aside the Flagellata and Myxomycetes, whose claim to be considered as plants is at least doubtful, the lowest group of genuine plants is the Schizophyta, - Fission-plants, - so called because of the formation of cells by fission only.

Among the Schizophytes are found the simplest known organisms, and there is every reason to believe that they represent the most ancient existing types of living things.

\section{Cell-structure}

The cell-structure of the Schizophytes has been the subject of many exhaustive studies, but the results of these are by no means uniform, and in spite of the assertions that even the simplest forms show nuclear structures, and other evidences of differentiation, it seems probable that these are wanting in the simpler Bacteria. In the larger forms, e.g. Beggiatoa and the Blue-green Algæ, a so-called "Central-body," which may represent a primitive nucleus, is present, 
and the outer part of the protoplast may contain chlorophyll, and perhaps constitute an imperfect chromatophore. The young cells of many Bacteria appear perfectly homogeneous, but there may usually be detected granules, some of which react much like the chromatin-granules of the higher plants, and very likely are homologous with them; but unlike the chromatin of the higher plants, these are not segregated into a definite nucleus. The view that the whole protoplast of the Bacteria represents a nucleus, the cytoplasm being nearly or quite wanting, is not confirmed by the latest researches.

Cell-wall. - The cell-wall of the Schizophyta usually does not show the cellulose reaction. In the Bacteria it generally contains nitrogen, while in the Schizophycex, it is very often mucilaginous or gelatinous in consistency. Where this is highly developed, the plants form colonies imbedded in masses of jelly, often of great size, as in Nostoc commune. This gelatinous matrix is not to be looked upon simply as a modified cell-wall, but is to a great extent a direct excretion from the protoplast. Similar gelatinous envelopes are found in many Bacteria; and, as these are of definite form in each species, it is easy to identify them, even without a microscopic examination (Fig. 52).

\section{Distribution}

The Schizophyta occur wherever any life is possible, and are adapted to extraordinarily varied conditions. Some of the Bacteria can endure temperatures above the boiling point of water, while no degree of cold can destroy their vitality. They can be dried up for prolonged periods without suffering, and indeed can be subjected to all sorts of unfavorable conditions without succumbing. Many forms live within the bodies of other organisms; some exist in the depths of the ocean, while others swim upon its surface. The nitrifying Bacteria live in the soil, while myriad bacterial germs floating in the air settle on every exposed object, and under favorable conditions multiply with great rapidity.

The extraordinary powers of resistance to heat and other conditions fatal to most organisms, as well as the great simplicity of their cell-structure, make it probable that the Schizophyta are the direct descendants of forms which lived before the conditions upon the earth were suitable for more highly organized forms of life.

\section{Classification of Schizophyta}

Two classes of the Schizophyta are usually recognized, - the Schizomycetes, or Bacteria, and the Schizophyceæ, or Blue-green Algæ, also known as Cyanophyceæ, or Phycochromaceæ. The first 
class comprises, with few exceptions, forms without chlorophyll, while the second comprises only forms with chlorophyll.

\section{Class I. Bacteria (Schizomycetes)}

The Bacteria comprise the simplest of all known organisms, as well as the smallest; but nevertheless they are of the highest importance in the economy of nature, the existence of all the higher forms of life being more or less directly dependent upon them.

Cell-structure of Bacteria. - Owing to the very small size of most Bacteria, it is excessively difficult to make out the structure of the cell, and there is much difference of opinion as to what the cell-structure really is. In some of the larger forms, e.g. Beggiatoa, structures similar to those visible in the Schizophyceæ have been demonstrated, but it is probable that these larger forms are more nearly related to the latter than they are to the true Bacteria. In many of the smaller Bacteria the young cells may appear perfectly homogeneous, except for the presence of a limiting cell-membrane, which, however, only in rare instances, e.g. Bacterium Pasteurianum, shows the cellulose reactions. The protoplasm usually stains strongly, and certain observers have considered that the whole represents a nucleus, and is comparable to the "central-body" in the Schizophyceæ. It has, however, been demonstrated that a vacuole may arise in the protoplast, which is hardly consistent with its being a nucleus. Granules, staining more deeply than the rest of the protoplast, are usually preseut, and may perhaps represent the nuclear substance, which is not segregated into a definite nucleus. In short, the evidence at present available is against the existence, in the bacterial cell, of an organized nucleus.

The cells may be isolated, or they may form colonies of characteristic form and color, which make it possible to recognize at once certain species. Thus a common species, Micrococcus prodigiosus, forms small blood-red specks on moist bread, and the colonies grown in culture-tubes, or on gelatine, always behave in a constant manner (Fig. 52).

\section{Movements}

Many Bacteria exhibit active movements, due to extremely delicate cilia, which may be attached either to the ends of the cells, or may grow out from all parts of the surface. By contracting the cellcontents, it is readily seen that the

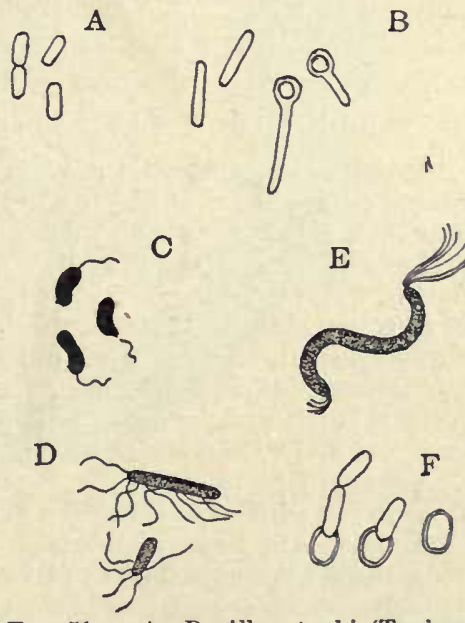

Fig. 51. $-A$, Bacillus typhi (Typhusgerm) $(\times 1000) . \quad B, B$. tetani (Tetanus-germ), showing spore-formation $(\times 1000)$. C, Microspira comma (Cholera-germ), stained to show the flagellum $(\times 1000) . \quad D, B$ acillus subtilis, showing the cilia $(\times 1000)$. $E$, Spirillum undula. $F$, Bacillus amylobacter, germination of the spores $(\times 1000)$. (Figs. $A, B, C, F$, after Mugula.) 
cilia are ontgrowths of the membrane, and are not connected with the protoplast. Only in rare instances are the cilia large enough to be detected in the living cell, and recourse must be had to various fixing and staining agents in order to demonstrate their presence. Some of the larger Bacteria show undulatory and creeping movements, very similar to those of certain Schizophyceæ.

The cells of the Bacteria may be globular-e.g. Micrococcus; but more commonly they are rod-shaped, either straight-e.g. Bacillus, or curved - e.g. Spirillum (Fig. 51).

\section{Reproduction}

The reproduction in the Bacteria is mainly by transverse fission, which may be repeated at intervals of half an hour or less, so that they multiply with great rapidity under favorable conditions, a single cell thus being able to give rise to several millions in the course of twenty-four hours. This accounts for their extraordinary multiplication in decomposing organic substances. Fission is accomplished by the formation of a delicate partition wall across the middle of the cell. The two new cells may separate at once, or they may remain together for a time, forming chains of cells. In case a vacuole is present, this may become divided before the division wall is formed, or the division of the vacuole nay be repeated, and a series of division walls are then formed in rapid succession.

Spores. - Many Bacteria produce at the end of their growing period special resting cells or spores (Fig. 51, B), which arise within the cell, appearing first as a minute, glistening speck, which gradually enlarges, absorbing into itself the protoplasmic contents of the cell, which is finally left filled only with a watery fluid in which the spore lies. The latter has a firm membrane enclosing a mass of apparently homogeneous, very dense protoplasm. These spores are extraordinarily resistant, and sometimes can endure without injury a temperature above the boiling point of water for several hours. On germinating, the outer membrane is burst, and the contents escape as a new cell, which at once begins to grow and divide, thus starting a new generation of Bacteria.

A second form of spores, the so-called arthrospores, have been described, but these seem to differ but little from the ordinary vegetative cells.

Gonidia. - In some of the large filamentous Bacteria, e.g. Cladothrix, the cells, which are enclosed in a tubular sheath, sometimes divide into smaller cells (gonidia) which are discharged from the sheath and grow into new individuals.

Nothing resembling any form of sexual reproduction is known among the Schizophyta.

\section{Biology of Bacteria}

No other group of organisms is capable of existing under such different conditions as do the Bacteria. One group of the Nitrogen Bacteria forms an exception to the general rule that only green 
plants can assimilate carbon-dioxide, and these Bacteria manufacture all of their organic substances from inorganic compounds. The greater number of Bacteria are saprophytes, feeding on dead organic matter, whose decomposition is due to their presence. Others are true parasites, and are the causes of disease in both plants and animals.

Holophytic Bacteria. - The holophytic Bacteria, i.e. those which, like green plants, are independent of organic food, are few in number, and all known forms belong to the Nitrogen Bacteria. These forms are capable of assimilating carbon-dioxide, but this power is not dependent on the presence of light, as it is in green plants.

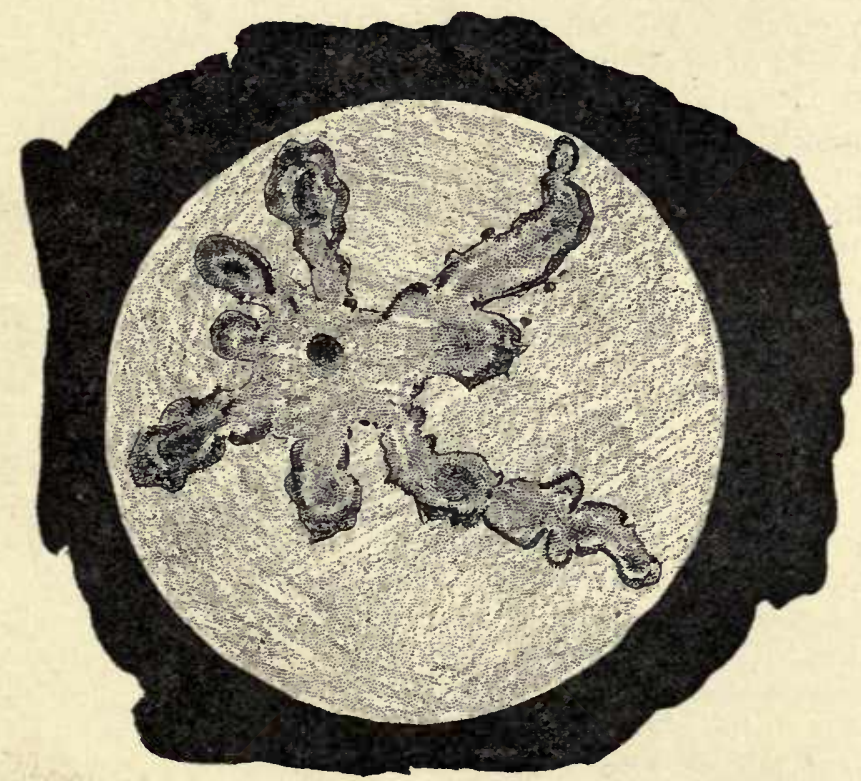

Fig. 52. - Micrococcus polypus. Plate-culture, eight days old ( $\times 6)$. (After Mrgula.)

Saprophytic Bacteria. - Bacteria are the principal agents in organic decomposition, and it is here that their enormous importance in the economy of nature is most evident. That Bacteria are the direct cause of decomposition is very simply shown by the behavior of dead organic substances when they are protected from the attacks of Bacteria. This is practically demonstrated in all the devices employed for preserving organic substances from decay. Fruit, meat, etc., are subjected to a temperature sufficient to kill all bacterial germs which may be present, and then hermetically sealed so as to prevent access of germs from without. If this is successfully done, 
the most perishable substances remain unchanged indefinitely. If, however, they are exposed to the air, even for a very short time, the germs which thus are introduced will quickly set up decomposition. The principle of cold storage is keeping perishable substances at a temperature too low for the growth of the decomposition germs.

The result of organic decomposition is the splitting of the complex organic substances into simpler forms, among which are water, carbon-dioxide, and the simpler nitrogen compounds, of which, perhaps, ammonia is the commonest.

Nitrogen Bacteria. - Water and carbon-dioxide are in condition to be used at once by the green plants, but the available nitrogen compounds must undergo further changes before they can be used by them; and here another group of Bacteria have been recently discovered to be essential. These Nitrogen Bacteria are of different kinds. Some of them are able to utilize free nitrogen, while others assimilate the ammonia and other simple nitrogen compounds, which are changed into forms suitable for absorption by the green plants. Of the forms which can utilize the free nitrogen the best known are the Bacteria (Bacillus radicicola) which inhabit the tubercles upon the roots of most Leguminosæ, which are thus rendered quite independent of any nitrogen in the soil. It is still a question whether in this case the Bacteria themselves assimilate the free nitrogen, which is most likely, or whether by their presence the green plant is enabled to do this. As it has been proved that one species, Clostri. dium Pastenvianum, can independently assimilate free nitrogen, it is highly probable that this is the case also with the Tubercle Bacteria.

Nitrification. - The change of ammonia into nitrites, and these into nitrates which are available for the roots of the higher plants, seems to be the work of two sets of organisins, the so-called Nitroso-bacteria and the Nitrate-bacteria.

Parasitic Bacteria. - It is now a familiar fact that most diseases are due to the attacks of specific "germs," i.e. species of Bacteria, and the modern science of medicine is based upon this fact, the treatment of disease being principally an effort to prevent the introduction of such disease germs into the body, as by boiling suspected water, or to find agents which will destroy these germs when they have effected lodgement in the system.

These disease germs, or "pathogenic" Bacteria, may be true parasites actually feeding upon the tissues of the host, or the symptoms of disease may be the result of the development of poisonous substances (toxins) which are produced by the growth of the organisms either within living or dead matter. Thus cases of poisoning from eating cheese, milk, or tainted meat are due to poisons resulting from the activity of Bacteria within these substances.

The whole science of aseptic and antiseptic surgery is also based 
on the knowledge that Bacteria are the agents which cause inflammation and blood poisoning in surgical operations.

Pigment Bacteria. - Many Bacteria develop characteristic pigments. A very small number show traces of chlorophyll, but in most cases the pigments are of very different kind, and probably not associated with carbon assimilation unless possibly the purple-red piginent of some of the Sulphur Bacteria. In other Bacteria the color is not contained within the protoplast, but is an excretion which stains more or less intensely the gelatinous matrix in which the colorless cells are imbedded; such, for instance, is the red pigment of Bacillus prodigiosus.

Iron Bacteria. - A small number of Bacteria, e.g. Cladothrix dichotoma, possess the power of depositing iron-oxide in the sheath in which the cells are imbedded. It still seems somewhat uncertain, however, how far the presence of iron is an essential for the growth of these Iron Bacteria.

Sulphur Bacteria. - The Sulphur Bacteria (Fig. 53) comprise a considerable number of forms which are distinguished by their ability to oxidize sulphuretted hydrogen, the sulphur being set free in the form of conspicuous granules of pure sulphur within the protoplast. It

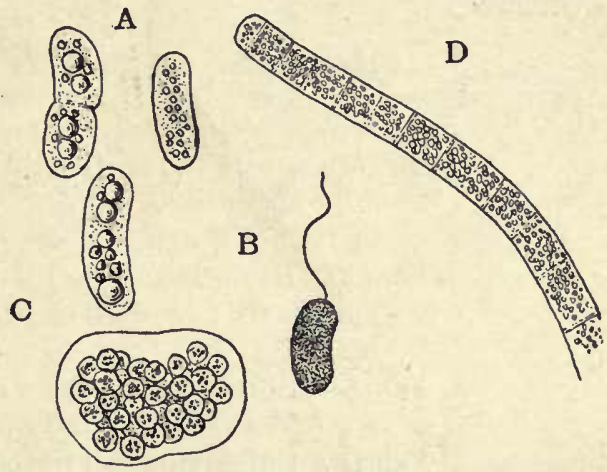

Fig. 53.-A, Chromatium Weissii, a purple Sulphur Bacterium, the round granules are sulphur. $B$, motile cell stained to show the flagellum. $C$, Thiocystis violacea, a purple Coccus-form. D, Beggiatoa alba. (All $\times$ about 1000.) is supposed that these organisms obtain energy by the oxidation of hydrosulphuric acid instead of by ordinary respiration, in which respect they differ from all other known organisms. Many of the Sulphur Bacteria possess a purplish pigment (Bacterio-purpurin), which may possibly be related to chlorophyll in its properties, but this is still by no means clear.

\section{Aërobic and Anaërobic Bacteria}

While many Bacteria, like other active organisms, require free oxygen in order to live, there are very many of them which grow normally only in the absence of free oxygen. These are the so-called Anaërobic Bacteria, which include a large number of the organisms causing decay in organic substances. 
Phosphorescence. - The phenomena of phosphorescence, sometimes seen in decaying substances, are often due to the presence of Bacteria.

\section{Artificial Cultures of Bacteria}

The recognition of the great importance of Bacteria has led to extensive development of methods of cultivating them artificially. It is possible, with care, to isolate most forms, and grow them in sterilized culture-media, from which all other forms are excluded. The medium may be either liquid, like inilk or meat-broth, or the nutritive substance is mixed with gelatine or some sinilar substance which solidifies when cold. When a pure culture of any species is established, it is a simple matter to propagate it indefinitely. The cultivation of Bacteria is not only important in the study of disease germs, but it is possible to isolate the specific Bacteria which flavor butter, cheese, etc., and by introducing these into the butter or cheese while it is being made the flavor may be controlled.

\section{Classification of Bacteria (Migula, 12)}

Ord. I. Eubacteria. Colorless, or occasionally chlorophyll-bearing forms, without central-body.

Fam. 1. Coccaceæ. Cells non-motile, globular: Divisions in 1, 2, or 3 planes; Micrococcus, Sarcina, etc.

Fam. 2. Bacteriaceæ. Cells more or less elongated, without sheath; motionless or ciliated. Bacterium, Bacillus, etc.

Fam. 3. Spirillaceæ. Cells elongated, curved or spiral, without sheath; usually motile. Spirillum.

Fam. 4. Chlamydobacteriaceæ. Cells in chains, surrounded by a common sheath. Cladothrix, Crenothrix, etc.

Ord. II. Thiobacteria. Relatively large forms, usually showing a central-body, and sometimes purple pigment, but no chlorophyll. Sulphur Bacteria.

Fam. 1. Beggiatoaceæ. Filamentous forms without pigment.

Fam. 2. Rhodobacteriaceæ. Cells of various forms, globular, rod-shaped, or spiral, containing purple pigment, bacterio-purpurin.

\section{The Myxobacteriaceæ (Thaxter, 21, 22)}

The Myxobacteriaceæ are forms which are undoubtedly related to the Bacteria, of which they may perhaps constitute a third order. Our knowledge of these interesting forms is due largely to the researches of Professor Thaxter. They consist of minute cells, closely resembling typical Bacteria, but the cells are united into structures of very 
characteristic form, suggesting the fructifications of the higher Fungi, with which some of the forms were formerly united. They produce spores, somewhat like those of the true Bacteria. The spores give rise to rod-shaped cells which in time produce the full-grown fructitication. Among the genera of Myxobacteriaceæ are Chondromyces (Fig. 54), Cystobacter, and Myxococcus.

\section{Classs II. Schizophyceat}

The Schizophyceæ (also called Syanophyceæ, Myxophyceæ) possess chlorophyll, in which respect they differ from all but a very few of the Bacteria. The Sulphur Bacteria are in their structure more like the Schizophyceæ than like the true Bacteria, and may be considered to connect the two classes of the Schizophytes.

Distribution. - Like the Bac-

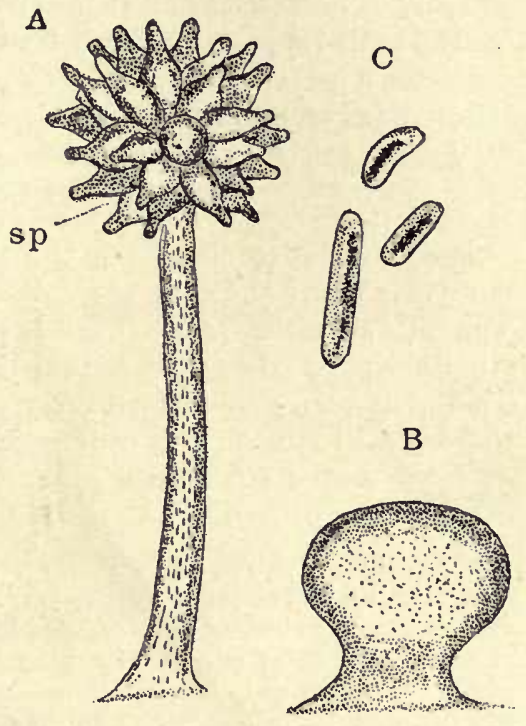

FIG. 54. - Chondromyces apiculata, one of the Myxobacteria. $A$, young, $B$, mature fructification; $s p$, sporangia. $C$, individual cells, very much enlarged. (After Thaxter.)

teria, the Schizophyceæ are very widely distributed, and are adapted to extremely varying conditions. While they are for the most part aquatics, many of them grow on moist earth, or upon wood and rocks in shady places. Like the Bacteria, also, many of them can endure drying up for long periods withont injury. They are abundant both in fresh and salt water, and some of them are floating forms, and may occur in enormous quantities in the open sea, or in lakes and ponds. The red color of the surface water of parts of the Red Sea owes its hue to enormous floating masses of one of these plants Trichodesmium erythroeum, which also occurs in the Caribbean Sea and other warm parts of the ocean.

Schizophyceæ are anong the principal plants in hot springs, and, like many Bacteria, they occur abundantly in water charged with various mineral salts. Many of them, are pseudo-parasites; i.e. they grow associated with other plants, without, however, apparently doing any harm to the host. Thus the little Water-fern, Azolla, has always associated with it one of these forms, Anabona Azollo, and species of Nostoc are always found within the thallus of some Liverworts, e.g. Anthoceros and Blasia. Among the Seed-plants, Cycas and 
Gunnera have a Nostoc associated with them, and many of the Lichens have species of Schizophyceæ forming their "gonidia." This habit of associating themselves with other living organisms, as well as their frequent preference for water containing organic matter, indicates a certain dependence on organic food which is not found in the higher green plants.

\section{Structure of Schizophyceæ}

The simplest forms among the Schizophyceæ are unicellular, but more commonly the cells are united into filaments of definite form. The cells are either approximately globular, e.g., Nostoc, Clíroöcoccus, Anabæna; or they are cylindrical, e.g. Oscillatoria, Scytonema. There has been much controversy over the structure of the cell, and there is still more or less difference of opinion concerning the nature of some of the structures. Some Schizophyceæ live isolated, but usually they occur in large masses.

The Cell-wall. - The cell-wall may be thin, but is more commonly thick and gelatinous, seldom showing the reaction of pure cellulose, but usually resembling more the cutinized membranes of the higher plants. It is often colored yellow, or sometimes red or purple. In many forms, e.g. Rivularia, Nostoc, etc., the plants are imbedded in large gelatinous masses, derived in part from a change in the cell-wall, but probably, for the most part, a direct secretion of the cells. Like the gelatinous colonies of Bacteria, which they much resemble, these are of characteristic form and color in each species.

The Protoplast. - In the larger Schizophyceæ the protoplast usually shows a more or less evident differentiation into a peripheral layer, to which the pigment is confined, and a central colorless part, the central-body, which is often irregula: in outline, and whose nature is still not certain. The central-body may represent a rudimentary nucleus, but this has been disputed. The chlorophyll, which is associated with a blue pigment (phycocyanin), is confined to the peripheral cytoplasm, but whether the whole cytoplasm is uniformly stained, or whether there is a special chromatophore, is not agreed upon. A definite chromatophore can certainly be detected in the young heterocysts of Anabæna (see Fig. 56, D), and it seems likely that a chromatophore may be assigned to all the higher forms, at least. Granules may generally be seen in the protoplast, and these it is claimed are of two kinds, the so-called Cyanophycin-granules, which are confined to the peripheral protoplasm, and are reserve-food granules, and the Central granules, which belong to the central-body, and are probably allied to the chromatin-granules of a true nucleus.

Pigments. - The Schizophyceæ contain, in addition to the chlorophyll, a second pigment, usually a blue one (Phycocyanin), but sometimes a violet or orange-yellow modification of this pigment. The phycocyanin is readily soluble in water, and in drying specimens for the herbarium, it often makes a bright blue stain on the paper. The extract obtained by placing dried and powdered specimens in water appears pure blue if seen by transmitted light, but by reflected light it shows a marked purplish red fluorescence. The 
residue, after the phycocyanin is extracted, yields a green solution if treated with alcohol, but this solution is usually tinged with brown on account of the mixture with phycoxanthin. The phycocyanin may be precipitated in the form of blue crystals by the action of ammonium-sulphate.

Vacuoles. - Vacuoles are usually absent from the vegetative cells, but occur in the heterocysts. Vacnoles filled with gas, which renders the cells buoyant, are found in those species which float at the surface of the water.

\section{Differentiation of the Plant-body}

The lowest of the Schizophyceæ, the Chroöcoccaceæ, are strictly unicellular forms, which live either isolated or in colonies. The cells are globular, and separate on division, although secondary divisions may follow before the cells have become completely rounded off. The cell-wall is usually gelatinous, and often striated.

The other forms are mostly filamentous. In the Oscillatoriaceæ, the lowest of these, the cells are short-cylindrical, but all alike, except that the tip of the filament is often somewhat attenuated. In the Nostocaceæ, the cells are rounded, and in addition to the ordinary cells, so-called "Heterocysts" are formed, sometimes at irregular intervals, as in Nostoc and Anabæna; sometimes at a definite place, as in Cylindrospermum (Fig. 57). The heterocysts
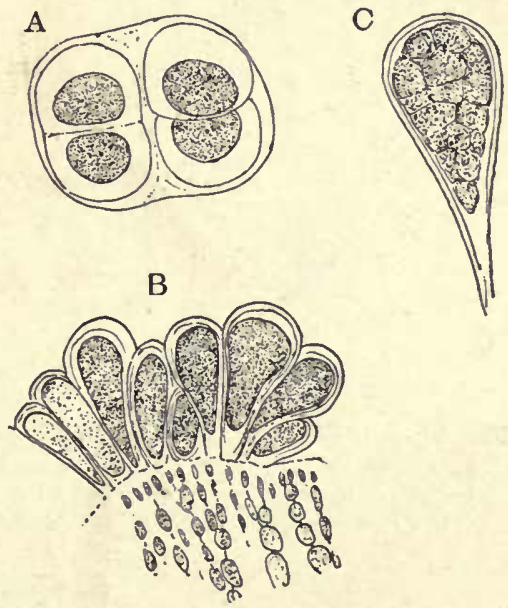

Fra. 55. $-A$, four cells of Chroöcoccus turgidus, surrounded by the gelatinous envelope $(\times 500) . \quad B$, colony of Dermoca:pa prasina, upon Gigartina spinosa $(\times 500) . C$, a single cell containing spores. are derived from the ordinary cells by their losing most of their protoplasmic contents, and becoming enlarged, with thickened, usually yellowish, cell-wall. In young heterocysts the chromatophore may sometimes be detected, but it finally disappears. When complete, the heterocyst is shut off from the adjacent cell by a sort of plug, which projects into its eavity. The heterocysts serve to separate the "Hormogonia" or segments into which the filaments finally separate.

The Nostocaceæ may also develop thick-walled resting-spores (Arthrospores). 
In the Scytonemataceæ (Fig. 56, E) the filaments branch, and in the Rivulariaceæ (Fig. 58), the filaments are much attenuated and have a single basal heterocyst.

Cell-division. - The cells multiply by simple cell-division, which is accomplished by the formation of a ring-shaped wall at the equator of the cell, which grows inward and gradually cuts the protoplast in two. The central-body, apparently, is quite passive, and takes no active part in the cell-division. In one family, Chamæsiphonaceæ, internal cell-division has been observed, resulting in the formation of numerous "conidia" (Fig. 55, C).

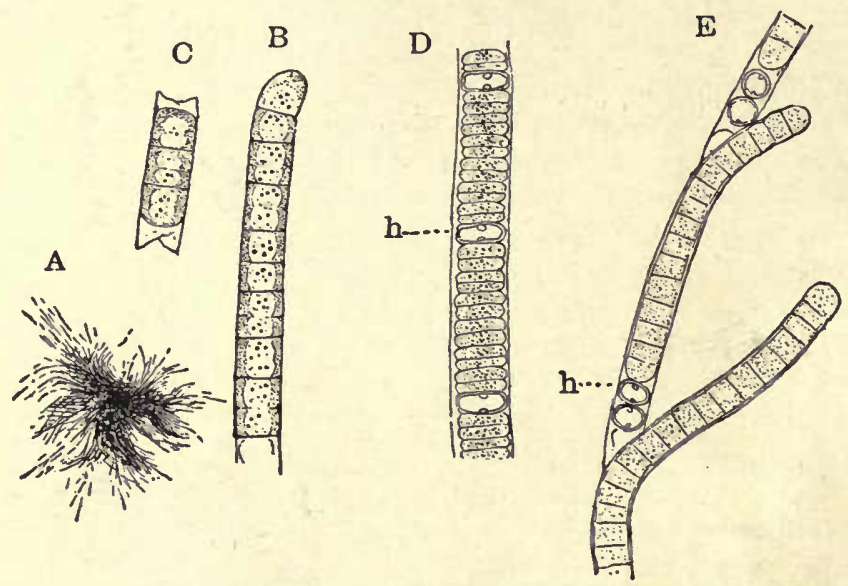

FIG. 56. $-A$, mass of Oscillatoria sp., showing the radiating arrangement of the filaments $(\times 2) . B$, a single filament, showing the central-body in each cell $(\times 500) . C$, three cells included in a fragment of the sheath. $D$, Nodularia major; $h$, heterocyst. $E$, Tolypothrix $s p . ; h$, heterocysts.

\section{Reproduction}

In the Chroöcoccaceæ (Fig. 55, A) there is no distinction between vegetative and reproductive cells, each cell-division resulting in the formation of two individuals. In the filamentous forms there is usually a breaking up of the filament into lengths - Hormogonia - which are usually motile, and creep out of the sheath or gelatinous envelope in which they are enclosed. In case heterocysts are present, they become detached, leaving the portions of the filament lying between them, as free hormogonia, which then separate to form the beginning of a new plant or colony. It is in this condition that they usually infect the plants with which they may be associated.

Resting-spores, or arthrospores, occur in many species. These are formed by a simple enlargement of a vegetative cell, or occasionally, e.g. Rivularia, apparently by a fusion of two or more into one large cell. The contents of the arthrospore become very dense by the accumulation of reserve-food, and a thick wall is developed about it. The spores may be formed from almost any cell in Nostoc and Anabæna, but in certain genera like Cylindrospermum and Rivularia they occupy a definite position in the filament. 
The arthrospores are more resistant than the vegetative cells, and remain after the rest of the plant is dead. On germination (Fig. 57, F, G) the contents, after contracting somewhat, divide once or twice by transverse walls, and the outer spore-membrane is ruptured, allowing the short filament to protrude. It elongates and grows rapidly until the new plant is complete.

In Anabcena Azolla, the vegetative cells may enter a resting-stage without assuming the forms of definite spores, simply separating and losing most of their color. When growth is resumed, these cells develop chlorophyll again and begin to divide and grow at once.

\section{Movements}

None of the true Schizophyceæ have cilia, although blue-green motile organisms, e.g. Cryptomonas, Cryptoglena, are known; but these are structurally quite different from the typical Schizophyceæ. Goebel, however, mentions having observed ciliated cells in Merismopœdia, one of the Chroöcoccaceæ, but they

A

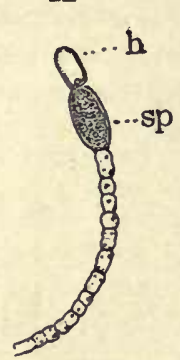

C D

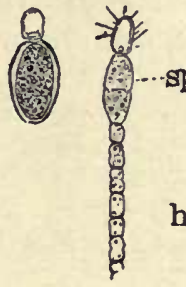

E
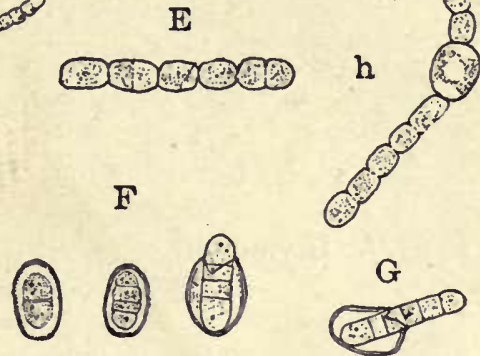

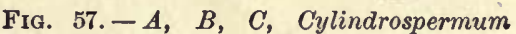
catenatum; $s p$, spore; $h$, heterocyst (× 500). D, E, Anabæna Azollæ. $E$, cells in process of fission. $F, G$, germinating spores of Cylindrospermum. have not yet been seen by other observers.

The most striking movements are those of the Oscillatoriaceæ. Oscillatoria is one of the commonest of the Schizophyceæ, abound-
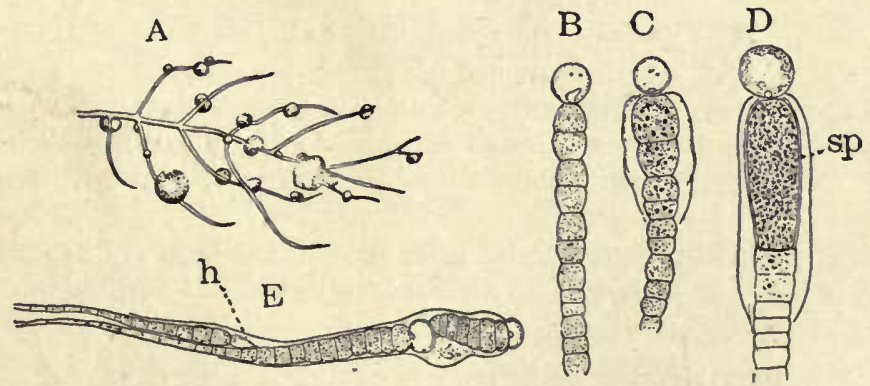

Fig. 58. - A, leaf of Myriophyllum with colonies of Glocotvichia natans, slightly enlarged. $B-D$, development of the spore $(\times 450) . E$, branching filament; $h$, young heterocyst.

ing in every fresh-water pool, and its movements have been repeatedly studied, but are still not clearly understood. The slender 
filaments show active swaying and revolving movements, and when in contact with a solid substratum, they creep about actively, soon spreading themselves in a film with the free ends of the filaments radiating from the centre of the mass (Fig. 56, A). The hormogonia of Nostoc, and other forms which do not usually exhibit movement, often show, for a time, active creeping movements by means of which they escape from the gelatinous envelope and seek a new spot to establish themselves.

\section{Classification of Schizophyceæ (Kirchner, 8)}

Schizophycem (Blue-Green Alg.te)

Ord. I. Coccogonece. Single-celled.

a. Reproduction by simple fission. Fam. 1. Chroöcoccaceæ.

b. Reproduction by conidia. Fam. 2. Chamæsiphonaceæ.

Ord. II. Hormogonece. Multiplication by cell-rows (hormogonia) which often show ereeping movements. Simple or branched filaments, often with sheath or gelatinous envelope.

a. Simple filaments of cylindrical cells, no resting-spores or heterocysts. Fam. 3. Oscillatoriaceæ.

b. Cells usually rounded: lieterveysts, and often arthrospores. Fam. 4. Nostocaceæ.

c. Filaments enclosed in sheath, showing false branching, usually showing base and apex; heterocysts and resting-spores usually present. Fam. 5. Scytonemataceæ.

d. Filaments enclosed in sheath, showing true brunching; branches often attenuated; heterocysts and arthrospores. Fam. 6. Stigonemataceæ.

e. Filaments much attenuated with basal heterocyst; arthrospores sometimes present. Fam. 7. Rivulariaceæ.

$f$. Filaments epiphytic, tapering at both ends; no heterocysts or arthrospores. Fam. 8. Camptotrichaceæ.

\section{PERIDINEA (PERIDINIALES) (SCHÚTT, 18)}

Among the important constituents of the surface life (Plankton) of the ocean, and to a lesser degree of fresh water, are numerous unicellular organisms whose affinities are not very clearly understood, but which show evidences of their plant-nature. The most impor- 
tant of these are the Peridineæ and the Diatoms. These organisms, although of minute, often microscopic, size, are of enormous importance, as they are the principal green organisms of the plankton, and are the original source of food for nearly all marine animal life.

\section{Structure of Peridineæ}

The Peridineæ (Fig. 59) show much resemblance to some of the Flagellata, with which they are probably related. Like them, they are provided with two flagella, which are, however, usually inserted laterally. They generally show a membrane of cellulose which is in the more specialized forms composed of a number of sculptured plates joined together. The lowest order, Gymnodiniaceæ, are either naked cells, like most Flagellata, or they possess a simple cellulose or gelatinous membrane. In the higher forms the membrane shows a division into two valves, or pieces which fit together, and in this respect the Peridinex much resemble the Diatomaceæ.

Some of the Peridineæ are destitute of chromatophores, but these are usually present. They may be pure green, or there may be present a yellow or brown pigment, as in the Diatoms, this being especially the case with the marine forms.

Reproduction. - Reproduction is principally by simple fission, but sometimes there is the formation of zoöspores, or motile reproductive
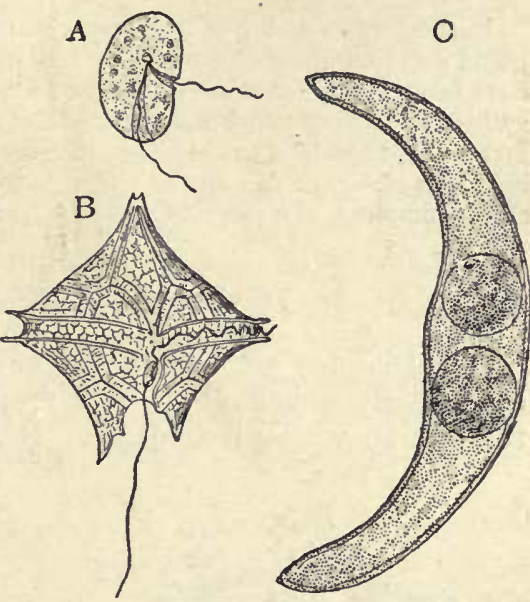

Fra. 59. - A, Hemidinium nasutum $(\times 260)$ $B$, Peridinium divergens $(\times 350) . C$, Pyrocystis lunula $(\times 350) . \quad(A$, after Stein ; $B, C$, after Schürt.) cells by internal cell-division. No sexual reproduction has been observed, but it is probable that there is a conjugation of the free-swimming cells.

Distribution. - The Peridineæ are most abundant floating on the surface of the sea, but they may also occur in fresh water. Some of the marine species, e.g. Ceratium tripos, are joined in chains, but more commonly they are isolated cells. Some of the Peridineæ, like Pyrocystis noctiluca, are among the important phosphorescent organisms of the ocean.

Affinities of Peridineæ. - The Peridineæ are probably related to the Flagellata, but they also show resemblances to the Volvocaceæ, the lowest of the Green Algæ, and also to the characteristic group of Seaweeds, the Brown Algæ. The zoöspores of the latter are strikingly similar to some of the simpler brown Peridineæ, and suggest a real relationship between the two groups. In their color, and the structure of the membrane, there is a suggestion of the Diatomaceæ. It seems likely, then, that the Peridineæ are a very primitive group of organisms, with affinities in several directions. 


\section{Classification of Peridineæ (Schütt)}

A. Cells naked, or with continuous membrane. Ord. I. Gymnodiniaceos.

B. Membrane composed of two pieces. Ord. II. Prorocentracece.

C. Membrane composed of several plates, arranged in two groups, or valves. Ord. III. Peridiniaceoe.

\section{Coccospheres and Rhabdospheres (Murray, I3, I5)}

In the surface water of the ocean, especially in the Tropics, there have been found great numbers of excessively minute organisms to which the above names have been given. Our knowledge of their structure is due mainly to the investigations of Murray and Blackman. They are globular cells, having a yellow pigment, and, imbedded in the cell-wall, calcareous plates of peculiar form. Fission has been observed in some of them, but our knowledge of their life-history is still incomplete, and their affinities are very obscure.

\section{DIATOMACE $\approx$ (BACILLARIALES)}

The Diatoms are among the most widespread of plants, being exceedingly abundant in both fresh and salt water, or even upon the ground where it is damp. It is estimated that there are about

A

B

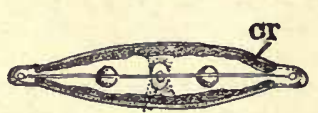

$\boldsymbol{n}$

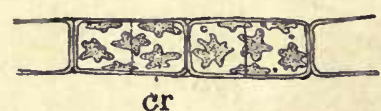

cr

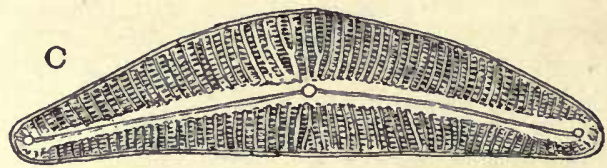

D

Fig. 60.-Diatomaceæ. A, Navicula sp., showing the two chromatophores and the nucleus, $n(\times 500)$. $B$, two cells of Melosira varians, showing the chromatophores, $\mathrm{cr}(\times 500)$. C, Cymbella lanceolata $(\times 500) . \quad D$, Nitschia sigmoidea, showing the two valves $(\times 250)$.

ten thousand existing species, and they may occur in enormous masses, at times discoloring large bodies of water in which they are suspended. While they exhibit great variety of form and size, the structure is essentially the same in all of them, and they constitute 
a very natural group. They are unicellular organisms, but may be united into chains or filaments, or by the secretion of a gelatinous matter they remain together in colonies of characteristic form, adhering to plants and other objects. Chromatophores are always present. These contain, besides chlorophyll, a golden-brown pigment, Diatomin. They are all characterized by the formation of a rigid silicious shell, which is composed of two pieces (valves), one of which fits over the other.

Cell-structure of Diatoms. - While the form of the Diatoms is extremely varied, the commonest of the fresh-water forms are oblong, or somewhat boat-shaped in outline, e.g. Navicula (Fig. 60, A), Pinnularia. The cell is enclosed in a shell composed of silica, which is in two parts, one fitting over the other like the cover of a pill-box. Each of these valves consists of two parts: the top, and the margin or girdle-corresponding respectively to the top (or bottom) of the pill-box, and the sides. Sometimes one or more plates are inserted between the top of the valve and the girdle. The flinty shell is usually elaborately sculptured (Fig. 60, C), the markings often being excessively fine, and sometimes used as tests for microscopic lenses.

In the elongated forms, like Pinnularia, there is usually a median straight or curved line, with an enlargement at the middle and end of the valve. This line is known as the raphe, and has been shown to form a cleft or system of openings communicating with the interior of the cell.

The cytoplasm in these elongated forms lines the cell-wall, and in the middle of the cell forms a bridge across it, in which lies the nucleus. In other forms the nucleus may be imbedded in the peripheral cytoplasm, or even suspended in the central vacuole by cytoplasmic threads extending to the peripheral cytoplasm. Conspicuous oil-drops are often to be seen within the cell.

Chromatophores. - The chromatophores of the Diatoms are usually large plates, most commonly two lying parallel and extending nearly the whole length of the cell. Sometimes, e.g. Cocconeis, but a single one is present, which may be variously cut, and of irregular 'form.

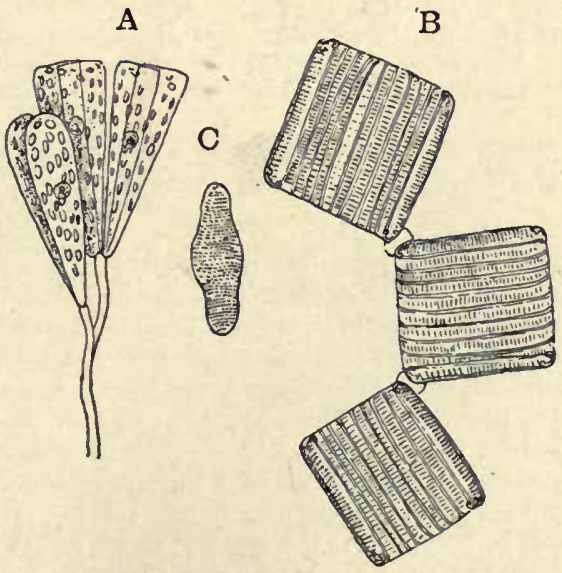

Fig. 61.-Marine Diatoms. A, Licmophora $s p$. $(\times 250) . \quad B$, Tabellaria sp., three individuals connected by gelatinous joint. $C$, end view of a cell $(\times 250)$. 
Less commonly, e.g. Isthmia, the chromatophores are numerous small oval ones, like those common in the higher plants.

The shape of the Diatom-cell is to a great extent correlated with

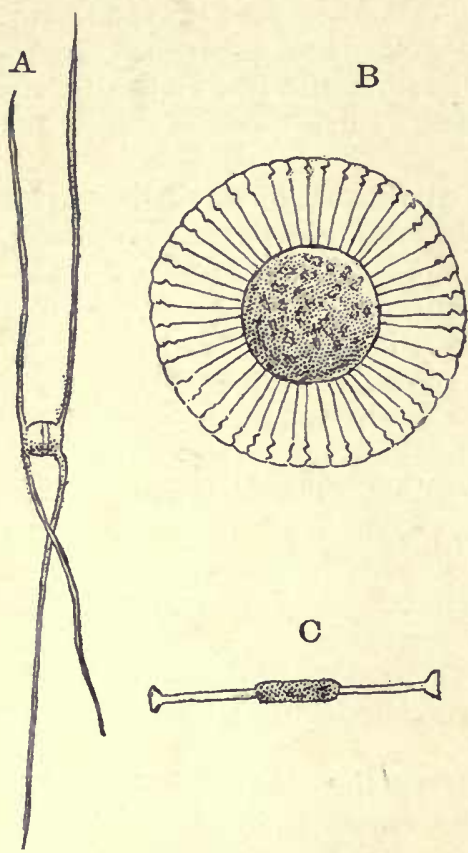

Frg. 62. - Pelagic Diatoms. A, Chætoceras boreale $(\times 175) . \quad B, C$, Planktoniella Sol. $B$, from above. $C$, from the side $(\times 125)$. (After Sснӥтт.) the habits of the different forms. The commoner fresh-water types, which live separately and form coatings upon various objects at the bottom of the water, are commonly oblong or spindle-shaped. Those which are attached at one end, e.g. Gomphonema, Isthmia, etc., are usually shorter, and often differently shaped at the free and attached ends. The floating forms, like the majority of those in the plankton of the ocean (Fig. 62), have special contrivances for increasing their buoyancy. They are either excessively slender, e.g. Rhizoselenia, or have slender extensions of the cell, e.g. Chætoceras, or they are thin dises, e.g. Coscinodiscus, Planktoniella.

Movements. - The elongated Diatoms, which live free, often show active creeping movements, that are probably caused by the protrusion of protoplasmic processes through the openings along the raphe. By the contraction of these pseudopodia it is supposed that the cell is dragged along the surface to which it is applied.

Cell-division. - The cells divide in a plane parallel with the surface of the valves. The protoplast increases in size, forcing the two valves apart until only their edges are in contact. The nucleus then divides, and this is followed by a division of the protoplast into two, but without a cell-wall between them. The division of the chromatophores may occur either before or after the division of the protoplast. There are thus two new protoplasts enclosed within the original pair of valves. Each of the protoplasts now forms a new valve on its inner side, i.e. the side in contact with the other protoplast, so that the two new valves are placed back to back, and fit into the old valves, and thus the two new Diatoms are complete. As the original valves are of unequal size, and each becomes the larger valve of one of the new Diatoms, it follows that the latter are of unequal size, and that after each division one of the resulting cells is smaller than the other. When the divisions are repeated rapidly, this soon results in a great diminution in the size of part of the cells, and the same species may exhibit 
great variation in this respect. After a minimum size is reached, however, the size is restored by the formation of "Auxospores."

It has been recently discovered that in some marine Diatoms (Coscinodiscus, Chætoceras) there may be formed, by successive division of the protoplast, several ( $8-16)$ rounded protoplasts (Fig. 63, B), each of which then secretes a new pair of valves, while still within the old pair. As the valves in these small individuals are very slightly silicified, it is not improbable that they are capable of increase in size, unlike the strongly silicified valves of most Diatoms. 'This formation of several young Diatoms, by repeated divisions of the protoplast of the mother-cell, is very much like that in some of the simpler Peridineæ, e.g. Pyrocystis.

Auxospores. - The formation of auxospores may be either non-sexual or sexual. The simplest case, such as that of Melosira (Fig. 60, D), consists in the separation of the valves, so that the protoplast is set free, and increases very much in size, finally developing a continuous membrane

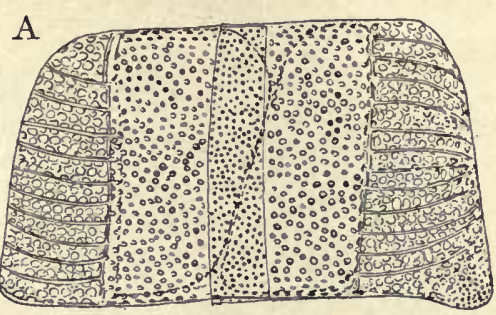

B

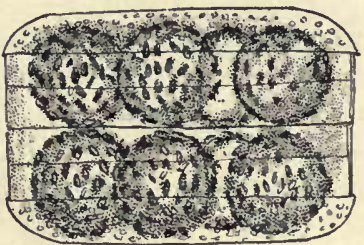

Frg. 63.-Isthmia nervos $\alpha$, showing celldivision. Each new individual has formed one new valve inside one of the old ones $(\times 200) . \quad B$, Coscinodiscus concinnus, showing internal cell-division $(\times 400) . \quad(B$, after Murray.)

about itself. Within this there is first formed a single valve, like one of the original ones, and soon after a second one fitting into it, thus forming a new Diatom of the maximum size of the species.

A
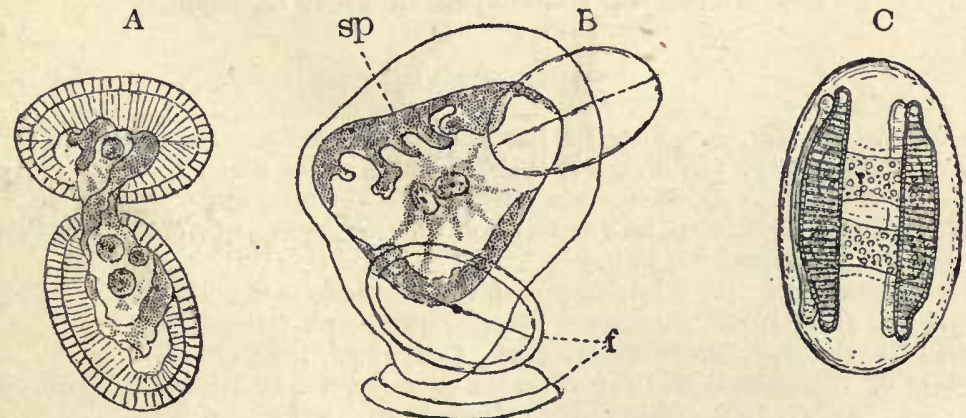

Frg. 64. - $A, B$, auxospore formation in Cocconeis placentula. (After Karster.) $C$, auxospore formation in Epithemia sp. (After Pfitzer.) In Cocconeis a single spore is formed by the fusion of the undivided protoplasts: in Epithemia the protoplast divides into two parts, each of which conjugates with the corresponding one of the other conjugating cell.

In other cases, e.g. Cocconeis (Fig. 64), the naked protoplast escapes from two cells, which are generally enclosed in a gelatinous envelope, and the two fuse 
into one; i.e. there is a true fertilization. From the cell thus formed a new Diatom is either formed at once or after a preliminary division of the protoplast.

\section{Affinities of Diatomaceæ}

The Diatoms are not, apparently, closely related to any other group of plants. In their cell-structure they approach the Desmids, one of the lower orders of Green Algæ, and in the structure of their shell, and their color, they may show some relation to the Peridineæ. With the true Brown Algæ they have little in common but their color.

\section{Fossil Diatoms}

The silicious shells of Diatoms are very resistant, and have been preserved, often in enormous quantities, in a fossil condition. It is remarkable, however, that they are quite unknown from the older formations, and it seems probable that the group as it now exists is of comparatively recent origin.

\section{Classification of Diatomaceæ}

The Diatoms have been divided-into seventeen families grouped under two orders. (Schütt, 18.)

Ord. I. Centricae. Valves usually circular or oval in transverse sections. No raphe.

Ord. II. Pennatce. Valves bilaterally symmetrical, markings usually pinnately arranged. Raphe usually present. Valves boat-shaped or rod-shaped in most of them.

\section{BIBLIOGRAPHY}

'87. 1. De Bary, A. Fungi, Mycetozoa, and Bacteria. Oxford, 1887.

'00. 2. Benecke, W. Ueber Farblose Diatomeen der Kieler Föhrde. Pringsheim. Jahrb. für wissenschaftliche Botanik, xxxv, 1900.

'97. 3. Davis, B. M. The Vegetation of the Hot Springs of Yellowstone Park. Science, VI, 1897.

'97. 4. Fischer, A. Vorlesungen über Bacterien. Jena, 1897.

'87. 5. Goebel, K. Outlines of Classification, etc. Oxford, 1887.

'99. 6. Green, J. R. Fermentation. Cambridge, 1899.

'96-1900. 7. Karsten, G. Papers on the Reproduction of Diatoms. Flora, '96, '97, 1900. Biologisches Centralblatt, 1900.

'98. 8. Kirchner, O. Schizophyceæ - in Engler and Prantl, Die natürlichen Pflanzenfamilien. Leipzig, 1898.

'94. 9. Lister, A. A Monograph of the Mycetozoa. London, 1894.

'00. 10. Macbride, T. H. The Myxomycetes of North America. London and New York, 1900.

'96. 11. Migula, W. Schizomycetes. Engler and Prantl, Nat. Pflanzenfamilien. Leipzig, 1896. 
'00. 12. Migula, W. System der Bacterieen. Jena, 1897-1900.

'95. 13. Murray, G. Introduction to the Study of Seaweeds. London and New York, 1895.

'96. 14. Murray, G. On the Reproduction of Some Marine Diatoms. Proc. Royal Socs., Edinburgh, December, 1896.

'98. 15. Murray, G., and Blackman, V. H. The Nature of Coccospheres and Rhabdospheres. Phil. Trans. Royal Society, Vol. 190, 1898.

'99. 16. Murray, G., and Whitting, F. G. New Peridiniaceæ of the Atlantic. Trans. Linnæan Soc., Vol. V, pt. 9, 1899.

'97. 17. Schröter, J. Myxomycetes. Engler and Prantl, Nat. Pflanzenf. Leipzig, 1897.

'96. 18. Schütt, F. Peridiniales, Bacillariales. Engler and Prantl, Nat. Pflanzenf. Leipzig, 1896.

'00. 19. Senn, G. Flagellata. Engler and Prantl, Nat. Pflanzenf. Leipzig, 1900.

'97. 20. Strasburger, E. Das Botanische Practicum. Jena, 1897.

'92. 21. Thaxter, R. On the Myxobacteriaceæ, a new order of Schizomycetes. Bot. Gazette, XVII, 1892.

'97. 22. - Further observations in the Myxobacteriaceæ. Ibid., XXIII, 1897.

'97. 23. Tubeuf, K. Diseases of Plants. London and New York, 1897.

'87. 24. Wolle, F. Fresh-water Algæ of North America. Bethlehem, Pa., 1887. 


\title{
CHAPTER V
}

\author{
THE ALGX
}

\section{Thallophytes}

AlL plants below the Mosses are often placed in a single subkingdom, Thallophyta, but there are good reasons for considering the two great divisions above the Schizophytes and below the Mosses, as entitled to the rank of subkingdons. Those forms which possess chromatophores are known as Algæ; those from which they are absent, Fungi. The Schizophytes are often included with the Algæ, but they, as well as the Myxomycetes and Flagellata, which are sometimes united with the lower Algæ under the name Protophyta, are probably also better regarded as subkingdoms.

\section{The Algæ}

The Peridineæ and Diatomaceæ, both of which groups are related more or less closely to the higher Algæ, may probably best be considered as the two lowest classes of the subkingdom. Leaving these aside, the Algæ are usually divided into three classes, the Green Algæ (Chlorophyceæ), the Brown Algæ (Phæophyceæ), and the Red Algæ (Rhodophyceæ). The supplementary pigments which distinguish the two latter classes from the Chlorophyceæ are associated with marked structural differences which sharply separate the three classes. One group of the Green Algæ, the Characeæ, may perhaps be better removed from that group and considered as a fourth class.

\section{Class I. The Green Alga (Chlorophyces)}

The Green Algæ are especially interesting because, with little question, they represent more nearly than any other existing plants the ancestors of the green land-plants. The Phæophyceæ and Rhodophyceæ, on the other hand, are to be regarded as much more specialized forms, especially adapted to a marine environment, and as having diverged widely from the forms which have given rise to the higher green plants.

Chromatophores. - The Chlorophyceæ always contain distinct chromatophores, which seldom show any other color than pure green, 
although occasionally a red pigment (Hæmatochrome) is present. Such forms, however, may usually have pure green chromatophores as well.

Nucleus. - A nucleus is always present in the cells, and there may be more than one.

'The greater' number of Green Algæ are fresh-water organisms, or may grow upon damp earth, trunks of trees, or other places where a sufficient amount of water is present for their needs. Some of them are marine, and others grow associated with other plants. Thus the so-called "gonidia" of many Lichens, are Green Algæ, which may grow quite independently. Less commonly they occur within the tissues of the higher plants. Chlorochytrium Lemnoe is a unicellular green Alga which lives within the intercellular spaces of the little floating plant, Lemna trisulca.

Plant-body. - The simplest of the Chlorophyceæ are unicellular, but they are more commonly cell-rows, either simple or branching. A smaller number (e.g. Ulva, Coleochæte) have a flat thallus. They show very little external differentiation, this being most marked in the Stoneworts, or Characeæ, which also contain the largest members of the class.

Reproduction. - In spite of their simple vegetative structure, there is a good deal of variety shown in their reproductive parts. Celldivision occurs much as in the higher plants. Where the cells are multinucleate, division-walls may be formed without a corresponding nuclear division, but in the uninucleate cells, the nucleus undergoes mitosis, as in the cells of the higher plants. In unicellular forms, of course, each cell-division results in the formation of new individuals.

In most forms special non-sexual reproductive bodies are developed. The simplest of these are naked, ciliated cells (Zoöspores, Swarmspores), which are formed either singly, or several together, from the nother-cell, and after a longer or shorter period of activity, settle down and form a new plant. Where these cells are destitute of cilia, and develop a cell-wall within the mother-cell, they are known as "Aplanospores." Less frequently, as in the buds, or gem$m æ$ of some Characeæ, these reproductive bodies are multicellular.

Sexual Reproduction. - Most Chlorophyceæ show a clearly marked sexual reproduction. The sexual cells in the lowest forms are not distinguishable from the vegetative ones; indeed, in some unicellular forms like the Desmids, the protoplasts of two ordinary individuals unite to form the sexual spore. More commonly, however, special sexual cells, or gametes, are produced. These may be entirely similar (Planogametes), or they may be more or less perfectly differentiated into male and female cells. The product of the united gametes is known as the Zygote, and usually becomes a thick-walled 
spore, which germinates only after a considerable period of rest. Much less commonly (e.g. Ulva), the zygote germinates immediately.

The simpler forms of gametes closely resemble the non-sexual zoöspores, from which they have undoubtedly developed. Occasionally gametes, males as well as females, have been observed to germinate without fecundation. This phenomenon is known as Parthenogenesis.

Certain groups of Green Algæ, e.g. Volvocaceæ, still exhibit all grades of development of the gametes, from non-sexual zoöspores to perfectly differentiated spermatozoids and eggs. The latter finally lose the power of movement, and remain within the mother-cell (Oögonium), where they are fertilized by the small active spermatozoid.
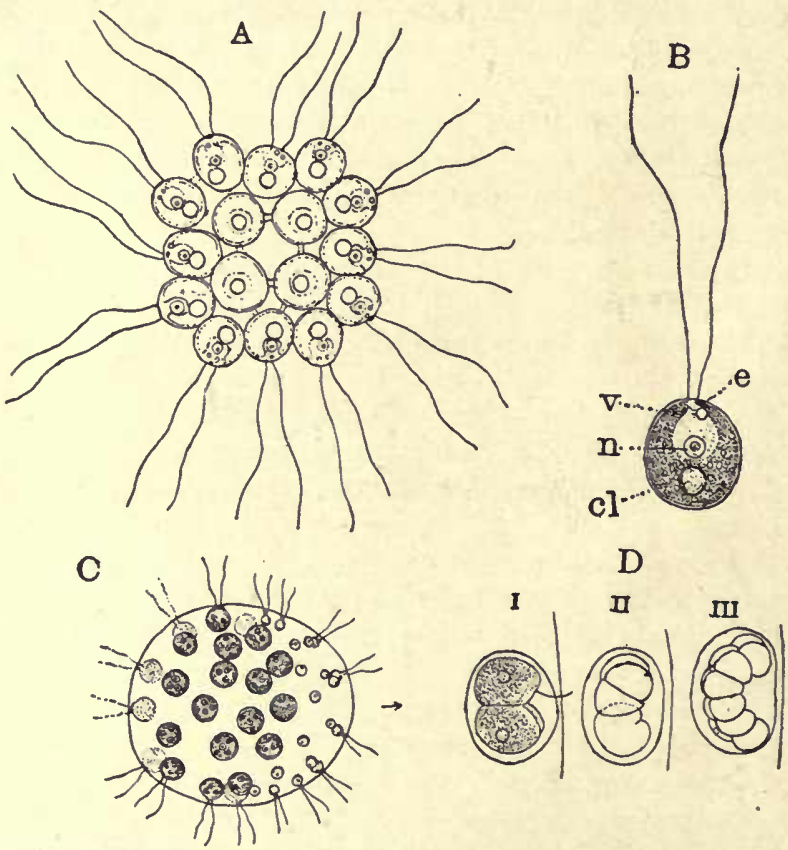

Frg. 65. $-A$, Gonium pectorale $(\times 450) . \quad B$, a single cell of Gonium $(\times 800)$; $c l$, chloroplast, with pyrenoid; $n$, nucleus; $v$, one of the contractile vacuoles; $e$, eye-spot. $C$, Pleodorina Californica $(\times 75)$; the arrow indicates the forward pole of the colony. $D$, three stages in the division of a gonidium. ( $D$, after SHaw.)

\section{Classification of Chlorophyceæ}

The Chlorophyceæ may be divided into the following six orders: I. Volvocacece; II. Protococcoidece; III. Confervoidece; IV. Conjugato; V. Siphonece; VI. Characeo. Of these, the first three 
are unquestionably closely related, and probably lead up to the higher green plants. The others are more specialized forms, probably derived from the other Chlorophyceæ, but not showing such obvious relationships. The Conjugatæare sometimes removed from the Chlorophyceæ, but this seems hardly warranted. As stated before, the Characeæ differ much from the other forms, and might with propriety be considered as a class, coördinate with all the other Chlorophyceæ.

\section{Order I. Volvocaceæ}

The Volvocaceæ are at once distinguished from the other Green Algæ by the fact that their vegetative cells are ciliated, and the plants are therefore actively motile. They may be either unicellular, or they are cell-families more or less intimately united. In the genus Volvox the cells are congenitally united by protoplasmic threads, and the whole should be considered as a single multicellular organism, and not a colony of unicellular individuals.

The cells of most Volvocaceæ resemble closely the zoöspores of many of the higher Chlorophyceæ. They are oval or globular in form, surrounded by a membrane which may be of unmodified cellulose, but is more often more or less gelatinous and very thick (Fig. 65, A, B). This membrane or envelope is perforated to allow the two long cilia to protrude. There is usually a single large chromatophore present. This is somewhat cup-shaped, and vivid green in color. Imbedded in the chromatophore is a large roundish body, the pyrenoid, a structure frequently found in the chromatophores of the Algæ, but whose nature is still somewhat obscure. The pyrenoid is of albuminous nature, and is probably associated with the assimilation of $\mathrm{CO}_{2}$ by the chromatophore. The pyrenoids are sometimes regarded as similar to the proteincrystals, found as reserve-food in the cells of many plants. The nucleus lies in the cytoplasm within the cavity of the cup-shaped chromatophore, and in the cytoplasin, near

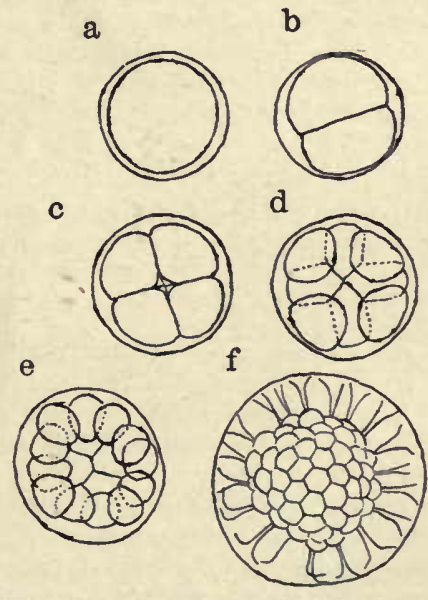

Fig. 66. - Successive stages in the division of a gonidium of Pleodorina Californica, seen from above at the following hours: $b, 3.20$ P.M.; $c, 4.15 ; d, 5.05 ; e, 5.40 ; f$, the same at 10.15 A.s. of the following day. (After Shaw.)

the base of the two long cilia, are usually two small contractile vacuoles. There is also present at the forward end a red piginent- 
spot (eye-spot), like that found in some Flagellata. Occasionally

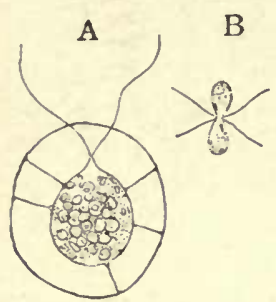

B

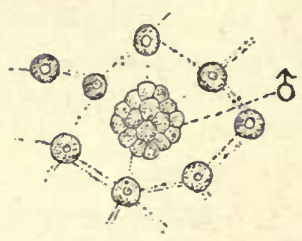

$\mathrm{E}$

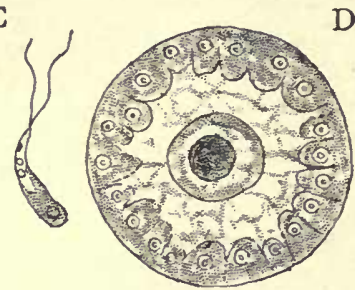

Fig. 67.- $A$, Sphærella pluvialis, active individual $(\times 300)$. $B$, conjugating gametes $(\times 750)$. $C$, cells of Volvox minor, showing protoplasmic connections, aud a young antheridium, $\hat{o}$ $(\times 500)$. $D$, section of egg-cell of Volvox minor, showing the large central nucleus, and the peripheral chromatophore containing numerous pyrenoids $(\times 550)$. $E$, a spermatozoid $(\times 700)$. ( $A, B$, after Blochmani ; $D, E$, after Oviertos.) cell-aggregates of definite form. The number of cells ranges from sixteen in Gonium to several thousand in the genus Volvox.

\section{Classification of Volvocaceæ}

The Volvocaceæ may be divided into three families: Chlamydomonadinæ, Phacoteæ, and Volvoceæ. The first two comprise unicellular forms, the latter are all multicellular.

Chlamydomonadinæ. - In the Chlamydomonadinæ the unicellular free-swimming cells may withdraw their cilia and assume a non-motile condition in which they are capable of repeated fission, giving rise to large colonies of non-motile cells which closely resemble certain Protococcoideæ, from which they are scarcely distinguishable. Sphorella nivalis, the "Red-snow" plant, is an example of this. In this plant, as well as in the spores of other Volvocaceæ, the red pigment hæmatochrome is present. These non-motile cells, however, may escape from their gelatinous matrix and resume their active form. Gainetes are formed by internal division of the cell, these being either quite similar or slightly different in size. The cell formed by their union becomes a resting-spore whose contents finally divide into several $(2-4)$ parts, each of which escapes as a freeswimming cell.

Phacoteæ. - The Phacoteæ include a small number of unicellular forms 
(Phacotus, Pteromonas, etc.), distinguished by having the cell-membrane firm, and often composed of two parts.

Volvoceæ. - The more striking Volvocaceæ belong to the third family. These are always multicellular. The simpler forms (Gonium, Pandorina) consist of (usually) sixteen similar cells (Fig. 65) inclosed in a common envelope. By repeated bipartition of these cells new cell-families arise which are set free by the softening of the gelatinous matrix of the mother-family. In the genera I'leodorina (Fig. 65, C) and Volvox two kinds of cells are present, small ones incapable of division, and much larger ones (gonidia) which by division give rise to the new plants. In Pleodorina the gonidia are ciliated, and except in size closely resemble the small vegetative cells. In Volvox the number of gonidia is small (rarely over 10-12), and they are many times larger than the other cells, which may be several thousand in number. The multiplication of the Volvocacer is sometimes extremely rapid, so that the water of small ponds may be colored green by the multitude of these swinming colonies.

In Pleodorina and Volvox the repeated division of the gonidium soon results in the formation of a hollow sphere in which the cells are at first in contact, but separate inore and more with the development of the mucilaginous cell-walls. The interior of the fully developed spherical plant is filled with soft mucilage. In Volvox the protoplasts of the cells remain connected by extensions of protoplasm, but no such communication can be demonstrated in Pleodorina.

Sexual Reproduction. - The Volvocaceæ show very beautifully the gradual evolution of the sexual cells.

In such forms as Sphærella and Pandorina there is very little difference between the sexual and non-sexual cells, and the gametes are alike (Fig. 67, B). In the genus Eudorina certain cells assume the function of eggs, while others undergo division into numerous much smaller elongated cells, the male cells or spermatozoids. The latter penetrate into the gelatinous envelope of the female plant, where they come in contact with the egg-cells and effect their fertilization. In Volvox (Fig. 67, D, E) the egg-cells, which exactly resemble the non-sexual gonidia, are quite destitute of cilia, and very much larger than the spermatozoids, which are largely composed of nuclear substance.

In all cases the product of fertilization is a resting-spore which becomes invested with a heavy membrane, and usually assumes a brown or red color. This spore on germination produces either single zoöspores (Chlamydomonas, Pandorina), or its contents, by repeated bipartition, give rise to a multicellular individual like those produced from the gonidia (Eudorina, Volvox).

\section{Affinities of Volvocaceæ}

The Volvocaceæ are probably directly related to the Flagellata, and through these show affinity with the lower animal forms. Indeed, they are actually claimed by some zoölogists as animals. Their very evident relationship with the Protococcoideæ, and through these with the higher plants, however, indicates that although they have certain resemblances to animals, they are, in all essential respects, true plants, and probably represent the starting-point for the line of development leading up to the higher green plants. It is, however, among the simpler forms, like Chlamydomonas, that we are to look for the connection with the Protococcoidex, and not among such highly specialized forms as Volvox. 


\section{Order II. Protococcoideæ}

The Protococcoideæ are unicellular plants distinguished from the Volvocaceæ by the absence of cilia in the vegetative cells. The cells may be isolated, or may be united into colonies or cell-families, often of characteristic form and large size. Many of thein produce motile reproductive cells, which are sometimes not distinguishable from such Volvocaceæ as Chlamydomonas. As the latter often multiply for a long time in a non-motile condition, it is sometimes

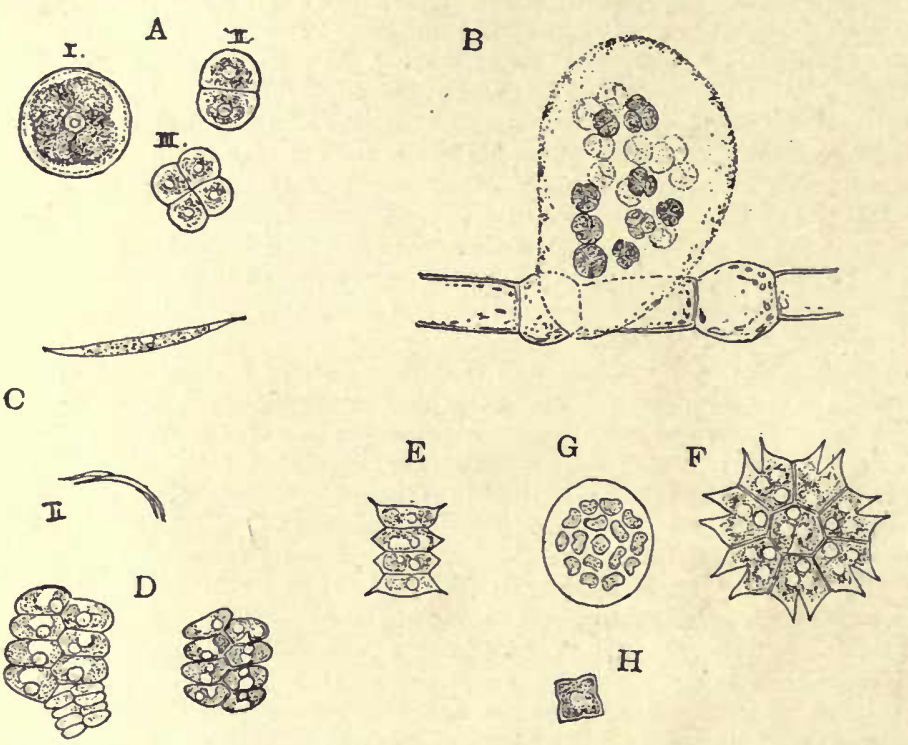

Frg. 68. $-A$, Pleurococcus vulgaris : $I$, full-grown individual ; $I I, I I I$, cells dividing. $B$, Apiocystis Brauniana. Young colony attached to a filament of Edogonium (×300). C, Rhaphidium polymorphum: II, cells dividing. D, Scenedesmus obtusus: one of the cells has divided to form a young colony. $E, S$. dimorphus. $F$, small colony of Pediastrum Boryanum. $G$, young colony still enclosed in the membrane of the mother-cell. $I I$, polyedrium, or resting-spore, probably of the same form. (All figures except $B, \times$ about 500 .)

impossible to be sure whether a given organism belongs to the Protococcoideæ or Volvocaceæ. It is extremely probable that the lower Protococcoideæ have been derived from the simpler Volvocaceæ, by the pernianent loss of motility in the regetative cells - a character common to all plants above the Volvocaceæ.

The Protococcoideæ are mainly fresh-water plants, growing either completely submersed, or simply in moist places, on shaded earth, trunks of trees, roofs, etc. A few of them grow associated with other organisms. The green color of certain animals - fresh-water 
sponges, Hydra, and some Infusoria - is due to the presence of minute Protococcoideæ. Other forms grow within the intercellular spaces of various aquatic Flowering Plants, while the gonidia of many Lichens are identical with certain species of Protococcoideæ.

Of the simpler Protococcoideæ, one of the commonest is Pleurococcus vulgaris (Fig. 68, A), the commonest of the dark-green slimes on bricks, flower-pots, and similar objects. The individual plant is a small globular cell with definite cell-membrane, several chromatophores, and a centrally placed nucleus. 'The cells multiply rapidly by repeated fission, but no motile cells are produced, and no sexual cells (gametes) are known. Other forms, e.g. Chlorosphæra, give rise to swarm-spores closely reseinbling the simpler Volvocacer, while a few of them, e.g. 'Tetraspora, have also simple sexual cells. The cells in Tetraspora

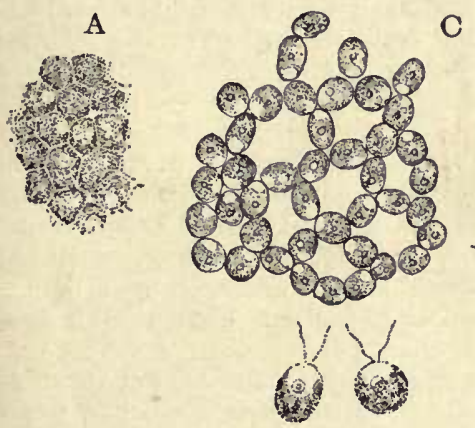

B
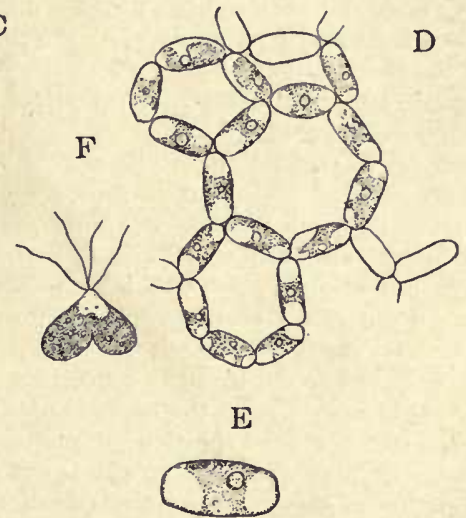

FIa. 69.-Hydrodictyon utriculatum. A, protoplasm of a cell dividing into zoöspores. $B$, two free zoöspores. $C$, zoöspores uniting to form the young net. $D$, a somewhat older stage tlian $C$. $E$, a single cell of $D$, more highly magnified, showing the single equatorial chromatophore with a single pyrenoid and a single uucleus. $F$, conjugating gametes $(\times 900) .(A, \times 600 ; B, E, \times 1000$ : the others, $\times$ about 500. $F^{\prime}$, after KLEBS.)

and Apiocystis (Fig. 68, B) are imbedded in a gelatinous matrix, which in the former is a flat green thallus closely resembling Ulva, to which probably these fornis are related.

Hydrodictyaceæ. - The most specialized of the Protococcoideæ, which consist of cell-families of definite form, are the Hydrodictyaceæ, in which no celldivision takes place, except when new families are to be formed. The simplest of these (sometimes placed in the Pleurococcaceæ) are represented by the common genus Scenedesmus (Fig. 68, D), whose cell-families consist of from two to eight spindle-shaped cells, sometimes with long appendages growing from the end cells. In reproduction, each cell divides into from two to eight daughtercells, which at once arrange themselves in the form of the mature plant. No other form of reproduction is known.

Hydrodictyon. - Hydrodictyon, the Water-net (Fig. 69), is the representative of the family. The fully developed colony has the form of an elongated hollow net, sometimes ten centimetres or more in length. The individual cells of which it is composed finally may reach a length of several millimetres. The cells are 
oblong, thick-walled, and the cytoplasm forms a thick layer next the wall, leaving a large central sap-cavity. Imbedded in the cytoplasm are numerous nuclei and many pyrenoids. The chromatophore forms an irregularly broken thin plate, which finally becomes separated into many small chromatophores.

Reproduction. - When the cells have reached a certain size, the protoplasmic contents may divide into a great many (sometimes several thousand) minute cells, each of which has a nucleus and a small piece of the chromatophore. These cells do not escape, but assuine the form of biciliate swarm-spores, which move about for a short time within the mother-cell, where they soon come to rest, having arranged themselves end to end, so as to enclose small polygonal areas (Fig. 69, C). In short, they form a very small network, fitted within the mother-cell as in a mould. The wall of the mother-cell slowly softens and dissolves, as the young net grows, and finally it is set free in the water, and finally grows to its full size, but no further divisions occur in the cells. In the young net (Fig. 69, E) each cell has a single nucleus and a girdle-shaped chromatophore containing a single pyrenoid. As the cells grow, the nucleus divides repeatedly, and the chromatophore grows with the cell, being broken through in places, and often presenting a somewhat reticulate appearance. Numerous pyrenoids also arise in the chromatophore.

Sexual Reproduction. - The sexual reproduction consists in the division of the contents of certain cells into a very large number (sometimes 30,000) of motile cells, much like the swarm-spores, but smaller. These escape from the mother-cell and unite in pairs (Fig. 69, F) to form the zygote, which, after increasing in size, gives rise later to several large swarm-spores, which in turn produce secondary resting-spores, known as polyedria. From these polyedria are formed small nets, much as in the ordinary cells.

It has been found that the conditions under which the plants are grown exert a strong influence upon the reproduction. Grown in certain nutrient solutions (e.g. a two per cent solution of maltose), the tendency to form new nets is immensely increased. So if plants are grown in a solution of cane sugar, the production of gametes is greatly stimulated.

The beautiful, star-shaped colonies of Pediastrum (Fig. 68, F) are familiar to all students of Algæ. The development of the plant is very much like that of Hydrodictyon, the main difference being that the swarm-spores escape from the mother-cell, enclosed in a delicate membrane, within which they arrange themselves in the form of the colony.

\section{Affinities of Protococcoideæ}

The simpler Protococcoideæ are closely related on the one hand to the simpler Volvocaceæ, on the other to the lower members of the Confervoideæ. Thus the genus Tetraspora resembles very closely. the genus Ulva, and many of the unicellular forms like Chlorococcum are extremely like the early stages of many of the filamentous Confervaceæ.

The Protococcoideæ (Engler and Prantl, 9) may be divided as follows : -

a. Vegetative cell-division present.

1. Zoöspores present. Families: Tetrasporaceæ, Chlorosphæraceæ.

2. Zoöspores absent. Family: Pleurococcaceæ. 
$b$. No vegetative cell-division.

1. Unicellular forms. Family: Protococcaceæ.

2. Multicellular colonies of definite form. Family: Hydrodictyaceæ.

\section{Order III. Confervoideæ}

The Confervoideæ, in their fully developed form, are always truly multicellular, although they not infrequently may vegetate for a long time in a unicellular condition (Palmella stage), which is hardly distinguishable from certain Protococcoideæ, and this has given rise to a good deal of confusion in their classification. While they are mostly

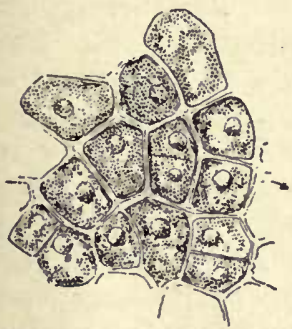

Fia. 70. - Cells from the thallus of Ulva latis$\operatorname{sim} a(\times 500)$.

fresh-water plants, some of them, like the Sea-lettuce (Ulva), and species of Cladophora and Chætophora, are characteristically marine. Others grow in moist air, attached to trees and other plants. Such, for instance, are the genera Tren-

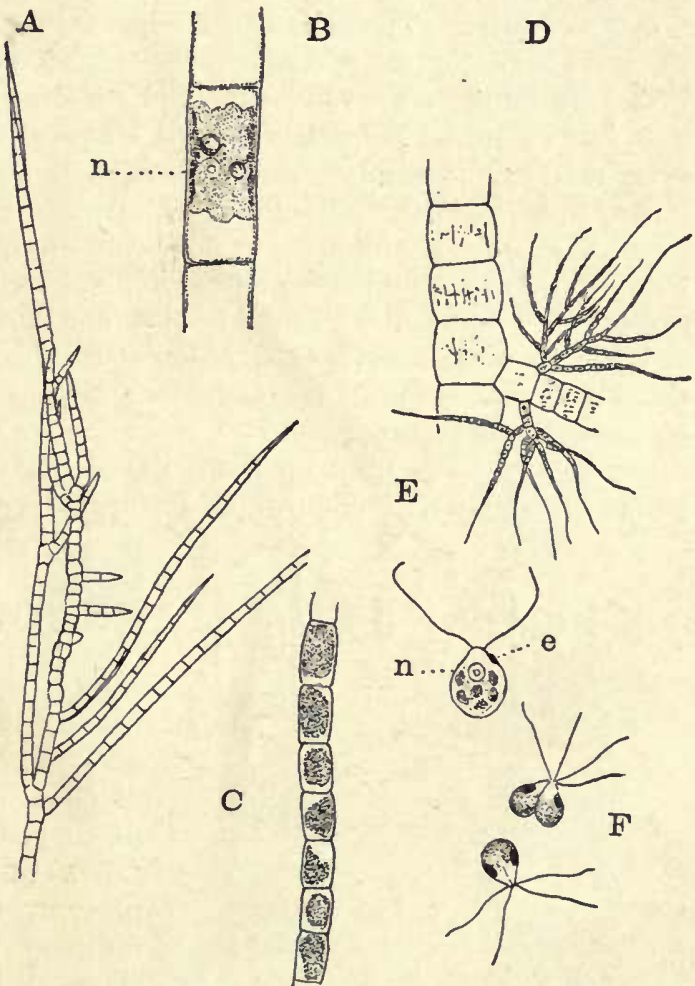

FIG. 71. $-A$, Stigeoclonium tenue $(\times 100) . B$, a single cell $(\times 600)$, showing the single chromatophore; $n$, nucleus. C, Microspora sp. $(\times 500)$. D, Draparnaldia $s p$. $(\times 100)$. E, zoöspore of Cladophora fracta; e, eye-spot; $n$, nucleus. $F$, conjugating gametes of Ulothrix zonata. $(F$, after Dodec.)

tepohlia, Mycoidea, and others. Still more remarkable is the curious genus Trichophilus, which grows among the hairs of the Sloth (Bradypus). Mycoidea is a true parasite upon the leaves of various plants. 
The Plant-body. - The Confervoideæ show considerable range of structure. The simplest forms (e.g. Conferva, Microspora, Fig. 71, C) are unbranched cell-rows, the cells entirely similar. In other forms, e.g. (Edogonium (Fig. 74), the unbranched filament is differentiated into base and apex, the former attached by a special root or disk. Branching filaments, e.g. Cladophora, Chætophora, are common, and sometimes, as in Draparnaldia (Fig. 71, D), the smaller branches contain most of the chlorophyll, and constitute very simple assimilative structures. Less commonly, as in Ulva and Coleochæte (Fig. 77), the plant-body has the form of a flat thallus.

Cell-structure. - The cells usually have the protoplasm confined to the periphery, leaving a single large central vacuole, but sometimes there are bands traversing this, and dividing it into more or less complete chambers (Cladophora). A single nucleus, imbedded in the peripheral cytoplasm, is found in most cases, but occasionally (Cladophora, Sphæroplæa), the cells are multinucleate. There may be a single large chromatophore, usually containing a single large pyrenoid, or there are numerous chromatophores distributed through the cytoplasm. The cell-wall may be thin and homogeneous, or it may show more or less evident striation (Cladophora). The plants are sometimes imbedded in a gelatinous matrix, such as is found in the common genus Chætophora.

Cell-division. - In multinucleate cells like those of the common genus Cladophora, division-walls are formed without any preliminary
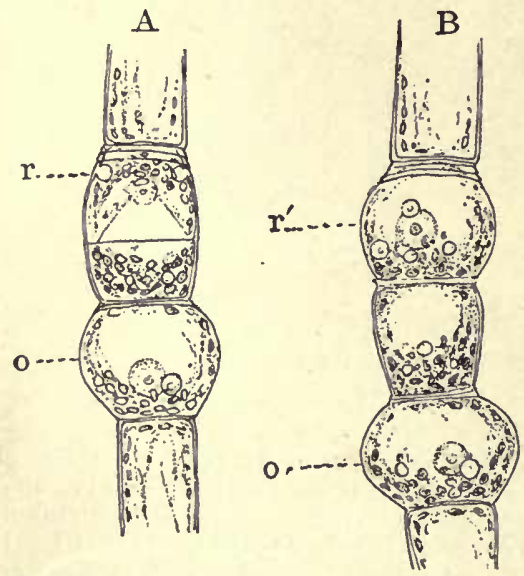

Frg. 72. $-A$, Edogonium autumnale, showing a cell in process of division; $r$, the cellulose ring, which stretches to form the new cell-wall, $r^{\prime}$, in $B$, which represents the same cell 15 minutes later; 0 , an oögonium $(\times 500)$. nuclear division. In this case the wall begins to form as a delicate circular ridge of cellulose projecting into the cellcavity. This ridge grows toward the centre of the cell, and finally forms a circular division-wall which cuts the protoplast in two.

Where a single nucleus is present, this divides in the ordinary way before the division-wall is formed. The latter may form gradually, as in Cladophora, or it may be formed simultaneously. A curious modification of the ordinary cell-division is seen in the common genus Edogonium (Fig. 72). Here, before the nucleus divides, there is formed, near 
the top of the cell, a thick cellulose ring which is attached to the inner surface of the cell-membrane. The division of the nucleus follows, and between these new nuclei the division-wall arises. The latter is not attached to the outer membrane of the cell, but is quite free at the margin, and can therefore shift its position. The cellulose ring at the top of the cell splits circularly, and is rapidly drawn out into a cylinder, thus causing a sudden lengthening of the cell. The division-wall is pushed up until it oceupies the centre of the divided cell, and then grows to the outer wall, completing the division into the two cells. Of these cells, the lower has its lateral walls composed of the original cell-wall, while the upper cell has its much thinner wall derived mainly from the cylinder formed from the cellulose ring. The small piece of the old wall above the ring is evident as a little cap surrounding the upper end of the cell. This process may be repeated several times, and the older cells of Edogonium show a series of these little caps, indicating the number of times the cell has divided.

Reproduction. - Most of the filamentous Confervoideæ may form new individuals by the separation of portions of the plant-body, or even by the separation of the individual cells in some cases. Most commonly, however, special reproductive cells are produced.

Zoöspores. - The commonest forms of non-sexual cells are zoöspores, or swarmspores, which arise either singly, by the escape of the whole protoplast, as in Edogonium (Fig. 73), or after a preliminary division of the protoplast into two or more parts. The swarm-spores may escape through a pore in the wall of the

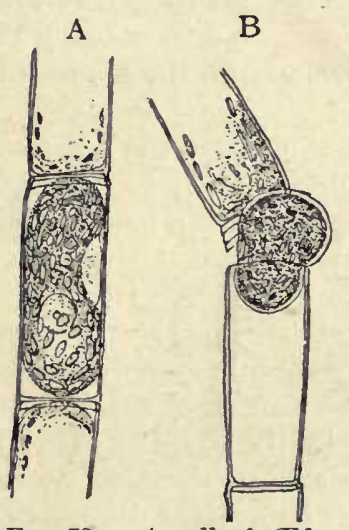

Fig. 73. - $A$, cell of EEdogonium $s p$, with a zoöspore about ready to escape. $B$, zoöspore escaping from the cell. $C$, free zoöspore $(\times 500)$. $D$, formation of zoöspores in the germinating resting-spore of Bulbochæte intermedia $(\times 250)$. ( $D$, after Pringsheim.)

mother-cell, or the filament may break, so as to open the end of the cell (Fig. 73). The escape of the swarm-spore from the mothercell is probably aided by the swelling of mucilage developed within the mother-cell.

The free swarm-spore has usually an oval form, with two or four cilia (Fig. 71, E). Less frequently there is but a single cilium (Con- 
ferva), or a crown of numerous cilia (CEdogonium). There is generally an eye-spot like that in the cells of the Volvocaceæ, and there

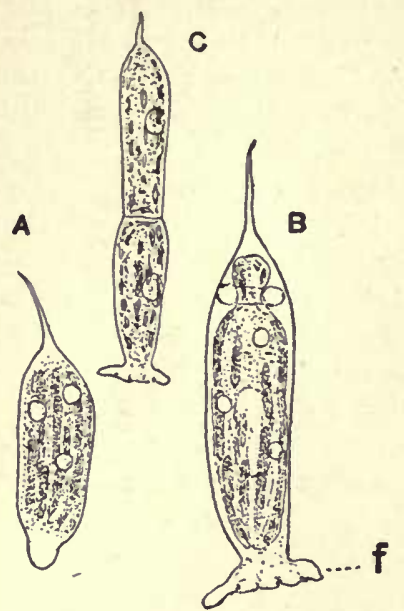

FIg. 74.-Germinating zoöspores of $(E$ dogonium $s p$.; $f$, hold fast $(\times 550)$.

may also be contractile vacuoles, so that the resemblance to the simpler Volvocaceæ is very striking. After a brief period of activity, during which the cells show marked sensitiveness to light, they come to rest, and secrete a thin cellulose membrane. The ciliated end becomes attached, and soou develops a disk or root-like organs which anchor it to the substratum. The cell elongates, and, dividing repeatedly, develops quickly into the characteristic filament.

In certain forms (e.g. Stigeoclonium) the plants often remain for a long time in a unicellular condition, the cells separating when they divide, and thus producing large colonies of unicellular plants, which are scarcely distinguishable from many Protococcoideæ. Sooner or later, these cells develop into the filamentous form of the mature Alga.

Aplanospores. - Less commonly the non-sexual reproduction is due to the formation of A planospores; i.e. the cell-contents contract, and develop a new cell-wall within the mother-cell, thus forming restingspores, which later develop into new plants. Very similar are the so-called "Akinetes," which differ from the Aplanospores only in having the cell-wall derived from the wall of the mother-cell.

Sexual Reproduction. - While sexual reproduction has not yet been demonstrated for all the Confervoideæ, it is probable that it always occurs. This is seen in its simplest form in Ulva and Ulothrix (Fig. 71, F). The gametes in these forms are quite similar (Ulva), or there may sometimes be a slight difference in size. They are distinguished from the swarm-spores by their smaller size and by having two cilia instead of four. The zygote resulting from their conjugar tion may either germinate at once (Ulva) or it may become a resting-spore, from which are developed swarm-spores.

In all of the higher types, the differentiation of the sexual cells is well marked, and the egg-cell is quite destitute of motion. The cells containing the gametes are generally more or less modified. This is well seen in (Edogonium (Fig. 75), where the oögonium, the cell containing the egg-cell, is a good deal enlarged, while the antheridium, containing the male cells (spermatozoids), is much smaller than the vegetative cells. In the peculiar genus Sphæroplæa, whose cells 
are multinucleate, the ordinary cells may be transformed, without change of form, into oögonia or antheridia, the former containing several egg-cells, the latter very numerous spermatozoids.

The oögonium in CEdogonium is usually the upper of the two cells formed from division of one of the older cells, so that several of the characteristic caps can usually be seen at the top of the oögonium (Fig. 75, A). Immediately after the division, the cellulose ring stretches out quickly, swelling out at the same time, so that the oögonium is broader than the vegetative cells. Sometimes the lower of the two cells also becomes an oögonium. The cell-contents at first fill the oögonium, but later they contract, becoming denser, also, much as in the formation of a swarm-spore. Generally at the apex, or slightly at one side, there is visible clear space, much like that at the ciliated end of the swarm-spore.
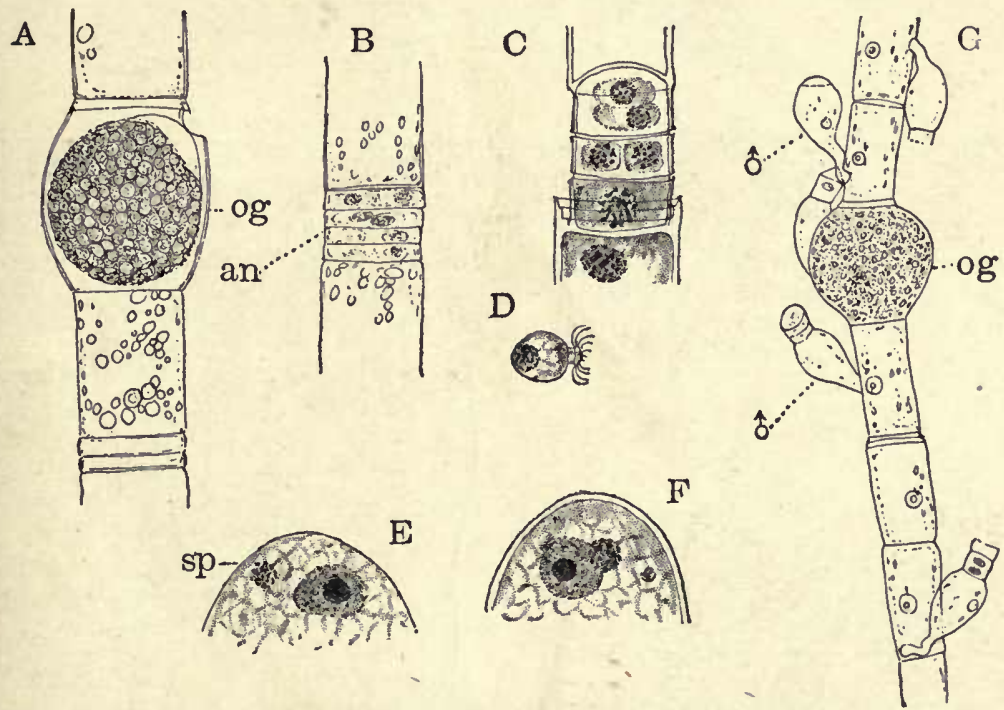

Fic. 75. $-A$, oögonium of $\alpha E$ dogonium stagnale $(\times 450), B$, antheridium of the same species. $C$, autheridium of $\mathscr{E}$. Boscii $(\times 600) . D$, spermatozoid of same species. $E, F$, fertilization in $G$. Boscii; $s p$, the spermatozoid within the egg-cell ; in $F$, the wall has begun to form about the spore. $G$, female plant of $Q E$. macrandrum, with several dwarf males, $\delta$, attached to it $(\times 450) .{ }^{\prime}(C-F$, after KLEBAHN.)

This is the "receptive spot," and it is here that the spermatozoid penetrates the egg-cell. At maturity the oögonium opens, either by a pore near the top or by the filament bending somewhat and leaving the top of the cell open, just as when a swarm-spore is to escape. However, in the oögonium, a new cell-wall is formed within the open space, and in this a pore is developed for the entrance of the spermatozoid.

Antheridium. - The antheridium (Fig. 75, B, C) consists of a series of short cells, formed by the rapid division of a vegetative cell, with very little elongation of the daughter-cells. The antheridium may be upon the same plants which bear the oögonia, or they may be upon different ones. In the latter case, they are often very small male plants ("dwarf males"), which, growing from special swarm-spores (Androspores), attach themselves to the female plants. 
There are usually two spermatozoids produced in each antheridial cell. These closely resemble the swarm-spores, but are much smaller, with little or no chlorophyll, and are largely made up of the nucleus of the mother-cell.

A
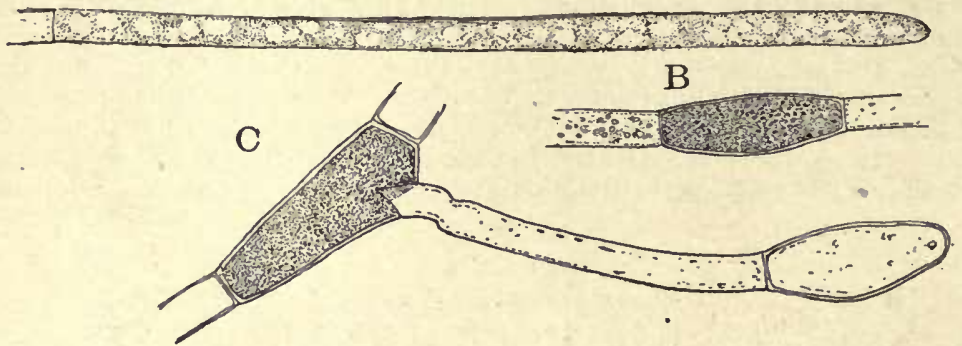

Fic. 76. $-A$, cell of Pithophora adogonia $(\times 75) . \quad B$, aplanospore. $C$, germinating spore.

Fertilization. - The spermatozoid enters the egg at the receptive spot, and quickly penetrates its substance, where it fuses with the egg-nucleus. The eggcell now secretes a firm meinbrane, which generally becomes dark colored, and the contents lose the chlorophyll and sometimes become bright red. Germina-
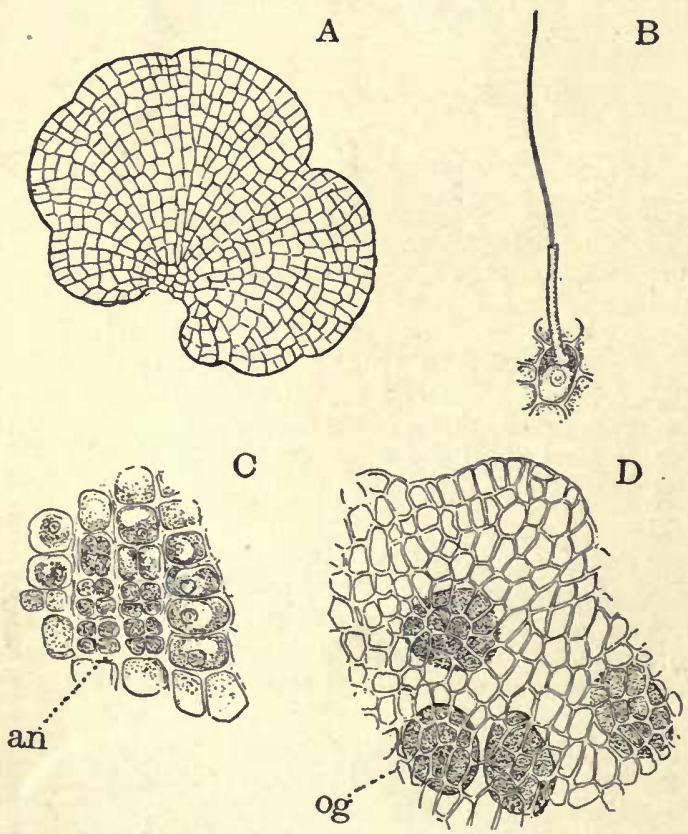

FiG. 77. $-A$, Coleochæte scutata $(\times 75) . B$, single cell with hair $(\times 200)$. $C$, vegetative cells and antheridia $(\times 200)$. $D$, young oöspores, $o g$, imbedded in the thallus. tion takes place after

B a period of rest, by the division of the contents of the spore, into four swarm-spores, each of which gives rise to a new plant.

Coleochæte. - The highest of the Confervoideæ belong to the genus Coleochæte (Figs. 77, 78), of which there are several species growing in fresh water, usually attached to the leaves and stems of various aquatics, such as Water-lilies, Rushes, etc. The commoner species (Fig. 77) are flat disks, the cells each containing a single chromatophore and nucleus. Growing from many of the cells are curious hairs, with a sheathing base, from which the plant gets its name. Swarm- 
spores are formed singly from any cell of the thallus. In C. scutata the oögonia arise from the end-cells of the radiating rows of cells of which the thallus is composed. These differ but little, except in size, from the vegetative cells. In $C$. pulvinata, which has the branches free, and forming a cushion-shaped mass, the oögonia are free at the ends of the branches, and, have a long neck, through which the spermatozoids enter.

The antheridia in the diskshaped forms like C. scutata (Fig. 77, C) are formed by the division of a thallus-cell into four small cells, which are colorless, and each of which gives rise to a single biciliate spermatozoid. In $C . p u l-$ vinata the antheridia are small oblong cells on the ends of the branches. After fertilization is effected, the egg-cell develops a thick wall, but in addition to this short branches grow out from the cells adjacent to the oögonium, which they envelop with a sort of rind, or cellular envelope, so that a "spore-fruit" is developed, consisting of the resting-spore, enveloped by the sterile protective mantle of cells (Fig. 78, B).

On germination the spore divides by cell-walls into a globular mass of cells, from each of which a
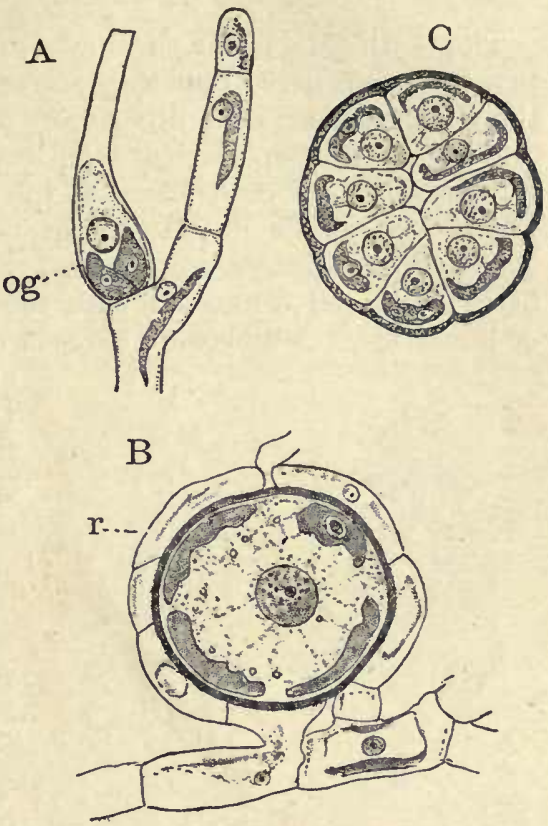

FrG. 78. - A, branch of Coleochæte pulvinata, with an oögonium, og. $B$, section of oüspore, surrounded by the cortex, $r$, developed from the adjacent cells. $C$, section of a germinated spore, divided into a mass of cells. (All after OLtManNs.)

swarm-spore arises. Each swarm-spore gives rise to a new plant. The germination of the spore in Coleochæte resembles closely the same process in the lowest of the Mosses, and in connection with the reproductive organs, as well as the form of the plant, has suggested a possible remote relation between the lower Mosses (Hepaticæ) and the Confervoideæ.

\section{Classification of Confervoideæ (Engler and Prantl, 9)}

A. Isogamoe. - Gametes alike.

Families: Ulvaceæ, Ulothricaceæ, Chætophoraceæ, Mycoideaceæ, Cladophoraceæ, Gomontiaceæ.

B. Oösporece. - Gametes differentiated into non-motile eggs and spermatozoids.

Families: Sphæropleaceæ, Cylindrocapsaceæ, Edogoniaceæ, Coleochætaceæ. 


\section{Order IV. Conjugatæ}

The Conjugatæ differ so much from the Chlorophyceæ that have just been considered that they are sometimes removed entirely from the Green Algæ. They differ most in their reproductive cells, which are never ciliated, so that fertilization is usually effected by the formation of a tube connecting the similar conjugating cells. The plants are either unicellular or simple rows of uniform cells. The cells are always uninucleate, the nucleus occupying the centre of the cell, and connected with the peripheral cytoplasm by more or less evident cytoplasmic threads or bands. The chromatophores

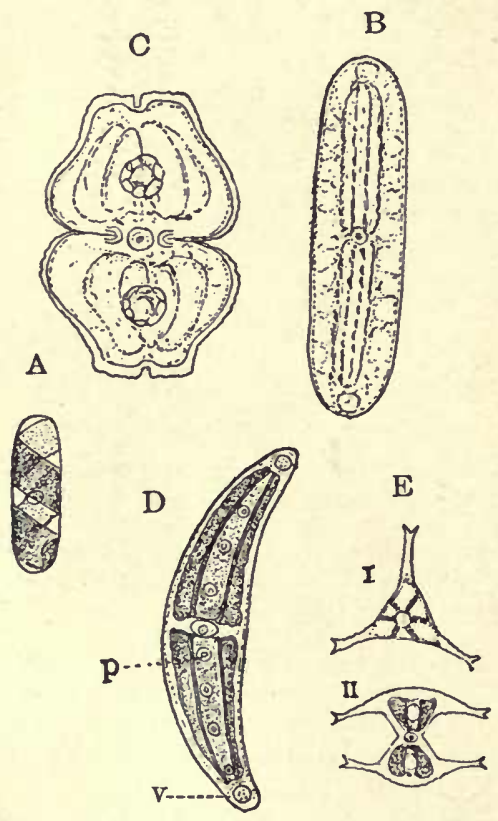

Frg. 79. $-A$, Spirotænia muscicola $(\times 350)$. (After DE BARY.) B, Penium interruptum $(\times 250)$. C, Euastrum pingue (×550). $\quad D$, Closterium lunula; $p$, pyrenoids; $v$, vacuole, containing gypsum-crystals. $E$, Staurastrum gracile; $I$, from above; $I I$, from the side. The chromatophores are shaded. are large, and of various characteristic forms, - spiral bands, flat plates, stellate masses, etc. Small bright drops (tannin vesicles) are characteristic of many species. The cell-wall is usually delicate, and the cells often secrete a gelatinous matter, in which they are imbedded, so that masses of the plants are slimy to the touch.

The Conjugatæ are widespread in fresh water, but never occur in the sea. 'They may be divided into two families, the Desmidiaceæ and Zygnemaceæ. A third family, Mesocarpaceæ, is sometimes recognized.

\section{The Desmidiaceæ}

The Desmids are unicellular Algæ, often of exceedingly beautiful form. The simplest (Mesotænium, Spirotænia) are oblong or spindle-shaped cells, with a delicate cell-wall. In the former genus there is a single flat chromatophore, which occupies the long axis of the cell, and contains a single pyrenoid. In Spirotænia (Fig. $79, A)$ the chromatophore is a spiral

band applied to the inner surface of the cell-membrane.

In most of the Desmids the cells show a marked bilateral symmetry. This is indicated by a division of the cell-wall into two valves, one of which overlaps the other, not unlike what is found in the Diatoms. The cell-contents also show a corresponding symmetry. There are usually two chromatophores, one 
in each half of the cell (Fig. 79, D). These are often composed of several radiating plates, united at the axis of the cell. Pyrenoids are present, and in the elongated forms, like Closterium (Fig. 79, D) and Docidium, there may be seen at each end of the cell a small vacuole, containing ininute crystals of sulpliate of lime, which show an active dancing movement in the fluid within the vacuole. Very generally there is also a more or less evident constriction on the equator of the cell.

Movements. - Movements not unlike those found in the Diatoms may often be detected in the 1)esmids, and are probably due to protrusions of protoplasm through minute openings in the cell-membrane.

Cell-division. - Where the cell is constricted, as it is in most forms, the celldivision is somewhat peculiar. While the nucleus is dividing, a short, cylindrical membrane is formed, just inside the place where the edges of the two valves meet, and the valves begin to push apart. Next a ring of cellulose is formed, running round the inner face of the cylindrical membrane, and this ring grows rapidly and cuts the protoplast in two. One of the original valves and half of the cylindrical membrane go with each of the new cells. The result is at first two very unsymmetrical cells (Fig. 80, B), but the new valves, developed from the cylindrical membrane, rapidly grow, and in a few hours reach the full size, and assume the characteristic sculpturing found upon the old valves. The chloroplast in each semi-cell also divides, and one of the new chloroplasts passes into the new semi-cell, and the two Desmids are complete.

In some genera of Desmids (e.g. Desmidium, Gymnozyga, Fig. 80, A) the cells remain together and form long chains.

Sexual Reproduction.-In Mesotænium, the lowest of the Desmids, the zygote arises by the complete fusion of two individuals, very much as in the lowest Volvocaceæ, the principal difference being that in Mesotænium the gametes are not ciliated. The result is a resting-spore, from which, after a period of rest, four to

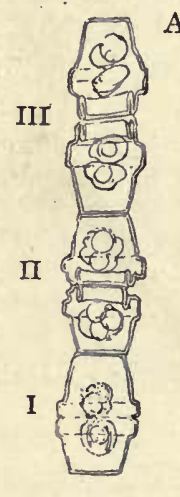

A

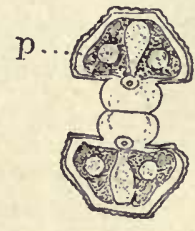

B eight cells are formed by internal division, much as in the formation of swarmspores from the germinating resting-spores of the Confervaceæ.

In the higher types (e.g. Cosmarium) only the protoplasts of the conjugating cells unite (Fig. 80, C, I)). Two cells approach each other, and may become invested with a mucilaginous envelope. More or less evident conjugating tubes grow out from between the valves, and when these come together they fuse and form a short channel, into which pass the contents of both conjugating cells, leaving the old valves empty. The zygote, thus formed, develops a heavy wall often having spines projecting from it (Fig. 80, D). It has been found that 
the spore develops without the fusion of the nuclei, which takes place only just before germination begins.

Germination. - The fusion of the nuclei is followed by two successive nuclear divisions, but of the four nuclei thus formed only two persist, and there are but two new cells formed from the spore, instead of 4-8, as in Mesotænium. The young Desmids are somewhat simpler in structure than the mature forms, and it is not until after the second division of the young Desmid that the complete form is attained. The division of the spore-contents takes place after they are set free from the thick membrane of the zygospore (Klebahn, 16).

\section{The Zygnemaceæ}

The Zyguemaceæ - "Pond-scums," as they are sometimes called - are among the commonest of the fresh-water Algæ. They are evidently closely related to the simpler Desmids, from which they have probably sprung, and from which they differ mainly in being

A

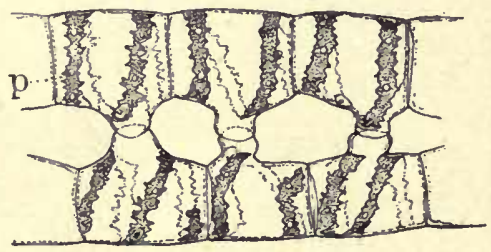

$\mathrm{B}$

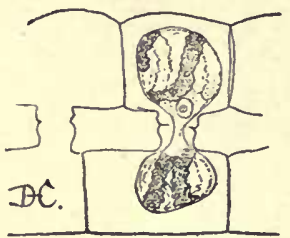

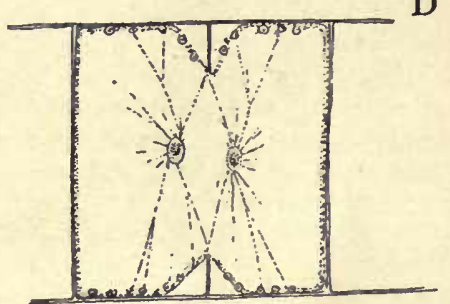

$\mathrm{E}$
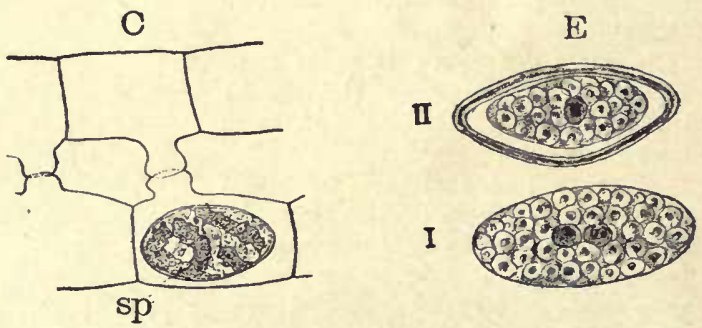

D

FIG. 81. $-A-C$, conjugation in Spirogyra sp. $(\times 200)$. D, cell-division in S. crassa $(\times 175)$. $E$, zygotes of $S$. communis, showing the fusion of the nuclei. ( $E$, after Overton.)

united into long filaments. Their cell-structure corresponds closely with that of certain Desınids. Thus Mesotænium resembles almost exactly a single cell of the filamentous genus Mesocarpus (Mougeotia), while Spirogyra is represented among the Desmids by Spirotænia, and Zygnema by Cylindrocystis.

In Spirogyra, the commonest genus, the thin-walled cylindrical cells show a thin cytoplasmic layer lining the wall, and contain one or more ribbou-shaped spiral chromatophores, in which are very conspicuous pyrenoids, about which 
may usually be seen numerous starch-granules. The large nucleus is suspended in the centre of the central vacuole by protoplasmic filanents attached to the pyrenoids. Cell-division may take place in any cell, and occurs normally at night. After the nucleus divides, the protoplast is cut in two by a ring-shaped wall, formed about the equator of the cell, and growing inward until the division is complete (Fig. 81, D).

Conjugation. - Conjugation in the Zygnemaceæ is very much like that in the Desmids (Fig. 81, $\Lambda-C$ ). From neighboring cells, either in the same filament or an adjoining one, protuberances are sent out which, fusing together, connect the cells. The protoplast may leave both cells and unite in the conjugating canal, or, as in most species of Spirogyra, one of the gametes remains within the cell, and the other passes through the canal to it. There is usually a contraction of the cell-contents preliminary to their fusion, but in the Mesocarpaceæ there is little or no contraction of the cell-contents, recalling in this respect the behavior of the very similar Mesotænium.

As a rule, the fusion of the nuclei, so far as it has been studied, occurs soon after the fusion of the gametes. A fusion of the chromatophores has also been demonstrated in Spirogyra. The ripe zygospore loses its chlorophyll, and generally assumes a dark brown color, and its contents appear coarsely granular, owing to the accumulation of reserve food matter.

The spores may retain their vitality for several years. On being placed in water they quickly absorb water, and within a week or so begin to
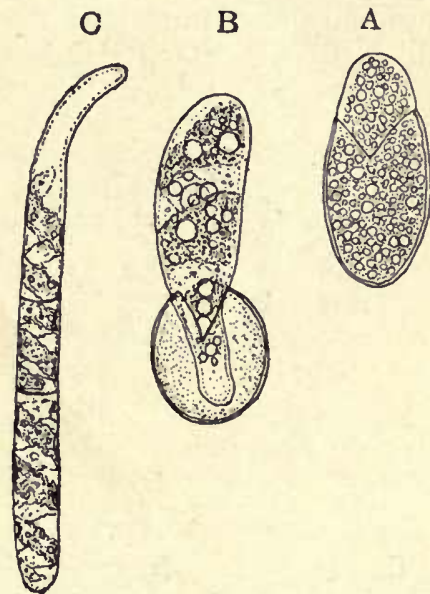

Frg. 82.- Germination in Spirogyra longuta (?). $\quad A, B \times 250 . \quad C$ $\times 100$.

show signs of germination. The green color is restored, and growth begins. The outer membrane is ruptured, and the young plant pushes through the aperture. In Spirogyra (Fig. 82) the elongated primary cell tapers at the base, which is enclosed within the sporemembrane. Large drops of oil are seen, which gradually are used up as the young plant develops.

Occasionally Aplanospores (Fig. 83, D-E) are found, which closely resemble the zygospores except that they arise without fecundation.

Affinities of Conjugatæ. - The lower Desmids, both in their structure and reproduction, recall the simpler Volvocacer and Protococcaceæ, and are probably related to them. From these simpler Desmids the more specialized forms are easily derived.

The structure of the cell-wall, as well as the reproduction, suggests the Peridineæ and Diatoms, which may also be remotely related to the Desmids. The resemblances, however, are probably only analogies. 


\section{Order V. Siphoneæ}

Unlike the other Green Algæ, most of the Siphoneæ are marine plants, being especially abundant in the warmer seas. 'They are characterized by the absence of vegetative cell-division, so that the plant-body, which may often be of considerable size, is a tubular structure, often extensively branched, but without any cross-walls, and all parts of the internal cavity are in direct communication. The cytoplasm lines the interior of the tubular thallus, and in it are imbedded numerous nuclei and small chromatophores. It is doubtful whether the plant-body of the Siphoneæ can properly be

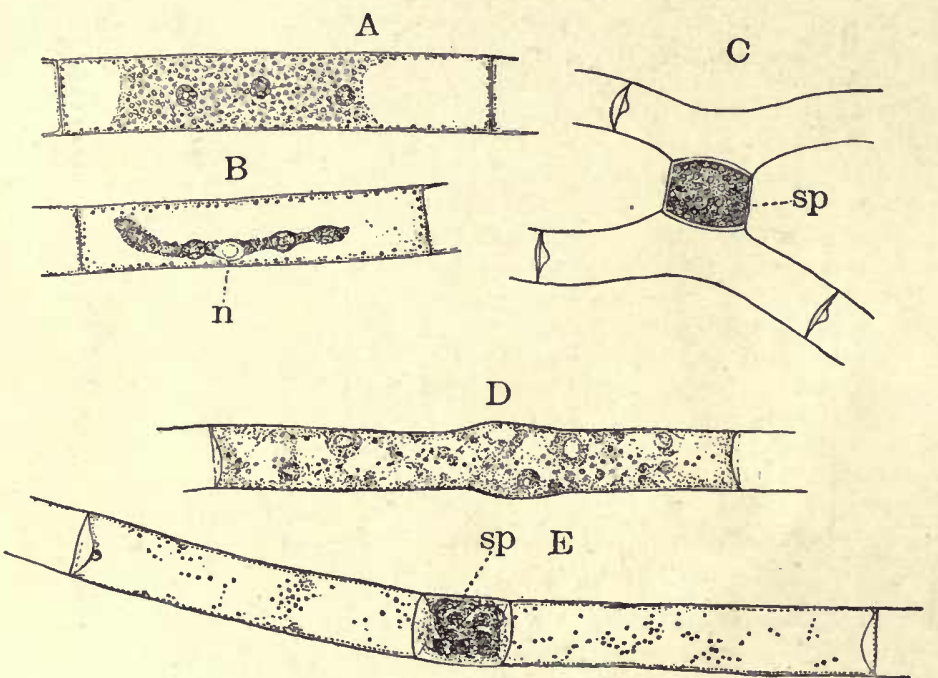

Fig. 83. $-A, B$, Mesocarpus sp.: cells showing the single axial chromatophore. $B$, seen from the side; $n$, nucleus. The small round bodies are tannin vesicles. $\dot{C}$, zygospore of Mesocarpus sp. $(\times 200)$. D, E, Gonatonema sp., showing aplanospore, $s p(\times 450)$.

considered a single cell, as is sometimes done. It seems better to look upon it as a "cœnocyte" - a cell complex, in which the divisionwalls are suppressed, and the protoplasts confluent.

The Plant-body. - One of the simplest members of the order is Botrydium (Fig. 84), a plant which is sometimes extremely abundant growing upon wet clay. The plant consists of a pear-shaped, dark green vesicle, about one-half millimetre in diameter, which is fastened into the earth by a system of dichotomously branched colorless roots. A microscopic examination shows that all parts of the interior of the plant are in open communication. The cytoplasm lines the wall as a thin layer, in which may be demonstrated many small nuclei. The 
chromatophore forms a more or less interrupted continuous thin plate, but may sometimes be replaced by numerous separate chlorophyll bodies.

The other fresh-water genus, Vaucheria (Figs. 88,89 ), consists of elongated tubular filaments, occasionally attached by colorless roots, but quite as often floating free in the water. The filaments branch irregularly, and may become constricted at the base, and separated as new individuals. The chromatophores are small oval plates, with their long axes coinciding with that of the filament. Drops of oil are often seen in the protoplasm,

A

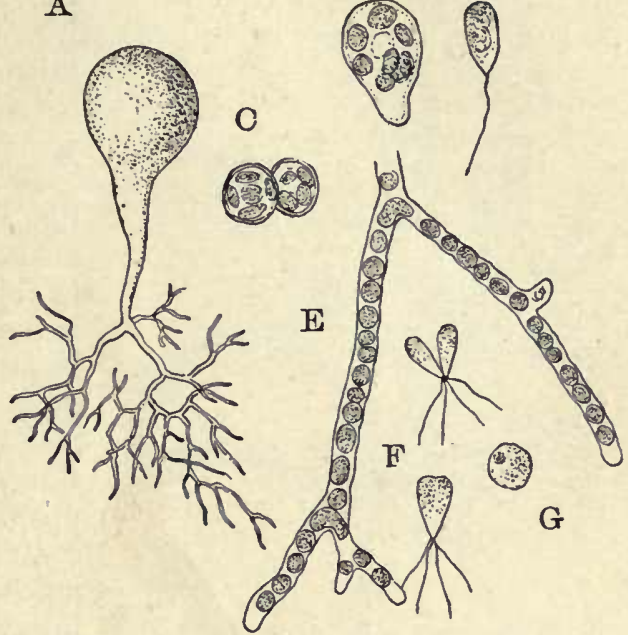

FIG. 84. $-A$, Botrydium granulosum $(\times 10) . B$, a zoöspore $(\times 540) . C, D$, germinating zoöspores $(\times 550) . \quad E$, part of root containing aplanospores $(\times 40) . \quad F$, conjugating gametes $(\times 540) . G$, zygote $(\times 540) .(B, F, G$, after StrasbURGer. $)$ probably the product of the photosynthesis in the chromatophores.

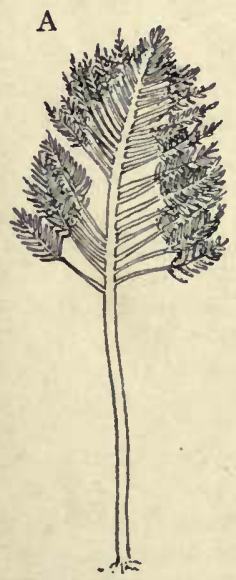

Fig. 85.-A, Bryopsis plumosa $(\times 2), \quad B$, Codium tomentosum, end of a filament with sporangium, sp. $(\times 50)$. C, gamete (?) $(\times 300)$. (C, after THURET.)

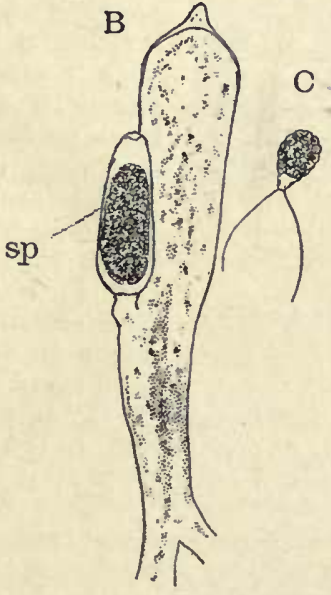

Marine Siphoneæ.-The most specialized of the Siphoneæ are marine. The beautiful feathery Bryopsis (Fig. 85, A), and the spongy-looking Codium, are the bestknown forms from the temperate seas. In the tropics, especially about coral reefs, the Siphoneæ reach their greatest development. Many of these forms, like Halimeda (Fig. 86), Penicillus, Acetabularia, are heavily incrusted with carbonate of lime, and play an important part in reef-building. 
In Caulerpa (Fig. 87) the plant resembles closely one of the higher land-plants, showing a creeping stem which produces roots from its lower side and leaflike branches from its upper surface. There is, however, no trace of cellular structure, the thick wall of the

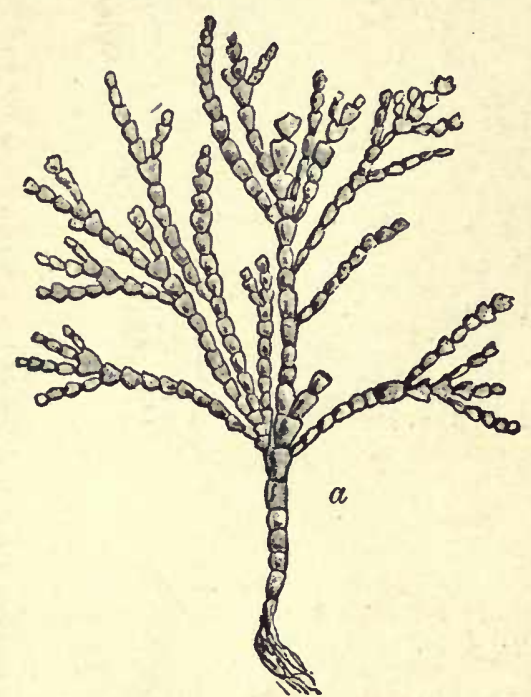

tubular thallus being supported by numerous threadlike braces, which traverse its interior.

In most of the large forms, like Codium (Fig. 85, B), Halimeda, and others, the thallus is composed of extensively branched, but nonseptate filaments, whose extremities are often composed of club-shaped, closely set branches which form a sort of cortex, or rind, upon the outside, while in the central part the filaments are much more slender and loosely interwoven.

Reproduction. - Non-sexual reproduction may be brought about by the separation of a portion of the thallus, this being the only form of

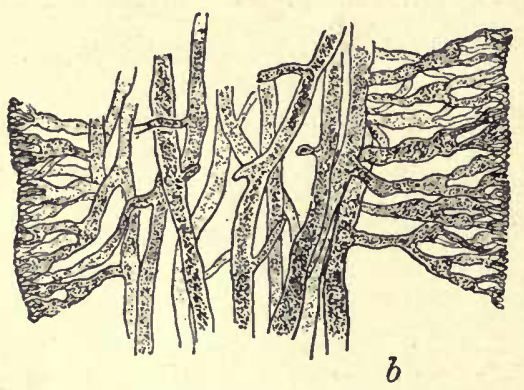

FIG. 86. $-a$, Halimeda monilis $\left(\times \frac{1}{2}\right) ; b$, longitudinal section, highly magnified. (After MURray.) reproduction known in Caulerpa. More commonly swarm-spores are produced, and in some instances aplanospores.

In Botrydium the whole protoplasmic contents of the plant may break up into swarm-spores, but in the higher forms a portion of the plant is shut off as a sporangium. The zoöspores in Botrydium have but a single cilium, or flagellum (Fig. 84, B), but in most Siphoneæ there are two. The very large zoöspores of Vaucheria (Fig. 88, D) have many cilia, but examination shows that these are in pairs, corresponding to the nuclei which are distributed in the colorless superficial layer of protoplasm. In this case the giant zoöspore is to be considered as a compound structure made up of many biciliate zoöspores. The zoöspores germinate at once.

Sexual Reproduction. - In Caulerpa no trace of sexual reproduction has been discovered, and our knowledge of many other marine forms is still incomplete. In Botrydium very small gametes are produced from aplanospores, which form in great numbers at the end of the growing period. These become red in color, and sometimes form a brick-red film upon the gronnd where the plants have been growing. They germinate quickly, after a proper period of rest, and the con- 
tents escape as numerous small biciliate gametes (F), which after conjugation germinate at once. A similar, but more complicated, type of reproduction occurs in the marine genus Acetabularia. In Codium and Bryopsis biciliate cells of two kinds are formed in special cells (Fig. 85, C). While the actual fusion of these cells has not been seen, it is highly probable that they are gametes. The larger ones are green, the smaller ones yellowish, in color.

The most highly developed reproductive organs occur in Vaucheria (Figs. 88, 89), where antheridia and oögonia of characteristic form are present, and the egg-cell has lost the power of motion and is retained within the oögonium. 'The latter is an oval cell, with a more or less definite beak at the apex. The antheridium is an elongated, often curved, cell, which may arise directly from a vegetative filament, or may be borne with the oögonium (or oögonia) upon a special branch (Fig. 89).

The young oögonium contains numerous nuclei, but before it is shut off from the filament, all but one of these retreat into the filament, leaving but a single nucleus in the oögonium. When ripe, the latter opens at the apex, and a portion of the contents is ejected. the remainder forming the egg (Fig. 89, C, D).

In the antheridia, which contain little or no chlorophyll, numerous minute spermato-

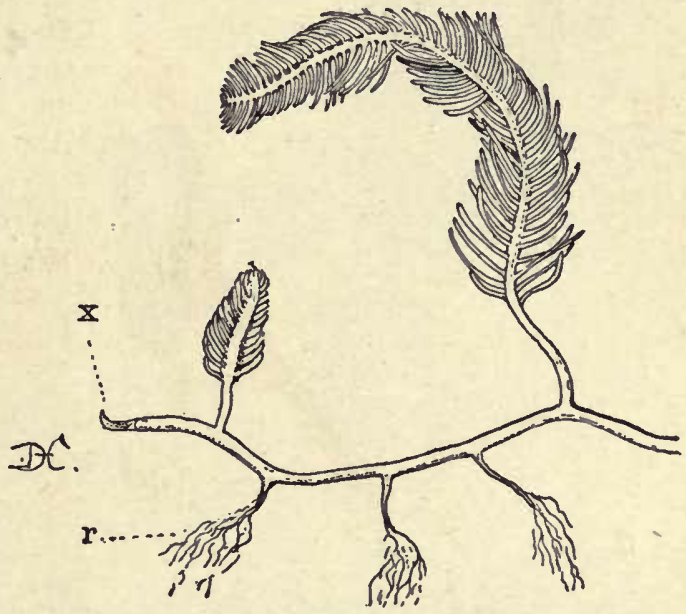

Fig. 87.- C'aulerpa plumaris. (Natural size.)

zoids are developed. They consist mainly of a nucleus, and possess two laterally inserted cilia. One of them penetrates the egg and effects fertilization. The egg now develops a thick membrane, loses its chlorophyll, and becomes . a resting-spore. This germinates by sending out a germ-tube, much as does the zoöspore.

\section{Classification of Siphoneæ (Engler and Prantl, 9)}

As the development of many of the Siphoneæ is still imperfectly known, their affinities are still somewhat doubtful. The following families are recognized: Botrydiaceæ, Phyllosiphonaceæ, Bryopsidaceæ, Derbesiaceæ, Vaucheriaceæ, Caulerpaceæ, Codiaceæ, Valoniaceæ, Dasycladaceæ. The Botrydiaceæ can be readily compared to the Protococcaceæ, while Vaucheria suggests some of the multinucleate forms among the Confervoideæ, especially the genus Pythophora. The affinities of most of the marine Siphoneæ are doubtful.

Phyllosiphon. - A very remarkable form is the genus Phyllosiphon, which resembles, in structure, Vaucheria, but is a parasite within the tissues of a species of Arisarum. In habit it closely resembles 
certain Fungi; and this, together with certain structural resemblances, suggests the derivation of some of the lower Fungi from Algæ.

\section{Order VI. Characeæ}

The Characeæ, or "Stoneworts," as they are sometimes called, on account of the abundant deposit of calcium-carbonate in many of

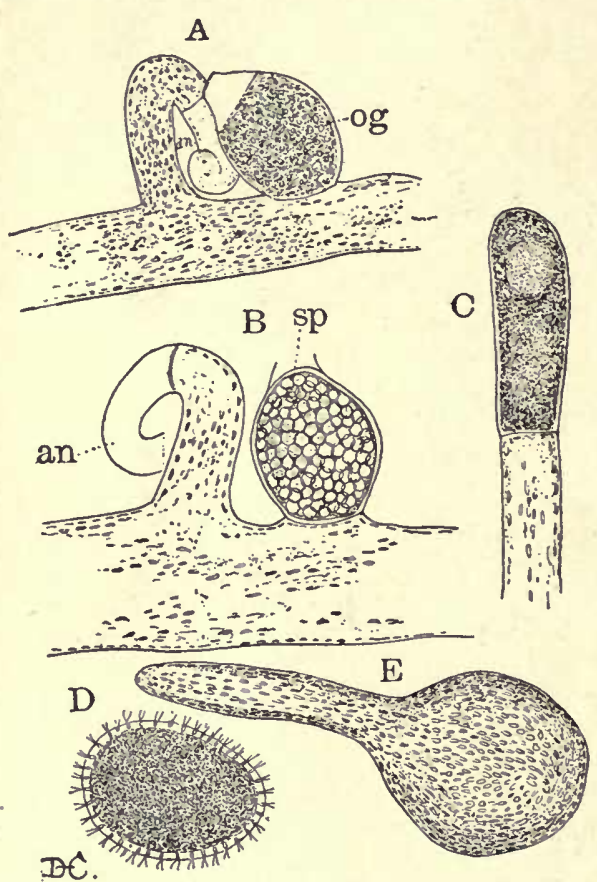

Fra. 88. - A, Vaucheria sessilis, with oögonium, $o g$, and antheridium, $a n(\times 200) . B, V$. aversa, with ripe oöspore, $s p(\times 200)$. C', zoösporangium of $V$. sessilis. $D$, active, $E$, germinating, zoöspores of $V$. sessilis. them, differ so much from the other Algæ as to make their position in the system very doubtful; and they are sometimes removed entirely from the Algæ.

The Characeæ are, for the most part, fresh-water plants of moderate size, usually a few centimetres in height, sometimes a metre or two in length. They all are much alike in structure, and the order is a very natural one.

The plants always grow from a single apical cell, and show a regular succession of nodes and internodes, with the lateral members growing in whorls from the nodes. The lateral appendages are usually of two kinds: branches of limited growth (usually called leaves) and a smaller number of branches which are, in their structure, entirely similar to the main axis from which they spring. The plant is fastened to the ground by numerous colorless roots.

Cell-structure. - The cells of the Characeæ may reach a very large size; the long internodal cells sometimes attain a length of ten centimetres or more, with a diameter of nearly a millimetre. In all of the cells exposed to the light there are numerous oval chromatophores, arranged in rows, usually running obliquely (Fig. 93, C). At one place, marking the boundary between the ascending and descending parts of the rotating protoplasm within the cell, is a 
strip quite destitute of chromatophores, known as the neutral zone, as here no movement can be detected. The cytoplasm forms a thick layer within the cell-wall surrounding the single, very large vacuole. The chromatophores are embedded in the outer layer, which shows no movement; but below this a thick layer of soft, very granular protoplasm is seen to be in active rotating movement, the whole mass moving in a single current. Numerous large nuclei, as well as other protoplasmic bodies, - some of peculiar form, like little spiny balls, - are carried along in the protoplasmic current.

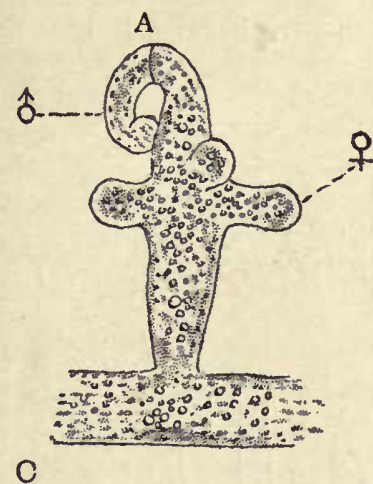

B

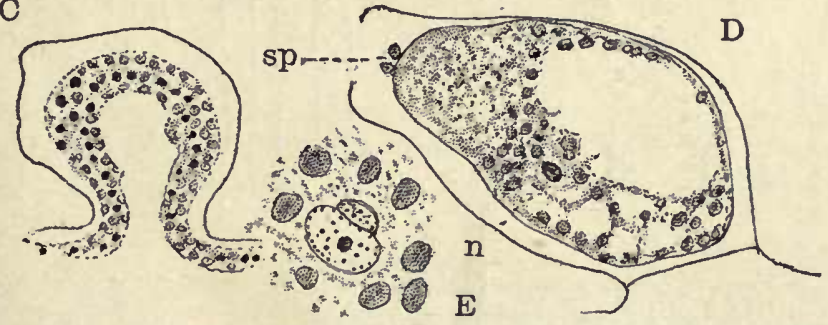

Fra. 89. - $A, B$, Vaucheria geminata, showing the development of the sexual organs. $C$, young oögonium of $V$. clavata; the nuclei are shown black. $D$, an open oögonium, with a single nucleus, $n$; $s p$, two spermatozoids. $E$, conjugation of the sexual nuclei, more highly magnified. ( $C-E$, after Ortmanns.)

Nuclei. - In the young cells there is a single large nucleus, of the ordinary form, which divides by mitosis when new cells are formed. In the large cells, however; the nucleus undergoes repeated direct division, or fragmentation, resulting in numerous large nuclei, often of very irregular form (Fig. 90, B).

Apical Growth. - All of the organs of the plant grow from an apical cell, which, in the larger shoots, has the form of a hemisphere (Fig. 90, B, v). From its base segments are cut off, in regular succession, by transverse walls. Each disk-shaped segment divides quickly by a second transverse wall, which is usually convex 
upward, into an upper cell $(x)$, from which the node arises, and a lower internodal cell $(y)$, which undergoes no further division, but finally increases enormously in size. In many species of Chara the long internodal cell is covered by a cortex, or rind, but in the other genera the cortex is very incomplete, or quite wanting.

All of the lateral organs are outgrowths of the nodes. The primary nodal cell in the stem of Chara (Fig. 90, B, C) divides first by a vertical wall into equal parts. From these two cells, by repeated division, a series of peripheral cells is cut off, so that a transverse section of the young node shows two central cells and a circle of peripheral cells of different ages. Each peripheral cell becomes the

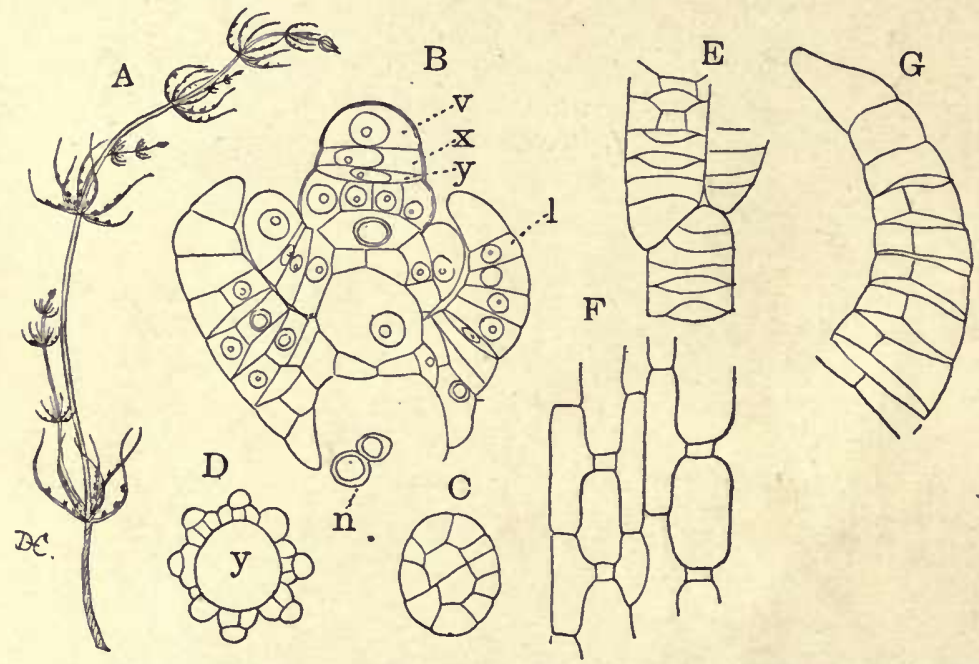

Fig. 90. - Plant of Chara fragilis (natural size). $B$, longitudinal section of stemapex of Chara sp.; $v$, apical cell; $x, y$, node and internode of youngest segment; $l$, a leaf $(\times 200) . C$, cross-section of a young node. $D$, cross-section of older internode, slowing cortex $(\times 50)$. $E$, young cortical lobes $(\times 200) . F$, older cortex of C. fragilis. $G$, longitudinal section of young leaf.

apical cell for a lateral branch or leaf, and divides very much like the apical cell of the main shoot, except that the divisions in the nodes are somewhat fewer, and the apical cell, after a certain number of segments have been cut off, ceases to divide further, and elongates to form the pointed terminal cell of the leaf (Fig. 90, G).

From the nodes of the leaves leaflets are developed, which may, in some cases, be replaced by the reproductive organs.

Cortex. - In most species of Chara the basal node of each leaf gives rise to two peculiar branches, which grow one upward and one down, closely appressed to the outer snrface of the internodes, which they completely conceal. The growth of these branches, or corti- 
cal lobes, is also apical, and nodes and internodes are developed (Fig. 90, E). The internodes, and sometimes the lateral nodal cells, become much elongated, and form the fluted cortex so conspicuous in Chara. The central nodal cells always remain short, and may give rise to spines or bosses, which encircle the stem at regular intervals. Upon the outer surface of the cells carbonate of lime is often present, deposited in large, irregular masses, which make the whole plant rough and brittle.

Branches. - Besides the leaves, or branches of limited growth, there are also formed branches like the main axis (Fig. 90, A). These always arise in the axil of the oldest leaf of a whorl (occasionally also from the next oldest). In Chara the branch replaces the upper cortical lobe of the oldest leaf of each whorl.

Roots. - The roots consist of slender filaments, also showing apical growth, which grow from the lower stem-nodes. The cells are destitute of chlorophyll, and the rotation of the protoplasm is exceedingly active.

\section{Reproduction}

No special non-sexual spores occur in these plants. Special budlike organs are sometimes developed from the old nodes, or upon the roots. These may be single cells, or multicellular bodies, with the cells filled with starch. Such resting-buds, or bulbils, give rise to new plants under favorable conditions. From almost any part of the plant, also, especially in old specimens, there may be developed the so-called "Pro-embryos," simple filaments from which a new plant grows, much as it does in the germination of the resting-spore, and branches with uncorticated base sometimes become detached and form new plants.

Sex-organs. - All of the Characeæ show very highly developed sexual reproductive organs, antheridia and oögonia of great complexity, and not closely resembling those of any other plants. They are always outgrowths of the leaves, and in their earliest stages show the same type of growth. Their structure is very uniform throughout the order.

In Chara they ordinarily occur in pairs (Fig. 91, B) on the upper side of the leaf-nodes. A section through the young complex shows that the antheridium replaces a leaflet, and that the oögonium is an outgrowth of its basal node, thus representing a leaflet of a lower order. In Nitella the antheridium is terminal upon a leaf, and the oögonia arise as leaflets about its base (Fig. 94, B).

Antheridium. - The young antheridium (Fig. 91, C-E) consists of a basal node and internode, above which is the globular apical cell separated from the node by an intermediate segment. The globular apical cell divides longitudinally into equal parts, these next divide transversely, and again vertically, so that 
the body of the antheridium is composed of eight cells. Each of these octants divides by a periclinal wall with an outer and inner cell (Fig. 91, C), and the latter of these by a secoud periclinal wall into two more. 'Thus each octant is divided into three concentrically arranged cells (D). The cell between the body of the antheridium and the basal node pushes up between the cells of the antheridium and becomes later very conspicuous (Fig. 91, E).

As the antheridium increases in size, the eight outer cells become much expanded laterally and form as many triangular plates, with deeply infolded cell-

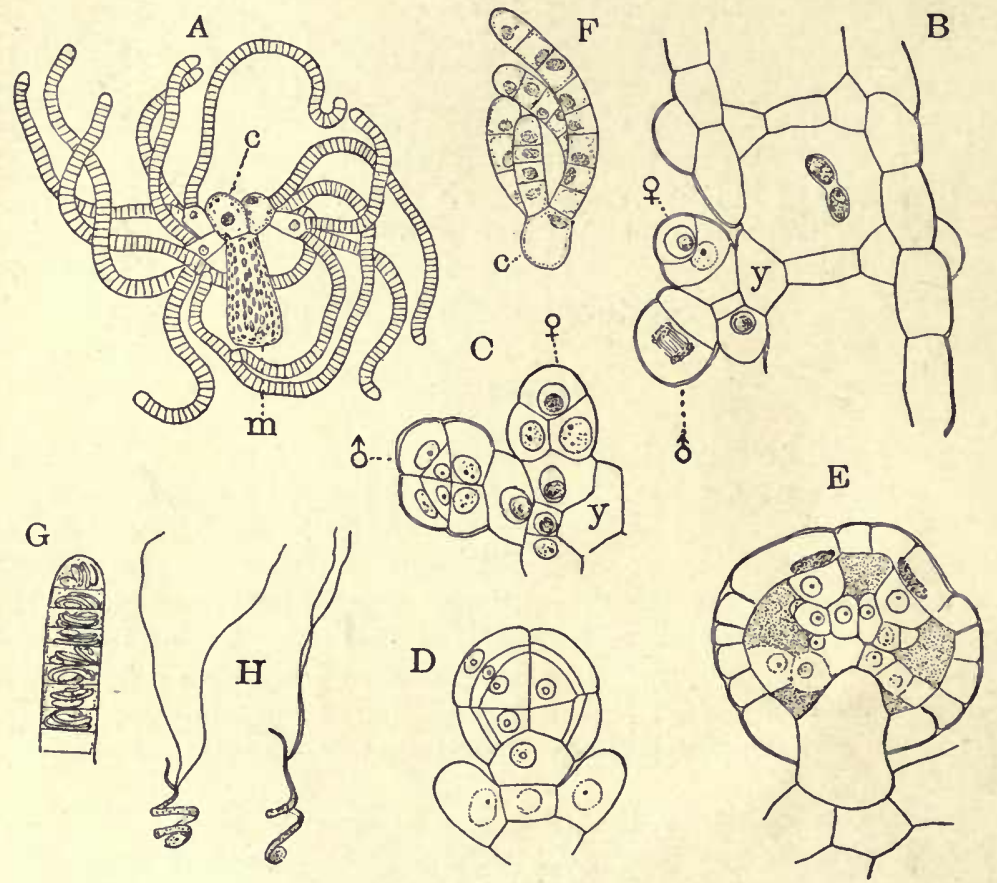

Fig. 91. $-A$, manubrium, $m$, of Chara $s p$., bearing numerous spermatic filaments attached to the capitula, $c(\times 75)$. $B$, longitudinal section of a young leaf of C. fragilis, showing the position of the sexual organs ; these arise from the basal node of a leaflet, which is joined to a node of the leaf by the basal internode, $y$ $(\times 200)$. $C, D, E$, development of the antheridium, seen in longitudinal section $(\times 200)$. $F$, secondary capitulum, $c$, with four young spermatic filaments. $G$, end of a ripe spermatic filament, showing the spermatozoids within the cells $(\times 500)$. $H$, two free spermatozoids $(\times 500)$.

walls, constituting the so-called "Shields," of which the antheridial wall is made up. The chromatophores within these cells, as well as those in the second series of cells, the Manubria, become of an orange-scarlet color as the antheridium ripens, and make it very conspicuous.

The manubrium (Fig. 91, A, $m$ ), or second cell of each octant, remains undivided, increases much in length but very little in breadth, and forms a clubshaped cell attached to the middle of each shield and projecting into the cavity of the antheridium. 
The innermost series of cells undergo extensive changes. Each one usually divides into two, which are known as the "Capitula" (c), and from these bud out numerous branches which may become at once divided into many cells by a series of transverse divisions; or the branches may form sccondary capitula, which in turn develop several (usually three or four) of the long filaments (F). In eacl cell of the filaments, which form a tangled mass filling the antheridium, there is developed a single large spermatozoid $(G, H)$. These arise inainly from the nucleus of the sperm-cell by its becoming elongated and coiled, but the two long cilia and part of the body of the spermatozoid arise from the cytoplasın.

When the antheridium is quite ripe, the shields separate, and expose the filaments to the water, and the slender, spirally coiled spermatozoids escape througl a pore in the wall of the sperm-cell.

Oögonium. - The oögonium, in Chara (Fig. 92), represents a leaflet springing from the basal node of the antheridium. It also produces a basal node, and internode. The former consists of a central cell and five peripheral ones. The latter elongate and form a covering about the apical cell, which becomes the oögonium proper. The five elongated cells which surround the oögonium become spirally twisted, and from the upper end of each is cut off a cell, which with the others form the five-celled crown at the apex (Fig. 92, C). In the Nitelleæ a second crown-cell

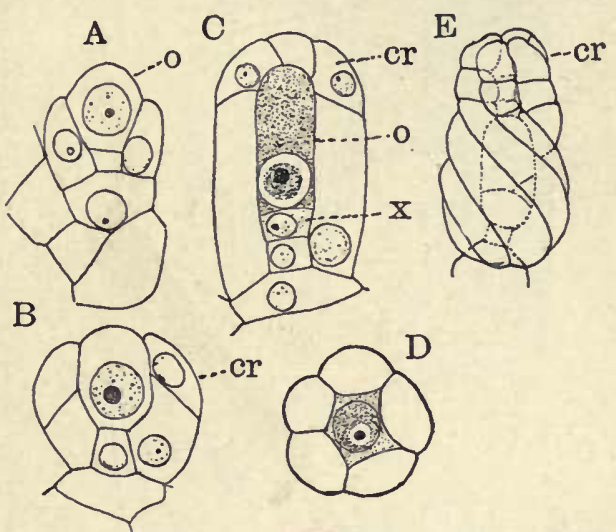

Fig. 92. $-A-D$, development of the oögonium in Chara sp. $A-C$, longitudinal sections; $D$, crosssection $(\times 200)$. E, young oögonium of Nitella sp. $(\times 200) ; 0$, egg-cell; cr, crown-cells.

is cut off from each of the long cells, so that the crown is composed of two tiers of cells which are sometimes thrown off (Fig. 92, E).

From the base of the oögonium in Chara a flattened cell (Fig. 92, C, x) is cut off, and in Nitella two or three. The larger cell then becomes the egg-cell and contains a very large nucleus, and is filled with large starch-granules and oildrops, which make it very opaque. The upper part, however, is comparatively free from granular contents, and forms the receptive spot.

Fertilization. - When ready for fertilization the long cells about the oögonium separate somewhat below the crown, with a slight elongation at this point. Five clefts are thus formed below the crown through which the spermatozoids enter the space above the apex of the oögonium. The wall of the latter becomes softened at the apex so that the spermatozoid can penetrate into the egg, with whose nucleus it fuses. The egg now becomes a resting-spore, and the inner walls of the surrounding cells become hard and woody, and sometimes the walls also are silicified. As the fruit ripens, the chromatophores sometimes become red or yellow. Finally the outer 
cell-membranes of the sheathing cells decay, leaving the hardened inner walls projecting from the surface of the spore like the threads of a screw (Fig. 93, A).

The ripe spore-fruit falls to the bottom of the water, and after a few weeks is capable of germination. 'The spore-contents first divide by a transverse wall into a large basal and a smaller apical cell. The latter contains but little granular contents, and soon

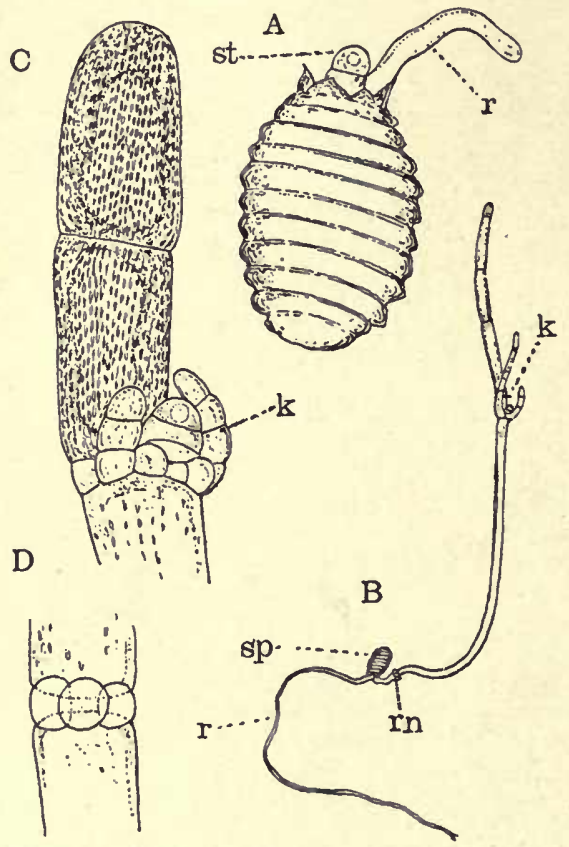

Fig. 93. $-A$, germinating spore of Chara $s p$. ; $s t$, apex of pro-embryo; $r$, primary root $(\times 40) . B$, an older stage; $s p$, spore; $r n$, root-node of pro-embryo; $k$, lateral bud which is to form the permanent axis $(\times 6)$. $C$, apex of pro-embryo, showing the lateral bud, $k(\times 85) . D$, root-node of the same pro-embryo.

In the Nitelleæ, represented by the genera Nitella and Tolypella (Fig. 94), the stem is always without cortex, and the oögonium has ten crown-cells. In the Chareæ, whose most important genus is Chara, there are but five crowu-cells, and a cortex is gemerally present.

In one species of Chara, $C$. crinita, the oöspores are developed without fertilization - one of the few well-authenticated cases of parthenogenesis. divides again by a vertical wall into two cells, one of which elongates, bends down, and forms a root, fastening the young plant to the mud. The other cell (Fig. 93, A, st.) develops chlorophyll, elongates upward, and by repeated divisions gives rise to a short, simple filament - the "Proembryo," or "Protonema." This develops two nodes, from the basal one (Fig. 93, D) of which roots are developed, while from the upper one is formed a whorl of branches, one of which soon assumes the character of the perfect shoot, the original apex of the pro-embryo not developing any further (Fig. 93, B, C, k).

\section{Classification of Characeæ (Engler and Prantl, 9)}

Two families of the Characeæ are recognized, but they are very closely related. 


\section{Affinities of Characeæ}

The Characeæ show no very evident affinity with any other group of plants. Perhaps, on the whole, they most nearly resemble some of the Siphoneæ, but the relationship, if it exists, is very remote. Certain resemblances in the reproductive organs have suggested a possible affinity with the Mosses, but this is, to say the least, exceedingly problematical.

Fossil Characeæ. - Abundant remains of Characeæ are found fossil, but not in the older formations, and all remains so far discovered are closely related to existing forms, and throw no light upon the origin of the group.

\section{Class II. Phaophycea (Brown Alge)}

Except the Diatoms and some of the Peridineæ, which may possibly be very remotely related to the true Phæophyceæ, the Brown Algæ are essentially marine plants, and, with the Red Algæ, make up the bulk of the shore vegetation of the Ocean. Among the Phæophyceæ are found some of the giants of the vegetable kingdom.

Color. - The Brown Algæ, as their name indicates, possess, in addition to the chlorophyll, certain brown or yellow pigments, of which two are demonstrable, phycoxanthine and phycophrine, the latter being soluble in fresh water. The mixture of these pigments has been termed "Phæophyll."

Plant-body. - None of the true Phæophyceæ are unicellular, the sim-

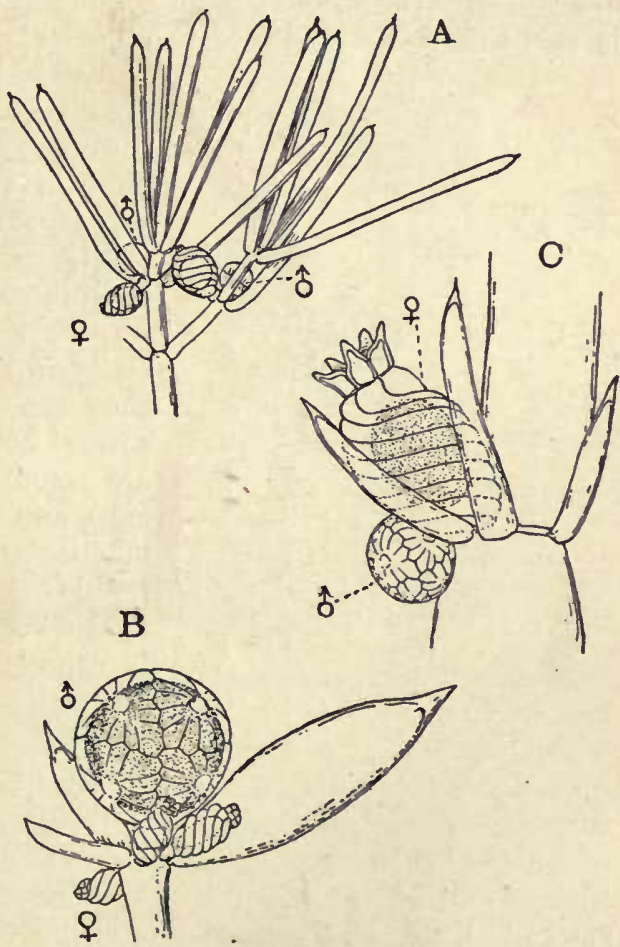

Fig. 94. $-A$, Tolypella $s p .(\times 20) . \quad B$, Nitella $s p$. $C$, Chara coronata $(\times 40)$. $\uparrow$, oögonium; ô, antheridium.

plest being cell-rows, as in Ectocarpus, or flat disks (e.g. Phycocelis). 
The larger Kelps and Fucaceæ have a highly developed body, with a leaf-bearing axis suggestive of the flowering plants. Between these extremes are many intermediate types. The plants are usually attached, the holdfasts, or hapteres, of the larger forms being stout branched roots, which anchor them very securely ( $\mathrm{Pl}$. 2). In many of the larger forms, air-vesicles are developed which act as floats, and in the attached forms bring the leaves to the surface of the water, where they may be exposed to the action of the light. While the leaves of these Algæ are structurally very different from those of the vascular plants, they serve the same purpose, being true assimilatory organs.

In size, some of the Kelps rival the giants among terrestrial plants. The great Bladder-kelp, Nereocystis (Fig. 98), of our own Pacific coast is sometimes forty to fifty metres in length, but is exceeded by the Giant-kelp (Macrocystis pyrifera), which also occurs along nearly the whole Pacific coast, and in the south Atlantic, and is said to attain a length of two hundred to three hundred metres.

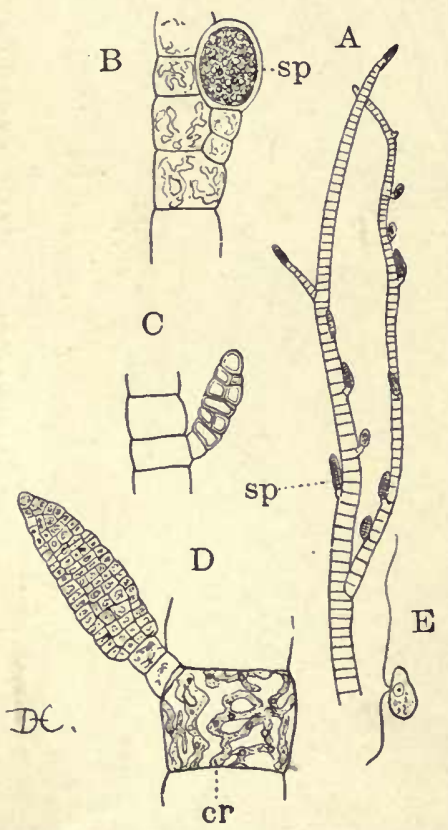

Fig. 95. $-A$, Ectocarpus granulosus $(\times 35)$; sp, sporangia. $B$, a unilocular sporangium, more highly magnified. $C, D$, plurilocular sporangia. $E$, gamete of $E$. siliculosus. ( $E$, after BERTHOLD.)

Distribution. - The Phæophyceæ are generally distributed thronghout the ocean, but are perhaps more abundant in the cooler and temperate waters, this being especially true of the larger Kelps. The Fucaceæ, on the other hand, are common in the warmer seas. Many species, especially in colder regions, grow where they are exposed by the tides for several hours at a time. Such forms are tough and leathery in consistence, and develop a large amount of mucilaginous matter which prevents rapid loss of water.

The Pacific coast of North America is especially rich in Phæophyceæ, especially the Kelps, of which a number of peculiar genera occur. Some of these, like the curious "Sea-palm" (Postelsia palmoformis) (Pl. 2), grow attached to rocks which are exposed to heavy s'irf, and we find in these forms an extraordinary development of the holdfast. A small number of Phæophyceæ, of which the best known is the Gulfweed (Sargassum bacciferum), of the 
warmer Atlantic, are found floating in great masses. It seems still somewhat questionable whether these masses are derived from originally attached plants, or whether they spend their whole existence floating on the surface.

Cell-structure. - The simpler Phæophyceæ are composed of mostly uniform cells, uninucleate, and within their cell-membrane several chromatophores may be seen, generally small oval disks, less commonly elongated, somewhat ribbon-shaped. Rarely but a single chromatophore is present. Sometimes, as in Ectocarpus, pyrenoids like those of the Chlorophyceæ are present.

Among the highly developed large Kelps and Fucaceæ, the tissues

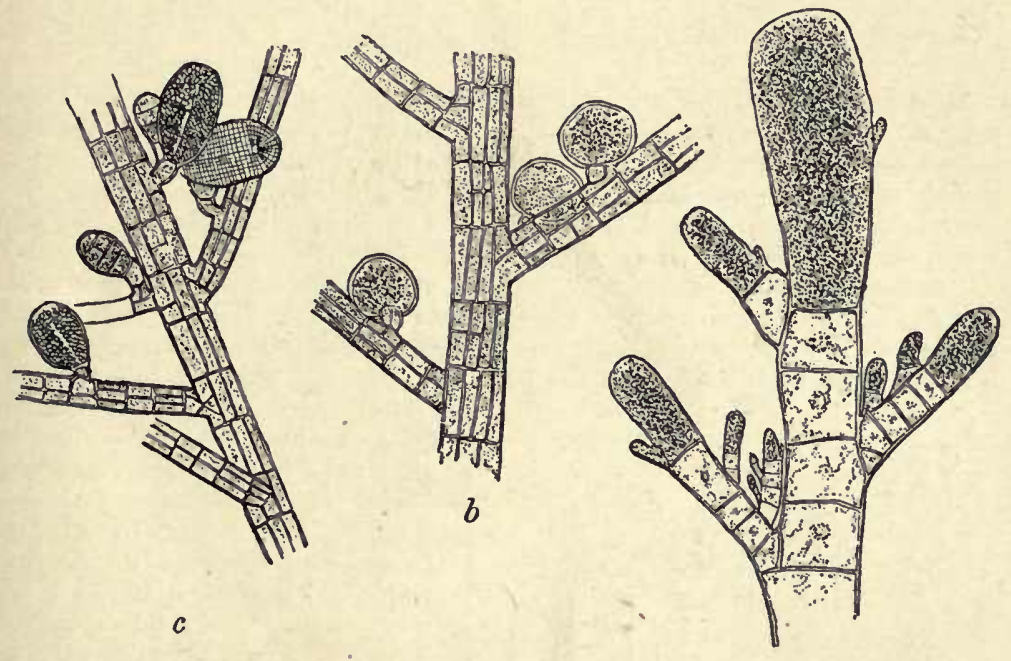

$a$

Frg. 96. - $a$, Sphacelaria filicina, top of filament; $b$, S. cirrhosa, showing unilocular sporangia; $c$, the same, showing plurilocular sporangia. (After Murray.)

are correspondingly well developed, assimilating, conducting, and mechanical tissues being demonstrable.

Reproduction. - Much the same development of the reproductive parts is seen as we have observed among the Chlorophyceæ; but on the whole, notwithstanding their very highly developed vegetative structures, the reproductive organs are simpler than in the Chlorophyceæ. Zoöspores, with two laterally attached cilia, occur in many of them (Fig. 99, D), but are not known in the Fucaceæ, the highest order. In some of the orders they are the only forms of reproductive cells known, this being the case in all of the giant Kelps.

Where sexual cells are produced, they are always ejected into the water when fertilization is effected. There is much the same 
evolution of the sexual cells that is found in certain groups of Chlorophyceæ. Thus in Ectocarpus (Fig. 95) the gametes are entirely similar; in Cutleria (Fig. 100) both gametes are motile, but one is much larger than the other, while in Fucus (Fig. 104) there is still greater difference in size, and the egg-cell is not ciliated.

The zygote developed from the union of the gametes grows at once into a new plant. The Phæophyceæ, never being exposed to complete desiccation or to great changes of temperature, do not need to develop resting-spores, such as characterize most of the freshwater Chlorophyceæ. The Phæophyceæ are divided into two orders, Phæosporeæ and Cyclosporeæ.

\section{Order I. Phæosporeæ}

Ectocarpaceæ. - The family Ectocarpaceæ include the simplest of the Phæosporeæ. Of these the genera Ectocarpus and Pylaiella are perhaps the best known. The plant-body in these genera consists of extensively branching filaments, which are sometimes prostrate and creeping, but more commonly are erect. The chromatophores are either disks or somewhat irregular bands in which are imbedded conspicuous pyrenoids.

The plants branch extensively, the cells at the ends of the branches being often tapering. Cell-division is most active in the basal part of the branches, where the cells are usually shorter. In some of the larger forms, slender branches grow downward from the base of the lateral branches and form an

A

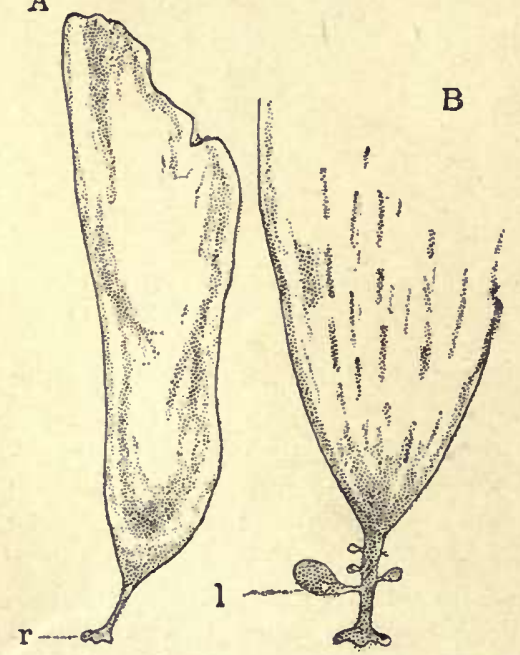

Fıg. 97. $-A$, Egregia Menziesii, young plant, natural size; $r$, holdfast. $B$, older plant with young leaves, $l$. imperfect cortex over the larger cells.

Sphacelariaceæ. - In the Sphacelariaceæ the growth is apical, the apical cell being extremely large, and may even show the beginning of the lateral branches before any actual division has taken place (Fig. 96). In the segments cut off from the apical cell longitudinal as well as transverse walls may be formed, so that the plant-body is no longer a simple cell-row as in Ectocarpus.

Laminariaceæ. - The commonest and largest of all the Phæophyceæ are the Laminariaceæ, or Kelps. They are common on rocky coasts in all the cooler seas, and reach an extraordinary development upon our own Pacific coast, where a number of peculiar genera occur. In the Atlantic the various species of Laminaria are the common representatives of the family; but in the Pacific, in addition to Laminaria, 


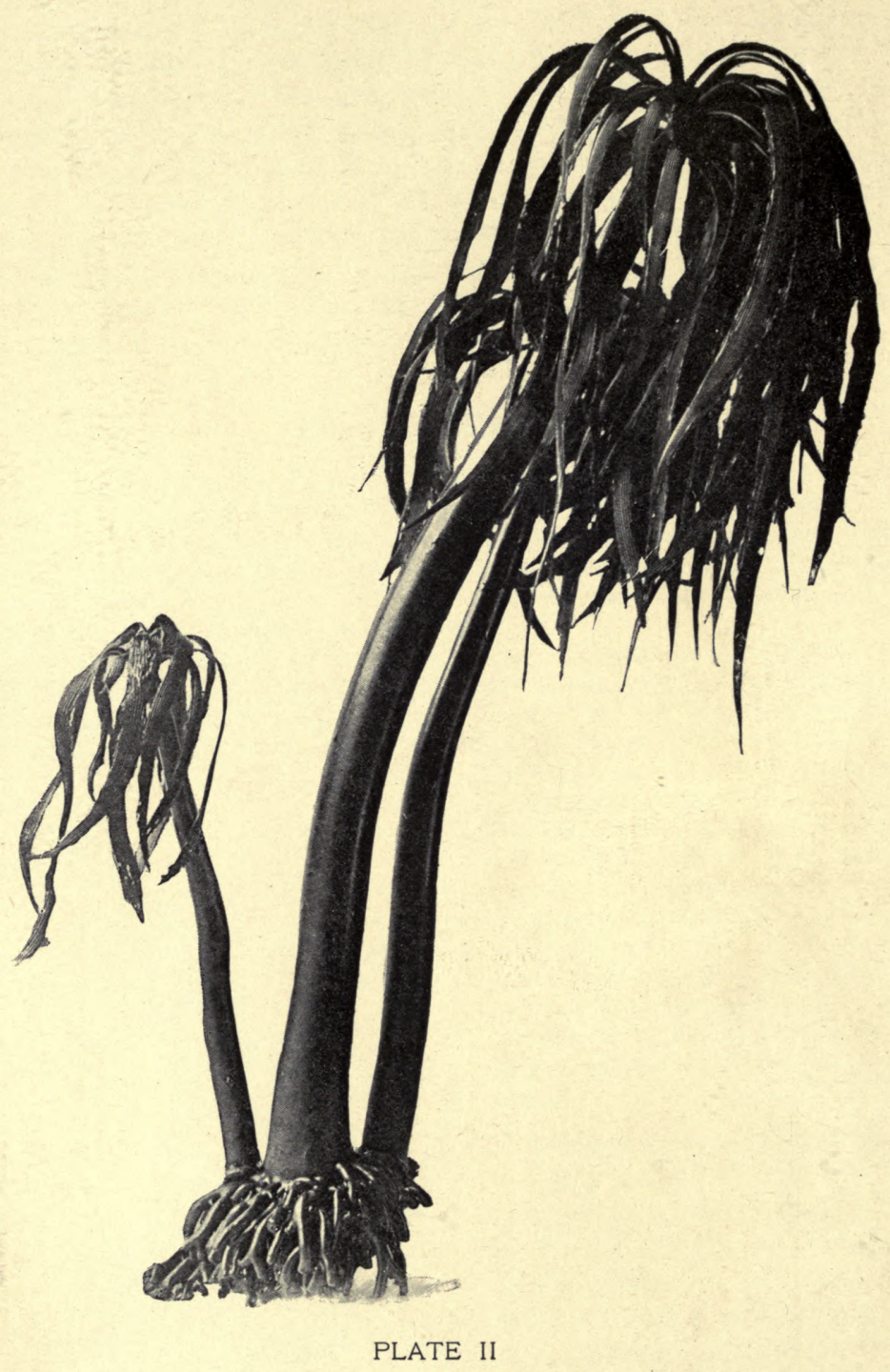

Postelsia palmaformis, a characteristic Kelp of the Californian coast. (Photograph by Dr. W. R. Shaw.) 
there are the giant Kelps (Lessonia, Nereocystis, Macrocystis, etc.) as well as other genera (e.g. Egregia [Fig. 97], Postelsia) which are quite unrepresented in the Atlantic.

The plant in all of these forms is very large and shows a high degree of differentiation. In Laminaria it consists of a cylindrical stalk expanding above into a leaflike lamina, and attached by a large rootlike holdfast. Similar to Laminaria, in general structure, are Egregia (Fig. 97) and Alaria, which have in addition to the

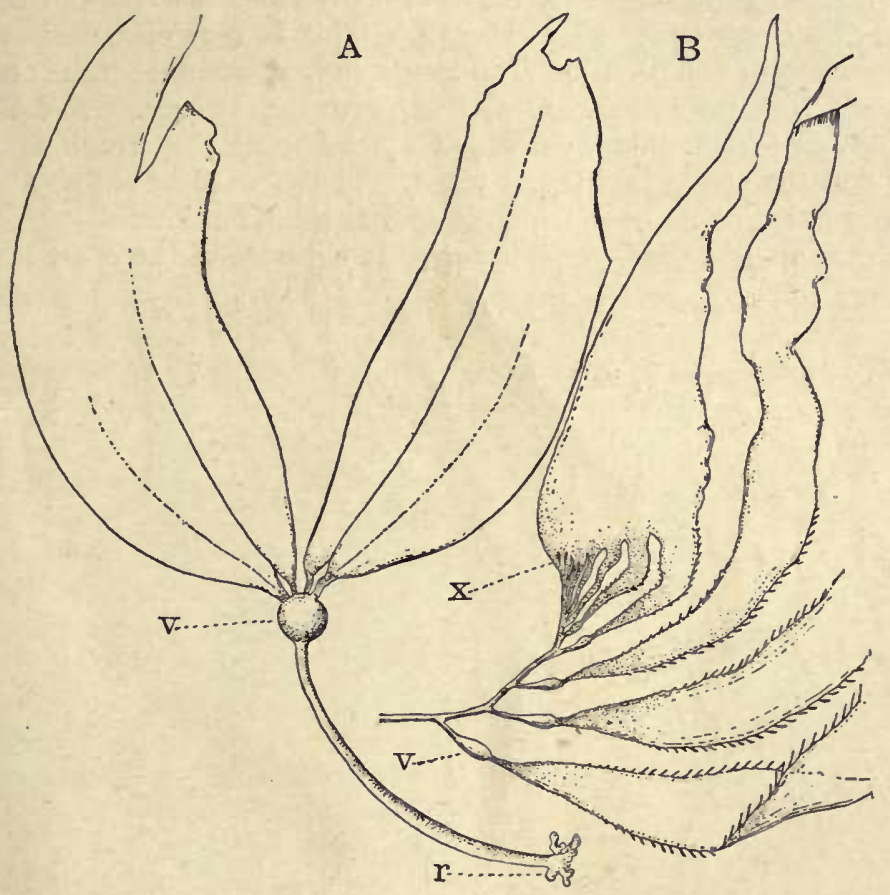

Fig. 98. $-A$, Nereocystis Lütkeana, young plant, reduced; $r$, holdfast. $B$, Macro. cystis pyrifera, tip of branch, showing the growing-point $\left(\times \frac{1}{8}\right) ; v$, air-vesicles.

single leaf-like lamina, numerous small lateral leaves growing from the stem. In Egregia some of these are sporophylls, and some are modified into air-vesicles.

Lessonia and Macrocystis branch extensively, and reach a very large size. Nereocystis (Fig. 98), a very conspicuous Kelp of the northern Pacific, has an enormously long stem, tapering to the large holdfast, and having the hollow upper portion enlarged at its upper end into a globular float as big as a croquet ball. To this are attached large leaves, three or four metres long. 
Tissues of Laminariaceæ. - The tissues of the Laminariaceæ are well developed. The outer tissues are composed of small, closely set cells, which contain numerous chromatophores, and constitute the assimilative tissue. Within this layer the cells are very much larger, and more delicate, and contain but few chromatophores. 'The central part forms a sort of pith with loosely woven elongated cells, some of which are elongated elements, closely resembling the sieve-tubes of the higher plants, and probably serving much the same purpose. The outer tissues are generally tough and flexible, so that the plants can endure the beating of the surf without being injured (Fig. 99).

The formation of the leaves is in many cases the result of a splitting of an originally entire lamina. This is very clearly shown in Macrocystis (Fig. 98, B). The sickle-shaped terminal piece of each branch consists largely of actively growing tissues. Short slits appear at regular intervals, which extend until they reach the margin and the young leaf is separated. The young leaf shows a slight enlargement at its base, which is at first solid, but later develops into the pear-shaped float which is found at the base of the older leaf.

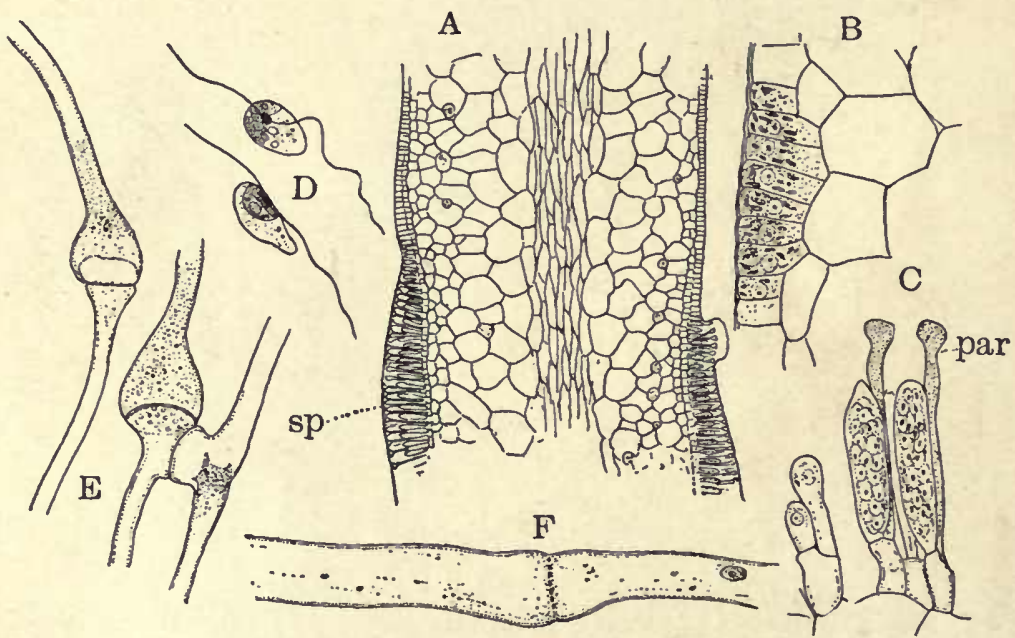

Fic. 99. - A, Nereocystis Lütkeana, transverse section of leaf, showing sporangia, $s p$.

$B$, outer tissue of leaf, more highly magnified. $C$, sporangia and paraphyses, par $(\times 500)$. D, Chorda filum, zoöspores $(\times 1000)$. E, Egregia Menziesii, trumpethyphæ $(\times 500) . \quad F$, Postelsia palmæformis, sieve-tube $(\times 500) . \quad(D$, after REINKE.)

\section{Reproduction}

Most of the Phæosporeæ give rise to biciliate zoöspores, which are formed in the so-called unilocular sporangia (Fig. 99, C). The nucleus of the sporangium divides repeatedly, and this is followed by the division of the cytoplasm, but no cell-walls are formed. The zoöspores are usually oval, or kidney-shaped, and have two lateral 
cilia. In the Kelps the sporangia are formed in dense masses (Fig. 99, A), either on the ordinary leaves, or upon special sporophylls. The sporangia are formed singly at the base of club-shaped hairs, or paraphyses. These are the only reproductive bodies known in the Laminariaceæ.

In many of the Phæosporeæ, however, there are formed the plurilocular sporangia, or, perhaps more correctly, gametangia, as it seems probable that the cells developed from these are gametes. In Ectocarpus the young gametangium is a short lateral branch, divided transversely into several cells (Fig. 95, C, D). In these, series of longitudinal and transverse walls arise, resulting in a large number of nearly cubical cells, each of which gives rise to a biciliate cell, much like the non-sexual zoöspores, but probably always incapable of developing further without fertilization, although this has only been demonstrated in a small number of forms.

The resulting zygote germinates at once, as do the zoöspores.

Germination. - So far as the development of these forms has been followed, the germinating spore develops first a cell-row, which, in the larger forms, like the Kelps, soon produces a flat thallus. This gradually assumes the characters of the mature plant. Nereocystis (Fig. 98, A) will illustrate the more important points. The young plant shows the stem, with the branching root, and above it the expanded lamina. The point of most active growth is at the junction of the stem and lamina. Here, by active growth, the first indication of the float is formed, and growth is very active at the base of the lamina, which soon splits along the middle line into two equal parts. These divide repeatedly in the same way, so that two bunches of leaves are finally produced.

In some of the perennial forms, like Laminaria, which renews the lamina each year, and Lessonia, the stem increases annually in thickness, and a section shows a series of rings curiously like those in the woody stems of the higher plants.

\section{The Cutleriaceæ}

Intermediate in some respects between the typical Phæosporeæ and Fucaceæ is a small family, the Cutleriaceæ. The
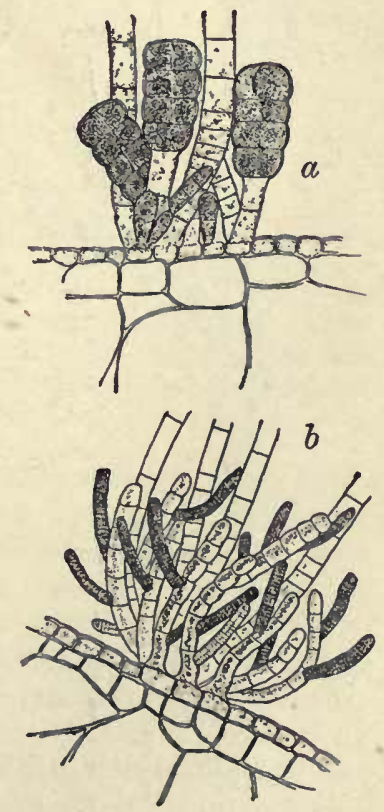

Frg. 100.-Cutleria multifida: $a$, female sorus; $b$, male sorus, highly magnified. (After Murray.) 
plant-body in Cutleria (Fig. 100) is a flat, dichotomously branched thallus, growing by intercalary divisions, much as in the Ectocarpaceæ. Zoöspores, like those of the other Phæosporeæ, are formed, and the gametangia are very similar, but are of two kinds, producing gametes of very unequal size, although both male and female gametes are ciliated.

\section{Order Cyclosporeæ}

The Fucaceæ comprise the most specialized, and next to the Laminariaceæ, the largest of the Phæophyceæ. They are distinguished

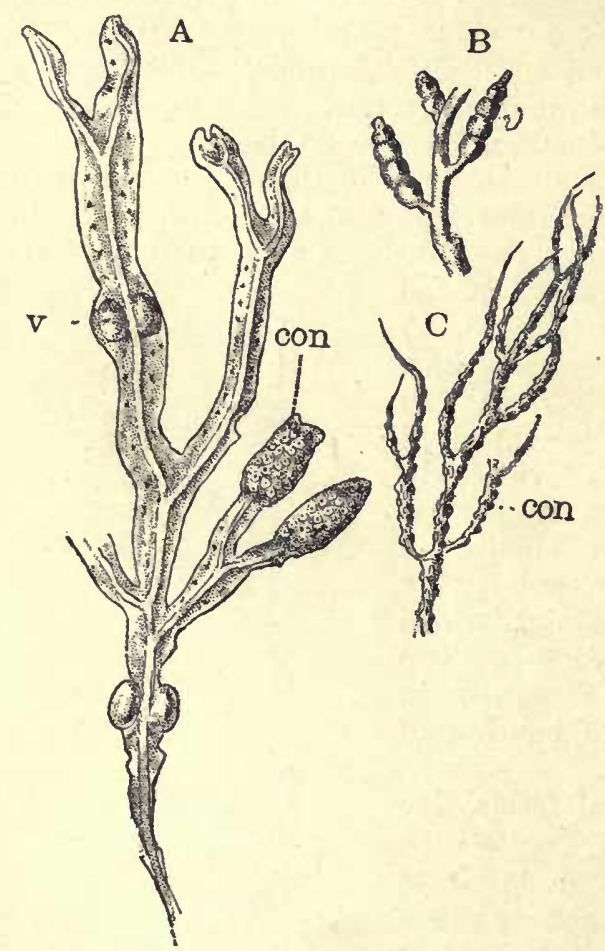

Fic. 101. - A, Fucus vesiculosus. B, C, Halidrys Osmundacea; $v$, vesicles; con, conceptacles. by having the egg-cell very much larger than the spermatozoids, and destitute of cilia.

The best known of these are the Rockweeds of the genus Fucus, which are widely distributed through the colder waters of the northern hemisphere. Another familiar form on our northern Atlantic coast is Ascophyllum nodosum, whose slender rubberlike branches, with large airvesicles at intervals, hang down from the rocks at low tide. In the warmer seas the Fucaceæ are represented by numerous genera, the largest being Sargassum. S. bacciferum, the Gulfweed, is common floating in the Gulf Stream.

The species of Fucus (Fig. 101, A) have a dichotomously branched thallus, tapering below into a stout stalk, which is attached by a disk. The branches are either nearly cylindrical or, in some species, flattened, with a prominent midrib and thin, winged margins. There may be seen, in some species, little tufts of fine hairs scattered over the thallus, and these are found to project from small pits (Cryptostomata), within which 
their bases are concealed. Similar cryptostomata have been found in some of the Phæosporeæ.

In Sargassum (Fig. 102) and Cystophyllum the much-branched axis has attached to it numerous leaflike appendages, so that the appearance of the plant is much like that of the ordinary terrestrial Flowering Plants. Where air-vesicles are present they may be buried in the thallus, as in Fucus vesiculosus (Fig. 101, A), or are borne upon short lateral branches, as in most species of Sargassum (Fig. 102).

Apical Growth. - Growth in the Fucacer is apical and due to the division of a single large apical cell. This in Fucus is situated at the bottom of a little pit at the end of the branches. The cell here (Fig. 103) has the form of a truncated wedge, whose outer face is oblong, the long axis being at right angles to the broad surface of the branch. Segments are cut off from the lateral pieces, and also from the inner truncate edge. The young segments divide rapidly and produce a mass of small-celled tissue surrounding

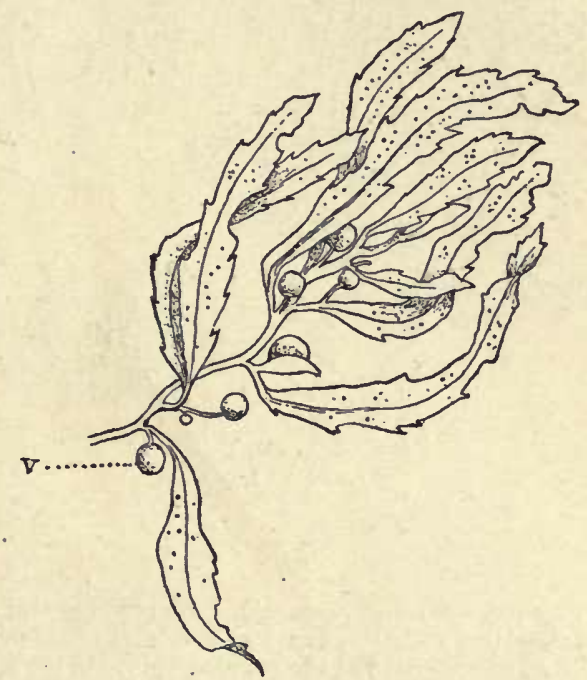

Fig. 102.-Sargassum sp.; $v$, air-bladders. (About natural size.)

the apical cell. These cells gradually pass into the tissues of the older parts.

The tissues of the mature parts closely resemble those of the Kelps. There are several layers of small cells joining the outside tissue, and these contain most of the chromatophores. The inner cells are elongated, and their cell-walls are highly gelatinous. Sieve-tubes may also be present.

Reproduction. - None of the Fucaceæ develop zoöspores, but small pieces of the plant may become detached and form new individuals.

The sexual organs are antheridia and oögonia, borne in pits much like the cryptostomata, of which they are probably modifications. These conceptacles are usually formed upon somewhat modified portions of the plant-body. In Fucus the fertile branches have their ends very much enlarged, and in Sargassum there are special fertile branches developed. The position of the conceptacles is indicated by papillæ. Antheridia and oögonia may be formed in separate conceptacles (in different plants) as in Fucus vesiculosus and Halidrys; or they may be borne in the same conceptacle (Fucus fastigiatus).

Antheridium. - The antheridia in Fucus (Fig. 104, D, E) are small oval cells borne at the ends of branches of some of the hairs within the conceptacle. They 
closely resemble in their structure the unilocular sporangia of the Kelps. The nucleus of the young antheridium divides repeatedly, and there follows a division of the cytoplasm into as many parts as there are nuclei. The spermatozoid (II) has a large nucleus and an orange-r'ed pigment-spot, so that in mass the

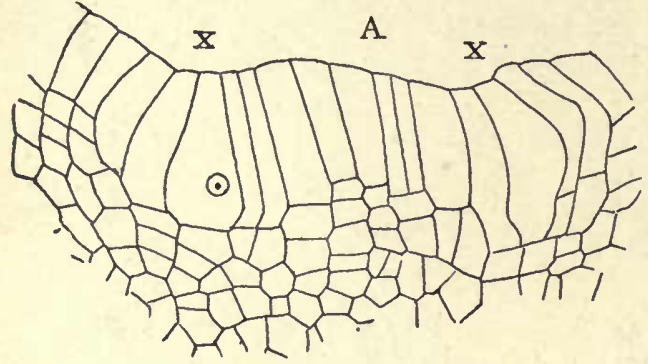

B

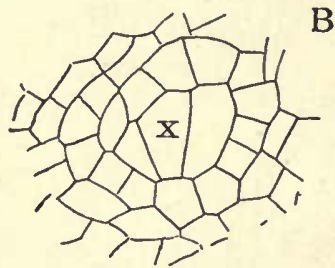

Frg. 103. - Fucus evanescens. A, growing-point of a dividing shoot; $x, x$, apical cells of the new shoots. $B$, cross-section of the growing-point; $x$, the apical cell $(\times 450)$. parts, but in some species into a smaller number (i.e. two in $F$. fastigiatus). In Halidrys there is but a single egg in the oögonium. In all the forms that have been thoroughly investigated, the nucleus divides into eight, whether the full number of egg-cells is formed or not, the superfluous nuclei becoming disorganized.

Fertilization. - When ripe, the reproductive organs are easily broken away, and when exposed to the water, which happens in those forms growing between tide-marks when the tide rises, the wall of the oögonium or antheridium is dissolved, and the reproductive cells are gradually set free in the water. The minute spermatozoids have two laterally inserted cilia, one being often longer than the other. They collect about the eggs, and sometimes in such numbers that the egg is made to rotate by the movement of their cilia. A single spermatozoid only succeeds in penetrating into the egg, where it fuses with the nucleus (Fig. 104, J). The egg is then invested with a membrane, becomes pear-shaped, and attaches itself by the pointed end. Cell-division now proceeds rapidly, and in time an apical cell is established, but the details are still not quite clear. The attached end forms a holdfast, and the upper part develops into the branched thallus. 
While most of the Fucaceæ are attached, Sargassum, Cystophyllum, and some others are found floating and vegetating freely far from any land. It is still uncertain whether or not some of
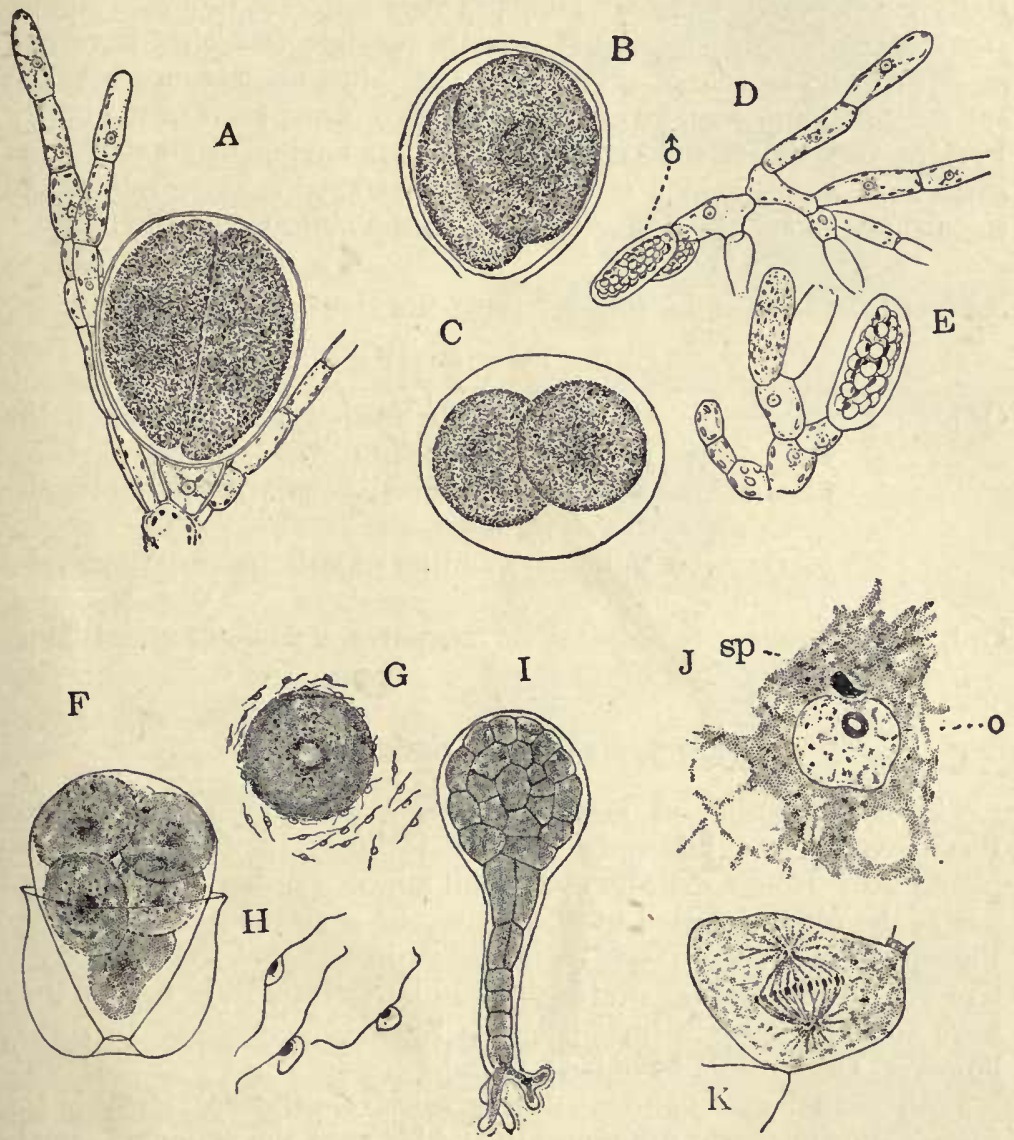

Fic. 104.-A-E, Fucus furcatus. A, oögonium $(\times 150)$. B, $C$, egg-cells escaping from the oögoninm. $D$, filaments, with antheridia. $E$, antheridia, more highly magnified. $F, F$. vesiculosus, oögonium discharging the egg-cells. $G$, fertilization of the egg. $H$, spermatozoids more highly eularged. $I$, young plant. $J$, conjugation of the sexual nuclei; 0 , egg-nucleus; $s p$, sperm-nuclens. $K$, young oögonium of Ascophyllum nodosum, with dividing nucleus. ( $J, K$, after FARMrR.)

these species may spend their whole life as free-swimming or pelar gic forms. These floating masses of seaweed serve as shelter for a great variety of marine animals, small fish even being found living in them. 


\section{Affinities of Phæophyceæ}

The Phæophyceæ must be considered to be a highly specialized group of plants, whose peculiarities are largely due to their essentially marine mode of life. They are very different in most respects from the Chlorophycex, and it is quite possible that they have had an entirely independent origin. The striking resemblance between the zoöspores and gametes of the Phæophyceæ and some of the brown Peridineæ suggests the possibility of their having originated from some such forms, which might bear somewhat the same relation to them that the simpler Volvocaceæ do to the other Chlorophyceæ.

\section{Classification of Phæophyceæ (Engler and Prant1, 9)}

Class Phaophycee

Ord. 1. Phocosporece. Producing both zoöspores and gametes, the latter always motile.

a. Gametes similar. Families: Ectocarpaceæ, Sphacelariaceæ, Laminariaceæ, etc.

b. Gametes unlike. Families: Cutleriaceæ, Tilopteridaceæ.

Ord. 2. Cyclosporece (Fucacex) ; no zoöspores. \& gametes non-ciliated. Fam. 1. Fucaceæ.

\section{Dictyotales (Williams, 39)}

This small group of marine Algæ is probably related to the Phæophyceæ, and might perhaps be included in that class. The plants grow from a definite apical cell and do not reach a large size, nor is the differentiation of the tissues as perfect as in the higher Phæophyceæ. Until recently, it was supposed that their reproductive cells were always destitute of cilia, and for this reason they have sometimes been included with the Rhodophyceæ. Recently, however, motile cells have been found.

Both sexual and non-sexual reproductive cells are formed, the former showing great difference in size between the male and female cells (Fig. 105).

\section{Class III. Rhodophyceæ (Red Alga)}

The Red Algæ comprise the majority of seaweeds, but in size they are much inferior to the Phæophyceæ. Most of them inhabit salt water, but a number of genera are found in fresh water, usually in cold, rapid streams, or on rocks washed by falling water. In size they range from almost microscopic forms to stout plants a metre or more in length. 
Color. - The characteristic red color is due to the presence of a red pigment, Phycoerythrin, which occurs in the chromatophores with the chlorophyll. This pigment is soluble in fresh water, and forms a rose-red. solution which is strongly fluorescent, appearing greenish yellow by reflected light. The pigment varies in amount, being least developed in the fresh-water species, which are generally blackish or olive-green, resembling in color the Cyanopliycex. The marine species exhibit all shades from delicate rose-red to blackish purple.

Chromatophores. - The chromatophores, except in the Bangiacer, which are not closely related to the other forms, are usually small, oval disks, several in each cell. Just what the relation of the phycoerythrin is to the chlorophyll is not quite clear, but it is evident that it modifies the light-
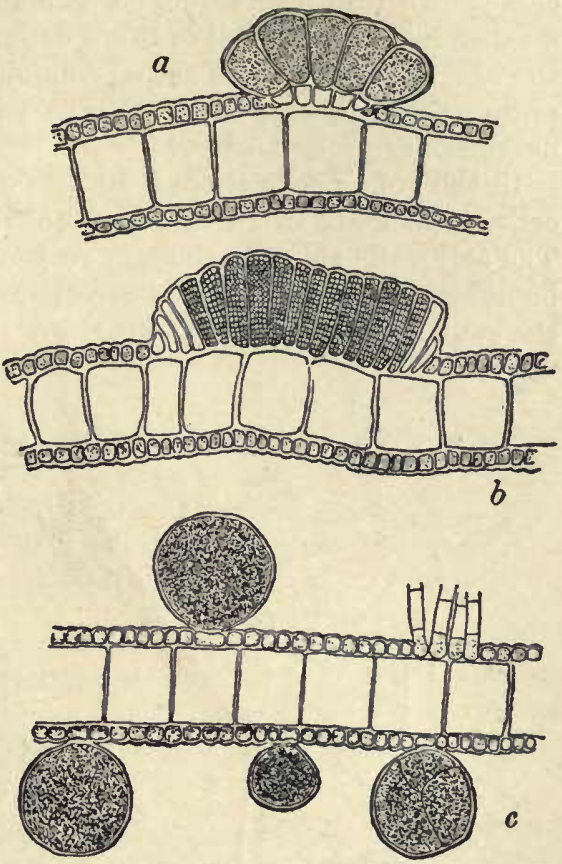

Fia. 105.-Dictyota dichotoma: $a$, female .sorus ; $b$, male sorus ; $c$, sporangia. (All highly magnified.) (After MuRrAY.)

rays, as it is found by experiment that the rays most efficient in photosynthesis are noticeably nearer the violet end of the spectrum in the Rhodophyceæ than they are in the Chlorophyceæ. The phycoerythrin no doubt neutralizes the absorption of certain rays in the passage of light through the water, where these plants grow in deep water.

Plant-body. - Some of the Rhodophyceæ are simple filaments (Griffithsia), or branched filaments, as in Callithamnion. A thin, flat thallus is found in Grinnellia and Porphyra, while some of the forms living where they are exposed to the surf, such as Chondrus or Gigartina, are tough and leathery in texture like some of the Kelps. Much more rarely there is an incrustation of lime, and the plants become of stony hardness. This occurs in the peculiar Corallines.

Cell-structure. - With the exception of the Bangiales, which are sometimes removed from the Rhodophyceæ, the protoplasts of adjacent 
cells are connected by very evident protoplasmic filaments (Fig. 106). There is a large pit in the middle of the division-wall, which is closed by a thin membrane, on each side of which is a thick plate of a substance somewhat like the mucilage masses in the sieve-tubes of the higher plants. The actual communication is effected by delicate pores around these plates, through which fine threads connect the neighboring protoplasts.

In the young cells there is always a single nucleus, but the older cells, which are often large, frequently possess numerous nuclei. The cell-walls show a tendency to become gelatinous, and there may be developed an abundant intercellular gelatinous substance in which the cells appear to be imbedded.
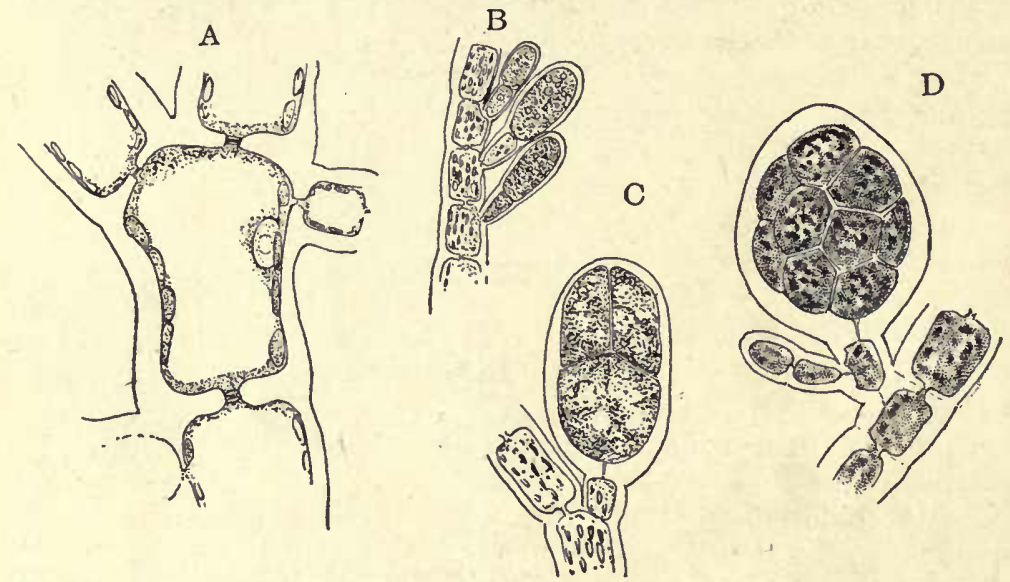

Fig. 106. - A-C, Callithamnion floccosum. $A$, cells showing the connection between the protoplasts $(\times 600)$. $B$, young, $C$, mature, tetrasporangia $(\times 250)$. $D$, polysporangium of $C$. dasyoides.

Apical Growth. - The growth of the plant is, with few exceptions, apical. In the more delicate forms there is a single apical cell; in the larger ones there may be a group of these (e.g. Champia). When there is a massive thallus, it can usually be shown to be composed of extensively branching filaments congenitally united by the tenacious intercellular substance, and in such cases each of the individual branches has its own apical cell. Ordinarily the cells divide no further, but in Nitophyllum and the Corallines there are intercalary divisions.

\section{Reproduction}

A marked characteristic of the Rhodophyceæ is the complete absence of ciliated cells. Non-sexual reproduction is usually effected by the so-called Tetraspores, which, as their name indicates, are formed 
in groups of four within a mother-cell. In a few cases, e.g. Chantransia, Monospores are formed, and very rarely the sporangia develop more than four spores (Callithamnion dasyoides).

Sexual Reproduction. - The sexual reproductive organs are special cells, Carpogouia, which are fertilized by non-motile inale cells (Spermatia). The carpogonium may at once give rise to a mass of spores (carpospores), or it may be associated with other cells into a multicellular organ, the Procarp, which after fertilization develops into a complicated spore-fruit (Cystocarp). The more important of these forms will be taken up in connection with the special orders. As in the Phæophyceæ, no resting-spores are produced, and both tetraspores and carpospores germinate as soon as they are ripe.

Classification. - There are two subclasses of the Rhodophyceæ, the Bangiales, with a single order, Bangiaceæ, and the Florideæ, which comprise the greater part of the class, and differ so much from the Bangiales that the latter are sometimes considered to be more nearly related to the Chlorophyceæ than to the Florideæ.

\section{Bangiaceæ}

The Bangiaceæ comprise a small number of simple Algæ, which, aside from their color, show certain resemblances to the Chlorophyceæ, and may perhaps connect these with the higher Rhodophyceæ. While most of them are marine, there are also a number of freshwater species.

Plant-body. - The plants are either filaments or very simple cell-plates, as in Porphyra (Fig. 107), which except for its color closely resembles Ulva. The cells contain a single large chromatophore and a single nucleus. No protoplasmic connections can be discerned between the cells.

Reproduction. - Non-sexual reproduction consists in the escape of the contents of a thallus-cell, either directly, or after one or two preliminary divisions. These monospores thus closely resemble the zoöspores of many Confervaceæ, from which they differ in the absence of cilia. It is said, however, that slight amœboid, or creeping, movements have been detected, in which they are different from the monospores of the Florideæ. The sexual reproduction is also very simple. Apparently any thallus-cell may become an oögonium (carpogonium). There is no contraction of the contents, and a slight prominence is developed, which perhaps represents the trichogyne, or fertilizing-tube found in the carpogonium of the Florideæ, but also recalls the same structure in Coleochæte (Fig. $107 \mathrm{D})$.

The antheridia (Fig. 107, C) are formed from vegetative cells by a division into a number of small cells which lose their color, and both in position and structure are very similar to those in the disk-shaped species of Coleochæte like C. scutata. Each of these small cells discharges its contents as a small globular spermatium. When one of these comes in contact with the projection from the carpogonium it fuses with it, and the contents pass into the carpogonium, whose contents then divide into a number of cells, carpospores, which closely resemble the non-sexual spores, and like them germinate as soon as they are set free. 


\section{Affinities of Bangiales}

Aside from their color, and the absence of cilia in the reproductive cells, the Bangiaceæ recall certain Confervaceæ, especially such forms as Coleochæte, and it is by no means impossible that they connect these with the higher Rhodophyceæ, although this view must be considered for the present as nothing more than a conjecture.

\section{THE FLORIDEA}

This is the largest group of Algæ, and includes the greater number of the common Seaweeds.

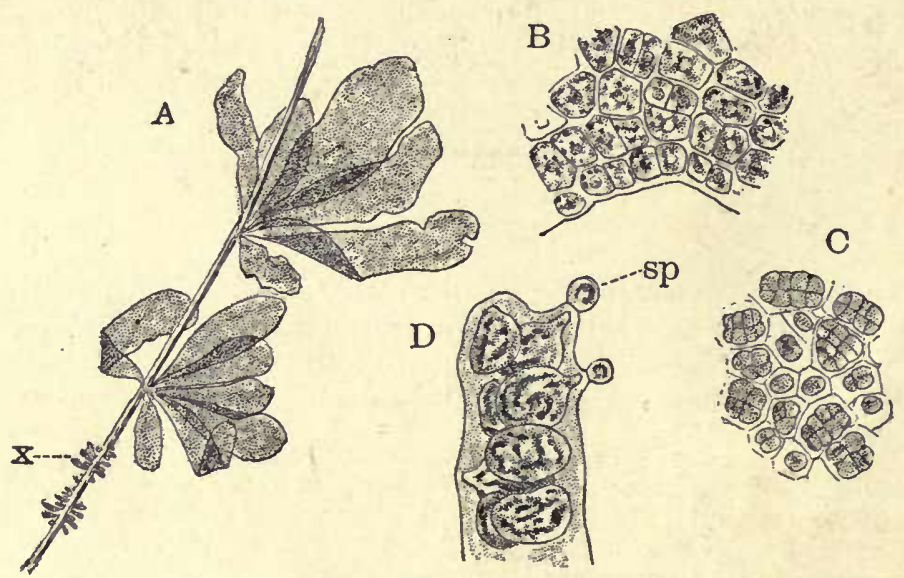

Fic. 107. $-A$, Porphyra sp., plants growing upon a leaf of Phyllospadix; $x$, young plants. (Natural size.) $B$, cells from the thallus of $P$. vulgaris $(\times 450), C$, antheridia (?) of $P$. vulgaris $(\times 250)$. D, Erythrotrichia ceramicola, showing fertilization; $s p$, spermatium $(\times 600)$. ( $D$, after BerTHoLd.)

The Plant-body. - In a few forms, like Griffithsia, the plant is a simple cell-row, but usually it is either a branching filament or a broad thallus of some size. The Florideæ, however, are inferior to the Phæophyceæ in size and in the complexity of their tissues.

Apical Growth. - With few exceptions the growth of the plant is apical. Where it is a simple or branching filament the apical cell is elongated, and has here segments cut off from it which undergo no further divisions except as lateral branches are formed. In others, such as Polysiphonia (Fig. 111), the segments cut off from the base of the conical apical cell here undergo further longitudinal divisions, whereby the outer vertical cells are cut off from the axial row of cells. In other forms, e.g. Champia (Fig. 116), there is a group of initial cells at the apex of the thallus. 
Tetraspores. - In most of the Florideæ the non-sexual reproductive cells are tetraspores. These are formed in special cells, which may either project as short branches (Fig. 106) or are formed from an inner cell of the thallus. Not infrequently the groups of tetrasporangia are found upon special branches called Stichidia. Tetraspores are wanting in some of the lower Florideæ, e.g. Nemalion, or they may be replaced by monospores (Batrachospermum) (Fig. 109), where they are borne upon a special non-sexual plant, which was described as another genus, Chantransia, under the impression that it was an independent plant. In this case the sexual plant (Batrachospermum) develops as a special branch from the Chantransia-form, somewhat as the perfect Chara-plant arises from the pro-embryo.
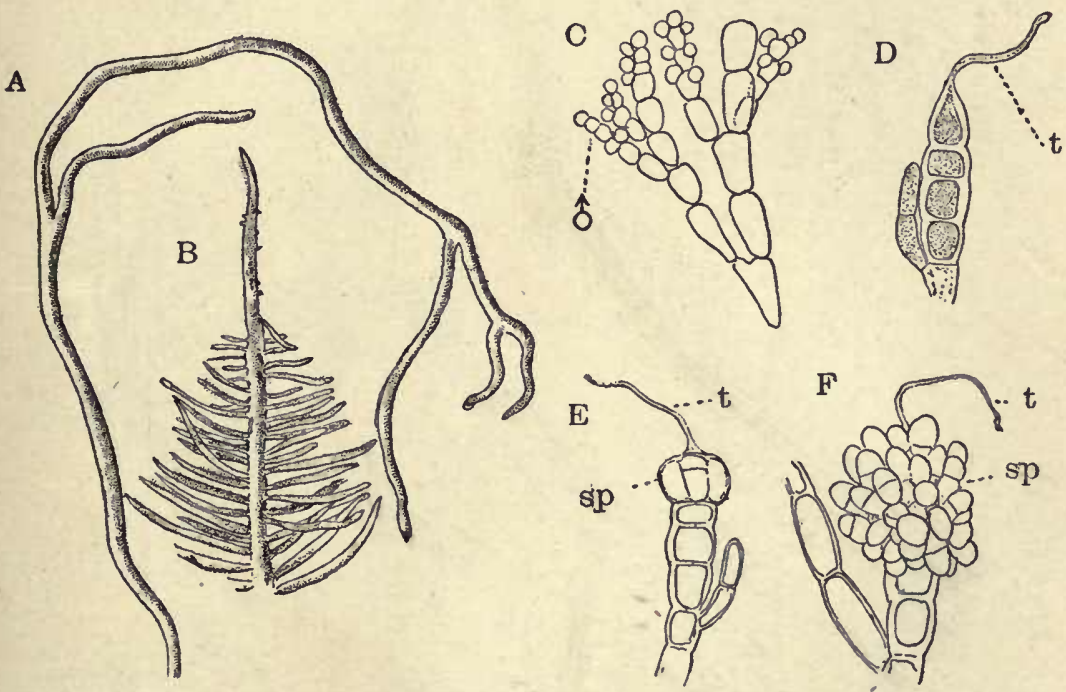

Fig. 108. - A, Nemalion multifidum. (Natural size.) $B, N$. Andersonii. (Natural size.) $C, N$. multifidum, branch with antheridia; $\delta(\times 500)$. $D$, carpogonial branch $(\times 500) ; t$, trichogyne. $E$, young gonimoblast, or spore-fruit, $s p . F$, older gonimoblast.

Tetraspores may be formed by successive division of the mothercell, or by a simultaneous division of the protoplast after the nucleus has divided into four. Sometimes (e.g. Corallina, Fig. 115) the tetraspores are arranged in a row (zonate).

\section{Classification (Engler and Prant1, 9)}

As already stated, there is a good deal of variation in the character of the sexual organs in the Floridex, and upon this the division into orders is based. Four of these orders are usually recognized, 
viz. Nemalionales, Gigartinales, Rhodymeniales, Cryptonemiales. These are further divided into about twenty families.

\section{Order I. Nemalionales}

These are the simplest of the Florideæ, and include most of the fresh-water species. They are usually densely branched Algæ, but may develop a tubular thallus as in Lemanea and other genera. In the fresh-water genera the color is usually blackish or olive instead of the red of the marine genera. The commonest of the fresh-water forms are Batrachospermum and Lemanea.

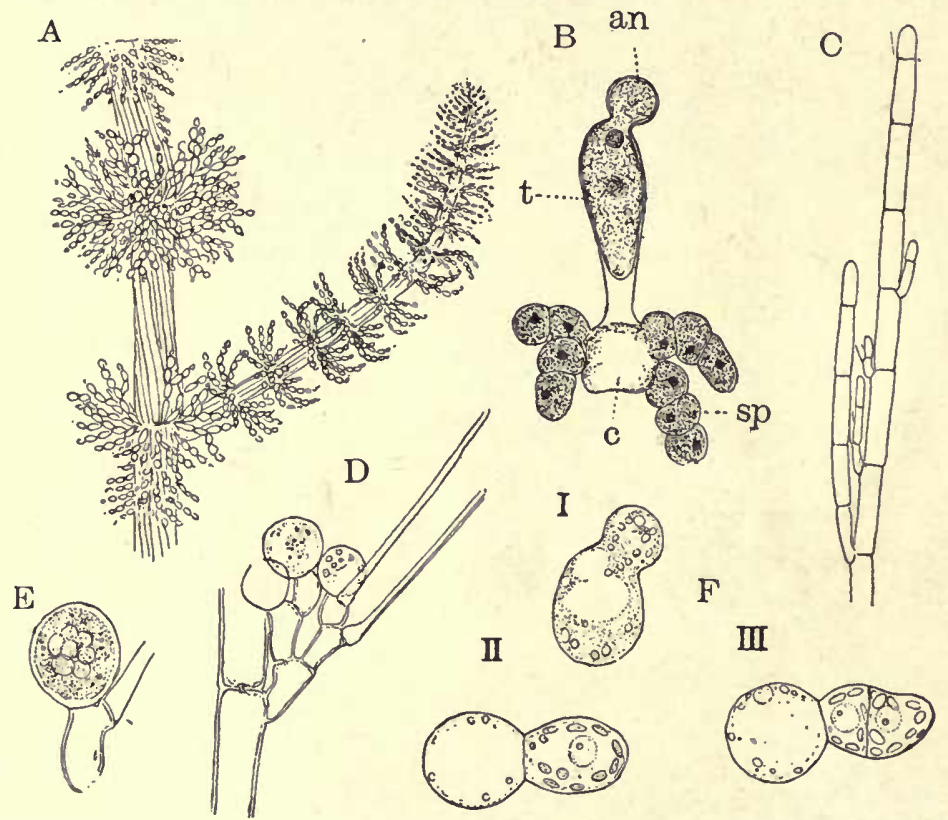

Frg. 109. $-A$, Batrachospermum vagum $(\times 85) . B$, fertilized carpogonium; an, spermatium; $s p$, spores developing from the carpogonium. $C$, Chantransia macrospora, the young form of Batrachospermum $\mathrm{sp} .(\times 85) . \quad D$, monosporangia of $C$. macrospora $(\times 250)$. $E$, single monosporangium $(\times 500) . F$, germinating monospores. ( $B$, after DAvis.)

Reproduction. - In most of the Nemalionales non-sexual reproductive cells are unknown, or are monospores, although tetraspores are known in some of the marine genera.

The sexual reproductive organs are the carpogonium and antheridium, which are readily studied in Nemalion (Fig. 108). The carpogonium is a flask-shaped cell at the end of a branch. The antheridia are groups of small globular cells also at the ends of short branches. Each antheridium-cell produces a single 
globular spermatium, naked at first, but later developing a delicate membrane. This comes in contact with the trichogyne, and its colitents pass into the carpogonium, the nucleus passing into that of the carpogonial cell. The fertilized cell does not develop into a spore, as in the other Algæ, but begins to grow and divide, forming a large mass of short branches, whose end-cells become the spores, the whole structure being known as the "Spore-fruit," or Sporocarp. The spore-mass may in some forms be surrounded by a loose envelope of branches developed from the cells in the vicinity of the carpogonium.
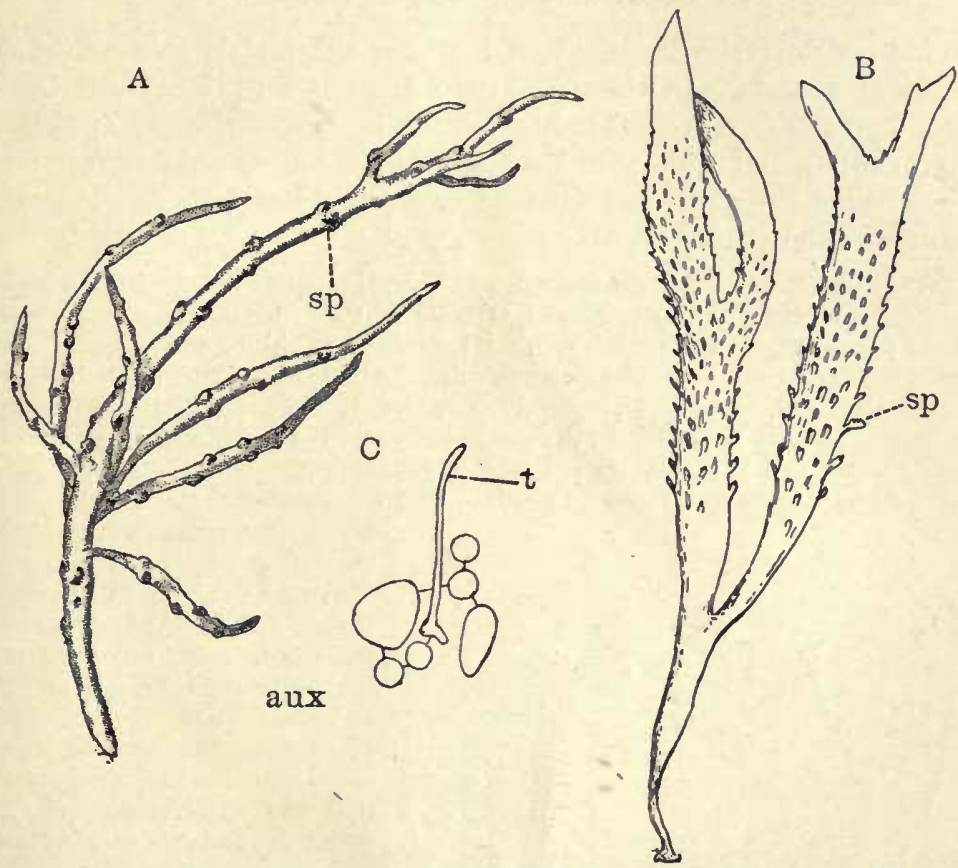

Fig. 110. $-A$, Rhabdonia tenera (natural size); $s p$, cystocarps. $B$, Gigartina spinosa, plant with cystocarps, reduced about one-half. C, Endocladia vernicata, procarp; aux, auxiliary cell; $t$, trichogyne. (After HauptrLeisch.)

\section{Order II. Gigartinales}

The Gigartinales are mostly Algæ of comparatively large size and coarse texture. Many of them, e.g. Chondrus crispus, the "Irish Moss," and various species of Gigartina (Fig. 110, B), grow attached to rocks where they are exposed to the surf. They are very tough and cartilaginous in texture, due to the large development of the gelatinous intercellular substance. Owing to this some of them are utilized to some extent for food. The tetraspores are usually buried in the thallus. The antheridia form patches of small superficial cells, each of which gives rise to a spermatium. 
The carpogonium in the Gigartinales is the end-cell of a short branch which is buried in the thallus (Fig. 110, C), but the trichogyne projects above the surface, so that it may be fertilized. After fertilization the carpogonial cell comes into contact with a neighboring cell (Auxiliary cell) from which the spores are developed. About the mass of spores a more or less definite wall is formed, the whole constituting the cystocarp.

\section{Order III. Rhodymeniales}

This order is the largest, and includes the majority of the most beautiful species. In these the carpogonium, as in the last order, is the end-cell of a special branch, which is united with the auxiliary cell (or cells), and often with the beginning of the cystocarp-wall, into the so-called Procarp. This is seen in its simplest form in the genus Callithamnion (Fig. 112, D).

One of the cells of the filament sends out a short branch of two cells, the upper one developing into the carpogonium with its long trichogyne $(\mathrm{D}, t)$. On each side of the carpogonial branch is found a large cell $(x)$, which after the fertilization of the carpogonium divides into two cells, - a large upper one, which becomes the auxiliary cell, and a smaller basal one which develops no further. The carpogonium, after it is fertilized, divides into two cells (E, $c$ ), and from each of these a small cell is cut off on the side in contact with the auxiliary cell, into which its nucleus passes, but does not fuse with the nucleus of the auxiliary cell,

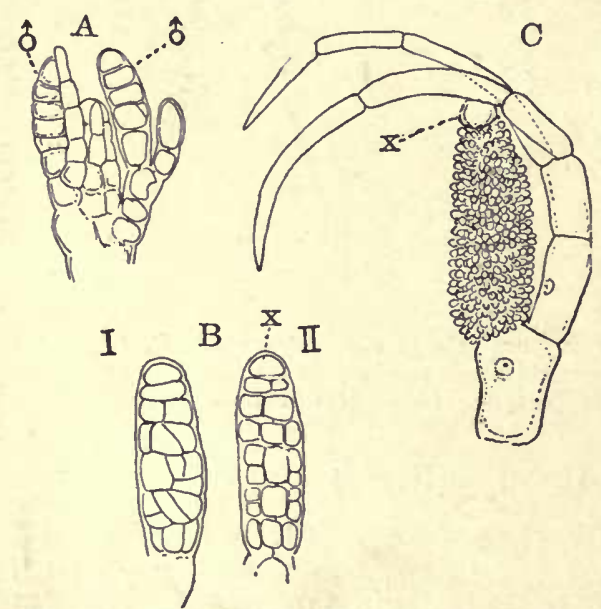

Fig. 111. - Polysiphonia $s p$. A, tip of branch with young antheridia, $\widehat{\odot}(\times 500) . B$, older antheridium: $I$, from without; $I I$, optical section; $x$, apical cell. $C$, ripe antheridium $(\times 250)$. which remains passive, although the cell is stimulated into very active growth. In the divisions which follow and gradually transform each auxiliary cell into a mass of spores, the nuclei all come from the repeated division of the nucleus which came from the carpogonium, so that the spore-nuclei are the direct descendants of the fertilized carpogonial nucleus. There are thus formed two masses of spores on opposite sides of the cell from which the carpogonium was developed.

The common genus Polysiphonia may be taken to represent the more specialized reproductive organs of the Rhodymeniales.

Antheridia and procarps are borne upon the hairs, which grow from near the apex of the shoot.

The hairs which bear the antheridia (Fig. 111, A) are forked, and one of the branches develops into the antheridium, while the other grows into a slender 
hair, apparently attached to its base. The young antheridium shows a definite apical growth, the segments dividing into a central cell and a series of peripheral cells, the latter dividing into many small cells, each of which produces a single spermatium. 'The apical cell persists as a large transparent cell $(x)$ at the apex of the ripe antheridium.

Procarp. - The procarp, also, is formed upon a hair, but this is not usually forked. 'The procarp develops from the second cell of the hair. This cell divides into a central cell and five peripheral ones. Of the latter, the one turned toward the shoot, i.e. - the inner one - gives rise to a short carpogonial branch, usually of four cells (Fig. 112, B). The two posterior cells undergo but little
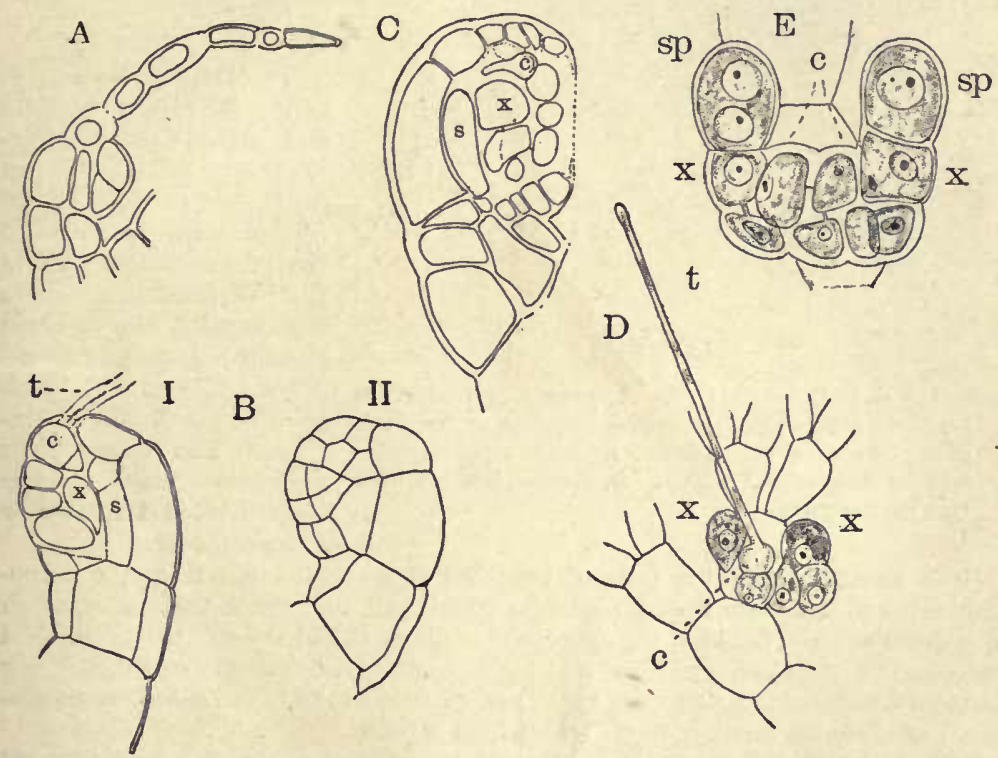

Fig. 112. $-A-C$, Polysiphonia $s p$. A, very young procarp (optical section) $(\times 500)$. $B$, two sections of an older procarp: $I$, medium section; $I I$, superficial cells; $c$, carpogonial cell; $x$, auxiliary cell; $s$, central cell of the joint. $C$, fertilized procarp (optical section). $D$, Callithamnion corymbosum; procarp with two auxiliary cells, $x$, and long trichogyne. $E$, fertilized procarp, the auxiliary cells beginning to develop the spores, sp. ( $D, E$, after OLtarasss.)

change, and help to form the wall of the cystocarp, which owes its greater part to the two lateral pericentral cells from which arise two lobes, something like a bivalve shell, and completely enclosing the carpogonial branch, except for the long trichogyne. The auxiliary cell $(x)$ arises by a transverse division from the cell from which the carpogonial branch grows. After fertilization a small cell is cut off from the carpogonium, which fuses with the auxiliary cell, this later fusing with the neighboring cells forming a large cœnocyte or multinucleate cell. The latter occupies the centre of the young spore-fruit, and from it the large pear-shaped spores are budded off. The wall of the cystocarp finally forms an urn-shaped envelope enclosing the spores (Fig. 113). The development of the sporocarp in Rhodymenia is very similar. 


\section{Order IV. Cryptonemiales}

In the Cryptonemiales the auxiliary cells are often remote from the carpogonial branch, and from the carpogonium there grow out filaments which fuse

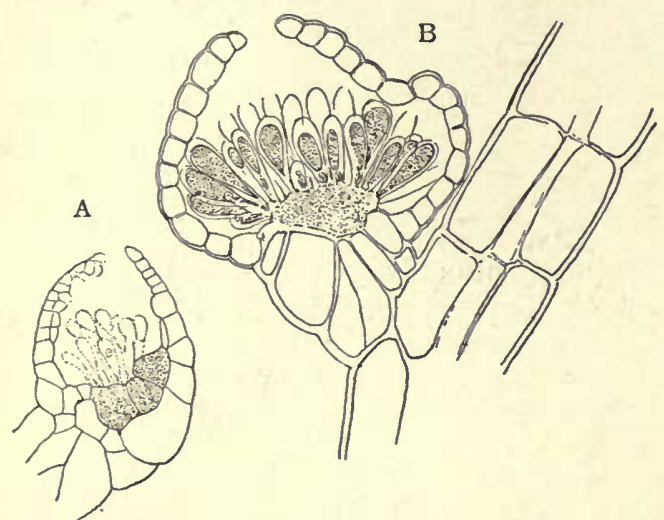

FIG. 113.-Polysiphonia sp. A, young cystocarp, in longitudinal section, the spores developing from the group of central cells formed from the auxiliary cell and its neighbors $(\times 200)$. $B$, median section of a ripe cystocarp.

The auxiliary cells are cells of branches at some distance from the carpo. gonium, and the sporogenous filaments grow until they reach these cells, when fusion takes place between the sporogenous filament and the auxiliary cell. Not infrequently the filament grows, and reaches another, or even two or three other auxiliary cells, but in this case there are as many cells in the sporogenous filament as there are auxiliary cells with which it fuses.

An enlargement forms at the point of junction of the sporogenous filament and the auxiliary cell (Fig. 114, B), and the upper part of this is cut off by a wall, the nucleus of this cell being derived from the division of the nucleus of the sporogenous filament, and not from that of the auxiliary cell. From this cell, by repeated divisions, arises the mass of spores, so that a single fertilization results here in a number of spore-fruits, which are, however, all connected with the carpogonium by the sporogenous filaments.

Corallineæ. - In the peculiar family, the Corallineæ, very extensive cell-fusion follows the fertilization. In Corallina the reproductive bodies are borne in cup-shaped receptacles at the ends of the branches (Fig. 115). A great many carpogonial branches are formed near together, and after fertilization there is a complete fusion of the protoplasts of these branches, as well as of the neighboring cells, and from the large multinucleate fusion-cell resulting, the spores are finally produced. 


\section{Nature of the Spore-fruit}

In the lowest of the Rhodophyceæ, the Bangiaceæ, a direct comparison can be made between the product of fertilization and the oöspores of the Chlorophyceæ.

The division of the contents of the carpogonium into spores is directly comparable to the germination of the resting-spores in the Chlorophyceæ.

In the Floridex, however, no resting-spore is produced, but the carpogonium either develops into a mass of spores by further growth, as in Nemalion, or transmits the nuclei to auxiliary cells, which are stimulated into growth and produce the spores. Oltmanns, whose researches have been important in explaining the process of fertilization, considers the structures developed from the fertilized carpogonium as a new plant, - "Sporophyte," - com-

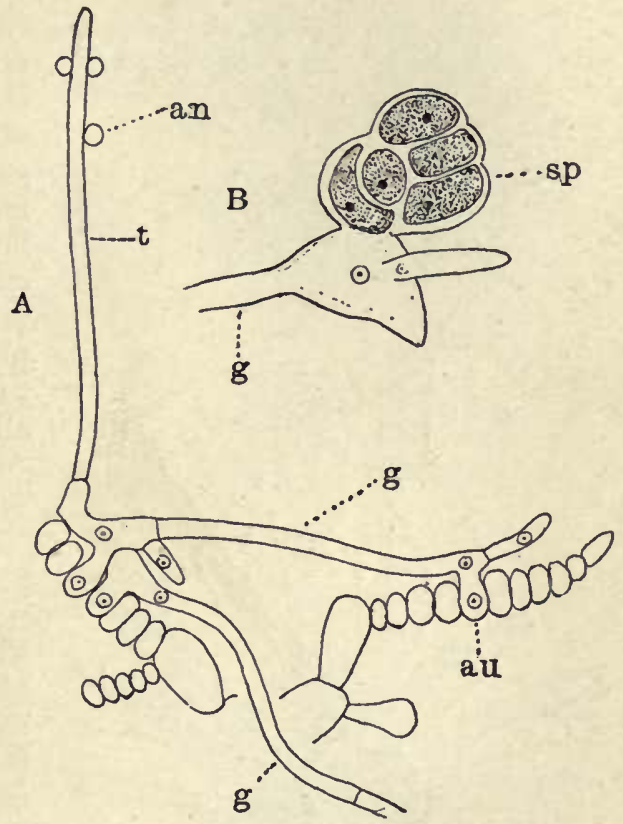

Fig. 114.-Dudresnaya purpurifera. A, fertilized carpogonium sending out from the base the filaments, $g$, which conjugate with the auxiliary cells, $a u$. $B$, gonimoblast, or spore-fruit, produced from the union of the filament and auxiliary cell. (After Oltmanns.)

parable to the sporophyte of the higher plants. All of the nuclei of the sporophyte are derived from the carpogonial nuclei, and when the spores are derived from the auxiliary cells these seem merely to furnish food, as it were, for the growth and division of the sporophytic nuclei, as the nuclei of the auxiliary cells do not enter into the structures of the sporophyte, which grows to some extent as a parasite upon the sexual plant, or gametophyte.

\section{Affinities of Rhodophyceæ}

The Bangiaceæ, as already intimated, show evident relationships with the Chlorophyceæ, and perhaps connect them with the Flori- 
deæ. The latter must be regarded as an extremely specialized group

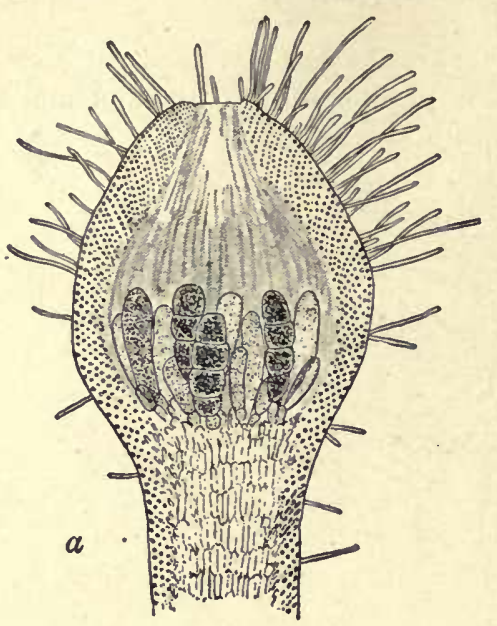
without any near affinities with other plants.

There have recently been shown among certain Fungi (Ascomycetes) a type of reproduction strikingly similar to that of the Florideæ, and it has even been suggested that the two groups may be related. This is, however, by no means generally admitted, and at present the higher Rhodophyceæ must be considered to be widely separated from all other plants.

\section{Fossil Rhodophyceæ}

Some of the Corallineæ, which have a heavy incrustation of carbonate of lime, have been very perfectly preserved in a fossil condition; but the fossil forms are all much like the existing ones, and throw no light upon the origin of the group.

The living genus Lithothamnion is common in the Mesozoic formations, but there are other genera which are much older.

\section{BIBLIOGRAPHY}

'94. 1. Belajeff, W. Ueber die Bau und Entwickelung der Spermatozoiden. Flora, 1894 (supplement).

'97. 2. Brannon, M. A. The Structure and Development of Grinnellia Americana. Ann. of Bot., XI, 1897.

'96. 3. Chester, G. D. Notes concerning the development of Nemalion multifidum. Bot. Gaz., XXII, 1896. 
'94. 4. Davis, 13. M. Notes on the Life History of a Blue-green Motile Cell. Bot. Gaz., March, 1894.

'94. 5. _ Euglenopsis, a new Alga-like Organism. Ann. of Bot., VIII, December, 1894.

'96. 6. Development of the Cystocarp in Champia parvula. Bot. Gaz., XXI, 1896.

'96. 7. Fertilization of Batrachospermum. Ann. of Bot., X, 1896.

'98. 8. Kerntheilung in der Tetrasporenmutterzelle bei Corallina. Ber. der Deutschen bot. Gesellschaft, XVI, 1898.
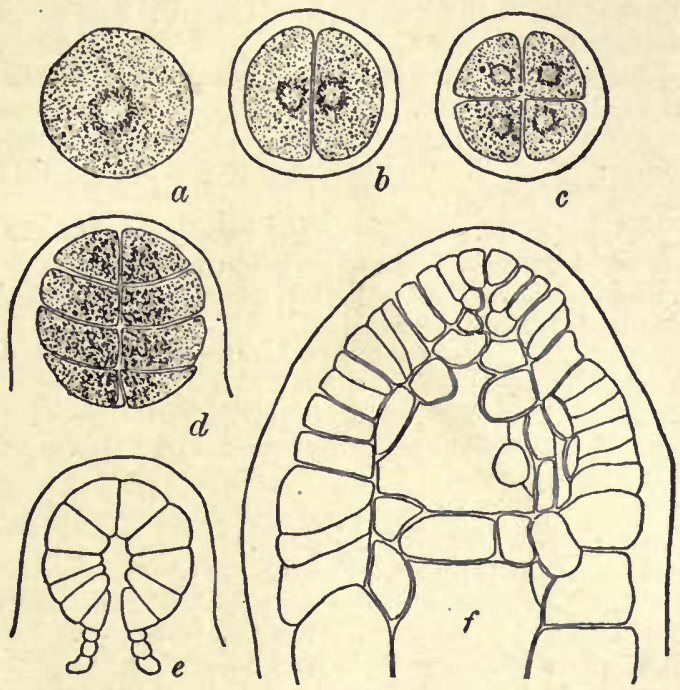

Fia. 116.-Champia parvula. $a, b, c, d$, successive stages in the germination of carpospore; $e$, optical section of further stage in segmentation of spore; $f$, longitudinal section of apex of young plant. (After DAvis.)

97-00. 9. Engler and Prantl. Die natürlichen Pflanzenfamilien. 1 Theil. 2 Abt. Algæ, 1890-97. Chlorophyceæ, N. Wille; Phæophyceæ Dictyotales, F. R. Kjellmann ; Rhodophyceæ, F. Schmitz, P. Falkenberg, P. Hauptfleisch. This contains a full bibliography.

10. Falkenberg. See Engler and Prantl.

'81. 11. Farlow, IV. G. Marine Algæ of the New England Coast. Washington, 1881 .

'98. 12. Farmer, J. B., and Williams, J. L. Contributions to our Knowledge of the Fucacere. Phil. Trans. Royal Soc., London. Ser. B, vol. $190,1898$.

'87. 13. Goebel, K. Outlines. Oxford, 1887.

'00. 14. Organography. Vol. I. Oxford, 1900.

15. Hauptfleisch. See Engler and Prantl.

'91-'92. 16. Klebahn, H. Studien tiber Zygoten, Pringsheim, Jahrb. f. Wiss. Bot., XXII, XXIV, 1891-1892.

'96. 17. Klebs, G. Ueber die Fortpflanzungsphysiologie der niederen Organismen. Jena, 1896. 
'79. 18. Luerssen, Ch. Handbuch der Systematischen Botanik, Vol. 1. Leipzig, 1879.

'95. 19. Murray, G. Guide to the Study of Seaweeds. London and New York, 1895.

96. 20. Nott, C. P. The Antheridia of Champia parvula. Erythea, IV, 1896.

'97. 21. - Some Parasitic Florideæ of the Californian Coast. Erythea, V, 1897.

'00. 22. Nitophylla of California. Proc. Cal. Acad. of Sciences. 1900.

'88. 23. Overton, C. E. Ueber den Conjugationsvorgang bei Spirogyra. Ber. d. Deutsch. Bot. Gesellschaft, VI, 1888.

95. 24. Oltmanns, F. Ueber die Entwickelung der Sexualorgane bei Vaucheria. Flora, LXXX, 1895.

'98. 25. Die Entwickelung der Sexualorgane bei Coleochate pulvinata. Flora, LXXXV, 1898.

'98. 26. — Zur Entwickelungsgeschichte der Florideen. Bot. Zeit., 1898.

'96. 27. Osterhout, W. J. V. On the Life-history of Rhabdonia tenera. Ann. of Bot., X, 1896.

'95-'98. 28. Phillips, R. W. Studies on the Development of the Cystocarp of the Rhodophyceæ. Annals of Botany, 1895-1898.

'98. 29. Saunders, De A. Phycological Memoirs. Proc. Cal. Acad. 3 ser. Botany. I, No. 4, 1898.

'93. 30. Setchell, W. A. Distribution of Laminariaceæ. Trans. Connecticut Acad., V, 9, 1893.

'98. 31. Seward, A. C. Fossil Plants. Cambridge, University Press, 1898.

'94. 32. Shaw, W. R. Pleodorina, a New Genus of Volvocineæ. Bot. Gaz., XIX, 1894.

'96. 33. Smith, A. A. The Development of the Cystocarp of Griffithsia Bornetiana. Bot. Gaz., XXII, 1896.

'91. 34. Solms-Laubach, H. Count. Fossil Botany. Oxford, 1891.

'97. 35. Strasburger, E. Botanisches Practicum. 3d edit., Jena, 1897.

'92. 36. - Histologische Beiträge. Heft IV, Jena, 1892.

37. Van Tieghem, Ph. Traité de Botanique.

'95. 38. Warming, E. W. (and Potter). Handbook of Systematic Botany. London and New York, 1895.

39. Wille, N. See Engler and Prantl.

'98. 40. Williams, J. L. Reproduction in Dictyota dichotoma. Annals of Bot., XII, 1898.

'87. 41. Wolle, F. Fresh-water Algæ of North America. Bethlehem, Penn., 1887.

'84. 42. — Desmids of North America. Bethlehem, 1884. 


\section{CHAPTER VI}

\section{THE FUNGI}

The Subkingdom Fungi includes a very large number of plants, nearly forty thousand species having already been described. These differ primarily from the Algæ in being destitute of chlorophyll, but there are also very marked structural differences. Owing to the absence of chlorophyll, they are incapable of assimilating $\mathrm{CO}_{2}$. This absence of chlorophyll is not, probably, a primitive condition, and they are presumably derived from algal forms with chlorophyll. Doubtless many of the peculiarities of the Fungi are secondary ones connected with their peculiar habits, necessitated by their dependence upon organic food. A small number of Fungi, the Phycomycetes, show more or less obvious evidences of their algal ancestry, but much the larger number have become so modified as to leave little or no traces of structural resemblances to other plants. Where the Fungus lives upon dead matter, it is known as a saprophyte; where it attacks living plants or animals, a parasite.

A few Fungi are aquatic, but most of them live either within the bodies of their hosts or within the nutrient medium upon which they feed.

Parasitism. - Many Fungi, such as the Rusts, Smuts, and many Mildews, are absolutely dependent upon living organisms, so-called "obligate parasites." Less frequently a Fungus which is ordinarily a saprophyte may assume parasitic habits; i.e. it becomes a "facultative" parasite. While some species of Fungi are dependent upon a specific host, more commonly they may grow upon several - sometimes many - different hosts. Some forms, like certain species of Rusts, in the course of their development live upon two hosts, often quite unrelated. Thus the Cedar-rust (Gymnosporangium) passes part of its life upon the Red Cedar, and part upon the Crabapple or Hawthorn. This change of host, or "Heterœeism," is curiously like the behavior of certain animal parasites, like the Tapeworm and 'Trichina, which live successively in the bodies of different hosts.

Symbiosis. - A special form of parasitism, called Symbiosis, is exhibited by a number of Fungi. The most familiar of these are the Lichens, where a Fungus is intimately associated with an Alga, upon which it is parasitic to a greater or less extent, but to which it affords shelter, and probably certain food-elements, so that the association is to some extent mutually advantageous. 
Mycorhiza. - It has been found, also, that the roots of many of the higher plants are infested by a Fungus, whose delicate filaments apparently serve the purpose of root-hairs; the Fungus apparently receives for its services a certain amount of nourishment from the roots with which it is associated. These Root-fungi have been named Mycorhiza, but as they are always sterile, it is not known with what other Fungi they are related.

Parasitic Fungi, as a rule, are very injurious to the host, and are the principal causes of plant diseases. Their growth within the tissues of the host not infrequently causes an abnormal growth of its cells, causing gall-like swellings, as in the case of the Cedar-rust already referred to. It is not unlikely that these growths are due to the action of certain secretions (enzymes) similar to those by means of which the Fungus is enabled to dissolve and penetrate the cellwalls of the tissues in which it is growing. It is thus that some germinating spores make their way through the outer cells of the host and reach the inner tissues.

Fermentation. - Fungi which live upon dead matter, by its decomposition play a similar thongh less important rôle to that of the Bacteria, in reducing the organic compounds to simpler ones. One characteristic form of organic decomposition is the alcoholic fermentation of sugary solutions through the agency of certain low Fungi, especially the Yeast-fungi.

\section{Structure of Fungi}

A small number of Fungi are unicellular, but much the larger number are composed of filaments, or "Hyphæ," which are massed into the vegetative body, or "Mycelium," upon which are borne the various reproductive bodies. The mycelium may be a delicate weblike structure, or the hyphæ may be densely matted together so that the mycelium has an almost leathery texture.

In the Phycomycetes, the hyphæ are nearly or quite undivided; but the hyphæ of the higher Fungi are divided by transverse septa, which are generally formed in regular succession from an apical cell.

Cell-wall. - The membrane of the hyphæ may be composed of ordinary cellulose; but as it becomes older, there is usually a change into fungus-cellulose, which differs slightly from that of the green plants. In some cases, too, it becomes very hard, and the Fungus may be almost woody in texture, as is seen in the so-called sclerotium of the Ergot of Rye, for instance.

Protoplast. - The protoplasm may fill up the cells completely, but usually there are large vacuoles. No chromatophores are present, and the nuclei are small, and often difficult to demonstrate, but not essentially different from those of other plants. In the very long 
undivided hyphæ of some of the Phycomycetes, active streaming of the cytoplasm can sometimes be demonstrated. Where the hyphæ are colored, this may result from a coloration of the cell-wall, as in Mucor, or from the presence of pigment-granules within the cytoplasm, e.g. the scarlet pigment of species of Peziza.

Mycelium. - The mycelium may live but a few days, or it may grow indefinitely, as in the case of many species of Toadstools, where the mycelium, buried in the ground, continues to spread, giving rise to successive crops of the fruiting bodies.

The hyphæ of the fruiting structures are usually more compact, and often grow together, so that a section has the appearance of a true parenchymatous tissue.

Reproduction. - The lower Fungi, or Phycomycetes, resemble certain Algæ in their reproduction. They may form free-swimming zoöspores, or sexually produced resting-spores closely resembling those of the Green Algæ. The more typical Fungi, however, differ much in their reproduction from any green plants, and it is very hard to make any comparisons between them. A great variety of non-sexual spores are produced, which generally differ much from those of any other plants. The most important of these will be considered in connection with the special groups to which they belong.

Sexual Reproduction. - Sexual reproduction is known for only a small part of the Fungi, and has been apparently quite lost in a very large part of the group. In some of the Phycomycetes, fertilization is effected much as in the Green Algæ, but in the more specialized Fungi the reproductive organs are more like those of the Red Algæ, and as in those, there is not a resting-spore produced, but a complicated spore-fruit, or sporocarp, from which the spores are produced secondarily. With very few exceptions, fertilization is effected by direct conjugation of the antheridium with the carpogonium, or by means of non-motile spermatia like those of the Rhodophyceæ.

\section{Affinities of Fungi}

A small number of the Fungi, the Phycomycetes, or Alga-Fungi, show a more or less evident resemblance to some of the Chlorophyceæ, and perhaps have some such relation to them as do such colorless parasites or saprophytes as the Dodder, or Indian-pipe, to their green relations among the Flowering Plants. The occurrence of such parasitic Algæ as Phyllosiphon, or Mycoidea, make the derivation from $\Lambda$ lgæ of quite colorless forms, or Fungi, by no means improbable.

The greater number of Fungi, the Eumycetes, show much less evidence of being derived directly from algal ancestors, and their affinities are in most cases very obscure. 


\section{Classification of Fungi (Engler and Prantl, 4)}

The Fungi are divided into three classes, - Phycomycetes, Ascomycetes, and Basidiomycetes; the two latter constitute the larger group of the Eumycetes, or True Fungi.

\section{Class I. Phycomycetes}

The Phycomycetes, or Alga-Fungi, include a number of plants which, while not all evidently related among themselves, show more or less affinity with the Green Algæ, from which they have probably sprung. A few forms, the Chytridineæ, are either unicellular, or produce only imperfect hyphæ; but most of them develop branched hyphæ, which are non-septate, like the filaments of the Siphoneæ. The Phycomycetes are either saprophytes or parasites, attacking both animals and plants.

The Phycomycetes are divided into two groups, the Oömycetes and the Zygomycetes, the former showing a difference in the size of the gametes, which in the Zygomycetes are alike.

\section{Subclass I. Oönycetes}

\section{Order I. Chytridineæ}

The simplest of the Phycomycetes are the Chytridineæ, many of which are aquatics, parasites upon various Algæ. Others attack many Flowering Plants, sometimes causing a good deal of damage. A common example of the former group is seen in species of Chytridium, one of which, $C$. olla (Fig. 117, A), often attacks the oögonium of various species of Edogonium. The Fungus produces small uniciliate swarm-spores which on germination send a short germtube into the cell of the host. The body of the swarm-spore then develops into a sporangium $(s p)$ within which numerous swarm-spores are produced. At certain times, thick-walled resting-spores are produced, apparently non-sexually, and these in time give rise to new zoösporangia.

A somewhat more complicated form is the genus Polyphagus. P. Eugleno (Fig. 117, C-F) sometimes occurs in great numbers as a parasite upon Euglena viridis, whose encysted cells it attacks and destroys. The zoöspores of the parasite on germination send out delicate threadlike germ-tubes, which penetrate the Euglena-cells, and absorb from them their contents (Fig. 17, C). The body of the swarm-spore increases rapidly in size at the expense of the Euglenacells, and finally sends out a large saclike growth into which the contents pass, and divide into numerous zoöspores. In other cases (Fig. 117, F), there is a simple form of sexual reproduction, by which an oögonium and antheridium are formed, the latter fusing with the oögonium, which develops a resting-spore. This, on germinating, develops a zoösporangium, much like that formed from the ordinary zoōspores. 
Of the forms attacking the higher plants, the commonest belong to the genus Synchytrium. S. papillatum is sometimes very common in California upon Erodium cicutarium, whose leaves become contracted, and covered with minute brilliant crimson pustules, caused by the enlargement of the epidermal cells which are infested by the parasite. The reproduction is by zoöspores, much as in Chytridium, but no sexual organs are known.

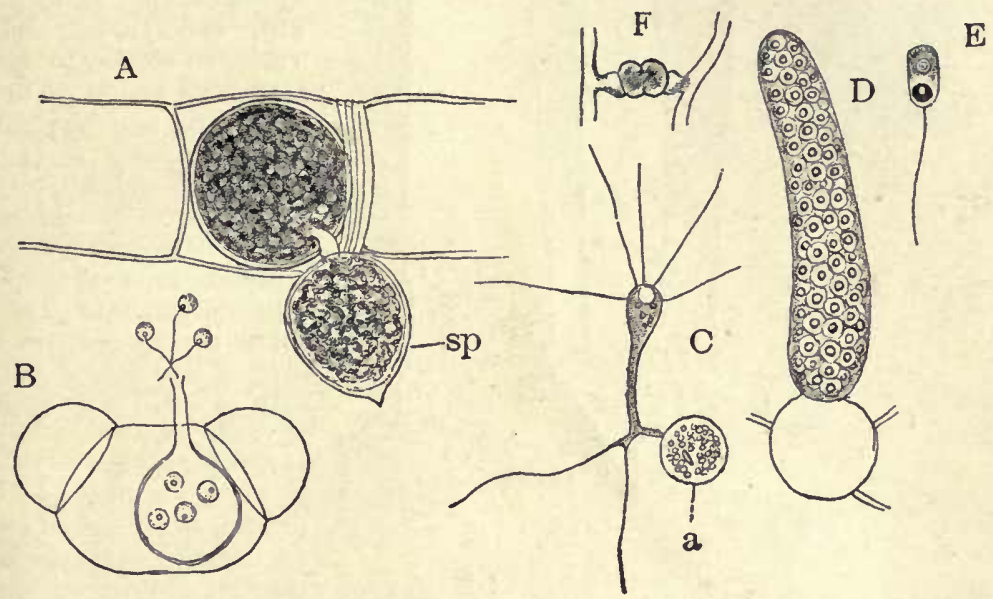

Fıc. 117. $-A$, Chytridium olla, zoösporangium, $s p$, attached to the oöspore of EEdogonium sp. $(\times 400)$. B, Olpidium pendulum, growing upon a pollen-grain of Pinus, sp. C-E, Polyphagus Euglenæ. C, germinating zoöspore attached to a resting-cell of Euglena, $a(\times 275)$. $D$, zoösporangium $(\times 325)$. $E$, zoöspore $(\times 450) . \quad F$, conjugating gametes of Zygochytrium aurantiacum $(\times 325) . \quad(B$, after ZoPF; $C-E$, after NowAKowski ; $F^{\prime}$, after Sorokin.)

\section{Order II. Saprolegniineæ (Humphrey, Io)}

The most important family of the Saprolegniineæ is the Saprolegniaceæ, or Water-moulds. These are aquatics, much resembling in appearance a colorless Vaucheria. The cominonest ones belong to the genus Saprolegnia (Fig. 118), which occur as saprophytes upon the bodies of dead insects and crustaceans. One species, $S$. ferax, is a very destructive parasite, attacking the eggs and young of fishes, which are thus destroyed in great numbers.

The plant consists of delicate branching hyphæ which send rootlets into the body of the animal upon which it is growing. The protoplasm, which lines the cell-wall, contains many small nuclei, and often shows active streaning movement. Except for the absence of chromatophores, there is a strong resemblance to the filaments of Vaucheria.

Reproduction. - The plants multiply rapidly by the formation of zoöspores, which are formed in terminal club-shaped sporangia (B-D), much like those of 
Vaucheria. The zoöspores are produced in great numbers, by the division of the protoplasm of the sporangium into as many parts as there are nuclei present.

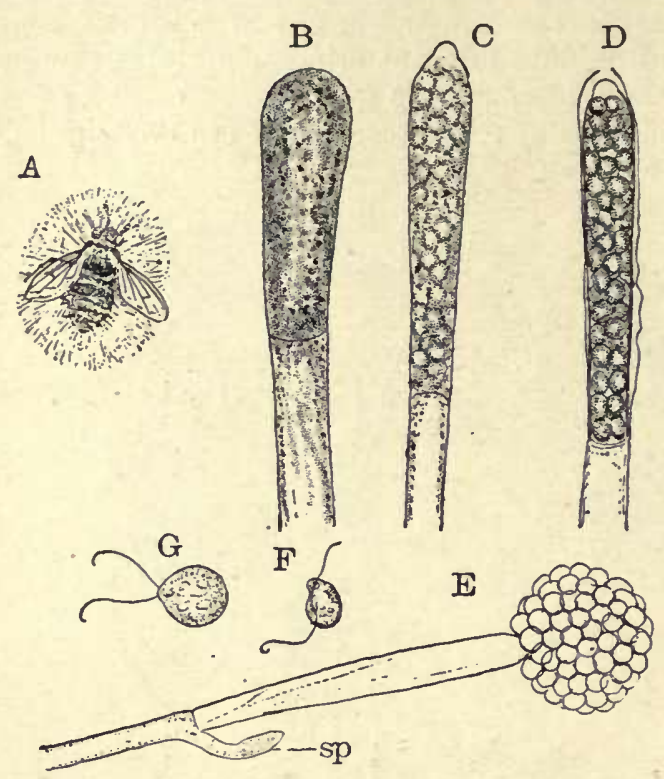

Fug. 118.- $A-D$, Saprolegnia ferax. $A$, dead fly covered with Saprolegnia. $B-D$, development of zoösporangium ( $\times 225)$; in $D$, a new sporangium has formed within an empty one. $E$, Achlya $s p$., sporangium discharging the encysted zoöspores; $s p$, young sporangium developing below the empty one $(\times 175)$. $F$, Aphanomyces sp., free zoöspore. G, Saprolegnia $s p$. zoöspore ( $\times 475) . \quad(F, G$, after HuMphrey.)
In Saprolegnia they escape from a terminal pore, and are pear-shaped with two terminal cilia. They usually become encysted, and escape from the cysts as bean-shaped zoöspores with two lateral cilia. These, on coming to rest, send out a germ-tube and grow into a new plant. In other genera (e.g., Achlya, Aphanomyces), the zoöspores become encysted immediately upon escaping from the sporangium (E). In Dictyuchus the sporangium is divided into chambers in each of which a zoöspore is produced.

After the sporangium is empty, a new one is formed, either by the end of the filament growing through the empty sporangium (Fig. 118, D), or by pushing out below its base and forming a new sporangium by the side of the old one. This process may be repeated several times.

Sexual Reproduction. - Oögonia, globular in form, are found in most species. Within the oögonium one or several egg-cells are formed (Fig. 119). The antheridium is smaller than the oögonium and formed usually from another branch. In S. hypogyna, the antheridium develops from the same branch as the oögonium. The antheridia are irregular in form, and there may be a single one, or several, formed in connection with each oögonium. The antheridium is closely applied to the wall of the oögonium, into which it sends a tube, which comes into contact with the egg-cell, into which, in some cases, e.g. S. dioica, a nucleus passes from the fertilizing tube, and fuses with the single nucleus in the egg-cell. In most species examined, hovever, it has been found that although the fertilizing tubes are present, they are not functional, and the oöspores are formed without fertilization. Still other forms, e.g. S. ferax, seldom or never produce antheridia.

The ripe spores, after a period of rest, germinate by sending out a germ-tube which penetrates the nutritive body.

Related to the Water-moulds is the genus Pythium, some species of which are very destructive parasites. One of these, $P$. De Barya- 
num, is the cause of the disease of young seedlings called "dampingoff," the Fungus attacking the plant close to the ground, and causing the stem to rot off. The reproduction in Pythium is much like that of the true Water-inoulds.

Monoblepharis, etc.-Similar in many respects to the Water-moulds, are a number of curious aquatic Fungi, which have been especially studied by Professor Roland Thaxter (22). One of these, Myrioblepharis (Fig. 120, C), has large multiciliate zoöspores like those of Vaucheria. Monoblepharis (Fig. 120, A, B) has uniciliate zoöspores, and fertilization is effected by motile spermatozoids, as in the Chlorophyceæ.

\section{Order III. Peronosporineæ}

This very characteristic order includes a number of very destructive parasitic

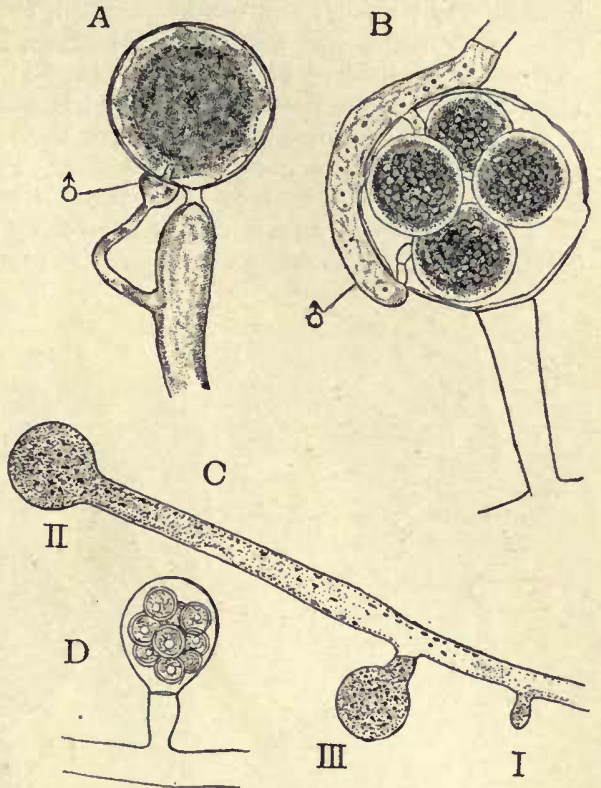

F1g. 119. - A, Rhiphidium Americanum, fertilization of the ooggonium by antheridium ; $\odot(\times 240)$. (After Thaxter.) $B$, Achlya Americana, fertilization $(\times 300$.) (After Trow.) $C, D, S a p$ rolegnia ferax, development of the oögonium $(\times 110)$; the oöspores, $D$, develop without fertilization.

Fungi, causing some of the most serious diseases of plants. The Fungus lives within the tissues of the host plant, occupying the spaces between the cells into which suckers (Haustoria) are sent, by which the parasite absorbs the contents of the cells.

Albugo Candida. - One of the best known of the Peronosporinere is the "White-rust" (Albugo caridida), which often attacks the Shepherd's-purse (Capsella) and other Cruciferæ, where its growth causes great deformation of the host, the flowers and young fruits being especially affected (Fig. 121). The common name is derived from the white blisters which are produced by the masses of spores formed below the epidermis of the host. The epidermis is finally broken through and the masses of spores set free. In the Eastern States, a common species is $A$. bliti, which grows upon the Pigweed (Amarantus sp.) and allied plants and $A$. portulaco, upon the Purslane (Portulaca oleracea). 
The vegetative portion of the Fungus consists of irregular, thick-walled, undivided hyphæ, which follow closely the intercellular spaces in the stem and leaves. Toward the outside of the stem, where the cells are smaller, the hyphæ become very irregular and much branched, their extremities forming close tufts of short branches just below the epidermis. The haustoria, which are freely developed, are little globular bodies connected with the hypha by a slender neck (Fig. 121, D). The protoplasm of the hypha is multinucleate.

Conidia. - The non-sexual spores, or Conidia, are cut off in succession from the short terminal branches of the hyphæ. These conidial branches are known as "Basidia." The end of the basidium becomes somewhat enlarged, and slightly constricted, and is finally cut off by a transverse wall. 'This process is repeated until a chain of oval spores is produced, the lowest ones being the
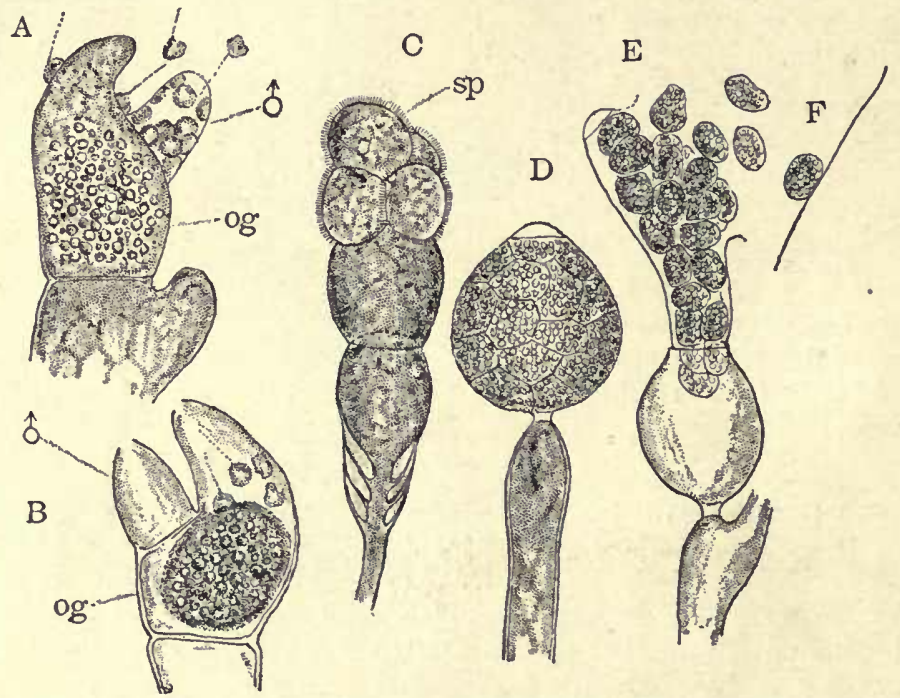

Fig. 120.-A, B, Monoblepharis insignis ; og, oögonium; ô antheridium. $C$, Myrioblepharis paradoxa, development of the multiciliate zoöspores, sp. $D, E, R h i$ phidium Americanum, zoösporangium $(\times 280)$; in $E$, the biciliate zoöspores, $F$, are escaping. (All after ThaxtER.)

last formed. In the young conidium the basal wall is thick, and most of this thickened wall becomes later absorbed, leaving only a narrow neck between the conidia, which are then very easily broken apart. With the growth of the conidial masses, the epidermis of the host is finally ruptured, and the spores are thus set free.

Germination. - Each conidium (Fig. 121, F) is an oval cell containing several nuclei. The conidia germinate promptly if supplied with water, the contents of each conidium dividing into as many parts as there are nuclei, and escaping from the conidium (zoösporangium) very much like the zoöspores of Saproleg. nia. The zoöspores are bean-shaped, with two lateral cilia. After a short period of activity they come to rest, and send out a germ-tube which penetrates the tissues of the young seedling plant or the very young axillary buds of the older ones. 
In the Mildews of the genera Peronospora, Plasmopara, etc., the conidia are formed singly at the ends of branching conidiophores which grow out through the stomata of the host and form a delicate downy coating upon the affected parts (Fig. 121, I).

Sex-organs. - Antheridia and oögonia (Fig. 122) much like those of the Sapro. legniaceæ are found in Albugo. They arise from the deep-seated hyphæ, the oögonium and antheridium forming from separate branches. The former is a globular cell filled with colorless protoplasm, and contains many nuclei. As it approaches maturity, there is found a single large egg-cell, surrounded by a nearly transparent layer of cytoplasm in which are numerous nuclei. In
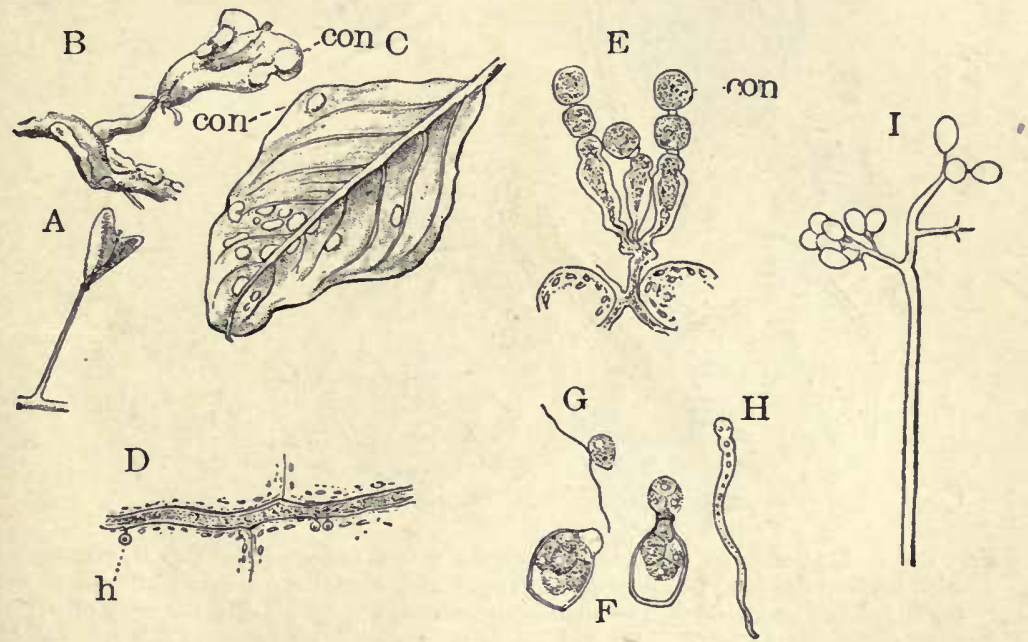

Fig. 121. - $A$, normal capsule of Capsella, slightly enlarged. $B$, capsule hypertrophied by the growth of Albugo candida; con, masses of conidia. $C$, leaf of Amarantus with patches of $A$. bliti. (Natural size.) D, hypha of $A$. candida, showing a haustorium, $h(\times 300) . \quad E$, conidiophores of $A$. candida $(\times 225) . F$, Germinating conidia of $A$, bliti $(\times 375)$. $G$, active, $H$, germinating zoöspores. $I$, conidiophore of Plasmopara viticola $(\times 150)$.

A. candida the egg-cell contains but a single nucleus, in $A$. bliti there are many.

The antheridium is irregular in shape and contains several nuclei. It sends a tube through the oögonium wall to the egg, into which its contents are discharged. When the egg contains but one nucleus, a single antheridial nucleus fuses with it; where the egg is multinucleate, there is a fusion of each eggnucleus with an antheridial one.

The egg now develops a wall and becomes a resting-spore (Fig. 122, D), about which is developed a dark brown sculptured wall, which is deposited npon it principally by the activity of the nucleated protoplasm in which the young spore is imbedded.

The resting-spores are not set free until the tissues of the host decay. They germinate either by forming zoöspores, or by developing a germ-tube at once. 
Among the common Peronosporineæ may be mentioned Phytophthora infestans, the Potato-fungus; Plasmopara viticola, the Vinemildew; Peronospora Schleideni, the Onion-mould, as well as many other destructive species.
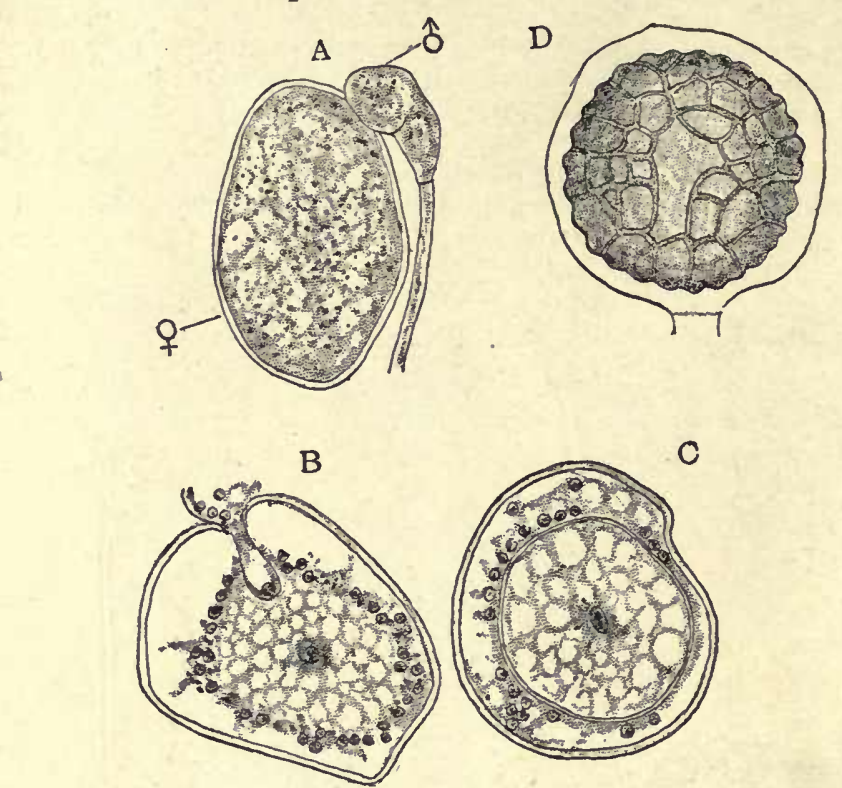

Fig. 122. - A, $C$, Albugo candida. A, young sexual organs $(\times 450) . \quad B$, oögonium, with antheridial tube penetrating the egg, which contains a single nucleus. $C$, the fertilized egg surrounded by a membrane, outside of which lies the zone of nucleated periplasm $(\times 525) . \quad D, A$. bliti, oögonium with ripe spore $(\times 525) .(B, C$, after WAGER.)

\section{SUbClass II. Zygomycetes}

The Zygomycetes, of which the Black-moulds are the most familiar examples, differ from the other Phycomycetes in not producing motile reproductive cells. Where a sexual reproduction is known, it consists in the fusion of two similar cells by a process of conjugation not unlike that of the Conjugatæ, but it is not likely that this resemblance indicates any relationship between the two groups. There are two orders, Mucorineæ and Entomophthorineæ, the former being mostly saprophytes, the latter parasites.

\section{Order I. Mucorineæ}

The order Mucorineæ includes several families, mostly saprophytes but some parasitic, known popularly as Black-moulds, as the spores and fruiting hyphæ are usually black. As a type of the order 
we may select the very common Mucor stolonifer (Rhizopus nigricans), belonging to the family Mucoraceæ (Figs. 123, 124). This common Mould forms a dense fleecy white mycelium upon the surface of many articles of food, and appear's spontaneously upon bread exposed to a moist warm atmosphere. The hyphæ are thin-walled, colorless at first, but turning dark with age. Slender rootlets are sent down into the nutrient substratum, and from this point, branches of two kinds are produced, - upright ones (sporangiophores) and horizontal slender runners, or stolons, which strike root, and produce a new crop of sporangiophores. The protoplasmic contents are quite colorless,
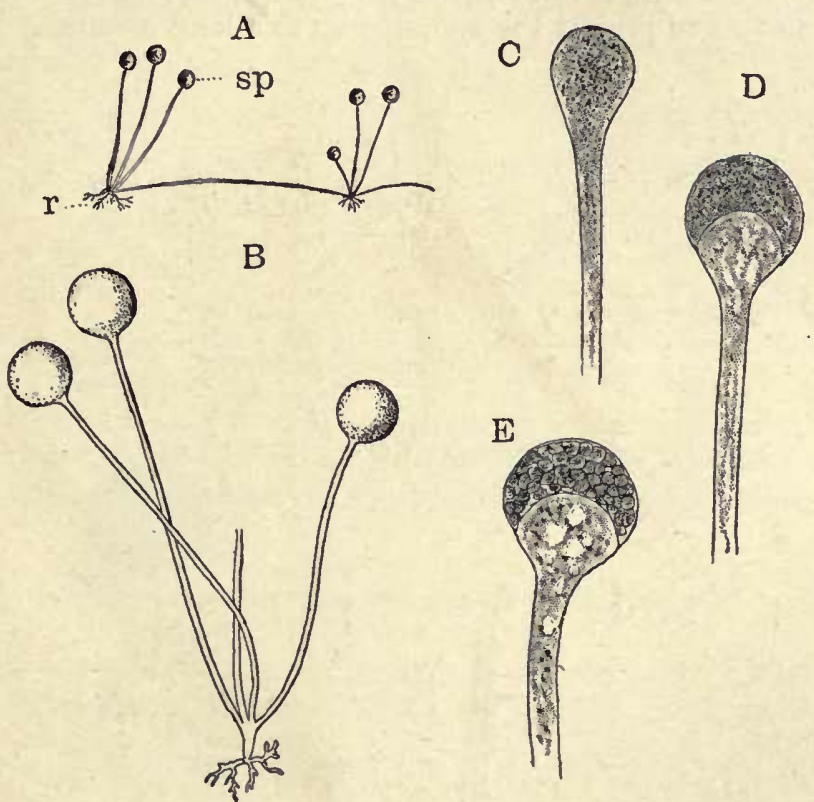

FIG. 123. - Mucor stolonifer. A, sporangiophores connected by stolon, and sending down roots, $r$, slightly enlarged. $B$, young sporangiophores, more highly magnified. $C-E$, development of sporangium $(\times 200)$.

densely granular in the growing branches, and often containing conspicuous granules. Sometimes, as in the Water-moulds, streaming movements are visible.

Sporangium. - Each sporangiophore becomes enlarged at the end, which finally is cut off as a globular sporangium. The partition wall is convex, and grows into the sporangium in the form of a dome, leaving only a narrow space between it and the outer sporangium-wall. The protoplasm within this space becomes divided by deep clefts into a number of parts which divide further until a large number of small bodies (spores) are produced. Fach of these becomes surrounded by a thick wall, which assumes a smoky black color, this being also 
the case with the wall of the stalk of the sporangium. At maturity the outer membrane of the sporangium, which in many Mucoraceæ contains minute calcareous bodies, becomes mucilaginous, and on being wet, dissolves and sets free the ripe spores, which germinate promptly if placed in water; and if supplied with proper nutriment they grow with great rapidity, and soon develop a new mycelium.

Pilobolus. - In the genus Pilobolus (Fig. 125, B, C), which grows abundantly upon stable manure, the stout sporangiophores are much distended just below the sporangium. When the latter is ripe, a ring-shaped break occurs around its base, and the fluid contained in the distended bulb below the sporangium is suddenly liberated with such force as to project the sporangium to a long distance. Where
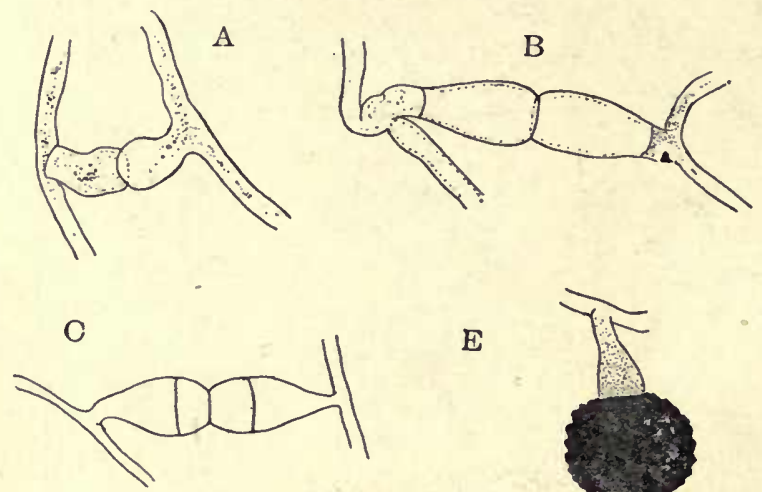

E
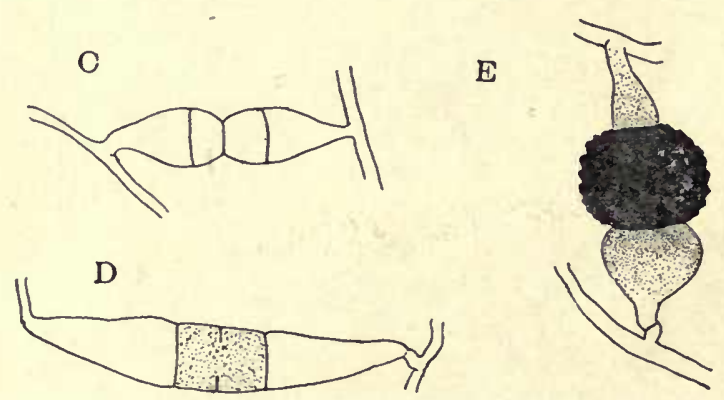

FIG. 12t. - Mucur stulonifer. Development of zygospore. $A-B, \times 225$. $C-E, \times$ about 90 .

the plants are grown under a bell-jar, its inner surface soon appears dotted with the adherent sporangia thrown off in this way.

In other genera, e.g. Chætocladium and Syncephalis, the spores are conidia, somewhat like those of Albugo. They may be borne singly or in chains (Fig. 125, A).

Sexual Reproduction. - Zygospores, formed from the union of two cells borne at the end of short branches, are found in many of the Mucorineæ, but as a rule they are of somewhat rare occurrence. In Mucor stolonifer (Fig. 124) the process begins by the sending out of short branches from neighboring hyphæ, which grow toward each other and finally come into contact. The protoplasm in these branches, which become much enlarged, is very dense and granular, and from the end of each a cell is cut off which forms one of the 
gametes. The cell-wall separating the two cells now is absorbed and their contents fuse. Whether the nuclei fuse in pairs, as in Albugo bliti, is not known, but it is not improbable. The zygote increases greatly in size, at the expense of the protoplasm in the branches upon which the gametes were formed. It becomes finally filled with dense granular contents, and the wall becomes black and opaque. The ripe zygote (zygospore) shows three membranes, the outer of which is formed from the original membrane of the conjugating cells.

In Piptocephalis the zygospore

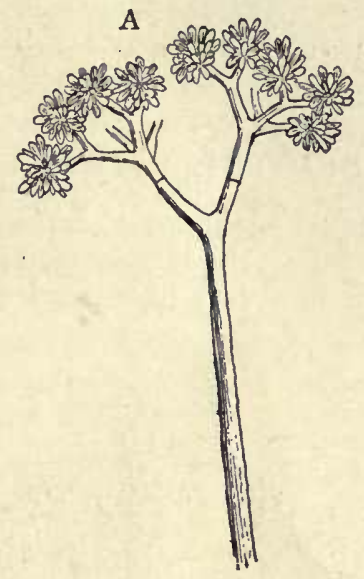

Frg. 125. - A, Piptocephalis Freseniana $(\times 300)$. (After Brefeld.) $B, C$, Pilobolus crystallinus $(B, \times 25 ; C$, $\times 50) ; w$, drops of water; sp. sporangium.

is formed as an outgrowth at the point of junction of the gametes, and not by their direct fusion. In Mortierella the zygospore is surrounded by a dense growth of hyphæ, which completely conceals it.

\section{Order II. Entomophthorineæ (Thaxter, 20)}

The Entomophthorineæ are Fungi parasitic upon insects of various kinds, which are killed by their attacks (Fig. 126). The commonest form is Empusa musco, which attacks the common house-fly. The infested flies are sometimes met with, especially in the autumn, stuck to window-panes, and surrounded by a whitish halo of the Fungusspores. The germinating spores penetrate the body of the insect, probably through the thin membrane between the rings of the body or through the stigmata. Within the body of the host, the Fungus grows rapidly, forming, by budding, a great number of short hyphal joints, which sometimes become dormant for a longer or shorter period. After these have completely exhausted the nutritive matter from the host, which then dies, if suitable conditions of temperature and moisture are provided each hyphal body develops one or more basidia which break through the thin places in the integument of the insect. Upon emerging, each basidium has cut off from its extremity a single conidium, or perhaps more exactly a sporangium containing a single spore which completely fills it. These conidia are shot off, 
much as in the case of Pilobolus, and it is these discharged conidia which form the halo about the dead fly.

Zygospares.-Zygospores, quite like those of the Mucorineæ, have been found in a number of the Entomophthorineæ (Fig. 126, C), and in some forms similar spores are developed without fertilization

\section{SERIES II. EUMYCETES (TRUE FUNGI)}

Very much the greater part of the Fungi belong to the Eumycetes, or, as they are sometimes called, the Mycomycetes. The Eumycetes are so modified that they show very little trace of any relationship
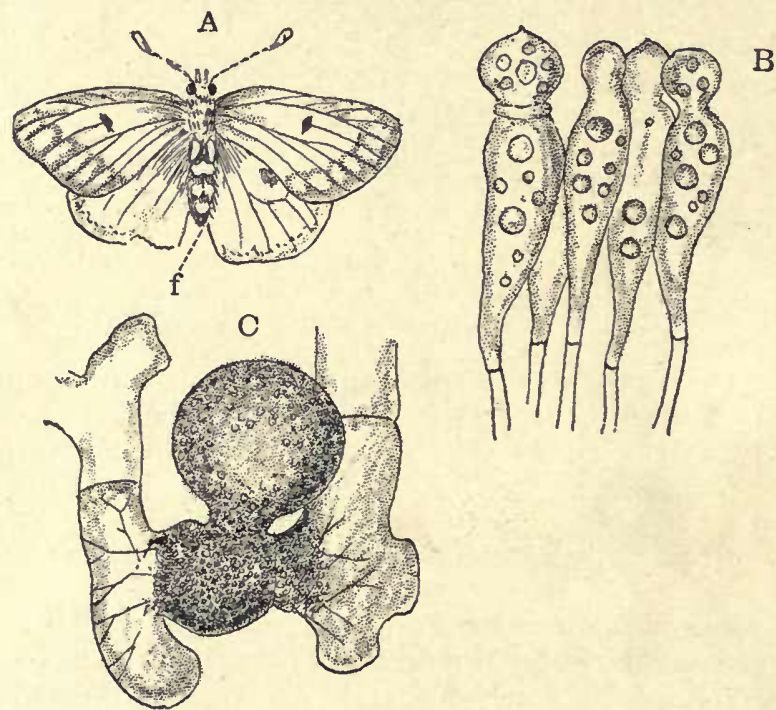

Fic. 126. - A, Buttertly (Colias), attacked by Empusa sphærosperma, f. $B, E$. musc, group of conidiophores $(\times 230)$. C, zygospore-formation in $E$. sepulchralis $(\times 230)$. (All after Thaxter.)

with the green plants, and their classification presents many difficulties. With a few exceptions they readily fall into two great divisions or classes, which are not evidently related to each other. These are the Ascomycetes or Sac-fungi, and the Basidiomycetes, which include the Toadstools, Puffballs, Rusts, and many of the most familiar of the larger Fungi. A third class, Lichenes, is sometimes added, but this is a somewhat artificial group, as some of its members are related to the Ascomycetes, others to the Basidiomycetes.

Mycelium. - The mycelium in the Eumycetes is usually composed of hyphæ with cross-walls or septa at regular intervals, and formed 
in succession back of the apex of the hyphæ, which thus shows a definite apical growth.

Reproduction. - Spores of various kinds are produced, sometimes borne directly upon the mycelium, but more cornmonly confined to special structures, the spore-fruit or sporocarp, which may reach a large size in the large fleshy Fungi. Sexual reproduction has been demonstrated in a small number of the Eumycetes, but in most of thein no trace of any form of sexuality has been found, although it is quite likely that it exists in a larger number than is at present supposed.

Biology. - Both parasitic and saprophytic forms are found among the Eumycetes. Some forms, like the Rusts and Smuts, are extremrely destructive parasites, others, like the Mushrooms, Puffballs, etc., are saprophytes, usually living upon dead vegetable matter. In these forms the mycelium is buried in the nutrient substratum, only the large sporophores being visible above its surface.

\section{Class I. Ascomycetes}

The Ascomycetes, or Sac-fungi, include the major part of the Fungi and exhibit great variety in structure and size, as well as in their habits. While they may develop several kinds of spores, there are always found the ascospores, which are formed by freecell formation within special cells, kuown as asci. In the lowest types, the Hemiascii, the number of ascospores in the ascus is large, but in much the greater number it is regularly eight.

Ascospore-formation. - The young ascus (Fig. 127, A) in typical Ascomycetes contains two nuclei lying in the

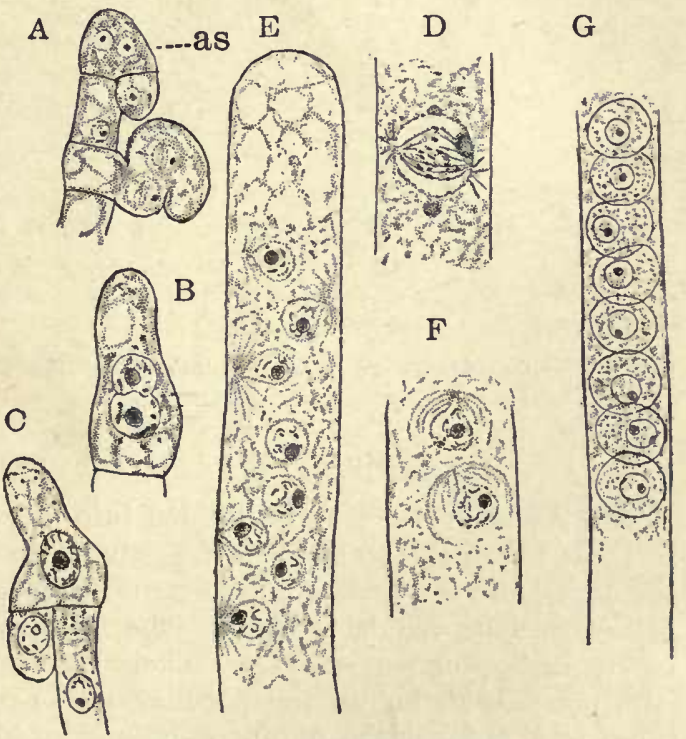

Fig. 127.- Pyronema confluens. Development of the ascus. (After HARPER.) $A$, ascogenous hypha, with young ascus at the summit, containing two nuclei. $B$, older ascus, the nuclei fusing. $C$, ascus with single nucleus derived from the fusion of the two primary nuclei. $D$, nucleus of ascus, dividing. $E-G$, develop.ment of the ascospores. 
granular vacuolated cytoplasm. The two nuclei fuse into a single one, which then undergoes repeated divisions until eight free nuclei are formed. At the poles of the nuclear spindle there is a conspicuous "aster" of radiating fibres. Each free nucleus has close to it a well-marked aster which persists after the division is complete (Fig. 127, E-G). The nucleus develops a beak from which the aster-fibres radiate. The latter next arrange themselves in the form of a wheel about the beak of the nucleus and gradually increase in length and finally cut out a nearly spherical mass from the cytoplasm, which encloses the nucleus, and thus forms the young spore. A firm wall is developed about the spores, which are imbedded in the remaining cytoplasm of the ascus $(G)$.

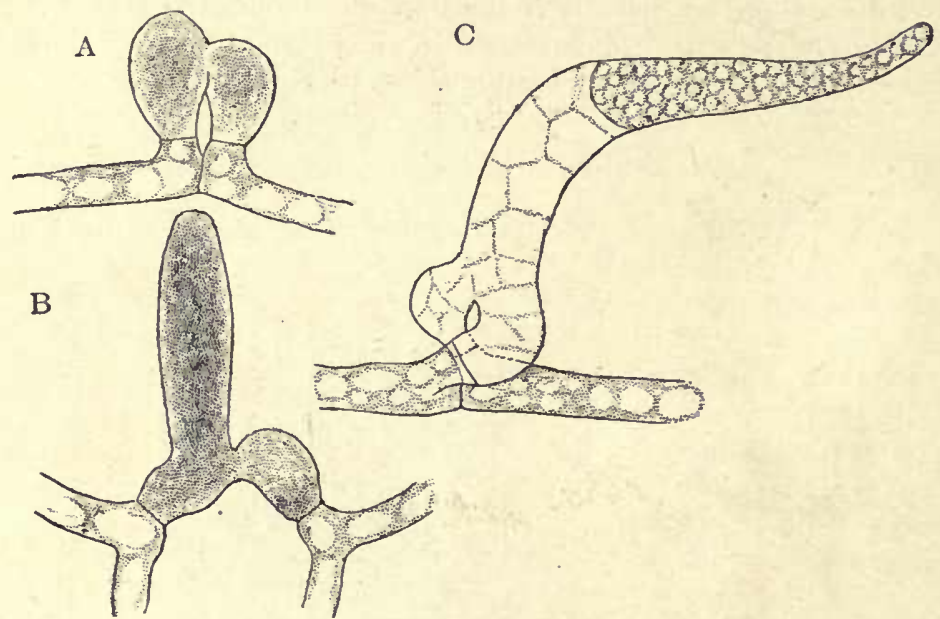

Fig. 128.-Dipodascus albidus. Development of the ascus. (After LAGerheim.) $(\times 500$.

\section{Subclass I. Hemiascinea}

The Ascomycetes may be divided into two subclasses, the Hemiascineæ, in which the spores are produced in large numbers within the ascus, and the Euasceæ, where the number of ascospores is, with few exceptions, regularly eight. The Hemiascineæ are few in number, parasites or saprophytes. Their reproduction is for the most part non-sexual, but in the peculiar genus Dipodascus (Fig. 128) there is a fertilization of an oögonium by fusion with the antheridium, the fertilized oögonium developing into an ascus containing numerous spores. In the genus Protomyces, which is not always placed among the Ascomycetes, the numerous spores formed in the asci (?) fuse in pairs before germination, much like the gametes of the lower Algæ. 


\section{Subclass II. Euasceas}

\section{Order I. Protoascineæ}

The lowest of the Euasceæ, the Protoascineæ, comprise two families, the Saccharomycetaceæ and the Endomycetaceæ. The former include the Yeast-fungi, whose relation to the Ascomycetes is somewhat doubtful; the second family includes a small number of very simple but unmistakable Sac-fungi.

Yeast-fungi. - The Saccharomycetaceæ or Yeast-fungi, unlike the other Eumycetes, develop no mycelium, but consist of isolated oval cells which multiply by rapid budding, and only exceptionally become elongated enough to suggest a hypha. The oval vegetative cells contain granular cytoplasm, wbich usually has one or more conspicuous vacuoles (Fig. 129). A nucleus is prob-

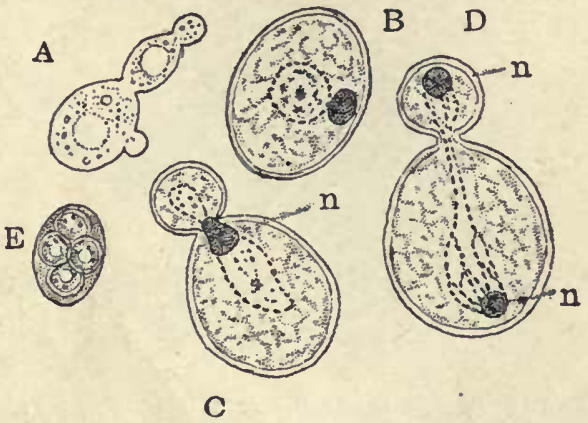

FIG. 129. - Sacharomyces cerevisiz. $A$, active cell, budding $(\times 1000)$. $B-D$, dividing-cells (after WAGER); $n$, nucleus. $E$, cell containing four spores. (After ReEss.)

ably always present, but it is not readily demonstrated. Under certain conditions, as for example when the cells are cultivated upon slices of carrot or potato, the contents of the cells may form (usually) four spores, so that the cell is transformed into a very simple ascus.

Alcoholic Fermentation. - It is from an economic standpoint, however, that the Yeast-fungi are of special interest, as they are the most important agents of alcoholic fermentation. If the cells are placed in a solution of sugar, or a starchy mixture, there soon begins the development of alcohol, with an evolution of $\mathrm{CO}_{2}$. It is the escape of the latter in the fermenting dough which causes it to rise. The yeast-cells feed upon the starch and sugar, which are attacked by certain peculiar substances (ferments) excreted by the growing yeast-cells. Of these, diastase converts starch into soluble sugar's, and invertase cbanges cane-sugar into glucose and fructose, which are available to the yeast-cells for food.

The different species of yeast behave very differently with regard to the fermenting substance, and in making wine and beer the character of the fermented product is largely dependent upon the kind of yeast employed; hence the importance of regulating this.

Endomycetaceæ. - The Endomycetaceæ comprise a small number of forms differing from the Yeasts in having a true mycelium and usually 4-8-spored asci. In Eremascus the asci arise from the fer- 
tilization of an ascogonium; in Endomyces and the other genera, the plants are entirely non-sexual.

\section{Order II. Protodiscineæ}

The Protodiscineæ comprise a small number of very simple Ascomycetes, which are mostly parasites upon Flowering Plants.

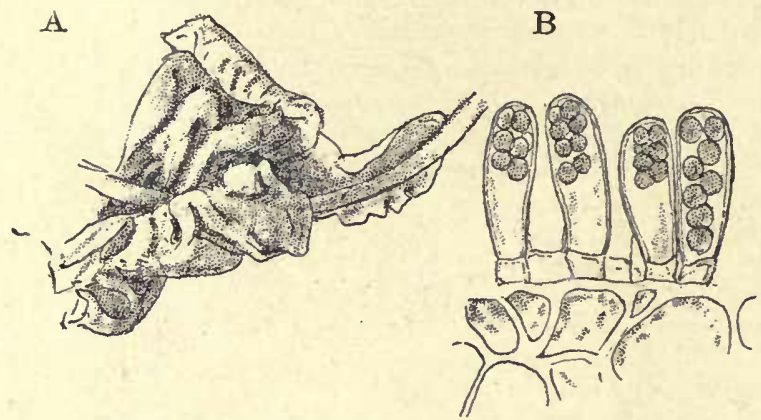

Frg. 130. - $A$, base of a Peach leaf distorted by Exoascus deformans. $B$, asci $(\times 550)$.

One of the most familiar is Exoascus deformans, which causes the distortions of peach leaves known as "Curl" (Fig. 130). The mycelium of the Fungus grows between the layers of the cuticle of the epidermal cells of the host, and is composed of many short joints, all of which become ultimately transformed into the asei which burst through the cuticle and form crowded patches covering the leaf. This is thereby very much enlarged and crumpled, and of ten made bright red in color. The masses of ripe asci form a delicate gray powdery film over the affected parts.

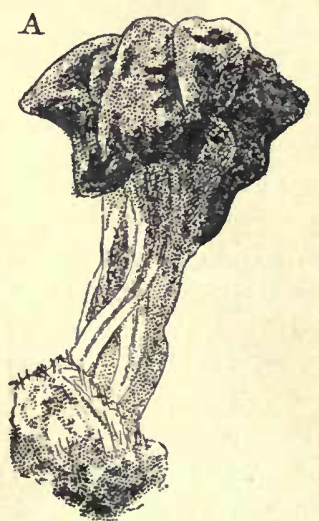

Fir 131. $A$, Helvella lacunosa. $B$, Morchella conica. (Natural size.)

\section{Order III. Helvellineæ}

In these Fungi the mycelium is well developed, and the asci are borne upon large, characteristic fruiting-bodies, upon parts of which the closely set asci form a continuous layer (Hymenium) consisting of the asci interspread with sterile filaments, or paraphyses. One of the commonest forms belonging to this order is the Morel (Morchella), whose spore-fruit consists of a stout stalk terminating in a conical cap which is deeply honeycombed with broad pits lined with the 
hymenium. This is one of the best known of the edible Fungi (Fig. 131, B).

\section{Order IV. Pezizineæ}

The Pezizineæ are a large order containing more than three thousand species, among which are a number of conspicuous forms. Among the most familiar are the Cup-fungi (Peziza, Ascobolus, etc.). The mycelium is well developed, composed of extensively ramifying hyphæ which are usually buried in the nutrient substratum. Most of the genera are saprophytes, growing both upon animal and vegetable matter. A smaller number are parasites, either strictly so, as in the genus Pyrenopeziza, one species of which, $P$. emergens, has been found

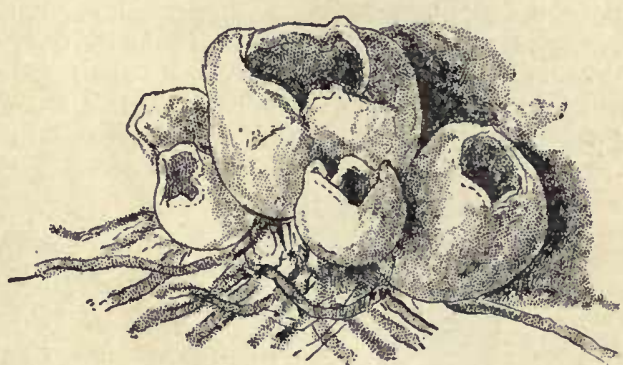
FIG. 132. - A Cup-fungus. Peziza sp. (Natural size.) upon the Blue-gum (Eucalyptus globulus) in California; or they may be parasitic in their earlier stages and complete their development in the dead tissues of the host. This is seen in various species of Sclerotinia.

Reproduction. - A few of the Pezizineæ produce conidia, but in most of them there are only the ascospores, which are commonly

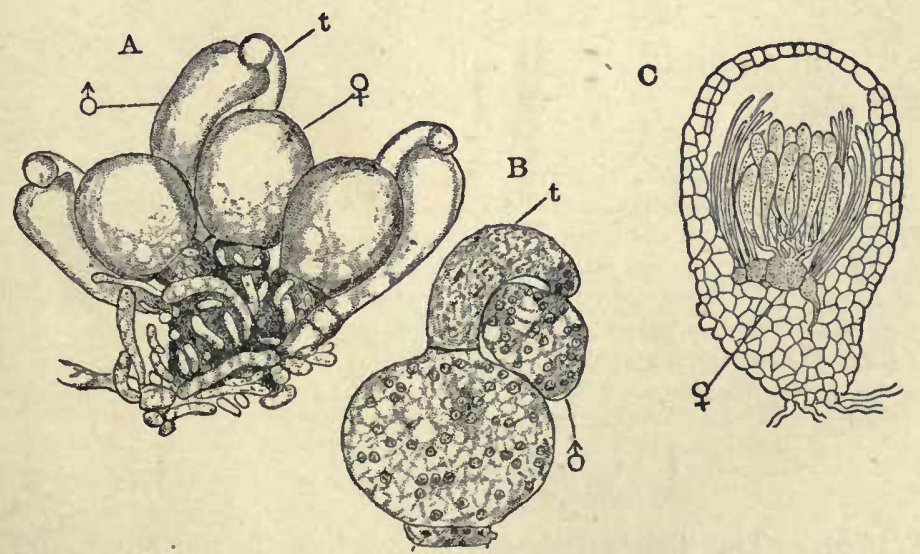

Fig. 133. - A, B, Pyronema confluens. (After Harper.) A, group of sexual organs, highly magnified. ' $B$, antheridium, $\diamond$, fusing with the trichogyne, $t$. $C, A s-$ cobolus sp. Young spore-fruit, in optical section, showing the ascogenous cell, $\&$, from which the ascogenous filaments arise ( $X$ about 225). (Somewhat schematic.) 
eight in number, but may be much more numerous; e.g. Streptotheca Boudieri has thirty-two. The asci are closely set, and with the paraphyses form a continuous hymenium lining the interior of the usually cup-shaped, large spore-fruit. These are often very conspicuous and brilliantly colored - yellow, orange, or scarlet.

Sex-organs. - The formation of the spore-fruit is usually purely vegetative. but in a few instances, of which the best known is Pyronema confluens (Fig. 133), there are well-developed sexual organs. These in Pyronema consist of a nearly globular oögonium, having a curved tubular outgrowth, the conjugating tube, which is later cut off by a basal wall from the body of the oögonium. The antheridium is a somewhat club-shaped body and fuses with the conjugating tube, into which its contents pass. The basal wall of the conjugating tube next becomes partially absorbed, and allows the contents of the antheridium to pass over into

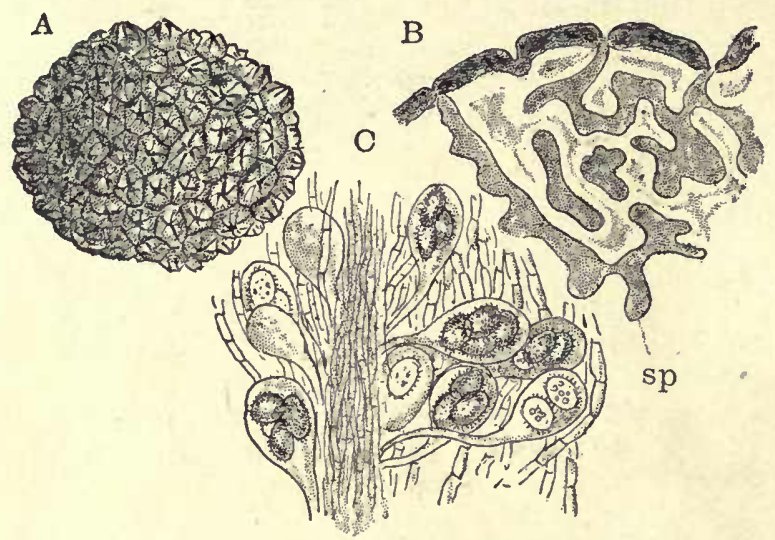

FIG. 134. - A, a Truffle (Tuber æstivum). (Natural size.) $B$, section of another form, T. rufum, showing the sporogenous region, sp. C, asci of T. rufum. (All after 'Tulasne.)

the body of the oögonium, where each antheridial nucleus fuses with one of those in the oögonium, sonewhat as in the compound fertilization in Albugo bliti.

Fruit-body. - From the fertilized oögonium filaments bud out, the ascogenous hyphæ, and upon these are later formed the asci. From the hyphæ adjacent to the oögonium numerous branches develop which grow in among the ascogenous hyphæ, and form the paraphyses which contain the pigment and give the fruit its color. 'The subhymenial tissue and the outer tissues of the fruit also arise from the sterile filaments. The asci produce eight spores in the manner already described.

\section{Order V. Tuberineæ}

Truffles. - The Tuberineæ, or 'Truffles, live for the- most part entirely underground. It is supposed that the mycelium in many of them grows connected with the roots of various trees, forming the so-called Mycorhiza, but the development of the group is imperfectly 
known. The fruits are also borne underground, and in the genuine Truffles are tuberlike bodies which contain numerous canals or chambers lined with the ascogenous hyphæ. In most of the genera there are the usual eight ascospores, but in the genuine Truffle ('Tuber) (Fig. 134) the number may be reduced to two, or even a single one. The order is poorly represented in America, but in the Pacific States a number of forms have been recorded.

\section{Order VI. Plectascineæ}

The Plectascineæ are, for the most part, saprophytic Fungi, whose well-developed mycelium may be either buried in the nutrient substratum or is superticial. Some of them, e.g. species of Penicillium, may produce alcoholic fermentation. In many species conidia of characteristic form are developed, in addition to the asci. The latter in the lowest types, the Gymnoascaceæ, are borne directly on the mycelium, but in most of them closed fruits, somewhat like those of the Tuberineæ, are produced; and these in a few eases have been shown to result from the fertilization of an oögonium.

\section{Aspergillaceæ. -} The most familiar members of the order belong to the Aspergillaceæ, and are known popularly as Blue or Green Moulds from the color of the conidia, which are produced in great numbers. Of these forms, the Herbarium-mould (Aspergillus herbariorum) and the common Bluemould (Penicillium glaucum) are well known (Fig. 135). The latter grows on almost any organic substances, and is the most ubiquitous of all Moulds. From the white mycelium there are sent up delicate upright conidiophores, which in Aspergillus develop a bulbous swelling at the apex, while in Penicillium the conidiophore forms several short terminal branches. From the enlarged terminal body, or from the ends of the 
branches, small papillæ (sterigmata) grow, from each of which is developed a chain of small conidia, very much as in Albugo.

Sex-organs. - In both Aspergillus and Penicillium the sexual organs (Fig. 135, C) consist of two nearly similar short filaments, which become closely intertwined, and presumably the contents of one pass into the other. About them there is then formed a mass of sterile hyphæ, which completely encloses them and forms the wall of the Perithecium, as the closed fruit is called. From the oögonial body the ascogenous hyphæ are developed, and the small oval asci (Fig. 135, E) are formed in large numbers. The outer cells of the perithecium form a yellow rind.
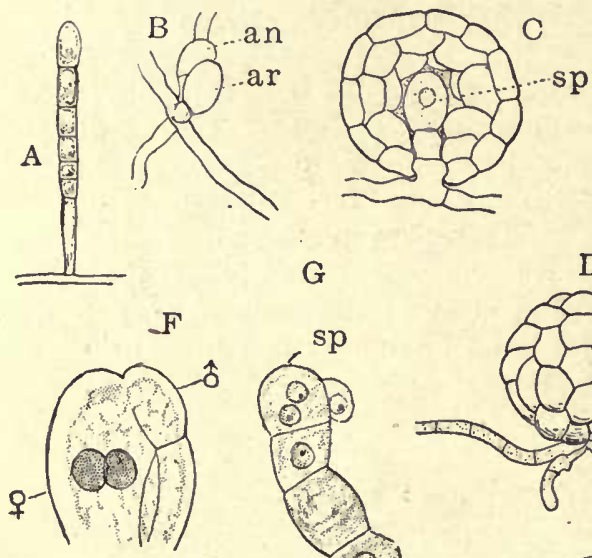

G
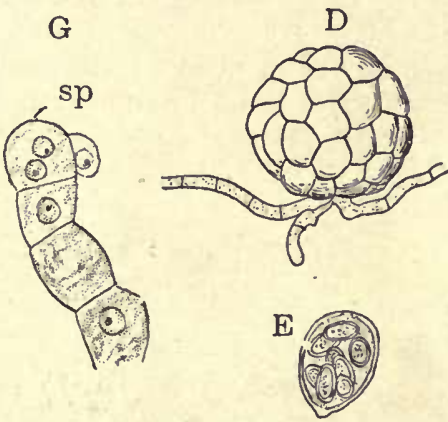

Fig. 136. - Sphærotheca castagnei. A, conidiophore. $B$, sexual organs. $C$, young perithecium, optical section. $D$, mature perithecium. $E$, single ascus. $F$, fertilization; the nucleus of the antheridium has passed into the ooggonium. $G$, ascogenous filament developed from the fertilized oögonium. ( $F, G$, after HARPER.)

\section{Order VII. Pyrenomycetes}

The Pyrenomycetes, or Black Fungi, comprise over ten thousand species, and include a great variety of both parasitic and saprophytic forms. The mycelium may be composed of delicate, quite distinct hyphæ, as in the common powdery Mildews, or the vegetative body of the Fungus may be composed of closely coherent hyphæ, which in sections apparently form a parenchymatous tissue. Often this cohesion is so great, and is combined with such a thickening and blackening of the cell-walls, that the cell-structure becomes very obscure, and a large, hard, black mass (Stroma) is produced, from which later the fruiting bodies arise.

Reproduction. - The Pyrenomycetes are many of them characterized by a marked polymorphy; i.e. spores of several kinds are 
produced, which in some cases have led to confusion in their classification. The formation of the spore-fruit is in some cases preceded by the development of sexual organs and a genuine fertilization, but there is little question that in many of them no trace of sexuality remains.

Perisporiales. - The simplest of the Pyrenomycetes are the Mildews and their allies (Perisporiales). The best known of these are those belonging to the family Erysipheæ, including many common plant-parasites. The Rose-mildew (Sphcerotheca pannosa) is, perhaps, the best known. These Mildews are superficial parasites, the mycelium forming a delicate webby growth upon the surface of the leaves of the host, into which are sent short haustoria (Fig. 138). The mycelium sends up numerous upright conidiophores, which divide into a series of short cells. These cells then swell somewhat, and break off as barrel-

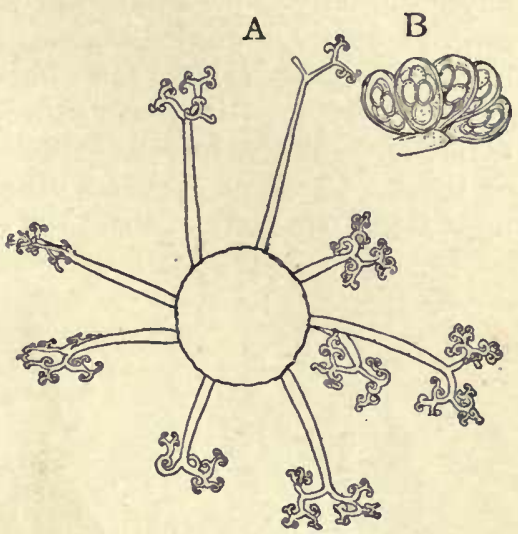

FIG. 137.-Microsphæra Alni. A, perithecium, with dichotomously brauched appendages $(\times 150), B$, asci.

shaped conidia. It is these masses of conidia which give the powdery appearance to the actively growing Fungus.

Sex-organs. - The sexual organs have been especially studied in Sphorotheca castagnei (Fig. 136), which is conmon upon the Dandelion, and upon a variety of other plants as well. The sex-organs are first formed after the production of conidia begins to decline. The oögonium is an oval cell with a single nucleus. From a branch close by, the antheridial branch grows up, in close contact with

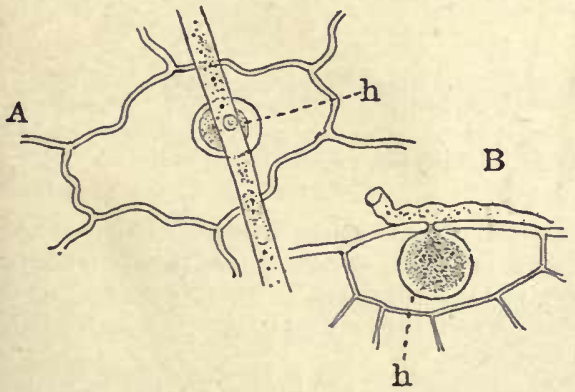

Fig. 138. - Erysiphe sp. (on Chrysanthemum), showing the haustoria, $h$. $A$, from above; $B$, in section $(\times 450)$.

dark-colored, so that the ripe perithecia appear the whitish mycelium.

In Erysiphe and other genera the ascogenous hypha derived from the oögonium develops several asci (Fig. 137). From the outer and'fuses with the oögonium, into which its nucleus passes, the nucleus fusing with that of the oögonium (Fig. 136, F). The fertilized oögonium divides transversely, and forms a short filament, the end-cell of which becomes the single ascus found in the ripe perithecium $(G)$. The wall of the perithecium is formed from filaments growing up about the ooggonium and completely enclosing it. It is not unlike that of Aspergillus, and also has its outer cells r as black specks scattered over

the oögonium. The antheridial

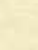


cells of the perithecium there are developed curious appendages, upon the form of which the genera are largely based (Fig. 137, A).

Of the higher Pyrenomycetes, some are parasites, others saprophytes, usually growing on dead wood, leaves, etc. Xylaria, Cordyceps, Pleospora, Sordaria, are among the common genera. The large black masses of Xylaria are sometimes very conspicuous upon dead wood. Cordyceps is a parasitic genus, some of whose species, e.g. C. militaris, attack insects, especially caterpillars, which are killed by them. Claviceps purpurea causes the disease known as "Ergot" upon Rye. In many of these the ascospores are multicellular.
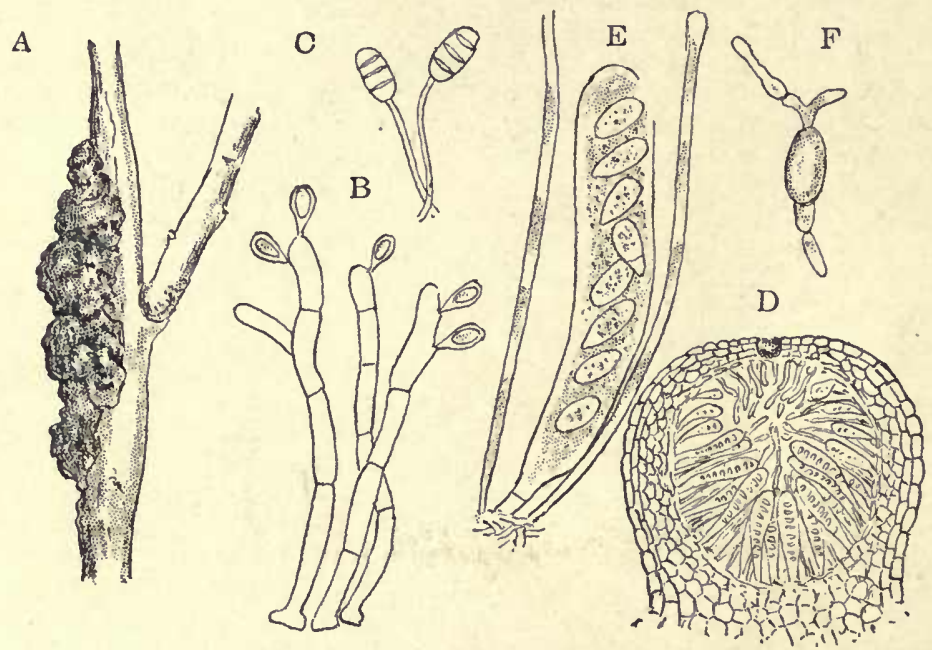

Fig. 139. - Black-knot (Plowrightia morbosa). A, Plum twig attacked by Blackknot. (Natural size.) $B$, conidia. $C$, stylospores. $D$, section of perithecium, showing asci and paraphyses. $E$, single ascus, with two paraphyses, more highly magnified. $F$, germinating ascospore. ( $B-F$, after FARLow.)

As a type of the higher Pyrenomycetes, we may select a very striking form of the eastern United States, Plowrightia morbosa, which causes the destructive disease of plums and cherries, known as "Black-knot." The mycelium grows within the tissues of the younger twigs, where it produces unsightly rough swellings which give the disease its common name.

In the spring the mycelium shows active growth, and breaks through the outer layers of the bark, upon which it produces dense masses of conidia, borne upon rather thick-jointed conidiophores (Fig. 139, B). This conidial form was at first described as a distinct genus under the name of Cladosporium.

As the summer advances the knot grows larger, and in its outer part may be detected the young perithecia, which were present, however, earlier in the season. These form little papillæ with a pore at the apex opening into the cavity within. Late in the autumn the young asci, intermixed with paraphyses, may be seen lining the perithecia, but the asci $(\mathrm{E})$ are not ripe until midwinter. 
The ascospores escape early in the spring, and probably infect the tender shoots of the trees as they begin their growth.

Stylospores. - In cavities, much like the perithecia, there are found in smaller numbers the stylospores, single spores, divided into four cells (C) and borne upon long stalks.

Spermogonia. - Another form of reproductive bodies are the Spermogonia, or Pycnidia, sulall receptacles like the perithecia, but containing many extremely small bodies, which are ejected in a mass surrounded by a mucilaginous substance. It is possible that these may be male reproductive cells, but this is by no means certain.

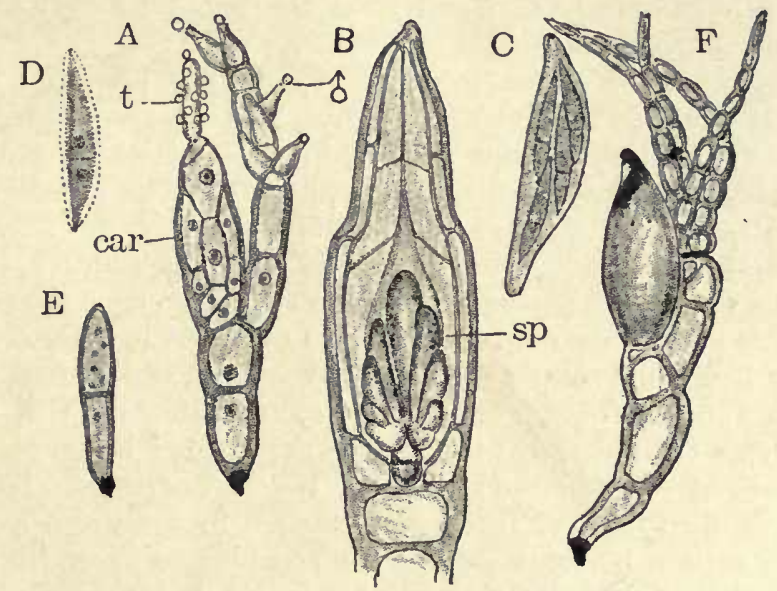

Fig. 140.-A-E, Stigmatomyces Baeri. A, mature plant, with antheridia, o, and carpogonium, car. The trichogyne, $t$, has numerous spermatia attached to it. $B$, young perithecium, optical section; $s p$, asci. $C$, ripe ascus. $D$, ascospore. $E$, germinating ascospore. $F$, Laboulbenia compressa. (All after Thaxter.)

\section{Order VIII. Laboulbeniaceæ (Thaxter, 2I)}

Our knowledge of this remarkable order of Fungi is principally due to the important researches of Professor Thaxter. They are minute forms parasitic upon insects, especially beetles, the majority attacking such forms as are aquatic or living near the water. The asci are produced as the result of fertilization of an organ which closely resembles the procarp of the higher Rhodophyceæ, and fertilization is effected by means of spermatia which attach themselves to the trichogyne of the procarp. The asei bud out from a sort of auxiliary cell, and each ascus contains four or eight spores, which are generally two-celled. The germinating spores attach themselves to the surface of the insect, and form a more or less developed haustorium which may penetrate into the host, but the host is not killed by the attacks of the Fungus, as is the case with most other entomogenous Fungi (Fig. 140). 


\section{Class II. Basidionycetes}

The second great division of the Eunycetes, the Basidiomycetes, comprises a large number of the most conspicuous and highly developed Fungi, such as the Mushrooms and Toadstools, Puffballs, Rusts, Smuts, etc. They always possess a well-developed mycelium, which may be composed of quite distinct elements, or these may be closely compacted into rootlike masses, or leathery plates, which grow to great size. The latter type is found in some Fungi which grow upon decaying wood and form the tough leathery mycelium between the woody layers.

Reproduction. - Various forms of spores are produced, but the characteristic type is the basidiospore. The basidiospores are single conidia borne upon special structures, basidia, which are usually undivided club-shaped cells, upon whose end the spores are produced, attached to delicate prominences, the sterigmata (Fig. 147, F). The basidiospore appears first as a sinall swelling at the apex of the sterigma, into which passes part of the protoplasm from the basidium. The spore usually develops a thickened wall, but in the lower forms like the Rusts and Smuts the wall of the basidiospore remains very delicate, and the spores germinate as soon as they are ripe. In the lower types (Hemibasidii) the basidia are divided by septa, and are less constant in form than those of the ligher types (Eubasidii), which are also in most instances arranged in a definite hymenium covering certain portions only of the conspicuous spore-fruit. This arrangement is not nearly so evident in the lower members of the class. The latter are largely parasites upon Flowering Plants, while the Eubasidii are, for the most part, saprophytes.

The Basidiomycetes may be arranged in two series, the Hemibasidieæ, a small group of parasitic forms in which the basidia arise directly from certain resting-spores; and the Eubasidieæ, in which true basidia are found which do not, as a rule, arise directly from resting-spores. Of the Hemibasidieæ the greater part are the socalled Smuts (Ustilagineæ), very destructive parasites upon many of the higher plants.

\section{Subclass I. Hemibasidieze}

The Ustilagineæ derive their popular name from the masses of sooty-black chlamydospores which they produce. The most familiar of these to American students is the common Corn-smut (Ustilago maydis), which so commonly attacks the flowers and young ears of Indian-corn. The sprouting corn is infected soon after it appears above ground, and the parasite grows within its tissues much as does the White-rust within the tissues of its host. While the mycelium grows for the most part in the intercellular spaces, it sends suckers into the host-cells, and the hyphæ may themselves penetrate into the cells. The hyphæ are septate, thick-walled, and irregular in outline. 
Reproduction. - As a rule the formation of spores is confined to the flowers of the host, but almost any part of the plant may show the galls containing spores. In the Corn-smut (Fig. 141) the spores may be formed either in the male flowers of the tassel, or in the female flowers forming the younger ear. The infected tissue becomes enormously enlarged, so that a single kernel may become as large as a walnut. $\boldsymbol{A}$ section of such infected tissue shows the extensively branched irregular mycelium of the Smut packed in the intercellular spaces between the enlarged host-cells, and at the ends of the short branches myriads of small black spores are seen, which arise singly or in groups within the ends of these branches. These black masses of spores shiminering through the overlying white tissue give the peculiar livid color to the hypertrophied kernels, which are finally burst open, exposing the dense sooty mass of spores mixed with the disorganized fragments of the mycelium and the dead tissue of the host.

The spores do not germinate at once, but remain until the next season, when they germinate by sending out a short, thick hypha

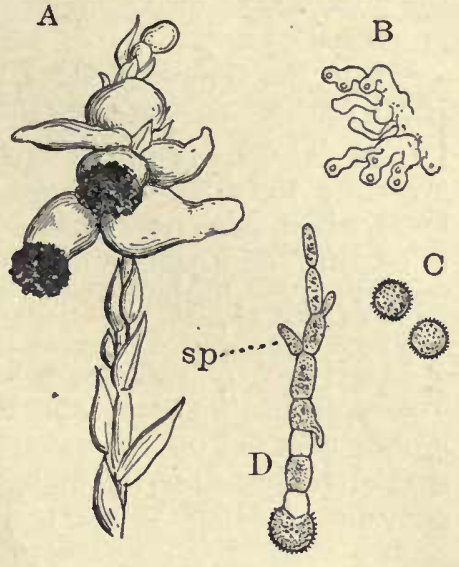

FIg.141.-Ustilago maydis. A, staminate flowers of Indian-corn, attacked by "Smut." $B$, mycelium, showing the beginning of spore-formation. $C$, ripe spores $(\times 600)$. $D$, germinating spore, developing a promycelium, with sporidia, $s p . \quad(D$, after BREFELD.)

which becomes divided into a row of short cells, each giving rise to a single conidium. The conidia may multiply by budding, very much like the Yeast-fungi, if grown in a fluid medium. Ordinarily the conidium grows by sending out a germ-tube which penetrates the delicate tissues of the seedling as it appears above ground, and insures its infection by the parasite.

Tilletiineæ. - A second order of Smuts, the Tilletiineæ, contains also a number of destructive parasites. Tilletia tritici causes a serious disease of Wheat, and Urocystis cepulce is very destructive to Onions. The genus Doassansia attacks various aquatic and marsh plants, especially species of Arrow-head (Sagittaria).

\section{Subclass II. Protobasidiomycetes}

These resemble in some respects the Hemibasidii, and differ from the Autobasidiomycetes, or higher forms, in having the basidia divided. There are two orders, Auricularineæ and Tremellineæ. The most important members of the first order are the Rusts (Uredinales, Acidiomycetes), resembling in some respects the Ustilaginex, and like them among the most destructive of plant-parasites. 
They are endoparasites; the mycelium, which is often colored orange by the presence of an oily pigment, grows vigorously within the host, upon which sometimes there are produced distorted growths or galls.

While the Smuts produce but one type of spores, many of the Rusts are characterized by the production of several quite different forms. This polymorphy is complicated in some species by heterœcism; i.e. the different stages may be borne upon entirely different hosts, often quite unrelated. This has resulted in much confusion in naming the Rusts, as different stages of the same plant have been named under the impression that they belonged to quite unrelated Fungi.

Five forms of spores are known, the Acidiospores, Uredospores, Teleutospores, Sporidia, and Spermatia. The last named are very minute cells cut off from slender basidia contained in special flaskshaped receptacles (Pycnidia, Spermogonia), which usually accompany the Ecidia. It has been supposed that the spermatia may be
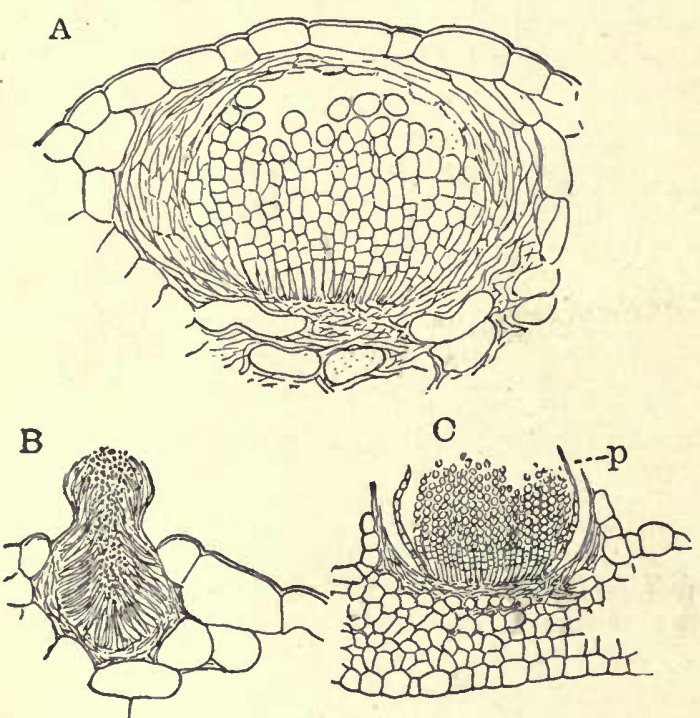

Fig. 142. - Uromyces caladii. A, section of the leaf of Arisæma triphyllum, with young æcidium $(\times 150) . B$, section of spermogonium. $C$, section of ripe æcidium ( $\times$ about 40$) ; p$, peridium. male reproductive cells, but there is no direct evidence as to their real nature, no oögonium, or corresponding structure having been demonstrated in any of them.

The duration of the mycelium in the Rusts is various. Where the host is an annual, the life of the parasite may be limited to a few weeks, but where the host is perennial, the mycelium often persists from year to year, growing with the developing tissues of the host-plant, upon which the same mycelium produces annual crops of spores.

The number of Rusts is very large, probably not far from two thousand species, which may be arranged in two categories, the 
Autœcious forms, in which the different kinds of spores are produced upon the same plant, and the Heterœcious forms, in which the æcidium is produced upon another host, as in the Wheat-rusts and the Cedar-rusts.

Of the former type a common species in the Eastern United States is Uromyces caladii (Fig. 142), which often appears in great numbers upon the leaves and stems of the Indian 'Jurnip (Arisama triphyllum) as well as upon some other Araceæ. The diseased plants have the leaves much reduced in size, and thickly covered with the small yellowish pustules caused by the æcidia, or first form of spores produced by the Fungus. A careful examination of the upper surface of the infected leaves will also show minute blackish specks, the spermogonia. A section of the leaf shows the crowded mycelial threads occupying the intercellular spaces, which become densely interwoven and compacted where the young spore-groups are to form. The young æcidium is a globular mass of hyphæ, within which a closeset layer of basidia is developed, from whose ends chains of conidia (Acidiospores) are cut off. These have colorless walls and orange-red, oily contents, and from mutual pressure appear polygonal in section. The outer row of basidia develop similar chains of cells, which become thickwalled, and are coherent so that they form a distinct receptacle which encloses the æcidiospores, the whole structure constituting the Ecidium, or æcidium fruit. This breaks through the epidermis of the leaf, and the æcidium opens, so that it becomes cup-shaped, and as the pressure on the spores is relieved, they become rounded in shape and drop off.

Teleutospores. - If the same plants are examined a few weeks later, there will be found similar pustules, which appear black, and on examination are found to be composed of single, thick-walled spores, borne upon long stalks. These are the Teleutospores, and in this species germinate only after a long period of rest (probably not until the next spring).

In California an extremely common Rust is Puccinia malvacearum (Fig. 143), which is especially abundant upon Malva borealis, but also causes much damage to the Hollyhock in gardens. Teleuto- 
spores only are developed, and these germinate as soon as they are ripe. From each of the two cells, a short tube (Basidium, Promycelium) is sent out, into which pass all the spore-contents. The basidium divides usually into four cells. Each of these develops a single sterigma, which swells at the end, and forms the single sporidium into which all of the contents of the basidial cell pass. The sporidium germinates at once, sending out a short tube which prob-

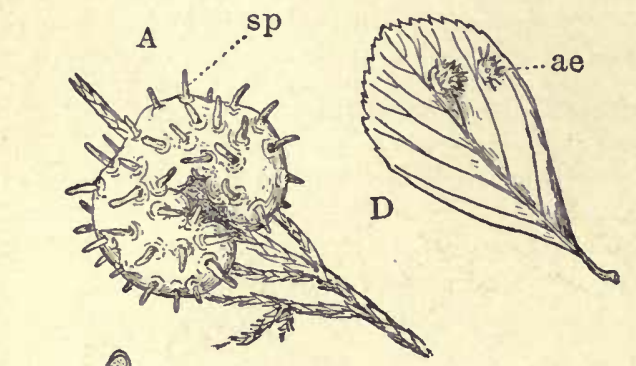

ably, as in other cases observed, enters the host through a stoma.

Gymnosporangium. Of the heterocious Rusts, one of the most striking is Gymnosporangium, of which there are several species causing the "Cedar-apples," gall-like excrescences (Fig. 144) upon the twigs of the Juniper and Red-cedar. If these galls are examined in the early spring, the surface shows slight elevations, beneath which masses of young teleutospores may be found. As these mature, they burst through the epidermis and appear as little orange-colored spikes (Fig. 144, A). These consist of masses

Fig. 144.-Gymnosporangium macropus. $A$, "Cedarapple" upon Juniperus Virginiana, with young masses of teleutospores, $s p$. (Natural size.) $B$, two teleutospores; in one the promycelium, pr, has begun to grow. $C$, promycelia, with sporidia, $x$. $D$, leaf of Cratægus crus-galli, with the æcidium (Rœstelia) of Gymnosporangium.

of two-celled spores borne upon long stalks, which are of gelatinous consistence, and swell up into large masses of soft, orange-yellow. jelly, when they are wet. Spores taken from such a mass may be found germinating, much as those described for the Mallow-rust. Sometimes, instead of forming sporidia, the promycelium divides into joints which separate as single spores.

The sporidia germinate promptly, but will not infect the Cedar. If placed upon the young leaves of Apple or Hawthorn, however, the germ-tube will penetrate them, and in the course of a few weeks there will be produced orange-colored, somewhat thickened spots, upon whose upper surface the black spermogonia are borne; upon the lower side, the æcidia appear, which were first described under 
the generic name, Rœestelia. The wall of the æcidium is very much developed, and finally protrudes as a long tube (Fig. 144, D). The æcidiospores are carried back to the Cedar, and infect it afresh.

Wheat-rust. - Heterœcism was first observed in one of the Wheatrusts (Puccinia graminis) whose æcidia are produced upon species of Berberis. Upon the Wheat two sorts of spores are borne, the redrust, or uredospores, long-stalked unicellular spores (143, D), and the black-rust, or-telentospores. The former appear first, and.germinate promptly, entering the young leaves through the epidermal cells, and rapidly spreading the rust. The teleutospores appear later, generally upon the stalks. These remain dormant during the winter as black spots upon the stubble, forming the next season the sporidia, which in the spring infect the young Barberry leaves.

The commonest species of Wheat-rust in the United States is Puccinia rubigo-vera, which is universally distributed. This species forms its æcidia upon various members of the Borage family, e.g. Hound's-tongue (Cynoglossum), but the infection of the wheat is mainly due to the uredospores developed from the mycelium which has passed the winter within the wheat-plant-often the "volunteer wheat," or possibly other Grasses.

\section{The Auriculariaceæ}

This is a small family of which the best known is the genus Auricularia, which develops conspicuous ear-shaped fruit-bodies upon rotten wood. The spores in these forms are borne upon jointed basidia, much like those of the Rusts.

\section{Order II. Tremellineæ}

The Tremellineæ resemble the Auricularineæ in having the basidia divided, but in these the division is longitudinal, the spores being formed upon very long sterigmata, which are in twos or fours, resulting from the splitting of the primary basidium (Fig. 145). Various species of Tremella are common upon dead

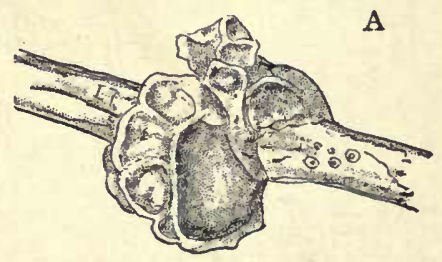

B

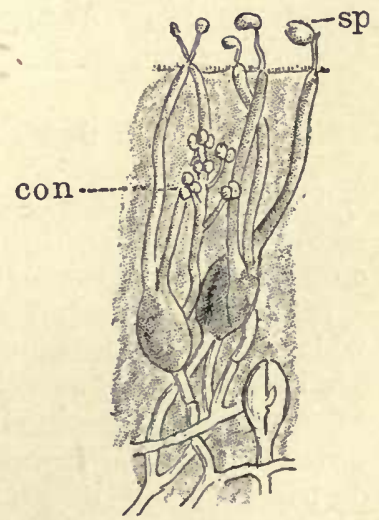

Fig. 145. - A, Tremella sp., the gelatinous fruit-body attached to a dead twig. (Natural size.) $B$, conidia, con, and basidiospores, $s p$, of $T$.lutescens $(\times 400)$. ( $B$, after BREFELD.) 
twigs, etc., where their bright orange-yellow or amber-colored gelatinous fruit-bodies are conspicuous.

\section{Subclass III. Autobasidiomycetes}

The greater number of the more familiar larger Fungi belong to the Autobasidiomycetes, of which the Toadstools and Puffballs are the types. The lowest members of the group do not form a definite fruiting-body, but in most of them this is large and of very characteristic form.

\section{Order I. Exobasidiineæ}

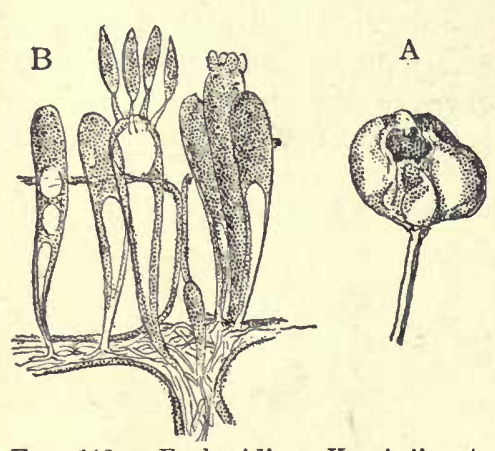

FIG. 146.-Exobasidium Vaccinii. A, flower of Menziesia, hypertrophied by Exobasidium. (Natural size.) $B$, basidia and spores $(\times 525)$. ( $B$, after WORONIN.)
Among the simplest members of the Autobasidiomycetes, are the Exobasidiineæ, represented by the genus Exobasidium. E. Vaccinii (Fig. 146) is widespread throughout northern regions, where it attacks Cranberry, Huckleberry, and related forms. The plant is strictly parasitic, growing within the intercellular spaces of the host, upon which it causes extraordinary gall-like deformations of the leaves and flowers. These diseased parts are sometimes entirely destitute of cholorophyll and present a pink or white color.

The spores are borne upon basidia of typical form, which are developed from the ends of the mycelial filaments which break through the epidermis of the host.

\section{Order II. Hymenomycetineæ}

The Hymenomycetineæ comprise more than ten thousand species, - the largest order of the Fungi, - and exhibit great variety in the character of both the mycelium and the fruiting parts.

Mycelium. - The mycelium always consists of septate hyphæ, which may be loose and delicate in texture, but more commonly are compacted into rootlike strands, or sometimes hard masses or sclerotia. In some species growing in decaying wood, the mycelium grows between the layers of wood, and develops continuous leathery or papery layers of great extent. In such forms as the common Mushroom, the mycelium spreads widely through the substratum, which it binds together, so that large masses may be taken out, which consist in large part of the mycelium. This constitutes the "spawn" of the Mushroom which is used for propagation. 
Biology. - Most of the Hymenomycetinere are saprophytes upon dead vegetable matter, but a few are parasites, like certain species of Polyporus, whose large, bracket-shaped fruits are so conspicuous upon the trunks of trees, into whose living tissues the Fungus penetrates through wounds in the bark.

Reproduction. - No form of sexual organs have yet been certainly demonstrated for any of the Hymenomycetinex, and the large fruiting-bodies arise as vegetative growths from the mycelium. In most of them basidiospores only are known, but conidia borne upon branching hyphæ have been found in some species-e.g. Coprinus (Fig. $147, \mathrm{~F})$. The basidia form a definite layer, or hymenium, which may cover the whole surface of the fruiting-body, but is more commonly restricted to certain definite regions, such as the "gills" of the Mushroom.

The fruit is made up of more or less closely compacted hyphæ, which may be grown together, so as to resemble a true parenchyma. In the persistent fruits, such as that of Polyporus, the walls of the cells are hard and woody in texture, but they are more commonly delicate, and the fruit may be very ephemeral. Cells containing pigments, and extensive milk-tubes, occur in some species.

The mycelium, in the larger forms, lives for many years, growing constantly and producing successive crops of fruits, or occasionally the fruits are themselves perennial.

Classification. - The classification of the Hymenomycetineæ is based upon the form of the fruiting-body and the arrangement of the hymenium. In the simpler forms like Clavaria (Fig. 149, A), the hymenium covers uniformly nearly the whole of the branching fruiting-body. In Hydnum (Fig. 149, B) the form of the fruit varies, but the hymenium is confined to the pointed spikes which grow from certain portions of its surface.

The best-developed pembers of the order belong to the families Polyporaceæ and Agaricaceæ. The former include many conspicuous forms, of which the genus Polyporus is the type. To these belong the large, massive, shelf-shaped Fungi, which grow upon the trunks of trees or dead stumps. Another common genus is Boletus, which has an umbrella-shaped fruit, like a Mushroom, from which it differs, however, in the arrangement of the hymenium. This in all the Polyporaceæ lines the walls of tubular, or more open cavities, which appear as small pores upon the under surface of the fruit (Fig. 149, C).

\section{Agaricaceæ}

The Agaricaceæ comprise all the common Fungi known popularly as Mushrooms and Toadstools, and are characterized by the wellknown umbrella-shaped fruiting-body, bearing upon the lower face of the cap the dependent lamellæ or gills, upon whose surface the hymenium is borne. 
Most of the Agaricaceæ are saprophytes, growing most commonly upon soil rich in humus or decaying vegetable matter, but many of them grow also upon animal excrement, like the common genus Coprinus (Fig. 147), several species of which usually appear spontaneously upon horse-manure which is kept for a week or two under a bell-jar. The common field Mushroom (Fig. 148), also, grows especially well in pastures which have been enriched by the droppings of animals.

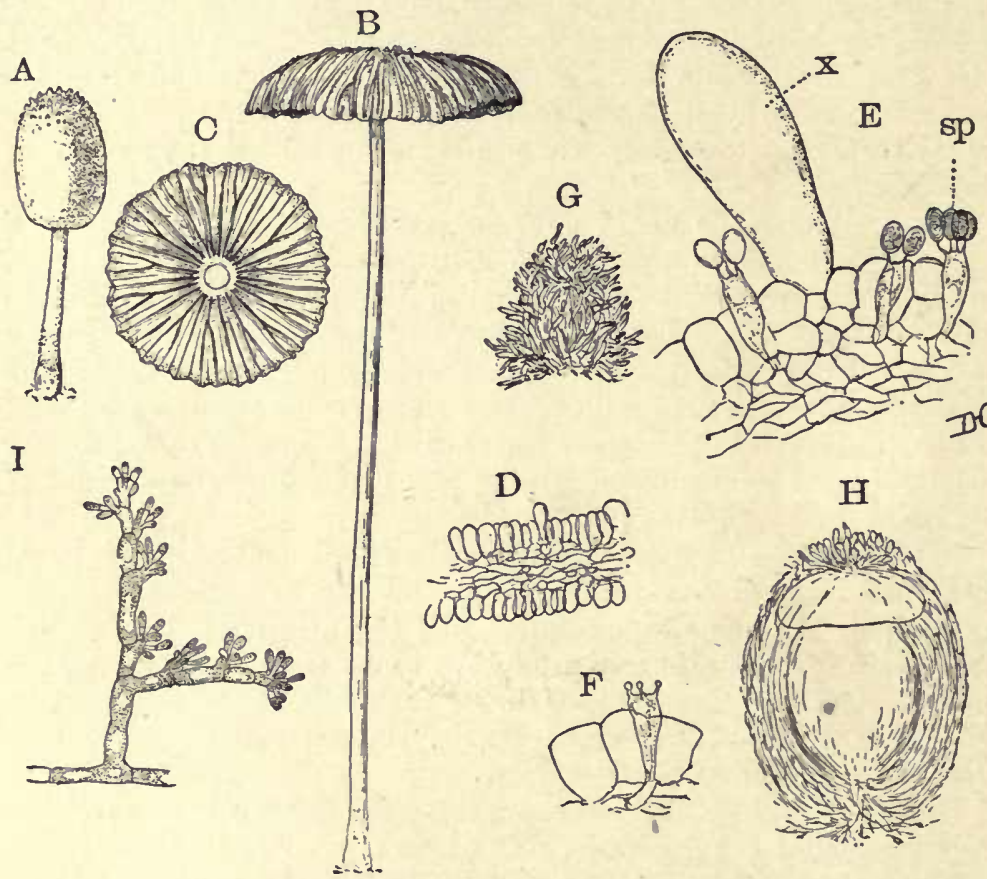

Fig. 147. - Coprinus. $A-H$, development of the fruit-body in Coprinus $s p . \quad A-C$, slightly enlarged, the others more highly magnified. $D$, section of young lamella. $E$, hymenium with mature basidia and cystidium, $x$. $F$, young basidium, with developing spores. $G, H$, young fruit-bodies. $I$, conidia of $C$. lagopus. ( $I$, after BREFELD.)

The mycelium in these forms spreads extensively through the substratum, and in the Mushroom must have a long period of growth before the fruits begin to form. Occasionally, as in Coprinus lagopus, branching filaments may arise from the mycelium, upon which conidia are borne; but usually the only type of spore developed is the basidiospore.

The formation of the fruiting-body begins in a small, compact mass of hyphæ (Fig. 147, G), which are at first entirely similar. In most 
forms this shows a central more compact body surrounded by a weft of looser filaments, which completely invests the young fruit. In Coprinus the young fruit soon shows the expanded cap (Pileus) at the top of the short, thick stalk. The cap, which is flat at first, grows downward over the stalk, which it completely covers. As the cap develops, there are formed upon its inner surface the radiating lamellæ or Gills, upon which later the hymenium is formed. A section of the gill shows that the inner tissue ('Trama) is composed of large, rather loose hyphæ, much like those forming the body of the fruit. The ends of these hyphæ are turned outward and form a layer of papillate cells covering the whole of the surface of the gill. This superficial layer is the hymenium, and some of its cells become later transformed into the basidia, while others remain sterile. Some of these sterile cells may become very much enlarged and form the "Cystidia."

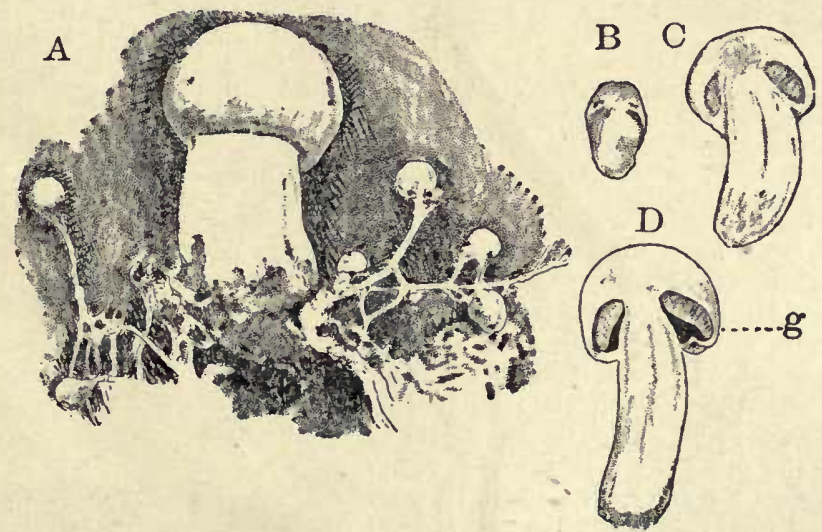

Fig. 148. - Mushroom (Psalliota campestris). A, mycelium with fruit-bodies in various stages of development. $B-D$, sections of young fruit-bodies, showing the development of the gills, $g$. (All after Atrinson.)

The basidia in Coprinus are club-shaped bodies tapering below and soinewhat flattened at the top, from which grow the sterigmata, which are usually four in number, but may be reduced to two or three (Fig. 147, E, F).

Development of Spores. - The development of the basidia and spores has been specially studied by Wager (26). In the young basidium there are two or more nuclei. These fuse into a single one, which later divides into four, corresponding to the four spores. The sterigmata begin to form after this division is complete, and most of the granular contents of the basidium pass into the spores, which reach their full size, and sometimes develop the brown wall, before the nuclei pass over from the basidium. The way in which the nuclei pass through the narrow sterigma into the spore has not been clearly demonstrated. After entering the spore, the nucleus divides into two. 
When the fruit is complete, there is, in Coprinus, a very rapid elongation of the stalk, due to absorption of water and great stretching of the cells.

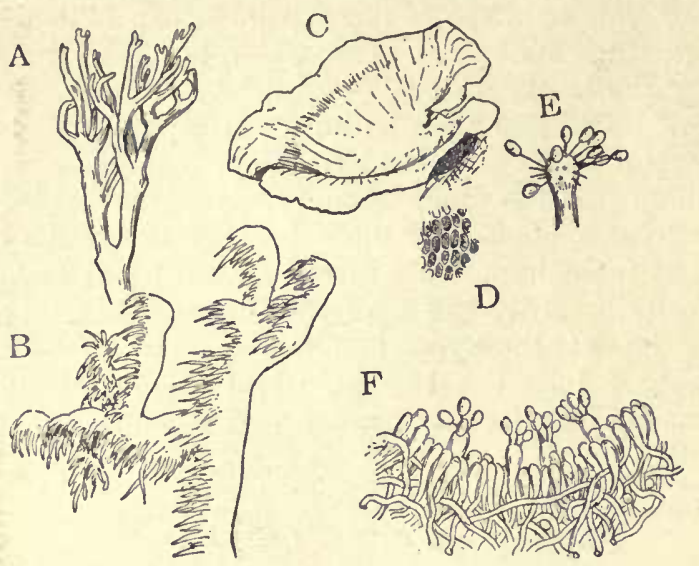

Fia. 149. - $A$, Clavaria cristata. (Natural size.) $B$, Hydnum ramosum. C, Polyporus $s p$. D, underside of $C$, enlarged to show the pores. $E, F, F$ omes annosus. $E$, conidia; $F$, hymenium, with basidia. $(E, F$, after BREFELD.)
The cap, which is closed up, opens like an umbrella, the gills splitting from the outside and flattening out very much like the silk between the ribs of an umbrella. 'The ripe spores are quickly shed, and the whole fruit collapses into a structureless, almost liquid mass.

Psalliota campestris. - The cominon Mushroom (Fig. 148) differs in some respects from the form just described, and is perhaps more typical of the family. The young spore-fruit is more solid than in Coprinus, and the formation of the cap takes place somewhat later. The gills are developed within a cavity which is only exposed when the spores are ripe. A longitudinal section through the young Mushroom shows two small cavities, which are really sections of a single circular canal, which separates the cap from the stalk. Almost completely filling this canal are the young gills, covering the lower face of the cap. At first the cap is no broader than the stalk, with which its margin is connected by a continuous layer of tissue - the Velum. As the lateral growth of the cap continues, the velum is finally torn away and the gills are exposed. The remains of the velum surround the upper part of the stalk like a collar, while fragments of the velum may often be seen fringing the margin of the cap.

The Agaricaceæ are the largest family of Fungi, including nearly five thousand species. Many of them are among the most valuable of edible Fungi, such as the true Mushroom (Agaricus [Psalliota] campestris), the Chanterelle (Cantharellus cibarius), and many others. On the other

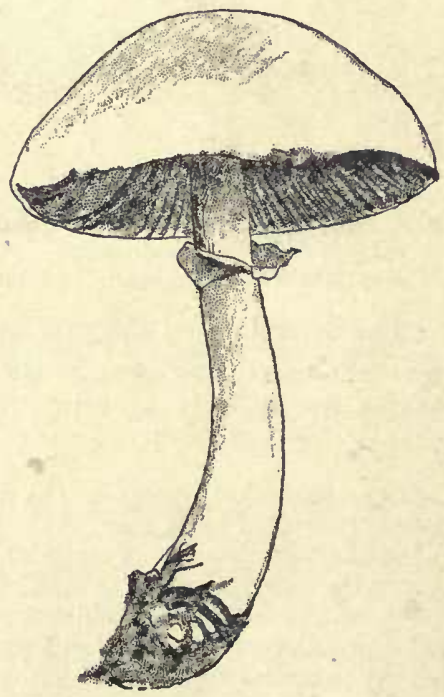

Fig. 150. - Lepiota naucina. (After Atrinson.) 
hand, some of them are extremely poisonous. Of the latter, the deadly Agaric (Amanita phalloides) is sometimes mistaken for the true Mushroom, from which, however, it differs very much. It has white gills, and the eap, when wet, is slimy. Moreover, it grows from a sort of cup or volva, which is quite absent from the edible Mushroom. Another very poisonous species is the Fly-agaric ( $A m a$ nita muscaria). It may be recognized by the bright yellow or red pileus covered with warty scales.

\section{Gasteromycetes}

The highest orders of the Basidiomycetes are often grouped together under the name Gasteromycetes, which are distinguished from the Hymenomycetineæ by having the spores borne within closed chambers, so that the interior of the fruit often shows a honeycombed structure. The fruiting-body may reach a very large size, as in the Giant Puffball, where it may be thirty to forty centimetres in diameter. Many of the so-called hemi-angiocarpous Hymenomycetes are to some extent intermediate in character between the lower ones and the more specialized Gasteromycetes. One very remarkable order, the Phallineæ, which is often in-

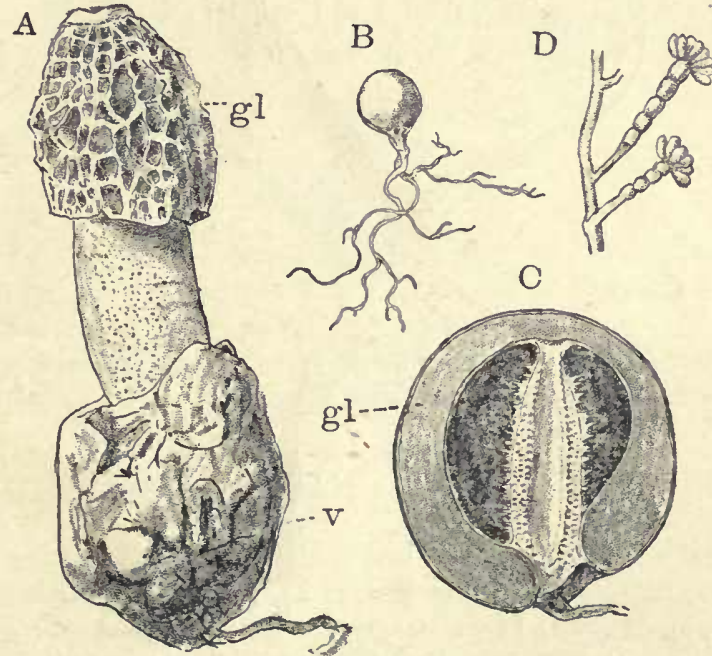

Fig. 151. $-A, C$, Ithyphallus impudicus. $A$, ripe fruitbody $(\times$ 8) ; $v$, volva; $g l$, gleba. $B$, mycelium with young fruit-body, slightly reduced. $C$, section of nearly ripe fruit-body. $D$, spores of Anthurus borealis. ( $D$, after BuRr.)

cluded with the Gasteromycetes, is also somewhat intermediate in character between them and the Hymenomycetineæ. In the Phallineæ the formation of the spores takes place within closed chambers, but when the spores are ripe, the tissue to which they are attached breaks through the outer covering of the fruit, and the spores are thus exposed. 


\section{Order III. Phallineæ}

The development of the fruit has been carefully studied in several forms, among them Ithyphallus impudicus, the common "Stink-horn," so called on account of its disgusting odor (Fig. 151).

Upon the subterranean mycelium the fruit-bodies are borne much as in the Mushroom, and in their early stages are solid, roundish bodies, white in color. These enlarge until they are nearly as large as a hen's egg, and on sectioning such a young fruit it is found to consist of an outer white shell, the Peridium, and a central-body of very complicated structure (Fig. 151, C). The latter

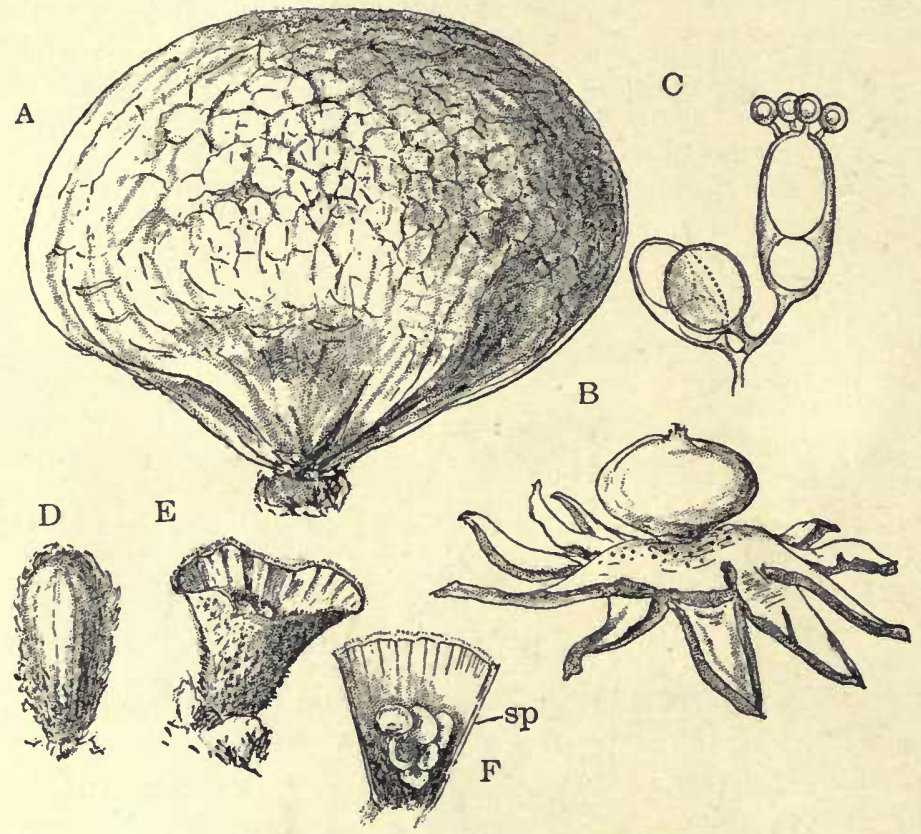

FIG. 152.-A, Lycoperdon cxlatum $\left(\times \frac{2}{2}\right) . \quad B$, Geaster sp. $(\times 1) . \quad C$, basidia of G. rufescens. $D-F$, Cyathus striatus $(\times 2)$. (C, after Tulasse.)

consists of a central elongated hollow core, which extends the whole length of the central-body. The outer portion of the latter forms a dome-shaped structure, whose interior is divided into chambers lined with the hymenium. This spore-bearing structure is the "Gleba." At maturity the cylindrical core elongates very rapidly, and, bursting through the peridium, carries up the capshaped gleba upon a stout hollow stalk. The tissues of the fruiting-parts are very mucilaginous, and the spores.are surrounded by a slimy fluid, which gives off a most offensive odor. This odor attracts carrion-insects, which are possibly of use in transporting the spores. In the curious genus Clathrus the complete central-body has the form of a hollow lattice-work, which is bright red in color. 


\section{Order IV. Lycoperdineæ}

The best known of the Gasteromycetes are the Puffballs, of the genus Lycoperdon (Fig. 152, A). The large fruits are globular, oval, or pear-shaped solid bodies, often of large size. A section through the young fruit shows a dense white mass of apparently homogeneous tissue; but later there are formed many chambers lined with the hymenium. As the fruit develops, the wall becomes differentiated into a firm, somewhat leathery peridium, which in the genus Geaster (Earth-star) is double. The sterile tissue between the spore-chambers is partly composed of delicate cells, which finally become completely disintegrated, and others whose walls become hard and persistent, and form much-branched threads (Capillitium), filling the interior as a loose, spongy mass mingled with the ripe spores. At maturity, the peridium breaks, and the powdery mass of spores is discharged. In Geaster (Fig. 152, B), the outer peridium splits into strips, which bend back, exposing the inner peridium, within which are contained the spores. The outer peridium is strongly hygroscopic.

\section{Order V. Nidularineæ}

The curious little Fungi of the genera Nidularia and Cyathus (Fig. 152, D-F) differ from the Puffballs in having the sporechambers surrounded by a separate peridium, so that they form little bodies, $s p$, lying within the open outer peridium, like eggs in a nest, hence the popular name of Bird's-nest Fungi for these little plants.

\section{LICHENS}

The remarkable group of Fungi known as Lichens do not constitute a natural morphological group, as its members belong to several widely separated orders of the Ascomycetes and Basidiomycetes; the greater part belonging to the former class. These Fungi are intimately associated with certain low Algæ or Schizophyceæ, upon which they are parasitic to a greater or less degree. The Algæ are completely included within the thallus, formed by the mycelium of the Fungus, or in some of the gelatinous Lichens, like Collema, the form of the Lichen is determined by the gelatinous Nostoc-colony, which is the host of the Fungus.

The Lichens were formerly ranked as a class coördinate with the Algæ and Fungi, it being supposed that the green cells, or "gonidia," were outgrowtlis of the fungal hyphæ. The researches of De Bary and Schwendener first showed that the green cells were 
really independent orgthisms, and these researches were followed by many others which soon placed the dual nature of the Lichenthallus beyond any question. It has been conclusively shown that the Algæ can live quite as well, or better, when removed from their association with the Fungus, which, on its side, dies, if deprived of its algal associates, or if not artificially supplied with the necessary food constituents. Careful experiment has also demonstrated the possibility of producing a Lichen-thallus by associating the germinating spores of the Lichen with Algæ which were growing free, and Möller even succeeded in producing small Lichens upon sterilized glass plates, by supplying them with artificial nutriment, but eliminating the Algæ from which the food ordinarily is derived.

Germination. - Under normal conditions, the Lichen-spores, on germinating, produce a mycelium of limited growth, which on coming in contact with the proper algal cells (Fig. 154, A) attaches itself to them and ultimately produces the complete Lichen. In case the green cells are not available, the mycelium dies as soon as it has exhausted the food-materials within the spore.

The Algæ which occur within the body of various Lichens are identical with species which also live quite independently. They represent most of the families of the Schizophyceæ and several of the lower families of Chlorophyceæ, most of the latter being Protococcaceæ, although a few Confervaceæ have also been found as the gonidia of Lichens. These Algæ, when associated with the Lichen, multiply only by fission; but in some cases, at least, when removed from their association with the Fungus, they develop zoöspores.

Parasitism and Symbiosis. - The amount of injury caused by the Fungus to the algal cells varies in different cases. Sometimes haustoria are sent into the cells, which are finally killed. Sometimes the haustorium penetrates the wall of the algal cell, but does not injure the protoplast. In still other instances, there is no penetration of the algal cells, and the substances taken from them must diffuse through their walls. It is clear, however, that the association of the two Lichen elements must be considered as a case of parasitism. It is true that the Algæ may derive certain advantages in being protected by the enveloping Fungus filaments, which also retain water somewhat tenaciously, and thus enable the Algæ to grow where otherwise they could not. This mutual association has been termed Symbiosis. A further remarkable phenomenon is the occasional parasitism of one complete Lichen upon another.

Semi-lichens. - A small number of Ascomycetes have been described which live as saprophytes during their earlier stages, but later become associated with Algæ, which as a rule are injured by the attacks of the Fungus. Sphceria lemanea and Thermutis velutina are examples of the Half-lichens. 
Distribution. - The number of Lichens is very large, and they are of almost universal distribution, their peculiar structure enabling them to live where scarcely any other vegetation is possible, this being especially the case on exposed rocks, where Lichens are among the first organisms to appear. They play a very important rôle in the decomposition of rocks, being able, by the development of special solvent substances, to disintegrate even such hard rocks as granite and gneiss. The hyphæ of Vermucaria marmorea have been found
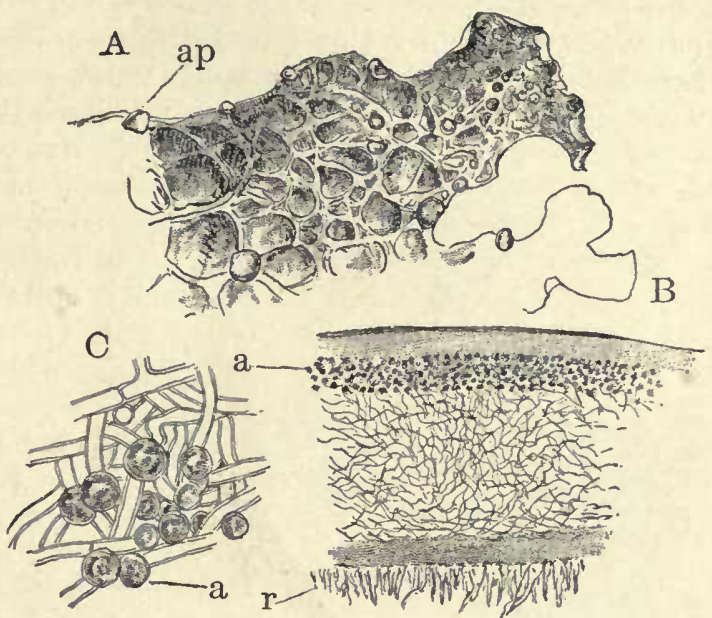

FIg. 153. - A, Sticta pulmonacea, a foliose Lichen (natural size); $a p$, apothecia. $B$, section of the thallus showing the algal cells, $a$, and the rhizoids, $r(\times 40)$. $C$, Usnea barbata, algal cells (Pleurococcus) surrounded by the fungal filaments $(\times 450)$.

to penetrate to a depth of nearly two centimetres into limestone upon which it was growing. Where the Lichen grows closely attached to the smooth bark of trees, as in the so-called crustaceous forms, it is often to a greater or less extent parasitic, penetrating into the tissues of the bark. Such forms are often deficient in the green algal cells.

\section{The Lichen-thallus}

The Lichens show several well-marked types in the form of the thallus. This may be closely adherent to the substratum (Crustaceous); flat or leaflike (Foliaceous); gelatinous, or bushy (Fruticose). The internal structure also shows more or less variety.

Gelatinous Lichens. - The simplest type is shown in the gelatinous Lichens, where the independence of the two constituents of the thallus is evident. In these forms the Alga is usually a species of Nostoc, as in Collema (Fig. 155, A, B), which very much resembles a normal Nostoc-colony. The gelatinous mass is penetrated by the loose filaments of the Fungus, which finally produces the characteristic fruiting-bodies.

In the more typical Lichens the hyphæ are densely interwoven, and form a tough, often leathery thallus, within which the algal 
cells are distributed, either without any definite order (Hoömerous) or in definite layers (Heteromerous). In most of the prostrate forms the latter arrangement is the rule. A section of one of these (Fig. 153, B) shows the densely interwoven and often coherent superficial hyphæ, forming a tough outer rind or cortex, beneath which is a somewhat looser stratum, in which the green cells form a

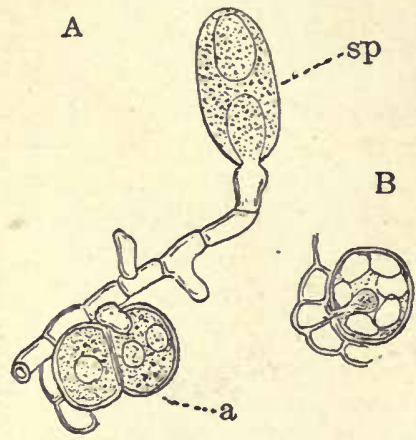

Fig. 154. $-A$, Xanthoria parietina, filament from a germinating spore attaching itself to cells of Pleurococcus, $a(\times \$ 50)$. (After DE BARY.) B, Ramalina reticulata, filament sending a haustorium into a Pleurococcus cell (× 900). (After Peirce.) continuous layer. The inner portion of the thallus is made up of loosely interwoven hyphæ, forming a sort of pith. The lower part of the thallus is usually quite destitute of green cells, and often develops rootlike outgrowths, which fasten it to the substratum.

The fruticose Lichens, such as the common Usnea barbata and the striking Ramalina reticulata (Fig. 156, A), very common in the coast region of California, are attached either by a small disk, or in the latter sometimes merely by being caught by the small twigs upon which a fragment has fallen. In these forms it is evident that the substratum serves simply as a point of attachment.

Where the gonidia of the Licheu are filamentous Algæ, the growth of the Lichen follows very closely the form of the Alga, which is only slightly invested with the hyphæ.

Chemical Peculiarities of Lichens. - The young hyphæ usually show the reaction of pure cellulose, but later the cell-walls become modified, forming either Fungus-cellulose or a change into a gelatinous substance, lichenin, or isolichenin, the latter substance turning blue on the application of iodine, thus reacting like starch. A great variety of peculiar products, such as special organic acids, pigments, and various excretory products, are also found in the Lichens.

\section{Reproduction}

The thallus of a Lichen may multiply by means of fragments torn off accidentally, or by the detachment of special bodies known as "Soredia." These consist of roundish bodies composed of a tangle of hyphæ enclosing a number of the green cells. These soredia are sometimes formed in large numbers upon the surface or margins of the thallus, where they form a greenish gray powder. Conidia, or nonsexual spores like those of many ordinary Ascomycetes, occur in a 
very small number of Lichens, but are usually absent. Pyenidia, or spermogonia (Fig. 155, B), like those of the Rusts, and mainy Ascomycetes, are of common occurrence. Minute conidia are produced in these, and may germinate and produce a myceliun in many cases. Whether these are sometimes male reproductive cells is still somewhat doubtful.

With the exception of two genera of tropical Lichens (Cora and Corella), which produce. basidiospores, the characteristic spores are ascospores, which are borne in fructifications very much like those of the typical Ascomycetes. The ascospores are usually eight in number, and may be either unicellular or inulticellular (Fig. 155, C).

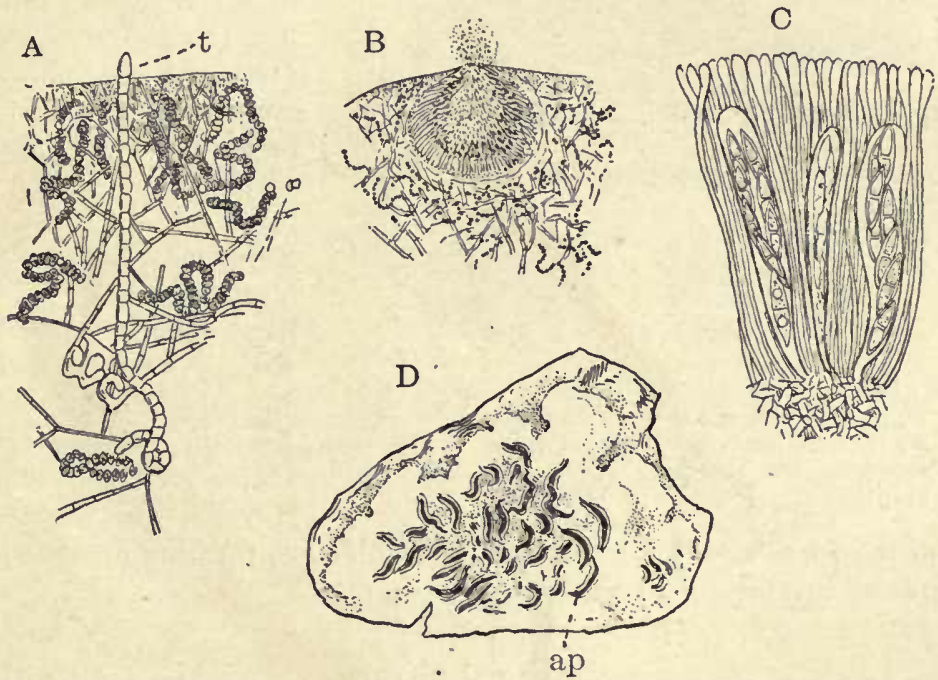

FIG. 155. $-A$, Collema microphylla, showing ascogenous hypha, with trichogyne, $t$. (After Stanu.) B, spermogonium of Collema sp. $(\times 45)$. C, Sticta pulmonacea, asci and paraphyses $(\times 250)$. D, crustaceous Lichen (Graphis) growing on the bark of a Beech; ap, apothecia $(\times 3)$.

The type of the fruit is either open (Apothecium), like that of the Cup-fungi, or closed (Perithecium), like that of the Pyrenomycetes.

In the Collemaceæ, a family of simple gelatinous Lichens, the formation of the apothecium is preceded by a specially modified, enlarged hypha, whose extremity forms a slender projecting structure, which has been compared to the trichogyne of the Red Algæ (Fig. 155, A). According to Stahl, this is fertilized by means of spermatia derived from the spermogonium. The question of actual fertilization has, however, been disputed. From this ascogonium the apothecium, or at least the ascogenous portion, is developed, much as in such a Cup-fungus as Pyronema. In most of the 
Lichens no trace of an ascogonium has been found, but the fruits arise in a strictly non-sexual manner.

\section{Classification of Lichens}

The Lichens may be divided into three orders, based upon their affinity with special groups of Fungi. These are: 1. Discolichenes;

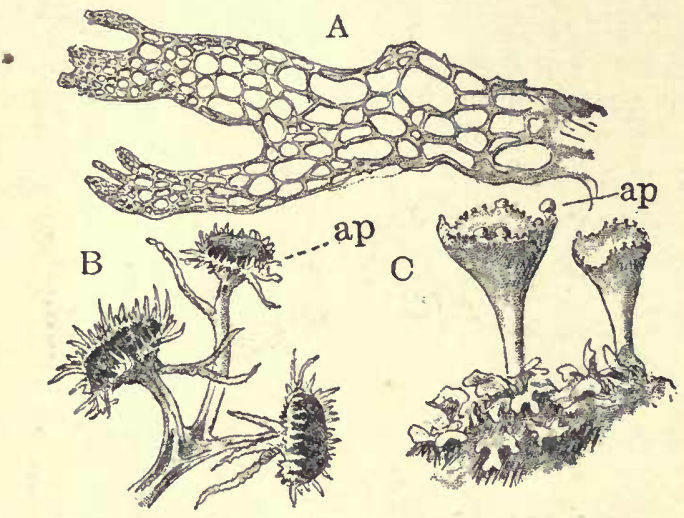

Fig. 1556. - A, Ramalina reticulata. (Natural size.) $B$, Evernia vulpina $\left(\times \frac{1}{2}\right)$, a fruticose Lichen showing the very large terminal apothecia. C, Cladonia pyxidata, the apothecia borne upon cup-shaped branches or "podetia" ( $\left.\times 1 \frac{1}{2}\right)$. spicuous, but most of them are inconspicuous, forming crusts upon exposed surfaces of rocks, trees, fences, etc.

\section{BIBLIOGRAPHY}

'01. 1. Atkinson, G. F. Mushrooms, Edible, Poisonous, etc. Ithaca, 1901.

'87. 2. De Bary, A. Fungi, Mycetozoa, and Bacteria. Oxford, 1887.

'71. 3. Cook, M. C. Handbook of British Fungi. London, 1871.

'92-'97. 4. Engler and Prantl. Natürliche Pflanzenfamilien. 1 Theil. 1 Abt. 1892-97. (Bibliography of the special groups with each section.)

'88-'91. 5. Farlow, W. G., and Seymour, A. B. A Provisional Host-index of the Fungi of the United States. Cambridge, Mass., 1888-'91.

6. Government publications. Many special papers and bulletins on Fungi issued by the Department of Agriculture.

'92. 7. Frank, A. B. Lehrbucl der Botanik. Leipzig, 1892.

'00. 8. Harper, R. A. Sexual Reproduction in Pyronema confluens and the Morphology of the Ascocarp. Ann. of Bot., XIV. 1900. (Includes full bibliography of the subject.)

'89. 9. Hartwig, R. Lehrbuch der Baumkrankheiten. 2d ed. Berlin, 1889.

'92. 10. Humphrey, J. E. Monograph of the Saprolegniaceæ of the United States. Mem. Boston Soc. of Nat. History. 1892. 
'79. 11. Luerssen, Chr. Handbuch der systematischen Botanik, Vol. 1. Leipzig, 1879.

'99. 12. Peirce, G. J. The Nature of the Association of Alga and Fungus in Licliens. Proc. Califor. Acad. Sciences. 1899.

'82-'92. 13. Saccardo, 1'. A. Sylloge Fungorum, Vols. 1-14. Padua, 1882'92. The most important systematic work upon Fungi.

'97. 14. Schneider, A. 'Text-book of Lichenology. Binghamton, N.Y., 1897.

'98. 15. _ Guide to the Study of Lichens. Boston, 1898.

'99. 16. Stevens, F. L. The Compound Oösphere of Albugo Bliti. Bot. Gaz. XXVIII. 1899.

17. Strasburger, E. Text-book of Botany.

18. - Das Botanische Praktikum.

'90. 19. Sturgis, W. C. On the Carpologic Structure and Development of the Collemaceæ and Allied Groups. Proc. American Acad., Vol. XXV. May, 1890.

'88. 20. Thaxter, Roland. The Entomophthoraceæ of the United States. Mem. Boston Soc. of Nat. History, Vol. IV. 1888.

'96. 21. Monograph of the Laboulbeniaceæ. Mem. American Acad., XII, No. 111. 1896.

22. - Many important papers in the Botanical Gazette and elsewhere, dealing principally with aquatic Fungi.

'97. 23. Tubeuf, K. Diseases of Plants. Longmans, Green \& Co., 1897.

'99. 24. Underwood, L. M. Moulds, Mildews, and Mushrooms. New York, 1899.

'98. 25. Van 'Tieghem, $\mathrm{Ph}$. Traité de Botanique. Paris, 1898.

'96. 26. Wager, H. On the Structure and Reproduction of Cystopus candidus. Ann. of Bot., X. 1896. (Includes full bibliography of subject.)

'98. 27. — The Nucleus of the Yeast-plant. Ann. of Bot., XII. 1898.

'99. 28. — The Sexuality of Fungi. Ann. of Bot., XIII. 1899.

'00. 29. - On the Fertilization of Peronospora parasitica. Ann. of Bot., XIV. 1900.

'95. 30. Warming, E. W. Handbook of Systematic Botany. London and New York, 1895.

'90. 31. Zopf, W. Die Pilze. Breslau, 1890. 


\section{CHAPTER VII}

\section{THE ARCHEGONIAT $\mathrm{E} ;$ MUSCINE E}

THE Algæ are typically aquatic plants, and even those forms which are adapted to life out of the water can vegetate only when an abundant water supply is present, and remain dormant when the supply is withdrawn. These plants reach their most perfect development in the sea, where the water supply is constant, and the highest expression of the algal type is seen in the large Red and Brown Algæ.

From the much simpler fresh-water Green Algæ another group of plants has been derived which has far outstripped all other competitors and developed the most perfect of all plant-structures. These are the terrestrial green plants which at present are the prevailing plant-types. The lowest of these terrestrial plants, the Archegoniatæ, show unmistakable evidences of their aquatic origin, and although no existing Green Algæ can be pointed out as the direct ancestors of the land-plants, still there is strong evidence that the lower Archegoniates, the most primitive of the terrestrial plants, have arisen from forms allied to the existing Chlorophyceæ. On the whole, the Confervaceæ offer the closest analogies with the Archegoniates, and of these the genus Coleochæte shows the nearest affinity, although the character of the reproductive organs in the Characeæ also gives some suggestions of the archegoniate type. The Archegoniatæ include the Mosses and Ferns and their allies.

The substitution of an aerial for an aquatic environment was no doubt very gradual, and there are still some forms among the Green Algæ and lower Archegoniates which show how this may have come about. The advantages of being able to grow with a diminished water supply are obvious. Most fresh-water Algæ are subjected to destruction by the drying up of the shallow ponds in which they grow, and their vegetative period may be very short. To provide against this there are developed the various forms of resting-spores, which remain dormant until the supply of water is renewed. A few forms, like Botrydium and some species of Vaucheria, grow on the mud left by the receding water, but their growing period is entirely dependent upon the length of time during which the mud remains moist, and they also produce resting-spores at the end of their short vegetative existence. 
In the lower Archegoniates, however, although they are more or less dependent upon an ample supply of moisture, the plant develops various devices for protecting it against the loss of water. Roots of some kind are always present, which penetrate into the substratum and renew the supply lost by evaporation, which is, moreover, checked by the development of an impervious cuticle upon the cells exposed to the air. These devices, which are only imperfectly developed in the lower forms, become extraordinarily perfect in many of the higher types of land-plants. 'The conditions being so much more variable on land than in the water, the terrestrial plants show a correspondingly greater diversity of structure than is ever found in aquatic forms.

None of the Archegoniates possess motile cells corresponding to the non-sexual zoöspores of the Algæ, but all of them give rise to motile spermatozoids, which require water in order to reach the archegonium which contains the egg; and this reversion to the aquatic condition as a preliminary to fertilization indicates the aquatic origin of all these forms.

The formation of resting-spores occurs in all of the Archegoniates; but instead of the fertilized egg developing at once into a restingspore, as it does in most Green Algæ, the egg develops into a multicellular plant, the Sporophyte, which then gives rise, non-sexually, to a large number of resting-spores. One fertilization may therefore result in an enormously larger number of spores than is the case among the Green Algæ. The development of the carpospores of the Red Algæ offers an analogy to this, although the method of spore-formation is totally different.

In a few Liverworts (e.g. Ricciocarpus, Fig. 163) the plant usually lives as an aquatic, but it may assume a terrestrial form by settling on the mud after the subsidence of the water, and there grow even more vigorously than it did when floating in the water. Sometimes the plant only develops its reproductive parts when it thus assumes the terrestrial form. The behavior of Ricciocarpus probably illustrates the way in which the terrestrial Archegoniates first began to take possession of the land.

With the Seed-plants the Archegoniates are sometimes put in a single great division, the Embryophytes, so called because the fertilized egg develops into a multicellular embryo before the spores are formed. All of the Archegoniates agree closely in the character of their reproductive parts, and there is little question that the subkingdom is a very natural one.

Alternation of Generations. - All Archegoniates show two phases of development. The spore, on germination, produces a plant, the gametophyte, upon which are borne the sexual reproductive orgaus, archegonia and antheridia. From the egg, within the archegonium, 
after it is fertilized, is developed the embryo, which becomes a more or less highly organized plant, the sporophyte. The latter, sooner or later, gives rise to the spores, which are invariably produced in tetrads, derived from the division of a common mother-cell. It has lately been suggested that the spore-fruit of the Red Algæ may be considered as a sporophyte, but, aside from this, the nearest approach to the condition prevailing among the Archegoniates is that found in the genus Coleochæte, where a rudimentary sporophyte is developed from the oöspore.
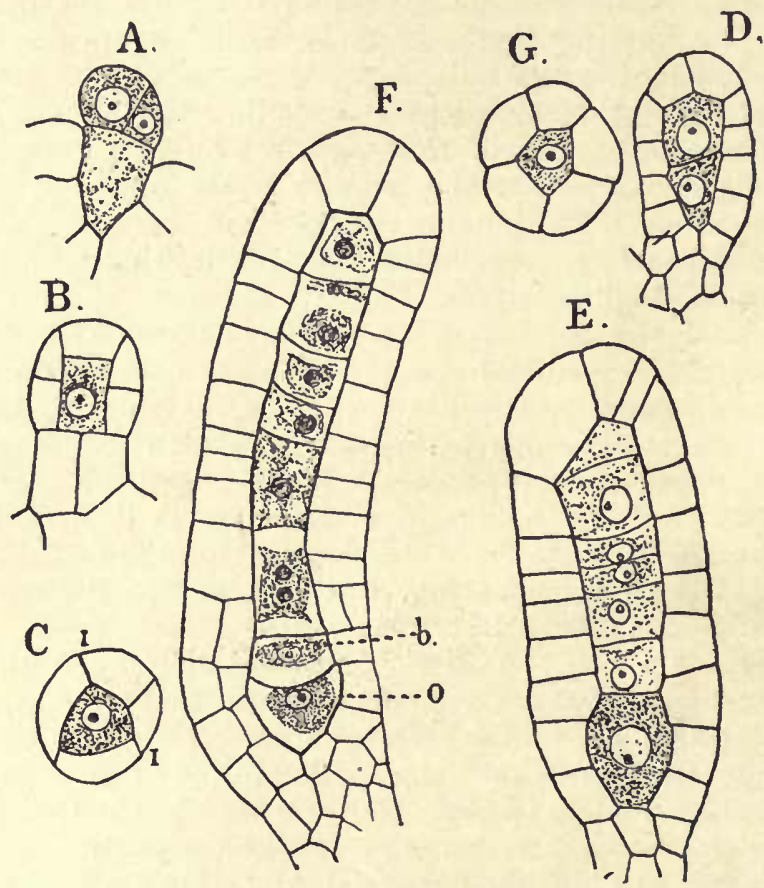

FIg. 157.-Madotheca (Bellincinia) Bolanderi. Development of the archegonium $(\times 600)$. C, cross-section of young archegonium. $G$, cross-section of the neck of an older one. The others are longitudinal sections; $b$, ventral canal-cell; $a$, egg.

Gametophyte. - The gametophyte of the Archegoniates may be a plant of large size, attaining a length of thirty to forty centimetres or more in some of the larger Liverworts and Mosses; or it may be reduced to a microscopically small body composed of a few cells, as in the male gametophyte of some Ferns. Whether large or small, the structure of the reproductive organs is remarkably uniform.

The Archegonium. - The archegonium (Fig. 157) is usually a flaskshaped body composed of many cells, instead of being a single cell 
like the oögonium of most Green Algæ. The archegonium generally consists of a single superficial layer of cells, and an axial row of cells, of which the lowest one is the egg-cell. The upper part is the Neck, the lower enlarged portion the Venter. At maturity the axial row of neck-cells ("Canal-cells") become disintegrated, and when water is applied, these swell up and burst open the apex of the neck, through which they are forced out, leaving a passage open to the venter, within which lies the egg, ready for fecundation.

The Antheridium. - The antheridium (Fig. 158) is also multicellular, but more variable in structure than the archegonium. It most commonly is a stalked body, the upper part being composed of an outer layer of sterile, often chlorophyll-bearing cells, and an inner mass of sperm-cells. Within each of these a single coiled spermatozoid is developed. The body of the spermatozoid is derived mainly

A

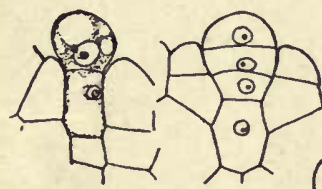

C.

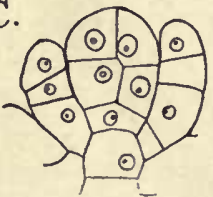

B.

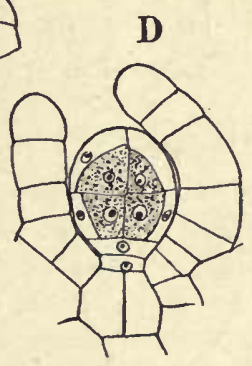

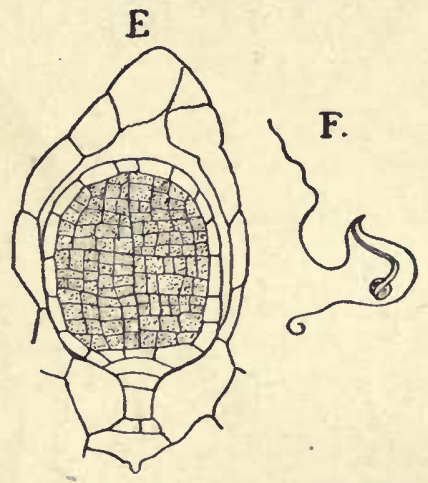

Fra. 158. - Sphærocarpus cristatus. Development of the autheridium. $A-D$, median longitudinal sections $(\times 450) . \quad E$, an older one $(\times 225)$. $F$, spermatozoid $(\times 900)$.

from the nucleus of the sperm-cell, while the cilia arise from a special body, the Blepharoplast, which, in its position, recalls the centrosomes of certain cells, but is found only in the later stages of the sperm-cells. Like the walls of the canal-cells of the archegonium, the walls of the sperm-cells become mucilaginous, and when the ripe antheridium is wet, the swelling of this mucilaginous mass bursts open the antheridium and sets free the sperm-cells, from which the spermatozoids are liberated by the complete dissolution of the cell-wall.

The liberated spermatozoids swim about actively in water and make their way to the open archegonium, to which they are attracted by substances ejected from it. This attractive substance in the Ferns is malic acid. The spermatozoids often collect in large numbers about the mouth of the archegonium and several may make their 
way into it; but normally only a single one penetrates into the egg and fuses with its nucleus.

The Embryo. - The fertilized egg does not form a resting-spore,
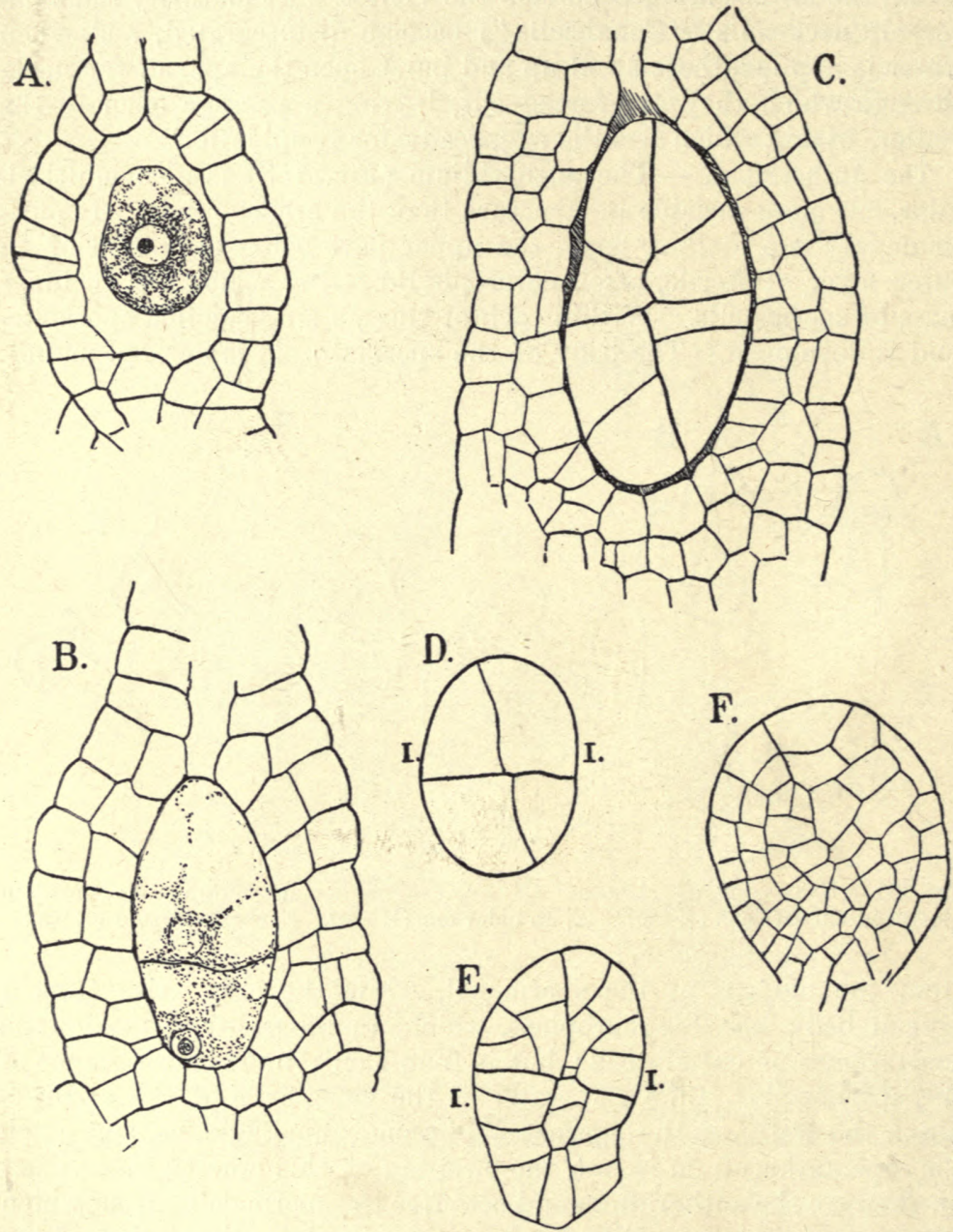

Fig. 159. - Targionia hypophylla. A, section of the venter of a ripe archegonium $(\times 500)$. $B-D$, development of the embryo, seen in longitudinal section $(\times 500)$. $E, F, \times 250$.

but grows into a mass of tissue, the embryo (Fig. 159), which sooner or later develops into the sporophyte, the plant which gives rise to the non-sexual spores. 
Sporophyte. - The sporophyte (Fig. 160) shows a very different degree of development among the Archegoniates. In its simplest form (e.g. Riccia) it is a globular body which is almost entirely composed of sporogenous tissue. In the Ferns, spore-production is largely subordinated to the vegetative existence of the sporophyte, which becomes a large, leafy plant. Sooner or later the sporophyte develops a special sporogenous tissue, each cell of which, by a further division into four parts (Fig. 161), produces the spores, which are very similar in

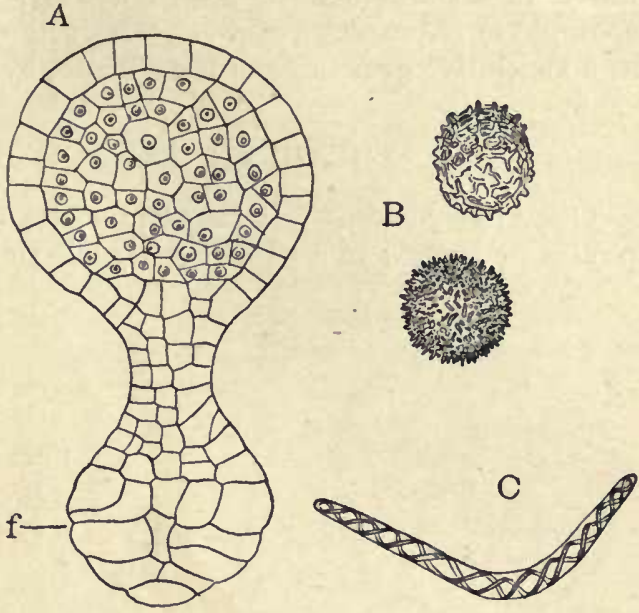

FIG. 160.-A, Sphærocarpus cristatus; median section of young sporophyte $(\times 2: 5)$, the nucleated cells constitute the archesporium; $f$, foot. $B, C$, Fossombronia longiseta, two ripe spores, $B$, and an elater, $C(\times 225)$.

structure throughout the group. The sporogenous tissue (Archesporium) may be developed from the inner tissue of the sporophyte, or there may be a special organ, the sporangium, in which the spores arise.

Spore-formation. - The development of the spores among the Archegoniates is very uniform, and is one of the strongest proofs of a common origin for all of them. The sporogenous cells arise from a single archesporial cell, or from a group of these. Each sporogenous cell contains a large nucleus which divides twice. The divisions inay be followed at once by a division-wall, but more often the four daughter-nuclei lie free in the cytoplasm of the mothercell. Division-walls are then formed simultaneously between the nuclei, and the resulting four spores are tetrahedral in form. The ripe spores usually contain a large amount of starch, oil, or albuminous reserve-food, and are protected by a heavy outer spore-coat, or Perinium, marked with characteristic thickenings.

Reduction of Chromosomes. - It has been ascertained that, in some cases at least (e.g. Osmunda regalis, Pallavicinia decipiens), the number of chromosomes in the nuclei of the sporophyte is double that of the gametophytic nuclei. The reduction takes place in the last division of the archesporial cells, which results in the spore mothercells. 
The germinating spores produce in turn the gametophyte. The latter, in abnormal cases, may arise as a direct outgrowth of the sporophyte (Apospory), and conversely the sporophyte may develop as a vegetative growth from the gametophyte (A pogamy).

\section{THE MUSCINE玉 (BRYOPHYTA)}

The Archegoniates fall into two series of equal rank, the Bryophytes or Mosses in a wider sense, and the Pteridophytes or Ferns

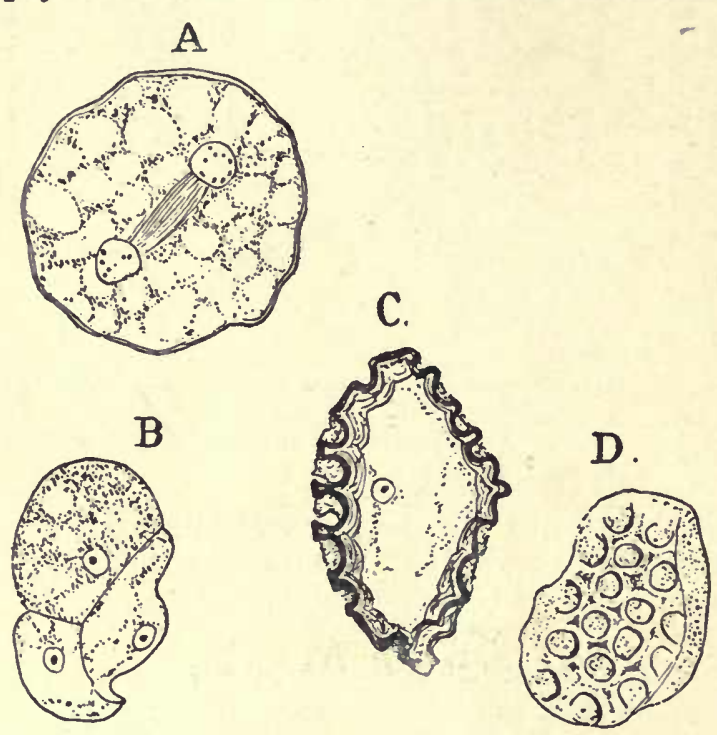

Fra. 161. - Riccia trichocarpa. A, sporogenous cell nndergoing the first nuclear division $(\times 600)$. $B$, section of young spore-tetrad $(\times 300), C$, section of a ripe spore. $D$, surface view of the epispore. and their allies. In the former group, the gametophyte is the predominant phase; in the latter, the sporophyte, which becomes an independent, longlived plant.

The Bryophytes are usually divided into two classes, Liverworts (Hepaticæ) and Mosses (Musci). It seems best, however, to add a third class, Anthocerotales, to include certain forms which have hitherto usually been united with the Liverworts. The Anthocerotales are, to some extent, intermediate in character between Bryophytes and Pteridophytes.

Gametophyte. - The gametophyte in the Bryophytes may be a delicate thallus, not essentially different from that of some Algæ, or it may be highly differentiated, showing well-developed stem and leaves, as is seen in the higher Mosses. These structures differ, however, from the similar parts of the sporophyte of the vascular plants (Ferns and Seed-plants).

The Sporophyte. - The simplest sporophyte is that of Riccia, which consists of a globular body, all of whose cells, except a single superficial layer, produce spores. In all other Bryophytes a greater or smaller part of the sporophytic tissue is sterile, and is connected with 
the vegetative existence of the sporophyte itself. - In the more specialized forms like the True Mosses and Anthoceros, spore-formation is subordinated, and the sporophyte develops green assimilative tissue and a system of conducting tissues, and is dependent upon the gametophyte only for its supply of water.

Biology. - The Bryophytes are, for the most part, inhabitants of moist localities, and a few are true aquatics (e.g. Riccia fluitans, Fontinalis). Their favorite habitat is shaded earth and moist rocks, bases of trees, and similar places. They may, however, be adapted to a dry situation, and become completely dried up without injury. This is strikingly shown by many Californian Bryophytes, which remain dormant through the long rainless summers, resuming
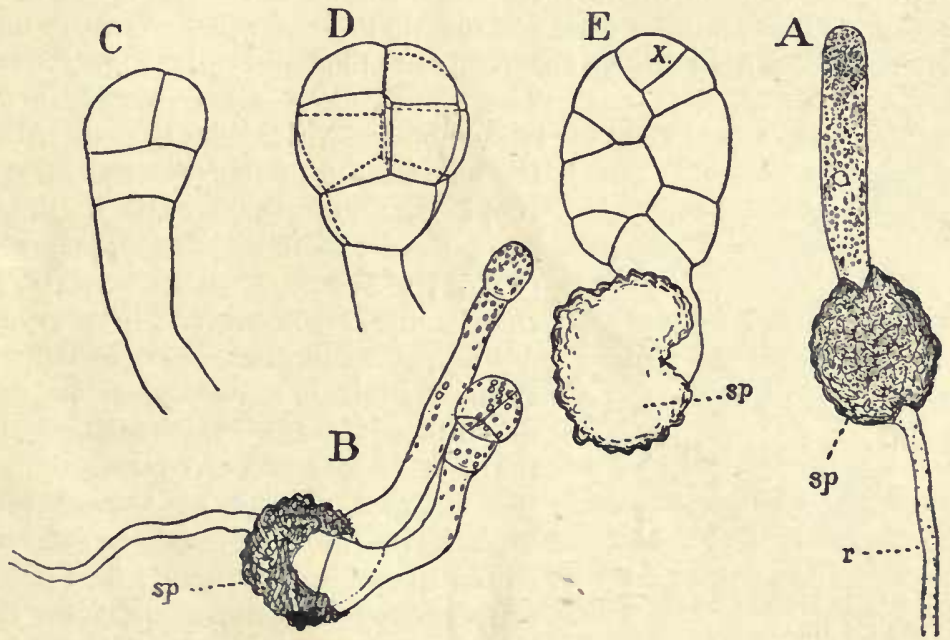

Fra. 162. - Targionia hypophylla. Germination of spores ( $\times$ about 200 ). $C, E$, optical sections; $x$, apical cell; $r$, primary rhizoid; $s p$, spore-membrane.

growth at once with the advent of the autumn rains, and completing their season's growth during the rainy winter.

Liverworts seldom occur in sufficient numbers to constitute a conspicuous feature of the flora, but the Mosses are often gregarious, and in the wet northern regions often cover large tracts, almost to the exclusion of other vegetation. This is seen especially in northern bogs, where the Peat-mosses (Sphagnum), Hypnum, Polytrichum, etc., are the most important factors in the vegetation. In the northern forests, also, the ground. and the decaying trunks of the fallen trees are covered with dense cushions of large Mosses. Similar conditions prevail in the cooler regions of the southern hemisphere. 


\section{Class I. Hepatice}

The lowest of the Archegoniates are the Hepaticæ, or Liverworts, which are of importance, botanically, because they probably represent the forms from which all the higher types of green plants have come. They are usually of small size, and most of them frequent moist, shady places, although many species have adapted themselves to dry localities. They reach their greatest development in the moist mountain forests of the Tropics, where they occur in great numbers upon the stems, or even the leaves, of many trees and shrubs.

\section{The Gametophyte}

The gametophyte in the Liverworts shows considerable range of structure. The simplest forms have a thallus composed of nearly uniform cells, or with a midrib consisting of elongated cells (Fig. 172, B).

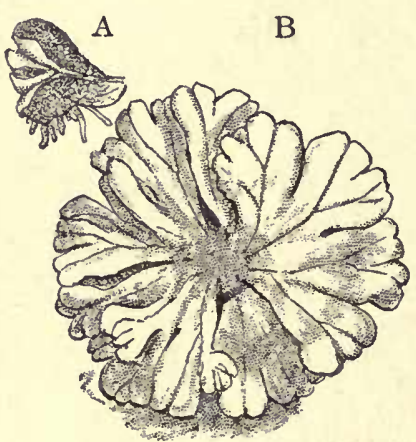

Fra. 163.-Ricciocarpus natans. $A$, floating form. $B$, terrestrial form $(\times 2)$.

The branching is most commonly dichotomous. The thallus is fastened to the substratum by delicate unicellular root-hairs. The growth of the thallus is due to the divisions of a single apical cell (Fig. 173, A, x). Most Liverworts, in their earlier stages, conform to this type.

From this simple thallose structure, specialization has developed in two directions. In the Marchantiales the thallose form has been retained, but the uniform tissues of the simpler type have been replaced by tissues suited to special purposes. The green cells occupy the dorsal part of the thallus, and constitute a well-developed assimilating apparatus, and the reproductive organs are often restricted to special branches.

The second line of development is seen in the leafy Liverworts, or Scale Mosses. The tissues in this type remain alike, but the plant-body becomes a leafy axis, the assimilative function being relegated to special outgrowths (leaves) (Fig. 172, F). These leafy shoots sometimes arise as outgrowths of a thallose "Protonema," like that found in the True Mosses. This protonema may be a flat thallus (Lejeunia metzgeriopsis) (Fig. 180), or it may be filamentous (Protocephalozia).

Reproduction. - The gametophyte multiplies normally by branching, but in many Liverworts special buds or gemmæ are developed. In Aneura multifida, these are two-celled bodies, which are formed inside a mother-cell, and are discharged much like the zoöspores of 
the Green Algæ. They may properly be considered as homologous with zoöspores. In other cases the gemmæ are developed superficially, and break off from the thallus. In Marchantia (Fig. 169) and Lunularia these are produced in special receptacles.

The Archegonium. - The sexual organs may be borne upon the same plant, or the plants may be unisexual.

The development of the archegonium (Fig. 165) is remarkably uniform throughout the Hepaticæ. It arises from a superficial cell which usually, but not always, divides by a transverse wall into a stalk-cell and an upper cell. The latter divides by three intersecting vertical walls, with a central cell and three peripheral ones. These peripheral cells undergo later another longitudinal division, so that the central cell becomes surrounded by six peripheral ones. In the Jungermanniales, this longitudinal division is usually suppressed in the case of the smallest primary peripheral cell, so that there are but five of these formed.

The next division is transverse and divides the young archegonium into two tiers, the upper giving rise to the neck, the lower one to the venter. From the axial cell of the neck a cover-cell is cut off, which now divides by intersecting walls into four, placed crosswise. Repeated transverse divisions take place in all the neck-cells, so that the neck rapidly increases in length. The axial row of cells constitute the neck-canal cells. The axial cell of the venter divides once transversely, and of the two resulting cells, the lower becomes the egg, the upper the ventral canal-cell.

At maturity the transverse walls of the neck-canal cells become mucilaginous, and dissolve when the ripe archegonium absorbs water. The protoplasm of the egg-cell contracts and assumes a globular form. The cytoplasm is usually densely granular, except at the top, where a more or less evident clear "receptive spot" can usually be made out.

The neck-cells become strongly distended by the water absorbed, and the pressure exerted by the swelling mucilaginous mass formed from the disorganized canal-cells finally becomes so great, that the apex of the neck is ruptured, and the contents of the canal are forced out, leaving an open channel through the neck, down to the central cavity of the venter in which the egg lies.

The Antheridium. - The antheridium (Fig. 166) shows much more variation than the archegonium. With the exception of the Anthocerotales, it is developed from a single superficial cell, which generally divides into a basal and a terminal cell. The latter develops a mass of central sperm-cells, surrounded by a layer of larger sterile cells, which often contain chlorophyll. The nucleus of the spermcell is relatively large, and assumes a spiral form as the spermatozoid develops. The two long cilia always found in the spermatozoids of 
the Bryophytes arise from the blepharoplast, which is of cytoplasmic origin. When the spermatozoids escape, the remaining cytoplasm of the mother-cell adheres to the end, as a small vesicle.

The walls of the sperm-cells becone mucilaginous at maturity, and the dehiscence of the antheridium is due to the swelling of this mucilaginous matter, when water is applied.

\section{Sporophyte}

The fertilized egg becomes at once invested with a cellulose mem- brane, and grows until it completely fills the cavity of the venter. The development of the sporophyte in the Liverworts is not always the same. In the simplest type, that of Riccia (Fig. 171), all but a single superficial layer of cells constitutes the archesporium of the globular sporophyte, and all the archesporial cells give rise to spores. In all other forms there is a greater or smaller amount of sterile tissue in the sporophyte. In the Anthocerotales, especially the genus Anthoceros, the sporophyte becomes very complicated. A distinct system of green assimilative tissue, with stomata, is developed, and the archesporium is relatively small.

As the embryo grows, the venter of the archegonium also shows active growth, and, except in the Anthocerotales, the sporophyte is retained within the venter of the archegonium, now known as the "Calyptra," until the spores are ripe. Then by a sudden elongation of the stalk, or "Seta," of the sporophyte, it breaks through the calyptra, and carries up the spore-bearing capsule at the top, soon shedding the spores.

In most of the Liverworts certain cells of the archesporium remain undivided, and develop into spindle-shaped cells, upon whose walls are developed spiral thickenings, which are strongly hygroscopic. These cells are the Elaters (Fig. 160, C), and it is probable that they are of assistance in breaking open the capsule containing the spores, and possibly the hygroscopic movements may also be useful in scattering the spores after they are shed. The wall of the capsule, or upper spore-bearing portion of the sporophyte, often shows similar thickenings upon the walls, and these are also instrumental in opening the capsule.

In all Liverworts except the Ricciaceæ, the base of the sporophyte forms a bulblike organ, the Foot (Fig. 160, A, f), whose cells are in close contact with the adjacent cells of the gametophyte, from which it absorbs water and food for the needs of the growing sporophyte, which is thus parasitic, as it were, upon the gametophyte.

The Spores. - The ripe spores of the Liverworts are tetrahedral cells, with a double or triple outer wall and dense contents. Where the spores can germinate at once, as in most forms from the moist 
tropical forests, the spores contain chlorophyll; but where the spores are adapted to endure a long period of drought, as in most Californian species, the ripe spores contain no chlorophyll, but are filled with food materials, largely oil and albuminous granules. Such spores have much heavier walls, also, than those which contain chlorophyll.

Germination. - Where chlorophyll is absent from the ripe spores, the first step in germination is the appearance of chlorophyll in the spore, although the amount is sometimes small. The exospore and perinium are ruptured (Fig. 162), and the spore-contents, included within the endospore, or intine, appear as a papilla, the germ-tube, which often becomes much elongated. Usually from the base of the germ-tube a small papilla is cut off, which rapidly elongates into the primary rhizoid.

At the end of the germ-tube a mass of cells is developed, which soon becomes a flattened thallus, growing from a definite apical cell. This apical cell, in most cases, is of the two-sided type, found permanently in Metzgeria and Aneura. Sooner or later, this is replaced by the type found in the mature gametophyte. With few exceptions, the young plant assumes gradually the characters of the adult.

\section{Classification of Hepaticæ}

The Hepaticæ (exclusive of the Anthocerotales) may be divided into two orders, the Marchantiales and the Jungermanniales. The gametophyte in the former is always thallose, and may become very complex; in the latter, it may be either thallose or foliose, but always is relatively simple in its cellular structure.

\section{Order I. Marchantiales}

These very characteristic plants possess a prostrate, fleshy thallus (Figs. 163, 164), which usually grows upon the earth, to which it is attached by numerous root-hairs of two kinds, - large, thin-walled ones, and smaller hairs, with undulate walls, having peculiar spikelike thickenings projecting into the cavity of the cell.

The branching of the thallus is usually dichotomous, but adventitious shoots are common in many forms. With the exception of the tropical genera, Dumortiera and Monoclea, in which the differentiation of the tissues is poorly marked, the Marchantiales show two definite regions of the thallus (Fig. 167), a central portion, composed of compact, colorless tissue, sometimes containing special mucilagecells, or ducts, and cells with oil-bodies. The dorsal tissue, which may merge somewhat gradually into the ventral tissue, is composed of green cells, with large air-chambers, or lacunæ. These chambers 
communicate with the air outside by means of pores, which, in the higher Marchantiaceæ, may have the form of chimney-shaped stomata.
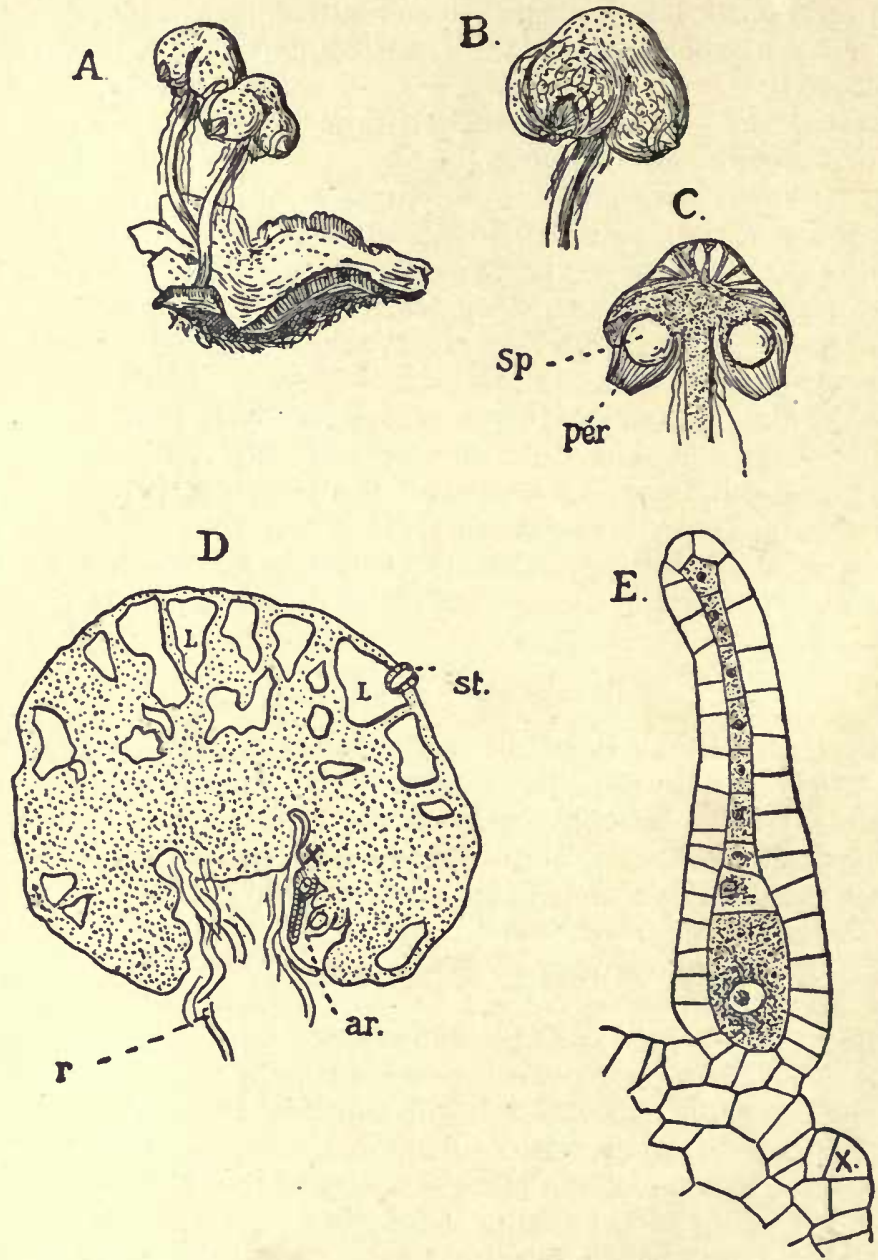

Fig. 164. - Fimbriaria (Hypenantron) Californica. A, plant with two sporogonial receptacles, slightly enlarged. $B$, a receptacle (carpocephalum) $(\times 4)$. $C$, the same cut longitudinally, showing the " perianth," per, surrounding the sporophyte, $s p$. $D$, young carpocephalum, in longitudinal section, showing one of the growingpoints, $x$, and an archegonium, $a r$. $L$, air-spaces; st, stoma; $r$, rhizoids $(\times 40)$. $\mathcal{E}$, growing-point and archegonium $(\times 300)$.

The air-chambers may be clearly defined, each with a single stoma, and, in such cases, the upper surface of the thallus presents a regu- 
larly marked areolation, as in Marchantia and Conocephalus (Fegatella).

Upon the lower surface of the thallus are usually two series of delicate scales, often of a dark purple color. These sometimes are provided with a glandular tip, which secretes a mucilaginous substance, and they are donbtless protective in their function, closely investing the delicate growing apex of the shoot.

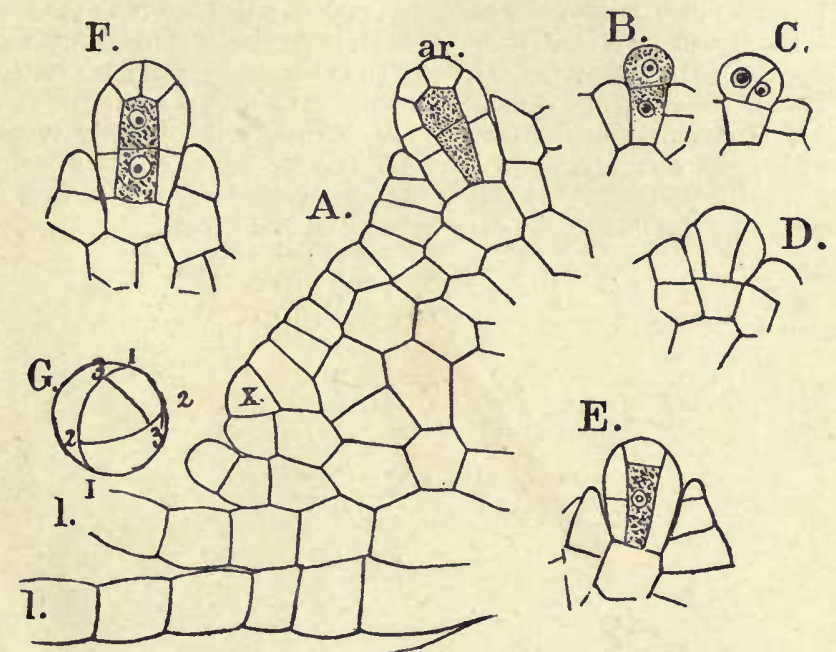

Fig. 165.-Riccia glauca. A, longitudinal section of the apex of the thallus, with young archegonium, ar $(\times 525) ; l, l$, ventral lamellæ. $B-F$, development of the archegonium, longitudinal sections. $G$, diagram showing the arrangement of the primary divisions in the archegonium.

\section{Classification of Marchantiales}

The Marchantiales may be divided into three suborders - Ricciaceæ, Corsiniaceæ, and Marchantiaceæ.

\section{Suborder I. Ricciaceæ}

The lowest of the order are the Ricciaceæ, containing the two genera, Riccia and Ricciocarpus (Fig. 163). Most of them are terrestrial forms, but Ricciocarpus and Riccia fluitans are genuine aquatics.

Apical Growth. - The thallus grows from an apical cell (or possibly more than one), which is wedge-shaped, with segments cut off alternately from the dorsal and ventral faces. Segments are also cut off from the lateral faces. The greater part of the tissue of the thallus is derived from the dorsal segmenis. 'The ventral segments develop only the lower epidermis, from which the root-liairs 
grow, and the overlapping lamellæ, which are formed by the rapid growth of the free margin of the segments, and curve upward over the apex. These lamellæ are very inconspicuous in certain species $(e . g ., R$. glauca), while in others they subsequently split in the middle, and form two rows of scales like those of the Marchantiaceæ.

The dorsal segments grow much more rapidly, and divisions occur in all directions, so that the thallus becomes thick, and the upper cells are arranged in more or less definite vertical rows, which separate at an early period, and give rise to narrow air-spaces between the rows of green cells. In some species, these airspaces become much larger, and approach the condition found in the Marchantiaceæ. The green cells are thus brought into direct contact with the air containing the $\mathrm{CO}_{2}$ necessary for photosynthesis. The terminal cell of each row is usually colorless, and somewhat enlarged, so that a sort of epidermis is developed. Differences in the turgescence of these cells probably regulate, to some extent, the communication between the air-spaces and the atmosphere outside. In Ricciocarpus, where the air-spaces are large, there is a definite epidermis with pores like those of the higher Marchantiaceæ.
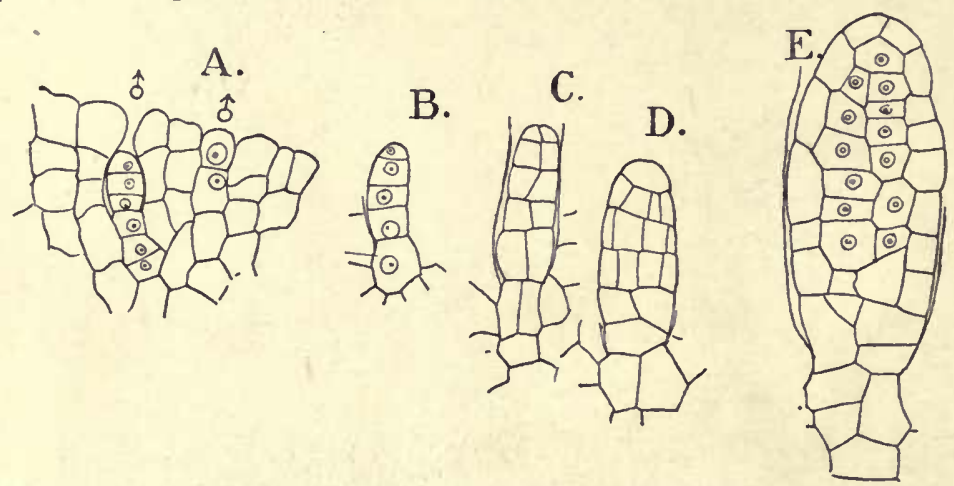

Fig. 166. - Fimbriaria $s p$. A, part of a vertical section of a young antheridial receptacle, showing two very young antheridia $\hat{\delta}$. $B-E$, older stages of the antheridium $(\times 420)$.

Sex-organs. - The sexual organs of Riccia (Fig. 165) are borne upon the dorsal surface of the thallus, but, owing to the growth of the tissue about them, they are surrounded by an envelope, which, in the case of the antheridium, extends above its apex in the form of a tube. Both antheridium and archegonium arise from similar superficial cells, and closely resemble each other at first. The development of the archegonium conforms to the regular type. At maturity it has an enlarged venter and elongated neck.

The antheridium, after a short basal cell is cut off, divides by a series of transverse divisions, which are followed in each of the segments by two intersecting vertical walls : a periclinal wall in each of the segment-quadrants separates a central cell from a peripheral one. The central cell, thus produced by further divisions, gives rise to the sperm-cells, which are very numerous.

The Embryo. - The globular egg divides first by a transverse wall, and then undergoes quadrant and octant divisions by walls passing through its centre (Fig. 171). After several other divisions, a single layer of peripheral cells is cut off, and all the central mass of cells becomes the archesporium, all of whose cells develop spores. The outer sterile cells become more or less completely 
destroyed as the spores mature, and they then lie free in the venter of the archegonium, which has kept pace with the growth of the embryo and has become two-layered.
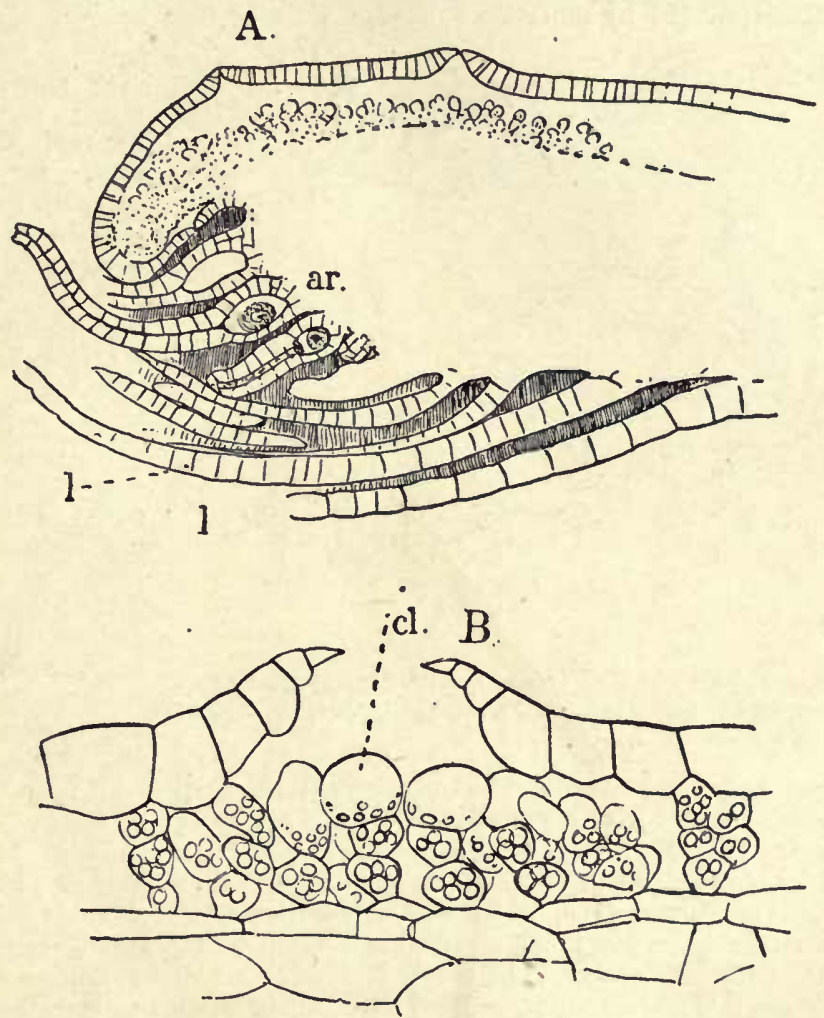

Frg. 167.- Targionia hypophylla. A, longitudinal section of the thallus, showing the archegonia, ar, and ventral scales, $l, l(\times 100)$. $B$, section through a pore, showing the chlorophyllous cells, $c l$, in the air-chamber $(\times 300)$.

\section{Suborder II. Corsiniaceæ}

This is a small group intermediate in character between the Ricciaceæ and the Marchantiaceæ. There are no species found within the United States. They differ from the Ricciaceæ in having the lower part of the embryo developed into a foot, and some of the archesporial cells remain sterile, and form rudimentary elaters. There are two genera, Corsinia and Funicularia (Boschia).

\section{Suborder III. The Marchantiaceæ}

The Marchantiaceæ, with the exception of the aberrant genera Dumortiera and Monoclea, have the assimilative tissue of the thallus sharply differentiated 
from the ventral tissues. The air-chambers may be irregular, or they may be clearly circumscribed, and visible to the naked eye as polygonal areolations upon the dorsal surface of the thallus. The pores in the epidermis may be openings surrounded by radiating epidermal cells, or there may be a definite

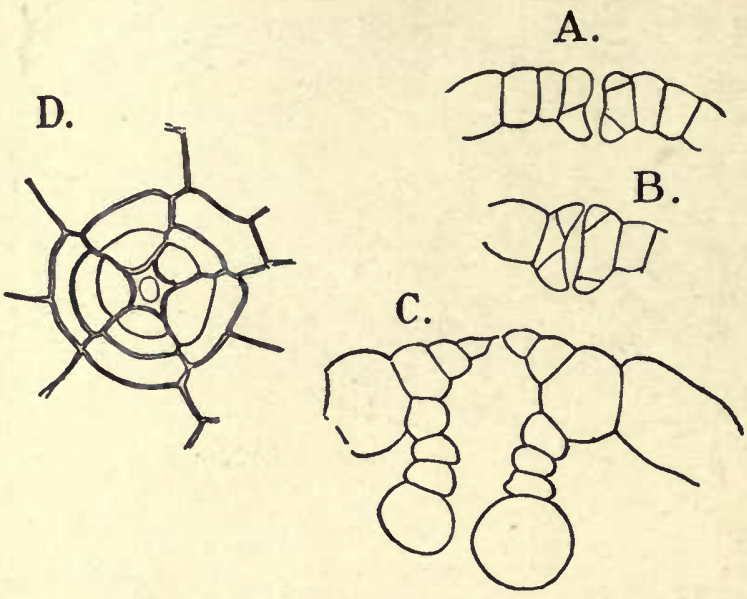

Fra. 168. - Fimbriaria Californica. $A-C$, development of the pores upon the receptacle, longitudinal sections. $D$, surfaceview of a pore.

in special cells, and mucilage-ducts, occur in some species.

Gemmæ. - Gemmæ of a peculiar type (Fig. 169) occur in Marchantia and Lunularia. They are flattened buds which are borne in large numbers in special receptacles, cup-shaped in Marchantia, senicircular in Lunularia. They arise from single epidermal cells, which divide transversely into a short basal cell which remains undivided, and a terminal cell which by repeated divisions gives rise to the bud. This becomes lenticular in form, with an indentation on each edge, so that it is fiddle-shaped. These indentations mark two growing-points, and when the bud falls upon the earth they grow out in opposite directions into two shoots. The buds are detached by the swelling of a mass of mucilage secreted by small glandular hairs growing with them. Both surfaces of the bud are alike, and over these are scattered colorless cells which grow into rhizoids on coming into contact with the ground. Whichever surface of the bud falls downward becomes the ventral surface of the young plant, and the upper surface develops into the characteristic dorsal tissues.

Sex-organs. - The sexual organs, which closely resemble those of Riccia, are borne in groups upon more or less modified parts of the thallus. The plants are either monœcious or diœcious. The antheridial receptacle may form a cushion upon the dorsal surface of an ordinary shoot, as in Fimbriaria (Hypenantron), or there may be special antheridial branches, as in Targionia and Marchantia (Fig. 166).

The archegonia are always borne upon more or less modified shoots, which more commonly develop into the mushroom-shaped receptacles (Fig. 164) so familiar in Marchantia and other genera. These receptacles may represent a single branch, or they may be composed of a system of short branches. 


\section{The Sporophyte}

As in Riccia, the first division in the fertilized egg is transverse; but only the upper half of the embryo gives rise to sporogenous tissue, the proximal half developing into a short stalk, or seta, whose lower end forms a foot, which is buried in the tissue of the gametophyte (Fig. 159).

The upper part of the sporophyte, the capsule, has a definite wall composed usually of a single persistent layer of cells, whose walls may develop thickenings upon their inner surface. The rest of the capsule is composed of the archesporium, some of whose cells develop into wellmarked elaters, the others forming spores in the usual way. 'The dehiscence of the capsule may be irregular, or there may be a lid formed, which falls away when the spores are ripe. The

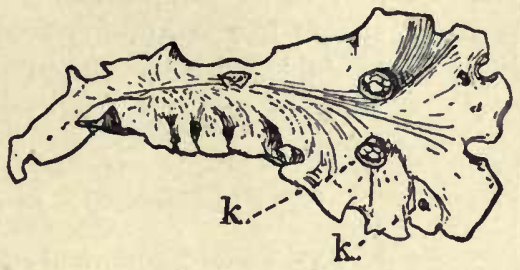

A.
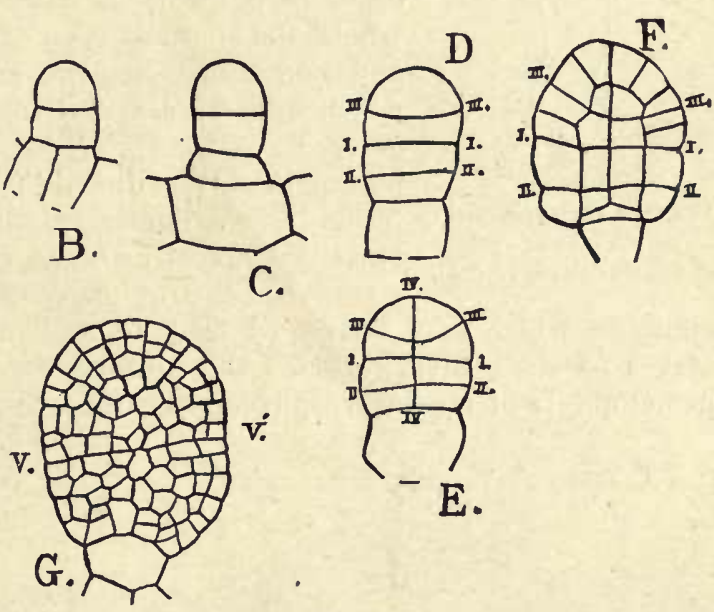

Fig. 169. - Marchantia polymorpha. A, plant with gemmacups, $k$ (natural size). $B-F$, development of the gemma $(\times 525)$. $G$, an older gemma, attached to its pedicel, and showing the two growing-points, $v, v^{\prime}(\times 260)$.

Marchantiace $\%$ com-

prise the most conspicuous of the Hepaticæ, such genera as Marchantia, Conocephalus, and Lunularia being among the best-known forms.

\section{Order II. Jungermanniales}

The majority of the Hepaticæ belong to the Jungermanniales, which are especially abundant in the mountain forests of the Tropics. Most of them are epiphytes, and may be found on the bark of trees in every wood, although a few - e.g. Blasia, Fossombronia-occur upon the ground. The gametophyte in the lower forms is a simple thallus, but the greater number are leafy forms - the so-called "Scale Mosses." With very few exceptions, the gametophyte is markedly dorsiventral in structure. 
The Jungermanniales are divided into two suborders, the Anacrogynæ, or Metzgeriaceæ, and the Acrogynæ, or leafy Jungermanni-

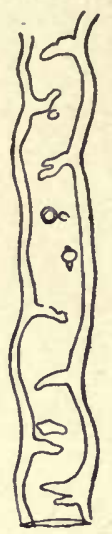

Frg. 170. - Marchantia polymorpha; tuberculate rhizoid $(\times 525)$. aceæ. In the former, the archegonia are dorsal, and never arise directly from the apex of the shoot; in the Acrogynæ, the apex of the archegonial shoot becomes transformed into an archegonium, and its longitudinal growth is thus stopped.

\section{Suborder I. J. Anacrogynæ}

The anacrogynous Jungermanniales are of especial interest, as they represent, on the whole, the simplest type of the Archegoniates, and one suggesting the ancestral form from which the more specialized types have been derived. Among the Anacrogynæ are many interesting transitional types. The lowest forms have a delicate thallus growing from a two-sided apical cell, and closely resemble the younger stages of many of the higher Archegoniates, which may be traced back to such a form. The early stages of such Liverworts as the Marchantiaceæ, and the young gametophyte of most Ferns, usually conform to this type. Some of

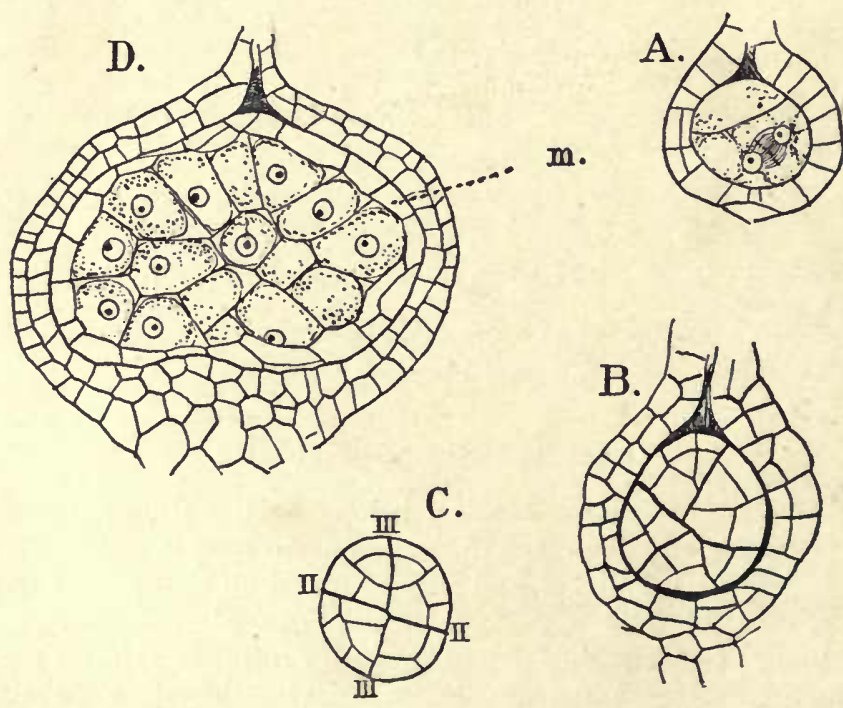

Fig. 171.- $A-C$, Riccia glauca. $D, R$. trichocarpa. $A, B$, longitudinal, $C$, transverse, sections of young embryo $(\times 260)$. $D$, an older embryo, showing the layer of sterile cells, $m$, surrounding the sporogenous cells $(\times 220)$. 
the Anacrogynæ, like Blasia and Symphyogyna (Fig. 172, E), show a development of rudimentary leaves, or special assimilatory organs, like those which characterize the more specialized Acrogynæ.

Anelatereæ. - The simplest of the Anacrogynæ are the Anelatereæ, intermediate in some respects between the typical Anacrogynæ and the Ricciaceæ, which they resemble somewhat in the apical growth of the thallus and the character of the sexual organs. The genus Sphærocarpus (Fig. 160) is, on the whole, the lowest of these. Riella, and the monotypic Geothallus of Southern California (Campbell, 3), are the other genera. The Anelatereæ are so called because the sterile archesporial cells do not develop into perfect elaters, but remain as oval, thin-walled cells, usually containing starch and some chlorophyll. In
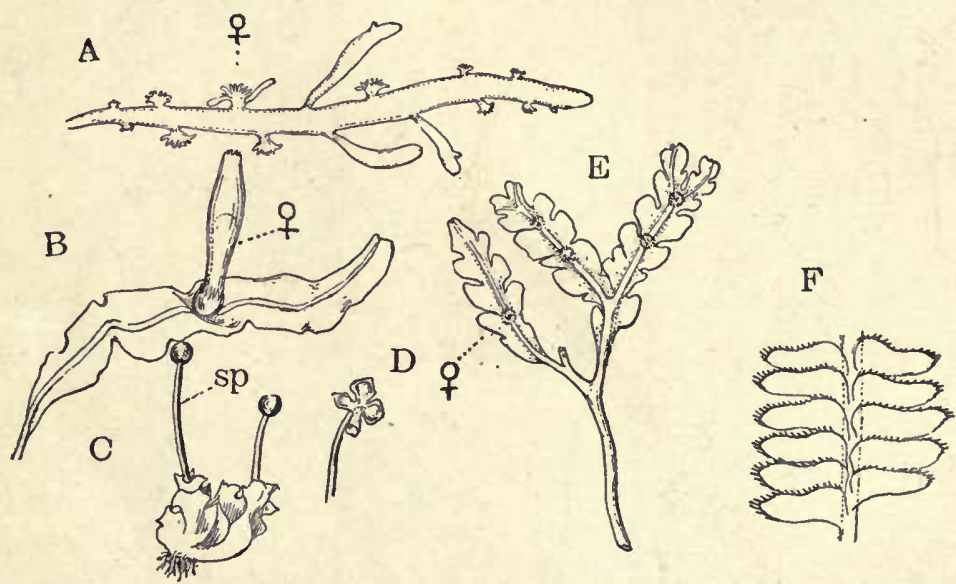

Fig. 172. $-A$, Aneura (Riccardia) pinnatifida $(\times 4), B$, Pallavicinia cylindrica (×2). C, D, Fossombronia longiseta $(\times 3)$; sp.; sporophyte. E, Symphyogyna, $s p .\left(\times 1 \frac{1}{2}\right) . \quad+$, archegonial receptacle. $F$, Bazzania sp. $(\times 2)$.

the typical Anacrogynæ (e.g. Pellia, Aneura, Fossombronia, etc., Fig. 172) the reproductive organs are borne, singly or in groups, upon the dorsal surface of the thallus, or that of special branches. The archegonium is much like that of the Marchantiales, but except in the lowest forms, there are but five peripheral cell-rows in the neck. The antheridium (Fig. 173), however, is quite different, and agrees with that of the Acrogynæ. The first division-wall in the upper part of the antheridium is vertical and divides it equally into two cells, in which the next divisions separate a central cell from three peripheral ones, so that the antheridium consists of two central cells which subsequently give rise to the sperm-cells and six peripheral cells, which produce the wall. The spermatozoids are relatively larger, and coiled several times. At the anterior end are two very long cilia.

The root-hairs of the Jungermanniales are always of the simple type, and the scales found upon the ventral surface of the Marchantiales are replaced in these forms by glandular hairs, which serve to protect the growing-point of the shoot. 
Gemmæ. - In Aneura multifida, two-celled gemmæ have been described, which escape from the cells of the thallus in a manner resembling the escape of zoöspores in the Green Algæ. In other genera-e.g. Blasia-multicellular gemmæ, not unlike those in Marchantia, are formed.

Tubers. - In some Anacrogynæ of dry regions, such as Geothallus tuberosus, there is developed toward the end of the growing season a subterranean tuber, which remains dormant during the dry season, and starts into growth again with the advent of the winter rains.

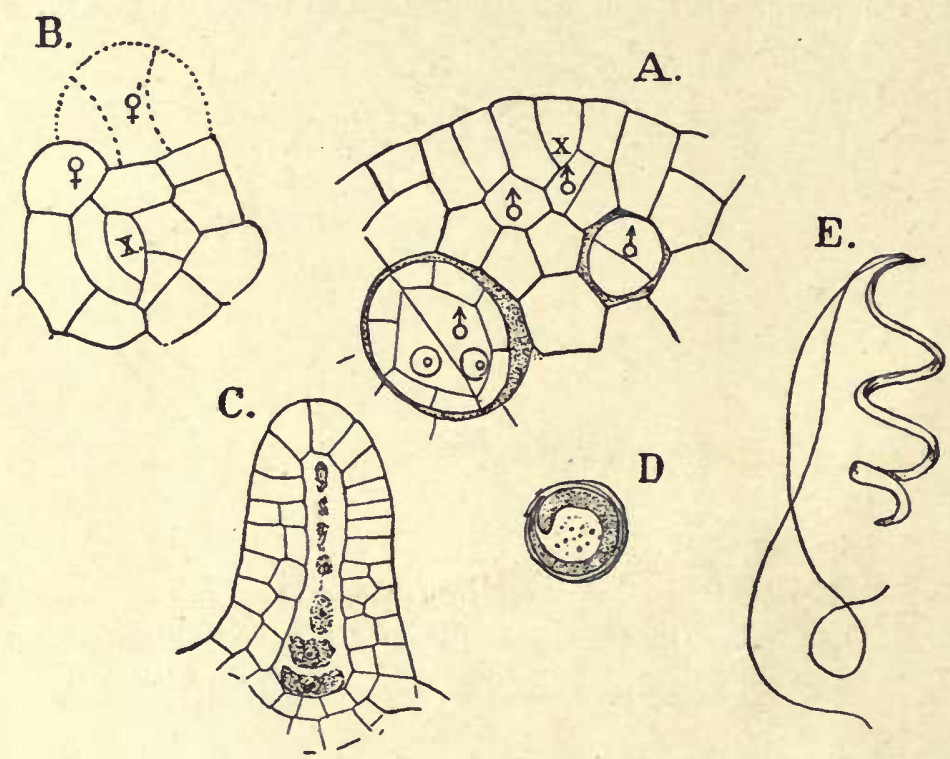

Fig. 173. - A-C, Aneura pinnatifida. D, E, Pellia calycina. A, horizontal section of young antheridial branch $(\times 565) ; x$, apical cell; 0 , antheridia. $B$, transverse section of archegonial shoot, passing through the apical cell, $x$; $\uparrow$, young archegonia. $C$, nearly ripe archegonium $(\times 260)$. $D, E$, spermatozoids of Pellia calycina $(\times 1225)$. (D, $E$, after GUIGNARD.

The Sporophyte. - The first division in the embryo is always transverse. In the Anelatereæ this division at once separates the capsule from the foot; but in the typical Jungermanniales the lower of the two primary cells remains undivided, or develops into a small appendage of the foot, and from the upper ("epibasal") cell are derived all the other parts of the sporophyte. This, in typical cases, shows three parts : the capsule, seta, and foot.

The sporogenous cells divide, as usual, into four parts, but the division is indicated before the nucleus divides, in the form of four saclike outgrowths of the cell, before any indication of division is shown by the nucleus. A "quadri-polar" spindle is then developed, and the division-walls are formed between the four young spores. 
The sporophyte remains included within the calyptra until the spores are ripe, when there is a sudden elongation of the seta, which

A

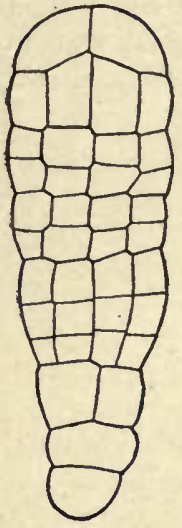

\section{B}

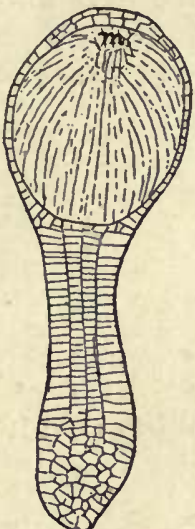

C

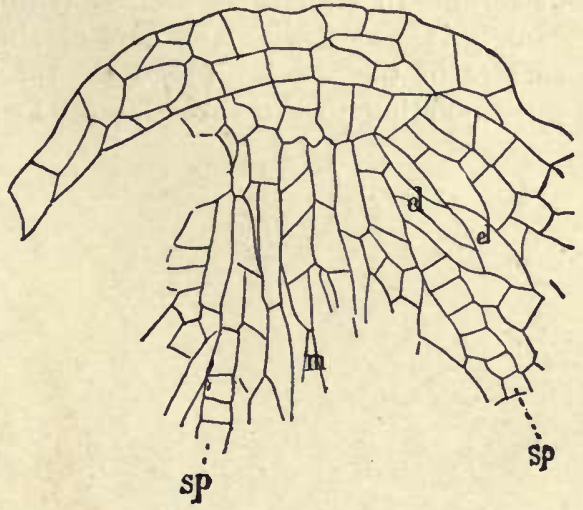

Fig. 174. $-A$, Aneura multifida. Young embryo, optical section ( $\times 235)$. (After Leitgeb.) $B, A$. pinguis, longitudinal section of young sporophyte $(\times 35)$. $C$, upper part of $B(\times 200) ; s p$., sporangenous cells; $e l$, young elaters; $m$, apical mass of sterile tissue.

may increase many times in length within a few days, owing to the stretching of the cells, brought about by the consumption of the substances within the cells. In Pellia epiphylla, the seta has been observed to increase from one millimetre to nearly eighty millimetres in three or four days. This extraordinary growth is at the expense of starch which fills the cells of the young seta. The capsule usually opens by four valves, but this is not always the case.

\section{Suborder II. Acrogynæ}

The acrogynous Jungermanniales comprise the larger number of the described species of Hepaticæ, but the type is a much more fixed one than that of the Anacrogynæ.

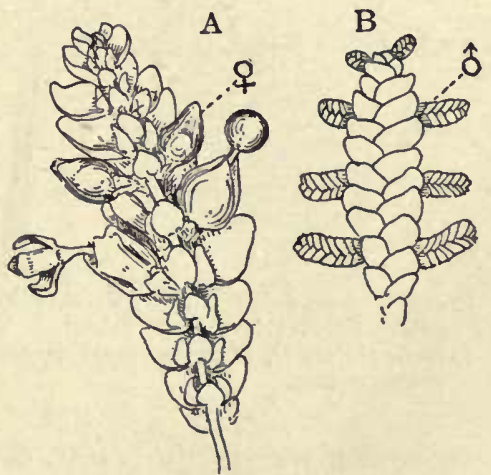

Fra. 175. - Madotheca Bolanderi. A, female, $B$, male, plants $(\times 4)$; archegonial branch; ô, antheridial branch.

Such foliose forms among the latter group as Blasia, Fossombronia, and especially the peculiar genus Treubia, are intermediate, to some extent, between the Anacrogynæ and the Acrogynæ; but the num- 
bers of the latter group conform invariably to a single structural type. The apex of the shoot (Fig. 176) is occupied by a single apical cell which, except in the genus Physiotium, is tetrahedral in form. In transverse section it appears as a triangle, which is usually isosceles, with the shorter side turned toward the ventral surface of the shoot. There are three series of segments formed, corresponding to the three lateral faces of the apical cell, and each
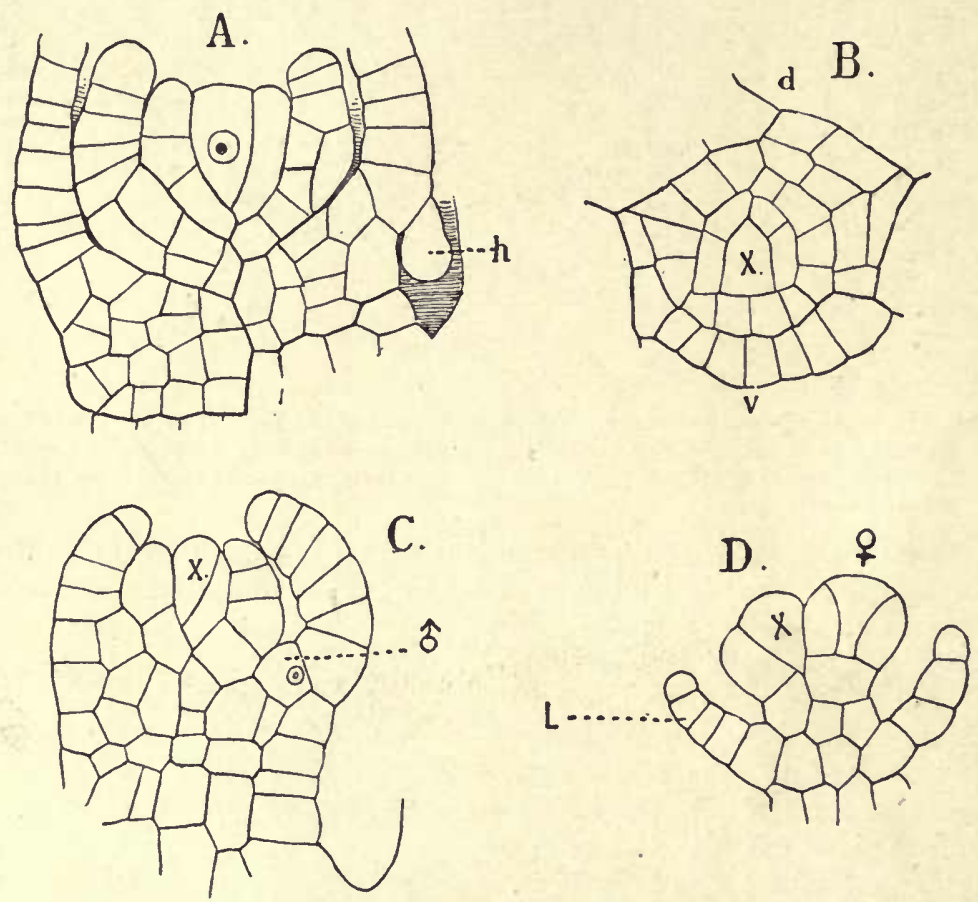

Fig. 176. - Madotheca Bolanderi. A, longitudinal, $B$, transverse, section of a vegetative shoot $(\times 500) ; d$, dorsal, $v$, ventral, surface. $C$, longitudinal section of antheridial, $D$, of archegonial, shoot; $\delta$, mother-cell of antheridium; $\$$, young archegonium.

segment gives rise to a leaf, except where the ventral face of the apical cell is very narrow, in which case the ventral series of leaves, the "Amphigastria," are not developed.

The fully developed shoot shows a definite central axis, upon which the leaves are arranged in three rows, two dorsal and one ventral. The dorsal leaves are usually two-lobed, the lobes being either of equal size, or, more commonly, the upper lobe is larger, and overlaps the lower lobe of the leaf in front of it. The leaves and stem 
are composed of almost perfectly uniform, green parenchyma, and no trace of a midrib is ever found in the leaves.

The lower lobe of the dorsal leaves, especially in many of the epiphytic tropical species of Lejeunia, becomes folded over so as to form a little sac (Fig. 181), which is apparently useful in storing water. It is said that in some instances these sacs serve to entrap small crustaceaus or insects, acting like the traps found upon the leaves of Utricularia.

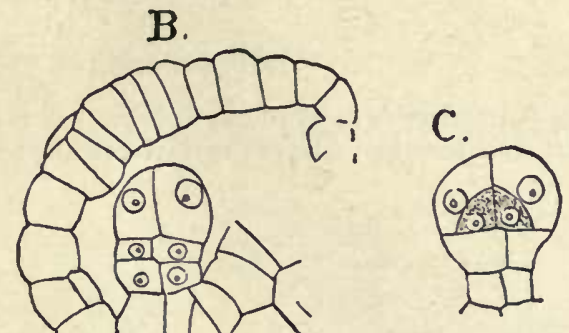

Branching. - The branching in the Acrogynæ is always monopodial. The lateral branch replaces the lower lobe of a leaf. In the ventral half of the

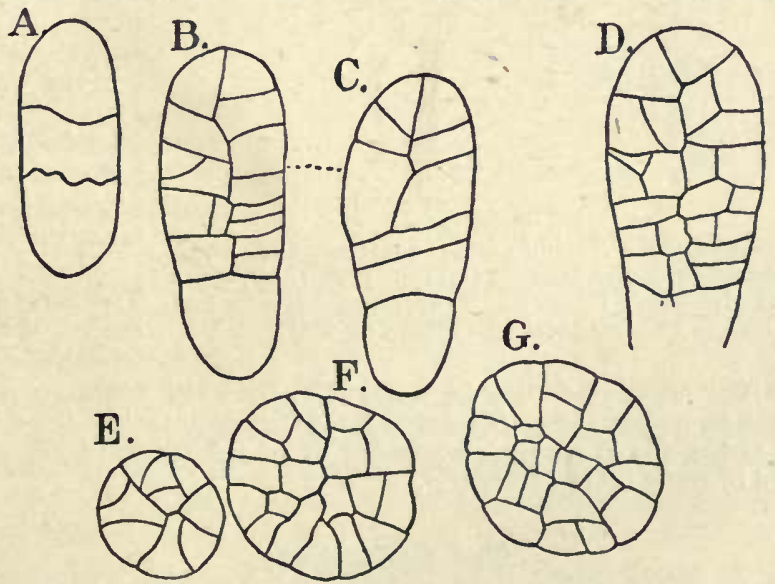

Fia. 178. - Madotheca Bolanderi. Development of the embryo. $A-D$, longitudinal sections. $E-G$, series of transverse sections of an embryo. $B$ and $C$ are successive longitudinal sections of the same embryo $(\times 525)$. 
young leaf, which would ordinarily develop into its lower lobe, intersecting walls arise which cut out a tetrahedral cell, at once transforming it into the apical cell for the new shoot.

\section{Reproduction}

Gemmæ. - Unicellular or bicellular gemmæ are found in many forms, and usually arise from marginal cells of the leaves, falling of readily and germinating
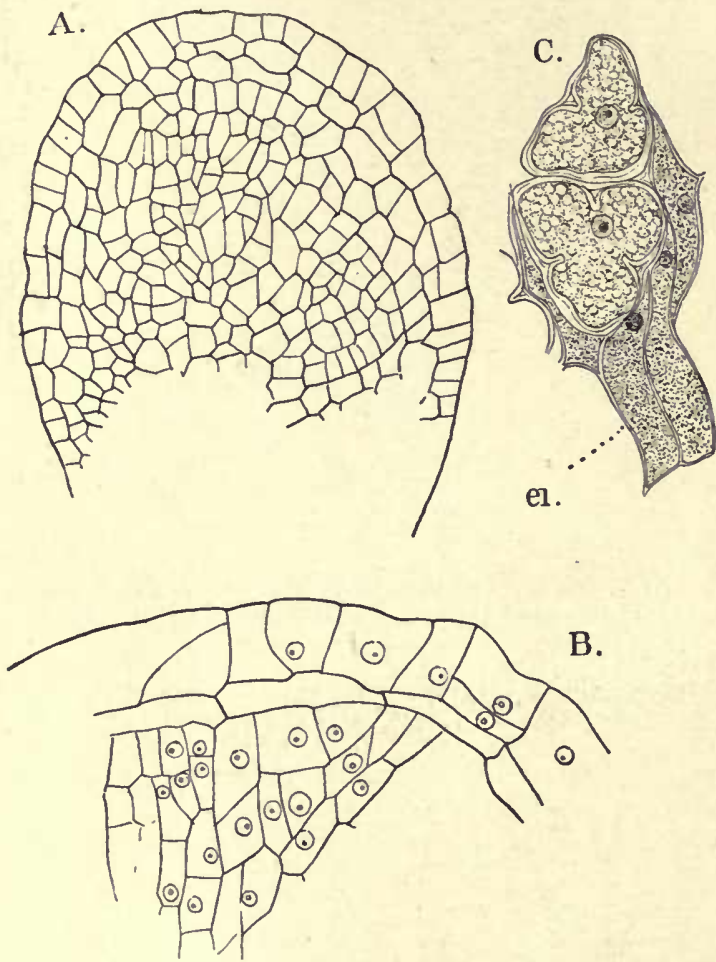

Fig. 179. - Madotheca Bolanderi. A, nearly median longitudinal section of an advanced embryo $(\times 260) . B$, upper part of the same $(\times 525)$. $C$, sporogenous cells and young elaters from an older sporophyte $(\times 525)$. much as the spores do. Less commonly, e.g. Lejeunia metzgeriopsis, multicellular gemmæ are produced.

Sex-organs. The plants may be either monœcious or diøcious. In the latter case, as in the commoll genus $\mathrm{Ma}$ dotheca (Bellin. cinia), (Fig. 175), the reproductive branches are somewhat different from the sterile ones. The antheridia (Fig. 177) are borne singly in the axils of closely imbricated leaves, upon short lateral branches. The antheridium corresponds in its development with that of the Anacrogynæ, but is often long-stalked, and in Madotheca has the lower part of the wall more massive than is usually the case.

Archegonium. The archegonia are borne upon short lateral branches also, and arise from segments of the apical cell $(176, \mathrm{D})$, which finally becomes transformed into an archegonium. This arrests the further growth of tle shoot. The group of archegonia is usually surrounded by an inflated involucre, similar to that found in many other Liverworts.

\section{The Sporophyte}

The development of the sporophyte in the Acrogynæ is very much like that of the lower Jungermanniales. Here, also, the whole of the sporophyte, except 
the small appendage at the base, arises from the epibasal half of the two-celled embryo.

\section{Classification of the Acrogynæ}

The division of the Acrogynæ into separate families offers some difficulties, as the group as a whole has comparatively few marked differences. The following families have been proposed by Schiffner (Engler and Prantl, 4):

I. Epigoniantheæ;

II. Trigonantheæ;

III. Ptilidioideæ;

IV. Scapanioideæ ;

V. Stephaninoideæ;

VI. Pleurozioideæ;

VII. Bellincinioideæ;

VIII. Jubuloideæ.

Class II.

\section{Axthocerotales}

The Anthocerotales include three genera which agree closely among themselves, but are so different from the other Hepaticæ, with which they are usually associated, that it seems best to separate them as a class coördinate with the whole of the Hepaticæ.

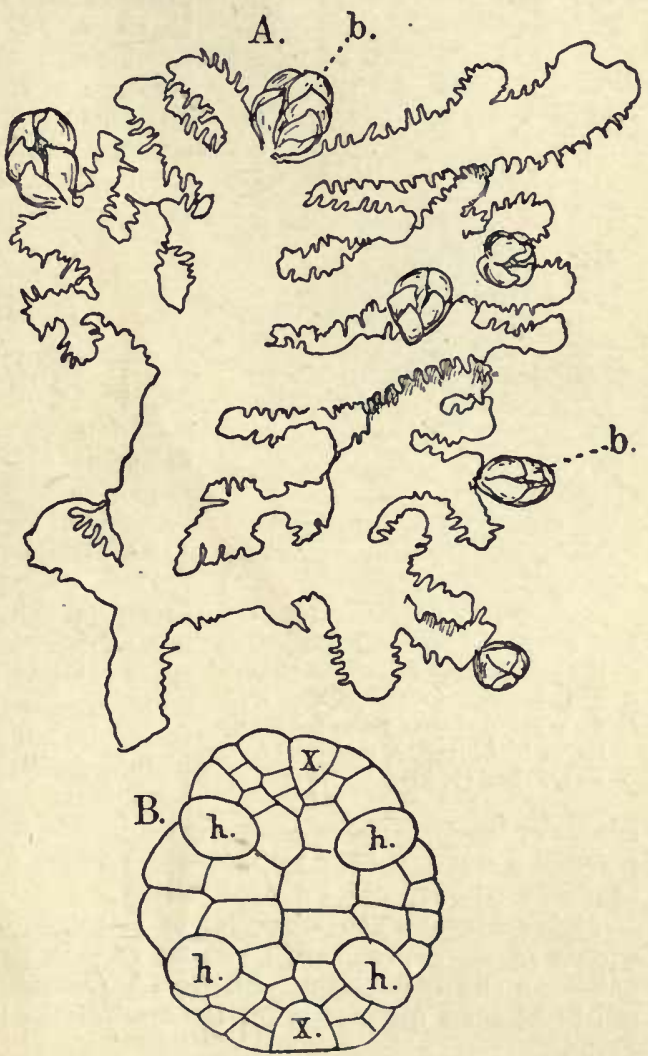

Fra. 180. - Lejeunia metzgeriopsis. A, thallose protonema with terminal leafy buds, $b(\times 14)$. $B$, gemma of Cololejeunia Goebelii. (After Goebel.)

The gametophyte (Fig. 182) is a simple thallus in most species, but in Dendroceros there is sometimes an indication of a rudimentary leaf-formation, not unlike that of Fossombronia. In this genus, the thallus has a definite midrib, while the rest of the thallus is but one cell thick. In the other genera, Anthoceros and Notothylas, the thallus is fleshy and has no midrib. Dendroceros is a tropical genus, and is epiphytic in its habits. The other genera occur also in temperate regions and are terrestrial. 
Cell-structure. - All Anthocerotales agree in the structure of the thallus. The apical growth is similar to that in the lower Jungermanniales, but a pecul-
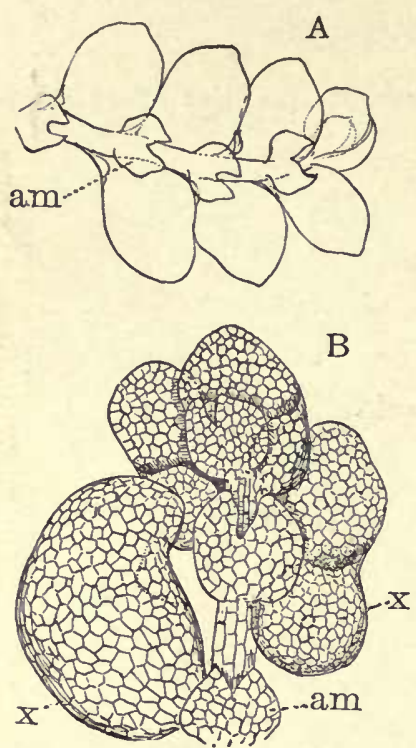

Fig. 181. - A, Lejeunia sp., showing the ventral leaves, or amphigastria, am (× about 40$)$. $B$, a West Indian Lejeunia, the lower leaf-lobes, $x$, modified into water sacs $(\times 75)$. iarity is the presence of a single chromatophore in each cell, which thus recalls that of many Confervaceæ, like Coleochæte or Chætophora. Upon the lower side of the thallus, which is attached to the substratum by simple root-hairs, are stoma-like clefts, which communicate with cavities filled with mucilage. Through these mucilage-clefts filaments of Nostoc enter the thallus and establish themselves there. These endophytic Nostoc-colonies are constant features in all species of Anthocerotales.

\section{Reproduction}

The reproductive organs are formed together upon the dorsal surface of the thallus much as in Riccia, but they differ in certain respects from those of the true Hepaticæ, and suggest rather those of the lower Pteridophytes.

Antheridium. - The antheridium (Fig. 184) is always formed endogenously. A superficial cell divides by a transverse wall into an outer and an inner cell, of which the latter develops into the antheridium or may divide further, so as to produce a group of antheridia lying within a closed cavity. The mature antheridium is an oval or globular body borne upon a stalk, which in some species of Dendroceros becomes very long. The wall of the antheridium is composed of a single layer of cells, each containing a chromatophore, which often assumes a red or yellow color at maturity.

Archegonium. - The archegonium mother-cell does not project above the surface of the thallus, and it remains very inconspicuous, the outer neck-cells not being clearly distinguishable from the adjacent thallus-cells, and the eggcell being some distance below the level of the thallus, as is the case in the Ferns.

\section{The Sporophyte}

The sporophyte in the Anthocerotales differs very much from that of the Hepaticæ. The archesporium, or sporogenous tissue, is reduced to a single primary layer of cells, which later divides into two, or in Notothylas into four.

The first divisions in the embryo (Fig. 185) result in several tiers of cells, which become next divided by periclinal walls into a central part, the " Endothecium," and an outer portion, the "Amphithecium." The endothecium takes no part in spore-formation, but persists as a central strand of tissue, the colu- 
mella, which in position suggests the primary vascular bundles of the Fernembryo. From the amphithecium, by a second series of periclinals, there is separated on its inner side a layer of cells which forms the archesporium.

The lower part of the embryo develops a large foot like that in the embryo of the Hepaticæ; but between the foot and the upper part of the embryo there is developed a zone of actively dividing cells, which cause the sporophyte to elongate rapidly by basal growth. This growth may be limited, as in Notothylas, where the sporophyte never assumes a large size; but in some species of Anthoceros it continues for several mouths, - indeed, as long as the gametophyte remains active, - and the slender sporophyte may reach a length of six to eight centimetres. These large sporophytes have a well-developed assimila-

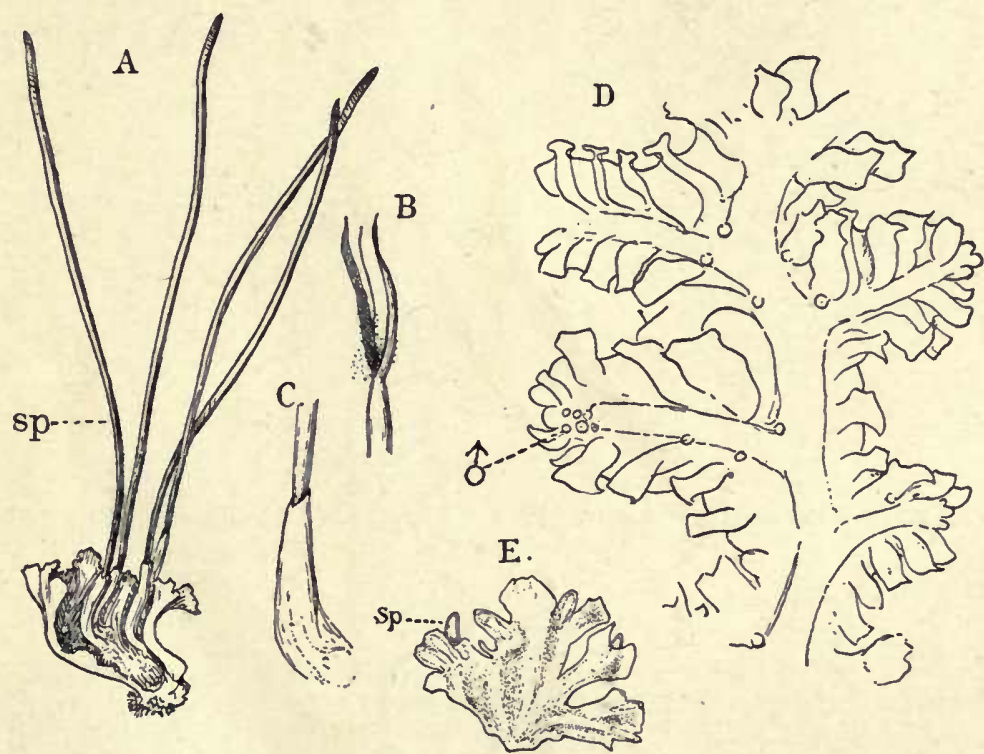

Fig. 182.-A-C, Anthoceros fusiformis. A, gametophyte with four sporophytes attached $(\times 2)$. $B$, upper part of full-grown sporophyte, discharging spores. $C$, base of sporophyte surrounded by the calyptra, or sheath $(\times 4)$. D, Dendroceros Javanicus, enlarged. (After Leitgerb.) $E$, Notothylas orbicularis $(\times 4)$.

tory tissue-system, several layers of the outer cells forming a spongy green parenchyma which communicates with the outside by means of stomata, precisely like those in the leaves of the higher plants. Were the sporophyte put into communication with the earth by the development of a root, it would be quite independent of the gametophyte.

The archesporium shows a more or less evident separation into fertile and sterile portions, which suggest a condition something like the formation of sporangia in the simplest Ferns. The sterile cells in some cases develop into elaters, but these differ somewhat from those of the Hepaticæ. 


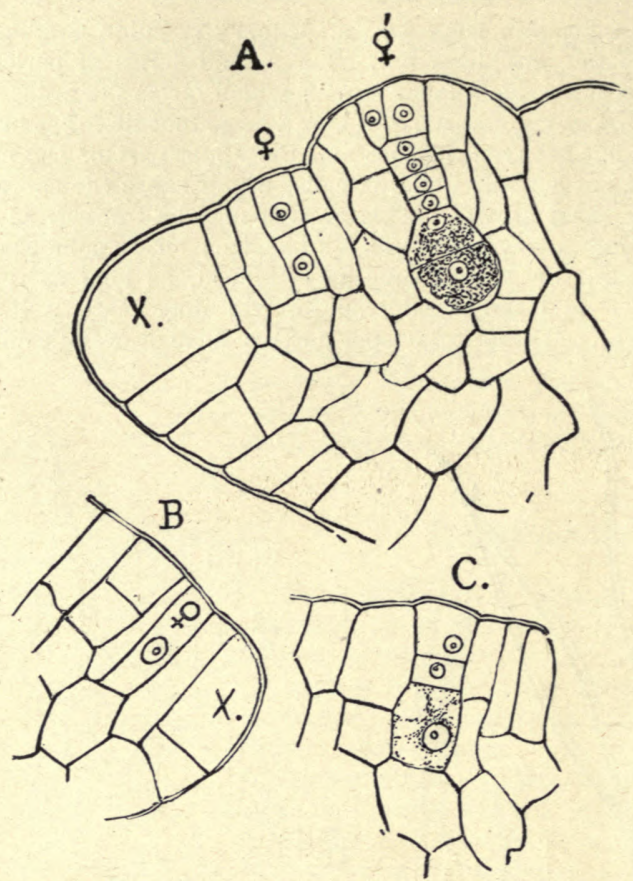

Fig. 183. - Notothylas orbicularis. Apex of thallus and archegonia $(\times 600) ; x$, the apical cell.

A.
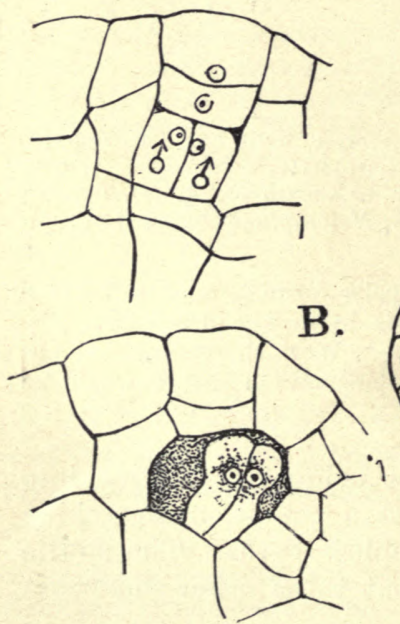

FIG. 184. - Notothylas orbicularis. Development of the antheridium. $D$, crosssection, the others longitudinal sections. $A-D, \times 600 . \quad E, \times 300$.
E.

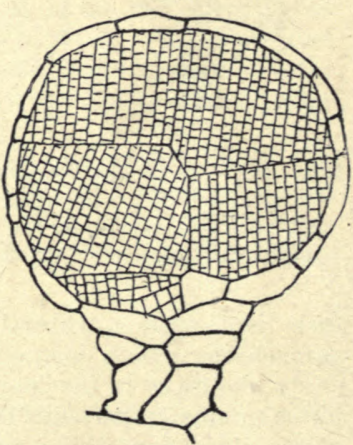


At maturity the sporophyte splits into two valves, and the spores are gradually thrown out as they mature. Owing to the formation of new sporogenous tissue at the base of the sporophyte, spores in all stages of development occur in the same individual.
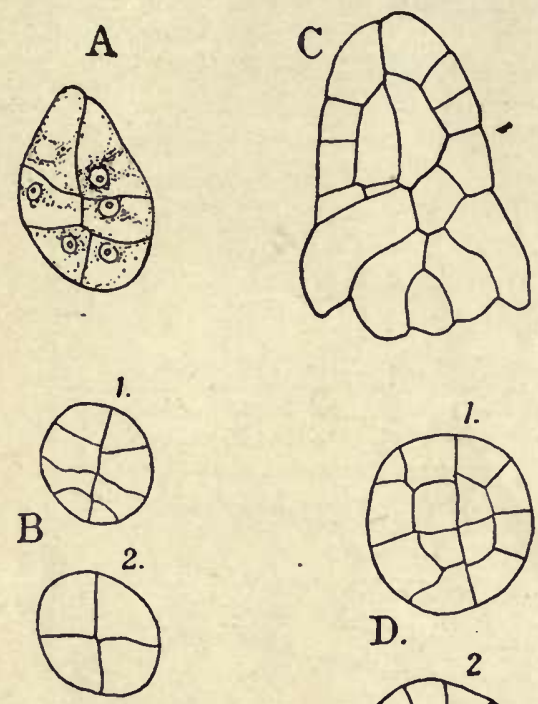

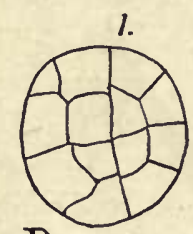

D.

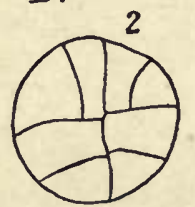

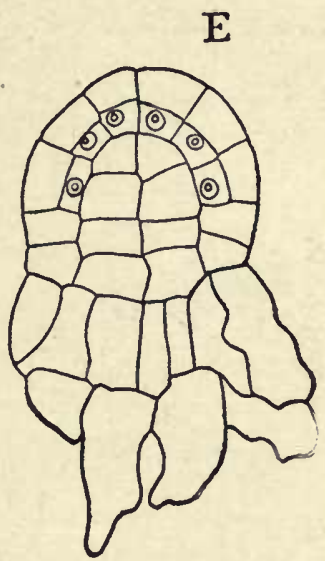

Fig. 185. - Anthoceros Pearsoni, Development of the embryo $(\times 300)$. $A, C, \boldsymbol{L}$ median longitudinal sections. $B, D$, successive cross-sections of embryos of about the age of $A, C . E$, older embryo, showing the archesporium.

\section{Class III. Musci}

The true Mosses (Musci) are nuch more abundant than the Hepaticæ, especially in colder regions, where they often constitute an important feature of the vegetation. While the number of species is much greater than that of the Liverworts, the general type is a very uniform one, and were it not for the peculiar genera, Sphagnum and Andreæa, they might all be reduced to a single order.

\section{The Gametophyte}

Protonema. - The gametophyte of the Musci always shows a preliminary stage, the protonema, which is usually an extensively branching growth, resembling an Alga, or, less commonly, is a flat thallus 


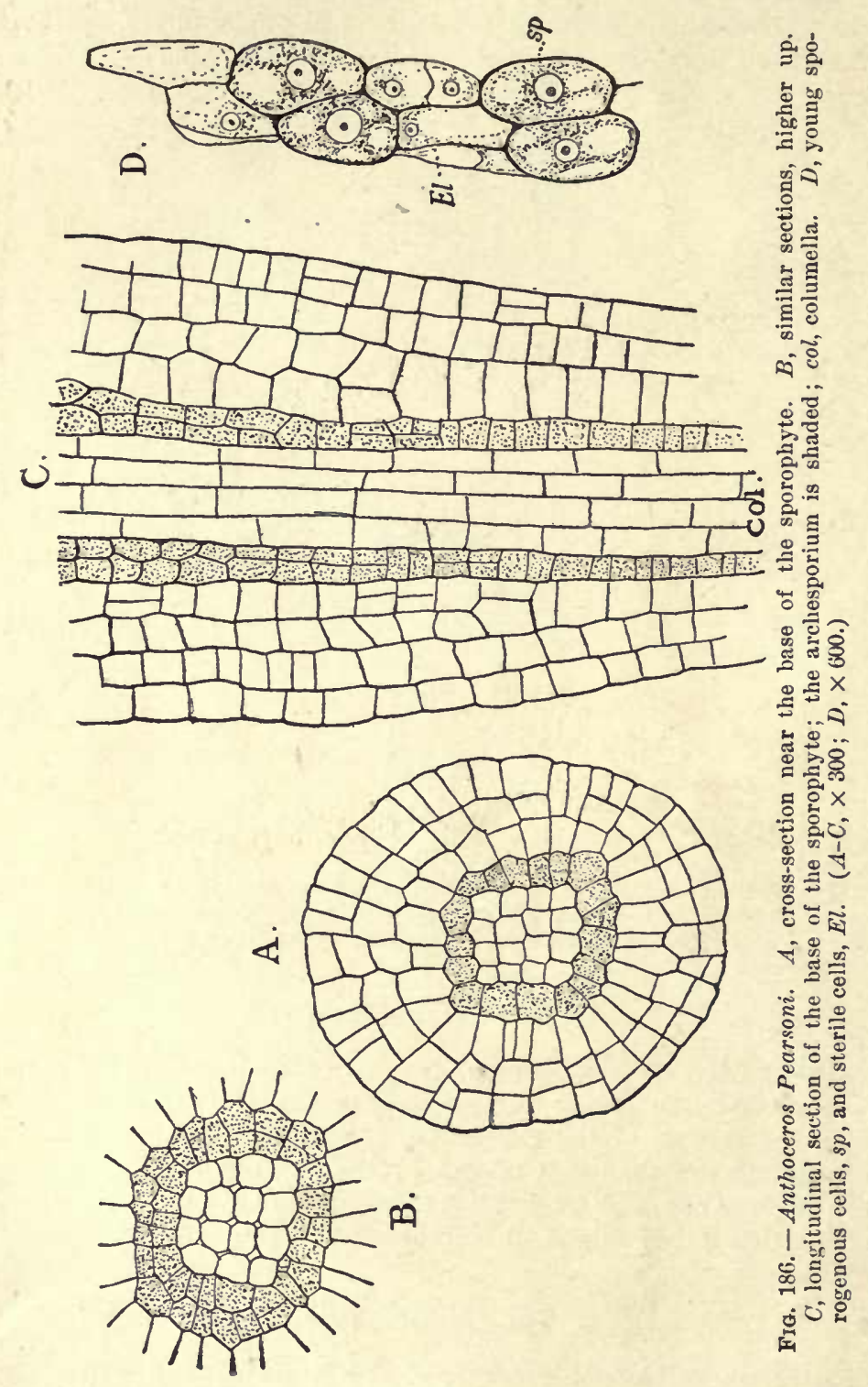


like that of the simple Hepaticæ. The protonema arises primarily from the germination of the spore, but may develop secondarily from various parts of the gametophyte, or even, in exceptional cases, from the spoiophyte. From the protonema special branches arise, which become the leafy shoots, or gametophores, upon which the sexual organs are borne.

The growth of the filamentous protonema is apical, and the division walls are often strongly oblique, this being especially the case in the branches which penetrate the earth and assume the character of rhizoids. These branches lose the chlorophyll, and their cell-walls

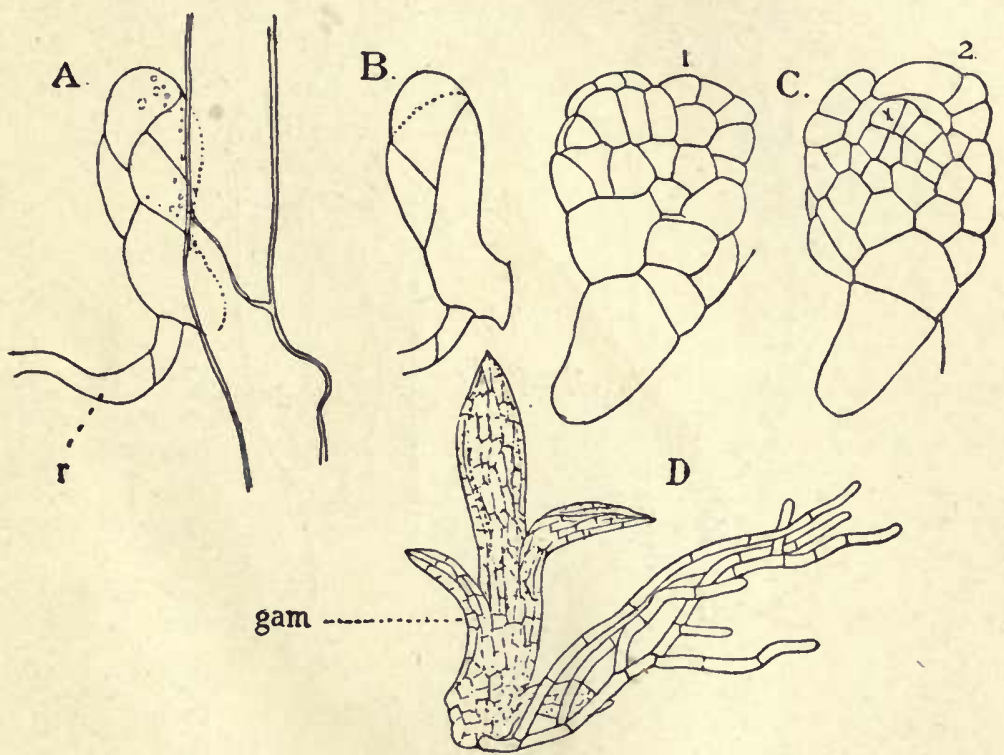

Fig. 187.-Funaria hygrometrica. A, fragment of a protonemal filament, with young bud developing from it. $B$, the same bud in optical section. $C$, an older bud, 1 , from the surface; 2 , in optical section; $x$, apical cell $(\times 225)$. $D$, protonemal filameuts with an older bud, gam, attached $(\times 36)$.

become thick and brown in color. In Sphagnum the protonema is a flat thallus, which in its earlier stages often shows a two-sided apical cell, like that in the lower Hepaticæ. From the margin of this thallus, filaments like those of the typical moss-protonema may be formed. It is probable that the thalloid protonema of Sphagnum is an older type than the filamentous one of the typical Mosses.

Gametophore. - The leafy shoot begins as a lateral branch of the protonema (Fig. 187). The bud enlarges slightly, and there are formed, in rapid succession, three intersecting walls, which cut out a tetrahedral apical cell, from which are then cut off three series of 
segments, each of which gives rise to a leaf and a portion of the stem. From the base of the young shoot rhizoids grow out, which fasten it to the ground. These rhizoids may, under proper conditions, give rise to new protonemal filaments.

Apical Growth. - With very few exceptions (e.g. Fissidens), the growth of the shoot in the Musci is from the activity of a tetrahedral apical cell (Fig. 189), and the shoot is radially symmetrical. Each segment of the apical cell gives rise to a leaf and a portion of the

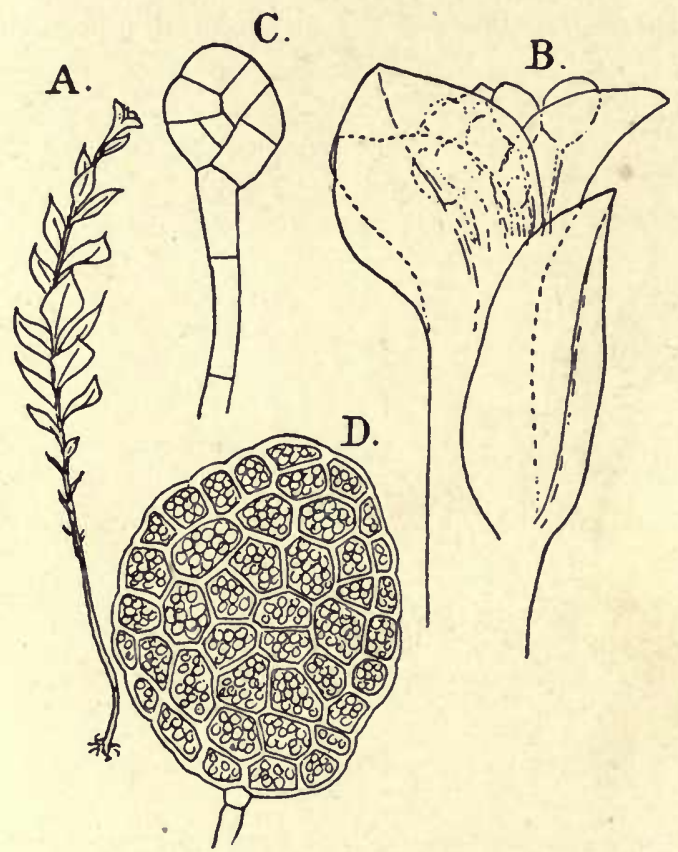

FIG. 188. - Tetraphis pellucida. $A$, leafy shoot with gemmæ $(\times 6) . \quad B$, upper part of the same $(\times 50)$. C, young gemma $(\times 600)$. $D$, older gemma $(\times 300)$.

stem. The branching is always lateral, the apical cell of the branch being cut out from an outer cell of the stem, below one of the young leaves.

The Leaf. - The growth of the young leaf is from a two-sided apical cell, whose growth is limited. The later growth is basal. In Sphagnum, Fontinalis, and a small number of other Mosses, the leaf develops no midrib; but the typical moss-leaf shows a median thickened strand, whose central cells are for purposes of conduction. The rest of the leaf is usually composed of a single layer of uniform green cells; but in Sphagnum there are two kinds of cells, large empty 

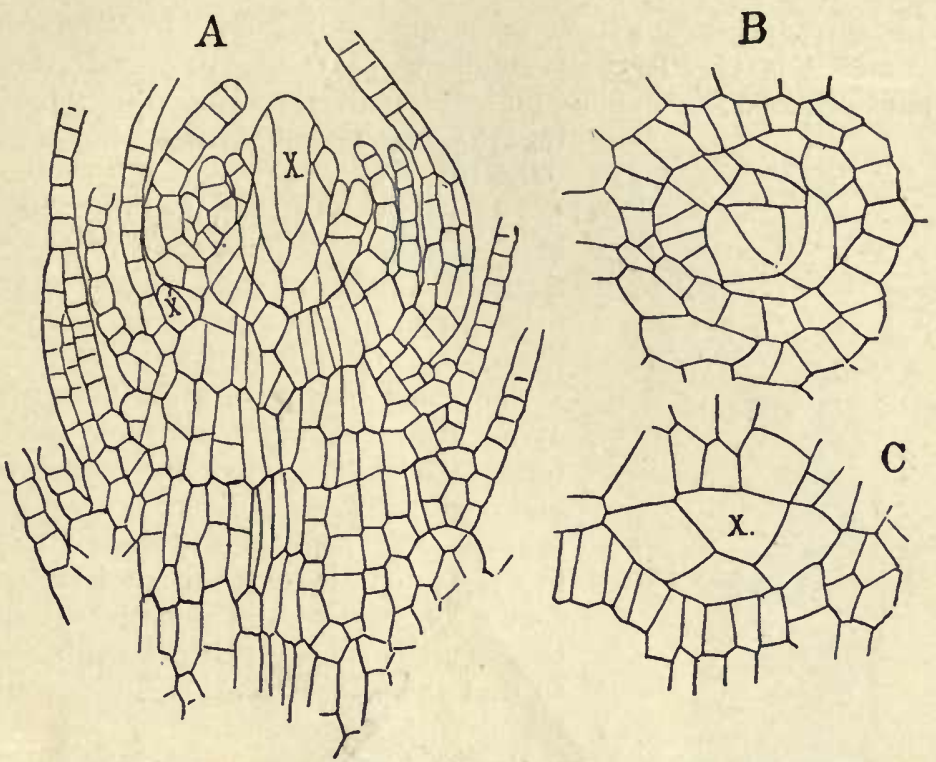

Fig. 189. - Amblystegium riparium, var. fluitans. $A$, median longitudinal section of a strong shoot; $x$, apical cell; $x$, initial of a lateral branch $(\times 250)$. $B$, transverse section of the apex $(\times 250)$. $C$, similar section of a young branch $(\times 500)$.
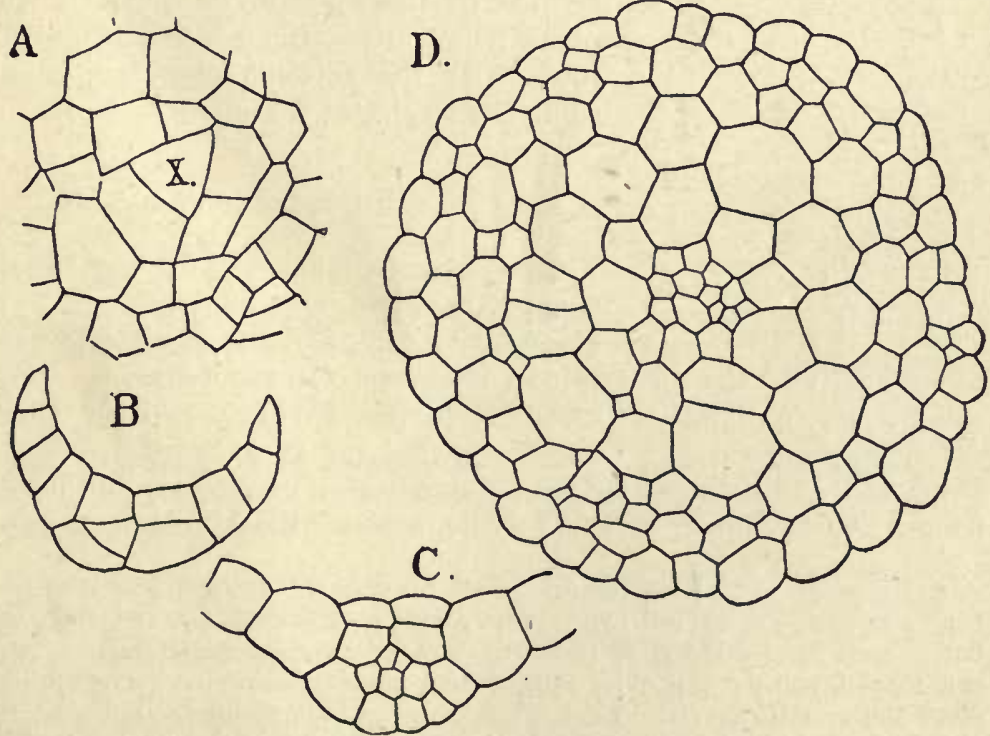

Fra. 190. - Funaria hygrometrica. A, transverse section of the apex of a young shoot $(\times 515) . B, C$, cross-sectious of young leaves $(\times 515) . \quad D$, cross-section of stem $(\times 257)$. 
ones, surrounded by narrow green ones (Fig. 202). In Polytrichum the midrib is very largely developed, and there are special vertical plates of green tissue, placed longitudinally, and thus largely increas-
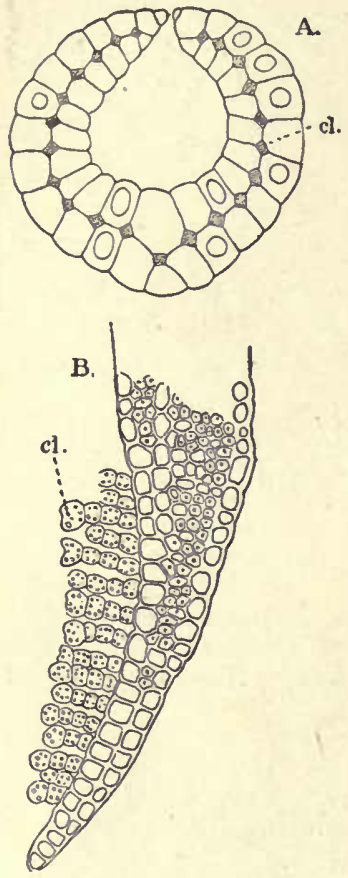

Fig. 191. - $A$, cross-section of leaf of Leucobryum. $B$, similar section of leaf of Polytrichum commune; $\mathrm{cl}$, chlorophyllous cells. (After GOEBEL.) ing the amount of assimilating surface (Fig. 191, B).

The primitive three-ranked arrangement of the leaves is in most cases replaced by a greater number of rows, caused by early inequalities in the growth of the young parts.

The shoot may have a limited growth, dying after the reproductive organs are formed; or it may grow for many years, giving rise to special branches upon which the reproductive organs are borne. Except in Sphagnum there is an axial strand of conducting tissue, and usually the outer tissues are composed of thick-walled cells, so that the stem is more or less woody in texture.

In the peculiar genus Buxbaumia the gametophoric shoot is rudimentary, and the leaves almost absent. This seems to be due to the saprophytic habit of the plant which lives upon decaying wood, into which the rhizoids penetrate, much as do the hyphæ of a Fungus.

\section{Reproduction}

Gemmæ. - In many Mosses the formation of sexual reproductive organs is exceedingly rare, and the plants increase non-sexually by the separation of branches. In some Mosses special gemmæ, not unlike those of the Hepaticæ, are developed, but these are not common. The best-known example is Tetraphis pellucida (Fig. 188). Resting-buds are common, however, upon the protonema. These appear to be, as a rule, arrested gametophoric buds.

Sex-organs. - The antheridium, in all investigated Mosses, grows at first from a two-sided apical cell (Fig. 192). A long stalk is developed in Sphagnum, but in most Mosses the stalk is short. The full-grown antheridium is usually club-shaped, and the peripheral cells contain numerous chromatophores, which often show a red or orange color when ripe. In Sphagnum the large, nearly globular antheridium opens by several lobes, which bend back, and set the sperm-cells free. In the Bryaceæ the upper cells separate, and after the whole 
mass of sperm-cells has been discharged, the opening closes, so that the antheridium looks very much as it did before it opened. The spermatozoids are coiled filaments, with two extremely long cilia (Fig. 193, C).

The early development of the archegonium (Fig. 194) in the Musci is much like that in the Hepaticæ. However, a difference is soon evident. The terminal cell of the neck, which in the Hepaticæ divides by intersecting walls to form the cover-cells, in the Musci becomes the apical cell of the archegonium, whose further growth is due to its divisions. It has the form of a truncated, three-sided pyramid. Segments are cut off from the three lateral faces, and from the inner, truncated portion. The latter segments contribute to the

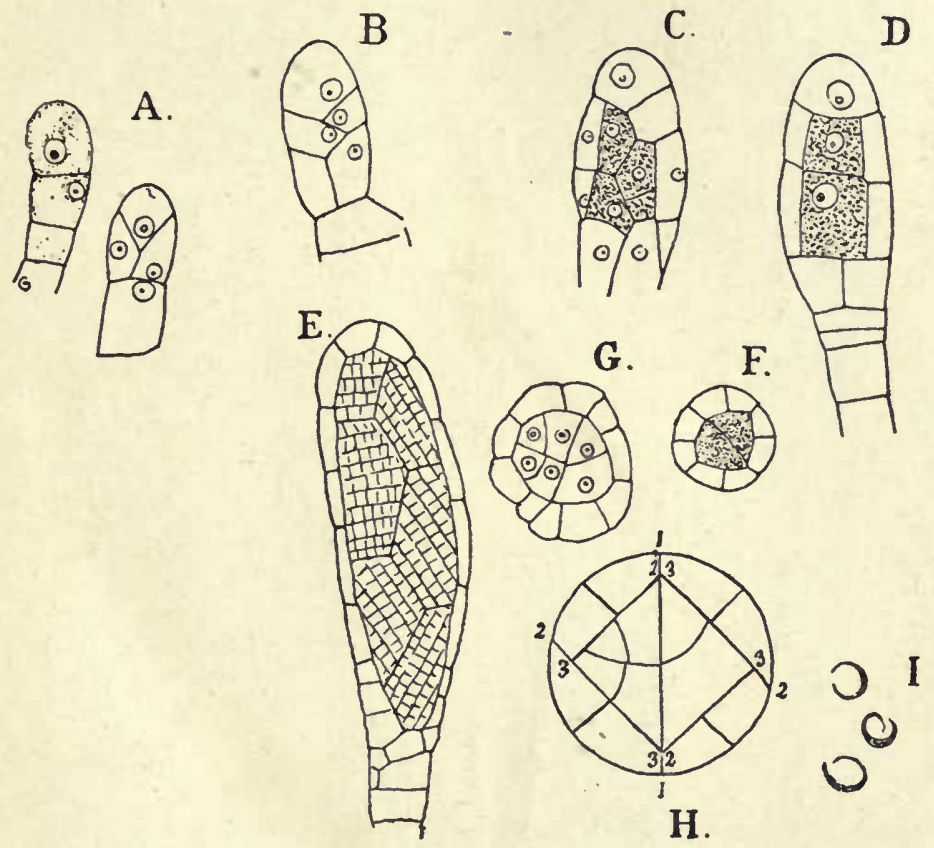

Fig. 192.-Funaria hygrometrica. Development of the antheridium. $A-D$, longitudinal sections $(\times(i) 0) . D$, section in a plane at right angles to $C . \quad E$, optical section $(\times 300) . F, G$, cross-sections. $H$, diagram of cross-section, showing the early divisions. $I$, young spermatozoids $(\times 1200)$.

neck canal-cells, the lateral segments, which undergo a longitudinal division, add to the six rows of outer neck-cells. The egg-cell and its sister cell, the ventral canal-cell, are formed as in all the Archegoniates.

Fertilization.-Fertilization is effected when the sexually mature plants are covered with water. - The substance which attracts the spermatozoids to the open archegonium has been shown to be canesugar.

The reproductive organs are sometimes surrounded by somewhat modified leaves, which gives the end of the shoot the appearance 


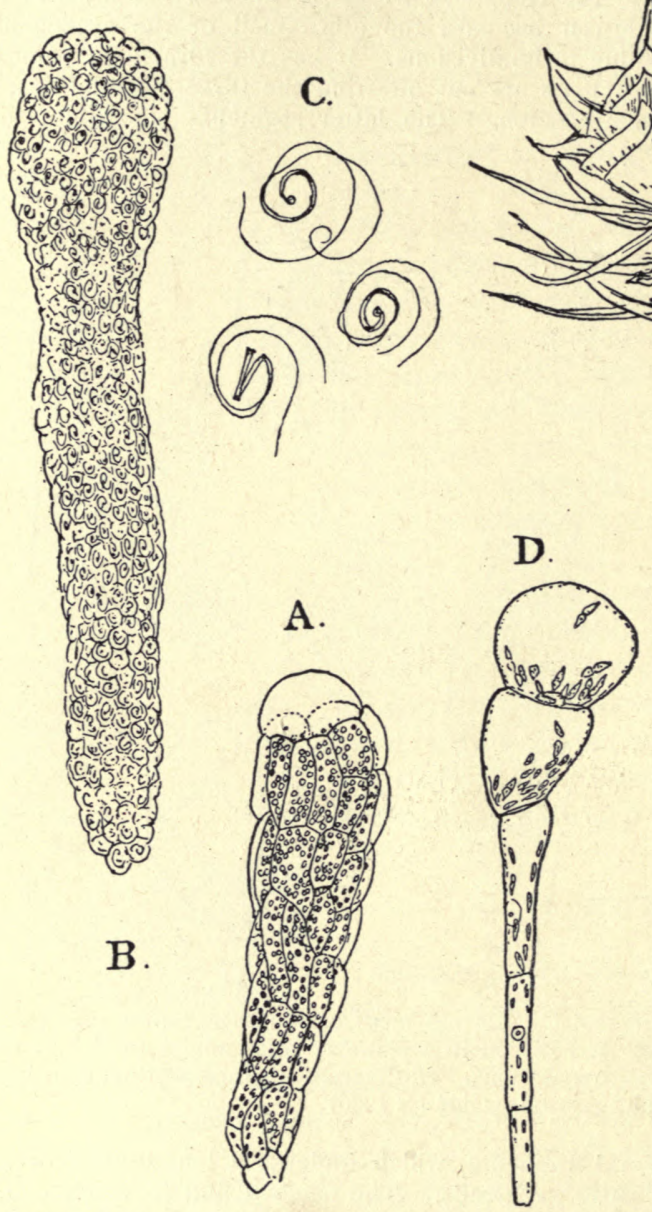

Fig. 193. - Funaria hygrometrica. A, ripe antheridium which has just discharged the sperm-cells, $B,(\times 300)$. $C$, spermatozoids $(\times 1300)$. $D$, paraphysis $(\times 300)$. $E$, male "flower" of Atrichum undulatum $(\times 6)$. 
of a flower. This is especially noticeable in the antheridial receptacles of some Mosses, like Polytrichum and Funaria. In Sphagnum the antheridia are borne singly in the axils of closely imbricated leaves which are red or yellow in color, so that the antheridial catkin-like shoots are very noticeable.

The Sporophyte. - The sporophyte in the higher Mosses becomres highly specialized, but in all but Sphagnum the development in the earlier stages is uniformly the same.

Sphagnum. - The embryo of Sphagnum resembles very much that of the Anthocerotales, and suggests an affinity with that group. The young embryo (Fig. 203) shows the formation of several tiers of cells, and an early differentia-

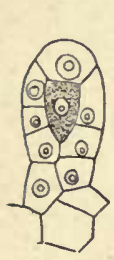

A.

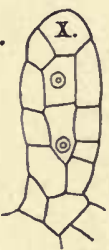

B

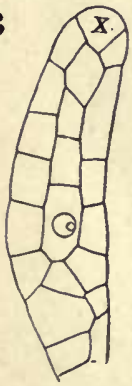

C.

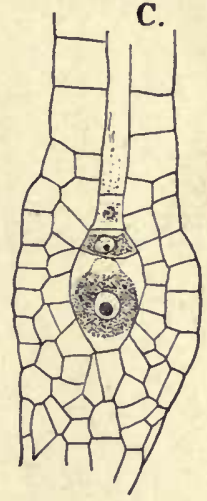

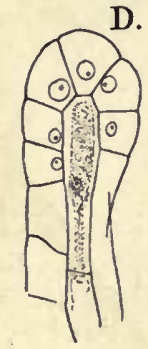

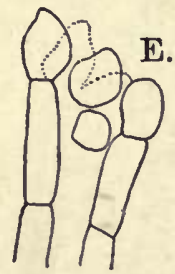

G.

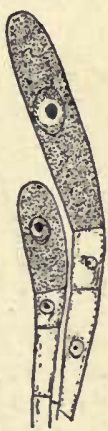

Fic. 194. - Funaria hygrometrica. Development of the archegonium. $B$, optical section; $F$, surface view; the others longitudinal sections. $G$, paraphyses. $(F, \times 150$; the others, $\times 400) . x$, apical cell.

tion of endothecium and amphithecium. As in the Anthocerotales, the archesporium is derived from the amphithecium, in which respect Sphagnum differs from all the other Musci. The archesporium extends over the top of the columella as it does in Anthoceros.

The basal growth of the young sporophyte is limited, and at maturity it is a globular or oval capsule, with a large foot imbedded in the end of the gametophoric shoot. Stomata are developed in the epidermis of the capsule, which opens by a circular lid.

Bryales. - In the typical Mosses (Bryales) the embryo (Figs. 195, 196) first divides by a transverse wall into two nearly equal cells. In the upper (epibasal) half, the next walls are inclined and a large two-sided apical cell is formed, which continues to divide for a long time, and causes a rapid increase in length of the embryo, which becomes spindle-shaped. Later the apical growth 

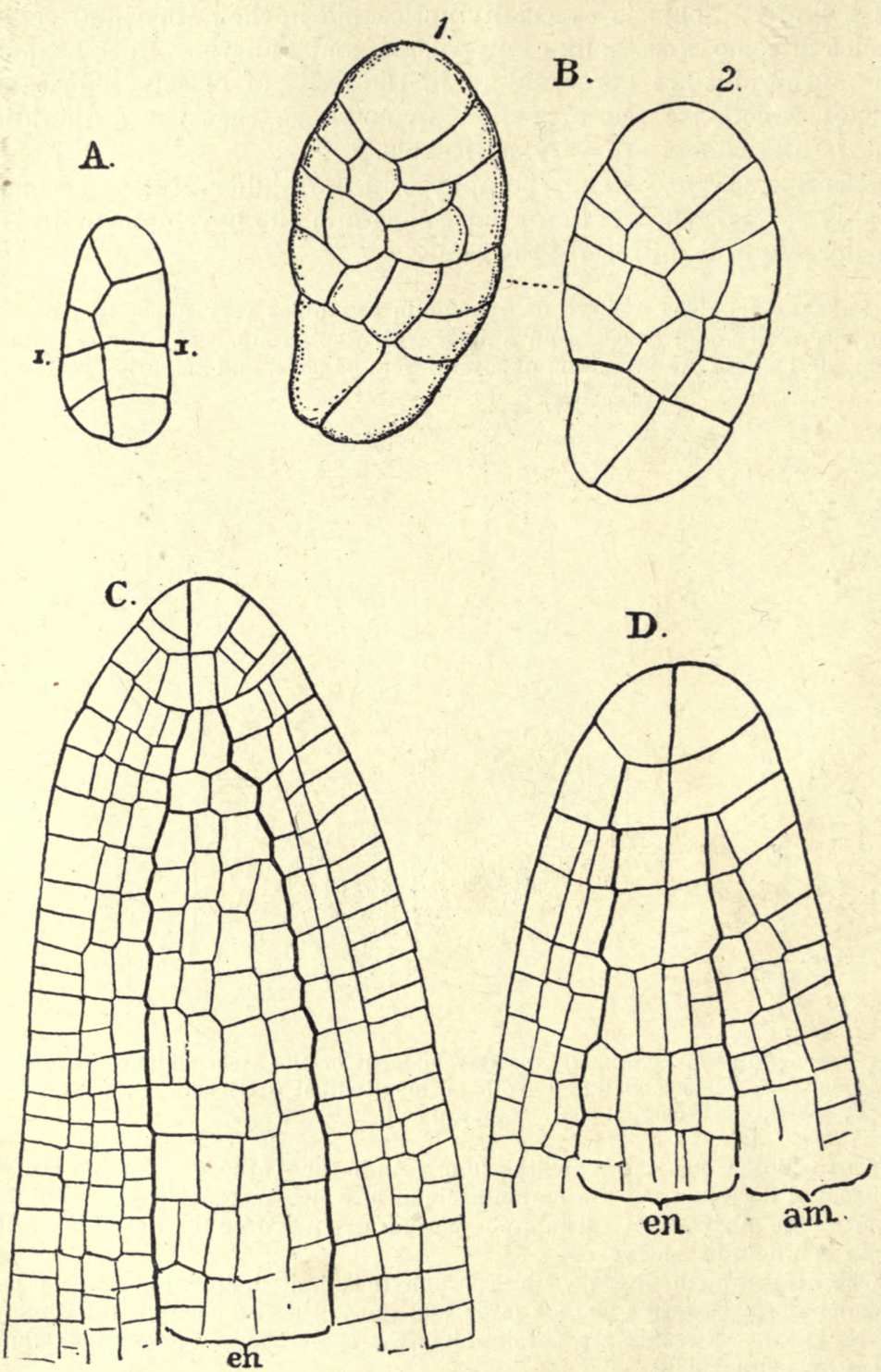

FIG. 195. - Funaria hygrometrica. Development of the embryo. A, optical section of very young embryo. $B, 1,2$, surface view and optical section of an older one $(\times 600)$. $C, D$, median sections of older embryos $(\times 600)$; en, endothecium; $a m$, amphithecium. 
ceases, and the subsequent growth of the sporophyte is basal, much as in Anthoceros.

An early division of the tissues into endothecium and amphithecium is apparent, but the archesporium is derived from the outer layer of the endothecium, and not from the amphithecium as in Sphagnum. The archesporium is restricted to a relatively small part of the sporophyte. In the aberrant genus Archidium no definite archesporium is developed, but otherwise the sporophyte conforms to the usual type.

As the sporophyte develops, the upper part enlarges and forms the capsule (Fig. 197). This enlargement is in part due to increase in the number of cells, partly to the development of a large air-space between them. This space arises
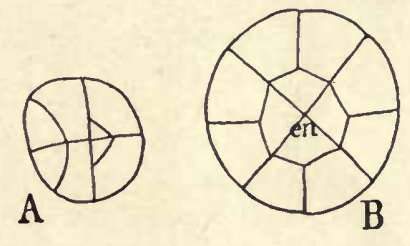

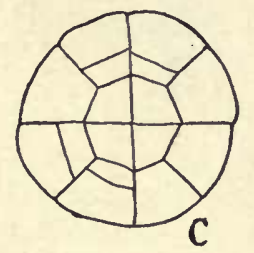

D
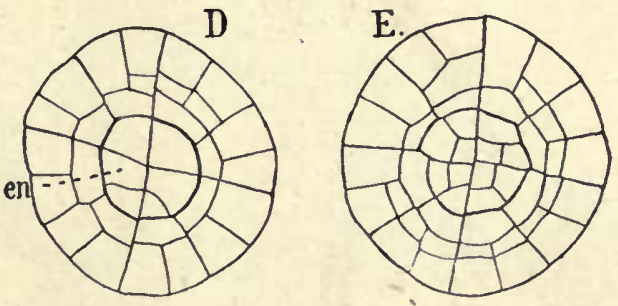

Fig. 196. - Funaria hygrometrica. Five transverse sections of a young embryo. $A$, just below the apex; the others successively lower down $(\times 450)$.

in the amphithecium, and is separated from the archesporium by two or three layers of cells. Soine of the cells remain in contact, and elongate as the space enlarges, and form alga-like filaments extending across it. These cells, as well as those outside the space, contain numerous chromatophores. The lower portion of the capsule does not develop any sporogenous tissue, but forms a mass of green parenchyma, often with conspicuous air-spaces, and constituting the principal assimilating part of the sporophyte. In the higher Mosses this "A pophysis" has perfect stomata (Fig. 198) developed in the epidermis.

The lower part of the sporophyte forms a slender stalk or seta, which terminates below in a more or less well-developed foot. The endothecium in the seta develops into a definite central strand of conducting tissue, suggesting the vascular bundles of the higher plants.

The archesporium forms a cylindrical layer about the central columella of the capsule, but does not extend over it. The upper portion of the capsule becomes the lid or "Operculuin," which is found in most but not all Bryales. Where the operculum joins the Theca, or spore-bearing part of the capsule, the latter 
has the cells forming its margin much thickened. Above these is a ring of large, thin-walled cells, the Annulus, which finally are destroyed, and effect the separation of the operculum from the theca.
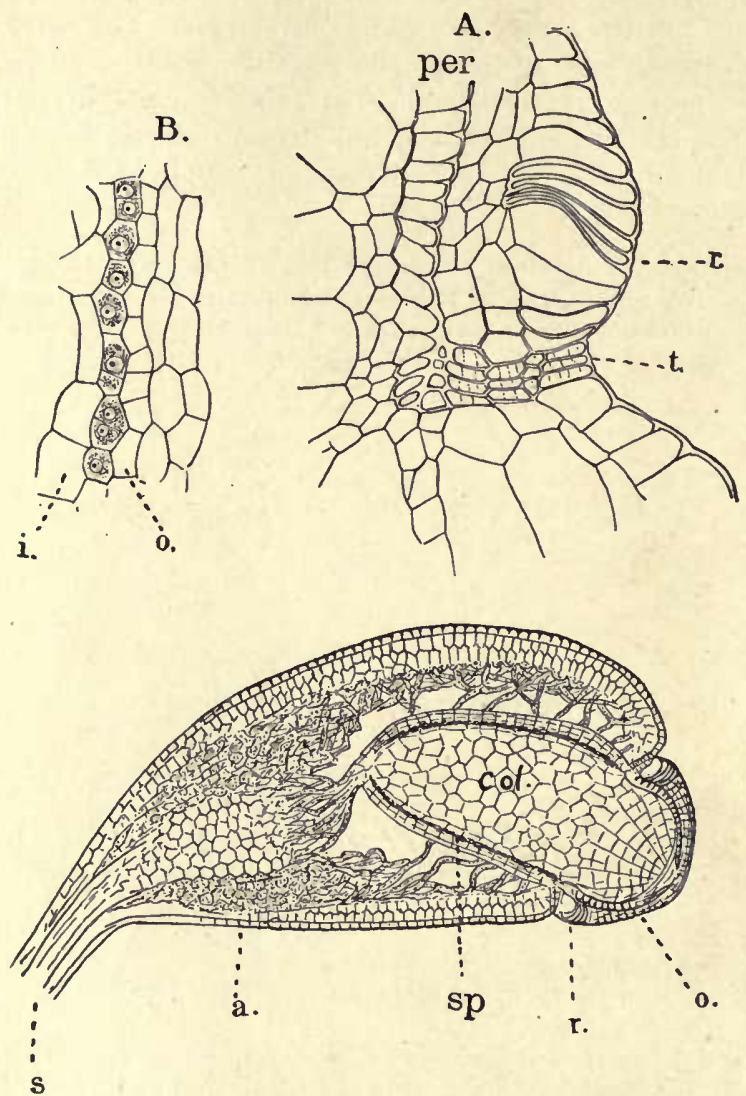

FIG. 197. - Funaria hygrometrica. A, longitudinal section of a nearly ripe capsule $(\times 200)$; per, peristome; $r$, annulus; $t$, thickened cells forming the rim of the theca. $B$, sporogenous cells, shortly before the final division $(\times 400) ; i$, inner, 0 , outer, spore-sac. $C$, longitudinal section of a mature capsule $(\times 30) ; s$, seta; $a$, apophysis ; $s p$, spores; col, columella ; $r$, annulus ; $o$, operculum.

Beneath the operculum there are developed, in most Bryales, the peculiar structures forming the "Peristome." The peristome is usually composed of the remains of the thickened cell-walls of special cells, which are separated from the wall of the operculum by two or three layers of thin-walled cells which wither away as the capsule ripens. The peristome usually has the form of teeth fringing the margin of the theca. These generally are in two rows, representing 

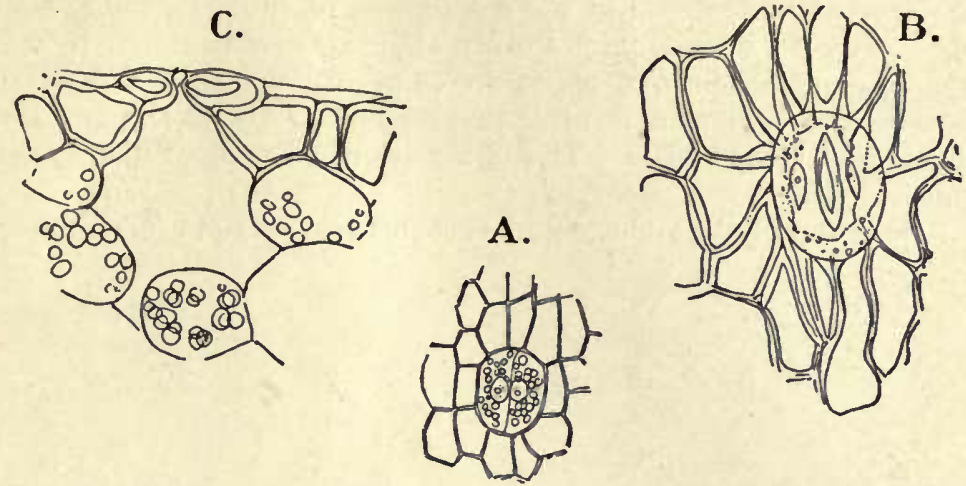

Fia. 198. - Funaria hygrometrica. A, young, $B$, older, stoma, from the base of the capsule. $C$, section of a stoma $(\times 360)$.

the inner and outer walls of rows of cells extending from the edge of the theca, under the operculum. The peristome is highly hygroscopic, and as the water evaporates on the sporophyte approaching maturity, the outward pressure of the peristome helps to throw off
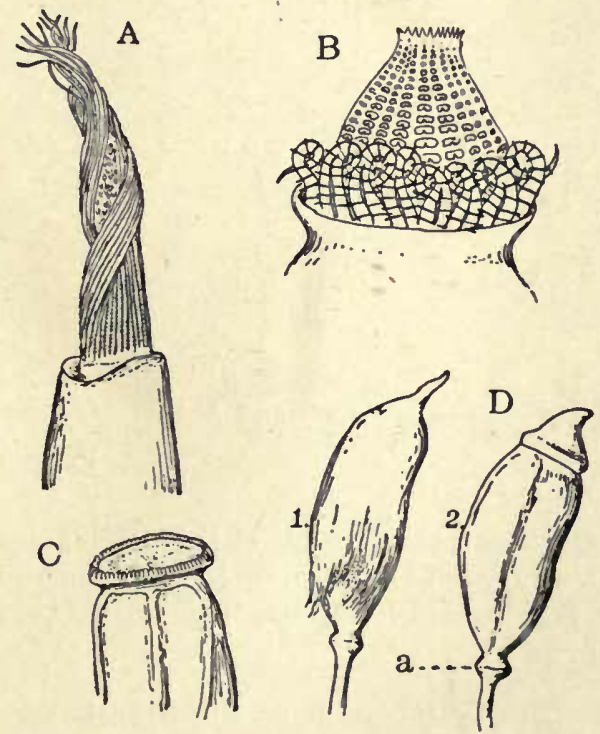

Fia. 199. - A, Barbula fallax, upper part of capsule, showing the slender, twisted teeth of the peristome ( $\times$ about 20 ). $B$, Fontinalis antipyretica, showing double peristome. (After Schimper.) C, Polytrichum commune, peristome and epiphragma $(\times 8) . D, P$. commune, ripe capsule; 1 , with, 2 , without, the calyptra $(\times 3)$. 
the operculum, loosened by the destruction of the cells of the annulus. After the operculum is thrown off, the peristome teeth, by their hygroscopic movements, assist in emptying the spores from the theca. The seta also, is often hygroscopic. All of the archesporial cells develop spores. The latter are usually small and contain chlorophyll.

The venter of the archegonium becomes very large in most Mosses,

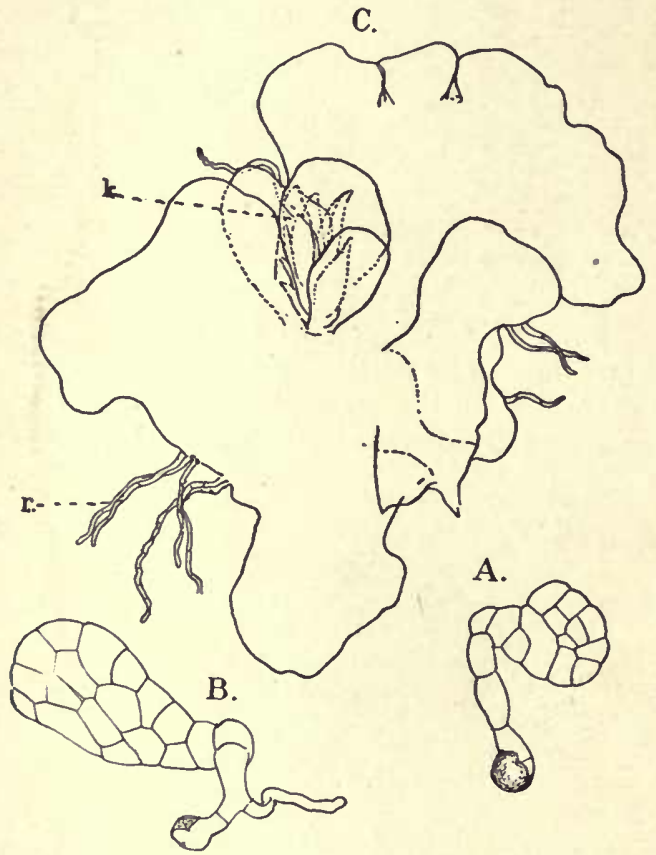

FIG. 200.-Sphagnum sp. A, B, young protonemata $(\times 200)$. $C$, older protonema with leafy bud, $k$ $(\times 35) ; r$, marginal rhizoids.

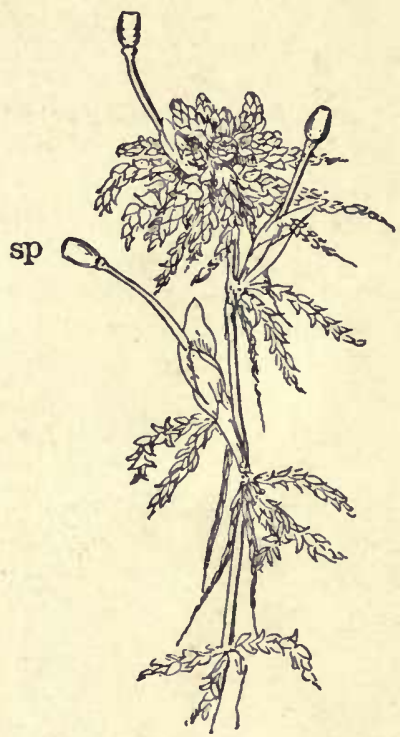

FIG. 201.- Sphagnum squarrosum. Leafy shoot, with sporophytes, borne at the end of leafless branches $(\times 2)$

and forms a bell-shaped calyptra about the slender embryo. Finally it becomes torn away, and is carried up by the elongating sporophyte, whose summit is protected for a long time by this conspicuous membranaceous cap.

\section{Classification of the Musci}

The Musci may be divided into three orders, - Sphagnales, Andreæales, and Bryales, - of which the latter comprises an overwhelming majority of existing Mosses. 


\section{Order I. Sphagnales}

The Sphagnales are represented by the single genus Sphagnum. They are aquatic or semiaquatic Mosses of simpler structure than
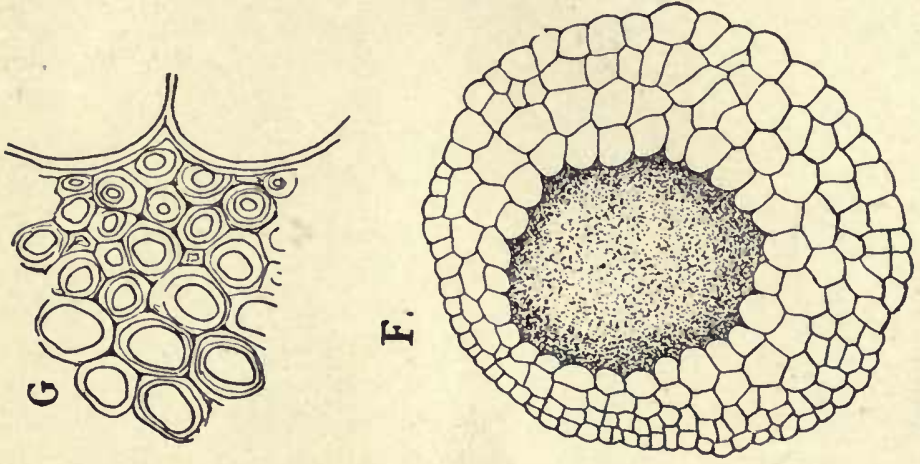

范
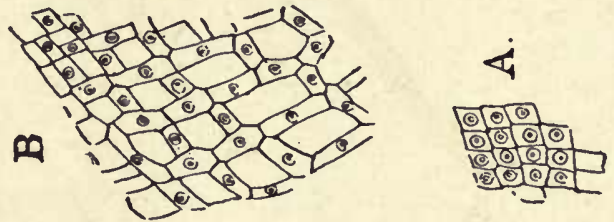

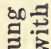

है:

$\infty$

घ)

近

열 줄

ङ्ठำ

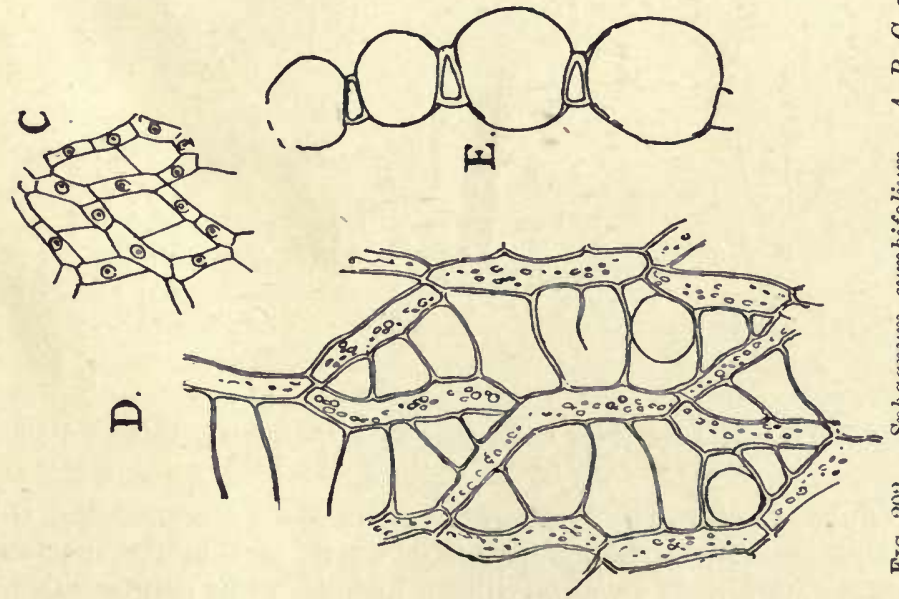

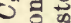

so:

in

in

ह่

政计

S.

हึ.

लें

듕 ำ

今.

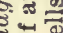

2.

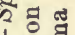
1

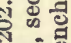
परिष्य

the Bryales, and, as already indicated, showing certain affinities with the Anthocerotales. The thallose protonema and the peculiar embryo have been referred to. 
The shoot grows much as in the Bryales, but no midrib is developed in the leaves and no central strand in the stem. The leaves are characterized by the peculiar empty cells between the narrow green cells, and these empty cells usually are marked with thickened bars, and have round holes in them, so that the cells take up water
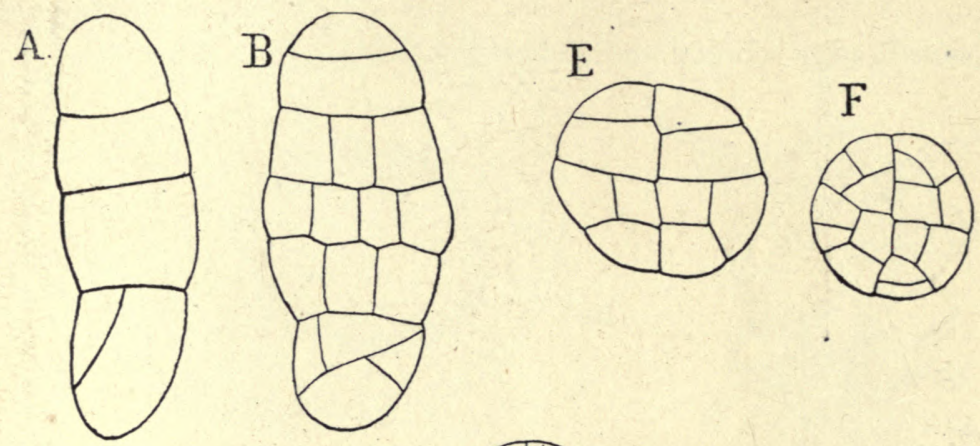

c.
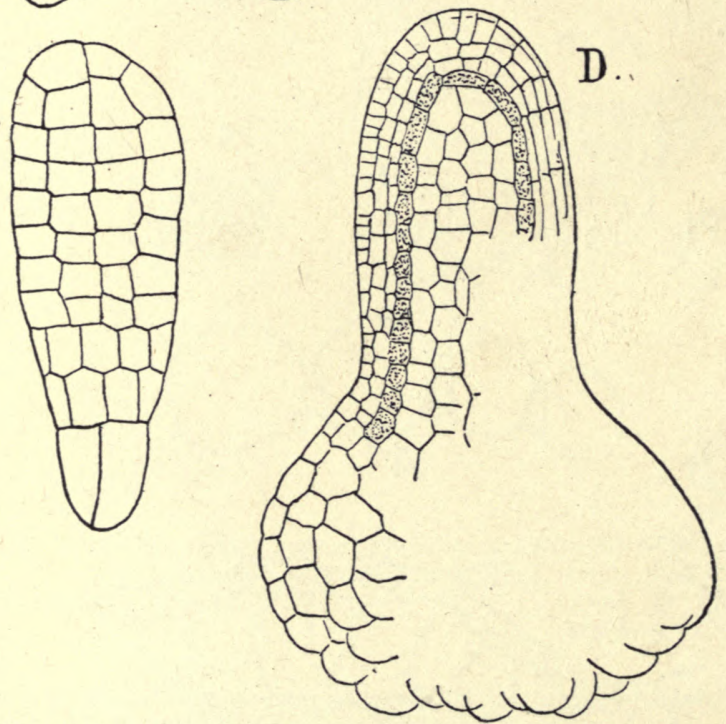

FIG. 203. - Sphagnum acutifolium. Development of the embryo. (After WALdner.) $\left(A, B, E, F^{\prime}, \times 350 ; C, \times 315 ; D, \times 150\right.$.)

very quickly. Similar empty cells form the cortex of the stem, and also soak up great quantities of water, so that the masses of growing plants take up water like a sponge. The empty cells give them a pale green color.

The sporophyte develops no seta, but the end of the shoot to which it is attached often grows out beyond the leaves, forming a "pseudo- 
podium," which gives the capsule the appearance of having a seta (Fig. 201).

The species of Sphagnum are especially abundant in moist northern countries, where they form the most important element in the peatbogs. The plants are perennial, forming new shoots at the top and slowly dying away below, the compact masses of dead tissue becoming gradually transformed into peat.

\section{Order II. Andreæales}

This order has but a single genus, Andreæa, small, dark-colored Mosses growing upon rocks, and to some degree intermediate between the Sphagnales and Bryales, but on the whole approaching more nearly the latter order (Fig. 204). The protonema is more or less flattened, and the archesporium, although derived from the endothecium, extends over the top of the columella. The capsule opens by four longitudinal slits.

\section{Order III. Bryales}

All of the commoner Mosses except Sphagnum belong to the Bryales.

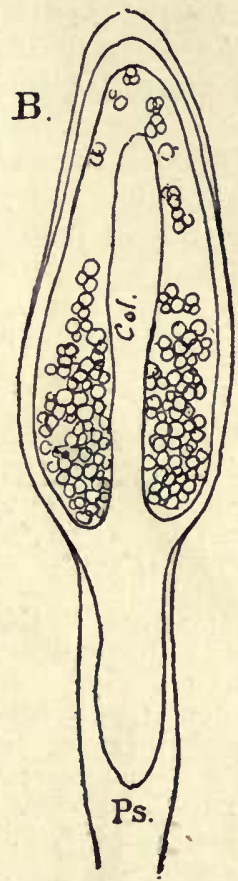

Fig. 204.-Andreæa petrophila. A, plant with mature sporophyte $(\times 10) . B$, longitudinal section of sporophyte $(\times 80) ; p s$, pseudopodium; col, columella.

They show great range of size and have adapted themselves to a great variety of environment. A few, like Fontinalis and Amblystegium, are true aquatics. Most of them prefer moist, shaded situations upon the earth or upon trunks of trees; some, however, thrive in exposed, dry places, where they receive water only at long intervals.

Classification. - The Bryales are sometimes divided into two orders, Cleistocarpæ and Stegocarpæ, based upon the method of dehiscence of the capsule. The former, e.g. Phascum, Ephemerum, do not develop an operculum, but the capsule breaks irregularly. There is no question, however, that the two groups are closely related.

Another division, based upon the position of the sporophyte, is 
sometimes made. Where it is terminal, i.e. borne upon the main shoot, as in Polytrichum or Funaria, it is said to be "acrocarpous"; where the fertile shoots are lateral ones, the plant is said to be "pleurocarpous," as the genus Hypnum.

The division into genera is largely made upon the character of the sporophyte, and especially the peristome. The latter is wanting in a few of the simple Stegocarpæ (e.g. Gymnostomium). In Tetraphis the peristome arises from the splitting of the whole mass of tissue beneath the operculum into four teeth. In the Polytrichaceæ (Fig. 198, C) the peristome is composed mainly of peculiar fibrous cells, and the mouth of the theca is covered with an "epiphragm" composed of a single layer of cells. In much the greater number the peristome is composed merely of the remains of the cell-walls of the peristomial cells.

\section{BIBLIOGRAPHY}

'96. 1. Barnes, C. R., and Heald, F. D. Analytic Keys to the Genera and Species of North American Mosses. Madison, Wis., 1896.

'95. 2. Campbell, D. H. Structure and Development of the Mosses and Ferns. London and New York, 1895. (Contains full bibliography of the subject.)

'96. 3. - The Development of Geothallus tuberosus. Ann. of Bot., X. 1896.

'93-'01. 4. Engler and Prantl, Nat. Pflanzenf. Theil 1, Abt. 3. Hepaticæ. Schiffner, V. 1893. Musci. Müller, C., and Ruhland,W. 1898-1901. (Contains full bibliography.)

'87. 5. Goebel, K. Outlines. Oxford, 1887.

'00. 6. - Organography of Plants. Oxford, 1900.

'99. 7. Howe, M. A. The Hepaticæ and Anthocerotes of California. Mem. Torrey Bot. Club, Vol. 7. 1899.

'84. 8. Lesquereux, I., and James, T. P. Manual of the Mosses of North America. Boston, 1884.

'79. 9. Luerssen, Chr. Handbuch der Systematischen Botanik, I. Leipzig, 1879.

'97. 10. Müller, C. See Engler and Prantl.

'79. 11. Ruhland, W. See Engler and Prantl.

79. 12. Schiffner, V. See Engler and Prantl.

'90. 13. Underwood, L. M. The Hepaticæ. Gray's Manual of Botany, 6th ed. 1890.

'96. 14. Vines, S. H. Text-book of Botany. London and New York, 1896.

'85. 15. Warming, E. W. Handbook of Systematic Botany. London and New York, 1885. 


\section{CHAPTER VIII}

\section{P'TERIDOPHYTA (FERNS)}

In most Bryophytes the gametophyte is the predominant phase, and the sporophyte is relatively unimportant; in Anthoceros and some Mosses, however, the sporophyte is large and develops a complex system of assimilating tissue, so that it becomes almost independent. In no Bryophytes, however, does the sporophyte develop roots. In the Pteridophytes, or Ferns, and their allies, the sporophyte early develops a root which puts it into communication with the earth, and it thus becomes quite independent of the gametophyte.

With the increasing importance of the sporophyte, which is always a leafy plant, often of large size, there is a reduction of the gametophyte, which in the most specialized Pteridophytes may be reduced to a few cells, completing its whole development within twentyfour hours, or less.

In most Pteridophytes the gametophyte (called the "Prothallium") is a small plant closely resembling the simpler thallose Liverworts. In exceptional cases it may reach a length of several

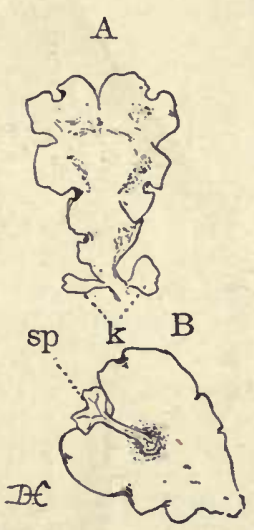

Fig. 205. - A, B, Marattia Douglasii. $A$, old gametophyte, the apex divided dichotomously, and with lateral buds, $k(\times 2)$. $B$, gametophyte with young sporophyte, $s p$, attached. $C$, Anthoceros fusiformis. Gametophyte, $g$, with four sporophytes attached, sp. (Natural size.) centimetres and live for several months, or even years (Fig. 205). In certain forms, e.g. Botrychium, Lycopodium clavatum, it is a subterranean, tuberous body, quite destitute of chlorophyll, and living as a saprophyte.

Budding of Gametophyte. - Where the gametophyte is large and long-lived, it not infrequently multiplies by the formation of special 
buds, or gemmæ, which may be produced in large numbers. It also bears monœciously or diœciously the sexual organs.

Archegonium. - The sexual organs of the Pteridophytes are similar to those of the Bryophytes. The Archegonium (Fig. 206) has the venter imbedded in the tissue of the gametophyte, and the neck has but four rows of peripheral cells. The four rows of neck-cells probably represent a further development of the four cover-cells of the archegonium of the Liverworts. Of the Bryophytes, the Anthocerotales come nearest the lower Pteridophytes in the character of the sexual organs. Except in Lycopodium, where the number of canalcells is larger, the neck shows but two canal-cells in the Pterido-

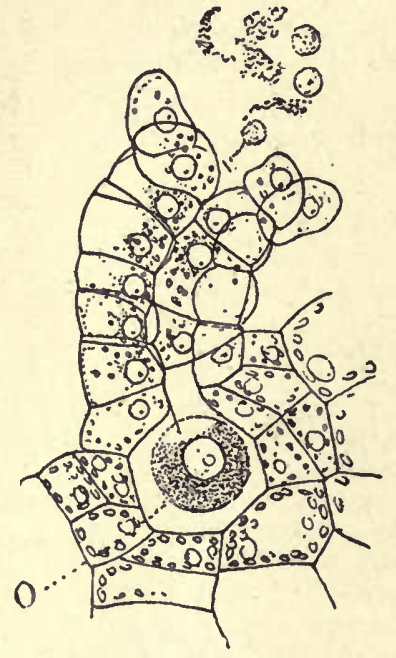

FIG. 206. - Struthiopteris Germanica, open archegonium $(\times 300) ; 0$, the egg.
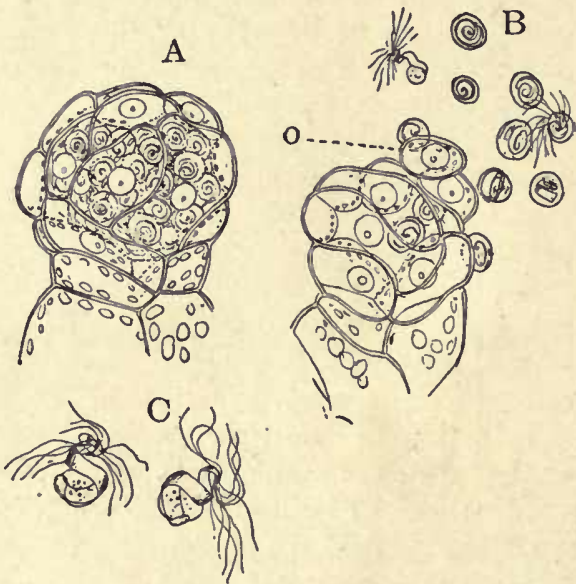

Fra. 207.-Osmunda Claytoniana. A, ripe antheridium. $B$, the same discharging the spermcells $(\times 400)$. C, spermatozoids $(\times 800)$.

phytes. The ventral canal-cell is always present, and as in the Bryophytes is the sister-cell of the egg.

Antheridium. - The antheridium (Fig. 207) in the lower types, such as Lycopodium and Marattia, is buried in the prothallial tissue as it is in Anthoceros. In the more specialized Ferns it projects and forms a nearly spherical body, whose wall is composed of a single layer of chlorophyll-bearing cells, within which is a mass of colorless sperm-cells. In the Club-mosses, the small spermatozoids are biciliate like those of the Bryophytes; in the Ferns and Horsetails they are larger, and have many cilia.

The development of the spermatozoids (Fig. 208) has been followed in several Ferns and in Equisetum. In the later divisions 
of the sperm-cells, a peculiar body, the blepharoplast, becomes visible. This closely resembles the centrosomes found in some plants, and is sometimes considered to be of the same nature. After the final division, each sperm-cell coutains a single blepharoplast lying close to the nucleus, in which no nucleolus can be seen.

The nucleus becomes elongated, and assumes a crescent form, gradually becoming longer and assuming the coiled form of the perfect spermatozoid, most of which is derived from the nucleus of the sperm-cell. The blepharoplast also elongates, and is closely applied to the nucleus, beyond which it projects as the anterior cilia-bearing end of the spermatozoid. The cilia are, apparently, developed exclusively from the blepharoplast.

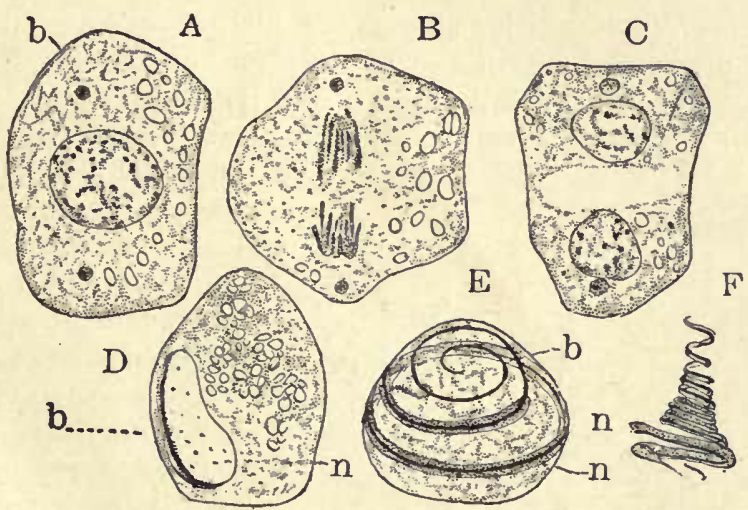

Frg. 208. - Marsilia vestita. Development of the spermatozoid $(\times 1500) ; b$, blepharoplast. $A-C$, last division, preliminary to the formation of the spermatozoid. $D-F^{\prime}$, development of the spermatozoid; $n$, nucleus of sperm-cell. (After SHaw.)

Fertilization. - As in all other Archegoniates, the opening of the reproductive organs is dependent upon the access of water, and is accomplished exactly as in the Bryophytes. In the matter ejected from the open archegonium of various Ferns, it has been shown that malic acid is present, which exercises a strong attraction upon the spermatozoids. On reaching the open archegonium, the spermatozoids crowd into its neck, often completely choking it. The mucilage filling the neck retards their movements somewhat, and detaches the vesicle attached to the hinder coil of the active spermatozoid. The spermatozoid moves slowly by a spiral motion, through the narrow neck-canal, until it reaches the central cavity in which is contained the egg. The first spermatozoid to enter penetrates at once into the egg.

The fusion of the spermatozoid with the egg-nucleus (Fig. 215) is slow in the common Ferns, where it has been most completely 
studied. The spermatozoid retains its original form for some time, and is recognizable even after it has penetrated into the cavity of the egg-nucleus. Here it slowly changes form, approaching the condition of the original sperm-nucleus. The chromosomes become more evident, and finally are not distinguishable from those of the egg-nucleus.

The egg-cell has, in the meantime, been slowly growing, and is provided with an evident cell-membrane. The first division may occur after an hour or so, as in species of Marsilia; but in the common Ferns it is probably at least a week in most cases, and in other Ferns still longer.

\section{The Embryo}

The embryo in its earlier stages (Fig. 209) closely resembles that of the Bryophytes, and in the lower types of Pteridophytes the development of the special organs, leaf, stem, and root, may not occur until the embryo has reached a relatively large size. Sooner
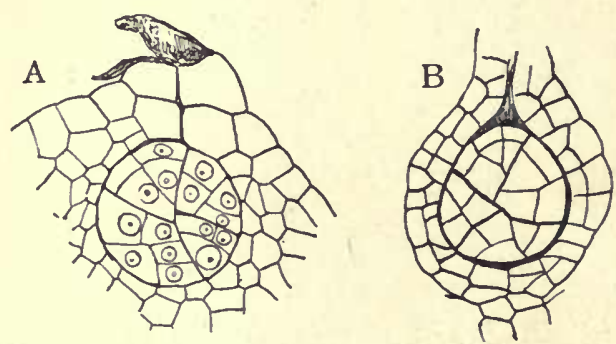

Fig. 209. - A. Onoclea sensibilis. B, Riccia glauca. Embryos, showing the similarity in the embryo of the Ferns and Liverworts in the early stages $(\times 200)$. the plant is shown by the production of spores, which resemble in all respects those of the Bryophytes. They are borne in special organs, Sporangia, which are of very characteristic structure in the different groups of Pteridophytes. In the simplest case, that of Ophioglossum, they are cavities in the leaf tissue filled with a great number of spores. Usually (Fig. 210) they are capsules, often stalked, borne upon special leaves, sporophylls, which are sometimes quite different from the foliage leaves, and arranged in a spike or cone, suggesting the flowers of the simplest Seed-plants.

\section{Spore-division}

The sporogenous tissue may sometimes be traced back to a single archesporial cell, but this is not always the case. The sporogenous 
cells divide into four spores, precisely as in the Bryophytes, and the ripe spores have the same structure (Fig. 211).

The nearest approach among Bryophytes to the segregation of the sporogenous tissue found in the Pteridophytes occurs in the Anthocerotales, where the groups of sporogenous cells are separated by layers of sterile tissue somewhat as in Ophioglossum.

Apogamy and Apospory. - In several Ferns the sporophyte has been observed in certain instances to arise as a vegetative bud from the gametophyte instead of from the egg-cell. This non-sexual origin of the sporophyte is known as Apogamy.

Apospory is the development of the gametophyte as a bud of the sporophyte. These abnormal prothallia have been observed to develop from the margin or from the surface of a leaf, or in some cases from the transformation of a young sporangium into a prothallium.

Distribution of Pteridophytes. The sporophyte in most Pteridophytes is terrestrial, but a few forms are aquaties. Thus Isoetes

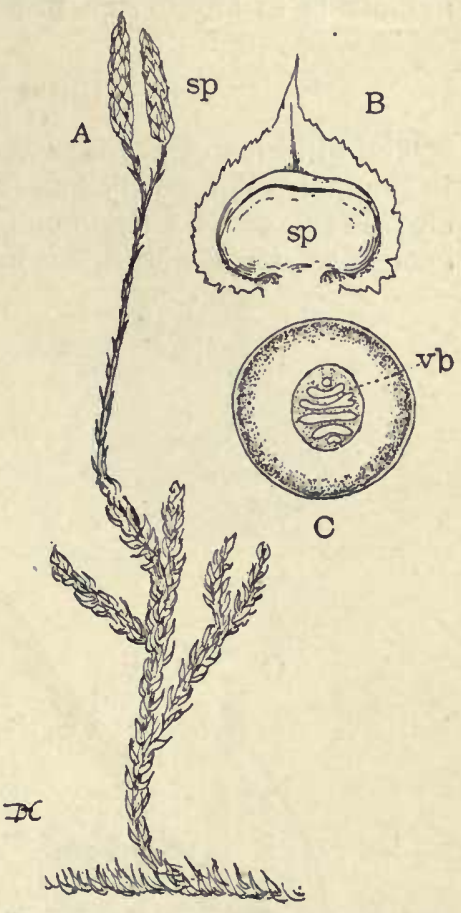

Fig. 210. - Lycopodium clavatum. $A$, leafy shoot having two cones composed of sporophylls, $s p$ (reduced). $B$, a single sporophyll, with sporangium, $s p$, enlarged. $C$, crosssection of the stem.

lacustris is completely submersed, while Salvinia and Azolla are floating forms. Marsilia is usually amphibious. The Pteridophytes, like the Hepaticæ, reach their greatest development in the moist mountain forests of the Tropies, where they constitute an important and most beautiful feature of the vegetation. A small number, like the little Gold-back Fern (Gymnogramme triangularis), are adapted to a dry region, and can endure complete desiccation without injury.

The living Pteridophytes are usually divided into three classes, Filicales, Equisetales, and Lycopodiales. Of these the first comprises much the greater number of existing species. The Equisetales, which during the Palæozoic age were numerous and varied, now comprise but a single genus. The Lycopodiales were also at this period much better developed than they are at present. There 
are also a number of fossil types of Pteridophytes which are not assignable to any of the three existing classes.

\section{Class I. Filicales}

The Filicales, or Ferns, are cosmopolitan, but much more abundant in the moist Tropics than elsewhere. In northern regions a few species like Pteridium aquilinum or Osmunda regalis may be abundant enough to attract notice, but most of the northern Ferns are compar-

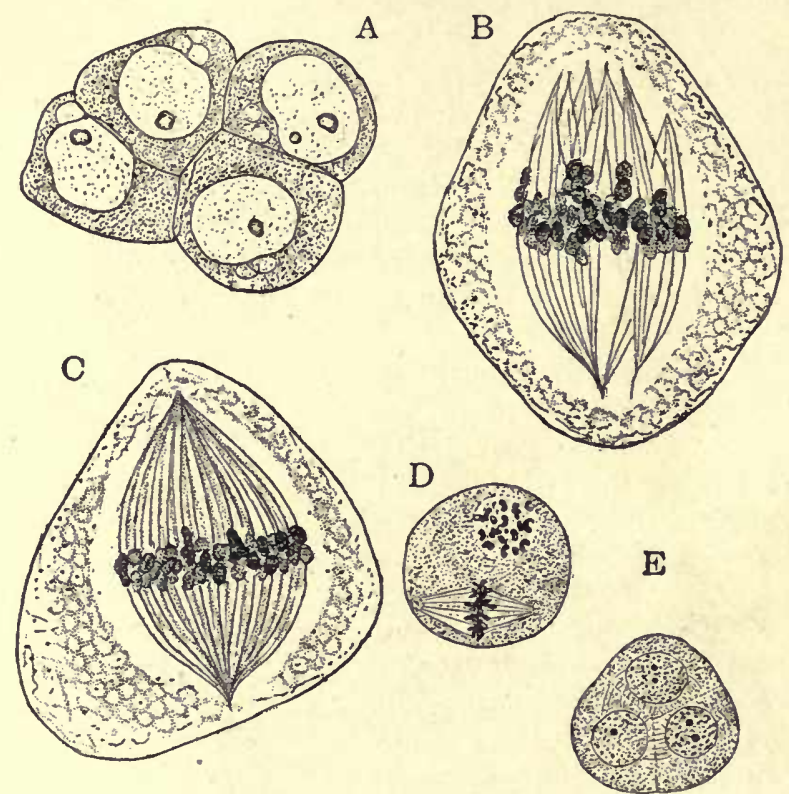

Fig. 211. - Spore-division in Equisetum. $A, D, E, E$. telmateia $(\times 400) . \quad B, C$, $E$. limosum, more highly magnified. $A$, group of four sporogenous cells. $B, C$, first nuclear division; in $B$, multipolar spindle. $D$, second nuclear division. $E$, division of the cell into the young spores. ( $B, C$, after OsterHout.)

atively insignificant. In the Tropics, however, especially in the mountains, they often occur in great numbers and variety, and some of the Tree-ferns are among the most striking of all plants.

\section{The Gametophyte}

The gametophyte (Fig. 212) in most Ferns is a flat, green thallus, which in exceptional cases (e.g. Vittaria sp.) may reach several centimetres in length and branch repeatedly.

The ripe spore usually shows three membranes, the inner cellulose 
membrane (Intine), the cuticularized exine or "Exospore," and the outermost sculptured coat or perinium ("Epispore") which some-

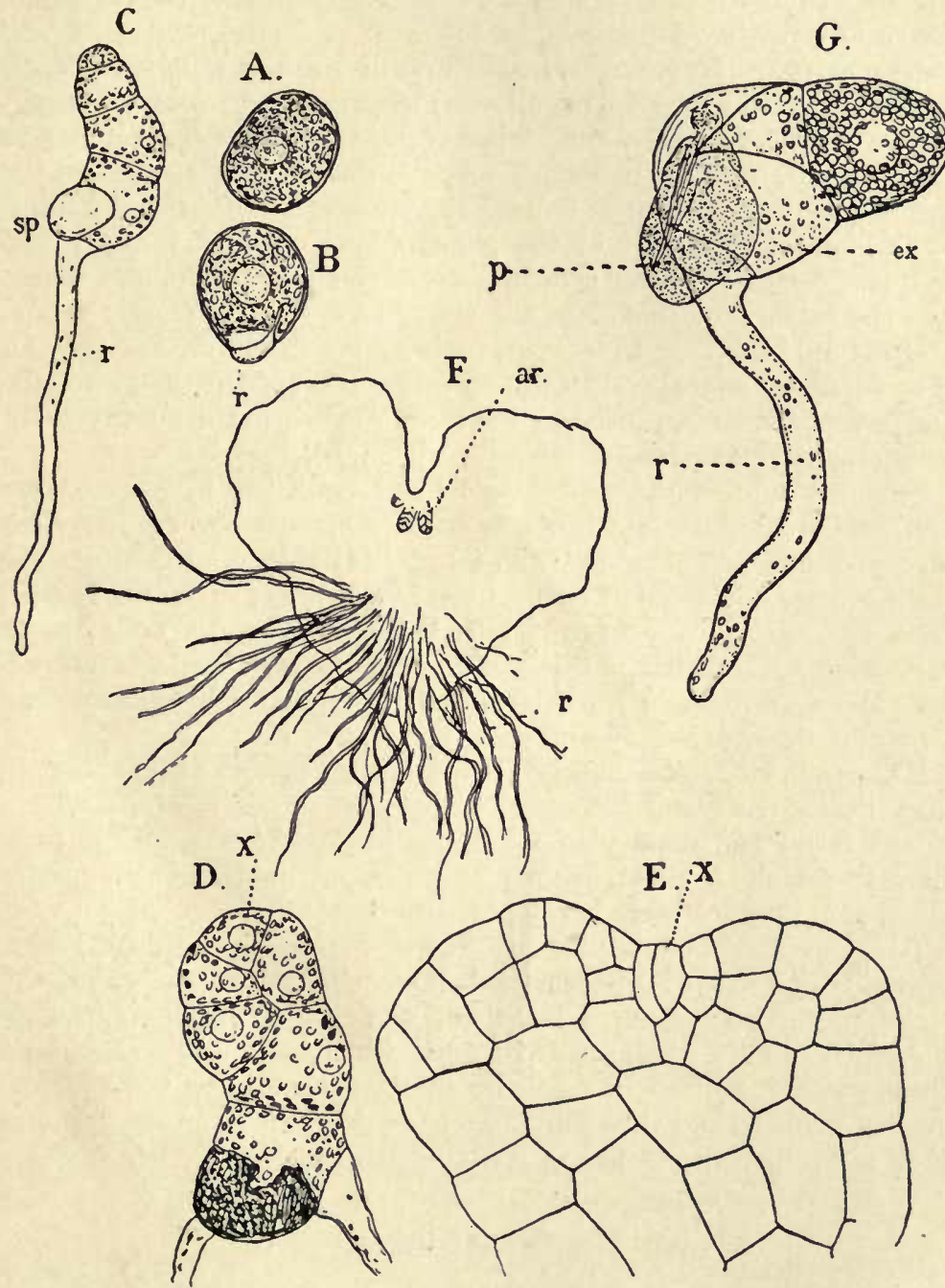

FIG. 212.- Struthiopteris Germanica. $A, B$, germinating spores, with perinium removed $(\times 300)$. C, young gametophyte $(\times 100) . \quad D, E$, older stages with apical cell, $x(\times 300) . F$, small female gametophyte, seen from below; $r$, rhizoids; $a r$, archegonia.

times becomes detached from the exospore. In case the spore contains chlorophyll at maturity the germination is usually rapid; in 
Osmunda the first division of the spore may take place within less than twenty-four hours. Where chlorophyll is not present the process of germination is retarded, as chlorophyll must be developed before any further growth takes place.

Germination. - In most Ferns the first division in the germinating spore (Fig. 212) cuts off a small cell, which at once lengthens and forms the first root-hair, from a larger green cell which gives rise to a row of cells varying in length under different conditions. In the terminal cell of the row a two-sided apical cell is formed by intersecting oblique walls, and the gametophyte rapidly forms a flat thallus. New root-hairs grow out from the lower side, and fasten it to the earth. At this stage the young gametophyte closely resembles a simple thallose Liverwort, such as Metzgeria or Aneura, and as in these, the apical cell lies in an indentation of the margin of the heart-shaped thallus, caused by the rapid growth in the outer cells of the young segments cut off from the apical cell.

Sooner or later the two-sided apical cell is divided by a trausverse wall, and from this time inner or basal segments are regularly cut off, which undergo horizontal divisions, so that back of the apex the thallus forms a cushion of tissue, upon whose lower surface the archegonia are later developed. If this thickening begins early, as in Osmunda and Marattia, a thickened midrib is developed. The roothairs develop little or no chlorophyll, but the other cells contain numerous discoid chromatophores.

Both archegonia and antheridia are borne upon the same plant in most Ferns, but some are diœcious (e.g. Struthiopteris Germanica). In the latter the male plants are smaller and less regular in form than the females. Small male plants are not uncommon in species which also produce large hermaphrodite prothallia.

The largest gametophytes are found in certain tropical Ferns, especially species of Vittaria and Hymenophyllum, in which the gametophyte may reach a length of several centimetres and fork repeatedly, like a thallose Liverwort, which it closely resembles. These prothallia often increase in numbers rapidly by the development of gemmæ, and thus they may occur in great numbers, forming thick mats upon the trunks of trees, or upon rocks.

\section{The Sexual Organs}

Antheridium. - The antheridium in the lower Ferns shows a slight analogy with that of the Anthocerotales, especially those forms in wlich a single antheridium is developed in each cavity. As in the Anthocerotales, the cell from which the antheridium develops arises by a transverse division of a superficial cell into an outer and an inner cell. The latter, which in the Anthocerotales gives rise to the 
whole antheridium, in the lower or eusporangiate Ferns, develops at once into the mass of sperm-cells, while the outer cell serves as the covering for these (Fig. 235). It is not impossible that this type of antheridium may have been derived from that of the Anthocerotales by a suppression of the sterile cells of the endogenous antheridium, whose peripheral cells are replaced by the superficial cells covering the cavity in which the antheridium is situated.

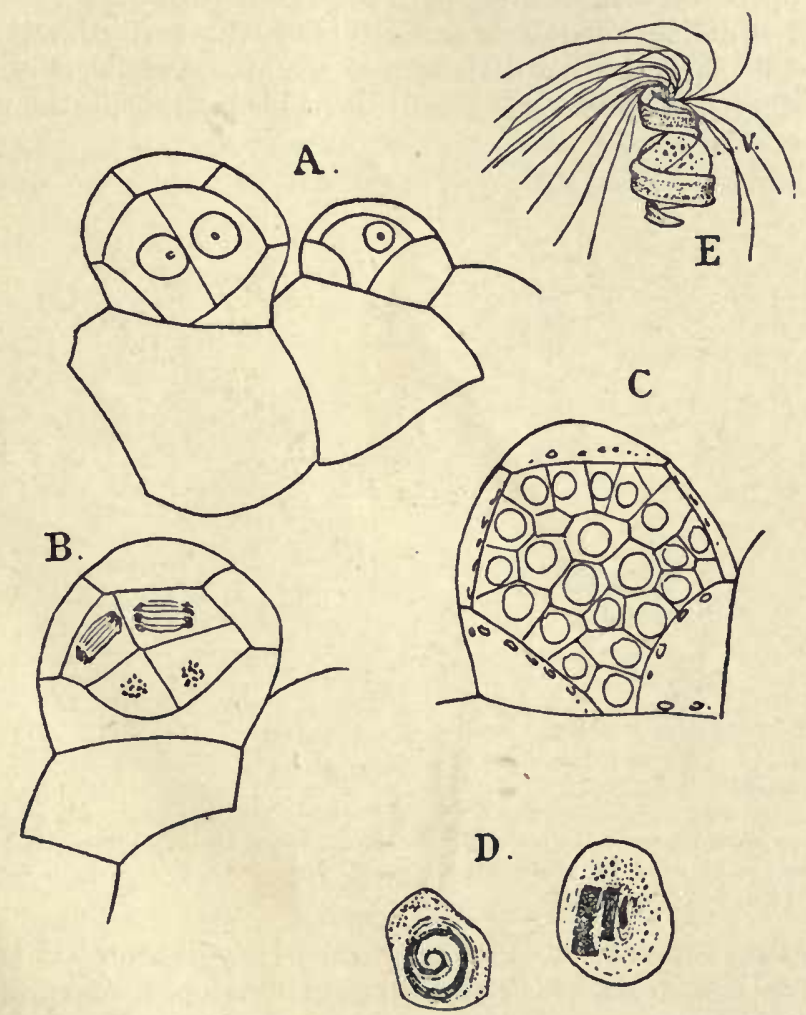

FIG. 213. - Struthiopteris Germanica. Development of antheridium. A-C, vertical sections $(\times 600)$. $D$, nearly ripe sperm-cells. $E$, spermatozoid $(\times 1200)$.

In the more specialized Ferns (Leptosporangiatæ), especially the Polypodiaceæ, the antheridium (Fig. 213) projects as a nearly spherical body, in which the cell-divisions are very regular. In the Polypodiaceæ the hemispherical mother-cell is first divided by a funnelshaped wall (Fig. 213, A-C), whose sinaller end is usually in contact with the basal wall of the antheridium. The next wall is dome-shaped, and its base is in contact with the first-formed wall. 
Finally a concave wall is formed above the dome-shaped one and meeting it. The young antheridium now consists of a central cell enclosed by three peripheral cells, the two lower being ring-shaped, the upper one somewhat lenticular. These outer cells contain chromatophores which are absent from the central cell.

In the lower Leptosporangiatæ-e.g. Osmunda, Hymenophylluin - there are more than three peripheral cells, and there may be a special opercular cell, as there is in the Marattiaceæ.

The first division of the central cell is usually vertical, and this is followed by several other divisions, so that there are usually thirtytwo to sixty-four sperm-cells finally developed, although the number
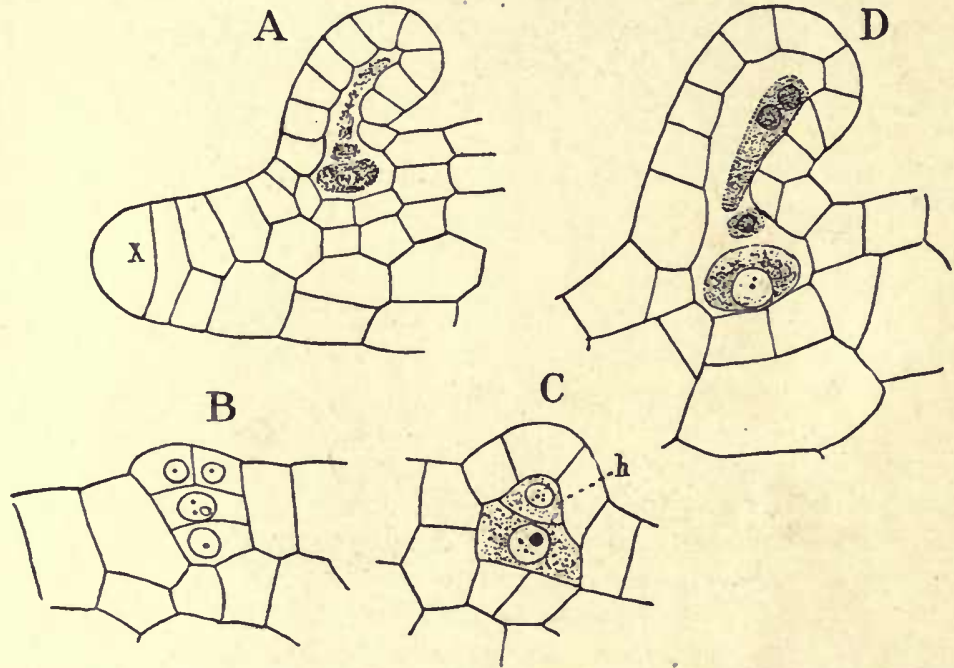

Fig. 214. - Struthiopteris Germanica. Development of archegonium. A, longitudinal section of apex of prothallium; apical cell, $x(\times 215) . B-D$, archegonia $(\times 430) ; h$, neck canal-cell.

is not always the same. Previous to the last division but two, the blepharoplasts, from which the cilia are developed, make their appearance.

The dehiscence of the antheridium is caused either by the rupture of the cover-cell, or a small opercular cell is thrown off. The great distention of the peripheral cells then forces out the separated spermcells, whose membrane soon completely dissolves and sets free the spermatozoid. In the typical Ferns the spermatozoids are relatively large and consist of a spiral band, tapering at the forward end, from which the numerous cilia extend. The larger posterior coils are mainly composed of the nucleus of the sperm-cell, and enclose a delicate vesicle containing the remains of the cytoplasm of the sperm- 
cell. This may become much distended, and often contains small granules of starch.

Archegonium. - In the typical Ferns the archegonium (Fig. 214) is formed upon the lower surface of the thickened cushion back of the apex. In Botrychium it is borne upon the upper surface of the subterranean gametophyte, and in Osmunda the archegonia forms two rows along the sides of the midrib. The mother-cell divides into two by a transverse wall, and the inner cell usually divides again into an inner or basal cell, and a central cell from which the egg-cell and canal-cells are formed. The outer cell, which corresponds to the terminal or cover-cell of the Liverwort archegonium, divides by cross-walls into four cells, which, by a series of transverse divisions, give rise to the four-rowed neck characteristic of the

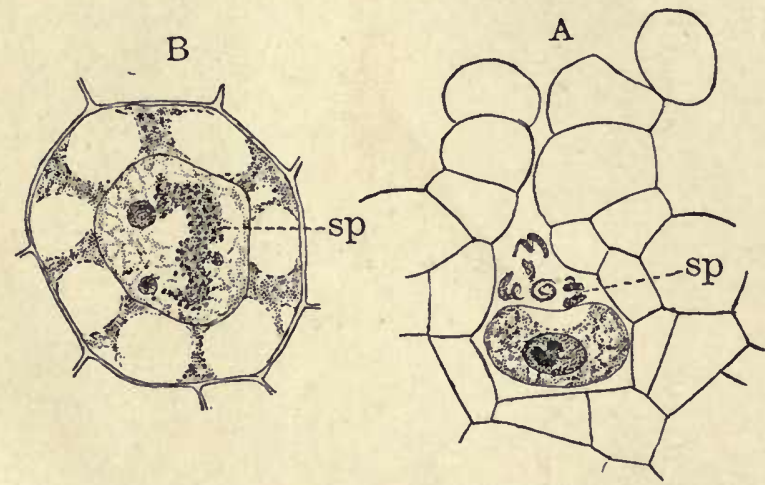

Fig. 215. $-A$, Osmunda cinnamomea, section of recently fertilized archegonium $(\times 450)$. A spermatozoid has penetrated the nucleus of the egg, and several are in the space above the egg. $B$, Onoclea sensibilis. Egg fourteen hours after the penetration of the spermatozoid, which is still recognizable within the egg-nucleus $(\times 900)$. (B, after SHAw.)

Pteridophytes. In the Polypodiaceæ the two posterior rows remain shorter than the anterior ones, and the neck is curved backward, probably an adaptation for facilitating the entrance of the spermatozoids. In the lower Leptosporangiatæ, and all the Eusporangiatæ, the neck is straight. The base of the archegonium is always coherent with the surrounding tissue, as in the Anthocerotales.

The middle cell of the original three becomes pointed above, and this portion is cut off as the neck canal-cell, which subsequently divides more or less completely into two. A second transverse, or concave division-wall, cuts off the ventral canal-cell from the egg, which later contracts so as not to fill the cavity of the venter. The walls of the canal-cells, as in the Bryophytes, become mucilaginous, and effect the opening of the ripe archegonium, when water is 
applied. As already stated, the attractive substance thrown out has been shown to be malic acid.

\section{The Embryo}

In the common Ferns the first division of the embryo does not occur for a week or more after fertilization. The globular embryo (Fig. 216) then divides by a nearly vertical " basal" wall into two cells, an epibasal (anterior) and an hypobasal (posterior). Each of
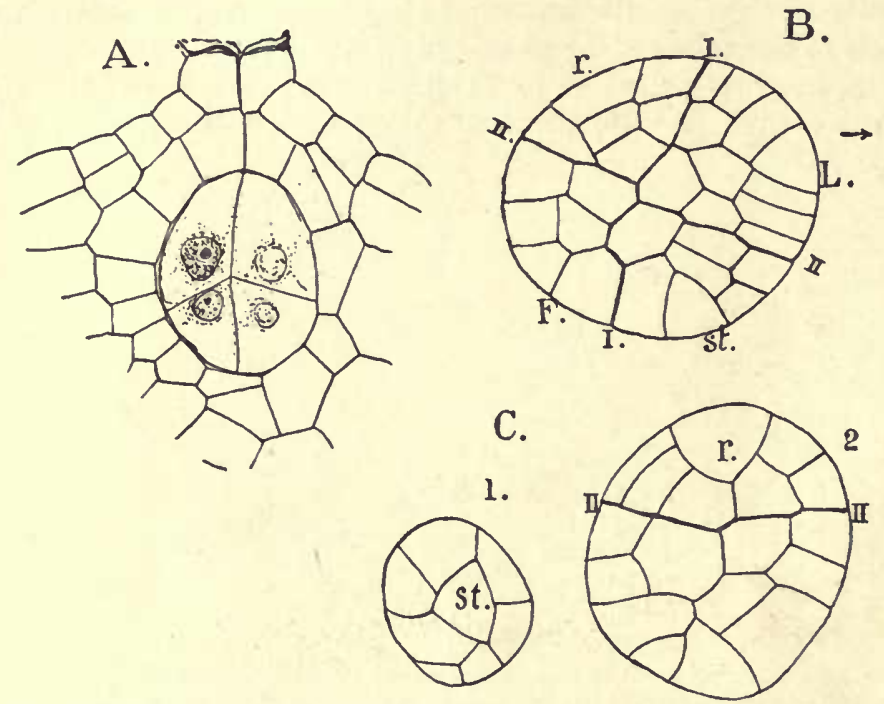

FIG. 216. $-A, B$, Osmunda Claytoniana. $C$, O. cinnamomea. $A$, vertical section of an 8-celled embryo $(\times 260)$. $B$, median longitudinal section of an older embryo, showing the primary organs; stem, st; leaf, $l$; root, $r$; foot, $f . C$, two transverse sections of an embryo, showing the apical cells of stem and root; the first root-cap cell has not yet been cut off.

these is next divided by a transverse wall into two usually equal parts, and this establishes the primary organs of the sporophyte. Of the epibasal quadrants, the outer one becomes the cotyledon, or primary leaf; the inner one, the stem-apex. Of the hypobasal quadrants, the outer gives rise to the primary root, the other to the foot.

Stem and Cotyledon. - Following the quadrant-walls are the octantwalls, which are not always exactly median in position, this being especially the case in the root-quadrant, where one octant is usually noticeably smaller than the other. Each octant is a tetrahedron, and the next divisions in all of them are parallel to the lateral faces of the octaut-cells. These divisions persist in one of the stem and leaf octants which assume the function of apical cells for these organs. 
In the foot, the apical growth is of very brief duration, and the divisions do not show any definite succession.

Root. - In the root-quadrant, the larger of the two octants at once assumes the rôle of an apical cell, the smaller one undergoing very little further growth. After one or two series of lateral segments, a periclinal wall cuts off the first cell of the root-cap, and thenceforth there are four series of segments, as in the roots of the mature sporophyte.

Cotyledon. - The primary leaf or cotyledon behaves at first much like the root. One of the octants develops faster than the other, and the growth is also apical; but, of course, no cap-cells are formed, and later the tetrahedral apical cell is replaced by a twosided one, and the leaf begins to assume its characteristic flattened form.

The establishment of the separate growing-points in the embryo soon canses the growing organs to project, and the embryo loses the globular form found in the early stages. Growth is rapid in both root and leaf, and these presently break through the overlying tissue of the gametophyte. The root turns downward and penetrates the earth, and the leaf, expanding and growing upward, spreads its flattened blade to the light-rays. So soon as this is accomplished, the young sporophyte, which has hitherto obtained its nourishment from the gametophyte by means of the foot, now is completely independent, and the gametophyte soon dies, leaving the sporophyte rooted in the ground.

The cotyledon in most Ferns is fanshaped (Fig. 217), due to an early dichotomy of the apex, which is repeated several times.

Of the two stem-octants, one becomes at once the tetrahedral apical cell of the permanent stem, the other develops into the second leaf, whose growth is much like that of the cotyledon, but which becomes larger.

During its early growth, the embryo is protected by the enveloping tissue of the archegonium venter, which

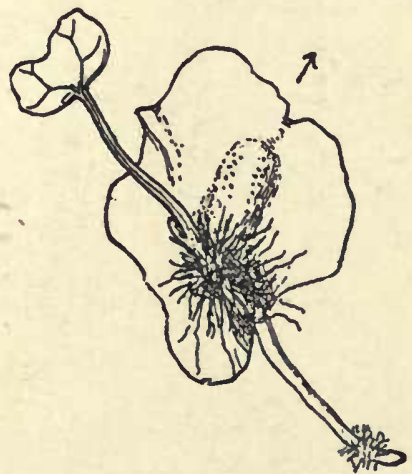

Fig. 217.-Osmunda Claytoniana. Young sporophyte attached to the gametophyte $(\times 6)$. forms a calyptra like that found in the Bryophytes.

Tissues of the Embryo. - The young sporophyte is composed of perfectly uniform parenchyma, but as the organs develop, there soon becomes evident a separation of the tissue elements into definite tissue systems. A single layer of epidermal cells is generally evident at an early period, and somewhat later the axis of each of the primary organs shows a strand of elongated cells, especially 
conspicuous in the root and leaf. These are at first composed of thin-walled elements (procambium), but later some of them begin to show the characters of the elements found in the older vascular bundles - these being met with for the first time among the Pteridophytes. The first recognizable elements are short spiral or reticulate tracheids, which appear near the junction of the young bundles in the middle of the embryo, and develop from this point toward the apices of the elongating members.

Vascular Bundles:- The completed vascular bundle of the young stem shows a central mass of tracheary tissue, some of whose cells have the scalariform markings found in the tracheids of the older stem. Around these are several rows of cells forming the phloem, but at this stage perfect sieve-tubes cannot be made out. The endodermis, or bundle-sheath, is also much less evident than in the older sporophyte.

The tracheary tissue of the cotyledon is composed entirely of spiral tracheids, - and, like the stem-bundle, the sieve-tissue and endodermis are poorly developed.

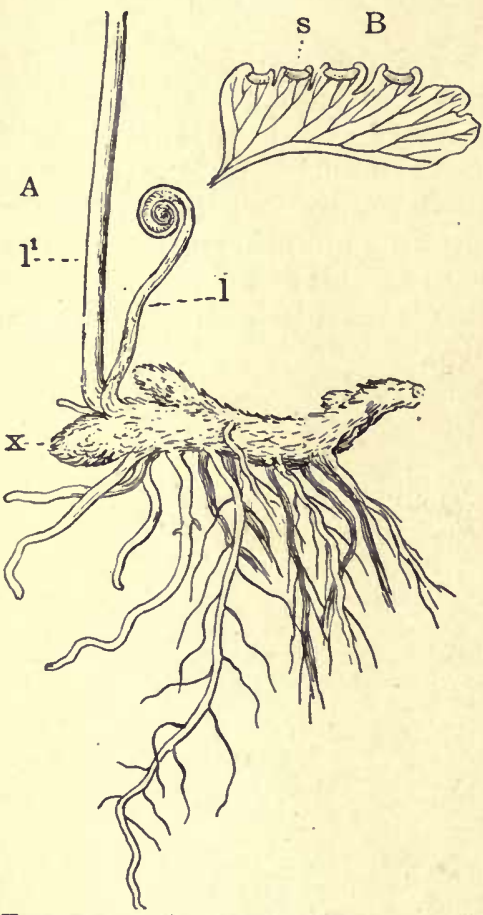

Fig. 218. - Adiantum pedatum. A, rhizome, with young leaf, $l$, and base of an older one, $l^{\prime} ; x$, stem-apex, slightly enlarged. $B$, leaf-segment, showing the venation, and sori, $s$, covered with the marginal indusium.

The bundle of the primary root is "monarch"; i.e. there is a single strand of primary wood, and as in the other organs, the other elements of the bundle are not well developed.

Ground - Tissue. - The tissue lying around the vascular bundles is usually known as the ground-tissue. This remains very much like the original parenchyma, but in the lamina of the leaf it forms the spongy mesophyll, which is the principal green tissue of the plant, and its spaces communicate with the external atmosphere by means of the stomata developed in the epidermis.

\section{The Mature Sporophyte}

The sporophytes of the various Ferns differ much in size. In some of the Hymenophyllaceæ there is a slender creeping stem with upright leaves less than a centimetre in length. Some of the Cyatheaceæ are Tree-ferns with upright stems ten to fifteen metres in height, and leaves four to five metres long. Ferns of temperate regions usually have a subterranean stem, which forms an upright or creeping rhizome. This may branch monopodially, or adventitious buds may be developed from the old leaf-bases. A conspicuous case of this adventitious budding is 


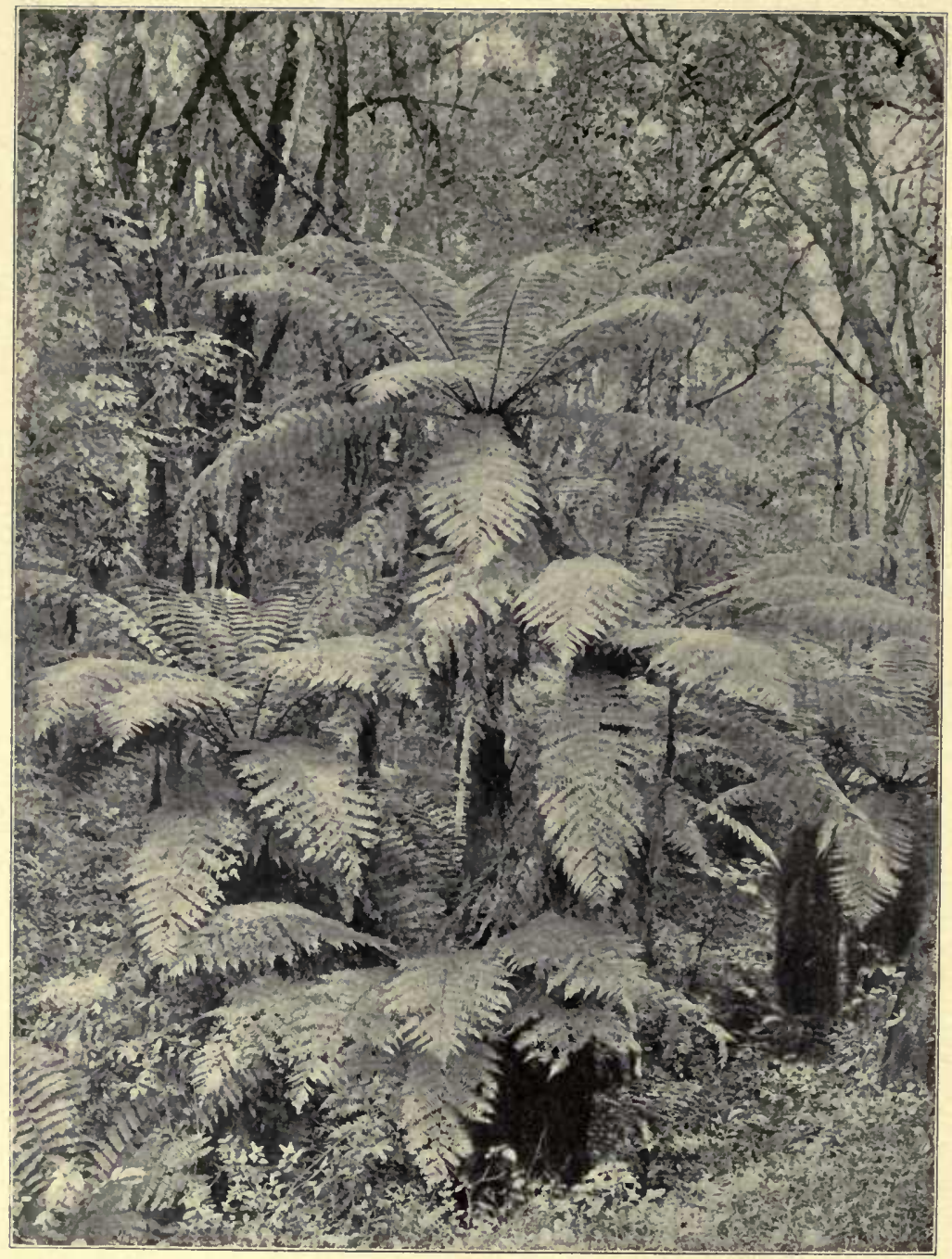

PLATE III

Tree-ferns growing in a Brazilian forest. (Photograph by Dr. J. C. Branner.) 
seen in Struthiopteris, where numerous stolons develop from the old leaf-bases.

\section{The Stem}

The growth of the stem, in the typical Ferns, is due to the division of a single tetrahedral apical cell, which in unbranched stems is the direct descendant of the orginal stem-quadrant of the embryo. The segmentation of the apical cell is usually slow, and it is generally impossible to determine the exact relation of the leaves and lateral branches to the primary segments of the apical cell.

Early divisions in the young segments separate a central cylinder, in consequence of which the vascular bundles and pith (when pres-
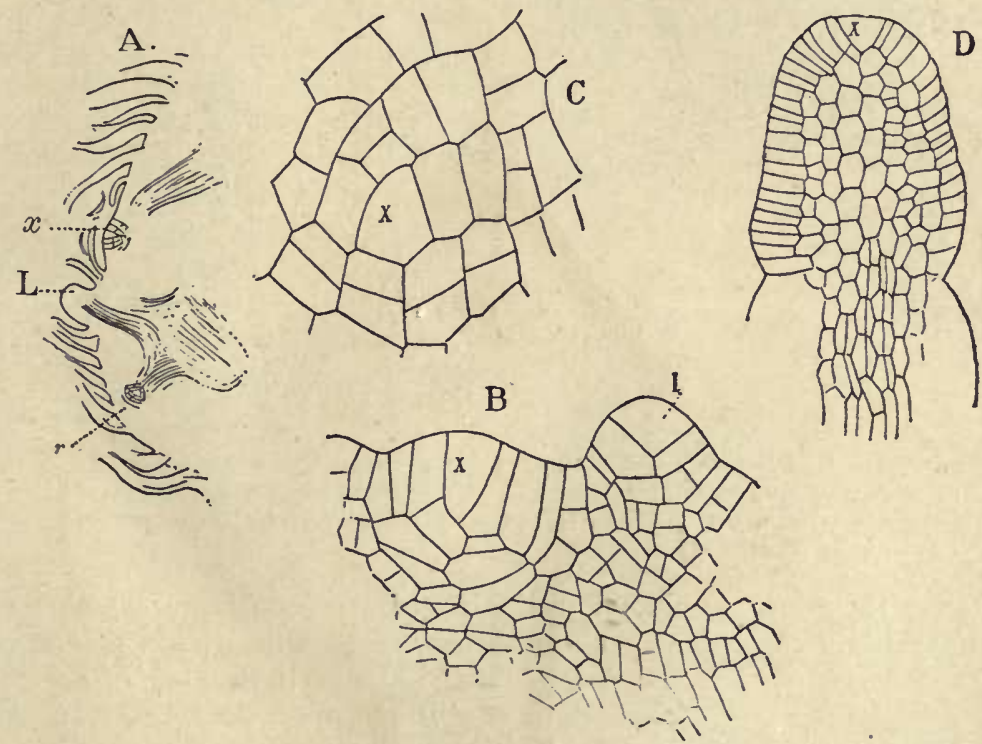

Fig. 219. $-A-C$, Adiantum emarginatum. $A$, longitudinal section of stem-apex $(\times 25) ; x$, apical cell; $l$, young leaf. $B$, apex of the same $(\times 180) . C$, crosssection of the stem-apex $(\times 180)$. D, young leaf of Struthiopteris Germanica, showing apical cell, $x$.

ent) are delimited from the cortex. In case there is a single axial bundle, the stem is "monostelic"; if more than one vascular bundle is present, the stem is "polystelic." The ground-tissue may remain permanently parenchymatous, or it may develop sclerenchyma, which is characteristic of the stems of many Ferns. The typical sclerenchyma (Fig. 221) is made up of cells with very thick striated and pitted walls of a golden or dark-brown color.

Vascular Bundles. - The vascular bundles of the stem, in most Ferns, form a hollow network within which lies the pith. The spaces between the bundles are the "foliar-gaps," and it is at these 
points that the bundles are given off to the leaves. 'The bundles are usually concentric in structure, but in the Ophioglossaceæ and Osmun-

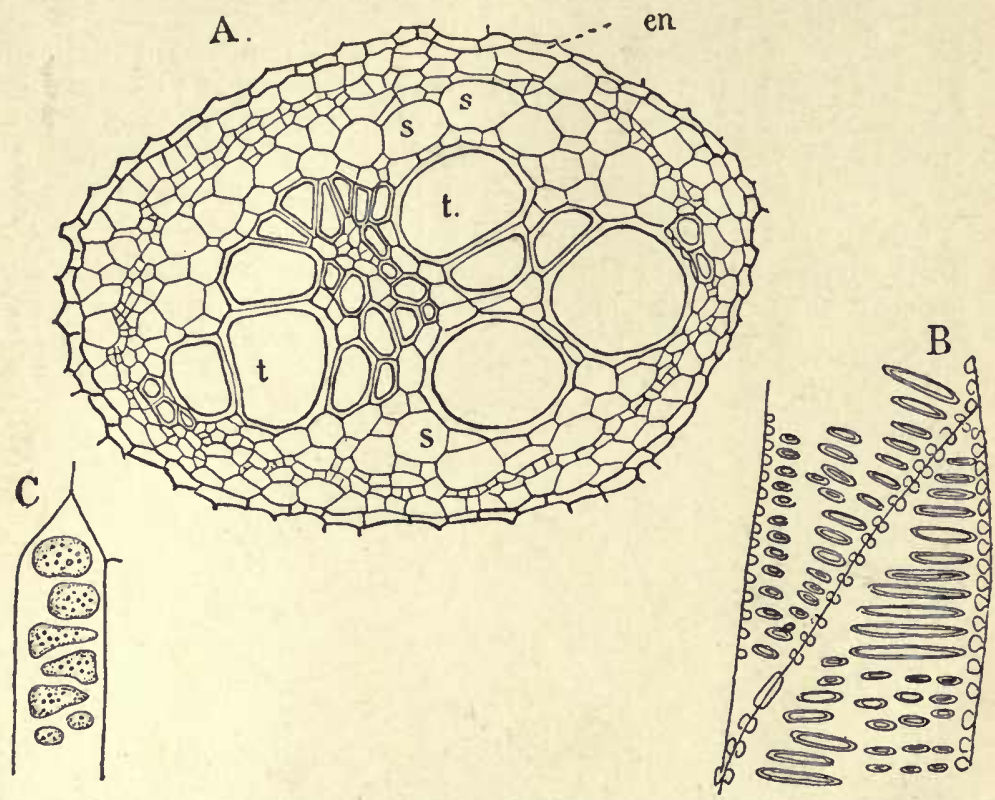

Fig. 220.-A, Pteridium aquilinum. Cross-section of vascular bundle from the rhizome; en, endodermis; $s$, sieve-tubes; $t$, scalariform vessels. $B$, part of two large scalariform tracheæ. C, sieve-tube of Struthiopteris Germanica $(\times 375)$. ( $A, B$, after Atrinson.)

daceæ they are truly collateral. In some of the larger species of Botrychium there is a genuine secondary growth, with a true cam-

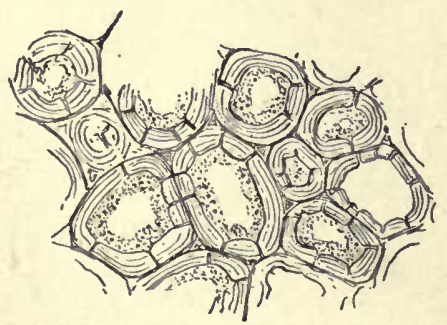

F1G. 221.-Aneimia hirsuta. Sclerenchyma from the rhizome, showing the lamination of the cell-walls and pits $(\times 250)$.

made up of large prismatic trach conspicuous narrow transverse pits - the "scalariform" elements which are typical of the Dicotyledons or Conifers. In the typical Ferns (Fig. 220) a section of a stem-bundle appears circular or oval. It is clearly separated from the ground-tissue by a wellmarked bundle sheath or endodermis, composed of cells with radially folded walls. The endodermis is the innermost layer of the cortex. Within this are one or two layers of cells forming the "Pericycle." The tracheary tissue is bium, like that in the stem of normal 
Ferns. Two strands of much sinaller tracheids, with spiral or reticulate thickenings, occupy the foci of the elliptical section. These are the primary tracheids, "Protoxylem," and from these the development of the tracheary tissue proceeds centripetally.

The phloem, which completely surrounds the xylem, is composed of elongated walled cells, some of which are developed into sievetubes. These have numerous sieve-plates upon their lateral walls. Vessels, i.e., tracheary elements composed of several fused cells, are rare in the Ferns.

\section{The Leaf}

Where the stem is prostrate, leaves are developed upon the dorsal side only. Where it is upright, the leaves usually form a crown at its summit. In their early stages, the growth of the leaf is usually apical, generally from a two-sided cell. In Osmunda the apical cell of the young leaf is tetrahedral. Later the growth is chiefly basal. The segmentation of the apical cell is much like that of the stem, and the separation of the primary tissues is accomplished in much the same way, and takes place very early.

The leaves in most young Ferns are dichotomously branched, but this is not usually the case in the mature leaf, although it may be; e.g., species of Gleichenia, Trichomanes, Adiantum pedatum, etc. Much more commonly the leaves are pinnately divided, and the

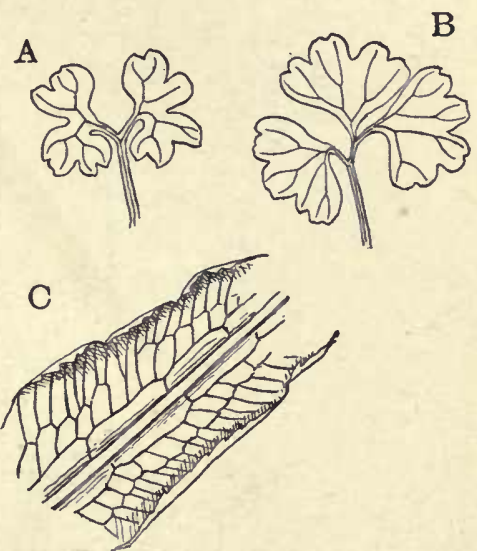

F1G. 222:- $-A, B$, Struthiopteris Germanica; $A$, tirst; $B$, second, leaf of young sporophyte, showing dichotomous venation $(\times 3)$. C, Woodwardia radicans, areolated vellation $(\times 2)$. branching is monopodial, the primary divisions corresponding to the two series of segments of the apical cell.

The growth of the leaf is very slow in many Ferns, especially those of cooler regions, where it often takes three years for the complete development of a single leaf. A section through the apex of the stem of such a Fern will show two, and sometimes three, complete series of leaves, representing as many seasons' growth. 'The lamina remains rudimentary until the season preceding its expansion, when it rapidly develops, so that it is completely formed by the end of the growing season, and is ready to expand very quickly in the following spring. This accounts for the extraordinary rapidity with which the leaves of many Ferns expand in the spring or early summer. 
The early growth of the leaf is much stronger upon the outer side, so that most Ferns show the marked inward rolling of the leaf which is so characteristic of these plants. In the Ophioglossaceæ, however, the young leaves are usually folded straight in the bud.

A few Ferns, e.g. Scolopendrium, Asplenium nidus, etc., have simple leaves, but usually they are pinnately compound, or decompound, the leaves of many Tree-ferns being among the most complex and beautifully segmented known. The leaf commonly has a well-marked stalk ("Stipe"), which when young is often covered with thin, chaffy scales or "Paleæ," and these sometimes are tipped with a glandular cell.

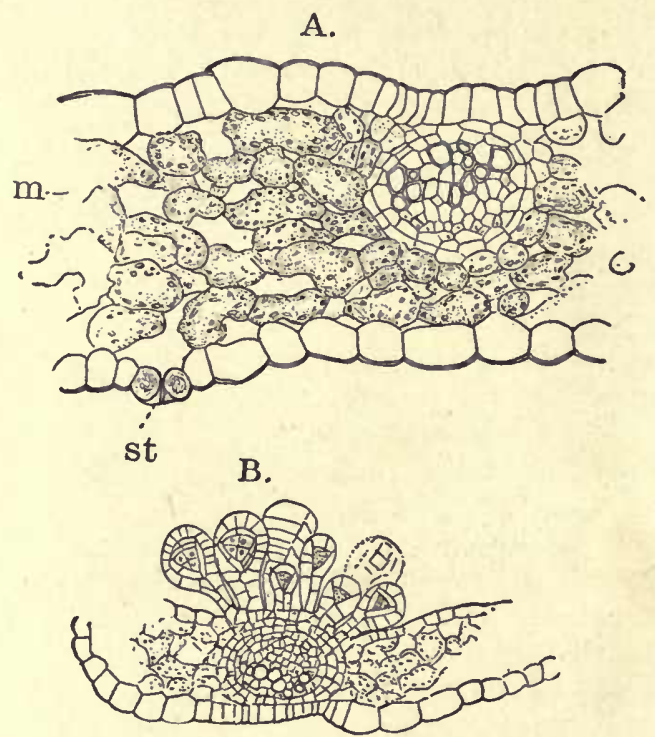

FIG. 223. - Polypodium falcatum. Cross-section of a leaf cutting across a vein; st, section of a stoma; $m$, mesophyll $(\times 200)$. $B$, section of young sorus $(\times 75)$.

Hairs are less common, but occur upon some Ferns. They are espe- . cially conspicuous upon the young leaves of Osmunda cinnamomea.

Venation. - The venation of the leaves is usually pinnate, but the ultimate divisions are generally dichotomons. Sometimes connecting veins, enclosing reticulations, are developed (Fig. 222). The venation is of some importance in classification.

Epidermis. - The epidermis of the leaf is composed of flat cells with strongly undulating outline, and, unlike the epidermal cells of most vascular plants, they contain chlorophyll. Stomata are usually developed upon the lower epidermis only, but may occur upon the upper surface in some instances. The Hymenophyllaceæ differ from the other Ferns in having the lamina of the leaf reduced to a single 
layer of green cells, and of course in these, stomata are absent. The developinent of a stoma (Fig. 224) in the Polypodiaceæ is preceded by the formation of a $U$-shaped wall in a young epidermal cell. Within the cell thus eut off, a second similar cell is cut out, and this becomes the mother-cell of the stoma. Below the stoma is developed an air-space, which communicates with those between the very loose cells of the mesophyll. The guard-cells of the stoma are filled with chlorophyll-granules, which probably bear some relation to the opening and closing of the pore between the guard-cells, this being de-

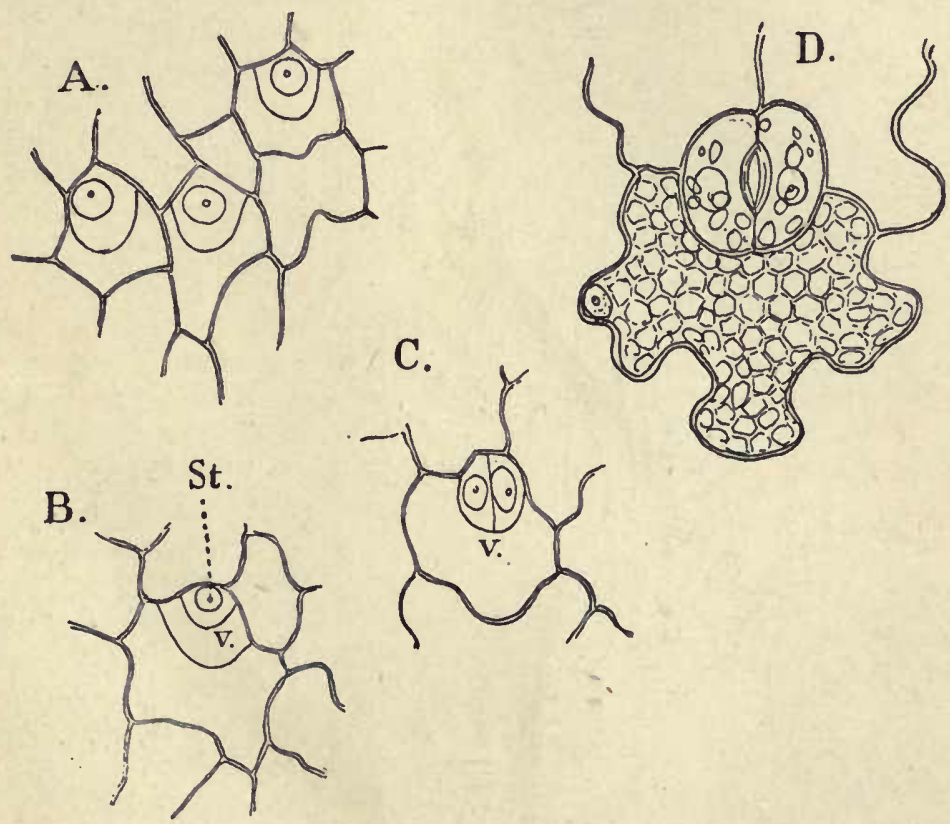

Frg. 224. - Adiantum emarginatum. Development of the stomata $(\times 525) ; v$, accessory cell; st, mother-cell of stoma.

pendent upon light. The causes of the movements in the guard-cells are changes in their turgor, which are supposed to be due to the development of certain soluble substances in these cells under the influence of light. Beneath the upper epidermis the green cells are often closely set, and form the so-called "Palisade-parenchyma."

Vascular Bundles. - The vascular bundles of the stipe and larger divisions of the leaf closely resemble those of the stem, with which they are joined. The small bundles in the finer veins are usually collateral, the xylem lying upon the upper side.

The ground-tissue of the stipe often shows a large development of 
sclerenchyma. It is this tissue which gives the polished black appearance to the leaf-stalks of such Ferus as Adiantum.

Scale-leaves. - Scale-leaves, with completely suppressed lamina, are not uncommon. These are especially conspicuous in Struthiopteris, where they form, with the persistent bases of the foliage leaves, a complete covering for the rhizome. In many Tree-ferns, and the Marattiaceæ, the leaf falls away, leaving a clearly marked scar upon the stem. In the Marattiaceæ the base of the leaf-stalk is provided with large stipules which are usually wanting in Ferns.

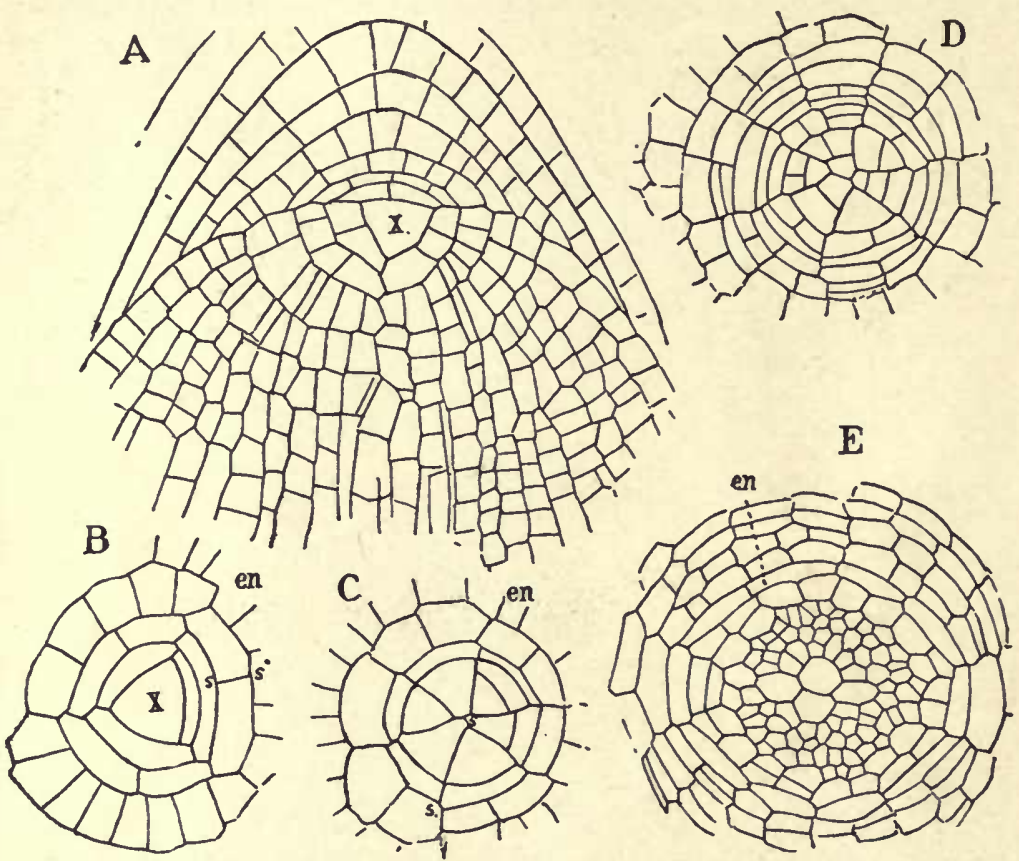

Fra. 225. - Adiantum emarginatum. Development of the root. A, longitudinal section of root-apex. $B-E$, series of transverse sections $(\times 200) ; x$, apical cell; $s, s$, sextant walls; en, endodermis.

Trichomes. - The paleæ and hairs covering the young parts are undoubtedly protective. Where they develop mucilage-glands, their importance in preventing loss of moisture is sufficiently apparent.

\section{The Root}

The primary root of the sporophyte is of limited duration, and is soon replaced by others which continue to develop as long as the sporophyte lives. The roots always arise near the base of the leaves, 
and in some of the Tree-ferns form a thick matted mass completely covering the stem. The roots arise endogenously, the apical cell being derived from a cell of the endodermis of the vascular bundle of the stem, and the root finally breaks through the overlying tissues of the stem and leaf-base.

Secondary roots are found in most Ferns, developed laterally upon the larger roots. These rootlets (Fig. 226) always arise from a special rhizogenic cell, which is an endodermal cell opposite the primary xylem. When the roots are diarch, as in the Polypodiaceæ, there are, therefore, two rows of lateral roots developed. The rhizogenic cells are especially conspicuous in Marsilia. In the rhizogenic cell three intersecting walls, enclosing a tetrahedral cell, are developed, and the latter at once becomes the apical cell of the new root. The basal cells, formed by the first three walls, form a sort of pedicel connecting the rootlet with the vascular bundle of the main root, with which its tissues are continuous. The layer of cells immediately surrounding the end of the young root form what has been called a "digestive pouch" (Fig. 226).

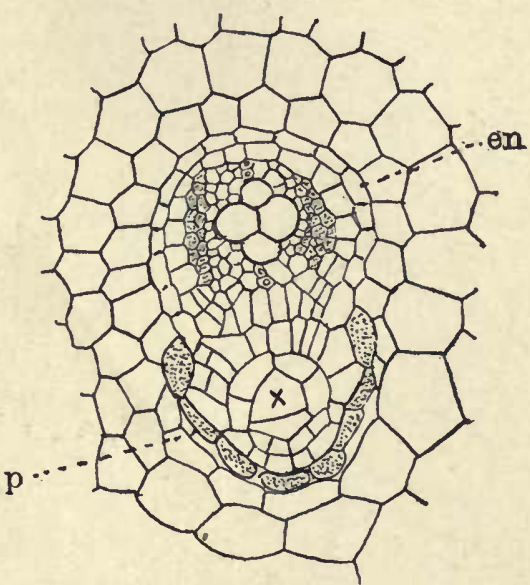

FIG. 226. - Pteris Cretica. Origin of lateral rootlet from the endodermis of the root (after VAN TIEGHeM); en, endodermis of root; $x$, apical cell of rootlet; $p$," digestive pouch."

The segmentation of the apical cell of the root in the typical Ferns is extremely constant. Segments are cut off in regular succession from the lateral faces, and corresponding to each series of lateral segments there is one cut off from the outer face, which contributes to the root-cap (Fig. 225). Each lateral segment is first divided by a nearly radial wall into two, so that a cross-section back of the root-apex shows six radially arranged cells, three of which do not extend quite to the centre. Periclinal divisions next separate a central group of cells which gives rise to the central stele, or vascular cylinder. The outer cells later become separated into the cortex and epidermis.

The cap segments divide first by intersecting vertical walls into four cells, which undergo repeated divisions and form the regular layers of the root-cap. Each layer of cells divides once by periclinal walls, so that two layers of cells arise from each primary cap segment. 
The innermost layer of the cortex forms the endodermis, or the bundle-sheath, whose radial walls are usually folded, giving the appearance, in transverse section, of dark spots. From special cells of this layer, as already stated, the secondary roots arise.

The root-bundle, as in other vascular plants, is of the radial type. In the greater number of Ferns the bundle is "diarch"; i.e. there are two groups of xylem alternating with as many phloem masses. Monarch roots occur in Ophioglossum vulgatum. Botrychium Virginianum has usually tetrarch root-bundles, and in the larger roots of
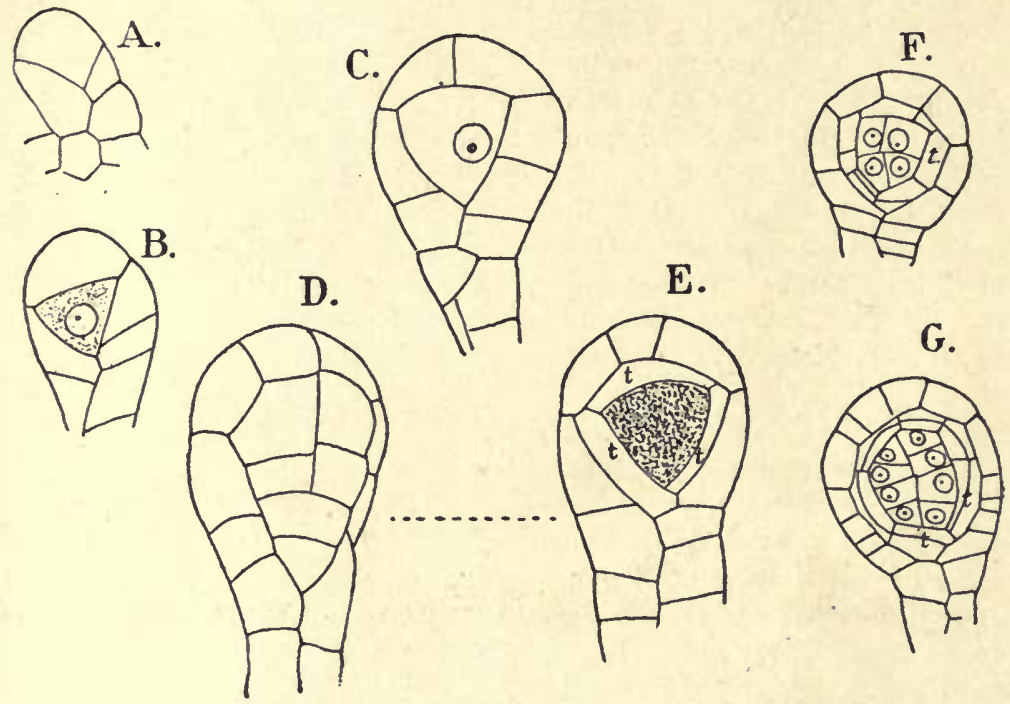

FIG. 227. - Polypodium falcatum. Development of sporangium. A-E, from fresh specimens $(\times 400) . F^{\prime}, G$, microtome sections $(\times 200) . B, C, E$, optical sections; $t$, tapetal cells.

Marattia and Angiopteris, the number of xylem and phloem masses is much greater.

Between the endodermis and the outer xylem and phloem elements which it encloses, there is a layer of tissue, usually a single layer of cells, the pericycle. As in the bundles of the stem, the primary xylem-elements are small spiral or reticulate tracheids, and the secondary ones larger scalariform elements developed toward the centre of the bundle. The structure of the phloem is much like that in the stem-bundles.

The cortical part of the root is composed in part of parenchyma, but the inner portion usually shows a greater or less development of sclerenchyma. 


\section{The Sporangium}

The formation of spores may not occur for many years after the sporophyte is established. Finally upon certain leaves, sporophylls, which may or may not differ from the foliage leaves, the sporangia are developed. The most generalized type is that of Ophioglossun (Fig. 232). Here the sporogenous tissue arises from a hypodermal layer, very much as in Anthoceros, and the distinction between sporogenous and sterile cells is not at first evident. The masses of spores are very large, and are discharged through a transverse cleft in the overlying tissue. In other related Ferns - e.g. Botrychium, Angiopteris - the archesporium is also of hypodermal origin, but there is very early an elevation of the superficial tissue so that the sporangium projects above the surface of the sporophyll.

In the most specialized Ferns, the Leptosporangiates, the sporangium can be traced back to a single epidermal cell, and the stalked sporangia of these Ferns are most characteristic structures, which are of importance in classifying them.

Spore-formation. - The sporogenous cells in all cases divide precisely as in the Bryophytes, into four spores. These may be either tetrahedral in form, or sphere-quadrants resulting from two successive divisions of the globular mother-cell. Surrounding the mass of sporogenous cells is the tapetum, consisting of one or more layers of cells, in the

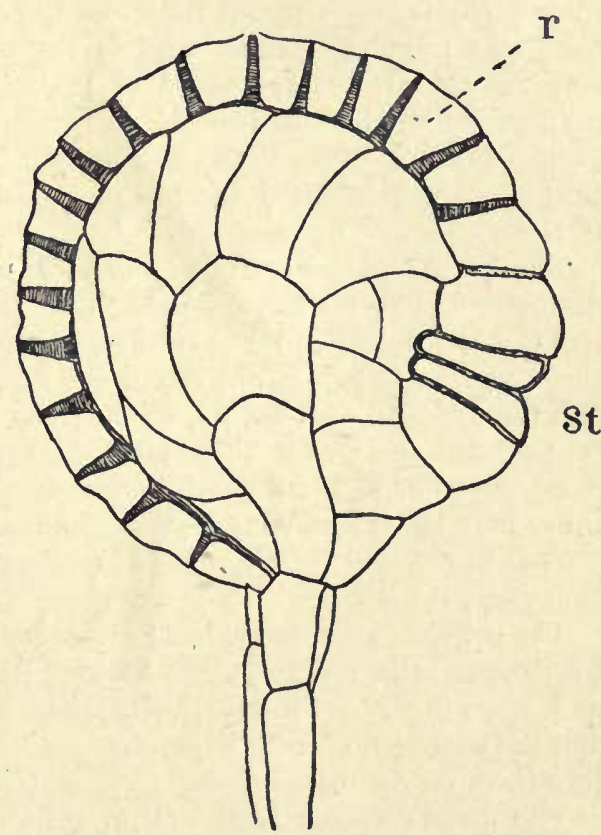

Fia. 228. - Polypodium falcatum. Surface view of a nearly ripe sporangium $(\times 175)$; st, stomium; $r$, annulus.

Leptosporangiates cut off from the archesporium. The tapetal cells become broken down during the later stages of the spore-development, and the nucleated protoplasm is brought into direct contact with the developing spores, whose growth is doubtless in part due to the activity of the tapetal protoplasm.

In the typical Ferns, the sporangia are usually in groups, or sori, 
upon the back of the sporophyll. A sorus bears a definite relation to the veins of the leaf, usually standing above one of these, or at its extremity (Fig. 223). At this point a more active growth of the superficial tissue results in a slight elevation, or receptacle, into which sometimes passes a short branch from the vascular bundle, above which the sorus is situated. In most Leptosporangiates the sorus is more or less completely covered by a membranaceous outgrowth of the epidermis, the Indusium.

In the Polypodiaceæ, each sporangium (Figs. 227, 228) arises from a single superficial cell of the receptacle. Sometimes one or two transverse walls are formed before the tetrahedral apical cell, from which the young sporangium grows, is developed. Usually the first wall in the young sporangium is nearly vertical, and is followed by two similar ones which intersect the first wall so as to include a tetrahedral apical cell like that in the stem-apex. From the apical cell are cut off several series of lateral segments, the earlier ones giving rise to the three-rowed stalk which is found in the sporangium of the Polypodiaceæ. Finally a periclinal wall separates a terminal seginent from the apical cell, and the longitudinal growth of the sporangium is stopped.

The upper part of the young sporangium rapidly increases in diameter and forms the sporogenous capsule.

After the apical cell has formed the terminal segment, it becomes the archesporium. From it are cut off four more segments, which may divide into two layers, so that the young capsule consists of a central cell and two or three outer layers. Of the latter, the outermost persists, and forms the wall of the ripe sporangium. The inner layer or layers constituting the tapetum later have their walls broken down, and form a mass of nucleated protoplasm in which the sporogenous cells lie.

The primary archesporial cell divides repeatedly, until about twelve to sixteen cells are formed. These contain very dense protoplasm and large nuclei. Finally the division-walls are partially absorbed, and the sporogenous cells separate completely. Each cell then divides into the four spores.

The young spores have a thin cellulose membrane, which later becomes differentiated into an inner (intine) and outer (exine) layer. As the spores approach maturity, there is usually deposited upon the outside, largely through the activity of the tapetal protoplasm, an outer sculptured membrane, the epispore, or perinium.

The wall of the sporangium consists of a single layer of large, thin-walled cells, except for the peculiar annulus, or ring of thickened cells running over its apex, and ending just above the "Stomium" (Fig. 228), which is composed of two narrow cells, between which the transverse opening occurs. The stomium is formed in the 
last lateral segment of the apical cell. The inner and radial walls of the annulus cells become very much thickened, and when the ripe sporangium dries, the strong contraction of these cells acts like a spring stretched over the apex of the sporangium, and pulls it open at the stomium, the split extending far back through the lateral cells of the wall. The annulus bends far back and then returns to its original position with a quick jerk, which throws the spores for a long distance.

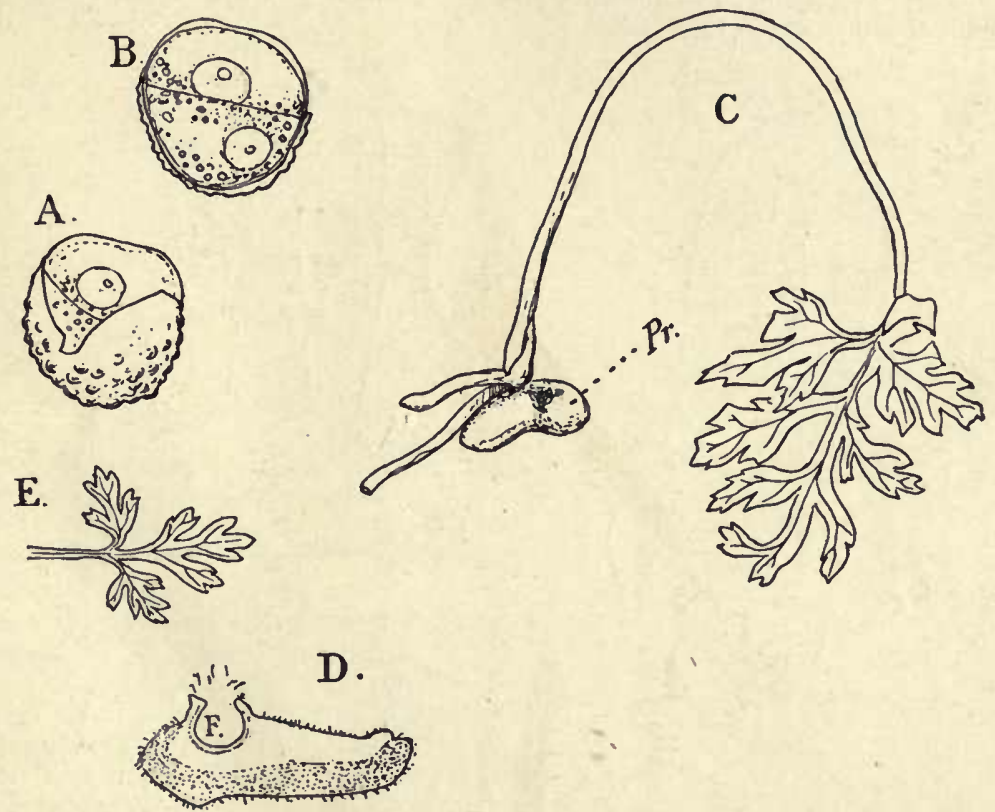

Fig. 229. - Botrychium Virginianum. $A, B$, germinating spore $(\times 600)$. $C$, sporophyte attached to the gametophyte, $p r(\times 2)$. $D$, section of gametophyte, showing the foot of the young sporophyte. $E$, young leaf $(\times 2)$.

\section{Classification of Filicineæ}

The Filicineæ may be divided into two subclasses - Eusporangiatæ and Leptosporangiatæ.

\section{Subclass I. Eusporangiate}

The Eusporangiatæ comprise but a small proportion of existing Ferns, and show many evidences of being the most primitive members of the class. This is evinced both by the characters of the gametophyte and of the sporophyte. The three orders included 
here, Ophioglossaceæ, Marattiaceæ, and Isoetaceæ, are not closely related among themselves, and the affinity of the latter with any of the Ferns may be questioned.

\section{Order I. Ophioglossaceæ}

The Ophioglossaceæ differ much from the typical Ferns, both in the gametophyte and sporophyte. They constitute a small order, comprising the two widespread genera, Ophioglossum and Botrychium, and the monotypic Helminthostachys of the East Indies.
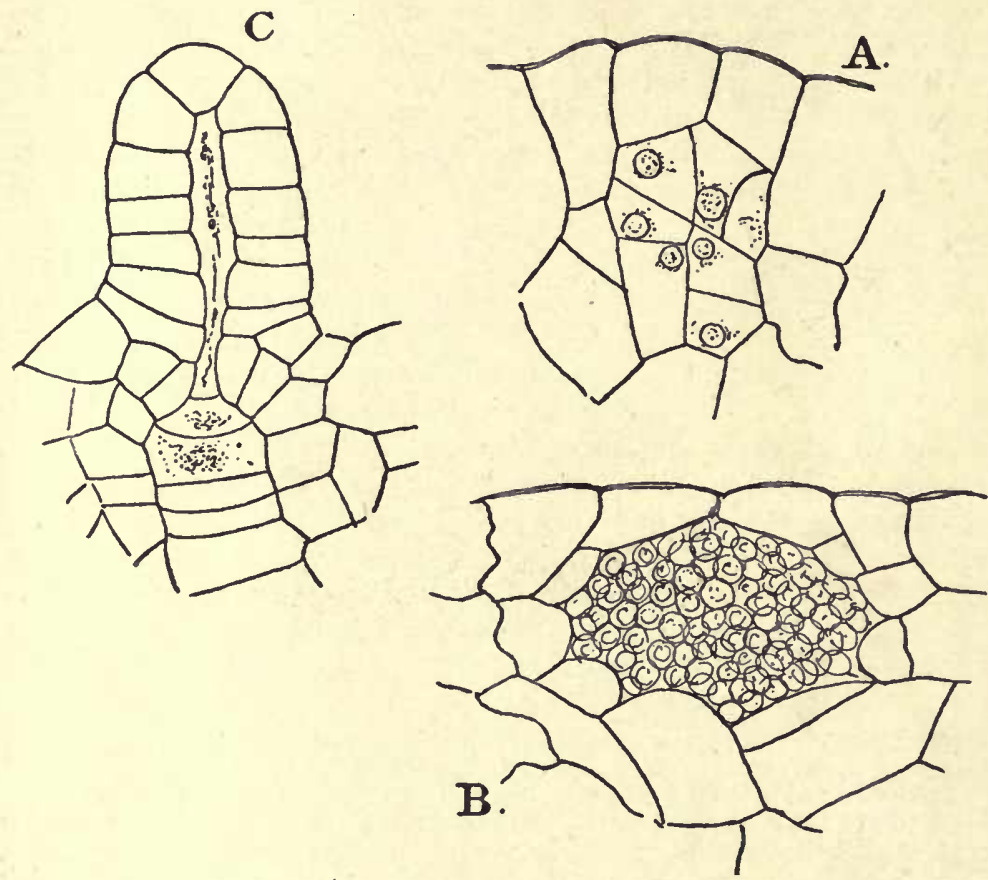

Fig. 230.-Botrychium Virginianum. $A, B$, antheridia $(\times 600) . \quad C$, archegonium $(\times 300)$.

Gametophyte. - The gametopbyte is best known in Botrychium Virginianum. It is a subterranean, tuberous body, quite destitute of chlorophyll, and always showing a ventral mass of tissue which contains an endophytic Fungus, closely resembling the "mycorhiza" associated with the roots of many saprophytic Seed-plants. The presence of this Fungus is doubtless associated with the saprophytic nature of the gametophyte.

The sexual organs are borne upon the upper surface of the gametophyte. The antheridia appear first and occupy a median ridge, upon whose flanks are later developed the archegonia. 
Antheridium. - The mother-cell of the antheridium (Fig. 230) divides by al transverse wall into a superficial cell which develops into the outer wall, and an inner cell which, by repeated divisions, produces the mass of sperm-cells. 'The outer cells, according to Jeffrey (19), always divide ultimately into two layers, like the cells covering the antheridial cavity in the Anthocerotales. The large multiciliate spermatozoids are much like those of the typical Ferns.

Archegonium. - The archegonium (Fig. 230, C) does not differ essentially from that of the typical Ferns. It has a straight neck, which is longer than

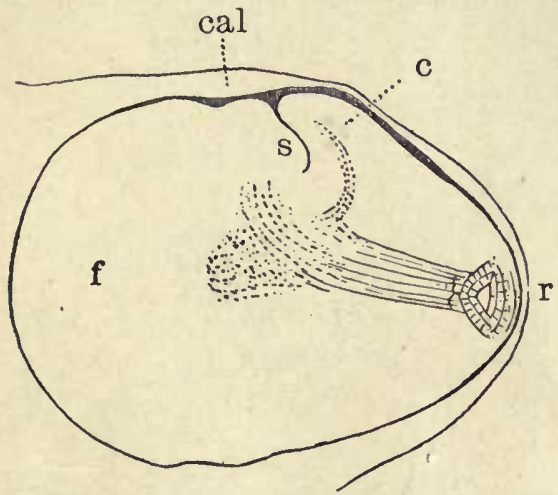

Fig. 231. - Botrychium Virginianum. Longitudinal section of an advanced embryo $(\times 35) ; s$, stem-apex; $c$, cotyledon $f$, foot; $r$, root; cal, calyptra. (After JeFrreX.)

that of Ophioglossum, which it otherwise resembles.

The Embryo. - The first division in the embryo is transverse, and the development of the organs of the young sporophyte is much later than in the more specialized Leptosporangiatæ (Fig. 231). This late external differentiation, and the correspondingly long dependence of the sporophyte upon the gametophyte, approach the condition found in the Bryophytes. The stem and root grow from a tetrahedral apical cell which is similar to that found in the same parts of the typical Ferns. The foot is very large, and the sporophyte may remain for several years attached to the gametophyte.

\section{The Mature Sporophyte}

The sporophyte in both Ophioglossum (Fig. 232) and Botrychium (Fig. 233) has a short, upright stem which, in our native species, is subterranean. The thick, fleshy roots contain a mycorhiza like that in the gametophyte. In some tropical species - e.g. Ophioglossum pendulum - the plant is epiphytic. The 
1 leaves are undivided in most species of Ophioglossum, but in the larger species of Botrychium they are repeatedly divided, not unlike those of the true Ferns. The leaf-bases are developed into sheaths which completely enclose the apex of the stem. The leaves often require three to four years, or even five, for their complete development.

Sporangium. - The sporangia are borne upon peculiarly modified outgrowths of the leaf, the Sporangiophore. This has the form of a spike in Ophioglossum, but may be extensively branched in Botrychium, where the individual sporangia are much more clearly defined than in Ophioglossum. The tetrahedral spores

A

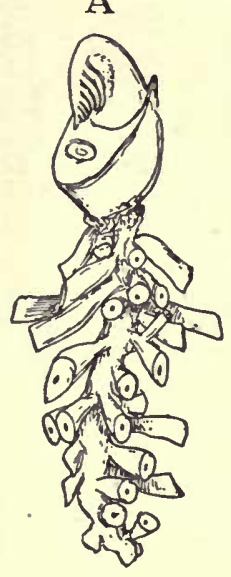

B.

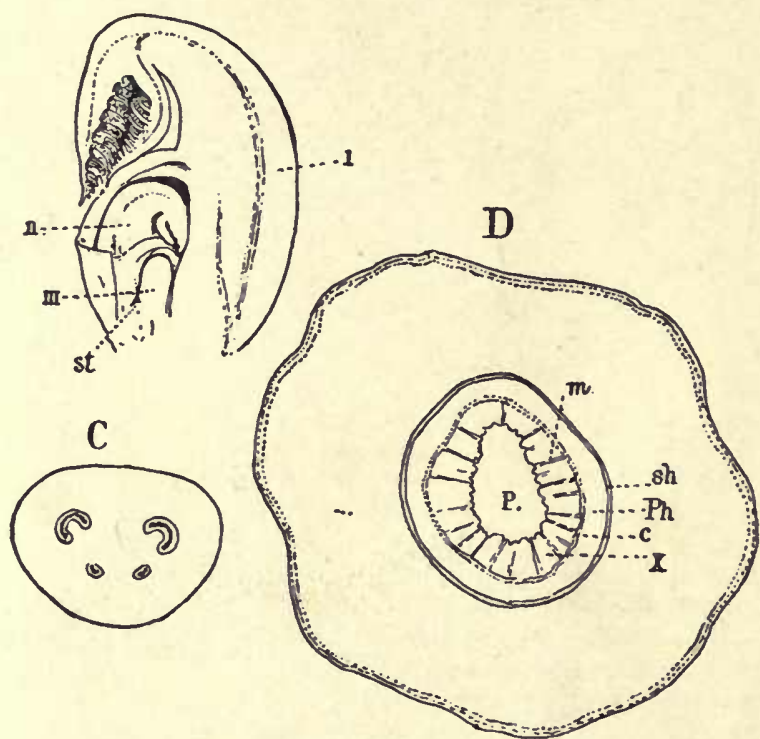

Fig. 233. - Botrychium Virginianum. A, rhizome and terminal bud of a strong plant, the roots, and all but the base of the oldest leaf cut away $(\times 1) . B$, longitudinal section of the terminal bud $(\times 3)$. I, II, III, leaves of different ages; $s t$, stem-apex. $C$, cross-section of the petiole $(\times 4) . D$, cross-section of rhizome $(\times 16) . P$, pith; $x$, wood; $p h$, phloem; $s h$, endodermis; $m$, medullary rays.

are quite destitute of chlorophyll, and are discharged from the sporangia through a transverse cleft.

Histology of Sporophyte. - The ground-tissue is mainly composed of parenchyma. In the outer cortical region of both stem and root there may be a development of cork. The vascular bundles of the stem are collateral, and in the larger species of Botrychium form a woody cylinder, suggesting the structure of a woody coniferous or dicotyledonous stem. In these a true cambium is developed which causes a regular secondary thickening of the stem. The bundles of the leaves are also collateral in Ophioglossum, but in the large species of Botrychium they approach the concentric type, but never of so perfect a form as in the true Ferns. 


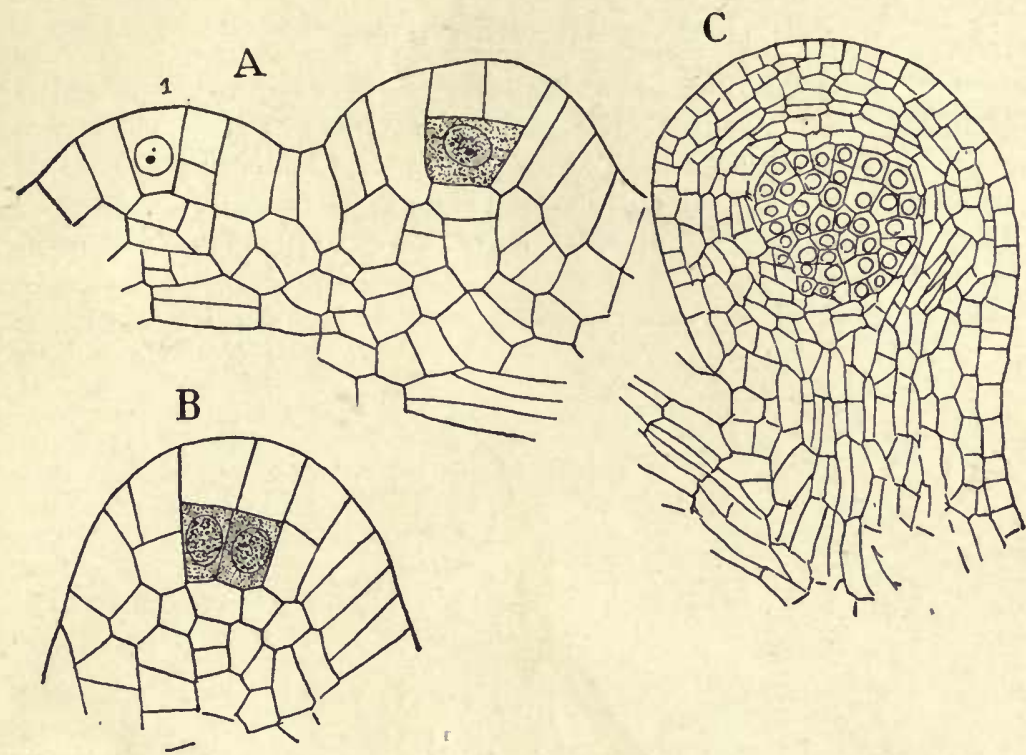

FIg. 234. - Botrychium Virginianum. Development of the sporangium. $A, B$, young sporangia $(\times 480) . C$, an older one $(\times 240)$; all median sections; the sporogenous cells have the nuclei shown.
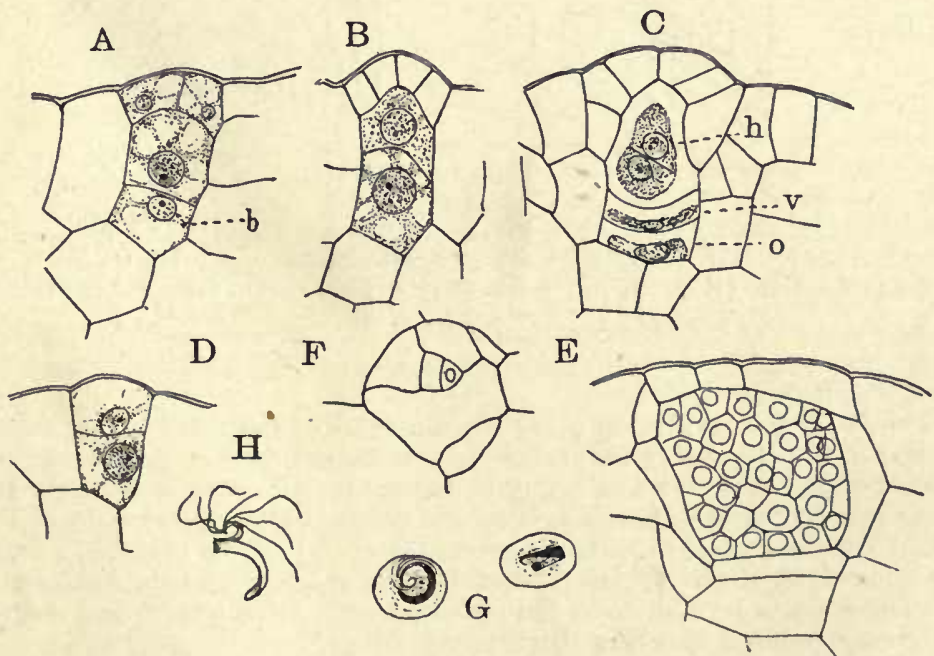

Fig. 235. - Marattia Douglasii; development of sexual organs. $A, B, C$, archegonium. $D-F$, antheridium. $F$, surface view of antheridium, showing opercular ceil. $G$, two sperm-cells, containing ripe spermatozoids. $H$, free spermatozoíd. $(A-F, \times 400 ; G, H, \times 800$. 


\section{Order II. Marattiaceæ}

The Marattiaceæ include a small number of tropical forms which resemble, in their general appearance, the typical Ferns. The sporophyte may be of large size, as in Angiopteris and some species of Marattia, where the thick, tuber-like stem is half a metre or more in diameter, with a crown of thick leaves three to four metres or more in length.
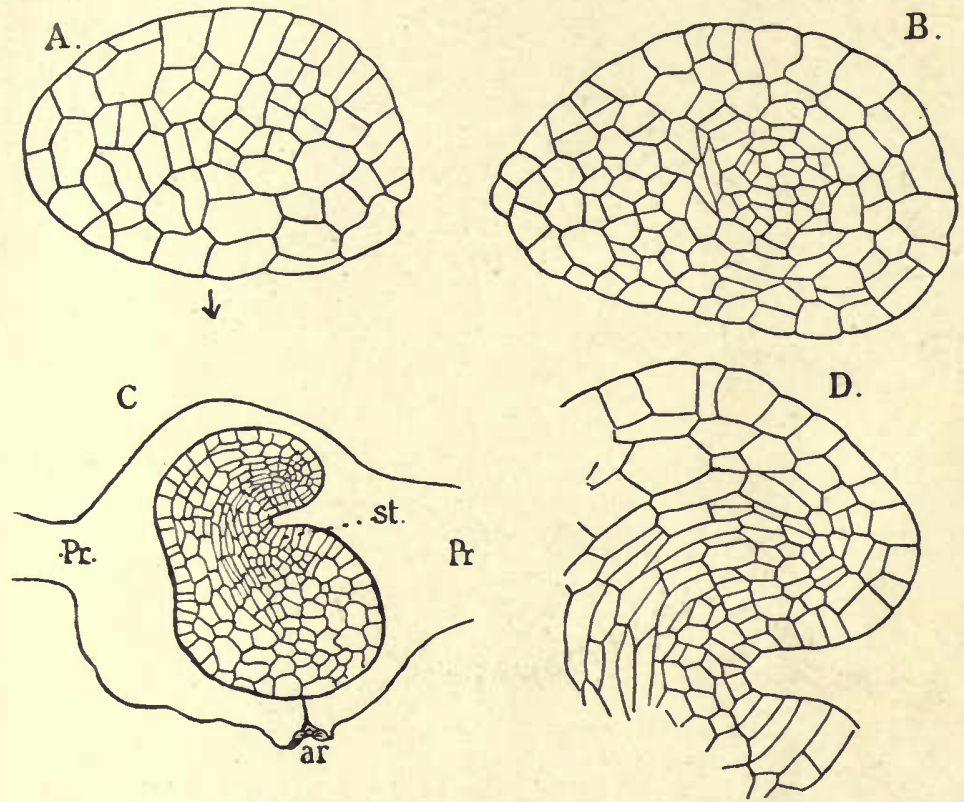

FIG. 236. - Marattia Douglasii. Embryo. A, longitudinal, $B$, transverse, sections of embryo $(\times 215)$. $C$, vertical section of older embryo, showing its position in the prothallium $(\times 72)$; $a$, archegonium. $D$, upper part of same embryo $(\times 215)$.

\section{The Gametophyte}

The small, colorless spores germinate slowly, the first division occurring in about a month after the spores are sown. The gametophyte (Fig. 205) is a fleshy green thallus, much like a Liverwort in appearance, and upon it are borne both antheridia and archegonia. The latter are confined to the lower side, as they are in the common Ferns. In structure, the sexual organs (Fig. 235) closely resemble those of the Ophioglossaceæ, but the outer wall of the antheridium has but a single layer of cells, and opens by a small triangular opercular cell. The archegonium neck is very short.

The gametophyte frequently multiplies by the formation of adventitious buds, and the apex may fork exactly as in a thallose Liverwort.

Embryo. - As in Botrychium, the basal wall of the embryo is transverse, and the differentiation of the organs is slow, so that the embryo remains long de- 
pendent upon the gametophyte. The young stem and primary root show a single apical cell, which is probably replaced by a group of initial cells in the massive stem and roots of the mature sporophyte. 'The cotyledon in Marattia is forked like that of the typical Ferns; but in Angiopteris and Danæa it has a midrib and pinnate venation.

\section{The Mature Sporophyte}

All of the existing Marattiacer are tropical. The stem in Angiopteris and Marattia is a nearly globular massive body, covered with the thick persistent stipules of the leaf-bases. In Dallæa the stem is prostrate, but otherwise much like the other genera. 'The leaves, which are fleshy in texture, are smooth, and coiled up when young.

Histology. - As in the Ophioglossacex, the ground-tissue is principally composed of parenchyma, but sclerenchyma (Fig. 237) occurs in the stem and larger leaf-stalks. It may, however, be replaced by thick-angled tissue (collenchyma). Conspicuous mucilageducts (Fig. 238) closely resembling those in the Cycads, occur abundantly in the ground-tissue, and cells containing tannin are of common occurrence. The vascular bundles (Fig. 238)

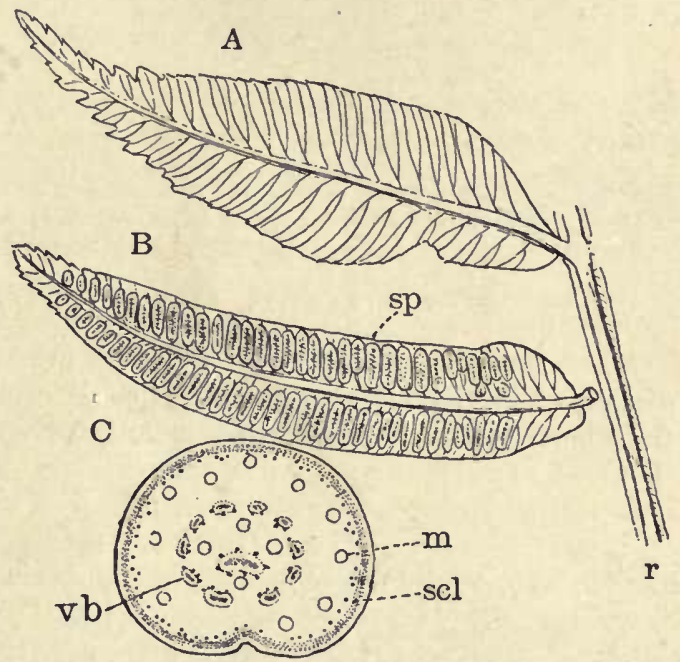

Fig. 237. - Danæa alata. A, sterile pinna, attached to the winged rachis, $r\left(\times 1 \frac{1}{2}\right) . B$, under surface of a fertile pinna, showing the synangia, $s p$. $C$, crosssection near the base of the petiole ( $\times$ about 6 ); $s c l$, sclerenchyma; $m$, mucilage-ducts; $v b$, vascular bundles.

are concentric and not strikingly different from those of the Leptosporangiates.

The Sporangia. - The sporangia (Fig. 239) are more or less completely united into synangia, in which the outlines of the individual sporangium are quite lost. In Angiopteris and Archangiopteris the individual sporangia can be recognized, and they possess an imperfect annulus. The sporophylls may be quite unınodified as in Angiopteris and Marattia, or contracted, and the whole lower surface almost completely hidden by the crowded synangia (Fig. 237, B). In all cases they are borne upon the lower surface of the sporophyll. The sporangium, or each loculus of the synangium, opens by a longitudinal slit, or pore.

Of the existing genera, Marattia is cosmopolitan; Angiopteris occurs in the eastern Tropics; Kaulfussia is East Indian, and Danæa is American. The recently discovered Archangiopteris comes from southwestern China.

Fossil Marattiaceæ. - Many fossil Ferns are known which are allied to the living Marattiacex, and it is evident from a study of these fossil forms that the 
Marattiaceæ are much older than the leptosporangiate Ferus which have now largely superseded them.

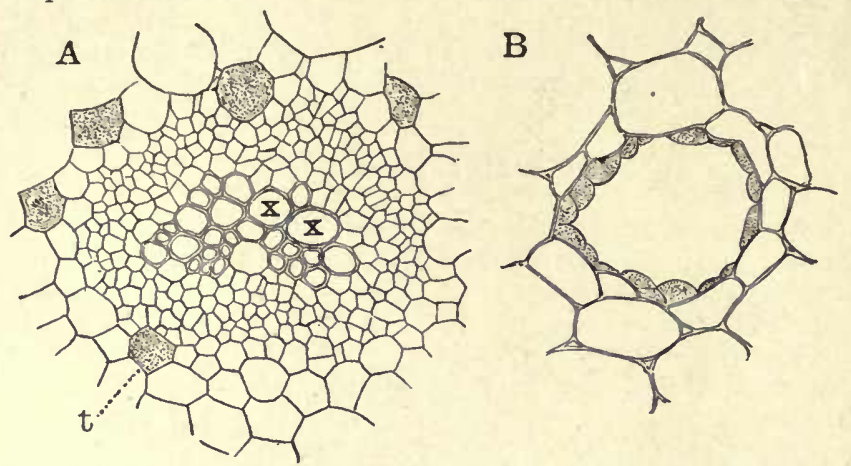

Fig. 238. - Danæa alata. A, transverse section of vascular bundle of the petiole

$(\times 175) ; x$, tracheary tissue ; $t$, tannin cells. $B$, cross-section of a mucilage-duct $(\times 175)$.

\section{Subclass II. Leptosporangiate}

Much the greater number of existing Ferns belong to the second division, the Leptosporangiatæ. These are characterized by having the sporangium the derivative usually of a single epidermal cell.
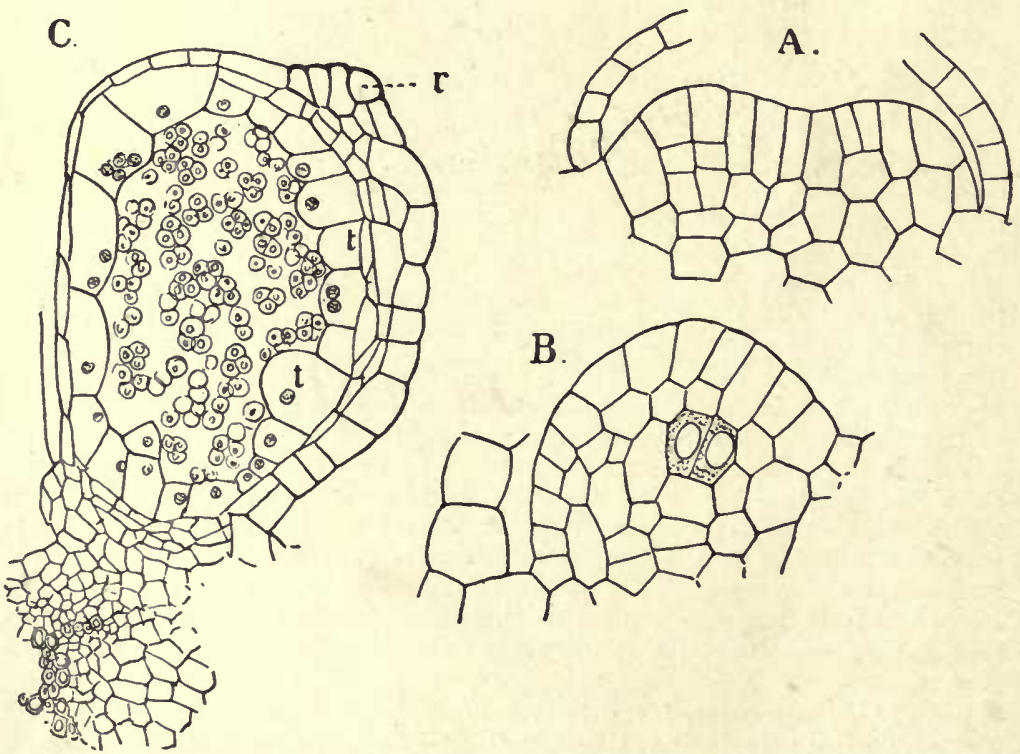

FIG. 239.-Angiopteris evecta. Development of sporangium. $A, B$, sections of young sporangia. (After GoEBEL.) $C$, section of a nearly full-grown sporangium, showing persistent tapetum, $t$, and annulus, $r(\times 75)$. 
The lower members of the series, however, especially the Osmundaceæ, are to some extent intermediate in this respect between the Eusporangiates and the more specialized Leptosporangiates.

The Leptosporangiatæ may be divided into two orders, the Filices, or homosporous forms, and the Hydropteridineæ, or heterosporous Ferns. The latter develop two sorts of spores, large ones (Macrospores, Megaspores) and sinall ones (Microspores). The megaspore gives rise to a female gametophyte, the microspore to the extremely reduced male plant.

\section{Order I. Filices}

The general characters of the Filices have already been given in the earlier part of the present chapter. The ganetophyte is always relatively large, and usually bears both archegonia and antheridia. The sporophyte ranges from a centimetre or less in height (Trichomanes parvulum) to ten or fifteen metres (Cyathea sp.). They are for the most part moisture-loving plants, and are sometimes genuine aquatics (Ceratopteris thalictroides). Some-e.g. Gymnogramme triangularis - are more or less marked xerophytes. In the Tropics many species, especially among the Hymenophyllaceæ and Polypodiaceæ, are epiphytes. Some of these epiphytic Ferns, like Platycerium, produce special sterile, closely overlapping leaves, which serve to hold moisture, and to accumulate decaying vegetable matter and dust which are utilized as sources of food.

Sporangium. - The sporangia in the homosporous Ferns are always borne upon the backs of sporophylls, which are usually not much modified, although sometimes - e.g. Onoclea, Struthiopteris, Blechnum spicant, etc. - the fertile and barren fronds are decidedly different. In other Ferns, like Lygodium and Aneimia, special fertile leaf-segments are developed. The sporangium in all cases develops a single tetrahedral archesporial cell, and the ripe sporanginm has its wall composed of but a single layer of cells. An annulus is always present, and the form and position of the annulus are the most important characters employed in dividing the Filices into families.

Classification:- The Filices may be divided into the following families: 1. Osmundaceæ; 2. Gleicheniaceæ; 3. Matoniaceæ; 4. Schizæaceæ; 5. Hymenophyllaceæ; 6. Cyatheaceæ; 7. Parkeriaceæ; 8. Polypodiaceæ.

\section{Family I. Osmundaceæ}

The Osmundaceæ are the lowest of the Leptosporangiates, and in the charac. ters of both gametophyte and sporophyte are to some extent intermediate between the typical Leptosporangiatæ and the generalized Eusporangiates. The gametophyte is large and not unlike that of the Marattiaceæ. The character of 
the sexual organs, and the early stages of the embryo, also approach the eusporangiate type.

The sporophyte shows certain analogies with both the Marattiaceæ and Ophioglossaceæ. With the latter it agrees in the character of the vascular bundles of the stem, which are collateral instead of concentric as in the typical Ferns. The leaves are circinately coiled as in the Marattiaceæ.

The sporangia (Fig. 241) may be borne upon the back of unaltered or but slightly modified sporophylls, e.g. Todea, Leptopteris; or special portions of
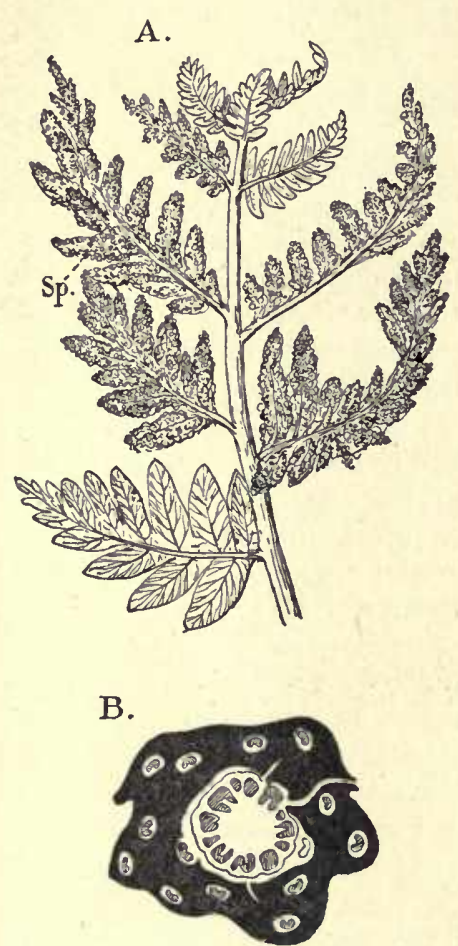

Fig. 240. - A, Osmunda Claytoniana. Sporophyll, natural size; $s p$, sporangia. $B$, section of the rhizome of $O$.regalis, showing the arrangement of the vascular bundles $(\times 3)$. $(B$, after DE BARY.)
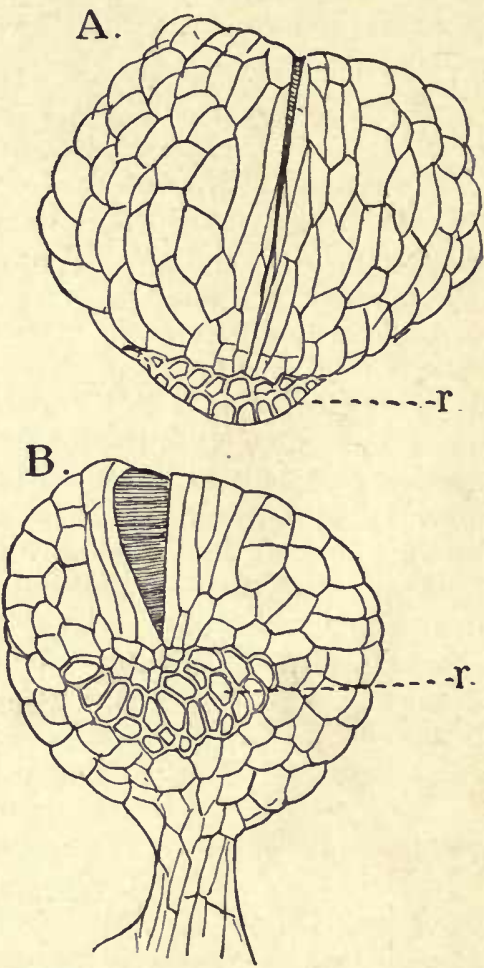

Frg. 241.-Osmunda cinnamomea. Ripe sporangium. $A$, from above. $B$, from in front; $r$, annulus $(\times 45)$.

the leaves may be completely covered with sporangia, as in Osmunda (Fig. 240). Osmunda cinnamomea has the whole sporophyll covered with sporangia. The sporangia are large, and the annulus consists of a group of thickened cells upon one side. The dehiscence is longitudinal. The sporangium in its earlier stages is much more massive than that of the typical Leptosporangiates, and caunot be referred to a single initial cell.

The apical growth of both stem and root is less regular than in the higher Leptosporangiates, and in this respect also the Osmundaceæ suggest the Eusporangiates. 
The Osmundaceæ are probably old forms which have largely disappeared. At present about a dozen species are known. Of these, three species of Osmunda occur in the eastern United States, but none are found on the Pacific coast. The other genera, Todea and Leptopteris, belong to the southern hemisphere.

\section{Family 2. Gleicheniaceæ}

The Gleicheniaceæ comprise about twenty-five species of Ferns, principally confined to the Tropics, but extending to the extreme
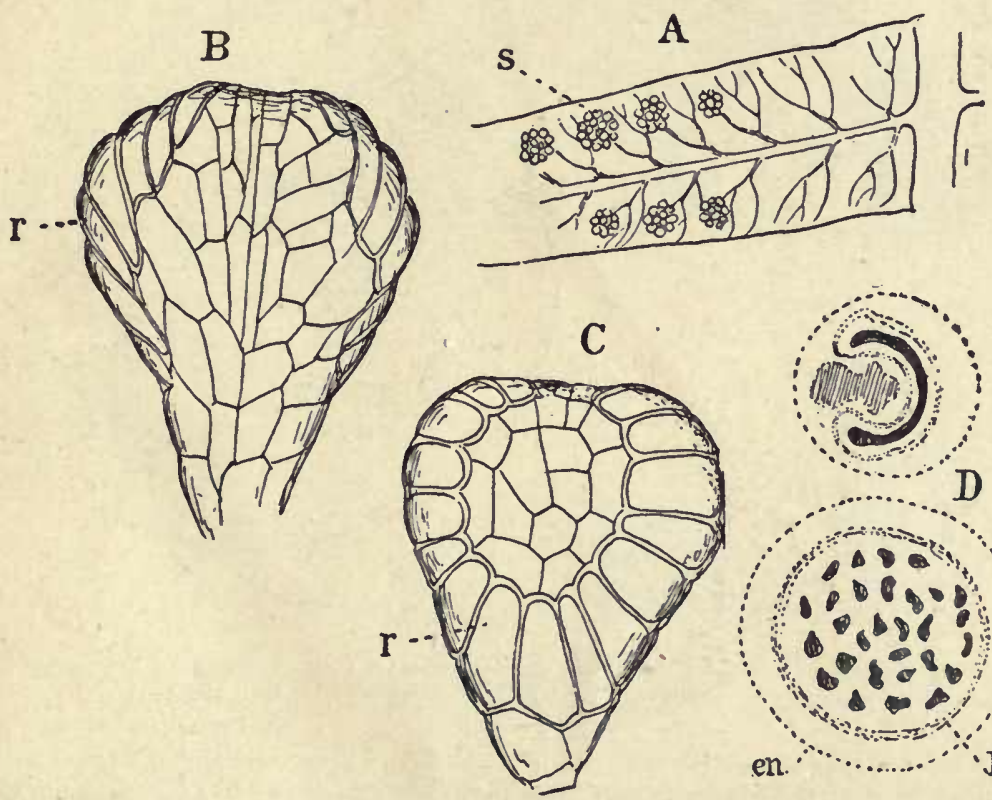

Fig. 242.-Gleichenia dichotoma. A, pinnule, showing the position of the sori, $s$ $(\times 4) . B$, ventral, $C$, dorsal, view of the ripe sporangium $(\times 85) . \quad D$, vascular bundles of the petiole and stem of Gleichenia sp.; the dark masses represent the xylem; $p h$, phloem; en, endodermis. ( $D$, after Poirault.)

southern part of South America. Except for the monotypic Stromatopteris moniliformis, they all may be included in the genus Gleichenia (Fig. 242).

Gametophyte. - The gametophyte is intermediate in character between that of Osmunda and the higher Leptosporangiates.

Sporophyte. - The sporophyte in Gleichenia has a slender creeping rhizome, which is monostelic. The leaves are in most species dichotomously branched, and have an unlimited apical growth, so that they become very long, and climb over shrubs and trees, often forming almost impenetrable thickets. Very often 
adventitious buds are developed, especially in the forks of the leaf. The tissues are very much like those of tlie typical Leptosporangiates.

The sporangia are sessile, with a broad, oblique annulus (Fig. 242), and open longitudinally. They are grouped in small, naked sori, upon the lower surface of unmodified leaves.

\section{Family 3. Matoniaceæ}

Sometimes included with the Gleicheniaceæ is the peculiar genus Matonia, represented by two species from the Malayan region. They differ from the Gleicheniaceæ in the sporangia, which are more like
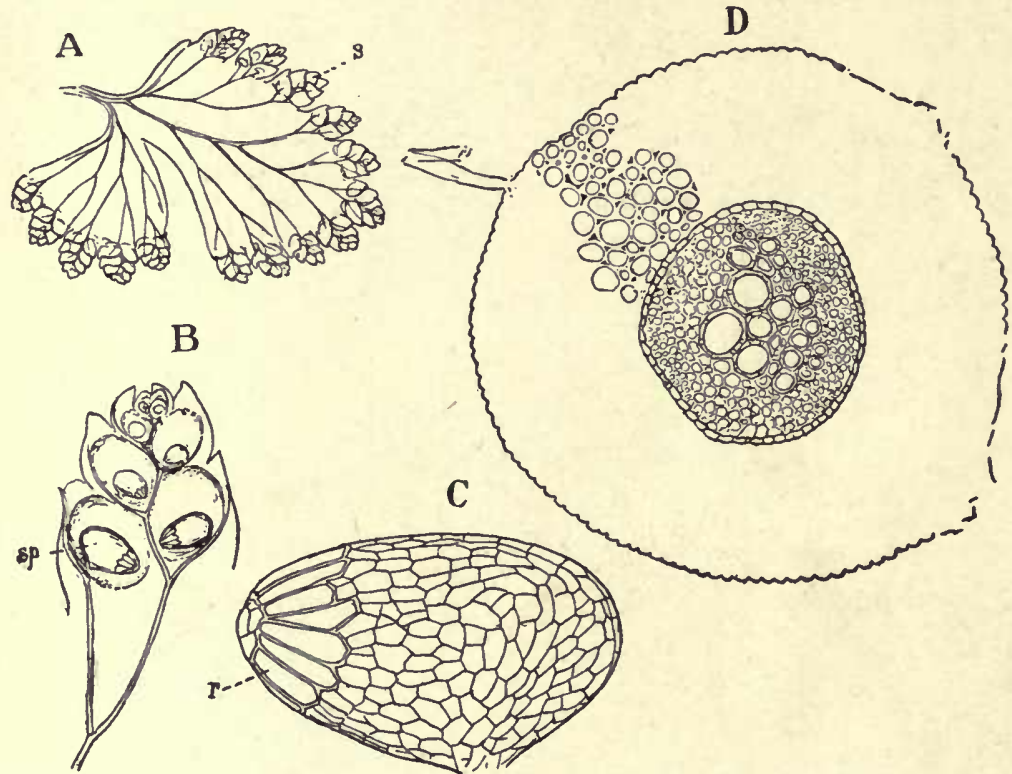

Frg. 243. - Lygodium Japonicum. $A$, pinnule $(\times 3) ; s$, the sporangial segments. $B$, section of sporangial segment, showing sporangia, $s p(\times 14) . C$, sporangium $(\times 65) ; r$, annulus. $D$, cross-section of petiole $(\times 65)$.

those of the Polypodiaceæ or Cyatheaceæ. The sorus is covered by a peculiar shield-shaped indusium. The Matoniaceæ are the last remnants of a family which was abundant in the earlier Mesozoic formations.

\section{Family 4. Schizæaceæ}

The Schizæaceæ, which include about one hundred species, like the Gleicheniaceæ are mainly tropical in their distribution, but there are several exceptions. In the Atlantic States, two species, Lygodium palmatum and Schizoea pusilla, occur, and in Texas there are several species of Aneimia. 
Gametophyte. - The gametophyte does not differ essentially from that of the Polypodiaceæ, and, so far as it is known, the embryo also is very similar.

Sporophyte. - The sporophyte has a prostrate, or short, upright rhizone, from which are sent up the leaves. The latter in Lygodium have an unlimited apical growth, and the leaf-stalk twines so that these are known as climbing Ferns. 'The tissues are much like those of the Gleicheniaceæ. The sporophylls are usually modified, either the whole leaf being strongly contracted, - e.g. Schizcea pusilla,_or special fertile leaf-segments are formed, as in Lygodium and Aneimia. In the latter genus, the lower pair of pinnæ are fertile, and often long-stalked. Some species of Aneimia are also characterized by the peculiar form of the stomata. The wall which cuts out the mother-cell is circular, so that the stoma lies in the middle of an epidermal cell.
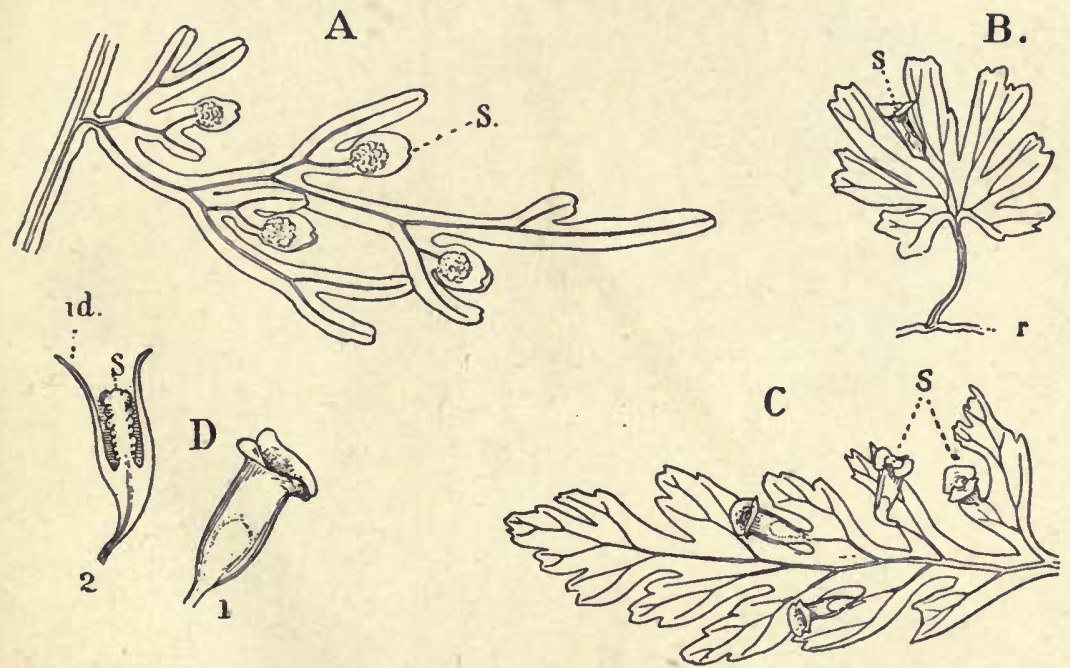

Fig. 244. $-A$, Hymenophyllum recurvum $(\times 3)$. B, Trichomanes parvulum $(\times 3)$. $C, T$. cyrtotheca $(\times 3)$. D, 1, indusium more enlarged; 2, section of indusium, showing the sorus, $s$.

Sporangium. - The sporangia (Fig. 245, C) are large, and possess a terminal annulus, which in Lygodium and Aneimia forms a conspicuous cap of thickened cells. The sporangia are covered by an indusium formed by the leaf-margin, or there may be a special indusium for each sporangium (Lygodium).

\section{Family 5. Hymenophyllaceæ}

The Hymenophyllaceæ are especially characteristic of the moist mountain forests of the Tropics, where their exquisite filmy fronds sometimes quite cover the trunks of trees with their graceful drapery. A few species extend beyond the Tropics, but only two species, and these extremely rare, occur within the United States. There are two genera, Hymenophyllum and Trichomanes, each com- 
prising about eighty species. A third monotypic genus, Loxsoma, is sometimes included in the family.

Gametophyte. - The gametophyte is very different from that of other Ferns, probably due to the excessively moist localities in which they usually grow, which induces an excessive vegetative development, so that sometimes great
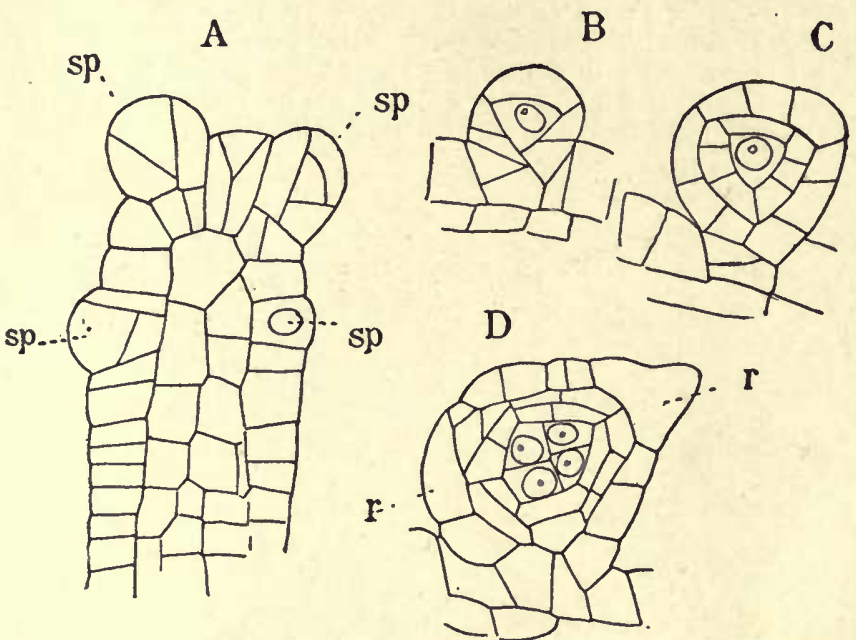

E.
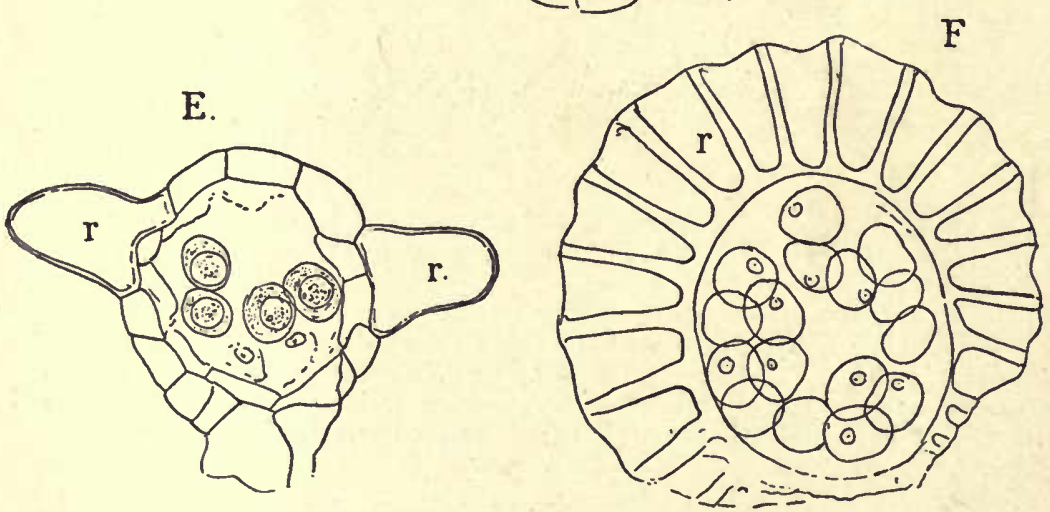

Fig. 245. - Trichomanes cyrtotheca. Development of the sporangium $(\times 225) . F$, horizontal section of a nearly ripe sporangium; $r$, annulus.

mats of the prothallia are met with, which may easily be mistaken for Liverworts. In many species of Trichomanes, the prothallium is an extensively branched filamentous growth resembling the protonema of a Moss. In Hymenophyllum, it resembles the prothallium of the Polypodiaceæ in its earlier stages, and always is flat, but may branch extensively and reach a length of several centimetres. Special gemmæ are comuon in these plants and permit a rapid 
multiplication of the gametophyte, independently of the spores. The sexual organs are similar to those of the Osmundaceæ.

Sporophyte. - The sporophyte of the Hymenophyllaceæ is usually small, and is characterized by the extreme delicacy of the leaves. The slender, creeping stem is monostelic, and roots are often quite absent. Where they are present they are much like those of the typical Ferns, but show much variation in the number of xylem-masses. The plants are very generally epiphytes, or grow upon rocks exposed to the spray of mountain streams or cataracts. The adaptation to an excessively moist atmosphere is seen in the leaves, which, with few exceptions,
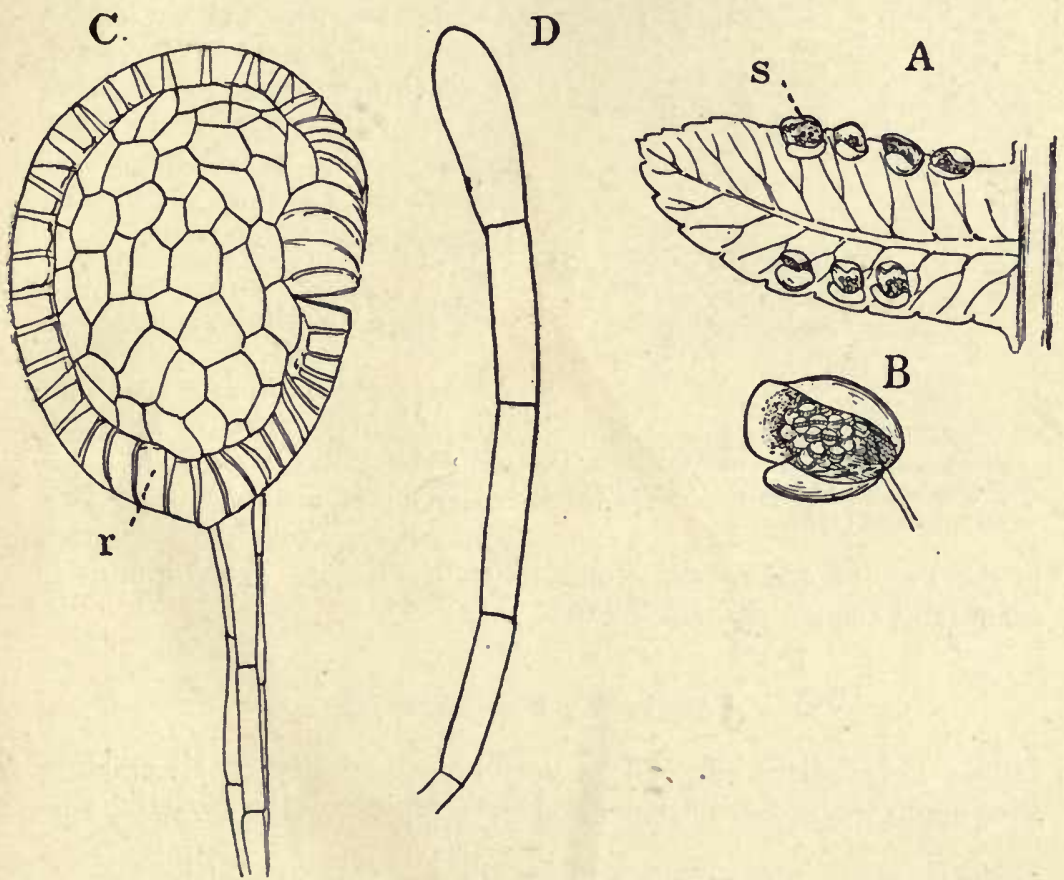

Fig. 246. - Cibotium Menziesii. A, pinnule with sori, $s(\times 3)$. B, sorus, with twovalved indusium $(\times 9)$. $C$, sporangium $(\times 80)$. $D$, paraphysis $(\times 80)$.

consist of a single layer only of green cells stretched between the veins. This gives the leaf the filmy texture of a Moss-leaf, and is the reason for their name.

Sporangium. - The sporangia (Fig. 245) are borne at the ends of the veins upon a receptacle which in Trichomanes becomes extremely elongated. The sorus is surrounded by a tubular or bilobed indusium. The sporangium has a broad, oblique annulus. The tetrahedral spores at maturity contain chlorophyll.

\section{Family 6. Cyatheaceæ}

The Cyatheaceæ are Tree-ferms which structurally closely resemble the Polypodiaceæ, from which they differ mainly in the oblique annulus of the sporangium and the cup-shaped indusium (Fig. 246). 
The gametophyte is much like that of the Polypodiaceæ, but very often develops upon its upper surface characteristic bristles.
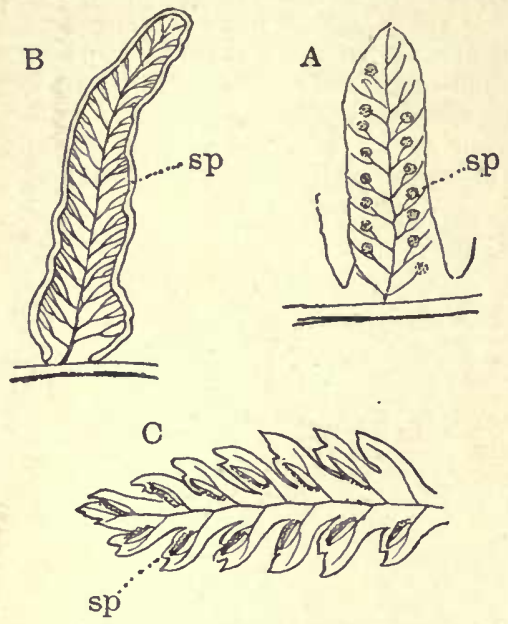

F.u. ' $2+\bar{i} .-A$, Polypodium falcatum.

Pinna with sori, $s p$; natural size. $B$, Pteridium aquilinum. $C$, Asplenium filix-fumina $(\times 3)$. in the Tropies, and reaching our limits in Florida. The annulus is sometimes completely suppressed.

\section{Family 8. Polypodiaceæ}

The Polypodiaceæ include a very large majority of all existing Pteridophytes, and are the most modern representatives of the sub-
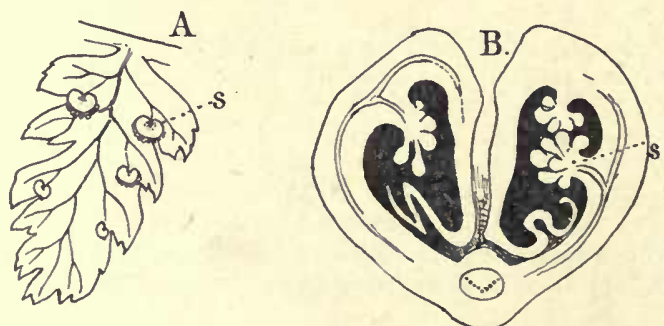

Fig. 248. $-A$, Aspidium spinulosum $\left(\times 2 \frac{1}{2}\right)$. B, Struthiopteris Germanica, crosssection of young fertile pinna $(\times 25) ; s$, sorus.

kingdom. The greater number of Ferns of cooler regions are Polypodiaceæ, and occasionally, as in the case of Pteridium aquilinum, 
they occur in numbers enough to be a conspicuous feature of the vegetation. The general characters of the family have already been discussed, and the family is an extremely natural one. The differences between the genera and species are of secondary importance, based upon the position of the sori, the character of the indusium, etc. (Figs. 247, 248). About one hundred and sixty species occur within the United States. 


\section{CHAPTER IX}

\section{PTERIDOPHYTA (Concluded)}

\section{ORDER HYDROPTERIDINEA}

There are two families of heterosporous Ferns, which although not closely related to each other, are evidently allied to the other leptosporangiate Ferns. These have been put together in the order Hydropteridineæ, or Water-ferns, as they are all aquatics.

They agree in the general characters of the sporangia, and in producing a single very large macrospore in each macrosporangium. The Hydropteridineæ fall into the two very natural families, Salviniaceæ and Marsiliaceæ.

\section{Family I. Salviniaceæ}

The Salviniaceæ are small floating plants which show very little superficial resemblance to the Filices, from which they have been derived. Their inner structure, however, and the development of

- the sporangium are very much like those of the typical Ferns. The character of the sporangium and its position suggest the Hymenophyllaceæ, to which the Salviniaceæ may possibly be remotely related.

There are two genera, Salvinia and Azolla. The former is represented in a few places in the United States by the European species, $S$. natans (Fig. 249, D, E), but there is some question whether it is really indigenous. Azolla is represented in the Atlantic states by $A$. Caroliniana, and on the Pacific coast by the larger $A$. filiculoides (Fig. 249), both species extending into South America. A third species, $A$. pinnata, has been introduced in some places, with the Japanese Lotus. The sporophyte in both genera has a slender horizontal stem, floating upon the surface of quiet water. Two or four rows of dorsal leaves quite conceal the stem. The dorsal leaves in Salvinia are oval; in Azolla, each leaf has two lobes, dorsal and ventral. Salvinia, which is quite destitute of roots, produces upon the ventral side of the stem two rows of leaves which are divided into many slender, rootlike segments, functionally replacing the true roots (Fig. 249, D, l). In Azolla roots are developed. In both genera more or less conspicuous hairs are found upon the leaves.

Lateral branches are freely produced, and by the detachment of 
these the plants often increase very rapidly, and completely cover the surface of the water over large areas.

Apical Growth. - The stem-apex is extended beyond the youngest leaves, in the form of a slender cone, which is bent upward in Azolla. It grows by an apical cell, from which two rows of segments are produced. Each segment divides into a dorsal and a ventral cell, so that a transverse section made just back of
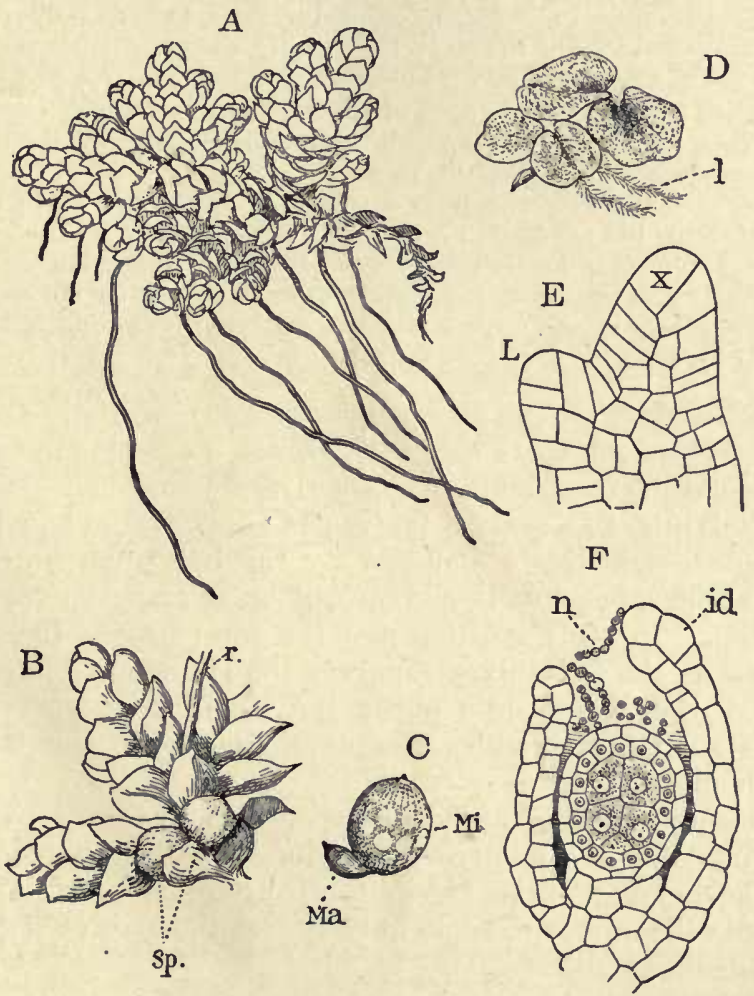

Fig. 249. $-A-C$, Azolla filiculoides. $A$, sporophyte $(\times 2) . B$, branch with two microsporangial sporocarps $(\times 6)$. $C$, macrosporangial, $m a$, and microsporangial, $m i$, sporocarps $(\times 10)$. D, $E$, Salvinia natans. $D$, small plant $(\times 2)$. $E$, horizontal section of stem-apex; $x$, apical cell; $L$, young leaf $(\times 400) . F$, Azolla filiculoides, section of young macrosporanginm enclosed in the indusium, $i d$; $n$, filaments of Anabæna $(\times 200)$.

the apex shows two dorsal and two ventral cells. From the former the dorsal leaves arise, from the latter the roots (or, in Salvinia, the ventral leaves) and the lateral branches.

The stem is traversed by an axial vascular bundle, like that of the stem in the Hymenophyllaceæ and Schizæaceæ. The bundle is typically concentric in structure. As in all aquatics, large air-spaces are developed, forming a series of longitudinal canals separated by thin plates of cells. 
The Leaf. - The leaves in Salvinia are arranged in alternating whorls of three, so that there are four rows of dorsal leaves and two of ventral ones. In both Salvinia and Azolla leafless segments alternate with leaf-bearing ones, thus dividing the stem into nodes and internodes.

The dorsal leaf in Salvinia is composed of large air-chambers, arranged in two layers. Between these are single layers of chlorophyll-bearing cells, which do not differ essentially from the epidermal cells. In Azolla the ventral lobe of each leaf consists of a single layer of cells, but the dorsal lobe is composed of elongated loosely placed mesophyll, bounded by the epidermis. There is always found in the dorsal lobe of the leaf a large cavity, communicating with the exterior, and containing a colony of blue-green Schizophytes (Anabcena azolloe). The Anabæna grows about the apex of the shoot, and a filament creeps into the cavity of each young leaf as soon as it is formed. Stomata are developed upon the upper epidermis of the leaf in Azolla.

The leaf in Salvinia grows from a two-sided apical cell, as in the typical Ferns, but this is not the case in Azolla.

Root. - The roots in Azolla arise from external cells, instead of endogenously. The first outer root cap-segment develops into a sheath, which encloses the root, and only one other cap-segment is formed. Otherwise the root is like that of the typical Ferns.

The Sporangium. - The sporangia (Fig. 249), which in their development correspond to those of the other Leptosporangiatæ, arise from special leaf-segments. The sori are borne upon the ventral leaf in Salvinia, and replace the ventral half of the leaf in Azolla. The sorus is completely enclosed by the indusium, which is cupshaped at first, but finally becomes globular and completely closed at the top. In their position and the form of the indusium, the sporangia of the Salviniaceæ suggest the Hymenophyllaceæ. The formation of the indusium about the single macrosporangium of Azolla strikingly resembles the development of the integument about an ovule.

The macrosporangia and microsporangia are in separate sori. The former are less numerous, and in Azolla reduced to a single one. The sporangia arise from a central receptacle, or placenta, and in Salvinia the microsporangia are borne at the ends of the divisions of a branching stalk.

The early divisions in all the sporangia are alike. From the central tetrahedral archesporium are cut off the tapetal cells, as in the typical Ferns, and the central cell then divides into eight, or in the microsporangium into sixteen sporogenous cells, all of which divide. In the microsporangium, all of the sixty-four young spores develop; in the macrosporangium, a single spore of one tetrad grows more rapidly than the others, and finally occupies the whole of the sporangium, destroying the other spores. The uucleated protoplasm derived from the disintegrated tapetum is not all used up in the development of the macrospore, but part of it persists in the form of the peculiar episporic appendages, which are especially conspicuous in Azolla (Fig. 251). In the microsporangia the spores do not nearly fill the cavity, but are imbedded in a foamy mass of hardened protoplasm, derived from the tapetum. This is divided into several parts, or "Massulæ," in Azolla, and upon the massulæ are developed curious anchorlike 
appendages, Glochidia (Fig. 250). The glochidia attach the massulæ to the episporic outgrowths of the macrospore, and thus facilitate fertilization, as the germinating microspores are thus kept near the macrospore.

The wall of the indusium (sporocarp) is composed of two layers of cells, which in Salvinia are partly separated by air-spaces. The absence of an annulus in the sporangia is to be explained by the aquatic nature of these plants.

In Azolla the infection of the plant by the Anabæna always associated with it, occurs while the macrosporangium is developing. The Anabæna filaments enter the young sporocarp and remain dor-
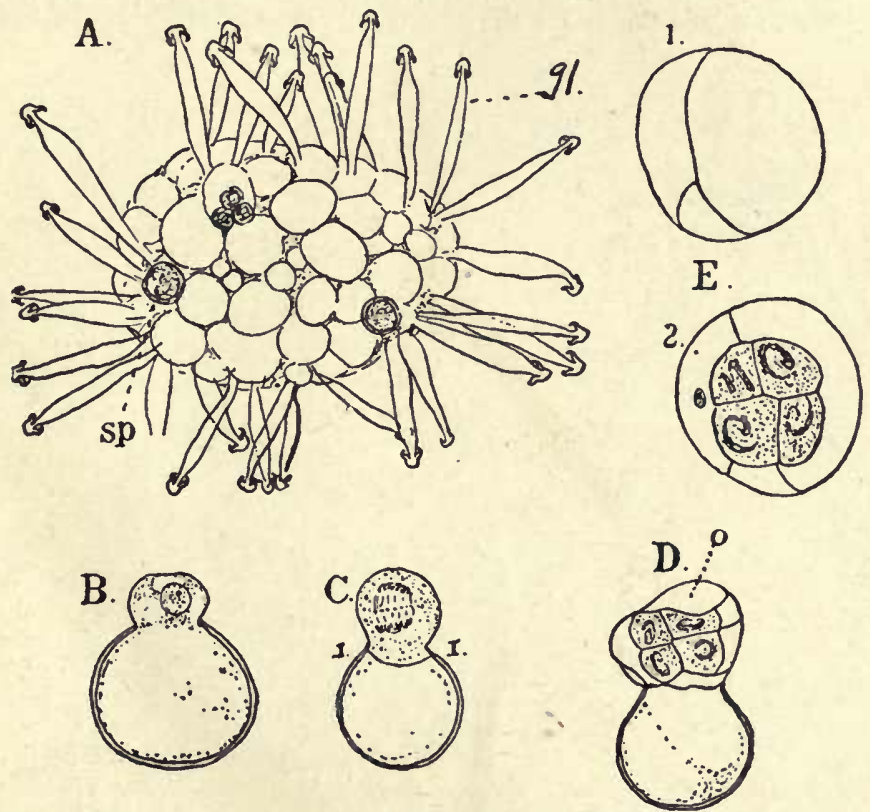

FIG. 250. - Azolla filiculoides. A, massula with enclosed microspores, $s p ; g l$, glochidia $(\times 250) . B-D$, development of male gametophyte $(\times 560) ; 0$, opercular cell. $E$, two cross-sections of an antheridium $(\times 750)$.

mant until the germination of the macrospore begins; and by the time the young sporophyte emerges from the gametophyte, the Anabæna is in condition to infect it.

\section{The Gametophyte}

The ripe sporocarps, with the enclosed sporangia, fall away from the sporophyte, and after a period of rest germinate. 'The spores are set free by the decay of the wall of the sporangium, and in Azolla the massulæ separate and soon attach themselves to the base of the macrospores. From each microspore a rudimentary prothallium is developed, consisting of a large basal cell, from which a smaller rhizoidal cell is later cut off, and a terminal cell, from which the 
antheridium is formed. The latter develops eight sperm-cells, which are in two groups, and are sometimes considered to represent two antheridia (Fig. 250). 'The spermatozoids are multiciliate, like those of the typical Ferns.

The ripe macrospore is a large oval cell, with a very thick outer wall (epispore), which in Azolla is curiously sculptured and provided with fine hairlike outgrowths, to which the glochidia become attached. In Azolla, also, the pointed apex of the indusium persists, and is only thrown off by the expansion of the growing gametophyte (Fig. 251). The spore is filled with dense granular cytoplasm, and the nucleus lies in its upper part. The first division of the nucleus is followed by a transverse wall, shutting off a small lenticular cell from the apex of the spore. This becomes the prothallium, the lower cell remaining undivided, and serving as a food-supply for the developing gametophyte. In Azolla, how- .
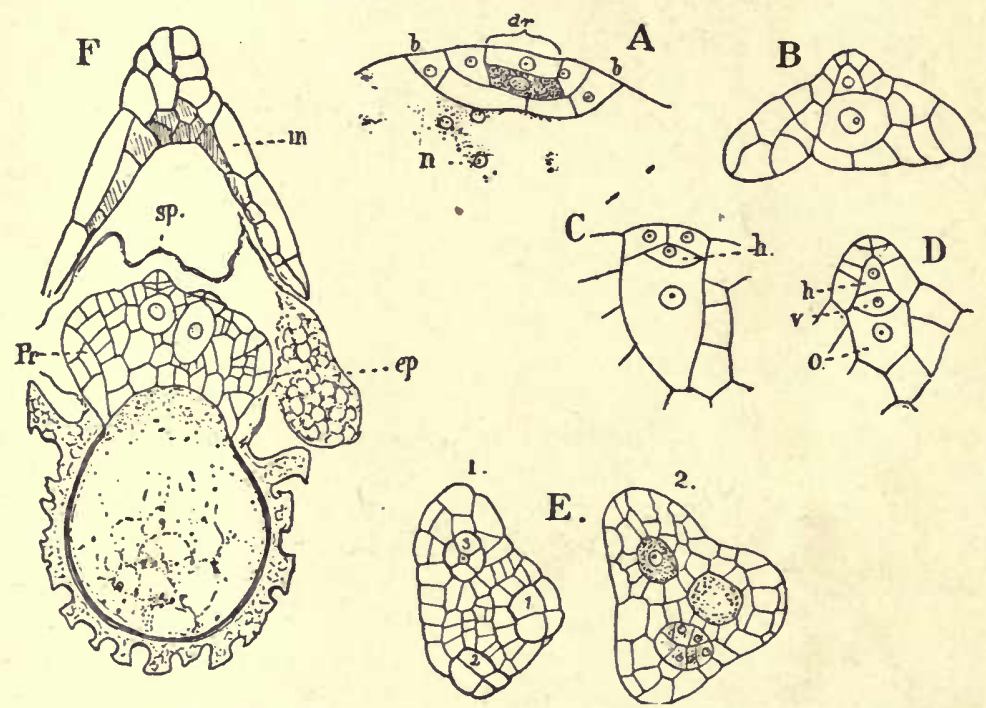

Fig. 251. - Azolla filiculoides. Female gametophyte and archegonium. $A, B$, longitudinal sections $(\times 220) . C, l$, archegonia $(\times 375)$. $E$, two transverse sections of gametophyte with three archegonia $(\times 220) . F$, section of macrospore and large prothallium $(\times 68)$; in, indusium.

ever, the nucleus of this large basal cell subsequently divides, but there is no cell-formation. It is not known whether this nuclear division also occurs in Salvinia.

The prothallial cell undergoes rapid divisions, and forms a projecting mass of tissue (Fig. 251), which develops chlorophyll. especially in Salvinia, where the gametophyte is much larger than in Azolla, and resembles more nearly that of the homosporous Ferns. The gametophyte is triangular in form, and in Salvinia two of the angles develop into large pendent lobes of green tissue. Several archegonia, much like those of the ordinary Ferns, are formed, the number being larger in Salvinia than in Azolla. The structure of the archegonium (Fig. 251, C, D) is much like that of the other Ferns.

Embryo. - The development of the embryo is much like that of the typical Leptosporangiatæ. It is still a question whether a primary root is indicated in 
the otherwise rootless Salvinia, but it is probable that such is the case, as in other respects the embryos of Salvinia and Azolla are much alike. The first leaf (cotyledon) is heart-shaped in Salvinia, funnel-form in Azolla, where it encloses the stem-apex and the younger leaves. The Anabæna filaments may be found about the apex of the young shoot, and as soon as the leaves develop the characteristic cavities, the Anabæna takes possession.

\section{Family 2. Marsiliaceæ}

The Marsiliaceæ also contain two genera, which are evidently related to each other, and differ less, so far as the sporophyte is con-

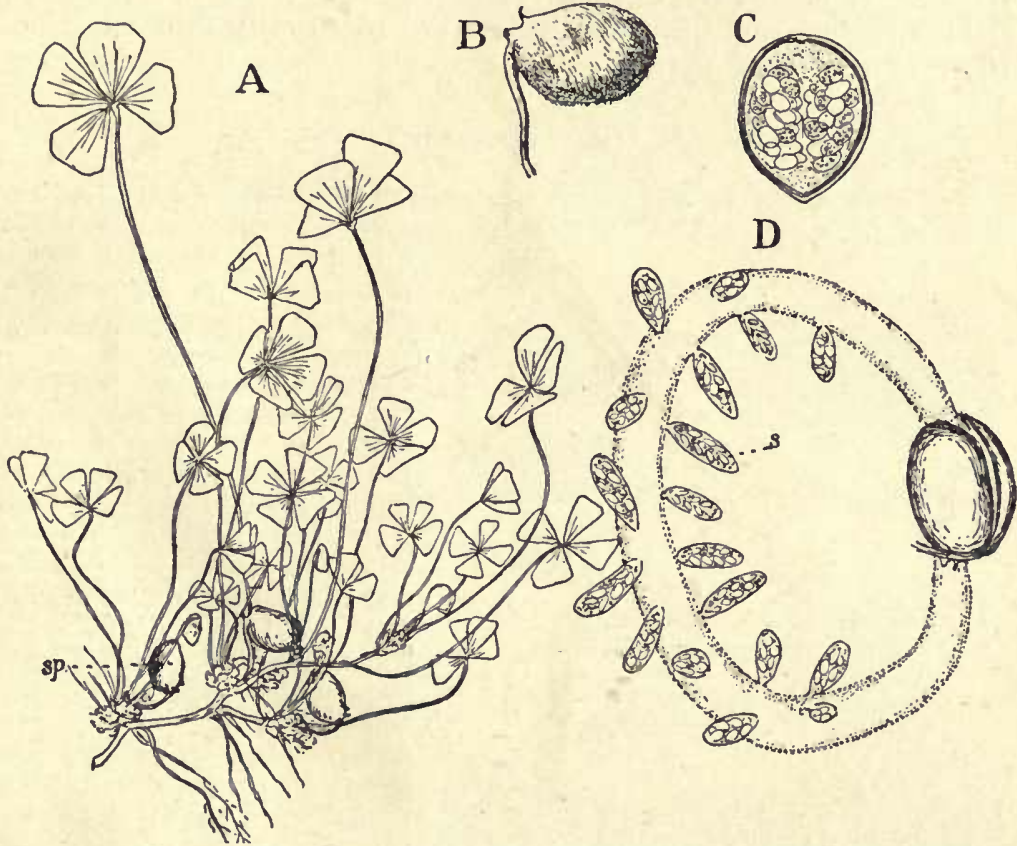

Fra. 252.- Marsilia vestita. $A$, fruiting sporophyte (natural size). $B$, sporocarp $(\times 4)$. $C$, cross-section of sporocarp $(\times 5)$. $D$, germination of sporocarp, the sori, $s$, attached to a gelatinous ring $(\times 3)$.

cerned, from the ordinary Ferns than do the Salviniaceæ. The two genera, Marsilia and Pilularia, are usually amphibious in habit, growing in the water during their early stages, but, at least in our species, ripening their spores after the water has subsided. The California species grow where they become completely dried up in summer, and in Marsilia vestita there are found buds, which probably survive the dry season, and thus make the plant perennial. The slender ereeping stem, and the position and coiled vernation of the young leaves, 
are very similar to the habit of the common Ferns. The apical growth of the stem and leaves, and their structure, are also very much like those of the true Ferns.

The prostrate stem is divided into nodes, which bear the lateral organs, leaves, roots, and branches, and between the nodes are slender, naked internodes (Fig. 252). The leaves are provided with a fourdivided lamina in Marsilia, but in Pilularia are slender, pointed structures, without any evident lamina. In Marsilia, the lamina is traversed by numerous dichotomously branched veins. The stem is monostelic, and the leaf-petiole has a single vascular bundle. The roots are produced freely from the ventral side of the nodes, and in their structure and development are not essentially different from those of the other Ferns.

\section{The Sporocarp}

The sporangia in the Marsiliaceæ are borne in peculiarly modified leaf-segments or sporocarps (Fig. 252, B, C), which are very different from those of the

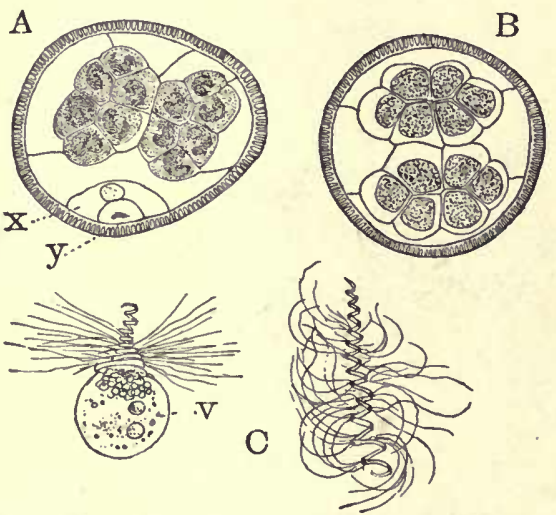

FIG. 253. - Marsilia vestita. A, longitudinal section of germinated microspore, showing two sterile cells, $x, y$, and the antheridium with two groups of sperm-cells $(\times 400), B$, transverse section of antheridium. $C$, two free spermatozoids $(\times 800)$.

Salviniaceæ. According to the recent studies of Johnson (21, $22)$, these are marginal in origin. Perhaps they may be most aptly compared to the modified sporangial leaf-segments of Aneimia, or Lygodium, with which the Marsiliaceæ show some evidences of affinity. The young sporocarp grows from a two-sided apical cell, and ultimately forms a globular (Pilularia) or bean-shaped (Marsilia) body. According to Johnson, the sporangia arise from marginal cells, as they do in the Schizæaceæ, but they are very early enclosed by the excessive growth of the outer tissue of the young sporocarp. There are four sori in the sporocarp of Pilularia, which is divided into four parts, perhaps corresponding to as many leaf-segments. In Marsilia the number is larger, and there are two series of sori, the ripe sporocarp splitting longitudinally.

Macrosporangia and microsporangia occur together, and in their earlier stages are alike. There are usually eight sporogenous cells, all of which give rise to microspores; but in the macrosporangium, as in the Salviniaceæ, but one spore reaches maturity. 'The epispore is thick, and composed of closely set prismatic elements. The outer episporic layers, as well as the sporangium-wall, and the tissues of the indusium and placenta, become mucilaginous, and swell up excessively when water is applied. The wall of the sporocarp is composed in Pilularia (Fig. 257) of three layers of cells, of which the middle one is extremely hard. If 


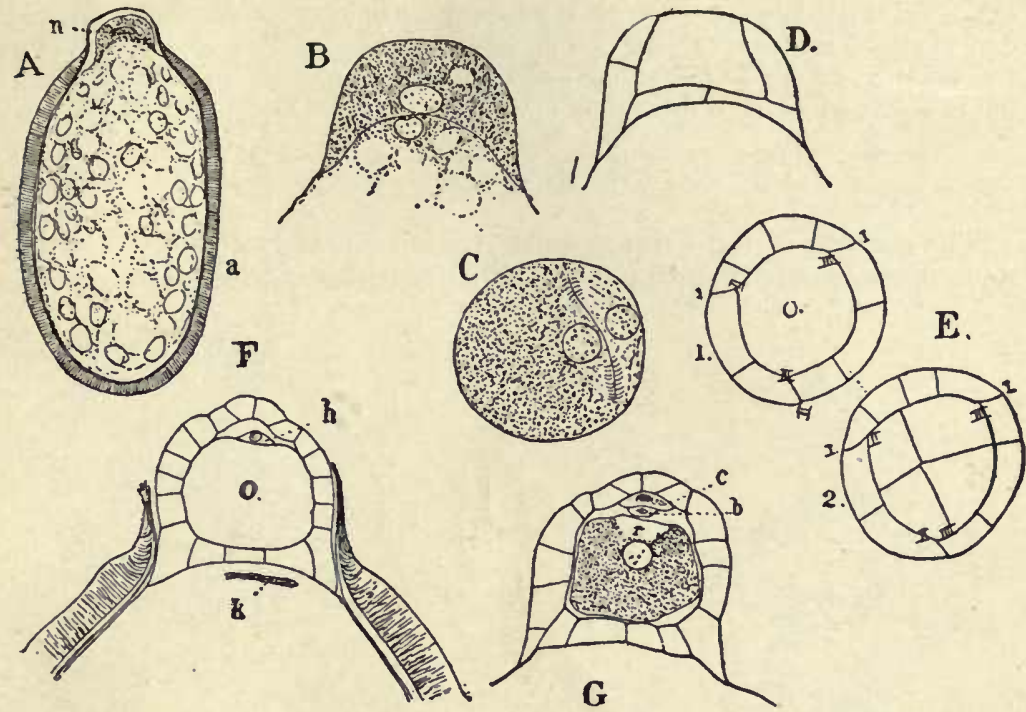

Fig. 254. - Marsilia vestita. Germination of the macrospore. A, longitudinal section of ripe macrospore $(\times 60) ; n$, nucleus. $B-G$, successive stages in the development of the archegonium $(\times 360) . C, E$, transverse sections. $c$, neck canal-cell; $b$, ventral canal-cell.

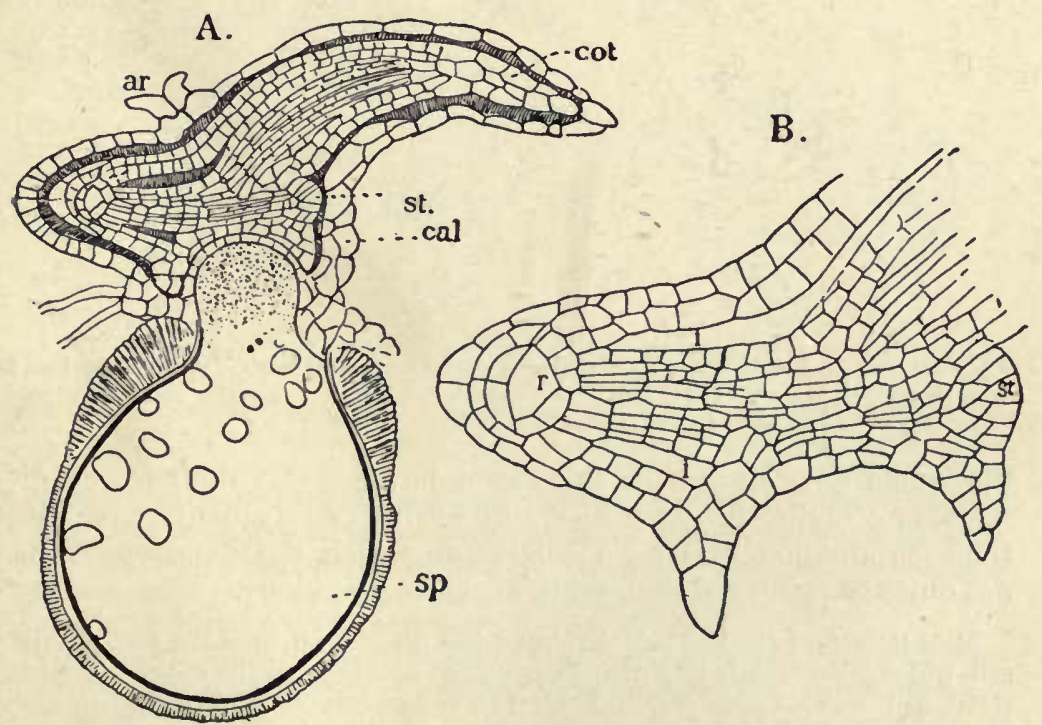

Frg. 255. - Pilularia globulifera. A, section of young sporophyte still enclosed in the calyptra, cal.; ar, neck of archegonium; cot, cotyledon; st, stem-apex; $s p$, macrospore $(\times 75)$. $B$, root, $r$, and stem-apex, st, of the same $(\times 215)$. 
this is cut through, so as to expose the inner mucilaginous tissue, and the sporocarp is placed in water, the swelling mucilage forces open the sporocarp and sets free the enclosed spores. The gelatinous mass has no definite shape in Pilularia, but in Marsilia it forms a thick ring, to which the sori are attached (Fig. 252, D).

\section{The Gametophyte}

The gametophyte in the Marsiliaceæ is extremely reduced, and its development may occupy but a few hours. Thus, in Marsilia vestita,
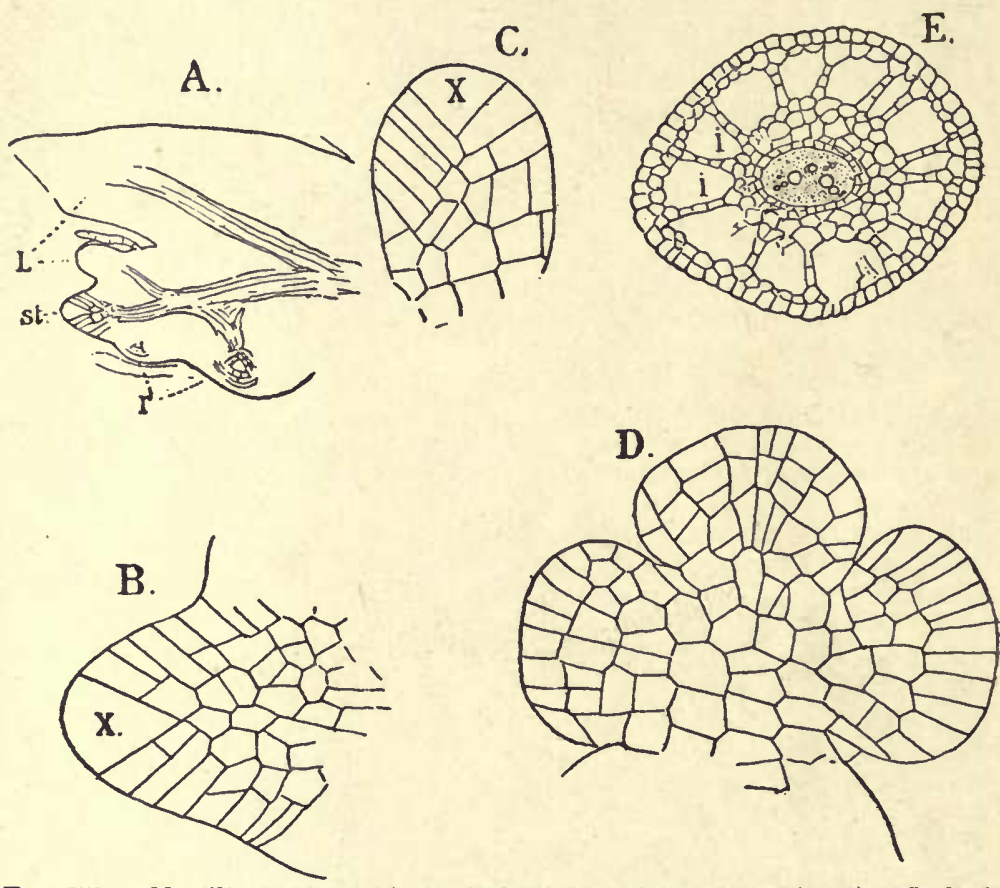

Fig. 256. - Marsilia vestita. A, vertical section of stem-apex $(\times 80) ; \quad L$, leaf; $r$, roots. $B$, stem-apex $(\times 450)$. $C$, young leaf $(\times 450)$. $D$, older leaf. $E$, crosssection of young stem $(\times 80)$. $x$, apical cell.

the whole development of the gametophyte, under ordinary conditions, is completed within about fifteen to twenty hours from the time germination begins. Pilularia, in which the gametophyte is not quite so much reduced, takes about twice as long.

Male Gametophyte. - The microspore has first cut off from it a small sterile cell, which subsequently may divide again (Fig. 253). From the upper, or antheridial, cell, a single large antheridium, with two groups of sixteen sperm-cells, is formed. Here, also, the two groups of sperm-cells are sometimes considered to represent two antheridia. The sterile cells and the wall-cells of the antheridium contain numerous starch-granules, which are also found abundantly in the 
macrospore. The spermatozoids are coiled, the coils being numerous in Marsilia, where all but the lower larger coils have been shown to be derived from the blepharoplast. The upperınost coils have no cilia.

Female Gametophyte. - The macrospore (Fig. 254) has the nucleus lying at the upper end, surrounded by cytoplasm, which is free from the large starchgrains found in the body of the spore. In Marsilia, the nucleus lies in a protuberance at the apex of the spore.

The first division in the spore usually, but not always, separates this papilla from the body of the spore, whose nucleus undergoes no further divisions. The

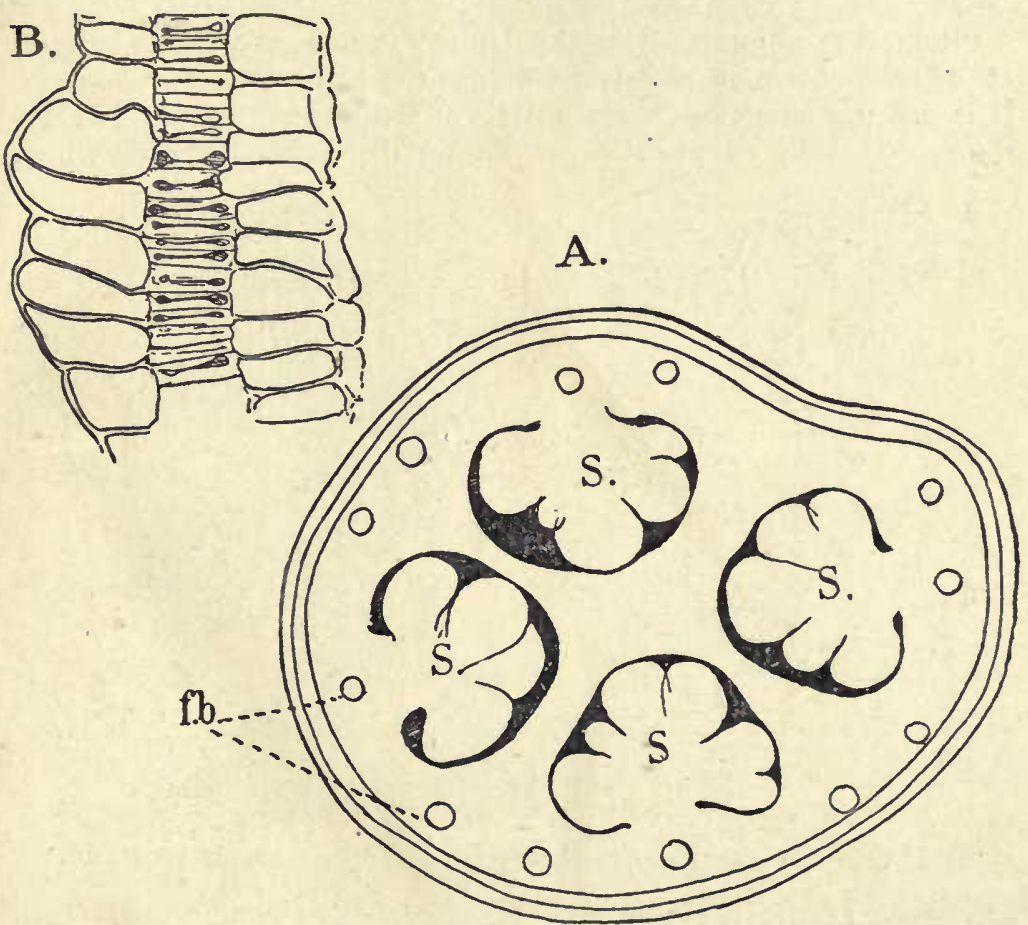

Fig. 257.- Pilularia Americana. A, cross-section of young sporocarp, showing four sori, $s ; f . b$, vascular bundles $(\times 85)$. $B$, wall of ripe sporocarp $(\times 255)$.

upper cell rapidly divides, and the single archegonium is soon complete. It has a very short neck, and the neck canal-cell does not divide further, but otherwise it is like the typical Fern archegonium. The spermatozoids collect in great numbers about the macrospores, and sometimes completely choke the funnelshaped space in the mucilage above the open archegonium.

In case fertilization is prevented, the prothallial tissue may continue to grow for some time, and develops chlorophyll, which, in Pilularia, may be formed in the absence of light.

It has recently been shown that occasionally the embryo may develop without fertilization - one of the very few certain cases of parthenogenesis in the higher plants. 


\section{The Embryo}

The first division in the embryo of Marsilia is completed within about one hour after fertilization. The divisions in the embryo and the development of the organs correspond in all respects with that of the typical Ferns. The cotyledon has no lamina, this being developed gradually in Marsilia, but remaining undeveloped in Pilularia.

\section{Distribution and Affinities of Marsiliaceæ}

Pilularia is represented in the United States by a single species, $P$. Americana, which closely resembles the European $P$. globulifera. It is not uncommon in various parts of California. Marsilia is represented within our territory by a number of species, of which
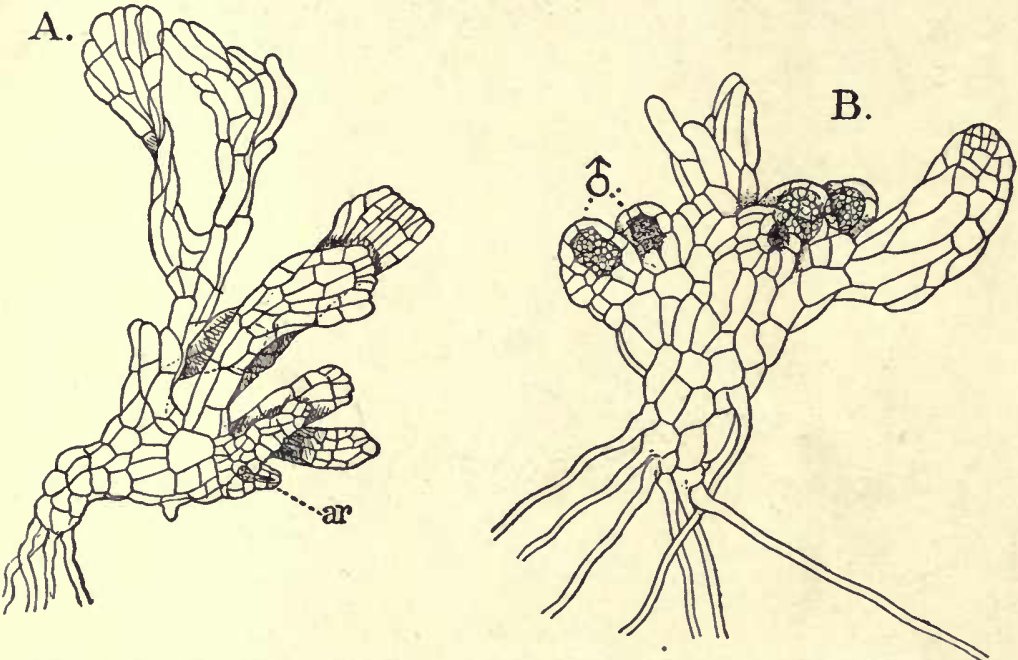

FIG. 258. - Equisetum telmateia. A, female; $B$, male, gametophyte $(\times 70)$.

$\boldsymbol{M}$. vestita is the best known. M. quadrifolia, which occurs in a number of localities in the Eastern states, may have been introduced from Europe.

The gametophyte of Pilularia is less reduced than that of Marsilia, but the sporophyte of the latter is probably more like that of the true Ferns. Of these, probably the Schizæaceæ are the nearest existing relatives of the Marsiliaceæ.

\section{Class II. Equisetales}

The second class of Pteridophytes, the Equisetales, is at present represented by a single genus, Equisetum, with twenty-four species, of which fourteen occur within the United States. The habit of 
the sporophyte is most characteristic, the hollow, jointed shoots and rudimentary leaves presenting a marked contrast to the Ferns. The sporophylls are always arranged in a cone at the apex of the shoot, and the globular green spores, which germinate at once, are provided with hygroscopic appendages, or elaters.

\section{The Gametophyte}

The germination of the spores begins within a few hours, and within twentyfour hours the root-hair is cut off from the larger prothallial cell. The latter shows more or less irregularity in its development, and the gametophyte shows more variation in its growth than is usually the case in the Ferns. Sometimes, but not always, a definite apical cell can be found in the young gametophyte. The older

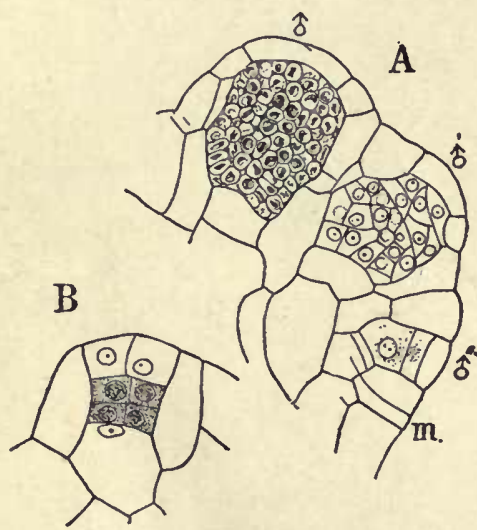

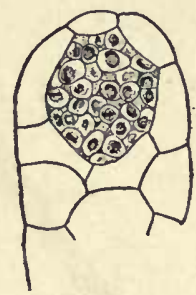
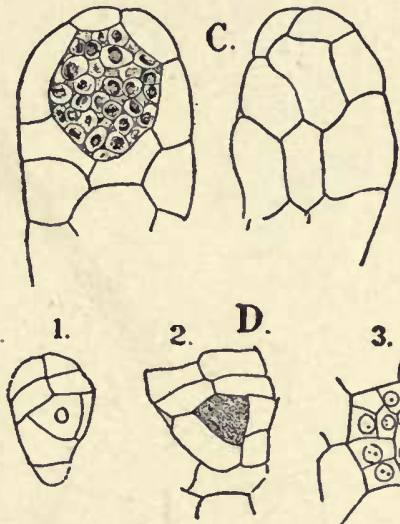

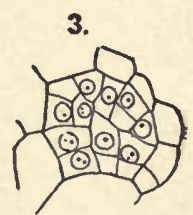

Fig. 259. - Equisetum telmateia. Antheridium. A, section of antheridial meristem, with three antheridia of different ages $(\times 190)$. $B$, young antheridium $(\times 375)$. $C$, two longitudinal sections of a nearly ripe antheridium $(\times 190)$. $D$, three transverse sections of young antheridium $(\times 190) ; o$, opercular cell.

gametophyte (Fig. 258) is an irregularly branched, green plant, not unlike the gametophyte of some of the lower Ferns, or the thallus of some Liverworts. When fully grown, it generally shows an axial, fleshy body, with numerous irregular leaflike lateral lobes. There is an apical meristem, which gives rise to several short dichotomous shoots. The prothallia are usually diøcious, the male plants being generally smaller and more irregular in shape than the female. The sex of the prothallium is largely a matter of nutrition, the better nourished ones being usually female, the others male. It has been demonstrated that a prothallium which has already developed archegonia can, by insufficient feeding, be forced to develop antheridia.

Antheridium. - The antheridia are first formed within a month or six weeks after the spores are sown. They develop either upon the lateral branches or they may (in E. telmateia) be formed upon an apical meristem in much the same way as the archegonia are. In their development they correspond very closely to those of the Marattiaceæ, and, like the latter, there may be present a triangular opercular cell. In the development of the large, multiciliate spermato- 
zoids, the presence of a blepharoplast, from which the cilia are derived, has been demonstrated.

Archegonium. - The archegonium is formed upon the lower side of the apical meristem, much as in the Ferns ; but each archegonium is formed in connection with a lobe which grows out on one side of the apex of the gametophyte, and grows for some time from an apical cell. The young archegonium appears near the base of this, and is pushed over to the upper side of the prothallium by the growth of the adjacent tissue. Each archegonium thus lies between two lobes,
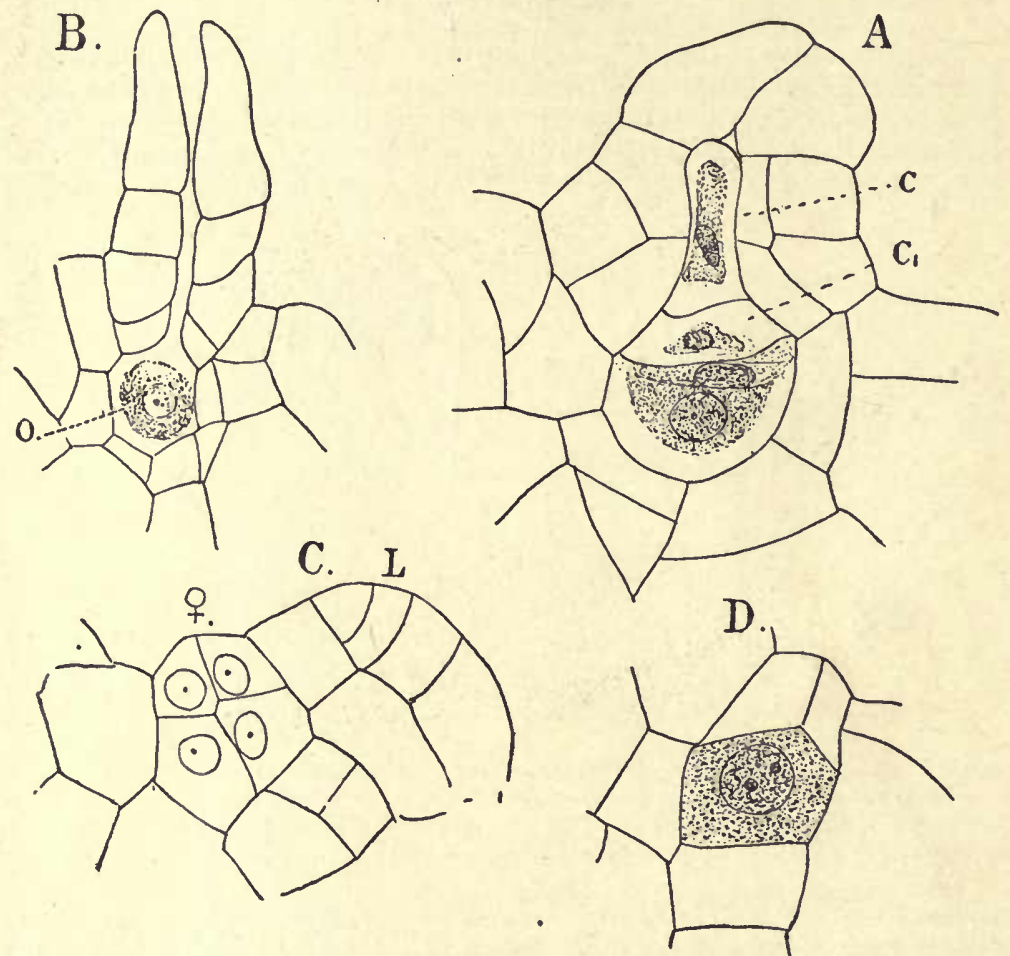

Fig. 260.-Equisetum telmateia. Archegonium. A, section of nearly ripe archegonium, with two neck canal-cells. $B$, section of open archegonium $(\times 275)$. $C, D$, two cross-sections of a young archegonium $(\times 550) ; L$, lobe.

its own and that of the next younger archegonium. In its structure it closely resembles that of the Ferns. The terminal cells, however, are longer, and when it opens these bend outward. There are usually two distinct neck canal-cells.

\section{The Embryo}

As in the eusporangiate Ferns, the primary, or basal, wall of the embryo (Fig. 261 ) is transverse. The next divisions, which are somewhat oblique, divide the stem and first leaf in the upper (epibasal) part, while in the hypobasal half the root is separated from the foot.

The larger of the two epibasal cells becomes at once the apical cell of the 
shoot. From it are soon cut off two lateral segments, which with the primary leaf-segment give rise to the first whorl of three leaves surrounding the base of the young shoot. From this time on the apical cell of the young shoot grows in the same way as that of the shoots in the mature sporophyte. The root behaves like that of the Fern embryo, and growing vertically downward, penetrates the gametophyte, and enters the earth. The young sporophyte is thus completely surrounded by the gametophyte, like that of the Marattiaceæ. According to Jeffrey (20), the root in E. hiemale seems to arise from the epibasal half of the embryo, but this is not certain.

The growth of the primary shoot is limited. After it has formed about a dozen whorls of leaves, which are almost always in threes, its growth stops, and

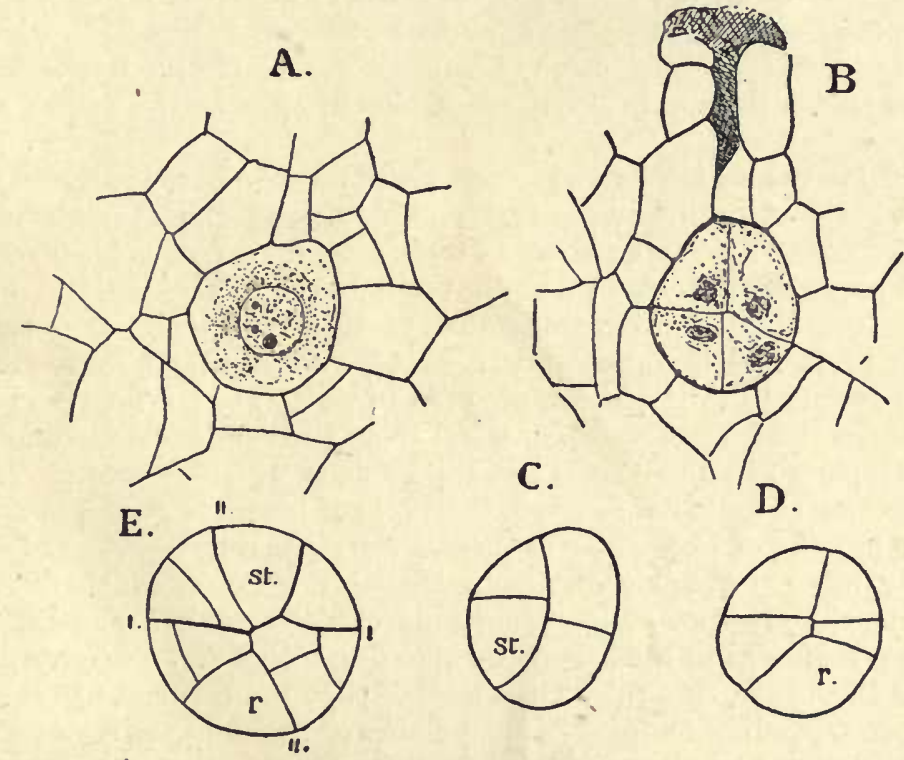

Fia. 261. - Equisetum telmateia. Development of embryo. A, venter of recently fertilized archegonium $(\times 300) . B$, young embryo. $C, D$, two cross-sections of a young embryo. $E$, longitudinal section of an older one. $r$, root; st, stem.

its place is taken by a lateral shoot, which develops from a bud formed at the base of the shoot near the point of junction with the primary root. This second shoot, which grows to be somewhat larger than the primary one, and usually has four-toothed foliar sheaths, is soon replaced by a tertiary shoot formed from a basal bud in the same way. This is repeated until a cluster of slender shoots is formed, when finally a bud is formed at the base of one of them, which grows horizontally into the earth, and forms the rhizome, or underground stem, found in the older sporophyte.

\section{THE MATURE SPOROPHYTE}

The rhizome, or underground stem, found in all species of Equisetum, shows the same division into nodes and internodes which is found in the primary shoot. Surrounding the nodes are the leaf- 
sheaths, in whose axils are formed buds, which may later develop into aerial shoots, or may remain undeveloped and give rise to the roots. Not infrequently some of the buds develop into thickened tubers, with hard outer tissues, and the inner cells filled with starch (Fig. 262). A section of an internode of the rhizome shows a large central cavity, and a circle of smaller ones corresponding to the furrows upon the surface of the internode. Alternating with these are the small vascular bundles.

Some of the buds at the nodes develop into the aerial shoots. These may be all alike - e.g. E. robustum, E. hiemale; or there may be special sporogenous shoots, as in E. telmateia (Fig. 262), which are followed by very much branched, green, sterile ones. The sporogenous shoots, in such cases, die as soon as the spores are scattered.

The internodes are strongly furrowed, and the nodes concealed by the whorls of rudimentary leaves, which form the characteristic toothed sheaths. The number of leaves in a whorl ranges from three in E. scirpoides to forty or more in some of the larger species. The leaves are almost entirely destitute of chlorophyll, and are exclusively protective in function. In size the aerial shoots range from about twenty to thirty centimetres (E. scirpoides) to ten metres in $E$. giganteum, which has a slender stem, about two centimetres in diameter, supported by the bushes and trees among which it grows. The shoots may be quite unbranched, or whorls of branches corresponding to the number of leaves may be formed about the internodes, as in the sterile shoots of E. telmateia. The epidermis in all species is characterized by the presence of large amounts of silica, which renders the surface rough, as in the common "Scouring-rush," $E$. hiemale. The aerial shoots are, as a rule, much thicker than the rhizome, and there is a corresponding increase in the number of leaves at the nodes, and in the vascular bundles and lacunæ in the section.

Apical Growth. - The apex of the growing shoot is terminated by a very large tetrahedral apical cell whose divisions are extremely regular (Fig. 263). The first division-wall in each segment is parallel to the lateral face of the apical cell, so that there are formed two superimposed semisegments, each of which next divides by nearly radial walls, and in cross-section each series of segments shows six cells arranged like the sextants of a circle. Of the two superimposed sets of sextant cells, the upper series gives rise to the nodes, the lower to the internodes. Early periclinal divisions in the young segments separate a central cylinder of tissue, the pith, from the outer cortical region. The pith becomes destroyed in the internodes by subsequent tearing apart of the tissue, leaving the large central cavity found in most species. The central tissue of the nodes remains intact, and there is thus formed a series of diaphragms between the cavities of the internodes.

The leaf-sheaths arise as annular outgrowths of the nodes. The initial cells of the separate teeth arise at regular intervals from the margin of the young sheath. These initial cells divide rapidly by alternate dorsal and ventral walls, and the 


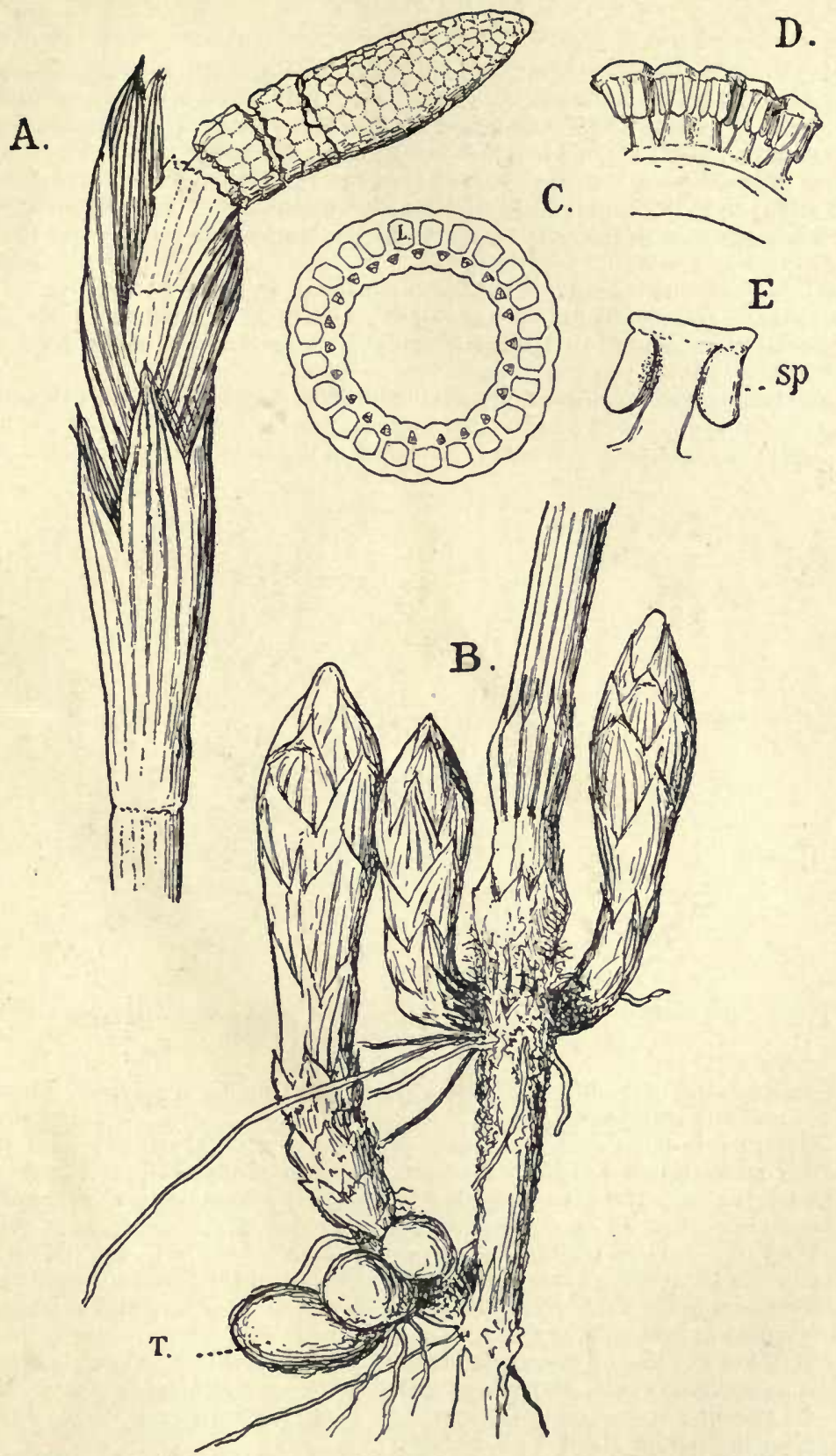

Frg. 262. - Equisetum telmateia. A, upper part of fertile shoot $(\times 1) . \quad B$, part of rhizome with lateral shoots; $T$, tubers. $C$, cross-section of an internode $(\times 4)$; $L$, cortical lacunæ. $D$, sporophylls $(\times 4)$. $E$, single sporoplyyll $(\times 6): " l$, sporangium. 
teeth soon become very evident, and the margin of the young sheatl has a scalloped outline. The number of the primary teeth may be subsequently increased by dichotomy of the apex. Occupying the axis of each tooth is a strand of elongated cells, which develops into a vascular bundle bending downward into the stem, where it joins a zone of narrow cells (procambium) immediately outside the pitl, and in the procambial zone the stem-bundles are later differentiated. The first permanent elements to appear in the bundles are several small spiral tracheids which arise upon its inner side.

All of the tissue elements in the nodes remain short, and a certain amount of active tissue (cambium) has been shown to persist in $E$. telmateia, and possibly is present in some other large species, so that a limited increase in the diameter of the stem is possible.

The bundles run downward through the internodes and divide into two equal parts at the node. Each branch joins a similar one for the neighboring bundle, so that in any interuode a bundle is composed of the fusion of two branches for

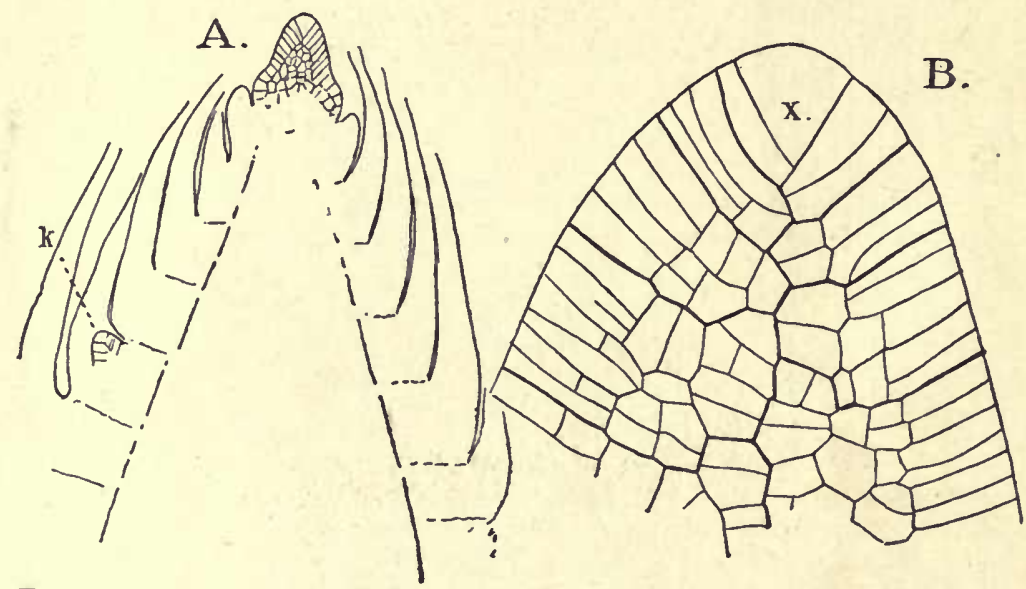

FIG. 263. - Equisetum telmateia. A, section of a strong vegetative bud $(\times 30)$; $k$, lateral bud. $B$, stem-apex $(\times 200)$.

separate bundles of the internode upon it, and the bundles in succeeding internodes alternate with each other.

The structure of the completed bundle is collateral, with the xylem inward, the phloem outward, like that of the Seed-plants, especially suggesting that of many Monocotyledons. The primary tracheids are usually completely destroyed by the development of an air-chamber on the inner side of the bundle (Fig. 264). A group of secondary tracheids is formed on each side of this, but the other xylem-elements remain unchanged. The outer part of the bundle, the phloem, contains sieve-tubes not unlike those of the Ferns, and there may also be present thick-walled fibrous cells.

Outside of the ring of vascular bundles there is present in E. telmateia a continuous endodermis (Fig. 264), and in other species - e.g. E. hiemale - there may also be present a second inner endodermis. Less frequently each bundle has a complete endodermis about it (E. limosum).

The green assimilative tissue is confined to the stems, especially to the slender secondary branches. In the main shoots the green tissue, in transverse section, 
appears as a series of separate masses of cells, separated by groups of thickwalled sclerenchyma, continuous with the hypoderma. 'This sclerenchyma constitutes the chief mechanical tissue ("Stereome") of the shoot, and is especially developed in the longitudinal ridges so conspicuous upon the surface of the shoot. 'The green tissue lies beneath the furrows between the ridges, and communicates with the stomata, which are arranged in vertical rows in the furrows. In the slender lateral branches the amount of green tissue is relatively much greater.

The epidermal cells are heavily incrusted with silica, which usually forms conspicuous tubercles upon its surface. Upon the inner surface the guard cells of the peculiar stomata have conspicuous transverse bars. 'The stomata themselves are usually sunk below the level of the other epidermal cells, and completely covered by two accessory cells of much the same form as the true guard cells.

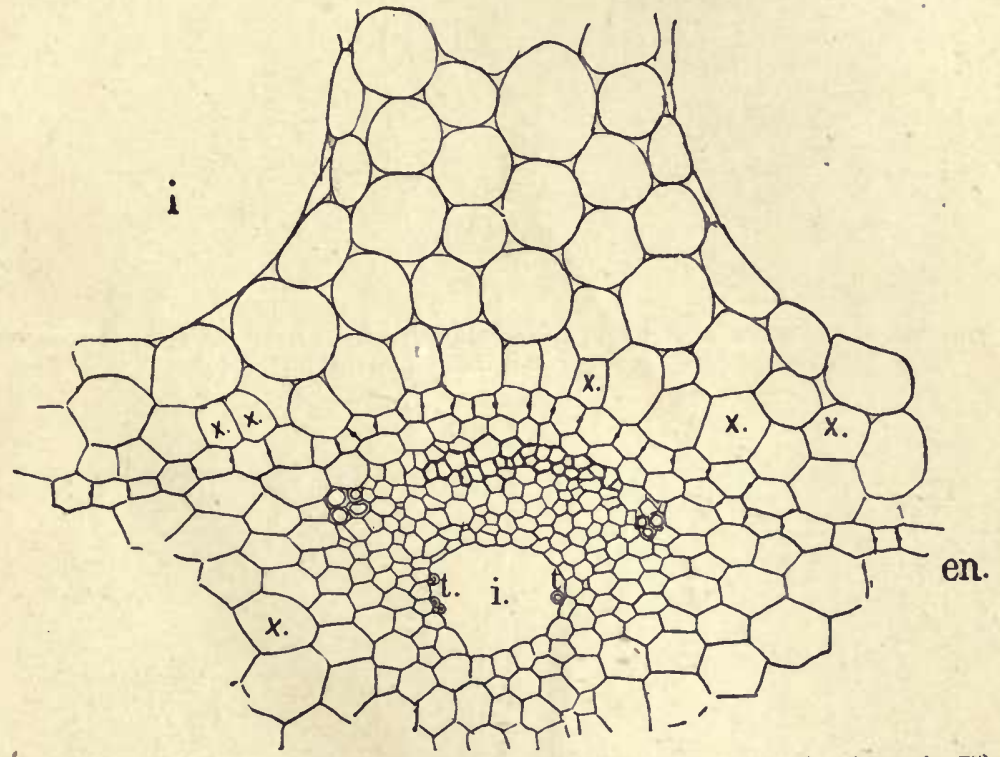

Fra. 264. - Equisetum telmateia. Vascular bundle from a sterile shoot $(\times 75)$; $i, i$, lacunæ; $x, x$, tannin-cells; $t$, remains of the primary tracheæ; en, endodermis.

The branches arise as axillary buds, one corresponding to each tooth of a foliar sheath. The bud originates from a single superficial cell of the stem, in which intersecting walls cut out the characteristic tetrahedral apical cell. At an early period, the inner surface of the leaf-sheath, above the bud, becomes grown to the surface of the stem, and the young bud is thus enclosed in a cavity, and has to break through the base of the foliar sheath, so that it looks as if, like the roots, it arose endogenously. The buds often remain undeveloped, but may be stimulated into growth under suitable conditions. Occasionally - e.g. E. sylvaticum - the branches may give rise to secondary branchlets. 


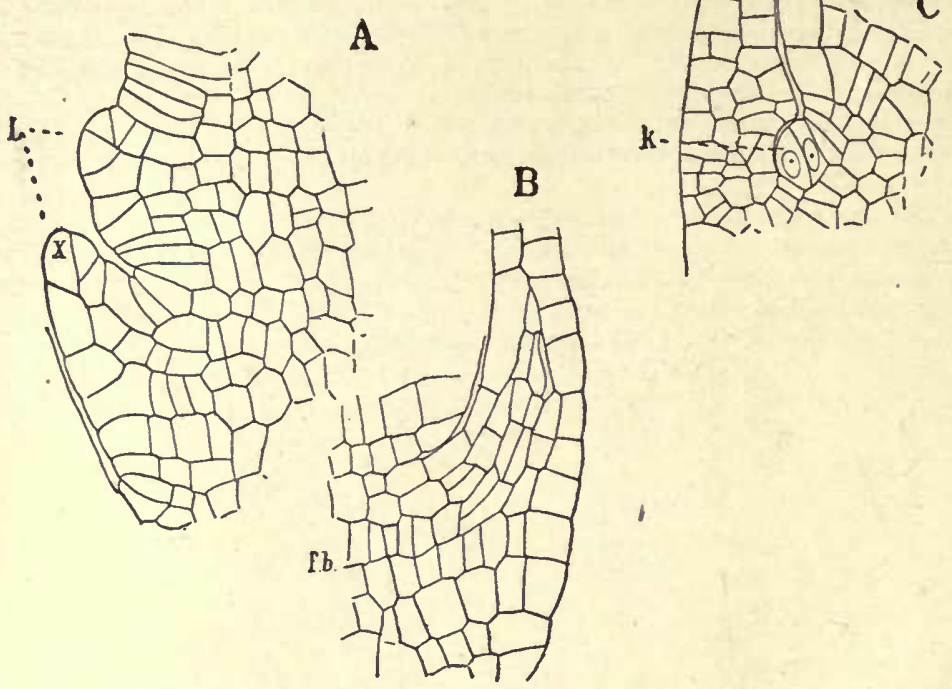

FIG. 265. - Equisetum telmateia. Longitudinal sections near the apex of a sterile shoot, showing young leaves, $L$, and lateral bud, $k(\times 200)$.
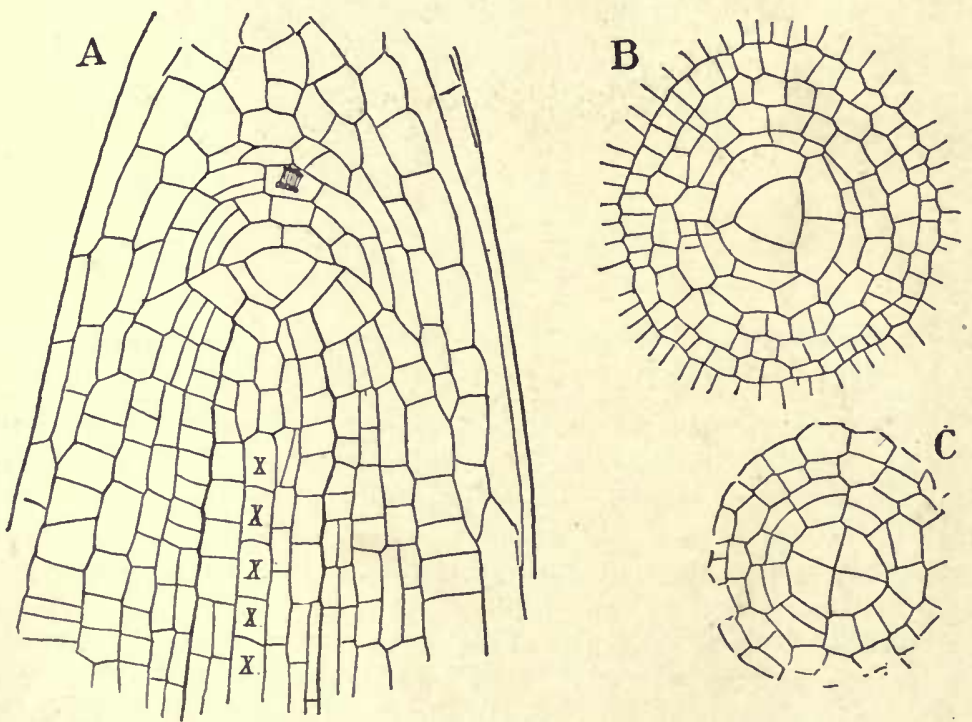

Fra. 266. - Equisetum telmateia. A, longitudinal section of root-apex $(\times 200)$; $x, x$, central vessel of the vaseular bundle. $B, C^{\prime}$, two transverse sections through the apex. $C$ shows the first division in the root-cap. 


\section{The Root}

The roots arise from the lowest nodes of the buds, but do not usually develop except from the buds formed upon the rhizome. The dormant roots of the aerial shoots may, however, be forced into growth under special conditions of light and moisture.

The origin of the roots and their development follow very closely those of the typical Ferns (Fig. 266). The root-cap is somewhat more massive and the stratification not so evident as in most Ferns. The root-bundle in $E$. telmateia is triarch or tetrarch, with a single very large vessel occupying the centre. The

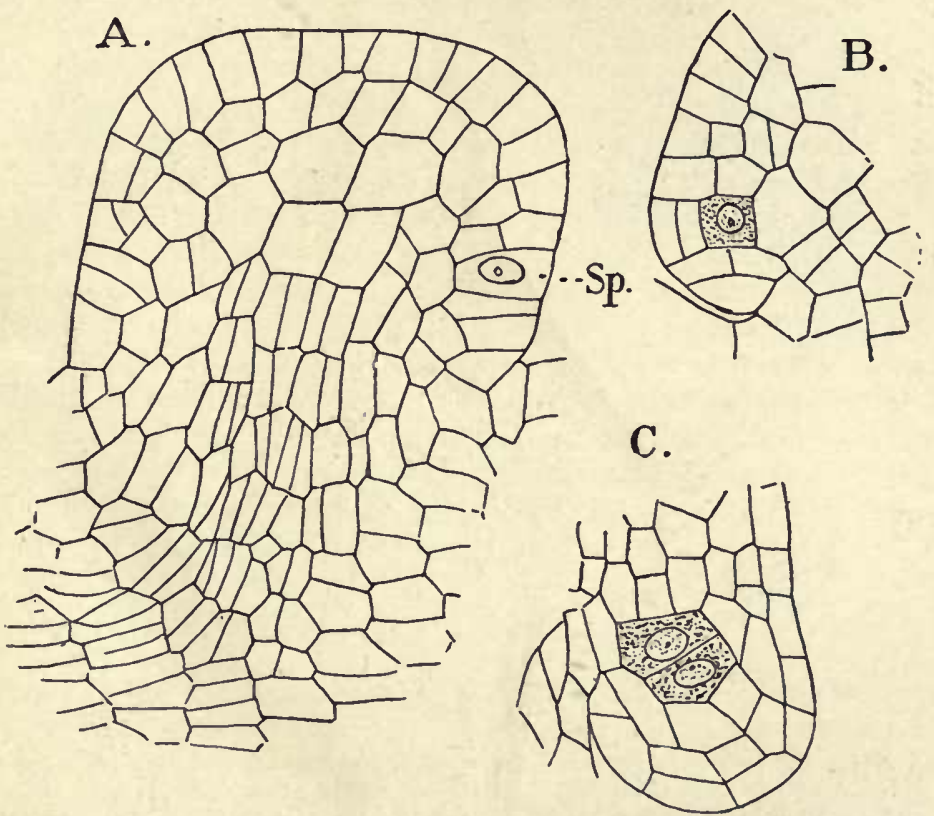

FIG. 267. - Equisetum telmateia. A, young sporophyll with primary sporangial cell, $s p(\times 260) . B, C$, sections of young sporangia; the archesporium is shaded.

endodermis is double, and no pericycle is developed. The secondary roots arise from the inner endodermis, and there is a double row of these corresponding to each xylem-mass. The endodermal cell outside of the root-rudiment also grows and divides for a time, forming a "digestive pouch" enclosing the young root.

\section{The Sporangium}

The sporangia are borne upon umbrella-shaped sporophylls, which are arranged in close circles, forming a cone at the top of the fertile shoot, and represent as many foliar sheaths. The young sporophyll (Fig. 267) is a nearly hemispherical body, which soon assumes a mushroom form. The sporangia arise 
along its lower margin, and sometimes a single larger cell may be seen, to which possibly may be referred all the cells of the older sporangium, but this is not always certainly the case. The primary cell divides into an inner and an outer cell, the former giving rise to the greater part, at least, of the sporogenous tissue. From the outer one is developed the tapetum and the outer sporangium wall.

The sporangium increases rapidly in size, and forms an oblong sac, pendent from the lower margin of the peltate sporophyll. The sporogenous cells are very numerous, but the limits of the sporogenous tissue are not readily determined, and a large number of the cells become broken down without forming spores.
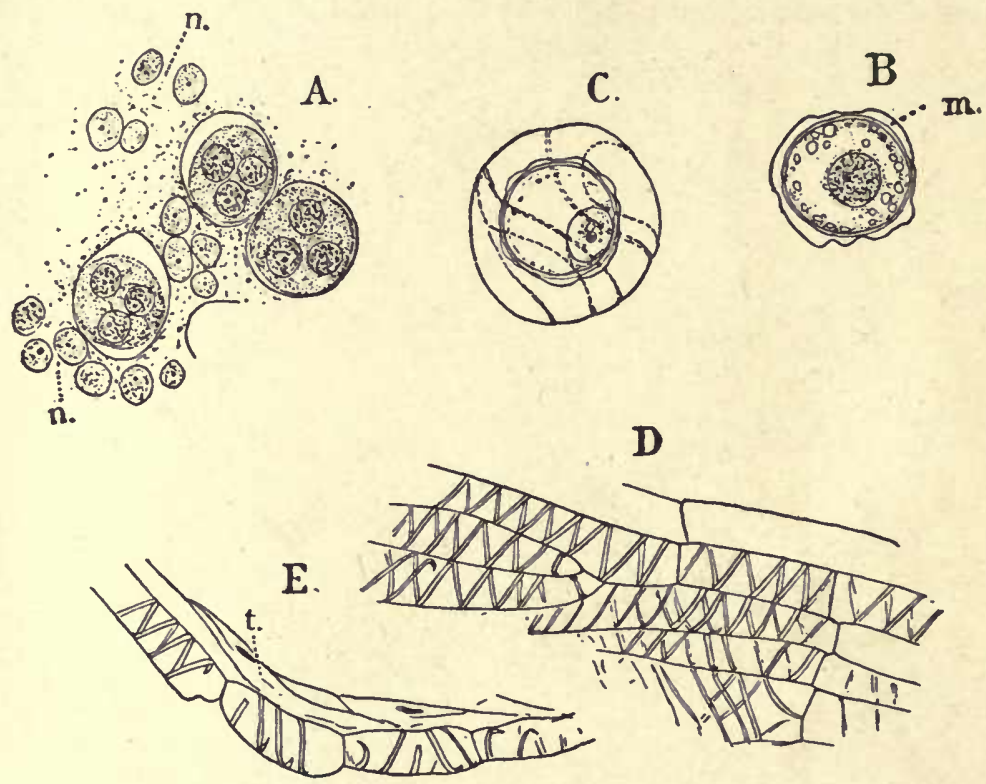

FIG. 268. - Equisetum telmateia. A, group of sporogenous cells, just before the fiual division of the spores, imbedded in the nucleated protoplasm derived from the disintegrated tapetum, and sterile archesporial cells $(\times 500) . \quad B$, optical section of young spore, showing the three membranes; $m$, the middle lamella $(\times 500) . \quad C$, an older spore, showing the formation of the elaters $(\times 500) . D$, surface view. $E$, section of the wall of a ripe sporangium $(\times 250)$.

The sporogenous cells, before their final division, separate into small groups, which are surrounded by a mass of nucleated protoplasm, derived partly from the tapetum, partly from the sterile sporogenous tissue. The sporogenous cells finally separate completely, and each divides into four spores in the usual manner (Fig. 268). 'The ripe spores have the outer spore-coat split into four strips, elaters, which are exceedingly hygroscopic, and by their pressure, as the sporangium dries, they help to force it open. The elaters, when moist, coil up tightly about the globular spore, but spread out when they are dry, and by their movements probably aid in distributing them. The ripe spore contains numerous crowded chloroplasts. 
The ripe sporangia open by a ventral cleft. The dehiscence is caused, in part, by the contraction of the cells which form its outer wall (Fig. 268). These cells develop upon their walls spiral thickenings like those upon the walls of the tracheids. The expansion of the elaters also contributes to the opening of the sporangium.

\section{Classification and Distribution}

The existing species of Equisetales are all referable to a single order, Equisetaceæ, with one genus, Equisetum, which is represented in all parts of the world except Australia. From a study of the fossil Equisetales, it is clear that many of these were much larger and more specialized than their living descendants. These specialized types may be referred to a well-defined order, Calamarieæ, the best known being the species of Calamites, which differed from the Equisetaceæ in being much larger and showing a secondary thickening of the stems, now merely hinted at in such species as $E$. telmateia. The leaves of some of these fossils have been described under the name Anuularia, and the best known of their fructifications belong to the type known as Calamostachys. These fossil Equisetales have in many cases been preserved so perfectly that their internal structure is readily made out. The earliest forms appeared in the Devonian, and they reached their maximum during the Carboniferous, declining rapidly in importance in the later formations. Heterospory has been demonstrated for some of them, but it never was as well developed as in the Ferns and Lycopods.

\section{Class III. Lycopodiales}

The existing Lycopodiales, or Club-mosses, are intermediate in number of species between the Equisetales and Ferns. About 450 species have been described. The great majority are tropical, but several species of Lycopodium and Selaginella are common plants in the cooler parts of the earth.

The gametophyte is now well known in several species of Lycopodium and Selaginella, and possibly in Psilotum, but is quite unknown in the other genera. Of special importance are the investigations of Treub, Goebel, and Bruchmann (13) upon Lycopodium.

The sporophyte of all the existing species is of moderate size, never exceeding a few metres in length and commonly is much smaller. It usually consists of a creeping stem, with upright, leafy shoots, but in some of the larger tropical species of Selaginella the long, half-climbing stem is supported by other plants. Many tropical forms are also epiphytes, and may have the roots absent (Psilotum). The existing Lycopodiales may be divided into three orders: 
Lycopodiineæ, Psilotineæ, Selaginellineæ. The two first are homosporous, the latter heterosporous.

\section{Order I. LyCOPODIINEE}

The Lycopodiineæ include about one hundred species, all of which, except the peculiar Phylloglossum Drummondii of Australia, belong to the genus Lycopodium, which includes the common "Clubmosses," "Ground-pines," etc., of

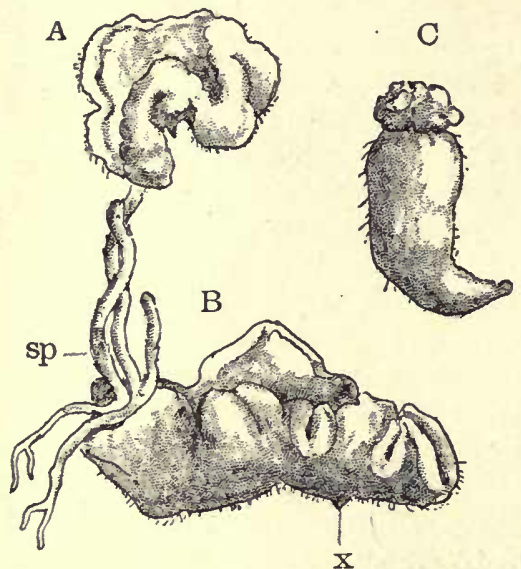

Fig. 269. $-A$, Lycopodium clavatum, gametophyte $(\times 3) . B, L$. annotinum, gametophyte with sporophytes, $s p$, attached $(\times 3) . \quad C$, gametophyte of L. complanatum $(\times 3)$. (All after Bruchuann.)

the northern forests. Some of the tropical species, like L. phlegmaria, are epiphytes.

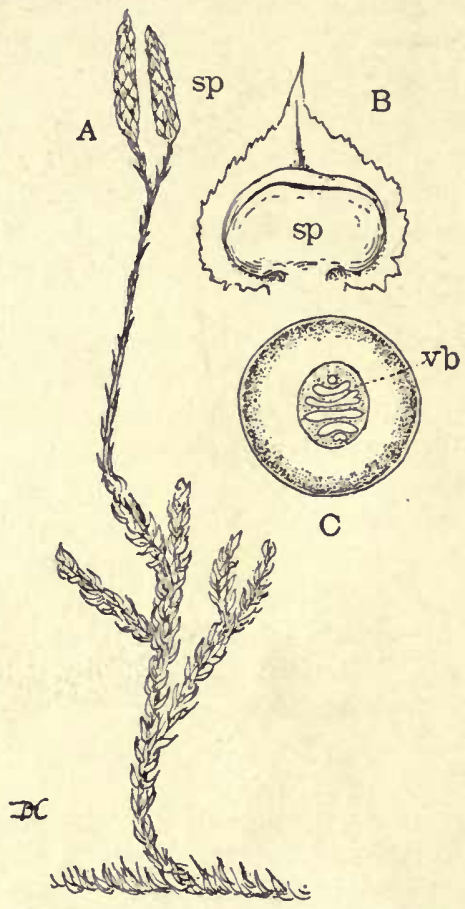

Fig. 270. $-A$, Lycopodium clavatum. $B$, sporophyll of $L$. obscurum. $C$, section of the stem of $L$. obscurum.

\section{The Gametophyte}

Our knowledge of the gametophyte of Lycopodium is now quite complete. There are a number of distinct types, which ought, perhaps, to lead to a separation of the species into several genera. In some species - e.g. L. inundatum, $L$. cernuum - the prothallium (Fig. 271) consists of an upright cylindrical body terminating in a crown of green leaflike lobes, among which the sexual organs are found. In the other species (Fig. 269) it is a subterranean, saprophytic plant, like that in Botrychium. In $L$. phlegmaria, the saprophytic gametophyte grows below the bark of decaying branches. Where the germination of the spores has been studied, the spore first gives rise to a small cellular body, the primary tubercle, from which the gametophyte develops as a branch. 
Sexual Organs. - The gametophyte is usually monocious. The antheridium closely resembles in its structure and development that of Equisetum or the eusporangiate Ferns. The spermatozoids, however, are much smaller, and are biciliate like those of the Bryophytes. This fact, together with the structure of the archegonium, indicates a nearer resemblance to the Bryophytes than is found among the other Pteridophytes. The archegonium usually has a large number of neck canal-cells, instead of the two found in most of the other Pteridophytes, and the neck in cross-section sometimes shows five to six rows of outer neckcells.
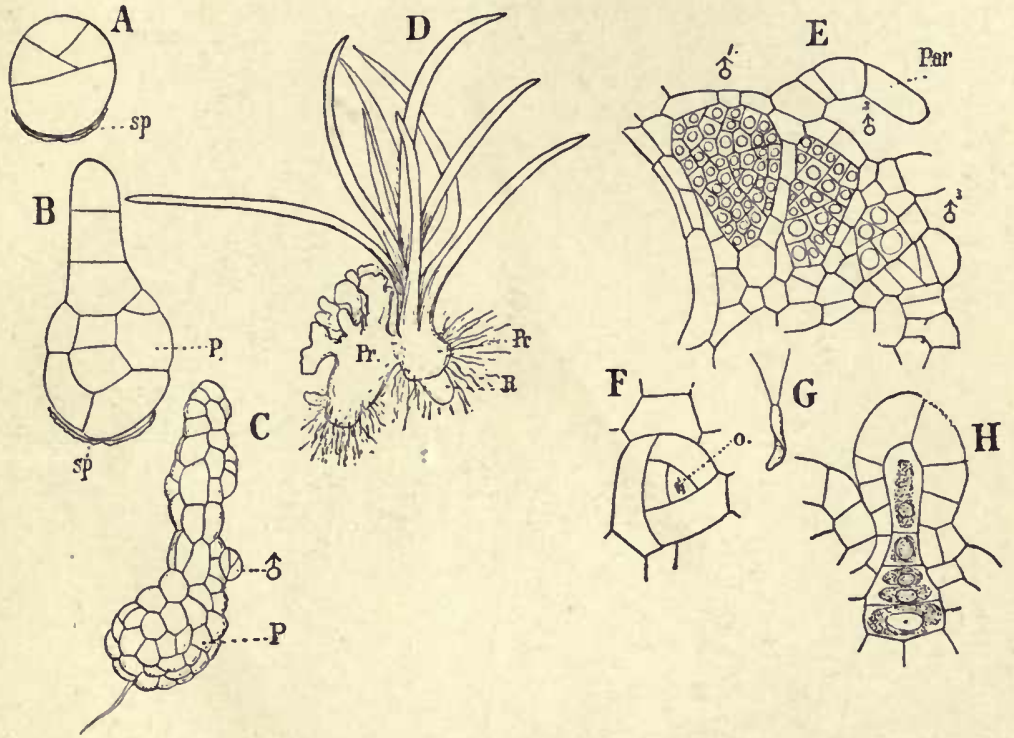

Frc. 271. $-A-D$, Ly copodium cernuum. $A-C$, young gametophytes. $D$, an older one, $P r$, with sporophyte attached $(\times 12) ; P c$, protocorm; $R$, root. E-H, L. phlegmaria. $E, F$, antheridia. $G$, spermatozoid. $H$, archegonium. (After Treub.)

Bruchmann (13), who has made the most recent study of the gametophyte in Lycopodium, recognizes five types of gametophyte, all except one being subterranean, but in some cases developing ehlorophyll if exposed to the light. The upright cylindrical body, with its crown of leaflike lobes, he compares to the radially symmetrical gametophyte of the Mosses, and he seems inclined to connect Lycopodium with these rather than with the Hepaticæ. The great differences in the character of the gametophyte should be sufficient ground for a separation of the genus into at least five.

\section{The Embryo}

The embryo (Fig. 272) of Lycopodium differs from that of all other Pteridophytes except Selaginella, in having only a part of the embryo devoted to the formation of the sporophyte. The first division in the young embryo, which 
becomes very much enlarged before dividing, is transverse. The cell next the archegonium neck is the larger, and either remains undivided or divides only a few times, forming the "Suspensor." The embryo itself is developed entirely
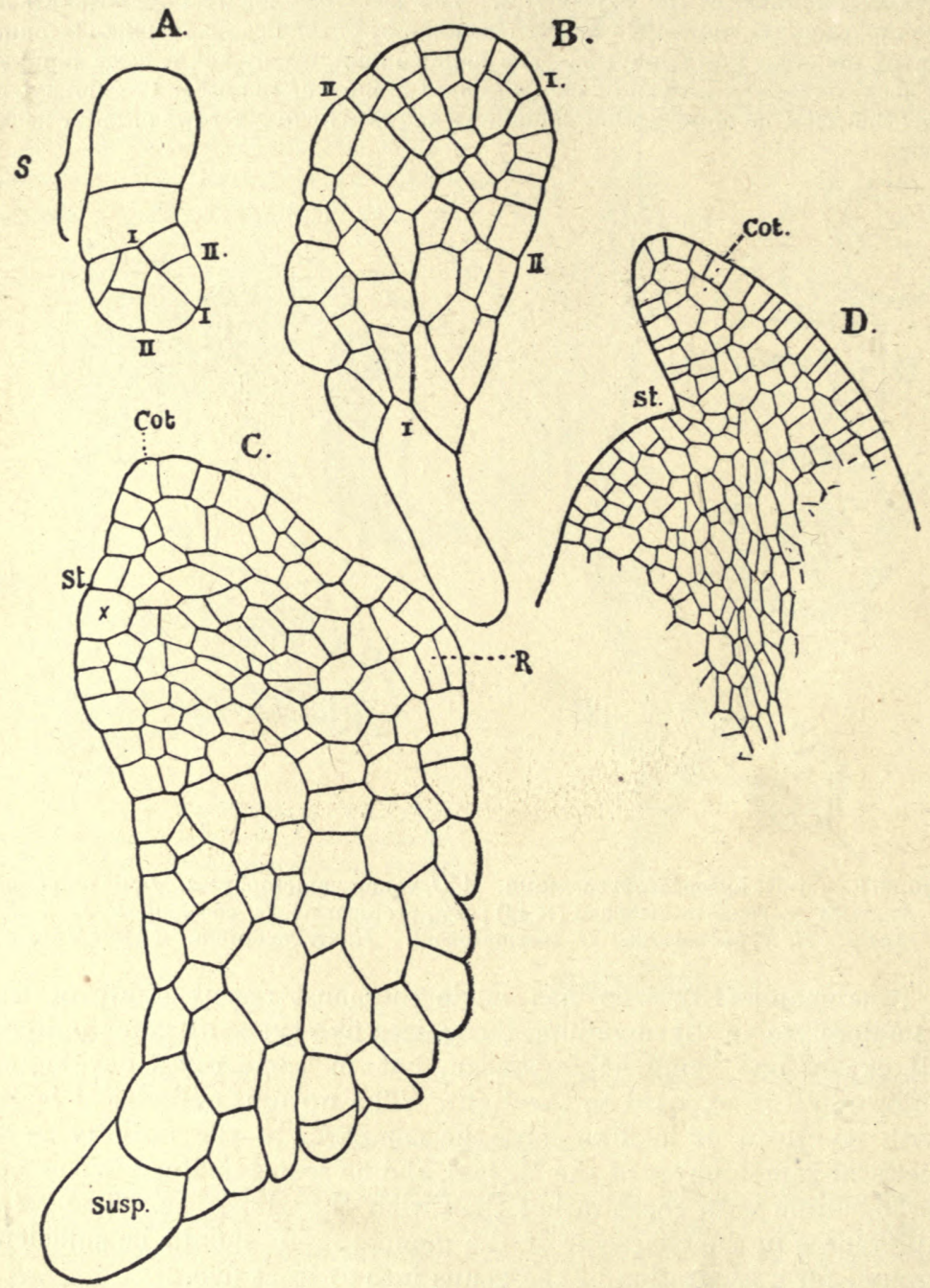

Fig. 272. - Lycopodium phlegmaria. Development of embryo; St, stem; Cot, cotyledon; Susp, suspensor; $R$, root. $(A, \times 315 ; B, C, \times 235 ; D, \times 175$. (After Treub.)

from the lower of the two primary cells. The early divisions are like those in other Archegoniates, and a division into quadrants, and generally into octants, may usually be demonstrated. 
The development of the organs of the young sporophyte is slow, and there is a good deal of difference in this respect among the several species which have been investigated. In $L$. cernuum and the related $L$. inundatum, there is developed a body, the "Protocorm," which gives rise secondarily to the other organs. In the other species the embryo shows a division into two tiers, of which the one next the suspensor becomes much enlarged and forms the foot (Fig. 272); the terminal one gives rise to the other organs of the embryo. A single cotyledon is present in $L$. cernuum and $L$. phlegmaria, but in $L$. clavatum, and other European species, Bruchmann states that the primary leaves are opposite, as they are in Selaginella. In these species, also, the first root to develop is endogenous, instead of exogenous as described by Treub for $L$. cernuum, in which, moreover, the stem remains short, and numerous leaves are formed before the root develops. Where the sporophyte is developed underground, as in L. clavatum, the leaves remain small and scalelike (Fig. 269, B).
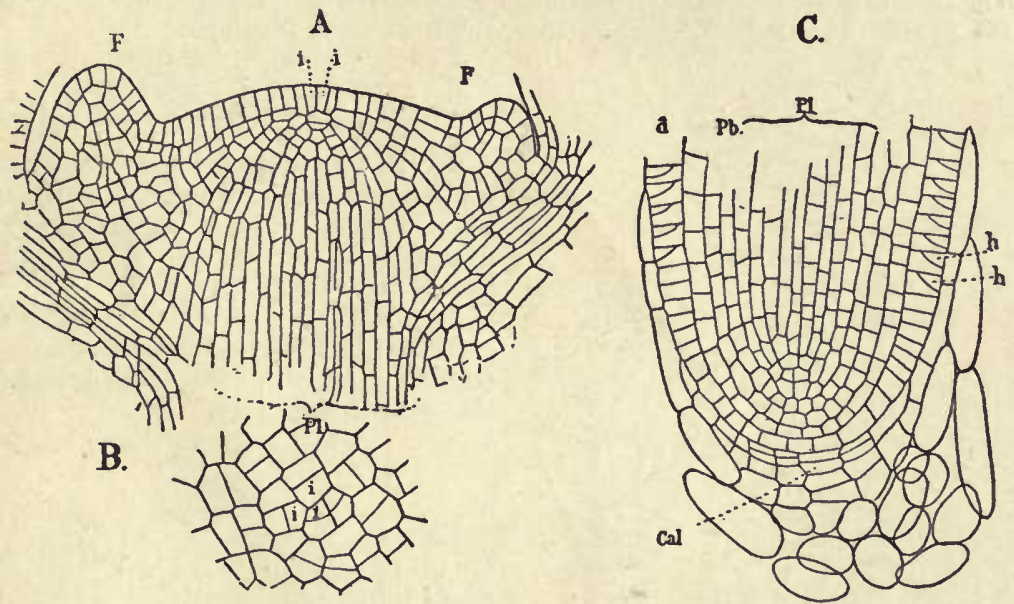

Fig. 373. - Lycopodium selago. $A, B$, stem-apex $(\times 260)$. $C$, apex of root $(\times 120)$. $A, C$, longitudinal sections. $B$, Cross-section. $i$, $i$, stem-initials ; $P l$, plerome ; $P b$, periblem; $d$, epidermis; $h$, root-hair initials; Cal, calyptrogen. (After Strasburger.)

Several embryos are formed upon the same gametophyte, and the sporophyte remains for a very long time dependent upon the gametophyte. This and the slow development of the organs and tissues all point to the very primitive character of Lycopodium.

\section{THE MATURE SPOROPHYTE}

In most species of Lycopodium (Fig. 270) the small crowded leaves are arranged spirally about the axis, which branches freely. The branching may be either monopodial or dichotomous. In a few species - e.g. L. complanatum - the leaves are closely imbricated, and arranged in four rows, much as they are in most species of Selaginella. The roots branch dichotomously. The leaves are always very simple in structure, with a single median vascular bundle. 
Growth of the Stem. - The apex of the stem is usually a broad, much-flattened cone (Fig. 273). The centre of this is occupied by a group of small initial cells, from which lateral and basal segments are cut off, apparently without any definite order. From the lateral segments are derived the epidermis and cortex; from the basal ones, the central vascular cylinder of the stem. Branches may arise laterally, or there may be a true dichotomy of the apex.

A section of the stem (Fig. 270, C) shows within the epidermis a mass of cortical tissue, which in most species is composed, largely, of sclerenchyma. Bounding the central vascular cylinder is a well-detined endodermis, within which there is a pericycle composed of one or several layers. This tracheary tissue is arranged in plates which are transverse in the horizontal stems, but more or less confluent in the upright shoots, so that the xylem in the latter presents, in crosssection, a stellate appearance. Alternating with the xylem plates, are masses of phloem elements, the rest of the cylinder being occupied by parenchyma. The tracheary elements are for the most part scalariform tracheids, like those of the Ferns. The sieve-tubes are smaller, and not so well developed.
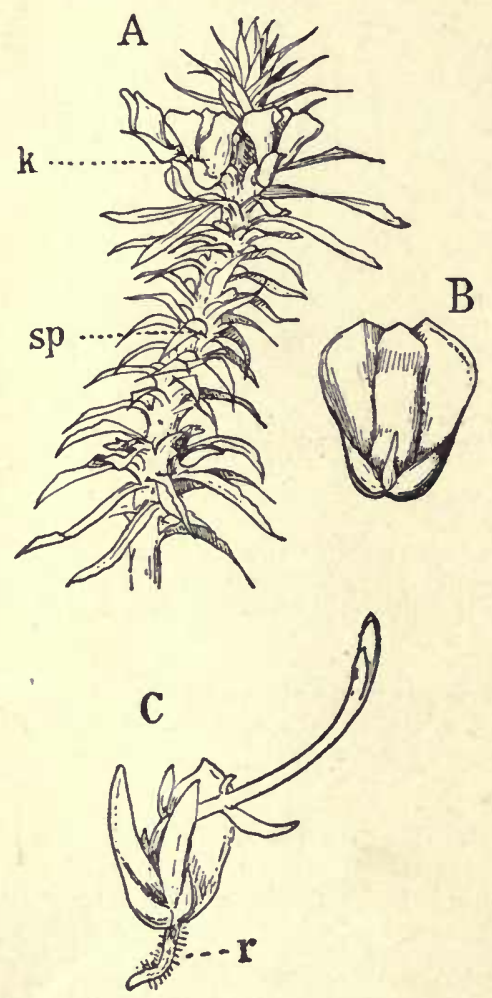

Frg. 274.-Lycopodium lucidulum. A, shoot with geunmæ, $k$, and sporangia, $s p$ ( $\times 2)$. B, single gemma $(\times 4)$. $C$, germinating gemma of $L$. selago $(\times 4)$. ( $C$, after CRAMER.)

\section{The Leaf}

The leaves are small, lanceolate, with broad sessile base. The simple median vascular bundle is concentric, but without a definite endodermis. Where the leaves are spirally arranged, stomata occur upon both surfaces. In those species with decussate leaves, like $L$. complanatum, they are formed upon the lower surface only.

\section{The Root}

Like the stem, the root (Fig. 273, C) in Lycopodium does not show a single initial cell. There are separate initials for each of the primary tissues, Calyptrogen, Dermatogen, Periblem, and Plerome. The first gives rise to the tissues of the root-cap; the second to the epidermis; the third to the cortex, and the last to the central vascular cylinder. Branching of the roots is a true dichotomy, the initial tissues at the apex dividing into two perfectly similar groups. The structure of the tissues in the complete root is much like that in the Ferns. The vascular bundle is diarch.

\section{The Sporangium}

The sporangia (Fig. 270) are kidneyshaped capsules placed singly upon the inner surface of the sporophylls, which 
may be very little modified - e.g. L. lucidulum (Fig. 274) — or they may form cones at the ends of the shoots. In the latter case, the sporophylls have little chlorophyll, and are broader and shorter than the foliage leaves.

The young sporangium consists of a group of cells near the base of the young sporophyll. 'The central cells of the group, by periclinal divisions, give rise to the hypodermal archesporium from which later the tetrahedral spores are derived. The limits of the sporogenous tissue are not clearly defined. The wall of the ripe sporangium consists of three layers of cells, of which the inner one is the tapetum. Unlike the tapetum of the other Pteridophytes, the cells here do not become broken down. The sporangium opens by a longitudinal cleft.

\section{Gemmæ}

In Lycopodium selago and $L$. lucidulum, peculiarly modified buds, or gemmæ (Fig. 274), are often produced in large numbers. The lower leaves of these buds are thick and fleshy, and protect the young stemapex until the buds are ready to grow after they are detached.

\section{Phylloglossum}

Phylloglossum Drummondii is a little Australian plant, evidently related to Lycopodium, and having a striking resemblance to the young sporophyte of $L$. cernuum, so that it has been thought that it may represent the primitive type of the order. Unfortunately nothing is known of the gametophyte and embryo.

\section{Order II. Psilotineæ}

This is a small order of mostly tropical plants, represented in our terri-

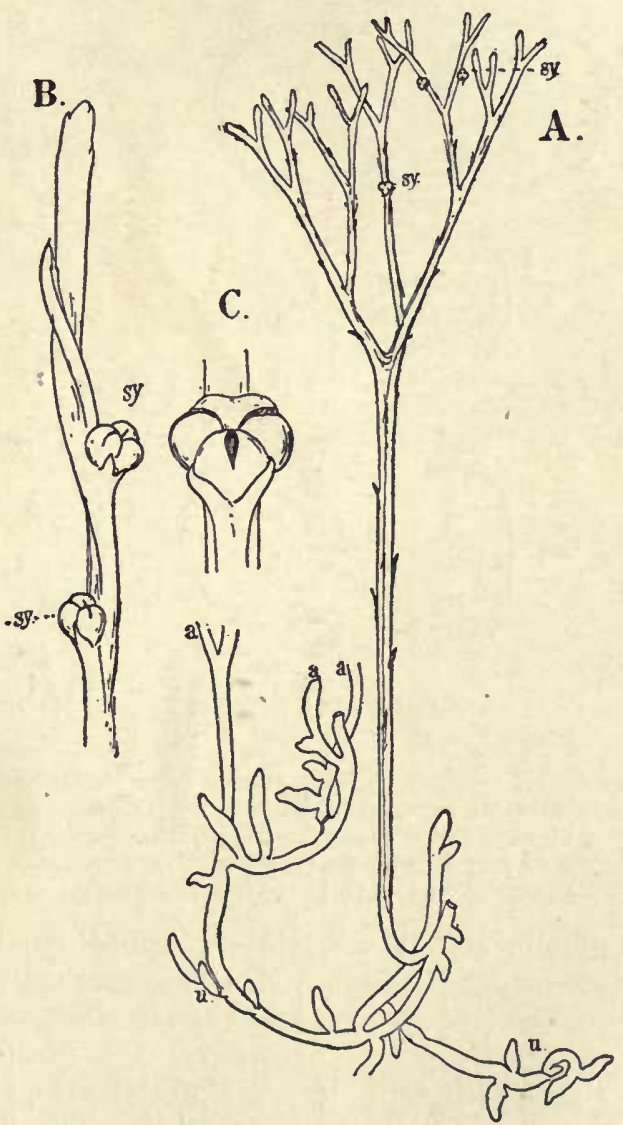

FIG. 275. - Psilotum triquetrum. A, dichotomously branched aerial shoot, growing from the rootlike rhizome $(\times b), B$, branch with synangia, $s y$, slightly enlarged. $C$, trilocular synangium, with two-lobed sporophyll below it. (After BERTRAND.) 
tory by Psilotum triquetrum, which is found sparingly in Florida and the adjacent region. A second genus, Tmesipteris, occurs in the Australasian region. They are usually epiphytes of peculiar habit, and their affinity with the Lycopodiales is somewhat doubtful. In the stem-structure they show a resemblance to the extinct class Sphenophyllales, with which they may possibly be remotely related. Unfortunately nothing is certainly known of the gametophyte.

The sporophyte in Psilotum (Fig. 275) is leafless, and the roots are replaced by creeping rhizomes from which the dichotomously.
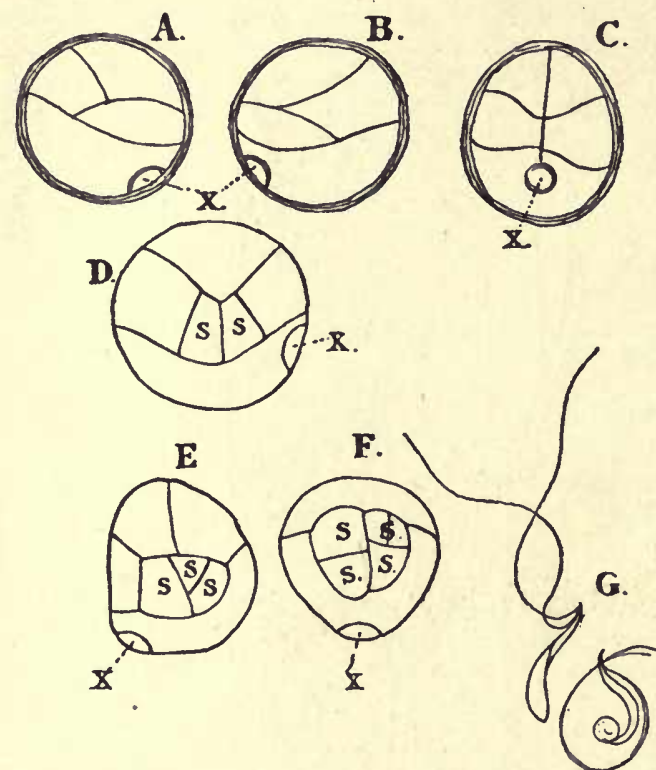

Fig. 276. $-A, B, C$, three views of the young antheridium of Selaginella Kraussiana $(\times 450) ; x$, prothallial cell. $D$, an older antheridium $(\times 480)$. $E, F, S$. stolonifera $(\times 480) . G$, spermatozoids of S. cuspidata $(\times 1170)$. (After BeLAJEFF.) branched shoots develop. The large sporangia are in groups of three, and probably take the place of a leaf. It is questionable whether or not the whole synangium is the equivalent of a single sporangium in Lycopodium.

\section{Ord. III. Selaginellineæ}

The majority of the Lycopodiales belong to the Selaginellineæ, which includes the single large genus Selaginella, most of whose species are tropical, although a small number occur in temperate regions. In general aspect, Selaginella closely resembles Lycopodium, but it differs in one very important particular, viz., it is markedly heterosporous. Some of the species have the leaves all alike, and arranged spirally about the stem-e.g. S. rupestris; the greater number have prostrate stems with four rows of dorsal leaves, two large and two small e.g. S. apus, S. Kraussiana, etc. (Fig. 279). The creeping forms usually develop peculiar leafless pendent branches (Rhizophores), from which the dichotomously branched roots are produced. The apparently dichotomous branching of the shoots is really monopodial. The sporangia are borne in the axils of slightly modified leaves 
arranged in a spike. In most species, the oldest (lowest) sporangium contains four very large macrospores; the others, many small microspores.

\section{The Gametophyte}

Male Gametophyte. - At the time the microspores are shed, there has already been cut off from the body of the spore a small sterile cell (Fig. 276, x). The large cell now undergoes repeated divisions, resulting in a single antheridium,
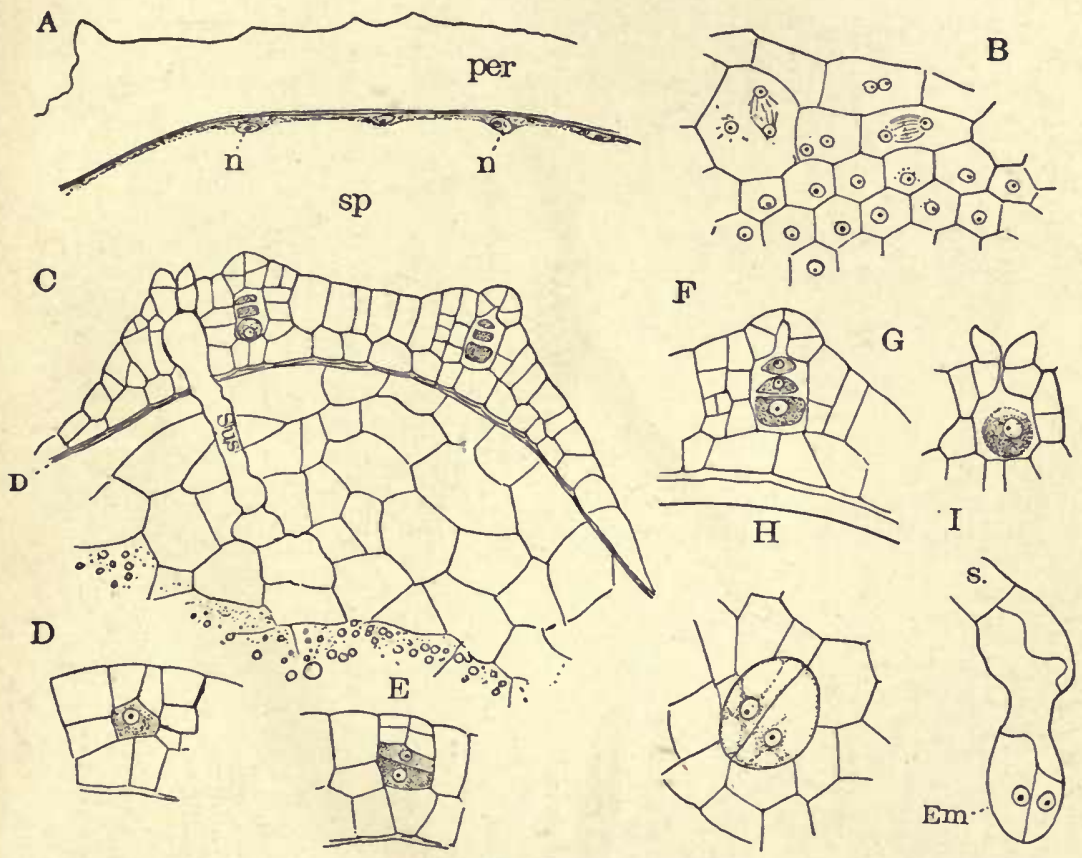

Fıg. 277. - Selaginella Kraussiana. Female gametophyte and embryo. $A, B$, sections of germinating macrospore. $A$, with free nuclei, $n$. $B$, showing first cell-formation $(\times 350)$; per, spore-membrane. $C$, section of fully developed gametophyte, with young embryo $(\times 200)$. $D-G$, development of archegonium $(\times 350) . H, I$, young embryos $(\times 350) ; s$, suspensor.

consisting of a central mass of sperm-cells, and a layer of peripheral cells, which are finally broken down. The minute spermatozoids are biciliate like those of Lycopodium.

Female Gametophyte. - The macrospore begins its germination while still within the sporangium, in this respect approaching the condition found in the Seed-plants. The young macrospore contains a single, relatively small nucleus and very little cytoplasm, most of its cavity being filled with transparent cell-sap. As the spore enlarges, the protoplast becomes entirely free from the wall, and the nucleus, surrounded by the contracted cytoplasmic membrane, has the appearance of a large nucleus with a nucleolus. As the nucleus divides, the cytoplasm 


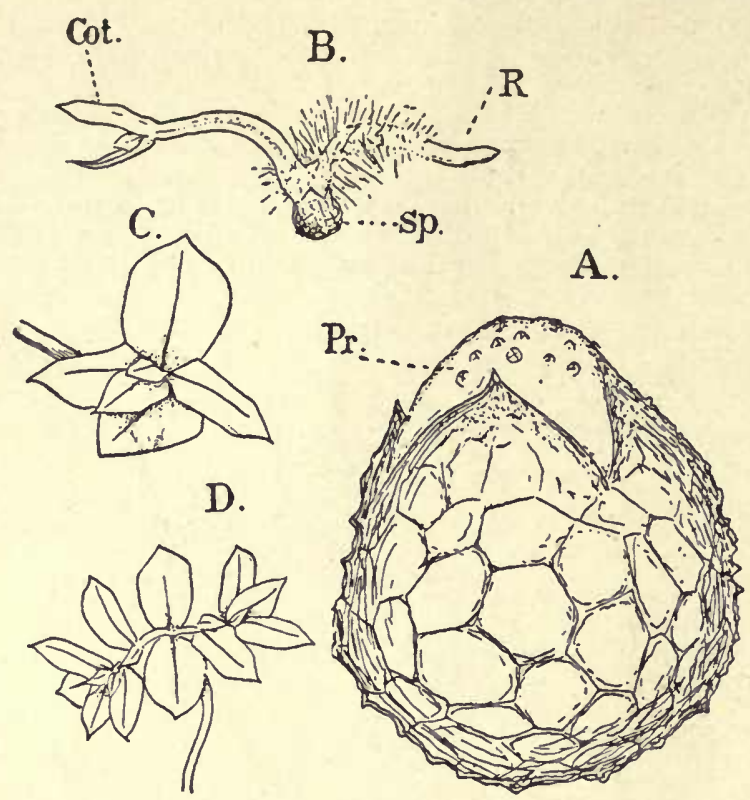

FIG. 278. - Selaginella Kraussiana. A, macrospore with gametophyte, $\operatorname{Pr}(\times 50)$. $\mathrm{B}$, young sporophyte, still attached to the spore $(\times 8)$. C, D, older stages $(\times 4)$.

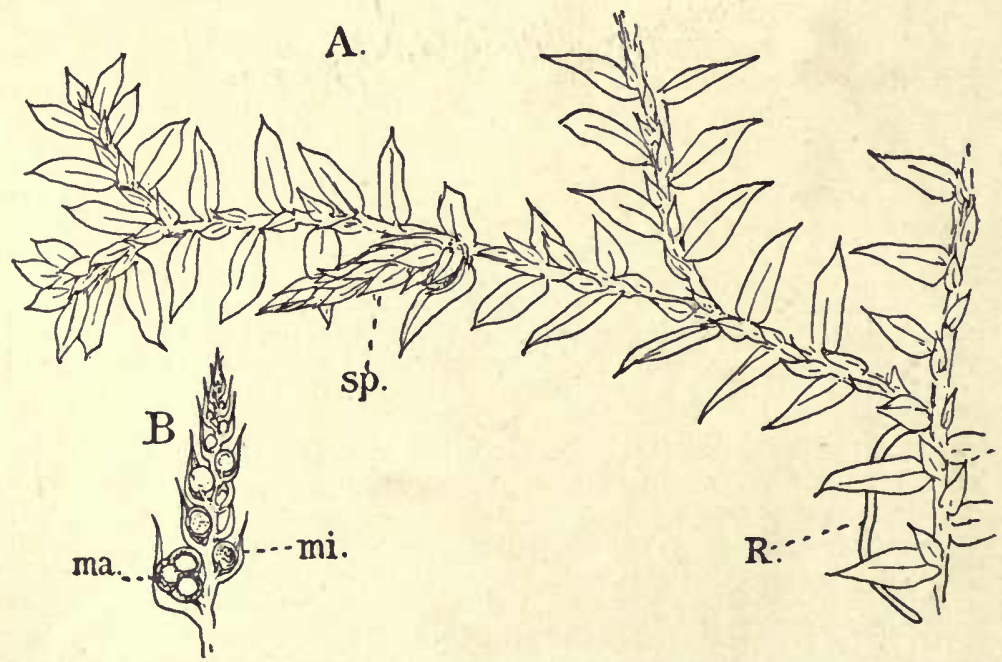

Fug. 279. - Selaginella Kraussiana. Branch with sporangial cone, $s p(\times 3) . \quad R$, young rhizophore. $B$, section of cone; $m a$, macrosporanginm; $m i$, microsporangium $(\times 5)$. 
increases in quantity, and when the spore is about half grown, a section through it shows a thin layer of cytoplasm in contact with the wall, and containing numerous free nuclei (Fig. $277, \mathrm{~A}, \mathrm{~B}$ ). This closely resembles the early stages in the development of the gametophyte among the lower Seed-plants. 'The cellformation begins at the apex of the spore. Between the free nuclei there are developed connecting fibrils, forming more or less evident bundles of fibres, and between each pair of nuclei a cell-wall is developed, so that the protoplasmic layer is divided up into (usually) hexagonal cells. The subsequent nuclear divisions are followed by the formation of cell-walls; and there is then formed in the apex of the spore a flat mass of tissue, upon which the archegonia are developed. About this time the spores are ripe, and when discharged from the sporangium, continue to develop the gametophyte, which finally breaks open the sporemembrane, and exposes the upper part of the gametophyte with the archegonia. The latter are small, and the neck canal-cell is undivided.

\section{The Embryo}

The embryo (Fig. 277, H, I) is much like that of Lycopodium, but the first division occurs before the egg has increased much in size, and the suspensor is much longer. A definite apical cell is present in the stemapex, and the two cotyledons arise on either side of it. A foot is developed, and the root arises between it and one of the cotyledons. The first division of the primary shoot seems to be a true dichotomy. The elongation of the suspensor forces the young embryo into the lower mass of tissue of the gametophyte, and this is destroyed by the embryo in its growth. When it emerges from the spore (Fig. 278, B), it very much resembles a typical dicotyledonous seedling.

\section{THE MATURE SPORO- PHYTE}

In the creeping stems, the structure is monostelic, but this may be replaced in the upright shoots by a bistelic or polystelic structure. The individual bundles are concentric in structure, with usually two protoxylem groups (Fig. 280, B). The apical growth of

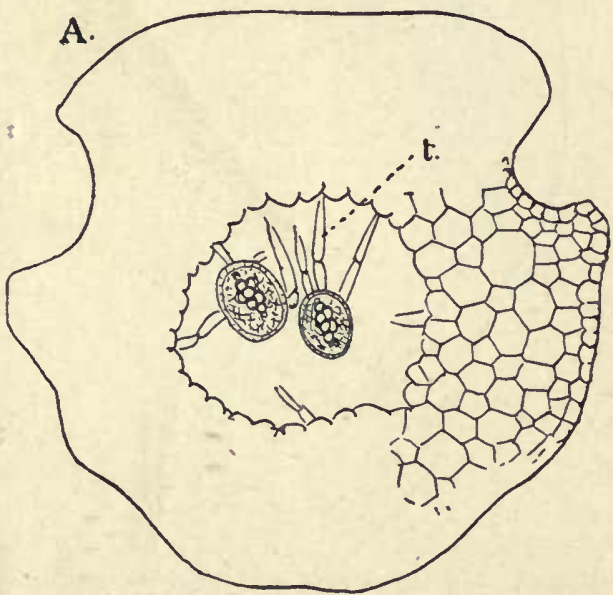

B

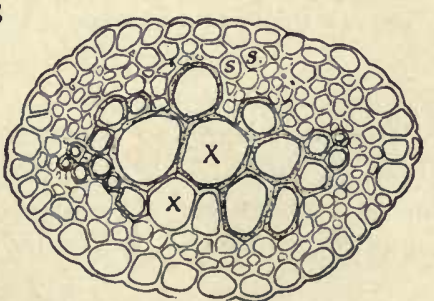

Fig. 280. - Selaginella Kraussiana. A, section of stem, showing the two vascular bundles suspended in the central lacura $(\times 75) . \quad B$, a single bundle $(\times 450) ; x$, tracher ; $s$, sleve-tubes. 
the shoot is variable. Usually, but not always, a single initial cell can be seen. The cortical tissue is in most species composed of delicate parenchyma, and about the vascular bundles are large airspaces. In species of dry regions, like $S$. rupestris, the cortical tissue is largely sclerenchymatous.

\section{The Leaf}

The general structure of the leaf is like that of Lycopodium, but there is always present a peculiar structure, the ligule (Fig. 281, l). Like the stem, the leaf in most species is traversed by longitudinal air-channels. A marked peculiarity of the green tissue of Selaginella is the presence of but a single chloroplast in each cell.
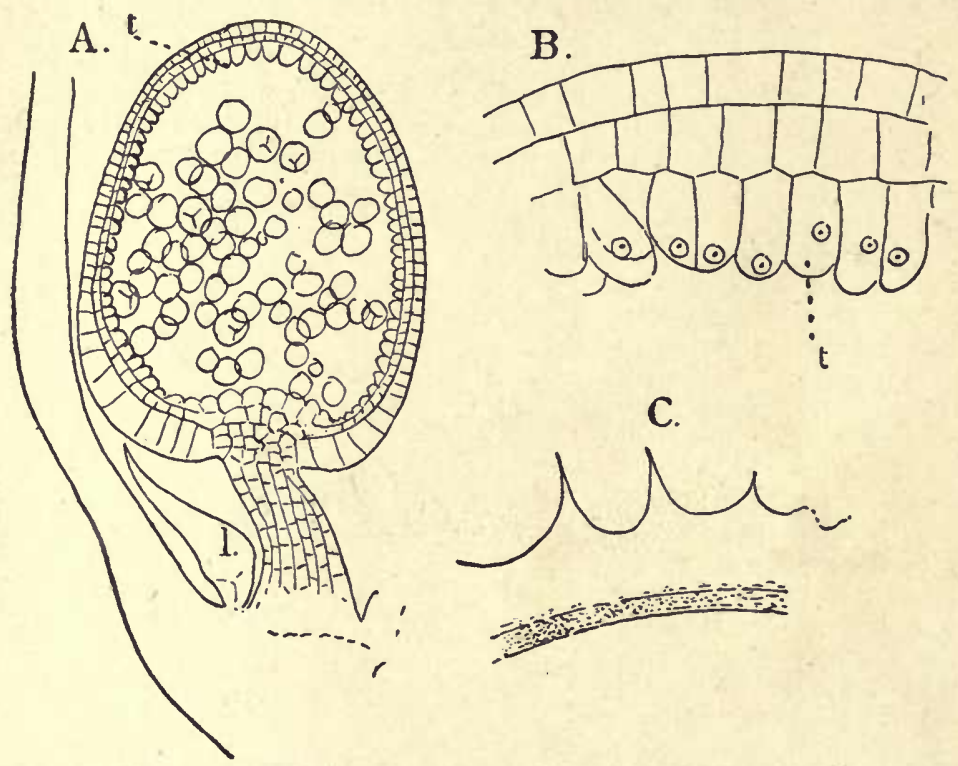

FIG. 281. - Selaginella Kraussiana. Section of microsporangium $(\times 100) ; l$, ligule of subtending leaf; $t$, tapetum. $B$, wall of young macrosporangium; $t$, tapetal cells $(\times 600) . \quad C$, membrane of young macrospore.

\section{The Root}

The root, like the shoot, shows a single initial cell. The apparently dichotomous branching is stated to be a false dichotomy, similar to that of the stem-apex. The vascular bundle of the root is monarch, and a distinct endodermis is not developed.

\section{The Sporangium}

The sporangia (Fig. 281) in the investigated species of Selaginella arise from the axis, just above the origin of the subtending leaf. In 
their development they agree closely with Lycopodium, and, as in that genus, the tapetum is the innermost of the three layers of cells forming the wall of the sporangium. The tapetal cells remain intact, and form an epithelial layer in contact with the developing spores, to which they doubtless furnish food in a manner analogous to that found in the corresponding cells of the ovule in the Seedplants.

Up to the separation of the individual sporogenous cells, microsporangium and macrosporangium develop alike; but while all the sporogenous cells in the microsporangium produce tetrads of spores, in the macrosporangium this is true only of one of them, the others remaining undivided, and finally be. ing destroyed by the developing macrosporic tetrad, whose spores reach a very large size.

\section{The Isoetineet}

The Isoetineæ are so different from the other Pteridophytes that there is much difference of opinion as to where they should be placed. While they are most commonly associated with Selaginella, and undoubtedly show certain structural resemblances, they also have some points in which they seem to approach more nearly the eusporangiate Ferns, with which they are sometimes associated. Whether they are assigned to the Filicales or Lycopodiales, they must be placed in a dis-

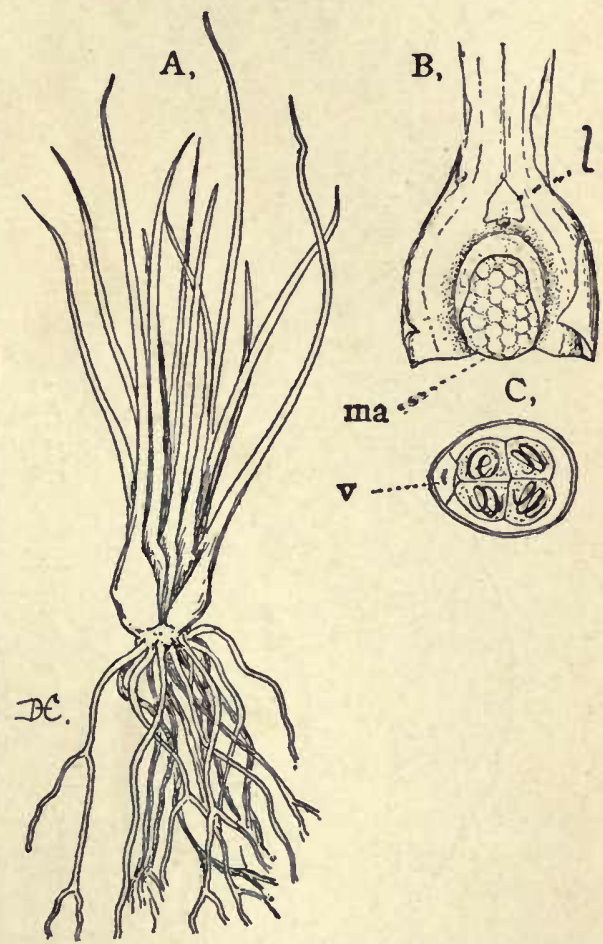

Fig. 282. - A, Isoetes Bolanderi. Sporophyte, slightly reduced. $B$, base of leaf with macrosporangium, ma $(\times 3)$; l, ligule. $C, I$. echinospora, male gametophyte, reduced to a single antheridium and a vegetative cell, $v(\times 700)$. tinct order. There is a single genus, Isoetes, with perhaps fifty species, of which sixteen occur within the United States.

The sporophyte (Fig. 282) is very similar in all of them, and is usually aquatic, although there are a number of terrestrial and amphibious species. The stem is very short, and completely concealed 
by the broad, overlapping leaf-bases, forming a structure like the scaly bulb of an Onion. The slender cylindrical leaf also suggests

A.

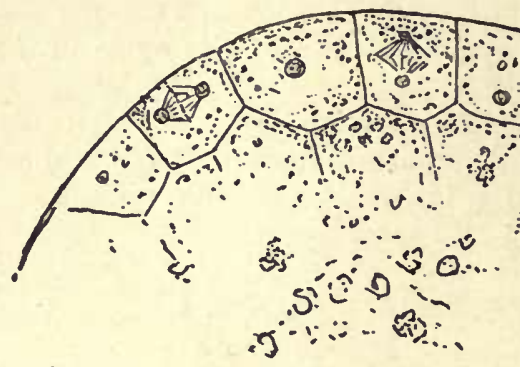

B.
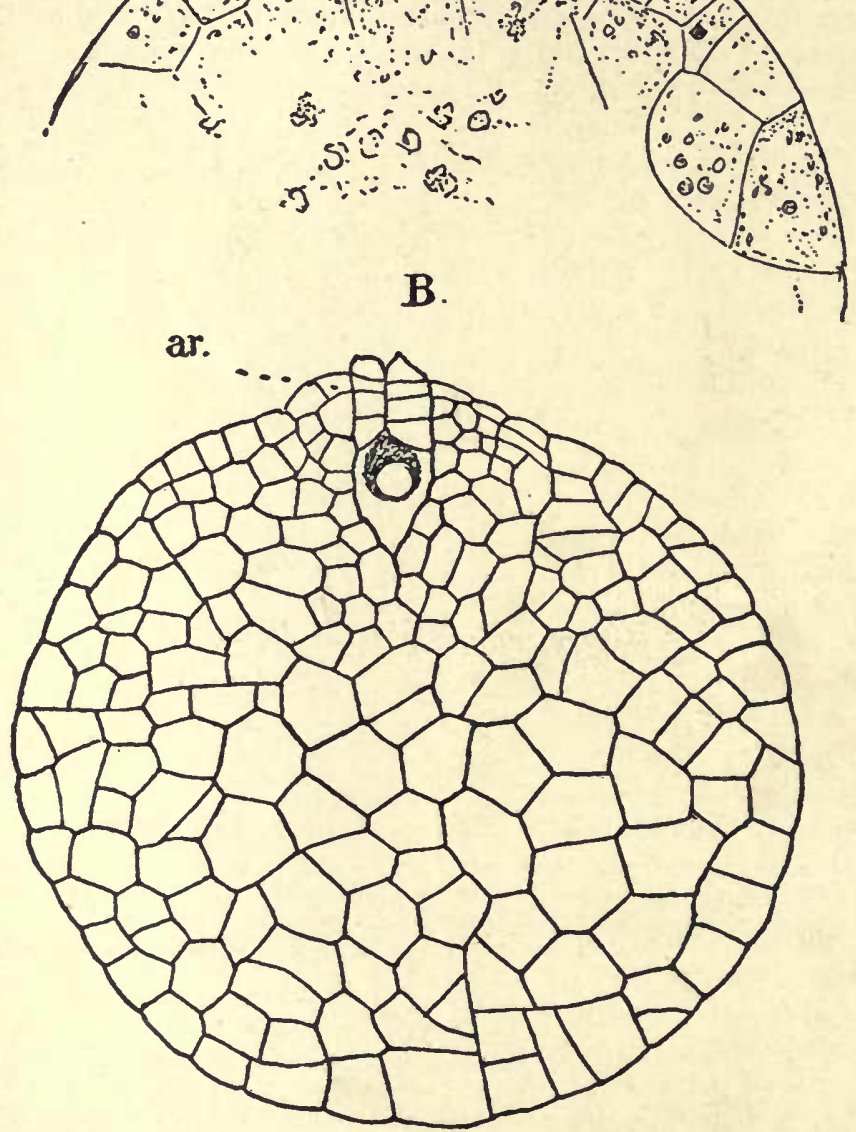

FIG. 283. - Isoetes echinospora. A, upper part of germinating macrospore, showing first cell-formation $(\times 300)$. $B$, section of complete gametophyte with the first archegonium, ar.

the Monocotyledons. The stem is deeply divided into two or three lobes, between which the numerous, dichotomously branched roots are developed. 
The leaves are developed in a compact spiral. Each season's growth is separated from the next by a series of sterile leaves, which are more or less rudimentary. In the mature sporophyte all of the foliage leaves are sporophylls, each having a single large sporangium upon the inner face of its expanded base (Fig. 282, B). The sporangium is oval in outline, and sunk in a depression (Fovea), whose margin (Velum) may almost completely cover the sporangium, suggesting a structure comparable to the integument of an ovule. Above the Fovea is a small scalelike outgrowth, the Ligula.

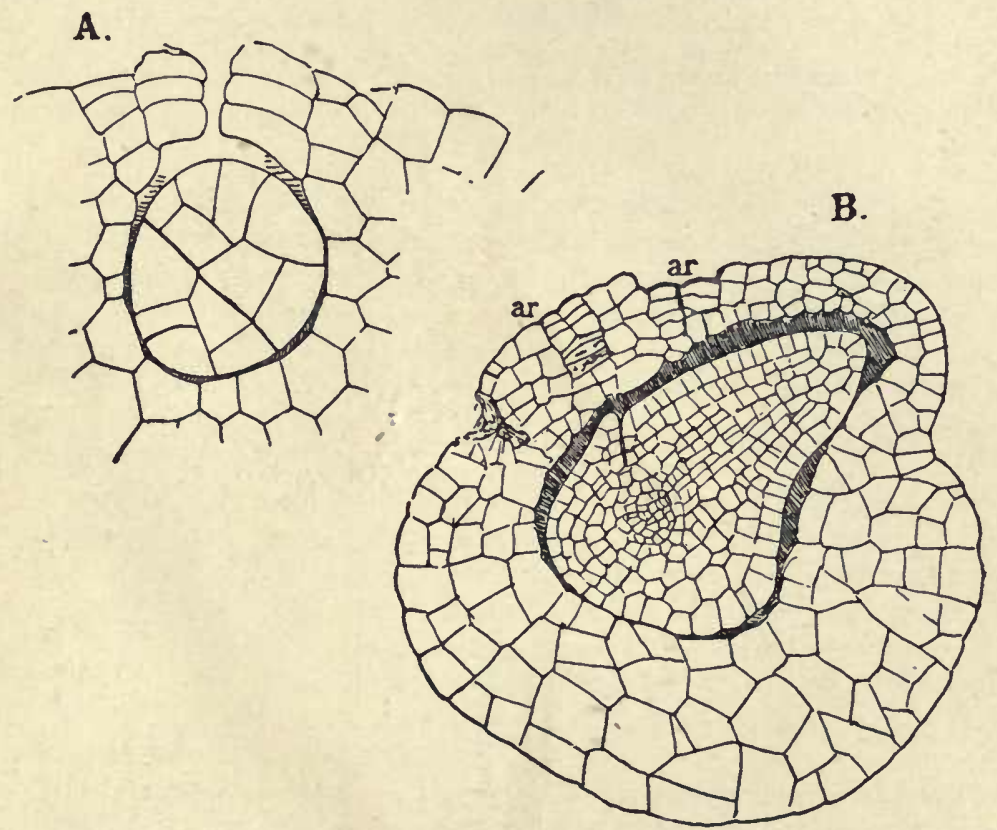

Fra. 284. - Isoetes echinospora. A, young embryo $(\times 450) . \quad B$, older embryo, still enclosed in the gametophyte $(\times 150) ;$ ar, archegonia.

\section{The Stem}

The stem is composed of a central vascular cylinder, made up largely of short tracheids. Outside of this is a layer of prismatic cclls, which perhaps represent the phloem. Outside this is a layer of meristematic cells, which add to the prismatic cells on the inner side, and to the cortex outside. A true secondary thickening thus takes place, but it is quite different from that of other plants.

\section{The Leaf}

The leaf is traversed by a single very simple vascular bundle, surrounding which are four large air-channels, separated at intervals by diaphragms. Where 
the sporophyte is entirely immersed no stomata develop, but where the leaf is exposed to the air, stomata are always present. Neither stem nor root develops a single apical cell.

\section{The Root}

The arrangement of the tissues at the root-apex is not unlike that found in some Spermatophytes. There may be distinguished three initials, one for the plerome, one for the inner cortex, and one for the remaining outer tissues. The vascular bundle is monarcl.

\section{The Sporangium}

The development of the sporangium (Fig. 285) is not unlike that of Lycopodium. According to R. Wilson Smith, who has recently studied the develop-

A

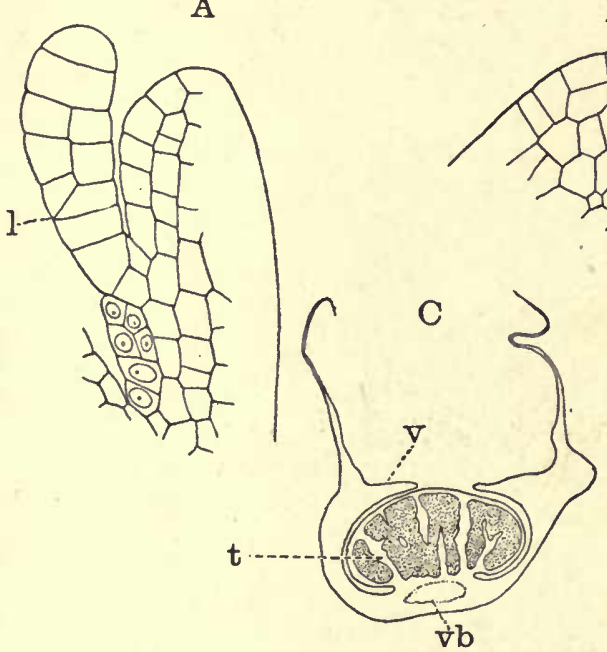

B

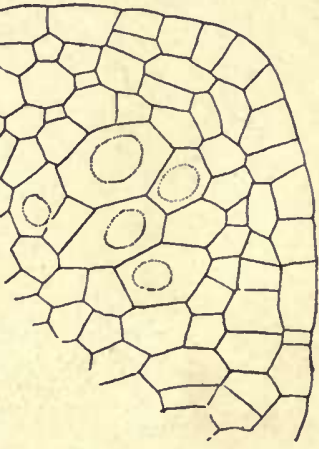

Fra. 285. - Isoetes echinospora. A, section of young sporophyll $(\times 325)$; $l$, ligule; the sporangial cells have the nuclei shown. $B$, section of a portion of a young macrosporangium $(\times 3 \dot{25})$; the sporogenous cells have the nuclei indicated. $C$, cross-section of base of sporophyll, with young microsporangium $(\times 25)$; v, velum; $t$, trabeculæ. (After Wilson SMiтh.)

ment in Isoetes echinospora, the young sporangium arises from a group of superficial cells, some of which, by periclinal divisions, give rise to an inner layer of sporogenous tissue. All of the sporogenons cells do not develop, and these sterile cell-masses form rods or strands (Trabeculæ), partially dividing the mass of fertile cells. In their early stages the macro- and microsporangia are not distinguishable, and it is claimed that the mother-cell of a macrospore tetrad cannot be traced to the division of a definite hypodermal cell, as was formerly supposed to be the case. The microspores are usually of the bilateral type, the macrospores, tetrahedral. The number of microspores in $I$. echinospora is 150,000 to 300,000 , of macrospores 150 to 300 . 


\section{The Gametophyte}

The microspores produce an exceedingly reduced gametophyte (Fig. 282, C). A small sterile cell is first cut off, and the body of the spore then divides further, so that four sperm-cells, surrounded by as many sterile cells, which are finally broken down, result. The spermatozoids are multiciliate like those of the Ferns.

The development of the female gametophyte (Fig. 283) is much like that of Selaginella, but does not begin until the spores are set free. About fifty free nuclei are formed before any cell-divisions occur. The archegonia are much larger than those of Selaginella, and resemble more nearly those of the eusporangiate Ferns, with which the embryo (Fig. 284) also shows some points in common, notably the absence of a suspensor. In the origin of the stem-apex of the embryo, Isoetes resembles also some of the Monocotyledons.

\section{Fossil Pteridophytes}

On comparing the fossil Pteridophytes with their living descendants, it is clear that the proportion of species in the different groups has changed very much. During the Palæozoic age, the Ferns were almost entirely eusporangiate types, the Marattiaceæ being especially well represented. The Leptosporangiatæ do not become at all prominent until the Mesozoic, from which time they increase rapidly in importance, until they häve now very largely supplanted the more primitive Eusporangiatæ.

The other two classes, Equisetales and Lycopodiales, have not succeeded so well in adjusting themselves to modern conditions, and these classes, especially the former, are but degenerate remnants of once much more important types. The more highly specialized arborescent forms, like Calamites and Lepidodendron, have entirely disappeared, and it is the much simpler types that have persisted. Whether Lepidodendron may have given rise to seed-bearing descendants is a disputed question.

It is evident that some of the fossil Pteridophytes are not readily assignable to any of the existing classes. This is notably the case with the Sphenophyllales, a group which in its anatomical structure seems to partake of the character of both Equisetales and Lycopodiales. It is possible that the Psilotacer may be remotely related to the members of this class. Another important class of extinct plants are the Cycado-filices, which were intermediate in their characters between Ferns and Cycads.

\section{BIBLIOGRAPHY}

'96. 1. Arnoldi, W. Die Entwickelung des weiblichen Vorkeims bei den heterosporen Lycopodiaceen. Bot. Zeit., LIV. 1896.

'92. 2. Atkinson, G. F. The Study of the Biology of Ferns. London and New York, 1892. 
'96. 3. - Some Problems in Sporophyll-transformation. Bot. Gaz., XXII. 1896.

'87. 4. Baker, J. G. Handbook of the Fern-allies. London, 1887.

'87. 5. De Bary, A. Comparative Anatomy of Ferns and Flowering Plants. Oxford, 1887.

'98. 6. Belajeff, W. Die männlichen Protballien der Wasserfarne. Bot. Zeit., LVI. 1898.

7. Bitter, G. See Engler and Prantl.

'99. 8. Boodle, L. A. On some Points in the Anatomy of the Ophioglossacer. Ann. of Bot., XIII. 1899.

'99. 9. - Stem structure in Schizæaceæ, Gleicheniaceæ, and Hymenophyllaceæ. Ann. of Bot., XIII. 1899.

'93-'99. 10. Bower, F. O. Studies in the Morphology of Spore-producing Members. Phil. Trans. Royal Soc. London, 1893-99.

'96. 11. Brebner, G. On the Prothallium and Embryo of Danaea simplicifolia. Ann. of Bot., X. 1896.

'01. 12. Britton, E. G., and Taylor, A. Life-history of Schizad pusilla. Bull. Torrey Bot. Club, XXVIII. 1901.

'98. 13. Bruchmann, H. Die Prothallien und die Keimpflanzen mehrerer europäischer Lycopodien. Gotha, 1898.

'95. 14. Campbell, D. H. Structure and Development of the Mosses and Ferns. London and New York, 1895. (Contains full bibliography.)

'83. 15. Druery, C. T. On Apospory, etc. Gard. Chronicle. 1883.

'79-'80. 16. Eaton, D. C. Ferns of North America. Boston, 1879-80.

'98-'00. 17. Engler and Prantl. Natürliche Pflanzenfamilien. Leipzig, 18981900.

Bitter, G. (Marattiaceæ, Ophioglossaceæ.)

Diels, L. (Parkeriaceæ, Polypodiaceæ.)

Potonié, H. Fossil Pteridophyta.)

Pritzel, E. (Lycopodiales.)

Sadebeck, R. (Pteridophyta in general; Cyatheaceæ, Hymenophyllaceæ, Hydropteridineæ, Equisetales.)

18. Goebel, K. Outlines.

'00. 19. Organographie der Pflanzen. Th. II. Jena, 1900.

'98. 20. Jeffrey, E. C. The Gametophyte of Botrychium Virginianum. Proc. Canad. Inst., V. 1898.

'99. 21. — Development, Structure, and Affinities of the Genus Equisetum. Mem. Boston Soc. Nat. Hist., V., No. 5. 1899.

'98. 22. Johnson, D. S. On the Leaf and Sporocarp of Marsilia. Ann. of Bot., XII. 1898.

'98. 23. On the Leaf and Sporocarp of Pilularia. Bot. Gaz., XXVI. 1898.

'98. 24. Lang, W. H. On Apogamy and Development of Sporangia upon Fern-prothalli. Phil. Trans. Royal Soc., Ser. B, 190. 1898.

'01. 25. _ _ Preliminary statement on the Prothallia of Ophioglossum pendulum, Helminthostachys Zeylanica, and Psilotum sp. Proc. Royal Soc., May 23, 1901. (Reported in Bot. Centralblatt, LXXXV1I. 1901.

'01. 26. Lyon, F. M. A Study of the Gametophytes of Selaginella apus and S. rupestris. Bot. Gaz., XXXII. 1901.

'97. 27. Osterhout, W. J. V. Ueber Entstehung der karyokinetischen Spindel bei Equisetum. Pringsheim, Jahrb. für wiss. Botanik, XXX. 1897.

28. Potonié, H. See Engler and Prantl.

29. Pritzel, E. See Engler and Prantl. 
30. Sadebeck, R. See Engler and Prantl.

'00. 31. Scott, D. H. Studies in Fossil Botany. London, 1900.

'98. 32. Schenk, H. Cryptogams (in Textbook of Botany, Strasburger, Noll, Schenk, and Schimper). London and New York, 1898.

'98. 33. Seward, A. C. Fossil Plants. Cambridge, 1898.

'97. 34. Shaw, W. R. Parthenogenesis in Marsilia. Bot. Gaz., XXIV. 1897.

998. 35. — Ueber die Blepharoplasten bei Onoclea und Marsilia. Ber. der Deutsch. Bot. Gesellschaft, XIV. 1898.

'98. 36. — The Fertilization of Onoclea. Ann. of Bot., XII. 1898.

'00. 37. Smith, J. W. The Structure and Development of the Sporophylls and Sporangia of Isoetes. Bot. Gaz., XXIX. 1900.

'91. 38 Solms-Laubach, H., Count. Fossil Botany. Oxford, 1891.

39. Strasburger, E. Das Botanische Practicum.

'96. 40. Underwood, L. M. Pteridophyta (Britton and Brown, Illustrated Flora). New York, 1896.

'00. 41. — Our Native Ferns and their Allies. New York, 1900.

42. Van Tieghem. Traité de Botanique.

43. Vines, S. H. Students' Text-book of Botany.

44. Warming, E. W. Handbook of Systematic Botany. 


\section{CHAPTER $\mathrm{X}$}

\section{SUBKINGDOM SPERMATOPHYTA (SEED-PLANTS)}

\section{Class I. Gymnospermat}

Heterospory arose independently in all of the classes of Pteridophytes. Two types may be recognized, that in which the contents of the germiuating macrospore divide at once by cell-walls, as in Marsilia and Salvinia, and that in which there is a repeated division of the nucleus, before cell-formation begins. The latter occurs in Isoetes and Selaginella, and much more nearly resembles the condition found among the Spermatopliytes or Flowering-plants, also known as "Phanerogams."

In Selaginella, the growth of the gametophyte within the macrospore begins before the latter has reached its full size, and while it is still retained within the sporangium, whose wall-cells remain active until the growth of the macrospore is complete, and the development of the latter is largely due to material conveyed to it throngh the agency of the outer sporangial cells. In both the early development of the gametophyte and the participation of the outer sporangial tissue in the growth of the spore and the contained gametophyte, Selaginella resembles more nearly than any other living Pteridophyte, the condition found in the Spermatophytes, or Seed-plants.

\section{The Seed}

In the Spermatophytes, as in Selaginella, the germination of the macrospore begins before it is full grown; but unlike Selaginella, the ripe macrospore is not expelled from the sporangium, but remains permanently within it, and usually, although not always, fertilization of the archegonium is effected while the sporangium is still attached to the sporophyte. After fertilization has been effected, the outer tissues of the macrosporangium harden, and form a protective covering for the enclosed macrospore, within which lie the gametophyte and embryo-sporophyte. Sooner or later, the sporangium falls away, and the collective structure, the sporangium, with the enclosed gametophyte and embryo, is known as a Seed. This modified macrosporangium is the characteristic of all Spermatophytes, but as it is 
highly probable that seeds have arisen independently in different groups of Pteridophytes, it is by no means certain that all Spermatophytes are derived from a common stock.

The protection of the macrospore with the enclosed gametophyte, within the macrosporangium, or ovule, is apparently very advantageous, as the Spermatophytes are the plants which have succeeded best in adjusting themselves to the conditions now prevailing upon the earth.

\section{Fertilization in Spermatophytes}

The position of the female gametophyte in the Spermatophytes necessitates a different method of fertilization, and in all of these the germinating microspore (pollen-spore) produces a long tube, the pollen-tube, into which pass the male generative cells, and these are thus conveyed to the egg-cell. Among the lowest of the Seed-plants, i.e. Cycads and Ginkgo, large ciliated spermatozoids are developed within the pollen-tube, but in all other cases the male cells are destitute of cilia, and the pollen-tube discharges the generative nuclei directly into the egg-cell, or into a neighboring cell (Synergid), through which it is conveyed to the egg. In case the pollen-tube has to traverse the tissues of the pistil or ovule, it grows through them very much as the hypha of a Fungus would do, undoubtedly growing at the expense of the cells among which it passes.

\section{The Flower}

The sporophylls of the Spermatophytes are usually aggregated, and form the Flower of these plants, which are often, therefore, called the Flowering-plants. It must be remembered, however, that the cone of sporophylls in Equisetum or Selaginella might, with equal propriety, be considered a flower, and it is the seed and pollen-tube, and not the flower, which must be considered the distinctive features of this group.

\section{The Spores}

Microspore. - The microspores of the Spermatophytes, or pollenspores, as they are more commonly termed, agree in all respects with the spores of the Archegoniates. They always arise from the division of a sporogenous cell into four spores, and these in their structure agree exactly with those of the typical Archegoniates. Like them, also, they are always discharged from the sporangium, and complete their germination away from it.

Macrospore. - The macrospores agree in their early development with those of the Pteridophytes, but a true tetrad division is usually absent, and only in rare cases does the spore develop an outer thick- 


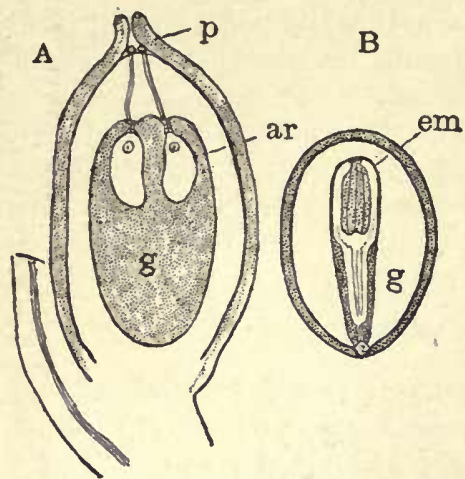

Fia. 286. - Pinus Virginiana. $A$, section of ovule, showing the gametophyte, $g$, with two archegonia, ar; $p$, pollen grains sending pollen-tube through the tissue of the ovule. $B$, $P$. edulis, section of ripe seed $(\times 2)$; $g$, gametophyte ("endosperm"), enclosing the embryo sporophyte.

ened membrane. It always remains permanently within the sporangium.

Ovule. - Within the macrosporangium (Fig. 286), known in the Spermatophytes as the "Ovule," the single macrospore gives rise to the female gametophyte. The sporangium is invested by one or two envelopes, or integuments, which are characteristic of the ovule in all typical Spermatophytes.

\section{The Gametophyte}

Male Gametophyte. - The male gametophyte is always extremely reduced. There are from one to three sterile cells, and a small antheridial cell (Fig. 287, C, D) within which is a nucleus, which usually divides later into two, the male or generative nuclei. These correspond to the sperm-nuclei of

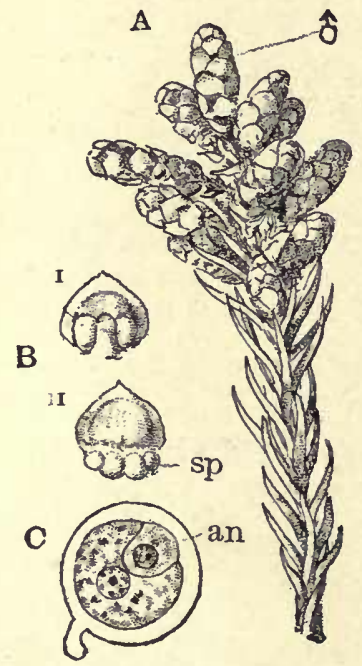

E

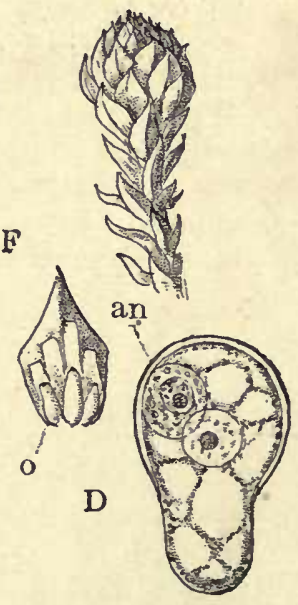

Fig. 287. - Cryptomeria Japonica. A, branch with male flowers, of, slightly enlarged. $B$, scale with pollen-sacs (microsporangia), I, from within; II, from without $(\times 4) . \quad C$, pollen-spore $(\times 600) ; a n$, antheridial cell. $D$, germinating pollen-spore. $E$, female flower $(\times 2) . \quad F$, a scale with three ovules, o, more enlarged. 
the Pteridophytes, and in exceptional cases - e.g. Cycas, Zamia large ciliated spermatozoids develop from them. The pollen-spore, when ripe, often has the antheridial cell separated from the sterile cell, and when it germinates, which it will readily do in a 10 to 15 per cent sugar solution, sends out a germ-tube, or pollen-tube, through a rupture in the outer spore-coat. The division of the generative nucleus commonly takes place within the pollen-tube.

Female Gametophyte. - Among the lower Spermatophy tes the female gametophyte closely resembles that of the heterosporous Pteridophytes, especially Isoetes and Selaginella. Archegonia of the same type are developed, and the gametophyte resembles much more that of the Pteridophytes than that of the higher Spermatophytes. In the latter the gametophyte becomes excessively reduced, and the homologies of the structures found in the fully developed macrospore, or embryo-sac, are not entirely clear.

\section{The Embryo}

Usually, each fertilized egg-cell gives rise to a single embryo, either by direct cell-division, or after several free nuclei have been formed. In some Coniferæ, however, each egg gives rise to four embryos. A suspensor, similar to that in the embryo of the Lycopodiales, is found in most Spermatophytes.

\section{Classification of Spermatophytes}

Two classes of Spermatophytes are recognized, Gymnosperms and

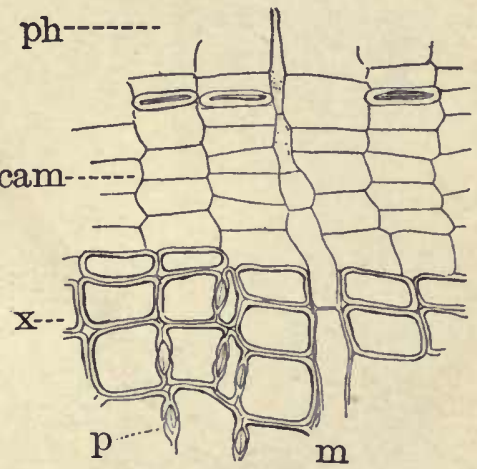

FIG. 288. - Taxodium distichum. Transverse section of the stem at the beginning of the growing season; cam, cambium; $x$, xylem; $p h$, phloem; $m$, medullary ray; the xylem is composed of tracheids with bordered pits, $p$, on their radial walls $(\times 400)$.

Angiosperms; but whether these are directly related may be questioned. In the former the ovules, or macrosporangia, are exposed upon open sporophylls, as they are in the Pteridophytes; in the Angiosperms the ovules are always borne in a closed cavity, the ovary, formed from the base of the carpel (sporophyll) or from the coherent bases of two or more carpels. A more important distinction is the very much reduced female gametophyte of the Angiosperms.

\section{Class I. Gymnosperme}

The Gymnosperms are the oldest types of seed-bearing plants, and in many respects, especially in the character of the gametophyte, 
are more nearly related to the Pteridophytes than they are to the Angiosperms. The recent discovery of spermatozoids in several of the lower forms has emphasized the near relation of the Gymnosperms to the other Archegoniates, with which perhaps they should be included. In number, the Gymnosperms are very much inferior to the more recent and specialized Angiosperms. They nevertheless include some of the largest and most important of all plants. The prevailing modern Gymnosperms are the Conifers, especially well developed upon the Pacific slope of North America. The Cycads are mostly tropical forms, much inferior in size and numbers to the Conifers. The Gnetales comprise a small number of plants of doubtful affinities.

A

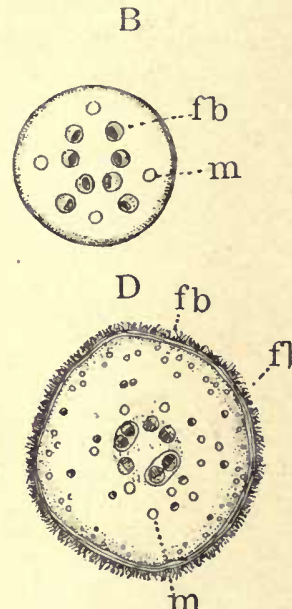

im

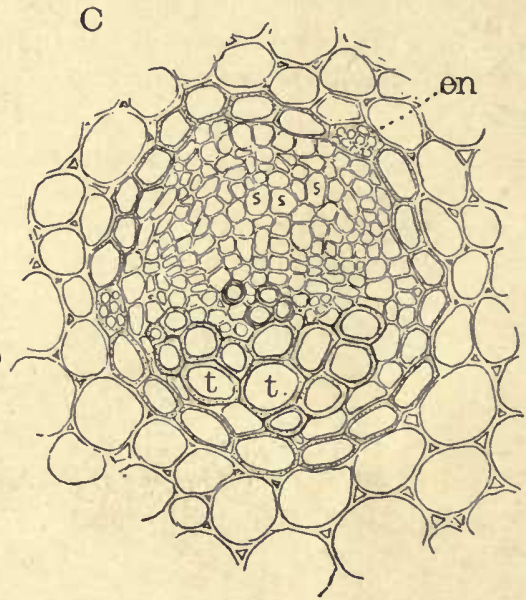

Fia. 289. $-A-C, C y c a s$ revoluta. $A$, young leaf from a small plant, showing the incurved pinnæ. $B$, cross-section of the petiole $(\times 6)$; $f b$, vascular bundles; $m$, gum-passage. $C$, vascular bundle of petiole $(\times 175)$; en, endodermis : $s$, sievetubes; $t$, tracheids. $D$, cross-section of the peduncle of the cone of Zamia integrifolia $(\times 2)$.

Classification of Gymnosperms. - The existing Gymnosperms may be divided into four orders - Cycadales, Ginkgoales, Coniferæ, and Guetales. To these may be added two extinct orders, Cycado-filices and Cordaiteæ.

\section{Order I. Cycadales}

The lowest of the existing seed-bearing plants, with the possible exception of Ginkgo, are the Cycads, comprising about seventy-five species, for the most part confined to the Tropics. A single species, Zamia integrifolia, occurs in Florida, and Cycas revoluta (Pl. IV) reaches beyond the northern tropic in Japan. 

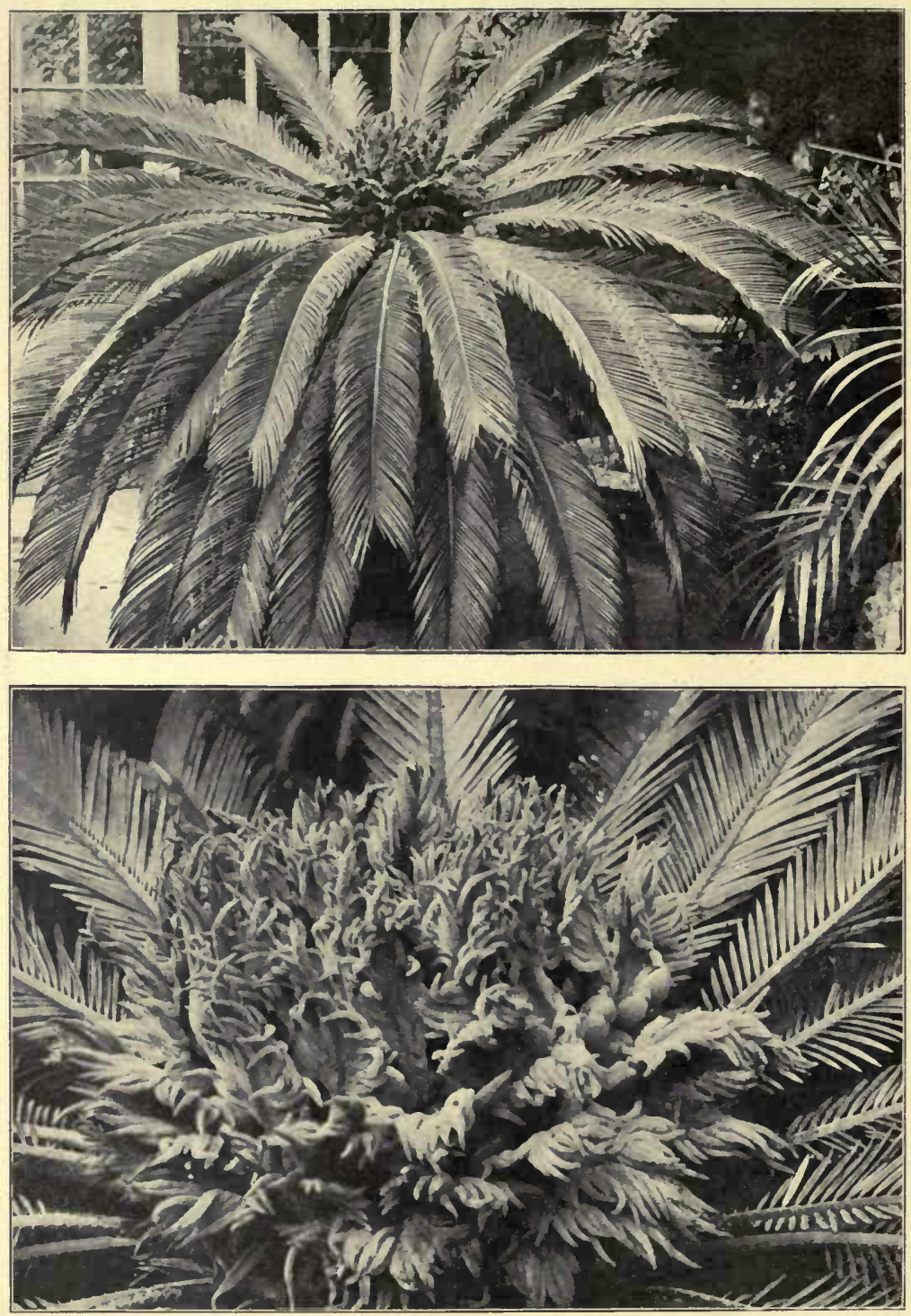

PLATE IV

Cycas revoluta. The upper figure shows a female plant in flower; the lower figure the group of sporophylls more enlarged. 
The habit of the sporophyte in the Cycads is fern-like, and one species, Stangeria paradoxa, was actually first described as a Fern. The large pinnate, or in Bowenia bi-pinnate, leaves spring from the summit of a trunk, which may be cylindrical and several metres in height, or is short and almost globular. The leaves may form a close crown, like that of a Palm, or they may be few in number. In the former case-e.g. Cycas - they are formed in series, a whorl of foliageleaves, which unfold simultaneously, alternating with a whorl of scale-leaves, the arrangement being much like those in certain Ferns with regular periodic growth, such as Struthiopteris Germanica. The young leaves in Cycas (Fig. 289) have the pinnæ coiled inward, very much as in the Ferns. The leaflets may have a single median vascular bundle, as in Cycas, but usually there are several reins, which either run parallel or, in Stangeria, are forking, like those in the leaves of many Ferns.

\section{The Stem}

The stem may remain unbranched, but in the large species, especially Cycas revoluta, the older plants are frequently branched, this looking as if it were the result of dichotomy. Small adventitious buds are often formed in large numbers at the base of the stem, usually from the leaf-bases. There is a secondary growth in thickness in the stem, but it is very slow, so that the stem increases but little in diameter after the crown of leaves
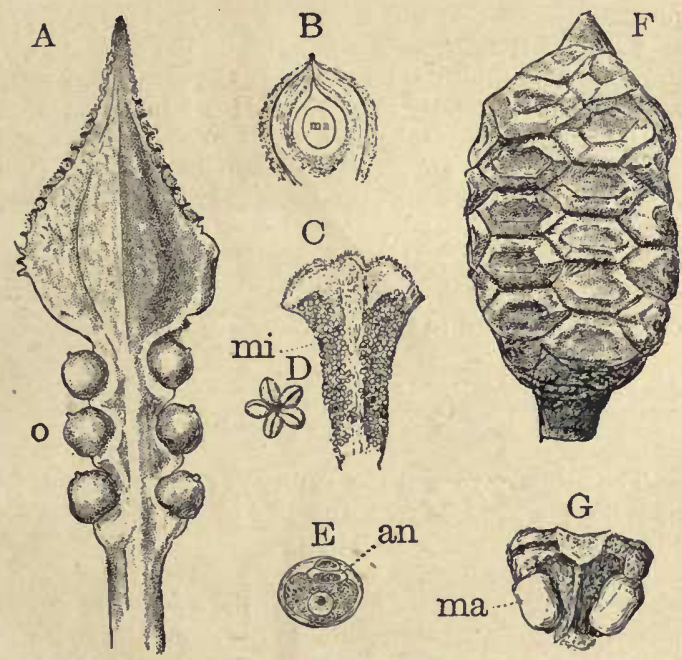

Fig. 290. - A, Cycas circinalis, sporophyll with ovules, o $\left(\times \frac{2}{3}\right) . \quad B-E, C$. revoluta. $B$, section of young ovule (natural size); ma, macrospore (embryo-sac). $C$, sporophyll with microsporangia (pollen-sacs), mi $\left(\times \frac{i}{)}\right.$. $D$, sorus of microsporangia, enlarged. $E$, ripe pollen-spore $(\times 400)$; an, antheridium. $F, G, Z$ amia integrifolia. $F$, female cone $\left(\times \frac{1}{2}\right)$. $G$, sporophyll with two macrosporangia $(\times 1)$. has attained its full size.

Histology of Stem. - The growth of the stem-apex is due to a group of initial cells. The stein shows a large central pith about which is arranged a circle of collateral bundles, very much as in the stem of Botrychium, and the bundles show a slight development of secondary wood, due to the activity of the cambium; but a large part of the stem is composed of fundamental tissue. The cambium, in Cycas, finally ceases its growth, and a new cambium-ring is developed in the cortex, outside the ring of bundles, and this gives rise to a second ring of wood and bast. This is repeated, resulting in alternating rings of wood 
and bast. In addition to the primary ring of bundles, there nuay also be developed accessory bundles, both in the pith and cortex, resulting in a very complicated arrangement of the tissues in the older stem. The bundles are always collateral, and in structure approach most nearly those of the eusporangiate Ferns. Between the primary vascular bundles are extensions of the pith, or medullary rays, such as are found in the stem of the Coniferæ, but which are also found in Botrychium. There is developed in the outer cortex a mass of growing tissue, or Periderm.

\section{The Leaf}

Two vascular bundles enter each leaf, and fork several times, so that a crosssection of the petiole (Fig. 289, B) shows several bundles arranged in the form of an $\Omega$. Branches are given off into each leaflet, where they may remain undivided (Cycas), or may divide.

Mucilage-ducts. - Traversing the petiole are numerous conspicuous gum and mucilage-ducts $(m)$ which resemble very closely those of the Marattiaceæ.

Vascular Bundle. - The bundles of the petiole in Cycas (Fig. 289, C) show a group of small spiral tracheids near the centre, outside of which is a mass of large scalariform tracheids. The rest of the bundle is composed of the phloem, which contains large sieve-tubes with lateral sieve-plates, somewhat like those of the Ferns. There is a conspicuous bundle-sheath (en), associated with which are often encountered cells containing crystals. In Dioon, concentric bundles, also, are found in the petiole. The green tissue of the leaf forms a palisade-parenchyma above, the cells having their walls more or less thickened so as to give firmness to the leaf. The stomata, which show accessory cells about the guardcells, are confined to the lower surface.

\section{The Root}

The primary root of the embryo (Fig. 292, E) develops into a thick tap-root, as it does in the Conifers, and like these it shows a secondary thickening due to the development of a cambium.

Tubercular Roots. - Curious secondary roots are sometimes developed, especially in Cycas. These arise near the surface of the ground and show a dichotomous branching, which results in dense coral-like masses. Associated with these are always found Bacteria and a species of Anabæna. These root-tubercles always contain large air-spaces, and may perhaps be special organs for aeration of the roots. The presence of the Schizophytes within the tissues may possibly be associated with the assimilation of nitrogen.

\section{The Sporangia}

The macrosporangia (ovules) and microsporangia (pollen-sacs) are in all Cycads borne upon different plants. In Cycas the macrosporophylls (Pl. IV) are separate, and arranged like the foliage-leaves, which they also resemble in their pinnate form. In all of the other genera both kinds of sporophylls are arranged in a thick cone (Fig. 290, F) upon special shoots.

The microsporangia are borne upon the lower side of the sporophyll (Fig. $290, \mathrm{C})$, and may be arranged in sori like those of a Fern. In their origin and developinent they are strikingly like the sporangia of the Marattiaceæ, even 
showing a rudimentary annulus like that of Angiopteris. The spores are bilateral in form, and the pollen-sac opens by a longitudinal cleft.

The macrosporangia in Cycas are borne laterally upon very slightly modified sporophylls (Fig. 290, A). 'The ovule consists of a central part, the nucellus, enclosed by a thick integument, which becomes pulpy and bright colored, looking like a large cherry or plum.

The young ovule develops a mass of sporogenous tissue, a single cell of which, after preliminary division, gives rise to the single macrospore or Embryo-sac. This develops a double wall, like the macrospore of the Pteridophytes, but never escapes from the sporangium.

\section{The Gametophyte}

The microspore, before it escapes from the pollen-sac, has already divided into three cells (Fig. 290, E), one of which is much larger than the others. Of the two smaller cells the inner one is the antheridial cell, and is carried into the pollen-tube when the spore germinates.

The development of the female gametophyte (Figs. 291, 292) is much like that of Isoetes. The primary nucleus of the macrospore divides into a large number of free nuclei, between which the primary cell-walls arise simultaneously. Finally the spore becomes filled with the prothallial tissue, and several archegonia are developed at the apex. These have each a very large egg-cell, from which a canal-cell is later cut off. Two neck-cells are developed.

\section{Fertilization}

The fertilization (Fig. 291) has been recently studied in Zamia integrifolia and Cycas revoluta. At the apex of the ovule there is developed a cavity, the pollen-chamber, into which the pollen falls, and begins its germination. The pollen-tube grows into the tissue of the nucellus, from which it doubtless obtains its nourishment. The upper end, to which the

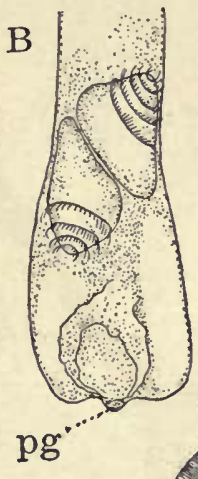

A

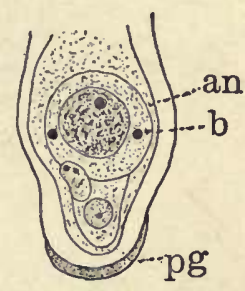

pc, $\mathrm{O}$

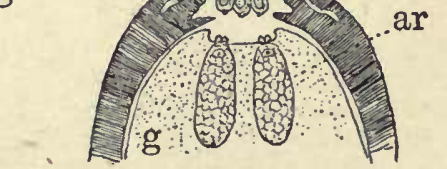

Fig. 291.-A, Cycas revoluta, pollen-tube containing the large antberidial cell, an; the nucleus has not yet divided, but two blepharoplasts, $b$, are present; $p g$, wall of pollen-grain. $B, C, Z$ amia integrifolia. $B$, pollen-tube containing the two large spermatozoids $(\times 75)$. C, upper part of ovule (somewhat diagrammatic), showing three germinating pollen-spores in the pollen-chamber above the archegonia, $a r$. ( $A$, after Ikexo. $B, C$, after Webber.) meinbrane of the pollen-spore is still attached, increases very much in size, and becomes distended with the watery fluid within. Shortly before fertilization is to take place the nucleus of the antheridial cell divides, and two very large spermatozoids, each provided with a spiral ciliated band, derived from the large blepharoplast, are set free within the tube. The pollen-tube then bursts, and discharges the fluid contents, together with the spermatozoids, into the chamber above the archegonia, into which the sperniatozoids then enter as they do in the Ferns. 


\section{The Embryo}

Within the egg-cell the nucleus of the spermatozoid fuses with that of the egg. The nucleus thus formed gives rise to many free nuclei (Fig. 292, B), and the cell-formation in the young embryo in Cycas is much like that of the gametophyte. The lower part, only, of the egg, forms the embryo, the upper portion remaining as a sac. A very long suspensor is developed, and the embryo develops two thick cotyledons, which remain in the large seed when it germinates, the first foliage-leaf arising between them (Fig. 292, E).

Where fertilization is not effected, the gametophyte has been observed to continue its growth, and protrude from the ovule as a mass of green tissue, a condition unknown elsewhere among the Spermatophytes.
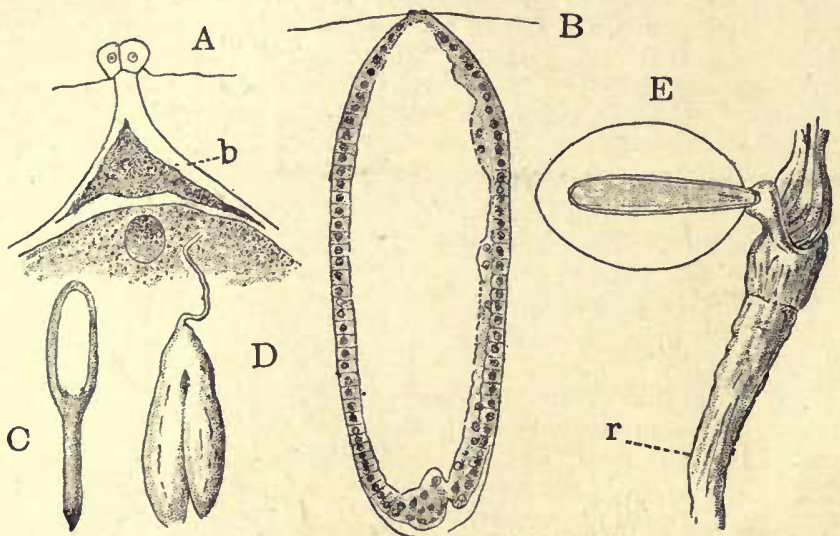

Fig. 292. $-A$, Cycas revoluta, upper part of archegonium $(\times 60) ; b$, ventral canalcell. $B-E, C$. circinalis. $B$, fertilized egg-cell, showing an early stage in the development of the embryo $(\times 15)$. $C$, an older embryo $(\times 6)$. $D$, a still older one, showing suspensor and two cotyledons. $E$, germinating seed $\left(\times \frac{1}{2}\right)$; the cotyledons remain in the seed; $r$, the large tap-root of the young sporophyte. ( $A$, after Ikeno. $B-E$, after Treub.)

\section{Order II. Ginkgoales}

The second order of the Gymnosperms includes but a single plant, the curious "Maidenhair-tree," Ginkgo biloba (Fig. 294), of China, but which is extensively cultivated in Japan, and to some extent in the United States. It is a large tree, which has usually been associated with the Coniferæ, from which it differs in several important respects, especially the character of the gametophyte, which is much more like that of the Cycads.

The leaves are deciduous, and in their form and dichotomous venation are much like those of such Ferns as Adiantum. The trees are diœcious, like the Cycads, and the structure of the ovule and ripe seed is much the same as in the Cycadaceæ. The pollen-sacs are 
borne upon small sporophylls arranged upon slender spikes. 'The germination of the pollen-spores, and the development of motile spermatozoids, is the same as that of the Cycads, and the development of the embryo is similar.

The histology of the stem of the older sporophyte, however, is more like that of the Coniferæ.

Geological History of Ginkgo. - Ginkgo is, even more than the Cycads, a left-over type. Forms undoubtedly related to Ginkgo

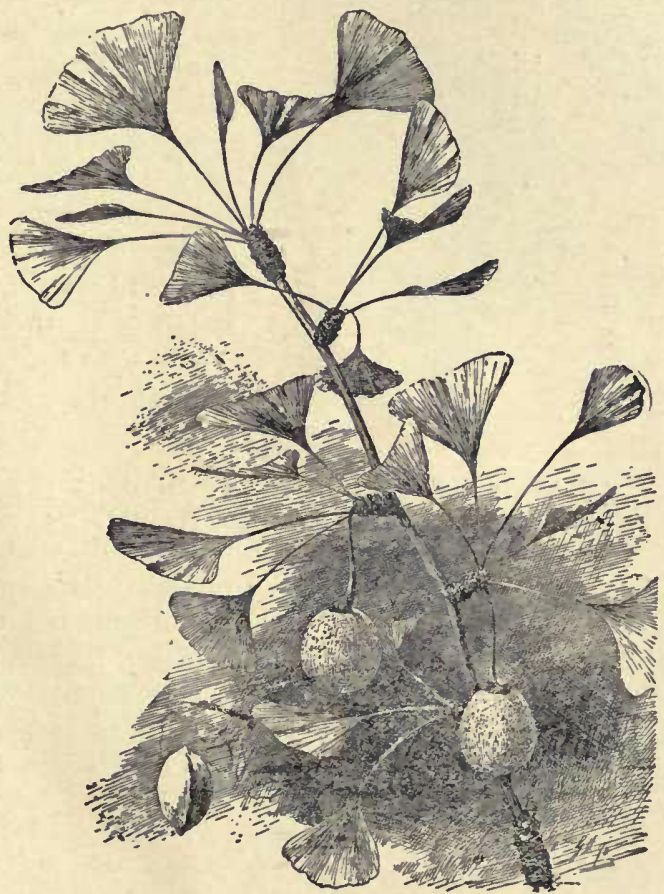

Fig. 293. - Ginkgo biloba. Brauch of a fruiting tree, reduced. (After BaILEx.)

occur in the later Carboniferous, and during the late Palæozoic and early Mesozoic Ages, the order was represented by numerous species.

\section{Order III. Coniferæ}

Much the greater number of existing Gymnosperms belong to the Coniferæ, which include all the familiar "evergreen" trees of the northern forests. The sporophyte may reach gigantic dimensions and live many hundreds of years. Several species of the Pacific coast forest attain a height of over one hundred metres, with a stem- 
diameter in Sequoia of ten metres or more, near the base (Pl. I, frontispiece). The leaves are always sinall, and often needlelike, differing very much in this

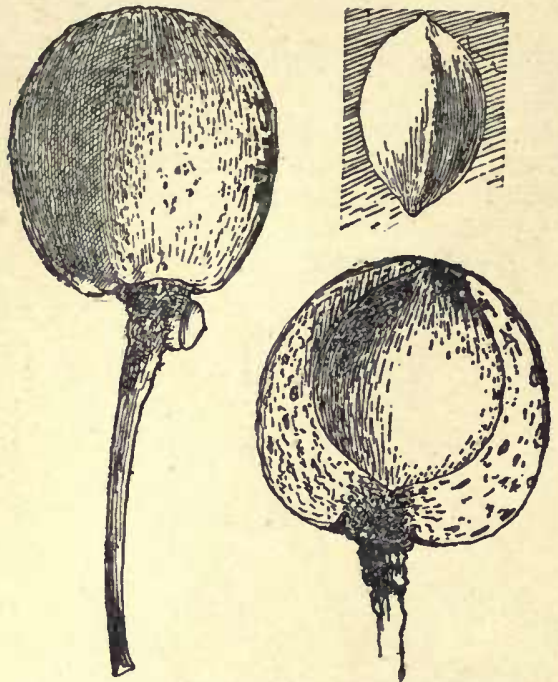

FIG. 294. - Ginkgo biloba. Fruit and seed. (Natural size.) (After BaILEx.) respect from the Cycads. In Agathis and Araucaria, the leaves are broader than in the other genera; and in Sciadopitys, the leaves are rudimentary and replaced by flattened branches, or phylloclades.

The stem branches freely, the branching being usually very symmetrical, so that the trees often assume a perfect conical shape. This is mainly due to the persistence of the apical bud, which results in a straight central shaft about which the lateral branches are regularly disposed.

A tap-root is present in the young sporophyte, and may persist for a long time, but is often replaced by secondary roots.

Distribution. - The Coniferæ are cosmopolitan, but are best developed in the temperate regions of the northern hemisphere. They reach their maximum development in the countries about the northern Pacific, both in Asia and America. The forest of our own Pacific slope is composed in great part of coniferous trees, which here reach their greatest size.

\section{The Stem}

The apex of the stem in the Coniferæ probably never grows from a single initial cell. A group of terminal initials, much like that in the Cycadaceæ and Lycopodium, has been demonstrated in the Abietineæ. In other forms, e.g. Araucaria, Cunninghamia, Sequoia (Fig. 295), a single group of initials is not present, but the primary tissue-systems are continuous over the apex of the shoot. The central tissue-cylinder, from which is derived the pith, can be easily followed to the apex. Overlying this is the periblem, from which the cortex and vascular bundles arise, and the dermatogen, or primary epidermis, forms a single layer over the apex.

The leaves arise as lateral outgrowths of the stem, and show much the same distribution of their young tissues. A single leaf-trace, or vascular bundle, passes from each leaf into the stem, and the unions of these leaf-traces form the 



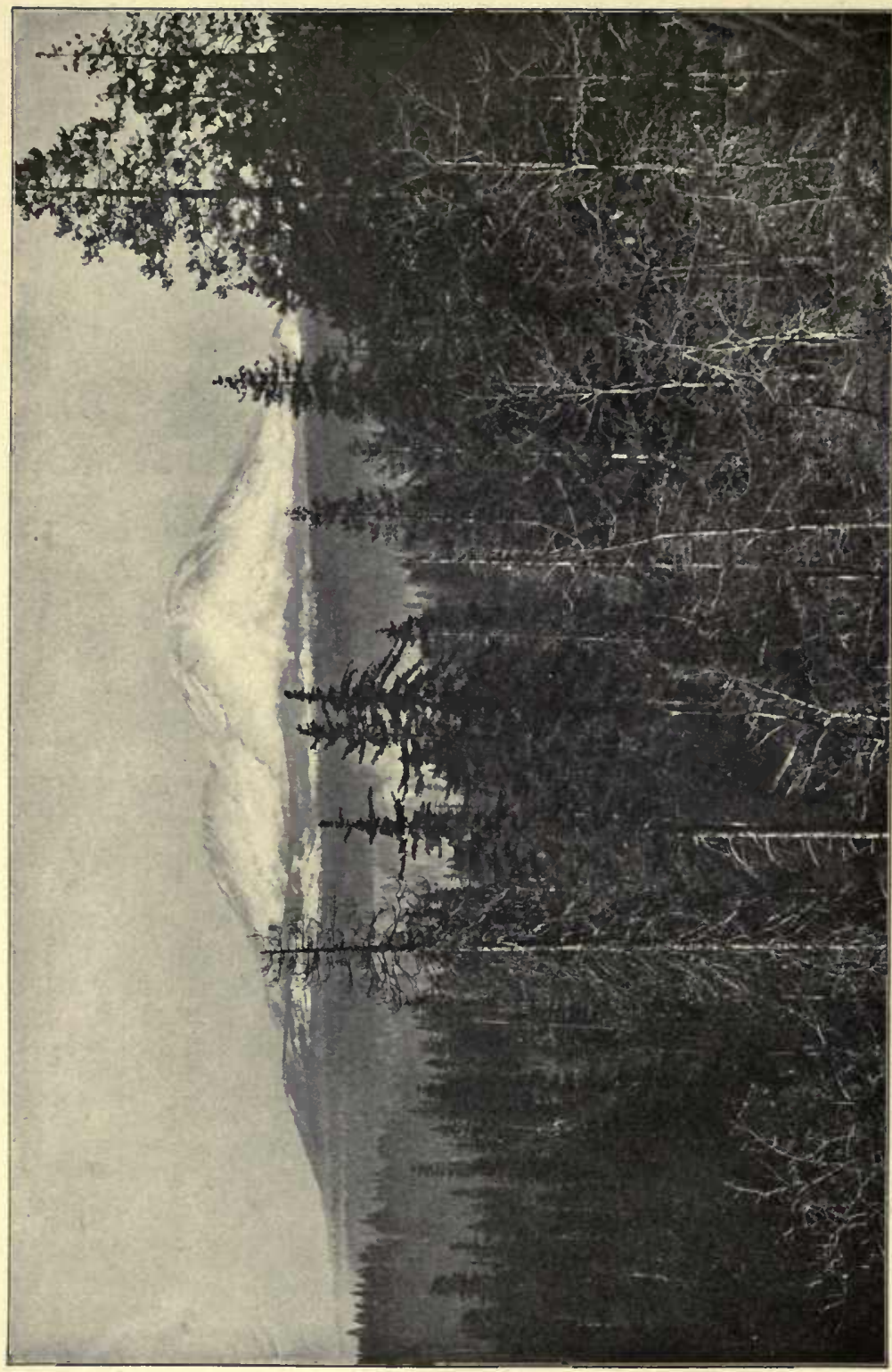

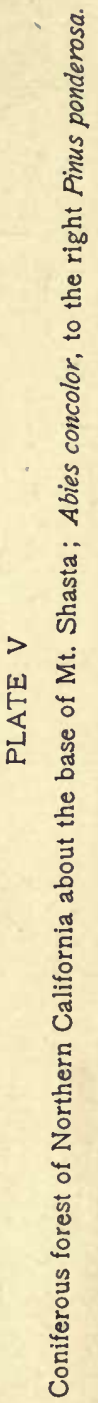


vascular bundles of the stem, very much as in Equisetum. The branching of the stem is monopodial, the buds arising in the axils of the young leaves.

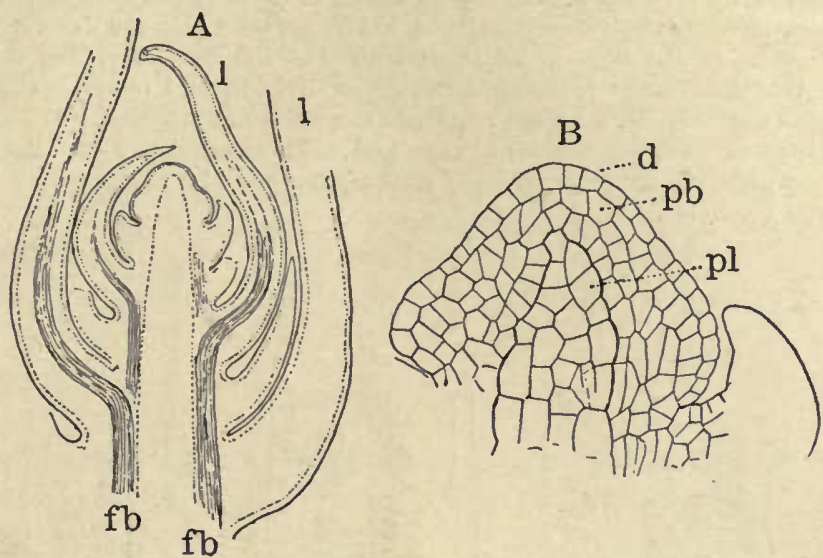

Fig. 295. - Sequoia sempervirens. Section of shoot apex $(\times 25) ; l, l$, leaves; $f b$, vascular bundles. $B$, apex of shoot $(\times 150) ; d$, dermatogen; $p b$, periblem; $p l$, plerome.

The older stem (Fig. 296) in all Coniferæ shows a central pith surrounded by a ring of vascular bundles composed of the united leaf-traces. The bundles are collateral, and the woody portion, or xylem, extraordinarily developed. The

m B
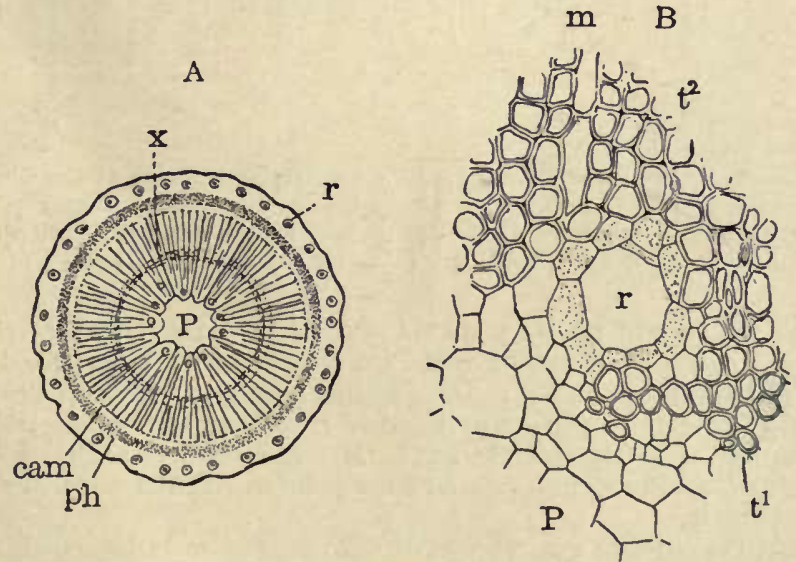

Fig. 296. - A, Pinus Virginiana, cross-section of two-year-old branch. $P$, pith; $x$, wood, showing two annual rings; cam, cambium; $p h$, phloem; $r$, resin-ducts in the cortex. $B, P$. insignis, cross-section of the inner part of the wood $(\times 250)$. $P$, pith; $t^{1}$, primary trachere; $t^{2}$, secondary tracheids; $r$, resin-ducts; $m$, medullary ray.

first-formed woody elements are small spiral tracheids in contact with the pith, and the development of the wood is centrifugal. The secondary xylem is made 
up of tracheids of very characteristic form, arranged in radiating series. These traclieids have their radial walls marked with characteristic bordered pits (Fig. 297, A), which are usually nearly round in outline, but may be somewhat elongated, like those of the Cycads and Ferns. These pits are developed upon opposite sides of the wall in adjacent tracheids, the bottoms being separated by the thin membrane forming the original division-wall between the young tracheids (Fig. 297, B). At intervals the tracheids are replaced by radially extended rows of cells, the medullary rays $(m)$. These consist of radiating plates of cells, which are usually parenchymatous, but may be composed in part of horizontal tracheids.

A

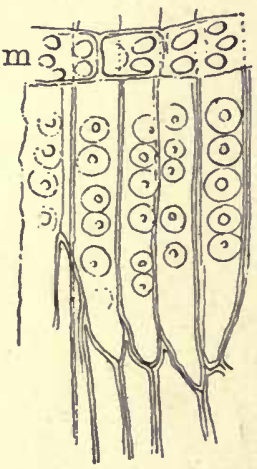

C

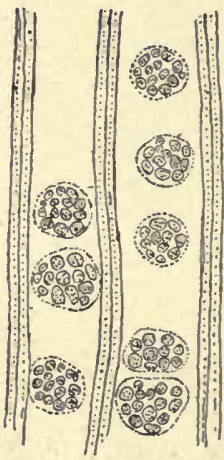

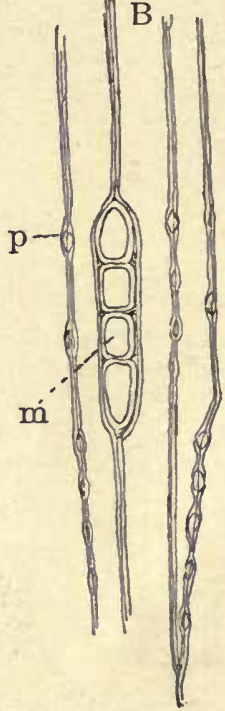

Fig. 297. $-A, B$, Pinus insignis. $A$, radial longitudinal section of the wood, showing bordered pits upon the walls of the tracheids; $m$, medullary ray. $B$, tangential section, cutting across the pit, $p$, and a medullary ray, $m(\times 250)$. C, sieve-tubes of $P$. sylvestris $(\times 500)$. ( $C$, after Strasburger.)

Outside the mass of the wood is the Cambium (cam.), a zone of meristematic cells, which divide by periclinal walls, the cells upon the inner side becoming transformed into wood-elements, those upon the outside adding to the phloem. The most important elements of the latter are the sieve-tubes, which have numerous lateral sieve-plates (Fig. 297, C). Elongated parenchyma cells and fibrous cells (bast-fibres) also occur in the phloem, and the medullary rays are continued into it.

Bark. - The outer or cortical part of the young stem is compneed largely of green parenchyma. Later a zone of meristematic tissue, the Pri derm, is developed below the epidermis, and it is to the activity of this layer that the development of the bark is due. Part of this is the Phellogen or "Cork-cambium."

In both cortex and wood there occur numerous large resin-ducts which are structurally much like the gum and mucilage ducts of the Cycads. The secondary wood of Conifers, unlike that of dicotyledonous trees, is composed exclusively of tracheids. 
In most Conifers there are regular periods of growth, followed by a dormant period, which in northern regions falls in the winter. With the sudden renewal of activity in the spring, the growth of the young tracheids is especially marked, and these first formed tracheids are much larger in the radial diameter, and have thinner walls than the tracheids last formed in the autumn. This results in the sharp line between the rings of wood marking two successive years' growth. Under normal conditions, one growth-ring is formed each year, and the rings of wood constitute a very fair index of the age of the tree. It is probable that the largest of the living Sequoias are two thousand to twenty-five hundred years old.

\section{The Leaf}

The leaves of the Conifers may be inserted singly upon the shoot, as in Taxus and Tsuga (Figs. 308, 309); or they may be in clusters, or fascicles upon special short shoots, as in Pinus, Cedrus, and Larix. In the latter, and in the Baldcypress ('laxodium) of the Gulf states, the leaves are shed each year. In most Conifers they persist for several years.

Each leaf receives a single vascular bundle from the stem. This may remain undivided, or it may divide into two or more. A transverse section of the leaf of Pinus (Fig. 299) shows the epidermal cells to be very thickwalled, and the stomata are sunk in pits, overlying an airspace in the mesophyll. Below the epidermis is a greater or less amount of hypodermal tissue, composed of colorless, very thick-walled fibrous cells, with

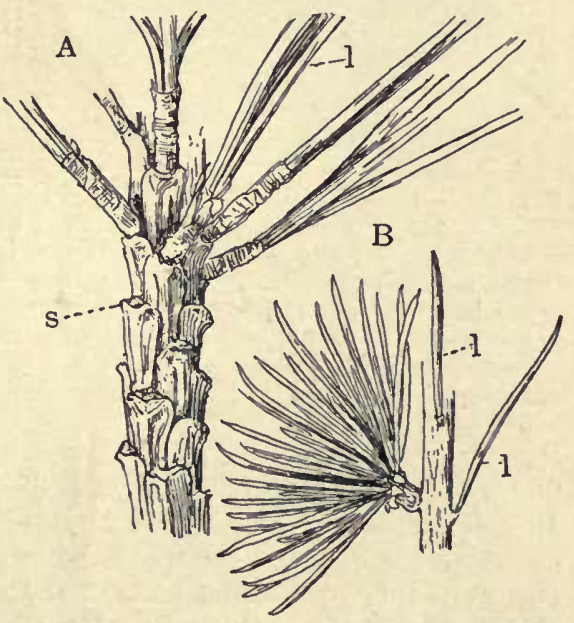

Frg. 298. - A, Pinus Coulteri, branch showing scars, $s$, where the short leafy shoots (fascicles), $l$, have fallen off (natural size). $B$, Cedrus Libani, showing many-leaved fascicle and two single leaves, $l$ (natural size). connecting canaliculi between their cavities.

The green tissue is composed of irregular cells, with large intercellular spaces. In Pinus, these cells have conspicuous infoldings of the cell-walls, which increase the area occupied by the chloroplasts.

In the middle of the leaf are the two vascular bundles, closely resembling those of the stem. The xylem is turned toward the upper side of the leaf. Surrounding the two bundles is a large oval area (in section), sharply separated, by a definite row of cells, from the green mesophyll. 
Scale-leaves. - Besides the typical foliage-leaves, scale-leaves, which are purely protective and quite destitute of chlorophyll, are of cominon occurrence.

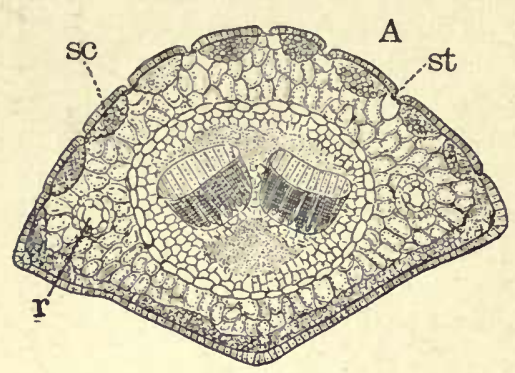

These are especially well developed in the Pines and Firs, where the winter-buds, terminating each season's growth, are completely covered by them. Similar protective leaves usually enclose the young flowers.

\section{Branching}

All of the Coniferæ branch freely, and owing to the persistence of the terminal bud, both in the main axis and the lateral

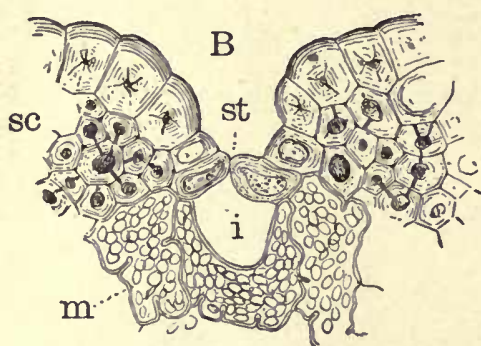

Fra. 229. - Pinus Coulteri. A, section of leaf $(\times 3 \overline{5}) ; r$, resin-ducts in the green mesophyll; st, stomata ; $s c$, hypodermal masses of sclerenchyma; the two vascular bundles lie in the central colorless area. $B$, stoma, and surrounding tissues $(\times 400) ; s c$, sclerenchyma; $i$, air-space below the stoma; $m$, mesophyll-cells. shoots, the trees are exceedingly symmetrical in form. A bud may be formed in the axil of each leaf, but only a small proportion of these develop. In the Pines, while buds are formed in all the axils of the leaves of a shoot, only a small number, developed just below the terminal bud, give rise to the branches, which thus are arranged in circles, the successive circles being separated by internodes representing a season's growth. This is still more marked in Araucaria. In case the terminal bud is destroyed, one of the lateral branches below it grows upright and takes its place. In a few species - e.g. Pinus Sabiniana - the main axis very early ceases its growth, and the tree is widely branched, and the same thing occurs in some other species as they grow old. This is seen in the Italian Stone-pine ( $P$. pinea), $P$. rigida, and other species. Adventitious buds are developed in some forms, this being especially conspicuous in Sequoia sempervirens.

\section{The Root}

The tap-root of the young sporophyte is usually replaced by numerous lateral roots, which often spread horizontally for a long distance.

The young root shows a central plerome-cylinder, covered with a common initial layer of tissue from which the other tissues are developed. The primary root is diarch in most forms, but in the Abietineæ, where the number of cotyledons is more than two, the number of primary xylem-masses in the root is more than two (Fig. 307, G), although not necessarily as many as the coty- 
ledons. The lateral roots, as a rule, liave more than two xylem-masses. The lateral roots originate from the pericycle, the tissue lying within the endodermis, and not from the endodermis itself, as among the Ferns.

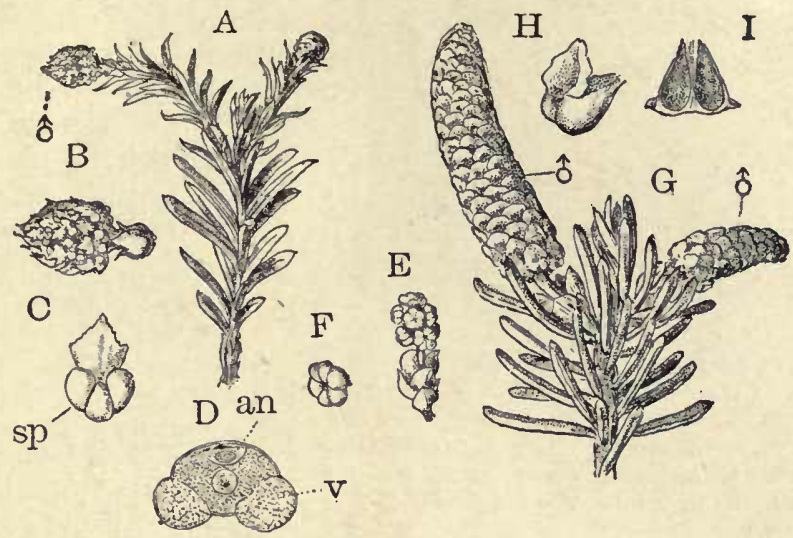

Fig. 300.-A-C, Sequoia sempervirens, branch with male flowers (natural size). $B$, flower, slightly enlarged. $C$, scale with three microsporangia. D, Pinus insignis, pollen-spore, showing the wings, $v$, and the antheridial cell, an, highly magnified. $E, F$, Taxus baciata. $E$, male flower $(\times 3) . F$, single sporophyll, with six sporangia $(\times 6) . G-I, P i c e a$ orientalis, shoot with two male flowers, 0 , slightly enlarged. $H$, sporophyll with two sporangia $(\times 4)$. $I$, sporophyll from below, with two empty sporangia.

A cambium-ring is developed in the root, outside the ring of alternating xylem and phloem masses of the primary bundle, and a secondary increase in thickness, very much like that in the stem, is thus inaugurated.

\section{The Flowers}

The flower of the Coniferæ, except the female flower of the Taxaceæ, consists of a strobilus, or cone, comparable to that found in the Equisetales or Lycopodiales. Each sporophyll bears one or more sporangia (ovules or pollen-sacs), which structurally are much like those of the Pteridophyta.

In the Taxacer the ovule is axial in origin, being the transformed apex of a shoot (Fig. 303).

The male flowers (Figs.
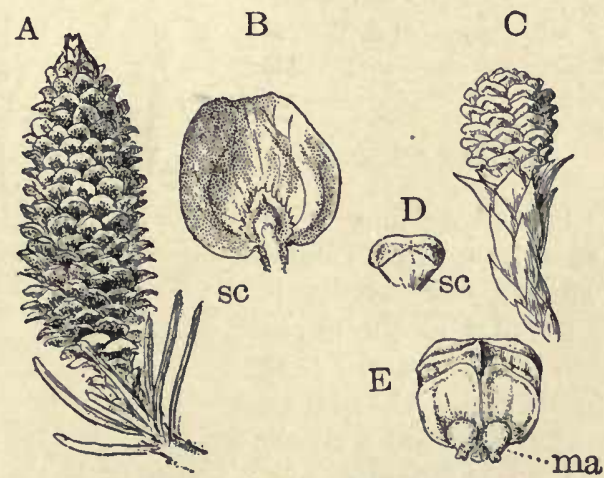

Fia. 301.-A, B, Picea excelsa. $A$, female cone, slightly enlarged. $B$, a sporopliyll, seen from below, with the subtending scale, $s c(\times 4) . C-E$, Pinus Halapensis. $C$, female cone, ready for pollination $(\times 2)$. $D$, sporophyll, seen from behind with subtending scale, $s c(\times 4)$. $E$, scale from an older cone, with the two ovules, $m a$. 
287,300 ) are similar in structure in all Coniferæ. The sporophylls are sometimes brightly colored, red or yellow, and may be peltate

A

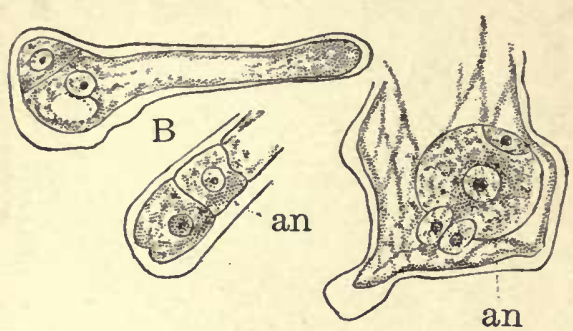

Fig. 302. - Taxus baccata. Germination of the pollen. (After BELAJEFr.) $A$, germinating pollen-spore, showing the division. into two cells. $B$, second division, forming antheridial cell, an. $C$, an older stage, the antheridial cell, an, divided into two. $(A, B, \times 375$; $C, \times 200$.) ('laxus), or scales with the sporangia upon the lower surface. The male flowers are usually borne singly, but may be in clusters (Pinus). The number of pollen-saes upon each sporophyll ranges from two (Pinus, Abies, etc.) to a dozen or more in Araucaria.

The development of the pollen-sac is much like that of the sporangium in the Lycopodiales, and each sporogenous cell gives rise to a tetrad of spores. In the Pinaceæ the outer membrane of the ripe

pollen-spore is provided with two saclike outgrowths, or wings, which assist in the distribution of the spores by the wind. The outer cells of the wall of the ripe pollen-sac are sometimes provided with spiral thickenings like those in Equisetum. The pollen-sac opens by a longitudinal cleft (Fig. 300, I).

The pollen-spore, when discharged from the sporanginm, may be undivided (Taxus), but usually it has already divided into two cells (Fig. 300, D), of which the smaller one becomes the antheridium. The formation of the latter may be preceded by one or more divisions (Pinus, Larix), the first-formed cell, or cells, being disorganized before the pollen-spore is ripe.

\section{Female Flower}

The ovule may arise from the apex of a shoot (Taxus), but usually it is borne upon the upper side of a scale. The number in the latter case varies from a single one in Araucaria and Agathis, to many in Cupressus.

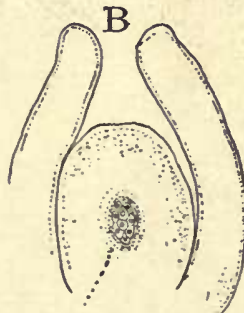

$\mathrm{sp}$
A

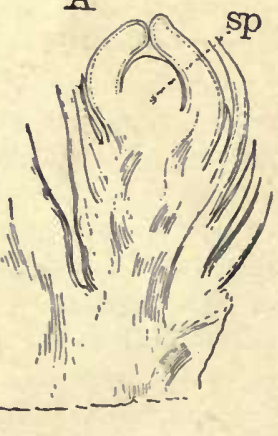

FIG. 303. - Taxus bacca:a. A, section of shoot, terminating in the young ovule, $s p(\times 30)$. $B$, a slightly older one, more enlarged, showing the sporogenous tissue, $s p$.

The ovules may arise directly from the sporophyll, as in Sequoia (Fig. 305) and Cupressus ; or there is present a "seminiferous scale," which is placed in the axil of the sporophyll. The nature of this 
seminiferous scale has been much discussed, but it is probably to be considered as an outgrowth of the sporophyll, perhaps comparable to the placenta of the Angiosperms. In the Abietineæ the seminiferous scales become very much developed, and form the hard, woody scales of the ripe cone.
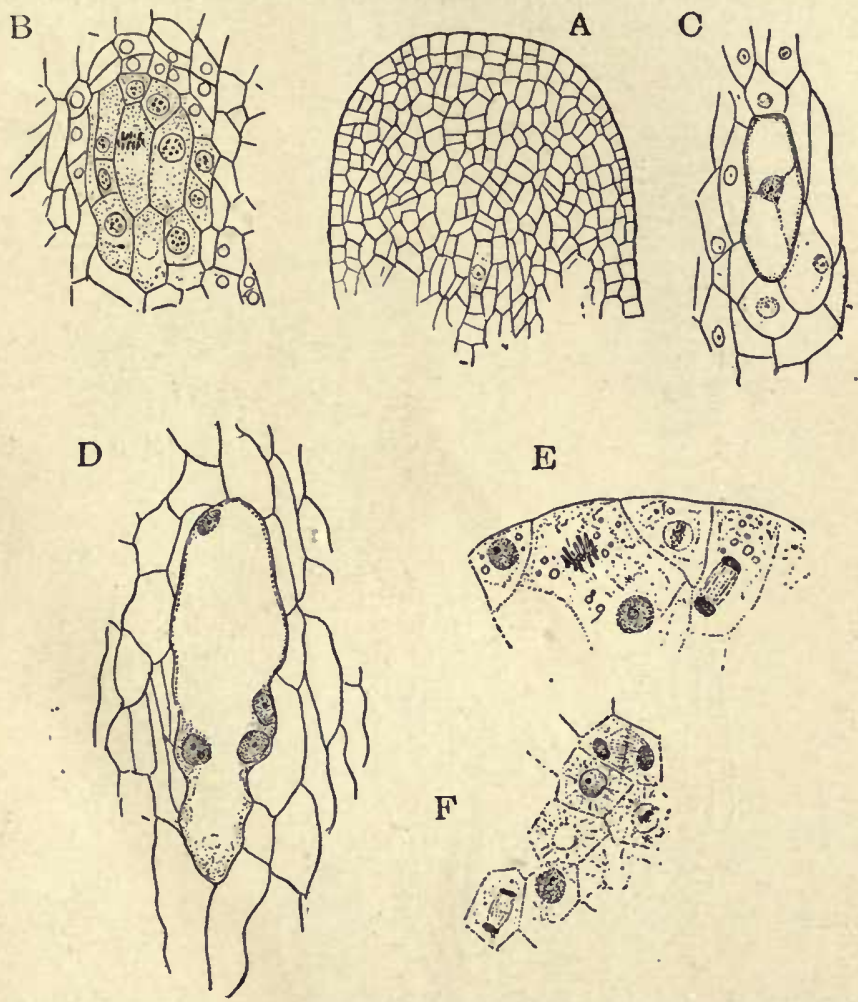

Fia. 304. - Taxus baccula. $A$, section of the nucellus of a very young ovule $(\times 150)$. $B$, sporogenous tissue from an older ovule. $C$, an older stage showing young embryo-sac (macrospore) $(\times 200) . \quad I$, an older stage, with numerous free nuclei. $E, F$, cell-formation in the young gametophyte $(\times 500)$.

The young ovule is a nearly hemispherical body, about which, at a very early stage, is developed the single integument (Fig. 305, C). The sporogenous tissue may be traced, in some cases at least, to a group of cells which are the lowest members of rows of cells, probably derivatives of single hypodermal cells. These sporogenous cells enlarge, and usually divide into two or four cells, the young macrospores, or embryo-sacs. Sometimes but a single one of these develops; but in Sequoia (Fig. 305) several of the embryo-sacs begin to develop, although only a single one reaches maturity.

Female Gametophyte. - The primary nucleus divides repeatedly, the nuclei being arranged about the wall of the young embryo-sac (Fig. 304, D). Between 
these division-walls are then formed, so as to divide the peripheral protoplasm into "areoles," which are at first open below. With the following nuclear divisions the embryo-sac is gradually filled with a continuous tissue, the gametophyte, or " Endosperm," as it is usually termed in the Spermatophytes.

Archegonium. - The archegonia (Figs. 305, F, 306) may be found in large numbers over the whole of the upper part of the gametophyte (Sequoia), or they may be much fewer in number, and restricted to the apex of the gametophyte,

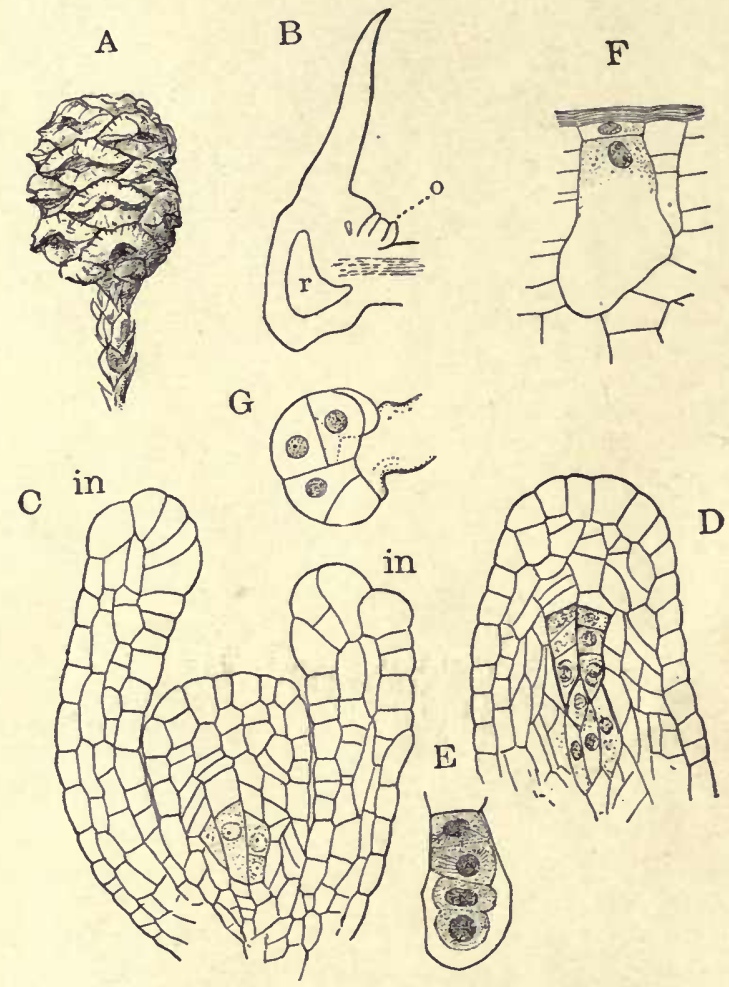

Fra. 305. - Sequoia sempervirens. $A$, ripe cone (natural size). $B$, scale from young cone, showing an ovule, $o$, and resin-duct, $r(\times 30)$. C, section of young ovule showing integument, in, and young sporogenous tissue. $D$, nucellus of an older ovule, the sporogenous cells divided. $E$, sporogenous cell divided into four (×275). $F$, young archegonium. $G$, young embryo $(\times 275) .(B, E, F, G$, after SHAw.)

as in Pinus. In the Cupressineæ they are close together. The neck may consist of but two cells (Sequoia), or there may be several (Pinus). In Abies the neck-cells are in two tiers. The egg-cell is very large in the Abietineæ, and presents a peculiar foamy appearance. Surrounding it is a well-defined layer of cells, some of whose nuclei pass into the egg-cell before fertilization. Usually a ventral canal-cell is cut off from the egg, but this is probably not the case in Sequoia and some Cupressineæ. 
Fertilization. - When the female cone is ready for pollination, the scales separate and the pollen falling upon them sifts into the spaces between them. The scales then close, and very often the upright flower bends over, which probably assists in bringing the pollen upon the apex of the ovule. 'The integument of the latter is often provided with prominences, which serve to hold the pollen, and a drop of fluid is sometimes excreted, which by its evaporation deposits the pollen upon the apex of the nucellus, where it begins to grow.

In the Pines the development of the cones requires two years. Pollination is effected in the spring, and the growth of the pollentube into the tissue of the nucellus begins; but growth then stops,

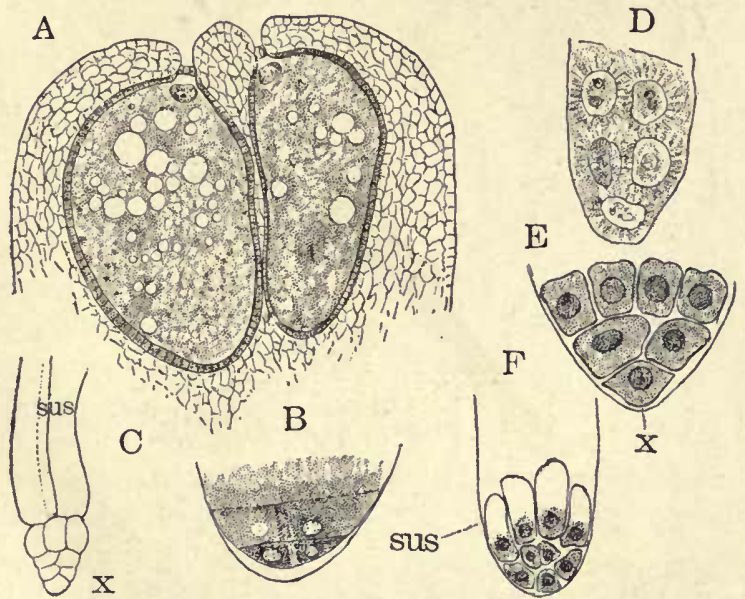

FIG. 306.- $A, B$, Pinus insignis. $A$, upper part of gametophyte, with two archegonia $(\times 35) . B$, lower end of fertilized egg, showing first divisions $(\times 75)$. $C$, young embryo; sus, suspensor; $x$, apical cell. $D-F$, Taxus baccata. Development of embryo; $x$, apical cell; sus, suspensor. $(D, E, \times 500 ; F, \times 270$.) ( $D-F$, after JAEGER.)

and is only resumed the following spring, during which the female gametophyte develops and fertilization is effected. The ovule then has the integument hardened, and becomes the seed.

The development of the pollen-tube is very much like that of the Cycads (Fig. 302), but the male nuclei do not develop into spermatozoids. 'The pollentube pushes through the neck of the archegonium, and in Pinus sylvestris discharges its contents, including all the nuclei, into the egg-cell, where one of the generative nuclei fuses with that of the egg and completes the fecundation.

\section{The Embryo}

The egg may form a single embryo (Taxus, Sequoia), or each egg gives rise to a group of four embryos (Pinus, Abies). The formation of the division-walls 
is usually preceded by a repeated division of the nucleus (Fig. 306). The embryo is always provided with an elongated suspensor, and usually grows from a single apical cell (Fig. 306, C), which is later replaced by a group of initial cells. The cotyledons range from two to six or more.

The ripe seed is provided with a hard integument, or Testa, within which lies the embryo surrounded by the endosperm, or prothallial tissue (Fig. 286, B). In Cephalotaxus (Fig. 308, F) the outer part

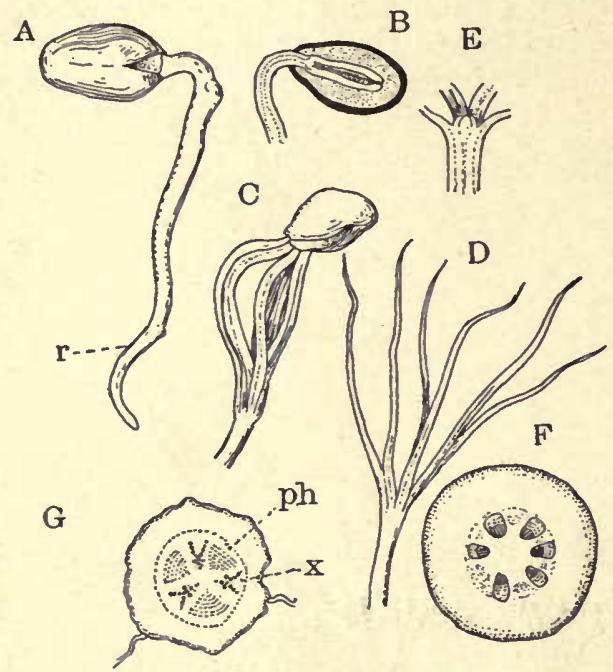

Fic. 307.-Pinus Virginiana, germination of the seed. $(A, B, \times 4 ; C, \times 3 ; D, \times 2$.) $E$, median section of $D$, more enlarged. $F$, cross-section of the stem of the seedling, showing the ring of vascular bundles. $G$, similar section of the root; both enlarged. of the integument becomes pulpy, as it does in Cycas, and in Taxus a special outer fleshy integument, or Aril, is formed. The scales of the cone usually become hard and woody, but in some Cupressineæ-e.g. Juniperus - they become pulpy and coherent, so that the cone resembles a berry.

\section{Germination (Fig. 307)}

The germinating seed absorbs water, and the embryo begins to enlarge, drawing upon the endosperm, whose cells are filled with reserve food, especially oil and albuminous granules. Chlorophyll may be developed while the cotyledons are still enclosed in the seed.

The root, which is directed toward the opening in the integument (Micropyle), pushes out through it, and bends down into the earth. As the cotyledons exhaust the contents of the endosperm-cells they withdraw from the seed-coat, which is cast off. A section through the apex of the young seedling shows the conical apex of the stem surrounded by the cotyledons. Each of the latter is traversed by a single vascular bundle, which bends down into the stem. This in section shows the circle of separate collateral bundles, which are the primary leaf-traces. These soon become connected by a ring of cambium, developed between xylem and phloem, and also between the bundles, and the secondary thickening of the stem begins. 


\section{Classification of Coniferæ}

The Coniferæ may be divided into two suborders, Taxaceæ and Pinaceæ. The Taxaceæ comprise a single family, Taxeæ, characterized by not having the female flowers in cones, but the ovules developed as axial structures. These are represented in the United States by species of Taxus (Yew) and Torreya, one species of the latter growing upon the Pacific slope, the other in Florida. Cephalotaxus (Fig. 308, F), from China and Japan, is sometimes cultivated. The largest genus of the family is Podocarpus, most of whose species belong to the southern hemisphere and tropical Asia.

The Pinaceæ include inany of the largest and most important of forest trees. There are two families, Abietineæ and Cupressineæ, which are further subdivided into a number of inferior groups. Of the Abietineæ the majority of the species belong to the Abietinæ (A bietineæ in a restricted sense). The principal American genera
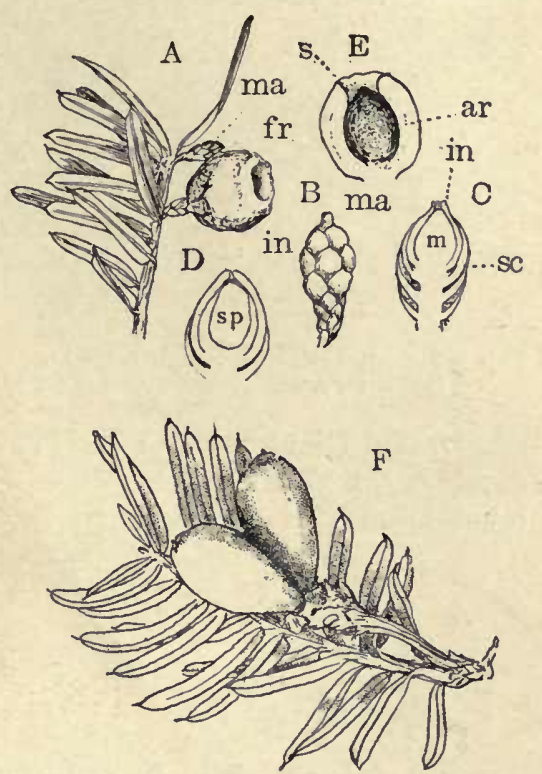

Fig. 308. $-A, E$, Taxus baccata; ma, female flower; $f r$, ripe seed surrounded by the aril. $C$, section of ovule, $m$, enclosed by scale-leaves, sc. $D$, an older one with the embryo-sac, $s p$. $E$, ripe seed surrouuded by the aril, ar. F, Cephalotaxus Fortunei, branch with two nearly ripe seeds. (Natural size.)

are Pinus, Larix, Abies, Picea, Tsuga, Pseudotsuga.

The subfamily Taxodiinæ includes the Sequoias of the Pacific coast, and Taxodium, the Bald-cypress of the Southern states. The Japanese Cryptomeria (Fig. 287) also belongs to this group.

The Cypress family is much smaller. The American genera are Cupressus, Chamæcyparis, Libocedrus, Thuja, Juniperus. Several of these trees are popularly known as "Cedar" in the United States, although the true Cedar - Cedrus - belongs to the Abietineæ, and does not occur in America.

The Coniferæ reach their greatest development upon the Pacific slope. All of the American genera occur here except Taxodium. Some of them, like the two Sequoias, are confined to California, which contains a number of other species of extremely limited range, like the Monterey Cypress, Cupressus macrocarpa (Fig. 310, A) 
(Pl. XV). Of the numerous West-coast Conifers, the most important are the Redwood (Sequoia sempervirens), Sugar-pine (Pinus Lambertiana), Yellow-pine ( $P$. ponderosa), Incense-cedar (Libocedrus
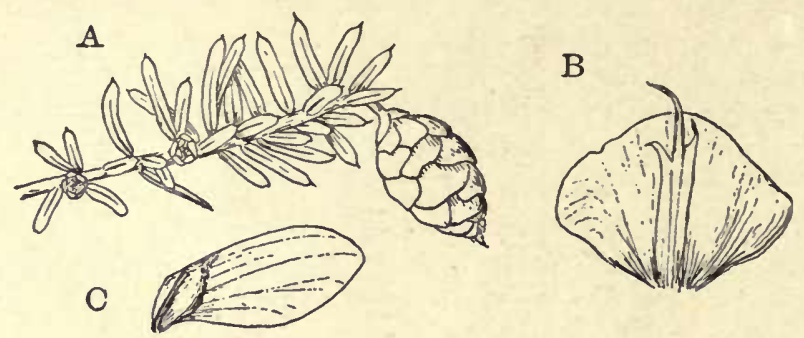

Fig. 309. $-A, T$ suga Canadensis $(\times 1) . \quad B$, seminal scale, with large subtending scale of Pseudotsuga Douglasii (× 1). C, seed of $P$. Douglasii $(\times 2)$.

decurrens), Giant Arbor-vitæ (Thuja plicata), Douglas-fir (Pserdotsuga Douglasii), Sitka-spruce (Picea Sitchensis), and several other species of Spruces and Firs. These are all gigantic trees,
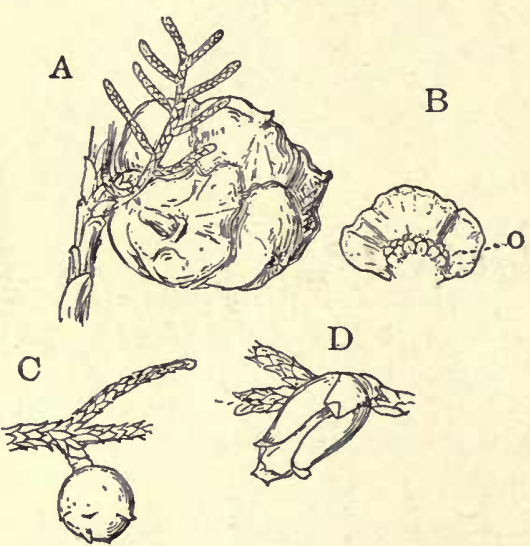

FIG. 310. $-A$, Cupressus macrocarpa $\left(\times \frac{3}{4}\right)$.

$B$, ovuliferous scale, with young seeds, $o(\times 2)$. C, Juniperus Virginian $a(\times 2)$. $D$, Thuja occidentalis $(\times 2)$. attaining a height of two hundred to three hundred feet, or even more.

\section{Order IV. Gnetaceæ}

This order includes three genera which differ much from each other, but nevertheless show certain structural resemblances in the flowers and development of the seed. They differ from the Coniferæ in having the flowers provided with rudimentary floral envelopes, and are sometimes considered to be intermediate in character between the Gymnosperms and Angiosperms. The secondary wood contains vessels, in which respect they resemble Angiosperms. Of the three genera, but one, Ephedra (Fig. 311), is found within our territory, several species occurring in our southwestern arid regions. Gnetum is a tropical genus, found both in the old and new worlds. Welwitschia is a monotypic form, occurring in West Africa.

The species of Ephedra are shrubs with jointed branches, suggesting an Equisetum. The leaves are reduced to dry sheathing 
scales about the joints. The plants are usually diœcious. The male flower (Fig. 311, C) consists of two to eight sessile stamens at the apex of a bare axis, which is surrounded at the base by scalelike leaves.

The female flowers have a single ovule, surrounded by a membranaceous integument which projects beyond the perianth. The ovule (Fig. $311, \mathrm{~B})$ is either solitary at the end of a shoot, or there may be two or three in the upper axils of a cluster of bracts, the lower bracts being sterile. In the species figured, these bracts are thin and membranaceous, but they usually become thick and pulpy.

The female gametophyte in Ephedra is much like that of the Conifers, and the archegonia are well developed. After fertilization, several free cells are formed in the egg-cell, each one of which produces an embryo. The embryo, in all the Gnetaceæ, has two cotyledons.

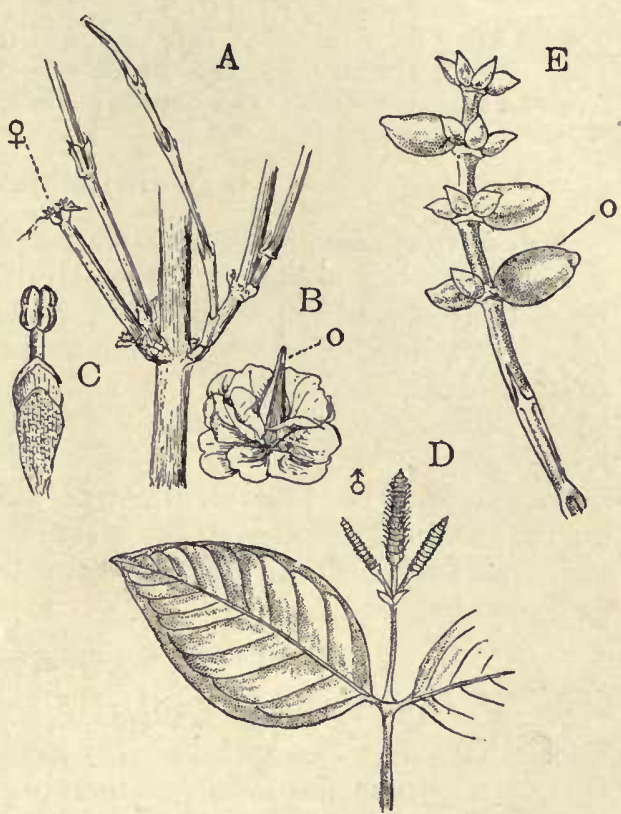

Fig. 311. $-A-B$, Ephedra trifurca. $A$, fragment of plant, of natural size, showing where the flowers, $q$, have fallen off. $B$, seed, 0 , surrounded by the imbricated scale-leaves $\left(\times 1 \frac{1}{2}\right)$. $C$, staminate flower of $E$. altissima. D, Gnetum latifolium $(\times 4) ; \delta$, staminate flowers. $E$, female flowers, or young fruits, of $G$. gnemon $\left(\times \frac{2}{2}\right) . \quad(C, D$, after Eichler ; $E$, after LotsY.)

The genus Gnetum (Fig. 311, D) comprises a number of plants which are either trees or climbers. The broad, opposite leaves are strikingly similar to those of the Dicotyledons, with which Gnetum is possibly related. The flowers (E) are borne in whorls at the ends of the shoots, usually upon different plants, and structurally are similar to those of Ephedra. According to Lotsy (Coulter, 4) there is but a single integument and a double perianth, the latter becoming fleshy in the fruit.

Embryo-sac. - The embryo-sac shows certain resemblances to that of the lowest Angiosperms. While the basal part becomes filled with prothallial tissue, the nuclei of the upper portion remain free, and any one may become the eggnucleus, as there is no archegonium developed. The zygote resulting from the fusion of a generative nucleus from a pollen-tube with an egg-nucleus, 
develops, finally, into an embryo, but this does not occur until after the seed germinates.

\section{Histology}

Except for the presence of true vessels in the secondary wood, Ephedra is much like the typical Coniferæ. In the climbing species of Gnetum, there is formed a second cambium ring, outside the original one, somewhat as in Cycas.

\section{Welwitschia}

Welwitschia mirabilis is an extraordinary plant, with a long taproot terminating above the ground in a short, thick stem, which bears two enormous, persistent, strap-shaped leaves. The seedling has two cotyledons, which are followed by the single pair of strapshaped leaves, persisting as long as the plant lives. In the axils of these leaves are borne numerous branching inflorescences. Each branch terminates in a cone, composed of closely set bracts, arranged in four series. The individual flowers are borne in the axils of these bracts. The male flowers have six stamens and a rudimentary ovule; the female flower has a single ovule, much like that of Gnetum, and no trace of stamens.

\section{Fossil Gymnosperms}

Many of the existing types of Gymnosperms also occur fossil, being the oldest Seed-plants. The oldest are the Ginkgoales and Cycadales, which are met with first in the later Palæozoic formations. There are also several types which have become entirely extinct. Most important of these are the Cordaiteæ, which are much the oldest seed-bearing plants, occurring abundantly in the Devonian and Carboniferous strata, where they have been preserved with marvellous perfection, even the structure of the ovules and pollen-spores being recognizable. They were slender trees with long leaves, which were first supposed to belong to Monocotyledons. The large pollen-spores sometimes show traces of the male gametophyte, which was evidently better developed than in any existing Spermatophytes, and probably gave rise to numerous spermatozoids. Fertilization was apparently effected much as in the Cycads.

Cycado-filices. - Another remarkable group of extinct plants are the Cycado-filices, including a large number of Palæozoic forms, intermediate in character between the Ferns and the true Cycads. Many of these were described as Ferns, and probably approach these more nearly than they do the Cycads - e.g. Lyginodendron. Others - e.g. Cycadoxylon, Cycadospadix - were probably more like Cycads than Ferns.

Cycadales. - The Cycadales were especially well developed during the Mesozoic age, when numerous types, closely related to the living 
genera, occurred. Besides these, a second suborder, now quite extinct, was represented by numerous species. These were the Bennettiteæ, which were much like the existing Cycads, but had much more complicated flowers.

Coniferæ. - Most of the Coniferæ appear in the later Mesozoic and early 'Tertiary, when certain genera, like Sequoia, Torreya, and Taxodium, which are now much restricted in their range, were very widely distributed.

\section{Affinities of Gymnosperms}

The origin of the Gymnosperms and their relation to the Angiosperms are by no means clear. The Cycads are undoubtedly related to the Ferns, but the origin of the Conifers and Gnetaceæ is extremely uncertain. There is evidence that the Conifers have arisen from Lycopods, perhaps like the fossil Lepidodendra, but this is by no means generally accepted. The Cordaiter have been suggested as forms intermediate between Cycads and Conifers, but this is open to doubt. Still more uncertain is the origin of the Gnetaceæ.

1. De Bary, A. Comparative Anatomy.

'96. 2. Britton, N. I., and Brown, A. Illustrated Flora of the Northern United States, Vol. I. 1896.

'80. 3. Brewer, W. H., and Watson, S. Botany of California (Geological Survey of California), Vol. IF. 1880.

'01. 4. Coulter, J. M., and Chamberlain, C. J. Morphology of Spermatophytes. Pt. I, Gymnosperms. New York, 1901.

(This is the most recent work on Gymnosperms, and contains a full bibliography.)

97. 5. Chapman, A. W. Flora of Southern United States. Cambridge, Mass, 1897.

'89. 6. Eichler, A. W. Cycadaceæ, Coniferæ, and Gnetaceæ, in Engler and Prantl, Nat. Pflanzenfamilien, II Theil. 1889.

7. Goebel. Outlines.

8. - Organography.

9. Gray, A. Manual of Botany.

'95. 10. Lemmon, J. G. Handbook of West-American Cone-bearers. San Francisco, 1895.

'82. 11. Luerssen, Chr. Handbuch der syst. Botanik, Bd. II. Leipzig, 1882.

'96-'98. 12. Sargent, C. S. Silva of North America, X, XI, XII. Boston, 1896-1898.

13. Strasburger, E. Botanisches Practicum.

14. Van Tieghem, Ph. Traité de Botanique.

15. Vines, S. H. 'Text-book of Botany.

16. Warming, E. W. Handbook of Systematic Botany.

17. Watson. See Brewer. 
The essential parts of the flowers are, of course, the sporophylls, stamens and carpels, which, in the lower floral types, are in separate flowers, often upon different plants. Such flowers are "Diclinous." In the more specialized flowers, stamens and carpels are usually together, and the flowers are "Perfect" or "Hermaphrodite." In the typical angiospermous flower, the sporophylls are surrounded by a series of sterile leaves, the floral envelope, or Perianth. These leaves

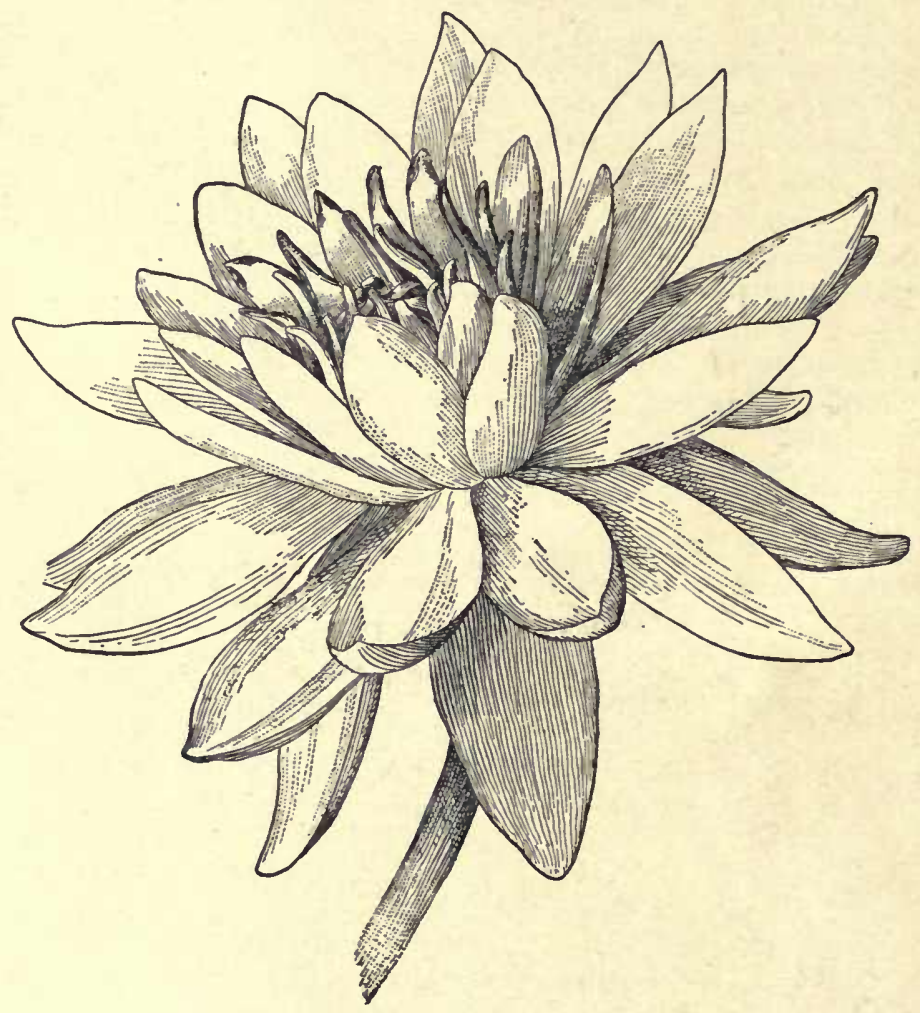

Fig. 314. - Nymphæa tuberosa, showing gradation of floral leaves. (After BAILEX.)

are in part protective, but they may also be conspicuously colored, and so render the flowers attractive to insect visitors.

The typical angiospermous flower consists of a series of floral leaves, arranged either spirally or in whorls about the apex of the shoot, or floral axis. Where this axis is expanded it is termed a Receptacle. The outermost leaves, the Sepals, are usually green, and are mainly protective in function. These together constitute the Calyx. The second series, the Petals, are generally larger and 
conspicuously colored, and together form the Corolla. Within the corolla are the stamens, upon which are borne the pollen-sacs. The stamen is usually differentiated into a stalk (Filament) and the Anther, which is made up of the microsporangia, or pollen-sacs. Collectively, the stamens form the Andrœcium. The innermost sporophylls, the carpels, may be separate, but more commonly they are united to form a compound Pistil. Collectively, the carpels constitute the Gynæcium. The typical pistil shows three portions, the basal Ovary, within which are borne the ovules; the intermediate Style, and the terminal Stigina, upon which the pollen-spores are deposited. 'The stigma has usually a papillate surface, with a viscid secretion, which serves both to hold the pollen and to induce its germination.

\section{Development of the Flower}

The development of the typical flower follows closely that of a vegetative shoot. The receptacle corresponds to the growing-point of the shoot, and about this are produced the various floral leaves in precisely the same way that the foliage leaves arise from a vegetative shoot (Fig. 316). The sepals are first to develop, commonly followed by the stamens, the

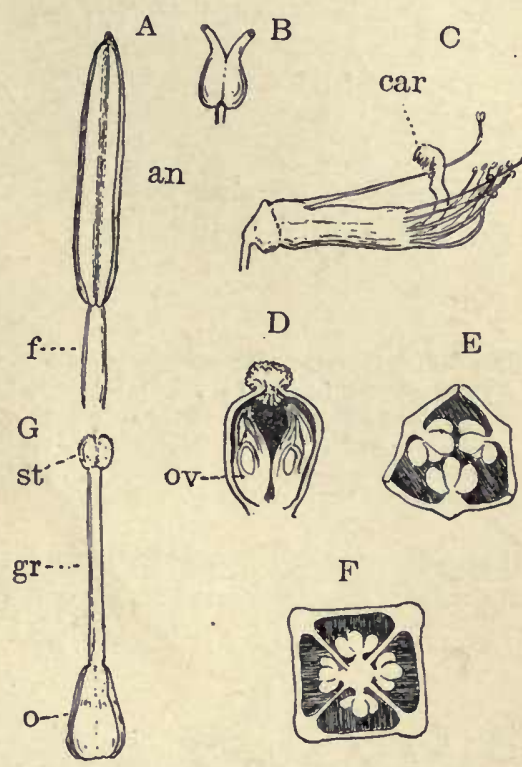

Frg. 315. - A, Calochortus venustus, stamen, showing filament, $f$, and auther, un. $B$, Chimaphila maculata, stamen opening by terminal pores. $C$, "diadelphous" stamens of Pea; car, pistil. D, Arisæma triphyllum, section of the ovary, showing the erect, basal ovules, ov. $E$, Reseda odorata, cross-section of ovule, showing the three carpels and parietal ovules. $F$, Epilobium spicatum, ovary composed of four carpels, ovules axial. $G$, Brodiæa capitata, pistil, showing ovary, $o$, style, $g r$, and stigma, st. petals not infrequently becoming evident at a later period.

The ovary may arise as a continuous wall about the apex of the floral axis, or the separate carpels may be evident from the first. Usually the formation of the gynæcium stops the further growth in length of the floral axis.

\section{The Sporangia and Gametophytes}

The stamen is in most cases a true foliar organ, but exceptionally e.g. Naias - it is a direct development of an axis, and the anther 
is the transformed stem-apex.

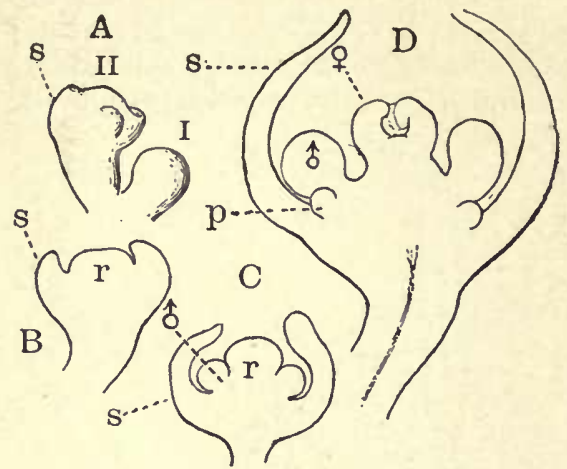

FIG. 316. - Capsella bursa-pastoris. Development of the flower ( $\times$ about 75). $A$, two very young flowers; in II the sepals, $s$, have just appeared. $B-D$, older stages, optical sections; $r$, receptacle; $s$, sepals; $p$, petals ; o, stamen; $\uparrow$, carpels.

ther-cells usually separate before the first nuclear division oceurs, and often have very thick gelatinous walls. The first nuclear divi-

ovule, or macrosporangium,
may also be of axial origin instead of an outgrowth of the carpel (Naias, Peperomia, etc.).

The microsporangium corresponds in its development with that of the higher Pteri. dophytes and Gymnosperms. With few exceptions, - e.g. Naias, Lilæa (Fig. 317), where the sporogenous tissne arises from the plerome, this tissue is derived from a layer of hypodermal cells by the formation of a series of periclinal walls which form a tapetal layer between the sporogenous tissue and the epidermis. The pollen mo-
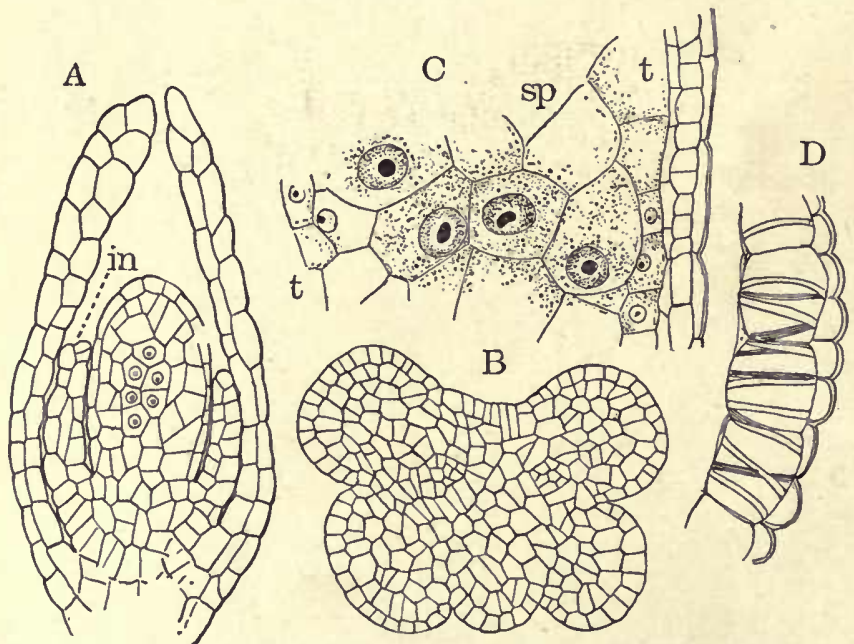

Fig. 317. - A, Naias flexilis. Section of young staminate flower, highly magnified; the anther is terminal aud closely resembles the young ovule, both in position and in the possession of an integument, in; the sporogenous cells have the nuclei indicated. $B-D$, Iilæa subulata. $B$, cross-section of young anther, showing the four lobes or pollen-sacs $(\times 200)$. $C$, part of an older pollen-sac, showing the large sporogenous cells and tapetum, $t$. $D$, cells from the wall of a ripe anther, showing the "fibrils" $(\times 400)$. 
sion (Fig. 318) in the cell may be followed by a division-wall (many Monocotyledons), or more cominonly the division-walls are not formed until after the second mitosis, and the resulting spores are of the tetrahedral type. In aquatic forms the spore-membrane may remain thin and uncuticularized; but usually there is an outer thickened perinium like that found in the spores of the Archegoniates. The pollen-spore begins its germination within the pollen-sac. A small cell, the antheridial cell, is cut off (Fig. 318, E), and the nucleus of this subsequently divides into the two generative nuclei. In exceptional cases - e.g. Sparganium simplex (Fig. 318, G) - a small sterile cell is cut off from the spore before the antheridial cell is formed.
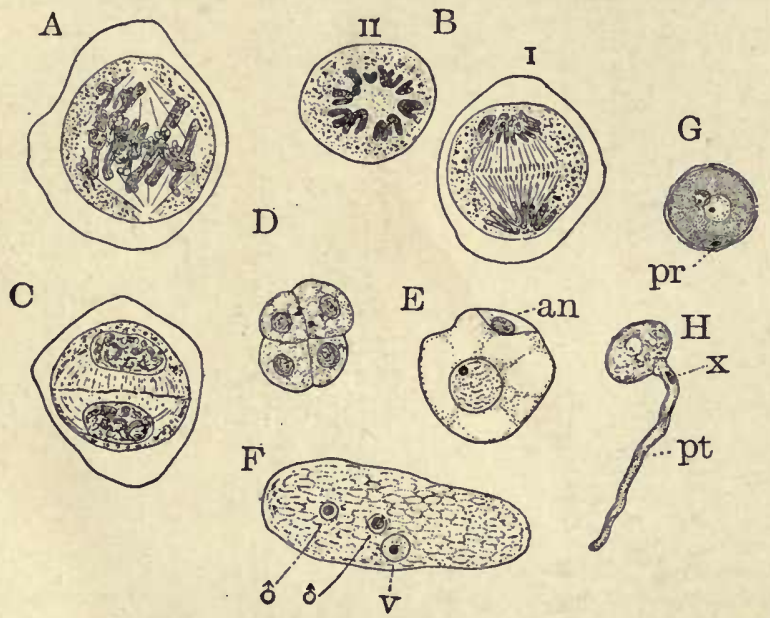

Fig. 318. $-A-C$, Allium Canadense. First nuclear, division of the pollen mothercell $(\times 400) . D-F$, Naias flexilis. $D$, young pollen-tetrad $(\times 200) . E$, pollen-spore with antheridial cell $(\times 400) . \quad F$, older pollen-spore, with two generative nuclei, $\delta$. $G$, Sparganium simplex, pollen-spore with sterile prothalliar cell, pr $(\times 400)$. $H$, Lathyrus odoratus, germinating pollen; $x$, generative nucleus.

The anther is usually composed of four pollen-sacs, and the walls of the nearly ripe sporangium consist of three layers of cells, of which the inner one at maturity becomes more or less completely disorganized. The middle one of these thin layers develops upon its walls thickened bands ("fibrils"), which are hygroscopic, and by their contraction effect the dehiscence of the pollen-sacs. They closely resemble the similar spiral thickenings found in the pollensacs of many Gymnosperms and in the sporangium of Equisetum. Within the three layers of cells forming the wall of the sporangium is a layer of tapetal cells, which is broken down before the division of the spores begins. 


\section{The Ovule}

The macrosporangium, or ovule, in many of the lower Angiosperms (many Araceæ, Peperomia), is formed directly from the apex of the floral axis, as it is in Taxus. Usually it is an outgrowth of the carpel. In either case the tissue from which it grows is called the Placenta. The development of the ovule is very similar to that
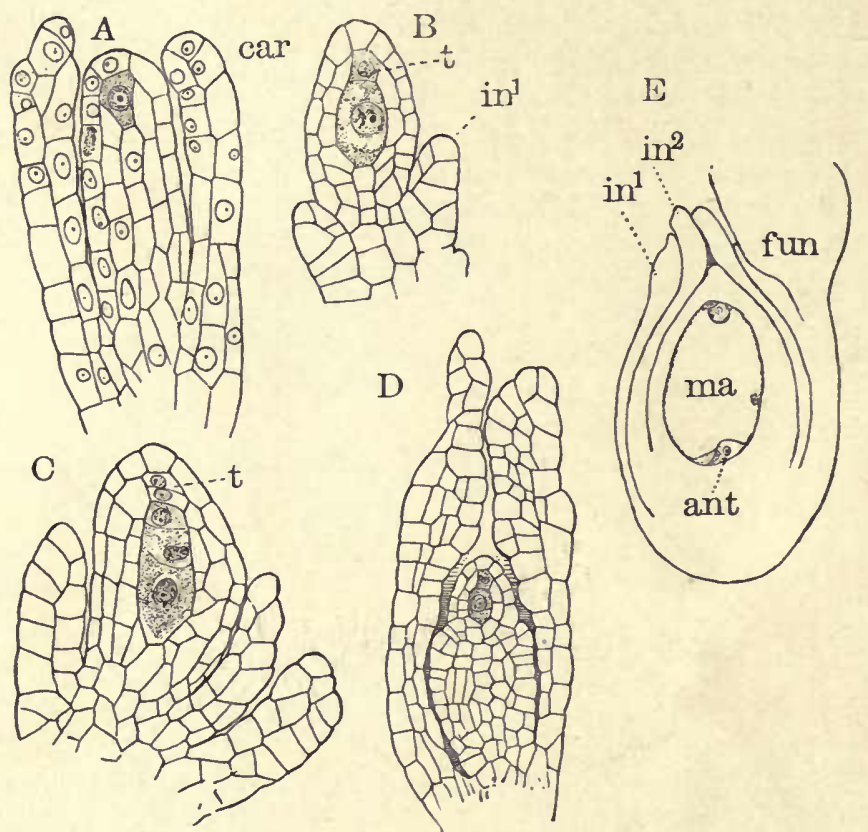

Fig. 319. - A-D, Naias flexilis. Development of the ovule. A, section of very young ovule, formed from the axis of the shoot, showing the sub-epidermal archesporial cell $(\times 400)$; car, the carpel. $B$, an older ovule, with the first iutegument, in $^{1}$, and the tapetal cell, $t$, cut off from the archesporium. $C$, a still older stage, the tapetal cell and sporogenous cell both divided, the latter into three. $D$, young ovule inclosed in the ovary $(\times 200)$. E, Sparganium simplex, section of mature ovule; $i n^{1}, i n^{2}$, the integuments; fun, funiculus; $m a$, embryo-sac.

of the Gymnosperms. Sometimes but a single integument is present, but more commonly there are two. When the growth of the ovule is alike on all sides, it is symmetrical, "erect," or "orthotropous"; where growth is stronger on one side it is bent over, "anatropous." More rarely, as in the Cruciferæ and Caryophyllaceæ, it is bent in the middle, or evenly curved, " campylotropous."

The archesporium can usually be traced back to a single hypodermal cell (Fig. 319). This may at once give rise to the embryo-sac 
(Tulip), but usually it divides by transverse walls into a row of 2-4 cells. Sometimes (Rosa livida, Ariscema triphyllum) there may be several of these sporogenous cells.

The primary archesporial cell usually has cut off from it an outer cell, the tapetum, which, by further divisions, gives rise to the tissue at the apex of the nucellus. The inner cell may at once form the embryo-sac, but more commonly divides into two or more cells, one of which grows faster than the others, and destroys them. It may ultimately destroy the whole of the nucellar tissue, except the apex, and forms the single large macrospore, or embryo-sac.

The primary nucleus of the embryo-sac divides, and in the typical Angiosperms (Fig. 320) one nucleus moves to each end of the embryo-
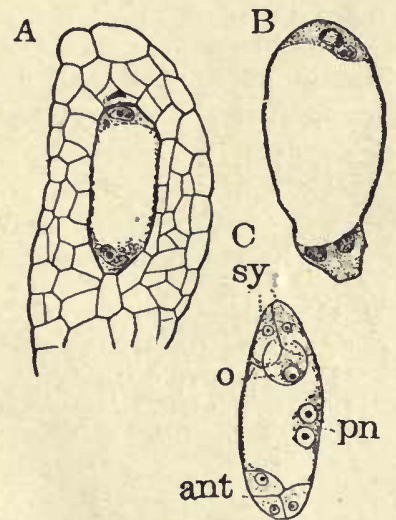

D

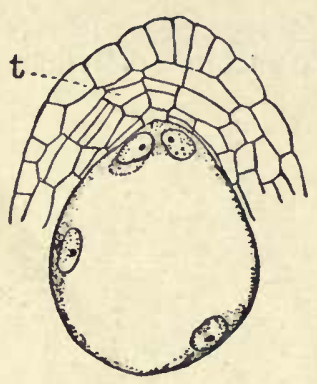

FIG. 320.-A, $B$, Naias flexilis. A, young embryo-sac with two nuclei. $B$, older embryo-sac with four nuclei. $C$, diagram of typical angiospermous embryo-sac; at the upper (micropylar) end, the egg-apparatus consisting of the synergids, sy, and the egg, $o$; at the lower (chalazal) end, the three antipodal cells, ant; $p n$, the two polar nuclei. D, Peperomia pellucida, section of young embryo-sac, which contains sixteen free nuclei, not all shown in the section $(\times 400)$.

sac. The upper end is the micropylar end, the lower the chalazal, or antipodal end. Each nucleus then divides twice, and of the four nuclei at each end one moves toward the centre of the embryo-sac, where these "Polar-nuclei " unite to form the "Endosperm nucleus." This fusion of the polar nuclei usually occurs before the fertilization of the egg-nucleus, but it may not occur until afterward. The three micropylar nuclei become invested with thin cytoplasmic membranes, and one of them is the egg-cell (o), the other two being known as Synergids. The three antipodal nuclei form a similar group of cells, the antipodal cells, which, unlike the cells of the egg-apparatus, very often develop a cellulose wall.

Peperomia. - The genus Peperomia (Fig. 320, D) shows a marked departure from the other Angiosperms in the development of the gameto- 
phyte. The primary nucleus of the embryo-sac divides into sixteen, instead of eight, nuclei, and these nuclei are uniformly distributed through the peripheral cytoplasm, instead of forming a definite eggapparatus and antipodal cells. In this respect the gametophyte of Peperomia resembles the early stages of that in Isoetes and Selaginella, and still more the condition found in the mature embryo-sac of Gnetum. As in Gnetum, apparently any nucleus may become differentiated to form that of the egg. In Peperomia no polar nuclei are developed, but after fertilization several (usually eight) of the nuclei fuse into one very large nucleus, which by division gives rise to the endosperm, or secondary prothallial tissue.

\section{The Antipodal Cells}

The antipodal cells generally remain unchanged, and apparently take little part in the further development of the embryo-sac. There
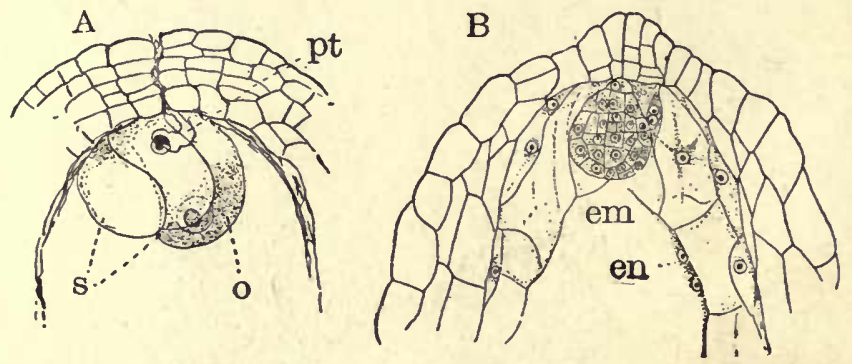

Fig.321. - A, Naias flexilis. Pollen-tube entering the embryo-sac $(\times 400)$; $p t$, pollentube; $s$, synergids; $o$, egg. $B$, Sparganium simplex, embryo, em, surrounded by the young endosperm-cells; en, free endosperm nuclei $(\times 200)$.

are, however, many exceptions to this. Thus in most Grasses the number of antipodal cells is much increased, and they become large and conspicuous, and are evidently actively concerned in the nutrition of the developing embryo-sac and embryo. A similar condition has been observed in many Compositæ, and the very large antipodal cells of some Ranunculaceæ show a division of the nucleus, although no cell-division occurs. The most remarkable case yet observed is that of Sparganium simplex (Fig. 322), where the three small antipodal cells of the unfertilized embryo-sac subsequently give rise tc 2 . mass of one hundred and fifty or more active cells.

\section{Pollination}

The pollen-spores are sometimes so placed that they fall spontaneously upon the stigma of the same flower. More commonly cross 
pollination takes place, the pollen of one flower being carried to the stigma of another, either by the wind or by insects.

The germination of the pollen-spore is stimulated by the secretion usually developed from the stigmatic surface, and may be induced artificially by placing the pollen in a solution of sugar. The pollentube is sometimes emitted within a few minutes, and its growth is often extremely rapid. Either before or after germination has begun the generative mucleus divides into two, and these are carried into the developing tube, probably by the movements of the cytoplasm, which are very active in the growing pollen-tube. The latter grows rapidly
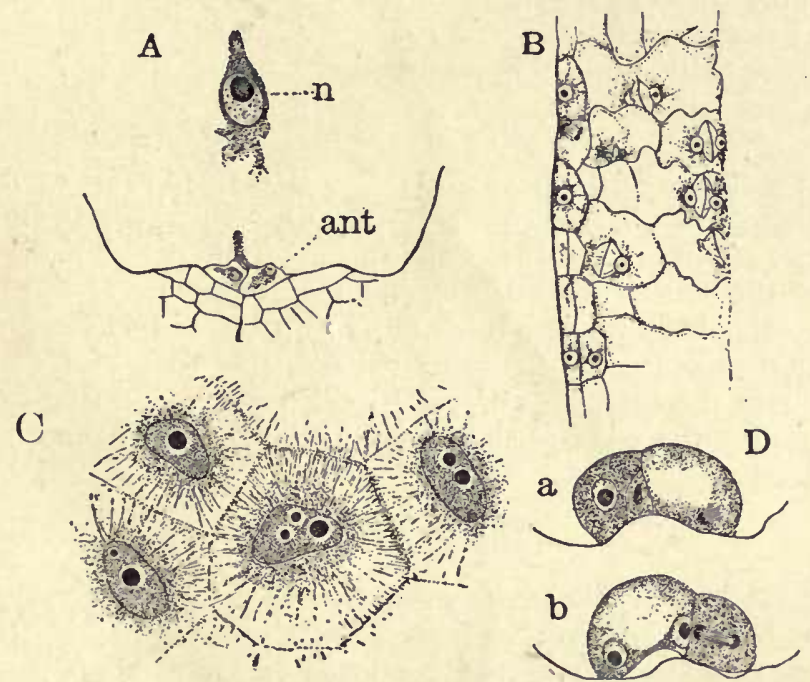

Fig. 322.-Sparganium simplex. A, section of chalazal end of embryo-sac, showing two of the antipodal cells and the endosperm nucleus, $n . \quad B$, longitudinal section of the developing endosperm $(\times 200)$. C, first cell-formation in the endosperm, surface view $(\times 800)$. $D$, two sections of the antipodal cells after fertilization of the egg $(\times 400)$.

through the style, where there is developed a special "conducting tissue," whose cells contribute the material necessary from the growth of the pollen-tube, which grows precisely like the hypha of a Fungus through the tissues of its host. The conducting tissue is continued into the placenta, or tissue to which the ovules are attached, and along this the pollen-tube advances until it reaches the micropyle of the ovule, into which it penetrates, and pushes through the tissue at the apex of the nucellus and enters the embryo-sac. In most instances it grows through one of the synergids, which is destroyed, and discharges one of the generative nuclei into the egg, where it fuses 
with the egg nucleus. The second generative nucleus is discharged into the cavity of the embryo-sac, and sometimes, at least, fuses with the endosperm-nucleus, formed by the union of the polar nuclei.

\section{Homologies of the Embryo-sac}

The embryo-sac represents the macrospore of the heterosporous Pteridophytes, and the structures developed within it, the gametophyte. From a comparison of the condition found in Peperomia with that of the Pteridophytes and Gymnosperms, it is probable that the egg-cell represents the archegonium reduced to a single cell. In the typical Angiosperms the two synergids may probably be considered as also, potentially, one-celled archegonia. All of the other nuclei, endosperm-nuclei, and antipodals, represent the vegetative part of the gametophyte. The fusion of the nuclei preliminary to the formation of the endosperm is probably a stimulus to further active division, but ean hardly be considered a true fertilization, as is sometimes done. This is also true of the fusion of the second generative nucleus of the pollen-tube with the endosperm-nucleus. Some interesting experiments have been made in hybridizing Indian-corn, which show that the endosperm of the grains resulting from cross-pollination combines the characters of the parent plants, indicating that in all probability the endosperm-nucleus had united with one of the pollen-nuclei.

\section{The Embryo}

The embryo of the Angiosperm shows a good deal of variation. It may remain undifferentiated until after germination, or it may become so large as to completely fill the cavity of the ripe seed. Usually, but not always, a suspensor is developed, as in the Gymnosperms.

Polyembryony. - Polyembryony, or the development of several embryos from a single ovule, which is the rule in many Coniferæ, is unnsual in Angiosperm, but there are numerous exceptions. Thus in Citrus (Orange and Lemon), several embryos are not infrequently found in the ripe seed. It has been shown that these extra embryos arise apogamously, by a budding of the tissue surrounding the embryosac, and the same is true in Funkia. Jeffrey (15) has described in Erythronium Americanum the development of several embryos from a division of the egg itself, comparable to that in the Gymnosperms. In Iris Sibirica, and some Leguminosæ, polyembryony has been referred to a fertilization of the synergids, and in Allium odorum embryos may be developed apogamously from the antipodal cells. 


\section{The Endosperm}

After fertilization has been completed, the endosperm-nucleus divides. This is sometimes followed immediately by the formation of a division wall (Monotropa, some Araceæ), and the embryo-sac is at once filled with a continuous mass of tissue. Much more commonly (Figs. 321, 322) there is a repeated nuclear division resulting in many free nuclei lying in the peripheral layer of cytoplasm, while the centre of the embryo-sac is occupied by a large sap-cavity. Sooner or later, walls are formed between the nuclei, precisely as in the formation of the prothallial tissue in the Gymnosperms. In case the embryo remains small, this tissue usually completely fills the embryo-sac, and the small embryo is imbedded in a mass of cells, filled with starch or other nutrient matter. If the embryo is large, it often fills the cavity of the embryo-sac at an early period, and the endosperm may remain rudimentary. In such cases, there is a large suspensor developed, and the embryo receives nourishment directly from the outer tissues of the nucellus. Very rarely, as in the Cocoanut, the sap-cavity of the large embryo-sac remains permanently open.

Sometimes the embryo-sac remains small, and the development of the endosperm is slight. In such cases (Peperomia, Nymphæa), the cells of the nucellus become filled with food materials, and take the place of the endosperm. This tissue is the "Perisperm."

\section{The Seed}

The integument (testa) of the seed may remain thin, as in the kernel of various stone fruits (Cherry, Peach, etc.), but usually it is hard and the ripe seeds have no further protection. Sometimes there are outgrowths of the integument forming hairs, or wings, as in the seeds of Cotton, Milkweed, Catalpa, etc., and these assist in the distribution of the seeds by the wind. More rarely, as in some Araceæ, the outer part of the integument is pulpy.

\section{The Fruit}

In the Angiosperms the stimulus exerted by pollination extends beyond the transformation of the ovule into a seed. Sometimes, at the time of pollination, the ovule is rudimentary (Oak, Orchidaceæ), and it develops during the slow growth of the pollen-tube throngh the tissues of the pistil. In all cases the carpels are stimulated into growth, and keep pace with the development of the enclosed seeds, about which they form a protective envelope. The structure thus formed is the Fruit, using the term in its strict sense. The 
fruit of the Angiosperms (Figs. 332-337) is extremely varied, and may be either a dry fruit, like a grain of Wheat or the pod of a Lily, or it may be a fleshy fruit, like the berry of a Currant, or the stone fruit (Drupe) of a Cherry or Plum. Besides these true fruits, there are various forms of spurious fruits, where the conspicuous part is not the product of the carpels. Such are the Fig, where the edible portion is the enlarged hollow stem, within whose cavity are born numerous small flowers, producing one-seeded fruits. Similarly the "seeds" of a Strawberry are really one-seeded fruits imbedded in the fleshy receptacle or enlarged apex of the floral axis. The development of edible fruits in the Angiosperms is connected with their distribution by animals.

\section{Germination}

The germination of the seed is like that in the Gymnosperms. In Angiosperms also, chlorophyll may be developed in the cotyledons before they are withdrawn from the seed: Where the embryo fills the seed, as in the Pea or Oak, the root quickly makes its way out through the micropyle, and the second leaves, which are already indicated in the embryo, soon unfold. The cotyledons may remain

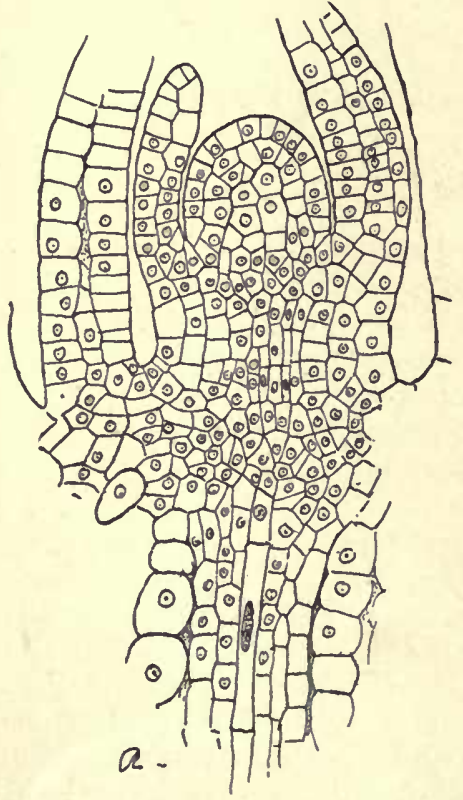

Frg. 323. - Naias flexilis, longitudinal section through the stem-apex of the young plant $(\times 250)$. permanently within the seed, or they may be withdrawn, and become assimilating organs. When the embryo in the ripe seed is small, it grows for some time at the expense of the endosperm before the root pushes out of the seed. The cotyledons are usually decidedly simpler in structure than the leaves formed later.

\section{The Stem}

The stem-apex in the Angiosperms never shows a single apical cell, but the primary tissues are all separated at the apex (Fig. 323). The epidermis is continuous, and below this is the primary cortical tissue, the periblem, while the central part is occupied by the plerome-cylinder. It is not always possible to separate the two latter at the apex, but the dermatogen is always clearly defined. 
In a very small number of Angiosperms, probably all reduced types, there is no properly developed stem, the sporophyte approaching the condition of a thallus. Such are the minute aquatic Lemnaceæ, the Rafflesiaceæ and Balanophoraceæ, which are endophytic

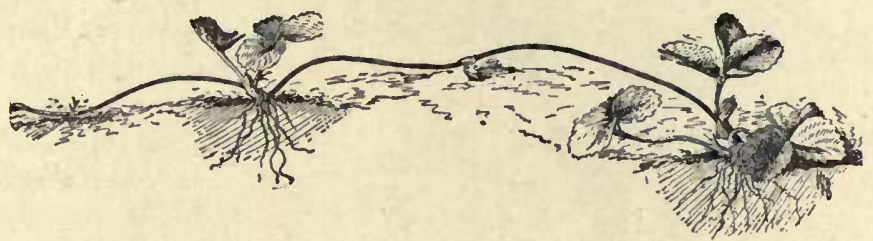

Fig. 324. - Runners of Strawberry. (After BaIley.)

parasites, resembling Fungi in their habits, and the Podostemonaceæ, aquatic Dicotyledons, some of which might be mistaken for Algæ.

Branching. - Usually the stem is well developed and shows great variety. The shoot may be unbranched (Erythronium Americanum, Trillium), or it more commonly branches freely, either to form

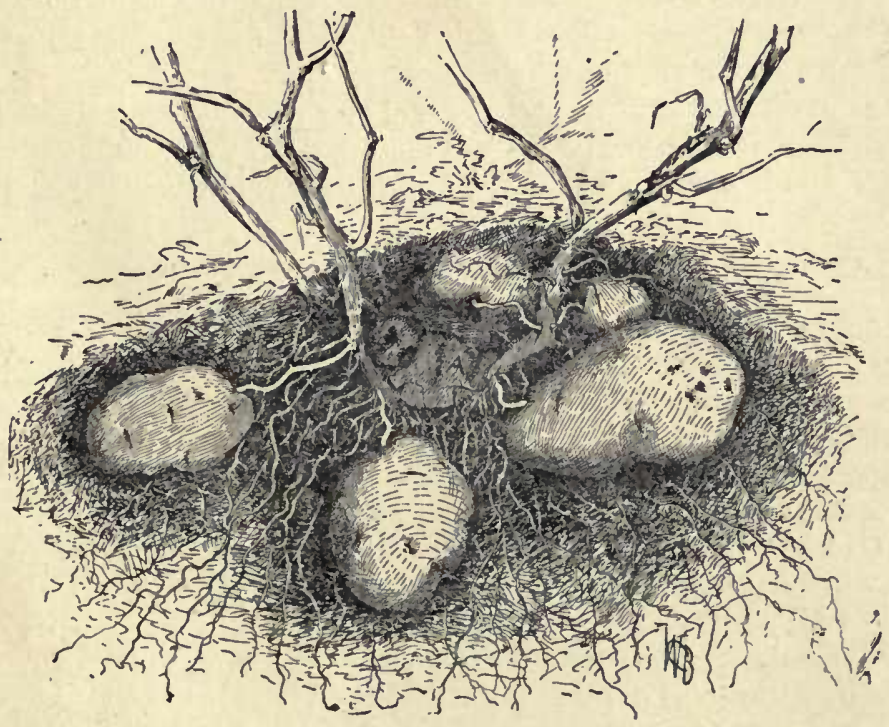

Fra. 325. - Tubers of Potato. (After Bailey.)

flowers or for secondary vegetative shoots. True dichotomous branching is rare (Zannichellia), and, with few exceptions, lateral members arise in the axils of leaves. If the stem develops little woody tissue, it is said to be herbaceous; if wood is well developed, it is "woody" or "ligneous." 
Modifications of Stem. - Some of the more striking modifications of the stem in Angiosperms (Figs. 324-326) have been described in

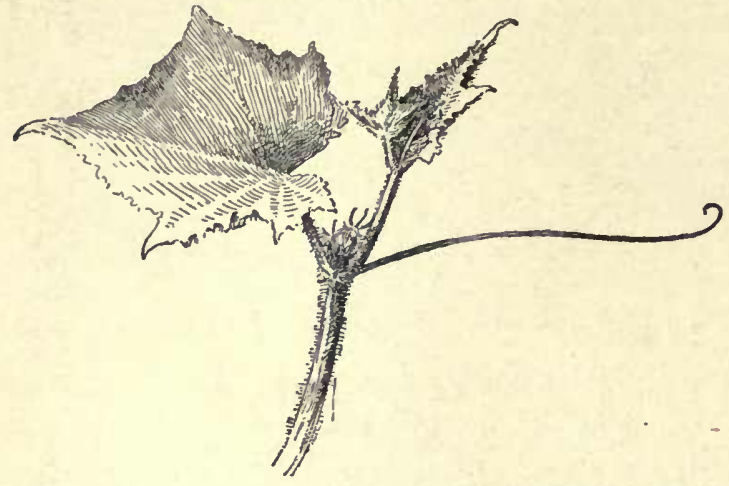

Fig. 326. - Stem-tendril of Cucumber. (After BAILEY.)

a former chapter. These include the various subterranean forms (Bulb, Corm, Tuber, Rhizome), which are reservoirs of reserve food; Runners, or Stolons, and similar prostrate stems, are important organs of propagation; while twining stems and the stem-tendrils are adaptations for assisting plants to reach the light. The strong thorns of such trees as the Honey-locust (Gleditschia) and the Hawthorn are stemstructures which are presumably protective.

The development of succulent green stems where the water supply is deficient, is connected with a reduction or complete suppression of leaves, and is obviously to reduce the surface exposed to evaporation.

\section{The Leaf}

The various forms of foliage leaves, already described in Chapter II, are all found among the Angiosperms. The Dicotyledons offer much greater variety in this, as they do in other respects, than do the Monocotyledons.

Modified Leaves. - The leaf, like the stem, may be greatly modified for special functions. Scale-leaves, such as those in scaly bulbs, or winter-buds, consist of the leaf-base only, as may be readily seen in some instances where there are transitions between them and the typical foliage-leaves.

In submersed aquatics, like Naias or Myriophyllum, the leaves are either linear, or divided into slender divisions, and the epidermal cells are not cuticularized, nor are stomata developed. In xerophytes, i.e. plants of arid regions, the leaf surface is reduced, and sometimes the leaves are very thick and fleshy, as in species of Agave and Aloe. Parasitic plants, not needing organs for photosynthesis, have the leaves rudimentary.

Spines, tendrils, and the traps like those in the Pitcher-plants and Bladder-weed, are also foliar structures. 


\section{The Floral Leaves}

The peculiar leaves making up the floral structures are, next to the seeds, the most characteristic structures of the Angiosperms. Besides the sporophylls and perianth-leaves, we may include under this head of floral leaves the showy bracts which occur in many plants, surrounding the inflorescence and often performing the functions of showy petals. Such are the Spathes of the Araceæ, the bracts of the showy Dogwood (Cornus florida), of many species of Euphorbia, etc.

\section{The Root}

The root in the Angiosperms, like the stem, never shows a single apical cell, but the tissues at the apex form two or more layers of primary meristem, showing some variation in different cases. The branching of the roots is always monopodial, and the secondary roots arise from the pericycle, as they do in the Gymnosperms.

The primary root of the embryo may persist as a tap-root (Radish, Dandelion, etc.), or it may be replaced by secondary lateral roots, a condition always found in the Monocotyledons, and common in many Dicotyledons.

The modifications of roots are similar to those of the stem. Roots may be enlarged for purposes of storage, a condition found in many plants useful as vegetables (Beet, Turnip, Carrot, etc.). Aerial roots are developed, which serve for support, - e.g. those developed near the base of the stem in Indian-corn, and the very much larger ones of many tropical trees, - e.g. Screw-pines, Banyan, Mangrove, etc. Aerial roots also serve for tendrils, - e.g. Ivy, Poison-ivy

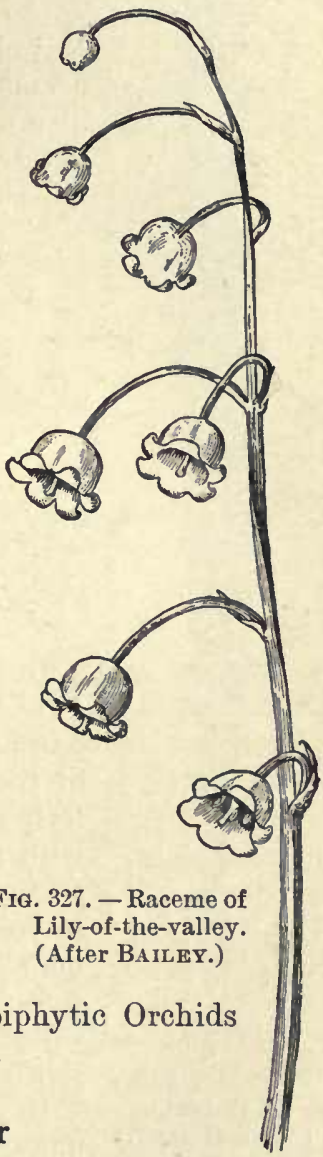
(Rhus toxicodendron), etc., - and in some epiphytic Orchids and Araceæ they absorb moisture from the air.

\section{Structure of the Flower}

The more primitive types of flowers have all the parts separate, and may be reduced to little more than a single carpel or stamen. The floral envelopes may be entirely absent (Peperomia, Saururus), but there are usually rudiments, at least, of a perianth. 
Somewhat more specialized flowers are the "Apocarpous," flowers with well-developed perianth, such as Asimina (Fig. 313), but all

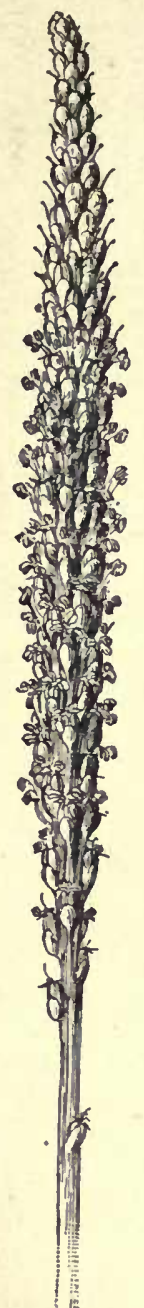

FIG. 328. - Spike of Plantain. (After BaILEy.)

of the floral leaves quite separate. These simple flowers, too, may have the number of parts indefinite, and are often radially symmetrical, or actinomorphic.

As flowers become more specialized, the parts become definite in number, and there is a tendency to reduction in the number of parts, and to cohesion of the floral leaves. Thus in the members of the Lily family the flower is made up of several threeleaved whorls, the three carpels being united into a compound pistil. In most Dicotyledons there is also a difference in the character of the sepals and petals, and the former are grown together into a cup-shaped or tubular calyx, as in Dianthus.

A

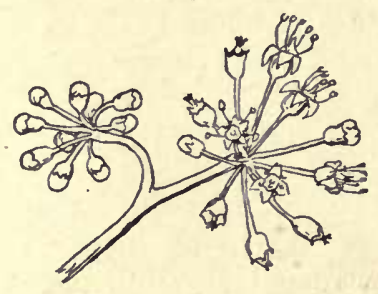

$\mathrm{B}$

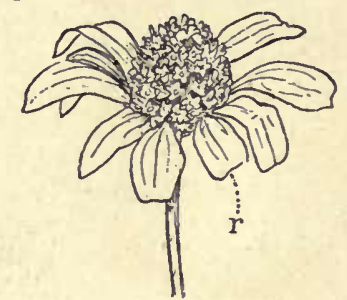

Fig. 329. - A, umbels of Aralia racemosa. B, bead of Anthemis cotula; $r$, ray-florets.

In such highly specialized flowers as the Orchids (Fig. 338, C), the reduction and cohesion of the parts is carried to the extreme. Of the six stamens of the more generalized Monocotyledons, only one is left, and the base of the perianth-tube is coherent with the base of the carpels. Moreover, the single stamen is united with the upper part of the pistil to form the peculiar structure known as the "Column," or "Gynostemium." Where all of the parts are free from the ovary the flower is "Hypogynous"; where the ovary is more or less completely adherent to the floral axis, "Epigynous," or "Perigynous."

In the reduction of parts in the dicotyledonous flower the carpels are the first to diminish, the number of carpels being less, as a rule, than that of the other floral leaves. Where the flowers are markedly zygomorphic, or bilaterally symmetrical, like the lipped flowers of the Foxglove or Sage, the stamens are less in number than the corolla lobes. In the less 
specialized forms related to these, like the Morning-glory or Nemophila, the flowers are actinomorphic, and the number of stamens is the same as the corolla lobes.

In the Compositæ (Daisy, Sunflower, etc.), which are usually considered to be the most specialized of the Dicotyledons, there is often a division of labor among the flowers. In a large number of them there are developed the so-called "Ray-florets" (Fig. 329, B), which are often quite sterile, and serve merely to make the inflorescence conspicuous.

All of these modifications of form are associated with adaptations to cross-pollination, and with them are to be classed the extraordinary development of color and scent in flowers.

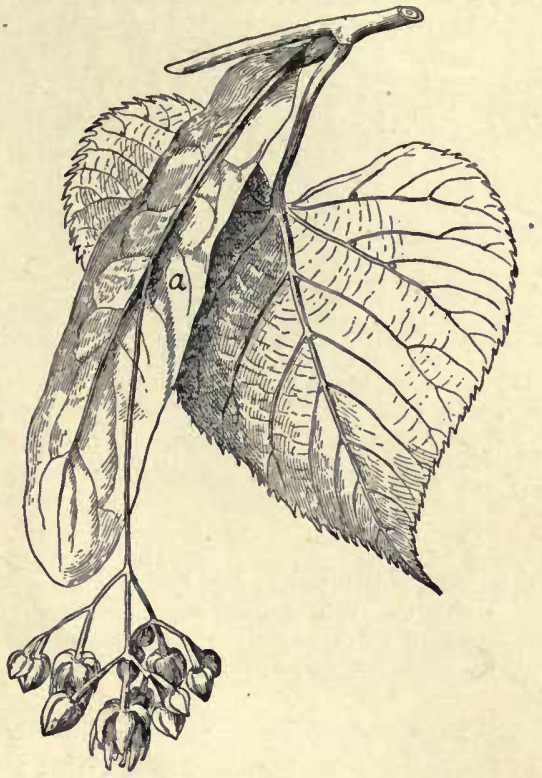

Fra. 330 - Cyme of Tilia Americana. (After BaIlikY.)

\section{The Inflorescence}

(Figs. 327-331.) - A flower may be formed singly at the end of the shoot, as in most species of Narcissus, Trillium, Sanguinaria, etc. Such a floral axis is called a Scape. Much more commonly,

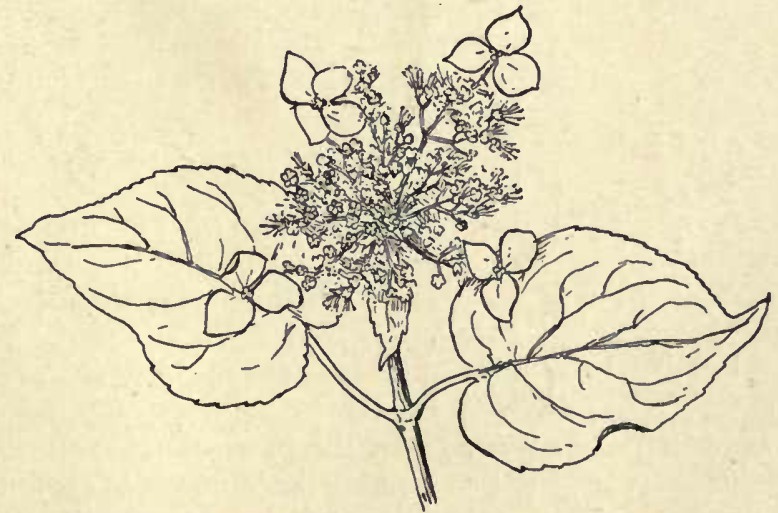

Fic. 331. - Compound cymc of Hydrangea arborescens. 


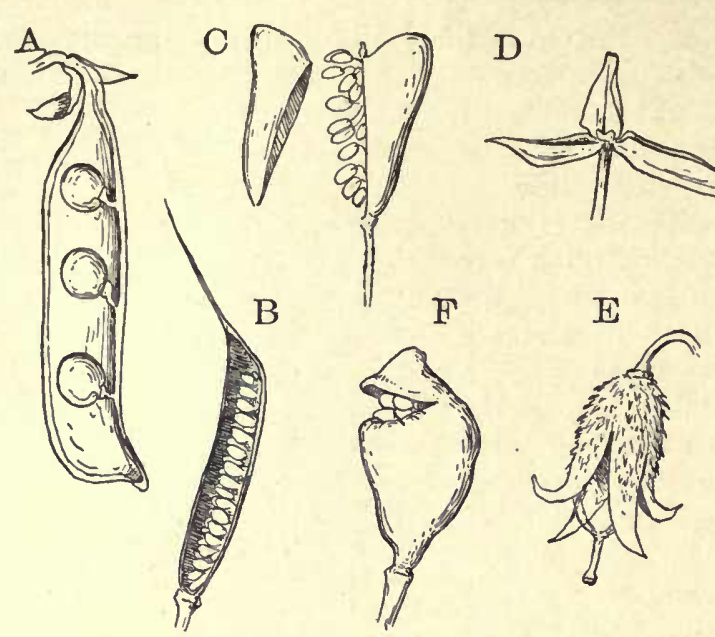

FIG. 332,-Dehiscent dry fruits. $A$, Pea (legume). $B$, Aquilegia Canadensis (follicle). C, Capsella bursa-pastoris (silicule). D, Viola cucullata (capsule, opening by three valves). $E$, Stylophorum diphyllum (capsule). F, Jeffersonia diphylla (capsule opening by a lid).

flowers are arranged in an "Inflorescence." There are two princi

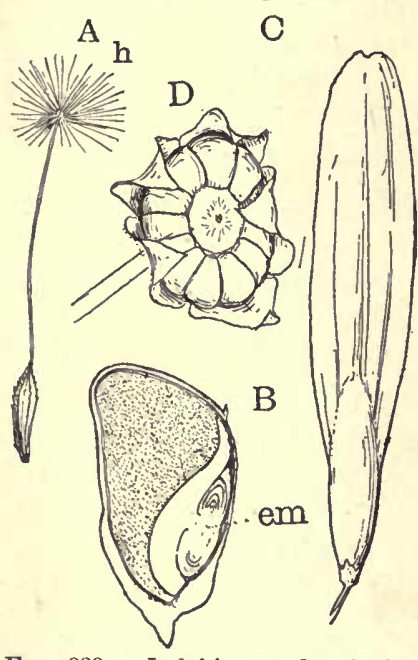

Fig. 333. - Indehiscent dry fruits. $A$, Taraxacum officinale, achene, with plumose pappus. $h$. $B, Z e a$ Mays, caryopsis (section); em, embryo. C, Fraxinus Americana, "key" or samara. D, Malva rotundifolia, schizocarp. pal types of inflorescence, the "Racemose" and the "Cymose," which, in turn, have various subdivisions. In the racemose or monopodial inflorescence, the apex of the floral shoot continues to grow indefinitely, giving rise to a varying number of lateral shoots, developed in acropetal succession, the youngest being nearest the apex. Its simplest form is the Raceme (Fig. 327), where single stalked flowers are strung along the central axis, the oldest ones at the bottom. If the flowers are sessile, as in the Plantain (Fig. 328) or Pepper family, we have a "Spike"; if the raceme is very much shortened, an "Umbel" (Fig. 329, A) or a "Head," as the flowers are respectively stalked or sessile.

In the cymose, or sympodial inflorescence, each flower is terminal on its axis, and the lateral axes grow more 
vigorously than the main axis. Thus the older flowers are uppermost or central. There are three types of cymose inflorescences: (1) The Monochasium, where each partial axis produces a single branch. Where these all arise on one side, the helicoid cyme, such as occur's in Heliotrope, Myosotis, etc., is produced. (2) The Dichasium; two branches are produced from each axis. (3) Pleiochasium; each axis produces more than two branches.

\section{The Fruit}

The fruits of Angiosperms may be first divided into the apocarpous and syncarpous fruits. The first are those derived from a single earpel (e.g.

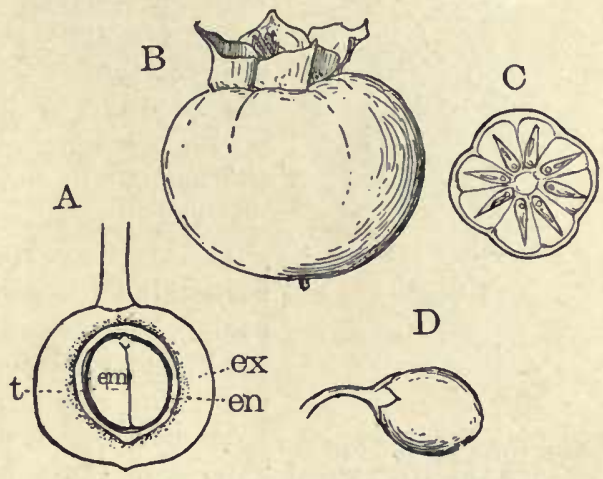

FIG. 334. - Indehiscent succulent fruits. $A$, section of young cherry (drupe). $B$, Persimmon, Diospyros Virginiana (berry). $C$, section of young Persimmon, showing the four carpels of which it is composed. D, Solanum dulcamara (berry).

Ranunculus, Sagittaria), the second from two or more united carpels. The fruit consists of two parts, the seed and the Pericarp, or

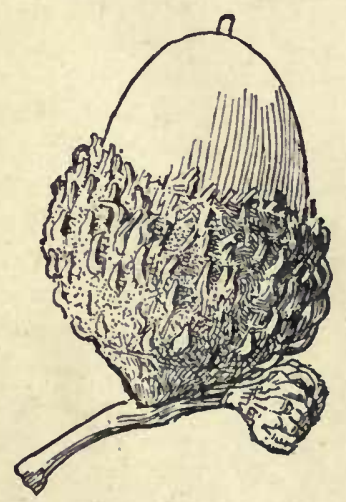

Fig. 335. - Acorn of Quercus macrocurpa. (After BAILEY.) wall. When the latter, as in the various stone-fruits, is differentiated into several layers (Fig. 334, A), these are known as the Exocarp, Mesocarp, and Endocarp; the mesocarp may be pulpy, and known as Sarcocarp.

The principal types of fruits are the following (Figs. 332-337):

I. The Capsule, a dry fruit with a dry pericarp opening regularly at maturity. The capsule opens most frequently

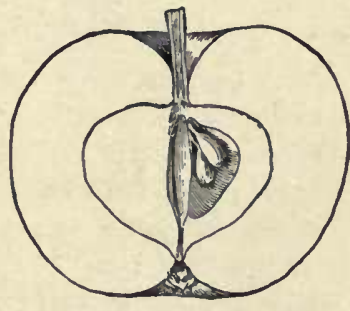

FIG. 336. - Section of an Apple (pome). (After BAILEY.)

by longitudinal fissures, which follow either the line of separation of the carpels (septicidal dehiscence), or each carpel is split longitudinally (loculicidal). More rarely the capsule opens by pores (Papaver) or by a lid (Jeffersonia). The "Follicle" (Aqui- 
legia) and "Legume" (Bean, Pea, etc.) are examples of apocarpous capsules.

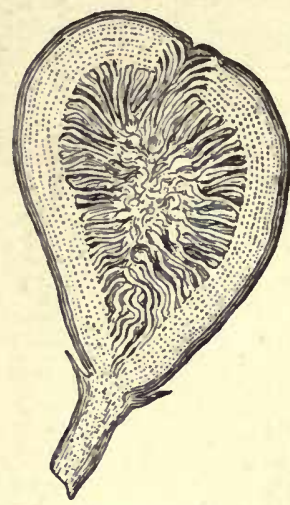

Fig. 337. - Section of a Fig. The "fruit" is a hollow receptacle containing many flowers, each of which produces a single oneseeded fruit ("seed"). (After BaILEY.)

II. Dry, indehiscent fruit. These are fruits with hard, dry pericarp, which does not separate from the seed. The "Nuts" of Hazel, Acorns, the "Caryopsis" (grain) of Grasses, the seedlike fruits (Achenes) of the Compositæ, are examples of these. Differing from the achene in having a loose pericarp, is the "Utricle"-e.g. species of Carex.

III. Schizocarp. A dry fruit composed of several indehiscent carpels which separate from each other - e.g. Hollyhock, Unbelliferæ.

IV. The Berry. The berry has the endocarp and mesocarp pulpy. The Grape and Gooseberry are examples, and Melons and Pumpkins show much the same structure on a large scale.

V. The Stone-fruit or Drupe. The Cherry, Plum, Peach, etc., are familiar examples of stone-fruits. The inner part of the endocarp forms the "stone." The seed is the kernel enclosed within the stone. Among the Monocotyledons, the Date and Cocoanut offer examples of stone-fruits.

A

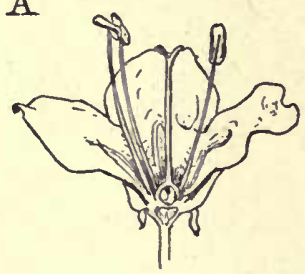

B
$\mathrm{C}$

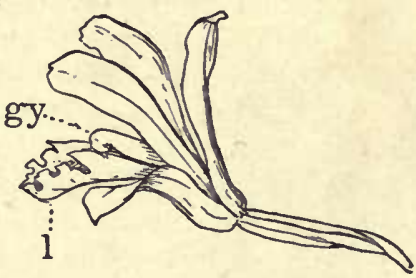

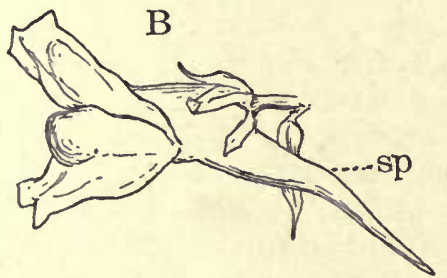

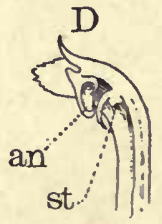

Fig. 338. - Specialization of the flower. A, hypogynous flower, with sympetalous, actinomorphic corolla (Hydrophyllum appendiculatum). B, Zygomorphic, hypogyuous flower of Linaria vulgaris. C, zygomorphic epigynous flower of an Orchid (Aplectrum hiemale); $l$, lip, or labellum; $g y$, gynostemium, or column, formed of the coherent stamen and pistil. $D$, section of the column of an Orchid (Arethusa bulbosa); an, anther; st, stigma. 


\section{Classification of Angiosperms}

The Angiosperms agree so closely in their fundamental structure as to leave little question that they form an entirely natural class. With very few exceptions they readily fall into two series, Monocotyledones and Dicotyledones. In the former, the embryo has the first leaves alternate; i.e. a single cotyledon is developed. In the Dicotyledons, the cotyledons are opposite.

\section{SUBCLASS I. MONOCOTYLEDONES}

The Monocotyledons are much less numerous, and, on the whole, less specialized, than the Dicotyledons. There is greater uniformity in the tissues, and the structure of the flowers also shows less variation.

The simplest sporophyte is found in the Lemnaceæ, minute, floating aquatics in which the sporophyte is, in Wolffia, a globular or oval mass of tissue, without any external differentiation, but flattened, and producing roots in Lemna. It is not entirely clear whether the plant body in the Lemnaceæ is mainly a leaflike stem, or a foliar structure. The largest Monocotyledons are the Palms, some of which have an erect trunk fifty metres in height, with the largest leaves found in any plants. The Rattan Palms (Calamus) have slender, climbing stems of even greater length.

The Monocotyledons are universally distributed, some forms, like the Grasses, being cosmopolitan. A majority of the aquatic Spermatophytes are Monocotyledons, which play an important rôle in the vegetation of marshes. The Reeds, Sedges, Bulrushes, etc., are all Monocotyledons, and the same is true of the Pondweeds and most other types of floating and submersed aquatics. In the sea there are a number of characteristic types, especially in the Tropics. Of these marine forms, Zostera and Phyllospadix may be mentioned as American genera. Some of the fresh-water aquatic species occur in great numbers, like Elodea Canadensis and Eichhornia crassipes ("Water-hyacinth"). The latter, a floating plant, has become very troublesome in some of our southern streams, where it was introduced from the Tropics because of the beauty of its flowers. Of the terrestrial Mouocotyledons, the Grasses are the most widespread and abundant. These are almost the only terrestrial monocotyledonous plants which are sufficiently abundant, at least in temperate climates, to give a decided character to the vegetation of any region. In the warmer parts of the world, the Palms, and some of the treelike Yuccas, and related forms are abundant enough to be very conspicuous. 'This is especially true of the latter in dry regions like the deserts of Arizona and Southern California, where the Yuccas and 
Agaves, next to the Cacti, are the most couspicuous plants. Parasites and saprophytes are of rare occurrence among the Monocotyledons, and are confined to the Orchidaceæ and the related Burmanniaceæ.

\section{The Gametophyte}

With few exceptions, the gametophyte conforms to the ordinary angiospermous type. The ripe pollen-spore contains either one or two generative nuclei, besides the single vegetative nucleus. In addition to these three nuclei, there have been observed, in Sparganium simplex, and exceptionally in Lilium tigrinum, a small sterile cell, which possibly represents a prothallial cell like that in the microspores of Selaginella. A division of the pollen-tube nucleus has also been recorded for Lilium auratum.

The embryo-sac may arise directly from the primary hypodermal cell. This is the case in many Liliaceæ. More commonly the cell divides, by a transverse wall, into an outer tapetal cell (Fig. 319) and an inner one, which may develop at once into the embryo-sac, or may divide into a series of cells, one of which destroys the others, and becomes the embryo-sac.

In Ariscema triphyllum, and this not improbably may be found in some other Araceæ, after the tapetal cell is cut off, the archesporial cell divides longitudinally into four cells, one of which grows faster than the others. This cell divides once more by a transverse wall, and the lower cell is the embryo-sac.

The complete gametophyte ordinarily shows the typical structure found in Angiosperms; but in many Grasses the three original antipodal cells generally increase in number, sometimes thirty or more being found in the embryo-sac at the time it is fertilized. In abnormal cases in Naias and Zannichellia and in some Araceæ indications of an increased number of nuclei in the unfertilized embryo-sac have been observed, but these are all exceptional cases. Further research in the lower Monocotyledons will probably bring to light other departures from the typical structure.

\section{Pollination}

Pollination may be effected by the wind (Palms, Grasses, etc.), by water, or by insects. 'The adaptations for water pollination are of two kinds. In forms with submersed flowers (Zostera, Naias), the pollen is thin-walled, and in the former extremely elongated, so that the pollen-grains readily attach themselves to the stigma when they come in contact with it. In Vallisneria (Fig. 361) the pistillate flower opens above the surface of the water; and the minute male flowers break away from the submersed inflorescence, and rise to the surface, where they expand and float about until the open anthers come in contact with the stigmas of the female flower, upon which the pollen is deposited.

Monocotyledons with showy flowers, like the Lilies, Iris, Orchids, etc., are entomophilous (insect-pollinated); and some, like species of Iris, and many Orchids, are quite dependent upon insects to insure pollination.

Sometimes a long interval elapses between pollination and fertili- 
zation, as is the case in many Gymnosperms. This is especially true of many Orchids, where the whole development of the ovules may take place subsequent to pollination.

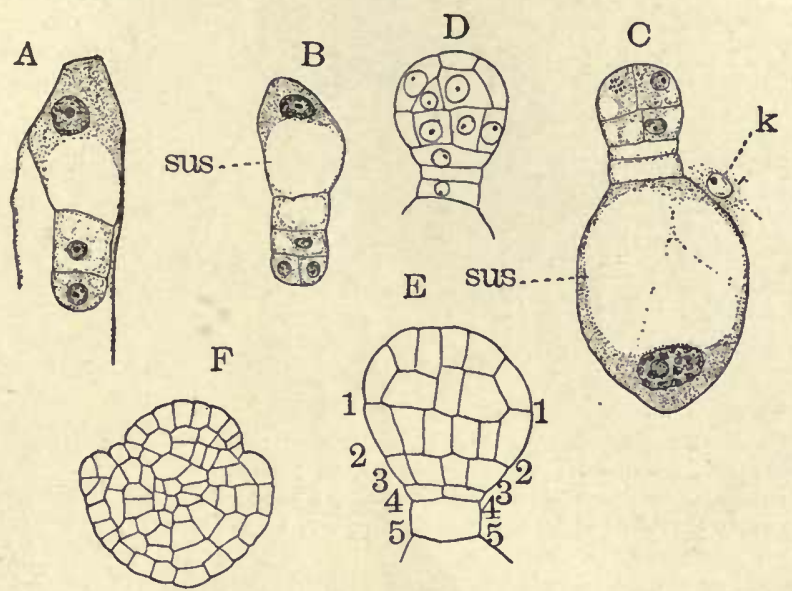

Fia. 339. - Naias flexilis. Development of embryo. $A-E$, longitudinal sections $(\times 250)$. $F$, transverse sectión of older embryo $(\times 200)$; sus, suspensor-cell; $k$, a free endosperm-nucleus.

\section{The Embryo}

The Embryo (Figs. 339-341) may remain very rudimentary, as in the Orchids, where it is a nearly globular mass of perfectly undifferentiated tissue. On the other hand, the embryo in the ripe seed may be large, and completely fill the embryo-sac, as in Naias and Sagittaria, and the organs of the young sporophyte are well developed.

The fertilized egg usually divides by a transverse wall into two cells, of which the basal one, which is in contact with the upper end of the embryo-sac, does not divide further, but may become much enlarged, and serve as an organ of absorption. The outer cell may at once develop into the young embryo, or it may undergo several transverse divisions, and form a suspensor with the embryo at the apex (Fig. 339). The latter, in typical cases, develops the single cotyledon from the apical portion, while the root arises from the region which is in contact with the suspensor. The stem-apex is lateral in origin, and is first recognizable at a late
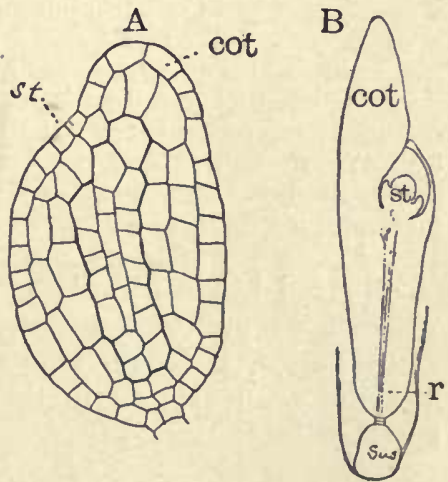

Fig. 340. - Naias flexilis, older embryos. $(A, \times 200 ; B, \times 70)$; cot, cotyledon; st, stem-apex; $r$, root; sus, suspensor.

stage in the development of the embryo. In this respect the Monocotyledons resemble Isoetes. 
Less frequently the stem-apex arises from the terminal segment of the young embryo, and the single cotyledon is borne at its side. This occurs in Sparganium

A

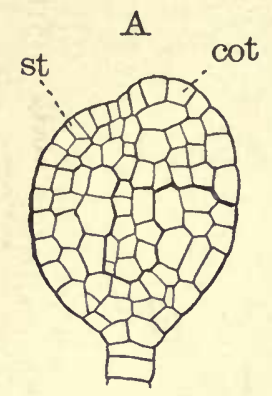

B

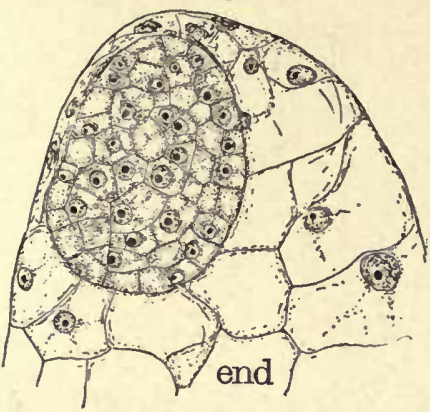

Frg. 341. $-A$, Zannichellia palustris, section of embryo $(\times 250)$; cot, cotyledon; st, stem-apex. B, Lysichiton Kamchatcense, the embryo does not develop a suspensor, and is early surrounded by the endosperm, end $(\times 250)$. and Zannichellia (Fig. 341 ), and has also been described for the Dioscoreaceæ and some other Monocotyledons. The embryo in these forms is intermediate in character between the typical Monocotyledons and the Dicotyledons.

Sometimes a suspensor is quite wanting (some Araceæ and Gramineæ), and there is a suggestion of the regular quadrant divisions found in the Pteridophytes.

The absence of a suspensor is associated with the early investment of the embryo by the endosperm-cells.

\section{The Endosperm}

The primary endosperm-nucleus always divides, and usually gives rise to many secondary nuclei before any cell-walls appear. Where the embryo develops early, as in Naias, the endosperm remains rudimentary, but in most Monocotyledons it is largely developed. In Naias flexilis the endosperm is formed from the upper one only of the two nuclei resulting from the division of the primary endospermnucleus. The lower one remains undivided, but increases very much in size. 'The endosperm is usually formed by free-cell formation, - that is, by the simultaneous formation of cell-walls between the free nuclei, - and the formation of cellular tissue proceeds from the periphery toward the centre of the sac (Fig. $322, \mathrm{~B})$. In some Araceæ, cell-walls extending across the cavity of the embryosac are formed at an early stage, and the embryo-sac is from the first completely filled with the prothallial tissue.

Where the endosperm is present in the ripe seed, its cells are filled with starch, oil, or other nutritive substances. In other cases - e.g. many Palms (Date, Phytelephas) - the reserve food is in the form of cellulose, developed in the greatly thickened walls of the endosparm-cells.

\section{Germination}

The cotyledon may become a foliage-leaf (Onion) (Figs. 342-344); but more commonly, as in the Grasses and Palms, the cotyledon remains permanently within the seed, acting as an organ for the absorption of the food-materials in the endosperm. By the downward 
growth of its base, the young plant may be forced deep down into the earth; and the first leaf to appear above the surface is the first

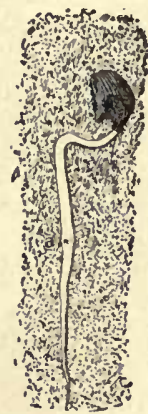

Fig. 342. - Allium cepa, early stage of germination. (After BAILEY.)

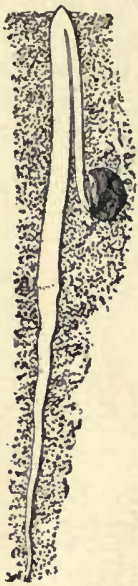

Fig. 343. - Allium cepa, sproutipg seed; $a$, junction of cotyledon and stem. (After BAILEY.)

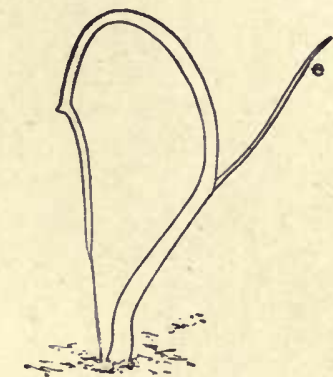

Fig. 344. - Allium cepa, later stage of germination; the tip of the cotyledon is still held in the ground; $e$, the second leaf. (After BaILEx.)

foliage-leaf, and not the cotyledon. Where no endosperm is present, the food substances are stored in the cells of the embryo.

The primary root, although often well developed, is of limited growth; and soon others arise, so that a cluster of roots is developed instead of the single tap-root commonly met with in the Gymnosperms.

Where the embryo is well developed, as it is in Naias or the Grasses, the young secondary leaves, and sometimes the early secondary roots, are present in the ungerminated embryo.

The stem of the sporophyte may remain short, as in

A

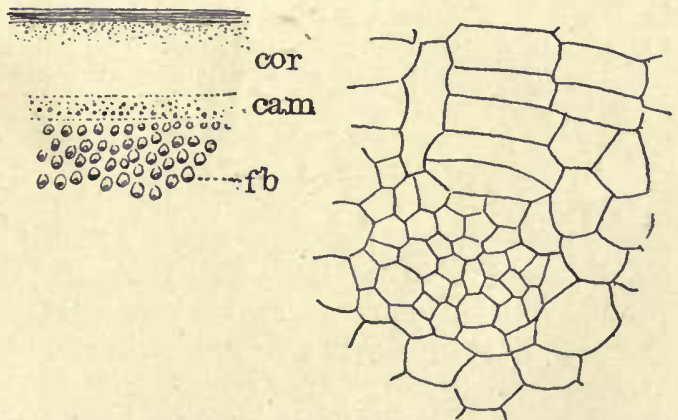

Fra. 345. - Yucca aloifolia. A, Cross-section of outer part of the stem $(\times 4)$; cor, cortex; cam, cambium, with young vascular bundles. $B$, a single young vascular bundle $(\times 250)$.

many bulbous plants, and in such cases the leaves when numerous are closely set about the thickened axis. In the Palms and some 
treelike Liliaceæ, - e.g. Yucca - the stem ultimately forms a trunk, which may in the latter increase in diameter as the plant grows older, but in the Palms rarely shows any thickening after the crowil of leaves has reached its full size. In most Palms the elongation of the stem does not begin until the crown of leaves is full grown, and then the elongating trunk remains of nearly uniform diameter throughout. Sometimes the stem is slender and freely branched - e.g. Zannichellia, Potamogeton, Asparagus.
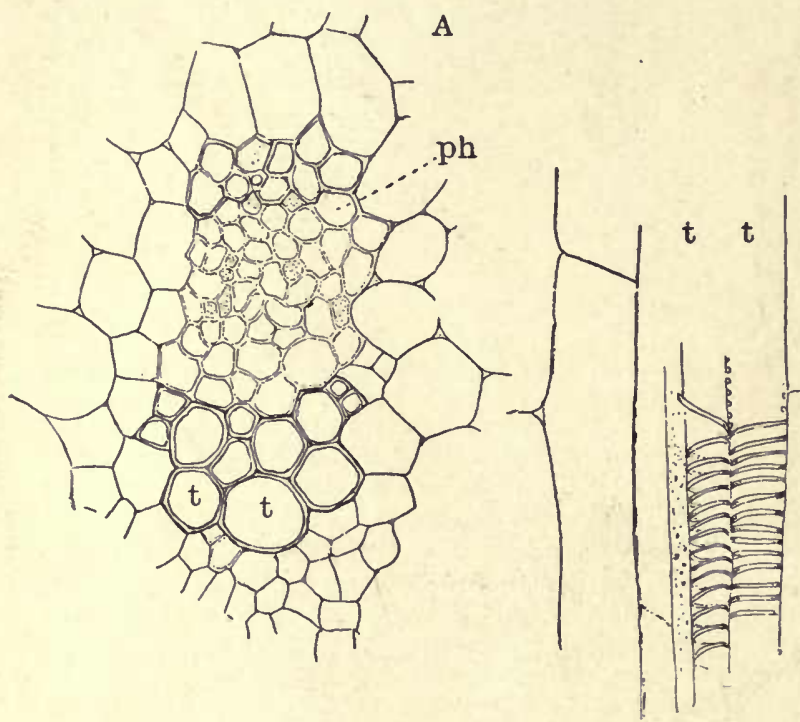

$\mathbf{B}$

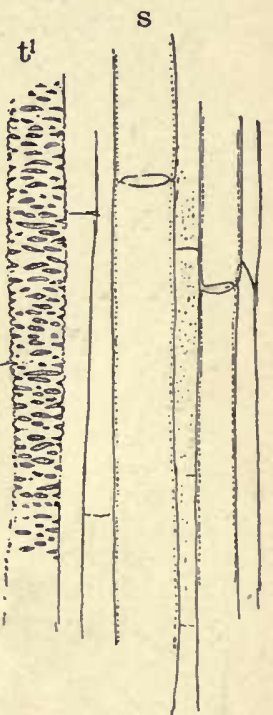

Fia. 346. - Iris Florentina. Vascular bundle from the scape $(\times 250)$. A, cross-section. $B$, longitudinal section; $p h$, phloem; $t$, tracheids; $s$, sieve-tube.

\section{THE MATURE SPOROPHY'TE}

\section{The Stem}

The internal structure of the stem is much the same in all Monocotyledons (Fig. 347, D). The bulk of the stem is composed of parenchyma, through which are scattered the numerous collateral vascular bundles, which never show the secondary thickening found in the stem-bundles of the Gymnosperms and Dicotyledons. These bundles are all leaf-traces, and in large stems, like those of the Palms, each bundle is surrounded by a sheath of fibrous cells, which act as mechanical or supporting elements, as the xylem of the bundles is always slightly developed and serves only for conduction. The other mechanical elements consist of hypodermal tissue, which may be collenchyma or fibrous tissue. 
The vascular bundles (Fig. 346) have upon the inner side a group of tracheary tissue, composed mainly of spiral or reticulately marked vessels, which are often of large size. With these are associated elongated parenchyma cells. The outer part (phloem) is made up of similar elongated parenchyma, mingled with sievetubes.

Monocotyledons are usually perennial plants, but in cooler regions the aerial shoots are sent up each year from the underground stem, which may be a rhizome (e.g. many Grasses, Iris Germanica, Smilacina, etc.), a scaly bulb (Lilium, Erythronium, etc.), or a corm (Gladiolus, Brodiæa). The aerial shoots are often of very brief duration, as in Erythronium, Tulip, etc., and the green shoots live only long enough to ripen the seeds and prepare the starch and other substances which are stored up in the underground stem for next season's growth. Where the growth of the aerial shoots is interrupted by drought, as in many Californian and Cape bulbous plants, the bulbs are small, and the growth of the new shoots is only in a small measure dependent upon the reserve-food stored up in the bulb.

Sometimes the growth of the aerial shoots is extraordinarily rapid. Thus in some of the large species of Bamboo, the shoots attain a height of thirty to forty metres, this whole growth being completed within a few weeks' time, and a growth of nearly a metre has been recorded in twenty-four hours.

Secondary Thickening. - Where the stems are perennial, as in Yucca, Dracæna, and Pandanus, there may be an increase in diameter, such as occurs in Gymnosperms, but it is caused in a different way. There is not a ring of vascular bundles, with cambium, but the section of the stem (Fig. 345) shows the typical monocotyledonous structure, with numerous scattered bundles. In the outer cortex, however, a zone of meristematic tisşue is found, in which new bundles are formed as well as new ground-tissue. In such forms the growth rings are either very obscure or quite unrecognizable.

In the arborescent Monocotyledons, like the Palms and Yuccas, the leaves often persist for several years, and when they drop off, they may leave a definite scar. Where, as in the Cocoanut and Royal Palm (Oreodoxa), the base of the leaf forms a sheath about the apex of the stem, these scars form clean rings surrounding the trunk at regular intervals.

Climbing Stems. - Climbing stems are comparatively rare among Monocotyledons. Various tropical Araceæ (Philodendron, Pothos, etc.), Smilax, some species of Asparagus, Dioscorea, Vanilla, are exceptions to the rule.

Branching. - The branching of the stem is almost always monopodial, and the branches arise in the axils of the leaves. A dichotony of the apex probably takes place in the peculiar "Dom-palm" 
(Hyphoene Thebaica), of Upper Egypt, and perhaps Pandanus, but this has not been critically investigated.

\section{The Leaf}

The leaves of Monocotyledons are usually simple in form, the commonest type being the lanceolate or linear, sessile leaf, with entire margin. 'The leaf may have a definite midrib, but often the parallel veins are all alike. A petiole is sometimes present, as in the Palms and Araceæ; and in these the leaves may be of great size. True compound leaves occur in some Araceæ (e.g. Ariscema

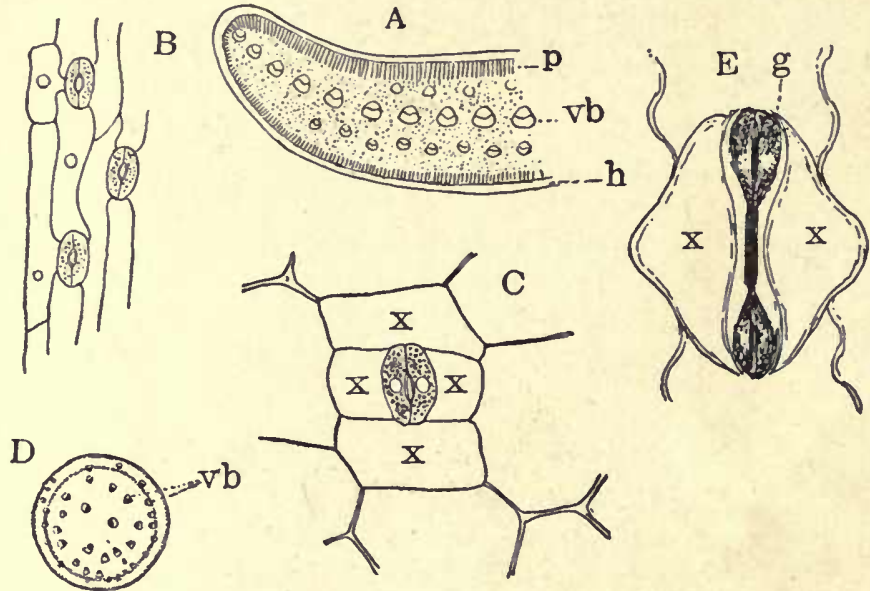

Fig. 347.- A, Agave Americailu, cross-sectiun of leaf $(\times 4) ; h$, colorless hypoderma; $p$, palisade-parenchyma; $v b$, vascular bundles. $B$, Erythronium Americanum, epidermal cells and stomata $(\times 75)$. C', Tradescantia zebrina, stoma with four accessory cells $(\times 200)$. D, Iris xiphium, cross-section of stem $(\times 4)$; $v b$, vascular bundles. $E$, stoma of Zea Mays; $x$, accessory cell; $g$, guard cell $(\times 600)$.

triphyllum), but the apparently compound leaves of Palms owe their pinnate form to a tearing into strips of the originally entire lamina.

The attachment of the Ieaf-base may be narrow, but it is common to find it. much expanded, and often developed into a large sheath, which envelops the internodes of the stem. Such sheaths are especially conspicuous in the Grasses and Sedges (Fig. 35̃8, C), and in many aquatic forms, like the Pondweeds and in the Palms. Free stipules are never found. In most aquatic Monocotyledons, between the sheaths are found membranous axillary scales, which sometimes resemble stipules. Sometimes paired outgrowths (ligules) are formed at the junction of the sheath and the base of the lamina (Fig. 358, C). 
Venation. - Besides the simple parallel venation usually found, there is sometimes a true reticulate venation, much like that in the Dicotyledons. Such reticulate venation is found in many Araceæ (e.g. Anthurium, Symplocarpus), in Smilax, Dioscorea, Lilium cordifolium, and others. In the Scitamineæ (e.g. Canna, Maranta, Musa, etc.) the very large leaves have a strong central midrib, with lateral parallel veins running to the margin. Many Helobieæ (e.g. Sagittaria) are somewhat intermediate in character, the radiating parallel veins being conuected by lateral ones. The leaves are usually smooth, with a shining surface, or covered with a waxy bloom (e.g. Agave). Hairs sometimes occur (Cypripedium spectabile), and in the epiphytic Bromeliaceæ there are formed peculiar epidermal scales, which collect moisture as it falls upon the leaves.

\section{Histology of the Leaf}

In upright linear leaves, such as those of many Liliaceæ, the dorsiventral character of the leaf is not clearly indicated by the tissues. The epidermis is alike upon both sides, and stomata are equally developed. No palisade-parenchyma is present, and the mesophyll is uniform throughout. Where the leaves are broad and placed horizontally the tissues are arranged as in the leaves of Dicotyledons, and the stomata are more abundant upon the lower side. In xerophytic forms, like Yucca and Agave (Fig. 347, A), the epidermal cells have thick walls, and a layer of thin-walled hypodermal cells lies between the compact palisade-parenchyma and the epidermis. The epidermal cells (Fig. 347, B) are usually elongated, sometimes with undulate walls, and in many cases accessory cells are developed around the stomata. These are very marked in the Grasses, and in other forms like Canna and Tradescantia.

Scale-leaves. - Scaleleaves are developed in many bulbs, and upon the stems of such saprophytes as Corallorhiza or Cephalanthera, and in Asparagus and similar forms where the foliage leaves are replaced by phylloclades or green branches. Bracts occur in connection with the inflorescence, and nay be very conspic-

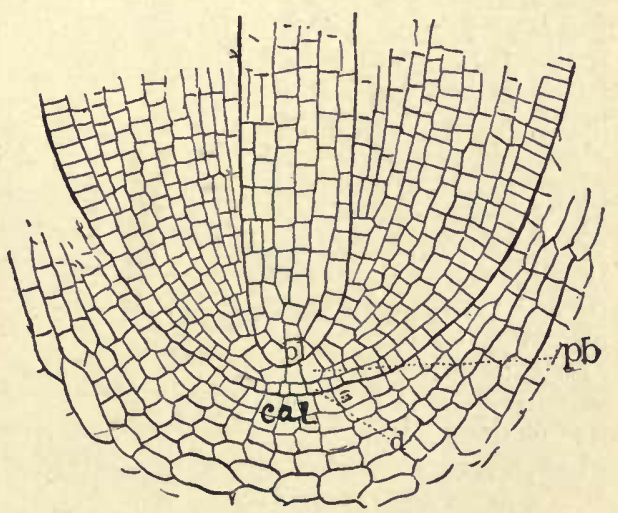

FIG. 348. - Zannichellia palustris. Longitudinal section of root-apex $(\times 200) ; p l$, plerome; $p b$, periblem; $d$, dermatogen; cal, calyptrogen.

uous. Such showy bracts are the spathes of many Araceæ and the brilliantly colored bracts of some Bromeliaceæ (Tillandsia, Bilbergia) and Scitamineæ (Heliconia, Zingiber). 


\section{The Root}

The primary or tap-root of the Monocotyledons never persists, and the roots never show a secondary thickening, although in the Palms

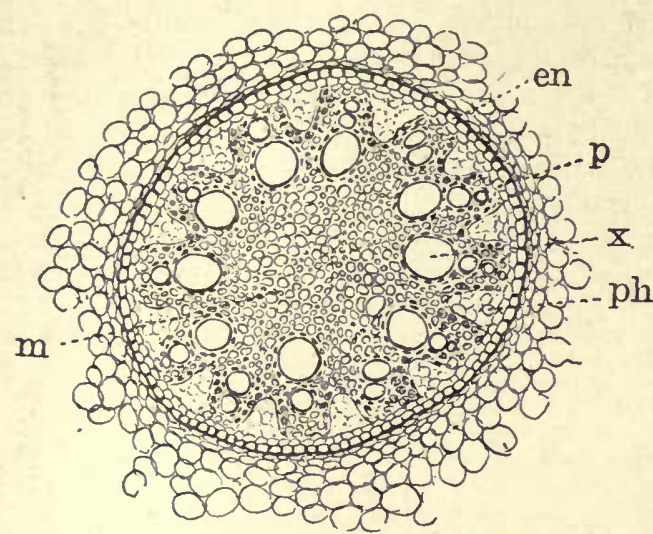

Fig. 349. - Phoenix Canariensis, cross-section of the vascular cylinder of the primary seedling root $(\times 90) ; m$, medulla; $x$, xylem; $p h$, phloem; $p$, pericycle; $e n$, endodermis.

and Pandanaceæ they may be several centimetres in diameter. Aerial roots are common, especially among tropical forms, like the epiphytic Orchids and Araceæ, and some Palms and Pandanaceæ. In the latter they may originate upon the trunk far above the surface of the ground, or even from the branches.

The typical root (Fig. 348) shows three layers of meristem at the apex, plerome, periblem, and calyptrogen, but there may also be a distinct dermatogen. The root-cap is well developed, and in aerial roots it often forms an extremely conspicuous spongy body, which is of importance in absorbing moisture. Roots are quite absent in Corallorhiza, where they are replaced by branching rhizomes, and this is probably true of other saprophytic forms. In these there is a mycorhiza or endophytic Fungus present, which is of importance in the nutrition of these forms.

\section{The Flower}

In the simplest flowers, like those of Naias, or some Araceæ

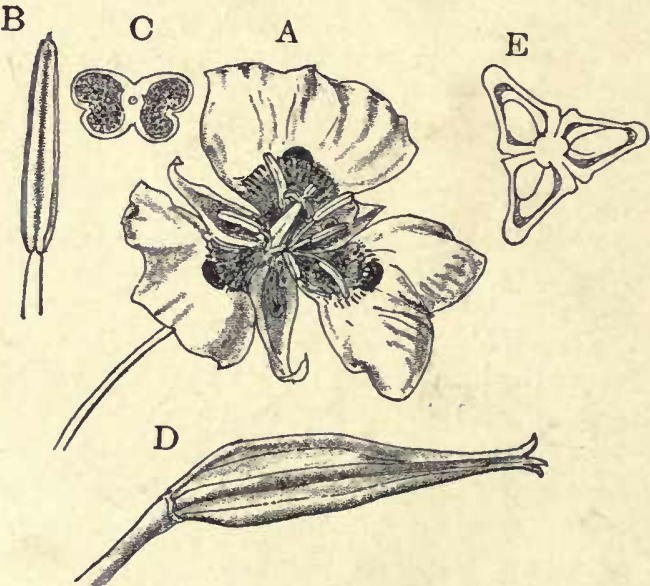

Fig. 350.-A, Calochortus luteus, var. oculatus. $B-E$, $C$. venustus. $B$, stamen $(\times 2)$. $C$, cross-section of anther $(\times 4)$. $D$, capsule (natural size). $E$, crosssection of young capsule $(\times 2)$. (Fig. 352), the flower may be reduced to a single carpel or stamen. In many of these forms the ovule is terminal, i.e. is derived from 
the floral axis, and not from the carpel, and this is probably the primitive condition among the Angiosperms.

These very simple flowers are commonly crowded into heads or spikes, as in Sparganium, Typha, the Araceæ, etc., and are either destitute of any floral envelopes or these are inconspicuous scales.

A somewhat higher type of flower is found in the Alismaceæ (Sagittaria, Alisma, etc.). In these (Fig. 355) the flowers may be either diclinous or hermaphrodite, but are furnished with showy petals. The carpels, as well as the other floral leaves, are entirely separate. 'These apocarpous Monocotyledons show marked resemblance to some of the lower families of Dicotyledons, notably the Ranunculaceæ and Nymphæaceæ, which may be related to them. The latter family, indeed, has recently been referred to the Monocotyledons.

The majority of the Monocotyledons have the parts of the flower definite in number, and the flower is usually composed of whorls of three leaves (Fig. 350). The carpels are united into a compound pistil, the ovary being divided into three chambers, or having a single cavity, with three placentæ bearing the

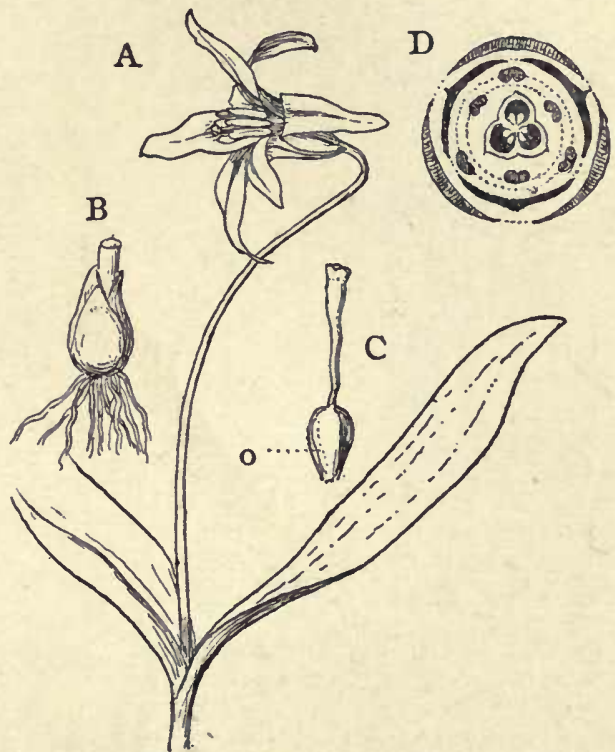

Frg. 351.-Emythronium Americanum. A, flower and leaves. $B$, bulb $\left(\times \frac{1}{2}\right) . C$, pistil $(\times 1)$. $D$, plan of the flower.

ovules upon its wall (Figs. 350, 351). In the simpler types (e.g. Lilium, Trillium, Calochortus, etc.) the perianth is composed of two whorls of entirely free leaves, the outer ones somewhat smaller and sometimes green, two sets of three stamens, and three coherent carpels. When all the parts of the flower are free and inserted below the carpels the flower is "Hypogynous."

In the Amaryllis family (Fig. 368), to which belong the Narcissus, Crinum, etc., the same arrangement of parts is found, but the perianth leaves are coherent, and form a tubular perianth, whose base is coherent with the ovary, which thus lies apparently below the outer parts of the flower. Flowers with an "inferior" ovary are called "Epigynous." 
In the Iridaceæ (Iris, Gladiolus, Sisyrinchium, etc.) the flower (Figs. 353, 369) is much like that of the Amaryllidaceæ, but the stamens are reduced to a single whorl of three. Some of these are otherwise specialized, the peculiar form of the flower in Iris being associated with pollination by special insects, and the same is true of the zygomorphic flowers of Gladiolus.

The most highly specialized monocotyledonous flowers are found in the Scitamineæ and Orchidaceæ. In Canna (Fig. 372) the epigynous

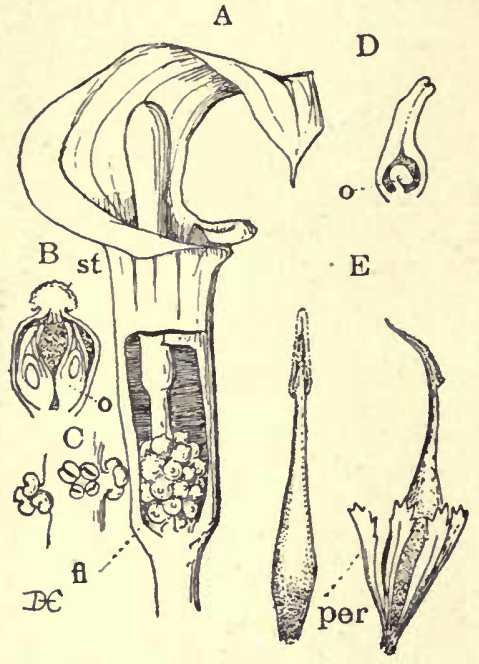

FIG. 352. - A-C, A risæma triphyllum. $A$, inflorescence, the spathe cut away at the side to show the pistillate flowers, $f\left(\times \frac{1}{2}\right) . \quad B$, pistillate flower cut longitudinally. ' $C^{\prime}$, male flowers. $D$, Lemna minor, pistillate flower, cut longitudinally and eniarged, showing ovule, $o$. E, Sparganium simplex, two pistillate flowers enlarged; in one the perianth leaves, per, have been removed.

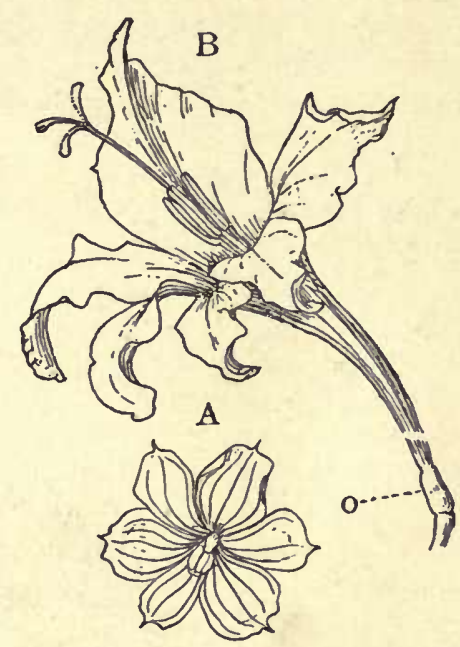

Fig. 353. - $A$, actinomorphic flower of Sisyrinchium bellum $(\times 1)$. $B$, zygomorphic flower of Gladiolus $s p ; 0$, inferior ovary.

flower has all the stamens present, but only one is fertile, the others being changed to petal-like "Staminodia," the conspicuous part of the flower.

In the Orchidaceæ the stamens are reduced to a single one in most cases, and this is united with the upper part of the pistil into the peculiar structure known as the gynostemium or column (Figs. 373, $374)$. The flowers are strongly zygomorphic, and with few exceptions they are absolutely dependent upon insects for pollination.

The flowers of the Monocotyledons may be borne singly, as in some species of Narcissus and Tulip, but more commonly they are in inflorescences of various kinds, which sometimes are of enormous size, as in the Century-plant (Agave Americana), and many Palms, Yucca, etc. 


\section{The Fruit}

The fruit of the Monocotyledons may be a dry capsule (Lilium), or achene (Sagittaria), or caryopsis (most Grasses), or it may be a pulpy berry (Asparagus, Smilacina, most Araceæ), or a stone-fruit like the Date, Cocoanut, and other Palms. Pseudo-fruits occur in some Bromeliacex, notably the Pineapple, where the edible part of the fruit is derived from the enlarged floral axis and perianth.

\section{Classification of Monocotyledons}

The Monocotyledons may be divided into the following orders :-

Order I. Helobieæ (Fluviales).

Order II. Pandanales.

Order III. Glumifloræ.

Order IV. Principes.

Order V. Synanthæ.

Order VI. Spathifloræ.

Order VII. I ililiflloræ.

Order VIII. Farinosæ.

Order IX. Scitamineæ.

Order X. Microspermæ.

\section{Order I. Helobieæ (Fluviales)}

The Helobieæ (Figs. 354, 355) are aquatic plants, mostly of simple structure. They may be completely submersed with slender stems and delicate leaves (Naias, Zannichellia, species of Potamogeton), or the plant may be rooted in the mud, the leaves floating at the end of slender petioles (Limnocharis, Potamogeton natans, etc.). A third type is that found in Lilæa, Tri-
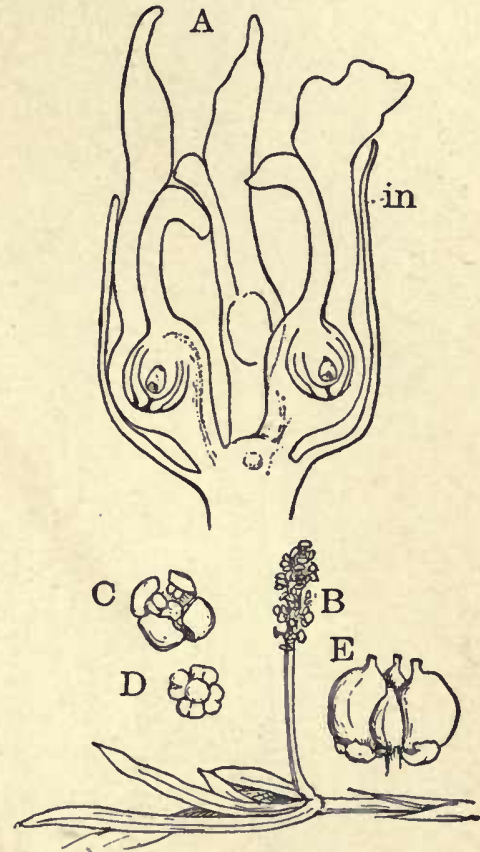

Fia. 354.-A, Zannichellia palustris, section of $q$ inflorescence surrounded by the cup-shaped involucre, in $(\times 40)$. B-E, Potamogeton sp. B, shoot with inflorescence $(\times 1) . C$, single flower, enlarged. $D$, the same, with the four scales removed to show the stamens and pistil. $E$, four nearly ripe fruits. glochin, Alisma, etc., where the short stem is rooted in the mud, and sends up the rigid leaf-stalks and scapes above the surface of the shallow water in which they usually grow.

The leaves are linear, with broad sheathing base and axillary scales in the completely submersed forms, rigid and awl-shaped like those of Isoetes in Lilæa and 'Triglochin, with broad lamina and long petiole in Limnocharis, Alisina, and Sagittaria. In the latter forms the leaves are often reticulately veined, suggesting certain of the Dicotyledons, with which these forms have other points in common. 
'The tissues in these aquatic forms are very simple, and there are large airspaces developed, as is always the case in plants having an aquatic habit.

The simplest flowers are found in the Naiadaceæ and Lilæa. The flowers here may consist of a single stamen or carpel, in both cases developed as the apex of a shoot, and quite destitute of any proper floral envelopes (Fig. 354). In the more specialized forms, like Butomus and Sagittaria (Fig. 355), a conspicuous perianth is developed, and the carpels and stamens are numerous, but all separate. In Triglochin and Aponogeton the carpels are usually three in number, and in the former more or less completely united into a compound pistil. The most
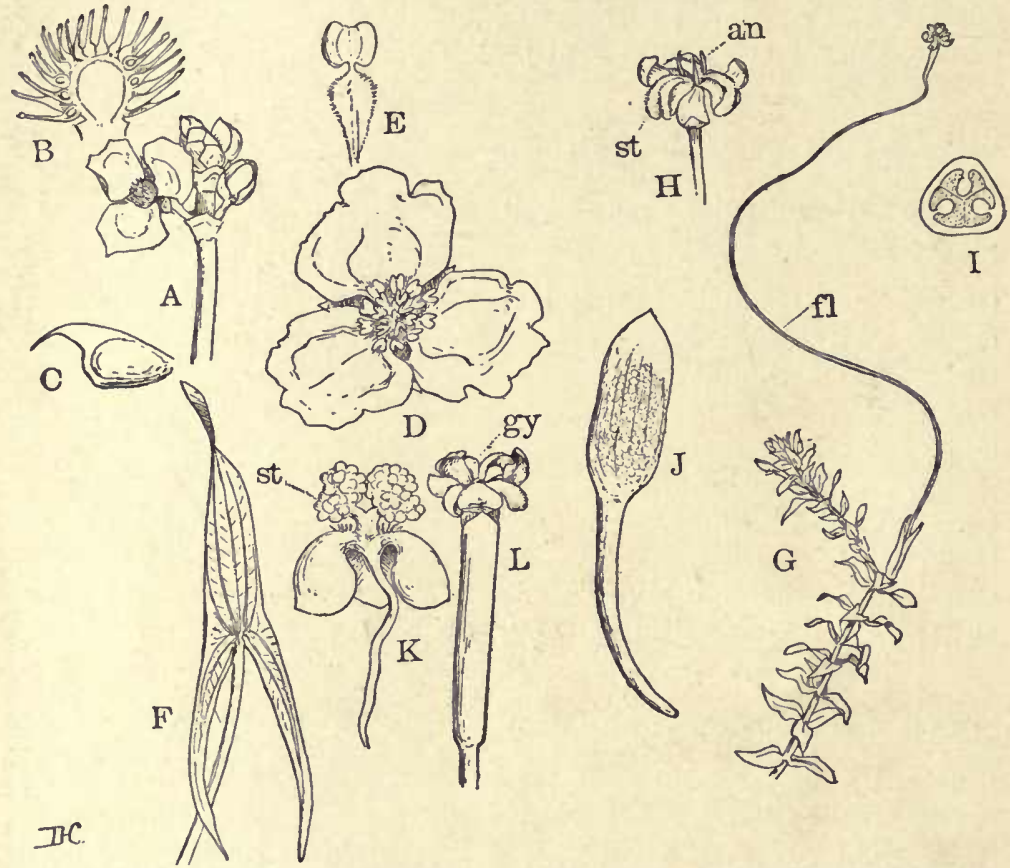

Fig. 355. - $A-F$, Sagittaria variabilis. $A$, young inflorescence with pistillate flower

$\left(\times \frac{3}{5}\right) . \quad B$, section of gynœcium, enlarged. $C$, ripe fruit, enlarged. $D$, staminate flower $\left(\times 1 \frac{1}{2}\right) . E$, single stamen enlarged. $F$, leaf $\left(\times \frac{1}{3}\right) . \quad G-I$, Elodea Canadensis. $G$, flowering plant $\left(\times \frac{3}{8}\right)$. $I I$, flower, enlarged. $I$, cross-section of ovary. $J-L$, Vallisneria spiralis. $J$, male inflorescence, flowers enclosed in the spathe. $K$, open staminate flower, much enlarged. $L$, female flower (about natural size); $g y$, lobes of the stigma.

aberrant forms are found in the Hydrocharitaceæ, which perhaps should not be included in the Helobieæ. These are mostly tropical plants, but two genera, Vallisneria and Elodea, are represented by common species in the Eastern United States. The fernale flower in these (Fig. 355) has a large inferior ovary, and is borne upon a long pedicel which raises it to the surface when ready for pollination, and in Vallisneria coils up afterward, drawing the young fruit under water, where it completes its growth.

All the marine Monocotyledons belong to the Helobieæ. Zostera and Phyllospadix are the principal American genera. 
The fruit in all of the Helobieæ, except the Hydrocharitaceæ, is a nutlet, or a dry or fleshy drupe-like achene (Potamogeton). In Vallisneria and Elodea it is a leathery, elongated pod, containing a gelatinous substance, which finally bursts open the fruit, and discharges the seeds.

The Helobieæ are divided into the following families : Naiadaceæ, Potamogetonaceæ, Lilæaceæ, Juncaginaceæ, Aponogetonaceæ, Alismaceæ, Hydrocharitaceæ.

\section{Order II. Pandanales}

The Pandanales comprise only a few forms, which are to be considered as primitive types. Some of them, like Typha and Sparganium, are simple aquatic plants,

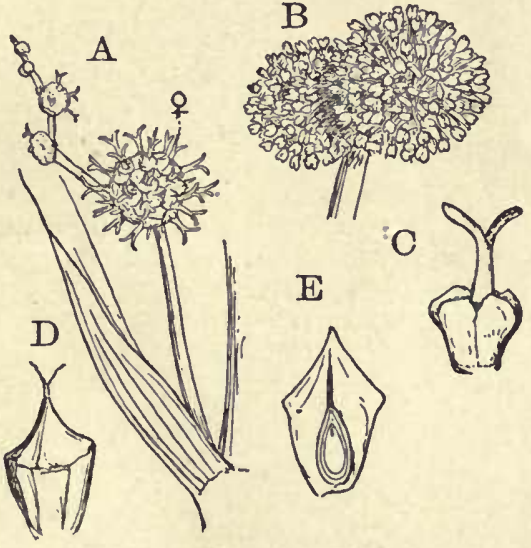

Fig. 356.- Sparganium eurycarpum. A, part of inflorescence, with pistillate flowers, $\&$. $B$, two heads of staminate flowers, enlarged. $C$, single pistillate flower, enlarged. $D$, fruit, enlarged. $E$, section of the fruit (nutlet) containing the seed.

while others, the Screw-pines (Pandanaceæ) are among the largest members of the group.

\section{Classification of Pandanales}

The Pandanales are divided into

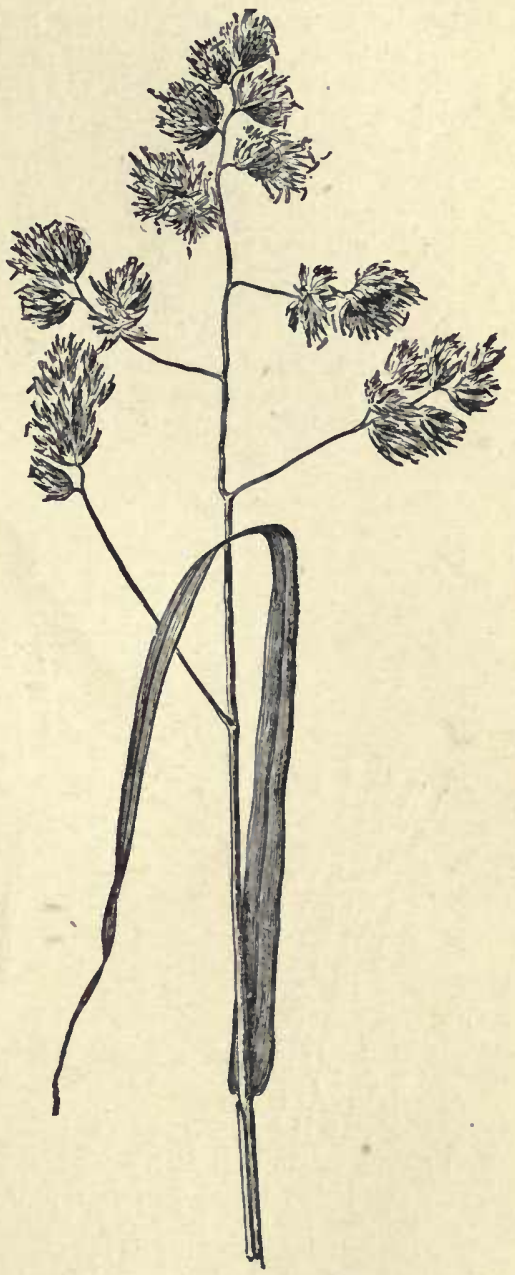

Fig. 357. - Dactylis glomerata $(\times 1)$. (After BAILEY.) the following families: Typhaceæ, Sparganiaceæ, and Pandanaceæ.

Fam. I. Typhaceæ. - The Typhacer are represented by the single genus Typha, the common Cat-tail. These are considered to be the simplest nembers 
of the order. The flat, two-ranked leaves and slender scapes arise from a rhizome. The pistillate flowers are crowded together at the lower part of the thick spike, the staminate flowers being at the apex, later falling away from the axis, which projects beyond the dark-brown fruit-spike.

Fam. 2. Sparganiaceæ. - This family also consists of a single genus, Sparganium, with six to eight species. S. eurycarpum, the Bur-reed, is the common species of the Fastern United States. S. Greenii, a similar species, occurs in California, and several other species occur within our territory, The flowers are borne in globular heads, the pistillate below the staminate (Fig. 356). The flowers have a rudimentary perianth.

Fam. 3. Pandanaceæ. - The Pandanaceæ, or Screw-pines, are tropical plants of peculiar structure and doubtful affinities. The structure of the flowers and fruit suggest the Sparganiaceæ, and they have been placed next these, although they are sometimes supposed to be rearer the Palms. There are two genera, Freycinetia, climbing plants especially abundant in the Malayan regions, and Pandanus, mostly arborescent forms of wider distribution than Freycinetia, but not found in the American tropics. A single species of each genus is found in the Hawaiian Islands.

'They are characterized by narrow leaves, arranged upon the stem in a spiral series, hence the name "Screw-pine." The stems branch freely, and show a

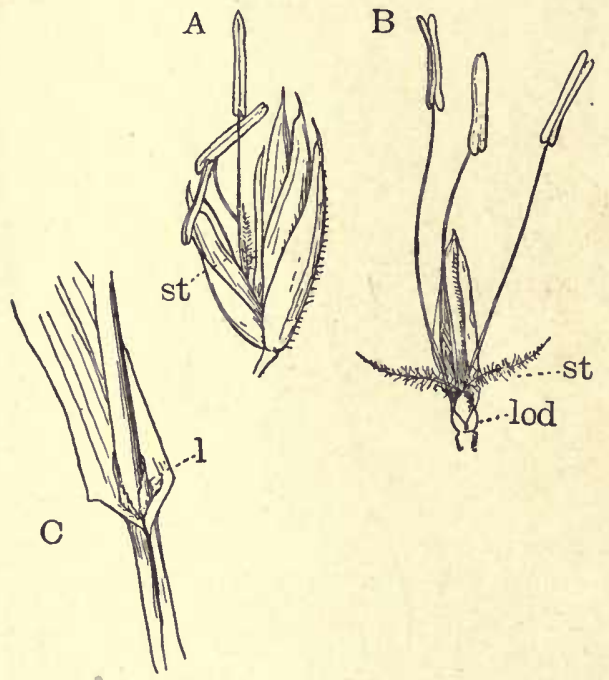

Fig. 358. - Dactylis glomerata. A, spikelet, enlarged. $B$, single flower, showing lodicules, lod, and the stigmas, st. C, stem with sheathing leaf-base, showing ligule, $l$. busa) there are six stamens, and in some cases (Luziola $s p$.) there may be more. There are usually two plumose styles, which may be joined together, as in the Indian-corn, where each thread of the "silk" is composed of two united styles.

The flowers of the Grasses are arranged in "Spikelets," which are enclosed by two glumes, each flower of a spikelet consisting of two bracts ("Paleæ"), 
surrounding the sporophylls. The inner palea belongs to the floral axis, while the outer one ("flowering glume") belongs to the axis of the spikelet. Above the outer palea there are usually present two small bodies (Lodicules), which, by their enlargement, force open the palex. These are sometimes considered to be rudimentary perianth leaves, but there is much doubt about this.

In the Sedges (Fig. 360) the flowers are more commonly diclinous than in the Grasses, but structurally are similar to them.

'The fruit is indehiscent, a nutlet or caryopsis, and the abundant starchy endosperm of many Grasses makes these the most important of all food plants. The grain (caryopsis) of the Grasses consists of the ovary, which is closely adherent to contained seed. The embryo in the ripe grain is well-developed in the Grasses, and the cotyledon (Scutellum) acts as an absorbent organ for the laterally placed embryo. In the Sedges the embryo is at the apex of the endosperm (Fig. 360, G), and much less developed than it is in the Grasses.

The Grasses and Sedges are widespread, especially important in the cooler parts of the world. The Sedges are largely water-plants, but the Grasses often grow in dry exposed regions, where they are the most important plants, as upon our own western prairies. All the members of the group have jointed stems and long sheathing leaves, two-ranked, with

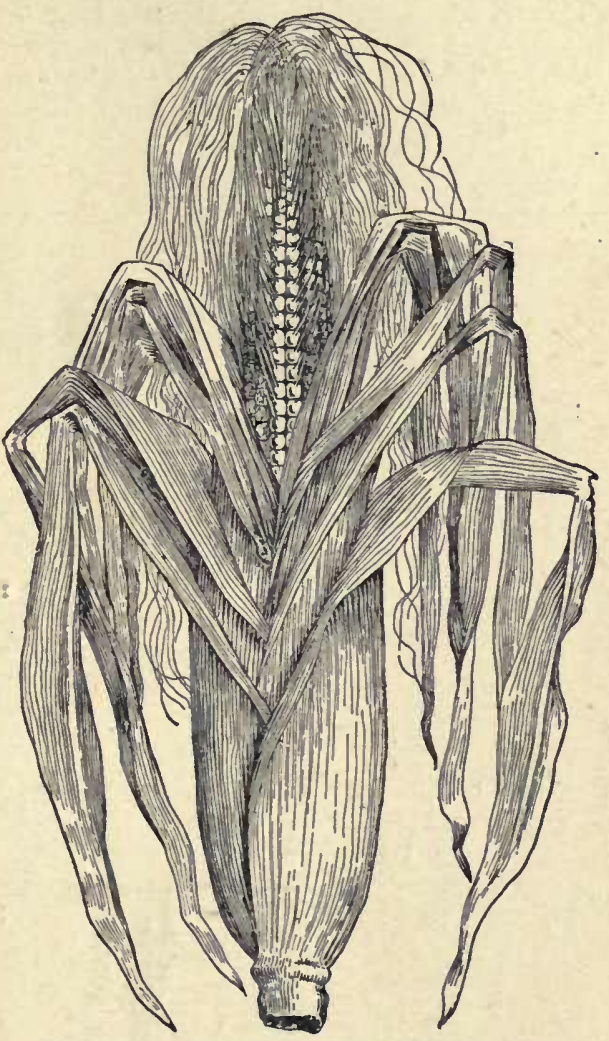

Frg. 359. - Zea Mays. Pistillate flowers. (After Bailey.) split sheaths, in the Grasses; three-ranked, with entire sheath, in the Sedges. The stems are usually hollow in the Grasses, and solid in the Sedges. The giants of the order are the Bamboos, some of which are 30 to 40 metres in height. The outer tissues of all of them are heavily impregnated with silica.

Economically the Sedges are of small importance. Perhaps the most noteworthy of these is the Papyrus (Cyperus papyrus). The Grasses, on the other hand, are the most important of all plants. In temperate climates they form the staple food of herbivorous animals, and all the cereals - Wheat, Rice, Corn, etc. - are Grasses. The Bamboos and Sugar-cane are also Grasses. Of our native Grasses, the Wild-rice (Zizania aquatica) is the most important as a source of food. 


\section{Order IV. Principes (Palmæ)}

The Palms constitute an extremely natural order. While they are mainly tropical forms, several species extend into the warm-temperate zones. In the Atlantic States the Palmettoes (Sabal, Chamærops, etc.) occur, while in Arizona and Southern California are found species of Washingtonia (Pritchardia) and Erythea. All of these are Fan-palms.

Some of the smaller Palms do not develop an erect stem, but in most of them the stem forms a columuar trunk, sometimes fifty metres in height. In spite of

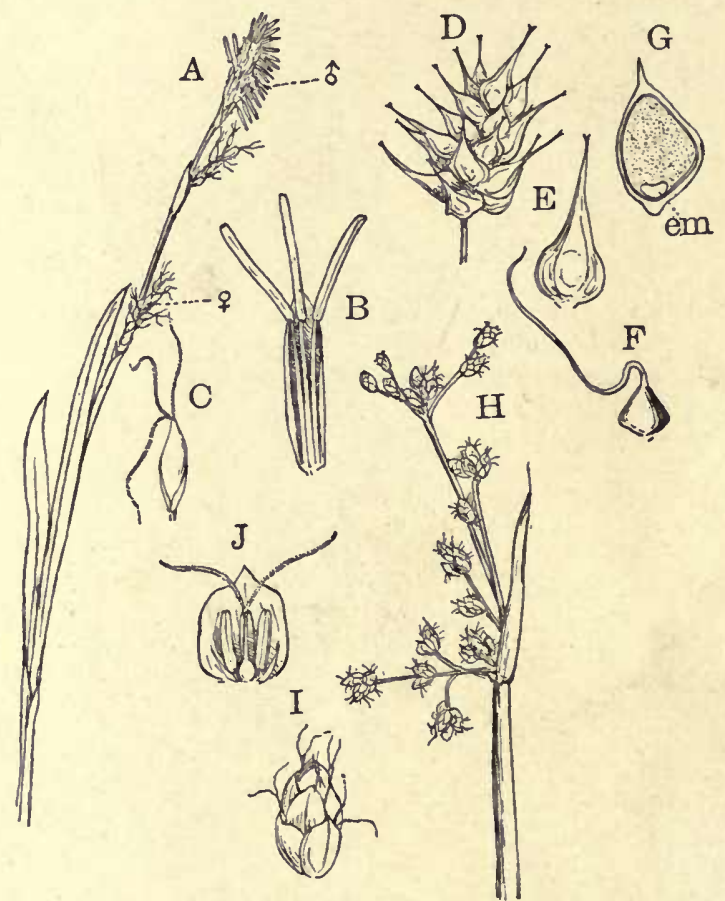

Fig. 360.- $A-C$, Carex sp., plant with staminate, $\delta$, and pistillate, $\&$, inflorescence. $B$, staminate tlower, enlarged. $C$, pistillate flower. $D$, fruits of $C$. Asa-Grayi $\left(\times \frac{3}{3}\right) . E$, single fruit, slightly enlarged. $F$, akene, removed from the involucre. $G$, section of akene; em, embryo. $H$, Scirpus lacustris. $I$, single spikelet. $J$, flower, enlarged.

its size, its structure does not differ essentially from that of the typical mono- cotyledonous stem, and the same is true of the roots, which are produced in great numbers, sometimes from a distance above the ground.

The formation of the trunk does not begin until the crown of leaves has reached nearly its full size. Branching of the trunk, apparently a true dichotomy, occurs in the "Dom-palm" (Hyphæne) of Upper Egypt, but is absent in otler genera, although small lateral (adventitious?) shoots may occur at the base of the stem (Phonix Canariensis). In the Rattan-palms (Calamus) 



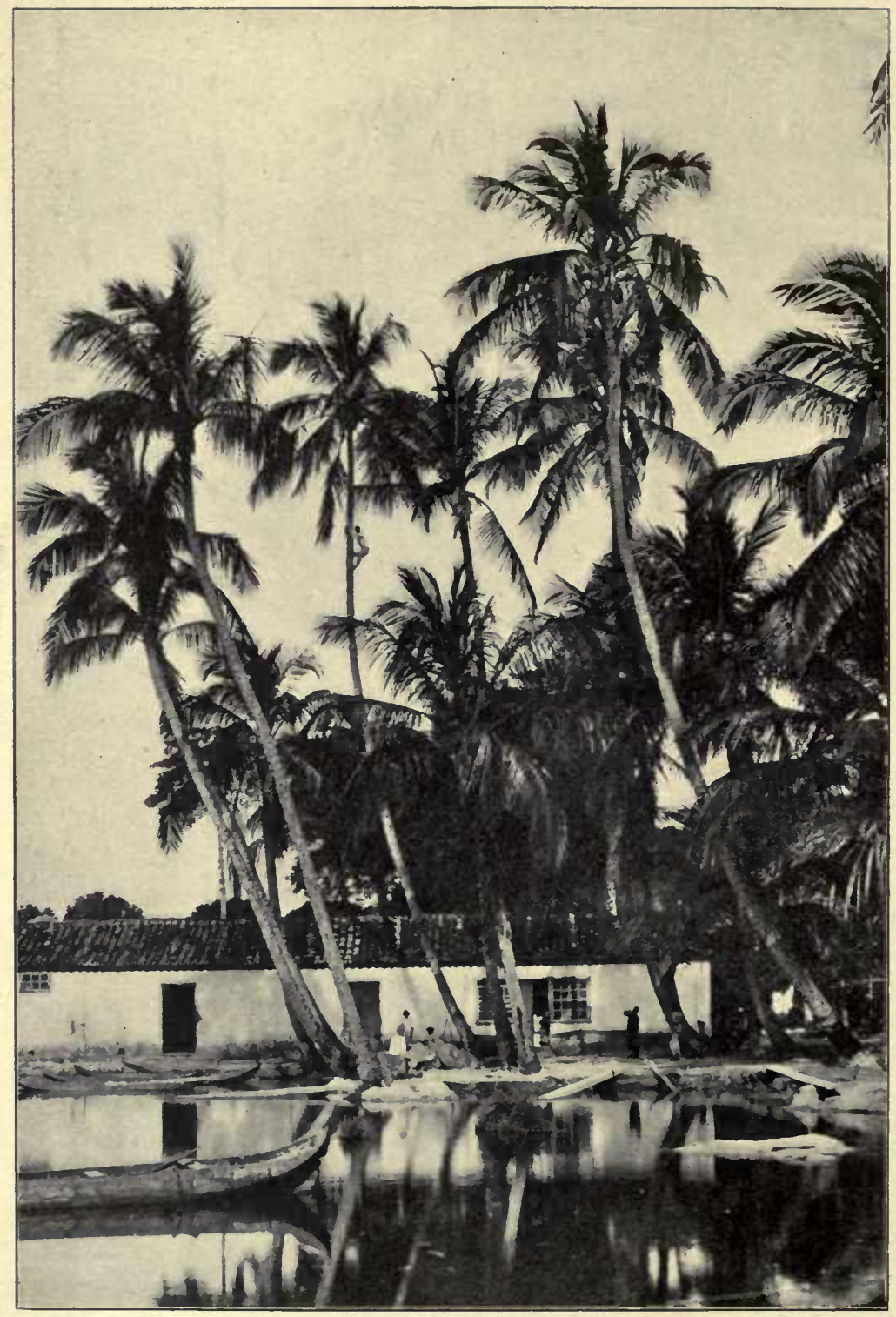

PLATE V!

Cocoanut Palms, Brazil. (Photograph by Dr. J. C. Branner.) 
the extremely slender stem reaches a great length, and climbs by means of hooks developed upon the scattered leaves.

The leaves are suarply plaited when young, and split more or less completely along the lines of these folds. Two types of leaves occur, the fanshaped (Sabal, Washingtonia, Chamærops, etc.) and the pinnate (Phœnix, Cocos, Oreodoxa, etc.). Bipinnate leaves are found in Caryota. The leaves may remain attached for a long time, and the trunk then is rough with the adherent leaf-bases. In many Palms, however, like the Royal-palm (Oreodoxa regia), the leaves fall off, leaving a smooth scar encircling the trunk below the sheath of the next younger leaf.

The flowers of the Palms (Fig. 361) are simple in structure, and may be hermaphrodite (Sabal) or diclinous (Phœnix); in the latter genus they are dicecious, but most Palms are monœcious. A perianth of three to six leaves is generally present, and there are from six to many stamens. The carpels are
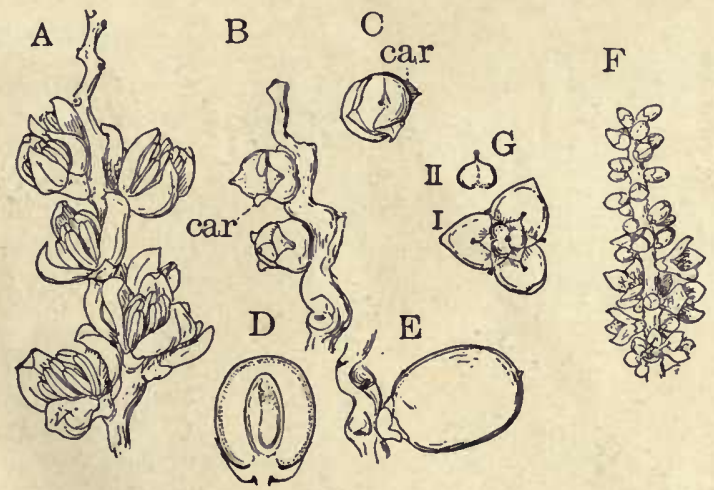

Fig. 361.-A-E, Phonix Canariensis. $A$, staminate flowers $(\times 2)$. $B$, two pistillate flowers which have been fertilized; two of the three carpels, cur, are abortive. $C$, a similar flower, seen from in front, showing the single fertile carpel, and two sterile ones. $D$, section of young fruit $\left(\times 1 \frac{1}{2}\right) . E$, ripe fruit $\left(\times \frac{2}{3}\right) . E-G, L i v i-$ stona Chinensis. $F$, part of inflorescence $(\times 1) . G$ I, single flower $(\times 2)$. GII, the pistil.

always three, and may be separate or united. In the latter case, not infrequently but a single one matures.

The flowers are borne in large inflorescences, often extensively branched, and of gigantic size. In a few instances, like the Talipot-palm (Corypha Taliera), the tree dies after it has developed the single enormous terminal inflorescence. In other Palms the inflorescence arises as a lateral branch, and is surrounder: while young by large bracts, or spathes.

The fruit is usually a berry, or stone-fruit, which may reach great size (Cocos). The edible fruits of many Palms, as well as the value of the Palms in furnishing building materials, fibre, etc., make them among the most important of all plants. Besides the fruit, other parts of the tree, the young shoots, the fermented sap, and the pith (Sago-palm), are important articles of food.

Distribution. - Some of the Palms, e.g. Washingtonia filifera, of Southern California, are inhabitants of arid regions; but it is in the moist forests of the Tropics that they reach their greatest development. Here they become stately trees with leaves of gigantic size. Some species of Arenga and Caryota have 
pinnate leaves, ten to fifteen metres in length, and the fan-shaped leaves of Corypha umbraculifera are four to five metres in diameter.

\section{Order V. Synanthæ}

The order Synanthæ comprises a single small family of palm-like plants, the Cyclanthaceæ. They are confined to the American Tropics, and in appearance closely resemble small Fan-palms (Fig. 362). The flowers, however, are more

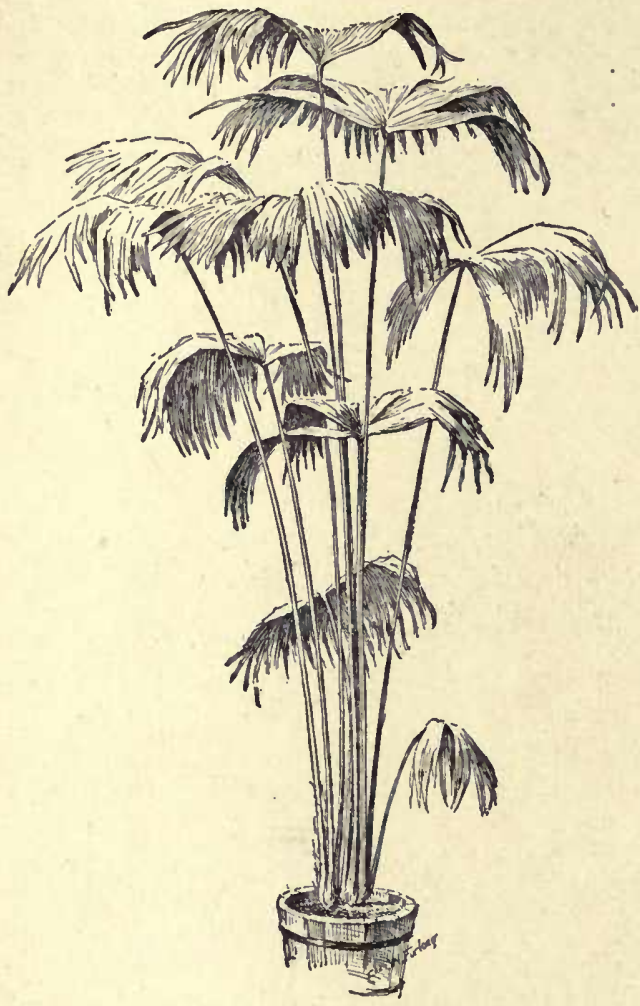

Fig. 362.-Carludovica palmata. (After Barlex.) like those of the Araceæ. From the leaves of species of Carludovica are manufactured the famous Panama hats.

\section{Order VI. Spathifloræ}

The Spathifloræ include two families, the Araceæ, to which the greater number belong, and the Lemnaceæ.

Fam. I. Araceæ. The Araceæ are principally tropical plants, but a small number of genera (Acorus, Calla, Symplocarpus, Arum, Arisæina) occur in temperate regions as well. Several Araceæ, like the familiar "Callalily" (Richardia), and various species of Anthurium and Caladium, are cultivated for their fine foliage or showy inflorescences. The latter owe their beauty to the large bract (Spathe) which surrounds the flowers (Fig. 364). Tlie flowers are borne upon a thick spike, or Spadix. In Spathicarpa (Fig. 363) the spadix and spathe are completely coherent. The flowers may be unisexual or hermaphrodite, and the fruit is a berry, which is often brilliantly colored (e.g. Ariscema triphyllum). The embryo may fill the seed (Lysichiton) or there may be endosperm present (Philodendron).

The leaves, with few exceptions (Acorus), are large, and sometimes compound. The venation may be parallel (Richardia), but more often it is reticulate. The Araceæ are represented in the moist tropical forests by many striking forms. Some, like Dracontium gigas, of Central America, are terrestrial plants with giant leaves; others, like Philodendron, and species of Anthu- 
rium, are climbers, reaching to the tops of trees, and are among the most characteristic of all plants. Monstera deliciosa, with its big perforate leaves, is familiar in conservatories.

The flowers of the A raceæ show a good deal of variety. In the simplest forms, e.g. Aglaonema, Spathicarpa, the flowers consist of a single carpel, with a basal ovule, or of a single stamen. In others, e.g. Anthurium, Lysichiton, there is a compound ovary, and the flowers are hermaphrodite, with a rudimentary perianth. The flowers may be confined to the base of the spadix (Arisæma), or they may cover it completely (Symplocarpus). 'The inflorescence sometimes reaches an enormous size. In Amorphophallus titanum, the spathe is nearly a metre in length. In these large forms the evolution of heat by the inflorescence is very marked, and a thermometer thrust into the spathe, especially at the time that the pollen is being shed, indicates a much higher temperature than that of the surrounding atmosphere. In Philodendron melanochrysum, an East Indian

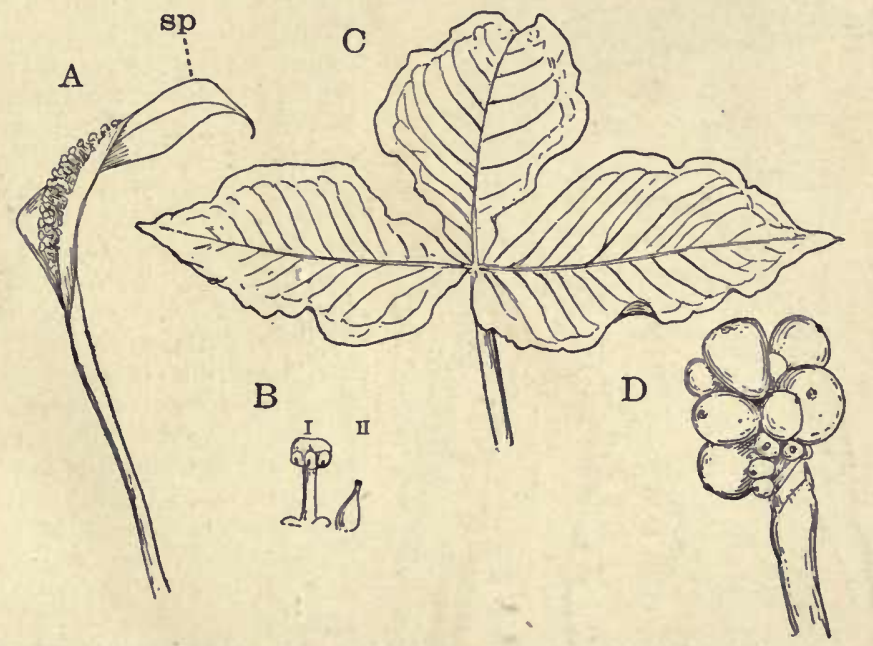

Frg. 363.- A, Spathicarpa sagittefolia, the simple flowers attached to the leaflike spathe, $s p(\times i)$. $B$, staminate, $I$, and pistillate, $I I$, flowers, enlarged. $C$, leaf of Arisæma triphyllum $\left(\times \frac{1}{2}\right)$. D, Nephthytis Liberica, fruits $\left(\times \frac{1}{)}\right.$.

species, Kraus found a maximum difference of $12.6^{\circ} \mathrm{C}$. This took place in the evening, and was accompanied by an increase in the odor, which is often very pronounced in these plants. The biological significance of this rise in temperature Kraus considers to be the attraction of insects, which seek shelter in the warm spathe, and thus receive the pollen, which they afterward carry to another inflorescence. The odor of many Araceæ is extremely offensive, and the colors dull. Such forms attract carrion-insects, which serve to pollinate them.

Histology. - The tissues of the Araceæ usually contain numerous needleshaped crystals, or rliaphides, to which has been attributed the extremely acrid taste of many of them. Some of them (Dieffenbachia seguine) possess a milky juice, which is said to be extremely poisonous.

Fam. 2. Lemnaceæ. - The very much reduced plants, the Lemnaceæ (Fig. $365)$, are related to the Araceæ, and are sometimes included with them. Lemna bas roots, Wolffia is rootless. The latter is the smallest of all vascular plants, 
being a little oval body a millimetre or so in diameter. Two species occur in the Eastern United States. The flowers in the Lemnacer consist of a single carpel or stamen, the flowers being grouped in a small inflorescence.

\section{Order VII. Liliifloræ}

The Liliifloræ are often considered to be the "typical" Monocotyledons, and comprise many of the most familiar and showy forms, both wild and cultivated.

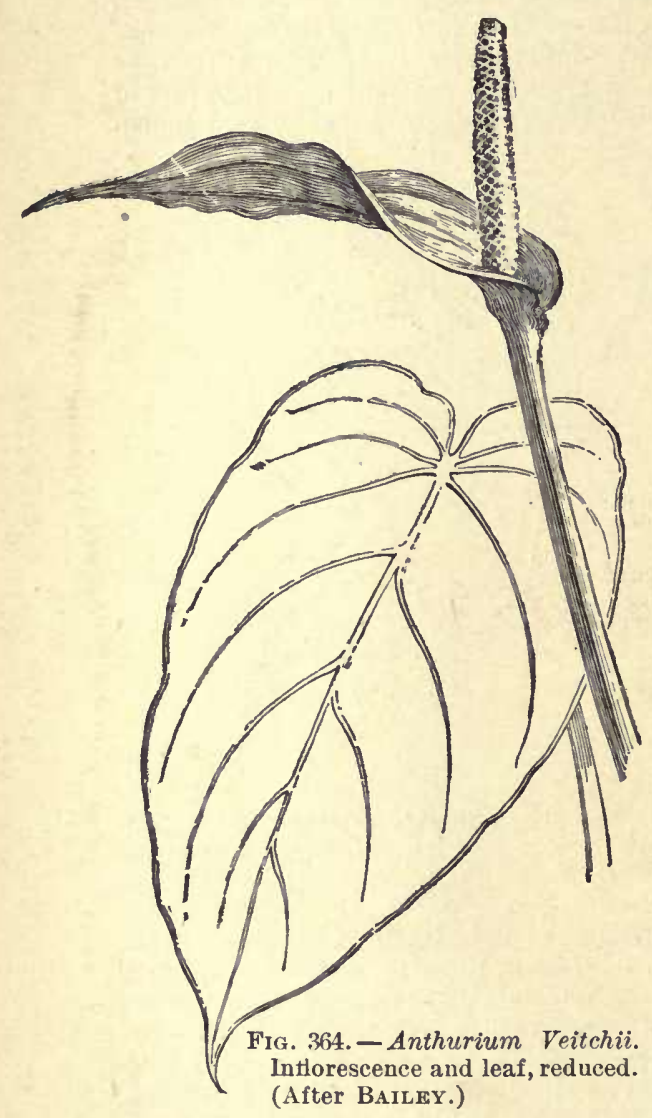

With few exceptions the flowers show the typical arrangement, i.e. five whorls of three members (Fig. $350)$. The two whorls of perianth leaves may be alike, or occasionally the outer ones are smaller and green (Trillium). Within the order are found all gradations between the radially symmetrical, hypogynous flowers of the true Lilies, and the epigynous, zygomorphic flowers of many Iridaceæ. The fruit is usually a dry, trilocular capsule, but it may be a pulpy berry, as in Asparagus, or Clintonia. The embryo is small, surrounded by abundant endosperm.

The Liliifloræ are, for the most part, perennial herbaceous plants, sending up each season anuual flowering shoots. In the warmer parts of the world they may become small trees, like the Yuccas of the Southwestern States, and the Dracænas and Cordylines of the Old World. A small number of forms (Smilax, Dioscorea, Bryonia) are climbers.

The families included in the Liliifloræ are the Juncaceæ, Liliaceæ, Amaryllidaceæ, Iridaceæ, Dioscoreaceæ, Taccaceæ, and IIæmadoraceæ.

Fam. 1. Juncaceæ. - The Rushes (Juncaceæ) are insignificant plants, resembling in their floral structure the more showy Liliaceæ, but with the perianth composed of inconspicuous scalelike leaves. They are sometimes considered to be degraded Liliacer, but this is open to question.

Fam. 2. Liliaceæ. - This is the largest family of the order, and includes many of the most beautiful of all flowers. They are especially well developed il many semi-arid countries, like the Mediterranean region of Europe, and California. The true Lilies (Lilium), Tulip, Hyacinth, Erythronium, Trillium, are familiar examples. Among the characteristic western genera may be mentioned Calochortus (Fig. 350), Brodiæa (Fig. 366), Fritillaria, and Yucca. 


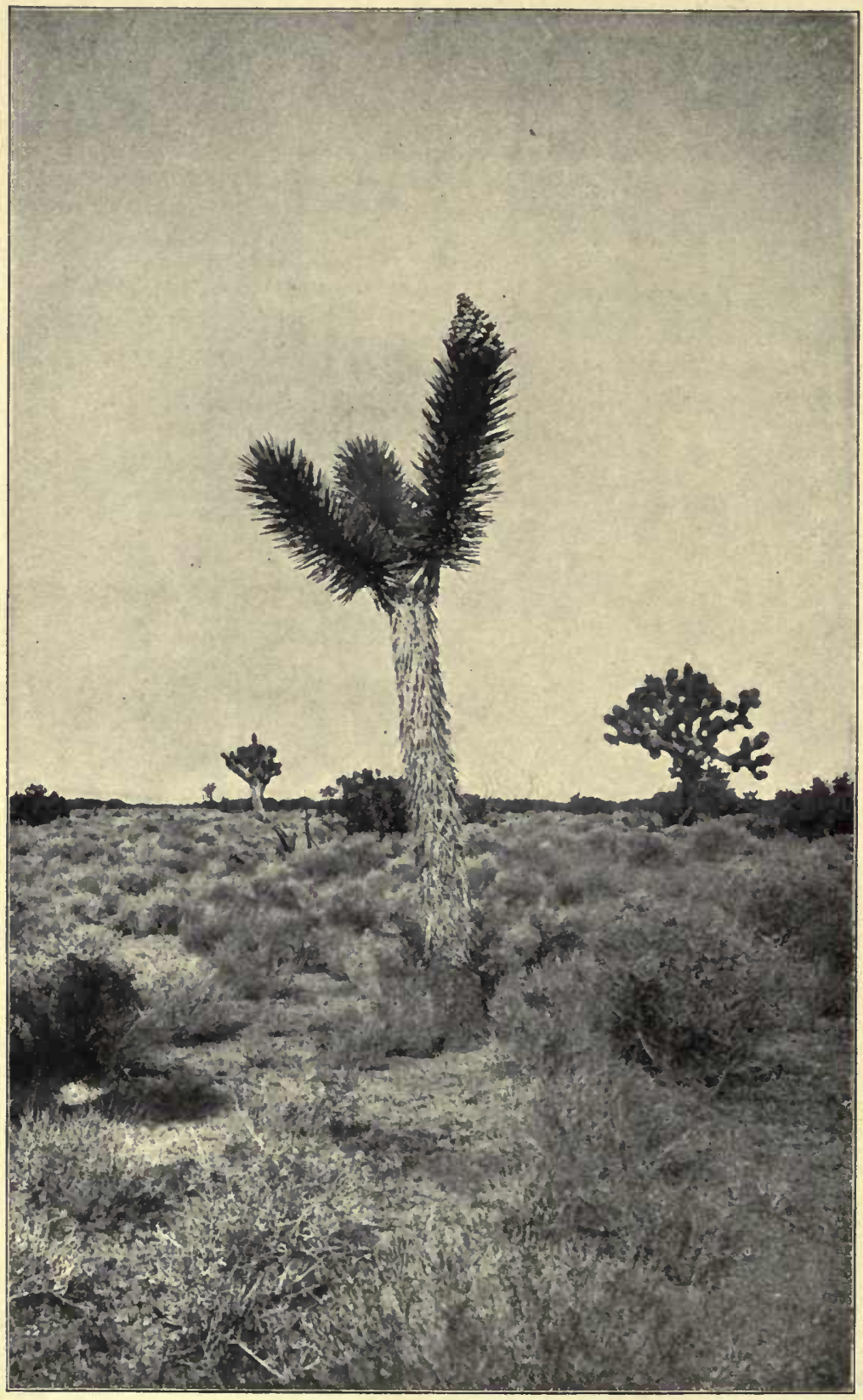

\section{PLATE VII}

Yucca arborescens, growing in the Mojave Desert of Southern California.

(Photograph by Prof. W. Trelease.) 
Fam. 3. Amaryllidaceæ. - The Amaryllidaceæ differ from the Liliaceæ in having an inferior ovary, and sometimes zygomorphic flowers. Very few of these grow within our territory. The Agaves (Century-plant), and Zephyranthes ("Atamasco-lily"), and Hymenocallis (Pancratium) are the most important. A number of common garden flowers - Galanthus, Narcissus, Amaryllis - belong to this family.

Fam. 4. Iridaceæ. - The Iridaceæ have epigynous flowers, like the Amaryllidaceæ, from which they differ in having the stamens reduced to three. Some have actinomorphic flowers, with the segments all alike (Sisyrinchium, Ixia), or the inner segments (petals) may be different from the outer ones, as in Iris (Fig. $369)$ and Tigridia. In many others (Gladiolus, Freesia) the flowers are markedly zygomorphic.

The Iridacex are especially abundant in the Cape region of Africa, whence many beautiful forms have

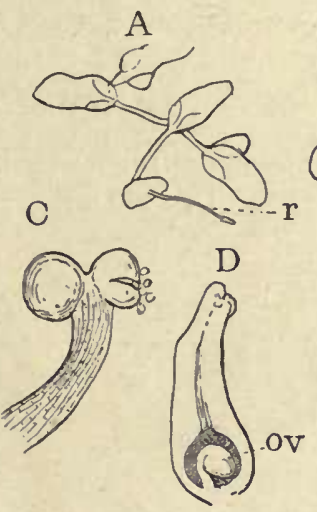

B

FIg. 365. - Lemna trisulca. Plant, showing method of branching. $B-D, L$. minor. Two plants $(\times 8) ; r$, root; $f$, flowers. $C$, staminate flower, much enlarged. $D$, section of female flower.

been introduced into cultivation. Gladiolus, Ixia, Freesia, Sparaxis, are among the most striking of these.

The leaves of most Iridaceæ are sharply folded longitudinally, and the leafy shoots with their two-ranked leaves are thus strongly flattened. Such leaves are termed "Equitant."

Fam. 5. Dioscoreaceæ. - The Dioscoreaceæ, or Yam family, include a num-

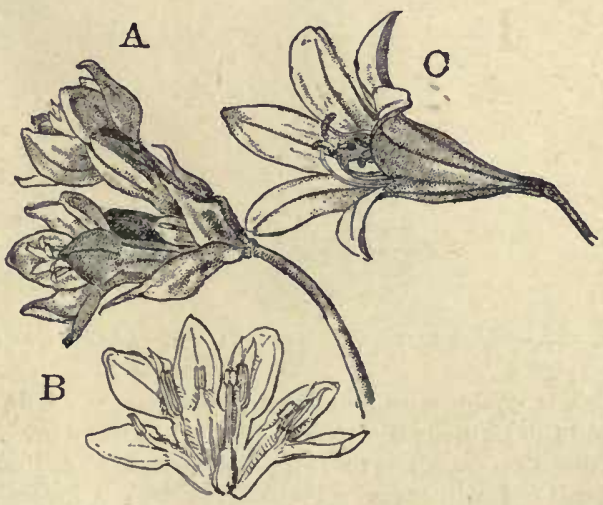

Fig. 366. $-A, B$, Brodiza capitata. $A$, inflorescence $(\times 1) . B$, flower opened to show arrangement of parts. $C$, flower of $B$. laxa.

ber of twining, mostly tropical, plants, with heart-shaped, reticulate-veined leaves, and inconspicuous, mostly diclinous flowers, the pistillate flowers with 
inferior ovary. A single species (Dioscorea villosa) is common in the eastern United States. D. batatas is the common Yam.

Fams. 6, 7. Taccaceæ, Hæmodoraceæ. - The Taccaceæ and Hæmodoraceæ are small families without any common representatives.

\section{Order VIII. Farinosæ}

The Farinosæ comprise several families, some of which are often included with the Liliifloreæ. They are distinguished especially by the character of the

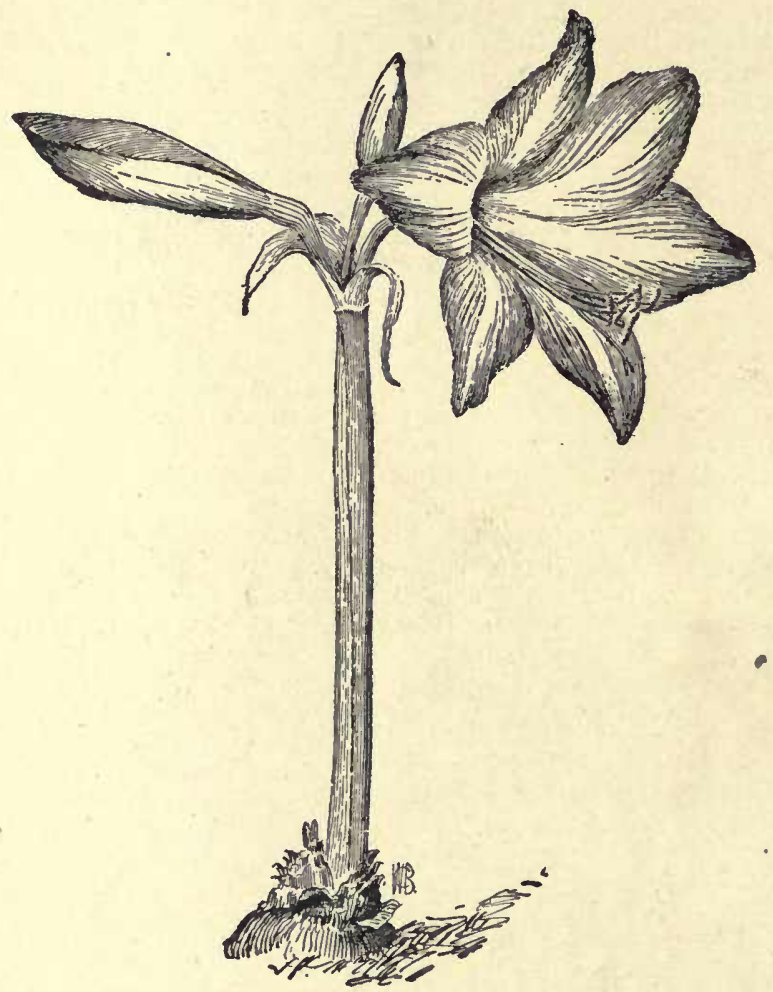

FIG. 367. - Hippeastrum vittatum $\left(\times \frac{1}{2}\right)$. (After BAILEY.)

endosperm, which is copious, and mealy in consistence. The ovules are often orthotropous, and the stamens sometimes reduced in number. They are largely tropical in their distribution. The most familiar genus is Tradescantia (Fig. 369), belonging to the Commelinaceæ. Pontederia and Tillandsia represent the Pontederiaceæ and Bromeliaceæ. The other families represented in the United States are Mayacaceæ, Xyridaceæ, and Eriocaulaceæ.

Pontederiaceæ. - These are aquatic plants, mostly confined to the Tropics. Pontederia cordata, the Pickerel-weed (Fig. 370), is our only common representative. The Water-hyacinth (Eichhornia crassipes) is now commonly planted in 
ponds, and at the South has become naturalized, and in some places causes much trouble by the rapidity with which it has increased. The flowers are strongly zygomorphic, and in Pontederia cordata are trimorphic, i.e. there are three different lengths of styles and stamens.

Bromeliaceæ. - The Bromeliaceæ are exclusively American, and especially developed in the tropics of South America and the West Indies. A few species of Tillandsia, among them the familiar "Spanish-moss" (T. usneoides), represent the family in the United States. The flowers, structurally, are much like those of the true Lilies. They are often in spikes, the flowers in the axils of showy pink or scarlet bracts. With few exceptions they are epiphytes, and are a conspicuous feature of the flora of tropical America. The

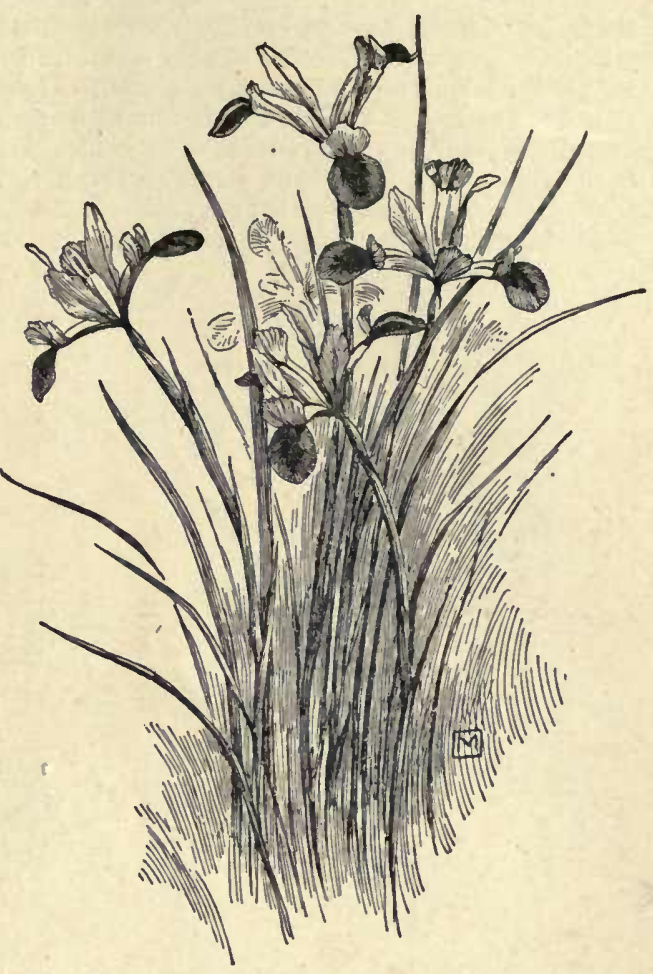

FIG. 368. - Iris xiphium ( $\left.\times \frac{1}{4}\right)$. (After BaILeY.)

leaves are long and slender, often crowded together at the base of the plant

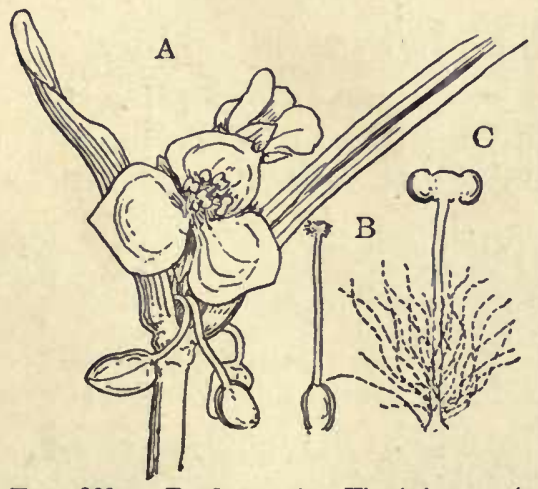

Fia. 369. - Tradescantia Virginica. A, inflorescence, reduced. $B$, pistil. $C$, stamen, enlarged, showing the staminal hairs.
(Fig. 371), where their expanded bases serve as reservoirs of moisture, and accumulate, also, dust and humus. Upon the surface of the leaves are scurfy scales, which also serve to catch water. The Pineapple (Ananas sativa) is the most familiar member of the family. The fruit, here, is an aggregation of enlarged flowers, attached to the juicy floral axis - the whole structure is much like a gigantic mulberry.

The roots in these plants serve mainly as organs of attachment, and may be quite absent.

\section{Order IX. Scitamineæ}

The Scitamineæ are, with very few exceptions, tropical plants, fre- 
quently of large size, and extremely characteristic. They have ample leaves, often very large, as in the Banana (Musa). The leaves are rolled up trumpetwise when young and have a strong midrib, from which lateral parallel veins run to the margin. The leaves are usually. stalked, and the leaf-base is largely developed, forming a conspicuous sheath enwrapping much of the stem. There is commonly an underground stem, or rhizome, from which the aerial shoots are produced. These, with few exceptions, bear a terminal inflorescence which ends the growth of the shoot.

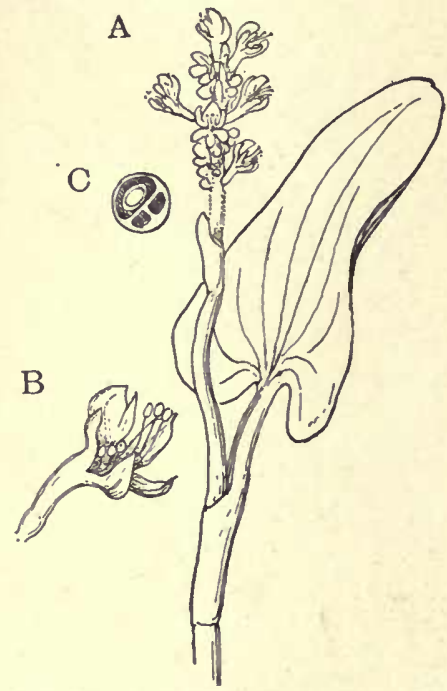

Fia. 370.- Pontederia cordata. A, leaf and inflorescence, reduced. $B$, single flower, showing the two sets of stamens. $C$, cross-section of ovary, showing one fertile and two sterile carpels.

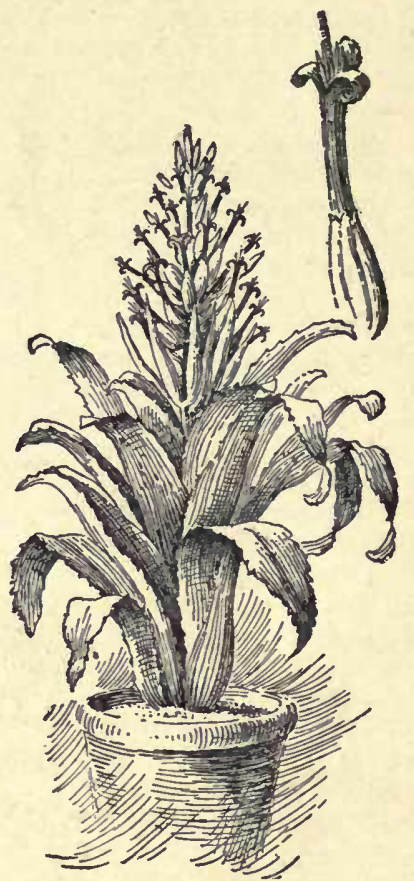

Fig. 371.-Bilbergia vexillaria. (After BaILEx.)

In the "Traveller's-tree" (Ravenala) there is a perennial upright trunk, and the inflorescences are lateral. The enlarged leaf-bases of this plant serve as reservoirs of water.

The flowers are zygomorphic, and only very rarely are all the stamens developed. The ovary is inferior, and the seeds contain a small embryo, which is imbedded in perisperm, or nutrient tissue developed from the nucellus of the ovule. The flowers are often borne in the axils of conspicuous bracts, which sometimes are very vividly colored. Some of the species of Heliconia have yellow, or scarlet and yellow, bracts of great beauty, and the bracts of some species of Zingiber are white or pink.

The least specialized flowers are found in the Musaceæ, or Banana family. Here five perfect stamens are generally present, and a rudiment of the sixth one is often apparent. In the Ginger family (Zingiberaceæ) only one perfect stamen is developed, and one of the others is broad and petal-like, curiously resembling the labellum of an Orchid (Fig. $372, \mathrm{G}$ ). 
Cannaceæ. - In the familiar genus Canna (Fig. 372), which is the only genus of the Cannacer, and very common in our gardens, five of the stamens are changed into petaloid staminodia, which form the showy part of the flower, the perianth being quite inconspicuous. The sixth stamen is also petaloid, but upon one side it develops pollen. A single species of Canna, C. flaccida, occurs native in Florida.

Marantaceæ. - The Marantaceæ are principally confined to the American Tropics, and include a number of slowy-leaved forms cultivated in greenhouses.

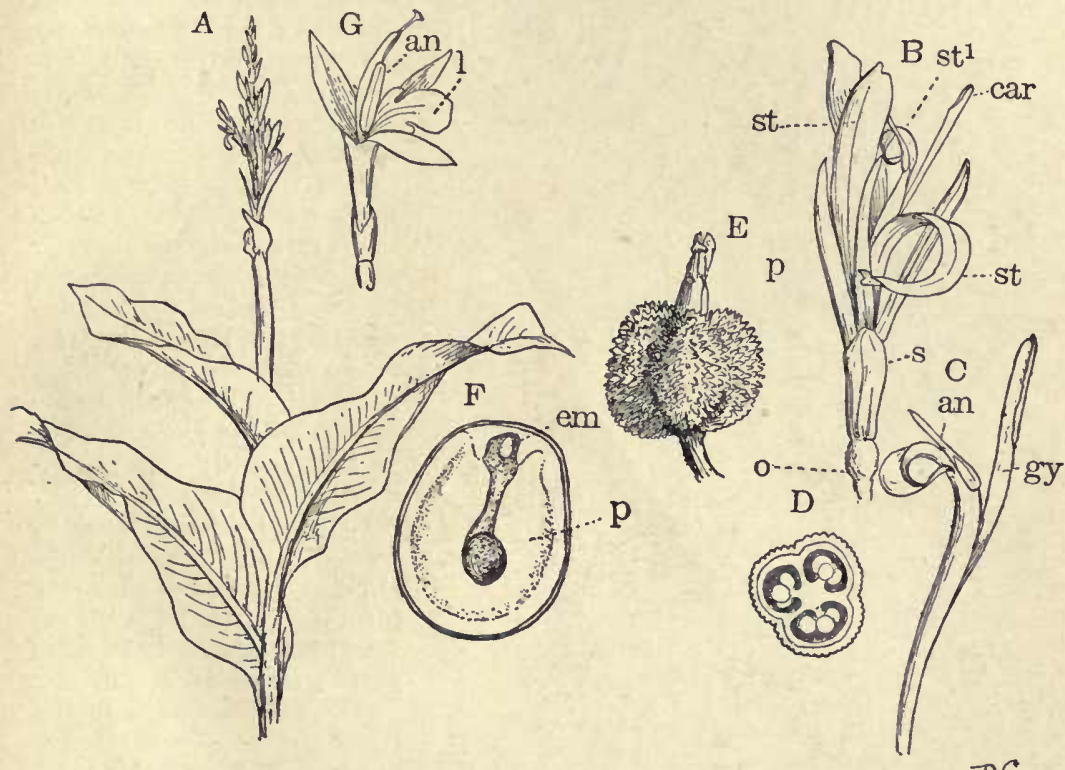

$D C$.

Fig. 372. - $A-F$, Canna Indica. $A$, upper part of flowering shoot, much reduced. $B$, flower, showing the staminodia, st, and fertile stamen, $s t^{1}$; car, style with stigma. $C^{\prime}$, fertile stamen and pistil. $D$, section of ovary, enlarged. $E$, nearly ripe capsule. $F$, section of seed, enlarged; em, embryo; $p$, perisperm. $G, Z$ ingiber officinalis. (After BERG and SchMidT.)

The structure of the flowers is much like that of Canna. Maranta arundinacea furnishes Arrow-root.

Economically, the genus Musa holds the first rank among the Scitamineæ. The Plantain (M. paradisiaca) and Banana ( $P$. sapientum) are among the most important of food-plants, and $\boldsymbol{M}$. textilis furnishes Manila hemp.

\section{Order X. Microspermæ}

The Microspermæ, the most specialized of the Monocotyledons, are also the most numerous, the number of described species exceeding five thousand. Nevertheless, they are seldom common plants, and in spite of the extraordinary devices especially developed for insect-pollination, they do not appear to have been remarkably successful in the struggle for existence. There are two suborders, 
the Gynandræ and Burmannineæ. The flowers of the Gynandræ, which comprise nearly all the Orchids, are characterized by the reduction in the number of the stamens, and the complete coherence of the stamens with the style to form the "column" or "gynostemium" of these flowers (Fig. 373). The ovary is always inferior. The flowers are strongly zygomorphic, and the posterior leaf

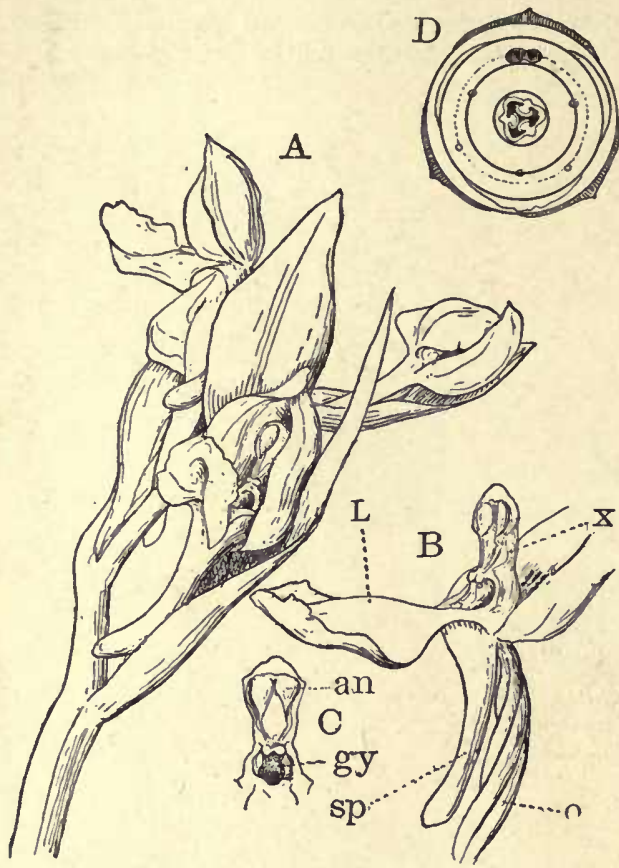

FIG. 373.-Orchis spectabilis. $A$, inflorescence $\left(\times 1 \frac{1}{5}\right)$. $B$, flower with the upper part of perianth bent back to show the column, $x ; L$, the labellum; $s p$, spur; $o$, ovary. $C$, the column, seen from in front; an, anther; $g y$, stigma. $D$, diagram of the floral parts.

The ovules are usually undeveloped at the time pollination occurs, and the growth of the pollen-tube is slow, sometimes requiring several months before it reaches the ovules, which have been developing in the meantime. The seeds are exceedingly sinall, and the embryo rudimentary. It is on account of the small size of the seeds that these plants are known as the Microspermæ.

The Orchids are cosmopolitan, but are especially abundant in the Tropics, especially in mountain regions. They show a greater range of habit than any other order of Monocotyledons. While in cooler regions they are terrestrial, in the Tropics many of them are epiphytes, and have developed special structures, such as aërial roots and enlargements of the leaf-bases ("Pseudo-bulbs"), which are connected with their epiphytic habit (Fig. 375). A considerable number are saprophytes (e.g. Corallorhiza, Neottia, Cephalanthera, etc.), and these are destitute of chlorophyll, and have their leaves reduced to scales. 
Many Orchids are cultivated for their curious or beautiful flowers, but they are of little economic value. Vanilla is the most important member of the order economically.

Classification. - The Orchids are divided into two main sections, the Diandræ, with two (rarely three) fertile stamens, and the Monandræ, with but one. The Niandræ, which are probably the more primitive forms, include the small tropical family, Apostasieæ, and the Cypripedilinæ, which is represented in the United States by about a dozen species of Cypripedium ("Lady's-slipper," "Moccasin-flower"). C. spectabile, of the eastern United States, is our finest species.

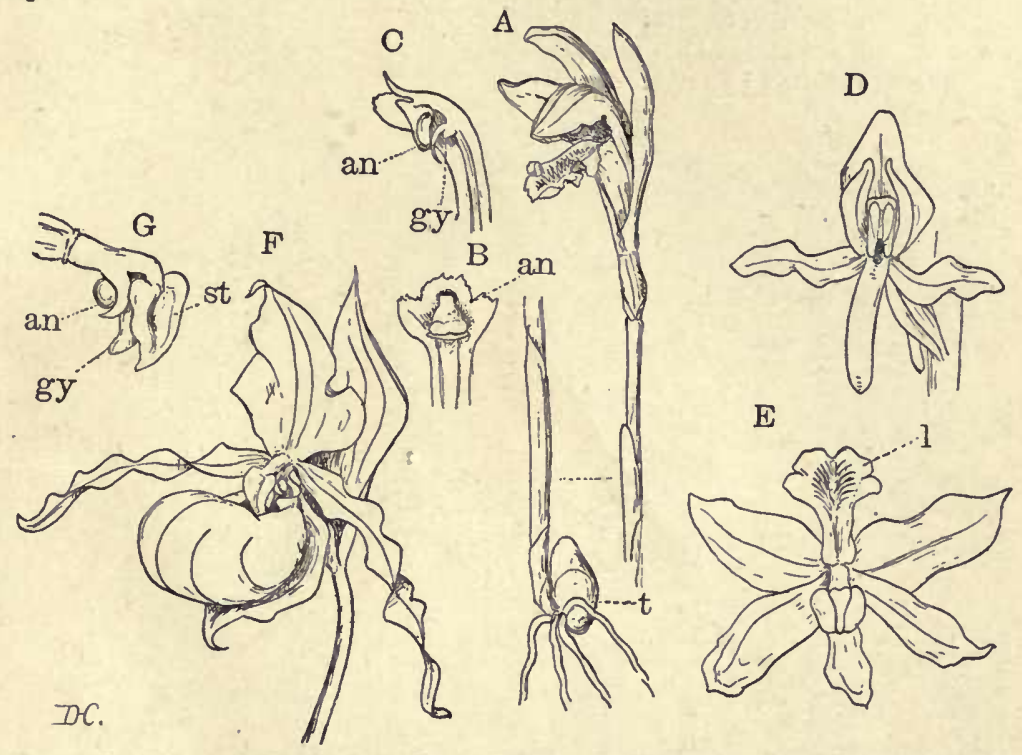

Fig. 374. - A-C, Arethusa bulbosa; $t$, tuber. $B, C$, column. $D$, Habenaria flava. $E$, Calopogon pulchellus. F', G, Cypripedium pubescens. G, column; st, sterile stamen.

The rest of our Orchids, as well as the great bulk of the exotic species, belong to the Monandræ. Some species of Pogonia, Arethusa, Calopogon, and Habenaria, are among our most beautiful wild flowers.

Of the exotic genera, cultivated in greenhouses, Cattleya, Lælia, Oncidium, Dendrobium, and Phajus, are among the commonest and most beautiful.

Burmanniaceæ. - The Burmanniaceæ are small plants, many of them saprophytes, which, on account of the character of the seeds, are often associated with the Orchids, and supposed to be intermediate between thein and the Amaryllidaceæ. The stamens, however, are not united with the style. Burmannia is represented by two species in the southern Atlantic states.

\section{BIBLIOGRAPHY}

'98. 1. Bailey, L. H. Lessons with Plants. New York, 1898.

'01. 2. - Cyclopedia of American Horticulture. New.York, 1900-1901.

'87. 3. De Bary, A. Comparative Anatomy. Oxford, 1887. 
'96-'98. 4. Britton, N. L., and Brown, A. Illustrated Flora of the United States and Canada. New York, 1896-98.

5. Brewer, W. H., and Watson, S. Botany of California (Geological Survey of California).

'99. 6. Caldwell, O. W. Life-history of Lemna minor. Bot. Gaz., XXVII. 1899.

'97. 7. Campbell, D. H. A Morphological Study of Naias and Zannichellia. Proc. California Acad. of Sciences. 1897.

'98. 8. — The Development of the Flower and Embryo in Lilaa subulata. Ann. of Bot., XII. 1898.

'00. 9. Studies on the Araceæ. Ann, of Bot., XIV. 1900.

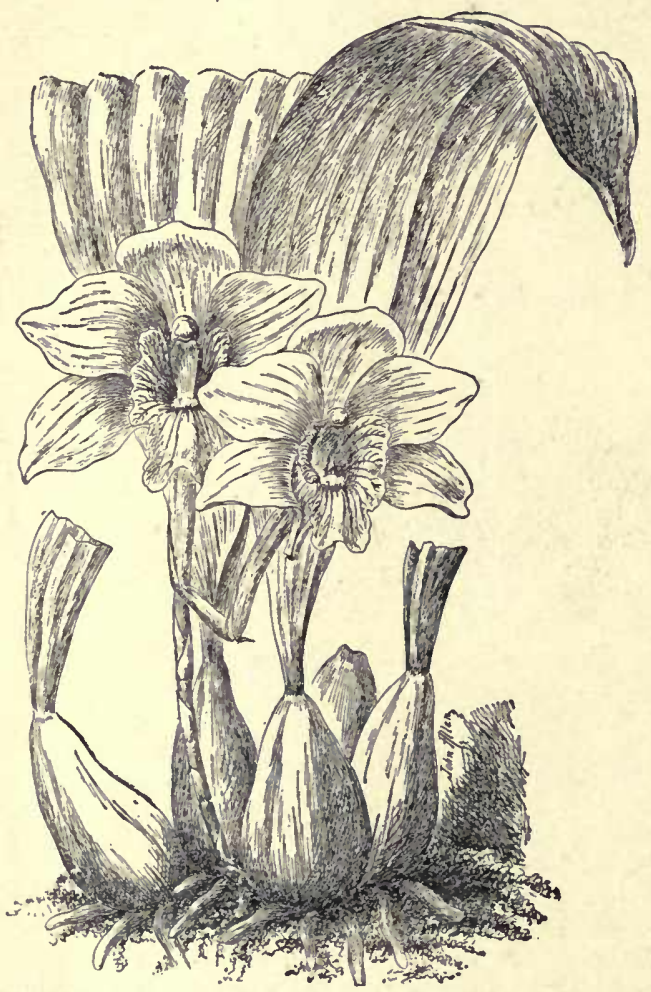

Fig. 375. - Lycaste Harrisoniæ $\left(\times \frac{1}{2}\right)$, showing pseudobulbs. (After BaILEY.)

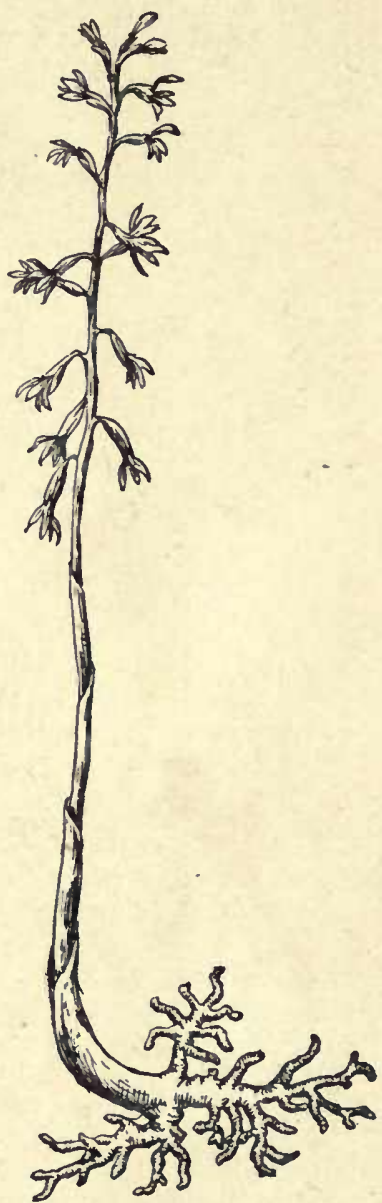

FIG. 376. - Corallorhiza multiflora. A saprophytic Orchid $\left(\times \frac{1}{2}\right)$. (After BAILEY.)

'00. 10. _ Studies on the Flower and Embryo of Sparganium. Proc. California Acad. of Sciences. 1900.

'01. 11. The Embryo-sac of Peperomia. Ann. of Bot., XV. 1901.

'00. 12. Cannon, W. A. A Morphological Study of Avena fatua. Proc. California Acad. of Sciences. 1900. 
'97. 13. Chamberlain, C. J. Life-history of Salix. See also Coulter. Bot. Gaz., XXIII. 18:77.

'७7. 14. Chapınan. Flora of Southern United States. Cambridge, Mass., 1897.

'97. 15. Coulter, J. M., Chamberlain, C. J., and Schaffner, J. H. Life-history of Lilium Philadelphicum. Bot. Gaz., XXXIII. 1897.

'98. 16. — Contribution to the Life-history of Ranunculus. Bot. Gaz., XXV. 1898.

75. 17. Eichler, A. W. Blüthendiagramme. Leipzig, 1875.

'88-'89. 18. Engler and Prantl. Natürliche Pflanzenfamilien. Th. II, 1888'89. The families of Monocotyledons. Bibliography of more important works is given. Also, Supplement, 1897.

'87. 19. Goebel, K. Outlines. Oxford, 1887.

'89-'91. 20. — Pflanzenbiologische Schilderungen. Marburg, 1889-1891.

'00. 21. — Organography. Oxford, 1900.

22. Gray, A. Manual.

23. - Structural Botany.

'01. 24. Holferty, G. M. Ovule and Embryo of Potamogeton natans. Bot. Gaz., XXXI. 1901.

'95. 25. Jeffrey, E. C. Polyembryony in Erythronium Americanum. Ann. of Bot., IX. 1895. (References to literature on l'olyeinbryony are given.)

'01.. 26. Jepson, W. L. Flora of Western Middle California. Berkeley, Cal., 1901.

'00. 27. Johnson, D.S. On the Endosperm and Embryo of Peperomia pellucida. Bot. Gaz., XXX. 1900.

28. Kerner and Oliver. Nátural History of Plants. New York, Holt \& Co.

'92. 29. Lubbock, J. Seedlings. New York, 1892.

'92. 30. Martin, G. W. Development of the Flower and Embryo-sac in Aster and Solidago. Bot. Gaz., XVII. 1892.

'93. 31. Mottier, D. M. On the Embryo-sac of Senecio aureus. Bot. Gaz., XVIII. 1893.

'98. 32. — Ueber das Verhalten der Kerne bei der Entwickelung des Embryosackes und die Vorgänge bei der Befruchtung. Pringsheim, Jahrb. für wiss. Botanik, XXXI. 1898.

'57. 33. Payer, J.B. Traité d'Organogénie comparée de la Fleur. Paris, 1857.

'00. 34. Sargant, E. Recent Work on the Results of Fertilization in Angiosperms. Ann. of Bot., XIV. 1900. (Contains full bibliography.)

'96. 35. Schaffner, J. H. 'The Embryo-sac of Alisma Plantago. Bot. Gaz., XXI. 1896.

'97. 36. — The Life-history of Sagittaria variabilis. Bot. Gaz., XXIII. 1897.

37. - Development of the Stamens and Carpels of Typha latifolia. Bot. Gaz., XXIV. 1897.

'98. 38. Smith, R. W. A Contribution to the Life-history of the Pontederiaceæ. Bot. Gaz., XXV. 1898.

39. Strasburger, E. Botanisches Practicum.

40. - Textbook of Botany.

41. — Histologische Beiträge.

'00. 42. — Einige Bemerkungen zur Frage nach der "doppelten Befruchtung" bei den Angiospermen. Bot. Zeit. 1900.

43. Von Tieghem, Ph. Traité de Botanique.

44. Warming, E. W. Handbook of Systematic Botany.

'00. 45. Webber, H. J. Xenia, or the Immediate Effect of Pollen in Maize. U. S, Dept. of Agriculture. Bull. 22, September, 1900. 


\section{CHAPTER XII}

\section{ANGIOSPERME (Continued.)}

\section{SUBCLASS II. DICOTYLEDONES}

The Dicotyledons are preëminently the modern plant type, far outnumbering the Monocotyledons both in the number of species and of individuals. They also show much greater range of structure. The lower Dicotyledons resemble to some extent the simpler Monocotyledons, to which they are undoubtedly related; but there is still some question as to which group is the older, and it is possible that the two groups may have originated independently from a common stock.

\section{The Gametophyte}

The male gametophyte of the Dicotyledons does not differ from that of the Monocotyledons. The small antheridial cell divides into two generative cells, and may occasionally (Caltha, Silphium, Peperomia) assume a coiled form suggestive of the spermatozoid of the Archegoniates. The germination of the pollen-spore, and development of the pollen-tube, is of the usual angiospermous type.

The female gametophyte is usually of the typical form, but there are some exceptions. Thus, in Peperomia, there are normally sixteen nuclei in the unfertilized embryo-sac, and no definite eggapparatus or antipodal cells are present. In Casuarina it is possible that a similar condition exists, but this is still doubtful. In some other low types among Dicotyledons, e.g. Santalaceæ, Phoradendron, the ovules are imperfectly developed, the embryo-sac arising from the tissue of the placenta. These latter forms are mostly parasites, and it is likely that their peculiarities are secondary acquisitions.

The antipodal cells are usually three, but the number is not infrequently greater (many Compositæ), or the nuclei of the large antipodals may divide, as in some Ranunculaceæ.

\section{Fertilization}

The lower Dicotyledons are often wind-pollinated, but as a rule they are entomophilous. In a number of cases that have been examined (e.g. Casuarina, Juglans, Betula, etc.) the pollen-tube, after 
reaching the ovary, penetrates the ovule from the base (chalaza) instead of entering the micropyle. It is not probable, however, that this can be considered to be of great importance in classification, as chalazogamy has been observed in several genera, which are probably not closely related. The fusion of the second generative nucleus with the endosperm-nucleus has been observed in a number of cases, but is probably not universal.

\section{The Embryo}

The typical dicotyledonous embryo (Fig. 377) differs from that of the Monocotyledons in having the apex of the stem terminal, with two opposite cotyledons of equal size. Sometimes - e.g. Peperomia,
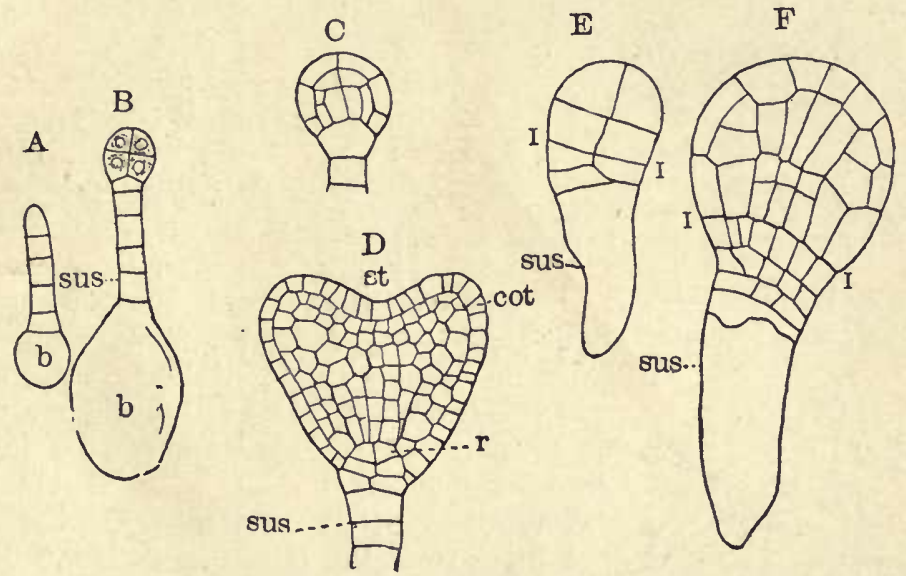

Fia. 377. $-A-D$, Capsella bursa-pastoris, development of the embryo; $I$, optical sections $(\times 200) . \quad E, F$, Senecio aureus, young èmbryos, longitudinal sections $(\times 270)$; sus, suspensor; $b$, primary suspensor-cell; cot, cotyledons; st, stem-apex; $r$, root. (E, $F$, after Motrikr.)

Monotropa - the embryo in the ripe seed (Fig. 378) is very small and its members undeveloped. More commonly the organs are well developed, and, besides the cotyledons, the terminal bud (Plumule) may be well developed. The stem (Hypocotyl) and root (Radicle) can usually be distinguished. The embryo may be surrounded by abundant endosperm (Convolvulus, Celastrus, Ricinus, etc.), or the thick, fleshy cotyledons may completely fill the embryo-sac (Fagaceæ, Leguminosæ). In a few instances (Nymphæaceæ, Piperaceæ) perisperm largely replaces the endosperm.

A single cotyledon has been reported for Nelumbo, and it is probable that the apparently coherent cotyledons of Podophyllum may represent a single one. Both of these plants show other monocoty- 
donous characters, and may perhaps be more nearly allied to the Monocotyledons than to the Dicotyledons with which they have

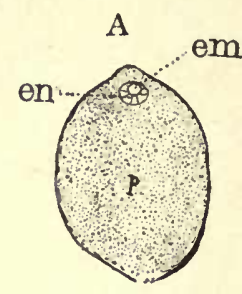

$\mathrm{E}$
B
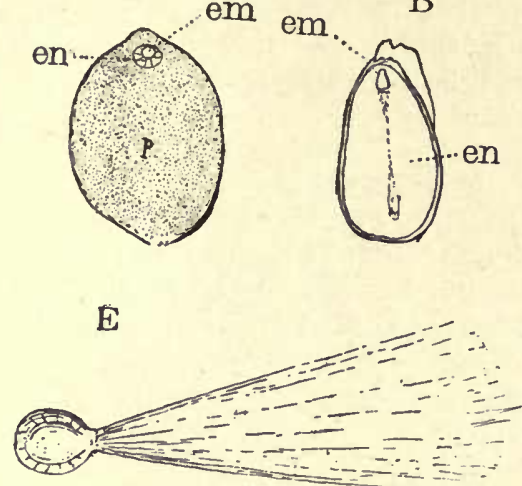

C

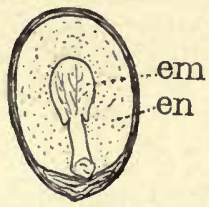

$\mathrm{D}$

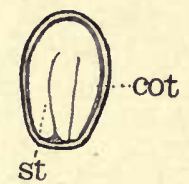

FIG. 378. - Types of dicotyledonous seeds. A, Peperomia subrotunda. B, Jeffersonia diphylla. C', Diospyros Virginiana. D, Lamium album. E, Asclepias Cornuti. en, endosperm; em, embryo ; $p$, perisperm.

usually been associated. It is possible that other anomalous Dicotyledons - e.g. Actæa, Thalictrum - may show a similar condition.

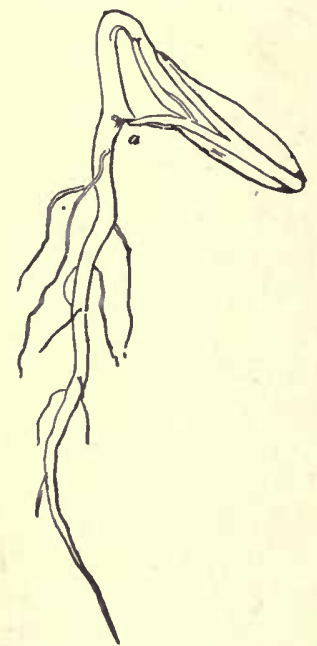

FIG. 379. - Cucurbita Pepo. Young seedling. (After BaIley.)
There is usually a well-developed suspensor, which may have its basal cell much enlarged, as is so often the case among the lower Monocotyledons.

Cotyledons. - The cotyledons may differ but little from the later leaves, but usually they are different in form (e.g. Ipomœa, Fig. 380 ), and may be thick and flesliy, in this case not infrequently remaining permanently within the seed.

Germination (Fig. 379). - When the embryo is small, it grows until the surrounding endosperm is nearly used up before the root protrudes through the micropyle. In seeds without endosperm, like the Horsechestnut or Pea, the first evidence of germination is the extrusion of the stout radicle, which at once bends downward into the soil. In such cases the thick cotyledons may remain within the testa, or shell, of the seed, or they may be withdrawn and develop chlorophyll, so as to
is, as well as for reservoirs of reserve-food. 
The primary root in many Dicotyledons persists as a tap-root, as in the Gymnosperms, but this is by no means always the case, and it may very soon be replaced by the secondary roots.

Tissues of the Young Sporophyte. - The cotyledons, like the later leaves of most Dicotyledons, are reticulately veined, and into each leaf passes one or more vascular bundles, forming the "leaf-trace." These proceed downward from the base of the leaf, and unite near the base of the hypocotyl, where they pass into the vascular cylinder of the primary root. Most commonly there are two bundles in each leaftrace, which unite into a single one within the hypocotyl; or one bundle of each trace unites with one belonging to the other cotyledon. In both cases a section of the young hypocotyl shows two bundles, in one case opposite the cotyledons, in the other alternating with thein. When the number of bundles in the traces is larger, some may remain separate, and a section of the hypocotyl (Fig. 383, B) shows a circle of four or more bundles (Cucumis, Ricinus).

Primary Root. - A section of the young root shows a central vascular cylinder, bounded by a more or less well-defined endodermis. The rootbundle is similar to that in other vascular plants, and is radial in structure. The xylem is composed of (usually) two or four masses, alternately along different radii with as many masses of phloem. This arrangement is soon obliterated by the development of a ring of cambium outside both xylem and phloem. The presence of the cambium enables the tap-root to grow in Fig. 380. - Seedling of Ipomcea thickness, as in the Gymnosperms.

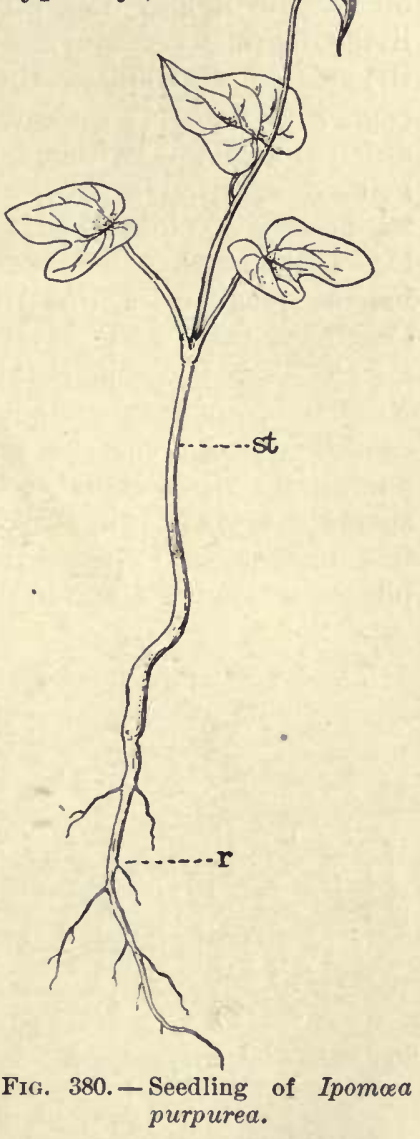

As the seedling develops new leaves, the number of leaf-traces increases, and these pass downward, uniting with those from the older leaves, and becoming more numerous, until the normal number is reached (Fig. 382). The bundles are, with very few exceptions, of the typical collateral form, and are arranged in a single circle. The development of cambium takes place early, and the secondary growth 
is thus inaugurated. In perennial stems there are thus formed regular growth-rings, like those of the Conifers.

\section{THE MATURE SPOROPHYTE}

The sporophyte in the Dicotyledons varies extremely in size and complexity. Sometimes it is a delicate annual herb, living but a few weeks or months, while on the other hand it may be a gigantic tree living for many centuries. Some of the parasitic and aquatic Dicotyledons (e.g. Rafflesiaceæ, Podostemonaceæ) are thallose plants, without any clearly marked external organs, aside from the flowers. While aquatic forms are less frequent than among Monocotyledons, some genera, like Utricularia, Ceratophyllum, and Myriophyllum, are characteristic submersed aquatics. Xerophytes, or forms adapted to dry conditions, are numerous, some of the xerophytic types, like the Cacti, and some Euphorbias, being especially perfect instances. Parasites and saprophytes are common, and in the Tropics

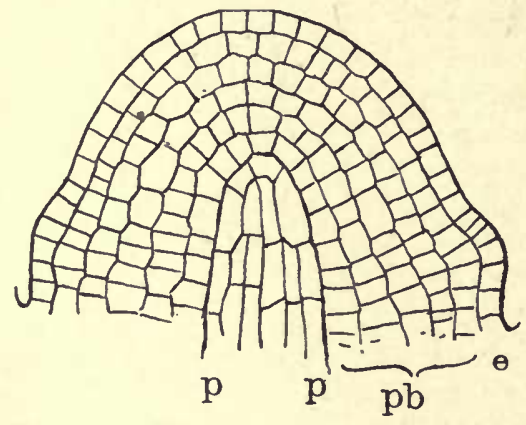

Frg. 381. - Hippuris vulgaris. Stem-apex, showing the primary tissues; $e$, epidermis; $p, p$, plerome; $p b$, periblem. (After DE BARX.)

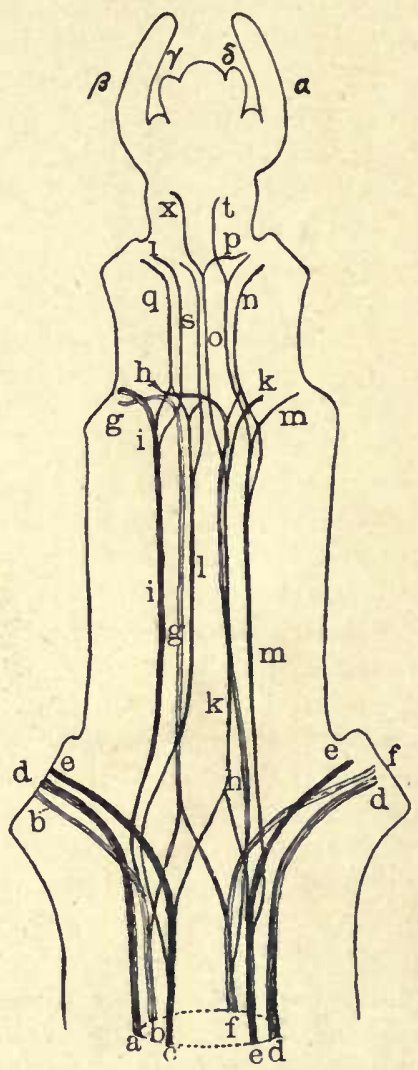

Frg. 382. - Clematis viticella. Diagram to show the arrangement of the vascular bundles. (After NÄGELI.)

many epiphytic and climbing Dicotyledons abound. One peculiar order (Sarraceniales) is noteworthy for the curious contrivances developed for entrapping insects and similar small animals. In short, among the Dicotyledons is to be found almost every type of plant-structure. 
While among the Monocotyledons, at least outside the Tropies, trees are rarely found, the Dicotyledons are very often arborescent; and, except for those regions where the Conifers predominate, make
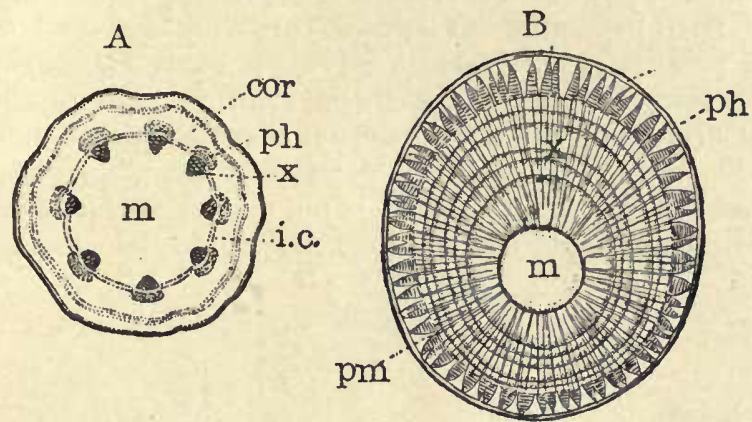

Fia. 383. - A, Ricinus communis, cross-section of bypocotyl, showing the arrangement of the primary vascular bundles $(\times 6)$. $B$, Tilia Americana, section of a branch, showing six annual growth rings $(\times 4)$; cor, cortex; $p h$, phloem; $x$, xylem; $m$, pith ; i.c., interfascicular cambium; $p m$, primary medullary ray.

up the greater part of the forests. Dicotyledons are, as a rule, more gregarious than the Monocotyledons. The few types of the latter, like the Grasses and some aquatic forms (Typha, Scirpus, etc.), often

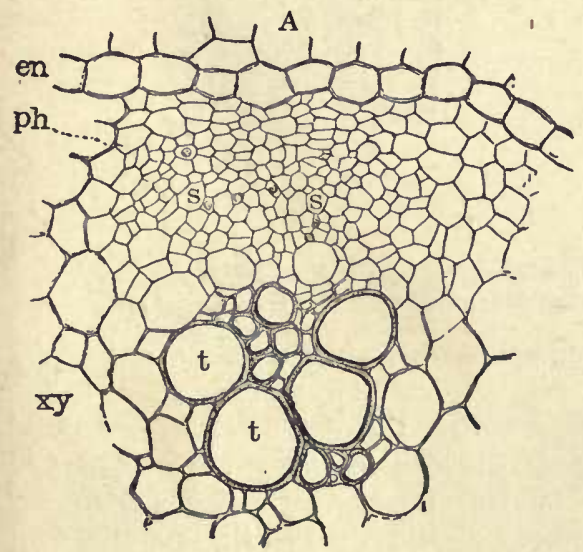

B

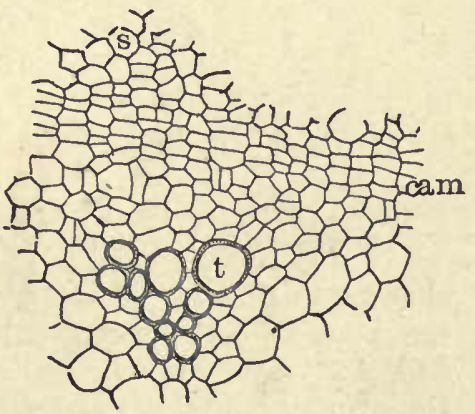

Fig. 384.-A, Tropæolum majus, cross-section of vascular bundle from the stem; no cambium is present. $B$. Pelargonium $s p$., cross-section of stem-bundle, showing cambium, cam $(\times 200)$. en, endodermis; $p h$, phloem; $s$, sieve-tubes; $x y$, xylem; $t$, vessels.

grow in large masses, but, aside from these, the plants which give the special character to the flora of most temperate regions are, with the Coniferæ, the Dicotyledons. 


\section{The Stem}

The apex of the stem, especially in some aquatic forms like Hippuris, is conical, but much oftener it is flattened. No single initial apical cell is to be found, but two or three initial layers of apical tissue are present (Fig. 381). An evident epidermal layer covers the apex, beneath which is the periblem, or primary cortex. The central cylinder (plerome, stele) is not always clearly distinguishable from the periblem, and the origin of the "procambium," or tissue which develops into the vascular bundles, is not always perfectly certain.

A typical herbaceous dicotyledonous stem in its simplest form

$\mathbf{A}$

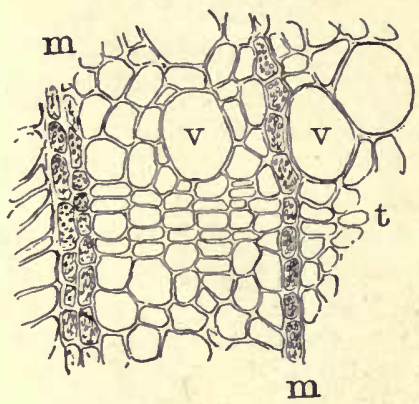

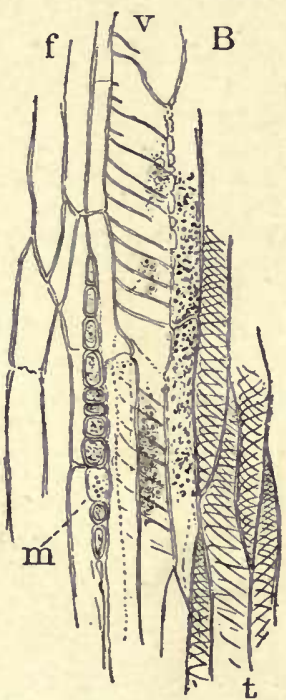

FIG. 385. - Tilia Americana. A, cross-section, $B$, longitudinal tangential section, of the wood $(\times 200)$; $v$, vessels; $t$, tracheids; $m$, medullary rays; $f$, wood-fibres.

shows a single layer of epidermal cells, within which lies a more or less massive cortex, composed largely of chlorophyllous cells (Fig. $383, \mathrm{~A})$. The cells immediately below the epidermis constitute the principal mechanical tissue, as they do in the stems of Monocotyledons. These mechanical elements may be either collenchyma or fibrous cells. The central tissue of the stem (pith, medulla) is usually composed of thin-walled parenchyma, which in such hollow stems as those of the Umbelliferæ, Dandelion, etc., is torn apart and destroyed at an early period.

The vascular bundles, except in a few anomalous cases (e.g. Peperomia, Podophyllum, Nelumbo), are arranged in a circle surrounding the pith, with a common endodermis derived from the innermost layer of the periblem. They are formed of the united leaf-traces, which 
usually pass downward through several internodes before they unite with the older ones. The arrangement of the bundles is often very complicated, and is dependent upon the number of bundles in each leaf-trace, and on the arrangement of the leaves upon the stem.

The bundles are somewhat wedge-shaped in sections (Fig. 384), the xylem consisting of rows of tracheæ, with more or less parenchyma and fibrous tissue between. The tracheary elements are largely made up of true vessels, which exhibit various forms of thickenings upon their walls.
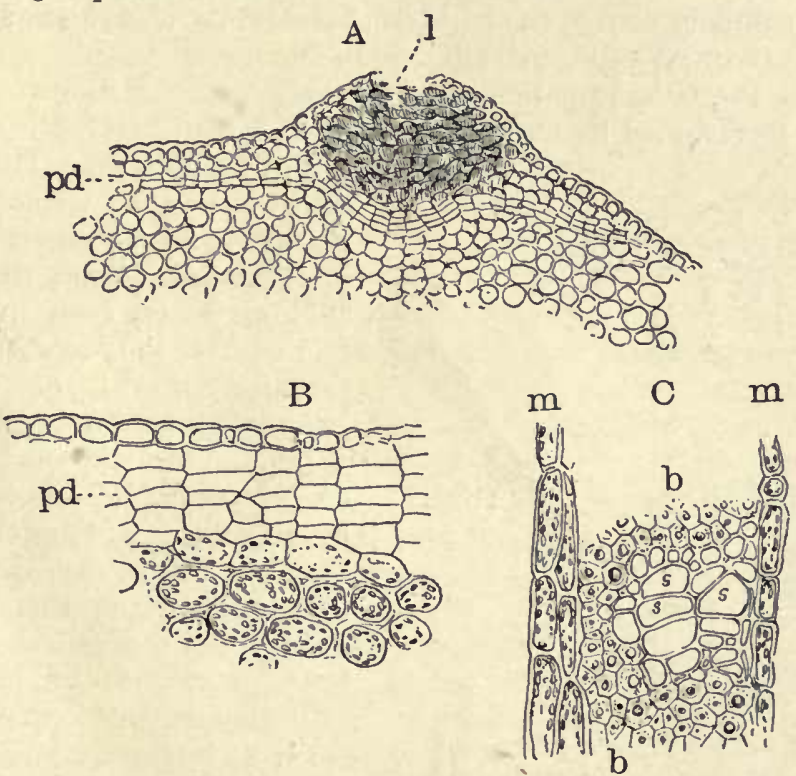

Fig. 386. - Tilia Americana. A, cross-section of the cortex of a young twig, cutting through a lenticel, $l$; $p d$, the periderm. $B$, outer cortex of an older branch; $e$, epidermis; $p d$, periderm. $C$, cross-section of the phloem, showing medullary rays, $m$, sieve-tubes, $s$, and bast-fibres, $b(\times 200)$.

The phloem is composed of sieve-tubes, "companion cells," or cambiform elements, and often groups of fibrous cells (bast-fibres). Outside the ring of bundles is the common endodermis, marking the inner boundary of the secondary growth. Even in herbaceous Dicotyledons there is developed in the vascular bundles of the stem a zone of cambium, which permits a greater or less amount of secondary growth, but it is in perennial woody stems that this is best developed. The cambium, as in the bundles of the Conifers, is composed of several layers of radially compressed cells, lying between the xylem and phloem. The central cells of the cambium zone divide actively by periclinal walls, and the cells thus formed 
are transformed into the permanent elements of the wood and bast. Connecting the cambium zones of the separate primary bundles, there is formed a similar zone in the primary medullary rays, or the ground-tissue between the primary bundles. There is thus developed a complete cylinder, composed of "fascicular" and "interfascicular" cambium. The endodermis is not always clearly distinguishable. In such stems the primary cortex early disappears, and is often replaced by a secondary bark developed through the activity of a special meristem, or "Periderm," developed in the cortex. Very commonly part of the periderm assumes the character of "Corkcambium," or "Phellogen" (Fig. 386).

As in the Gymnosperms, the tracheary tissue of the wood (Fig. $385)$ is interrupted by medullary rays $(m)$, which may be continued

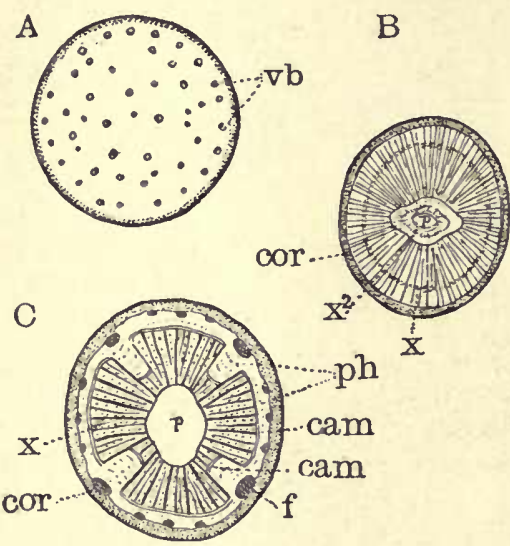

Fig. 387.- Anomalous stem-structure in Dicotyledons. A, Podophyllum peltatum. Numerous scattered vascular bundles, $v b(\times 3)$. B, Tecoma radicans, secondary wood, $x^{2}$, formed inside the primary wood, $x^{1}(\times 2)$. C, Bignonia. Unequal growth of wood, resulting in fuur principal wood-masses with alternating masses of phloem $(\times 4)$; cor, cortex; $f$, bast-fibres; cam, cambium; $p h$, phloem ; $x$, xylem; $p$, pith.

occur, but must be passed over here. See De Bary (2). medullary rays. into the phloem. These are sometimes very conspicuous, as in the wood of various species of Birch and Maple, where the shining flakes, seen in radial sections of the wood, are the

Anomalous Thickening. While the secondary thickening of the stem in Dicotyledons usually results in regular concentric growth-rings, like those of the Conifers, there are a good many exceptions. Sometimes a second cambium ring is developed inside the ring of wood (Tecoma radicans) (Fig. 387 ), or each primary bundle may be surrounded by a separate cambium ring, giving rise to several masses of wood surrounded by a common cortex. This is especially characteristic of some woody climbers (e.g. Serjania). Other variations cher, but must be passed over here. See De Bary (2).

\section{The Bark}

The bark (Fig. 386) of most woody Dicotyledons consists of two portions, the inner bark, or bast, belonging to the vascular bundles, and the outer bark which belongs to the cortex. This outer bark is 
often composed largely of cork. The cork may form a uniform, smooth layer, as in the smooth twigs and stems of many shrubs and trees, or it may be developed in irregular masses, which become split by deep, longitudinal fissures and ridges, often scaling off in large flakes, or shreds, as in the Plane, Hickory, or Eucalyptus. These masses of cork are sometimes very thick, and may form winglike growths (Ulmus alata). Commercial cork is obtained principally from the bark of Quercus suber.

The stem in Dicotyledons is usually extensively branched, and shows great variety of form, all of the principal modifications, such as bulbs, stolons, climbing stems, etc., being represented. The branching is almost always axillary.

\section{The Leaf}

The leaves of Dicotyledons show much greater variety than is found among Monocotyledons. While they may be reduced to scales, or be entirely absent in some parasites and saprophytes, they are usually well developed and have all the parts present. The typical form is a broad, stalked leaf, with reticulate venation. A midrib is usually present, or if the leaf is palmately lobed, there is a corresponding number of stout, radiating veins from which are given off the smaller lateral veins, and these are joined by an intricate system of smaller ones. Stipules are often present. The margin of the leaf is often variously cut and lobed, this finally resulting in the various types of compound leaves. These may be either palmately compound (Clover, Horsechestnut, Ampelopsis), or they may be pinnately compound (Rose, Locust). Where the primary segments are themselves compound, decompound leaves result (Aquilegia, Acacia).

Scale-leaves. - Scale-leaves of two kinds may be recognized: first, the rudimentary scale-leaves found in various colorless parasites and saprophytes; and second, the protective scales, such as the thick scales of the winter-buds of deciduous trees.

Phyllotaxy. - The arrangement of the leaves upon the stem also shows great variety. The leaves may be either opposite or alternate, and in the latter case may show a divergence of one-third,

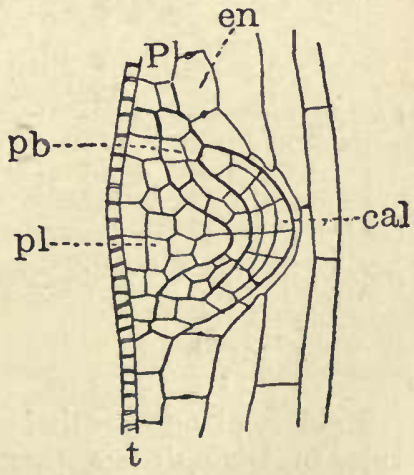

Fig. 388.-Amarantus chlorostachys. Longitudinal section of a root, showing the origin of a rootlet, from the pericycle, $p$; en, endodermis of the primary root; cal, calyptrogen; $p b$, periblem; $p l$, plerome of rootlet. (After Van Tieghem.) 
two-fifths, three-eighths, etc. (For an extended discussion of leafforms and arrangement, see Gray, "Structural Botany.")

Bracts, and the organs of the flower, are also foliar structures.

\section{The Root (De Bary, 2; Van Tieghem, 20)}

The primary root in the Dicotyledons, like that of the Gymnosperms, is a continuation of the hypocotyl, and often persists as a tap-root.

The apex of the root in most Dicotyledons shows three sets of initials (Fig. 388). Overlying the apex of the plerome cylinder is a

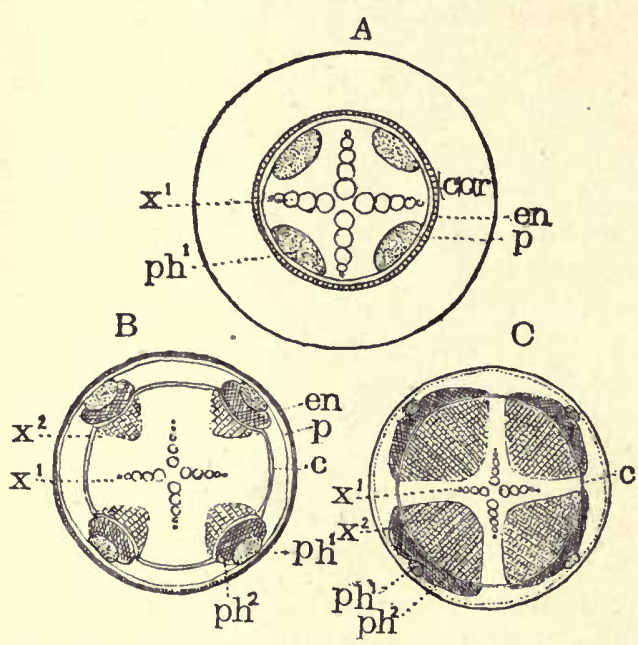

Fig. 389. - Diagrams to show normal secondary thickening in the roots of Dicotyledons; cor, cortex; $e n$, endodermis; $p$, pericycle; $c$, cambium; $x^{1}$, primary, $x^{2}$, secondary, wood ; $p h^{1}, p h^{2}$, primary and secondary phloem.

codendron), aerial roots (Ficus sp., Mangrove) single initial layer, or two, which belongs to the periblem. Outside this is a common initial layer for root-cap (calyptrogen) and dermatogen. 'The structure of the older roots is essentially the same as in the root of the seedling.

The secondary roots arise from the pericycle, and very early show the differentiation of the three primary tissue-meristems.

Like the stem and leaves, the roots of $\mathrm{Di}$ cotyledons show various modifications, such as root-tubers (Dahlia), root-tendrils (Rhus toxi(See Chapter II.)

\section{Trichomes}

Epidermal outgrowths, or Trichomes, are better developed, as a rule, in Dicotyledons than in Monocotyledons. These trichomes show great variety, ranging from delicate downy hairs to coarse bristles or scurfy scales. Glandular hairs are very common in many Dicotyledons, and are probably mainly defensive, either repelling animals by their strong-scented secretions, or in some cases e.g. Salpiglossis - actually capturing Aphides and similar small insects which would injure the plant. The dense felted masses of hairs 
upon the leaves of xerophytes act as a screen against the too intense light rays.

\section{Flowers of Dicotyledons}

Much the same range of structure is found in the flowers of Dicotyledons that obtains among the Monocotyledons. Some of the lower forms are destitute of any proper floral envelopes, and in rare instances - e.g. Ascarina-may consist of but a single carpel or stamen. In these simplest Dicotyledons, stamens and carpels are frequently in different flowers (Quercus), or even upon different plants (Morus, Cannabis). While some of these simple flowers may be reduced forms, most of them cannot be so regarded, and must be considered to be primitive types.

A

B

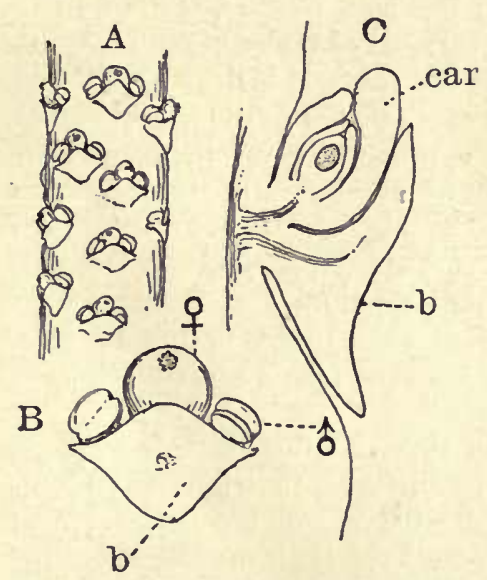

Fig. 390.-A, B, Peperomia blanda. $A$, portion of the spike, showing the arrangement of the simple flowers $(\times 6)$. $B$, single flower, more enlarged; $b$, the subtending bract; o, carpel; o, stamen. $C, P . s u b-$ rotunda. Median section of flower (× 40) ; car, carpel.
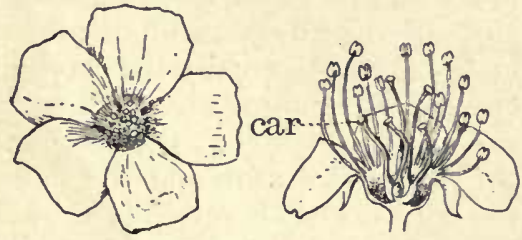

$\mathrm{D}$

C

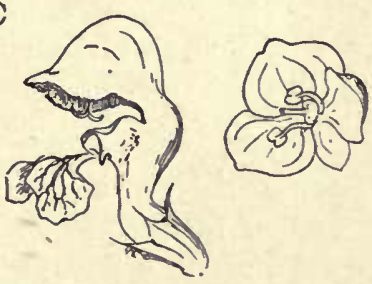

FIG. 391.-A, Oxalis sp. Actinomorphic choripetalous flower. $B$, Spirza $s p$. Section of the actinomorphic flower; all the parts separate; car, carpels. $C$, Lamium album. Sympetalous, zygomorphic corolla. D, Veronica sp. Showing zygomorphic sympetaly, and reduction of stamens to two.

In the greater number of Dicotyledons the flowers possess welldeveloped floral envelopes, which are differentiated into calyx and corolla. Sepals and petals are most commonly four or five in number, although there are numerous exceptions. In one group (Ranales) the number of parts is often indefinite (Magnolia, Calycanthus), and this is true of the stamens and carpels as well. These Ranales usually are "apocarpous," i.e. have the carpels separate, and 
in many ways suggest the Alismacere and allied families of apocarpous Monocotyledons, with which they are probably remotely related.

More commonly, the stamens are equal to, or twice as many as, the petals, and the carpels either the same or fewer.

Reduction and Cohesion. - In the further development of the flower, the same tendency to reduction in the number of parts, and coliesion of parts, seen in the Monocotyledons, obtains also among the Dicotyledons. The carpels in the majority of them are more or less completely united in a compound (Syncarpous) ovary, and their number is generally less than that of the other parts of the flower. There may also be a more or less complete cohesion of the floral axis with the carpels, so that an "inferior" ovary is developed, as in the Fuchsia.

Cohesion of the sepals with the margin of the floral axis is very common, and results in the cup-shaped or tubular calyx found in so many flowers (Hollyhock, Carnation, ete.). In such forms the teeth alone of the calyx-cup represent the sepals. While the showy part of the flower is usually the corolla, this may be absent, as in Anemone and Fremontia (Fig. 432), where the calyx is brilliantly colored, and mimics a corolla. Or, in other cases (Bougainvillea, Euphorbia), the corolla is absent, and the flowers proper are inconspicuous, but the inflorescence is surrounded by showy bracts, similar to the showy spathe of the Araceæ.

Zygomorphy. - Zygomorphy of the flower, exhibited in such flowers as Delphinium, Tropoelum, Pelargonium, etc., is also a form of specialization, and like most of such adaptations, is directly associated with the visits of insects. Where the petals remain separate, the flowers are termed "Choripetalous."

Sympetaly. - The most specialized types of flowers found among the Dicotyledons are those of the Sympetalæ, in which the petals are more or less completely united with a tubular outgrowth of the floral axis into a cup-shaped corolla. Both hypogynous and epigynous flowers occur among the Sympetalæ, where a reduction in the number of stamens (Labiatæ, Schrophulariaceæ, etc.) is common, and associated with strongly marked zygomorphy. The Sympetalæ are more numerous than the Choripetalæ, and probably represent a more modern type of structure. At the head of these are placed the Compositæ, the largest existing family of plants. These show a peculiar form of specialization which seems to have been extremely successful. The individual flowers are usuallv small, but are aggregated into desse heads, the outer (ray) flowers being often different from the central disk-flowers, and serving to render the head conspicuous.

\section{The Fruit and Seed}

The Fruits of the Dicotyledons exhibit all the different types known among the Angiosperms, and the same is true of the seeds. 
For a detailed account of these, the student may refer to any of the special works on the subject.

Many special devices for distributing the seeds, either through the agency of the wind, or by bursting of elastic capsules, or by animals, have been developed. Such are the numerous edible fruits, and the winged seeds and fruits, as well as the adhesive ones, so often encountered.

\section{Classification of Dicotyledons}

The classification of the Dicotyledons is in a very unsettled condition, and the one adopted here ${ }^{1}$ can only be considered a provisional one. They are commonly divided into two series, Archichlamydeæ (Apetalæ, Choripetalæ) and the Metachlamydeæ (Sympetalæ). In view of recent studies upon the Apetalæ, it seems best to recognize these as a distinct series, so that we may recognize three series (subclasses of Engler), of equal rank, A petalæ, Choripetalæ, and Sympetalæ (Archichlamydeæ, Mesachlamydeæ, Metachlamydeæ).

\section{SERIES I. APETALÆ (ARCHICHLAMYDEA)}

The Apetalæe comprise several orders of Dicotyledons which are very different from the typical Choripetalæ, and are probably the most primitive members of the group. Some of them, especially the Piperales, show certain resemblances to some of the simple Monocotyledons, and may be remotely related to them. For the most part, they show but little affinity with the higher Dicotyledons, and should probably be removed from their association with the Choripetalæ.

The flowers of the Apetalæ are of very simple structure, and often diclinous (e.g. Morus, Populus, Fagus), the plants being either monœcious (Quercus) or diøecious (Morus). The flowers may be quite destitute of envelopes (Peperomia, Saururus, Salix), or there may be a simple perianth, of usually inconspicuous scalelike leaves. In some Polygonales, the perianth is petaloid, but there is some question whether these are not more properly included in the Choripetalæ. In no case is the perianth differentiated into calyx and corolla.

Many of the Apetalæ are shrubs or trees, and some of the most important forest trees, especially in the temperate regions, belong to the Apetalæ. Among these are the Oaks, Beeches, Elms, Walnuts, Hickories, Willows, Poplars, Birches.

1 The classification adopted here is with very slight modifications that of Engler, "Uebersicht über Unterabteilungen, Reihen, Unterreihen und Familien der Embryophyten Siphonogamen," in Die Natürlichen Pflanzenfamilien, 2-4 Theil, Nachtrag, 1897. 
Engler includes under the Apetalæ the following orders :-

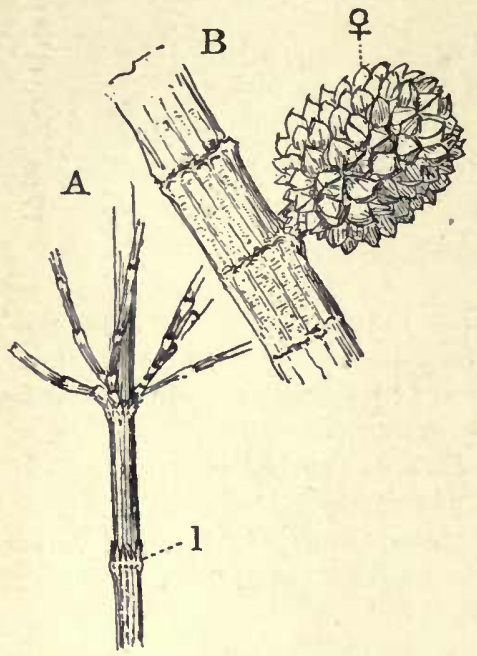

Fig. 392.-Casuarina equisetifolia. $A$, branch showing the reduced scaleleaves, $l . B$, branch with ripe cone of fruit ?.
1. Verticillatæ

2. Piperales

3. Salicales

4. Myricales

5. Balanopsidales?

6. Leitneriales?

7. Juglandales

8. Fagales

9. Urticales

10. Proteales

11. Santalales

12. Aristolochiales

13. Polygonales

\section{Order I. Verticillatæ}

This order includes but a single genus, Casuarina (Fig. 392), trees of very peculiar habit, with Equisetum-like, leafiess branches, and simple flowers consisting of a single stamen, or of two carpels, one of which is usually sterile. 'The genus is especially developed in Australia, but occurs also in tropical Asia and the Pacific islands. C. equisetifolia is not infrequently planted in California.

In the structure of the flowers and development of the embryo-sac, Casuarina shows certain resemblances to the Gnetales, and may be related to them. Fertilization is chalazogamous.

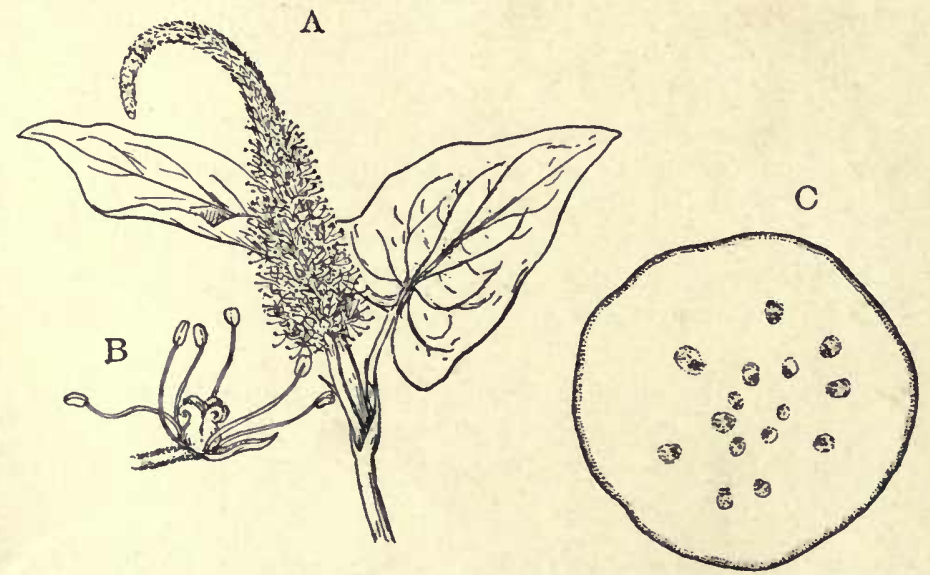

Fig. 393. - $A, B$, Saururus cernuus. $A$, branch with inflorescence, somewhat reduced. $B$, single flower enlarged. $C$, Peperomia trinervis. Cross-section of stem $(\times 14)$. 


\section{Order II. Piperales}

These are for the most part tropical herbs or woody climbers, with extremely simple flowers, in dense spikes, and broad leaves which suggest the Araceæ. The arrangement of the vascular bundles in the stem, especially in the genus Peperomia, is also like tliat of the Monocotyledons. The flowers are usually hermaphrodite, but may be diclinous (Nematanthera). They are quite destitute of floral envelopes, and arranged in the axils of bracts, upon a thick spike (Fig. 390).

leperomia differs from all other Angiosperms yet investigated, in having the number of nuclei in the embryo-sac sixteen instead of eight.

The fruit is a dry capsule (Saururus), or a berry (Piper), and the seeds are characterized

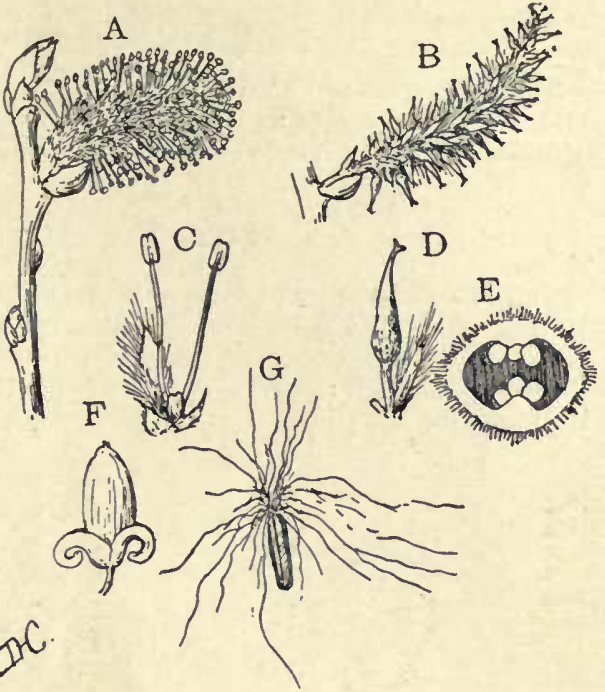

Fic. 394. - Salix $s p$. $A$, male, $B$, female, inflorescence. $C$, male flower. $D$, female flower. $E$, section of ovary. $F$, dehiscing ripe fruit. $G$, seed. by the development of abundant perisperm, in addition to the scanty endosperm.

The order is represented in the United States by Saururus (Fig. 393) and Anemopsis, the latter being Californian. Anemopsis has the spike subtended by petal-like bracts, sug-

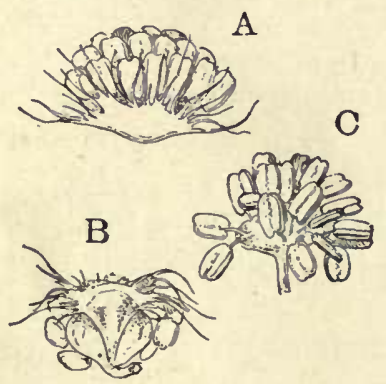

Fig. 395. - Populus trichocarpa. Male flowers enlarged. $A, B$, show the subtending, fringed bract.

gesting the spathe of the Araceæ. There are three families, - Piperaceæ, Saururaceæ, and Chloranthacer.

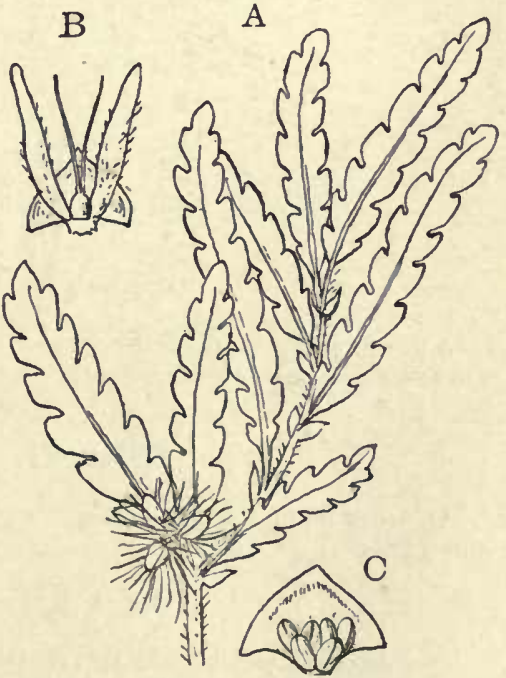

Fia. 396.-Myrica (Comptonia) asplenifolia. (After Britton and Brown.) 


\section{Order III. Salicales}

These are trees and shrubs with diœcious flowers of simple structure (Fig. 394). They are especially characteristic of northern regions. There are but two genera - Salix (Willow) and Populus (Poplar) - and one family, Salicaceæ.

\section{Order IV. Myricales}

This is a small order of slrubby plants or trees, comprising the single genus Myrica, which is sometimes subdivided. The flowers are structurally much like those of the Salicaceæ. Myrica cerifera is the Wax-myrtle of the eastern United States, M. (Comptonia) asplenifolia (Fig. 396) the "Sweet-fern." A single family - Myricaceæ.

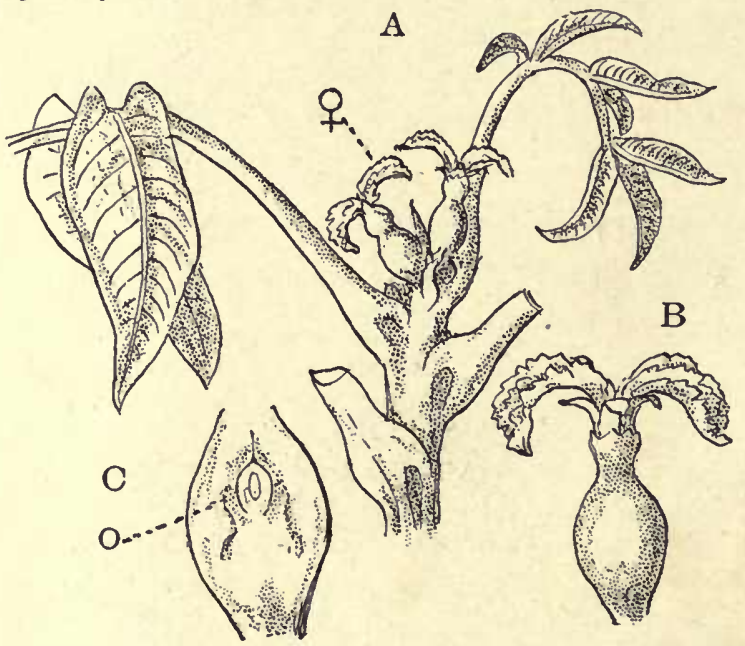

Fig. 397. - Juglans regia. A, young shoot with female flower, $\$$. $B$, a single flower. $C$, section of the ovary, showing the single ovule, $o$.

\section{Order V. Balanopsidales}

A group of doubtful affinity represented by a single genus, Balanops. There are several species, trees and shrubs inhabiting New Caledonia.

\section{Order VI. Leitneriales}

An order represented by two species of Leitneria, shrubby plants from Florida and Texas.

\section{Order VII. Juglandales}

The Juglandales include the single family Juglandaceæ, to which belong the Walnuts and Butternut (Juglans) (Fig. 397) and the Hickories (Carya) (Fig. 398). The staminate flowers are in drooping catkins, and the pistillate 
are borne at the tips of the branches. The fruit in the Walnuts is a sort of drupe; that of the Hickories has the outer pericarp split into lobes. The leaves are pinnately compound. The family is especially well represented in the United States.

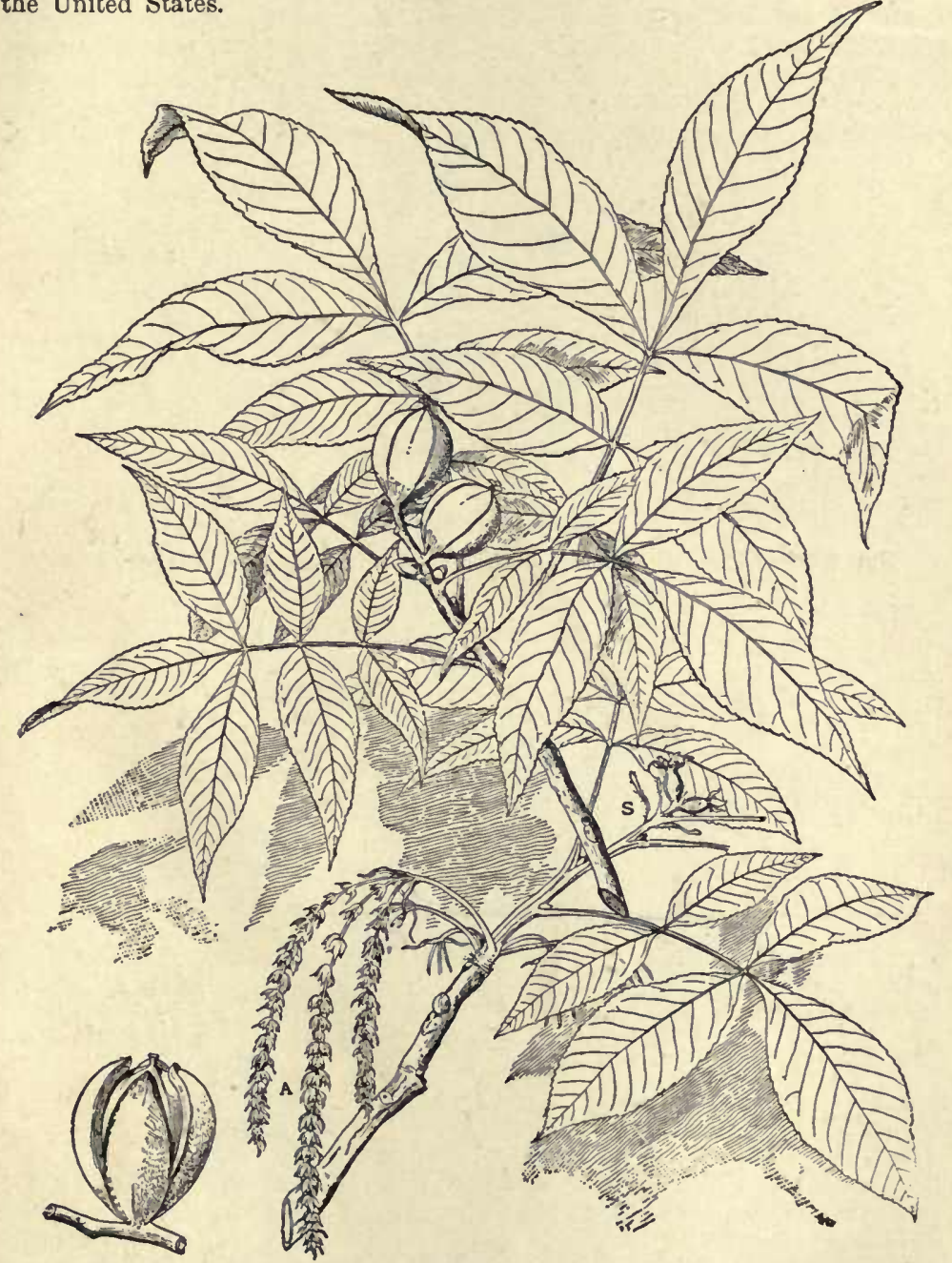

Fig. 398. - Carya (Hicoria) microcarpa. A, male, $S$, female, flowers. (After BaILEY.)

\section{Order VIII. Fagales}

The Fagales include two very important families of trees : the Betulaceæ, to which belong the Birches (Betula) and Alders (Alnus), Hornbeam (Ostrya, Carpinus), Hazel (Corylus); and the Fagaceæ, which comprise the Oaks (Quer- 


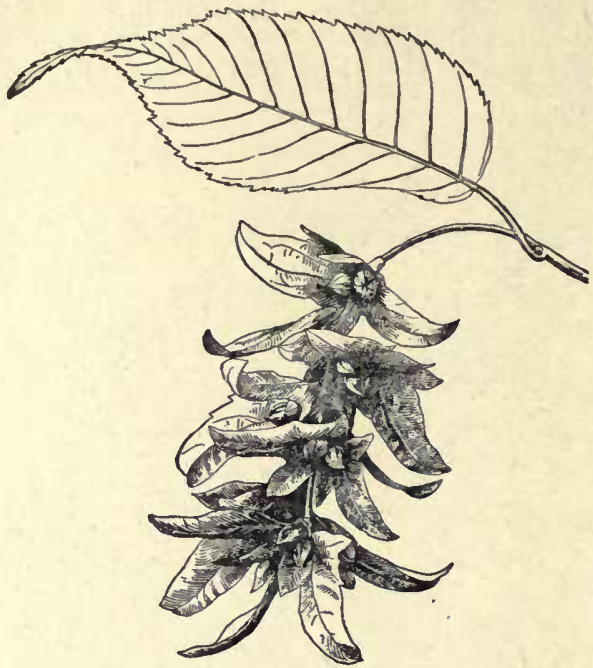

Fig. 399. - Carpinus Caroliniana. Pistillate catkin. (After BaIlex.)

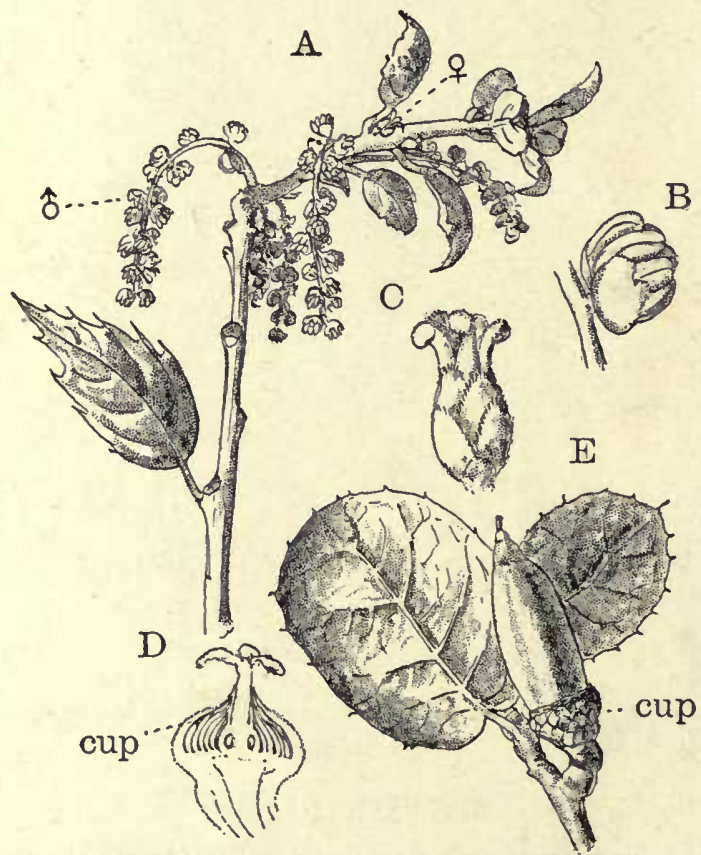

Fic. 400,-Quercus agrifolia. A, twig with male, $\delta$, and female, $\uparrow$, flowers. $B$, single male flower, enlarged. $C$, female flower, enlarged. $D$, section of older flower; cup, cupule. $E$, ripe acorn; cup, cupule. 
cus), Chestnut (Castanea), and Beech (Fagus). These are among the most important forest trees of cold temperate regions, where the Oaks and Beeches sometimes constitute the whole of the forest growth.

The flowers (Fig. 400) are, with very rare exceptions, monœcious, the staminate in drooping catkins, the pistillate solitary. The fruit is a nut, which not infrequently is enclosed by an involucre or thickened envelope, formed from the bracts surrounding the flower. This involucre forms the "cup" in the acorn, and in the Beech and Chestnut is the spiny husk in which the nuts are enclosed.

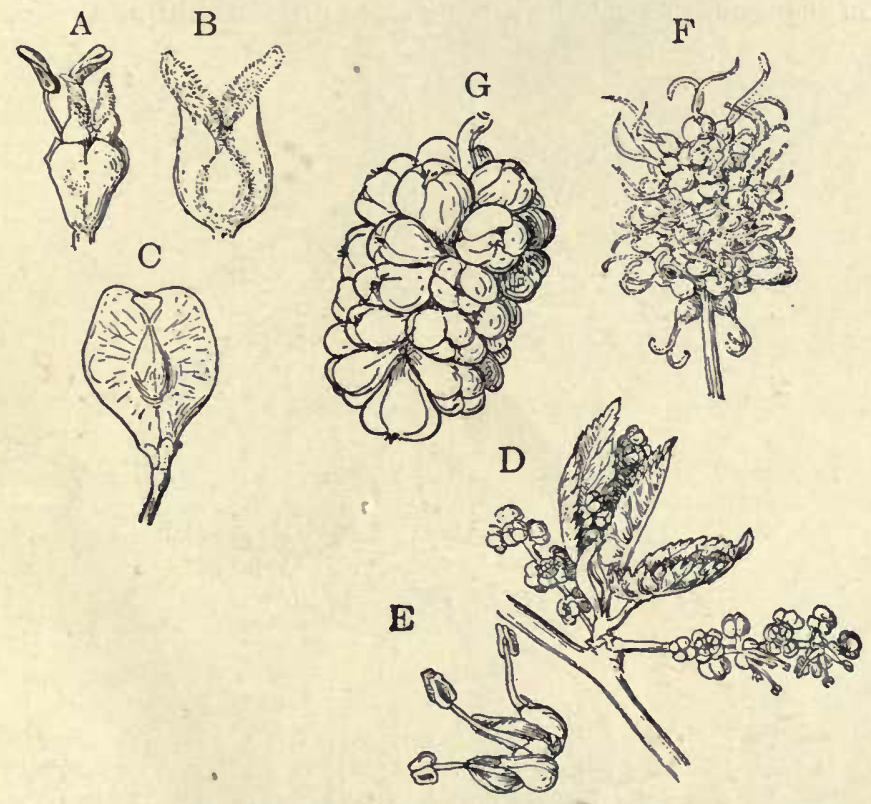

Fra. 401. - A-C, Ulmus campestris, var. suberosa. $\mathcal{A}$, flower with stamens and pistil. $B$, pistil showing the two stigmas. $C$, young samara, or winged fruit. $D-G$, Morus alba. $D$, male catkins. $E$, single male flower, enlarged. $F$, female inflorescence $(\times 2)$. $G$, Ripe fruits.

\section{Order IX. Urticales}

The Urticales comprise a large number of herbs, shrubs, and trees, being especially well represented in the warmer parts of the world. The flowers are usually diclinous, but may be hermaphrodite. They are generally borne in dense inflorescences of various kinds (Fig. 401). A single perianth is usually present, but is inconspicuous, and may be entirely absent. The stamens are generally attached to the perianth, which is often persistent, and may become pulpy and form a pseudocarp. The fruits (syncarps) of the Mulberry (Fig. 401) and Osage Orange (Maclura) are of this nature.

There are three families, - Ulmaceæ, to which belong the Elms (Ulmus) and Hackberry (Celtis); the Nettle family (Urticaceæ), largely composed of herbaceous plants; and the Mulberry family, Moraceæ, which is composed of trees, 
shrubs, and some herbaceous plants, and includes many tropical trees, some of great economic importance. The most important genus is Ficus, to which belong the common Fig (Ficus carica) (Fig. 402), the India-rubber tree ( $F$. elastica), and the various Banyan trees ( $F$. religiosa, etc.). The Hop (Humulus lupulus) and the Hemp (Cannabis sativa) are also members of the Moraceæ.

\section{Order X. Proteales}

The Proteales include the single large family Proteaceæ, mostly shrubs or trees of the southern hemisphere, being especially abundant in Australia and

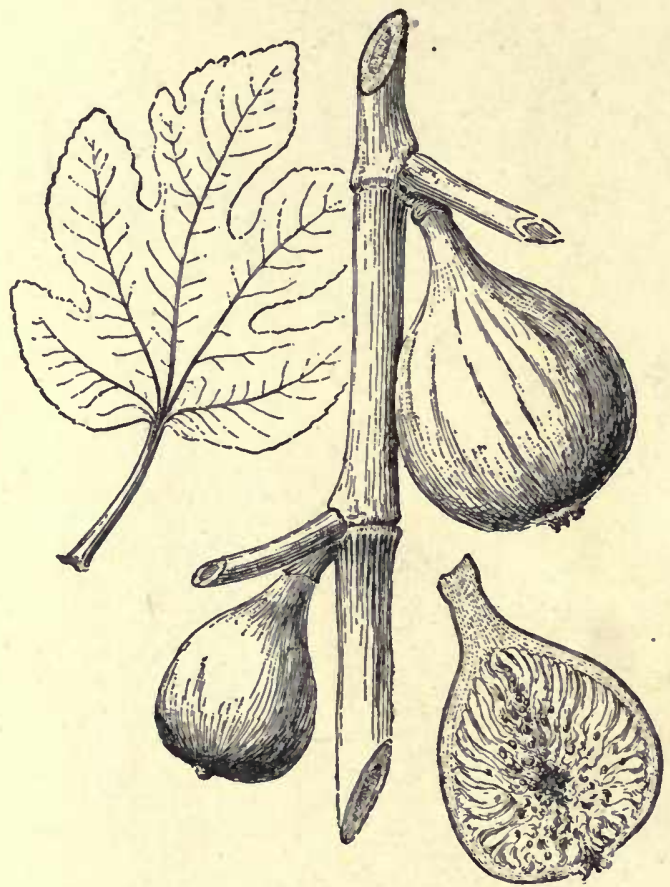

FrG. 402.-Ficus carica. (After BAILEY.)

the Cape region of Africa. None occur in North America, but species of Protea (Fig. 403) are occasionally grown in greenhouses, and Grevillea robusta, the "Silk-oak" of Australia, is a common ornamental plant, and frequently planted out of doors in California.

\section{Order XI. Santalales}

The Santalales comprise a large number of plants, often much reduced parasites, whose affinities are somewhat doubtful. The flowers are usually hermaphrodite, with a well-developed perianth. In many of them, the ovules are only imperfectly differentiated, and the embryo-sac may be imbedded in the tissue of the placenta, or even of the carpel. There are several families, two of which, Santalaceæ and Loranthaceæ, are represented in the United States. To the 


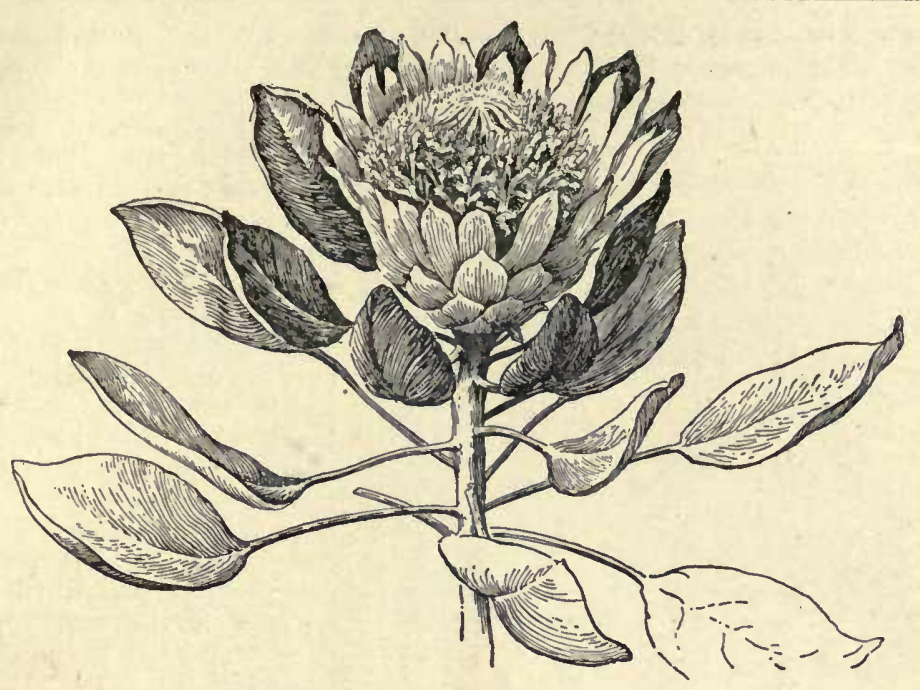

Fig. 403.- Protea cynaroides. (After Bailey.)

former belongs the Bastard Toad-flax (Comandra umbellata); to the latter the American Mistletoe (Phoradendron, Fig. 404) and Arceuthobium. The great majority of the Santalales are tropical plants.

\section{Order XII. Aristolochiales}

The Aristolochiales comprise three families, of mostly tropical plants, of which two, the Rafflesiaceæ (Fig. 405) and Hydnoraceæ, are parasites of the most pronounced type. These plants live within the bodies of other plants, much as a Fungus does, and their vegetative organs are reduced to an irregular thallus, which may closely resemble the mycelium of a Fungus. The flowers in Rafflesia are of enormous size, sometimes a metre in diameter.

The Aristolochiaceæ, the third family, are herbaceous or woody plants, with curious flowers, often of large size. Asarum Canadense (Fig. 406) is the common Wild-ginger, and several species of Aristolochia also occur wild. Of the latter, A. sipho is a common ornamental climber.

\section{Order XIII. Polygonales}

The Polygonales include the single famFia. 404. - Phoratiendron flavescens. (After BAILEY.)

ily Polygonaceæ, well represented within the United States by numerous species 
of Polygonum (Fig. 407, "Knot-grass," "Smartweed," etc.), Rumex (Sorrel, Dock), Eriogonum, and several other smaller genera. Of cultivated plants, the Rhubarb (Rheum) and Buckwheat (Fagopyrum) are the most important.

A

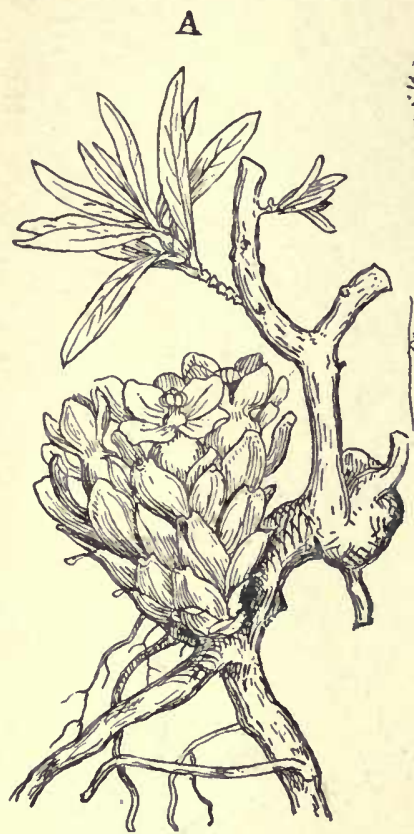

Fig. 405.-A, Cytinus hypocistis. Parasitic on the roots of Cistus. B, Rafflesia Patma. Section of the bast of Cissus sp., showing the Fungus-like character of the plant-body of the parasite Rafflesia. (All figures after SoLMSLAUBACH.)

The Polygonaceæ are usually herbaceous plants, but sometimes (e.g. species of Eriogonum) may be woody. The flowers are either diclinous or hermaphrodite, with a regular perianth, which is sometimes brightly colored. The leaves have usually sheathing stipules, and the form of the leaves and the structure of the pistil recall soinewhat the simpler Piperaceæ, with which there may be a remote affinity. On the other hand, the Polygonaceæ are probably related to the lower Centrospermæ, one of the lowest orders of the Choripetalæ.

\section{SERIES II. CHORI- PETALA (MESACHLA- MYDE正)}

The flowers in the Choripetalæ are usually hermaphrodite, and there are two series of perianth leaves, differentiated into calyx and corolla. In some of the lower members of the series, however (e.g. Anemone, Clematis), there are no petals developed. As a rule, the petals and sepals are four or five in number, but there are many exceptions.

Among the lower Choripetalæ, there are two types of flower, which recall, on the one hand, the flowers of the Apetalæ, and, on the other, the apocarpous Monocotyledons, and probably represent two lines of development. These two orders are the Centrospermæ and the Ranales.

In the Centrospermæ the flower may be extremely simple, as in Chenopodium or Amarantus. The ovary contains a single basal ovule, and the structure of the flower is very much like that of the Polygonaceæ or the Piperaceæ, which they further resemble in possessing perisperm in the seed. In the simpler Ranales (Nelumbo, Anemone) the flowers have numerous free carpels and stamens, and 
the perianth is composed of a varying number of petals and sepals, which are not always clearly separable, as in the Water-lilies. The latter recall in many ways the Helobieæ, and it is not impossible that they are really related to them.

The single terminal ovule of the lower Centrospermæ is replaced in the higher forms by an axial placenta, upon which are borne numerous ovules. Some of them have several carpels which may be united into a several-chambered ovary (e.g. Mesembryanthemum). The more specialized types, like Dianthus, Silene, Portulaca, etc.,

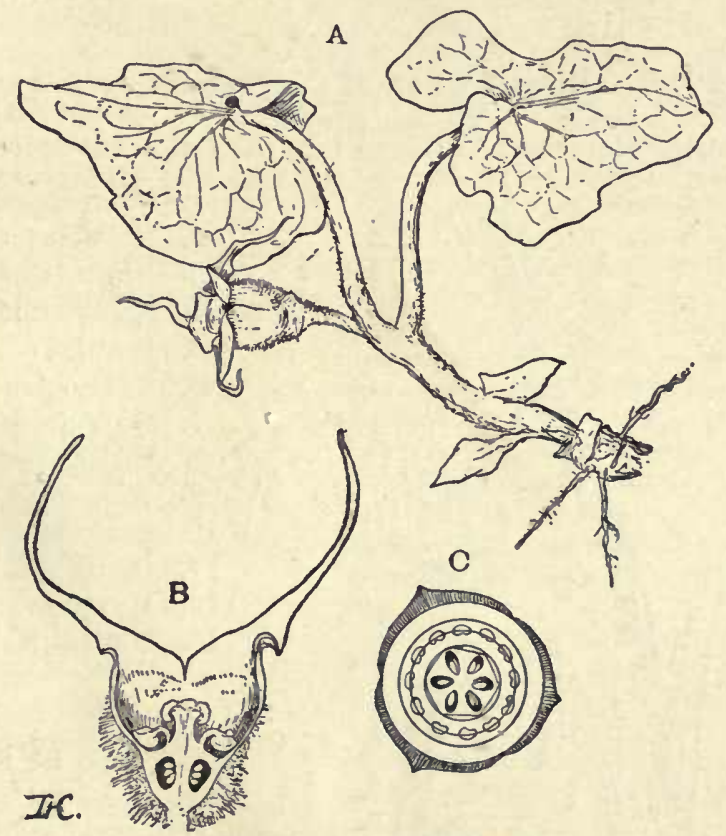

Fig. 406. - Asarum Canadense.

have showy petals, and the calyx is often tubular. In Mesembryanthemum (Fig. 409) many of the numerous stamens are transformed into petaloid staminodia.

In the higher Choripetalæ the calyx is usually composed of united sepals, and the parts of the flower are constant in number. The stamens, however (Myrtaceæ, Rosaceæ), may be more numerous, and sometimes the carpels also, suggesting an affinity with the Ranales. With the exception of some of the Rosifloræ, also, the carpels are almost always united into a compound pistil.

Among the less specialized forms the flowers are radially sym- 
metrical (actinomorphic), - e.g. Rosa, Papaver, Oxalis, — but many are markedly zygomorphic, as Viola, Tropæolum, Leguminosæ. All degrees of cohesion of the ovary with the floral axis are found, even in the same order. Thus in the Rosales, the Crassulaceæ have all the parts of the flower quite separate; in Pyrus, the carpels are more or less completely united with the floral axis, and in Ribes there is a true inferior ovary:

Among the Choripetalæ are found many types of specialization of the vegetative parts. 'The Sarraceniales (Pitcher-plants, Sundews) and the Cacti (Opuntiales) are among the most remarkable cases.

\section{Classification of Choripetalæ}

The Choripetalæ may be divided into the following orders :

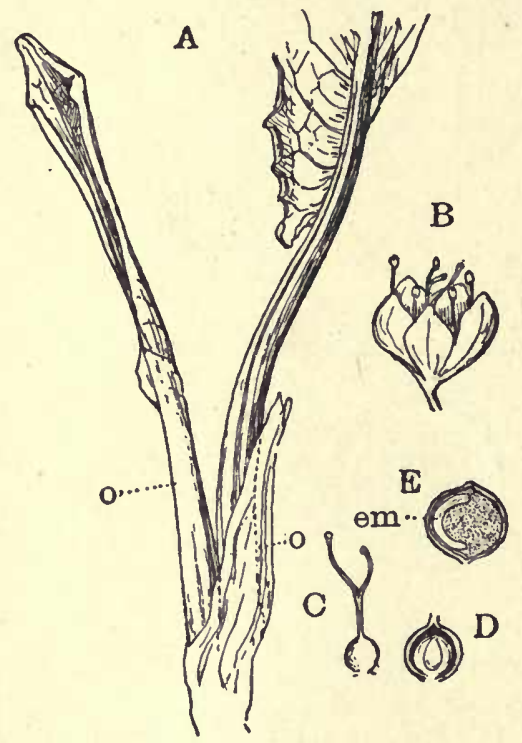

Fig. 407.-A, Rumex crispus. Base of young shoot, showing the ochrex, 0 . $B-E$, Polygonum sp. chlamydeous "; in the lower types, only one set of perianth-leaves are found, and the flowers are "Homochlamydeous." The ovary is in most cases " one-celled," and the seeds are borne upon a central placenta, which is developed from the apex of the floral axis. The ovule is usually bent (campylotropous), and the endosperm is partially replaced by perisperm. In the latter respect, as well as the character of the placenta, the Centrospermæ suggest the Piperales, with which they may possibly be connected through the Polygonales. 


\section{Order II. Ranales}

The Ranales comprise a large number of Dicotyledons, some of which, like the Nymphæaceæ and certain Ranunculaceæ, suggest affinities with the Monocotyledons. Some of them, like the Nymphæaceæ, Ceratophyllaceæ, and a few Ranunculaceæ, are aquatics, which recall in habit the Helobiex among the Monocotyledons. Others - e.g. Magnoliaceæ, Lauraceæ are trees or shrubs, and a few genera - e.g. Akebia, Menispermum (Fig. 413, $F$ ) - are woody climbers.

The flowers of the Ranales almost always have the parts entirely separate, although exceptionally the

B

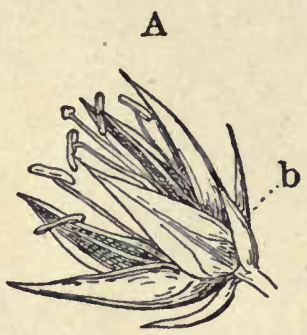

FIG. 408. $-A, B$, Celosia cristata $(\times 3) ; b$, bracts. $C, D$, Chenopodium album $(\times 8)$. carpels may be united. The number of petals and sepals may be definite (species of Ranunculus, Berberis), or there may be great variation in this

\section{A}

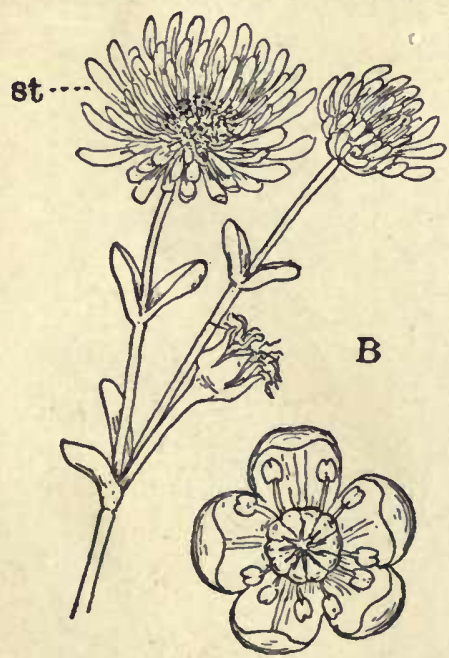

Fig. 409. - A, Mesembryanthemum $s p$. , the showy part of the flower consists of the narrow petaloid staminodia, st. $B$, Phytolacca decandra, single flower, enlarged. respect (Magnolia, Nymphæa), and in such cases there is often no marked difference between sepals and petals. Not infrequently - e.g. Anemone, Delphinium, Caltha - the sepals are petaloid, and the petals may be quite absent. The stamens are numerous, and this is true in most cases of the carpels, which may, however (Berberidaceæ), be reduced to a single one.

In most cases the flowers are radially symmetrical, but strongly zygomorphic flowers are occasionally met with-e.g. Delphinium. (Fig. 412, F), Aconitum. While hermaphrodite flowers are the rule, they may be diclinous (Thalictrum, Akebia).

Some of the Ranales show anomalies in the structure of the tissues, which also suggest a relationship with the Monocotyledons. Thus Podophyllum, Leontice, Thalictrum, the Nymphæaceæ, and several others have the vascular bundles scattered irregularly in the stem, instead of arranged in a single circle, as in the typical Dicotyledons.

The Ranales comprise many familiar and beautiful flowers as well as some characteristic trees, especially in the Eastern states, where the Magnolias and Tulip-tree (Liriodendron) are among the most striking forest trees. On the Pacific coast, the only tree of the order is the beautiful Bay-tree (Umbellularia Californica), (Fig. 415). 


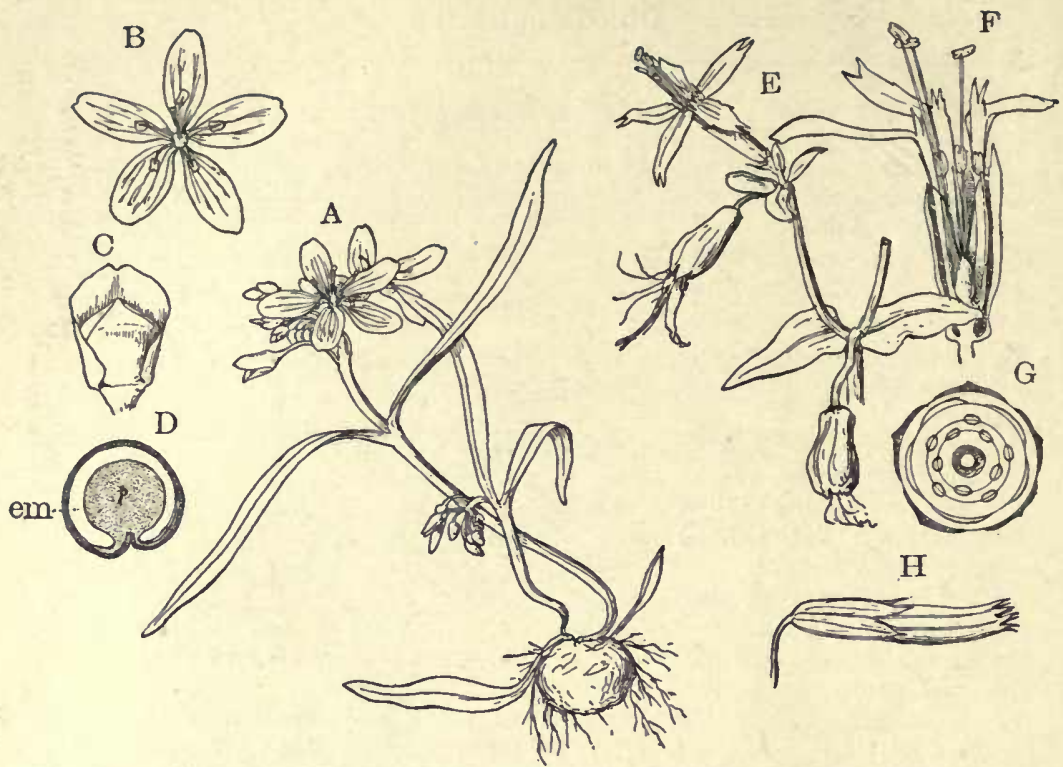

Fia. 410. - $A-D$, Claytonia Virginica. $D$, section of the seed, showing the curved embryo, em, and the perisperm, $p . \quad E$-G, Silene Virginica. $G$, diagram of the flower. $H$, Cerastium vulgatum. Capsule showing the dehiscence by teeth, enlarged.

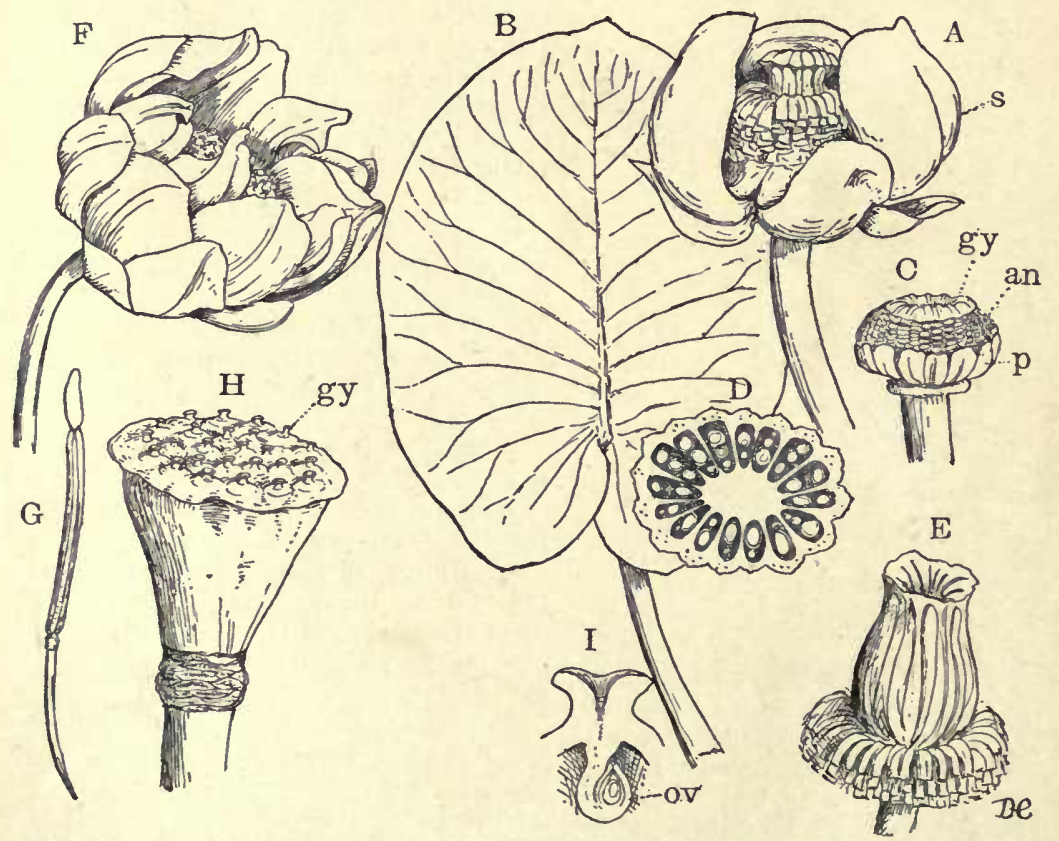

Fig. 411. - A-E, Nuphar advena. $C$, flower with the showy sepals, $s$, removed, to show the small petals, $p$, the stamens, an, and pistil, $g y . \quad F-I$, Nelumbo lutea. $H$, enlarged receptacle, or torus, bearing the separate carpels, $g y$, sunk in cavities. $I$, section of the npper part of a carpel, showing the single pendent ovule, ov. 


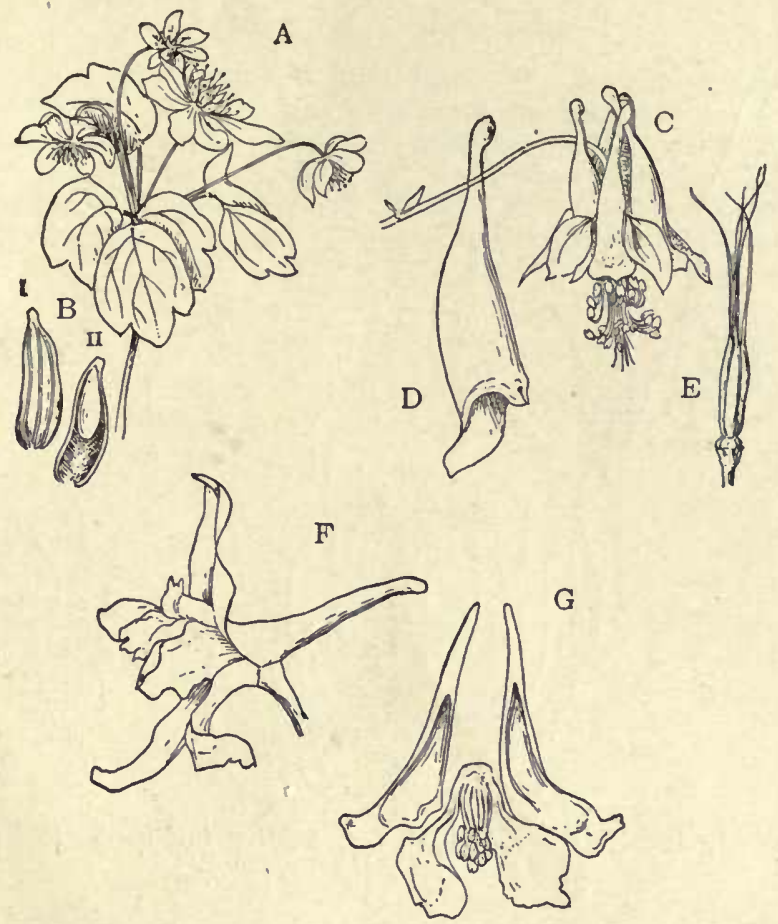

Fig. 412.- $A, B$, Thalictrum anemonoides. $B$, the ripe achene, in $I I$, split longitudinally and enlarged. $C-E$, Aquilegia Canadensis. $F, G$, Delphinium tricorne. In $G$ the sepals have been removed to show the four petals and the stamens.

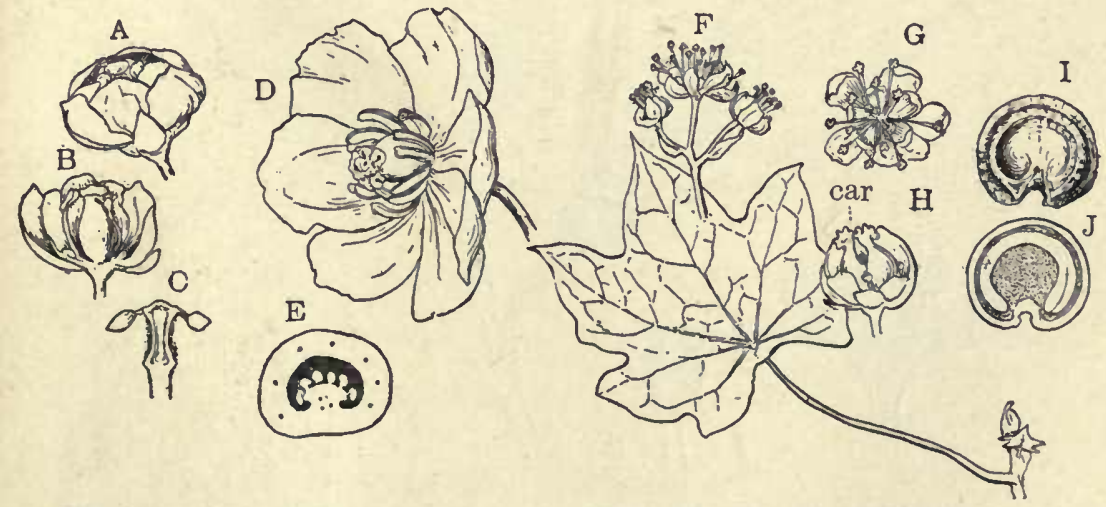

Fig. 413.-A-C, Berberis vulgaris. $C$, a stamen, showing its dehiscence. $D, E$, Podophyllum peltatum. $F-J$, Menispermum Canadense. $G$, staminate, $H$, pistillate, flower. $J$, seed split to show form of the embryo. 


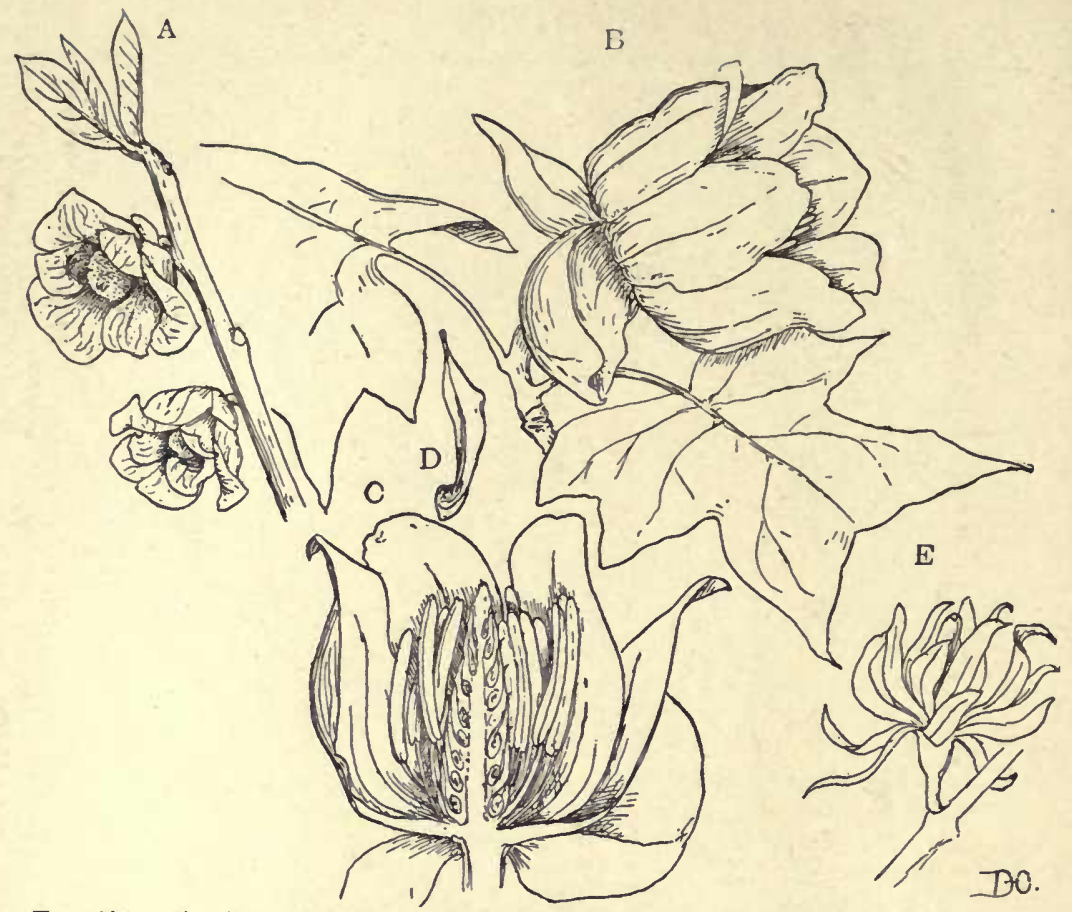

FIG. 414. - A, Asimina triloba. $B-D$, Liriodendron tulipifera. $D$, a ripe fruit. $E$, Calycanthus flomdus.

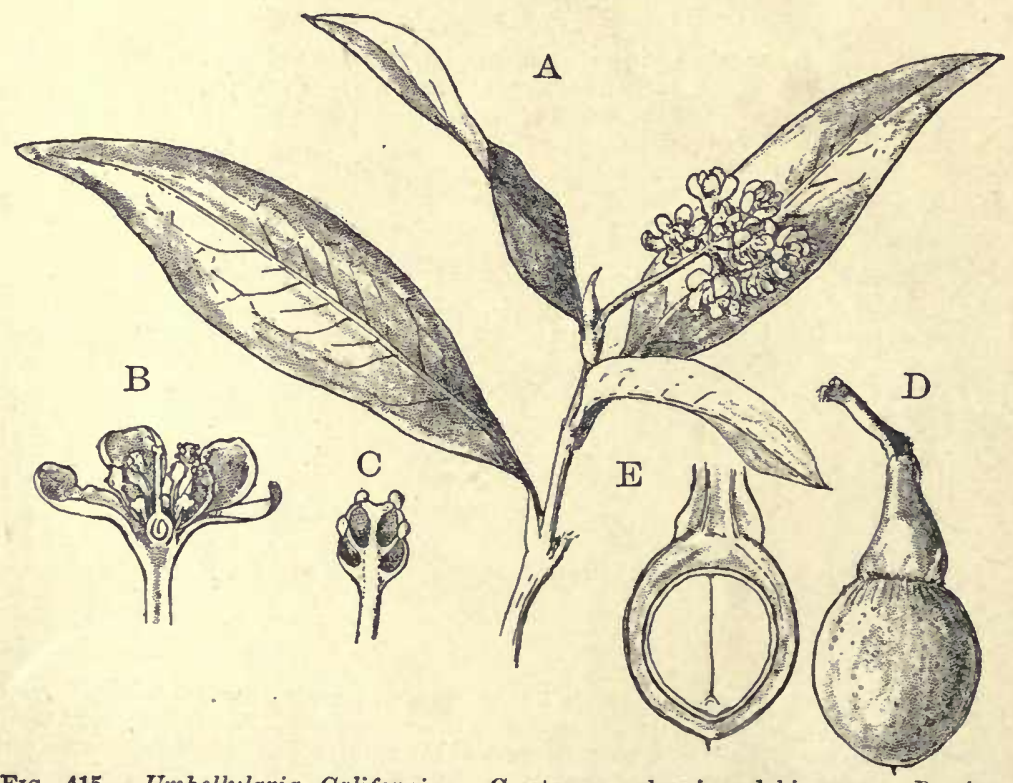

Fra. 415.-Umbellularia Californica. $C$, stamen, showing dehiscence. $D$, ripe fruit. $E$, fruit sectioned. 


\section{Order III. Rhœadales}

The Rhœadales are mostly herbaceous plants with showy flowers, the parts of which are hypogynous. The carpels are usually completely united with a compound pistil. To this order belong the Poppy family (Papaveraceæ), including a number of very showy flowers, especially well represented in California. Representative genera are Papaver, Eschscholtzia, Platystemon, and Romneya. In the Eastern states Sanguinaria (Fig. 416, A) and Stylophorum are characteristic

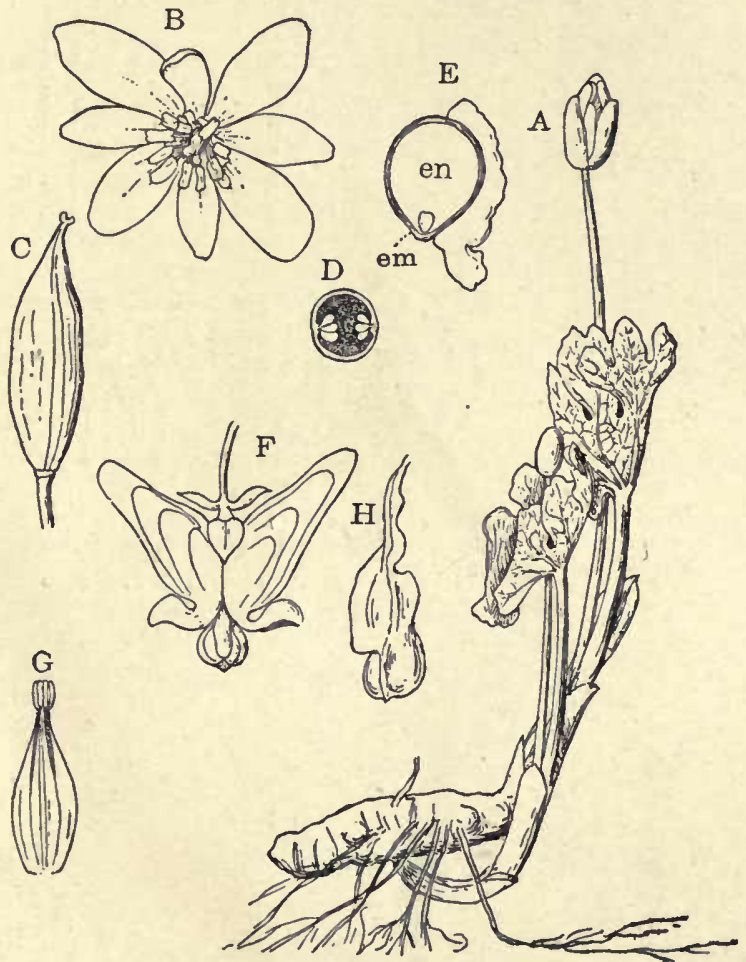

Fig. 416. $-A-E$, Sanguinaria Canadensis. $F-H$, Dicentra cucullaria. $G$, stamens. $H$, a single petal.

genera. Sometimes separated as a family are the Fumariaceæ, containing the genera Dicentra (Fig. 416, F), Adlumia, and Corydalis.

The Cruciferæ, or Mustard family (Fig. 417), comprises very many familiar plants, wild and cultivated. To the Rhœadales beloug also the Caper family (Capparidaceæ), and the Mignonette family (Resedaceæ).

\section{Order IV. Sarraceniales}

The Sarraceniales comprise three families of plants, remarkable for the extraordinary modifications of the leaves, which are transformed into traps for the 


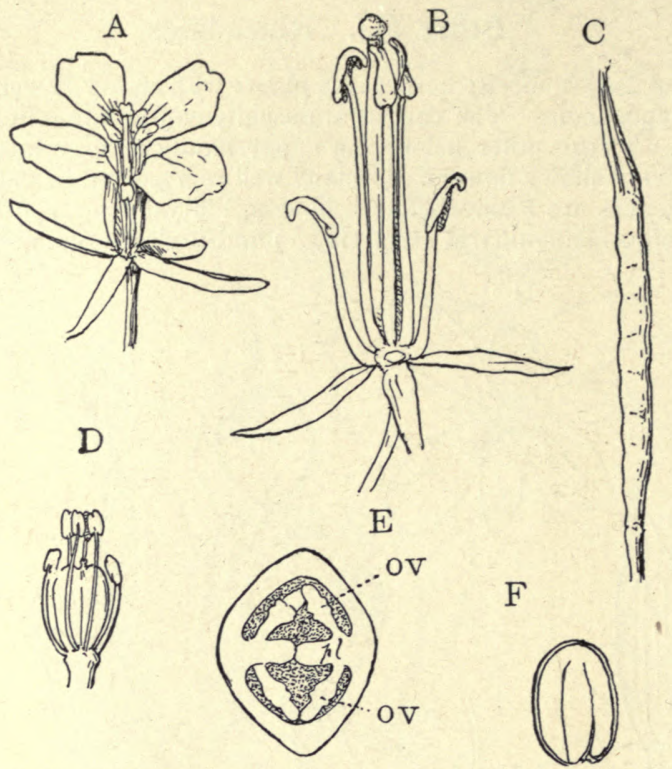

Fig. 417.-A-C, Brassica juncea. $D-F$, Capsella bursa-pastoris. $E$, transverse section of young ovary, showing the placenta, $p l$, and ovules, $o v$, highly magnified. $F$, section of ripe seed, enlarged.

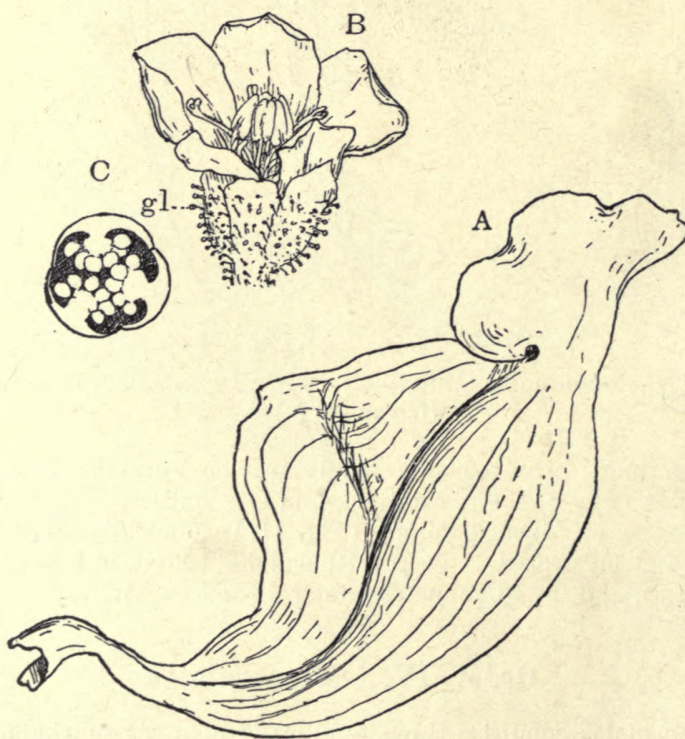

Fig. 418. - A, Sarracenia purpurea. $\quad B, C$, Drosera filiformis, enlarged; gl, glandular hairs. 
capture of insects. One family of Pitcher-plants (Sarraceniaceæ) is exclusively American. Two genera, Sarracenia of the Eastern states and Darlingtonia of the Sierra Nevada, are found in the United States. A second family, Nepenthaceæ, is confined to the Tropics of the Old World, while the Droseraceæ are cosmopolitan (Fig. 418).

\section{Order V. Rosales}

The Rosales include a large number of familiar plants, and show a good deal of range, both in the character of the vegetative parts and the flowers and fruits. The flowers are usually hermaphrodite and actinomorphic; but there are numerous exceptions.

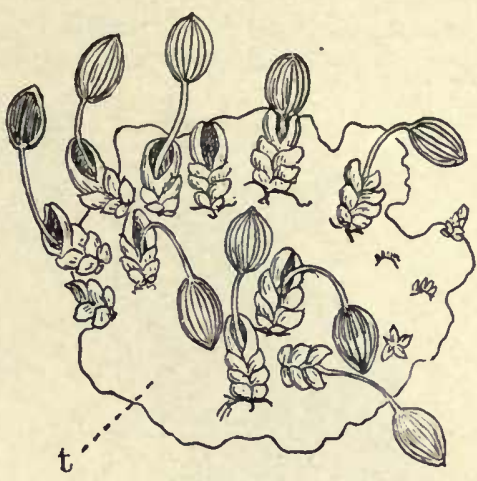

Fra. 419. - Podostemon oïvaceum, enlarged; $t$, the thalloid structure, from which the fruiting shoots arise. (After Warming.)

A few forms - e.g. Podostemonaceæ (Fig. 419) - are aquatics of very peculiar structure, sometimes resembling Algæ, rather than vascular plants. Other Rosales are herbaceous or shrubby, and some - e.g. Platanus, Robinia - are trees of large size.

Among the most primitive of the Rosales are the Crassulaceæ (Fig. 420, D), in

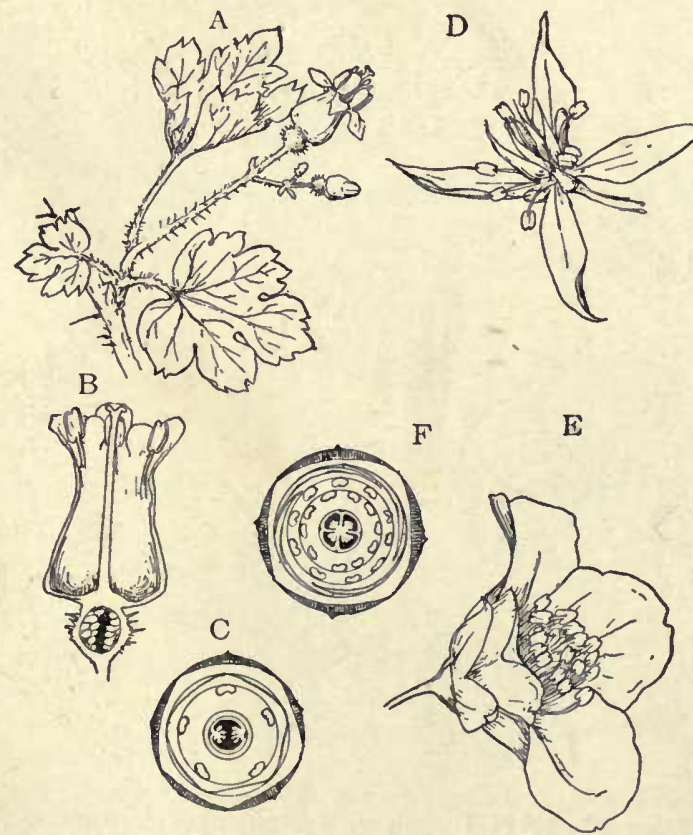

Fig. 420.-A-C, Ribes Cynosbati. D, Sedum sp. (× 2). E, F, Philadelphus grandiflorus. 


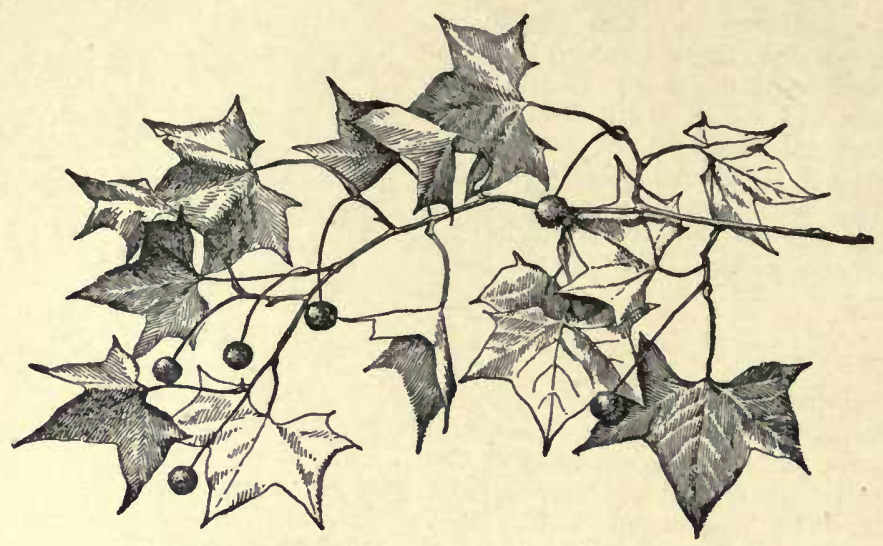

FIg. 421. - Platanus occidentalis. (After BaILEx.)

which the parts of the flower are all separate and of equal number. In the Saxifragaceæ (Ribes, Saxifraga, Philadelphus) (Fig. $420 A, E$ ) and the Rosaceæ the actinomorphic flowers show all gradations from strictly hypogynous forms with free carpels to those with true inferior ovaries. In most of these forms the number of stamens is indefinite.

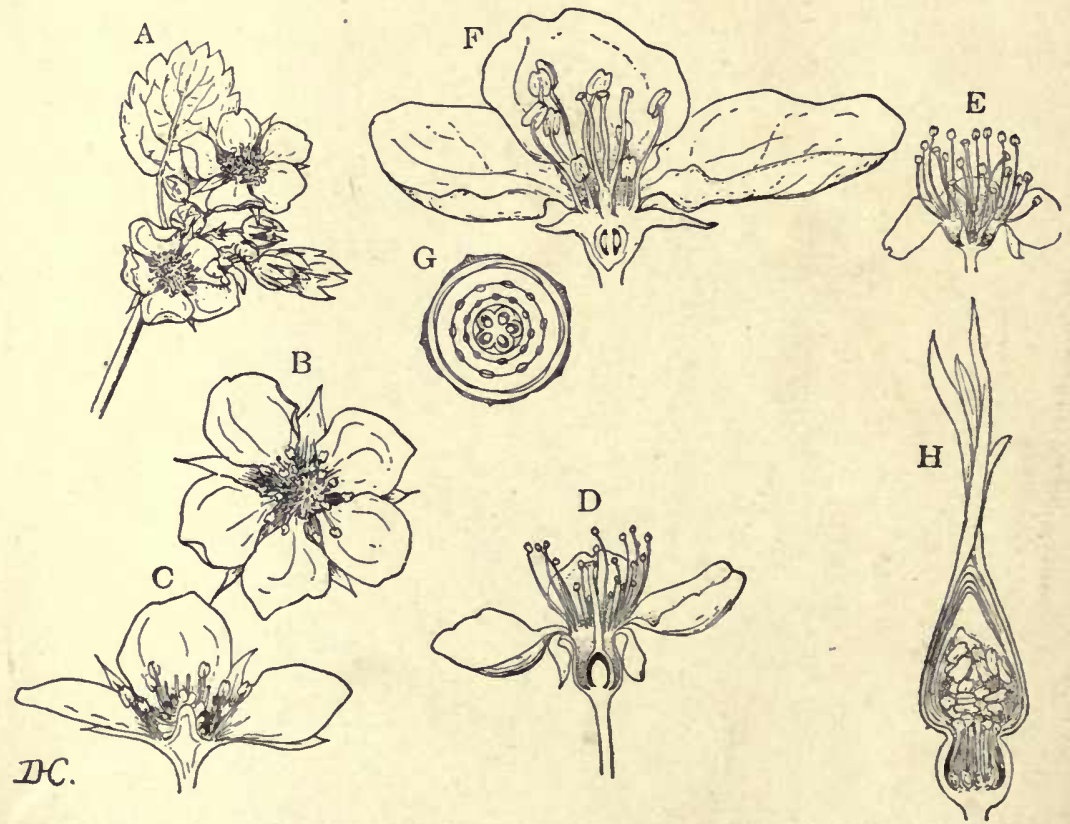

Fig. 422.-A-C, Fragaria Virginiana. D, Prunus Cerasus. $E$, Spiræa sp. $F, G$, Pyrus Malus. $H$, Rosa blanda, section of the flower-bud, enlarged, showing the numerous free carpels enclosed in the urn-shaped receptacle. 
Rosaceæ. - The Rosaceæ (Fig. 422) are economically of much importance, as they comprise the most valuable fruits of temperate regions. Apples, Pears, Peaches, Cherries, Strawberries, etc., are all Rosaceæ. The family is sometimes divided into three subfamilies Drupaceæ (Cherry family), Pomaceæ (Apple family), and Rosaceæ proper.

Leguminosæ. - The Leguminosæ, or Pea family, is the largest family of the Clioripetalæ. It is especially developed in the Tropics, where many Leguminosæ are trees of

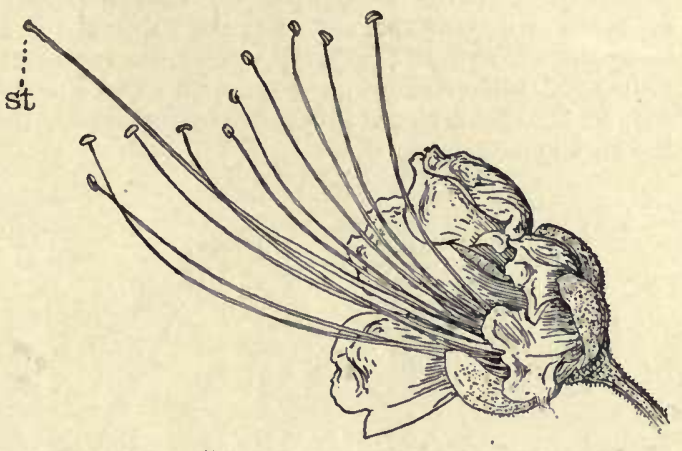

Fra. 423. - Cxsalpinia pulcherrima; st, stigma. great size, and many are giant woody creepers or lianas.

Three subfamilies are distinguished, - Papilionaceæ, Cæsalpineæ, and Mimoseæ. The two latter are mainly tropical, most of the Leguminosæ of temperate regions belonging to the Papilionaceæ.

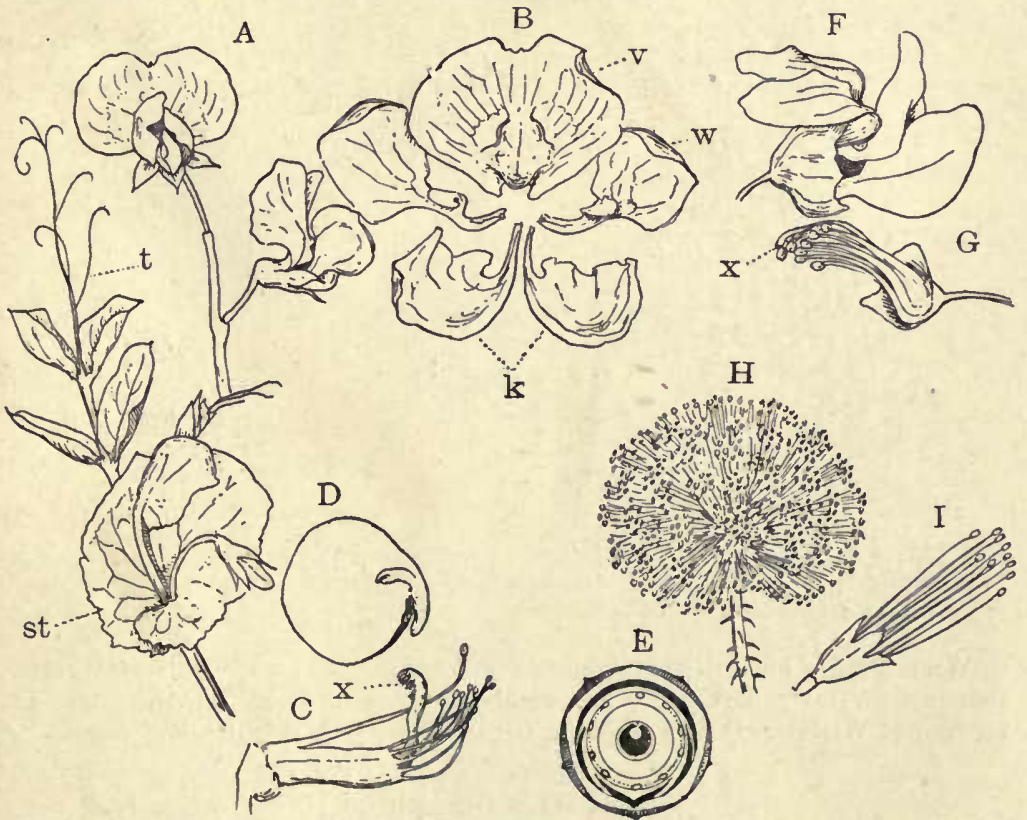

Fic. 424. - A-E, Pisum sativum. B, petals separated; $v$, standard (vexillum); $w$, wings; $k$, keel. $C$, stamens, and carpel, $x$. $D$, embryo with one cotyledon removed. $F, G$, Cercis Canadensis. $H, I$, Schrankia uncinata. I, single flower, enlarged. 
The flowers of the Leguminosæ regularly show ten stamens, and a single carpel which develops into the characteristic legume or pod.

The flowers of the Cæsalpineæ (Fig. 423) and Mimoseæ (Fig. 424, H) are nearly actinomorphic, with free stamens; the Papilionacer have the characteristic butterfly-shaped flowers (Fig. 424, A) and the stamens are "Monadelphous" (all united) or "Diadelphous" (nine united and a single free stamen). Cercis (Fig. $424, \mathrm{~F}$ ) is to some extent intermediate in character between the Cæasalpineæ and the Papilionaceæ.
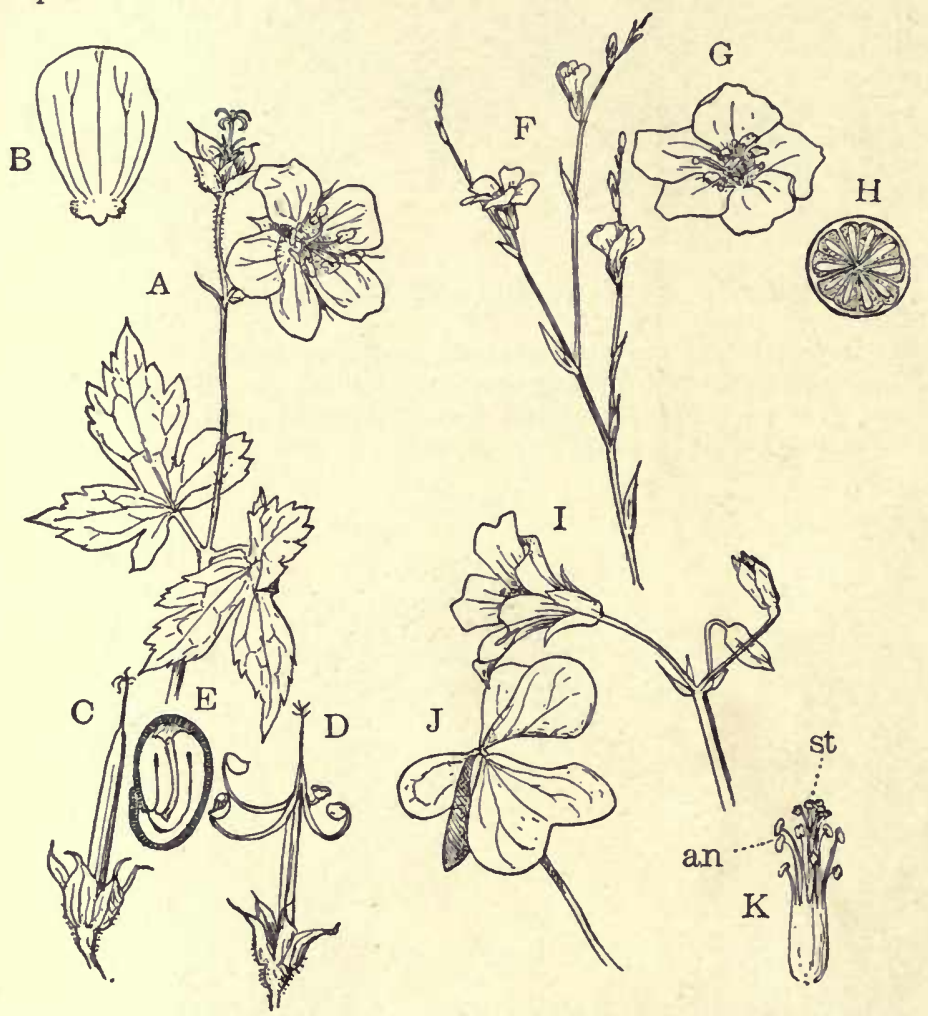

Fig. 425. - A-E, Geranium maculatum. $F-H$, Linum Virginianum. $H$, section of young fruit, enlarged. $I-K$, Oxalis violacea. $K$, androcium and gynæcium, showing the heterogamy of the flower.

While most of our native Leguminosæ are herbaceous plants of moderate size, there are several genera which are woody climbers or trees. Of these may be mentioned Wistaria, Cercis, Robinia, Gleditschia, Gymnocladus, and Acacia.

\section{Order VI. Geraniales}

The Geraniales include herbaceous and woody plants, some of them-e.g. Erythroxylon - trees of some size. The flowers are usually hermaphrodite (Geranium, Oxalis), but may be diclinous (Euphorbiaceæ). The flowers are either 


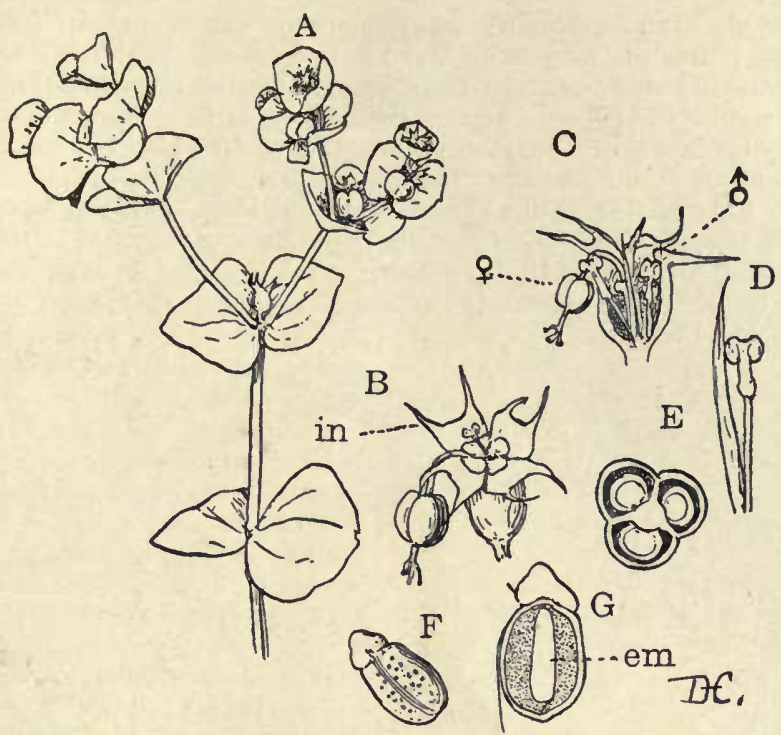

FIG. 426. - Euphorbia commutata. $B, C$. single inflorescence, showing the corollalike involucre, in, containing the separate male, ô, and female, \&, flowers. $D$, single male flower, enlarged. $E$, section of the ovary. $G$, section of ripe seed.

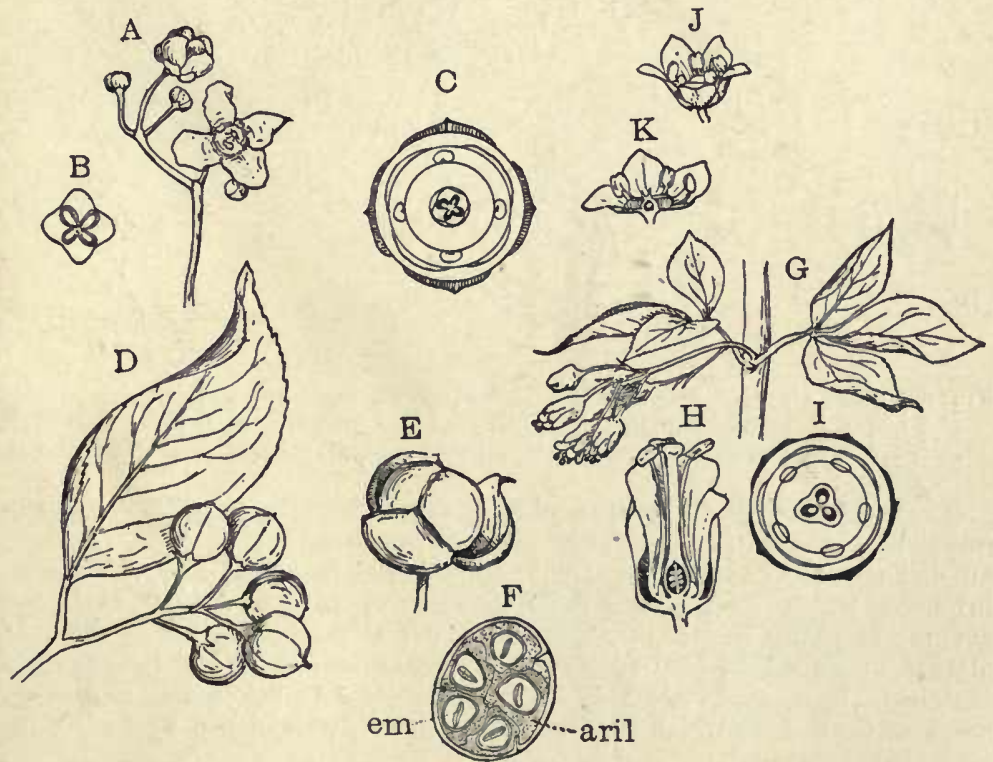

FIG. 427. $-A-C$, Euonymus atropurpureus. $D-F$, Celastrus scandens. $F$, section of fruit, showing the aril surrounding the seeds. $G-I$, Staphylea trifolia. $J, K$, Rhus cotinus. Flowers, enlarged. 
actinomorphic (Oxalis, Linum) or zygomorphic (Pelargonium, Tropœolum). In the latter case the number of stainens is reduced. The carpels are usually three to five, and may separate (Geranium) at maturity (Fig. 425, D).

The Geraniaceæ include several native species of Geranium, and the species of Pelargonium are favorite garden plants. Oxalidaceæ, Linaceæ, and Tropœolaceæ also include familiar forms. Linum usitatissimum is the common Flax.

'To the Rutaceæ belong the various species of Citrus (Orange, Lemon, etc.), and the Meliaceæ include the Umbrella-tree (Melia Azederach), often planted in the warmer parts of the United States.

The Polygalaceæ are represented by several species of Polygala, with strongly zygomorphic flowers.
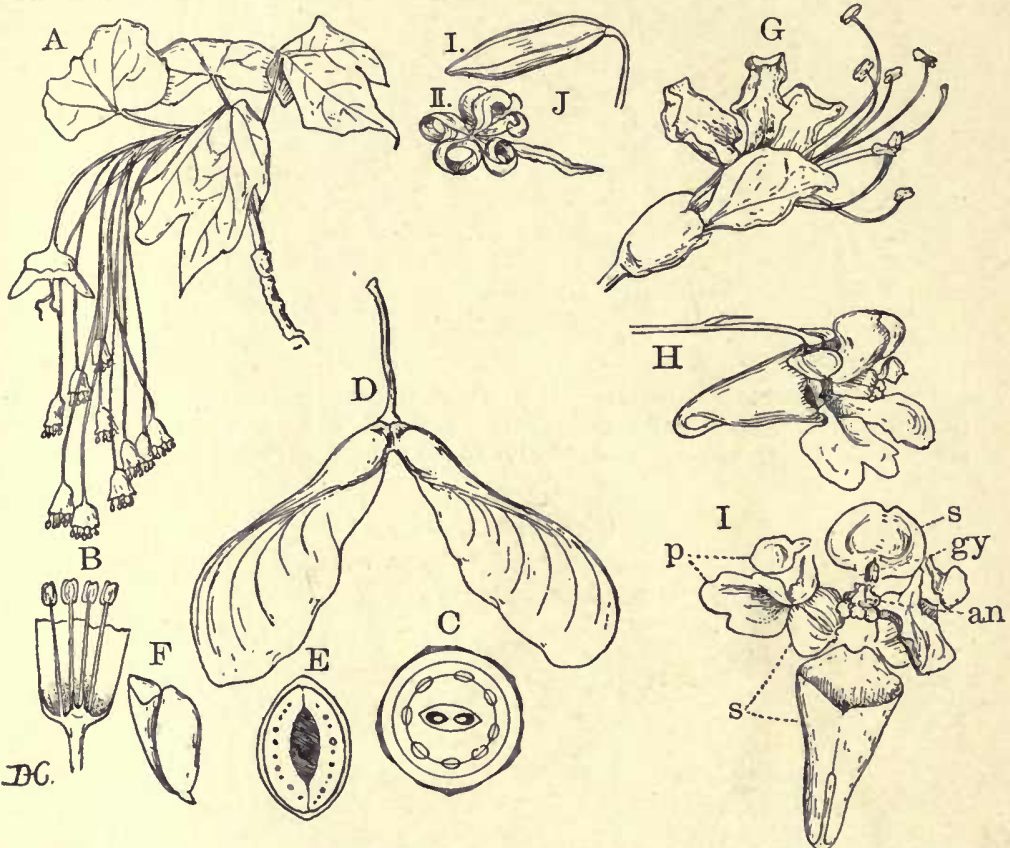

Fig. 428. - A, B, Acer saccharinum. $D-F, A$. dasycarpum. $E$, section of seed.

$F$, embryo removed from the seed. G, Asculus glabra. H-J, Impatiens fulva.

$J$, Hower with the parts displayed; $s$, sepals; $p$, petals; $a n$, stamens; $g y$, carpels.

The Euphorbiaceæ, which are doubtfully placed with the Geraniales, are plants especially abundant in the warmer parts of the earth. The flowers (Fig. 426) are diclinous and inconspicuous; but they are often surrounded by a corolla-like involucre which renders the inflorescence very conspicuous. This is seen among our native species in $E$. corollata and $E$. marginata, but is still more marked in such cultivated species as $E$. splendens and $E$. (Poinsettia) pulcherrima. Some of the South African Euphorbias are quite leafless and closely resemble Cacti, from which they may be at once distinguished by their milky juice.

The Castor-bean (Ricinus) and the showy-leaved Crotons are common cultivated members of the Euphorbiaceæ. 


\section{Order VII. Sapindales (Celastrales)}

The Sapindales are for the most part shrubs or trees, which in the character of the flowers closely resemble the Geraniales. To the Sapindales belong the Anacardiaceæ, represented by species of Rhus, some of which are excessively poisonous to the touch. The Aquifoliaceæ include the Hollies (Ilex); the Celastraceæ comprise species of Celastrus (Fig. 427) and Euonymus; and the Staphyleaceæ are represented by the single species Staphylea trifolia (Fig. 427, G).

Sapindineæ. - The suborder Sapindineæ includes the Maples (Aceraceæ) and the Buckeyes (Hippocastanaceæ).

Balsaminineæ. - A single family, Balsaminaceæ, represent the suborder Balsaminineæ. These are herbaceous plants, including the garden Balsam (Impatiens balsamina) and the wild

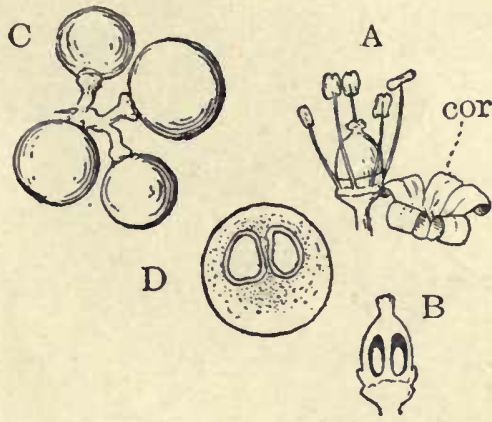

Fia. 429. $-A, B$, Vitis labrusca; cor, the coherent petals, which are thrown off when the flower expands. $C, D$, fruits of $V$. bicolor. Jewel-weed $\left(I\right.$. fulva) ${ }^{\circ}$ (Fig. 428, H).

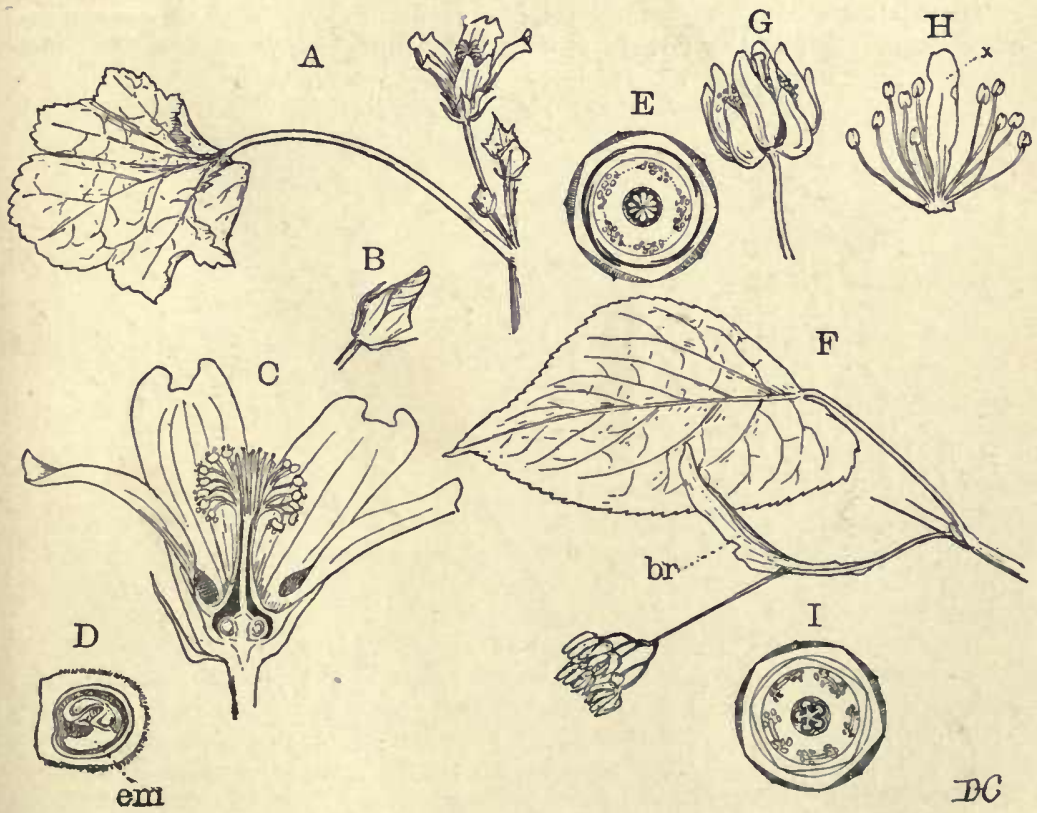

FIG. 430. - A-E, Malva rotundifolia. F-I, Tilia Americana; $b r$, bract subtending the inflorescence; $x$, scale to which the stamens are attached. 


\section{Order VIII. Rhamnales}

The order Rhamnales is a small one, and includes but two families, Rham-

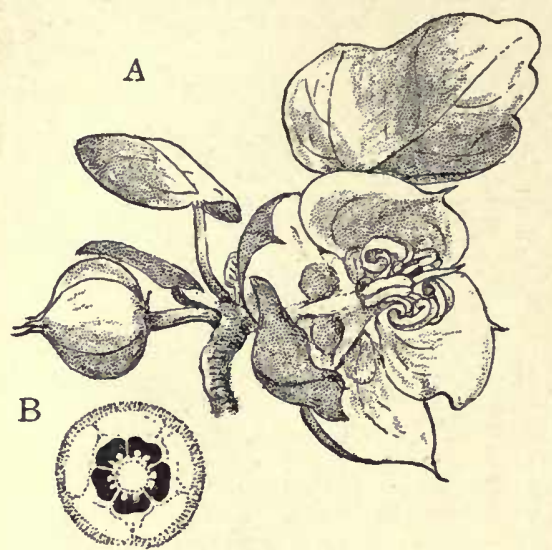

FIG.431.-Fremontia Californica. $B$, section of the ovary. naceæ and Vitaceæ. They are woody plants, often climbers, and the flowers, which are sometimes diclinous, are usually inconspicuous. The flowers may be either hypogynous or epigynous.

Rhamnaceæ. - The family Rhamnaceæ is represented by species of Rhamnus (Buckthorn) and Ceanothus. The latter genus is especially well represented in California, where species of Ceanothus are important components of the dense serub or "chaparral" upon the dry mountain sides.

Vitaceæ. - The Virginia creeper (Ampelopsis quinquefolia) and various species of Grape (Vitis) represent the Vitaceæ (Fig. 429).

\section{Order IX. Malvales}

The Malvales comprise several families, some of which have very conspicuous flowers. While the flowers usually are heterochlamydeous, a few, like

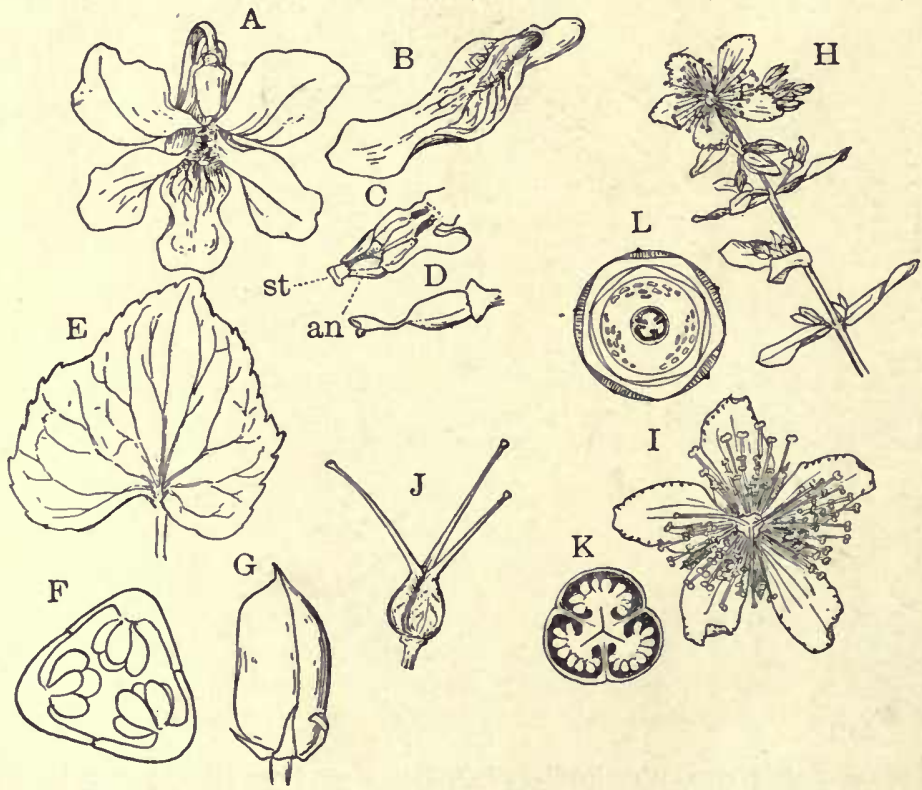

Fig. 432. $-A-G$, Viola cucullata. H-L, Hypericum perforatum. 
Fremontia (Fig. 431), have no corolla, but the sepals in this case are petaloid. The carpels are usually completely united, but in the Malvaceæ the fruit is a "schizocarp," and separates at maturity into as many parts as there are carpels. The stamens are usually numerous, and may be united into a tubular column (Fig. 430).

Most of the Malvales of temperate regions belong to the Mallow family (Malvaceæ). Examples are the various species of Mallow (Malva), Hollyhock (Althea), and Hibiscus. $H$. moscheutos of the Eastern states is one of the showiest of our native plants.

The Bass-woods (Tilia sp.) (Fig. 430, F) represent the Tiliacer, and the Sterculiaceæ, for the most part a tropical family, has in California a single representative, - Frenontia Californica.

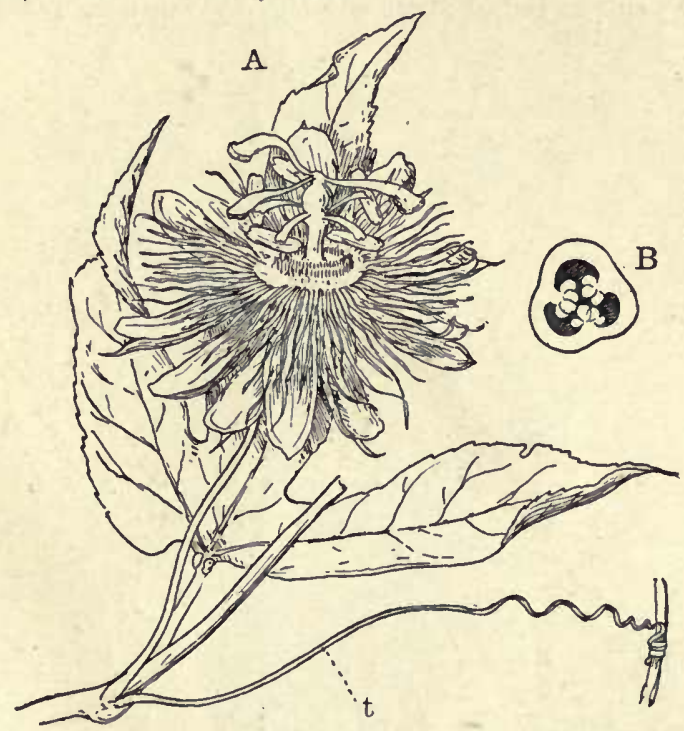

FIG. 433. - Passifiora incarnata; $t$, tendril. $B$, section of the ovary.

\section{Order X. Parietales}

The order Parietales is a very large one, but the majority of the families included are not represented within our territory. There is great variety in the structure of the flowers, but most of them agree in having the ovules attached to the wall of the ovary ; i.e. the placenta is "parietal." (Figs. 432, 433.)

The most important families represented in the American flora are the Theaceæ, Hypericaceæ, Cistaceæ, Violaceæ, Passifloraceæ, and Loasaceæ.

To the Theaceæ belong the genera Stuartia and Gordonia, related to the genus Camellia, one of whose species furnishes tea. The numerous species of St. John's-wort (Hypericum) represent the Hypericaceæ. Helianthemum and several cultivated species of Cistus are the most familiar examples of the Cistaceæ. The Violets (Violaceæ) and Passion-flowers (Passifloraceæ) are represented by numerous cultivated species, as well as by some native ones.

The family Loasaceæ is a characteristic Amertcan one, mostly tropical, but 
represented in the West by several species of Mentzelia, with showy flowers, resembling those of the Cacti, to which they are probably related.

Of the exotic families, the Begoniaceæ comprise many beautiful species cultivated in our gardens and greenhouses. The curious Papaya (Carica Papaya), belonging to the Caricaceæ, is familiar to every traveller in the Tropics.

\section{Order XI. Opuntiales}

A single very characteristic family, Cactaceæ, whose members are almost exclusively American, represents the order Opuntiales. A few forms - e.g. Rhipsalis - are epiphytes, but much the greater number are inhabitants of the arid regions of the southern United States and Mexico. In these regions the Cacti

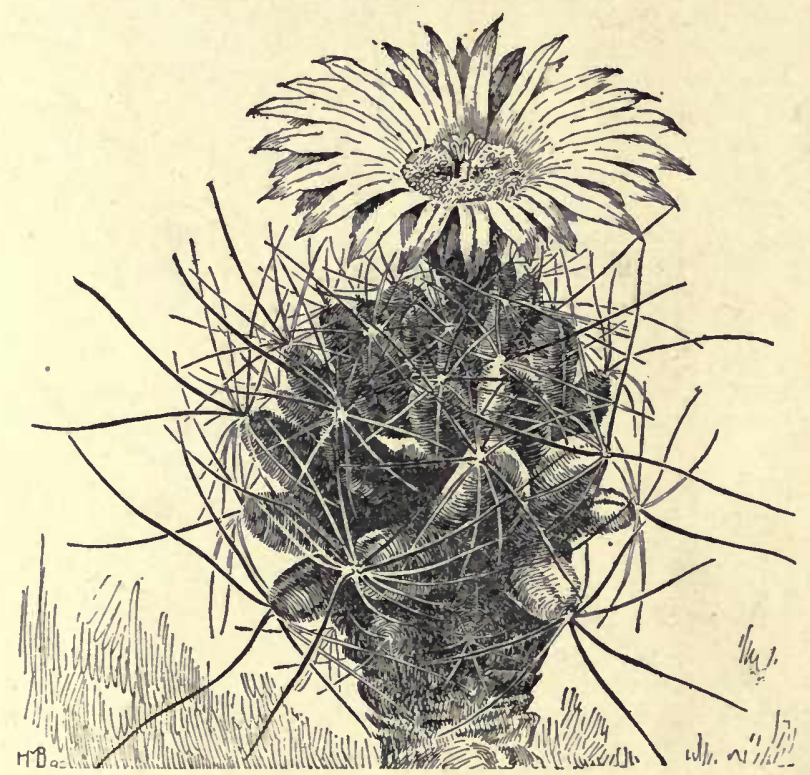

FIa. 434. - Mammillaria macromeris. (After Balley.)

are the most striking members of the native flora. Their massive, leafiess, and spiny stems are perfectly adapted to their peculiar environment. The flowers (Fig. 431) are very uniform in structure, and make the separation into genera extremely difficult.

Some of the smaller species of Prickly-pear (Opuntia) extend well northward, but it is in the hot arid regions of the Southwest that they reach their greatest development. In Arizona the Giant-cactus (C'ereus giganteus) reaches a height of twenty metres or more.

\section{Order XII. Myrtifloræ}

The Myrtifloræ are largely tropical in their distribution, and in the warmer parts of the world are represented by many species, some of which are gigantic trees, like the Australian Gum-trees (Eucalyptus). 


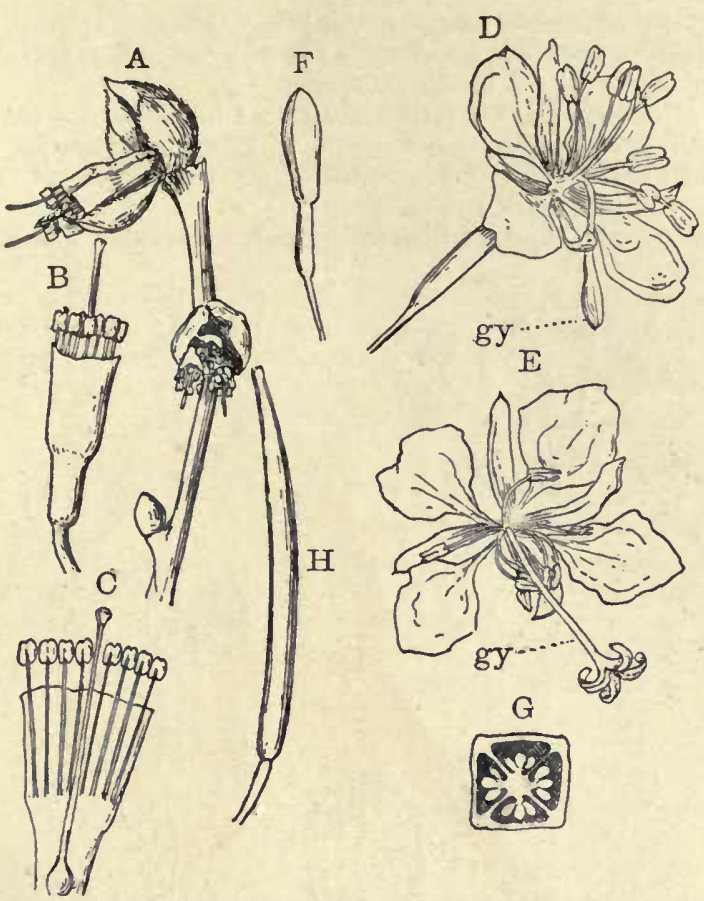

Fia. 435.-A-C, Dirca Palustris. D-H, Epilobium spicatum.

The flowers are perigynous or epigynous, and sometimes the petals are wanting (Eucalyptus). Where the petals are absent, their function as attractive organs is taken by the numerous white or red stamens, which render the flowers very conspicuous.

Thymelæineæ. - Of the suborder Thymelæineæ two families occur within the United States. The Thymelæaceæ are represented by the Moose-wood (Dirca, Fig. 435), the Elæagnaceæ by species of Elæagnus and Shepherdia.

Myrtineæ. - The suborder Myrtineæ comprises, among others, the Loosestrife family (Lythraceæ), Pomegranate family (Punicaceæ), Mangrove family (Rhizophoraceæ), Myrtle family (Myrtaceæ), Melastomaceæ, and Onagraceæ.

The Myrtle family is very largely tropical and comprises many beautiful and useful trees,

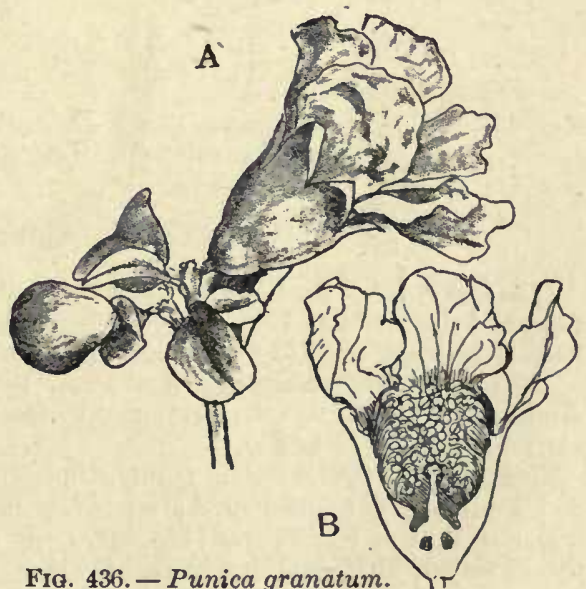

Fia. 436. - Punica granatum. 
e.g. Clove (Caryophyllum), Eugenia, and others with edible fruit, Eucalyptus, etc. The Melastomaceæ are also largely tropical, but several species of Rhexia represent the family within the United States.

The largest family of the Myrtifloræ within our territory is the Onagraceæ, especially well developed in the western part of the country. Among the characteristic genera may be mentioned Epilobium, Enothera, Zauschneria, Godetia, Fuchsia, and Clarkia (Fig. 435, D).

The Water-milfoil (Myriophyllum) represents the peculiar family Halorrhagidaceæ.

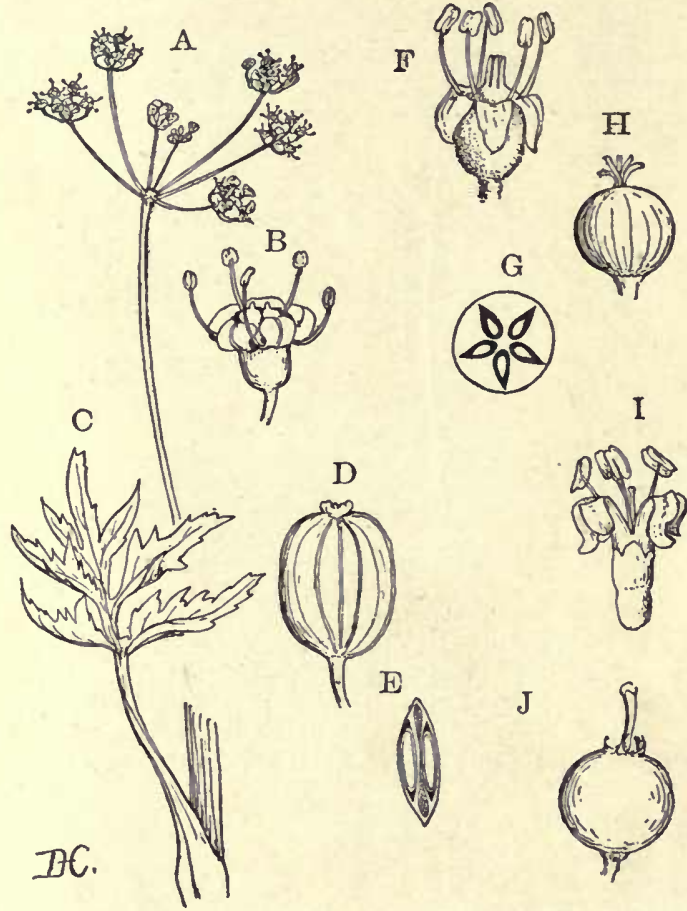

Fig. 437. - A-E, Pastinacı sativa. $F-H$, Aralia racemosa. I, Cornus florida, a single flower enlarged. $J, C$. stolonifer, ripe fruit.

\section{Order XIII. Umbellifloræ}

The last order of the Choripetalæ is the Umbellifloræ, so called from the small flowers being arranged in umbels. The flowers are usually inconspicuous, usually with the parts in 4's or 5's. The flowers are always epigynous.

There are three families: Araliaceæ, Umbelliferæ, and Cornaceæ. The Araliaceæ (Fig. 437, F) are represented by species of Aralia (Spikenard, Ginseng, etc.) and the Ivy (Hedera).

Umbelliferæ. - The second family, Umbelliferæ, is an extremely natural one, and especially developed in the temperate parts of the northern hemisphere. The structure of the flowers (Fig. 437, B) is extremely uniform, and the compound leaves, with sheathing bases, are almost equally characteristic. 
The Cornaceæ are mostly shrubs or trees with flowers in umbels, which are sometimes compact and surrounded by showy bracts as in Cornus florida.

\section{The Families of Choripetalæ (Engler and Prantl, 9)}

\section{Order I. Centrospermæ}

Suborder Chenopodiineæ

Homochlamyd. bracteoid perianth...... $\left\{\begin{array}{c}\text { fam. 1. Chenopodiaceæ } \\ \text { " 2. Amarantaceæ }\end{array}\right.$

Suborder Phytolaccineæ

\begin{tabular}{|c|c|}
\hline 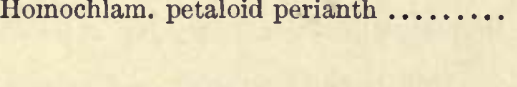 & $\begin{array}{l}\text { fam. 1. Nyctaginaceæ } \\
\text { " 2. Batidaceæ } \\
\text { "6 3. Cynocrambaceæ }\end{array}$ \\
\hline $\begin{array}{l}\text { Mostly homochlam. ........... } \\
\text { Homo- or heterochlam........ }\end{array}$ & $\begin{array}{l}\text { “ 4. Phytolaccaceæ } \\
\text { "5. Aizoaceæ }\end{array}$ \\
\hline
\end{tabular}

Suborder Portulacineæ

Heterochlam................... $\left\{\begin{array}{c}\text { fam. 1. Portulacaceæ } \\ \text { " 2. Basellaceæ }\end{array}\right.$

Suborder Caryophyllineæ

fam. 1. Caryophyllaceæ

Order II. Ranales

Suborder Nymphæineæ

Homo-heterochlam. .............. fam. 1. Nyınphæaceæ

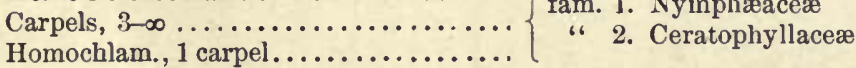

Homochlam., 1 carpel............... Suborder Trochodendrine

Flowers naked, spirocyclic.......... fam. 1. Trochodendraceæ

Suborder Ranunculineæ

Flowers spiral or cyclic............ fam. 1. Ranunculaceæ

Homo-heterochlam., cyclic-homochlam.. " 2. Lardizabalaceæ

Cyclic, bomo-heterochlam........... “ 3 . Berberidace

Cyclic ...................... "4. Menispermaceæ

Suborder Magnoliineæ
Acyclic - Spirocyclic.............. fam. 1. Magnoliaceæ
Acyclic ................. " 2. Calycanthaceæ
Cyclic ................. " " 3 . Lactoridaceæ
Spirocyclic, mostly heterochlam........ “ 4. Anonaceæ
Cyclic-homochlam............... " 5 . Myristicaceæ
Spirocyclic, homo- or heterochlam. ..... “ “ 6. Goinortegaceæ
Cyclic-homochlam................. “ 7 . Monimiaceæ
Epigynous ................ $\quad$ “ 9. Hernandiaceæ 


\section{Order III. Rhœadales} fam. 1. Papaveraceæ

Suborder Capparidineæ

Four sepals or more............. $\left\{\begin{aligned} & \text { fam. } 1 . \text { Cruciferæ } \\ & \text { " } \text { 2. Tovariaceæ } \\ & \text { " } \text { 3. Capparidaceæ }\end{aligned}\right.$ Suborder Resedineæ

Spirocyclic fam. 1. Resedaceæ

Suborder Moringineæ

Cyclic-homochlam............... fam. 1. Moringaceæ

\section{Order IV. Sarraceniales}

Spirocyclic

Cyclic-homochlam.

Heterochlam. fam. 1. Sarraceniaceæ

" 2. Nepenthaceæ

" 3. Droseraceæ

Order V. Rosales

Suborder Podostemonineæ

Submersed aquatics............... $\left\{\begin{array}{c}\text { fam. 1. Podostemonaceæ } \\ \text { 66. Hydrostachyaceæ }\end{array}\right.$

Suborder Saxifragineæ

Flowers isomerous fam. 1. Crassulaceæ

Flowers isomerous, tubular leaves...... Gynœc. mostly oligomerous........... Resin-ducts

"2. Cephalotaceæ

"3. Saxifragaceæ

"4. Pittosporaceæ

Flowers opposite or whorled, stipules... 4 "5. Brunelliaceæ

Flowers naked.

"6. Cunoniaceæ

"7. Myrothamnaceæ

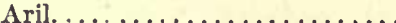

"8. Bruniaceæ

Homo-heterochlam. or naked

“ 9. Hamamelidaceæ

Suborder Rosineæ

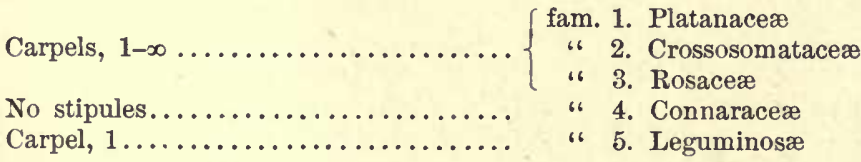

\section{Order VI. Geraniales}

Flowers heterochlam., seldom apetalous,
actinomorphic, or rarely zygomorphic.
Stamens usually twice as many as
petals, no secretory cells............. $\begin{cases}\text { fam. 1. Geraniaceæ } \\ \text { " } \\ \text { " } & \text { 3. Oxalidaceæ Tropœolaceæ } \\ \text { " } & \text { 4. Linaceæ } \\ \text { " } & \text { 6. Humiriaceæ } \\ \text { " } & \text { 7. Zygthroxylaceæ }\end{cases}$




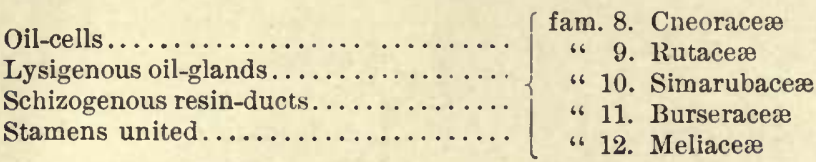

Suborder Malpighiineæ

Stamens, 5-10 fam. 1. Malpighiaceæ

Stamen, $1 \ldots \ldots \ldots \ldots \ldots \ldots \ldots \ldots \ldots \ldots\{$ " 2. Trigoniaceæ

"3. Vochysiaceæ

Suborder Polygalineæ

Actinomorphic ................ fam. 1. Tremandraceæ

Zygomorphic ................ " 2. Polygalaceæ

Suborder Dichapetalineæ

Perianth segments free or united..... fam. 1. Dichapetalaceæ

Flowèrs diclinous, much reduced, ovary of 3 carpels

Suborder Tricoccæ

fam. 1. Euphorbiaceæ

fam. of doubtful affinity, Callitrichaceæ

\section{Order VII. Sapindales (Celastrales)}

Homochlam.

Suborder Buxineæ

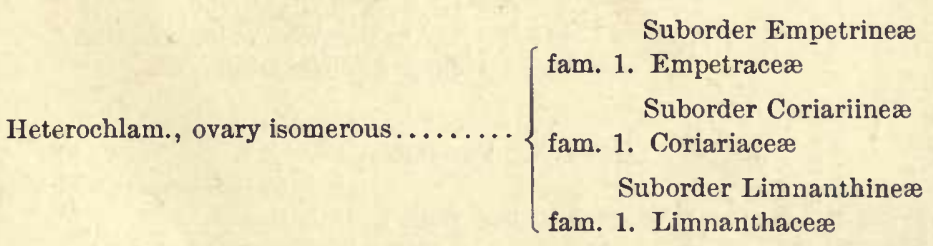

Heterochlam., rarely apetalous, resin-

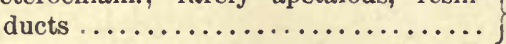

No resin-ducts

Flowers actinomorphic

66 zygomorphic
Suborder Anacardiineæ fam. 1: Anacardiaceæ

Suborder Celastrineæ

fam. 1. Cyrillaceæ

" 2. P'entaphyalaceæ

"6 3. Corynocarpaceæ

"4. Aquifoliaceæ

"6. Celastraceæ

“6 6, Hippocrateaceæ

“7. Stackhousiaceæ

“ 8. Staphyleaceæ

Suborder Icacinineæ

fam. 1. Icacinaceæ

Suborder Sapindineæ

fam. 1. Aceraceæ

" 2. Hippocastanaceæ

"3. Sapindaceæ 
Flowers zygomorphic

Suborder Sabiineæ

fam. 1. Sabiaceæ

Suborder Melianthineæ

fam. 1. Melianthaceæ

Suborder Balsaminineæ

fam. 1. Balsaminaceæ

\section{Order VIII. Rhamnales}

fam. 1. Rhamnaceæ

" 2. Vitaceæ

\section{Order IX. Malvales}

Suborder Elæocarpineæ

Anthers bilocular, opening by pores.... fam. 1. Elæocarpaceæ

Suborder Chlænineæ

Anthers bilocular, opening by clefts..... fam. 1. Chlænaceæ

Suborder Malvineæ

Anthers bilocular

fam. 1. Gonystylaceæ

Anthers multilocular.

" 2. Tiliaceæ

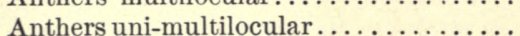

Anthers bilocular.

" 3. Malvaceæ

" 4. Bombacaceæ

" 5. Sterculiaceæ

Suborder Scytopetalineæ

fam. 1. Scytopetalaceæ

\section{Order X. Parietales}

Flowers sometimes spiral and apocarpous

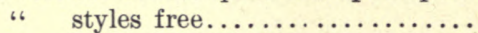

" " " united ................

" " " sessile................

" " " " united $\ldots \ldots \ldots \ldots \ldots \ldots \ldots$

" " " separate..............

" " " free or united.

" " united

Endosperm starchy or absent, placenta central

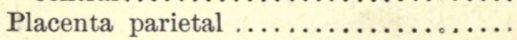

" basal or central

Endosperm oily

Endosperm starchy
Suborder Theineæ

fam. 1. Dilleniaceæ

" 2. Eucryphiaceæ

" 3. Ochnaceæ

" 4. Caryocaraceæ

“ 5. Marcgraviaceæ

"6 6uiinaceæ

“ 7. Theaceæ (Ternstrœmiaceæ)

" 8. Guttiferæ

“ 9. Dipterocarpaceæ

Suborder Tamaricineæ

" 10. Elatinaceæ

" 11. Frankeniaceæ

" 12. Tamaricaceæ

Suborder Fouquierineæ

fam. 1. Fouquieriaceæ

Suborder Cistineæ

fam. 1. Cistaceæ

2. Bixaceæ 
Suborder Cochlospermineæ

Endosperm oily and proteid........... $\left\{\begin{array}{cc}\text { fam. 1. Cochlospermaceæ } & \text { 2. Kœberliniaceæ }\end{array}\right.$

Suborder Flacourtiineæ

Flowers actinomorphic

"6 " or zygomorphic.

Petals eligulate

Petals ligulate, convolute............. Gynophore

" a a

Sympetalous

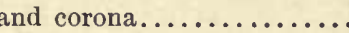

Sympetalous, milky juice.

Hermaphrodite, abundant endosperm...

Diclinous, scanty endosperm

Diclinous, endosperm absent

\section{Order XI. Opuntiales}

Flowers homocyclic, heterochlamyd.; sepals, petals, and stamens $\infty$; epigynous carpels, $4-\infty$; succulents

\section{Order XII. Myrtifloræ}

Ovary 4-celled, endosperm.

" " 6 endosperm absent...... " 3 to 5 celled

Carpels, 2

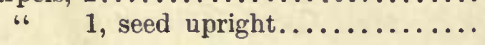

Vascular bundle, bicollateral, ovary, partly superior.................

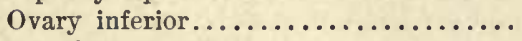

Bundles collateral.................

Hypogynous or epigynous............

Ovary 1-celled...................

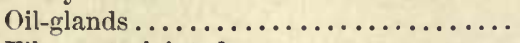

Filaments jointed.................

Ovary 1 to 6 celled. fam. 1. Cactaceæ

fam. 1. Canellaceæ (Winteranaceæ)

" 2. Violaceæ

"3. Flacourtiaceæ

"4. Stachyuraceæ

“ 5. Turneraceæ

“ 6. Malesherbiaceæ

“ 7. Passifloraceæ

"6. Achariaceæ

Suborder Papayineæ

fam. 1. Caricaceæ

Suborder Loasineæ

fam. 1. Loasaceæ

Suborder Datiscineæ

Suborder Begoniineæ

Suborder Ancistrocladineæ

fam. 1. Ancistrocladaceæ

\section{Suborder Thymelæineæ}

fam. 1. Geissolomaceæ

" 2. Penæaceæ

" 3. Oliniaceæ

“4. Thymelæaceæ

“5. Elæagnaceæ

Suborder Myrtineæ

fam. 1. Lythraceæ

"2. Sonneratiaceæ (Blattiaceæ)

"3. Punicaceæ

"4. Lecythidaceæ

" 5. Rhizophoracer

"6. Combretaceæ

“ 7. Myrtaceæ

" 8. Melastomaceæ

“ 9. Onagraceæ 
Suborder Halorrhagidineæ

Endosperm present, aquatics......... fam. 1. Halorrhagidaceæ

Suborder Cynomoriineæ

fam. 1. Cynomoriaceæ

\section{Order XIII. Umbellifloræ}

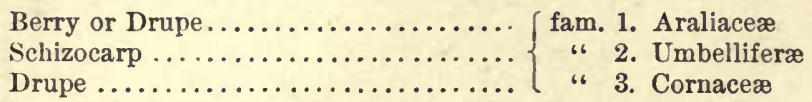

\section{SERIES III. SYMPETALE (METACHLAMYDEF)}

The Sympetalæ are, as a whole, the most specialized of the Dicoty. ledons, and therefore stand at the head of the vegetable kingdom. While the number of species is much greater than that of the Choripetalæ, they are much more uniform in type, and there are fewer orders and families.

The most characteristic feature is the marked sympetaly of all but a very small number of them. While a small number, like Monotropa and Clethra, have the petals nearly or quite free, in most of them the corolla is tubular or cup-shaped.

In none of the Sympetalæ is the number of stamens more than twice that of the corolla-segments, and frequently the number of stamens is less than the corolla-lobes; due to a suppression of one or more of them. This reduction in the number of stamens is usually combined with another indication of specialization; i.e. very marked zygomorphy.

Both hypogynous and epigynous flowers are met with. In some of the simpler types (Ericaceæ, Primulaceæ) the carpels equal in number the petals, and these forms are sometimes known as the "Isocarpæ," in distinction from the "Anisocarpæ," in which the number of carpels is less than the petals.

The Sympetalæ are especially developed in the Tropics, where many of them become trees. Relatively few of them attain treelike proportions in more temperate regions. Of native trees belonging to the Sympetalæ, may be mentioned species of Catalpa, Arbutus, Arctostaphylos, Diospyros, and Fraxinus.

Whether the Sympetalæ form a homogeneous group, or whether sympetaly has been developed in more than one series, is not certain. It has been suggested that the isocarpous forms constitute one series, perhaps related to the Centrospermæ, and that from these have been derived the Tubifloræ. A second series, derived from the Umbellifloræ, is assumed to have given rise to the Rubiales and Campanulatæ. 
Of the Sympetalæ, one family, the Compositæ, is the largest one of all plants, comprising over ten thousand species.

Classification. - The Sympetalæ fall into eight orders.
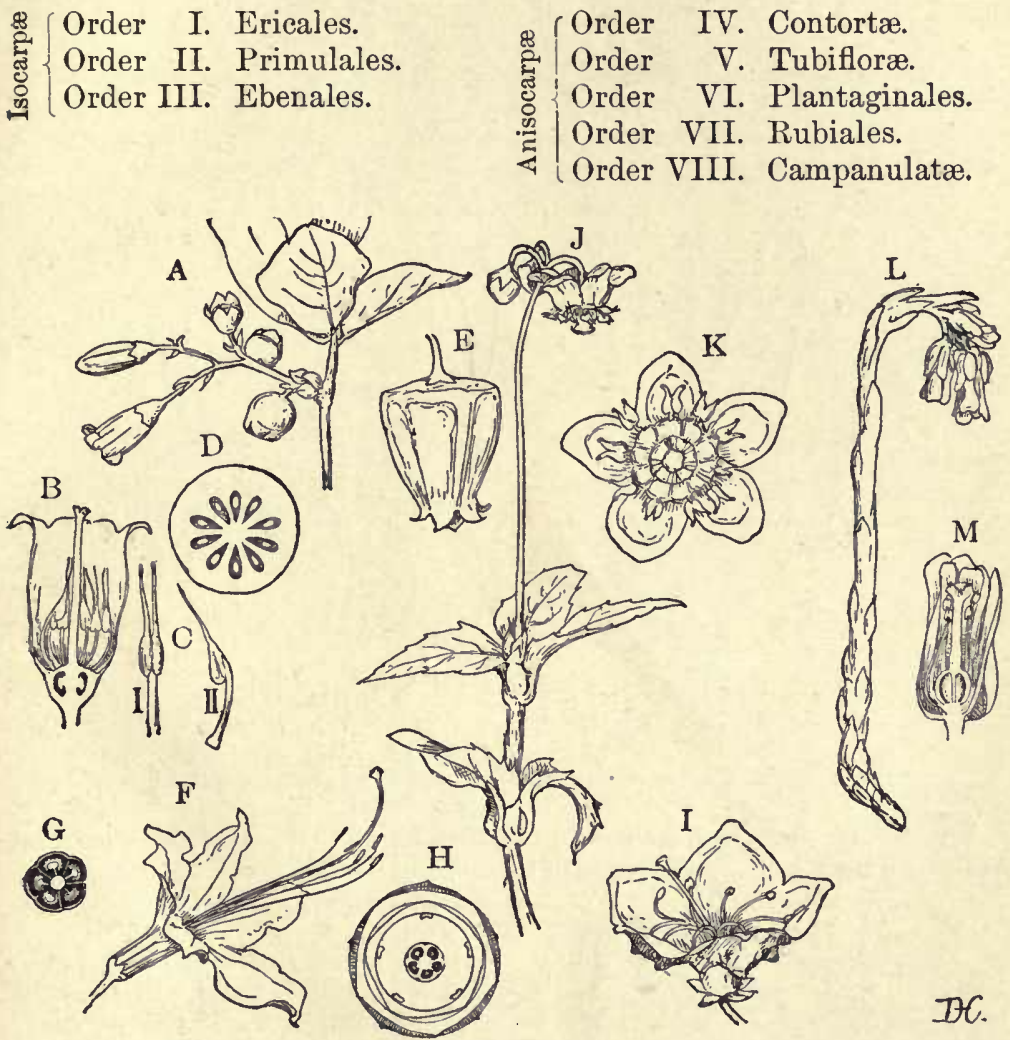

Fig. 438.-A-D, Gaylussacia resinosa. E, Oxydendrum arboreum, single flower, enlarged. $F-H$, Azalea canescens. I, Kalmia latifolia. $J, K$, Chimaphila maculata. L, M, Monotropa hypopitys.

\section{Order I. Ericales}

The Ericales comprise many forms of temperate regions, largely shrubs, but some of them herbaceous forms. Trees are rare, but sometimes they are trees of considerable size, like the beautiful Madroño (Arbutus Menziesii) of the Pacific Coast.

In a few cases, e.g. Clethra, Monotropa, the petals are quite free, but, more commonly, sympetaly is very complete (Fig. 438). The flowers are always isocarpous, except in the family Diapensacer, and the stamens the same in number, or twice as many as the carpels. Both hypogynous and epigynous flowers are found. 


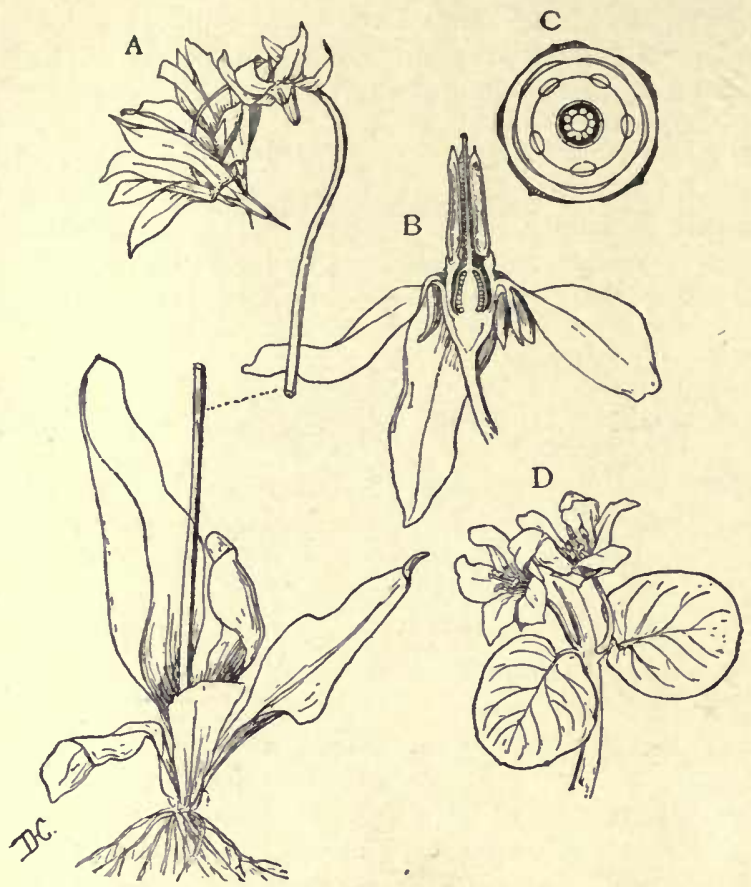

Fig. 439. - A-c', Lodecatheon Meadia. D, Lysimachia nummularia.

Many of the Ericales have flowers of great beauty, like the Rhododendrons, Azaleas, Kalmias, etc., and several of them furnish edible fruits, e.g. Cranberry,

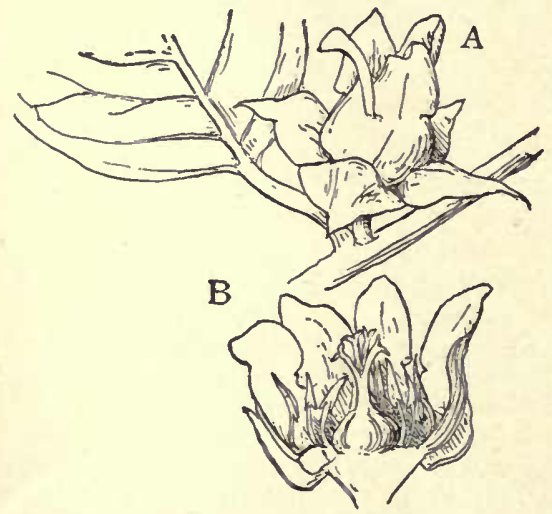

Fia. 440.-Diospyros Virginiana.

Huckleberry, Wintergreen, and others.

A number of forms are chlorophylless saprophytes. Of these the Indian Pipe (Monotropa uniflora) and the Snow-plant (Sarcodes sanguinea) are striking examples. The Ericales comprise six fanilies - Clethraceæ, Pyrolaceæ, Lennoaceæ, Ericaceæ, Epacridaceæ, Diapensaceæ.

\section{Order II. Primulales}

The second order of the Sympetalæ contains three isocarpous families, Myrsinaceæ, Primulaceæ, and Plumbaginaceæ. The most important is the Primulaceæ, which includes the beautiful Primroses (Primula) as well as several other characteristic 
genera-e.g. Lysimachia (Fig. 439, D), Dodecatheon (Fig. 439, A), Cyclamen, and others. Plumbago Capensis is sometimes cultivated.

\section{Order III. Ebenales}

The third order of isocarpous Sympetalæ comprises, for the most part, only tropical forms. The Persimmon (Diospyros Virginiana, Fig. 440) represents the Ebony family, Ebenaceæ. The other native representatives of the order are confined to a few southern types-e.g. species of Bumelia, Symplocos, and Styrax.

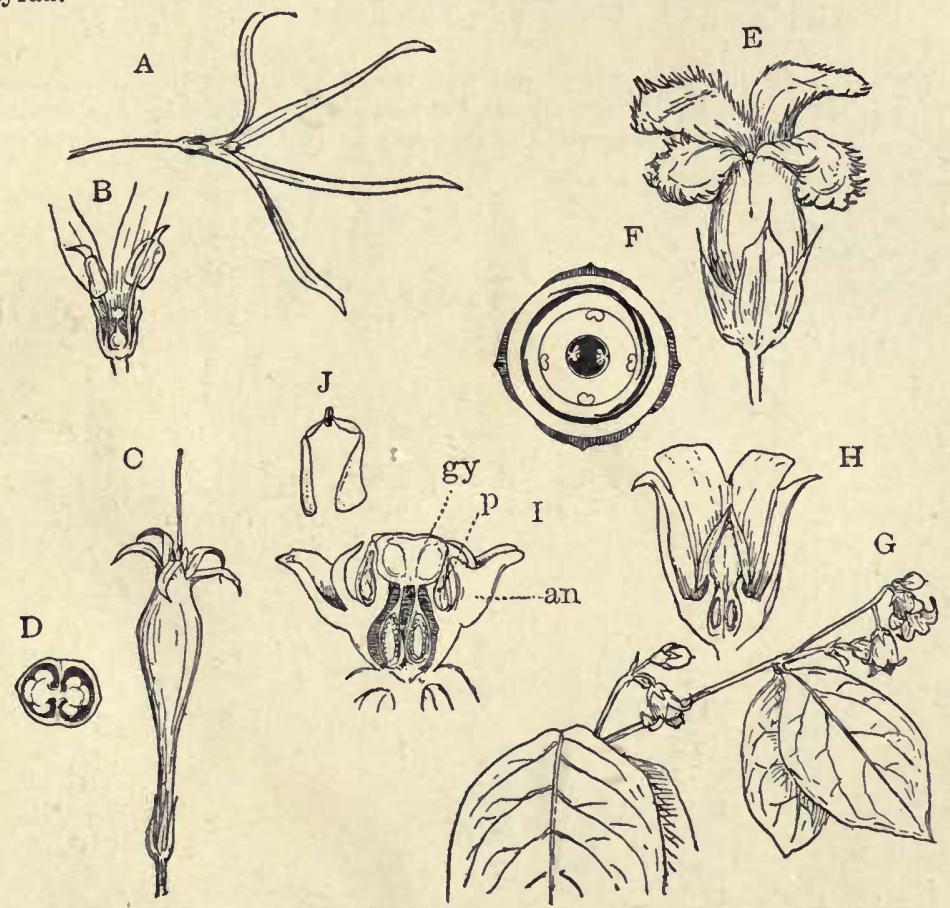

Frg. 441.- $A, B$, Chionanthus Virginica. $C, D$, Spigeliu Marylandica. $E, F$, Gentiana crinita. $G, H$, Apocynum androsæmifolium. $I, J$, Asclepias Cornuti. $I$, section of the flower. $J$, pollinia. an, stamens; $p$, pollinium; $g y$, stigma.

\section{Order IV. Contortæ}

The Contortæ include several families of anisocarpic forms, all having the carpels two in number, and united into a compound ovary, which may be superior, but is more often inferior. The flowers are commonly pentamerous, but may have the parts varying from two to six. The corolla lobes are commonly convolute in the bud (hence the name), but may be valvate or imbricate. Fxceptionally, the flowers may have the petals free, or even wanting. The flowers are almost always actinomorphic, and often very showy. The plants are eitler 
herbaceous (most Gentianaceæ) or woody shrubs or trees-e.g. Oleander, Ash, Lilac. The most important families are the following:-Oleaceæ, the Olive family, including the Lilac (Syringa), Ash (Fraxinus), Jasmine. The Gentianaceæ are all herbaceous plants, of which the various species of Gentian (Fig. $441, \mathrm{E})$ are familiar examples. The Apocynacere include the species of Dogbane (Apocynum) and various showy cultivated plants - e.g. Oleander (Nerium), Periwinkle (Vinca). The last family, Asclepiadaceæ, is represented by several native species of Asclepias, or Milkweed, some of them showy plants well worthy of cultivation.

\section{Order V. Tubifloræ}

The order Tubifloræ is a large one and includes many familiar sympetalous flowers. The flowers may be isocarpous, but more commonly, as in the Contortæ, the number of carpels is reduced, and this may be true of the stamens as well,
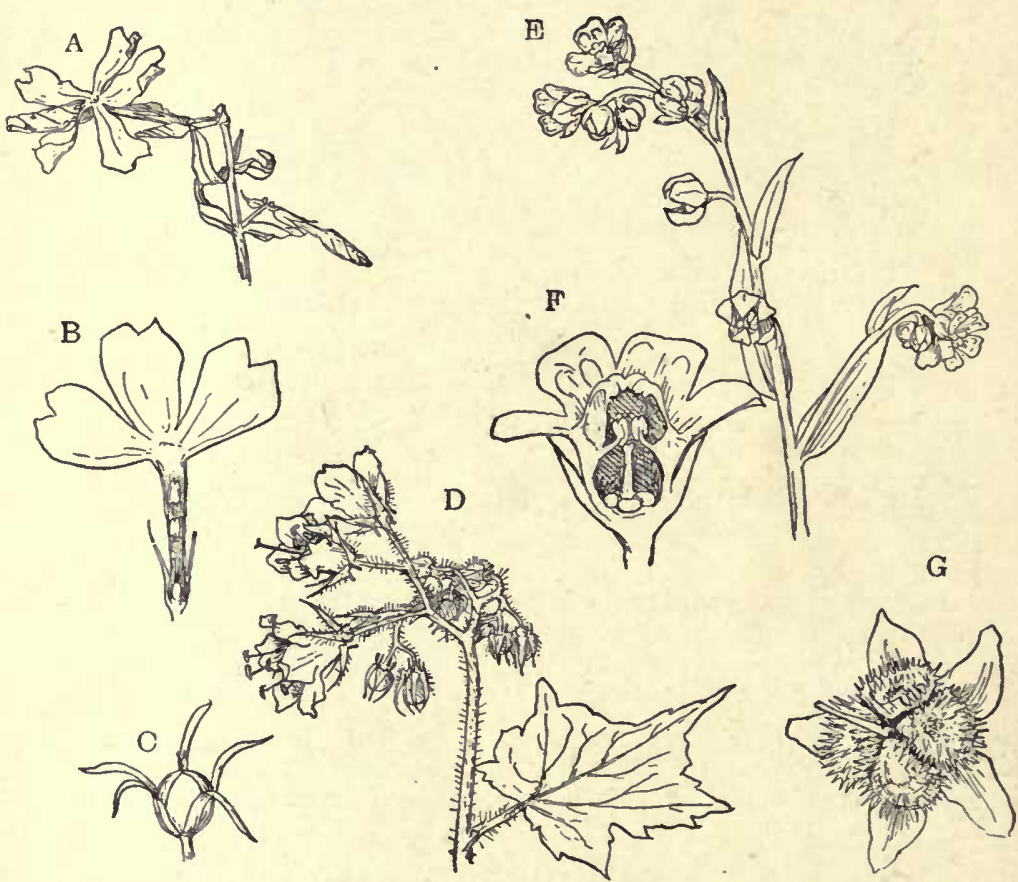

Fig. 442.-A-C, Phlox divaricata. D, Hydrophyllum appendiculatum. $E-G, C y n o g l o s s u m$ officinale.

especially in such zygomorphic types as the Labiatæ and Scrophulariacez. The corolla is always markedly sympetalous, and the tubular corolla, characteristic of most of them, gives the name to the order. The stamens are always inserted on the corolla-tube, and the flowers are in all cases hypogynous. The more primitive types (Fig. 442) - e.g. Convolvulus, Phlox, Hydrophyllum - 
have actinomorphic flowers, which often have the petals convolute in the bud. In the more specialized types, such as the Labiatæ (Fig. 443), Scrophtalariaceæ (Fig. 444), and Bignoniacex (Fig. 444, A), the flowers are markedly zygomorphic, and the number of stamens is reduced to four or two. Sometimes, as in Verbascum (Fig. 444, D) and Pentstemon, a more or less developed fifth stamen is present.

Most of the Tubifloræ are herbaceous plants, but there are woody plants among them, sometimes trees (Catalpa, Paulownia), sometimes woody climbers (Bignonia, Tecoma).

'I'wo families are especially well developed in the western United States, viz. : Polemoniaceæ and Hydrophyllaceæ. To the first belong many beautiful species

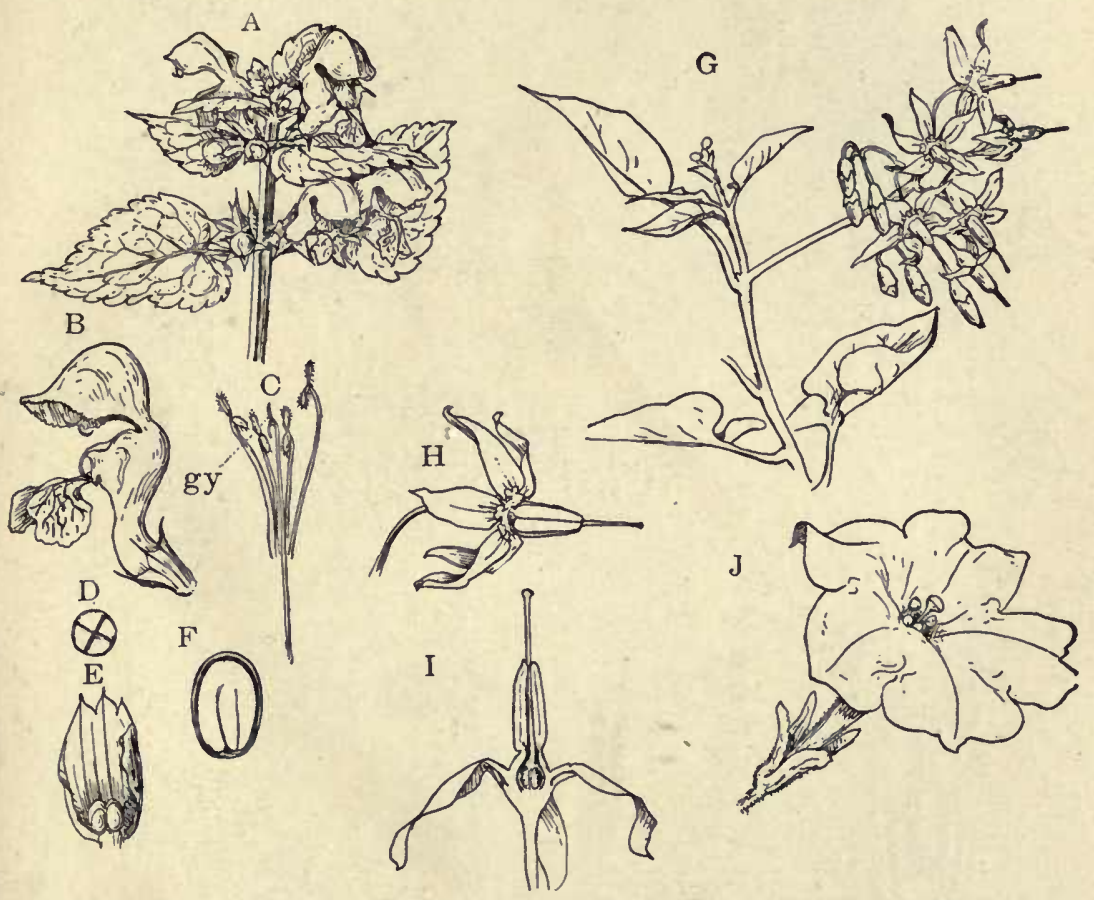

Fig. 443. - A-F, Lamium aıbum. G-I, Solanum dulcamara. J, Petunia sp.

of Phlox and Gilia, to the latter the characteristic genera, Nemophila, Phacelia, and Hydrophyllum (Fig. 442, D).

Belonging to the Tubifloræ is the very peculiar family Lentibulariaceæ, represented by Utricularia and Pinguicula, characteristic carnivorous plants. Parasitic forms are not uncommon, e.g. Orobanche, Cuscuta.

\section{Order VI. Plantaginales}

The order Plantaginales contains a single family, Plantaginaceæ. The flowers are inconspicuous, actinomorphic, and may be either hermaphrodite or diclinous. 
They are probably reduced forms. The principal genus is Plantago, represented by the common Plantain ( $P$. major) and several other weedy species.

\section{Order VII. Rubiales}

There are five families included in the Rubiales. The family Rubiaceæ is the most important, and contains many genera and species, especially in the Tropics. Of the common genera there may be mentioned Houstonia (Fig. 445, A), Galium, and Cephalanthus. The Honeysuckle family (Caprifoliaceæ) includes various

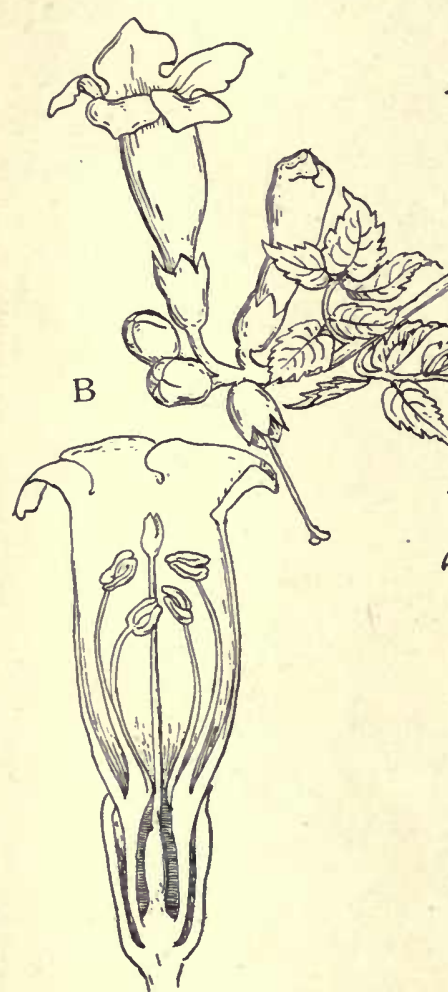

A

Fig. 444. - A-C', Tecoma radicans. D, Verbascum blattaria, showing the rudimentary fifth stamen, st. $E-G$, Veronica scutellata.

species of Honeysuckle (Lonicera), Viburnum, Elder (Sambucus), Snow-berry (Symphoricarpus), some other shrubs and small trees. The beautiful little Twin-flower (Linnæa) also belongs to the Caprifoliaceæ.

To the Valerianaceæ belong the species of Valerian (Fig. 445, G), and to the Dipsacaceæ, the Teazel (Dipsacus) and the garden Scabious.

The Rubiaceæ, and some of the Caprifoliacer, have actinomorphic flowers; in the others zygomorphy is very pronounced, and may be (Valerian) accompanied by a reduction in the number of stamens. The flowers are always epigynous. 


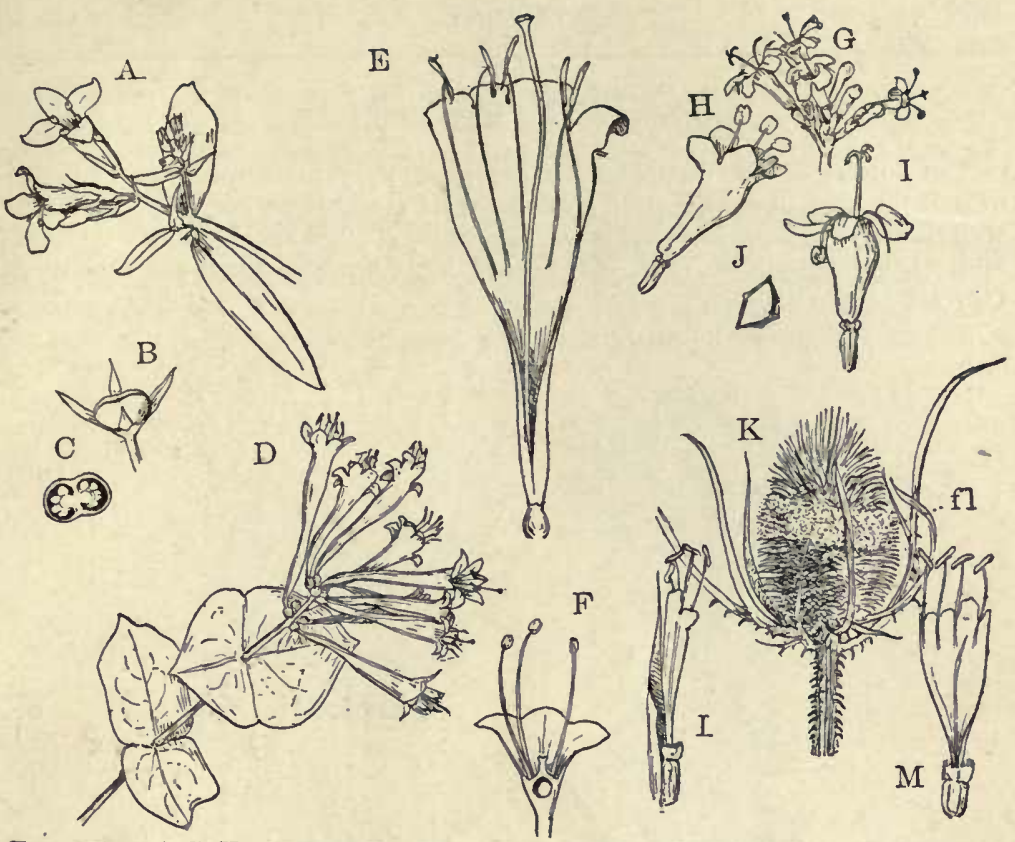

Fig. 445. - A-C, Houstonia purpurea. $\quad D, E$, Lonicera sempervirens. $F$, Viburnum $s p$. $G-J$, Valeriana officinalis; $H$, young, $I$, older, flower. $J$, section of ovary, showing two abortive earpels. $K-M$, Dipsacus sylvestris.

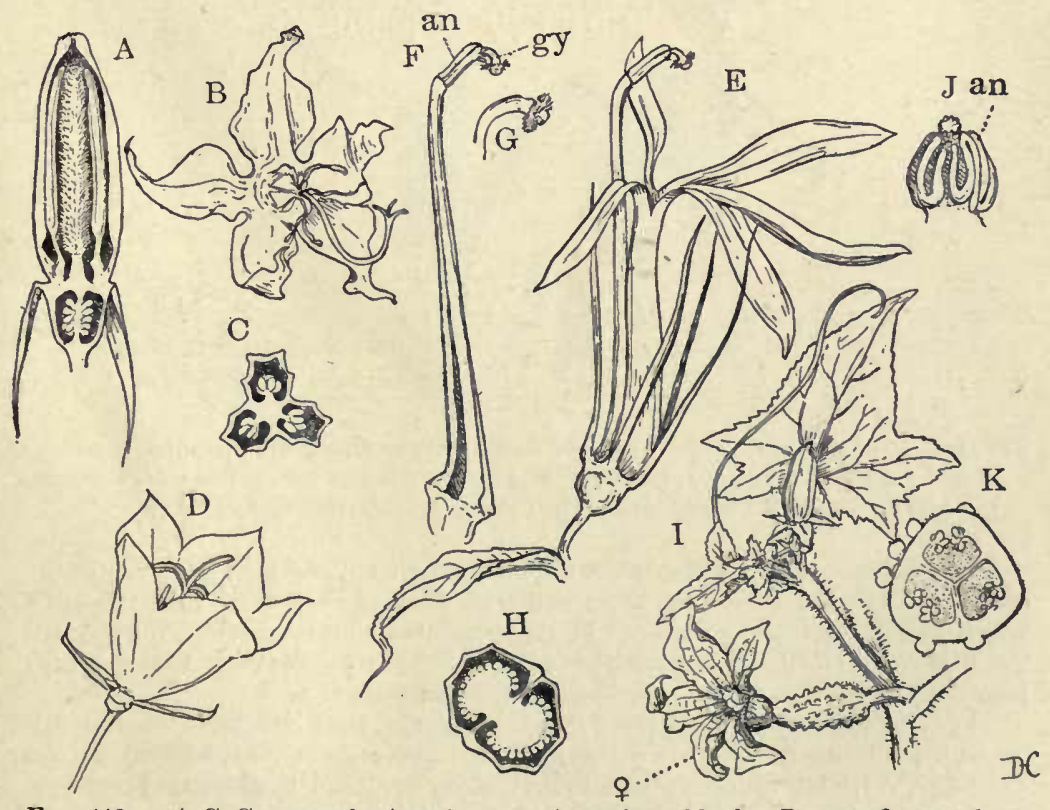

Fig. 446. - $A-C$, Campanula Americana. $A$, section of bud. $B$, open flower, showing the withered stamens and receptive stigma. D, C. Carpatica. E-H, Lobelic cardinalis. $I-K$, Cucumis sativus. 


\section{Order VIII. Campanulatæ}

The flowers of the Campanulatæ are typically pentamerous, with inferior ovary composed of a single one-ovuled carpel (Compositæ) or compound, and with numerous ovules in each loculus of the ovary. The lower families - Cucurbitaceæ, Campanulaceæ (Fig. 446) - have large flowers, which are sometimes (Cucurbitaceæ) diclinous.

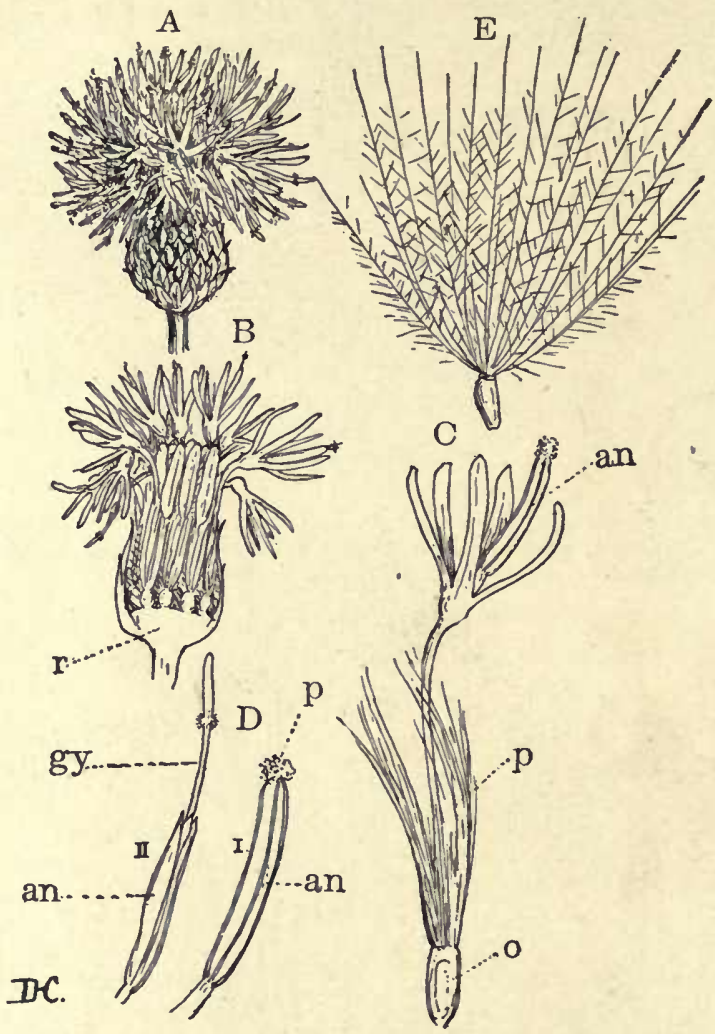

Fig. 447. - Cirsium arvense. $C$, single flower, enlarged, showing pappus, $p$, ovary, $o$, and stamens, an. $D, I$, stamens from a young flower; $p$, pollen; $I I$, stamens, $a n$, and pistil, $g y$, from an older flower. $E$, ripe fruit, showing downy pappus.

Compositæ. - In the Compositæ, the most important and highest family of the order, the individual flowers are small, but they are collected into "heads" which are often rendered showy by the petal-like split corollas of some or all the flowers. The head is surrounded by a series of closely set bracts, which form a calyx-like involucre about the inflorescence.

The Compositæ are often divided into two families, the Ligulatæ (Cichoriaceæ), in which all the flowers are alike and provided with a strap-shaped corolla (Fig. 447, A), and which possess milky juice; and the Compositæ proper, in 
which either all the flowers are tubular and alike (Cirsium, Cynara), or the marginal or ray flowers are provided with showy flattened corollas, while the centre of the inflorescence is occupied by the tubular "disk-florets" (Fig. 448, D).

The Compositæ are cosmopolitan, and are admirably adapted to survive in the struggle for existence. Innumerable devices for distributing the seeds have been developed, and render some of the Compositre the most troublesome of weeds. The winged fruits of Dandelions and Thistles, and the burs of Burdock and Clotbur, may be cited as examples of these devices for distributing the fruits.
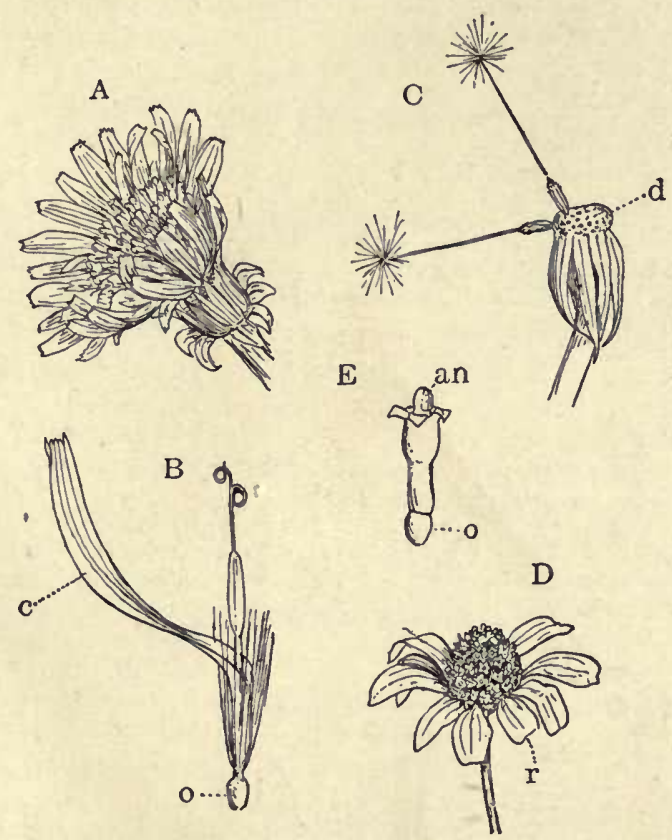

Fig.448.,-A-C, Taraxacum officinale ; c, strap-shaped corolla ; o, ovary ; $d$, receptacle with two fruits attached. $D, E$, Anthemis cotula; $r$, ray-florets. $E$, single diskfloret; an, stamens.

\section{Classification of Sympetalæ}

\section{Series III. Metachlamydee (Sympetal}

\section{Order I. Ericales}

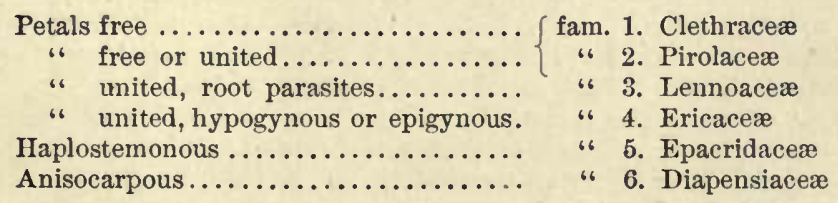


Order II. Primulales

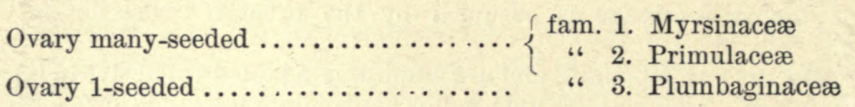

Order III. Ebenales
Seeds erect....................... fam. 1. Sapotaceæ
Suborder Diospyrineæ
Suborder Sapotineæ
Seeds pendulous.$\ldots \ldots \ldots \ldots \ldots \ldots \ldots\left\{\begin{aligned} \text { fam. } & \text { 1. Ebenaceæ } \\ \text { " } & \text { 2. Styracaceæ } \\ \text { " } & \text { 3. Symplocaceæ }\end{aligned}\right.$

Order IV. Contortæ

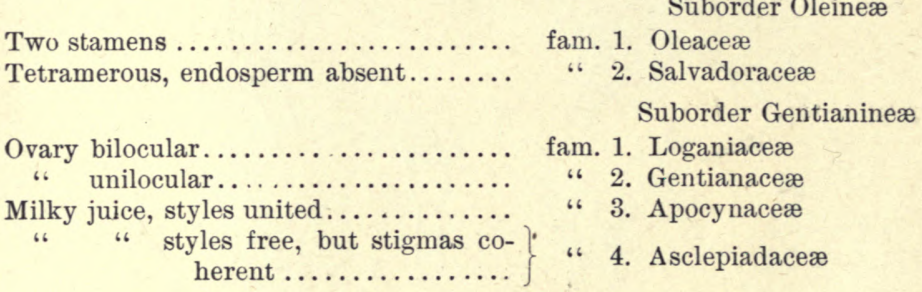

\section{Order V. Tubifloræ}

Suborder Convolvulineæ

Corolla folded, convolute; flowers ac- (fam. 1. Convolvulaceæ

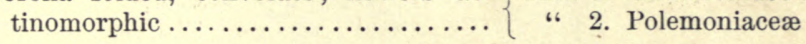

Suborder Borraginineæ

Fruit a capsule, nutlet, or pod, flowers $\int$ fam. 1. Hydrophyllaceæ actinomorphic ................ " 2. Borraginaceæ

Suborder Verbenineæ

Zygomorphic, fruit drupe or pod...... fam. 1. Verbenaceæ

Zygomorphic, fruit nutlet........... " 2. Labiatæ

Suborder Solanineæ

Fruit separating into nutlets.......... fam. 1. Nolanaceæ

Fruit a berry or capsule............ " 2. Solanaceæ

Ovary bilocular, endosperm.......... " " 3. Scrophulariaceæ

" " " no endosperm........ " " 4. Bignoniaceæ

" " "

" quadrilocular ............... " 6. Martyniaceæ

Parasites .................... " 7. ()robanchaceæ

Stamens normal ................ " 8. Gesneriaceæ

" with S-shaped thecæ........ " " 9. Columelliaceæ

Ovary unilocular, placenta central..... " 10. Lentibulariaceæ

" unilocular or bilocular, 1-seeded. " " 11. Globulariaceæ 


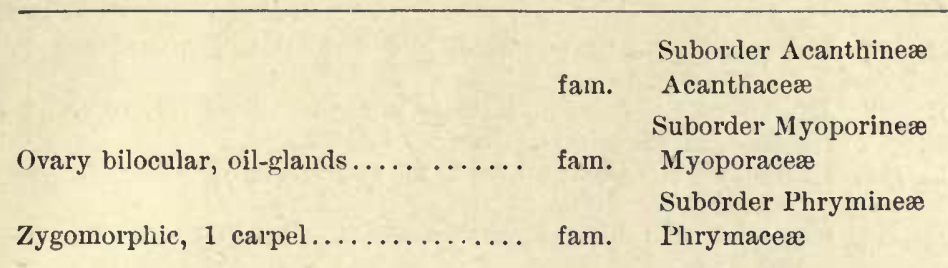

Order VI. Plantaginales

fam. Plantaginaceæ

\section{Order VII. Rubiales}

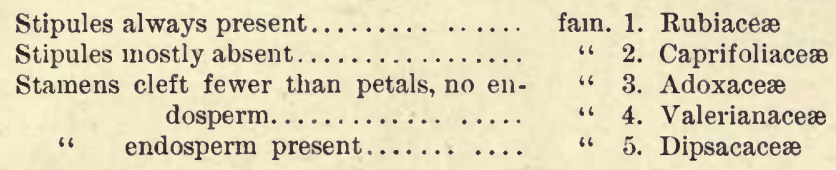

\section{Order VIII. Campanulatæ}

\begin{tabular}{|c|c|c|}
\hline ine & fam. & $\begin{array}{l}\text { Suborder Cucurbitineæ } \\
\text { Cucurbitaceæ }\end{array}$ \\
\hline & & Suborder Campanulineæ \\
\hline thers free, milk vessel & fam & 1. Can \\
\hline mens free, or united with & & 2. Goodeniaceæ \\
\hline 2, united with gynæciuun & “" & 3. Candolleaceæ \\
\hline united, endosperm. & " & 4. Calyceraceæ \\
\hline " no endosperm......... & "، & 5. Compositæ \\
\hline
\end{tabular}

\section{BIBLIOGRAPHY}

'67-'79. 1. Baillon, H. Histoire des Plantes. Paris, 1867-1879.

'87. 2. 1) Bary, A. Comparative A natomy. Oxford, 1887.

'62-'80. 3. Benthain, G., and Hooker, J. D. Genera l'lantarum. London, 1862-1880.

'76-'80. 4. Brewer, W. H., and Watson, S. Botany of California (Geological Survey of California). 1876-1880.

'96-'98. 5. Britton, N. L., and Brown, A. Botany of the Northern United States. New York, 1896-1898.

'97. 6. Chapman, A. W. Flora of the Southern United States. 3d ed. Cambridge, 1897 .

'85. 7. Coulter, J. M. Botany of the Rocky Mountains. New York, 1885.

75. 8. Eichler. Blüthendiagramme. Leipzig, 1875.

'94-'01. 9. Engler and Prantl. Natïrliche Pflanzenfamilien. Th. III-1V. 1894-1901. The separate families of Dicotyledons are discussed, with bibliography of each group.

'79. 10. Gray, A. Structural Botany. New York, 1879.

'89. 11. - Manual of Botany. 6th ed. New York, 1889. 
'88. 12. Gray, A. Synoptical Flora of North America, The Gamopetalæ. Washington, 1888.

'01. 13. Jepson, W. L. Flora of Middle California. Berkeley, 1901.

'92. 14. Lubbock, J. Seedlings. New York, 1892.

'00. 15. Merrell, W. D. Contribution to the Life-history of Silphium. Bot. Gaz., XXIX. 1900.

'91-'98. 16. Sargent, C. S. Silva of North America. Boston and New York. 1891-1898.

'98. 17. Strasburger, E. Text-book of Botany. 1898.

'97. 18. — Bot. Practicum. Jena, 1897.

'91. 19. Van Tieghem, Ph. Traité de Botanique. Paris, 1891.

'95. 20. Warming, E. W. Handbook of Systematic Botany. London, 1895.

21. Wood, A. Class-book of Botany. 


\section{CHAPTER XIII}

\section{PHYSIOLOGY}

\section{Nutrition, Respiration, Growth, and Irritability}

THE chemical elements necessary for the normal growth of plants have already been referred to (Chap. I), and we have now to consider how these are taken in and used by the plant. In ordinary plant-tissues, the presence of a cell-wall precludes the entrance into the cells of solid particles. Where the protoplast is not enclosed by a cell-wall, as in the plasmodia of the Slime-moulds, solid bodies are ingested, and, within the cells of ordinary plants, solid bodies, like starch-granules or crystals, may be taken up from the vacuoles by the protoplast, or ejected into the cell-sap. It is necessary, however, before such bodies can be incorporated into the substance of the protoplast, that they should be dissolved, and all the food of the plant, before it can be used, must be in soluble form.

\section{FOOD OF PLANTS}

All food substances enter the plant in the form of compounds of greater or less complexity. These undergo many complicated changes, destructive and constructive, before they are incorporated into the living substance of the protoplasm. It is these changes which comprise the nutritive processes of the plant, the destruction of certain substances being necessary to furnish the energy as well as the chemical constituents required for the constructive activity. Fuel as a source of energy is as necessary for the living engine as it is for the mechanical one. Two principal types of products result from these activities: (1) plastic substances, or those which are used to build up the tissues and are capable of various transformations, like starch, and various proteids; (2) aplastic substances, which, once formed, are incapable of further transformations - i.e. crystals of calcium oxalate, wood, resin, cork, and the other dead substances of the plant. Another important group of compounds, which do not themselves take part in building up protoplasm, are the enzymes, 
which are of the greatest importance in rendering other substances

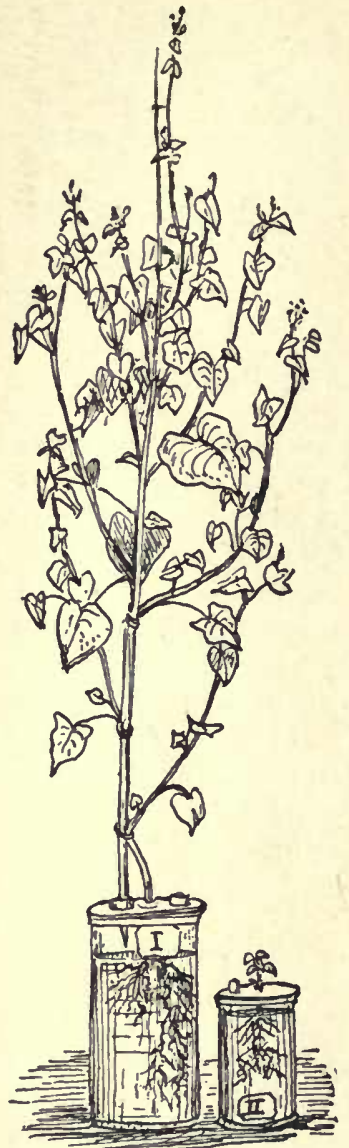

Fia. 449. - Two water-cultures of Buckwheat. II has no potassium. (After NоввE.) available for the construction of protoplasm.

\section{Sources of Food}

Terrestrial green plants derive their food in part from the air, in the form of $\mathrm{CO}_{2}$, and partly from the earth, from which they absorb water, holding in solution the other substances which the plant needs for its growth.

In all the higher plants, except a few submersed aquatics, the entrance of $\mathrm{CO}_{2}$ into the plant takes place ordinarily through the stomata. A typical stoma consists of the two guard-cells (Fig. 450) which, unlike the other epidermal cells, contain numerous chromatophores. The wall of the guard-cells is much thickened above and below, so that the guard-cells might be compared to two short rubber tubes, closed at the ends, and with the wall thicker on one side, the thickened wall being in contact. When the guard-cells are strongly turgescent, the thinner part of the wall naturally stretches more strongly than the thicker inner face, which is forced to assume a more or less concave position, leaving the open pore between the guard-cells, communicating with the intercellular spaces. It is probable that the presence of chlorophyll in the guard-cells is associated with the production of osmotically active substances in these cells, the result of photosynthesis, as the stomata open normally only in the light.

It has been recently demonstrated by Blackman, Escombe, Brown, and Stahl, that it is only through the stomata that the gases enter the plant. It has also been shown that the absorption of $\mathrm{CO}_{2}$ increases rapidly as the size of the openings decreases, and that the amount taken up by an absorbing surface completely exposed is no greater than when the same surface is covered by a perforated plate. Thus it has been demonstrated that the diffusion of atmospheric $\mathrm{CO}_{2}$ through an aperture $1 \mathrm{~mm}$. in diameter is 40 times greater than the rate of absorption of a free alkaline 
surface of equal area. In this way it is possible to explain the power of leaves to absorb so large a quantity of $\mathrm{CO}_{2}$ from the atmosphere, where it is present in such small proportion.

\section{Imbibition}

The imbibition of water is one of the most marked characteristics of organized substances, and plays a most important part in the nutrition of protoplasm. In their normal condition, both cell-wall and protoplasm contain very large amounts of imbibed water, the amount in living protoplasm being so great as to render the protoplasm of semifluid consistency. The mechanism of transport for the food substances from cell to cell within the plant is directly dependent upon this property of imbibition, though other factors are connected with the transfer of watery solutions through the special conducting tissues.

A

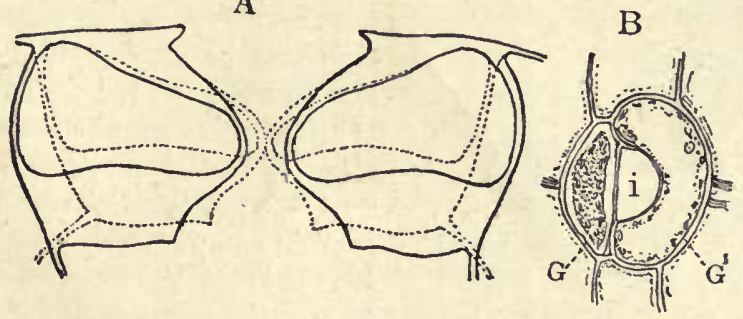

FIG. 450. - $A$, diagram to show the mechanism of the opening of a stoma in Helleborus $s p$., seen in transverse section. The heavy lines indicate the position of the guard-cells when open, the dotted lines the position when closed. (After ScHwENDENER.) $B$, Galtonia candicans, surface. view of a stoma, showing a turgid guard-cell, $G^{1}$, and a guard-cell contracted by plasmolysis, $G$. (After LEITGEB.)

\section{The Mechanics of Absorption}

The cellulose cell-wall, when saturated with water, is more permeable than the plasma-membranes lying within it. In the typical cell there are two of the latter, the ectoplasm, or bounding layer immediately within the cell-wall, and the endoplasm, which bounds the central vacuole. That these plasma-membranes, in the living cell, are less permeable than the cell-wall, is shown in cells with colored cell-sap, like those in the Beet root, or in many red leaves. The pigment is dissolved in the cell-sap, and does not pass through the bounding membranes so long as the cell is alive. If the protoplast is killed, however, the colored cell-sap diffuses through the dead plasma-membranes, and then readily passes out of the cell through the cell-wall. So, also, if the cell is plasmolyzed with a 
colored solution, the latter may pass readily through the cell-wall, without being able to penetrate through the plasma-membranes into the cell-sap, so long as the cell is alive.

The cell-wall, being much more coherent, as well as more permeable, than the plasma-membranes, allows a high degree of osmotic pressure within the cell, without being ruptured. This would be impossible in a cell provided only with a plasma-membrane. The

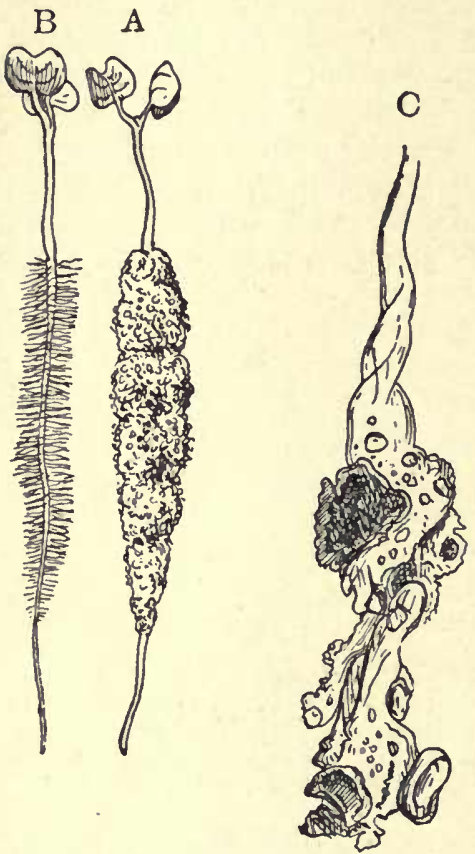

Fig. 451. $-A, B$, seedlings of Mustard. In $B$, the root-hairs are freed from the adherent soil-particles, covering the root in $A$. $C$, root-hair of wheat, much magnified, showing the adhesion of the soil-particles. (After SACHs.) tically continuous, and, in growing parts, the young cells are in a condition of perpetual turgor.

In unicellular plants, or plants like the simpler Algæ, composed of but a few similar cells, every cell can absorb water containing the dissolved food substances, whether solids or gases. In the higher plants, especially terrestrial plants, there are special absorptive organs, roots, and root-hairs developed, whose principal function is the imbibition of food solutions from the earth. The cells directly 
concerned in this are the surface cells of young rootlets, and espeeially the root-hairs (Fig. 451). In these plants, where the exposed cells are euticularized to prevent loss of water into the air, the entrance of oxygen and carbon-dioxide is provided for by the development of stomata, which communicate with the intercellular spaces. The gases, entering the latter, are brought into contact with the thin-walled cells, by which they are absorbed. Water and gases may be excreted by the active cells into these intercellular spaces, and from them be discharged through the stomata. The impermeability of the cell-wall is usually the result of a change of the cellulose into cork or some similar substance. This change may completely destroy its power of imbibition. Such changes are associated with the exposure of the cells to a dry atmosphere, and are universally found in the epidermal cells and outer cortex of terrestrial plants, and on wounded parts exposed to the air.

The living protoplasmic membranes are not only less permeable than the cellulose wall, but their permeability is probably much more variable. This is functionally important for retaining within the cell certain dissolved substances which would otherwise pass out and be lost. It also allows for the accumulation of large amounts of soluble matter from very dilute solutions, such as exist normally in the soil or water when the plant is growing. The accumulation of substances within the cell-sap is easily shown by exposing absorbent cells (e.g. root-hairs of various water-plants, cells of Vallisneria, etc.) to a dilute solution of methylene blue, which soon accumulates so that the cell-sap is deeply colored. Sometimes a precipitate is formed, or it is otherwise rendered incapable of passing out of the cell.

Oils, fats, etc., are capable of passing through membranes, probably in the form of a fine emulsion, i.e. in excessively fine drops mixed with water.

\section{Translocation of Substances}

While in unicellular or filamentous water-plants the substances absorbed may be at once used by the cells into which they pass, in the higher plants this is usually not the case, and the substances must be carried long distances before they are used. While diosmosis is the principal means by which solutions pass through living tissues, it must be remembered that there are frequently protoplasmic connections between the cells, which must play some part in the transfer of substances from one cell to another, as well as being the means of transmitting stimuli of different kinds. Occasionally, as in sieve-tubes, the communications between the cells are sufficiently evident, and permit of the passage of small solid bodies, such as starch-grains, as well as solutions. 
In the "vascular" plants, i.e. Pteridophytes and Spermatophytes, the vascular bundles are of great importance in the transportation of food solutions. The woody tissue, composed principally of dead tracheary elements, is the main channel for the passage of water absorbed by the roots. The mechanism of those movements is still imperfectly understood, but the capillary action of the empty tubular tracheæ is doubtless of great importance in the process.

\section{Movements of Gases}

Certain gaseous substances, notably free oxygen and carbon-dioxide, are of the first importance in the life of normal plants. It is true that certain anaërobic Bacteria are independent of free oxygen, and plants without chlorophyll do not use $\mathrm{CO}_{2}$, but in all green plants both of these gases are necessary.

The entrance of gases into the cell is always by diosmosis, and can only take place through the cell-wall, when it is saturated with water. Through a dry membrane no diffusion of the gases occurs. In submersed aquatic plants the gases, like other substances held in solution in the water, may enter through the outer membrane of the superficial cells. In aerial organs, however, like the leaves of land plants, the euticularized membranes of the epidermal cells prevent the entrance of gases, which must first enter the intercellular spaces through the stomata.

\section{Osmotic Pressure in the Cell}

The substances dissolved in the cell-sap attract water osmotically with a force proportioned to the differences in concentration of the cell-sap and the solution outside the cell. If the amount of osmotically active substances in the cell-sap remains nnchanged, either by not escaping from the cell, or by being constantly renewed, there will be a continuous absorption of water, and the volnme of the cell will tend to increase proportionally. The internal pressure will force the protoplast into close contact with the cell-wall, and the latter, heing more resistant than the protoplast, will become stretched and tense. This tense condition of the cell is known as "Turgescence"; the stretching force which produces it, "Turgor." This pressure within the cell may anount to five to ten atmospheres, and under certain conditions, as when pollen-spores are placed in water, the pressure is sufficient to burst the cell-membrane. The turgescence of the normal cells gives the plant-tissues their elasticity and firmness, and when the turgescence is diminished by loss of water from the cells, as happens, for instance, when plants are exposed to the hot sun, the drooping of the leaves, or "wilting," is the result of this diminished 
turgescence of the cells of which the wilted organs are composed. A similar loss of turgescence may be produced by placing the tissues in a solution denser than the cell-sap-e.g. transferring a plant from fresh to salt water.

Osmotic pressure in the cell, indicated by its turgescence, is necessary in order that the cell may perform its functions. The transfer of most plants into a concentrated solution, as from fresh to salt water, results in death, unless this is done gradually enough for the plant to accustom itself to the changed conditions, and to change the concentration of the cell-sap so as to maintain the normal osmotic pressure. The maintenance of turgor may be due to the osmotically very active salts of organic acids developed in the cell in the processes of nutrition.

\section{Transpiration}

All aerial organs are subject to a certain loss of water by evaporation. This loss of water is one of the most important factors in the change of turgor in the cells, and is therefore of much importance in regulating the movements of water within the plant.

The gases circulate freely through the intercellular spaces, and are absorbed by the cells where they are needed. Thus within the green tissue, or mesophyll, of ordinary leaves, the cells are irregular in form, leaving large spaces between, through which the $\mathrm{CO}_{2}$ circulates, to be taken up by the green cells which used it in the process of photosynthesis. Where air spaces are large and communicate with the external atmosphere, the pressure within the plant is practically the same as outside; but in the closed cavities, like those in the tracheids, the pressure may be quite different, and these differences in pressure must affect the movements of the gases. Certain external conditions, such as changes in temperature and barometric pressure, and movements of the plant body due to wind, all affect more or less strongly the movements of both gases and liquids within the plant.

Special Aerating Organs. - Sometimes special organs for aeration are developed. Such are the lenticels upon the twigs of many woody plants, and the curious outgrowths ("knees") developed from the submersed roots of the Cypress (Taxodium).

\section{Absorption of Water}

In vascular plants the water is generally absorbed from the earth by the roots, the root-hairs being usually the direct absorbent organs. There are exceptions to this, however, and some plants can absorb water from the atmosphere. This is the case in Gymnogramme triangularis, a common Californian Fern, whose leaves 
become completely dried up during the summer, but absorb water and again become active with the first rains. A similar absorption by aerial organs is seen in many Liverworts and Mosses; and some epiphytic plants, like Bromeliaceæ, often have upon their leaves scales which absorb water from the atmosphere. So also the aerial roots of many Orchids can absorb atmospheric moisture.

The absorption of water by ordinary foliage leaves is usually prevented by the character of the epidermis, which often has a waxy coating that sheds water. Fluid water is necessary to restore turgidity to the cells, but sometimes this may be obtained by the condeusation of watery vapor from a saturated atmosphere. This is seen in such Lichens as Ramalina reticulata.

\section{Properties of the Soil}

The soil serves a twofold purpose to the roots. It is both a means of attachment to hold the plant in place, and the source of the greater part of the food of the plant aside from carbon-dioxide. Air is present in the interstices of the soil, and this is necessary for the healthy action of the roots.

Ordinary soils consist of two kinds of elements, both of which are important to the plant. The first of these comprise mineral detritus, sand, clay, etc., but these are mixed with a certain amount of organic matter - humus - derived largely from the decomposition of vegetable tissues. The humus seems to be especially important in the retention of moisture in the soil.

The root-hairs push through the interstices in the earth, and apply themselves very closely to the solid particles composing the soil. These particles are, in ordinary soils, invested with a film of water, and the air in the spaces is also saturated with water. Soils abounding in humus are more retentive of moisture than those which have little or no humus.

Within the soil, through the agency of water, or water combined with $\mathrm{CO}_{2}$, the soluble food constituents of the soil are dissolved, and thereby put in such form that they may be absorbed by the roots. The water in the soil is a weak saline solution, containing substances washed into the soil by rain, or formed from the dissolving of the solid mineral particles of the soil. The decomposition of the humus, through the agency of Fungi or Bacteria, also furnishes some food materials. The great importance of certain Bacteria in fitting the soil for the growth of the higher plants has only recently been fully recognized.

The roots themselves, by the evolution of $\mathrm{CO}_{2}$, and in a lesser degree by excreting various organic acids and salts of these acids, exercise a solvent action upon the mineral constituents in the soil. 
If the roots of a plant are brought in contact with a polished marble slab, a pattern of the growing roots will be etched upon this by means of $\mathrm{CO}_{2}$ given off by the roots. Lichens and other low plants growing upon rocks are able to decompose the rock, probably by the excretion of organic acids similar to those developed by the roots of higher plants.

The disintegration of rocks, such as lava, begins through the agency of Bacteria, and the lower green forms, like the Schizophyceæ, and possibly Green Algæ. Lichens soon form, if conditions are suitable, and their action is very marked in the disintegration of rock. The detritus is soon sufficient for the establishment of Mosses, etc., which continue the process until Ferns and other vascular plants can effect lodgment in the soil formed by the mixture of decomposed rock and humus derived from the decay of the dead tissues of the Lichens and Mosses. These changes go on most rapidly in the Tropics, and are studied to especial advantage on the fresh lava masses thrown out by such large volcanoes as Mauna Loa in Hawaii, and some of those in the Malayan Archipelago. 'The reëstablishment of the flora, following the terrific eruption of Krakatoa in the Strait of Sunda, in 1883, has been studied by several botanists, especially Treub.

In the preparation of ordinary soils for the use of the higher plants, the nitrifying Bacteria are of the first importance. Darwin has also called attention to the rôle played by earth-worms in the production of vegetable mould. The latter are probably of much greater importance in England than in the hotter and dryer regions of most parts of America.

\section{The Root System}

The roots in most vascular plants form a complicated system of branches which ramify widely through the soil, and serve both to anchor the plant firmly, and to act as absorbent agents. Only the younger parts of the root act in the latter capacity, and the root-hairs are the direct absorbents in most instances. The great number of root hairs developed from the younger parts of the roots increases enormously the absorbent surface. 'The root-hairs apply themselves closely to the solid soil particles, and exhibit extraordinary powers of absorption in wresting from the soil the moisture which is so tenaciously held by the soil particles. It is the root-hairs, also, which excrete the solvents of the soil components.

\section{MOVEMENTS OF WATER}

In ordinary terrestrial plants the water amounts to 60 per cent to 90 per cent of their total weight. In order to maintain this the 
plant must absorb from the soil the amount necessary to restore the loss caused by evaporation, as well as the water needed to convey the food constituents.

The factors concerned in the movements of water within the plantbody are extremely complicated, and are still not entirely understood. In plants composed of simple cellular tissue, like most Algæ, the movements are due, probably, entirely to osmotic agencies; but in large complicated plants, like trees, where the water must all be absorbed from the soil, such cell-to-cell transfer is not sufficiently rapid to provide for the transmission from the roots to the actively transpiring leaves at the summit. Hence in such plants special conducting tissues are developed - the vascular bundles. It is the xylem, or woody part of the vascular bundles, which is preëminently the water-conducting tissue (Hadrom).

The water osmotically absorbed by the root-hairs passes into the vascular bundle of the root, whence it is conveyed, mainly through the agency of the tracheary elements, and probably partly by capillarity, to the tracheary tissue of the stem-bundles, and thence to the transpiring leaves. The loss of water in the latter, due to evaporation, is, of course, an important factor in regulating the upward current of water from the roots.

The evaporation from the aerial parts of a plant in clear, hot weather is very great, and the disturbance of the equilibrium thus caused must powerfully affect the movement of water in the stem. But just how far the upward movement is a purely mechanical one through the dead tracheary tissue, and to what extent it is influenced by the living cells adjacent, is still undetermined.

The tracheary tissue is not all equally active in the transport of water. In large woody stems, such as the trunks of trees in which "heart-wood" is present, it is only the outer wood which is active. 'The heart-wood is alnost entirely without importance in the conduction of water.

That the vascular bundles are the principal channels of conduction for solutions can be shown by a simple experiment. If the cut end of a flower-stalk of a white flower, like a Narcissus or Lily, is placed in a colored solution, such as a watery solution of indigo, carmine, eosin, etc., the dye is carried rapidly up the stalk, and follows the delicate veins in the white floral leaves, in which the veins are clearly traced by the colored fluid. In species of Cucurbita, the ascent of the fluid may be at a rate of six metres in an hour.

\section{Transpiration}

The amount of water lost by transpiration varies with the temperature and air-moisture. While a small amount of water may be 
lost from the stem and branches, it is the leaves which are the principal transpiring organs, and their size and number are regulated by the air conditions to which the plant is exposed. The reduction of the evaporating surface, or the checking of evaporation by the development of a thick cuticle, or other protective devices, characteristic of xerophytic plants, are associated with the checking of evaporation. So perfectly is this accomplished in such plants as a Cactus, for example, that a cut branch may lie exposed to the hot sun for weeks without losing all its water.

Sometimes in hot weather transpiration is so active that for a time the absorption of water by the roots is insufficient to supply the loss of water by transpiration, and the plant becomes wilted. So soon as the evaporation is checked, as is the case at night, the wilted organs become turgid again.

The temperature of the soil is of importance in the absorption of water by the roothairs, which become inactive below a certain temperature. Thus the Tobacco plant, even when there is abundant moisture in the soil, wilts if the soiltemperature falls below $2-4^{\circ} \mathrm{C}$.

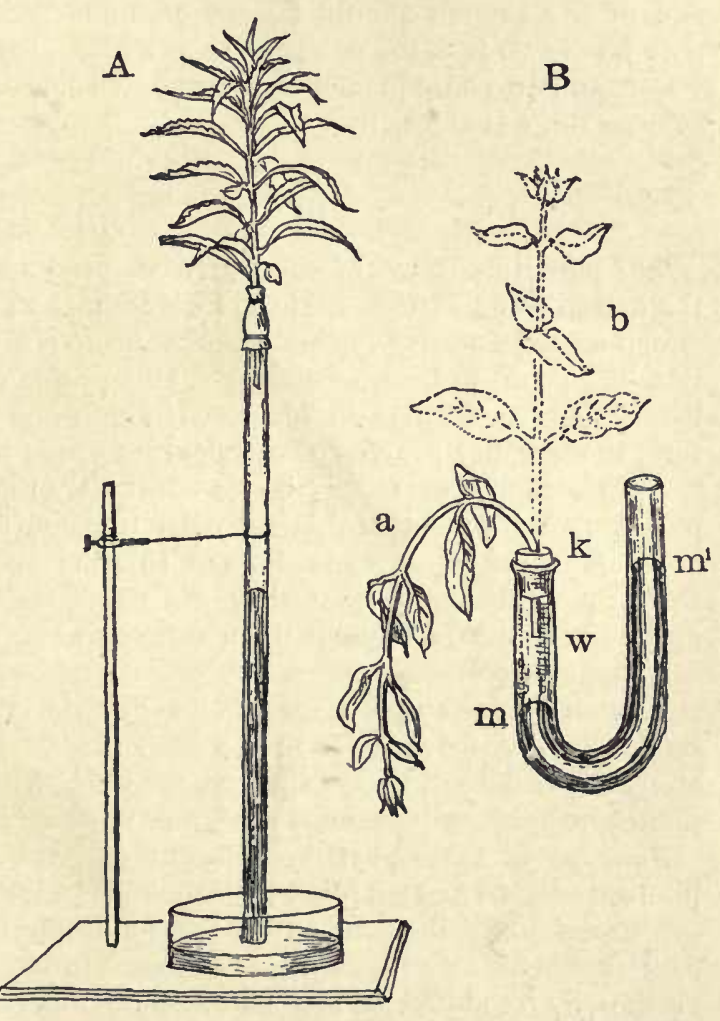

Fig. 452. - $A$, apparatus to show lifting force of a transpiring branch, indicated by the column of mercury in the tube, the upper part being filled with water into which the cut end of the branch descends. $B$, Apparatus showing a wilted branch $a$, restored to its normal condition, $b$, by water forced into it by the pressure of the column of mercury, $m, m^{1}$. ( $A$, after MAcDougal; $B$, after SACHS.)

The amount of water which is lost by transpiration may be very considerable. A strong Sunflower plant, on a warn day, will lose 
over a litre of water by evaporation, and a large tree several hundred times as much.

The great force exercised by a transpiring plant can be readily shown by cutting off a vigorous leafy branch and fitting it air-tight into a glass tube filled with water (Fig. 452). If the lower end of the tube be placed in a vessel containing mercury, the latter will rise to a considerable height in the tube, by the force of suction resulting from the active transpiration from the leaves of the shoot. In making this experiment, as well as others of a similar kind, the end of the branch should be cut off under water, as otherwise air may be drawn into the cut tracheids, which prevents the entrance of water, and in consequence the leaves wither, as they are unable to replace the water lost by evaporation.

\section{PHOTOSYNTHESIS}

The most important of the nutritive processes in green plants is the assimilation of $\mathrm{CO}_{2}$. This is accomplished by the chloroplasts, which absorb and use the energy of the sun's rays. With the exception of a small number of Bacteria, this power of photosynthesis, as it is called, is peculiar to plants with chlorophyll, which are, therefore, the primary sources of carbonaceous food for all organisms.

As the supply of $\mathrm{CO}_{2}$ is being constantly renewed in the atmosphere, plants do not ordinarily need to shift their position in the quest for food, as animals do, and this may be the explanation of their immobility. Where they are destitute of chlorophyll, they must, like animals, depend upon other plants (or animals) for their sustenance.

A necessary condition for photosynthesis is a certain amount of light, varying in intensity in different cases. Artificial light, espe- . cially electric light, is also efficient for photosynthesis, but ordinarily photosynthesis is dependent upon sunlight.

Function of Chlorophyll. - The chloroplasts, or green chromatophores, are the organs directly concerned in the process of photosynthesis. The importance of the chlorophyll in the chloroplast consists apparently in its absorbing certain light-rays, whose energy is thereby rendered available to the plant. Faint traces of the assimilation of $\mathrm{CO}_{2}$ have been detected in etiolated chromatophores.

Accessory Pigments. - Where the chlorophyll is accompanied by other pigments, the latter are supposed to influence the rays of light absorbed by the chromatophores. Thus in the Brown Algæ, which as a rule are floating plants, and are often completely exposed at low tide, it may be that the brown pigment (phycophæin) serves as a screen which cuts off excessive light, while the red pigment (phycoerythrin), found in the Rhodophyceæ, which as a rule live in deeper 
water, permits the absorption of certain rays in addition to those absorbed by the chlorophyll. The ability of the purple Bacteria to assimilate $\mathrm{CO}_{2}$ is due possibly to the presence of a small amount of chlorophyll mixed with the purple pigment.

Even isolated chloroplasts can perform photosynthesis, provided they are kept in a proper nutrient medium. This is demonstrated by the evolution of oxygen from such isolated chloroplasts, in the presence of light, indicated by the accumulation of aërobic Bacteria about them.

An excess of free oxygen is given off during photosynthesis, and this is popularly confused with respiration, which is a very different process. This evolution of oxygen ceases at once when the plant is removed from the light.

The evolution of gas from actively assimilating plants is easily seen in any submersed aquatic exposed to the light. The foamy appearance of floating masses of Spirogyra and other similar Algæ is due to the accumulation of bubbles of oxygen given off during the process of photosynthesis. If the bubbles of gas given off by a submersed water plant are collected and tested, they are found to be nearly pure oxygen.

A very delicate test for oxygen was devised by Engelmann. Certain Bacteria have a great affinity for oxygen, and will collect at a point in the water where the amount of oxygen is greatest. Hence, if green cells are present, the collecting of Bacteria at different places indicates very accurately the relative amount of oxygen given off.

The light-rays which are most effective in assimilation of plants exposed to ordinary light are the red, orange, and yellow. Where there are accessory pigments, the maximum assimilation occurs at a different place in the spectrum. 'Thus, in the Rhodophyceæ, it is the green rays which are most efficacious ; and in the purple Bacteria, the infra-red rays. The red or purple pigments, in these forms, act as sensitizers, which permit the chloroplast to use rays otherwise unavailable for photosynthesis.

While the chlorophyll is the important agent in photosynthesis, the yellow pigment, xanthophyll, always associated with it, also takes part in the process, though much more feebly than the chlorophyll. 'This is indicated by the feeble assimilating power of etiolated chromatophores.

\section{The Products of Photosynthesis}

What the first steps in the process of photosynthesis are we do not know, although it is probable that the early steps in the decomposition of $\mathrm{CO}_{2}$ and water, and the first-formed products, are the same in all cases. The first visible product is usually starch; but 
sometimes no starch can be detected in the chloroplast, and instead we find oil or sugar. It is not impossible that the first substance developed is sugar, or there may, perhaps, be a simple carbohydrate like formic-aldehyde ( $\mathrm{COH})$, which is volatile and may be easily converted into more easily detected compounds, as sugar, starch, or oil.

The development of starch in the chloroplast under the influence of light can readily be observed in many green plants. Within a short time after the green cells are exposed to the light, the presence of small starch grains may be detected in the chloroplasts. Removed from the light, the starch soon disappears, A very simple demonstration of the development of large quantities of starch as the result of photosynthesis is seen, where part of a leaf is covered with an opaque shield, such as a strip of tinfoil, and the leaf then exposed to the sun for several hours. If the leaf is now treated with alcohol until the chlorophyll is entirely removed, and then with a solution of iodine, the portion of the leaf exposed to the sunshine will show the characteristic blue colom, indicating the presence of starch in the cells,

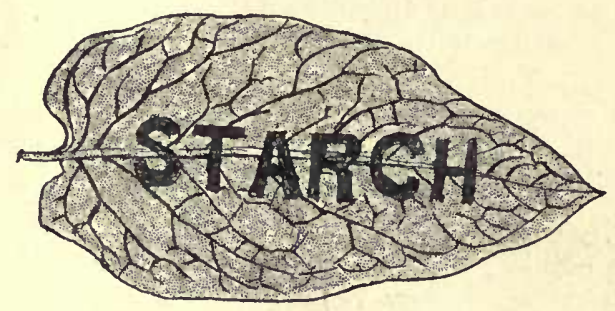

Fig. 453. - A leaf which has been covered with a stencil plate, leaving only the letters exposed to the action of light. The leaf has had the chlorophyll removed with alcohol, and was then treated with iodine, which colors the exposed parts blue, on account of the starch formed there, under the action of light. (After Prefrer.) while the shaded portion will simply show the yellow tinge of the protoplasm stained by the iodine solution (Fig. 453).

While sugar may replace starch as the first demonstrable product of carbon-dioxide-assimilation, it is not entirely certain that the oil found in the chloroplasts of some of the Monocotyledons (e.g. Strelitzia), and in such Algæ as

Vaucheria, is the direct product of photosynthesis, and the same is true of the proteids generally assumed to be of this nature. In these cases, it is not impossible that the cytoplasm may also be concerned in the manufacture of these substances, which perhaps arise chemosynthetically, and not photosynthetically.

No carbon compounds, except $\mathrm{CO}_{2}$, can be assimilated photosynthetically. In certain succulent plants (Crassulaceæ, Cacti, etc.) there are produced in darkness certain organic acids (malic, isomalic, and oxalic). These are decomposed when the plants are exposed to the light, with evolution of oxygen and production of starch, but this does not seem to be a case of true photosynthesis. The process seems to be an oxidation of the acid, with a corresponding evolution of $\mathrm{CO}_{2}$, which is then made use of by the chloroplast. This peculiar- 
ity of these succulents is associated with the small development of the stomata, and the consequent difficulty of procuring a sufficient supply of $\mathrm{CO}_{2}$ and perhaps free oxygen from the atmosphere.

In some instances (Spirogyra, leaves of Phaseolus), where the green cells are deprived of $\mathrm{CO}_{2}$, or kept in darkness, they are capable, when they are placed in a solution of dextrose, of manufacturing starch, but they soon die unless the normal conditions are supplied. Lemna, also, can be grown for a time in darkness upon a sugar or glycerine solution.

\section{External Conditions for Photosynthesis}

Light is not only necessary for photosynthesis, but in most instances for the development of chlorophyll as well. There are numerous exceptions to the latter statement, however, as chlorophyll develops in darkness in the embryo of many Seed-plants (Coniferæ, Celastrus) and in the leaves of Ferns and the prothallium and embryo of Pilularia. The same rays, i.e. those between the Frauenhofer lines $\mathrm{B}-\mathrm{D}$ of the spectrum, which are most effective in $\mathrm{CO}_{2}$ assimilation, are also most active in causing the development of chlorophyll. Chlorophyll, moreover, does not form below a certain temperature. The blanched appearauce of Indian-corn, sprouted in cold weather, is an illustration of this point.

The amount of oxygen, warmth, the amount of $\mathrm{CO}_{2}$, and, in short, the conditions which in general affect the vital processes of the plant, all influence the activity of photosynthesis.

\section{Chemosynthetic Assimilation of $\mathrm{CO}_{2}$}

Until very recently it has been assumed that the assimilation of carbon-dioxide was entirely confined to cells containing chlorophyll, through energy derived from light. It is now known that the nitrogen Bacteria can assimilate $\mathrm{CO}_{2}$, by virtue of energy derived from the oxidation of ammonia into nitrites, and of nitrites into nitrates. The whole of the organic food of these organisms is obtained in this way, and they can develop in a fluid free from all organic matter, provided the necessary inorganic salts are present. Sulphur Bacteria obtain energy for $\mathrm{CO}_{2}$-assimilation from oxidation of $\mathrm{H}_{2} \mathrm{~S}$.

\section{Assimilation of Organic Food}

Plants which are unable to assimilate $\mathrm{CO}_{2}$ must obtain their earbonaceous food from organic compounds. Such plants are either parasites or saprophytes, as they obtain their food from living or dead organisms. Pfeffer calls all parasites, as well as organisms which live together without injury to either, Symbionts. In the 
former instance the symbiosis is antagonistic, in the latter, reciprocal. Certain true parasites, such as Saprolegnia ferax, may also live on dead matter, and are known as "Facultative parasites," while others, such as some of the Rusts, can live only upon living tissues, and are "Obligate" parasites.

Certain organisms in dying (or during their growth) provide conditions suitable for the growth of others, as in the disintegration of rocks and accumulation of humus by the lower plants, preparatory to the establishment of the higher ones. This is also the case among certain Bacteria which appear in succession in decomposing substances, each preparing the way for its successor. Thus putrefactive Bacteria are followed by Sulphur Bacteria and aërobic by anaërobic forms, and vice versa.

Among the higher plants all degrees of parasitism and saprophytism are found. Thus the species of Mistletoe (Viscum, Phoradendron) have chlorophyll, but are to some extent parasitic, although it has been questioned whether they obtain any organic food from the host. Certain Scrophulariaceæ, e.g. Gerardia, attach themselves to the roots of other plants and behave much like the Mistletoe. Other forms, like the Beech-drops (Epiphegus), Orobanche, and the tropical Rafflesiaceæ, are quite destitute of chlorophyll, and must obtain all their food from the host.

The penetration of the roots (or haustoria) of the parasite into the host is effected partly by pressure and partly by the aid of excreted enzymes, or ferments. The latter are substances of great importance in the economy of all plants, as they possess the power of dissolving very resistant organic substances, such as cellulose, starch, and even chitin.

Mycorhiza. - Many saprophytic plants growing in a humus soil, and some which are not saprophytes, have associated with their roots certain Fungi, whose mycelium either lives within the cells of the host (endophytic) or upon the outside of the root (epiphytic). This mycorhiza, as it has been called, is supposed to supply the host with certain elements derived from the decomposition of the humus, in return for other substances taken from the host. Endophytic mycorhizæ occur in the gametophyte of species of Botrychium and Lycopodium, as well as in the roots of their sporophytes, and in those of many of the Seed-plants, notably such saprophytic forms as Monotropa, Corallorhiza, etc. The mycorhiza found about the roots of the cupuliferous trees is usually epiphytic, and its close association with the host may be doubted.

\section{Assimilation of Oxygen and Hydrogen}

Oxygen and hydrogen, which, next to carbon, are present in the greatest quantity in plant-tissues, are derived from water, $\mathrm{CO}_{2}$, or 
from many other combinations. They are never assimilated in their uncombined state.

\section{Assimilation of Nitrogen}

Nitrogen constitutes a relatively small part of the weight of the plant, - sometimes less than 1 per cent, and never more than 7 per cent to $8 \mathrm{per}$ cent, - but is, nevertheless, an indispensable constituent of the protoplasm. Like the other elements, it always enter's the plant in combination, the only exception to this being the ability of certain Bacteria to utilize the free nitrogen of the atmosphere. Green plants, with few exceptions, obtain their nitrogen in the form of soluble nitrates from the soil.

Various nitrogen Bacteria are of great importance in supplying the higher plants with the nitrogen compounds necessary for their growth. The Bacteria which occur in the tubercles found upon the roots of Leguminosæ and a few other plants (Elocagnus sp.) can utilize the atmospheric nitrogen, and provide the host with a much larger amount of nitrogen than is found in the soil where it is growing. This power of fixing nitrogen makes leguminous plants (Clover, Beans, Peas, etc.) of such great value in restoring the fertility of worn-out soils, and also accounts for the high value of these as foodplants. The best known of the tubercle-forming Bacteria is Bacillus radicicola, while Clostridium Pasteurianum is a nitrogen-fixing form which lives free in the soil.

\section{Nitrite and Nitrate Bacteria}

The production of the nitrates, which are the principal source of nitrogen for the higher plants, is also largely the work of Bacteria. These are of two kinds, those which oxidize ammonia to form nitrites, and those which oxidize the nitrites to nitrates, available for the use of the higher plants. Their importance in the economy of nature is sufficiently evident.

\section{Processes in Nitrogen-assimilation}

As in the case of carbon-assimilation, the steps by which the higher organic compounds are built up are still very imperfectly understood. It seems probable, however, that they are chemosynthetic, rather than photosynthetic in their nature. While the carbon compounds are relatively simple in structure, the nitrogen compounds are extraordinarily complex. (A full discussion of this very difficult subject is given in Pfeffer (26 a), pp. 388-410). 


\section{Carnivorous Plants}

A small number of the higher plants are known, which have developed special means of obtaining nitrogen from organic bodies. These are the "carnivorous" plants, like the Sundew (Drosera) and Pitcher-plants (Sarracenia, Nepenthes, ete.). 'These are usually aquatic or bog-plants, which grow where the soil nitrogen is inadequate, and the traps formed by their leaves, for capturing insects and other small animals, are, with little question, adaptations for supplying the deficiency of nitrogen.

\section{Ash-elements}

In addition to the carbon, hydrogen, oxygen, and nitrogen, which constitute the greater part of the substance of the plant, there are present in the ash left after the plant is burned, an amount of incombustible matter, ranging from 1.5 per cent to as much as 30 per cent of the dry weight. Some of these ash-elements, like iron and potassium, are essential, others, like silica and iodine, are not necessarily present.

\section{METABOLISM}

The various products of chemosynthetic and photosynthetic activity of the plant undergo many further changes, both destructive and constructive, before they finally become part of the living protoplasm. It is these changes which constitute Metabolism, a subject much too extensive to be taken up here in detail.

\section{Proteids}

First in importance in the active life of the plant are the various nitrogen compounds, which contribute to the growth of the protoplasm. Of these the Proteids are the most abundant, and of first importance. Asparagin and other soluble nitrogenous substances (Amides) are often, but not always, present, and may be an important reserve-food, but are never constituent parts of the protoplast; while the living protoplast is probably composed largely of a mixture of proteids. Proteids also occur as reserve-food in seeds, tubers, etc.

\section{The Carbohydrates}

The carbohydrates are all, primarily, the product of photosynthesis, and are the principal source of energy to the plant, as well as the source of organic food. Starch, sugar, cellulose, are the common- 
est of these carbohydrates, and the fatty oils are related to them. The reserve-food found in seeds, tubers, bulbs, winter-bucls, etc., is very largely in the form of starch or oil, derived originally from the carbohydrates formed in the leaves by photosynthesis.

\section{Organic Acids}

Organic acids in some form are always developed in plants. They are usually the products of decomposition, but may arise synthetically from simpler compounds. They are sometimes excretions (e.g. lactic and acetic acids), but may, as in the case of succulents already referred to, serve as constructive materials. Except oxalic acid, which is combined in the common crystals of calcium-oxalate, the acids are usually found in solution.

\section{Construction of Organic Compounds}

The processes of construction of organic matter are best studied in the germination of seeds. The dry seed contains living protoplasm, in a dormant condition, which resumes its activity as soon as the proper conditions of heat and moisture are supplied. The necessary materials for the first growth of the embryo plant are stored up in the seed in the form of reserve-food. This, as we have already seen, may be of various kinds. It may consist principally of nitrogenous matter (proteids, amides, etc.), or more commonly of starch, sugar, or other carbohydrates, or fatty oil. Where these are insoluble, as in the case of starch and some proteids, they must be converted into soluble forms before they can be assimilated. After germination has fairly begun, tests show a great increase in the amount of soluble substances, - e.g. sugar instead of starch in barley, asparagin in the germinating seeds of Leguminosæ. The food substances are now in condition to be transferred, and subjected to the further metabolic changes which are to combine the different elements into the complicated living proteids.

\section{Ferments or Enzymes}

The conversion of the insoluble substances into soluble ones is the work of the remarkable class of substances, formed by the protoplasm, known as "Enzymes" or "Ferments." The first of these to be isolated was diastase, which converts starch into sugar of some kind. Some forms of diastase also dissolve cellulose. The development of ferments by certain plants, especially the yeast-fungi, is utilized in the processes of fermentation of beer and wine. 


\section{- Excretion}

During the complicated processes of metabolism, many substances are given off, which are not used for building up the protoplasm, but are excretions. Some of these are strictly waste-products, like the crystals of calcium-oxalate, or the alcohol and lactic or butyric acid found in fermenting substances. $\mathrm{CO}_{2}$ and water are always excreted during respiration, and in the process of photosynthesis

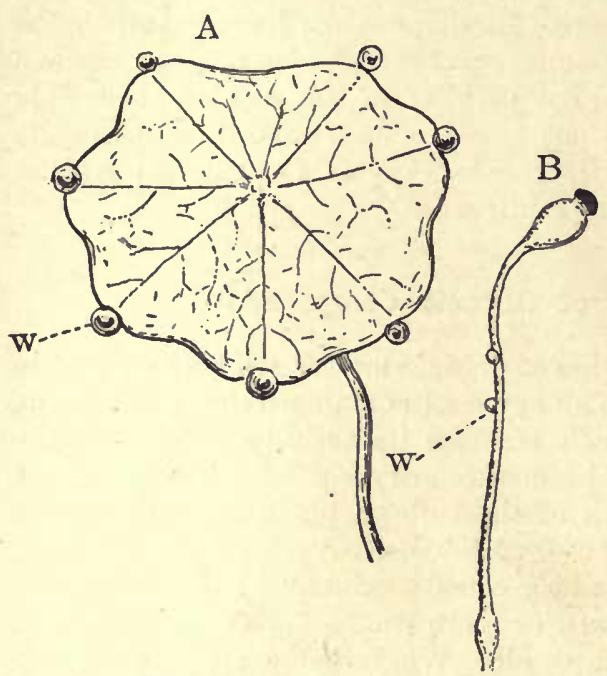

Fig. 454. - Excretion of water. A, leaf of Nasturtium. Drops of water excreted from water-pores at the apex of the larger leaf-veins. (After NoLL.) $B$, water execreted from the sporangiophore of Pilobolus (eularged). large amounts of free oxygen are liberated.

Some of the excreted substances remain in the plant, and are often of importance, biologically. Thus the poisonous alkaloids developed in many plants (nicotine, atropine, etc.), the ptomaines and toxalbumins, etc., are protective, or in the latter .case, by killing the host, Bacteria are provided with a food supply.

Other excreted substances may be useful in other ways. Thus the excretions of wax, or mineral substances like silica and calcium-carbonate, in the epidermal cells of many plants are useful either in preventing evaporation or giving rigidity to the tissues. The secretion of nectar in flowers, or upon other parts of the plant, and of pigments, is usually associated with the attraction of insects.

\section{RESPIRATION}

All activity of a living organism involves the breaking down of matter, converting it to simpler chemical compounds, with a corresponding freeing of energy. In its usual form, respiration consists in the absorption of free oxygen, which, combining with the hydrogen and carbon of the organic compounds, produces $\mathrm{CO}_{2}$ and water, with an evolution of heat. This physiological combustion is what is meant by Respiration. The carbohydrates, which have locked up in them the energy of the sun's rays, compose the fuel which is 
consumed by the plant in respiration, and are the principal source of energy upon which it draws in the metabolic processes. While respiration is not, as a rule, active enough in most plants to raise the temperature to a degree comparable to that found in warm-blooded animals, still, where respiration is active it may be very perceptible. A thermoneter thrust into a mass of actively germinating seeds will show a rise of several degrees, while in actively fermenting or decomposing matter the respiratory activity of the microorganisms concerned (although not involving a consumption of free oxygen) is very great. The rise of temperature in a hotbed is due mainly to the respiratory activity of the Bacteria in the manure.

Among the higher plants large flowers or inflorescences show the most marked evolution of heat. In some lárge tropical Araceæ and Palms the difference in temperature between the interior of the spathe and the outside air may amount to $10^{\circ}-12^{\circ} \mathrm{C}$.

\section{Sulphur, Nitro, and Iron Bacteria}

In some Bacteria the necessary energy is supplied by oxidation, not of carbon compounds, but of sulphur, nitrogen, or iron compounds. 'Thus Beggiatoa oxidizes sulphuretted hydrogen into sulphur and sulphuric acid; the Nitro-bacteria oxidize ammonia into nitrous and nitric acid; the Iron-bacteria oxidize ferrous into ferric oxide.

\section{Anaërobic Respiration}

While normal plants, like animals, require free oxygen for respiration, certain Bacteria (Anaërobes) can live in the absence of free oxygen, and, indeed, some of them (e.g. Bacillus polypiformis) are quickly killed by even small amounts of free oxygen. In the interior of decomposing bodies all the uncombined oxygen is soon exhausted by the growth of the Bacteria prèsent, and they must be able to live and grow in the absence of free oxygen. Indeed, the strictly anaërobic forms do not begin their activity until the free oxygen has been exhausted by their predecessors.

In these anaërobic forms the necessary supply of energy is furnished, not by the action of free oxygen, but by the chemical decomposition of substances within the cell, resulting in the evolution in many cases of large amounts of alcohol, lactic acid, butyric acid, etc., as well as $\mathrm{CO}_{2}$ and water. This form of respiration is often known as "intra-molecular" respiration, and may also take place in plants which normally are aërobic.

\section{GROWTH}

In unicellular plants cell-division at once results in the formation of two individuals, which immediately grow to the size of the 


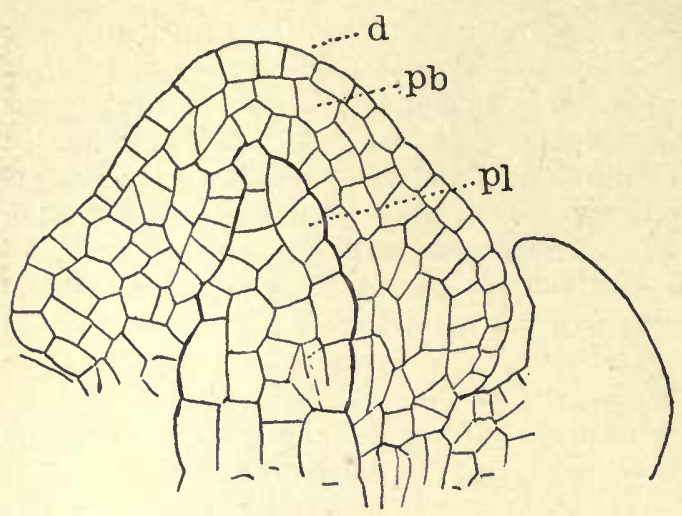

FIG. 455. - Median section of the apex of a shoot of the Redwood (Sequoia sempervirens); $d$, dermatogen ; $p b$, periblem; $p l$, plerome. original cell. In the lower Thallophytes, generally, cell-division is immediately followed by growth of the cells to the normal size. In more complex plants, however, this is not the case, and growth and cell-division are not necessarily immediately connected. In these plants there is a special region, usually the tip of the shoot, where cel]division is especially active, and very often all of the cells may be traced back to a single initial cell at the apex (e.g. Fucus, Polysiphonia, Chara). Sometimes, as in most Spermatophytes, the active tissue (meristem) at the apex cannot be referred to the activity of a single initial cell (Fig. 455). The small meristematic cells have relatively large nuclei, delicate walls, and usually abundant cytoplasm, - indeed, they are structurally much like the fully developed cells of some low 'Thallophytes.

The active multiplication of the meristematic cells at the apex of a growing organ is accompanied by very little increase in bulk. The region of most active growth (using this word in the sense of increase in size) is not the apex of the growing organ, but a zone some distance behind it (Fig. 456). In this subapical zone the volume of the cells increases many times, and is due largely to the great increase in the amount of water taken up by the cell, which is very greatly stretched. The amount of cytoplasm in these cells is very little more than in the young cell, and it forms a thin layer surrounding

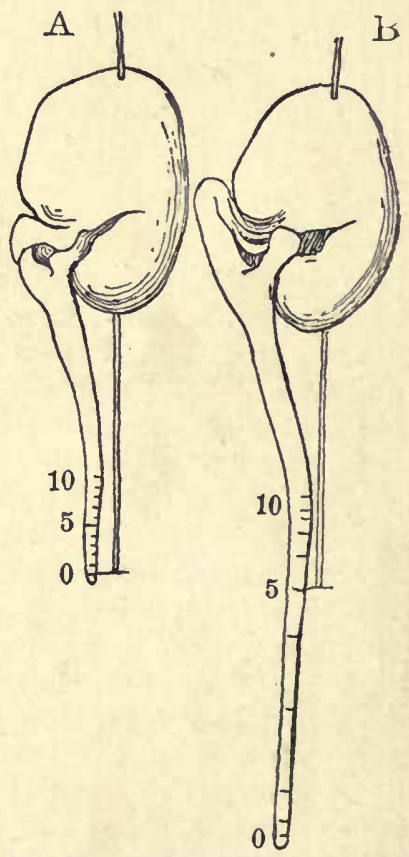

Fig. 456. - Two seedlings of Vicia $F a b a$, illustrating the unequal zones of growth back of the apex of the elongating root. (After SACHS.) 
the large sap-cavity which occupies the greater part of the cell. The stretching of the cell, which is a very important factor in its enlargement, is not the only factor, as there is also a large amount of inaterial added to the thickness of the cell-wall. This growth in bulk of the cell-wall is due in part to the addition of new layers of cellulose from within by "apposition," and probably, also, to "intussusception," or the insertion of new particles of cellulose between those in the wall. Whether these particles are, chemically speaking, molecules, or larger bodies (Micellæ), each composed of masses of molecules, is not certain.

The growth of the cell may be mainly longitudinal, as in most stems; or it may be lateral, as in flat organs like leaves.

The last phase in the development of the cell is its assumption of its specific character as part of a special tissue. The change in form, and secondary changes in the cell-wall, such as thickenings and chemical changes, found in wood-cells and other highly specialized tissue-elements, illustrate this. Such cells once formed, are, as a rule, either dead, or are incapable of further growth and division.

There are, then, three phases in the development of the tissues, cell-division, growth, and differentiation.

\section{IRRITABILITY (PFEFFER,}

$$
\text { pp. 10-23) }
$$

In discussing the nature of protoplasm, one of its most striking characteristics noted was irritability, i.e. sensitiveness to the various forces and substances which compose its environment. Indeed, all the vital processes are indissolubly associated with this property of protoplasm. Among its most evident manifestations are the various forms of movement characteristic of all living organisms. An exception must be made in the case of movements exhibited by dead structures, such as the hygroscopic movements shown by the elaters of Equisetum or Liverworts, the opening of sporan-

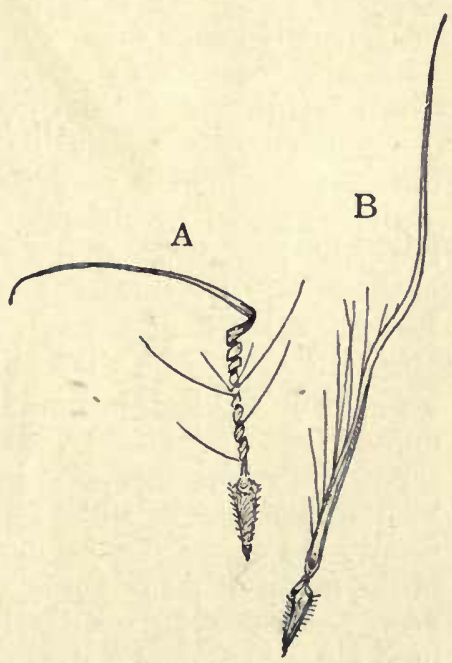

FIG. 457.- Hygroscopic movements shown by the awn of Erodium. $A$, dry; $B$, wet $(\times 2)$. gia, the movements of the awns of Erodium (Fig. 457) and Stipa, bursting of capsules in Viola or Impatiens, etc. These are purely mechanical, and quite unconnected with the irritability of the protoplasm. 


\section{Nature of Stimuli}

Stimuli may be either external or may develop within the protoplast. The latter are said to be autonomous, and arise from changes within the protoplast itself. Autonomous stimuli are usually much less readily determinable than external ones, but this is not always the case. For instance, the shape of a growing organ may be manifestly due, in part, to pressures arising automatically in the course of development. Stimuli may be thermal, chemical, mechanical, photic, or electric.

\section{Movements of Cellular Members}

The movements shown by the organs of the higher plants are of two kinds, - movements of growth and movements of variation.

\section{Movements of Growth}

In an actively growing shoot or root, the apex is moved upward (or downward) by the rapid elongation of the growing zone of tissue. The rate of growth is by no means uniform, and a familiar experiment readily shows this. The root of a seedling is carefully marked with a series of transverse lines, placed at equal intervals, and examined after a given time. It is then found that the rate of elongation shown by the separation of the marks has been very different at different points (Fig. 456).

During its earlier phases of development the growth of an organ is usually slow, although the cell-division may be rapid. The growth in extension then begins, and increases rapidly until a maximum is reached, when it decreases until it finally ceases entirely. This is especially well seen in the unfolding of leaves in the spring. The leaf, within the bud, has all its parts indicated, and, except for its minute size, is practically complete. With the unfolding of the bud there is a sudden increase in the size of the leaf, which within a week or two may reach its full size, after which no further enlargement takes place. Even more remarkable is the very slow growth of the leaves of many Ferns, which may require three, or even four years for their complete development, but which for their unfolding need but a few weeks, within which time they increase in bulk a hundred-fold.

While it is true that, in general, growth proceeds in a straight line, it is found that the tip of a growing organ describes an orbit about its axis. This "Circumnutation" is especially marked in rapidly growing organs, such as tendrils and the tips of climbing shoots. The path traced by the nutating apex varies from a circle to a straight line due to simple oscillation to the right and left. $\Lambda \mathrm{s}$ 
the growing apex is being constantly carried forward by the elongation of the shoot, the path traced by the apex will be either a spiral or a zigzag. These movements affect only the apex, and the stem does not necessarily become twisted, although where there is torsion of the stem it follows the direction of the nutating apex.

The length of the nutating apex may be considerable (about $40 \mathrm{~cm}$. in the Hop), and the time required for a complete revolution varies greatly, even in the same plant. Thus in Akebia quinata, the longest time (according to Darwin) necessary for a complete revolution of the apex was four hours, the shortest, one hour and fortyfive minutes.

The uncoiling or unfolding of

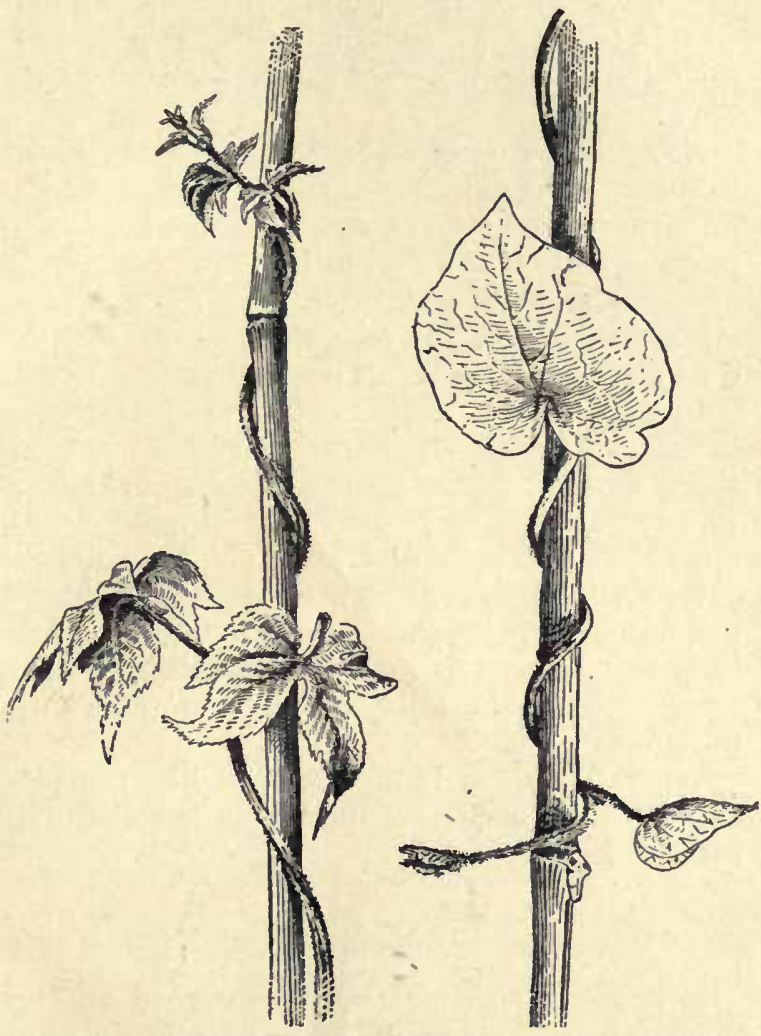

FIG. 458. - Twining stems. A, Hop. $B$, Morning-glory. (After BAILEY.) young leaves and of such coiled inflorescences as those of various Horraginaceæ (Myosotis, Heliotrope), and the opening and closing of flowers, are also forms of movement due to growth.

Rate of Elongation. - The rapidity of growth in elongating organs is sometimes extraordinarily great. Many climbing plants - e.g. Hop, Cobæa - will show an elongation of the shoot amounting to 10 to 15 centimetres or more in twenty-four hours, and this is far surpassed by the growth of many tropical plants, like the Bamboos, Agaves, etc. In the Bamboos the elongation may amount to 90 centimetres or more. The whole growth of a Bamboo, 30 to 40 metres in height, takes place in a single growing period. Drude found that 
the petiole of a rapidly growing leaf of Victoria regia elongated over 12 centimetres in the course of an hour!

Periodicity of Growth. - The rate of growth is affected by the external factors. In general, growth in length is accelerated by increased temperature, and diminished by increased illumination, but, aside from these, there does not appear to be a regular periodicity in the growth.

Mechanism of Growth-movements. - Aside from the movements due to simple elongation, the movements of growing organs, circumnutation, opening of flowers, etc., are caused by unequal growth. In a growing apex, if the growth is greater alternately on opposite sides of the stem, there will be an oscillation, right and left; but if, as more commonly is the case, the zone of growth follows the sun, or retreats from it, the result is an elliptical or circular orbit.

In the leaves of Ferns, and the coiled inflorescence of Myosotis, the growth is much greater upon the outer side, but the organ straightens out as the growth becomes greater upon the inner side. The opening of a flower-bud is accomplished by accelerated growth upon the upper side of the base of the petals, thus pushing them outward. Whether the extremely rapid opening and closing of such flowers as the Tulip and Crocus are referable entirely to growth, may be questioned. It is highly probable that temporary changes in the turgescence of the cells concerned are also an important factor in the process.

Where an organ is dorsiventral, like the petal of a flower, the extra growth upon the upper side is called "Epinasty," upon the lower side, "Hyponasty."

\section{Movement of Variation}

Besides the movements due to growth, all organisms show movements which are independent of growth, and are induced by various stimuli. The mechanism of these movements is usually to be found in changes in turgor of cells in the motile parts. Unicellular organisms may show active movements either by means of cilia or pseudopodia, and these are affected by the same stimuli which are efficient in the higher plants.

Among the latter, the movements of so-called "sensitive" organs, like the leaves of Mimosa pudica and Dionæa, the sensitive stamens of Berberis and Sparmannia, the stigmatic lobes of Catalpa, Tecoma, and Mimulus, are the most striking. The sleep-movements of many leaves, especially of Oxalidaceæ and Leguminosæ, come under the same category. These motile members may be provided with a special organ, the Pulvinus, which is especially well developed in the motile leaves of many Leguminosæ. This is an enlargement of the 
leaf-base, consisting principally of parenchyma capable of great changes in turgescence. In the ordinary position, the lower side of the pulvinus has its cells more strongly distended than the upper side, and there is pressure upon the lower side of the leaf-base which pushes upward and holds the leaf in its horizontal or obliquely upright position. In its relaxed condition, induced by shock, absence of light, or some other stimulus, there is a loss of water from the lower cells of the pulvinus, which lose their turgor, and the leaf sinks downward.

\section{External Stimuli}

In general, the conditions which govern the other activities of the plant also affect its movements. Thus well-nourished plants, provided with the optimum temperature and illumination, will react most vigorously in their movements. Beyond its general stimulating character, the temperature does not specially affect the character of plant-movements. Up to a certain optimum temperature the movements are accelerated, and beyond this they diminish, finally ceasing entirely, a state of rigor being induced which ends in death if the high temperature is long maintained.

\section{Chemical Stimuli}

Chemical stimuli must be of the greatest importance in the autonomic movements of plants, and are also evident in certain induced movements. Thus many low motile organisms are extremely sensitive to certain chemical substances. Among these "chemotactic" organisms are many Bacteria, which quickly accumulate at a point where some special substance such as oxygen is being excreted. Spermatozoids of Ferns are strongly attracted by salts of malic acid, and will quickly swim into a capillary tube containing a dilute solution of this substance, which it is assumed resembles that thrown out by the open archegonium. Pollen-tubes are negatively aerotropic, and they are also influenced in the direction of their growth by the sugary secretions of the stigma and the cells of the conducting tissue and ovule. The hyphæ of Fungi are also strongly chemotropic. Germinating spores, placed upon a perforated membrane (e.g. a bit of epidermis with stomata) will grow through the openings, if the membrane is placed over a chemically attractive substance, but will not do so if the membrane is floated upon water, or upon an indifferent fluid.

\section{Mechanical Stimuli}

Mechanical stimuli are of various kinds: pressure, shock, stretching, wounding, etc. To all of these there is a more or less evident 
response, both on the part of naked protoplasmic organisms, and of multicellular organs.

Pressure, Contact. - The effects of contact-stimuli are especially marked in the case of elimbing plants, this being particularly evident in tendrils. In the latter, the tip of the young tendril is extraordinarily sensitive, the sensitive area being sometimes confined to the concave surface (Cucurbita), in others (Cissus, Cobæa) all parts of the young tendril are sensitive. Pressure alone does not seem to be sufficient to induce coiling of the tendril, but there must be a certain amount of roughness in the surface to which the tendril is applied. Pfeffer found that a layer of moist gelatine excited no

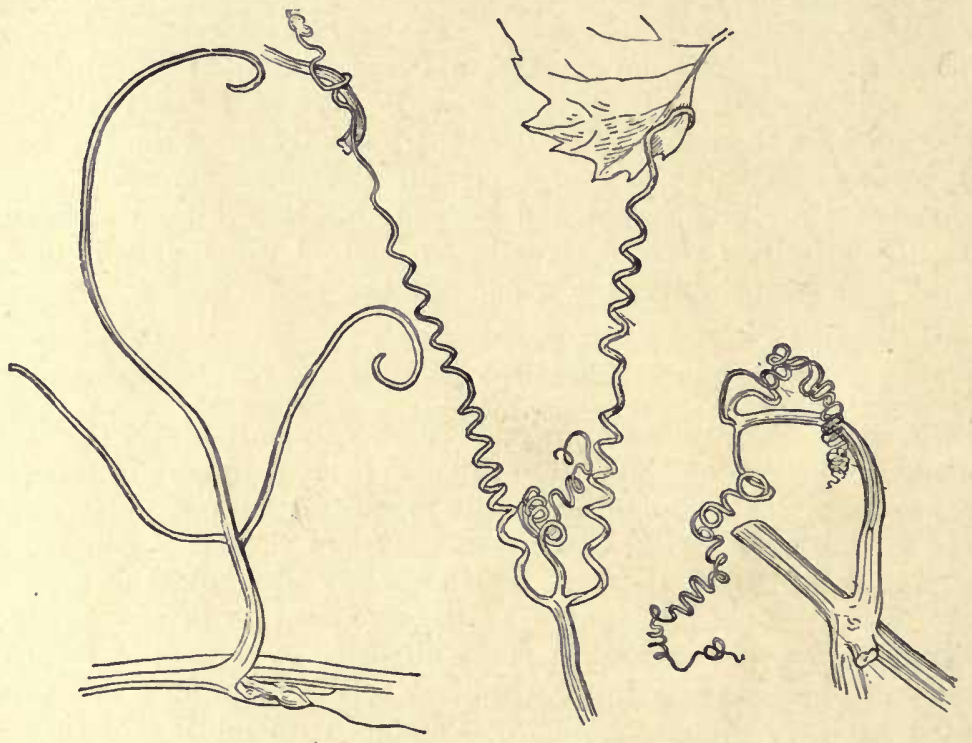

Fig. 459. - Tendrils of Sicana. (After Bailex.)

response in very sensitive tendrils, and Peirce found the same to be true in Cuscuta.

The effect of contact in tendrils is a checking of growth upon the side in contact with the support, and a greatly increased growth upon the opposite side, causing the close coiling of the tendril about the support (Fig. 459). In tendrils like those of Ampelopsis, the pressure-contact causes the development of suckers at the tips of the tendrils.

Many flowers show sensitiveness to contact in the stamens or pistil. Thus Berberis and Sparmannia have the stamens sensitive to touch, springing violently inward when they are touched near 
the base, as happens when a bee visits the flower. Many other cases might be cited of similar character, all having to do with the pollination of the flowers.

Shock. - The best-known case of rapid response to shock is the "Sensitive plant," Mimosa pudica. The closely related "Sensitive brier" (Schrankia), of the Southern states, behaves in the same way. A very slight.shock is enough to cause the dropping of the petioles and folding together of the leaflets (Fig. 460). A remarkable feature is the transmission of the stimulus to leaves situated a long distance from the part stimulated. As already explained, the movements are caused by loss of water from the cells of the pulvinus, which thus loses its turgidity, and causes the leaf to drop. The vascular bundles serve to transmit the stimulus, the cells especially concerned being in the phloem.

Wind. - The swaying of plants, due to the wind, exercises a powerful effect upon the development of the tissues, both of the stem and roots, which are developed as they are required to withstand the

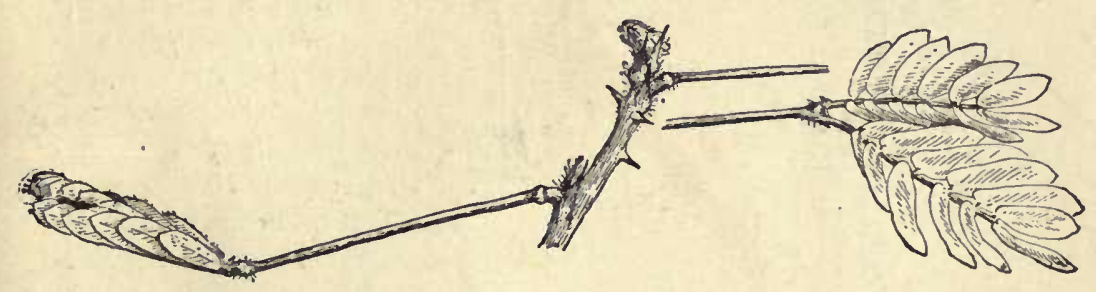

Fia. 460.-Mimosa pudica. The leaf at the right in its normal position, the one at the left contracted by shock. (After BAILEY.)

strains to which they are subjected. The mechanical contrivances, thus developed in plants, are extremely perfect. Some of our most important constructive materials, wood and vegetable fibres, are developed by plants in response to the necessity for resisting these strains.

Similarly, some water-plants are subjected to great strains, especially those which are exposed to violent surf. Some of the large kelps are admirable examples of the way in which there have been developed means of attachment, and tissues of extraordinary strength and flexibility to withstand the tremendous strains to which they are exposed.

\section{Water as a Stimulus (Rheotropism)}

Water is a necessity to all plants, and it is not strange that certain organs, especially roots, are influenced in the direction of their growth by the presence of water. We have already spoken of the movements of the plasmodia of Slime-moulds, against a current of water, 
and the roots of Maize and other seedlings behave the same way. The influence of water-currents has been called "Rheotropism."

\section{Geotropism}

Gravity may act in two ways. First, it acts in a purely mechanical way, as in the downward pull exerted upon a branch by the weight of the fruit borne upon it, or the drooping of a flower like a
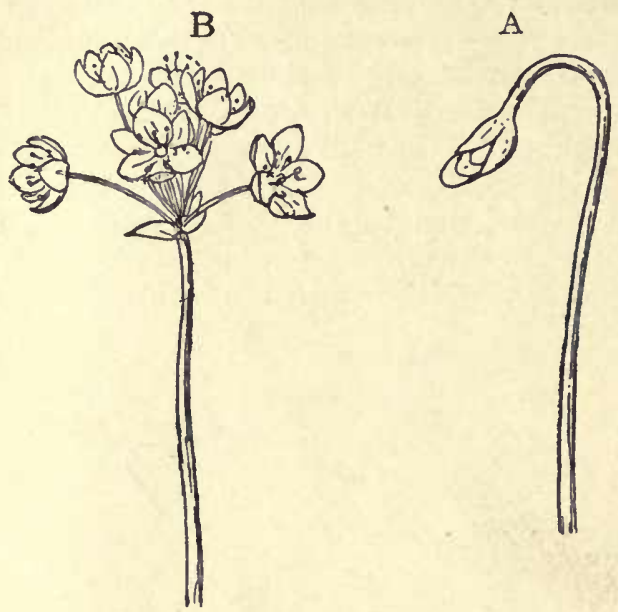

Frg. 461. - Carpotropic movements in Allium Neapolitanum. The young inflorescence, $A$, is positively geotropic; the open flowers, $B$, are negatively geotropic. (After MacDougaL.)
Fuchsia or Snowdrop, upon its slender stalk. A second sort of stimulus is Geotropism. This is the influence exerted by gravity upon the direction of growing organs. Thus, in most plants, roots normally grow downward (are positively geotropic), shoots are negatively geotropic, these movements being entirely independent of gravitation. Sometimes organs are at one time positively geotropic, at others negatively so. This is seen in many nodding flowerbuds, like the Poppy. These become erect when the flower opens, so that the seed-vessel stauds npright (Fig. 463).

The growth of a seedling illustrates the geotropic sensitiveness of the root and shoot. If a seedling is placed horizontally, the shoot will quickly bend upward, the root downward. Among the lower plants geotropism is equally manifest. Thus the sporangiophores of Fungi are negatively geotropic, as are the capsules of Mosses or Liverworts, while the rhizoids in all these are positively geotropic.

That gravity, and not light, is the factor determining the direction of growth of geotropic organs, is shown by placing the plant upon a klinostat, and causing it to rotate slowly upon a horizontal axis, so as to subject all parts equally to the effect of gravity. Under these conditions no change in the direction of growth can be detected.

Diageotropism. - Certain organs grow normally in a horizontal direction. Such are many rhizomes, stolons, lateral roots and branches, certain flowers, etc.; these organs are "diageotropic." It is, however, doubtful whether in all cases, e.g. many branches, other 
factors, such as light, may not also be concerned in the assumption of the horizontal position.

In the geotropic and rheotropic movements of roots, it has been shown that it is the root-tip which is the seusitive portion of the root, and the position in which this is placed regulates the movement in the older parts of the root. So long as the root-tip is prevented from assuming its normal position the movements in the other parts of the root will continue (Darwin, Pfeffer, Czapek). On the other hand, if a root is placed horizontally until the tip bends down, and the latter is then held in this position while the rest of the root remains horizontal, no change will take place in the position of the root.

Twining. - The movements of twining stems are caused by increased growth on one side, due to geotropic stimulus; this causes the revolving movement of the apex, and when the stem comes in contact with a support it twines about it.
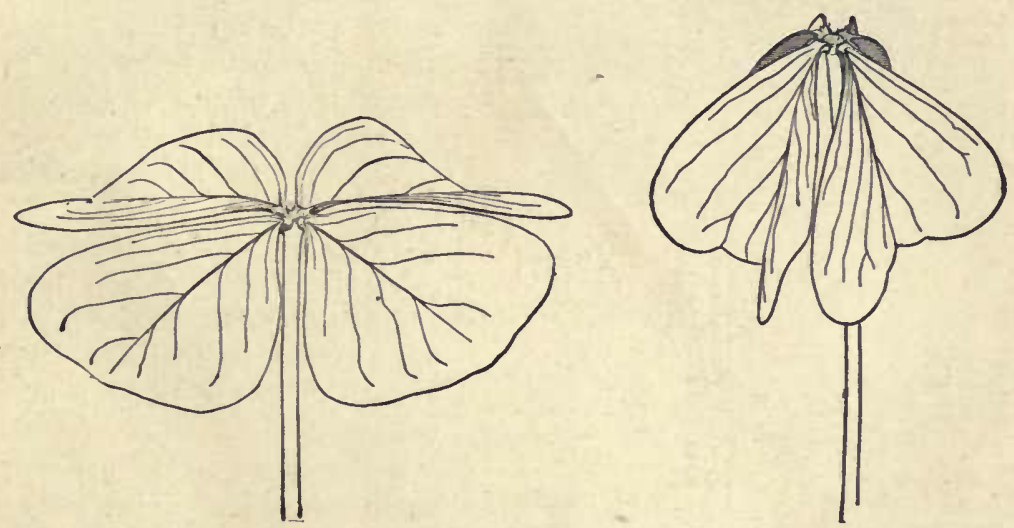

Fig. 462.- Leaves of Oxalis Bowei, showing day and night positions. (After BAILEY.)

\section{Light}

Light is a powerful stimulus both to the metabolic activity of the protoplasm and to its movements. The effect of light upon the movements of zoöspores and plasmodia has already been referred to, and light is an equally powerful stimulus in governing the movements of the organs of the higher plants.

The growth of green organs toward the light, the opening of flowers, and the sleep-movements of leaves, are familiar phenomena. These movements often depend upon the temperature, and even in bright sunshine some flowers will remain closed if the temperature is low. 
Nyctitropic Movements. - The sleep-movements, or nyctitropic movements, exhibited by many leaves and flowers, are usually the result of changes of turgor in the motile organs. Such leaves, which are especially common among the Leguminosæ (Trifolium, Phaseolus, Robinia, Mimosa, etc.), usually show a well-developed pulvinus. The significance of these sleep-movements, in which the leaves are closely folded together, is a diminution of the leaf surface exposed to radiation, thus protecting the plant against loss of heat.

The effect of light upon growing organs is generally to check the growth in length, so that, other things being equal, plants grow more

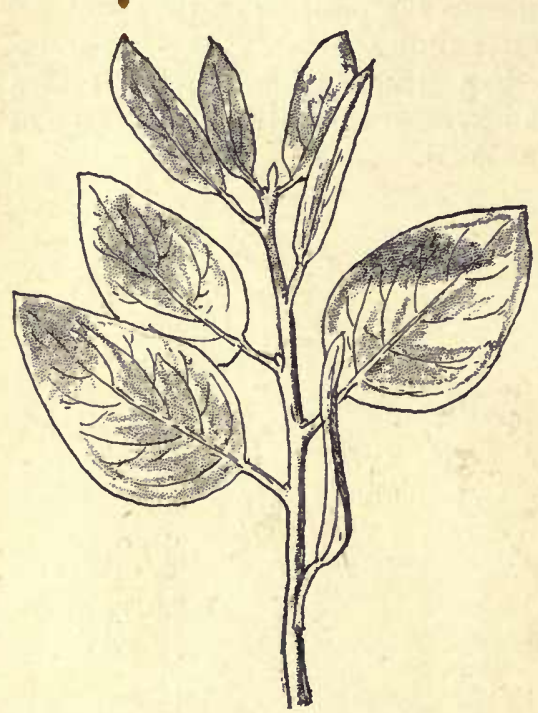

Fig. 463. - Twig of Manzanita (Arctostaphylos Manzanita), showing vertical position of the leaves. sumably, an adaptation connected with the attachment of the tendrils. Among the lower plants, green organs are as a rule positively heliotropic, and within the cell, the movements of the chromatophores are regulated by the direction and intensity of the light. The sporangiophores of Moulds, and the stalked spore-bodies of such large Fungi as Toadstools, are often strongly heliotropic. In the Ferns, the position of the archegonia is dependent upon illumination, and they may be made to develop upon the upper side of the prothallium, if the latter is illuminated from below.

The position of the leaf is most commonly horizontal, but in case the light is excessive the leaf may shift its position to avoid the direct rays of light. When a leaf is motile, as in Robinia and other 
Leguminosæ, this change of position is temporary; but in some xerophytes, which are exposed for prolonged periods to great heat and light, the leaf may permanently assume a vertical position. This is well shown in most species of Eucalyptus, and in Arctostaphylos Manzanita (Fig. 463). The phyllodia of many Acacias also illustrate this.

\section{Electric Stimuli. -} While plants are undoubtedly affected by electric stimuli, the reactions are not nearly so obvious as are those resulting from the stimulus of light or heat, nor are they ordinarily of any value to the plant. The study of electric stimuli requires further investigation.

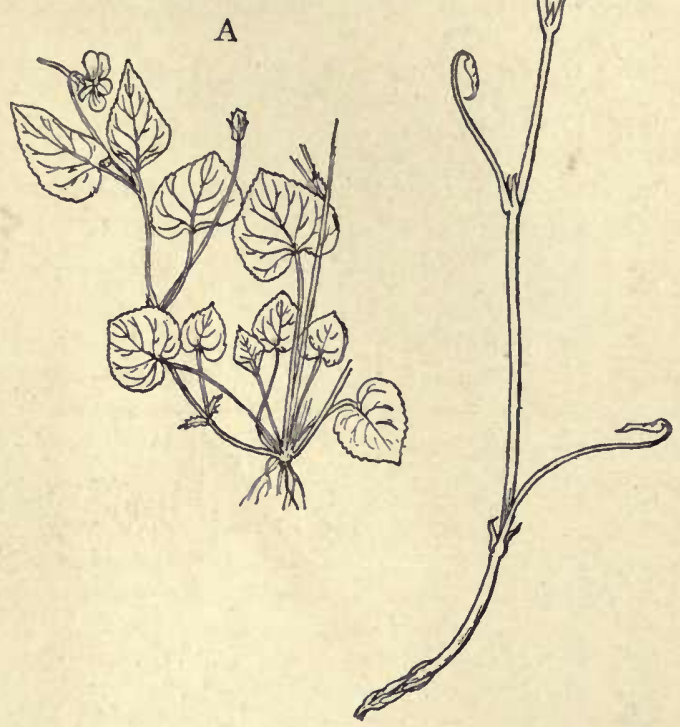

Fig. 464.-Viola rostrata. $A$, normal plant. (After Britton and Brown.) $B$, plant of the same species grown in the dark. (After MacDougal.)

\section{BIBLIOGRAPHY -}

'95. 1. Askenasy. Ueber das Saftsteigen. Verhandl, d. naturwiss. Vereins in Heidelberg. 1895.

'99. 2. Brown, H. T. The Fixation of Carbon by Plants. Nature. Sept., 1899.

'97. 3. Copeland, E. B. Relation of Nutrient Salts to 'Turgor. Bot. Gaz., XXIV. 1897.

'00. 4. Czapek, F. Kohlensäure-Assimilation und Chlorophyll. Bot. Zeit., LVIII. 1900. Includes bibliography of the most recent work on the subject.

'97-'99. 5. Davenport, C. B. Experimental Morphology. New York, 18971899. Includes extensive bibliography.

'94. 6. Dixon, H. H., and Joly, J. On the Ascent of Sap. Ann. of Bot., VIII. 1894.

'95. 7. The Path of the Transpiration-Current. Ann. of Bot., IX. 1895.

'97. 8. Ewart, A. J. On the Evolution of Oxygen from Colored Bacteria. Jour. Linn. Soc., XXXIII. London, 1897.

'01. 9. Fischer, A. Structure and Functions of Bacteria. Oxford, 1901.

'92. 10. Frank, A. B. Lehrbuch der Botanik. Leipzig, 1892. 
'92. 11. Frank, A. B. Die Pilzsymbiose der Leguminosen. Landwirthschaft. Jahrb., XXI. Berlin, 1892.

'91. 12. Goebel, K. Pflanzenbiologische Schilderungen. Marburg, 1889-1891.

'84. 13. Godlewski, E. Zur 'l'heorie der Wasserbewegung in den l'flanzen. Pringsh. Jahrb. f. Wiss. Bot., XV. 1884.

'99. 14. Green, J. R. Fermentation. Cambridge, 1899.

'00. 15. Introduction to the Physiology of Plants. London, 1900.

'96. 16. Haberlandt, G. Physiologische Pflanzenanatomie. 2d edit., Leipzig, 1896.

'82. 17. Loew, O., and Bokorny, 'T. Die Chemische Kraftquelle im lebenden Protoplasma. Munich, 1882.

'01. 18. MacDougal, D. T. Handbook of Plant-physiology. London and New York, 1901.

'92. 19. Molisch, H. Die Pflanze in ihren Beziehungen zum Eisen. Jena, 1892.

'94. 20. Newconib, F. C. Influence of Mechanical Resistance on the Development and Life-period of Cells. Bot. Gaz., XIX. 1894.

'95. 21. Ostwald, W. Outlines of General Chemistry. London and New York, 1895.

'99. 22. Palladine, W. Influence de la lumière sur la formation des matiè:"es protéiques actives et sur l'énergie de la respiration des parties veries's des vegetaux. Rev. gen. de Botanique, T. XI. 1899.

'93. 23. Peirce, G. J. On the Structure of the Haustoria of Some Phanerogamic Parasites. Ann. of Bot., VII. 1893.

'99. 24. - The Association of Alga and Fungus in Lichens. Proc. Calif. Acad. Sci., III, 1. 1899.

'01. 25. - Studies on the Coast Redwood. Ib. III-VI, Vol. 2. 1901.

'97-'01. 26. Pfeffer, W. Handbuch der Pflanzenphysiologie. 2te Auf. Leipzig, 1897-1901.

'00. 26a. (Translation of Vol. 1. Oxford, 1900.)

'87. 27. Sachs, J. Lectures on the Physiology of Plants. Oxford, 1887.

'92-'93. 28. G Gesammelte Abhandlungen über Pflanzenphysiologie. Leipzig, 1892-1893.

'98-'00. 29. Schäfer, E. A. 'Text-book of Physiology. London and New York, 1898-1900. Includes bibliography.

'98. 30. Schimper, A. F. W. Pflanzengeographie. Jena, 1898.

31. Schwendener, S. Various Papers on the Ascent of Sap, in the Proceedings of the Berlin Academy of Sciences. 1886, and later.

'94. 32. Stahl, E. Einige Versuche über Transpiration und Assimilation. Bot. Zeit., LII. 1894.

'91. 33. Strasburger, E. Bau und Verrichtung der Leitungsbahnen. Jena, 1891.

34. Text-book.

'99. 35. Verworn, M. General Physiology. London and New York, 1899.

'86. 36. Vines, S. H. Lectures on the Physiology of Plants. Cambridge, 1886. Includes bibliography.

37. Walker, J. Introduction to Physical Chemistry.

'89-'91. 38. Winogradsky, S. Recherches sur les organismes de la nitrification. Ann. de l'Inst.-Pasteur, T. IV, V. 1889-1891.

'87. 39. — Ueber Schwefelbacterien. Bot. Zeit., XLV. 1887.

'88. 40. — Beiträge z. Morphologie u. Physiol. der Bacterien. Leipzig, 1888.

41. Ueber Eisenbacterien. Bot. Zeit., XLVI. 1888.

'93. 42. Wieler, A. L. Das Bluten der Pflanzen. Cohn's Beiträge zur Biologie der Pflanzen, VI. 1893. 


\section{CHAPTER XIV}

\section{PHYSIOLOGY (Continued)}

\section{Relation to Environment}

There is every reason to suppose that the most primitive plants were unicellular forms which were aquatic in their habit. Some of the simpler existing fresh-water Algæ probably are very much like these ancestors of the higher plants. Somewhat higher are the related filamentous or thallose forms, represented by some of the Confervoideæ; and related to them, but differentiated in another direction, are the numerous marine Algæ.

Owing to the dense medium in which they grow, all submersed aquatic plants are unprovided with the mechanical tissues which give firmness to plants growing in the air, and consequently these Algæ, when removed from the water, collapse completely. Being exposed on all sides, too, to the nutrient medium, the water with its dissolved food elements may be absorbed at any point of the plant's surface, and roots, when present, serve merely for attachment. The surrounding water also serves as a vehicle for the transport of the reproductive bodies, both the non-sexual spores and the sexual cells, or gametes. Both may be provided with cilia, which may be present also in the vegetative cells of some of the most primitive forms like the Peridineæ and Volvocaceæ, which retain through life their animal character of active locomotion. This feature, as has been shown, persists in the male reproduative cells of all but the highest plants.

The formation of temporary, freely locomotive stages, becoming later stationary, is shared with plants by many low animals, such as the Corals, which, like the Algæ, live in a medium that is abundantly supplied with their food elements.

The conditions in fresh water are much the same everywhere, and we find the lower types of plants growing in fresh water to be much alike in all parts of the world. As the conditions have probably changed but little from very remote times, it is reasonable to suppose that most of these simple fresh-water organisms are of very ancient origin. Comparing the fresh-water Algæ with other plants, we may recognize two principal categories of the latter - marine plants and land plants, the former being principally Algæ, more or less remotely related to the fresh-water types. 
Fresh-water Algæ. - Bodies of fresh water are usually subject to greater or less fluctuations of level, and in the cooler parts of the world, to great extremes of temperature. It follows, therefore, that plants living in fresh water must be able to endure a wide range of temperature, and in case of shallow bodies of water, they must be able also to withstand complete desiccation. It is very easily ascertained that fresh-water Algæ, as a rule, can endure much greater changes of temperature without injury than can most marine Algæ. In special cases, such as Algæ living in hot springs, they can sometimes endure a temperature approaching the boiling point, while many Algæ may be frozen into ice without injury.

Protection against Drought. - As most fresh-water Algæ may be exposed to drying up, we find that almost all of them develop some means of resisting this. In many low forms like Oscillatoria, Pleurococcus, etc., the vegetative cells may become completely dried without suffering injury and will remain dormant for an indefinite period, reviving very promptly when again supplied with water.

Resting-spores. - In a large number of Algæ, however, special cells are developed which are capable of surviving both drought and cold, which destroy the vegetative cells. These resting-spores may be formed by a transformation of a vegetative cell, as in Anabæna, or Rivularia, or they may be the product of fertilization, as in the spores of Spirogyra or CEdogonium.

Marine Algæ. - When we compare the conditions in the sea with those of fresh water, it is evident that they are far more constant, and the marine plants are, as a rule, much more sensitive to changes especially in temperature, than are fresh-water forms, this being especially true of the forms from deeper water and those of the open ocean; and these forms are quickly killed by a change to warmer water.

The development of special pigments in the Red and Brown Algæ is associated with the modification of the light rays which are concerned in photosynthesis, and is characteristic of most of the marine forms.

While Seaweeds are never exposed to complete drying up for long periods, many of them, like the Rockweeds and other forms growing between tide-marks, are periodically exposed to the air at low tide. It is found that resting-spores, such as those of the majority of freshwater Algæ, are absent in most Seaweeds, and that the reproductive cells, as a rule, germinate at once. In the case of some northern forms, the plants die down in winter, but the basal part remains alive, sending up new shoots each season. Protection against temporary drying is provided for in most Algæ which are exposed at low tide. Such forms are often of a marked gelatinous consistence, the cell-walls being often highly mucilaginous, so that they retain water 


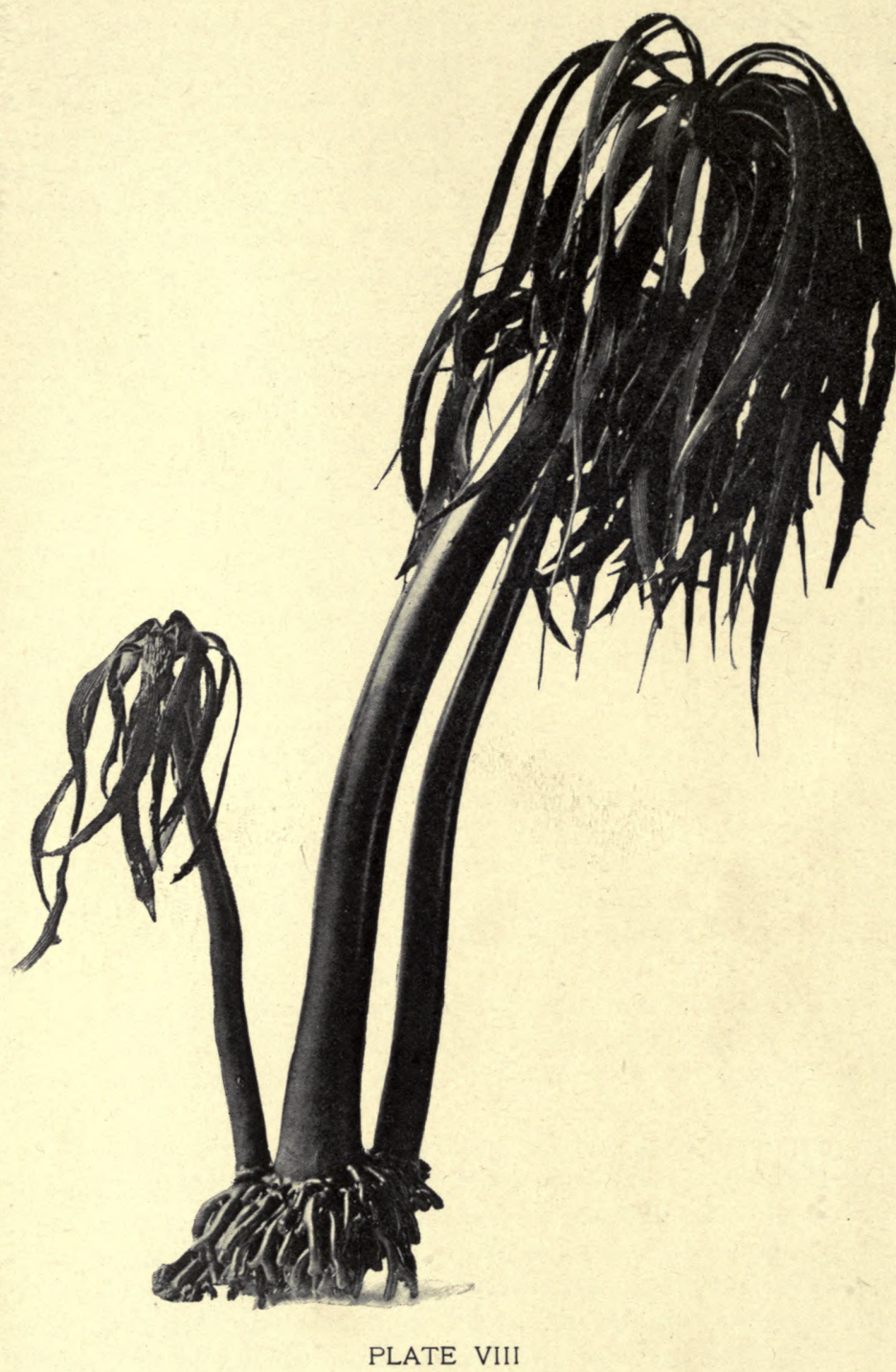

Postelsia palmaformis, a Surf-alga, showing the powerful rootlike holdfast by which it is attached to the rocks. (Photograph by Dr. W. R. Shaw.) 
with great tenacity, and these plants are very slow to dry, in strong contrast to the rapid loss of water from most submersed plants when exposed to the air.

Surf Algæ. - Algæ which grow upon rocks are often exposed to the heavy beating of the surf, and such species are provided with very efficient holdfasts, which are only torn away with great force. The tissues of these surf-plants are also very tough, so that they are of a leathery or cartilaginous consistence, and are perfectly adapted to withstand the buffeting of the waves without injury. Sometimes, where these grow only partly submersed, as in the Sea-palm (Postelsia) of the Pacific coast, the tissues are rigid enough so that the plant maintains an upright position in the air, which is rarely the case with Algæ (Pl. VIII).

In the larger seaweeds, also, a much better development of the plant-body occurs than among the simple fresh-water forms. As we have seen, many of these large Seaweeds develop leaves, or special organs for carbon-assimilation, and these may be brought to the surface by means of plants, so as to offer the most favorable exposure to the light. These large Algæ have, in short, adjusted themselves more perfectly to the peculiar conditions existing in the ocean, than have any other plants, and they are preëminently the characteristic types of marine shore-vegetation.

Plankton Forms. - Very different are the conditions prevailing in the open sea, where there are myriads of plants forming part of the floating life, or "Plankton" of the ocean. This floating vegetation, being the source of food for most of the inhabitants of the ocean, is of course of the greatest importance. While a small number of the higher Seaweeds, such as the Gulfweed and some related forms, may be found floating and regetating far from land, this is exceptional,

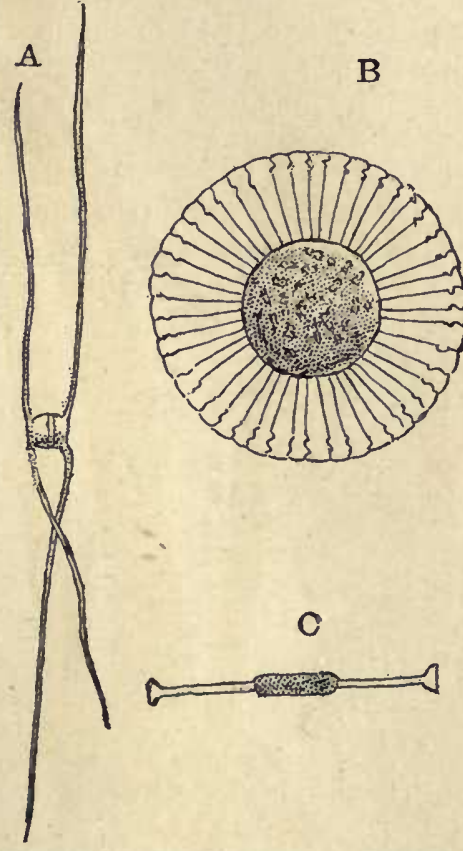

FrG. 465. - Pelagic Diatoms. A, Chætoceras boreale. $B, C$, Planktoniella Sol. (After SchüтT.) and the bulk of the floating plant life is made up of Diatoms, Peridineæ, and other minute, often microscopic, forms. Many of these show very beautiful adaptations to this floating life, having the 
form of delicate filaments, or being provided with appendages which serve as floats and make them extremely buoyant (Fig. 465). Others, like the Peridineæ, are ciliated and thus capable of independent locomotion.

\section{Land Plants}

When the ancestors of the terrestrial plants left the water, the conditions encountered were very different from those which they had left behind. The comparatively stable conditions of life in water were exchanged for far more variable ones for which the plant had to provide, and the struggle for existence was far keener, and soon resulted in a much greater diversity of types than was possible in the more uniform aquatic environment.

Being no longer surrounded by a dense medium, the plant must either lie prostrate on the earth, or must develop mechanical tissues which enable it to maintain itself erect in the rarer medium in which it is growing. Moreover, protection has to be provided against undue loss of water from the cells. We find, therefore, that all land plants have their exposed surfaces provided with a more or less perfectly impervious cuticle.

The transition from the aquatic to the terrestrial condition was not, probably, a sudden one, but took place gradually, much as it still

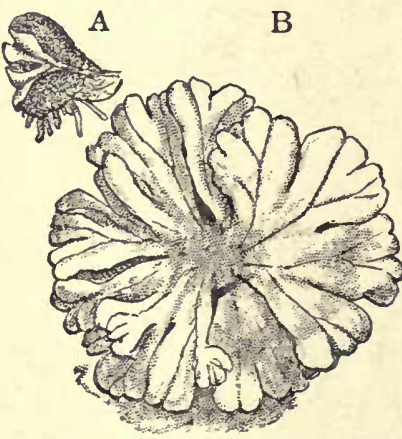

Fig. 466.- Ricciocarpus natans. $A$, floating form. $B$, terrestrial form. ordinarily grows as a floating aquatic, but if the water subsides so as to leave it stranded on the mud, the plant will root itself in the mud and begin a more vigorous growth than when floating free in the water, and very often it does this preliminary to forming its reproductive organs. It is very probable that in some such way as this the first genuine terrestrial plants had their origin. 


\section{ABSORPTION OF FOOD}

Where a plant is completely submersed, the outer cells of all parts are capable of absorbing water with the various food elements in solution. In terrestrial plants this is of course impossible, and these plants must have special organs for the absorption of food. For the absorption of $\mathrm{CO}_{2}$ from the atmosphere, the green parts are provided with stomata, which alone permit the entrance of gases from the atmosphere. For the absorption of water and dissolved mineral salts, the roots are the chief agents, serving not merely as organs of attachment, as in aquatic plants, but also as absorbents of water, both to supply the loss due to transpiration, and as a vehicle for the transport of the food constituents from the earth.

In most land plants there are well-developed special organs for the assimilation of $\mathrm{CO}_{2}$, leaves which are far better developed than

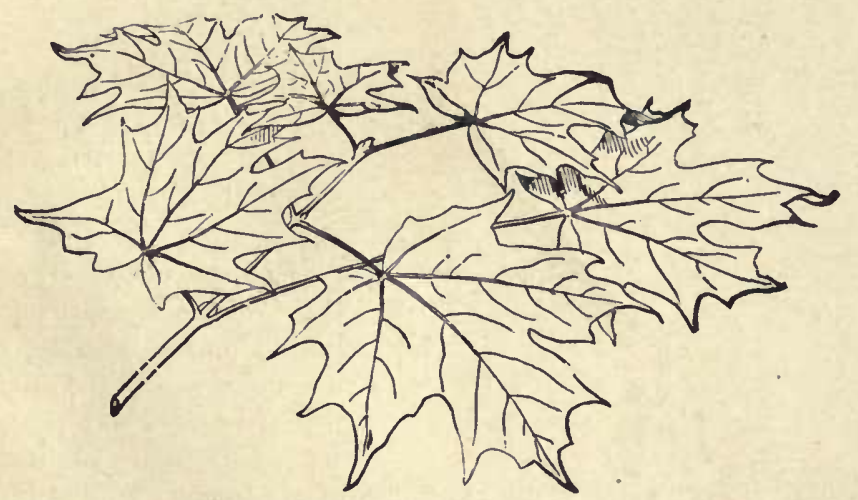

FIG. 467. - Acer saccharinum, showing the arrangement of the leaves to avoid shading. (After BAILEY.)

in even the highest of the Seaweeds. The leaf, in order to insure firmness, is in the most perfect forms provided with a complicated skeleton of woody fibres, the veins, between which are placed the spongy green cells which are concerned with photosynthesis. Covering it is the epidermis, checking loss of water except through the stomata, which communicate with the intercellular spaces of the green mesophyll. Stomata are never found except upon aerial organs.

The development of these special organs, and the segregation of special functions, necessitates a much more perfect system of conductive tissues than is found in aquatic organisms, and these tissues are best developed among the higher terrestrial plants.

The conditions which determine plant growth - i.e. light, heat, moisture, and food - are of course variable in quantity, and we find, as might be expected, that the plant-organism varies in response to changes in these life-conditions. 


\section{IIGH'T}

A certain illumination is necessary for the assimilation of $\mathrm{CO}_{2}$, and the adaptation to changes in the intensity of light are very obvious. The contrast between two individuals of the same species exposed to light of different intensity is very striking. Individuals growing in shade have the leaves many times larger than the same plant exposed to the full rays of the sun, and thus expose a much larger number of green cells to the action of the diffuse light rays. Where the light conditions are intermittent, it is possible, in many cases, to demonstrate a change in the position of the chlorophyll-bodies, dependent upon the change in the intensity of light. In the leaf of a Moss, for example, the disk-shaped chromatophores spread themselves evenly over the outer cell-wall in diffuse light, but retreat to the side-

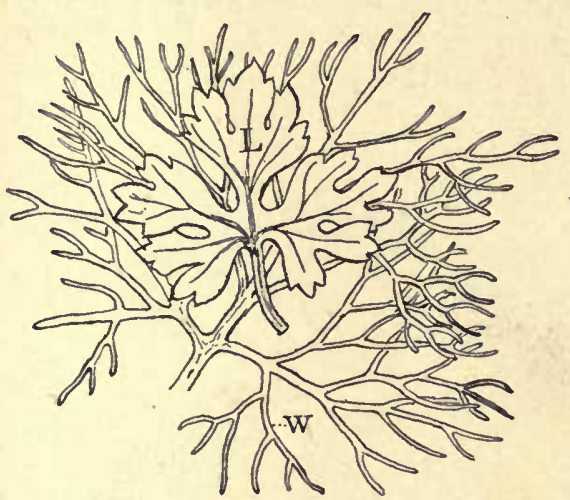

Frg. 468.-Ranunculus multịidus. L. aerial leaf ; $w$, submersed leaf. (After Goeber.) walls and turn their edges to the light, when it is strong.

Where the illumination is very intense, as in arid regions, the small size of the leaves is very marked, and there are sometimes temporary provisions against too intense illumination, of which one of the most conspicuous is the development of red pigments in the young leaves of many plants, especially in the Tropics, but also shown by the young shoots of Tea-roses, and the purple and red young shoots of such deciduous trees as the Red-maple. It is supposed that in these cases the red pigment acts as a screen for the protection of the young chloroplasts.

Mesophytes. - The term Mesophyte has been adopted for those plants which grow under average conditions of light, etc., and comprises the ordinary plants of temperate and moist tropical regions. In these plants the leaves are of normal size, and usually disposed so as to expose a maximum surface to the light. To this end, the leaves are so arranged as to avoid excessive overlapping and shading. In many cases, the leaves are placed in numerous rows along the stem, and not infrequently, where the leaves are closely set, the petioles of the lower ones are longer than the upper ones, so that the blade of the leaf projects beyond those lying above it (Fig. 465). In other cases the leaves are much divided, so as to let the light 


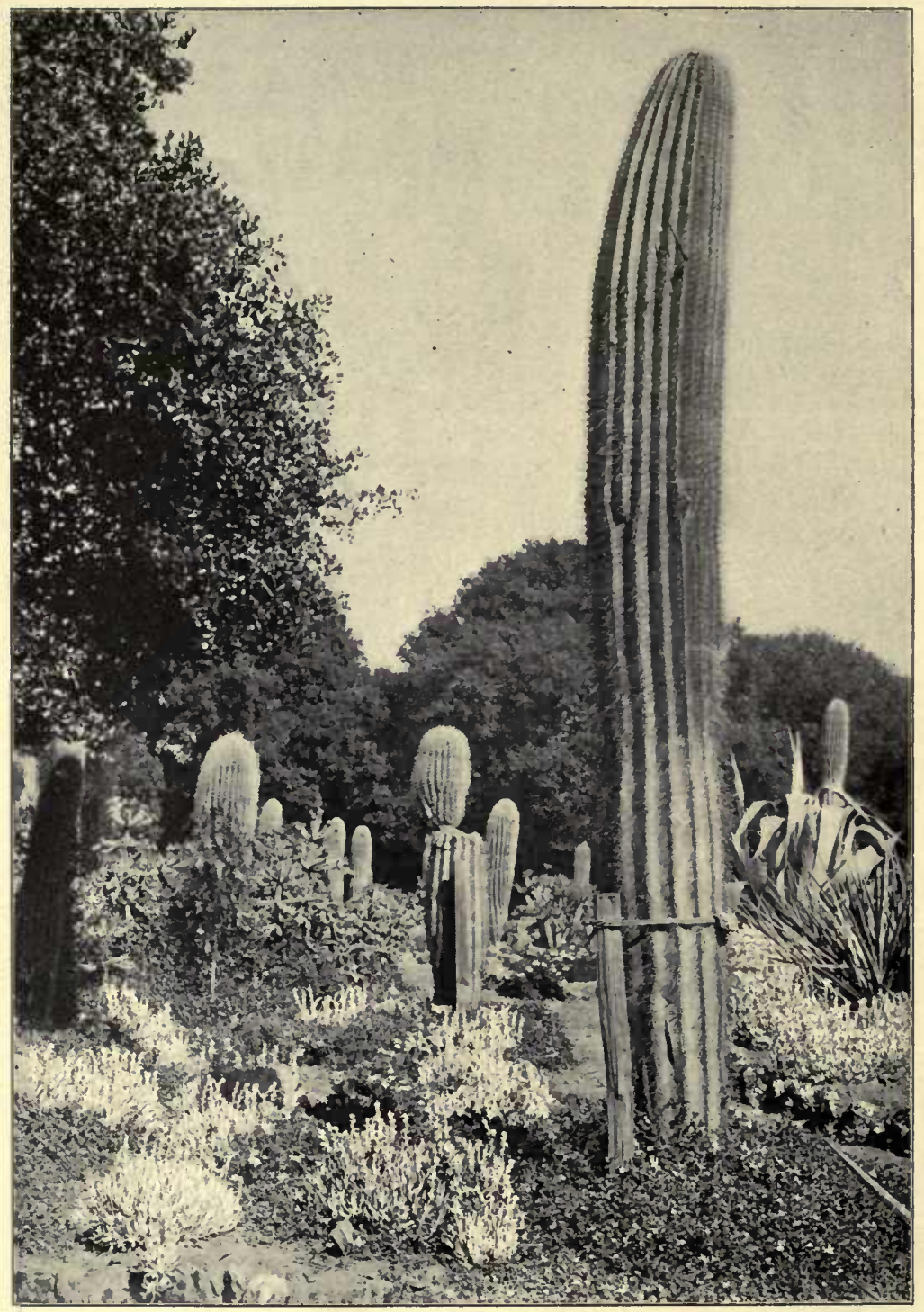

PLATE IX

Group of Xerophytes: Cereus giganteus; to the right Agave Americana, Yucca sp.; to the left Opuntia sp.; in the background Quercus agrifolia; on the ground Mesembryanthemum sp. and Sedum sp. (Photograph, Stanford University, Dr. F. M. MacFarland.) 
through between their segments. If the light is deficient, as we have already seen, the size of the leaf becomes much increased.

Xerophytes. - The name Xerophyte is given to plants which grow where the moisture is deficient, and which are more or less modified so as to guard against excessive loss of moisture. While xerophytes are especially characteristic of hot, arid regions, they are by no means confined to these.

Among the lower plants, especially the Green Algæ, special resistant spores are produced which carry the plant through periods of drought, and the same purpose is served by the spores of many Mosses and Ferns. Among the latter groups, however, there are a good many which can be completely dried up without injury, and may, therefore, be classed as xerophytes. In California, for example, where all vegetation is exposed to prolonged droughts each year, very many of the Mosses and Liverworts become completely dried up without being killed, and a few Ferns like the common Gold-back (Gymnogramme triangularis), and several species of Selaginella, e.g. $S$. lepidophylla, also become completely dried up, but on being moistened, the leaves absorb water and quickly become fresh and green again, and the plant at once resumes its growth.

It is anong the Spermatophytes, however, that the most perfectly developed xerophytes are found. The methods by which protection against drouth is attained are various. In typical xerophytic trees and shrubs, especially those with evergreen leaves, the latter are very greatly reduced in size, compared with the leaves of mesophytes; or where there is no

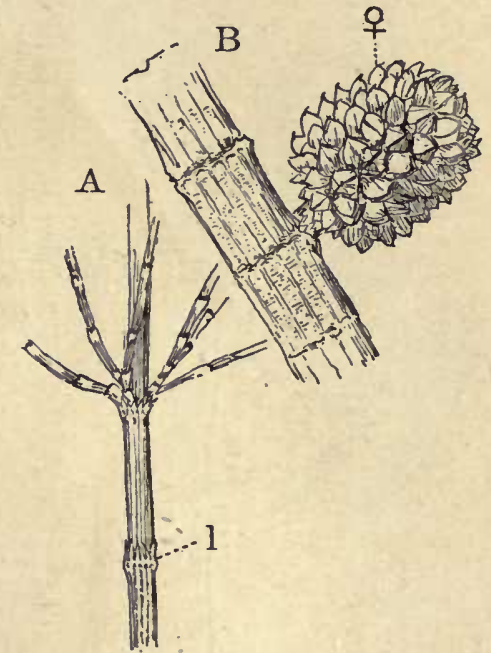

Fig. 469. - Casuarina equisetifolia. The leaves reduced to toothed sheaths.

noticeable reduction in size, the epidermis is very thick, so that the leaves are leathery in texture, as in the Oleander or Holly, or the needles of coniferous trees. The small leathery leaves of these xeropliytes offer a strong contrast to the large delicate leaves of shade-loving plants, or the exceedingly soft leaves of submersed aquatics.

The reduction of the leaves is carried so far in many xerophytes that they are degraded to mere scales, quite functionless as assimilating organs. Such forms, like the Broom, or Casuarina (Fig. 469), 
have the green tissue restricted to the stems, which are, moreover, provided with an impervious, thick epidermis.

Another type of xerophyte is seen in such forms as the Agaves (Pl. IX) and Aloes, where the stem is very short and the leaves enormously enlarged, and their inner cells gorged with water, so that they serve as reservoir's of moisture protected by the very heavy epidermis. An admirable example of this type is seen in the Centuryplant, which inhabits the deserts of Arizona and Mexico.

Cacti. - Perhaps the most perfect type of xerophytes are the Cacti, especially characteristic of the arid regions of the southwestern United States and Mexico, and the very similar Euphorbias of Africa. In these plants the leaves are usually entirely suppressed, and the greatly thickened stems expose a relatively small surface to the air. The stems may branch freely, but sometimes the stem forms a globular or oblong solid body, which exposes a minimum surface to the

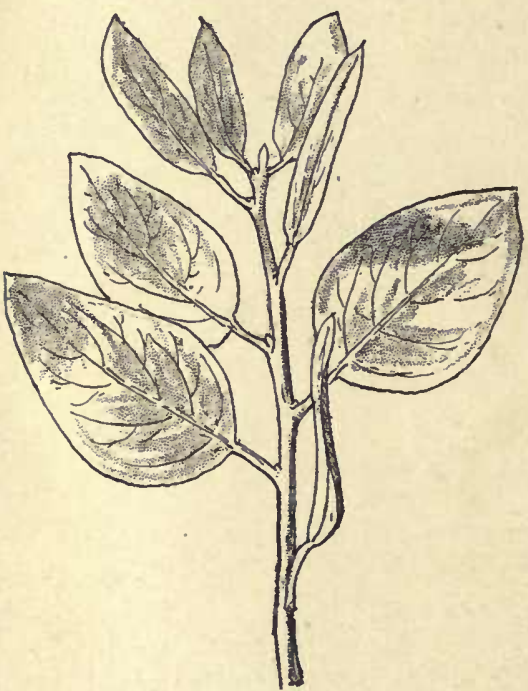

Fig.470.-Arctostaphylos Manzanita. With leaves placed vertically as a protection against too intense sunshine. atmosphere, and its surface is so thoroughly protected, and the supply of water in the mass of soft tissue within the stem is so great, that the plant may be exposed for weeks to the fierce rays of the sun without appreciable loss of water.

The surface of the leaves and stems in these xerophytic plants is very generally covered with a coating composed either of a waxy secretion forming a grayish coating or "blooin" upon the surface, or it is protected by a mass of hairs, which serve as a screen against the too active light rays. There is often, also, a layer of colorless hypodermal cells between the green mesophyll and the epidermis, which hold water and screen the cells beneath.

A similar protection against the force of the sun's rays is offered by the leaves of certain xerophytes, which are placed vertically, instead of in the normal horizontal position. This is seen in some species of Arctostaphylos, the "Manzanita" of the California mountains (Fig. 470), and still more markedly in most species of Eucalyptus. In the Blue-gum, E. globulus, the first leaves are horizontal, but are gradually replaced by the sickle-shaped mature leaves, which 


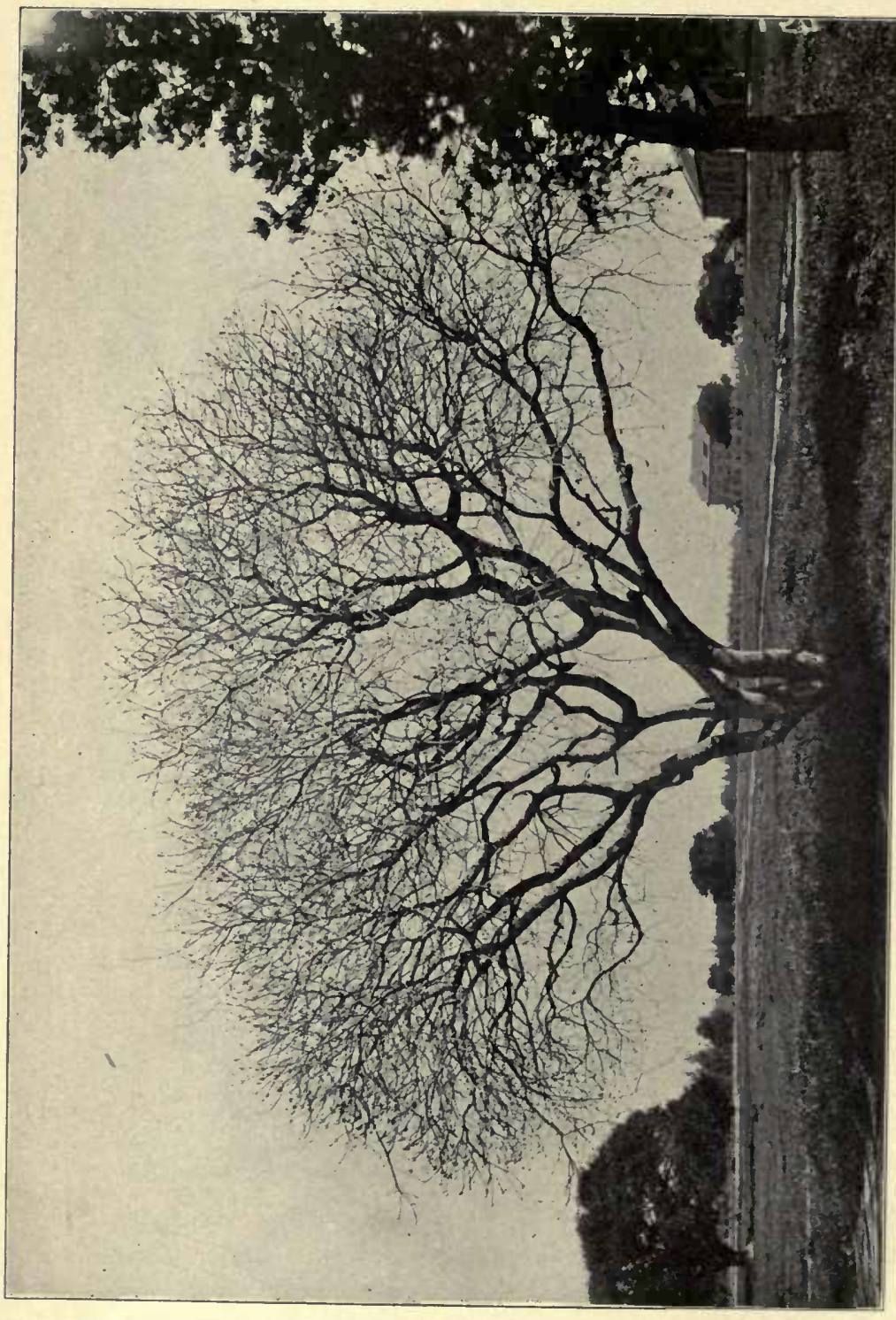

ปั

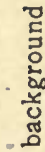

Е

트

$\therefore 2$

.

ह

¿

ठ

马्ड

路

过

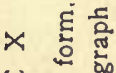

니

ᄂ 5

ㅁ.

虽

3

으

¿

$=$

$\infty$

동

的

क

ฮें

$>\frac{1}{8}$

동

응

.

है 
hang quite vertically, and are alike upon both sides. In many species of Acacia (Fig. 471) the characteristic pinnate leaves of the young plant are replaced by the vertically flattened phyllodes or leafstalks, the blade of the leaf having quite disappeared.

Differing from these protective measures are those of a host of herbaceous plants, whose aerial parts are produced afresh each season, the plant remaining dormant during the dry season, by means of subterranean bulbs, tubers, or similar

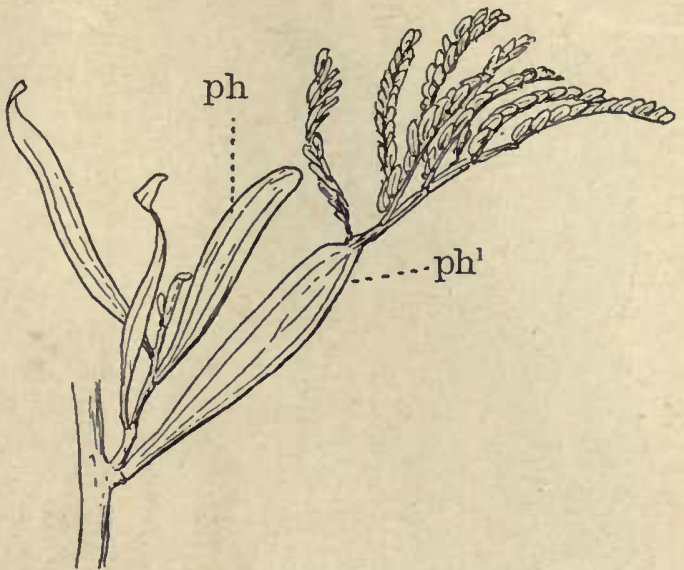

Fig. 471.-Acacia sp. Leaves replaced by pliyllodia, $p h$; one of these, $p h^{1}$, has the leaf-lamina developed, as it always is in the seedling.

structures. Bulbous and tuberous plants are especially common in semiarid regions, like the great valleys of California and the Cape region of Africa.

In some tropical regions, like the northern part of South Anerica, where there is a marked dry season, the trees shed their leaves during the dry period just as northern deciduous trees do on the approach of winter. In California the Buckeye (Pl. X) does this, being quite bare of leaves during the summer and autumn, and putting forth its new leaves in midwinter.

\section{Epiphytes}

In temperate regions, where the competition among organisms is not so keen as in the Tropics, epiphytes are not nearly so common, and as a rule belong to the lower groups of plants, Lichens and Mosses being the prevailing forms. In the Tropics, however, the number of epiphytes is very large, and includes many characteristic Ferns and Seed-plants. Where these grow in the deep shade of moist forests, they seldom show xerophytic characters; but where they are exposed to the sun, the necessity for economizing water is obvious, and they are then, as a rule, markedly xerophytic in their structure. Of the xerophytic epiphytes, the Bromeliaceæ, so characteristic of the American Tropics, and represented in the southern states by a few forms, e.g. the Spanish-moss (Tillandsia usneoides), 
are among the most striking. In these plants not only is the epidermis very thick, so as to check loss of water, but the leaves are often

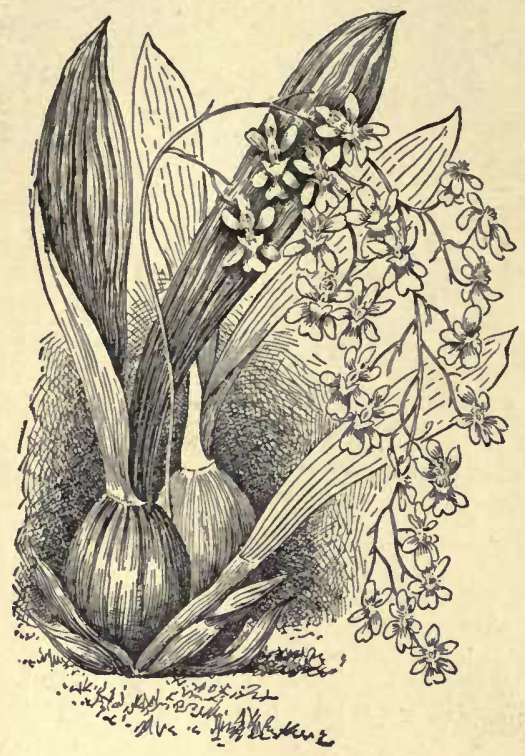

Fig. 472. - Oncidium ornithorhynchum. An epiphytic Orchid, showing the pseudo-bulbs at the base of the leaves. (After BAILEY.) covered with scurfy scales, which absorb water which falls upon the plants, and thus serve to supply part of the loss due to transpiration. The expanded leaf-bases, also, serve as reservoirs of water. In many epiphytic Orchids there are developed thick aerial roots provided with a massive spongy root-cap which serves the same purpose.

Where plants grow very much crowded together, as they do in the moist forests of the Tropics, the question of light becomes a very important one, and many ways have been developed in order that plants may reach the light. The epiphytic habit already described is a direct response to the necessity for light, and in the forests of the Tropics the branches of the trees are often completely hidden in the mass of epiphytic plants which are trying to maintain their existence (Pl. XI). These "air plants" are of the most diverse kinds-Mosses, Ferns, Orchids (Fig. 472), Bromeliads, and myriads of other types.

\section{Climbing Plants}

Another method of reaching the light is shown by climbing plants, which, like the epiphytes, reach their most perfect development in the Tropics, although in our own forests there are many striking examples. Climbing plants are either twiners, i.e. the stem winds about the support, as in the Morning-glory or Hop, or there are special climbing organs, tendrils, which may be branch-tendrils as in the Grape or Virginia-creeper, or root-tendrils as in the Ivy and Trumpet-creeper, or leaf-tendrils, - e.g. Clematis, Vetch. The Leguminosæ and Bignoniaceæ, represented in the United States by species of Wistaria and Tecoma, in the moist forests of tropical America include many "lianas" of gigantic size. 
$\because$ 


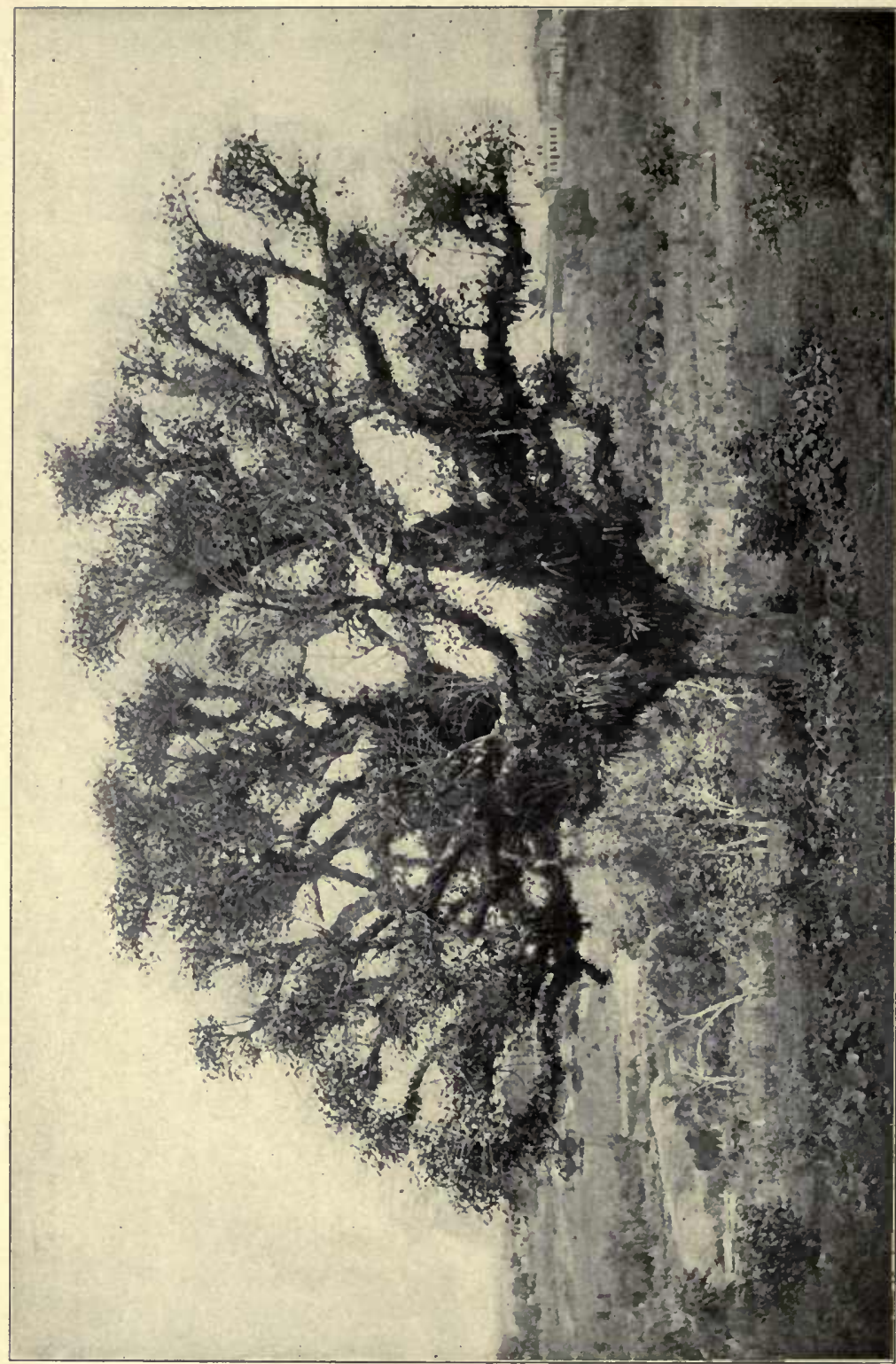

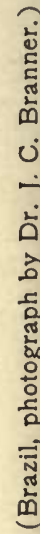

$\bar{x} \stackrel{\dot{0}}{0}$

반 을

过

a. 


\section{Arrangement of Leaves}

As a general thing, the leaves in most trees are principally confined to the younger branches at the periphery of the head of foliage. To insure perfect exposure to the light we have seen that the arrangement of the leaves is such as to prevent shading of the leaves, either by the alternate arrangement on the stem, or by the lower leaves having longer petioles, which make them project beyond the upper leaves.

\section{PROTECTION AGAINST COLD}

Plants of the colder regions must provide for protection against extreme cold. Except the Conifers, no northern trees are evergreens, and the trees become absolutely dormant during the winter. The fall of the leaves in autumn is no doubt a habit acquired by way of adaptation to winter conditions, and in such trees and shrubs, the growing point of each shoot is securely packed in the winter buds, and tightly covered with thick scale-leaves, which form a very efficient protection to the delicate organs contained within them (Fig. 473).

Many northern herbaceous plants develop underground tubers, bulbs, or rhizomes, from which are sent up in the early spring the rapidly developed shoots and flowers, which often complete their growth within a few weeks and die down to wait until the spring of the following year. This is the case with many of the early spring flowers, like the Bloodroot, Trilliums, Erythroniums, Hepaticas, and many others. These not infrequently grow under deciduous trees, and complete their growth before the leaves of the latter have expanded and thus shut off, the light.

\section{PARASITES AND SAPROPHYTES}

Normal green plants, being able to manufacture organic compounds from $\mathrm{CO}_{2}$ and water, are independent of other organisms for their carbonaceous food; but there are very many plants, especially the Fungi, which, not possessing chlorophyll, are

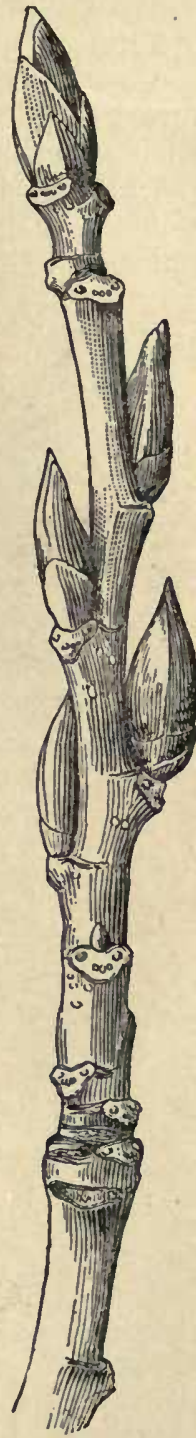

Fig. 473. - Рориlusbalsamifera, showing winter buds protected by thick resinous scales.

(After BaILEX.) 
incapable of utilizing the carbon-dioxide of the atmosphere, and are therefore either saprophytes or parasites.

Among the higher plants there are also numerous examples of such parasitic or saprophytic forms, which differ from their green relations in being more or less completely destitute of chlorophyll. Where the chlorophyll is quite absent, as in Cuscuta (Fig. 474), Monotropa, Sarcodes, etc., the leaves are reduced to inconspicuous scales, and the roots may be absent as well. These plants may be

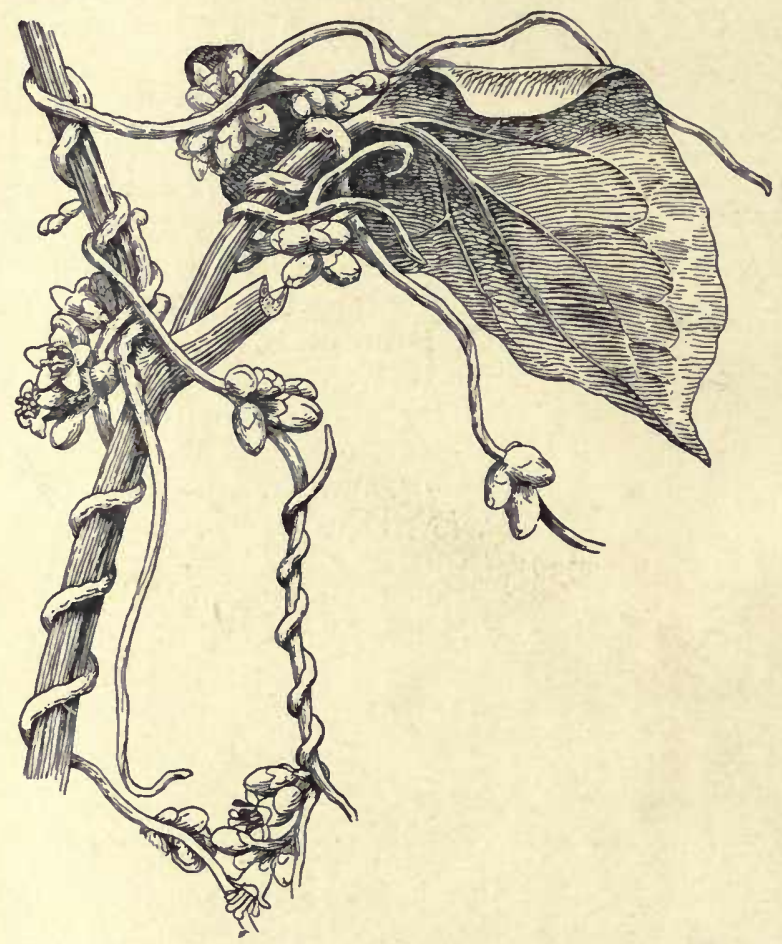

Fig. 474.-Cuscuta Gronovii. A parasite. (After BAILEY.)

parasites - e.g. Cuscuta, Epiphegus; or they may be saprophytes, e.g. Monotropa (Fig. 475), Corallorhiza. The latter are "humus plants," i.e. they grow in earth composed largely of leaf mould, from which they derive their nourishment. There are certain plants which may be called semiparasites, for while they possess chlorophyll, and can therefore assimilate carbon-dioxide, nevertheless they penetrate the tissues of other plants and take food from them. The Mistletoe and various other Loranthaceæ belong to this category; and various species of Gerardia and other Scrophulariaceæ attach 
themselves to the roots of other plants, and doubtless extract food from them.

Some of the most pronounced instances of parasitism among the higher plants are seen in the Rafflesiaceæ, where the degeneration of the plant body is so complete that it grows like a Fungus within the body of the host, finally bursting through to produce its enormous flowers.

A distinction must be made between proper parasites, which penetrate into the body of the host, and mere epiphytes, which attach themselves superficially. It is true that the latter may cause injury, or even death, to the host, by smothering or strangling it, but the epiphyte in no case feeds upon the host. A very marked instance of the destruction of the host by a purely epiphytic plant is seen in several tropical species of Ficus. These germinate upon the branches of various trees and send down aerial roots which finally reach the earth. These aerial roots finally completely

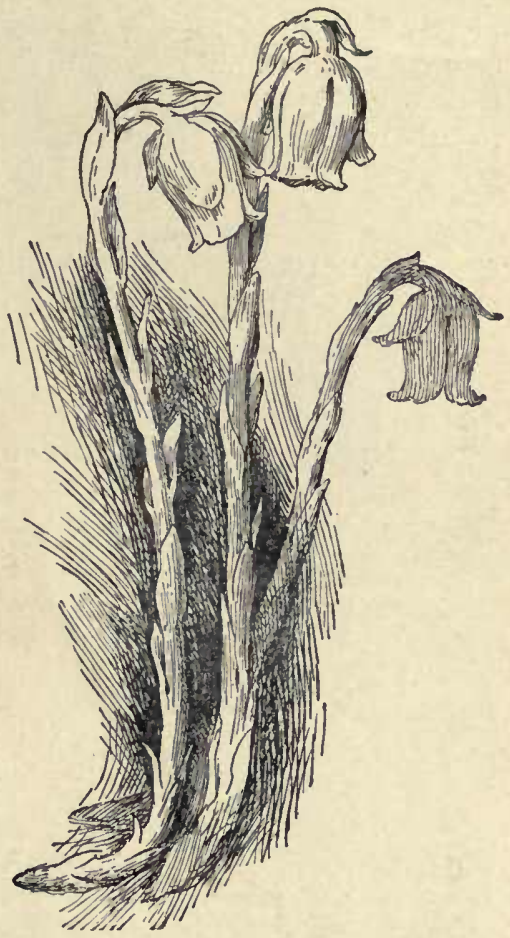

Fig. 475. - Monotropa uniflora. A saprophyte. (After BAILEY.) enclose the trunk of the host-tree, which is at last killed, leaving the Fig supported by a hollow trunk formed of the united aerial roots.

\section{CARNIVOROUS PLANTS}

Some plants, which are not properly parasites, nevertheless obtain part of their nitrogenous food from the bodies of animals which they capture. While most of these carnivorous plants belong to the Spermatophytes, it is said that certain tropical Liverworts develop traps upon their leaves, by means of which they capture small crustaceans, which they presumably use as food.

Among the Spermatophytes several types of traps are found, these being especially characteristic of certain families, e.g. Sarraceniaceæ, Droseraceæ, Utriculariaceæ, etc. The Sarraceniaceæ comprise two genera in the United States, Sarracenia of the $\Lambda$ tlantic states, and 
Darlingtonia of the Sierra Nevada. In these plants the petiole of the leaf is developed into a tubular receptacle, more or less completely covered by an overarching lid. This pitcher is often highly colored and conspicuous, and in some species attracts insects by means of a sugary secretion. The insect, entering the interior, can readily descend the walls, which are lined with downward-pointing

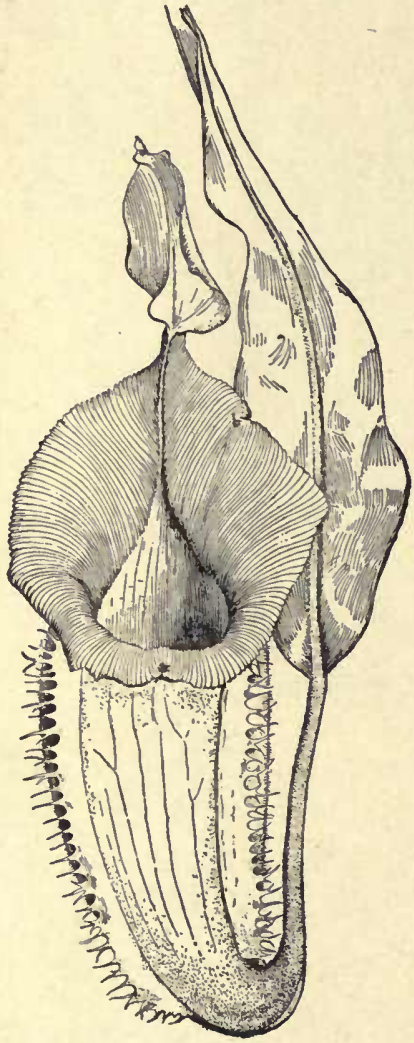

FIG. 476. - Nepenthes Veitchii. (After BAILEY.) hairs in their upper portion, but are smooth below. The cup is partly filled with a fluid secreted by the plant, and acting to some degree as

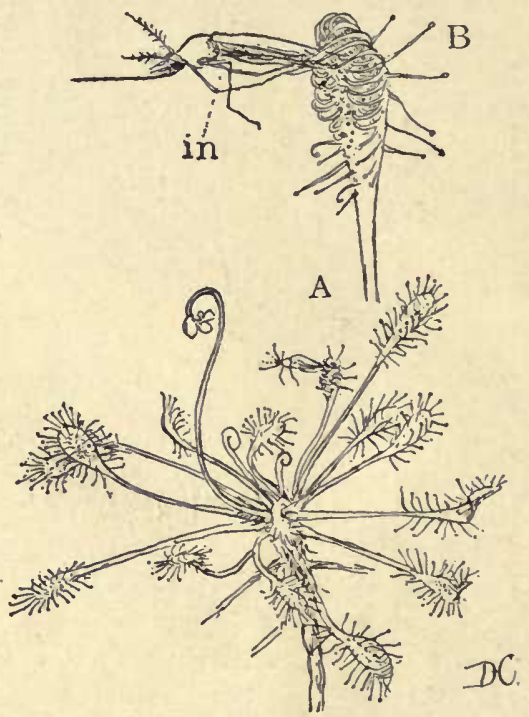

Fia. 477.-Drosera intermedia. A, plant, about natural size. $B$, a leaf, enlarged, which has captured a mosquito, in.

a digestive fluid; but the decomposition of the insects which fall into the fluid is largely due to Bacteria, which perhaps aid in putting the decomposing matter into such form that it can be absorbed by the plant. In Darlingtonia and some species of Sarracenia-e.g. S. variolaris - there are translucent spots in the hooded top of the pitcher, which perhaps prevent the imprisoned insects from noticing the real opening. In Darlingtonia, also, there is a curions forked appendage at the mouth of the pitcher, which may be an attractive body.

The pitchers of the tropical Nepenthes are produced at the ends 
of tendrils (Fig. 476), but their function is the same as those of Sarracenia.

The Droseraceæ comprise the well-known Sundews (Drosera), and the monotypic Venus's Fly-trap (Dioncea muscipula), of the bogs of North Carolina. In Drosera (Fig. 477) the leaves are either linear or spoon-shaped, in either case being more or less completely covered with reddish tentacles terminating in a knob which secretes a glistening viscid fluid. When a small insect comes in contact with these, it is held by the sticky secretion, and at the same time the leaf begins to wrap itself round its victim, which is soon rendered quite helpless, and finally killed. From small glands between the tentacles a digestive fluid is secreted, which is quite similar in its action to the gastric juice of animals, so that here there is a true digestion.

In Dionæa, the blade of the leaf is divided into two wings with spiny margins, and suggests a steel trap. Upon the upper surface of each half are three stiff hairs, which are sensitive, and when touched, as happens when an insect alights upon them, the two wings of the leaf close, so as to catch the insect in the trap, when it is digested by the action of the secretion from the surface glands.

Of the Utriculariaceæ, Pinguicula has glandular leaves, which behave much like those of Drosera, but the various species of Utricularia and Aldrovanda, which are aquatics, have little bladders upon the segments of the finely cut leaves, and these act as traps for small crustacea, and, it is said, for very young fish. The trap has the opening small, with the margins bent inward, so as to make ingress easy, but egress almost impossible. So far as known, there is no trace of a digestive process here, but the products of decomposition are absorbed, and help to supply nitrogenous food. These carnivorous plants are mostly either bog-plants or aquatics, and the root development is usually deficient. Their peculiar habits are probably to be attributed to an effort to obtain nitrogenous food.

\section{SYMBIOSIS}

By symbiosis is meant the association of two organisms, in a manner beneficial to both. The symbionts may be an animal and plant, but usually they are both plants. Of the first the best-known are the cases among various low aquatic animals, like Hydra, some species of Vorticella, Paramœcium, and other Infusoria, Spongilla, etc., in which very minute Algæ live within the bodies of these animals, which presumably derive from their assimilative activity certain food elements, giving in exchange shelter and probably nitrogenous food. The case of the Lichens, where an Alga and a Fungus are associated together, has already been discussed in a previous chapter. 
The association of Schizophyceæ and Algæ with the higher plants is by no means unknown, some species having always associated with them a specific form. Among the Liverworts, there are several-e.g. Blasia, Anthoceros - which always shelter within their tissues colonies of a species of Nostoc. Among the Ferns, Azolla always is associated with a species of Anabæua, and some Cycads have colonies of Nostoc within their roots. The nature of the symbiosis in these cases has not been critically studied, and its significance is not entirely clear.

\section{Mycorhiza}

This remarkable form of symbiosis has been referred to in the last chapter, and will not be treated further here.

Somewhat analogous to the Mycorhizæ is the rôle played by the soil Bacteria, especially those which inhabit the tubercles upon the roots of leguminous plants. The Bacteria penetrate the roots, and the formation of the tubercles is physiologically the same as the deformations of the parts of plants due to the attacks of Fungi, and the Bacteria must be considered as parasites. Nevertheless they enable the infected plants to assimilate the free nitrogen of the atmosphere, and thus more than compensate for any loss of matter due to the attacks of the Bacteria upon their tissues.

\section{REPRODUCTION}

The character of the reproductive parts of plants is often correlated with the nature of the environment, and many remarkable adaptations are connected with this, these being especially developed in the Spermatophytes; but they are by no means wanting among the lower plants.

In the Algæ the development of locomotive organs (cilia) in the zoöspores and spermatozoids is, of course, associated with their aquatic habit, and, in such of the higher plants as develop these, it is only in water that they are functional. So, also, the dehiscence of the sexual organs in the Archegoniates is dependent on the presence of water.

Where the reproductive cells are non-motile, as in the Rhodophyceæ, they are largely dependent upon chance for their distribution, and the same is true of the spores of most Archegoniates, although in these the roughnesses upon their exterior may, in some cases, make them adhere to animals, and thus be transported. The development of protective walls about resting-spores is usually more or less directly associated with the power to resist desiccation, and 
becomes still more marked in the spores of the terrestrial Archegoniates.

Among the Fungi, which are often extremely specialized forms, there are numerous instances of special adaptation of the reproductive parts associated with animals. In the Ergot (Claviceps purpurea), for example, the first-formed spores are accompanied by the production of a sweet secretion, that is attractive to insects, which are doubtless agents in the dissemination of the spores. These adhere to the insects when they are seeking the honey-like secretions. It is possible, also, that the sweetish substance exuded from the pycnidia of some of the Rusts, etc., may serve the same purpose. How far the vivid colors of many of the larger Fungi are attractive to insects does not seem to have been investigated, but it seems very doubtful whether, in most cases, these colors have any biological significance.

Odors of Fungi. - The extremely offensive odor of certain Fungi, especially the Phalloideæ, are, with little question, useful to the plants, as carrion insects are attracted by the odor, and are almost certain to carry away the spores, which in most of these are imbedded in a slimy fluid which adheres readily to the insect.

Special mechanical devices for scattering the spores are found in most of the lower plants. The violent projection of the sporangia in Pilobolus and other Moulds has been referred to, and the mechanical contrivances found in the sporangia of Mosses and Liverworts, and the annulus of the Fern sporangium, have also been sufficiently described. These mechanisms are usually regulated by the water supply, either by the rapid absorption of water, as in Pilobolus, or to hygroscopic action, as in the movements exhibited by the elaters of Liverworts, or the annulus of the sporangium in the Ferns.

Spermatophytes. - It is among the spermatophytes that the most perfect adaptations of the reproductive parts to their environment are found. The pollen-spores are adapted to transportation by the wind or by insects, or occasionally by other animals. In the former case they may be provided with special buoyant organs, like the inflated appendages of the pollen-spores of the Pines. Where insects are the agents of transportation, the outer surface of the spores is generally rough, or viscid, so that they adhere readily to the insect's body.

\section{Distribution of Seeds}

Among the Gymnosperms the distribution of the seeds is usually, like that of the pollen, due to the wind. Very often, as in the Pines and Firs, the seed is surrounded by a winged appendage, derived from the scale upon which the seed is borne. This forms a very efficient sail, and enables the seeds to be carried to a great distance. 
Less commonly, as in some of the Cycads and Ginkgo, and species of Ephedra, the outer part of the seed becomes fleshy and edible, and probably attracts animals, which help to distribute the seeds;

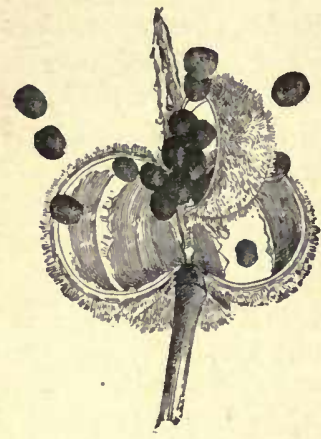

Fig. 478. - Impatiens balsamina, showing explosion of the ripe capsule. (After Bailey.) and in Juniperus the scales of the cone become sweet and pulpy, and are readily eaten by birds, through whose bodies the seeds pass uninjured.

Among the simpler Angiosperms the seeds are borne in dry carpels, which are often indehiscent, and there is no special provision for the distribution of the seeds; which fall off, and must depend on being washed or blown away, in order to be distributed to any considerable distance.

In the better-developed forms the carpels develop into a definite capsule, which often opens in such a way as to scatter the seeds with a good deal of force. This is illustrated by species of Viola and Impatiens (Fig. 478).

The provisions for distributing seeds through the agency of the wind are numerous and varied. In many plants - e.g. Bignonia, Catalpa, Tecoma, etc. - the seeds are provided with delicate membranaceous wings, similar to those in the Pine. In others, like the Milkweed (Asclepias), Willow-herb (Epilobium), Cotton, and many besides, the appendages of the seed are delicate hairs, which serve the same purpose as the flat wings of other seeds.

Sometimes it is the fruit containing the seed which bears the flying apparatus. This is seen in such winged fruits as those of the Elm and Maple, or the down attached to the fruits of many Compositæ, like the Dandelion and Thistle.

\section{Transportation by Water}

While many seeds and fruits are distributed by air-currents, some forms depend upon water for their transportation. Of the few forms which are regularly transported by salt water, the Cocoanut is perhaps the best known, the fibrous pericarp perfectly protecting the enclosed seed from the injurious action of the salt water. While but few forms of seeds and fruits are specially adapted to water transport, nevertheless, the current of large rivers is an important factor in the distribution of seeds and fruits, which are either floated free in the water, or carried along with masses of débris washed down from the banks. 


\section{Edible Seeds and Fruits}

Most seeds contain starch and other reserve-food which makes them suitable for the food of animals. In collecting these for food, and especially when these are stored, some are pretty sure to escape being eaten, and may be carried away and dropped at some distance from where they were gathered. So, also, seeds imbedded in mud may adhere to the feet of birds or animals, and thus be transported. These cases must be considered as more or less accidental, however, and there is no question of special adaptability.

Very different is the case of fruits in which the edible part is not the seed, but consists of a pulp in which the seeds are imbedded. Such edible fruits are in most cases obviously specially developed to facilitate the distribution of the seeds. The sweet pulp of these is often an important article of food, and the bright colors of such edible fruits may be looked upon, in many cases, as attractive to animals in much the same way that the colors of flowers attract them.

In some instances the pulp is eaten away and the seeds dropped upon the ground, or, where the seeds are small, and completely imbedded in the pulp, the whole fruit may be swallowed, and the seeds pass through the digestive tract without being injured. Birds are especially important in thus distributing seeds.

\section{Adhesive Fruits and Seeds}

Some seeds - e.g. species of Araceæ, Mistletoe, various tropical Loranthaceæ - develop a viscid substance either from the seed itself, or from the fruit, and this causes the seeds to adhere to the bodies of animals, especially birds, which thus transport them to other trees, to whose branches they may be transferred, and so establish themselves. Such adhesive seeds usually belong to epiphytic plants.

A nother sort of attachment is effected by the hooks, bristles, and similar organs with which the fruits of many plants are provided. The barbed awns

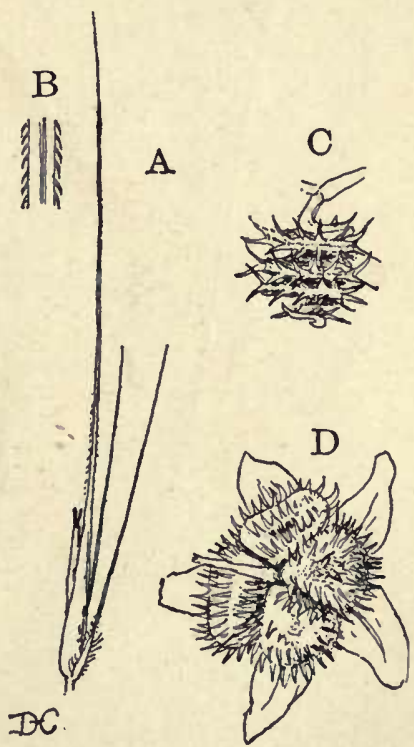
of certain Grasses, the rough spines of Bur-marigold (Bidens), the hooked burs of Clotbur (Xanthium) or Hound's-tongue (Fig. 479), 
etc., are familiar examples of these extremely efficacious adaptations. While these appendages usually belong properly to the fruit itself,

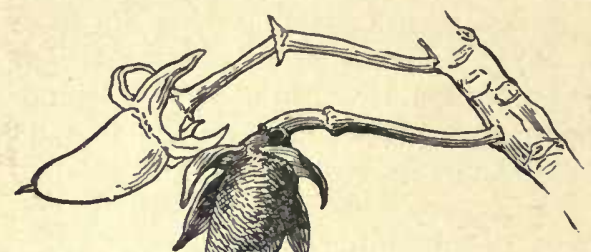
sometimes, as in the Burdock (Lappa), the hooks are appendages of the involucral leaves surrounding the head of fruits.

The Compositæ, the largest family of the Spermatophytes, offers an especially great variety of these devices for distributing the seeds, the efficiency of which is attested by the extraordinary success these plants have shown for holding their own in the struggle for existence.

\section{Pollination}

Many of the most remarkable modifications of plants are connected with the pollination of flowers. In the lower types of Spermatophytes, especially the Gymnosperms, the conveyance of the pollen to the ovule is largely the result of chance, and depends upon the wind. Wind-pollination is also known as "Anemophily." Still, as the pollen and ovules are produced in different flowers, crossfertilization is effected. In the lower Angiosperms, like the various Amentaceæ, i.e. Oaks, Poplars, etc., wind-pollination is the rule, and, in these forms, diclinous flowers prevail, so that self-pollination is precluded. Other characteristic groups of wind-pollinated plants are the Palms, Grasses, and Sedges. In all such forms the amount of pollen is very large and the pollen-grains are smooth and small, so that they are readily

Fra. 480. - Rhizophora mangle. Fruit germinating before it falls; $a$, the point where the enlarged hypocotyl becomes detached. (After BAILEY.)

carried by the wind. The stigma is frequently long and feathery, so that it readily catches the pollen-spores which fall upon it.

In most of the anemophilous trees of northern regions, the flowers 
appear before the leaves unfold, so that pollen more readily reaches the pistillate flowers. Where anemophilous flowers are hermaphrodite, they are almost always dichogamous, i.e. stamens and pistils mature at different times, so that self-fertilization is impossible.

\section{Hydrophilous Flowers}

A few water-plants have special modifications for pollination. In the submersed flowers of Naias, Zostera, Phyllospadix, etc., the pollen-spores are more or less elongated, sometimes threadlike, and are thus more easily caught by the stigma. In Vallisneria the staminate flowers, which are enclosed in a spathe-like envelope, break away at maturity, and rise to the surface of the water, where they open and

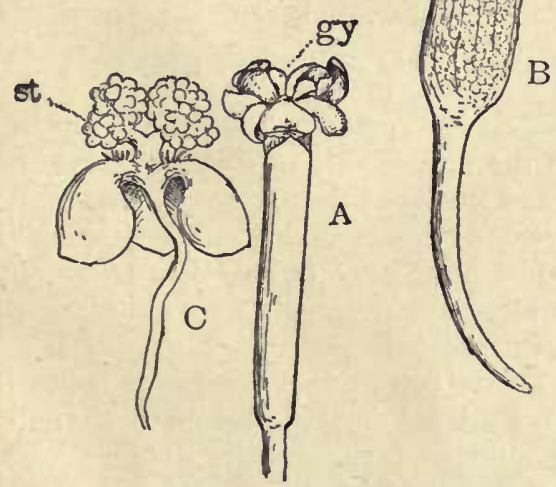

Fra. 481.-Vallisneria spiralis. A hydrophilous plant. $A$, pistillate flower ready for pollinatiou. $B$, male inflorescence. $C$, single open staminate flower, enlarged; the reflexed sepals serve as floats.

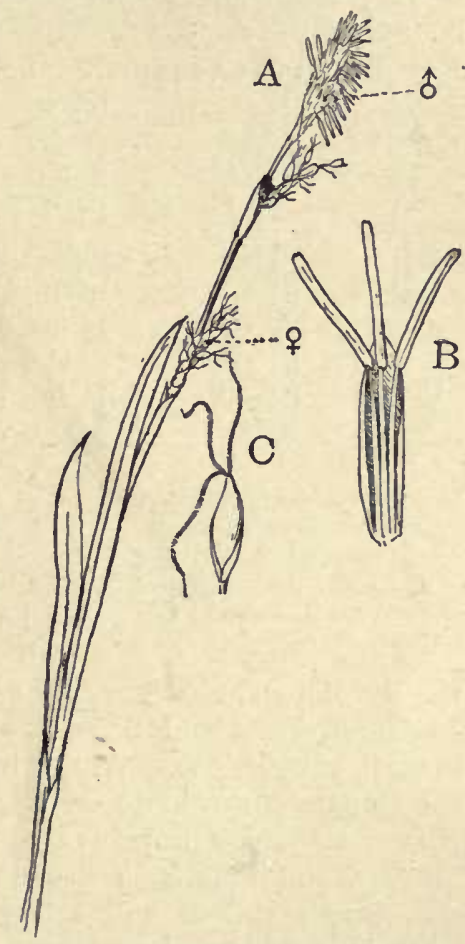

Fig. 482. - Carex sp. An anemophilous plant; the staminate flowers, $\delta$, are placed above the pistillate ones, \&. $B$, staminate flower, enlarged. $C$, pistillate flower.

float about until they come in contact with the expanded stigmas of the pistillate flowers which lie at the surface when ready for pollination. After the pollen is deposited upon the stigmas, the female flower is drawn beneath the surface of the water by the coiling of its stalk, and the fruit ripens under water. 


\section{Entomophilous Flowers}

Dichogamy. - In the majority of the Angiosperms the stamens and carpels are borne together in the same flower, and yet it is found that, as a rule, the pistil is not pollinated from the stamens of the same flower. The simplest device by which self-pollination is prevented is the maturing of the stamens and carpels at different times (Dichogamy). In case the stameus mature first, it is known as Proterandry; if the pistils are first mature, Proterogyny. The former is very common, the latter less so. Examples of proterandry are offered by the various forms of garden Geraniums (Pelargonium) and Nasturtium (Tropæolum). One of the commonest examples of pro-

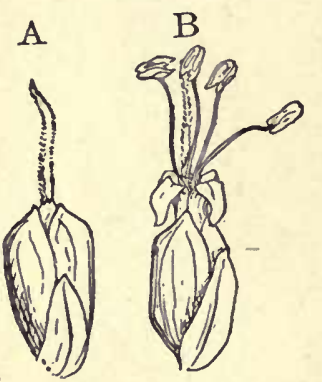

Fia. 483. - Plantagomajor. A proterogynous plant. $A$, younger flower, the pistil mature. $B$, older flower, with mature stamens. terogyny is the common Plantain (Plantago major) (Fig. 483). The younger flowers of a spike show the stigmas protruding before the stamens discharge their pollen. In the older flowers, where the stigma has already been pollinated, the stamens are conspicuous. Many Araceæ are also proterogynous.

Unless the flowers are close together, as in the Plantain, so that pollen from an older flower may be easily shaken upon or blown to a younger flower, some special agent must be sought to carry the pollen, and this is generally found in some insect, although other animals, especially snails, and birds, may be the agents. It is insects, however, which are the most important agents, and the development of the two great divisions of plants and animals - Angiosperms and Insects - has been very largely the result of mutual adaptations. Where insects are the agents in pollination, the flowers are said to be Entomophilous.

It is extremely probable that all the primitive flowers were anemophilous, and that from these have been derived the more specialized entomophilous and ornithophilous forms. It is evidently of advantage to the plant to have the great waste of pollen necessitated by wind-pollination reduced, and this is possible when insects or birds are the agents in its transfer. It is probable that entomophily began by the casual visits of insects to flowers, attracted by the pollen, which is still the principal object of visits by many insects, serving as an important source of food. Flowers which had more conspicuous stamens or perianth would stand a better chance of visits from insects, and, from the slight variations thus started, may have proceeded the development of the conspicuous flowers of the modern entomophilois plants. 
That the development of the showy parts of the flower is correlated with the visits of insects is readily seen by comparing

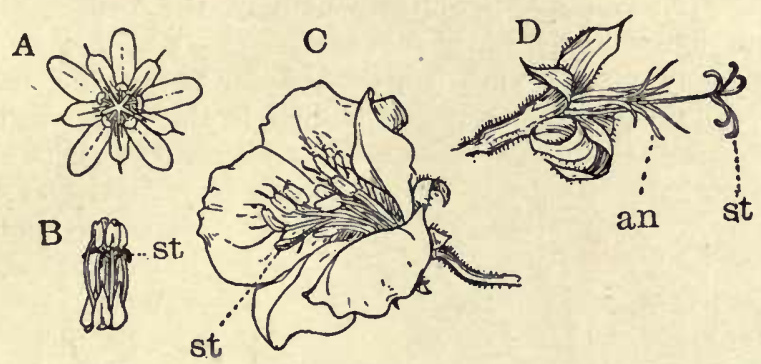

Fig. 484.- $A, B$, Erodium cicutarium, self-pollinated stamens anu pistil maturing at the same time (enlarged). C, D, Pelargonium sp., cross-pollinated. In Pelargonium, the stigma, st, is immature when the stamens shed their pollen. $D$, stamens and pistil from an older flower, the stigma, st, receptive.

closely related species of plants which differ in this respect. Some species of Ranunculus, for example, like $R$. sceleratus, have insignifcant flowers which are not visited by insects, while the showy species, like $R$. acris or $R$. Californicus, are freely visited by insects. So, in the genus Geranium, the inconspicuous flowers of $G$. molle are self-fertilized, while the showy flowers of the Crane's-bill (G. maculatum) are adapted to insect pollination.

In the simpler entomophilous flowers, like Ranunculus or Portulaca, the petals are nearly uniformly colored, but in more specialized forms there may be definite spots or streaks of sharply contrasting colors, such as the black markings in a Pansy, or the spots in a Foxglove. While the significance of these markings is not in all cases clear, it is pretty certain that they are in some cases guides to the nectaries, or honey-secreting organs of the flower.

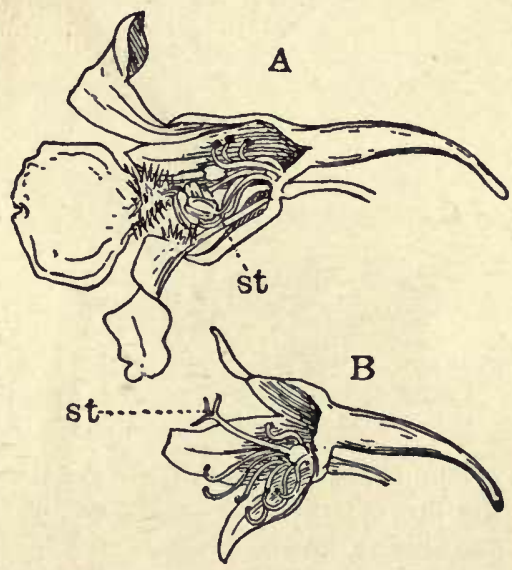

Fig. 485. - Tropæolum majus. A, young flower cut lengthwise to show the immature pistil, st, and the position assumed by the stamens as they discharge the pollen. $B$, pistil, st, and stamens from an older flower; the stigma is open, but the stamens have discharged their pollen.

The color of the flower is often associated with its attractiveness to special insects or birds. Yellow is probably the commonest, and perhaps the most primitive color, and next to this, white; blue, 
violet, and red seem to be more specialized colors, and are found in many of the most highly developed flowers. Red flowers are especially attractive to humming-birds, which are the principal agents in the pollination of many scarlet flowers.

While many insects visit the flowers for the pollen, most entomophilous flowers produce nectar, which is the principal object of

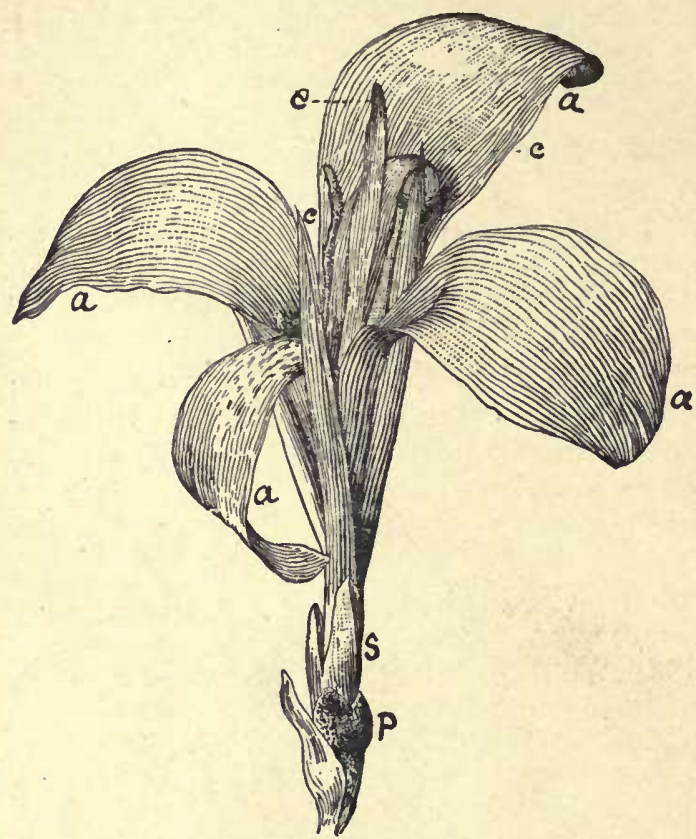

Fig. 486.-Canna sp. The petals, $c$, and sepals, $s$, are inconspicuous, the showy part of the flower being the petaloid stamens, or staminodia, $a$. (After BaILey.) the visits of insects and birds.

The more primitive types of flowers usually are actinomorphic, and are widely open so that they are accessible to a great variety of insect visitors. Such flowers as Ranunculus, or Rosa, are of this character, and the wide-open heads of many Compositæ, although decidedly more specialized than the former flowers, nevertheless are visited by many kinds of insects.

These entomophilous flowers are almost always conspicuously colored, and the petals are in most cases the showy part of the flower. Sometimes, however, as in Anemone (Fig. 487), the petals are absent, and the sepals are large and petaloid. In Fuchsia both sepals and petals are showy, and the same is true of most Monocotyledons. Sometimes, as in the flowering Dogwood (Cornus florida), species of Euphorbia, many Araceæ, Bougainvillea, etc., the flowers are inconspicuous, but are surrounded by showy bracts, which make the inflorescence conspicuous. Less frequently it is the stamens which make the flower noticeable, as in Eucalyptus, where the petals are undeveloped, but the numerous white or red stamens are very showy. Among Monocotyledons the genus Canna is notable for the brilliant petaloid stamens which constitute the attractive part of the flower (Fig. 486). 
Odors. - The characteristic odors of flowers are also associated with the visits of insects. While these are usually pleasant, many flowers develop odors suggestive of carrion, and are exceedingly offensive. Such flowers are commonly dullcolored, often marked with livid blotches or veins, like dead animal bodies, and attract carrion insects, especially flies and carrion beetles, which sometimes lay their eggs upon them and are the agents in pollination. Among these ill-scented flowers are many Araceæ, species of Stapelia, Smilax, Trillium erectum, Aristolochia, and others.

Nocturnal Flowers. - Nightblooming flowers are very generally white or light yellow in color, and often heavy-scented, the odor being especially noticeable at night. Among the most conspicuous of the nocturnal insects which are important agents in the pollination
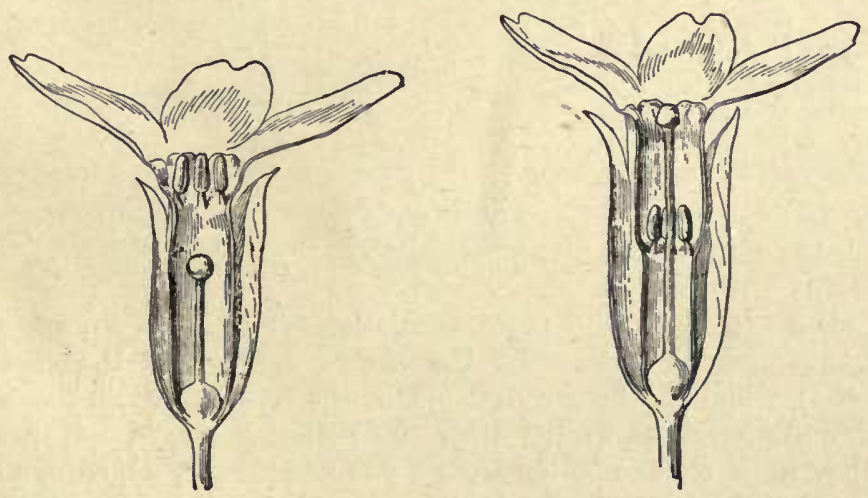

Fig. 488.- Primula polyantha. Showing dimorphic flowers. (After BAILEy.)

of these flowers are the hawk-Inoths, or Sphingidæ, which are especially adapted to such tubular flowers as Honeysuckle and Eveningprimrose. The long, slender, tubular flowers of such plants are 
especially fitted to the long tongues of these insects, which are frequently met with about these flowers, especially at dusk. Other moths are also agents in pollinating nocturnal flowers.

Preventions against Self-pollination. - In the most specialized entomophilous flowers self-pollination is often impossible, owing either to the relative position of the stamens and pistil, or to their maturing at different times. In the less specialized forms, such as many species of Ranunculus, while the flowers are visited by many insects which usually effect crossfertilization, still, where
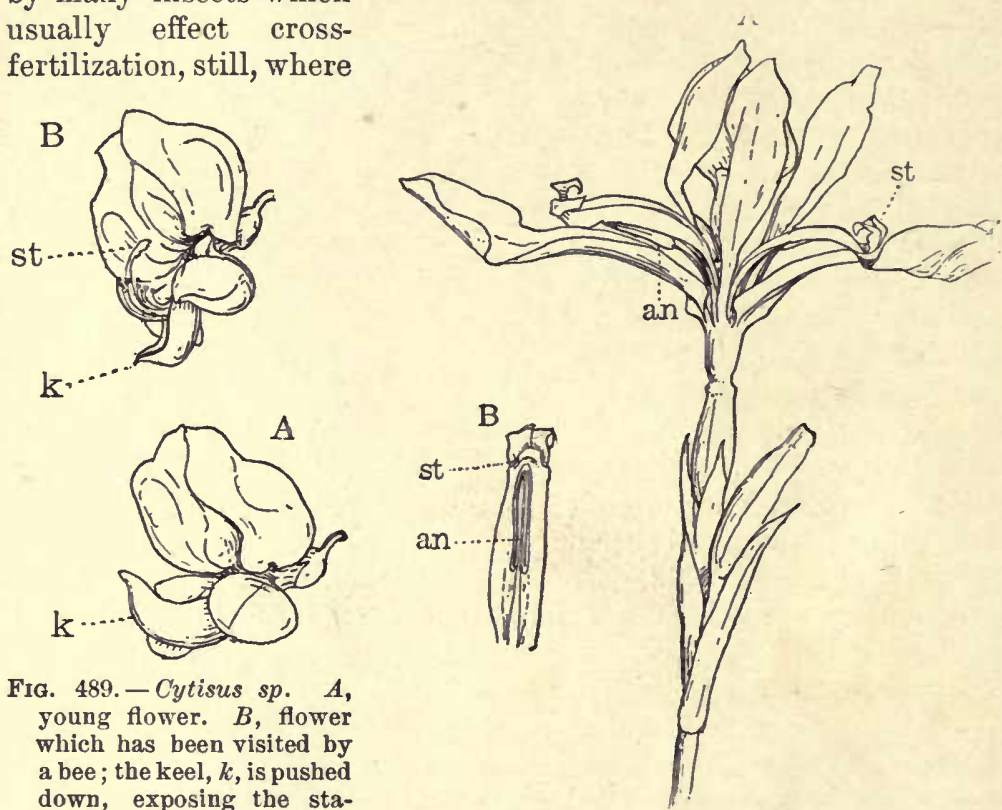

Fig. 489.-Cytisus $s p . \quad A$, young flower. $B$, flower which has been visited by a bee; the keel, $k$, is pushed down, exposing the stamens and pistil, st.

insect visits are prevented, the flowers can pollinate themselves.

Fig. 490. - Iris versicolor. A, flower showing the position of the stamens, an, under the overarching petaloid styles. $B$, under surface of the style, showing position of stamen, an, and stigma, st.

It is otherwise with the more specialized flowers, especially with most zygomorphic ones. In the showy species of Pelargonium (Fig. 484), when the flower first opens, the five stigmatic lobes are closed, and do not open until after the pollen has all been shed, so that they must receive pollen from a younger flower, which can only be done through the visits of insects. In Tropæolum (Fig. 485) the same thing is true, and here the flower is more modified, the two upper sepals being prolonged backward into a spur-shaped nectary, which is accessible only to insects with long tongues, especially bumblebees. Humming-birds are also frequent visitors of these 
flowers. In the freshly opened flowers the stamens are curved upward in front of the opening of the spur, and as they successively discharge their pollen they bend downward, and their place is taken by the three-parted stigma, which is thus in position to be dusted with pollen by any insect or bird which has previously visited a younger flower, and without such visitors the pistil must remain unpollinated. Similar tubular nectaries are found in the Larkspur and Columbine, which are visited by similar insects and humming-birds.

In many tubular zygomorphic flowers such as the Foxglove (Digitalis), Pentstemon, Gladiolus, many Labiatæ and Scrophulariaceæ, the stamens are pressed against the upper arching lip of the flower, while the stigma hangs with its stigmatic surface turned away from and hanging below the stamens, in such a position as to be readily pollinated by a bee on its arrival with a cargo of pollen taken from a younger flower, but usually is not mature when the pollen of its own stamens is shed; and, moreover, pollen falling from the stamens lodges on the back of the stigma and not upon its receptive

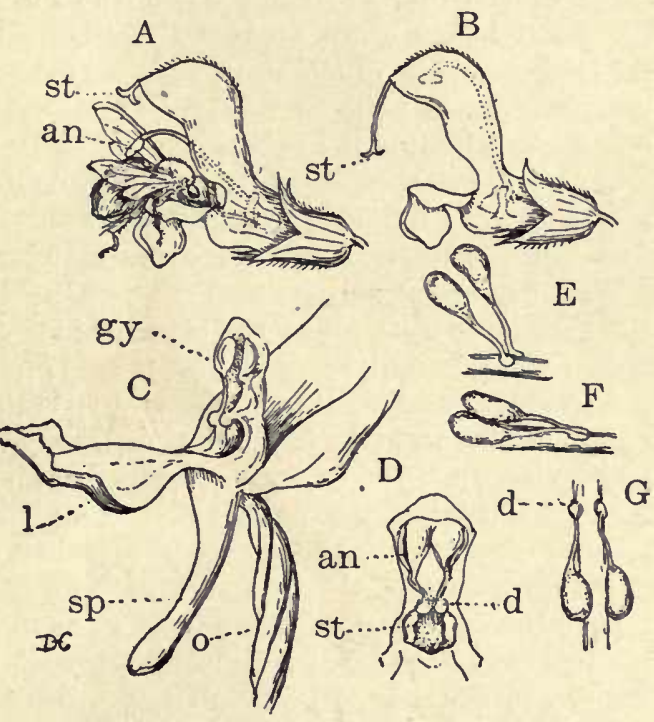

FIG. 491. $-A, B$, Salvia pratensis, illustrating pollination. $B$, an older flower. (After NoLL.) $C-G$, Orchis spectabilis. $C$, flower with the upper part of the perianth bent back to show the relative positions of the lip, $l$, and column, $g y . D$, column seen from in front; an, stamen; st, stigmatic surfaces; $d$, disk, at base of the pollinium. $E-G$, successive positions assumed by the pollinia after being removed from the anther.

surface. When a bee enters one of these bilabiate flowers, it clings to the lower lip and creeps more or less completely into the flower, thus bringing its back against the open anthers and carrying away the pollen, which is transferred to the stigma of the next flower it visits.

In various species of Salvia (Fig. 491) there is a special apparatus for insuring cross-fertilization. The stamens are reduced to two, and in these the connective of the anther is very much developed, and only one lobe of the anther produces pollen, the other forming a 
small knob at the end of the long connective, which is balanced upon the short filament so that it oscillates readily when the lower end is touched. This lower end is placed near the entrance of the nectary, and a bee, probing the throat of the flower, pushes against the lower end of the connective, whose upper, pollen-bearing end is forced down with a spring against the back of the bee, upon which it deposits the pollen, resuming its original position when the bee backs out of the flower. At this time the pistil is relatively short, and out of reach of the insect's body; but if the insect visits an older flower, the pistil hangs down, so that the stigma is directly in the way of its back, against which it in turn strikes, and receives the pollen brought from a younger flower. 'If insects are excluded from the flowers, pollination is impossible.

The various species of Iris offer excellent examples of strictly entomophilous flowers. In these the stamens are three in number, and quite concealed by the overarching petaloid styles, against which they are closely pressed (Fig. 492). The stigma forms a little shelflike outgrowth above the stamens, but quite out of reach of any pollen which might be accidentally shed from them, and also having the receptive surface turned outward so that an insect drawing away from the flower, after having carried off the pollen, does not leave any pollen upon the stigma. If, however, it visits another flower, as it crowds between the petal and the style, the edge of the'stigma scrapes off any pollen that may be attached to it.

Sensitive Parts. - In a number of flowers certain parts are sensitive to touch, and these are mostly concerned with the question of pollination. One of the simplest cases is seen in the stamens of various species of Berberis. 'These, when tonched near the base, as happens when a bee is probing for honey, will spring violently inward, shaking off the pollen, and scattering it upon the insect visitor. Somewhat similar is the case of Kalmia, where the stamens are bent over into little pockets, from which they spring out when touched, throwing the pollen to some distance. In many Leguminosæ-e.g. species of Cytisus (Fig. 489) - the pollen is deposited in the pouch formed by the coherent keel-petals. When a bee lights upon the flower, these are pushed down, and the stamens are liberated suddenly, sending out the mass of pollen in a little cloud, which dusts the body of the insect. At the same time the stigma is exposed, and is ready to be pollinated by the next bee which visits the flower.

In the Milkweed family there are a number of devices for insuring the transference of the pollen to the stigma, but these sometimes result disastrously to the insect. The pollen in the common Milkweed (Asclepias) is in little pear-shaped masses or pollinia, which are united in pairs, and must be withdrawn from the anthers, either by the proboscis of a butterfly or bee, or sometimes by the legs of 
the insects being inserted into the clefts through which the pollinia are withdrawn. It sometimes happens that the insect becomes entrapped, by not being able to withdraw the member, and may thus perisl. A plant belonging to the Milkweed family, Physianthus albens, a climber occasionally cultivated for ornament, is especially noted for its habit of capturing insects.

Orchids. - The Orchids offer innumerable examples of special adaptation to insect pollination, but only one or two of the simpler types can be given here. The numerous species of Orchis, and in America the species of Habenaria, including the handsome Fringed Orchids, are examples of a claracteristic arrangement. As in Asclepias, the pollen is aggregated into two pollinia, which are separate, each occupying one lobe of the single stamen. Each lies in a sort of pocket, its lower tapering end terminating in a little viscid disk, which is covered by a delicate membrane. The disks lie just above the opening of the spur into which the lip of the flower is prolonged, and which is the nectary. An insect searching for honey is sure to strike against the membrane covering the viscid disks, and this being broken, the insect's body is brought into direct contact with the viscid substance of the disks, which become at once firmly cemented to it. The insect, as it withdraws from the flower, drags the pollinia out of their receptacles and carries them away. The two pollinia change their position almost at once, and bend forward in such a way, that if the insect visits another flower, they strike against the two stigmatic surfaces which lie on each side of the entrance to the spur, below the disks of the pollinia (Fig. 492).

In the Lady's-slipper (Cypripedium), unlike most Orchids, there are two perfect stamens, one on each side of the column. These are pollinated mostly by bees, which enter the sac-shaped lip in front, where they can strike the stigma, but they can only escape at the sides, where they scrape off the pollen from the stamens. There are no pollinia, but the pollen-grains are separate, as in most other flowers, but covered with a viscid secretion which makes them adhere to the stigma of the next flower which is visited.

Araceæ. - In many Araceæ and Aristolochiaceæ the large spathe, or tubular perianth, is constricted near the base, and the cavity below the constriction has above it downward-pointing, stiff hairs, which enable the insects to enter it, but imprisons them, as they cannot creep out against the hairs. This continues until the stamens have shed their pollen, when the hairs wither, allowing the imprisoned insects, with their load of pollen, to escape.

Yucca. - One of the most extraordinary cases of the mutual dependence of an insect and a flower is found in the species of Yucca, a peculiarly American genus, especially abundant in the deserts of the Southwest, but better known by the common $Y$. filumentosa, of 
the Southern Atlantic states, and common in gardens. Most species of Yucca depend for their pollination upon a small nocturnal moth of the genus Pronuba. This moth deposits its eggs within the ovary of the Yucca, and the larvæ feed upon the young seeds. In order that the flower may be fertilized, and the ovules developed into the seeds necessary to nourish the larvæ, the moth deliberately collects a quantity of pollen, which it pushes into the cavity at the apex of the stigma, thus insuring the fertilization of the ovules. In most species of Yucea this is absolutely necessary in order that seeds may be formed, and if the insect is absent the flowers will all remain sterile. The larva of the Pronuba does not destroy all the seeds, a considerable number remaining uninjured in the ripe capsule.

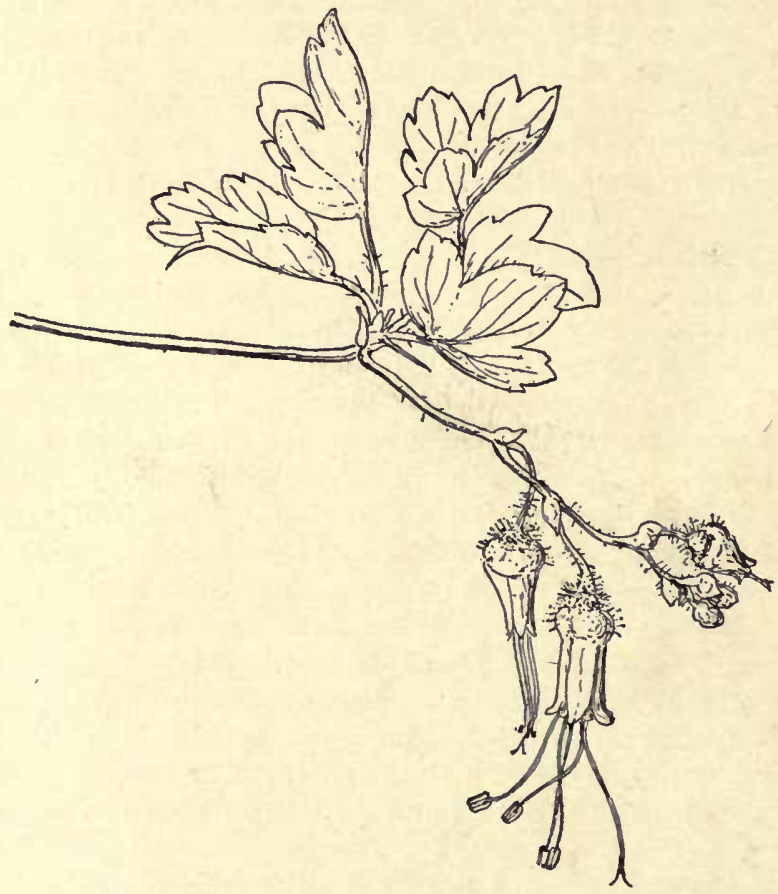

FIG. 492. - Ribes speciosum. A characteristic humming-bird flower.

\section{Ornithophily}

In America the humming-birds are important agents in pollinating many flowers, this being especially the case in tropical America, where the number of species of humming-birds is very great, and many flowers are especially fitted to their visits. In the Old World 
the sunbirds and honeysuckers are also agents in pollination. Most humming-bird flowers are tubular in form and vivid red in color, the flowers drooping or resting horizontally, so that they can be reached by the slender tongue of the bird as it hovers before the flower. Although but a single species of humming-bird occurs in the Northeastern states, a number of flowers are especially adapted to its visits. Of these the Coral-honeysuckle (Lonicera sempervirens), Columbine (Aquilegia Canadensis), Cardinal-flower (Lobelia cardinalis), Monarda didyma, Trumpet-creeper (Tecoma radicans), may be mentioned. In California the number of humming-birds is much greater, and there is a corresponding increase in the number of flowers adapted to their visits. Among the characteristic forms are the Scarlet-currant (Ribes speciosum, Fig. 492), various species of Castilleia, Zauschneria Californica, Mimulus cardinalis, probably also the scarlet species of Pentstemon, Gilia, Silene, etc.

Of garden flowers, the Cannas, Scarlet-sage (Salvia splendens), and Fuchsias are all humming-bird flowers.

\section{Heterostylism}

A peculiar arrangement for insuring cross-pollination occurs in the so-called heterostyled flowers. In these there are two, and sometimes three, types of flowers, differing in the relative length of the pistil and stamens. The long-styled flowers have short stamens, and vice versa. Where three lengths of the pistil occur, as in Lythrum salicaria and Pontederia cordata, there are two sets of stamens in each flower, corresponding in length to the other pistils, so that the part of the body of the insect which comes in contact with the stamens of a certain length will deposit it upon the pistil of corresponding length in another flower. In these trimorphous flowers it has been found that the size of the pollen-grains differs greatly in the long and short stamens, and the long-styled flowers are only imperfectly fertilized by the pollen from the shorter stamens. Of dimorphous flowers, or those with two lengths of pistil, may be mentioned various species of Primula (Fig. 488), many Borraginaceæ, like Myosotis and Mertensia; Epigcea repens, and others. In the California Poppy, Eschscholtzia Californica, the flowers are imperfectly heterostyled, longer styles being present in some flowers, and adapted to cross-pollination, while the short ones may be self-pollinated.

\section{Autogamy}

While most showy flowers are adapted to cross-pollination, it not infrequently happens that they are capable of self-pollination in 
case insect visits are prevented. It usually happens that such flowers are at first incapable of self-pollination, owing either to the pistil and stamens maturing at different times, or to their relative positions, so that usually cross-fertilization is effected. Should this early stage pass without insect visits, it may happen that the pollen is deposited upon the stigma of the same flower by a change in the position of stamens and pistil, or by some other contrivance. Thus in the Prickly-poppy (Argemone) the pollen falls from the stamens into the concavity of the widely spread petals. When the flower closes at night, the pollen is deposited npon the stigma, insuring fertilization in case insects have failed to visit the flower during the day. The same thing takes place in other widely expanded flowers which close at night.

Special inconspicuous flowers which never open, and are strictly autogamous, are found in a number of plants which also produce showy flowers. These Cleistogamous flowers are formed abundantly in the Jewel-weed (Impatiens fulva) and in various species of Violets, as well as other plants.

\section{Protection of Pollen against Moisture}

Except in the case of a few submersed aquatics, like Naias and Zostera, the pollen is quickly destroyed if it is placed in water, as the dense contents absorb water so quickly that the osmotic pressure bursts the pollen. It is therefore important that the pollen should be protected against wetting by rain or dew. This accounts for the drooping position of many flowers, and the overarching of the stamens by the petals which occurs in many others. Probably the closing of flowers at night and in cloudy weather is a provision against wetting, and in a few cases, like the Laurel, the pollen-sacs open by lids, which close when the stamen is moistened, and thus guard the enclosed pollen against wetting.

\section{Protection against Animals}

There are many devices by which plants are protected against the attacks of animals. These attacks may be in the way of robbing the plant of nectar or pollen, without being useful in pollination, or they may be attacks by animals which feed upon the leaves and stems of the plant. Of the first kind are the visits of small creeping insects, like ants, or the attacks of slugs and snails. The visits of the former may be prevented by the development of sticky glandular hairs upon the stalks and outer leaves of the flowers, a very common device in many plants, such as species of Catch-fly (Silene), Tomato, Petunia, and other "clammy-pubescent" plants. It is possible that 
the smooth waxy coating of the stems of other plants - e.g. Bloodroot (Sanguinaria), Dicentra, etc.-may be useful in preventing the ascent of creeping insects. Within the flower, also, there may be densely set hairs, which are impenetrable by the smaller insects that would rob the flower of honey but not assist in pollination. The dense felted masses of hairs at the base of the stamens in Cobcea scandens are examples of this, and the similar hairs upon the stamen-filaments in Tradescantia and other flowers are probably of the same nature.

Protection of Xerophytes. - The great development of thorns, spines, and bristles, especially in plants of dry regions, is largely protective, as these plants are especially liable to injury from hungry herbivorous animals. The dagger-leaves of the desert Yuceas and Agaves, and the terrible spines of the Cacti, are admirable examples of the efficiency of such protective structures, and the thistles and brambles of roadsides illustrate the same thing on a smaller scale.

Odors. - The strong odors and the poisonous or at least distasteful latex of many plants are probably also protective in their nature.

\section{Myrmecophilism}

Among the most remarkable instances of symbiosis between plants and animals is Myrmecophilism, or the association of ants with various plants for protection, or otherwise. The frequent presence of nectar glands upon leaves and stems, e.g. those on the petioles of species of Populus, Cherry, Ricinus, etc., is usually associated with the visits of ants, which protect the plants from the attacks of injurious insects, or even ward off the attacks of large herbivorous animals, which are attacked by the ants.

Much more remarkable are the various tropical myrmecophilous plants which provicle shelter for ants, in return for protection from other ants, principally leafcutting forms. Among the first described forms of these plants were species

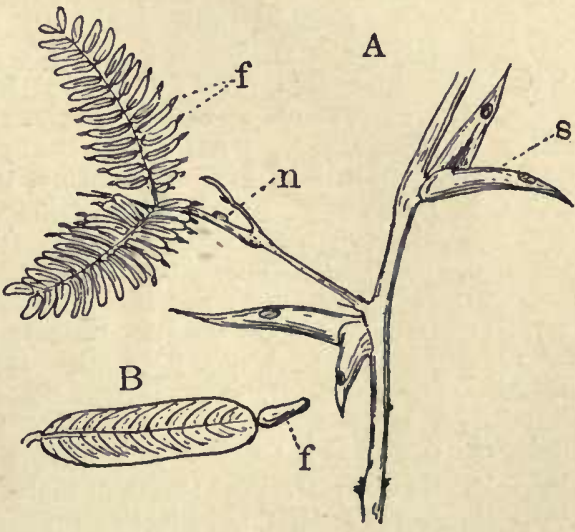

Fig. 493.-Acacia sphærocephala. A myrmecophilous plant. Ants live in the enlarged hollow thorns, $s$, and feed upon the special food-bodies, $f$, developed upon the leaves. (After NolL.) of Cecropia, a tropical genus of American trees. These possess hollow stems, within which ants live. There are also produced 
upon the petioles special food-bodies which are eaten by the ants. A similar provision is found in a species of Acacia (A. sphcerocephala), which provides food-bodies upon its leaves, and develops large hollow thorns which serve as domiciles for the ants (Fig. 493).

The genus Myrmecodia of Java comprises plants which develop a large tuber-like stem, which contains extensive chambers in which dwell colonies of ants. It was supposed that the formation of these chambers was caused directly by the presence of the ants; but it has been shown that they may form without the presence of the ants, and that the chambered tuber is probably a provision for storing water, and not primarily an adaptation to shelter the ants.

The leaf-cutting ants, of which a number occur in the Southern states, offer a very remarkable case of symbiosis, in this instance with a Fungus. The leaves which they, cut from various trees are carried into their subtcrranean dwellings, where they are packed together to form a sort of miniature hotbed, upon which, in course of time, a peculiar Fungus mycelium develops. These Fungi produce at the tips of the hyphæ abundant swollen bodies which are greedily eaten by the ants.

\section{BIBLIOGRAPHY}

'99. 1. Atkinson, G. F. Elements of Botany. New York, 1899.

'88. 2. Belt, Th. The Naturalist in Nicaragua. 2d edition. London, 1888.

99. 3. Campbell, D. H. Lectures on the Evolution of Plants. New York and London, 1899.

'99. 4. Coulter, J. M. Plant Relations. New York, 1899.

'99. 5. Cowles, H. C. The Ecological Relations of the Vegetation on the Sand Dunes of Lake Michigan. Bot. Gaz., XXVII. 1899.

'93. 6. Coville, F. V. Botany of the Death Valley Expedition. Cont. National Herbarium, IV. Washington, 1893.

7. Darwin, C. Insectivorous Plants.

8. _ Climbing Plants.

9. — Fertilization of Orchids.

10. - Forms of Flowers.

'77. 11. Darwin, F. On the Glandular Bodies of Acacia sphcerocephclla, etc. Journ. Linn. Soc. Bot., XV. 1877.

'89-'91. 12. Goebel, K. Pflanzenbiologische Schilderungen. Marburg, 18891891.

'93. 13. Geddes, P. Chapters in Modern Botany. London, 1893.

'88. 14. Henslow, G. The Origin of Floral Structures. London, 1888.

'95. 15. — The Origin of Plant Structures. London, 1895.

16. Kerner, A. von. Natural History of Plants. New York, Holt \& Co.

'96. 17. Klebs, G. Die Bedingungen der Fortpflanzung bei einigen Algen und Pilzen. Jena, 1896.

'00. 18. MacDougal, D. T. Nature and Work of Plants. New York, 1900.

'92. 19. MacMillan, C. Metaspermæ of the Minnesota Valley. Minneapolis, 1892.

'00. 20. - Minnesota Plant-life. Minneapolis, 1900.

'81. 21. Müller, H. Alpenblumen. Leipzig, 1881. 
'92. 22. Riley, C. V. The Yucca Moth and Yucca Pollination. 3d Annual Report Missouri Bot. Garden. St. Louis, 1892.

23. Robertson, C. Numerous papers on the Pollination of American flowers, in the Botanical Gazette.

'98. 24. Schimper, A. F. W. Pflanzengeographie. Jena, 1898. (This important work contains extensive bibliography.)

'89-90. 25. Scott-Elliot, G. F. Ornithophilous Flowers in South Africa. Ann. of Bot., IV. 1889-90.

'90-91. 26. - Fertilization of South African and Madagascar Plants. Ann. of Bot., V. 1890-91.

'92. 27. Wallace, A. R. Island Life. 2d edition, London, 1892.

'97. 28. Warming, E. W. CEkologische Pflanzengeographie. 1897.

'89. 29. Wilson, W. P. The Production of Aërating Organs on the Roots of Swamp and Other Plants. Proc. Acad. Nat. Soc., Philacielphia. 1889.

'01. 30. Wilson, W. M. The Compound and Mixed Nests of American Ants. American Naturalist, XXXV. Aug.-Oct., 1901. 


\section{CHAPTER XV}

\section{GEOLOGICAL AND GEOGRAPHICAL DISTRIBUTION}

WheN the first plants appeared upon the earth it is impossible to say, since these have left no traces in the rocks, and the earliest recognizable plant-remains belong to forms already much specialized. The perishable nature of the simplest plants, like most Alga, is such as to preclude their preservation in a recognizable condition in the fossil state. Consequently the geological history of the lower plants is exceedingly unsatisfactory.

\section{Thallophytes}

Schizophyta. - While certain evidence of the existence of the Fission-algæ and Bacteria are wanting in the oldest rocks, there are nevertheless suggestions of their presence in the occurrence of calcareous nodules, perhaps due to the growth of Schizophyceæ, and evidences of decomposition in the tissues of fossil plants, evidently the result of the activity of Bacteria. Indeed, actual bacterial cells have been described in a fossil condition, and there is every reason to suppose that Bacteria were among the very earliest organisms to appear upon the earth.

Algæ. - The perishable nature of most Algæ accounts for their rarity in a fossil condition, but there are certain fossils which have with some reason been supposed to be the remains of large Algæ, similar to the Kelps. Of these supposed Phæophyceæ, the best known is the genus Nematophycus, of Devonian age.

Green Algæ. - Of the Green Algæ, the Siphoneæ are especially well represented in a fossil state, owing to the deposit of lime with which they are incrusted. At the present day, these calcareous Siphoneæ are important agents in the building of coral-reefs, where their calcareous skeletons add materially to the growing reef. It is now known that similar forms occurred in Silurian, and possibly in older formations. These ancient forms were apparently similar to some of the existing types.

Rhodophyceæ. - Another group of calcareous Algæ, of possibly equal antiquity, are the Corallines, a group of the Rhodophyceæ, which also are still of importance as reef-builders. They are the socalled "Nullipore" corals, formerly supposed to be animals. 
Characeæ. - The Characeæ are known in a fossil condition in rocks of various ages. The genus Chara is first certainly met with in Jurassic rocks, but fossils closely resembling the characteristic spirally marked spore-fruits are met with in Devonian and Carboniferous strata. It seems probable that these really represent fossils allied, at least, to the true Characeæ.

Diatoms. - As might be expected, the Diatoms are found abundantly in a fossil state, their silicious shells being almost indestructible. The Diatoms, if we may trust the geological record, are not a very ancient group of plants. The oldest authentic record occurs in the Lias, but except for two species occurring there, all of the fossil Diatoms are of Cretaceous age, or more recent, and these fossil Diatoms, with few exceptions, are closely allied to, or identical with, existing species.

Fungi. - The occurrence of fossil Fungi has been recorded from rocks of various ages, but in most cases the remains are too uncertain to make a satisfactory determination possible. The Fungi are usually found associated with other vegetable structures upon which they were growing as parasites or saprophytes.

\section{Bryophytes}

The remains of Bryophytes, except a small number in the more recent formations, are so fragmentary and uncertain as to throw no light upon the geological history of the class. The extremely perishable character of the Liverworts, and the danger of confusing imprints of other plants with them, explains the almost complete absence in a fossil state of structures which can certainly be assigned to this group. Of the few forms which seem to be reasonably certain may be mentioned Marchantites Sezannensis, of the Oligocene, which is allied to the living Marchantiaceæ. The only fossils which are certainly to be referred to the Musci are all from the Tertiary aud later rocks, although some Palæozoic fossils have been doubtfully referred to this class.

\section{Fossil Pteridophytes}

The Pteridophytes are abundant in a fossil condition, and in many instances so perfectly preserved as to leave no doubt as to their character. Indeed, in some instances, the tissues themselves have been so little changed that the cellular structure may be made out with great clearness, and our knowledge of some of these extinct forms is very complete. It is evident, also, from a study of these fossil forms that many types have become entirely extinct, and that others have left but few and degenerate descendants at the present time. 
The oldest known Pteridophytes are of Silurian age, a small number of Ferns being referable to these formations. In the Devonian there were probably representatives of all the existing classes of Pteridophytes, as well as forms which had no certain relation to these. It is in the Carboniferous rocks, however, that there are found the greatest number of these plants, which during this period played a much more important part than they do at the present day, this being especially true of the now relatively unimportant Lycopods and Equisetales.

Ferns. - Recent studies have thrown much light upon the affinities of the Palæozoic Ferns. It seems pretty certain that these were for the most part related to the Marattiaceæ, which at present are confined to the Tropies and include but a small number of species belonging to but five genera. The Marattiaceæ of the Carboniferous rocks show very much greater variety than is found among their modern descendants, some of which, like Danæa and Angiopteris, do not seem to have altered much from their Palæozoic ancestors. The other living group of Eusporangiatæ, the Ophioglossaceæ, is scantily represented in a fossil state, although there is a good reason to assume that it is an ancient type.

The prevailing modern type of Ferns, the Leptosporangiatæ, are not certainly represented among Palæozoic fossils, although there are occasionally found annulate sporangia which seem to resemble those of the lower members of the group, the Osmundaceæ, Gleicheniaceæ, etc., and certain forms may have been synthetic types, combining characteristics of the several families which become later completely differentiated. One of these synthetic types has come down to the present time in the genus Matonia, represented by two rare Ferns of the Malayan region. Matonia is intermediate in character between the Gleicheniaceæ and Cyatheaceæ, and is the sole living representative of a family which was abundantly represented in the Secondary formations by numerous species. During the Mesozoic age the Marattiaceæ of the Palæozoic formations give way to the lower Leptosporangiates, like the Osmundaceæ and Gleicheniaceæ, which in the present flora are largely supplanted by the Polypodiaceæ, now comprising a very large majority of existing Pteridophytes. The heterosporous Ferns, the Hydropterides (Marsilia, Salvinia) are only scantily represented among fossils, and these all belong to the later formations.

Equisetales. - The class Equisetales is at present represented by about twenty-five species, all belonging to the genus Equisetum, the last survivors of a once important and widespread group, some of which were of tree-like proportions. The earliest remains of these plants occur in the Devonian, and during the Carboniferous they reached an extraordinary development. 
The largest of these fossil Horsetails were the Calamites, which have been so perfectly preserved that their structure is accurately known. They were like gigantic Equiseta, from which they differed in having a secondary growth of the vascular bundles of the stems, like that in the Coniferæ. There were also differences in the arrangement of the sporangia. Some of these Calamites were heterosporous, but heterospory was not as pronounced as in some of the Ferns and Lycopods.

The Calamites disappeared before the end of the Palæozoic; and in the Mesozoic and succeeding formations the forms encountered all belong to types closely resembling the existing genus Equisetum, although many of the Mesozoic forms were very much larger than any living species, and probably showed a secondary growth of the stem, which is completely absent in all living species, although a trace of this has been found in Equisetum telmateia.

Sphenophyllales. - Among the characteristic Palæozoic fossils are certain Pteridophytes, Sphenophyllales, which cannot be satisfactorily referred to any of the three existing classes. 'These, on the whole, resemble most nearly some of the Calamarieæ, to which they are probably remotely related. A recently described fructification, described under the name Cheirostrobus, is considered by Prof. D. H. Scott to represent a type combining characters of the Sphenophyllales, Calamarieæ, and Lycopodiales.

Lycopodiales. - Like the Equisetales, the Lycopods also reached a much greater development in Palæozoic times than at present, although there is not the disparity in numbers between the fossil and living forms that characterizes the former class. In their general characters, the Palæozoic Lycopods closely resembled their existing descendants, but most of them were of large size, often becoming lofty trees, thirty to forty metres in height, and showing a marked secondary thickening of the vascular bundles.

Like the modern Club-mosses, the branches forked dichotomously and were thickly beset with narrow leaves. These, in the very characteristic genera, Lepidodendron and Sigillaria, when they fell off left a scar, which persisted upon the stem, and was not unlike the scars found upon the younger branches of some large-leaved species of Pines.

The cones of some of these fossil Lycopods have been preserved, so that their structure is pretty well known. The cones described under the name Lepidostrobus are much like those of Lycopodiun or Selaginella, each of the sporophylls of which it was composed bearing a single sporangium upon its upper face. The sporangium was much larger than that of any existing forms, and sometimes two sorts of spores were developed. Whether heterospory was carried so far as to produce seeds in any plants of this series is a disputed question. 
The earliest Lycopods occur in the Devonian formations, and the group reached its greatest development in the Carboniferous. The arborescent Lepidodendrons and Sigillarias became extinct toward the end of the Palæozoic era, and the later forms are all smaller and more like the existing species.

\section{Gymnosperms}

The Gymuosperms, as might be expected, are found before any evidence of the existence of Angiosperms is apparent. The earliest remains of gymnospermous affinities occur in the Devonian, but these belong to a peculiar class, the Cordaiteæ, which became extinct toward the end of the Carboniferous. These were trees with large leaves, recalling those of Monocotyledons, but the structure of the stem was, on the whole, much like that of the Coniferæ. The flowers and seeds have been preserved in some cases in a remarkable state of perfection, so that the structure has been made out in detail. It is evident that the gametophyte, especially the male gametophyte, was better developed than in any living Spermatophytes. Within the pollen-spore a cellular body can be seen which is, perhaps, comparable to the group of sperm-cells within the antheridium of the heterosporous Pteridophytes. So perfectly are the ovules preserved in some instances, that the archegonia can be recognized, and the pollen-grains lying in a pollen chamber much like that found in the ovule of the Cycads. It has been suggested that the Cordaitex were synthetic forms, uniting the characters of Cycads and Conifers, although their affinities, on the whole, are rather with the latter.

Ginkgoales. - Of the existing Gymnosperms, the oldest type is Ginkgo, now reduced to a single species, $G$. bilobr, of China and Japan. This genus can be traced back to the early Mesozoic formations, and it may possibly have existed in the later Palæozoic, where fossils evidently related to Ginkgo certainly occur. It seems possible, however, that the Palæozoic forms were more nearly related to the Cordaiteæ, which show affinities with Ginkgo.

Cycadales. - The Cycads, like Ginkgo, represent a very ancient type of Spermatophytes, and are also met with abundantly in a fossil state. They reached their greatest development during the Mesozoic, but there are Palæozoic fossils of undoubted cycadean affinities, although it is doubtful, in most cases, whether they are true Cycads. Among the most important of recent discoveries is the fact that many Palæozoic fossils, supposed to be Ferns, are really forms intermediate between the Ferns and Cycads, and included by some botanists in a special class, the Cycado-filices. Of these may be mentioned the genera Heterangium, Isyginodendron. and Medullosa. Of the various types of fossil Cycads, some are not 
distinguishable from the living genera. Fossil sporophylls exactly like those of Cycas have been found, and forms resembling closely Zamia and other living genera, occur. Others of the fossil Cycads, however, especially the Bennettiteæ, differ very much from any existing genera.

Coniferæ. - The Coniferæ, at present the predominant type of Gymnosperms, can be traced back to the later Palæozoic, certain Permian fossils being probably true Conifers, although the remains of those early types are not well preserved. The Permian genus Walchia is said to present features resembling the living genus Araucaria.

Another Permian genus, Voltzia, has been referred to the Taxodineæ, which includes the Sequoias and Bald-cypress (Taxodium). Both of the latter genera occur abuudantly in a fossil state from the lower Cretaceous upward, and were evidently far more widely distributed than at present, the same being true with some other genera - e.g. Glyptostrobus, Cryptomeria, etc. Some of these fossils are not to be distinguished from living species.

The Cypresses (Cupressineæ) are first met with somewhat later than the Taxodineæ.

Taxacex. - The Yew family is less abundantly represented in a fossil state, but there are remains which can be referred to most of the living genera. Torreya, now represented by four widely scattered species, appears first in the lower Cretaceous, and the genus Cephalotaxus occurs in the same formation. Phyllocladus and Podocarpus have also been found in Cretaceous formations.

Pinaceæ. - The bulk of the living Conifers belong to the Pinaceæ. which comprise the Pines, Firs, Spruces, etc. Fossils resembling these have been described from the Permian, but it is not until the lower Cretaceous that cones of unmistakable Pinaceæ are encountered. Here are found numerous cones referable to the living genera Pinus, Cedrus, Abies, Tsuga, and others.

In the Tertiary the Conifers increase in importance, and some of the living genera which are now of very restricted range, like the genus Sequoia and Taxodium, were then widely distributed, as is testified by their fossil remains.

Gnetales. - The third class of living Gymnosperms, the Gnetales, is so scantily represented in a fossil state as to throw no light upon the history of these peculiar plants.

\section{Fossil Angiosperms}

There is much doubt as to the time of the first appearance of Angiosperms, their fossil remains in the earlier formations being too meagre and imperfect to make their nature certain. Many fossils formerly considered to be Angiosperms are now known to belong to 
other groups, and it is not until the upper Jurassic formations, and possibly still later, that fossils are encountered which can without question be assigned to the Angiosperms.

To judge from a study of the living forms, it is likely that the earliest members of the class, especially among the Monocotyledons, were plants of delicate structure, which were not fitted to leave fossil traces; and this makes it probable that the first Angiosperms appeared in somewhat earlier formations than those in which their first fossil traces are found.

Monocotyledons. - The Monocotyledons are largely plants without woody stems, and with delicate leaves, of such simple structure as to make their identification in a fossil state extremely difficult. A few types, like the Palms, have firm leaves, which are often met with fossil, but these are the exception.

Probably the oldest known fossil which is an unmistakable Monocotyledon is Alismacites, of which the leaf-prints are much like Alisma and other related forms. These prints oceur in the lower Cretaceous of Portugal. Palms are first encountered in the Cenomanian, middle Cretaceous, and in the upper Cretaceous they were evidently abundant, though less so than in the Tertiary, where examples of most of the existing types of Monocotyledous occur.

Dicotyledons. - While the lower Monocotyledons are mostly herbaceous plants, this is not true of the primitive Dicotyledons, many of which are shrubs and trees, with firm leaves well fitted to leave fossil remains. With few exceptions, the earliest fossil Dicotyledons may be assigned to living families, and often to existing genera. The age of these earliest Dicotyledons is about the same as that of the Monocotyledons, as they are found in the lower Cretaceous. The oldest known forms belong to the Apetalæ, species of Willow and Poplar occurring in the lower Cretaceous, and Oaks, Beeches, Chestnuts, and Birches being found in the upper Cretaceous.

During the Tertiary, as in the case of the Monocotyledons, the increase in the number and variety of the Dicotyledons was very great, and most of the families were probably represented. It is an interesting fact that the great family of the Compositæ, generally recognized as the most specialized of the Dicotyledons, and presumably one of the most recent, is very poorly represented in a fossil condition, and these are all from the later Tertiary and more recent formations.

\section{FACTORS INFLUENCING THE DISTRIBUTION OF LIVING PLANTS}

In considering the present distribution of plants upon the earth, several factors must be taken into account. First of all, we must consider the distribution of the ancestor's of the modern flora as 
revealed by the geological record. There are then to be determined the factors which influence the distribution at the present time.

Climate. - First in importance in the distribution of plants is the climate. The temperature and moisture of any district are of primary importance in determining the character of its flora.

Migrations. - The spreading of plants from one place to another is dependent largely upon suitable land communication. Regions separated by large bodies of water, high mountains, or extensive deserts, differ much more from each other than do those where no such barriers exist. Mountains, on the other hand, are important highways for the migration of plants from high latitudes to lower ones. Finally, plants are provided with special means of transport through the agency of air and water, or by the aid of animals.

\section{Changes in Climate}

It is evident from a study of the Palæozoic flora that it was essentially the same all over the world, the same forms being found, for example, in Africa, Australia, Europe, and North America. During this period the predominant plants were Pteridophytes, although some Gymnosperms were also present. 'The character of the Ferns, mostly allied to the living Marattiaceæ, which are tropical, indicates that the climate of the Carboniferous era was a warm and humid one, such as now prevails only in the Tropies.

The similarity in the flora over the surface of the earth continued through the early Mesozoic; but there are indications that the temperature was beginning to lower somewhat, although the greater number of plants of this period belong to types which are now either tropical or subtropical, this being noticeably the case with the characteristic Cycads.

In the Cretaceous many living genera appear, and from that time the number rapidly increases, this being especially the case with the Dicotyledons. Annong the Cretaceous genera may be mentioned Cycas, Sequoia, Betula, Quercus, Juglans, Platanus, Liriodendron, Acer, Eucalyptus, and numerous others. Some of these are still widely distributed; others, like Sequoia and Eucalyptus, have become much more restricted in their range; but during the Cretaceous they were all cosmopolitan, indicating a still uniform, probably subtropical, climate.

Toward the end of the Cretaceous and the beginning of the Tertiary, certain of the types which now live in low latitudes began to disappear from the more northern formations, indicating a cooling of the northern regions, and the beginning of the differentiation of the different climates with their more and more divergent floras. 
The tropical types, such as the Palms, Laurels, and Figs, disappear gradually from the northern regions, and their place is taken by the Oaks, Birches, Willows, etc., which characterize the cooler zones.

Toward the end of the Tertiary, as shown by Pliocene deposits, the flora of Europe was similar to that which prevails in North America to-day, the more southern regions also including a number of such subtropical types as Palms and Bamboos. Among the American genera living in Europe in Tertiary times, but which are now extinct, were Sequoia, Sassafras, Magnolia, Liriodendron, Oreodaphne, and others. These also occur in more northern regions, and extend into Asia, indicating a very similar flora for the whole of the northern hemisphere during the later Tertiary.

Our knowledge of the Tertiary flora of the southern hemisphere is very incomplete, but it would appear that although there were a number of forms allied to those of the northern hemisphere, the peculiar southern types were already differentiated.

The great factor in the changed distribution of the plants of the northern hemisphere was the rapid cooling of the northern regions with the gradual oncoming of the glacial epoch. With the lowering of the temperature, and the advance of the great ice-sheet, vegetation was driven southward. The hardier forms, like some of the Willows and Birches, and certain Alpine flowers, could maintain themselves up to the edge of the glaciers as they do to-day in the Arctic regions, and upon lofty mountains; but the tender forms were obliged to retreat to a more genial climate.

The fate of these plants was very different in America and in Europe. 'This was the result of the very different configurations of the two continents. In the former the great mountain systems run north and south, and there is direct land communication with the Tropics. In Europe, which lies farther north and was subjected to much more extensive glaciatiou than America, the mountain chains of the Alps and Pyrenees extend east and west, and moreover the Mediterranean lies between its southern shores and Africa. Thus overtaken by the advancing glaciers, nearly all the tropical and subtropical types which still exist in North America and Eastern Asia were completely exterminated. The extraordinary number of closely related plants which occur in Eastern Asia and Atlantic North America are therefore simply the survivors of the once continuous Tertiary flora, which have disappeared from Europe.

With the retreat of the ice-sheet the plants advanced north again, and the hardier forms which kept near the ice-sheet still form a continuous subpolar flora. A large number of northern plants are met with in the higher latitudes of both the old and new world. Among these are the White-birch, Aspen, Willow, Fir, and many species 
of herbaceous plants, like the little Linnæa, the Iceland-poppy, and other arctic and sub-arctic flowers.

Some of these northern plants oceur also on the summits of widely separated mountains, where they were probably left stranded at the close of the glacial epoch.

With the great differences in climate which now prevail in the different climatic zones, the uniform flora of the Tertiary has become extraordinarily varied, and the Angiosperms have shown themselves especially well fitted to modify their structure in accordance with the demands of their new environment. The Pteridophytes and Gymnosperms of the earlier geological formations have given way more and more to the aggressive and adaptable Angiosperms; and it is only in exceptionally favored localities, such as the mountains of the Pacific slope and the moist mountains of the Tropics, that they can now compete successfully. with their angiospermous rivals.

Aquatics. - The conditions in water have remained more uniform than those on land, and, as might be expected, the aquatic flora of the earth is much more uniform than that of the land. Most genera and many species of fresh-water Algæ are cosmopolitan, and many genera of aquatic Spermatophytes, like Nymphæa, Potamogeton, Naias, etc., are very widely distributed.

Terrestrial Plants. - With the terrestrial plants it is different, and the remote regions of the earth are characterized by their own types, which often have little affinity with those of other regions, this divergence becoming most marked as the equatorial regions are approached.

The Subpolar Zone. - As we have already seen, the flora of the high northern latitudes is much the same everywhere. The climatic conditions are very similar throughout, and the survivors of the preglacial flora which occupy it are much the same throughout its whole extent, the differences being most marked along the southern limits of the zone, where there is a mingling of southern forms.

The few trees which characterize this northern zone, Birches, Willows, Poplars, Firs, etc., are either identical throughout the whole subpolar zone or are closely related species. At the extreme limits of vegetation toward the pole all trees disappear. In Northern Europe, in Alaska, and in Canada, the peat bogs show many of the same plants - Sundews, Cranberries, Crowberries, and other Heathlike plants, Cotton-grass and Orchids. In the woods we meet the exquisite little Twin-flower (Linnæa) and the fragrant Pyrola, and on the rocks the same Harebell in Scotland and in Canada.

North Temperate Zone. - Going southward the uniformity of the vegetation becomes less marked in the Old World and the New. Thus while the Northern United States and Southern Canada have many plants similar to those of Europe and northern A sia, the num- 
ber of identical species is not large, and there is a large proportion of quite unrelated forms. In Europe the Oaks, Elms, Ashes, Beeches, etc., are all different species from those in America, and the latter continent shows various types, such as the Hickories, 'Tulip-tree, and Sassafras, which are quite absent from the present European flora. Ainong herbaceous plants the differences are perhaps even more marked, for although there are many genera in common, each has forms not represented in the other. 'Thus America has no true Heaths, no Foxgloves, no Crocus, Tulip, or Narcissus. On the other hand, Dicentra, Bloodroot (Sanguinaria), Mandrake (Podophyllum), some of the most beantiful Orchids, like Arethusa and Pogonia, Sarracenia, and many others, are quite absent from Europe.

Warm Temperate Zone. - The greater part of Europe lies within the northern zone, and it is only along the Mediterranean that a flora characteristic of a warmer region is noted. Here we meet with many types not occurring in Central and Northern Europe, and equally absent from our own flora, and which are related to the Asiatic and North African types.

In Asia and America there is no break between the temperate and tropical floras, as the land communication is continuous and the two mingle gradually. Thus in the middle part of Japan, Bamboos and Palms grow together with the northern Pines and Maples, and in the Southern United States the northern Oaks and Hickories are associated with Palmettoes, Magnolias, and other trees of tropical affinities. The contrast between the great variety of trees in the forests of Japan and the United States and the poverty in species of the European forests is extremely marked.

Tropics. - It is of course in the Tropics that plants reach their greatest development in number of species and individuals, but within the Tropics there is great difference in different regions, depending upon the rainfall. In the equatorial rain belt, and in other regions of heavy rainfall, the country is covered with an impenetrable forest in which myriads of plants are fighting for existence. Every available spot is occupied, not only upon the ground, but the trees are loaded down and often killed by the masses of climbing plants and epiphytes which are struggling for light and air. Unlike the monotonous forests of the far North, composed of a single species of tree, here one is bewildered by the variety of plant-forms. The tree trunks are completely hidden by the stems and leaves of climbing plants - Aroids, Rattan-palms, Leguminosæ, Bignonias, which ascend until their leaves mingle with those in the crown of the supporting tree. Clinging to the trunk and branches are innumerable epiphytes - Ferns and Mosses, Orchids, Bromelias, Loranthaceæ. In the gloomy recesses of such a forest showy flowers are not abun- 
dant. Although many of the climbers and epiphytes, especially the Orchids, may possess flowers of great beauty, these do not, as a rule, occur in numbers sufficient to balance the great mass of verdure, or they are borne high up above the tops of the trees.

Of course where the rainfall is deficient, as in the Sahara and other deserts, a luxuriant vegetation is impossible, and many tropical districts, like certain parts of Northern South America and India, which have a marked dry season, show a very different type of flora from the constantly rainy equatorial forests. Depending upon the amount of rainfall, these regions are either covered with heavy forests, which may shed their leaves during the dry season, or the country is an open savanuah diversified by seattered trees and shrubs, and covered with a rapid growth of plants after the rains. The veldts of South Africa and the elevated plateaus of Mexico are of this type.

The keen struggle for existence within the Tropies has produced a very much greater number of plant-types than exist elsewhere, and these are inuch more specialized. Hence we find very few forms common to the Tropies of the Old and New Worlds, and the floras of these regions have a very inarked character of their own. While certain families, like the Leguminosæ, Palms, Orchids, and Compositæ, are cosmopolitan, they are usually represented, not only by distinct speeies, but also by distinct genera in the Tropies of the Old and New Worlds. Thus among the Palms, the Date-palms (Phœnix) are OldWorld types, the Royal-palms (Oreodoxa) and Palmettoes (Sabal) are American. Of the Orchids, the showy Cattleyas and Oncidiums of our conservatories are American, the Vandas and Dendrobiums, Asiatic.

Where plants are distributed throughout the Tropics, like the Banana, Breadfruit, and Cocoanut, as well as certain weeds like the Sensitive-plant, this is due, directly or indirectly, to the agency of man.

Floras of the Southern Hemisphere. - The temperate zones of the southern hemisphere are much more restricted than those of the north. So far as it is known, the flora of the Antarctic Continent is exceedingly limited, and it is completely shut off from communication with the land of the north. Moreover, the wide water-areas lying between the southern extensions of South America and Africa prevent any such communication as exists between Asia and North America. Australia, also, is completely shut off from the other lands of the southern hemisphere. It is not surprising, then, to find very much less similarity in the floras of the southern hemisphere, than between those of the north.

Isolated Floras. - Where a region is completely shut off from communication with other land, as happens especially in remote oceanic islands like the Hawaiian Islands and New Zealand, new accessions to the flora are necessarily almost excluded; and where the isolation 
has existed for a long period, the adaptation of the plants to their peculiar environment and the competition with other plants results in a much specialized flora, and such isolated regions always show a very high proportion of "endemic" or peculiar species. It has been estimated that about eighty per cent of the Dicotyledons of Hawaii are endemic, and in Australia the proportion is probably almost as great. In the case of such volcanic islands as Hawaii, the ancestors of the existing flora must have reached the islands at various times, and from different sources; but in Australia the ancestors of most of the existing plants already existed in the Tertiary flora of the continent.

Alpine Floras. - Another type of isolated flora is seen in the Alpine vegetation of high mountains.

'There is a remarkable similarity in the character of the plants of high mountains in widely separated parts of the world, and in all cases the Alpine plants belong to northern types, which often are not found elsewhere within long distances. Thus upon the summits of mountains within the Tropics, one may encounter plants of familiar northern genera, which are quite wanting in the adjacent lowlands. The writer has collected upon the summit of the Blue Mountains of Jamaica, some 7000 feet above sea-level, such northern plants as Strawberries, Brambles, Buttercups, and others much like the species of the northern United States, but quite unknown elsewhere upon the island or the adjacent mainland.

Upon the summits of the White Mountains, the little Greenland Sandwort (Arenaria Groenlandica) is familiar to every one who has climbed these mountains, and other far northern plants occur upon the summits of the New England mountains.

The explanation usually offered for the presence of these plants, so far away from their original home, is that, driven southward by the advancing ice, some of them, instead of following the retreating ice northward, were stranded on the mountains up which they were compelled to ascend, as the increasing temperature of lowlands became unfitted to their needs, and the competition with the plants better fitted to the warmer climate compelled them to retreat.

Similarities in Remote Regions. - There are sometimes found two regions, geographically far apart, which show much greater similarity than do those much nearer to each other. Probably the bestknown case is that of the remarkable correspondence between the flora of temperate Eastern Asia, and the corresponding region of North America. The similarity of the vegetation in these two regions is far greater than that between California and either of the regions in question, and what is perhaps more extraordinary, than that which exists between Eastern Asia and Europe, although there is continuous land communication between these two continents. 



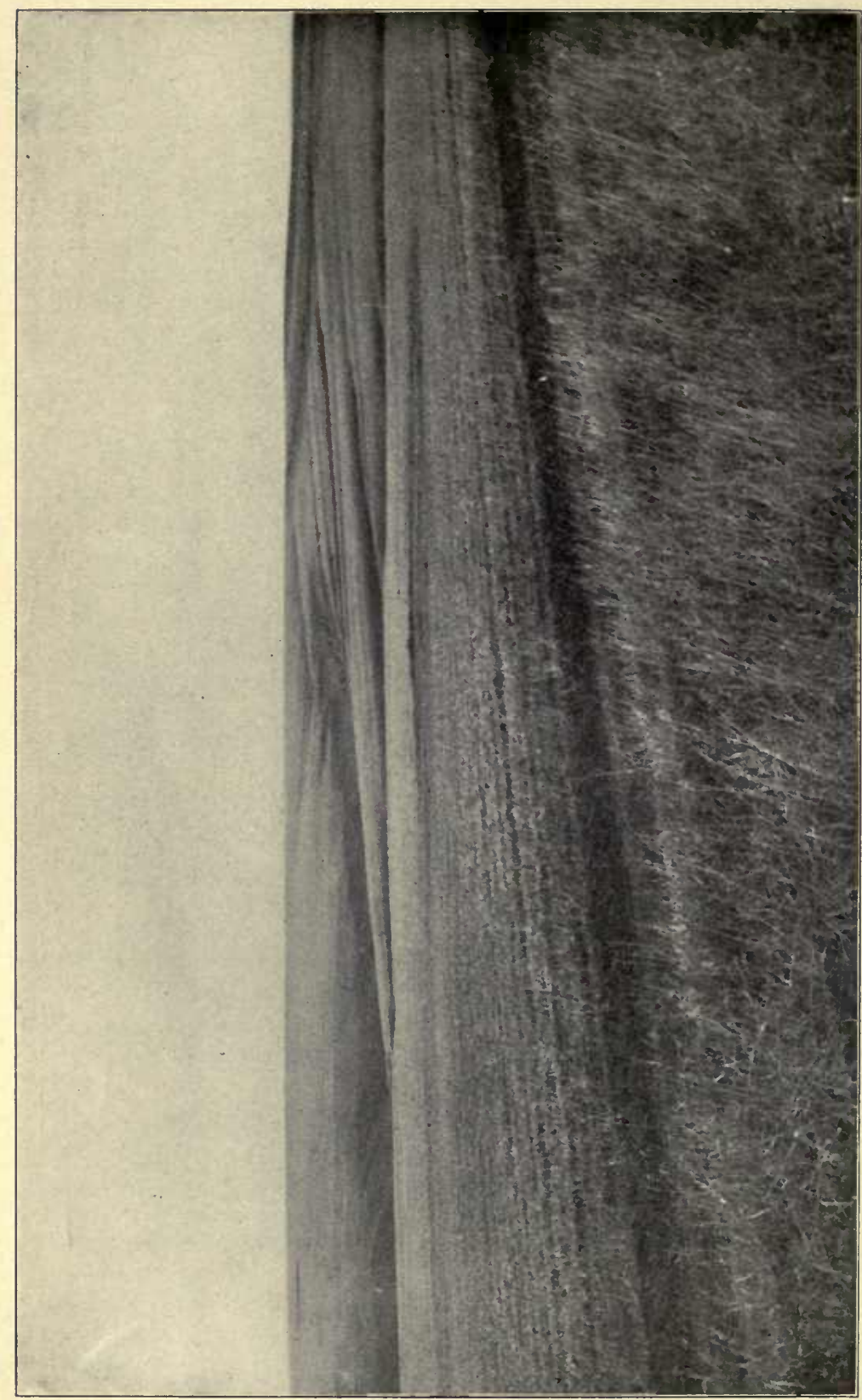

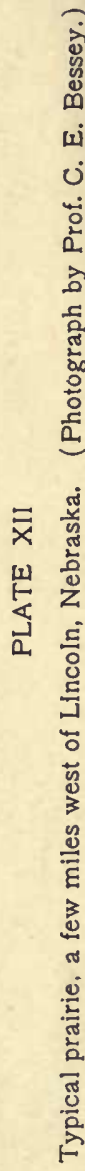


The writer recalls vividly the strangely familiar aspect of the vegetation of Japan, especially in the island of Yezo, where nearly all the more conspicuous plants were either the same, or closely related to common species of the Atlantic states. Such characteristic plants as the Fox-grape, Poison-ivy, Sumach, Bittersweet (Celastrus), Sensitive-fern (Onoclea sensibilis), Elms, Maples, Beeches, Oaks, and Magnolias, all closely resembling or identical with Eastern American species, were striking features of the vegetation. Were these forms also common to our Pacific coast, and extended across the continent, there would be nothing remarkable in encountering them in Japan, but most of them are quite wanting in the Pacific states and the intervening country.

Professor Asa Gray made a very careful study of the relation of the Japanese flora to that of North Anerica, and states that over 60 per cent of the Japanese plants are represented in our Atlantic states by either identical species or closely related ones. This is against 37 per cent for Pacific North America and 48 per cent for Europe. Ninety genera are given as common to Japan and America, which are absent from Europe, and of these the greater part are also wanting on our Pacific coast. Among the most characteristic of these may be mentioned Magnolia, Nelumbo, Ampelopsis, Wistaria, Hydrangea, Hamamelis, and Catalpa.

A study of these forms reveals the interesting fact that the trees are, almost without exception, genera which are represented in the Tertiary flora of Europe, as well as that of Japan and America, and it is highly probable that the herbaceous plants, like Dicentra, Podophyllum, Jeffersonia, and other peculiar types of the Asiatic and North American flora, are also descended from Tertiary ancestors.

The survival 'of these plants in such widely separated regions is accounted for by the topography of the country, which allowed them to retreat southward during the glacial period, and to reëstablish themselves northward with the increasing warmth. The climatic conditions of the present are very similar in the two regions, and are suited to the needs of these plants. Their absence from those parts of Europe where the climatic conditions are suited to their growth is due to their complete extinction during the severe glacieration to which all of northern Europe was subjected.

The absence of these from the Pacific coast is readily explicable from the character of the climate in the warmer parts, which is quite unsuited to the growth of most of these forms.

The occurrence of the same or closely related species of the same genus in widely scparated regions can also be explained usually as survivals of a once widespread type. A well-known case is the genus Torreya, a Conifer of the Yew-family. Four species are now known, one in Florida, one on the Pacific coast, and two in China 
and Japan. We know, however, that in Tertiary times this was a common genus all over the northern hemisphere. The Sequoias of California, and the Cypresses (Taxodium) of the southern swamps, are also disappearing remnants of widespread Tertiary genera.

\section{Flora of the United States}

The great extent of territory within the United States, as well as the great diversity of surface, is accompanied by a corresponding variety in the flora, the distribution of which offers many interesting problems, and illustrates nearly all types of vegetation.

The unbroken central plains possess a continental clinate of the most pronounced character, with a rapid decrease in rainfall westward. On the eastern seacoast there is abundant rainfall, increasing southward, while on the Pacific slope the reverse is the case. Finally, the arid central and southwestern plateaus are genuine deserts, whose scanty flora is extremely characteristic. The direct connection with the Tropics results in a strong infusion of tropical types in our southern flora, and the unbroken chain of mountains on the Pacific slope has been an important highway for the southward emigration of many northern types, including a few Asiatic forms; and at the east the Appalachian Mountains have also served to extend the southward range of many northern species.

Leaving aside the aquatic and strand floras, we may divide the flora of the United States, roughly, into a forest flora, a prairie flora, and a desert flora, these merging, more or less gradually, into each other in some cases.

The Eastern Forest. - The greater part of the country east of the Mississippi was originally covered with a dense forest, containing an extraordinarily large variety of deciduous trees, as well as a number of coniferous ones. This forest, on the extreme north, merges into the subpolar forest zone, which extends more or less completely across the whole continent, but hardly reaches the confines of the United States. Our northern forests, such as those of northern Michigan and Wisconsin, are characterized by the frequent occurrence of the White-pine (Pinus strobus), as well as Hemlocks, Spruces, and sometimes the Norway-pine (Pinus resinosa). Growing with these, however, are various "hardwood" trees, especially Sugarmaples, Beeches, Oaks, etc. Where the Pines predominate, there is little underwood, and the ground is thinly carpeted with Club-mosses, Wintergreen, and other, mostly evergreen, trailing plants.

Somewhat farther south, reaching its finest development in the Ohio Valley and along the Alleghany Mountains, is the great forest of deciduous trees, with relatively few Conifers, which are often entirely absent. Here the variety of trees is far greater than in the 



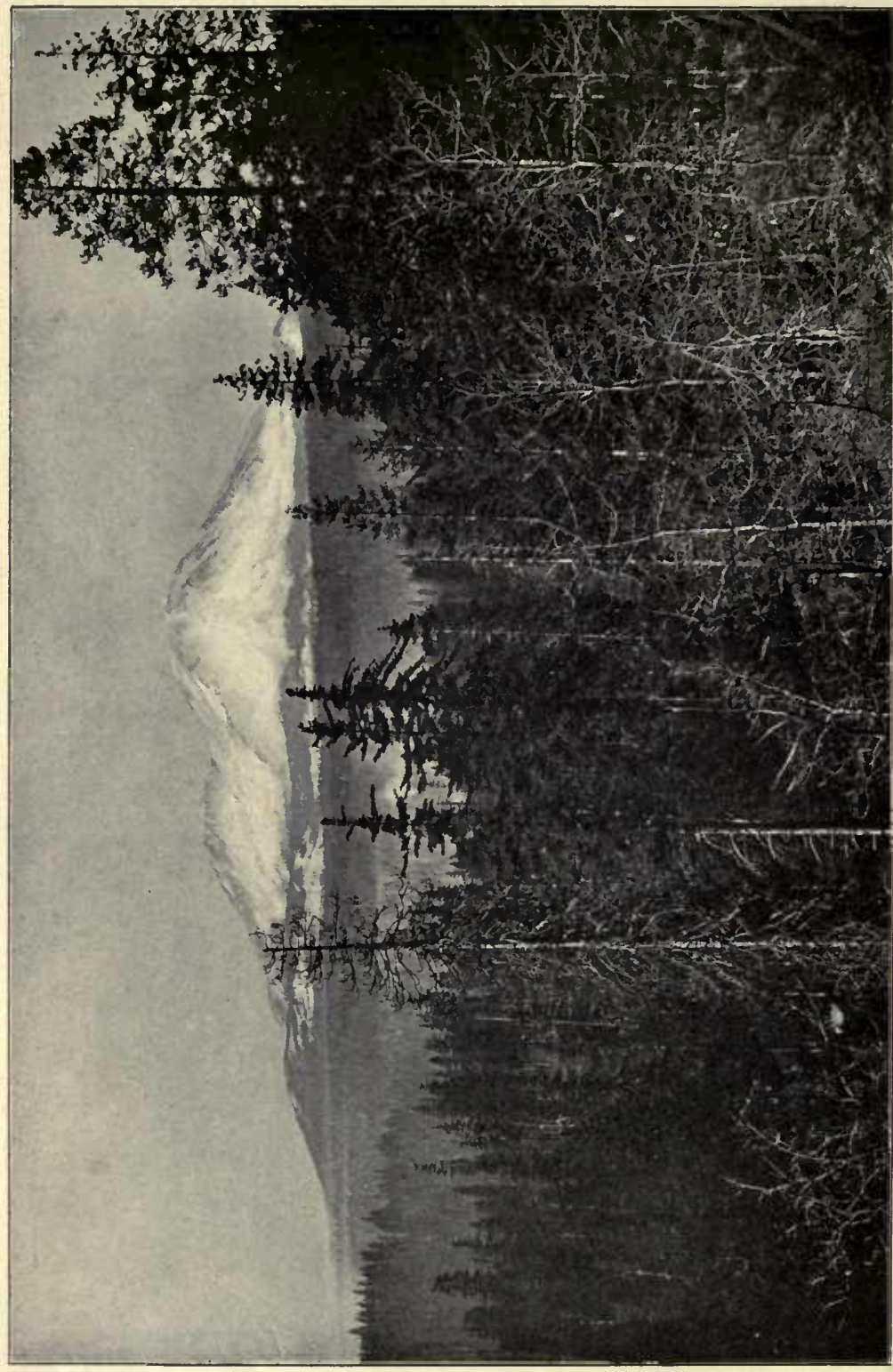

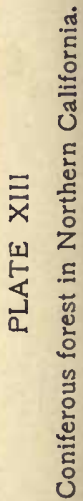


northern forest. Among the predominant trees are various Oaks, several Elms, Maples, Beech, Walnut, Hickories, Gums (Liquidambar and Nyssa), Ashes, Tulip-tree, Sycamore (Platanus), Poplar. Farther south appear the Magnolias, Persimmons, Papaw (Asimina), and some other southern types, which increase as the Gulf of Mexico is approached. These trees are, with few exceptions, deciduous, and in the spring the floor of the forest is carpeted with many beautiful flowers, which pass through their whole growing period in a few weeks. Of the early flowers especially characteristic of the Ameriean forest may be mentioned species of Claytonia, Dicentra, Erigenia, Sanguinaria, Erythronium, Trillium, Podophyllum, and Jeffersonia, which are associated with Hepaticas, Anemones, and Violets, much like those of the European woods.

The deciduous forest is much richer in undershrubs and climbers than the northern forest, and the number of these increases rapidly as we proceed southward, where many beautiful flowering shrubs like the Kalmias, Azaleas, Rhododendrons, Stuartias, Philadelphus, Hydrangea, etc., give an added charm to the woods. In these southern forests, also, the number of climbing plants increases, and gives a suggestion of the lianas of the Tropics. Clematis, Bittersweet, gigantic Grapevines, Ampelopsis, Trumpet-creeper, Wistaria, and other woody creepers cover the trunks of the trees with their garlands of leaves, or clusters of showy flowers.

Autumn gives an additional beauty to these great deciduons forests, when the Maples, Gums, and other trees display the magnificent colors of their ripening foliage.

Near the coast, and farther inland southward, are barren sandy districts, "Pine barrens," which are occupied almost exclusively by Pines (P. palustris, $P$. toeda, etc.), but these cover a relatively small area compared to the great deciduous forests.

Finally, in the extreme south of Florida is a small district where the forest is almost tropical in its composition, and contains a number of forms related to the adjacent West Indian types. Palmettoes, wild Figs, a few epiphytic Orchids and Tillandsias, recall faintly the exuberant growth of these plants in the neighboring islands of Cuba and Jamaica.

Prairies. - With the diminishing rainfall westward, the forests of the A tlantic states gradually give way to the prairies which cover most of the region between the Mississippi and the base of the Rockies. The transition is not a sudden one, and in southwestern Michigan, western Indiana, and Illinois patches of prairie occur in the forested area, or groves of trees occur scattered over the prairie region. The "Oak openings" of this region are of this nature. They consist of groves of somewhat scattered trees, mostly Oaks of several species, with little or no undergrowth of shrubs. Even these disappear as the 
true prairie region is reached. Here no trees can grow except in the shelter of ravines or along the beds of streams, where Cottonwoods and Willows are generally found, even in the arid western part of the prairie region. The typical prairie consists of various grasses (e.g. Andropogon, Chrysopogon), which form a continuous turf in the moister eastern prairies, but in the dry western plains are scattered in tufts over the bare soil. Of these bunch grasses one of the most characteristic is the Buffalo-grass (Bulbilis dactyloides).

The eastern prairies are gay in early summer with many beautiful flowers-Phlox, Dodecatheon, Violets, Verbena, Castilleia, Lithospermum; and later appear the showy Compositæ, Silphium, Rudbeckia, Erigeron, Solidago, Aster, Coreopsis, Gaillardia, etc. Further westward, where the ground has been broken up, Sunflowers (Helianthus annuиs) appear in countless legions.

Western Kansas, and Nebraska, and eastern Colorado are occupied by arid plains with sparse vegetation, and approach in the character of their vegetation the deserts of the far West. Yucca, various low Cacti, and Sage-brush (Artemisia) suggest the strictly xerophytic growths of the true deserts.

The great differences in the flora of the same latitude due to the topography are most strikingly seen in the journey from New Orleans to Los Angeles in Southern California. The Gulf region of Louisiana, with its swampy forests, presents an almost tropical luxuriance of vegetation. Passing westward across Texas, the dense forests of the coast soon give way to scattered groves of Pines, evidencing the marked falling off in the rainfall, which becomes still more pronounced in the western part of the state, where there is a prairie formation with only a scattered growth of stunted trees, principally the Mesquit (Prosopis). In the early summer these prairies show many beautiful flowers, several of which are garden favorites, such as the common Drummond's Phlox, Gaillardia, Enothera, etc.

Deserts. - Journeying westward, another factor in determining the vegetation is encountered, the southern extension of the Rocky Mountains. On the westward side of the divide, in New Mexico and Arizona, the region is a true desert with a very scant vegetation, including a number of most characteristic American types. Of these the first in importance are the Cacti, which reach their greatest development here and in the neighboring Mexican highlands. The strange forms of the giant Cactus (Cereus giganteus), once seen, are never to be forgotten. In June, many of the Cacti are covered with their showy crimson and yellow flowers, and with the magnificent flower-clusters of the Yuccas, make a very striking floral display. The Century-plant and other Agaves also occur in this region, but are more abundant farther south.

Entering California, we cross the desolate Mojave desert, absolutely 



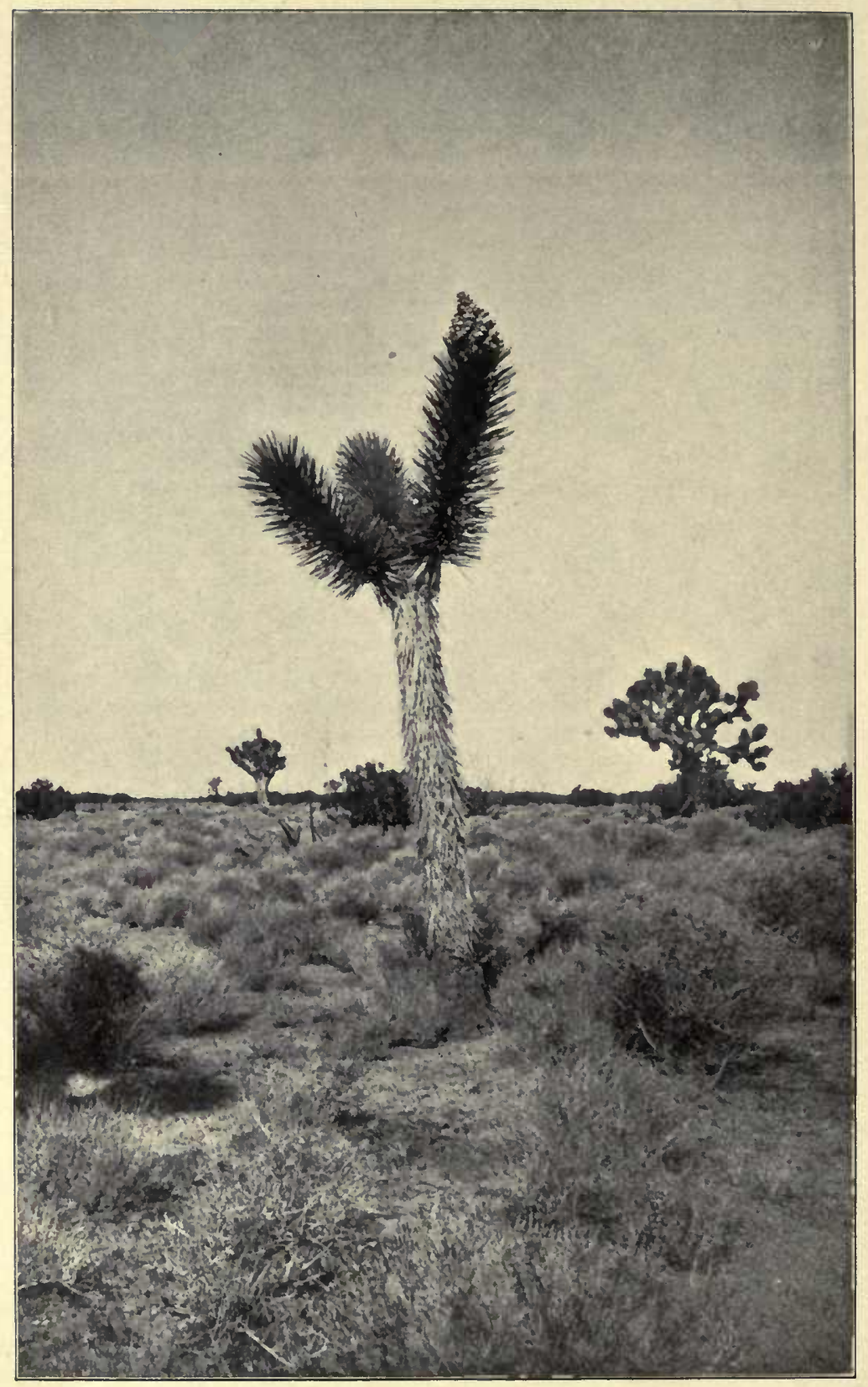

PLATE XIV

Vegetation on the Mojave Desert of Southern California; Yucca arborescens, the most conspicuous feature, accompanied by species of Juniperus, Larrea, Lycium, Ephedra, and several Grasses. (Photograph by Prof. W. Trelease.) 
barren throughout most of its extent, and with its most conspicuous plant the fantastic Tree-yuccas (Pl. XIII), which occur in scattered groves in a few places. Any more absolute contrast between the eastern and western ends of the journey it would be hard to imagine.

\section{The Flora of the Pacific Coast}

The distribution of the plants upon the Pacific coast, especially in California, offers most interesting problems to the student of phytogeography. Owing to the equalizing influence of the Pacific, and the position of the mountain ranges, the climate of the whole Pacific coast is extremely equable, luxuriant forests extending northward in Alaska to about latitude $60^{\circ}$. At Sitka, in latitude $57^{\circ}$, extreme cold is unknown, and the annual precipitation is nearly 250 centimetres, so that the vegetation is almost tropical in its luxuriance. Spruce, Hemlock, and Cedars, 30 to 50 metres in height, and with trunks 2 to 3 metres in diameter, are met with, and the ground is covered with an impassable thicket of shrubs and herbaceous plants. Many of these are northern types common to the whole sub-arctic zone; but others are evidently of Asiatic origin, and do not occur away from the Pacific coast. The commonest tree, the Sitka-spruce (Picea Sitchensis), is said to occur also on the northeast Asiatic coast, and a number of herbaceous plants are also Asiatic. Of the latter, the most conspicuous is the common Aroid (Lysichiton Kamtchatcense), which resembles somewhat the Skunk-cabbage of our Eastern states. Another Asiatic plant is Fritillaria Kamtchatica, belonging to a genus which occurs in America only on the Pacific slope.

The whole coast, as far south as Puget Sound, is covered with an extraordinarily heavy forest of coniferous trees which often come down to the water's edge. While at the far north the Spruce and Hemlock predominate, in British Columbia and Washington the Douglas Spruce (Pseudotsuga Douglasii) is the predominant tree. Here it attains a height of 100 metres or more, and forms the most important timber tree of the region.

Most of the herbaceous plants of this region are allied to the common northern species, and in many instances are identical; but there is a mingling of forms not found farther east, such as Lysichiton. Violets, Trilliums, Dicentras, White Clover, much like those of the Northeastern states, are common, and the general aspect of the woodland flowers resembles that of northern Michigan, or the Adirondacks.

The high mountain ranges of the northern Pacific coast are continued southward into California, where they divide into the Sierra Nevada and the series of Coast ranges. The rainfall diminishes rapidly southward, and most of California has an absolutely rainless summer. 
The outer range of Coast Mountains, however, especially in the northern part of the state, has an extraordinarily heavy winter rainfall, and the dense ocean fogs, which prevail all through the dry season, take the place of rain to some extent. It is upon these outer Coast ranges that the Redwood (Sequoia sempervirens) grows, the tallest of all our trees, some specimens reaching a height of nearly 115 metres (340 feet), with trunks 6 metres or more in diameter. Many of the northern plants have followed the mountains southward and established themselves in the moist Redwood forests. 'Trillium, Violets, Erythronium, Fritillaria, and, in the extreme north, Lysichiton and Linnæa, are found. The Redwood forests cease about 100 miles south of San Francisco (lat. $38^{\circ}$ ), and the forests from Monterey southward are much dryer, with smaller and more scattered trees, mostly Pines.

At Monterey itself are two trees, most interesting as the sole survivors of their kind. These are the Monterey Pine (Pinus insignis) and the Monterey Cypress (Cupressus macrocarpa) (Pl. XV), which form scattered forests close to the sea, but are unknown elsewhere. The Monterey Pine also occurs sparingly at one or two other points along the coast.

The second great forest region of California is that on the western slope of the Sierra Nevada, at a height of 1200 to 2000 metres. Here is perhaps the most magnificent forest of the world. Among giant Sugar-pines, Yellow-pines, Spruces, Firs, and Cedars, grow the monarchs of the American forests, the "Big-trees," Sequoia gigantea (Pl.1, Frontispiece). This forest is comparatively open and parklike, and while the large trees are all Conifers, there is an undergrowth of angiospermous trees, Oak, Dogwood, Maple, and some others, while many beautiful flowering shrubs also occur. Most beautiful of all is the fragrant Azalea occidentalis, which forms thickets, covered with beautiful rose-tinted white flowers in early summer.

Ascending the mountains, the trees diminish in size, and disappear entirely at about 3000 metres. On the east side of the mountains, owing to the very much diminished rainfall, the trees are much smaller, and the mountains slope into the deserts of Nevada, covered with Sage-brush and other desert vegetation.

The predominance of coniferous trees in all the forests of the Pacific coast is remarkable. Nowhere do the deciduous trees form any considerable element in the forest, although a considerable number of species occur. These are found either as an undergrowth of the coniferous forests or along streams, where they do not form true forests. Most of these trees are related to eastern species, but many of the characteristic trees of the Atlantic states are quite absent. There are no Elms, Beeches, Hickories, Magnolias, or Gums in the western forests, but the number of species of Conifers is very 



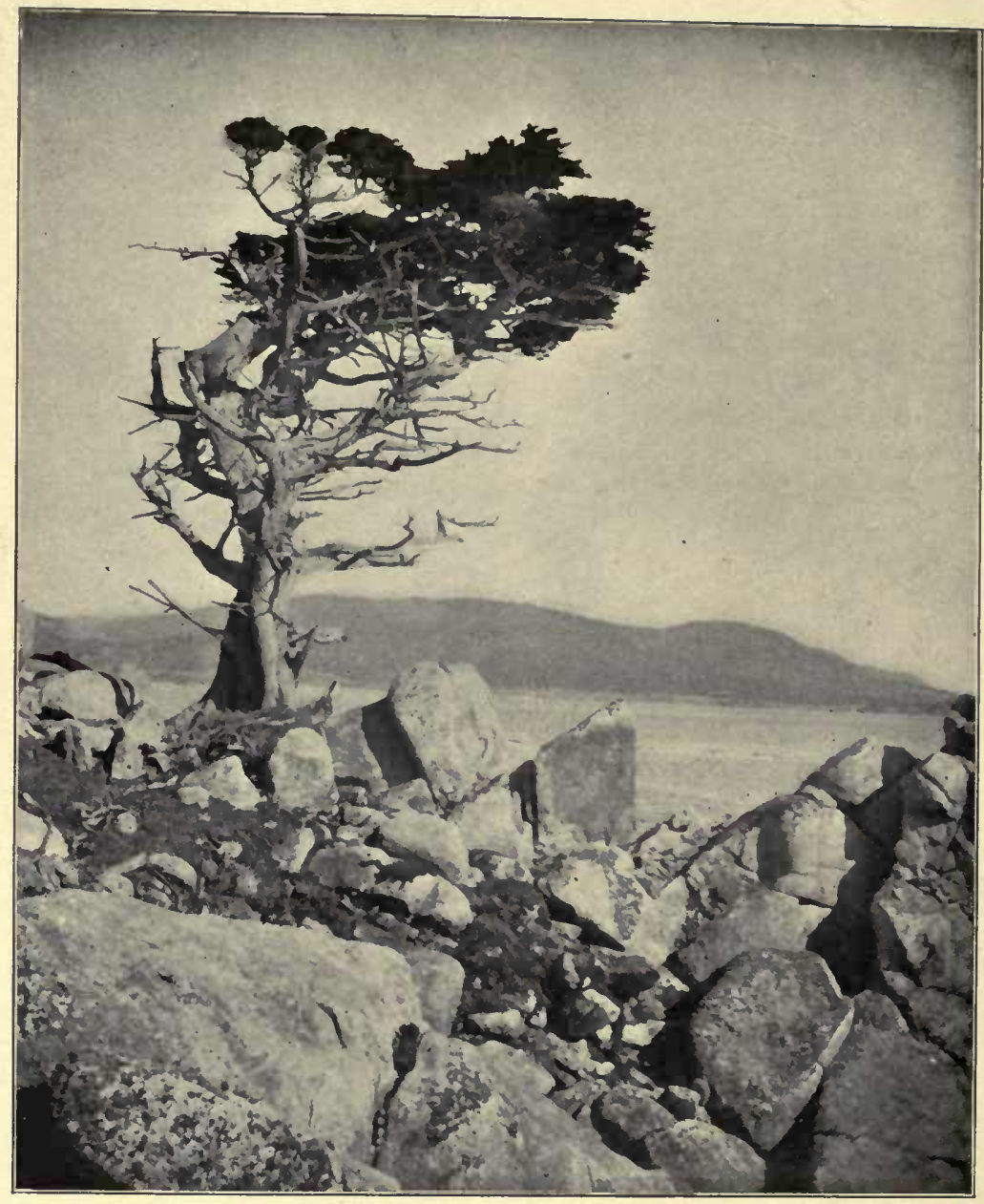

PLATE XV

Cupressus macrocarpa, growing upon the exposed coast near Monterey, California. This species is restricted to a few miles of the coast at this point. (Photograph by Dr. F. M. MacFarland.) 
much greater. California alone has more species of Conifers than the whole of the United States east of the Rocky Mountains.

Owing to the dryness of the summer, most of the trees and shrubs in the central and southern parts of the state are markedly xerophytic in character. The evergreen leaves are small and thick, well fitted to endure the hot, dry summer. The great valleys are too dry to allow the growth of forests, but the bottom-lands, and the foothills of the moister valleys, are covered with wide-spreading oaks, some of which, like the Live-oak (Quercus agrifolia), are evergreen. The lower mountain slopes and the foot-hills are generally covered with a dense growth of shrubs, sometimes thorny, and always difficult to traverse. This "chaparral" is composed of a variety of shrubs, including species of Oak and Chestnut, but largely composed of species of Ceanothus, Adenostoma, Poison-oak (Rhus diversilobus) and Manzanita (Arctostaphylos). Associated with these are many beautiful bulbous plants like the Washington-lily, Brodiæa, Calochortus, Zygadenus, etc., which are very largely represented in the Californian flora.

South of the Tehachapi mountains (lat. $35^{\circ}$ ) the country is much more arid, and much of Southern California, especially the southeastern part, presents genuine desert conditions. . Cacti, Yuccas, Sage-brush, and other characteristic desert plants prevail, and, except when irrigated, the land is quite useless for agriculture.

Constituents of the California Flora. - The position of California, extending for ten degrees of latitude along the Pacific Ocean, and absolutely shut off from communication with the eastern United States by impassable mountains and deserts, has resulted in a flora having but little in common with that of the Atlantic states. While a good many northern plants have made their way southward, following the mountains, few of these reach beyond the midrle of the state, where they are mingled with many types quite unlike any eastern forms, and which have undoubtedly been derived from the south. It is from Mexico, and to some degree from western South America, that the characteristic plants of the open dry valleys and hills of middle and southern California originally came, although a very large number of them have become modified into distinct genera and species. The open valleys and low hills in early spring are ablaze with a marvellous variety of brilliant flowers, most of which are quite new to the eastern student. The fiery orange Eschscholtzia, the pure blue Nemophila, the creamy Platystemon, golden Compositæ in great variety, blue, white, and yellow Lupines, violet Brodiæas, and parti-colored Calochortus, form wonderful flower-carpets, whose beauty must be seen to be appreciated.

These flowers, as well as many others, are either quite unrelated to eastern genera or represented only by a small number of forms, 
which are to be considered as stragglers from the West. Thus the genera Mimulus and Castilleia, which are especially numerous in California, have each a single representative in the Eastern states.

The central part of California is a meetiug-ground for the northern and southern forms. In the Redwood forests of the Coast range, the northern Violets, Trilliums, and Fritillarias flourish, and not infrequently follow the deep shady canyons almost to the level of the valley, where they meet the southern Poppies and Lupines.

Some of the commonest of the valley plants are not natives, but are importations, like most of the common roadside plants of the East. The Wild-oats (Avena fatua), which covers the foot-hills of many Californian valleys; the "Filaree" (Erodium), and the Burclover (Medicago denticulata), which are the commonest of weeds, are all emigrants from the South of Europe, probably arriving with the first Spanish settlers, but succeeding better in holding their own in the new country in their competition with the natives and with other invaders.

\section{BIBLIOGRAPHY}

'00. 1. Bray, W. L. Plant Geography of North America: The Relation of the North American Flora to that of South America. Science. 1900.

'01. 2. The Ecological Relations of the Vegetation of Western Texas. Botanical Gazette, XXXII. 1901.

'80. 3. Brewer and Watson. Botany of California. Boston, 1880.

'96-'98. 4. Britton and Brown. Illustrated Flora. New York, 1896-98.

'99. 5. Campbell, D. H. Lectures on the Evolution of Plants. New York, 1899.

'97. 6. Chapman. Flora of Southern United States. Cambridge, Mass., 1897.

'09. 7. Clements, F. E., and Roscoe, P. Phytogeography of Nebraska. Lincoln, Neb., 1900.

'85. 8. Coulter, J. M. Flora of the Rocky Mountains. New York, 1885.

'no. 9. Coulter and Chamberlain. Morphology of Spermatophytes. New York, 1900.

'93. 10. Coville, F. V. Botany of the Death Valley Expedition. Washington, 1893.

11. Engler and Prantl. Natürliche Pflanzenfamilien.

12. Gray, A. Manual of Botany.

'89. 13. - Scientific Papers. Boston, 1889.

'98. 14. Hitchcock, A. D. Ecological Plant Geography of Kansas. Trans. Acad. of Sc., St. Louis, VIII. 1898.

15. Kerner, A. von. Natural History of Plants.

'99. 16. Potonié, H. Lehrbuch der Pflanzenpalaeontologie. Berlin, 1899.

'91-'96. 17. Sargent, S. C. Silva of North America. Boston and New York, 1891-96.

'98. 18. Schimper, A. F. W. Pflanzengeographie. Jena, 1898. (Includes full bibliography.)

'00. 19. Scott, D. H. Studies in Fossil Botany. London, 1900.

'98. 20. Seward, A. C. Fossil Plants. Cambridge, 1898.

'91. 21. Solms-Laubach, H. Count. Fossil Botany. Oxford, 1891.

22. Ward, Lester F. Many papers on fossil plants, mostly published in the Government Reports. 


\section{INDEX}

Abies, 338, 340, 341, 343.

Abietineæ, 332, 339, 310, 343.

Abietinæ, 336, 343.

Absorption, of water, 467; of food, 499. Acacia, 22, 409, 434, 503, Fig. 471; $A$. sphærocephala, 527, Fig. 493.

Acanthaceæ, 459 .

Acanthinex, 459.

Accessory pigments, 49, 472 .

Acer, Aceraceæ, 436, 437, 449, 467, 537; A. saccharinum, Fig. 428 ; A. dasycarpum, Fig. 428.

Acetabularia, 113, 115.

Achene, 368.

Achlya, 154, 155; A. Americana, Fig. 119.

Aconitum, 425.

Acorn, 368.

Acorus, 388 .

Acrocarpous mosses, 240.

Acrogynæ (Jungermanniales), 212, 213, $215,219$.

Actæa, 402.

Actinomorphic flowers, 365 .

Adaptation, 44.

Adder-tongue (see "Erythronium," "Ophioglossum").

Adenostoma, 549 .

Adhesive fruits, 513 .

Adiantum, 254, 257, 259, 260, 330; A. emarginatum, Figs. 219, 224, 225 ; $A$. pedatum, Fig. 218.

Adlumia, 429.

Adventitious branching, 20, 21, 336 .

Ecidiomycetes (see also "Rust"), 175.

Acidiospore, 170.

Ecidium, 176, 179 .

Aerating organs, 467.

Aerial roots, 29, 363, 377, 410, 468, 504 .

Aërobic Bacteria, 77, 466, 473.

Esculus, 436 ; $E$. Californica, P1. X. ; A. glabra, Fig. 428.

Ethalium: A. septicum, 39, 68, 70.

Agaricaceæ, 181, 182, 184.

Agaricus: A. campestris, 181, 184, Fig. 148.

Agathis, 332, 338 .

Agave, 362, 370, 376, 377, 380, 391, 502, 527,$546 ;$ A . Americana, Fig. $347, \mathrm{Pl}$. IX.
Aglaonema, 389.

Air-chambers (of Marchantiales), 206, 210.

Air-plant (see "Epiphyte").

Air-vesicles, 127, 131.

Ailanthus, 21.

Aizoaceæ, 443.

Akebia: A. quinata, 425,485 .

Akinete, 104.

Alaria, 127.

Albugo, 155-156, 157-158, 160, 168, 170; A. Bliti, Figs. 121,$122 ; A$. candida, Figs. 121, 122; A. Portulacæ, 157; fertilization of, 157 .

Albumen, 39; crystals, 54, 55.

Alcohol, 480, 481.

Alcoholic fermentation, 150, 165, 169.

Aldrovanda, 509.

Alder, 417.

Aleurone, 35, 38, 54, 55 .

Alga, $4,6,7,15,16,30,39,41,42,43,46$, $64,66,67,91,92,149,151,164,187,188$, $190,194,195,361,464,474,495,509,510$, 530,539 .

Alga-fungi (see "Phycomycetes").

Alisma, Alismaceæ, 379, 381, 536; Alismacites, $\mathbf{5 3 6}$.

Alkaloid, 1, 480.

Allium: $A$. Canadense, 353, Fig. 318; A. Cepa, 372, Figs. $342,343,344$;

A. Neapolitanum, 490, Fig. 461; A. odorum, 358.

Almond, 56.

Alnus, 417.

Aloe, 362, 502.

Alpine flowers, 542.

Alsophila, 280.

Alternation of generations, 31, 195.

Althea, 438.

Amanita: A. phalloides, A. muscaria, 185.

Amarantus, 155 , 404, 422, 424 ; A. chlorostachya, Fig. 388.

Amaryllis, Amaryllidaceæ, 379, 380, 390, 3!)1, 396, 397.

Amblystegium, 227, 239; A. riparium, Fig. 189.

Amide, 478, 479. 
Ammonia, 3, 39.

Amœba, 12, 39, Fig. 2; amœboid movements, 39.

Amorphophallus titanum, 389.

Ampelopsis, 409, 438, 488.

Ampligastrium, 216.

Amphithecium, 220, 231, 233.

Anabæna, 80, $81,82,83,285,287,328,496$, $510 ;$ A. Azollæ, Fig. 57.

Anacardiacex, $437,445$.

Anacrogynæ, 212, 213.

Anaërobic Bacteria, 77, 481.

Ananas sativa, 393. (See also "Pineapple.")

Anaphase, 63.

Anatropous ovule, 354 .

Andreæa, 223, 236, 239; A. petrophila, Fig. 204.

Andreæales, 236, 239.

And rœeium, 351.

Andropogon, $5 \mathbf{4 6}$.

Audrospore, 105.

Anelatereæ, 213, 214.

Anemone, 412, 422, 425, 517, 518, Fig. 487.

Anemophily, 514, 516.

Anemopsis, 415.

Aneimia, 256, 273, 276, 277, 288; A. hirsuta, Fig. 221.

Aneura, 202, 205, 213, 214, 215, 248; $A$. multifida, 202, 214; $A$. pinguis, Fig. 174; A. pinnatifida, Fig. 172.

Angiopteris : $A$. evecta, 262, 263, 270, 271, 532, Fig. 239.

Angiosperms, Angiospermæ, 11, 325, 326, $339,344,345,347,348,512,514,516,535$, 536 ; classification of A., 369 .

Animal cells, 5 .

Anisocarpie, 448, 449.

Annulus, 234, 236, 264, 265, 271, 273.

Anomalous secondary growth in thickness, 408.

Anonaceæ, 443.

Anthemis cotula, 364, 457, Figs. 329, 448.

Anther, 351, 383.

Antheridium, 105, 119, 120, 131, 140, 141, $142,143,151,197,203,220,228,242$, 248, 267, 286, 290, 293; Anthocerotales, 220; Archegoniatæ, 197; Characea, 119, 120; Equisetum; 267 ; Filicales, 248; Fucus, 131; Fungi, 151; Hepaticæ, 203; Marsilia, 290; Musci, 228; Nemalion, 140; Ophioglossaceæ, 267 ; Polysiphonia, 142; Salviniace , 286.

Anthoceros, 79, 201, 204, 219, 221, 223, 224, $231,233,241,242,263,510$; $A$. fusiformis, Figs. 182, 205; A. Pearsoni, Figs. 185, 186.

Anthocerotaceæ (see "Anthocerotales").
Anthocerotales, 200, 203, 204, 205, 219, $220,231,237,242,245,248,249,251$; cell-structure, 220 .

Anthurium, 377, 388, 389.

Anthurus: A. borealis, 185, Fig. 151.

Antipodal cells, 355, 356, 370, 400 .

Ants, association with plants, 527,528 .

A petalæ, 413, 422, 514.

Aphanomyces, 154, Fig. 118.

Apical cell, 16, 20, 117, 131, 216, 266, 482.

Apical growth, 16, 117, 118, 131, 136, 138, $207,216,227,255,261,283,296,308$, $332,360,406,482$; Acrogynæ, 216; Angiosperms, 360; Characeæ, 117 ; Conifers, 332; Dicotyledons, 406; Equisetum, 296; Ferns, 255, 261 ; Fucus, 131 ; Lycopodium, 308; Musci, 227 ; Rhodophyceæ, 136, 138; Salviniaceæ, 283.

Apiocystis, 98, 99; A. Braunii, Fig. 68.

Aplanospore, 93, 104, 111, 115.

Aplectrum hiemale, 368, Fig. 338.

Apocarpous flowers, $364,379$.

A pocynaceæ, 452, 458.

Apocynum, 451, Fig. 441.

Apogamy, 200, 245.

Aponogeton, Aponogetonaceæ, 382, 383.

Apophysis, 233.

Apospory, 200, 245.

A postasieæ, 396, 397.

Apothecium, 191.

Apple, 367, Fig. 336.

Apposition, 483.

Aquatics, 539.

Aquifoliaceæ, 437,445 .

Aquilegia : A. Canadensis, 356, 367, 407, 427, 525, Figs. 332, 412.

Arace $\$, 8,29,177,354,359,363,370,372$, $375,376,377,378,379,381,388,389$, $412,415,481,513,516,518,519,523$.

Aralia: $A$. racemosa, 364, 442, Figs. 329 , 437.

Araliacex, 442, 448.

Araucaria, 332, 336, 338.

Arbutus: A. Menziesii, 448, 449.

Arceuthobium, 421.

Archangiopteris, 271.

Archegoniate, Archegoniatæ, 67, 194, 323, $326,353,400,510$.

Archegonium, 31, 195, 196, 203, 220, 299, $242,251,267,286,291,294,325,329$, 340,358 ; Anthoceros, 220 ; Cjcas, 329 ; Conifers, 340: Equisetum, 294; Ferns, 251; Hepaticæ, 203 ; Marsiliaceæ, 291; Musci, 229; Ophioglossaceæ, 267.

Archesporium, 199, 221, 231, 232, 233, 263, 264,354 .

Archichlamydeæ (see "Apetalæ"). 
Archidium, 233.

Aretostaphylos: A. Manzanita, 492, 493, 502,549 , Figs. 463,470 .

Arcyria, 70.

Arenga, 387.

Aretliusa : A. bulbosa, 368, 397, 540, Figs. 338,374 .

Argemone, 59, 526.

Aril, 34\%.

Arisæma : A. triphyllum, 177, 351, 355, $370,376,380,388,389$, Figs. 315,352 , 363.

Arisarum, 116.

Aristolochia, Aristolochiales, 414, 421; A. sipho, 421, 519, 523.

Arrow-head (see also "Sagittaria"), 175.

Arrowroot (see also "Maranta"), 54, 395.

Artemisia, 546.

Arthrospore, 74, 81, 82, 83.

Arum, 388.

Asarum: A. Canadense,421, 423, Fig. 406.

Ascarina, 411.

Asclepiadacer, 452, 458.

Asclepias, 402, 451, 452, 512, 522; A. Cornuti, Figs. 378, 441.

Ascobolus, 18, 167, Fig. 8.

Ascogenous hyphæ, 170, 177.

Ascogonium, 166, 191.

Ascomycetes (see also "Sac-fungi"), $146,152,162,163,187,191$.

Ascophyllum : A. nodosum, 130, 133, Fig. 104.

Ascospore, 64, 163, 164.

Ascus, 163, 165, 172, 191.

Asexual reproduction (see "Non-sexual ").

Ash (see also "Fraxinus"), 540, 545.

Ash-elements, 478.

Asimina triloba, 349, 364, 428, Figs. 313 , 414.

Asparagus, 24, 374, 375, 377, 381, 390 .

Asparagin, 478, 479.

Aspen, 538.

Aspergillaceæ, 169, 170.

Aspergillus: $A$, herbariorum, 169,170 , 171, Fig. 135.

Aspidium, 280; A. spinulosum, Fig. 248.

Asplenium: A. nidus, 258; A. filix foemina, 280, Fig. 247.

Assimilation (see "Photosynthesis").

Aster, 546.

Atamasco lily, 391.

Atropine, 480 .

Anricularia, 179.

Auriculariaceæ, 179.

Auricularineæ, 175.

Autobasidiomycetes, 175, 180.

Autœcious Rusts, 177.
Autogamy, 525.

Autonomous stimuli, 484 .

Auxiliary cells, $142,144$.

Auxospore, 89.

Avena: A. fatua, 550 .

Azalea, 448, 450; $A$. canescens, Fig. 438; A. occidentalis, 548.

Azolla, 64, 79, 245, 282, 283, 284, 285, 286 , 287,510 ; A. Caroliniana, 282; A. filiculoides, Figs. 46, 249, 251; A. pinnata, 282.

Bacillariales (see "Diatom").

Bacillus, 73, 74, 76, 77, 78, 477, 481; $B$. amylobacter, Fig. 51 ; B. prodigiosus, 73,$77 ; B$. radicicola, 76,$477 ; B$. typhi, Fig. 51.

Bacteria (see also "Schizomycetes"), 3 , $4,5,6,8,13,14,36,39,40,43,44,51$, $60,68,71,72,73,74,75,76,77,78,79$, $328,466,468,469,471,472,476,477,480$, $481,487,508,510,530$; classification, 78 ; structure and reproduction, 72-74.

Bacteriaceæ, 78.

Bacterium, 73, 78; B. Pasteurianum, 73.

Balauophoraceæ, $361,413,416$.

Balanops, Balanopsidales, 413, 416 .

Bald-cypress (see "Taxodium").

Balsam (see "Impatiens").

Balsaminaceæ, Balsamineæ, 437, 446.

Bamboo, 385, 485, 538, 540.

Bambusa, 384 .

Banana, 394, 395, 541; B. family (see "Musaceæ").

Bangiacea, Bangiales, 135, 136, 138.

Banyan, 28, 363, 420 .

Barberry (see also "Berberis "), 26, 179.

Barbula: B. fallax, 235, Fig. 199.

Bark, 334, 408, 409.

Basellaceæ, 443.

Basidiolichenes, 192.

Basidiomycetes, 151, 162, 174.

Basswood (see "Tilia").

Bast (see also" Phloem"), 58.

Batidaceæ, 443.

Batrachospermum, 16, 139, 140; $B . v a-$ gum, Fig. 109.

Bay-tree (Umbellularia), 425.

Bazzania, 213, Fig. 172.

Bean, 368, 477.

Beech (see also "Fagus"), 413, 419, 463, 536.

Beech-drops (see also "Epiphegus"), 7, $29,476$.

Bees, 348,420 .

Beet, 363.

Beggiatoa, Beggiatoaceæ, 71, 73, 77, 78; B. alba, Fig. 53 . 
Begonia, Begoniaceæ, 55, 57, 440, 447, Figs. 36, 38.

Bellincinia (see "Madotheca").

Bellincinioideæ, 219.

Bennettiteæ, 347, 535 .

Berberidaceæ, $425,433,486$.

Berberis, $179,425,427,522$; B. vulgaris, Fig. 413.

Berry, 368, 381.

Betula, 400, 417, 537.

Betulaceæ, 417.

Bignonia, Bignoniaceæ, 387, 453, 458, 512, 540, Fig. 387.

Bilateral symmetry, 21, 22.

Bilbergia vexillaria, 394, Fig. 371.

Biology, 1, 9, 10.

Biophore, 37.

Birch (see "Betula").

Birds, $513,516,524$.

Bird's-nest-fungus (see "Cyathus").

Bittersweet (see "Celastrus").

Bixaceæ, 446.

Blackberry, 30 .

Black-fungi (see " Pyrenomycetes").

Black-knot (Plowrightia morbosa), 172.

Black-mould (see "Mucor").

Bladder-kelp (see "Nereocystis").

Bladderweed (see also "Utricularia"), $26,362$.

Blasia, 18, 79, 211, 213, 214, 215, 510; B. pusilla, Fig. 9 .

Blattiaceæ, 447.

Blechnum: B. spicant, 273.

Blepharoplast, 47, 48, 197, 204, 243, 250.

Bloodroot (see also "Sanguinaria"), 23, $59,505,526,540$.

Blue-green Algæ (see "Schizophyceæ").

Blue-gum (see "Eucalyptus").

Blue-mould (see "Penicillium").

Bodo caudatus, Fig. 1.

Boletus, 181.

Bombacaceæ, 446.

Borage (see "Borraginaceæ").

Borraginaceæ, Borraginineæ, 458, 485, 525.

Boschia (see "Funicularia").

Botrychium, 241, 251, 256, 262, 263, 265, $266,267,268,270,304,327,328,476$; 13. Virginianum, Figs. 229-234.

Botrydiaceæ, 116.

Botrydium: $B$, granulosum, 12, 112, 113, 114, 115, 194, 498, Fig. 84.

Bougainvillea, 412,518 .

Bract, 26, 363, 377, 518.

Bradypus, 101.

Bramble, 542.

Branching, 20, 21, 119, 217, 316, 332, 336, 375 ; Characeæ, 119 ; Conifers, 332, 336 ; Liverworts, 217 ; Monocotyledons, 375.
Brassica, 430; B. juncea, Fig. 417.

Brazil-nut (Bertholletia), 55.

Bread-fruit, 541.

Brodiæa, 24, 351, 375, 390, 391, 549; B. capitata, Figs. 315,$366 ; B$. laxa, Fig. 366 .

Bromeliaceæ, 377, 381, 392, 393, 468, 503, 504.

Bromine, 38.

Broom (Cytisus), 501.

Brown Algæ (see also " Phæophyceæ"), $7,16,17,46,49,59,65,68,85,90,92$, $123,194,472,496$.

Bruniaceæ, 444.

Bryaceæ, 228.

Bryales, 231, 233, 234, 236, 239.

Bryonia, 390.

Bryophyllum, 21.

Bryophyta (see also "Mosses"), 200, $241,242,243,244,245,251,253,263$, $267,305,531$.

Bryopsidaceæ, 116.

Bryopsis: B. plumosa, 113, 115, Fig. 85.

Buckeye (see also "Assculus"), 437, 503.

Buckthorn (Rhamnus), 439.

Buckwheat (Fagopyrum), 422, 462.

Budding, 9, 63, 119, 241, 276, 299; Characeæ, 119 ; Equisetum, 296 ; Prothallia, 241 ; Yeast, 64.

Buffalo-berry (see "Shepherdia").

Buffalo-grass (see "Bulbilis").

Bulb, 23, 24, 26, 35, 362, 375, 503.

Bulbil, 119.

Bulbilis dactyloides, 546.

Bulbochæte, 103; B. intermedia, Fig. 73.

Bulrush (Scirpus), 369 .

Bumelia, 451.

Bundle-sheath (see "Endodermis").

Bur-clover, 550.

Burdock, 457, 514.

Burmanniaceæ, Burmannineæ, 370, 396, 397.

Bur-marigold (Bidens), 513.

Bur-reed (see "Sparganium").

Burseraceæ, 445.

Butomus, 382.

Buttercup (see also "Ranunculus"), 22, 542.

Butternut (Juglans cinerea), 416.

Buttress-roots, 29.

Butyric acid, 480, 481.

Buxaceæ, Buxineæ, 445.

Buxbaumia, 228.

Cactaceæ, 440, 447.

Cacti, 6, 24, 370, 424, 427, 440,471, 474, $502,546,549$, Pl. IX. 
Cresalpinia, 433; C. pulcherrinı, Fig. 423.

Cæsalpineæ, 433, 434.

Caladium, 388.

Calamariea, 303, 533.

Calamites, 303, 319, 533.

Calamostacliys, 303.

Calamus, $369,386$.

Calcareous algx, 58, 114, 119, 13.5.

Calcium, 7, 38, 39, 46, 52, 56, 109, 113, 119.

Calcium carbonate, 480 .

Calcium oxalate, $56,479,480$.

Calcium sulphate, 56 .

Calcium tartrate, 56 .

Callithamnion, $16,30,135,136,142,143$; C. corymbosum, Fig. 112 ; C.dasyoides, Fig. 106; C. floccosum, Figs. 5, 106.

Calochortus, 24, 351, 378, 379, 549; $C$. venustus, Figs. 315,350 ; C. luteus, Fig. 350.

Calopogon: C. pulchellus, 396, 397, Fig. 374.

Caltha, 400, 425.

Calycanthacer, 443.

Calycanthus floridus, 411, 428, Fig. 414.

Calyceraceæ, 459 .

Calyptra, 204, 236, 253.

Calyx, 350, 364 .

Cambium, 256, 268, 298, 334, 337, 342, 407.

Camellia, 439.

Campanula, 455; C. Americana, Fig. 446 ; C. Carpatica, Fig. 446.

Campanulacere, 457, 459.

Campanuliueæ, 459.

Campanulatæ, 448, 449, 456, 457, 459.

Campylotropous ovule, 354,424 .

Camptosorus, 20; C. rhizophyllus, Fig. 11.

Camptotrichacea, 84.

Candolleacere, 459 .

Canellaceæ, 447.

Canna, 54, 55, 377, 380, 395, Fig. 35; C. flaccida, 395; C. Indica, Fig. 372.

Cannaceæ, 395.

Cannabis, 411,420 .

Cantharellus cibarius, 184.

Capillitium, 70, 187.

Capitulum (see also "Head "), 120.

Capparidacere, 429, 444.

Capparidiueæ, 444.

Capsella : C. bursa-pastoris, 155, 352, 366, 401, 430, Figs. 316, 317, 332, 377.

Capsule, 367, 381.

Carbohydrates, $3,7,478$.

Carbon, 2, 7, 38.

Carbon-dioxide, 2, 3, 7, 8, 12, 42, 462, 463.

Carboniferous formations, $303,331,316$, $531,532,537$.

Cardamine, 23.
Carex, 368, 385, 386, Fig. 360 ; C. AsaGrayi, Fig. 360.

Caricaceæ, 440, 447.

Carices, 384, 385.

Carludovica: C. palmata, 388, Fig. 362.

Caruivorous plants, 7, 478, 507, 508.

Carotin, 50.

Carpel, 27, 32, 325, 349, 350, 363.

Carpinus, 417, 418; C. Caroliniana, Fig. 399.

Carpogonium, 137, 140, 142, 151.

Carrot, 28, 363 .

Carya, 416, 417 ; C. microcarpa, Fig. 398.

Caryoceracea, 446.

Caryopliyllaceæ, 21, 354, 443.

Caryophyllinex, 443.

Caryophyllum (Clove), 442.

Caryopsis, 368, 381, 385.

Caryota, 387.

Castilleia, 546, 550.

Castor-bean (see "Ricinus").

Casuarina, 400, 414, 501; C.equisetifolia, Figs. 392, 469.

Catalpa, 359, 448, 453, 486, 512, 543.

Catcli-fly (see "Silene").

Cat-tail (see "Typha").

Cattleya, 397, 541.

Caulerpa, 14, 114, 115; C. plumaris, Figs. 4, 87.

Caulerpacea, 116.

Caulome (see also "Stem"), 23.

Ceanothus, 438.

Cecropia, 527.

Cedar (see "Cedrus," " Juniperus," "Libocedrus").

Cedar-apple, Cedar-rust (see also "Gymnosporangium"), 144, 177, 178.

Cedar of Lebanon (see Cedrus Libani).

Cedrus, 335, 343, 535, 548; C. Libani, Fig. 298.

Celastrales, Celastraceæ, 437, 445.

Celastrineæ, 445.

Celastrus, $48,401,435,437,475,543 ; C$. scandens, Fig. 427.

Cell, 4, 10, 34, 44 .

Cell-colonies, 14, 15 .

Cell-formation, 60 .

Cell-plasm (see "Cytoplasm").

Cell-plate, 63.

Cell-row, 15.

Cell-sap, 46.

Cell-wall, 4, 12, 44, 45, 50, 461 .

Cellulose, $4,5,6,12,44,45,372,478$.

Celtis, 319.

Cenomanian formations, 536 .

Central body of Schizophycex, 36,71 .

Centricæ, 90.

Centrosome, 35, 46, 47, 62, 197, 243. 
Centrospermæ, 422, 423, 424, 443, 448.

Century-plant (see "Agave").

Cephalanthera, $377,396$.

Cephalauthus, 454.

Cephalotacex, 444.

Cephalotaxus : C. Fortunei, 342, 343, 535, Fig. 308.

Cerastium, 21, 426; C. vulgatum, Fig. 410.

Cereals, 385 .

Ceratium, 85 ; C. tripos, 85 .

Ceratophyllaceæ, $425,443$.

Ceratophyllum, 404.

Ceratopteris thalictroides, 273, 280.

Cercis, 433, 434; C. Canadensis, Fig. 424.

Cereus, 24, Fig. $15 ; C$. giganteus, 440, 546, Pl. IX.

Cetraria, 191; C. Islandica, 192.

Chætoceras : $C$. boreale, 88, 89, 497, Figs. 62,465 .

Chætocladium, 160.

Chætophora, 42, 49, 102, 220.

Chætophoraceæ, 107.

Chalaza, Chalazogamy, 401.

Chamæcyparis, 343.

Chamærops, 386, 387.

Chamæsiphonaceæ, 82,84 .

Champia, 136, 138, 146; C. parvula, Fig. 116.

Chantarelle, 184.

Chantransia, 139, 140; C. macrospora, Fig. 109.

Chaparral, 438, 549.

Chara, 40, 52, 63, 118, 119, 120, 121, 122, $123,139,482$, 530, Figs. $28,34,90-94$; C. coronata, Fig. 94 ; C. crinita, 122 ; C. fragilis, Fig. 90.

Characeæ, 47, 63, 66, 92, 93, 94, 95, 116, $117,118,119,120,122,123,530$.

Chareæ, 122.

Cheirostrobus, 533.

Chemical changes in cell-wall, 51,52 .

Chemical elements, 461.

Chemical stimuli, 487 .

Chemosynthesis, 475, 477 .

Chemotaxis, 43, 487 .

Chenopodiaceæ, 443; Chenopodiineæ, 443.

Chenopodium, 424, 425; C. album, Fig. 408.

Cherry, 172, 357, 360, 367, 368, 443, 527, Fig. 334.

Chestnut (Castanea), $319, \mathbf{5} 36$.

Chimaphila: C. maculata, 351, 449, Figs. $315,438$.

Chionanthus Virginica, 451, Fig. 441.

Chlænaceæ, 446; Chlænineæ, 446.

Chlamydobacteriaceæ, 78.

Chlamydomonadineæ, 96.

Chlamydomonas, 4, 96, 98, Fig. 1.
Chloranthaceæ, 415.

Chlorochytriuın: C. Lemnæ, 93.

Chlorococcum, 14, 100, Fig. 3.

Chlorogonium, 96.

Chlorophyceæ (see also "Green Algæ"), $91,92,93,94,95,125,126,134,137,145$, 151, 155, 188, 194.

Chlorophyll, 2, 3, 4, 6, 50, 472, 473, 475 .

Chloroplast, $12,16,17,46,48,49,50,472$, 473.

Chlorosphæra, 99, 100.

Chlorosphæraceæ, 100.

Cholera-germ (Microspira Comma), 73, Fig. 51.

Chondromyces: C. apiculatus, 79, Fig. 54 .

Chondrus, 135; C. crispus, 141.

Chorda, 128; C. filum, Fig. 99.

Choripetalæ, 412, 413, 422, 424, 443, 448.

Chromatophore (see also "Chloroplast," "Chromoplast "), 4, 12, 13, 35, 36, 41, $45,46,48,87,92,102,108,110,113$, $120,125,135,220$.

Chromatin, 48, 61 .

Chromatium Weissii, 60, 77, Figs. 42, 53.

Chromoplast, $36,48,49,50$.

Chromosome, 61, 62, 199.

Chromulina ovalis, 68, Fig. 48.

Chroöcoccaceæ, 82, 83, 84 .

Chroöcoccus, 80, 81; C. turgidus, Fig. 555.

Chrysopogon, 546.

Chytridinm, Chytridiaceæ, 152,$153 ; C$. olla, Fig. 117.

Cibotium: C. Menziesii, 279, Fig. 246.

Cichoraceæ, 457.

Cilia, 4, 5, 8, 13, 37, 40, 74, 510 .

Circumnutation, 484.

Cirsium : C. arvense, 456, 457, Fig. 447.

Cissus, 488.

Cistus, Cistaceæ, 439, 446.

Citrus, 358, 436.

Cladonia pyxidata, 191, Fig. 156.

Cladophora, $12,40,47,51,60,101,102$, Figs. 27, 42, 101.

Cladophoraceæ, 107.

Cladosporium, 172.

Cladothrix, 77, 78.

Clarkia, 442.

Classification, 11, 32, 66, 67 .

Clathrus, 186.

Clavaria, 181, 184; C. cristata, Fig. 149.

Claviceps, 172; C. purpurea, 173, 511.

Claytonia, 23, 424, 426, 545; C. Virginica, Fig. 410.

Cleistocarpæ, 239.

Cleistogamous flowers, 526.

Clematis, 26, 404, 422, 504, 545; C. viticella, Fig. 382.

Clethra, 448, 449. 
Clethracee, $450,457$.

Climate, factor in distribution, 537, 538, 539.

Climbing plauts, 24, 504.

Clintonia, 390.

Closterium, 108, 109 ; C. lunula, Fig. 79.

Clostridium Pasteurianum, 76, 477.

Clover (see also "'Trifolium"), 409, 477, 492.

Club-moss (see also "Lycopodium," "Lycopodiales"), 32, 242, 303, 304, 544.

Cueoraceæ, 445.

Cobrea, 485, 488, 527 .

Coccaceæ, 78.

Coccogoner, 84 .

Cocconeis, 87, 89; C. placentula, Fig. 64.

Coccospheres, 86 .

Cochlosperminex, Cochlospermaceæ, 447.

Cocoanut, 359, 368, 375, 381, 512, 541.

Cocos nucifera, 387.

Codiaceæ, 116.

Codiun, 113, 114, 115; C. tomentosum, Fig. 85.

Coenocyte, 12, 14, 60, 112.

Cold, protection against, 505 .

Coleochætacex. 107.

Coleochrte, 49, 51, 93, 102, 106, 107, 137, 138, 196, 220; C. pulvinata, Fig. 78 ; C. scutata, Fig. 77.

Collateral vascular bundles, 256.

Collema, 187, 189.

Collemaceæ, 191.

Collenchyma, 57, 271.

Columbine (see "Aquilegia").

Columella, 220, 231, 233, 239.

Columelliaceæ, 458.

Column (see also “Gynostemium ”), 364.

Comandra umbellata, 421.

Commelinacere, 392.

Companion cells, 407 .

Compositæ, 53, 349, 357, 365, 368, 400, 412, $449,457,458,459,512$.

Comptonia (see "Myrica").

Conceptacle (of Fucus), 131.

Concentric vascular bundles, 256.

Conducting tissues, 59.

Conditions for plant life, 6 .

Conferva, 15, 102, 104.

Confervaceæ, Confervoidex, $94,100,101$, $102,103,104,107,116,137,138,188$, $194,220,495$.

Conidium, 82, 156, 157, 167, 169, 171, 172, 181, 190.

Conifer, Coniferæ, 256, 325, 326, 328, 330, $331,343,358,405,407,408,475,505,533$, $534,535$.

Coniin, 1.

Conjugatæ, 94, 95, 108, 111, 158.
Conjugation, 64, 111.

Connaracex, 444.

Connate leaves, 25.

Conocephalus, 207, 211.

Contact stimuli, 488.

Con tortæe, 449, 451, 452, 458.

Contractile vacuoles, 4,12 .

Convolvulacer, Convolvulinex, 458.

Convolvulus, 401,452 .

Coprinus, 181, 182, 184, Fig. 147 ; C. lagopus, Fig. 147.

Copper, 39.

Cora, 191.

Coral, $5,9,52$.

Coral-honeysuckle (Lonicera sempervirens), 536.

Coralliua, 139, 144, 146; C. Mediterranea, Fig. 115.

Corallineæ, Coralline Algæe, 52, 135, 136, $144,147,530$.

Corallorhiza, 23, 28, 377, 378, 396, 398; C. multiflora, Fig. 376.

Cordaiteæ, $346,347,534$.

Cordyceps, $172 ; C$. militaris, 172.

Cordyline, 390.

Corella, 191.

Coreopsis, 546 .

Coria riaceæ, Coriariineæ, 445.

Cork, 52, 58, 268, 409, 461.

Cork-cambium (see also "Phellogen"), $334,408$.

Cork-oak (Quercus suber), 53, 409.

Corm, 23, 24, 362, 375.

Cornacex, 442, 443, 448.

Corn-smut (Ustilago Maydis), 174, 175.

Cornus, 27, 363, 442; C. florida, Flgs. 19, 437 ; C. stolonifer, Fig. 437.

Corolla, 351, 364 .

Corsinia, 209.

Corsiniacere, 207, 209.

Cortex, 117, 118, 255, 256.

Corypha Taliera, 387.

Corylus, 417.

Coscinodiscus, 88, 89; C. concinnus, Fig. 63.

Cosmarium, 109, Fig. 80.

Cotton, 359, 512.

Cottonwood (Populus), 540.

Cotyledon, 252, 253, 271, 287, 330, 342, $345,346,360,372,385,401,402,403$.

Crabapple, 149.

Cranberry, $180,450,539$.

Crassulace , 424, 431, 444, 474.

Creeping stems, 24.

Crenothrix, 78.

Cretaceous formations, $531,535,536,537$.

Crinum, 379.

Crocus, 24, 486, 540. 
Crossosomatacex, 444.

Cross-pollination, 365.

Crowberry (Empetrum), 539.

Cruciferæ, 155, 354, 429, 444.

Crustaceans, 7, 27.

Crustaceous Lichens, 189.

Cryptoglena, 83.

Cryptomeria, $324,343,535 ;$ C. Japonica, Fig. 287.

Cryptomonas, 83.

Cryptonemiales, 140, 144.

Cryptostomata, 130, 131.

Crystals, 35, 38, 46, 55, 56, 461, 479.

Cucumber (see also "Cucumis"), 362.

Cucumis, 403; C. sativus, 455, Fig. 446.

Cucurbita ; C. Pepo, 402, 470, Fig. 379.

Cucurbitaceæ, 457, 459.

Cucurbitineæ, 459 .

Cunninghamia, 332.

Cunoniaceæ, 444.

Cup-fungus (see also "Ascobolus," "Peziza"), 64, 167, 168, 191.

Cupressus, 338, 343, 344; C. macrocarpa, Fig. $310, \mathrm{Pl}$. XV.

Cupule, 318, 319.

Curl of Peach leaves (see also "Exoascus"), 166.

Currant, 360 .

Cuscuta, 29, 453, 488, 506; C. Gronovii, Fig. 474.

Cuticle, 53, 58.

Cutleria, 65, 125, 129; C. multifida, Figs. $47,100$.

Cutleriaceæ, 129, 134.

Cyanopbyceæ (see also "Schizophyceæ"), $72,79,80,81,82,83,135$.

Cyathea, 273, 280.

Cyatheaceæ, 254, 273, 276, 279, 280, 532.

Cycad, Cycadales, 8, 271, 319, 323, 326, $332,334,346,347,510,512,534,535$, 537.

Cycado-filices, 319, 326, 346, 534 .

Cycadospadix, 316.

Cycadoxylon, 346.

Cycas, 79, 325, 326, 327, 330, 341, 342 ; C. circinalis, Figs. $290-292$; C. revoluta, Figs. 289-292.

Cyclamen, 451.

Cyclanthaceæ, 388 .

Cyclosporeæ, 126, 130, 134.

Cylindrocapsacea, 107.

Cylindrocystis, 110 .

Cylindrospermum, 81, 82, 83; C. catenatum, Fig. 57.

Cymbella lanceolata, 86, Fig. 60 .

Cymose inflorescence, $366,367$.

Cynara, 457.

Cynocrambaceæ, 443.
Cyuomoriineæ, Cynomoriaceæ, 448.

Cyperus: C. papyrus, 385.

Cypress (see "Cupressus").

Cypripediliuæ, 397 .

Cypripedium, 377, 396, 397, 523; C. pubescens, Fig. $374 ;$ C. spectabile, 397.

Cyrillaceæ, 445.

Cystidium, 183.

Cystobacter, 79.

Cystocarp, 137, 142, 143.

Cystophyllum, 130, 133.

Cystopus (see "Albugo").

Cytinus hypocistis, 422, Fig. 405.

Cytisus, 520, 522, Fig. 489.

Cytoplasm, 4, 5, 12, 35 .

Dactylis, 383, 384; D. glomerata, Figs. $357,358$.

Dahlia, 410.

Daisy, 36 .

Damping off, 155 .

Danæa, 271, 272, 532; D. alata, Figs. 237 , 238.

Dandelion (Taraxacum), 363, 406, 457, 512.

Darlingtonia, 431, 508 .

Dasycladaceæ, 116.

Date, Date-palm (see also "Phœnix"), $368,372,381,541$.

Datiscaceæ, Datiscineæ, 447.

Deadly Agaric (Amanita phalloides), 185.

Decomposition-bacteria, 75 .

Delphinium, 412, 425, 427; D. tricorne, Fig. 412.

Dendrobium, $397,541$.

Dendroceros, 219, 221; D. Javanicus, Fig. 182.

Dentaria, 23.

Derbesiaceæ, 116.

Dermatogeu, 360 .

Dermocarpa, 81 ; D. prasina, Fig. 55.

Desert plants (see also "Xerophytes"), 7.

Desmid, Desmidiaceæ, $8,14,22,51,56$, $90,93,108,109,110,111$; structure and reproduction, $108-110$.

Desmidium, 109.

Devonian formations, $303,346,530,531$, $532,533,534$.

Diadelphous stamens, 434 .

Diageotropism, 490 .

Diandræ, 3)6, 397.

Dianthus, 364, 423, 424.

Diapensiacea, 449,457 .

Diarch root, 262.

Diastase, $165,479$.

Diatom, Diatomacere, $1,8,22,52,66,85$, $86,87,88,89,90,92,111,123,497$, Figs. $60,61-61,465,531$; Fossil D., 90, 
531 ; structure and reproduction, 8789.

Diatomin, 87.

Dicentra, 429, 540, 543, 545, 547; $D$. cucullaria, Fig. 416.

Dichapetalaceæ, Dichapetalineæ, 445.

Dichasium, 367.

Dichotomy, 20, 21.

Dicksonia, 280.

Diclinous flowers, 350 .

Dicotyledon, Dicotyledones, 11, 256, 345, 362,363 , 364, 365, 369, 372, 374, 377, $379,381,400,413,536,537,542$; classification of D., 413 .

Dictydium cancellatum, 70, Fig. 50.

Dictyostelium, 71.

Dictyota, 47, 135; D. dichotoma, Figs. $31,105$.

Dictyotales, 134.

Dictynchus, 154.

Dieffenbachia Seguine, 389.

Differentiation of tissues, 483 .

Digestive pouch, 261,301 .

Dilleniacen, 446.

Dioön, 328.

Dionæa muscipula, 486, 509.

Dioscorea, Dioscoreacer, 372, 375, 377, $390,391,392 ; D$. villosa, $392 ; D$. batatas, 392.

Diospyrinea, 458.

Diospyros, 367, 402, 448, 450, 451; $D$. Virginiana, Figs. 334, 378, 440.

Dipodascus albidus, 164, Fig. 128.

Dipsacus, Dipsacacere, 454, 455, 459; $D$. sylvestris, Fig. 445.

Dirca palustris, 441, Fig. 435.

Direct nuclear division, 47, 63 .

Discolichenes, 192.

Disease germs, 76 .

Disk-floret, 457 .

Doassansia, 175.

Docidium, 109.

Dock (Rumex), 28, 422, Fig. 20.

Dodder (see also "Cuscuta"), 3, 26, 29, 151.

Dodecatheon, 450, 451; D. Meadia, Fig. 439.

Dogbane (see also "Apocynum "), 452.

Dogwood (see also "Cornus"), 26, 363, 548 .

Dom-palm (Hyphæne), 375, 386.

Dormant buds, 21.

Dormant protoplasm, 35.

Dorsi-ventral organs, 22.

Douglas-fir (see "Pseudotsuga").

Dracrena, 375, 384, 390.

Dracontium gigas, 388 .

Draparualdia, 16, 101, 102, Fig. 71.
Drosera, Droseraceæ, 430, 431, 444, 478, 507,508 ; I. filiformis, Fig. 418; $D$. intermedia, Fig. 477.

Drupaceæ, 433.

Drupe, 360,368 .

Dudresnaya, 144, 145; D. purpurifera, Fig. 111.

Duinortiera, 205, 209.

Dwarf males (Edogonium), 105.

Earth-star (see "Geaster").

Earth-worms, 469.

Ebenacex, 451, 458.

Ebenales, 449, 451, 458.

Ectocarpaceæ, 126, 134.

Ectocarpus, 65, 123, 124, 125, 126, 129 ; E. granulosus, Fig. 95 ; E. siliculosus, Figs. $47,95$.

Ectoplasm, 37.

Edible Fung1, 184.

Egg-apparatus, 355.

Egg-cell, 9, 65.

Egregia: E. Menziesii, 126, 127, 128, Figs. 97, 99.

Eichhornia crassipes, $369,392$.

Elæagnaceæ, $441,447$.

Elæagnus, 29, 30, 441; $E$. argenteus, Fig. 22.

Elæocarpaceæ, Elæeocarpinea, 446.

Elater, 204, 211, 221, 293, 302, 303, 511; Equisetum, 293, 302, 304 ; Liverworts, 204 ; Marchantiales, 211.

Elatinacea, 446.

Elder (see also "Sambucus"), 454.

Electric stimuli, 42, 43, 493.

Elm (see also "Ulmus"), 413, 419, 512, $540,545,548$.

Elodea, 40, 369, 382, 383; E. Canadensis, Fig. 355 .

Embryo,'196, 198, 208, 221, 231, 244, 252, $267,270,286 ; 292,294,305,306,313$, $325,330,341,342,345,358,371,372$, 404; Angiosperms, 358; Anthoceros, 221 ; Bryales, 231, 234; Conifers, 341, 342; Cycads, 330; Dicotyledons, 401; Equisetum, 294; Ferns, 252; Gnetales, 345 ; Lycopodium, 305, 306; Marattia, 270; Monocotyledons, 371, 372; Ophioglossacer, 267; Riccia, 208; Sphagnum, 231.

Embryology, 10.

Embryoplyte (see "Archegoniatre," "Spermatophyta").

Embryo-sac, 325, 329, 339, 345, 354, 355, 370; Guetales, 345; Monocotyledons, 370 .

Emergence, 29.

Empetracex, Empetrivex, 445. 
Empusa, 161, 162; E. Musci, Fig. 126; E. spharosperma, Fig. 126.

Encryphiacere, 446.

Endocarp, 367.

Endocladia vernicata, 141, Fig. 110.

Endodermis, 254, 256, 262, 238, 407, 408.

Endomyces, Endom ycetacere, 165, 166.

Endoparasite, 176.

Endosperm, 310, 342, 359, 372.

Endosperm-nucleus, 355 , 358 .

Endothecium, 220, 221, 223.

Energid, 12, 14.

Energy (sources of energy), 2.

Enteridium splendens, 70, Fig. 50.

Entomophily, 370 .

Entomophthorineæ, 158, 161, 162.

Enzyme, 150, 461, 476, 479 .

Epacridaceæ, $450,457$.

Ephedra, 64, 344, 345, 316, 512; $E$. altissima, Fig. 345 ; E. trifurca, Fig. 345.

Ephemerum, 239.

Epidermis, 25, 254, 258.

Epigonianthere, 219.

Epigynous tlowers, 364, 379.

Epilobium, 351, 441, 442, 512; E. spicatum, Figs. 315, 435.

Epinasty, 486.

Epiphegus, 7, 29, 476, 506.

Epiphragm, $2+0$.

Epiphyte, 217, 273, 279, 304, 348, 393, 404, 503, 504, 507, 540; Bromeliaceæ, 393; Liverworts, 217 ; Ferns, 273.

Epispore (see also "Perinium"), 264.

Epithemia, 89, Fig. 64.

Equisetaceæ, 303.

Equisetales, 245, 292, 303, 319, 337, 532, 533.

Equisetineæ (see "Equisetales").

Equisetum, 21, 30, 40, 52, 57, 240, 242, 246, $292,298,299,305,323,333,338,344$, $353,483,532,533 ;$ E. giganteum, 296 ; E. hiemale, 295, 298; E. lævigatum, Figs. 34, 38; E. limosum, 240, 248, Fig. 211 ; $E$. maximum (see " $E$. telmateia"); E. robustum, 296; E. scirpoides, 296 ; E. sylvaticum, 299 ; E. telmateia, Figs. 258-268.

Equitant leaves, 391.

Eremascus, 165.

Ergot (see also "Claviceps"), 150, 172, 511.

Ericaceæ, 448, 450, 457.

Ericales, 449, 457.

Erigenia, 546.

Eriocaulaceæ, 392.

Eriogonum, 422.

Erisiphe, 171, Fig. 138.

Erisipheæ, 171.
Erodium: E. cicutarium, 153, 483, 550, Fig. 457.

Erythea, 386.

Erythronium, 24, 358, 361, 375, 376, 379, 390 , o05; E. Americanum, Figs. 347 , 351.

Erythrotrichia, 138, Fig. 10\%.

Erythroxylaceæ, 444.

Erythroxylon, 434.

Eschscholtzia, 59, 429, 549.

Essential oils, 1.

Euascex, 164, 155.

Euastrum, 14, 108; E. elegans, Fig. 3; E. pingue, Fig. 79 .

Eubacteria, 78.

Eubasidiex, 174.

Eucalyptus, 167, 409, 410, 441, 493, 502; E. globulus, 167 .

Eucryphiacen, 446.

Eudorima, 97.

Euglena, 4, 67, 152; E. viridis, Fig. 1.

Eumycetes, 151, 152, 162, 163; reproduction of E., 163.

Euonymus, $435 ; E$. atropurpureus, Fig. 427.

Euphorbia, 26, 55, 59, 363, 404, 412, 435, 436,$502 ; E$. commutata, Fig. 426; E. corrolata, 436 ; E. marginata, 436; E. pulcherrima, 436; E. splendens, 436.

Euphorbiaceæ, 434, 436, 445.

Euroglena volvox, 68, Fig. 48.

Eusporangiate, Eusporangiatæ, 249, 251, $265,273,294,305,315,319,328,532$.

Evernia vulpina, 192, Fig. 156.

Excretion, 480.

Exine, 264.

Exoascus, 166; E. deformans, Fig. 130.

Exobasidiineæ, 180.

Exobasidium, 180; E. Vaccinii, Fig. 146.

Exocarp, 367.

Exosporeæ, 71.

External stimuli, 484.

Eye-spot, 4, 42, 75, 96 .

Facultative parasites, 149.

Fagaceæ, 401, 417.

Fagales, 414, 417.

Fagopyrum : $F$. esculentum, 422.

Fagus, 413.

Fan-palm, 386.

Farinosæ, 381, 392, 393.

Fat, 38, 479.

Fatty acids, 39 .

Fegatella (see "Conocephalus").

Ferment (see also "Enzyme"), 150, 165, 476,479 .

Fern (see also "Filicales," "Filices"), 6, 
$8,17,19,20,27,31,32,37,43,48,51$, $56,57,66,194,196,197,199,200,212$, $220,221,241,242,243,244,246,293$, $214,295,301,303,308,319,327,330$, $334,346,347,469,475,454,487,492$, $501,503,504,510,532,533,534,537$.

Fertilization, 243, 323, 329, 341; Cycads, 329 ; Conifers, 341 ; Ferns, 343 ; Red Algæ, 143, 144; Spermatophytes, 323.

Fibre, 57, 58.

Fibril (of pollen-sac), 353.

Ficus, 56, 507; $F$. elastica, 56, 420; $F$. Carica, $420 ; F$. religiosa, 420 .

Fig (see also "Ficus"), 11, 28, 368, 420, 538,545 , Fig. 337.

Filament (of stamen), 351.

Filamentous plants, 15, 16.

Filaree (see "Erodium").

Filicales (see also "Fern"), 245, 246, 315.

Filices, 273, 282.

Fimbriaria, 51, 206, 208, 210; $F$. Californica, Figs. 33, 164, 166, 168.

Fir (see also "Abies," "Abietineæ"), $336,511,535,538,548$.

Fissidens, 226.

Fission, 8, 13, 15, 60, 111.

Fission-plants (see "Schizophyta").

Flagellata, $13,14,36,67,68,71,85,92,96$, 97.

Flagellum, 4.

Flax (see also "Linum"), 56.

Flora of the United States, 544.

Floral axis, $350,351$.

Floral envelope (see "Perianth").

Floral leaf, 32 , 363.

Floridea, 137, 138, 139.

Flower, $10,27,32,244,323,337,338,345$, $346,349,351,363,378,379,411,412$; Angiosperms, 349; Conifers, 337, 338; Dicotyledons, 411, 412; Gnetales, 345, 346 ; Monocotyledons, 378, 379.

Flowering-plants (see also "Spermatophyta "), $2,7,19,27,31,35,99,131$, $151,152,322$.

Fly-agaric (Amanita muscaria), 185.

Foliaceous Lichens, 189.

Foliar-gap, 255.

Follicle, 367 .

Fomes: $F$. annosus, 184, Fig. 149.

Fontinalis, $227,235,239 ; F$. antipyretica, Fig. 199.

Food of plants, 2, 7, 461, 462 .

Foot (of sporophyte), 204.

Formic-aldehyde, 474.

Fossil plants, 11, 90, 123, 147, 246, 271, 319, 346; Algæ, 530; Characeæ, 123, 530 ; Diatoms, 90,531 ; Gymnosperms, 316, 533, 534, 535; Marattiaceæ, 271,
532, 537 ; Pteridophytes, 246, 319, 532 ; Red Algre, 147, 530.

Fossombronia, 199, 211, 213, 215, 219; $F$. longiseta, Figs. 160, 17'.

Fouquieriacex, Fouquierinex, 446.

Fovea, 317.

Foxglove (Digitalis), 364, 517, 521.

Fox-grape (Vitis labrusca), $56,543$.

Fragaria, 432; $F$. Virginiana, Fig. 422.

Frankeniacex, 446.

Fraxinus, 366, 448, 452; $F$. Americana, Fig. 333.

Free cell-formation, 64 .

Freesia, 391.

Fremontia, 412, 438, 439; $F$. Culifornica, Fig: 431.

Fresh-water Algæ, 496, 498.

Fresh-water sponge (Spongilla), 99.

Freycinetia, 384.

Fritillaria, 24, 390,548, 550; F. Kamtchatica, 547.

Fruit, 32, 359, 360, 367, 381, 412, 413 ; Dicotyledons, 412-413; Monocotyledons, 381.

Fruit body (of Fungi) (see also "Sporefruit" ), 168.

Fucacex, 123, 125, 129, 130, 131.

Fuchsia, 412, 442, 490, 518, 525.

Fucus, 20, 65, 125, 130, 131, 133, 482; $F$. evanescens, Fig. $103 ; F$. fastigiatus, 131 ; F. furcatus, 133 ; $F$. vesiculosus, Figs. 47, 101, 104.

Fuligo varians (see " Ethalium").

Funaria, 45, 225, 228, 229, 230, 231, 232 , $233,234,235,240 ; F$. hygrometrica, Figs. 30, 187, 190, 192-198.

Fungi, 3, 4, 16, 17, 36, 48, 51, 64, 67, 68, $116,146,149,150,151,152,266,323$, $361,378,468,487,490,492,509,510$, 511, 528, 531; structure of, 150-151; classification, 152.

Fungus cellulose, 51, 150, 190.

Funicularia, 209.

Funkia, 358.

Galanthus, 391 .

Galium, 454.

Galtonia candicans, Fig. 450.

Gamete, 30, 31, (44, 65, 93, 16,129 ; Ectocarpus, 129; Volvocaceæ, 96.

Gametophore, 225.

Gametophyte, 17, 19, 31, 32, 145, 195, 196 , $200,223,246,248,266,270,275,277$, $278,280,285,290,291,293,294,304$, $311,312,319,324,325,329,330,338$, $340,345,370,400$; Archegoniates, 200 ; Conifers, 338-340; Cycads, 329, 330; Dicotyledons, 400; Equisetum, 293, 
294; Ferus, 246-248; Gnetales, 345 ; Hymenophyllaceæ, 278; Isoetes, 319; Lycopodium, 304; Marattiaceæ, 270; Marsiliacer, 290, 291; Monocotyledons, 370; Musci, 223; Ophioglossacer, 266; Salviniacer, 285 ; Selaginella, 311,312 .

Gases, movements of, 466 .

Gasteromycetes, 185.

Gaylussacia resinosa, Fig. 438.

Gazania splendens, 49, Fig. 32.

Geaster, 186, 187 ; G. rufescens, Fig. 152. Geissolomacer, 447.

Gelatinous cell-walls, 53.

Gelatinous Lichens, 189.

Gemma, 93, 202, 203, 210, 211, 214, 228, $242,248,278,308$, 309; Characer, 93; Hymenophyllacere, 278; Liverworts, 202, 214 ; Lycopodium, 308, 309 ; Marchantia, 210, 211; Mosses, 228; Prothallia, 242, 248.

Generative nucleus, 357, 358 .

Gentianacere, 452, 458.

Gentian, Gentiana, 451, 452; G. crinita, Fig. 441.

Gentianineæ, 458.

Geographical distribution, 11, 530 .

Geological distribution, 11, 66, 530.

Geothallus, 213, 214 ; G. tuberosus, 214.

Geotropism, 490.

Geraniaceæ, 436, 444.

Geraniales, 424, 434, 444 .

Geraniineæ, 414.

Geranium, 29, 41, 434, 436, 517; $G$. maculatum, 425, Fig. 517; G. molle, 517.

Gerardia, 29, 476, 506.

Germination of seeds, 342, 479 .

Gesneriacer, 458.

Giant Arbor-vitæ (Thuja plicata), 314.

Giant-cactus (see "Cereus giganteus"). Giant-kelp (see "Macrocystis").

Giant-puffball, 185.

Gigartina, 135, 141; G. spinosa, Fig. 110.

Gigartinales, 140, 141, 142.

Gilia, 453.

Gills (of Agaricacer), 181, 183, 184.

Ginger (see also "Zingiber"), 394, 395.

Ginkgo, 323, 326, 330, 331, 332, 534; G. biloba, Figs. 293, 294.

Ginkgoales, 326, 330, 346, 534 .

Ginseng (Aralia quinquefolia), 442.

Glacial epoch, 538.

Gladiolıs, 24, 375, 380, 391, 521, Fig. 353.

Glandular hairs, 29.

Gleba, 186.

Gleditschia, 362, 434 .
Gleichenia, 257, 275; G. dichotoma, Fig. 242.

Gleicheniaceæ, 273, 274, 276, 532 .

Globoid, 54.

Glochidium, 285, 286.

Gloeotrichia, 83; G. natans, Fig. 58.

Glucose, 1, 54, 55 .

Glume, 384, 385.

Glumifloræe, 381, 381, 385.

Gluten, 54, 55.

Gnetales, 326, 344, 345, 346, 347, 414, 535.

Gnetum, 344, 345, 346, 356; G. Gnemon, Fig. 311; G. latifolium, Fig. 311.

Godetia, 442.

Gold-back Fern (see "Gymnogramme").

Gomontegacer, 443.

Gomontiaceæ, 107.

Gomphouema, 88.

Gonatonema, 112, Fig. 83.

Gonidium, 74, 80, 93, 97, 187.

Gonium, 94, 97 ; G. pectorale, Fig. 65.

Gonystylaceæ, 446 .

Goodeniaceæ, 459.

Gooseberry, 368.

Gordonia, 439.

Graminex (see also "Grasses"), 372, 384.

Grape (see also "Vitis"), 24, 368, 438, 504.

Grasses, 7, 24, 38, 368, 369, 370, 372, 373, $375,376,377,381,384,385,405,513$, 546.

Green Alga (see also "Chlorophyceæ"), $49,66,85,90,92,93,94,151,152,194$, $195,197,203,214,469,501,530$; cellstructure of, 93.

Greenland-sandwort (Arenaria Gronlandica), 542.

Green-mould (see " Aspergillus," "Penicillium").

Grevillea robusta, 420 .

Griffitlusia, 135, 138.

Grinnellia, 135.

Ground-pine (sce "Lycopodium").

Ground-tissue, 254.

Growing-point, 20.

Growth, 461, 481, 482.

Growth-rings, 335.

Guanin, 39.

Gulfweed (see also "Sargassum"), 18, 124, 130, 497, Fig. 102.

Gum, 545, 548.

Gunnera, 80.

Guttiferæ, 446.

Gymnoascaceæ, 169.

Gymnocladus, 434 .

Gymnogramme, 245, 273, 467, 501.

Gymnospermæ, Gymnosperm, 64, 322, 
$325,348,349,352,353,354,359,363$, $371,373,374,403,408,410,511,514$, $534,535,537,539$.

Gymnosporangium, 149, 178; G. macropus, Fig. 144.

Gymnostomium, 240.

Gymnozyga, 109; G. Brebissonii, Fig. 80. Gynæcium, 351.

Gynandræ, 396, 397.

Gynostemium, 364, 380, 396.

Habenaria, 397, 523; H. flava, Fig. 374. Hackberry (see also "Celtis"), 11, 419.

Hadrom, 470.

Hæmadoraceæ, 390, 392 .

Hæmatochrome, 96.

Hair, 20, 22, 29, 30, 258, 377.

Halidrys, 130, 132 ; H. osmundacea, Fig. 101.

Halimeda, 113, 114; H. monilis, Fig. 86.

Halorrhagidaceæ, 442, 448.

Halorrhagidineæ, 448.

Hamamelidaceæ, 444.

Hamamelis, 543.

Hapteres ( see also "Holdfast"), 123.

Harebell (see also "Campanula"), 539.

Haustorium, 29, 155, 156, 171, 188, 476.

Hawk-moth, 519.

Hawthorn, 149, 178, 362.

Hazel (Corylus), 368.

Head ("Capitulum"), 356, 366.

Heart-wood, 470.

Heat, 8, 42, 43.

Heath (Erica), 540

Hedera (see also "Ivy"), 442.

Helianthemum, 439.

Helianthus annures, 546.

Heliconia, 377, 394.

Heliotrope, 367,385 .

Heliotropism, 492.

Helleborus, 61, 62; H. fcetidus, Figs. 144, 450.

Helminthostachys, $26 \%$.

Helobieæ, 377, 381, 382, 384, 423.

Helvella, 166; H. lacunosa, Fig. 131.

Helvellineæ, 166.

Hemi-angiocarpæ, 185.

Hemiascii, 174.

Hemiascineæ, 164.

Hemibasidiez, 174.

Hemidinium nasutum, 85, Fig. 59.

Hemitelia, 280.

Hemlock (Tsuga), 544, 547.

Hemp (see also "Cannabis"), 420.

.Hepatica, 505, 545.

Hepaticie (see also "Liverwort"), 107, $200,202,205.220,221,223,225,228$, $229,245,305$; classification, 205.
Herbaceous stems, 361 .

Herbarium-mould (see "Aspergillus").

Hermaphrodite flower, 350 .

Hernandiace $\boldsymbol{4}, 4+3$.

Heterangium, 532.

Heterochlamydeous flower, 424 .

Heterocyst, 81 .

Heterœcism, 149, 176.

Heterœcious Rust, 177.

Heteromerous Lichens, 190.

Heterospory, 273, 303, 322, 348.

Heterostylism, 525 .

Hibiscus: $H$. moscheutos, 439.

Hickory (Carya), 26, 409, 413, 416, 417, $540,545,548$.

Hicoria (see "Carya").

Hippocastanaceæ, 437, 445.

Hippocrateaceæ, $\mathbf{4 4 5}$.

Hippuris, 404, 406; H. vulgaris, Fig. 381.

Histology, 10.

Holdfast, 18, 123, 127.

Holly (llex), 437, 501.

Hollyhock (Althea), 30, 368, 412, 439, Fig. 22.

Hollyhock rust (Puccinia Malvacearum), 177.

Holophytic bacteria, 75 .

Homochlamydeous flowers, 424 .

Homosporous ferns (see also "Filices"), $273,282$.

Honey-locust (see also "Gleditschia"), $24,362$.

Honeysuckle (see also "Lonicera"), 26, 454.

Hoömerous Lichens, 190.

Hop (Humulus), 24, 420, 485, 504, Fig. 458.

Hordeum murinum, Fig. 479.

Hormogonieæ, 84.

Hormogonium, 81, 82, 84.

Hornbeam (see also "Carpinus"), 417.

Horsechestnut, 26, 402, 409, Fig. 18.

Horsetail (see also "Equisetum," "Equisetales"), 21, 32, 38, 242, 535.

Host, 155 .

Hound's-tongue (see also "Cynoglossum"), 179.

Houstonia, 349, 454, 455; H. purpurea, Figs. 313,445 .

Huckleberry (Gaylussacia), 180, 450.

Humming-birds, 520, 524, 525 .

Humulus lupulus, 420.

Humus, 468.

Hyacinth, 24, 390 .

Hyaloplasm, 35, 36, 37.

Hydnoraceæ, 421.

Hydnum, 181, 184; H. ramosum, Fig. 149.

Hydra: H. viridis, 4, 99, 509. 
IIydrangea, $365,543,545 ; H$. arborescens, Fig. 331.

Hydrocharitaceæ, 382, 383 .

Hydrodictyaceæ, 99, 100.

Hydrodictyon: H. utriculatum, 99, 101, Fig. 69.

Hydrogen, 7, 38, 42, 476.

Hydrophilous flowers, 515 .

Hydrophyllum, Hydrophyllaceæ: $H$. appendiculatum, $368,452,453$, Figs. 338 , 442.

Hydropteridineæ, 273, 282.

Hydrostachyaceæ, $4 \mathbf{4 4}$.

Hyd rotropism, 43.

Hydrurus, 67.

Hygroscopic movements, 483.

Hymenium, 166, 181.

Hymenocallis, 390.

Hymenomycetineæ, 180, 181, 185 ; classification of, 181.

Hymenophyllace $, 254,258,273,277,282$, $283,284$.

Hymeuophyllum, 248, 250, 277, 278; $H$. recurvum, Fig. 244.

Hypenantron (see "Fimbriaria").

Hypericaceæ, 439.

Hypericum, 21, 438, 439; H. perfoliatum, Figs. 12, 432.

Hypha, 17, 150, 151, 487.

Hyphæne Thebaica, 376, 386.

Hypnum, 201, 240.

Hypocotyl, 401, 403.

Hypoderma, 57.

Hypogynous flowers, 364, 379.

Hyponasty, 486.

Icacinaceæ, 445; Icacinineæ, 445.

Iceland-poppy (Papaver nudicaule), 539.

Imbibition, 463, 4(i).

Impatiens, 436, 437, 483, 512, 526; I. balsamina, Fig. 478; I. fulva, Fig. 428.

Incense-cedar (see "Libocedrus").

Inclusions of protoplast, 53.

Incrustation, 52.

Inḋian-corn, 29, 174, 358, 363, 384, 385.

Indian-pipe (see also " Monotropa"), 3, 7, $26,151,450$.

Indian-turnip (see also “Arisæma”), 177.

India-rubber (Ficus elastica), 56, 420.

Indusium, 264.

Inflorescence, 26, 365 .

Infusoria, 4, 39, 43, 68, 99, 509 .

Insects, $7,9,26,27,348,370,516$.

Integument of ovule, 324, 354, 359.

Internal cell-division, 64 .

Intine, 264.

Intra-molecular respiration, 481.

Intussusception, 52, 483.
Inulin, 53.

Invertase, 165.

Iodine, $7,38,478$.

Ipoincea (see also "Morning-glory"), 402, 403; I. purpurea, Fig. 350.

Iridaceæ, $380,390,391$.

Iris, $22,58,370,374,375,376,380,391,393$, 520,$522 ;$ I. Florentina, Figs. 39, 346; I. Germanica, 375 ; I. versicolor, Fig. 490 ; I. xiphium, Figs. 347, 368.

Irish Moss (see "Chondrus").

Iron, $7,38,77,481,478$.

Iron-bacteria, 77, 481 .

Irritability, 42, 461, 483.

Iso-bilateral organs, 22 .

Isocarpre, 448, 449.

Isoetaceæ, 266.

Isoetes, $245,315,319,322,325,329,356,371$, 381 ; I. Bolanderi, Fig. 282 ; I. echinospora, Figs. 282, 285; I. lacustris, 245.

Isoetinæ, 315,319 .

Isogamæ, 107.

Isolated floras, 541 .

Isolichenin, 190.

Isomalic acid, 474.

Isomeric compounds, 38 .

Isthmia, 88, 89; I. nervosa, Fig. 63.

Ithy phallus, 185, 186; I. impudicus, Fig. 151.

Ivy, 22, 28, 363, 492, 504; Figs. 13, 20.

Ixia, 391 .

Jasmine, 4 วั2.

Jefjersonia diphylla, $366,367,402,543,545$, Figs. 332, 378.

Jewel-weed (see "Impatiens").

Jonquil (see "Narcissus").

Jubuloidere, 219.

Juglandaceæ, 416.

Juglandales, 414, 416.

Juglans, 400, 416, 417, 537 ; J. regia, Fig. 397.

Juncaceæ, 390.

Juncaginaceæ, 383.

Jungermanniales, 203, 205, 211, 220.

Juniper, Juniperus, 178, 342, 343, 512.

Jurassic formations, $\mathbf{5 3 6 .}$

Kalmia, 449, 450, 522, 545; $K$. latifolia. Fig. 438.

Karyokinesis (see also "Mitosis"), 60, 61,

Karyoplasm, 35.

Kaulfussia, 271.

Kelp (see also "Phœosporex"), 17, 20, 38, $59,123,124,126,129,135,489$; structure of, 124.

Klinostat, 490, 530.

Knot-grass (see "Polygonum"). 
Koberliniaceæ, 447.

Krakatoa (Volcano of), reëstablishment of flora, 469 .

Labellum, 396, 397.

Labiatxe, 412, 452, 521.

Laboulbenia, 173; L. compressa, Fig. 140.

Laboulbeniacere, 173.

Lactic acid, 479, 480, 481.

Lactoridaceæ, 443.

Iady's-slipper (see "Cypripedium ").

Lælia, 397 .

Lamina (see "Leaf-blade").

Laminaria, 17, 126, 127, 129; L. Farlowii, Fig. 7.

Laminariaceæ, 126, 127, 128, 134; structure and reproduction, $127,128$.

Lamium, 402, 411, 453; L. album, Figs. 378,443 .

Land-plants, 498.

Larch (see "Larix").

Lardizabalacere, 443.

Larix, 335, 338, 343.

Larkspur (see also "Delphinium "), 521.

Laticiferous vessels, 59, 181.

Lauracex, 425, 443.

Laurel, 425, 526, 538.

Lead, 39.

Leaf, $10,14,18,19,24,25,26,202,227$, $238,257,284,288,296,308,314,317$, $328,335,362,363,376,377,409,499$; Angiosperms, 362, 363; Conifers, 335 ; Cycads, 328; Dicotyledons, 409; Equisetum, 296; Ferns, 257 : Isoetes, 317 ; Lycopodium, 308; Modified L., 26; Marsiliaceae, 288; Monocotyledons, 376; Salvinia, 284; Sphagnum, 238.

Leaf-base, 25.

Leaf-blade, 25.

Leaf-cutting ants, 528 .

Leaf-green (see "Chlorophyll").

Leaf-mould (see "Humus").

Leaf-spine, 26.

Leaf-tend ril, 26.

Leaf-trace, 403.

Lecethin, 39.

Iecythidaceæ, 447.

Legume, 368.

Leguminosæ, $3,76,401,424,433,434,477$, $479,486,492,493,521,540,541$.

Leitneriales, $414,416$.

Lejeunia, 202, 217, 218, 219, 220, Fig. 181 ; L. metzgeriopsis, Fig. 180.

Lemanea, 140.

Lemna, 93, 369, 380, 389, 391; L. minor, Figs. 352 , 365; L. trisulca, Fig. 365 .

Lemnaceæ, 361, 369, 389.
Lemon, 59, 358, 436.

Leunoaceæ, 357.

Lentibulariaceæ, 453,458 .

Leocirpus fragilis, 70, Fig. 50.

Leontice, 425.

Lepidodendron, 319, 347, 533, 534.

Lepiota naucina, 184, Fig. 150.

Leptopteris, 274, 275.

Leptosporangiate, Leptosporangiatre, 249, $250,251,263,264,265,267,271,272$, 319 .

Lettuce, 59 .

Leucobryum, 228, Fig. 191.

Leucoplast, 48, 49, 50, 55 .

Liana, 433.

Libocedrus decurrens, 343, 344; Pl. I.

Lichen, Lichenes, 17, 51, 64, 80, 93, 99, $149,162,187,188,189,190,191,192$, $468,469,503$, 509; classification, 192 ; structure of, 189 .

Lichenin, 190.

Licmophora, 87, Fig. 61.

Light, 6, 42, 473, 475, 491, 492, 500.

Lignification, 52 .

Ligulatæ, 456 .

Ligule, 314, 317.

Lilac, 452.

Lilæaceæ, 383, 390, 391.

Lilæa subulata, 352, 381, 382, Fig. 317.

Liliaceæ, $370,374,377$.

Liliifloræ, 381.

Lilium, Lily, 23, 360, 364, 370, 379, 381, $390,391,470 ; L$. auratum, $370 ; L$. cordifolium, 377 ; L. tigrinum, 370.

Lily-of-the-valley (Convallaria), 363, Fig. 327.

Limnanthaceæ, Limnanthineæ, 445.

Limnocharis, 381.

Linacere, 436, 444.

Linaria, 368 ; L. vulgaris, Fig. 338.

Linin, 61.

Linnxea, 454, 539, 548.

Linum, 20, 434, 436; L. usitatissimum, 436; L. Virginianum, Figs. 11, 425.

Liquidambar, 545 .

Liriodendron, 425,428, 537; 538; L. tulipifera, Fig. 414.

Lithospermum, 546.

Liverworts (see also " Hepaticæ"), 17, 20, $21,22,27,46,59,195,196,200,201$, $202,241,248,251,270,278,293,468$, $483,490,498,501,507,510,511,531$.

Living things (characters of), 1,2 .

Livistona Chinensis, 387, Fig. 361.

Loasaceæ, Loasineæ, 439, 447.

Lobelia, 455 ; L. cardinalis, 525, Fig. 446.

Loculicidal dehiscence, 367.

Locust (Robinia), 21, 409. 
Lodicule, 385.

Loganiaceæ, 458.

Lonicera, 454, 455, 525; L. sempervirens, 525, Fig. 445.

Loosestrife (see "Lythrum ").

Loranthace $, 420,506$.

Lotus (Nelumbo), 282.

Loxsoma, 278.

Lunularia, 203, 210, 211.

Lupinus, 549, 550 .

Luziola, 384.

Lycaste Harrisoniæ, 398, Fig. 375.

Lycoperdinea, 187.

Lycoperdon, 186; $L$. crlatum, Fig. 152.

Lycopodiaceæ, Lycopodiineæ, 304.

Lycopodium, 241, 242, 303, 304, 306, 307, $308,318,332,476$; $I$. annotinum, Fig. 269 ; L. cernuum, Fig. 271 ; L. clavatum, Figs. $210,269,270$; L. complanatum, Fig. 269 ; $L$. inundatum, 304, 307 ; L. lucidulum, Fig. $274 ; L$. obscurum, Figs. 210, 270; I. Phlegmaria, Figs. 270, 271; L. Selago, Fig. 273.

Lycopod, Lycopodiales, 245, 303, 315, 319, $337,338,347,533,534$.

Lyginodendron, 346,534 .

Lygodium, 273, 276, 277, 278; L. Japonicum, Fig. 243 ; L. palmatum, 276.

Lysichiton Kamchatcense, 372, 388, 389, 547, 548, Fig. 341.

Lysimachia, 450, 451; L. nummularia, Fig. 439.

Ly thraceæ, 44I, 447 .

Lythrum: L. salicaria, 525 .

Maclura, 419.

Macrocystis, 124, 126, 127, 128; M. pyrifera, Fig. 98.

Macrosporangium (see also "Ovule"), $284,285,315,318,322,323,324,352$; Isoetes, 318; Salviniaceæ, 284 ; Selaginella, 315.

Macrospore, 32, 273, 282, 286, 311, 325, $339,358$.

Madotheca, 31, 196, 215, 216, 217, 218; M. Bolanderi, Figs. 157, 175-179; M. platyphylla, Fig. 24.

Maguesium, 38.

Magnolia, 411, 425 .

Magnoliaceæ, 425, 443.

Magnoliineæ, 443.

Maidenhair-fern (see "Adiantum").

Maidenhair-tree (see "Ginkgo").

Male reproductive cells (see also "Spermatozoid"), 9.

Malesherbiaceæ, 447.

Malic acid, 43, 53, 197, 252, 474, 487.

Mallow (see also "Malva"), 178, 439.
Malpighiaceæ, Malpighiineæ, 445.

Malva, $177,366,437,439 ;$ M. borealis, $177 ; M$. rotundifolia, Figs. $333,430$.

Malvace $, 439,446$.

Malvales, 4:24, 438, 439, 446.

Mangrove, 29, 363, 411, Fig. 21.

Manila-hemp (Musa textilis), 395.

Mantle-fibres, 62.

Manubrium, 120.

Manzanita (see "Arctostaphylos").

Maple (see also "Acer"), 408, 512.

Maranta: M. urundinacea, 377, 395.

Marantacexe, 395.

Marattia, 241, 242, 248, 262, 269, 270; M. Douglesii, Figs. 205, 235, 236.

Marattiace $2,250,260,266,270,273,274$, $293,295,319,328,532,537$.

Marcgraviaceæ, 446.

Marchantia, 203, 210, 211, 212; $M$. polymorpha, Figs. 169, 170.

Marchantiaceæ, 206, 207, 208, 209, 210, 212 , $214,531$.

Marchantiales, 202, 205, 207.

Marchantites Sezannensis, 531.

Marigold (Calendula), 50.

Marine Algæ, 496.

Marine Diatoms, 87, Fig. 61.

Marine Siphoneæ, 113.

Mariposa-lily (see "Calochortus").

Marsilia, 47, 55, 243, 244, 261, 287, 322, 532; M. quadrifolia, 292; M. vestita, Figs. $31,208,252,253,254,256$.

Marsiliacex, 282, 287, 288.

Martyniacea, 458 .

Massula, 281, 285.

Matonia, 532.

Matoniaceæ, 273, 276, 532.

Mayacaceæ, 392.

Mechanical stimuli, 43,487 .

Mechanical tissnes, 19, 57, 58, 299, 406.

Mechanics of absorption, 463.

Mechanism of growth-movements, 486.

Medicago denticulata, 513, Fig. 479.

Medulla (see "Pith").

Medullary ray, $328,334$.

Medullosa, 534 .

Megaspore (see "Macrospore").

Megarrhiza Californica, 59, Fig. 40.

Melastomaceæ, 441, 442, 447.

Melia: M. Azederach, 436.

Meliaceæ, 436, 445.

Melianthaceæ, Melianthineæ, 446.

Melosira, 86, 89; M. varians, Fig. 60 .

Menispermaceæ, 443.

Menispermum, 427; M. Canadense, Fig. 413.

Mentzelia, 440.

Merismopœdia, 83. 
Mertensia, 5\%5.

Mesachlamydeø (see "Choripetalæ").

Mesembryanthemum, 423, 425; Fig. 409.

Mesocarp, 367.

Mesocarpaceæ, 108, 111.

Mesocarpus, 41, 49, 110, 112; Fig. 83.

Mesophyll, 254, 335.

Mesophyte, 500 .

Mesotænium, 109, 110, 112.

Mesozoic formations, 276, 319, 331, 346, $347,532,533,534,535,537$.

Metabolism, 4', 478 .

Metachlamydex (see "Sympetalæ").

Metaphase, 62, 63.

Metaspermæ (see "Angiosperm").

Metzgeria, 205, 248 .

Micella, 483.

Micrococeus, $73,74,75,78 ; \cdot M$. polypiformis, Fig. 52 .

Micropyle, 342.

Microsome, 35.

Microspermæ, 381, 395, 396, 397.

Microsphæra, 171; $M$. Alni, Fig. 137.

Microspira Comma, 73, Fig. 51.

Microspora, 101, Fig. 71.

Microsporangium, 284, 285, 315, 318, 322 , $323,324,352$; Isoetes, 318; Marsiliaсеæ, 288; Salviniaceæ, 284; Selaginella, 315.

Microspore (see also "Pollen"), 32, 273, $311,323$.

Mignonette (see "Reseda").

Migration of plants, 537.

Mildew, 149, 157, 132, 140.

Milk-tubes (see "Laticiferous vessel").

Milkweed (see also "Asclepias"), 59, $512,522,523$.

Mimosa: M. pudica, 486, 489, 492, Fig. 460.

Mimoseæ, 433.

Mimulus, 486.

Mint (see "Labiatæ").

Mistletoe (see also "Phoradendron"), 3, $421,476,506,513$.

Mitosis, 60 .

Moccasin-flower (see "Cypripedium").

Modifications of the leaf, 26,362 .

Modifications of the root, 28, 363 .

Modifications of the stem, 23, 362 .

Moisture, protection against, 526 .

Monandræ, 396, 397.

Monarch root, 262.

Monarda didyma, 525.

Monimiacere, 443.

Monoblepharis, 155, 156, Fig. 120.

Monochasium, 367.

Monoclea, 205, 209.

Monocotyledon, Monocotyledones, 27, 56,
$298,316,346,353,362,363,364,368$, $369,381,400,401,402,405,409,410$, $411,412,413,425,474,518,536$; classification, 381 .

Monodelphous stamens, 434.

Monopodial branching, 20, 21.

Monospore, 137, 139, 140.

Monotropa, 7, 359, 401, 449, 450, 476, 506, 507 ; M. hypopitys, Fig. 438 ; M. uniflora, Fig. 475.

Monstera deliciosa, 389.

Moose-wood (see "Dirca").

Moraceæ, $419,420$.

Morchella, 166; M. conica, Fig. 131.

Morel (see "Morchella").

Moringaceæ, Moringineæ, 444.

Morning-glory (see also "Ipomœa "), 19 , 24, 365, 485, 504, Figs. 10, 458.

Morphology, 10, 11, 32.

Mortierella, 161.

Morus, 411, 413, 419; M. alba, Fig. 401.

Mosses (see also "Bryophyte," "Musci"), $6,16,17,19,22,37,41,51,52,56,66$, $92,107,123,194,196,200,201,278,305$, $468,469,490,501,503,504,511$.

Mougeotia, 110.

Moulds (see also " Mucor," etc.) , 3, 7, 17, $492,511$.

Movements, $2,4,5,6,8,39,41,83,88,96$, $466,469,484,485$; of gases, 466 ; growth, 484, 485; orientation, 41 ; protoplasm, 39 ; sleep, 8 ; of water, 469.

Mucilage, 53, 59 .

Mucilage-clefts (Anthocerotales), 220.

Mucilage-ducts, 205, 210, 271, 328.

Mucor, 151, 159, 160, 161; M. stolonifer, Figs. 123, 124; sporangium, 159; zygospore, 161.

Mucoraceæ, 159, 160.

Mucorineæ, 158, 162.

Mulberry (see "Morus").

Multicellular organisms, 3.

Musa, 394, 39.7, 397 ; M. paradisiaca, 395 ; M. sapientum, 395; M. textilis, 395.

Musacere, 394, 345.

Muscineæ (see also "Mosses"), 200.

Musci, 200, 223.

Mushroom (see also "Agaricus," "Psalliota"), 163, 174, 180, 184.

Mustard (see also "Brassica"), 429, 464, Fig. 451.

Mycelium, 150, 151, 159, 162, 174, 176, 180 ; Mucor, 159; Eumycetes, 162.

Mycoidea, 101, 151.

Mycoideaceæ, 107.

Mycomycetes (see "Eumycetes").

Mycorhiza, 150, 168, 266, 378, 476, 510. 
Myoporacex, Myoporinere, 459.

Myosine, 39.

Myosotis, 367, 485, 486, 525 .

Myrica, Myricace $, 415,416 ; M$. asplenifolia, Fig. $396 ;$ M. cerifera, $\mathbf{4 1 6}$.

Myricales, 414, 416.

Myriobleplaris, 155, 156, Fig. 120.

Myriophyllum, 362, 404.

Myristicaceæ, 443.

Myrmecophily, 527, 528.

Myrothamnaceæ, 444.

Myrsinaceæ, 450, 458.

Myrsiplyyllum, 24, 442, Fig. 15.

Myrtaceæ, 423, 441, 447.

Myrtifloræ, 424, 440, 447.

Myrtle (Myrtus), 441.

Myxobacteriaceæ, 78.

Myxococcus, 79.

Myxogasteres, 71.

Myxomycetes, $11,34,67,68,69,70,71,92$; classification, 71; structure, 68-70.

Myxophycex (see "Schizophycex").

Naiadacer, $382,383$.

Naias, 56, 349, 351, 352, 353, 354, 355, 356 , $360,362,370,371,372,373,378,381,526$, 539; $N$. flexilis, Figs. 37, 312, 317, 318, $319,320,321,339,340$.

Narcissus, 23, 24, 365, 379, 380, 391, 470, $540 ; N$. Jonquilla, Fig. 14.

Nasturtium (see also "Tropæolum"), 50, 480,516 , Fig. 454.

Natural system of classification, 11.

Navicula, 86, 87, Fig. 60 .

Nectar, 480.

Nectary, 517, 520, 521, 527.

Nelumbo, 401, 406, 422, 426, $543 ; N$. lutea, Fig. 411.

Nemalion, 139, 140, 145; $N$. Andersonii, Fig. 108; N. multifidum, Fig. 108.

Nemalionales, 140.

Nematophycus, $5 \mathbf{3 0}$.

Nematanthera, 415.

Nemophila, 365, 453, 549.

Neottia, 396.

Nepenthacere, 431, 444.

Nepenthes, 478, 508; $N$. Veitchii, Fig. 476.

Nephthytis Liberica, 389, Fig. 363.

Nereocystis, 18, 124, 126, 127, 128; N. Lütkeana, Figs. 9, 98, 99.

Nettle, 11.

Nettle family (Urticaceæ), 419.

Nicotine, 480.

Nidularia, Nidularineæ, 187.

Nitella, 40, 119, 121, 122, 123, Fig. 92.

Nitellex, 122.

Nitophyllum, 136.

Nitrate-bacteria, $76,477$.
Nitrification, $3, \mathbf{7 2}, \mathbf{7 6}, 469, \mathbf{4 7 5}, 477$.

Nitrite-bacteria, 477.

Nitro-bacteria, 481.

Nitrogen, 3, 5, 7, 38, 74, 75, 76, 469, 477; fixation of, $3,74,75,76$.

Nitroso-bacteria, 76 .

Nitschia, 86 ; N. sigmoidea, Fig. 60.

Nocturnal flowers, 519.

Nodularia, 82, Fig. 56.

Nolanaceæ, 458.

Non-cellular plants, 14.

Non-sexual reproductiou, 8,9 .

Norway-pine ( $P$ inus resinosa), 544 .

Nostocacere, $81,84$.

Nostoc, 8, 72, 79, 80, 81, 82, 187, 189, 220.

Notothylas, $219,220,221,222 ; N$. orbicularis, Figs. 182-184.

Nuclear division (see "Karyokinesis").

Nuclear plate, 62 .

Nuclear sap, 47.

Nuclear spindle, 62.

Nucleolus, 47, 48.

Nucleoplasm, 35 .

Nucleus, 12, 13, 35, 38, 44, 46, 47, 61 .

Nullipore (see "Corallinea").

Nuphar advena, 426, Fig. 411.

Nut, 56, 368, 419.

Nutrition, 7, 9, 42, 461 .

Nyctaginacee, 443 .

Nyctitropic movements (see"Sleep-movements"').

Nymphrea, $350,359,425,539 ; N$. tuberosa, Fig. 314 .

Nymphracere, 379, 401, 425, 443.

Nymphæinea, 443.

Nyssa, 544.

Oak (see also "Quercus"), 22, 359, 360, 413, $417,419,514,536,540,543,544,545,548$.

Oat (see "Avena").

Obligate parasites, 149,476 .

Ochnaceæ, 446.

Odors of flowers, 519 .

CEcology, 10, 11.

OEdogoniaceæ, 107.

Edogonium, 15, 16, 31, 102, 103, 104, 105, $106,152,496 ;$ E. autumnale, Fig. 72 ; O. Boscii, Fig. 75; $E$. macrandrum, Fig. 75; E. stagnale, Fig. 75; structure and reproduction, 104-106.

Enothera, 442, 546.

Oil, 55, 56, 199, 205, 210, 474.

Oil-bodies (of Liverworts), 205, 210.

Oil-glands, 59.

Oleander (Nerium), 452, 501.

Olea (see "Olive").

Oleaceæ, 452, 458.

Oliniaceæ, 447. 
Olive, 452.

Onagraceæ, 441, 447.

Oncidium, $397,504,541$; O. ornithorhynchum, Fig. 472.

Onion (Allium), 26, 61, 316, 372.

Onion-mould (see "Peronospora").

Onion-smut (see "Urocystis").

Onoclea sensibilis, 251, 273, 543, Fig. 215.

Ontogeny, 32, 66 .

Oögonium, 30, 94, 121, 132, 137.

Oömycetes, 152.

Oösporeæ, 107.

Opening of flowers, 486.

Operculum, 233, 234, 236.

Ophioglossaceæ, 258, 266, 274, 532 .

Ophioglossum, 262, 263, 267, 268; O. pendulum, Fig. 232; O. vulgatum, Fig. 232.

Opuntia, 440.

Opuntiales, $424,440,447$.

Orange, $59,358,436$.

Orchid, Orchidace $, 22,349,359,363,370$, $371,378,380,395,396,397,468,504$, $523,538,540,541$.

Orchis, 396, 521, 523; O. spectabilis, Figs. 373,491 .

Oreodoxa, 375 ; O. regia, $387,541$.

Organic acids, $180,474,479$.

Organic bodies, 1.

Organography, 10.

Ornithophily, $516,524$.

Orobanchacex, 458.

Orobanche, 453,476 .

Orthotropous ovule, 354 .

Osage-orange (Maclura), 419.

Oscillaria (see "Oscillatoria").

Oscillatoria, 8, 20, 80, 82, 83, 496, Fig. 56.

Oscillatoriaceæ, $81,83,84$.

Osmunda, 30, 199, 246, 248, 250, 251, 257, $258,274,275$; O. cinnamomea, Figs. 215, 216, 241: O. Claytoniana, Figs. 25, 207, 217, 240; O. regalis, Fig. 240 .

Osmundaceæ, $273,274,275,279,532$.

Ostrya, 417.

Ovary, $325,349,351$.

Ovule, $22,27,32,284,317,323,324,328$, $329,338,339,349,351,352,354$.

Oxalic acid, 53, 474, 479 .

Oxalidaceæ, $436,444,486$.

Oxalis, $27,424,434,436,491$; O. Bowei, Fig. 462 ; O. violacea, Figs. 19, 425.

Oxidation, 7, 13.

Oxydendrum arboreum, 449, Fig. 438.

Oxygen, $7,12,38,42,473,476$.

Paleæ, 29, 258, 384.

Palæophytology (see "Geological distribution," "Fossil plants").
Palrozoic age, 245.

Palxozoic formations, 319, 331, 346.

Palisade-parenchyma, 259.

Pallavicinia, 199, 213; $P$. decipiens, 199; $P$. cyllindrica, Fig. 172 .

Palmella-stage of Alga, 5, 101.

Palmetto (Sabal), 386, 540, 541, 545.

Palms, Palmae, 6, 8, 29, 327, 369, 370, 373, $374,375,376,378,380,381,384,386$, $387,481,514,536,538,540,541$.

Pancratium, 391.

Pandanaceæ, 378, 383, 384.

Pandanales, 381, 383.

Pandanus, 28, 375, 376, 384 .

Pandorina, 64, 97.

Pangens, 37, 38, 44.

Pansy (Viola tricolor), 517.

Papaver (Poppy), 367, 424, 429, 490.

Papaveraceæ, 429, 444.

Papaya, 440.

Papayineæ, 447.

Papilionacer, $433,434$.

Pappus, 456.

Papyrus, 385.

Paracholesterine, 39.

Paramœcium, 509.

Paraphyses, 166, 172.

Parasites, 3, 7, 26, 29, 76, 149, 150, 163, $167,174,188,348,362,404,453,475$, $505,506$.

Parenchyma, 56, 57.

Parietales, 424, 439, 446.

Parkeriaceæ, 273, 280.

Parthenogenesis, 94, 122, 291; Chara crinita, 122; Marsilia, 291.

Passifloraceæ, 439, 447.

Passion-flower (Passiflora), 439; P. incarnata, Fig. 433.

Pastinaca sativa, 442, Fig. 437.

Pathogenic Bacteria, 76.

Paulownia, 453.

Paulovnia imperialis, 30, Fig. 22.

Pea, 54, 360, 368, 477, Fig. 35.

Peach, 35̃), 368, 433.

Pea-family (see also "Leguminosæ"), 26.

Pear, 433.

Peat-mosses (see also "Sphagnum"), 201.

Pedaliaceæ, 458.

Pediastrum, 14, 98, 100, Figs. 3,$68 ; P$. Boryanum, Fig. 68.

Pelagic Diatoms, 88, 497.

Pelargonium, 25, 99, 405, 412, 436, 516, 517,520 , Figs. $16,384,484$.

Pellia, 46, 213, 215; $P$. epiphylla, growth of seta, 215 .

Penaaceæ, 447.

Penicillium, 169, 170; P. glaucum, 169, Fig. $135 ; P$. crustaceum, Fig. 135. 
Penium, 108; $\boldsymbol{P}$. interruptum, 108, Fig. 79.

Pennatæ, 90.

Pentaphyalaceæ, 445.

Pentstemon, 453, 521.

Peperomia, 35:, 354, 355, 356, 358, 359, $363,400,401,402,406,411,413,415$; $P$. subrotunda, Figs. 378,$390 ; P$. blanda, Fig. 390 ; P. pellucida, Fig. 320 ; embryo-sac of, 355 .

Pepper, 50, 366.

Pepsine, 39.

Perfect flower (see "Hermaphrodite").

Perfoliate leaf, 25.

Perianth, 349, 350, 363.

Periblem, 360 .

Pericarp, 367.

Pericycle, 256, 262.

Periderm, 328, 334, 408.

Peridinex, 84, 85, 86, 89, 90, 92, 111, $134,495,497,498$; classification, 86 ; structure, 85 .

Peridiniaceæ, 86.

Peridiniales, 84.

Peridinium, $85 ; P$. divergens, Fig. 59.

Peridium, 186.

Perigynous flowers, 364 .

Perinium (see also "Epispore"), 199, 264.

Periodicity of growth, 486.

Periodic movements (see "Movement").

Perisperm, 359.

Perisporiales, 171.

Peristome, 234, 235, 236, 240.

Perithecium, 171, 172, 191.

Periwinkle (Vinca), 452.

Permian formations, 535.

Peronospora, 157; P. Schleideni, 158.

Peronosporineæ, 155, 157.

Persimmon (see "Diospyros").

Petal, 27, 32.

Petiole, 25.

Petunia, 41, 453, Fig. 443.

Peziza, 64, 151, 167, Figs. 44, 132.

Pezizineæ, 167, 168.

Phacelia, 453.

Phacoteæ, 96.

Phacotus, 97.

Phæophyceæ (see also "Brown Algæ"), $92,123,125,134,137,138,530$; classifcation, 134; structure, 125.

Phæophyll, 123.

Phæosporeæ, 126, 129, 130, 134.

Phajus, 49,397 ; $P$. grandifolius, Fig. 32.

Phallineæ, 185, 186.

Phanerogams (see "Seed-plant," "Spermatophyte").

Phascum, 239.
Phaseolus, 475, 492.

Phellogen, 334, 408.

Philadelphus, 431, 432 $P$. grandiflorus, Fig. 420.

Philodendron, 375,$389 ; P$. melanochrysum, 389.

Phlox, 452, 453: $P$. divaricata, Fig. 442.

Phœuix: P. Canariensis, 57, 378, 386, 387, 541, Figs. 38, 349, 361.

Phoradendron, 400, 421, 476; $P$. flavescens, Fig. 404.

Phosphoresceuce, 78.

Phosphorus, 7, 38 .

Photosynthesis, 2, 3, 6, 7, 8, 13, 449, 472, $473,474,475$.

Phrymineæ, Phrymaceæ, 459.

Phycochromaceæ (see "Schizophyceæ").

Phycelis, 123.

Phycocyanin, 80, 81.

Phycoerythrin, 135, 472.

Phycomycetes, 149, 150, 151, 152.

Phycophæin, 123, 472.

Phycoxanthin, 81, 123.

Phylloclade, 24, 332, 377.

Phyllodia, 22, 503.

Phyllosiphon, 116, 151.

Phyllosiphonaceæ, 116.

Phyllospadix, 348, 369, 382, 515.

Phyllotaxy, 409.

Phylogeny, 32, 66.

Physianthus albens, 523.

Physiological properties of Protoplasm, 39.

Physiology, 10.

Physiotinm, 216.

Phytelephas, 372.

Phyto-geography (see "Geographical distribution").

Phytolacca, 425; P. decandra, Fig. 409.

Phy tolaccacer, 443.

Phytomyxinæ, 71.

Phytophthora, 159; $P$. infestans, 158.

Picea, $337 ; P$. orientalis, Fig. $300 ; P$. excelsa, Fig. 301, 343; P. Sitchensis, $344,547$.

Pickerel-weed (see "Pontederia").

Pigments, 53, 77, 91, 151, 190, 480.

Pigweed (Amarantus), 155.

Pileus, 183.

Pilobolus, 160, 161, 162, 480, 511, Figs. 125, 454; P. crystallinus, Fig. 125.

Pilularia, 48, 287, 288, 289, 291, 292, 475, Figs. 255,$257 ; P$. Americana, Fig. 257.

Pinaceæ, 338, 343, 535; fossil, 535.

Pine, Pinus, 22, 32, 48, 324, 333, 334, 335, $336,337,338,340,341,342,343,344,511$, Figs. 286, 296, 297, 298, 299, 300, 301, 
306, 307, 535; P. Coulteri, Figs. 298, 299 ; P. Halupensis, Fig. 301; P. insignis, Figs. 296, 297, 300, 306; $P$. Lambertiana, $344 ; P$. Pinea, $336 ; P$. ponderosa, 344 ; P.sylvestris, Fig. 297; $P$. Virginiana, Fig. $286 ; P$. edulis, Fig. 286.

Pineapple (Ananas), 381, 393.

Pinguicula, 453, 509.

Pinnularia, 22, $87 ; P$. viridis, Fig. 13.

Piper, 415.

Piperacea, 401, 415, 422.

Piperales, 413, 414, 415, 424.

Piptocephalis, 161; $P$. Freseniana, Fig. 125.

Pistil, 351, 364.

Pisum, 433; P. sativum, Fig. 424.

Pitcher-plant (see also "Darlingtonia," " Nepenthes," "Sarracenia"), 7, 26, $362,424,431,478,508$.

Pith, 255.

Pithophora, 106, 116; P. odogonia, Fig.76.

Pittosporacex, 444.

Placenta, 284, 339.

Plankton, 84, 88, 497.

Plauktoniella, 88, 497, Figs. 62, 465.

Planogametes, 93.

Plantaginaceæ, 453, 459.

Plantaginales, 449, 453, 459.

Plantago: $P$. major, 453.

Plantain (Musa), 395.

Plantain (Plantago), 364, 366, 516, Fig. 328.

Plant-body, 12.

Plant diseases, 150.

Plants and animals compared, 6.

Plasmodiophora Brassicæ, 71.

Plasmodium, 12, 68, 69, 461, 491.

Plasmolysis, 45.

Plasmopora, 157, 158; $P$. viticola, Fig. 121.

Plastic substances, 461.

Plastids (see also "Chromatophores"), $35,36,38,44,45,46,48$.

Plastine, 39.

Platanacer, 414.

Platanus, $431,432,537 ; P$.occidentalis, Fig. 421.

Platycerium, 273.

Platystemon, 429.

Plectascineæ, 169.

Pleiochasium, 367.

Plendorina, 94, 95, 97; $P$. Californica, Figs. 65, 66.

Pleospora, 172.

Plerome, 360.

Pleurocarpous Mosses, 240.

Pleurococcaceæ, 100, 101.
Pleurococcus, 98, 99, 496; $P$. vulgaris, F'ig. 68.

Pleurozioidieæ, 219.

Pliocene formations, 538.

Plowrightia, 172, 173; P. morbosa, Fig. 139.

Plum, 172, 360, 368.

Plumbago, Plumbaginaceæ, 450, 451, 458; $P$. capensis, 451 .

Plumule, 401.

Plurilocular sporangia, 129.

Podocarpus, 343.

Podophyllum: $P$. peltatum, 62, 401, 406, 408, 425, 427, Figs. 44, 387, 413.

Podostemon, 431; $P$. olivaceum, Fig. 419.

Podostemonaceæ, 361, 404, 431, 444.

Podostemoniueæ, 444.

Pogonia, 25; P. ophioglossoides, Fig. 17.

Poison-ivy (Rhus toxicodendron), 363.

Poisonous Fungi, 185.

Polar nuclei, 35̃5, 358.

Polemoniacea, 453.

Pollen-sac, 22, 27, 328, 338, 353.

Pollen-spore, 27, 51, 64, 323, 325, 329, 338, $352,353,511$.

Pollen-tube, 323, 325, 348, 357, 487.

Pollination, 356, 357, 370, 514.

Pollinium, 523.

Polyedrium (Hydrodictyon), 100.

Polygala, Polygalaceæ, 436, 445.

Polygalineæ, 445.

Polygonaceæ, 421, 422.

Polygonales, 413, 414, 421.

Polygonum, 422, 424; Fig. 407.

Polyinorphy in Rusts, 176.

Polyphagus, 152, 153; P. Euglenæ, Fig. 117.

Polypodiaceæ, 249, 264, 273, 276, 278, 279, 280; fossil P., 532.

Polypodium: $P$. falcatum, 258, 280, Figs. $223,227,228,247,262,263,280$.

Polyporaceæ, 181.

Polyporus, 181.

Polysiphonia, 16, 138, 142, 143, 144, 482, Figs. 111, 112, 113; P. Woodii, Fig. 6 .

Polystelic stem, 255.

Polytrichace 240.

Polytrichum, 201, 228, 231, 235, Fig. 199; $P$. commune, Fig. 191.

Pomacer, 433.

Pomegranate (Punica), 441.

Pond-scums (see "Zygnemacer")

Pond-weed, 7, 369, 376.

Pontederia, 392, 393, 394, 525; $P$. cordata, 392, 525, Fig. 370.

Pontederiaceæ, 392.

Poplar, Populus, 413, 514, 527, 539, 545; $P$. balsamifera, Fig. 473 . 
Poppy, 59, 429.

Porphyra, 135, 138 ; P. vulgăris, Fig. 107. Portulaca, 155, 423, 517; $P$. oleracea, 155.

Portulacineæ, Portulacaceæ, 443.

Postelsia, 124, 126, 128, 4!7, Fig. 99; $P$. palmxformis, Pl. II, Pl. VIII.

Potamogetonaceæ, 383.

Potamogeton, 374, 381, 383, 539, Fig. 354; P. natans, 331.

Potassium, 38, 478 .

Potato, 54, 361 .

Potato-fungus (see "Phytophthora").

Pothos, 375.

Prickles, 29.

Prickly-pear (Opuntia), 24, 440.

Primula, 450, 519, 525; $P$. polyantha, Fig. 488.

Primulaceæ, 448, 450, 458.

Primulales, 449, 450, 458.

Principes, 381.

Pritchardia (see "Washingtonia").

Procambium, 254, 298.

Procarp, 137, 142, 143, 173.

Pro-embryo (Characeæ), 119, 122.

Promycelium, 178.

Pronuba, agent in pollination, 524.

Properties of soil, 468.

Prophases, 61, 63.

Prorocentraceæ, 86.

Prosenchyma, 57.

Protea, 420, 421 ; P. cynaroides, Fig. 403.

Proteales, 414, 420.

Proteacex, 420.

Protective tissues, 58 .

Proteids, 38, 478.

Protein, 59, 257.

Protein crystals, 55.

Proterandry, 516.

Proterogyny, 516.

Prothallium (see also "Gametophyte"), 241.

Protista, 67.

Protobasidiomycetes, $\mathbf{1 7 5}$.

Protocephalozia, 202.

Protococcaceæ, 116.

Protococcoideæ (Protococcaceæ), 94, 96, $97,98,99,100,101,104,111,188$; classification, 100 .

Protodiscineæ, 166.

Protomyces, 164.

Protonema, 16, 122, 202, 223, 225, 278.

Protophyte, 92.

Protoplasm, 2, 3, 6, 7, 8, 12, 34, 35, 36, 37, $38,41,45,97,136,465$; movements of, 41 ; physiological properties, 34 ; structure, 35.

Protoplast, 34, 35, 36.

Protoxylem, 257, 313.
Protozoa, 68.

Prunus, 432 ; $P$. cerasus, Fig. 422.

Psalliota (see also "Mushroom"), 182, 184; P. campestris, Figs. 148, 183.

Pseudo-bulbs, 396.

Pseudocarp, 419.

Pseudo-fruits, 381.

Pseudopodium, 37, 238.

Pseudotsuga, 343, 344; P. Douglasii, Fig. 309.

Psilotinex, 304, 319.

Psilotum, 23, 303, 309,310; P.triquetrum, Fig. 275.

Pteridium : $P$. aquilinum, 246, 256, 280, Figs. 220, 247.

Pteridophyta, Pteridophyte (see also "Ferus"), 200, 220, 241, 282, 322, $325,326,349,352,358,372,466,531$, 532, 533, 537, 539; fossil P., 531, 532, $533,537,539$.

Pteris Cretica, 261, Fig. 226.

Pteromonas, 97.

Ptilidioidere, 219.

Ptomaines, 480.

Puccinia, 172, 177, 179; $P$. aurea, 177, Fig. 143 ; $P$. graminis, $179 ; P$. Malvacearum, Fig. 143; P. rubigo-vera, 179.

Puffball (see also "Lycoperdon"), 162, 163, 174, 180, 187.

Pulvinus, 486, 487.

Pumpkin, 50, 368.

Punica, 441, Fig. 436.

Punicacer, 441, 447.

Pycnidia, 173, 176, 191.

Pylaiella, 126.

Pyrenoid, 14, 49, 95, 108, 109, Fig. 3.

Pyrenolichenes, 192.

Pyrenomycetes, 170.

Pyrenopeziza, 167.

Pyrocystis, 85,$89 ; P$. noctiluca, $P$. lunula, 85, Fig. 59.

Pyrola, 539.

Pyrolacere, 450, 457.

Pyronema, 163, 164, 167, 168, 191; $P$. confluens, Figs. 127, 133.

Pyrus, 424, 432; P. malus, Fig. 422.

Pythium: P. De Baryanum, 154.

Quadripolar spindle (spores of Jungermanniales), 214.

Quercus (see also "Oak"), 25, 367, 409, $411,417,418,537,53()$. Q. agrifolia, Figs. 19, 400, Pl. X.; Q. lobata, Fig. 17; Q. macrocarpa, Fig. 335; Q. suber, 409 .

Raceme, 366.

Racemose inflorescence, 366 . 
Radial symmetry, 21, 22.

Radicle, 401.

Radish, 363.

Raftlesia, 361, 421, 422, 507; R. Patma, Fig. 405.

Rafflesiaceæ, $361,404,421,476$.

Ramalina, $190,192,468 ; R$. reticulata, Fig. 156.

Ranales, 411, 422, 424, 425.

Ranunculacex, $356,425,443$.

Ranunculinea, $\$ 3$.

Ranunculus, 32, 367, 425, 500; R. multifidus, Fig. $468 ; R$. repens, Fig. 26.

Raphe, 363.

Raplides, 55, 56, 389.

Rattal-palm (Calamus), 369, 386.

Kavenala, 394.

Ray-floret, 365.

Receptacle (of flower), 350 .

Red Algx (see also "Rhodophycex"), 16, $49,92,190,191,194,195,196,496$.

Red Cedar (Juniperus Virginiana), 149, 178.

Red Maple (Acer mubrum), 500.

Red Snow (Sphærella nivalis), $\mathfrak{0 6}$.

Reduction of chromosomes, 199.

Redwood (see "Sequoia").

Reed, 369.

Regular flower (see "Actinomorphic flower").

Reindeer-moss (Cetraria Islandica), 192.

Reprodnction, 2, 8, 9, 13, 30, 510 .

Reseda, 351 ; $R$. odorata, Fig. 315 .

Resedacere, $429,444$.

Resedinere, 444.

Reserve-food, 54.

Resin, 39.

Resin-duct, 334.

Respiration, 2, 7, 8, 9, 13, 42, 461, 480, 481 .

Resting-spores, 30, 82, 194, 105, 496.

Rhabdonema, 141; R. tenera, Fig. 110.

Rhabdosphere, 86.

Rhamnacere, 435,459 .

Rhamnales, 124, 438, 416.

Rhamnis, 438, 459.

Rhaphidium, 98; R. polymorphum, Fig. 6.

Rheotropism, 489.

Rheum, 422, 423.

Rhexia, 442.

Rhiphidium, 155, 156; R. Americanum, Figs. 119, 120.

Rhizogenic cells, 261.

Rhizoid (see "Root-hair").

Rhizome, 23, 362.

Rhizophora mangle (see "Mangrove").

Rhizophoracex, 441.

Rhizophore, 310.
Rhizopus (see "Mucor stolonifer").

Rhizoselenia, 88 .

Rhodobacteriacea, 78 .

Rhododeudron, 450.

Rhodophycer (see also "Red Algre), $92,134,135,136,137,147,173,472,473$, 510,530 ; structure and reproduction, 135-137.

Rhodymeniales, 142, 145.

Rucarlales, $424,429,444$.

Rhoeadinere, 444 .

Rhubarb (see "Rheum").

Rhus, $363,435,437$; $R$. cotimus, Fig. 427 ; R. toxicodendron, $363,410$.

Ribes, 431, 432, 524, 525; R. Cynosbati, Fig. 420 ; R. speciosum, Fig. 492 .

Riccardia (see "Aneura").

Riccia, 20, 199, 200, 201, 204, 207, 208, 210, $211,212,220 ; R$. Huitans, 201, 207; $R$. glauca, Figs. 11, 165, 171; $R$. trichocarpa, Figs. 161, 171.

Ricciaceæ, 207.

Ricciocarpus natans, 195, 202, 207, 208, 498, Fig. 163.

Rice, 385.

Richardia, 388, 359, 519, Fig. 487.

Ricinus, 54, 401, 403, 405, 436, 527, Figs. $35,383$.

Rivularia, 80, 82, 496.

Rivulariaceæ, $82,84$.

Robinia, 431, 434, 492.

Rock-weed (see also"Fucus") , 20, 65, 130.

Roestelia (see "Gymnosporangium").

Romneya, 429.

Root, 10, 14, 15, 18, 19, 27, 28, 195, 241, $252,260,261,284,301,308,314,328$, $336,363,378,410,463$; aerial (see "Aerial root"); Angiosperms, 363; Azolla, 284; Conifers, 336 ; Cycas, 328; Dicotyledons, 410; Equisetum, 301; Ferns, 260, 261 ; Isoetes, 318 ; Lycopodium, 308; modified roots, 28 ; Selaginella, 314 .

Root-cap, 27.

Root-fungi (see "Mycorhiza").

Root-hair, 28, 205, 213, 464, 465 ; Jungermanniales, 213; Marchantiales, 205.

Root-tendril, 29.

Root-tubercle, $3,76,477,510$.

Rosaceæ, 423, 432, 433, 444.

Rosales, 424, 431, 444.

Rose-mildew (see "Sphrrotheca").

Rose, Rosa, 22, 25, 30, 49, 355, 409, 424, 432; $R$. blanda, Fig. 422; $R$. livida, 355; R. rubiginosa, Fig. 32.

Rosiflora, 423.

Rosinere, 414.

Rotation of protoplasm, 40, 117. 
Royal-palm (see also "Oreodoxa"), $375,387$.

Rubiaceæ, 454, 459.

Rubiales, 448, 449, 453, 454, 459 .

Rumex, 28, 422, 424; R. crispus, Figs. 20 , 407.

Runner, 24, 361, 362 .

Rust (see also " Ecidiumycetes," "Puccinia”), 149, 162, 163, 174, 175, 176, $191,476$.

Rutaceæ, 436, 445.

Sabal, $386,387$.

Sabiacex, 446.

Sabiiner, 446.

Saccharomyces, 60,$165 ; S$. cerevisiæ, Figs. 42, 129; structure, 165.

Saccharomycetaceæ, 165.

Sac-fungi (see also "Ascomycetes"), 162.

Sage (Salvia), 364.

Sage-brush (Artemisia), 546, 549.

Sagittaria, 75, 367, 371, 377, 379, 381, 382 ; S. variabilis, Fig. 355 .

Sago, 54 .

Sago-palm, 387.

Salicales, 414, 415 .

Salix, 413, 415, Fig. 394.

Salpiglossis, 410.

Salt-marsh plants (Halophytes), 7 .

Salvadoraceæ, 458.

Salvia, 521, 522, 525; S. pratensis, Fig. 491 ; S. splendens, 525.

Salvinia, 28, 282, 283, 287, 322, 532; $S$. natans, Fig. 249.

Salviniaceæ, $282,287$.

Sambucus, 454.

Sanguinaria, 23, 59, 365, 429, 526, 540, 545 ; S. Canadensis, Figs. 14, 416.

Santalacere, $400,420$.

Santalales, $414,420,421$.

Sapindaceæ, 445.

Sapindales, 424, 437.

Sapindineæ, $437,445$.

Sapotacer, Sapotineæ, 458.

Saprolegnia, 31, 153, 154, 155, 476, Figs. 23,119 ; S. ferax, Fig. 119; S. dioica, S. hypogyna, 154; reproduction, 154.

Saproleguiaceæ, Saprolegniineæ, 153.

Saprophyte, 3, 7, 26, 28, 75, 149, 163, 167, $174,348,405,450,475,476,505$.

Sarcina, 39 .

Sarcode, 34 .

Sarcodes, 7.

Sargassum, 124, 130, 131, 133; S. bacciferum, 124.

Sarracenia, 430, 431, 478, 508; S. purmerea, Fig. 418: S. variolaris, 508.
Sarraceniace $, 444,507$.

Sarraceniales, 404, 424, 429, 444.

Sassafras, 538 .

Saururus, $363,413,414,415$; S. cernuus, Fig. 393.

Saxifrage, Saxifragaceæ, 432, 444.

Scale-leaves, 260, 336, 362, 377, 409.

Scale-mosses (see also "Jungermanniales "), 202, 211.

Scales, 20, 22, 26, 29, 207, 210, 258, 377, 504; Bromeliacex, 504; Ferns, 258; Marchantiales, 207, 210.

Scapauioidex, 219.

Scape, 365 .

Scenedesmus, $98 ; S$. dimorphus, S. obtusus, Fig. 68.

Schizæa, 276, 277; S. pusilla, 276, 277.

Schizracer, 273, 276, 283, 292.

Schizocarp, 368, 439.

Schizophyceæ (see also "Cyanophyceæ"), $44,72,73,74,79,80,84,187,188,469$, 530 ; classification, 84 ; structure, 80.

Schizophyta, 36, 67, 71, 72, 91, 530 ; fossil S., 530 .

Schrankia uncinata, 433, 489, Fig. 424.

Sciadopitys, 332.

Scirpus, 386, 405; S. lacustris, Fig. 360.

Scitamineæ, 377, 380, 381, 393, 394, 395.

Sclerenchyma, 255, 256, 260, 262, 271, 299.

Sclerotinia, 167.

Sclerotium (of Slime-mould), 69.

Scolopendriun, 258.

Seouring-rush, 296.

Screw-pine (Pandanus), 29, 363, 383, 384.

Scrophulariaceæ, $452,453,458,476,506$, 521.

Scutellum, 385.

Scytomonas pusillus, 68, Fig. 48.

Scytonema, 80.

Scytonematacere, 82,84 .

Scytopetalaceæ, Scy topetalineæ, 446.

Sea-lettuce (see also "Ulva"), 17.

Sea-palm (see also "Postelsia"), 124, 497.

Seaweeds (see also "Algæ"), 6, 18, 496.

Secondary growth in thickness, 129,375 , $407,408$.

Secretory cells, 59 .

Sedges, 369, 376, 384, 385, 514 .

Sedum, 431, Fig. 420 .

Seed, $6,7,32,35,322,323,341,342,359$, $402,412,413,511,512$.

Seed-plants (see also "Spermatophyta," "Flowering plants"), 11, 27, 32, 195, $200,244,298,322$.

Selaginella, 303, 305, 310-315, 322, 323, 325, 356, 533; S. Kraussiana, Figs. 
276,281 ; S. rupestris, 310, 314; $S$. apus, 310 ; S. cuspidata, 310, Fig. 276; S. stolonifera, 310 , Fig. 276 ; S. lepidophylla, 501.

Selaginellineæ, 304, 310, 501.

Semi-lichens, 188.

Seminiferous scale, 338, 339.

Senecio: $S$. aureus, 401, Fig. 377.

Sensitive-fern (see "Onoclea sensibilis").

Sensitive orgaus, 486, 522.

Seusitive plant (see "Mimosa").

Sepal, 27, 32, 350.

Septicidal deliscence, 367 .

Sequoia, 332, 333, 335, 336, 337, 338, 339, $340,341,343,347,537,538,544$; S. gigantea, Pl. I. ; S. sempervirens, 333 , $336,337,339$, 340, 341, Figs. 295, 300, $305,455,548$.

Serjania, 408.

Sessile leaves, 25.

Seta, 204, 233.

Sexual reproduction, 9, 13, 65, 93, 119, $125,140,151,160,163,168,171,208,210$, $213,218,220,228,248,270,305$; Angiosperms, 355-357; Archegoniates, 196, 197; Fungi, 151; Plireophycere, 125; Rhodophycer, 140; Spermatophytes, $324,325$.

Shepherd's-purse (see also "Capsella"), 155.

Shield (in Characeæ), 120.

Shock, as stimulus, 481.

Shoot, 18, 22.

Sicana, 488, Fig. 459.

Sieve-tube, 59, 127, 131, 257, 298, 334, 465.

Sigillaria, 533, 534 .

Silene, 423, 424, 426; S. Virginica, Fig. 410.

Silicon, 7, 38, 52, 296, 299, 478, 480 .

Silphium, 400.

Silurian formations, $530,531$.

Silver, 39.

Sima rubacexe, 445 .

- Simplest living forms, 4, 67 .

Simplest plants, 66.

Siphoneæ, 12, 14, 47, 52, 94, 112, 113, 114, $115,122,152,530$; fossil S., 530 ; marine $S ., 113,114$; structure and reproduction, 112-114.

Sisyrinchium, 380, 391; S. bellum, Fig. 353.

Sitka-spruce (see "Picea Sitchensis").

Skeletal structures, 57.

Sknnk-cabbage (see also "Symplocarpus "), 547.

Sleep-movements, $8,486,491,492$.

Slime-moulds (see also "Myxomycetes,"
"Mycetozoa"), 12, 34, 39, 43, 68, 71, $461,489$.

Sloth (see "Bradypus").

Smilacina, 381.

Smilax, 24, 26, 375, 377, 519 .

Smuts, 149, 163, 174, 176.

Snails, agents in pollination, 516 .

Snapdragon (Antirrhiuum), 22.

Snow-berry (see "Symphoricarpus").

Snowdrop (Galanthus), 490.

Snow-plant (Sarcodes sanguinea), 450, 506.

Sodium, 7.

Sodium chloride, 39.

Soil, properties of, 468 .

Solanaceæ, Solanineæ, 458.

Solanum, 367, 453; S. dulcamara, Figs. $334,443$.

Solidago, 546.

Soluble substances in the protoplast, 53 .

Somatic cells, 8 .

Sonchus oleraceus, 59, Fig. 41.

Sonneratiacer, 447.

Sordaria, 172.

Soredia, 190.

Sorrel, 422.

Sorus, 263.

Sparaxis, 391.

Sparganiaceæ, 384.

Sparganium, 55, 352, 354, 356, 357, 371, $372,379,380,383,384$; S. simplex, Figs. $318,319,321,322,352$; S. eury carpum, Fig. 356 ; S. Greenii, 384.

Spadix, 388 .

Spanish-moss (see "Tillandsia").

Sparmannia, 486, 488.

Spathe, 363, 388, 389.

Spathicarpa: S. sagittæfolia, 388, 389, Fig. 363.

Spathifloræ, 381, 388, 389.

Spawn (of Mushroom), 180.

Spermatium, 137, 151, 176; Lichens, 191.

Spermatozoids, $8,39,43,48,65,66,94$, $195,197,203,213,242,243,250,323$, $325,329,331,487$.

Spermatophyta (see also "Seed-plants," "Flowering plants"), 11, 51, 329, 466, 482.

Sperm-cell, 31 .

Sperm-filaments of Characex, 120.

Spermogonia, 173, 176, 191.

Sphacelaria, 125; S. filicina, Fig. 96.

Sphacelariacere, 126, 134.

Sphagnales, 236, 237.

Sphagnum, 223, 225, 227, 231, 236, 237, 238 ; S. sp., Fig. 200; S. squarrosum, Fig. 201; S. cymbifolium, Fig. 202; S. acutifolium, Fig. 203. 
Sphwrella, 96,97 ; S. nivalis, 96 ; S. pluvialis, Fig. 67 .

Sphæria, 188; S. Lemanex, 188.

Sphærocarpus, 197, 199, 213, Figs. 158, 160 ; S. cristatus, Fig. 158.

Sphæroplæa, 102.

Sphæroplaace 107.

Sphrerotheea, 170, 171; S. castagnei, Fig. 136 ; S. pannosa, 171.

Sphenoplyyllales, 310, 319, 533.

Sphinx, Sphingidæ, agents in pollination, 51!.

Spigelia Marylandica, 451, Fig. 441.

Spikelet, 384, 385.

Spikenard (Aralia), 442.

Spindle-fibres, 61,62 .

Spine, 29, 262.

Spiræea, 411, 432, Figs. 391, 422.

Spirillacex, 78.

Spirillum, 40, 73, 74, 78; S. undula, Figs. 27,51 .

Spirogyra, 15, 20, 64, 110, 111, 473, 475; S. communis, S. crassa, Fig. 81.

Spirotænia, 108, 110; S. muscicola, Fig. 7!).

Spongilla, 4, 99, 509.

Sporangiophore, 159, 268.

Sporangium, 22, 27, 30, 32, 128, 159, 199, $244,263,264,268,269,271,279,281,288$, $301,308,314,315,317,318,322,328,329$, $338,339,351$; Angiosperms, 351 ; Archegoniates, 199; Kelps, 128; Mucor, 159; Pteridophytes, 244; Spermatophytes, 322.

Spore-fruit, 141, 144, 145.

Spores, $6,7,31,32,51,74,97,151,163$, $199,204,223,236,244,263,264,268$, 293, 302, 323; Algæ, 93; Archegoniates, 199; Bacteria, 74; Fungi, 151 ; Spermatophytes, 323 .

Sporidium, 176, 178.

Sporocarp, 141, 151, 163, 285, 288, 291.

Sporocyst, $69,70$.

Sporogenous filaments, 144.

Sporophore, 17.

Sporophyll, 27, 31, 32, 128, 244, 263, 268, $271,273,274,293,301,308,309,317$, $323,328,329,337,338,350,363$.

Sporophyte, 19, 22, 30, 145, 195, 196, 198, $199,200,204,211,214,218,220,231$, $238,241,244,245,254,267,268,271$, $274,275,277,279,295,301,307,308$, 313, 314, 374; Anthocerotales, 220; Hepaticæ, 204; Musci, 231; Pteridophytes, 2t4; Spermatophytes, 325.

Spring-beauty (see also "Claytonia"), 23. Spring-cress (see also "Cardamine," "Dentaria"), 23.
Spruce (see also "Picea "), 535, 5 44,547 , 548.

Spurious tissues, 18.

Squash, 50,

Stachyuraceæ, 447.

Stackhousiaceæ, 445.

Stamen, 27, 32, 350, 351, 363.

Staminodia, 380, 394, 395, 396, 423.

Stangeria paradoxa, 327 .

Stapelia, 519.

Staphylea, 435, 437; S. trifolia, Fig. 427.

Staphyleacer, $437,445$.

Starch, 2, 4, 35, 38, 50, 54, 55, 199, 473, $474,478,479$.

Starch formers, $48,50,54,55$.

Staurastrum, 108; S. gracile, Fig. 79.

Stegocarpæ, 239, 240.

Stem, 10, 14, 19, 22, 23, 252, 253, 255, 317, 327, 332, 333, 360, 406; Angiosperms, 360 ; Conifers, 332 ; Cycads, 327 ; Dicotyledons, 406 ; Ferns, 252 ; Isoetes, 317 ; Modified stems, 23.

Stemonitis, 70; S. fusca, Fig. 50.

Stephaninoideæ, 219.

Sterculiaceæ, 439, 446.

Stereome, 299.

Stichidia, 139.

Stigeoclonium, 101, 104; S. tente, Fig. 71.

Stigma, 351 .

Stigmatomyces, 173; S. Baeri, Fig. 140.

Stigonemataceæ, 84 .

Stink-horn, 186.

Stipe, 258.

Stipule, 25.

St. John's-wort (see "Hypericum").

Stolon, 24, 362 .

Stoma, 2, 25, 206, 221, 231, 254, 258, 259, $299,328,335,377,462,463,465$ : Anthoceros, 221; Cycas, 328; Equisetum, 299; Fern, 259; Marchantiaceæ, 206; Musci, 231; Pinus, 335.

Stoinium, 264, 265.

Stone-fruit (Drupe), 359, 360.

Stone-pine (see "Pinus Pinea").

Stonewort (see "Chara," "Characex").

Strawberry, 24, 360, 432, 433, 542, Fig. 422.

Streaming of protoplasm; 39, 41, 151.

Strelitzia, 474.

Streptotheca, 168; S. Boudieri, 168.

Strobilus, 337.

Stroma, 170.

Stromatopteris moniliformis, 275.

Structural resemblances of plants and animals, 3 .

Strutbiopteris, 17, 242, 247, 248, 249, 250, 
$255,256,257,260,273,280,327$; S. Germanica, Figs. 7, 206, 212, 213, 214, 219 , $221,222,248$.

Stuartia, 439, 545 .

Style, 351.

Stylophorum, 366, 429; S. diphyllum, Fig. 332.

Stylospores, 173.

Styracacere, 458.

Styrax, 451 .

Suberin (see also "Cork"), 53.

Suberized membranes (see also "Cork"), 52.

Suckers, 21.

Sugar, 2, 38, 53, 55, 474, 475, 478, 479.

Sugar-cane, $3 \$ 5$.

Sugar-maple (see also "Acer"), 544.

Sugar-pine (see "Pinus Lambertiana").

Sulpliur, 7, 38, 475; Sulphur Bacteria, $75,77,78,79,475,476$.

Sumach (see also "Rhus"), 543.

Sundew (see also "Drosera"), 7, 26, 424, $478,539$.

Sunflower (Heliauthus), 471.

Surf-algæe, 497.

Suspensor, $306,325$.

Swarm-spores (see also "Zoöspores"), 93, 152.

Sweet-pea, 26, 27, Fig. 19.

Symbiont, 475 .

Symbiosis, 149, 188, 476, 509, 510.

Symmetry, 21.

Sympetalæe, 412, 413, 448.

Symphoricarpus, 454.

Symplyyogyna, 213, Fig. 172.

Symplocacex, 458.

Symplocarpus, 377, 388, 389.

Symplocos, 451.

Synangium, 271.

Synanthre, 381, 388.

Syncarpous ovary, 412.

Syncephalis, 160.

Synchytrium, 153; S. papillatum, 153.

Syncytium, 5.

Synergidæ, 323, 355, 358 .

Tabellaria, 87, Fig. 61 .

Taccacere, 390 .

Talipot-palm (see "Corypha").

Tamaricacese, 446.

Tamaricineæ, 446.

Tannin-cells (Marattiacex), 271.

Tannin-vesicles (Zygnemaceæ), 36, 53, 108.

Tapetum, 263, 264, 302.

Tap-root, 27, 328, 332, 363.

Taraxacum, 366,$457 ; T$. officinale, Figs. $333,448$.
Targionia: $T$. hypophylla, 198, 201, 209, 210, Figs. 159, 161.

Taxaceæ, 337, 343, 535.

Taxere, 343.

Taxodiinæ, 343.

Taxodium : $T$. distichum, 325, 335, 343, 347, 467, 535, 544, Fig. 288.

Taxonomy, 10, 11.

Taxus, 335, 337, 338, 339, 341, 342, 343, 354 ; T. baccata, Figs. $300,302,303$, $304,306,308$.

Tea-rose, 500 .

Teazel (see "Dipsacus").

Tecoma: $T$. radicans, 408, 453, 454, 512 , Figs. 387, 441.

Teleutospore, $176,177,179$.

Temperature (factor in growth), 6.

Tendril, 24, 26, 29, 362, 484, 488, 504.

Ternstrœmiaceæ, 446.

Tertiary formations, $\mathbf{3 4 7 , 5 3 1 , 5 3 5 , 5 3 7 .}$

Testa, 342, 359.

'Tetanus-germ (Bacillus tetani), 73, Fig. 51.

Tetraphis pellucida, 226, 228, 240, Fig. 188.

Tetraspora, 99, 100 .

Tetrasporaceæ, 100.

Tetraspore, 30, 136, 137, 139, 140, 141.

Thalictrum, $402,425,427 ; T$. anemonoides, Fig. 412.

Thallophyte, 92, 530 .

Thallus, 17, 22.

Theaceæ, 439, 446.

Theca (Musci), 233, 234.

Thick-angled tissue (see "Collenchyma").

Thickening of cell-wall, 45,51 .

Thiobacteriaceæ, 78.

Thistle, 26, 28, 456, 457, 527 .

Thorn, 24, 362, 527 .

Thuja, 343, 344; T. occidentalis, Fig. 310; T. plicata, 344 .

Thymelicaceæ, Thymelæineæ, 441, 447.

Thyocystis: $T$. violacea, 77, Fig. 53.

Tigridia, 391.

Tilia, 365, 405, 406, 407, 437, 439; $T$. Americana, Figs. $330,383,385,386$, 430.

Tiliacere, 439, 446.

Tillandsia, 392, 393, 503, 545 ; T. usneoides, 393.

Tilietia, 175.

Tilletiinere, 175.

Tilopteridacer, 134.

Tissue, 10.

Tmesipteris, 310.

Toadstool (Agaricus), 3, 7, 151, 162, 174, $180,181,492$. 
Tobacco, 471.

Todea, 274, 275.

Tolypella, 122, 123, Fig. 94.

Tolypothrix, 82, Fig. 56 .

Tomato, 526.

Tonoplast, 35,36 .

Torreya, 343, 347, 535, 543.

Tovariaceæ, 444.

Toxalbumen, 480 .

Toxin, 76.

Trabecula, 318.

Tracheary tissue, 51, 58, 59, 254, 256.

Tracheid, 58, 298.

Tradescantia, 41, 44, 47, 63, 326, 377, 393; T. Virginica, Fig. 369 ; T. zebrina, Fig. 347.

Trama, 183.

Translocation of food, 465 .

Transpiration, 467, 470, 471, 472 .

Traps, 362, 404 .

Traveller's-tree (see "Ravenala").

Tree-fern, 246, 248, 260, 261, 279.

Tremella, 179, Fig. 145.

Tremellinea, 175, 179.

Trentepohlia, 101.

Treubia, 215.

Trichia, 69, 70, Figs. 49, 50.

Trichina, 149.

Trichodesmium : T. emythræum, 79 .

Trichogyne, 137, 142, 144, 173, 191.

Trichomanes, 257, 273, 277, 278, 279; $T$. cyrtotheca, Figs. 244, 245; T. parvulum, Fig. 244.

Trichome (see also "Hair," "Scale"), $22,29,260,410$.

Trichophilus, 101.

Tricoccre, 445.

Triglochin, 381.

Trigonantheæ, 219.

Trillium, 23, 361, 365, 379, 505, 519, 547, $5+8,550 ; T$. erectum, 519 .

Trimorphous flowers, 525 .

Trochodendraceæ, Trochodendrineæ, 443.

Tropæolum: T. majus, 405, 424, 516 , 517, Figs. 384, 485.

True Fungi (see "Eumycetes").

True Mosses (see also "Musci"), 201, $202,223$.

Truffle (see also "Tuber"), 168, 169.

Trumpet-creeper (see also "Tecoma"), $28,504,545$.

Tsuga, 335, 343, 344; T. Canadensis, Fig. 309.

Tuber, 23, 35, 362,.503; of Equisetum, 296; Liverworts, 214.

Tuber, Tuberinea (see also "Truffle") 168, 169, Fig. 134.

Tubifloræ, 449, 452, 453, 458 .
Tulip, 24, 26, 29, 362, 484, 488, 504 .

Tulip-tree (see also "Liriodendron"), $425,545$.

Turgor, Turgescence, 466 .

Turnip, 28, 363 .

Twining stems, 491, 504 .

Typha, 379, 383, 405 .

Typhaceæ, 383.

Ulmaceæ, 11, 419.

Ulmus, 11, 409, 419; U. alata, 409; $U$. Americana, 11; U. campestris, Fig. 401.

Ulothricaceæ, 107.

Ulothrix, 101, 104; U. zonata, Fig. 71.

Ulva, 17, $42,93,94,99,100,101,102,104$; U. lactuca, Fig. 7 ; U. latissima, Fig. 70.

Ulvaceæ, 107.

Umbel, 366.

Umbelliferæ, 442.

Umbellifloræ, 424, 442, 448.

Umbellularia Californica, 425, 428; Fig. 415.

Unicellular organisms, 3, 49.

Unicellular plants, 13.

Uredinales, 175.

Uredospore, 176, 179.

Uric acid, 1.

Urocystis Cepulæ, 175.

Uromyces, 176, 177 ; U. Caladii, Fig. 142.

Urticaceæ, 419.

Urticales, 11, 414, 419.

Usuea, 189, 190, 192; U. barbata, Fig. 153.

Ustilagineæ, 174.

Ustilago, 174, 175; U. Maydis, Fig. 141.

Utricle, 368.

Utricularia, 26, 217, 404, 453.

Vacuole, 35, 36, 46, 81 .

Valeriana, 45 4 , 455; $V$. officinalis, Fig. 445.

Valerianaceæ, 459.

Vallisneria, 370, 382, 383, 465; V.spiralis, Fig. 355.

Valve (of Diatom), 87.

Vanilla, 375, 397.

Vascular bundle, 57, 58, 59, 221, 254, 255, $262,271,274,283,296,298,308,313$, $314,327,328,333,334,335,374,403$, 406, 470; Cycads, 327, 328; Conifers, 334,335 ; Dicotylerinns, 403-406; Equisetum, 296; Fer'us, 255, 262; Lycopodium, 308; Marattiaceæ, 271; Monocotyledons, 374; Osmundacere, 274 ; Selaginella, 313.

Vascular plants, 22, 466 .

Vaucheria, 55, 113, 114, 115, 116, 153, 154, 155, 194, 474, 498; V. aversa, Fig. 88 ; 
$V$. olavata, V. geminata, Fig. $89 ; V$. sessilis, Fig. 88.

Velum, Isoetes, 317; Mushrooin, 184.

Venus's flytrap (see also "Dionea"), 7.

Verbascum, 453, 454; V. blattaria, Fig. 444.

Verbenaceæ, Verbenineæ, 458.

Veronica, 411, 454; V. scutellata, Figs. $391,444$.

Verrucaria marmorea, 189.

Verticillatae, 414.

Vessel, 58, 257.

Vetch, 504 .

Viburıum, 45ั4, 455, Fig. 445.

Vicia F'aba, 482, Fig. 456.

Victoria regia, 486.

Vinca, 452.

Vine-inildew (see "Plasmopora").

Violace e, 439, 447.

Viola, Violet, $22,366,438,439,483,493$, $512 ; V$. cucullata, Figs. 13,$332 ; \nabla$. rostrata, Fig. 464.

Virginia-creeper (Ampelopsis quinquefolia), 24, 504.

Viscum, 476.

Vitaceæ, $438,446$.

Vital functions, 9 .

Vitelline, 39.

Vitis, 437, 438; V. bicolor, V. labrusea, Fig. 429.

Vittaria, 246, 248.

Volvocacex, $5,13,46,49,68,94,95,96$, $97,98,100,104,109,111,495$; structure and reproduction, 95-98.

Volvox, 8, 22, 96; V. minor, Fig. 67.

Walchia, 535.

Walking-fern (Camptosorus rhizophylluss), 20, 21, Fig. 11.

Walnut (see also "Juglans") , 416, 417, 545 .

Washingtonia filifera, 386, 387.

Washington-lily (Lilium Washingtonianum), 549.

Waste products, 42,43 .

Water, 6, 7, 34, 41, 42, 467, 469, 512; absorption of, 467 ; agent iu transportation, 512 ; movement of, 469.

Water-conducting tissues, 58 .

Water-cultures, 462.

Water-fern (see "Hydropteridinea ").

Water-hyacinth (see "Eichhornia").

Water-milfoil (see "Myriophyllum").

Water-mould (see "Saprolegnia").

Water-net (see also "Hydrodictyon"), $46,47,99$.

Water-pollination (Hydrophily), 370.

Wax, 480.

Welwitschia mirabilis, 344, 346.
Wheat (Triticum vulgare), 175, 360, 385. Wheat-rust (see also "Puccinia"), 177, 179.

White-elm (see "Ulmus Americana").

White-pine, 544.

White-rust (see "Albugo").

Wild-oats (see "Avena").

Willow (see alsa "Salix"), 413, 415.

Willow-herb (see "Epilobium").

Wilting, 466, 471.

Wind, effect in growth, 489; wind pollination (see "Anemophily").

Winter-bud, 26, 336, 362, 409, 505.

Wistaria, $434,543,545$.

Wolffia, 389.

Wood, wood cells, $52,57,58$.

Woodwardia radicans, 257, Fig. 222.

Xanthine, 39.

Xanthophyll, 50, 473.

Xerophyte, 24, 273, 362, 404, 501, 502, 527.

Xylaria, 172.

Xylem, 257, 298, 333, 470.

Yam (see "Dioscorea").

Yeast (see also "Saccharomyces"), 60, $64,165,175,479$.

Yellow-pine, 548.

Yew (see "Taxus").

Yucca, 369, 373, 374, 375, 380, 390, 523, $524,527,546,547 ; \quad Y$. aloifolia, Fig. 345 ; Y. arborescens, Pl. VII ; pollination of, 527 ; Y. filamentosa, 523 .

Zamla, 325, 326, 327, 329 ; Z. integrifolia, Figs, 289-291.

Zannichellia, 361, 370, 372, 374, 377, 381; Z. palustris, Figs. 341, 348, 354 .

Zauschneria Californica, 525.

Zea Mays, 366, 376, Figs. 333, 347.

Zephyranthes, 391 .

Zingiber, 377, 394, 395; Z. officinalis, Fig. 372.

Zingiberacere, 394, 395.

Zonate tetraspores, 139.

Zoöglœa, 5.

Zoölogy, 9.

Zoöspore, 15, 30, 39, 41, 46, 64, 93, 151, $154,188,195,491$.

Zostera, 348, 369, 370, 382, 515, 566.

Zygadenus, 549 .

Zygnema, 36, 53.

Zygnemacer, 108.

Zygochytrium aurantiacum, 153, Fig. 117.

Zygomycetes, 152.

Zygophyllaceæ, 444.

Zygospore, 110, 161, 162; Entomoplithorinea, 162; Mucor, 161; Spirogyra, 110.

Zygote, 93. 



\section{WORKS ON BOTANY}

\section{PUBLISHED BY \\ THE MACMILLAN COMPANY}

66 FIFTH AVENUE, NEW YORK

Bailey. - Botany. An elementary text for schools, by L. H. Barley, Professor of Horticulture in Cornell University, with over 500 illustrations.

$12 \mathrm{mo}$.

Half Leather.

\$1.10 net.

"I have examined the book with much interest. It is easily seen that it is written with Professor Bailey's clearness and felicity of style, and I think it as a whole one of the most charmingly and appropriately illustrated of modern botanical text-books. I expect it to prove a stimulating and very useful work." - Prof. W. F. GANONG, Smith College.

Lessons with Plants. Suggestions for seeing and interpreting some of the common forms of vegetation, by L. H. BaILEy, with delineations from nature by W. S. HoldsworTH, Michigan Agricultural College, with 446 illustrations.
I2mo.
Half Leather.
$\$ 1.10$ net.

"It is an admirable book, and cannot fail both to awaken interest in the subject and to serve as a helpful and reliable guide to young students of plant life. It will, I think, fill an important place in secondary schools, and comes at an opportune time when helps of this kind are needed and eagerly sought." - Prof. V. M. Spalding, University of Michigan.

First Lessons with Plants. The first twenty chapters of the larger work described above.

\section{Pages. 116 lllustrations. Cloth, I2mo, 40 Cents.}

All of the illustrations of the original appear in these selected chapters, which are in no way abbreviated.

"A remarkably well-printed and illustrated book, extremely original and unusually practical." - H. W. Foster, South Orange, N.J.

The Principles of Agriculture. A text-book for schools and rural societies. Edited by L. H. BAILEY, with contributions from his colleagues in the Cornell University.

\section{Pages. $\quad 92$ Illustrations. $\quad \$ 1.25$.}

This is an attempt to analyze the complex subject of agriculture, and to present the underlying principles and factors in clear, terse English. Each chapter is in two parts : the first part, or the principles, is in numbered paragraphs in very large type (the size used in "Lessons with Plants"); the second part contains informal suggestions to the teacher and pupil, with illustrations. It is one of the few attempts to coördinate all the various agricultural subjects, showing the relative importance and position of each. It is a skeleton of agricultural science and practice. Full references are made to available literature. 


\section{WORKS ON BOTANY}

CAMPBELL. - The Evolution of Plants. By Douglas Houghton Campbell, Ph.D., Professor of Botany in Leland Stanford University.

Cloth, 12mo, \$r.25.

GANONG. - The Teaching Botanist. A manual of information upon botanical instruction, together with outlines and directions for a comprehensive elementary course. By Wilidam F. GANONG, Ph.D., Smith College.

Cloth, 12mo, \$r.10 net.

MACDOUGAL. - The Nature and Work of Plants: An introduction to the study of botany. By D. T. MAcDougal, Director of the Laboratories, New York Botanical Garden.

Cloth, $x 2 \mathrm{mo}, 80$ cents net.

SETCHELL. - Laboratory Practice for Beginners in Botany. By William A: Setchell, Ph.D., Professor of Botany in the University of California.

Cloth, I2mo, go cents net.

STRASBURGER. - Handbook of Practical Botany. For the botanical laboratory and private student. By Dr. E. STRASBurger, Professor of Botany in the University of Bonn. Translated and edited from the German, with many additional notes, by W. Hillhouse, M.A., F.L.S., Professor of Botany in the University of Birmingham.

Fifth edition, rewritten and enlarged, with over $\mathrm{r}_{50}$ original illustrations.

Cloth, 8vo, \$2.60 net.

STRASBURGER, NOLL, SCHENCK, and SCHIMPER. - A Text-Book of Botany. By Edward Strasburger, Fritz Noll, Heinrich Schenck, and A. F. W. Schimper. Translated by H. C. Porter, Assistant Instructor of Botany, University of Pennsylvania. With 594 illustrations, in part colored.

Cloth, 8vo, \$4.50 net.

VINES. - A Students' Text-Book of Botany. By S. H. Vines, Professor of Botany in the University of Oxford. With many illustrations.

Cloth, 8vo, \$3.75 net.

VINES. - An Elementary Text-Book of Botany. With 397 illustrations. Cloth, 8vo, $\$ 2.25$ net.

\section{THE MACMILLAN COMPANY}

66 FIFTH AVENUE, NEW YORK

ITLANTA

BOSTON

CHICAGO

SAN FRANCISCO 


$3 x^{2}+x^{3}=$

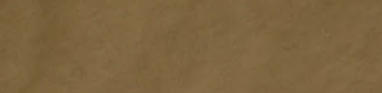

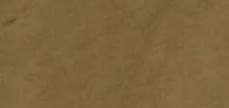

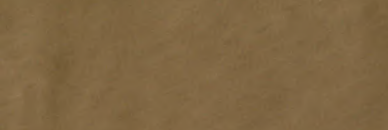

$x^{2} x^{2}=4$

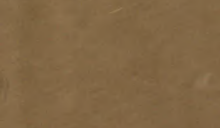

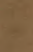

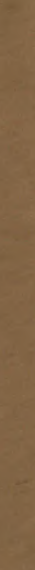
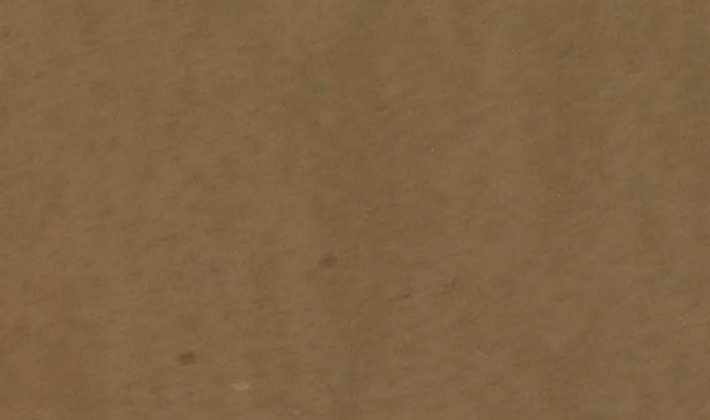

4.

Eutasis

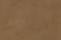
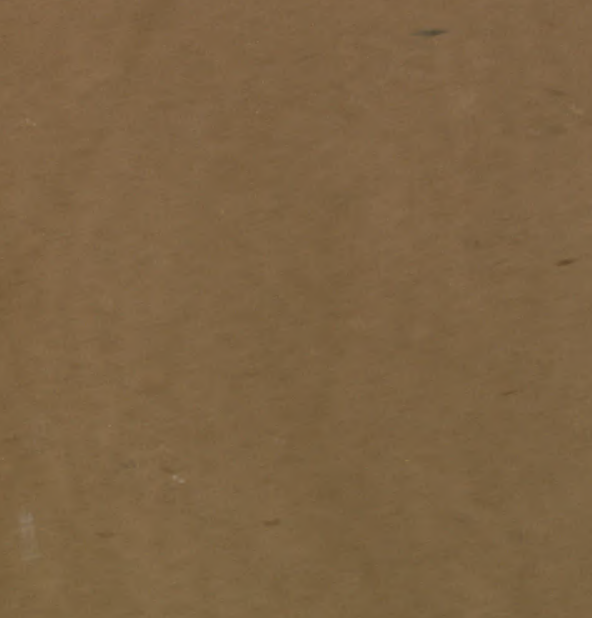

$x^{2}+x^{2} x^{2}=-$

$\left(c^{2}\right)^{3}+0^{3}$

(4)

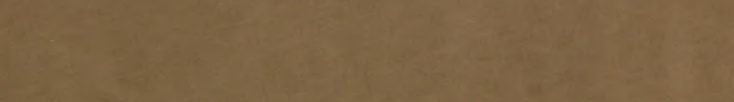





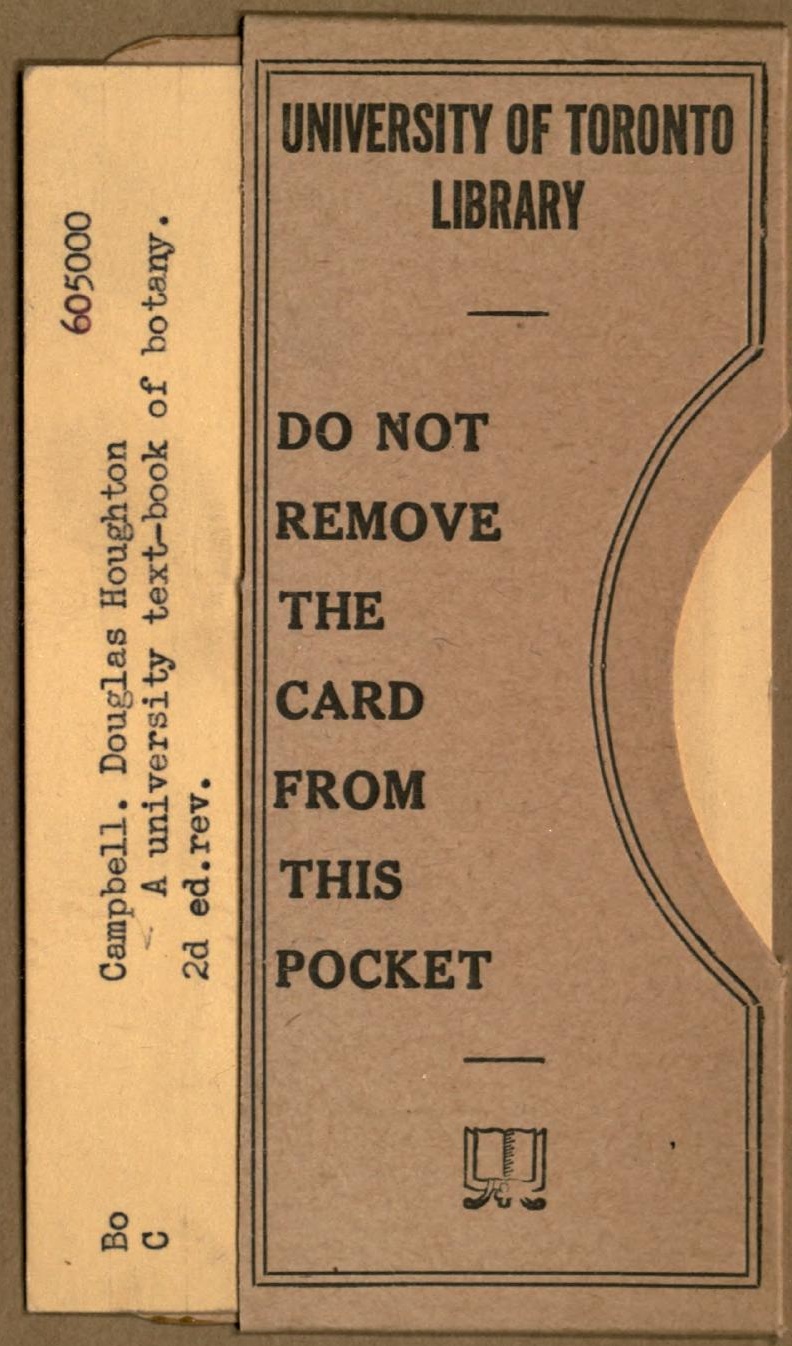


